SANTI FERRI

CONTRIBUIÇÕES AO ESTUDO DO COMPORTAMENTO MECÂNICO DE SOLOS DE SUBLEITO PARA FINS DE PROJETO DE PAVIMENTOS ASFÁLTICOS 
(página em branco) 


\title{
CONTRIBUIÇÕES AO ESTUDO DO COMPORTAMENTO MECÂNICO DE SOLOS DE SUBLEITO PARA FINS DE PROJETO DE PAVIMENTOS ASFÁLTICOS
}

\author{
Tese apresentada à Escola Politécnica da \\ Universidade de São Paulo para obtenção \\ do Título de Doutor em Ciências. \\ Área de Concentração: \\ Engenharia de Transportes \\ Orientador: \\ Profa. Dra. Liedi Legi Bariani Bernucci
}

São Paulo

2018 
Autorizo a reprodução e divulgação total ou parcial deste trabalho, por qualquer meio convencional ou eletrônico, para fins de estudo e pesquisa, desde que citada a fonte.

Este exemplar foi revisado e corrigido em relação à versão original, sob responsabilidade única do autor e com a anuência de seu orientador.

São Paulo, de de

Assinatura do autor:

Assinatura do orientador:

Catalogação-na-publicação

Ferri, Santi

CONTRIBUIÇÕES AO ESTUDO DO COMPORTAMENTO MECÂNICO DE SOLOS DE SUBLEITO PARA FINS DE PROJETO DE PAVIMENTOS

ASFÁLTICOS / S. Ferri -- versão corr. -- São Paulo, 2018.

$505 \mathrm{p}$.

Tese (Doutorado) - Escola Politécnica da Universidade de São Paulo. Departamento de Engenharia de Transportes.

1.Módulo de resiliência 2.Subleito 3.Desempenho de pavimentos 4.Dimensionamento de pavimentos 5.Pavimentos asfálticos I.Universidade de São Paulo. Escola Politécnica. Departamento de Engenharia de Transportes II.t. 


\section{AGRADECIMENTOS}

Agradeço, em primeiro lugar, aos meus queridos pais, Ferrino Ferri (in memoriam) e Cleide Ferri, por terem sempre, apesar de todas as dificuldades, colocado o aprendizado como prioridade nas vidas de seus filhos e, em especial, na minha.

Agradecimentos especiais à minha orientadora, professora Dra. Liedi Legi Bariani Bernucci, por ter me acolhido como seu orientado, pelos ensinamentos e também por sua paciência, dedicação e interesse na condução deste trabalho, além de todo o conhecimento dividido e pelas inúmeras contribuições que tanto enriqueceram esta tese. Agradecimentos especiais ao professor Dr. Carlos Yukio Suzuki, por todos os ensinamentos acadêmicos e profissionais, pelo exemplo de caráter e profissionalismo, além da amizade pessoal de anos.

Agradecimentos ao professor Dr. Glauco Tulio Pessa Fabbri, pelas contribuições técnicas que tanto enriqueceram este trabalho na etapa da qualificação. Ao professor Dr. Octavio Souza Campos, pelo apoio, e contribuição com material para pesquisa e antecipadamente, aos demais componentes da banca examinadora final.

Agradecimentos à ARTESP - Agência Reguladora de Transportes do Estado de São Paulo, às empresas Planservi Engenharia Ltda., Grupo ARTERIS, pela gentileza em ceder trechos experimentais, material de pesquisa, além contribuir com todo o know-how na área de pavimentação.

Agradecimentos especiais ao professor Dr. José Tadeu Balbo, professora Dra. Kamilla Vasconcelos, professora Dra. Rosangela dos Santos Motta, professor Dr. Edson de Moura e todos os demais professores do PTR - Engenharia de Transportes da Escola Politécnica da USP, por terem divido boa parte de seu enorme conhecimento e, além de tudo, por terem despertado em mim a paixão pelo conhecimento e o espírito crítico, itens fundamentais para o crescimento acadêmico e profissional. Agradecimentos a todos os profissionais e colaboradores do LTP - Laboratório de Tecnologia de Pavimentação da Escola Politécnica da USP.

Agradecimentos aos grandes amigos e colegas Amanda Helena Marcandali Silva, Caio Rubens G. Santos, Ângela Martins Azevedo, Flaviane M. Lopes, Cintia da Silva Arruda e Ana Luisa Aranha pela parceria nos estudos e intermináveis discussões técnicas. Agradecimentos aos meus irmãos, Piero Ferri e Micheli Ferri e aos demais amigos e familiares pelo apoio, carinho e paciência. 
(página em branco) 


\section{RESUMO}

O comportamento mecânico do subleito tem influência determinante no desempenho das estruturas de pavimento. Porém, muitas vezes, os estudos realizados para elaboração de projetos são simplistas e não levam em conta as variações de comportamento mecânico que podem ocorrer, seja por fatores construtivos, seja ambientais, como umidade, durante o período de operação. Neste sentido, métodos de dimensionamento mecanicistas-empíricos de estruturas de pavimentos empregam modelos de comportamento das diversas camadas da estrutura e do subleito, sendo alvos de constantes revisões para recalibração destes modelos, de modo que se aproximem mais da realidade do comportamento em serviço. As calibrações dos modelos são necessárias para aumentar a confiabilidade do dimensionamento de modo a garantir pavimentos mais duráveis, e para otimizar custos de execução e de manutenção ao longo da vida útil das estruturas. Neste contexto o presente trabalho propõe uma metodologia para compreender as propriedades dos solos do subleito e de suas variações, estabelecendo um programa de ensaios de campo e de laboratório, cadastramento, processamento e combinação de resultados de propriedades físicas e mecânicas de solos de subleitos de pavimentos de rodovias existentes. O objetivo final é estabelecer parâmetros de deformabilidade elástica de solos do subleito e sua variabilidade para auxiliar no dimensionamento de novas estruturas de pavimentos e reabilitação das antigas. $O$ trabalho utiliza estudos de casos de pavimentos rodoviários em operação. $O$ primeiro caso foi base para o estabelecimento metodológico de estudo desejável do subleito de um pavimento existente, concebendo modelos de previsão de comportamento resiliente do subleito para uso em futuros projetos de restauração deste pavimento ou para novos projetos em locais com similaridade de ocorrência de solos. Empregando a metodologia estabelecida no primeiro caso, fez-se uma busca minuciosa de dados em vários documentos existentes sobre pavimentos rodoviários de concessionárias do Estado de São Paulo, concebendo-se um banco de dados para análise do subleito destes pavimentos, de modo a ampliar a gama de solos pesquisados. Com resultados de caracterização de solos em laboratório e de deflectometria em campo, além de dados de localização dos pontos estudados em mapas geológicos e pedológicos, dados de precipitação, de terraplenagem, entre outros, pôde-se analisar os dados e identificar a influência de cada elemento na variação do módulo de resiliência dos solos de 
fundação de pavimentos em serviço. O banco de dados de ensaios laboratoriais de solos de subleito contou com um total de 3.894 registros e de ensaios não destrutivos deflectométricos de campo com um total de 169.525 registros (dados históricos de nove rodovias estaduais diferentes). Dentre as principais conclusões, verificou-se que grande parte dos modelos de correlações existentes na literatura entre parâmetros de propriedades físicas e de resistência (como $C B R$ ) de solos com o módulo de resiliência possui aplicação muito restrita, inviabilizando sua aplicação de forma indiscriminada em locais distintos daqueles onde foram obtidas as correlações. Além disso, verificouse que o módulo de resiliência do subleito em campo apresenta variações de grande magnitude e, portanto, é de difícil previsão, requerendo acumulação de dados históricos, bem como de um cadastro adicional de maior gama de informações. Recomenda-se que maiores quantidades de ensaios sejam realizadas e que permitam verificação, ou dupla checagem, para validação, bem como para futuramente ser possível o estabelecimento de modelos matemáticos mais confiáveis. Nos estudos, foi possível estabelecer parâmetros estatísticos que podem ser utilizados tanto em métodos de dimensionamento vigentes ou novos, como naquelas que consideram as variações do módulo de resiliência do subleito para determinação do risco de falha, ou da confiabilidade das estruturas. Palavras-chave: Módulo de resiliência; Subleito; Desempenho de pavimentos; Dimensionamento de pavimentos. Pavimentos asfálticos. 


\section{ABSTRACT}

Subgrade mechanical behavior has a determining influence on the performance of pavement structures. However, often, the studies carried out for project designs are simplistic and do not take into account the variations that can occur in the mechanical behavior, whether by constructive factors or environmental ones, such as the moisture content during the operation period. Thus, mechanical-empirical design methods of pavement structures employ performance models of the many layers of the structure and of the subgrade, being targets of constant revisions for adjustment of these models so that they come closer to reality in operation behavior. Model adjustments are necessary to increase design reliability to ensure more durable pavements and to optimize execution and maintenance costs during the structure life. In this context, the present work proposes a methodology to understand the subgrade soil properties and their variations, establishing a program of field and laboratory tests, registration, processing and combination of results of physical and mechanical properties of subgrade soils of existing highway pavements. The final objective is to establish parameters of the subgrade soil elastic deformability and their variability to assist in the design of new pavement structures and in the rehabilitation of old ones. This work uses case studies of road pavements in operation. The first case was the basis for the methodological establishment of a desirable study of the subgrade of an existing pavement, designing predictive models of the subgrade resilient behavior for use in future rehabilitation projects of this pavement or for new projects in places with a similar occurrence of soils. By using the methodology established in the first case, a thorough data search was carried out in several existing documents on road pavements of concessionaires in the State of São Paulo, and a database was prepared to analyze the subgrade of such pavements in order to expand the range of soils studied. With the results of soil characterization in the laboratory and by field deflections, in addition to location data of the points studied in geological and pedological maps, precipitation and earthwork data, among others, it was possible to analyze the data and identify the influences of each element on the variation of the subgrade resilient modulus of the pavements in operation. The database from laboratory tests of subgrade soils covered a total of 3,894 registers and of non-destructive deflectometric field tests - a total of 169,525 registers (historical data on nine different state highways). Among the main conclusions, it was verified that most of the correlation models existing in the literature 
between parameters of physical and mechanical strength properties (like the CBR) of soils with the resilient moduli have very restricted application, making it impossible to apply them indiscriminately in places other than those where the correlations were obtained. In addition, it was verified that the resilient modulus of the subbase in situ presents variations of great magnitude and, therefore, it is difficult to make predictions. Lots of historical data are required, as well as additional registers of a greater range of information. Therefore, it is recommended that a larger number of tests be performed in order to allow for checking and double-checking for validation as well as the possibility of a future establishment of more reliable mathematical models. In the studies, it was possible to establish statistical parameters that can be used both in current and in new design methods, like in those that consider variations of the subgrade resilient moduli to determine the risk of failure or of the reliability of structures. Keywords: Resilient modulus; Subgrade; Pavement performance; Pavement design; Asphalt pavements. 


\section{LISTA DE ILUSTRAÇÕES}

Figura 2.1 - Ocorrência de solos lateríticos e saprolíticos no Brasil (Medina e Motta, 1989) .53

Figura 2.2 - Gráfico para classificação MCT (Nogami e Villibor, 1981 apud Bernucci et al., 2010)

Figura 2.3 - Definição do módulo de resiliência (NCHRP, 2008). .58

Figura 2.4 - Definições de outros parâmetros elásticos (NCHRP, 2008). .59

Figura 2.5 - (a) Esquema do equipamento triaxial de cargas repetidas e (b) exemplo do equipamento (Bernucci et al., 2010)

Figura 2.6 - Exemplo da determinação do valor de $M R$ para utilização da equação de dimensionamento contida no Guia da AASHTO/93 .72

Figura 2.7 - Módulo de resiliência de um solo $\mathrm{CH}$ de Arkansas em função do teor de umidade (Elliot et al., 1988 apud NCHRP, 2008) .75

Figura 2.8 - Dispositivo de teste multiaxial (Wilson et al., 1990 apud NCHRP, 2008)

Figura 2.9 - Resultados de módulo de resiliência de subleitos granulares de Ohio (Wilson et al., 1990 apud NCHRP, 2008)... .77

Figura 2.10 - Influência dos procedimentos de teste AASHTO nos resultados de módulo de resiliência de diferentes tipos de agregados (Chen et al., 1994, apud NCHRP, 2008)

Figura 2.11 - Influência do teor de umidade pós compactação nos resultados de módulo de resiliência (Drumm et al. 1990, 1997)

Figura 2.12 - Configuração do ensaio "bender element" utilizado por Davich et al. (NCHRP, 2008)

Figura 2.13 - Comparação do módulo elástico a partir dos ensaios $R L T$ e "bender element test" (Davich et al.2004b apud NCHRP, 2008). .83

Figura 2.14 - Parâmetro 'a' para estimativa de $M R$ (Leet et al., 1997) 102

Figura 2.15: Gráfico para determinação dos módulos efetivos do subleito e pavimento de acordo com o procedimento de Noureldin (1993) 127

Figura 3.1: Fluxograma idealizado para determinação dos locais a sondar..... 132

Figura 3.2: Fluxograma dos procedimentos de campo para coleta de amostras ensaios "in situ" 
Figura 3.3: Localização dos poços de inspeção realizados em pavimento da rodovia federal em estudo

Figura 3.4: Mapeamento Geológico da região onde foram realizados os poços de inspeção

Figura 3.5: Legenda para o mapa geológico da Erro! Fonte de referência não encontrada.

Figura 3.6: Diretrizes para abertura dos poços de inspeção e coleta de amostras da pista 143

Figura 3.7: Sequência dos procedimentos de campo para realização do presente estudo de caso 144

Figura 3.8: Determinação do Módulo da camada sobrejacente ao subleito em função da relação de deflexões e equipamento $F W D$ ou $L W D$ 149

Figura 3.9: Módulos retroanalisados com LWD (camadas de sub-base e subleito) 150 Figura 3.10: Comparativo entre condições de peso específico aparente e umidade de campo versus laboratório (curva de compactação para a energia adotada)....159 Figura 3.11: Valores de módulo de subleito retroanalisado através da equação da AASHTO/93 160

Figura 3.12: Precipitação horária $(\mathrm{mm})$ no período do levantamento com FWD (2010 a 2014) 162

Figura 3.13: Precipitação horária $(\mathrm{mm})$ no período do levantamento com $F W D(2008)$ 163

Figura 3.14: Comparativo entre os valores de módulo de resiliência retroanalisados (Equação da $A S S H T O / 93$ versus software BAKFAA) 164

Figura 3.15: Comparativo entre os valores de módulo de resiliência retroanalisados (Equação da ASSHTO/93 versus módulo obtido diretamente com $L W D$ sobre a camada) 164

Figura 3.16: Gráficos comparativos entre os valores de módulo obtidos no campo (eq. AASHTO/93, $C=0,33$ ) e no laboratório, sendo: (a) todos os dados e (b) valores de módulo limitados em $140 \mathrm{MPa}$ 166

Figura 3.17: Correlações $C B R \times M R$ - campanha 1 - Ensaios na energia Intermediária (modelos da literatura versus resultados obtidos) 169

Figura 3.18: Correlações $C B R \times M R$ - campanha 2 - Ensaios na energia Normal (modelos da literatura versus resultados obtidos) 170 
Figura 3.19: Gráficos boxplot dos valores de módulo de resiliência por tipo de solo e energia de compactação (estudo BR-116).

Figura 3.20: Gráficos boxplot dos valores individuais da relação $M R / C B R$ por tipo de solo e energia de compactação (estudo BR-116) 172

Figura 3.21: Correlações diretas entre o parâmetro k1 e demais parâmetros de solos de graduação grossa não lateríticos 174

Figura 3.22: Correlações diretas entre o parâmetro k2 e demais parâmetros de solos de graduação grossa não lateríticos 175

Figura 3.23: Correlações diretas entre o parâmetro k3 e demais parâmetros de solos de graduação fina não lateríticos 176

Figura 3.24: Correlações diretas entre o parâmetro $k 4$ e demais parâmetros de solos de graduação fina não lateríticos 176

Figura 3.25: Tentativa de validação dos modelos propostos para (a) solos de graduação grossa e (b) solos de graduação fina 178

Figura 3.26: Gráficos boxplot dos valores de módulo de resiliência retroanalisados (AASHTO/93) por tipo de solo (estudo BR-116) 179

Figura 3.27: Gráficos boxplot dos valores de módulo de resiliência retroanalisados (AASHTO/93) por tipo de solo: (a) semana seca e (b) semana chuvosa 179

Figura 4.1: Resultados de CBR em função da classificação MCT. 185

Figura 4.2: Resultados de expansão em função da classificação $M C T$. 185

Figura 4.3: Resultados de $C B R$ em função da classificação HRB (solos classificados como não- lateríticos) 186

Figura 4.4: Resultados de CBR em função da classificação HRB (solos classificados como lateríticos) 186

Figura 4.5: Resultados de $C B R$ em função da classificação $H R B$ (solos lateríticos e não-lateríticos) 187

Figura 4.6: Resultados de Esl,retro em função da classificação MCT .... 189

Figura 4.7: Resultados de Esl,retro em função da classificação HRB (solos classificados como não- lateríticos) 189

Figura 4.8: Resultados de Esl,retro em função da classificação $H R B$ (solos classificados como lateríticos). 190

Figura 4.9: Resultados de Esl,retro em função da classificação HRB (solos lateríticos e não-lateríticos) 190 
Figura 4.10: Relação obtida no estudo teórico para Módulo de resiliência do subleito (E1) e Módulo retroanalisado a partir da equação da AASHTO/93. 193

Figura 4.11: Relação obtida no estudo teórico para Módulo de resiliência do subleito (E1) e Módulo retroanalisado a partir da equação da AASHTO/93 - Pavimentos tipicamente semirrígidos (Módulo E2 igual ou superior a $1.000 \mathrm{MPa}$ ) 195

Figura 4.12: Relação obtida no estudo teórico para Módulo de resiliência do subleito (E1) e Módulo retroanalisado a partir da equação da AASHTO/93 - Pavimentos tipicamente flexíveis (Módulo E2 igual ou inferior a 500 MPa) e espessura física total do pavimento entre 13 e $20 \mathrm{~cm}$. 197

Figura 4.13: Relação (Esl,reto / E1) em função da espessura total do pavimento (segundo estudo teórico) 198

Figura 4.14: Mapeamento dos sítios geológicos de acordo com CPRM (fonte: autor adaptado de GeoSGB e Google Earth $®$ ) . 201

Figura 4.15: Legenda para o mapa dos sítios geológicos de acordo com CPRM (fonte: autor adaptado de GeoSGB e Google Earth®) .203

Figura 4.16: Mapeamento dos sítios pedológicos de acordo com EMBRAPA (fonte: autor adaptado de EMBRAPA e Google Earth $\AA$ ) 207

Figura 4.17: Legenda de cores para o mapa pedológico 208

Figura 4.18: Mapa das unidades de gerenciamento de recursos hídricos de acordo com o $D A E E / S P$ 211

Figura 4.19: Mapeamento das estações pluviométricas cadastradas para análise.212 Figura 4.20: Mapa da região (fonte: autor, adaptado de Google Earth®) 217

Figura 4.21: Mapa geológico da região (fonte: autor, adaptado de Google Earth® e GeoSGB). 218

Figura 4.22: Mapa pedológico da região (fonte: autor, adaptado de Google Earth ${ }^{\circledR} \mathrm{e}$ EMBRAPA) 218

Figura 4.23: Mapa com a localização das estações pluviométricas 219

Figura 4.24: Gráficos empilhados de (a) Eslr da pista decrescente, (b) Eslr da pista crescente e diagramas retigráficos da (c) geologia, (d) pedologia, (e) seção de terraplenagem, (f) chuva acumulada de 1 dia, (g) chuva acumulada de 8 dias [BD2] .220

Figura 4.25: Média e desvio padrão do módulo de resiliência retroanalisado do subleito e média da chuva acumulada (para 1 dia e para 8 dias) para: (a) condição geral; 
(b) condição de chuva máxima verificada; (c) nenhuma chuva acumulada em 8 dias [BD2]..

Figura 4.26: Média e desvio padrão do valor de D120 e média da chuva acumulada (para 1 dia e para 8 dias) para: (a) condição geral; (b) condição de chuva máxima verificada; (c) nenhuma chuva acumulada em 8 dias [BD2] .223

Figura 4.27: Média dos dados de chuva acumulada de (a) 1 dia, (b) 8 dias; (c) média de Es/r da pista crescente e (d) Es/r da pista decrescente para os anos de 2011 e 2013 e para os segmentos homogêneos [BD3]

Figura 4.28: Média e desvio padrão da relação de módulo para as situações de chuva especificadas [BD3] 227

Figura 4.29: Estatísticas da relação de módulo (Es/r,máx / Es/r,mín) para cada um dos parâmetros em estudo, sendo: (a) classificação geológica / classificação pedológica e (b) tipo de seção de terraplenagem [BD3] . .228

Figura 4.30: Estatísticas da relação de módulo (Eslr,máx / Eslr,mín) para parâmetros combinados [DB3] 229

Figura 4.31: Média e desvio padrão do módulo de resiliência retroanalisado do subleito e média da chuva acumulada (para 1 dia e para 8 dias) para: (a) condição geral; (b) condição de chuva máxima verificada; (c) nenhuma chuva acumulada em 8 dias [BD2]...... 232

Figura 4.32: Média e desvio padrão da relação de módulo para as situações de chuva especificadas [BD3] .233

Figura 4.33: Estatísticas da relação de módulo (Es/r,máx / Es/r,mín) para cada um dos parâmetros em estudo, sendo: (a) classificação geológica / classificação pedológica e (b) tipo de seção de terraplenagem [BD3] .234

Figura 4.34: Estatísticas da relação de módulo (Eslr,máx / Eslr,mín) para parâmetros combinados [BD3]. .235

Figura 5.1: Relação entre chuva e valor do módulo de resiliência retroanalisado do subleito para chuva acumulada de 1 dia, 2 dias, 4 dias e 8 dias (BD2) 242

Figura 5.2: Relação entre chuva e valor do D90 para chuva acumulada de 1 dia, 2 dias, 4 dias e 8 dias (BD2) ... .243

Figura 5.3: Relação entre chuva e valor do D120 para chuva acumulada de 1 dia, 2 dias, 4 dias e 8 dias (BD2) 244 
Figura 5.4: Relação entre chuva e valor do módulo de resiliência retroanalisado para chuva acumulada de 1 dia, 2 dias, 4 dias e 8 dias (BD2) - Sítios solos potencialmente lateríticos ( LVAd3)

Figura 5.5: Relação entre chuva e valor do módulo de resiliência retroanalisado para chuva acumulada de 1 dia, 2 dias, 4 dias e 8 dias (BD2) - Sítios potenciais solos $N S^{\prime}(C X b d 1)$ 246

Figura 5.6: Relação entre chuva acumulada de 1 dia e valor do módulo de resiliência retroanalisado (BD2) - sítio pedológico $L V A d 3$, sítios geológicos Q1c e Q2a, seções em (a) corte e (b) aterro

Figura 5.7: Média e desvio padrão dos valores de módulo de resiliência retroanalisado para cada uma das rodovias em estudo para 3 condições de umidade distintas sendo: (a) condição geral; (b) chuva de 1 dia maior que $15 \mathrm{~mm}$, (c) sem chuva detectada no período de 8 dias [BD2] 249

Figura 5.8: Média e desvio padrão dos valores de módulo de resiliência retroanalisado por tipo de seção de terraplenagem para 3 condições de umidade distintas sendo: (a) condição geral; (b) chuva de 1 dia maior que $40 \mathrm{~mm}$, (c) sem chuva detectada no período de 8 dias [BD2]....

Figura 5.9: Média e desvio padrão dos valores de módulo de resiliência retroanalisado por sítio geológico para 3 condições de umidade distintas sendo: (a) condição geral; (b) chuva de 1 dia maior que $25 \mathrm{~mm}$, (c) sem chuva detectada no período

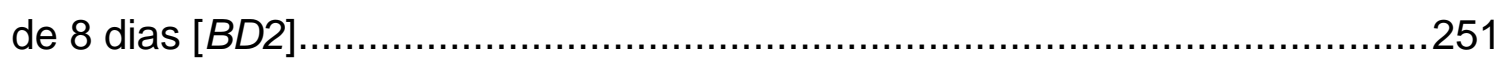

Figura 5.10: Média e desvio padrão dos valores de módulo de resiliência retroanalisado por sítio pedológico para 3 condições de umidade distintas sendo: (a) condição geral; (b) chuva de 1 dia maior que $15 \mathrm{~mm}$, (c) sem chuva detectada

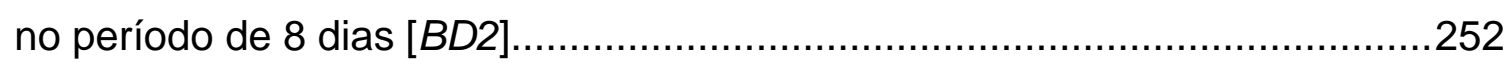

Figura 5.11: Média e desvio padrão dos valores de módulo de resiliência retroanalisado por classe $M C T$ identificada para 3 condições de umidade distintas sendo: (a) condição geral; (b) chuva de 1 dia maior que $15 \mathrm{~mm}$, (c) sem chuva

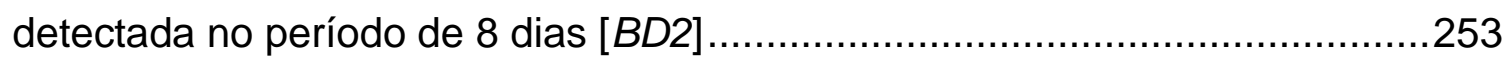

Figura 5.12: Gráficos de estatísticas para os valores globais de módulo obtidos para (a) rodovias em estudo, (b) sítios pedológicos identificados e (c) classes MCT identificadas 255

Figura 5.13: Gráfico de média e média+desvio padrão da relação de módulo para as situações de chuva especificadas - todas as rodovias em estudo [BD3] 257 
Figura 5.14: Gráfico de média e média+desvio padrão da relação de módulo para as situações de chuva especificadas - todas as rodovias em estudo (função da seção de terraplenagem) [BD3] 257

Figura 5.15: Gráficos de média e média+desvio padrão da relação de módulo para as situações de chuva especificadas - todas as rodovias em estudo (função do sítio geológico) [BD3] 258

Figura 5.16: Gráficos de média e média+desvio padrão da relação de módulo para as situações de chuva especificadas - todas as rodovias em estudo (função do sítio pedológico) $[B D 3]$ 259

Figura 5.17: Gráficos de média e média+desvio padrão da relação de módulo para as situações de chuva especificadas - todas as rodovias em estudo (função da classificação $M C T$ ] [BD3] 260

Figura 6.1: Probabilidades associadas à distribuição normal de valores 263

Figura 6.2: Estrutura do Pavimento prevista em projeto - Duplicação Tamoios Planalto (SP 099) 267

Figura 6.3: Analogia estrutural adotada para fins das análises através da ferramenta desenvolvida por Ferri (2013) .269

Figura 6.4: Tela de entrada e saída dos dados para as análises através da ferramenta desenvolvida por Ferri (2013) - variação de 0,5 vezes o desvio-padrão (14\%) 270

Figura 6.5: Tela de entrada e saída dos dados para as análises através da ferramenta desenvolvida por Ferri (2013) - variação de 1 vez o desvio-padrão (32\%) .....271

Figura 6.6: Tela de entrada e saída dos dados para as análises através da ferramenta desenvolvida por Ferri (2013) - variação de 1,5 vezes o desvio-padrão (33\%) 272

Figura 6.7: Nível de confiabilidade da estrutura em função do fator multiplicativo do desvio-padrão dos valores de módulo do subleito, de acordo com a metodologia proposta por Ferri (2013).

Figura 6.8: Estrutura do Pavimento prevista em projeto - Duplicação (SP 318).....275

Figura 6.9: Analogia estrutural adotada para fins das análises através da ferramenta desenvolvida por Ferri (2013) 276

Figura 6.10: Tela de entrada e saída dos dados para as análises através da ferramenta desenvolvida por Ferri (2013) - variação de 0,5 vezes o desvio-padrão (15\%) 
Figura 6.11: Tela de entrada e saída dos dados para as análises através da ferramenta desenvolvida por Ferri (2013) - variação de 1 vez o desvio-padrão (31\%) ....278

Figura 6.12: Tela de entrada e saída dos dados para as análises através da ferramenta desenvolvida por Ferri (2013) - variação de 1,5 vezes o desvio-padrão (47\%) 279

Figura 6.13: Nível de confiabilidade da estrutura em função do fator multiplicativo do desvio-padrão dos valores de módulo do subleito, de acordo com a metodologia proposta por Ferri (2013) 280

Figura 9.1: Mapa Geológico do local sondado - km 402 (Pista Norte) 309

Figura 9.2: Comparativo entre pesos específicos aparentes secos - laboratório $x$ campo (subleito, $\mathrm{km} \mathrm{402,} \mathrm{norte)}$

Figura 9.3: Retroanálise das bacias de deflexões (série histórica) - km 402 (pista norte)

Figura 9.4: Tensões no subleito calculadas para (a) 2011 e (b) 2014 311

Figura 9.5: Comparativo entre $M R$ de laboratório e modelos de previsão de $M R$ (condição de umidade ótima)

Figura 9.6: Comparativo entre $M R$ in situ $(L W D)$ e modelos de previsão de $M R$ (condição de umidade verificada no campo)

Figura 9.7: Comparativo entre $M R$ in situ mínimo verificado ( $F W D)$ e modelos de previsão de $M R$ (condição de saturação próxima a 100\%).

Figura 9.8: Gráficos de série histórica dos indicadores estruturais do pavimento no segmento do km 402 (pista norte)

Figura 9.9: Gráficos da série histórica dos dados de módulo de resiliência retroanalisado ( $F W D$ ) do pavimento no segmento do km 402 (pista norte) .....316

Figura 9.10: Estatísticas dos Parâmetros do pavimento (S. Homogêneo do km 402)

Figura 9.11: Mapa Geológico do local sondado - km 405 (Pista Norte) 320

Figura 9.12: Comparativo entre pesos específicos aparentes secos - laboratório x campo (subleito, $\mathrm{km} \mathrm{405,} \mathrm{norte)}$ 321

Figura 9.13: Retroanálise das bacias de deflexões (série histórica) - km 405 (pista norte). 322

Figura 9.14: Tensões no subleito calculadas para (a) 2010 e (b) 2014 322

Figura 9.15: Comparativo entre $M R$ de laboratório e modelos de previsão de $M R$ (condição de umidade ótima) 
Figura 9.16: Comparativo entre $M R$ in situ ( $L W D$ ) e modelos de previsão de $M R$ (condição de umidade verificada no campo).

Figura 9.17: Comparativo entre $M R$ in situ mínimo verificado $(F W D)$ e modelos de previsão de $M R$ (condição de saturação próxima a 100\%) 325

Figura 9.18: Gráficos de série histórica dos indicadores estruturais do pavimento no segmento do $\mathrm{km} 405$ (pista norte).... 326

Figura 9.19: Gráficos da série histórica dos dados de módulo de resiliência retroanalisado ( $F W D$ ) do pavimento no segmento do $\mathrm{km} 405$ (pista norte) ......327

Figura 9.20: Estatísticas dos Parâmetros do pavimento (S. Homogêneo do km 405) 328

Figura 9.21: Mapa Geológico do local sondado - km 414 (Pista Sul) 331

Figura 9.22: Comparativo entre pesos específicos aparentes secos - laboratório $x$ campo (subleito, $\mathrm{km} \mathrm{414,} \mathrm{sul)}$ 332

Figura 9.23: Retroanálise das bacias de deflexões (série histórica) - km 414 (pista sul) 333

Figura 9.24: Tensões no subleito calculadas para (a) 2013 e (b) 2014 333

Figura 9.25: Comparativo entre $M R$ de laboratório e modelos de previsão de $M R$ (condição de umidade ótima) 335

Figura 9.26: Comparativo entre $M R$ in situ $(L W D)$ e modelos de previsão de $M R$ (condição de umidade verificada no campo) 335

Figura 9.27: Comparativo entre $M R$ in situ mínimo verificado $(F W D)$ e modelos de previsão de $M R$ (condição de saturação próxima a 100\%) 336

Figura 9.28: Gráficos de série histórica dos indicadores estruturais do pavimento no segmento do km 414 (pista sul) 337

Figura 9.29: Gráficos da série histórica dos dados de módulo de resiliência retroanalisado ( $F W D$ ) do pavimento no segmento do km 414 (pista sul) 338

Figura 9.30: Estatísticas dos Parâmetros do pavimento (S. Homogêneo do km 414)

Figura 9.31: Mapa Geológico do local sondado - km 418 (Pista Norte) 342

Figura 9.32: Comparativo entre pesos específicos aparentes secos - laboratório $x$ campo (subleito, km 418, norte) 343

Figura 9.33: Retroanálise das bacias de deflexões (série histórica) - km 418 (pista norte).

Figura 9.34: Tensões no subleito calculadas para 2014 
Figura 9.35: Comparativo entre $M R$ de laboratório e modelos de previsão de $M R$ (condição de umidade ótima).

Figura 9.36: Comparativo entre $M R$ in situ $(L W D)$ e modelos de previsão de $M R$ (condição de umidade verificada no campo) 346

Figura 9.37: Comparativo entre $M R$ in situ mínimo verificado $(F W D)$ e modelos de previsão de $M R$ (condição de saturação próxima a 100\%)

Figura 9.38: Gráficos de série histórica dos indicadores estruturais do pavimento no segmento do $\mathrm{km} 418$ (pista norte). 348

Figura 9.39: Gráficos da série histórica dos dados de módulo de resiliência retroanalisado $(F W D)$ do pavimento no segmento do $\mathrm{km} 418$ (pista norte) .....349

Figura 9.40: Estatísticas dos Parâmetros do pavimento (S. Homogêneo do km 418) 350

Figura 9.41: Mapa Geológico do local sondado - km 423 (Pista Norte) .353

Figura 9.42: Comparativo entre pesos específicos aparentes secos - laboratório $x$ campo (subleito, $\mathrm{km} \mathrm{423,} \mathrm{norte).}$ .354

Figura 9.43: Retroanálise das bacias de deflexões (série histórica) - km 423 (pista norte)..... 355

Figura 9.44: Tensões no subleito calculadas para (a) 2013 e (b) 2014 .355

Figura 9.45: Comparativo entre $M R$ de laboratório e modelos de previsão de $M R$ (condição de umidade ótima)

Figura 9.46: Comparativo entre $M R$ in situ $(L W D)$ e modelos de previsão de $M R$ (condição de umidade verificada no campo) 357

Figura 9.47: Comparativo entre $M R$ in situ mínimo verificado $(F W D)$ e modelos de previsão de $M R$ (condição de saturação próxima a 100\%). 358

Figura 9.48: Gráficos de série histórica dos indicadores estruturais do pavimento no segmento do $\mathrm{km} 423$ (pista norte). 359

Figura 9.49: Gráficos da série histórica dos dados de módulo de resiliência retroanalisado ( $F W D$ ) do pavimento no segmento do $\mathrm{km} 423$ (pista norte) .....360

Figura 9.50: Estatísticas dos Parâmetros do pavimento (S. Homogêneo do km 423) 361

Figura 9.51: Mapa Geológico do local sondado - km 429 (Pista Norte) .364

Figura 9.52: Comparativo entre pesos específicos aparentes secos - laboratório $\mathrm{x}$ campo (subleito, km 429, norte) .365 
Figura 9.53: Retroanálise das bacias de deflexões (série histórica) - km 429 (pista norte) .366

Figura 9.54: Tensões no subleito calculadas para (a) 2013 e (b) 2014 366

Figura 9.55: Comparativo entre $M R$ de laboratório e modelos de previsão de $M R$ (condição de umidade ótima) 368

Figura 9.56: Comparativo entre $M R$ in situ ( $L W D)$ e modelos de previsão de $M R$ (condição de umidade verificada no campo) 368

Figura 9.57: Comparativo entre $M R$ in situ mínimo verificado $(F W D)$ e modelos de previsão de $M R$ (condição de saturação próxima a 100\%) 369

Figura 9.58: Gráficos de série histórica dos indicadores estruturais do pavimento no segmento do $\mathrm{km} 429$ (pista norte). 370

Figura 9.59: Gráficos da série histórica dos dados de módulo de resiliência retroanalisado ( $F W D$ ) do pavimento no segmento do $\mathrm{km} 429$ (pista norte) .....371

Figura 9.60: Estatísticas dos Parâmetros do pavimento (S. Homogêneo do km 429) 372

Figura 9.61: Mapa Geológico do local sondado - km 431 (Pista Norte) 375

Figura 9.62: Comparativo entre pesos específicos aparentes secos - laboratório $x$ campo (subleito, km 431, norte) 376

Figura 9.63: Retroanálise das bacias de deflexões (série histórica) - km 431 (pista norte). 377

Figura 9.64: Tensões no subleito calculadas para 2014 377

Figura 9.65: Comparativo entre $M R$ de laboratório e modelos de previsão de $M R$ (condição de umidade ótima) 379

Figura 9.66: Comparativo entre $M R$ in situ $(L W D)$ e modelos de previsão de $M R$ (condição de umidade verificada no campo) 379

Figura 9.67: Comparativo entre $M R$ in situ mínimo verificado $(F W D)$ e modelos de previsão de $M R$ (condição de saturação próxima a 100\%) 380

Figura 9.68: Gráficos de série histórica dos indicadores estruturais do pavimento no segmento do $\mathrm{km} 431$ (pista norte). 381

Figura 9.69: Gráficos da série histórica dos dados de módulo de resiliência retroanalisado ( $F W D$ ) do pavimento no segmento do $\mathrm{km} 431$ (pista norte) .....382

Figura 9.70: Estatísticas dos Parâmetros do pavimento (S. Homogêneo do km 431)

Figura 9.71: Mapa Geológico do local sondado - km 434 (Pista Norte) .386 
Figura 9.72: Comparativo entre pesos específicos aparentes secos - laboratório $x$ campo (subleito, $\mathrm{km} \mathrm{434,} \mathrm{norte).}$

Figura 9.73: Retroanálise das bacias de deflexões (série histórica) - km 434 (pista norte). .388

Figura 9.74: Tensões no subleito calculadas para 2014 388

Figura 9.75: Comparativo entre $M R$ de laboratório e modelos de previsão de $M R$ (condição de umidade ótima) 390

Figura 9.76: Comparativo entre $M R$ in situ $(L W D)$ e modelos de previsão de $M R$ (condição de umidade verificada no campo) 390

Figura 9.77: Comparativo entre $M R$ in situ mínimo verificado ( $F W D$ ) e modelos de previsão de $M R$ (condição de saturação próxima a 100\%) 391

Figura 9.78: Gráficos de série histórica dos indicadores estruturais do pavimento no segmento do km 434 (pista norte). 392

Figura 9.79: Gráficos da série histórica dos dados de módulo de resiliência retroanalisado $(F W D)$ do pavimento no segmento do $\mathrm{km} 434$ (pista norte) .....393

Figura 9.80: Estatísticas dos Parâmetros do pavimento (S. Homogêneo do km 434) 394

Figura 9.81: Mapa Geológico do local sondado - km 456 (Pista Norte) 397

Figura 9.82: Comparativo entre pesos específicos aparentes secos - laboratório $\mathrm{x}$ campo (subleito, km 456, norte). 398

Figura 9.83: Retroanálise das bacias de deflexões (série histórica) - km 456 (pista norte) 399

Figura 9.84: Tensões no subleito calculadas para (a) 2013 e (b) 2014. 399

Figura 9.85: Comparativo entre $M R$ de laboratório e modelos de previsão de $M R$ (condição de umidade ótima). 401

Figura 9.86: Comparativo entre $M R$ in situ $(L W D)$ e modelos de previsão de $M R$ (condição de umidade verificada no campo) 401

Figura 9.87: Comparativo entre $M R$ in situ mínimo verificado $(F W D)$ e modelos de previsão de $M R$ (condição de saturação próxima a 100\%) . 402

Figura 9.88: Gráficos de série histórica dos indicadores estruturais do pavimento no segmento do km 456 (pista norte). .403

Figura 9.89: Gráficos da série histórica dos dados de módulo de resiliência retroanalisado $(F W D)$ do pavimento no segmento do km 456 (pista norte) .....404 
Figura 9.90: Estatísticas dos Parâmetros do pavimento (S. Homogêneo do km 456)

Figura 9.91: Mapa Geológico do local sondado - km 460 (Pista Norte) 408

Figura 9.92: Comparativo entre pesos específicos aparentes secos - laboratório $\mathrm{x}$ campo (subleito, $\mathrm{km} \mathrm{460,} \mathrm{norte).}$ 409

Figura 9.93: Retroanálise das bacias de deflexões (série histórica) - km 460 (pista norte)

Figura 9.94: Tensões no subleito calculadas para (a) 2013 e (b) 2014 410

Figura 9.95: Comparativo entre $M R$ de laboratório e modelos de previsão de $M R$ (condição de umidade ótima)

Figura 9.96: Comparativo entre $M R$ in situ $(L W D)$ e modelos de previsão de $M R$ (condição de umidade verificada no campo)

Figura 9.97: Comparativo entre $M R$ in situ mínimo verificado ( $F W D$ ) e modelos de previsão de $M R$ (condição de saturação próxima a 100\%)

Figura 9.98: Gráficos de série histórica dos indicadores estruturais do pavimento no segmento do km 460 (pista norte).

Figura 9.99: Gráficos da série histórica dos dados de módulo de resiliência retroanalisado $(F W D)$ do pavimento no segmento do $\mathrm{km} 460$ (pista norte) .....415

Figura 9.100: Estatísticas dos Parâmetros do pavimento (S. Homogêneo do km 402)

Figura 9.101: Mapa Geológico do local sondado - km 482 (Pista Sul) 419

Figura 9.102: Comparativo entre pesos específicos aparentes secos - laboratório $\mathrm{x}$ campo (subleito, $\mathrm{km} \mathrm{482,} \mathrm{sul)}$

Figura 9.103: Retroanálise das bacias de deflexões (série histórica) - km 482 (pista sul) 421

Figura 9.104: Tensões no subleito calculadas para (a) 2012 e (b) 2014 421

Figura 9.105: Comparativo entre $M R$ de laboratório e modelos de previsão de $M R$ (condição de umidade ótima). .423

Figura 9.106: Comparativo entre $M R$ in situ $(L W D)$ e modelos de previsão de $M R$ (condição de umidade verificada no campo) 423

Figura 9.107: Comparativo entre $M R$ in situ mínimo verificado (FWD) e modelos de previsão de $M R$ (condição de saturação próxima a 100\%) 424

Figura 9.108: Gráficos de série histórica dos indicadores estruturais do pavimento no segmento do km 482 (pista sul) 425 
Figura 9.109: Gráficos da série histórica dos dados de módulo de resiliência retroanalisado $(F W D)$ do pavimento no segmento do $\mathrm{km} 482$ (pista sul). 426

Figura 9.110: Estatísticas dos Parâmetros do pavimento (S. Homogêneo do km 482) 427

Figura 9.111: Mapa Geológico do local sondado - km 492 (Pista Sul) 429

Figura 9.112: Retroanálise das bacias de deflexões (série histórica) - km 492 (pista sul) 431

Figura 9.113: Tensões no subleito calculadas para (a) 2013 e (b) 2014 431

Figura 9.114: Comparativo entre $M R$ de laboratório e modelos de previsão de $M R$ (condição de umidade ótima) 432

Figura 9.115: Comparativo entre MR in situ mínimo verificado $(F W D)$ e modelos de previsão de $M R$ (condição de saturação próxima a 100\%) .432

Figura 9.116: Gráficos de série histórica dos indicadores estruturais do pavimento no segmento do km 492 (pista sul) 433

Figura 9.117: Gráficos da série histórica dos dados de módulo de resiliência retroanalisado ( $F W D$ ) do pavimento no segmento do km 492 (pista sul) 434

Figura 9.118: Estatísticas dos Parâmetros do pavimento (S. Homogêneo do km 492) 435

Figura 10.1: Estatísticas dos Parâmetros do pavimento (S. Homogêneo 1 - NS') 437 Figura 10.2: Estatísticas dos Parâmetros do pavimento (S. Homogêneo 2 - NS') .438 Figura 10.3: Estatísticas dos Parâmetros do pavimento (S. Homogêneo 3 - NS') .439 Figura 10.4: Estatísticas dos Parâmetros do pavimento (S. Homogêneo 4 - NS') .440 Figura 10.5: Estatísticas dos Parâmetros do pavimento (S. Homogêneo 5 - NG').441 Figura 10.6: Estatísticas dos Parâmetros do pavimento (S. Homogêneo 6 - NA') 442 Figura 10.7: Estatísticas dos Parâmetros do pavimento (S. Homogêneo 7 - NG') 443 Figura 10.8: Estatísticas dos Parâmetros do pavimento (S. Homogêneo 8 - NA') 444 Figura 10.9: Estatísticas dos Parâmetros do pavimento (S. Homogêneo 9 - NA') .445 Figura 10.10: Estatísticas dos Parâmetros do pavimento (S. Homogêneo 10 - NA')

Figura 10.11: Estatísticas dos Parâmetros do pavimento (S. Homogêneo 11 - NA') 447

Figura 10.12: Estatísticas dos Parâmetros do pavimento (S. Homogêneo 12 - NA') 
Figura 10.13: Estatísticas dos Parâmetros do pavimento (S. Homogêneo 13 - NA')

Figura 10.14: Estatísticas dos Parâmetros do pavimento (S. Homogêneo 14 - NA')

Figura 10.15: Estatísticas dos Parâmetros do pavimento (S. Homogêneo 15 - NA')

Figura 10.16: Estatísticas dos Parâmetros do pavimento (S. Homogêneo 16 - LA')

Figura 10.17: Estatísticas dos Parâmetros do pavimento (S. Homogêneo 17 - LA')

Figura 10.18: Estatísticas dos Parâmetros do pavimento (S. Homogêneo 18 - LA'-LG')

Figura 10.19: Estatísticas dos Parâmetros do pavimento (S. Homogêneo 19 - LA')

Figura 10.20: Estatísticas dos Parâmetros do pavimento (S. Homogêneo 20 - NA)

Figura 10.21: Estatísticas dos Parâmetros do pavimento (S. Homogêneo 21 - LG')

Figura 10.22: Estatísticas dos Parâmetros do pavimento (S. Homogêneo 22 - LA') 458

Figura 10.23: Estatísticas dos Parâmetros do pavimento (S. Homogêneo 23 - LA') 459

Figura 10.24: Estatísticas dos Parâmetros do pavimento (S. Homogêneo 23 - NS'NA') 460

Figura 10.25: Estatísticas dos Parâmetros do pavimento (S. Homogêneo 24 - NS'NA'). 461

Figura 10.26: Estatísticas dos Parâmetros do pavimento (S. Homogêneo 25 - NS'NA'). 462

Figura 10.27: Estatísticas dos Parâmetros do pavimento (S. Homogêneo 26 - NS'NA') 463

Figura 13.1: Estatísticas dos valores de módulo de resiliência retroanalisado - todas as rodovias (sítios geológico /pedológico; classificações MCT e HRB) [BD3] .481 
Figura 13.2: Estatísticas dos valores de módulo de resiliência retroanalisado - todas as rodovias (sítio pedológico; classificações MCT e HRB; tipo de seção de terraplanagem) [BD3] ....................................................................... 482

Figura 13.3: Estatísticas dos valores de módulo de resiliência retroanalisado - todas as rodovias, nenhuma chuva acumulada em 8 dias (sítios geológico /pedológico; classificações $M C T$ e $H R B$, tipo de seção de terraplenagem) [BD3] 482

Figura 13.4: Estatísticas dos valores de relação de módulo retroanalisado - todas as rodovias (sítios geológico e pedológico; classificações MCT e HRB; tipo de seção de terraplanagem) (condições de chuva especificadas) [BD3] 483 


\section{LISTA DE TABELAS}

Tabela 2.1 - Dados qualitativos das propriedades mecânicas e hidráulicas da classificação MCT, segundo Nogami e Villibor (1995) .56

Tabela 2.2 - Faixas de variação dos valores da classificação MCT (Nogami e Villibor, 1995)

Tabela 2.3 - Procedimentos de laboratório para determinação do módulo de resiliência de solos (NCHRP, 2008).

Tabela 2.4 - Conclusões a partir de pesquisas em módulo de resiliência entre 19861996

Tabela 2.5 - Características das pesquisas em módulo de resiliência entre 1986 e 1996 (NCHRP, 2008)

Tabela 2.6 - Variável B para diferentes materiais e níveis de $\theta$ (ZAMAN et al., 1994)

Tabela 2.7 - Valores de módulo de resiliência para solos do estado de São Paulo (Franzoni, 1990 apud Balbo, 2007). 100

Tabela 2.8 - Modelos resilientes para solos granulares de Santa Catarina (Valle, 1966 apud Balbo, 2007) 100

Tabela 2.9 - Constantes de modelo baseado na tensão total (modelo 2l-1) por Rada \& Witczak (1981) 104

Tabela 2.10 - Fatores de correção para o modelo de Pezzo \& Hudson (1994)......108

Tabela 2.11 - Constantes do modelo de MR (Titus-Glover \& Fernando, 1995)......109

Tabela 2.12 - Constantes do modelo de MR para subleitos de New Jersey (Maher et al., 2000) 110

Tabela 2.13 - Gradiente de módulo de resiliência com respeito ao grau de saturação

Tabela 2.14 - Constantes de regressão do modelo

Tabela 2.15 - Constantes de regressão do modelo

Tabela 2.16 - Coeficientes de regressão (Modelo de Rada e Witczak para materiais de Base/Subbase)

Tabela 2.17 - Coeficientes de regressão para o modelo

Tabela 2.18 - Propriedades dos solos incluídos no estudo de Nazzal \& Mohammad (2010)

Tabela 2.19 - Constantes do modelo para R (Zhang e Sun, 2004) 124 
Tabela 2.20 - Constantes do modelo para Dc (Zhang e Sun, 2004) .....................125

Tabela 3.1: Faixas de valores do parâmetro AREA segundo WSDOT (2005) ........134

Tabela 3.2: Plano de amostragem inicialmente proposto .....................................136

Tabela 3.3: Classificação adotada para o plano de amostragem dos estudos .......137

Tabela 3.4 Locais selecionados para os ensaios de acordo com o plano de

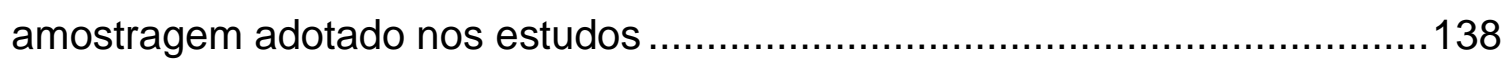

Tabela 3.5: Diretrizes para coleta de amostras para ensaios de laboratório............144

Tabela 3.6: Legenda de descrição das etapas indicadas na Figura 3.7 .................145

Tabela 3.7: Estruturas de pavimento identificadas .............................................146

Tabela 3.8: Resultados dos ensaios de módulo obtidos com uso do equipamento $L W D$

Tabela 3.9: Resultados dos ensaios de módulo obtidos com uso do equipamento $L W D$

Tabela 3.10: Resultados dos ensaios de campo (peso específico aparente seco, umidade e grau de saturação) …………………...................................152

Tabela 3.11: Resultados dos ensaios de granulometria......................................153

Tabela 3.12: Resultados dos ensaios de granulometria, limites de Atterberg,

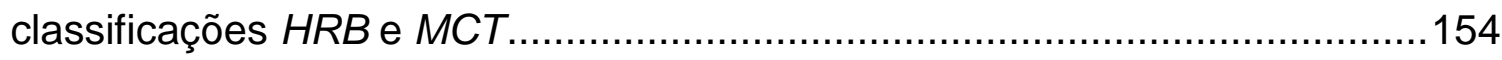

Tabela 3.13: Resultados dos ensaios de compactação, CBR e expansão ..............155

Tabela 3.14: Resultados dos ensaios de módulo de resiliência em laboratório ......156

Tabela 3.15: Comparativo entre ensaios de umidade e peso específico aparente in

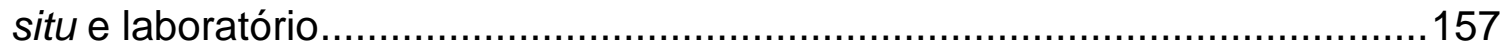

Tabela 3.16: Data dos levantamentos em cada local estudado ............................163

Tabela 4.1: (a) Média menos desvio-padrão e (b) número de amostras dos valores de CBR para cada combinação de classes de solos (HRB e MCT) .....................188

Tabela 4.2: (a) Média mais desvio-padrão e (b) número de amostras dos valores de expansão para cada combinação de classes de solos (HRB e MCT) ..............188

Tabela 4.3: (a) Média menos desvio-padrão dos valores de Esl,retro para cada combinação de classes de solos (HRB e MCT) ……...................................191

Tabela 4.4: Parâmetros mínimos e máximos das estruturas em função da relação de módulo (Ersl,retro / E1)

Tabela 4.5: Parâmetros mínimos e máximos das estruturas em função da relação de módulo (Ersl,retro / E1) - Pavimentos tipicamente flexíveis (E2 igual ou inferior a $500 \mathrm{MPa})$. 196 
Tabela 4.6: Segmentação das rodovias em estudo pelo critério do sítio geológico (fonte: autor adaptado de GeoSGB/CPRM) ... .204

Tabela 4.7: Descrição dos sítios geológicos identificados (fonte: autor adaptado de GeoSGB/CPRM) 205

Tabela 4.8: Segmentação da rodovia pelo sítio pedológico atravessado (fonte: autor adaptado de EMBRAPA) 209

Tabela 4.9: Composição e características dos sítios pedológicos citados (fonte: EMBRAPA)

Tabela 4.10: Áreas de influência adotadas para as estações pluviométricas nas rodovias em estudo. 213

Tabela 4.11: Dados dos segmentos homogêneos com relação ao tipo de solo pela classificação $M C T$ .237

Tabela 5.1: Correspondências encontradas nos estudos para Sítio Geológico e Classificação $H R B$ [BD3]. .239

Tabela 5.2: Correspondências encontradas nos estudos para Sítio Pedológico e Classificação $M C T$ [BD3] 240

Tabela 9.1: histórico de intervenções informado - km 402 (pista norte) . 309

Tabela 9.2: Estrutura do pavimento da faixa externa - km 402 (pista norte) 310

Tabela 9.3: Estatística dos resultados do ensaio com $L W D$. 310

Tabela 9.4: Estatística dos resultados de determinação do módulo da camada de BGS 310

Tabela 9.5: Resumo dos ensaios realizados com material próximo ao km 402 ......312 Tabela 9.6: histórico de intervenções informado - km 405 (pista norte) ...................320

Tabela 9.7: Estrutura do pavimento da faixa externa - km 405 (pista norte) ............321

Tabela 9.8: Estatística dos resultados do ensaio com $L W D$...................................321

Tabela 9.9: Estatística dos resultados de determinação do módulo da camada de BGS

Tabela 9.10: Resumo dos ensaios realizados com material próximo ao km 405 ....323

Tabela 9.11: histórico de intervenções informado - km 414 (pista sul)....................331

Tabela 9.12: Estrutura do pavimento da faixa externa - km 414 (pista sul) .............332

Tabela 9.13: Estatística dos resultados do ensaio com $L W D$...............................332

Tabela 9.14: Estatística dos resultados de determinação do módulo da camada de $B G S$ .332

Tabela 9.15: Resumo dos ensaios realizados com material próximo ao km 414 ....334 
Tabela 9.16: histórico de intervenções informado - km 418 (pista norte) 342

Tabela 9.17: Estrutura do pavimento da faixa externa - km 418 (pista norte) .........343

Tabela 9.18: Estatística dos resultados do ensaio com $L W D$. .343

Tabela 9.19: Estatística dos resultados de determinação do módulo da camada de

BGS 343

Tabela 9.20: Resumo dos ensaios realizados com material próximo ao km 418 ....345

Tabela 9.21: histórico de intervenções informado - km 423 (pista norte) .353

Tabela 9.22: Estrutura do pavimento da faixa externa - km 423 (pista norte) 354

Tabela 9.23: Estatística dos resultados do ensaio com $L W D$. .354

Tabela 9.24: Estatística dos resultados de determinação do módulo da camada de $B G S$ .354

Tabela 9.25: Resumo dos ensaios realizados com material próximo ao km 423 ....356

Tabela 9.26: histórico de intervenções informado - km 429 (pista norte) .364

Tabela 9.27: Estrutura do pavimento da faixa externa - km 429 (pista norte) 365

Tabela 9.28: Estatística dos resultados do ensaio com $L W D$. 365

Tabela 9.29: Estatística dos resultados de determinação do módulo da camada de $B G S$ .365

Tabela 9.30: Resumo dos ensaios realizados com material próximo ao km 429 ....367

Tabela 9.31: histórico de intervenções informado - km 431 (pista norte) . .375

Tabela 9.32: Estrutura do pavimento da faixa externa - km 431 (pista norte) 376

Tabela 9.33: Estatística dos resultados do ensaio com LWD. 376

Tabela 9.34: Estatística dos resultados de determinação do módulo da camada de $B G S$ 376

Tabela 9.35: Resumo dos ensaios realizados com material próximo ao km 431 ....378 Tabela 9.36: histórico de intervenções informado - km 434 (pista norte) ................386

Tabela 9.37: Estrutura do pavimento da faixa externa - km 434 (pista norte) .........387

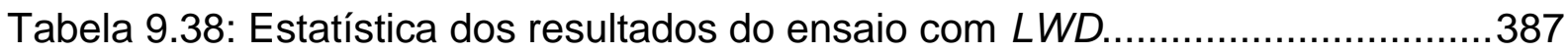

Tabela 9.39: Estatística dos resultados de determinação do módulo da camada de $B G S$ 387

Tabela 9.40: Resumo dos ensaios realizados com material próximo ao km 434 ....389

Tabela 9.41: histórico de intervenções informado - km 456 (pista norte) 397

Tabela 9.42: Estrutura do pavimento - km 456 (pista norte) 397

Tabela 9.43: Estatística dos resultados do ensaio com $L W D$. 398 
Tabela 9.44: Estatística dos resultados de determinação do módulo da camada de $B G S$ 398

Tabela 9.45: Resumo dos ensaios realizados com material próximo ao km 456 ....400

Tabela 9.46: histórico de intervenções informado - km 460 (pista norte) .................409

Tabela 9.47: Estrutura do pavimento da faixa externa - km 460 (pista norte) .........409

Tabela 9.48: Estatística dos resultados do ensaio com $L W D$.................................409

Tabela 9.49: Estatística dos resultados de determinação do módulo da camada de $B G S$ 409

Tabela 9.50: Resumo dos ensaios realizados com material próximo ao km 460 ....411

Tabela 9.51: histórico de intervenções informado - km 482 (pista sul). 419

Tabela 9.52: Estrutura do pavimento da faixa externa - km 482 (pista sul) .............420

Tabela 9.53: Estatística dos resultados do ensaio com $L W D$................................420

Tabela 9.54: Resumo dos ensaios realizados com material próximo ao km 482 ....422

Tabela 9.55: histórico de intervenções informado - km 492 (pista sul). 430

Tabela 9.56: Estrutura do pavimento da faixa externa - km 492 (pista sul) 430

Tabela 9.57: Estatística dos resultados do ensaio com $L W D$ 430

Tabela 9.58: Resumo dos ensaios realizados com material próximo ao km 492 ....431 Tabela 14.1: Matriz com estatísticas dos valores pontuais de módulo [MPa] (todos os tipos de seções de terraplenagem) [BD2] 485

Tabela 14.2: Matriz com estatísticas dos valores pontuais de módulo [MPa] (seções em corte) [BD2] 485

Tabela 14.3: Matriz com estatísticas dos valores pontuais de módulo [MPa] (seções em aterro) [BD2] 486

Tabela 14.4: Matriz com estatísticas dos valores pontuais de módulo [MPa] (seções mistas) [BD2] 486

Tabela 14.5: Matriz com estatísticas dos valores pontuais de chuva acumulada [mm] (todas as seções) [BD2] .

Tabela 14.6: Matriz com estatísticas dos valores pontuais de chuva acumulada [mm] (seções em corte) [BD2].

Tabela 14.7: Matriz com estatísticas dos valores pontuais de chuva acumulada [mm] (seções em aterro) [BD2] 488

Tabela 14.8: Matriz com estatísticas dos valores pontuais de chuva acumulada [mm] (seções mistas) [BD2] 
Tabela 14.9: Matriz com estatísticas dos valores de módulo (MPa), condição seca nenhuma chuva acumulada em 8 dias [mm] (todas as seções) [BD2] .............489

Tabela 14.10: Matriz com estatísticas dos valores de módulo (MPa), condição seca nenhuma chuva acumulada em 8 dias [mm] (seções em corte) [BD2] .............490

Tabela 14.11: Matriz com estatísticas dos valores de módulo (MPa), condição seca nenhuma chuva acumulada em 8 dias [mm] (seções em aterro) [BD2] ............491

Tabela 14.12: Matriz com estatísticas dos valores de módulo (MPa), condição seca nenhuma chuva acumulada em 8 dias [mm] (seções mistas) [BD2] ................491

Tabela 15.1: Matriz com estatísticas dos valores de Relação de Módulo* (todas as seções) [BD3].

Tabela 15.2: Matriz com estatísticas dos valores de Relação de Módulo* (seções em corte) [BD3] 494

Tabela 15.3: Matriz com estatísticas dos valores de Relação de Módulo* (seções em aterro) [BD3]... 495

Tabela 15.4: Matriz com estatísticas dos valores de Relação de Módulo* (seções mistas) $[B D 3]$. 495 


\section{LISTA DE SIGLAS E ABREVIATURAS}

AASHTO - American Association of State Highway and Transportation Officials (Associação Americana Oficial em Transportes e Rodovias)

ANEEL - Agência Nacional de Energia Elétrica

ARTESP - Agência Reguladora de Transportes do Estado de São Paulo

BD1 - Banco de Dados 1 desenvolvido no âmbito da presente pesquisa, contendo dados de ensaios de laboratório com solos de subleito

$B D 2$ - Banco de Dados 2 desenvolvido no âmbito da presente pesquisa, contendo dados históricos de ensaios deflectométricos

$B D 3$ - Banco de Dados 3 desenvolvido no âmbito da presente pesquisa, contendo dados diversos para segmentos homogêneos

BD4 - Banco de Dados 4 desenvolvido no âmbito da presente pesquisa, contendo dados diversos para segmentos homogêneos com base na classificação $M C T$

$B G S$ - Brita Graduada Simples

BGTC - Brita Graduada Tratada com Cimento

$C$ - Argila (Clay) de acordo com a classificação SUCS

$C A$ - Concreto Asfáltico

CBR - California Bearing Ratio (Índice de Suporte Califórnia)

CFT - Camada final de terraplenagem

COPPE - Instituto Alberto Luiz Coimbra de Pós-Graduação e Pesquisa de Engenharia

CPRM - Empresa Pública vinculada ao Ministério de Minas e Energia com as atribuições de Serviço Geológico do Brasil

$D A E E / S P$ - Departamento de Águas e Energia Elétrica do Estado de São Paulo

DCP - Dynamic Cone Penetrometer (Cone de penetração dinâmica)

$D E R-S P$ - Departamento de Estradas e Rodagem de São Paulo

$D N E R$ - Departamento Nacional de Estradas de Rodagem

DNIT - Departamento Nacional de Infraestrutura de Transportes

DOT - Department of Transportation (Departamento de Transportes nos EUA)

$D P$ - Desvio padrão

EMBRAPA - Empresa Brasileira de Pesquisa Agropecuária

EUA - Estados Unidos da América

Exp. - Expansão do solo

FWD - Falling Weight Deflectometer (Deflectômetro de Impacto) 
G - Cascalho (Gravel) ou Seixo Rolado de acordo com a classificação SUCS GeoSGB - Sistema de Geociências do Serviço Geológico do Brasil HRB - Highway Research Board (Órgão de Pesquisa em Rodovias nos EUA) $H$-Solos de alta compressibilidade (High) de acordo com a classificação SUCS IG - Índice de Grupo

INPE - Instituto Nacional de Pesquisas Espaciais

IP - Índice de Plasticidade

ISC - Índice de Suporte Califórnia

$L A$ - Areia laterítica quartzosa de acordo com a classificação $M C T$

$L A^{\prime}$ - Solo arenoso laterítico de acordo com a classificação $M C T$

LBR - Limerock Bearing Ratio (Índice de Suporte Limerock)

$L G^{\prime}$ - Solos argiloso laterítico de acordo com a classificação $M C T$

$L$ - Solos de baixa compressibilidade (Low) de acordo com a classificação MCT

$L L$ - Limite de Liquidez

$L P$ - Limite de Plasticidade

LTPP - Long Term Pavement Performance

LVDT - Linear Variable Differential Transformer (Transformador Diferencial Variável Linear)

LWD - Light Weight Deflectometer (Deflectômetro de Carga Leve ou portátil)

$M$ - Silte $(M o)$ de acordo com a classificação SUCS

MCT - Miniatura Compactado Tropical (método de classificação de solos tropicais)

MEPDG - Mechanistic-Empirical Pavement Design Guide (Guia mecanístico-empírico de dimensionamento de pavimentos)

MR (ou Mr) - Módulo de Resiliência

$N A$ - Areais, siltes e misturas de areias e siltes com predominância de grão de quartzo e/ou mica, não laterítico

$N A^{\prime}-$ Misturas de areias quartzosas com finos de comportamento não laterítico (solo arenoso)

NCHRP - National Cooperative Highway Research Program (Programa de Pesquisa em Rodovias Nacional Cooperativa nos EUA)

$N G$ ' - Solo argiloso não laterítico de acordo com a classificação $M C T$

$N S^{\prime}$ - Solo siltoso não laterítico de acordo com a classificação $M C T$

$O$ - Solo orgânico (Organic) de acordo com a classificação SUCS

OMC - Optimum Moisture Content (teor de umidade ótima)

$P$ - Solo mal graduado (poorly graded) de acordo com a classificação SUCS 
$P C D$ - Plataforma Automática de Coleta de Dados Ambientais

PI - Energia Intermediária de Proctor

$P l s$ - Poços de Inspeção

$P M$ - Energia Modificada de Proctor

$P N$ - Energia Normal de Proctor

$P t$ - Solo tipo Turfa de acordo com a classificação SUCS

QI-Quociente de Irregularidade

RAP - Reclaimed Asphalt Pavement (pavimento de asfalto reciclado)

$R C$ - Teste de coluna ressonante

$R L T$ - Repeated Load Triaxial (ensaio de carga triaxial repetida)

$S$ - Areia (Sand) de acordo com a classificação SUCS

SAFL - Solo Arenoso Fino Laterítico

SI - Sistema Internacional de unidades

SIGEL - Sistema de Informações Geográficas do Setor Elétrico

SINDA - Sistema Integrado de Dados Ambientais

$S L$ - Subleito

SUCS - Sistema Unificado de Classificação de Solos

SWCC - Soil-Water Characteristic Curve (Curvas Características Solo-Umidade)

TRB - Transportation Research Board (Órgão de Pesquisa em Transportes nos EUA)

UFRJ - Universidade Federal do Rio de Janeiro

USACE - United States Army Corps of Engineers (Corpo de engenheiros do exército americano)

$W$ - Solo bem graduado (well graded) de acordo com a classificação SUCS 


\section{LISTA DE SÍMBOLOS}

\pm = mais ou menos;

$\%=$ percentual;

$(u a-u w)=$ sucção matricial;

${ }^{\circ}=$ grau;

$\mathrm{cm}=$ unidade de distância - centímetro $(1 \mathrm{~cm}=0,01 \mathrm{~m})$;

$D 0$ = deflexão no ponto de aplicação de carga $(0,01 \mathrm{~mm})$;

$D 0, L W D=$ deflexão máxima medida com equipamento $L W D(0,01 \mathrm{~mm})$;

D20 = deflexão a $20 \mathrm{~cm}$ do ponto de aplicação de carga $(0,01 \mathrm{~mm})$;

D30 = deflexão a $30 \mathrm{~cm}$ do ponto de aplicação de carga $(0,01 \mathrm{~mm})$;

D60 = deflexão a $60 \mathrm{~cm}$ do ponto de aplicação de carga $(0,01 \mathrm{~mm})$;

$D 90$ = deflexão a $90 \mathrm{~cm}$ do ponto de aplicação de carga $(0,01 \mathrm{~mm})$;

$D 120$ = deflexão a $120 \mathrm{~cm}$ do ponto de aplicação de carga $(0,01 \mathrm{~mm})$;

$D 150$ = deflexão a $150 \mathrm{~cm}$ do ponto de aplicação de carga $(0,01 \mathrm{~mm})$;

$e=$ índice de vazios (\%);

et $=$ deformação de tração na fibra inferior do revestimento $(\mathrm{mm} / \mathrm{mm})$;

$E O$, calc = valor de módulo calculado $\left(\mathrm{MPa}\right.$ ou $\left.\mathrm{kgf} / \mathrm{cm}^{2}\right)$;

$E b=$ módulo da base (MPa ou $\left.\mathrm{kgf} / \mathrm{cm}^{2}\right)$;

Emax = módulo máximo (MPa ou $\left.\mathrm{kgf} / \mathrm{cm}^{2}\right)$;

$E r=$ módulo de revestimento $\left(\mathrm{MPa}\right.$ ou $\left.\mathrm{kgf/} / \mathrm{cm}^{2}\right)$;

$E s b=$ módulo da subbase $\left(\mathrm{MPa}\right.$ ou $\left.\mathrm{kgf} / \mathrm{cm}^{2}\right)$;

$E s l=$ módulo de resiliência do subleito $\left(\mathrm{MPa}\right.$ ou $\left.\mathrm{kgf} / \mathrm{cm}^{2}\right)$;

Esl, retro = módulo de resiliência retroanalisado;

Exp. - expansão (\%);

$g=$ unidade de massa - grama $(1 \mathrm{~g}=0,001 \mathrm{~kg})$;

$\mathrm{g} / \mathrm{cm}^{3}=$ unidade de medida de peso específico - grama por centímetro cúbico (1 $\left.\mathrm{g} / \mathrm{cm}^{3}=1000 \mathrm{kgf} / \mathrm{m}^{3}\right)$;

$\gamma d=$ peso específico aparente $\operatorname{seco}\left(\mathrm{g} / \mathrm{cm}^{3}\right)$;

$\gamma d$ máx. = peso específico aparente seco máximo $\left(\mathrm{g} / \mathrm{cm}^{3}\right)$;

$\gamma s$ = peso específico aparente seco real dos grãos do solo $\left(\mathrm{g} / \mathrm{cm}^{3}\right)$;

h mold - umidade de moldagem (\%);

h pós sat. - umidade pós saturação (\%); 
$\mathrm{kgf}=$ unidade de medida de massa no SI - kilograma-força $(1 \mathrm{kgf} \sim 9,81 \mathrm{~N})$;

$\mathrm{kgf} / \mathrm{cm}^{2}$ = unidade de medida de pressão - kilograma-força por centímetro quadrado $\left(1 \mathrm{kgf} / \mathrm{cm}^{2} \sim 0,1 \mathrm{MPa}\right)$;

$k N=$ unidade de medida de força - kilo Newton $(1 \mathrm{kN}=1000 \mathrm{~N})$;

ksi = unidade de medida de pressão - kilopound force per square inch $\left(1 \mathrm{ksi}=1000 \mathrm{psi} \sim 70 \mathrm{kgf} / \mathrm{cm}^{2} \sim 7 \mathrm{MPa}\right)$;

$m$ = unidade de distância no $S I-$ metro;

$\mathrm{m} / \mathrm{km}=$ unidade de medida de irregularidade longitudinal do pavimento - metro por quilometro;

$\mu=$ coeficiente de poisson da camada;

$\mu a=$ pressão atmosférica;

$\mu w=$ poro pressão da água;

$m m=$ unidade de medida de distância - milímetros $(1 \mathrm{~mm}=10-3 \mathrm{~m})$;

$\mathrm{mm} / \mathrm{m}=$ unidade de medida de irregularidade longitudinal do pavimento - milímetro por metro;

$\mathrm{MPa}=$ unidade de medida de pressão no SI - Mega Pascal (106 Pascal);

$\mathrm{MPa} / \mathrm{m}$ = relação entre pressão aplicada e deslocamento causado - Mega Pascal por metro;

$M R$ = módulo de resiliência (MPa ou $\mathrm{kgf/cm2})$;

$N=$ unidade de medida de força no SI - Newton;

$\mathrm{N} / \mathrm{m} 2$ = unidade de medida de pressão - Newton por metro quadrado $(1 \mathrm{~N} / \mathrm{m} 2=1 \mathrm{~Pa})$;

$p=$ carga distribuída por unidade de área $\left(\mathrm{kgf} / \mathrm{cm}^{2}\right)$;

pa = pressão atmosférica $\left(\mathrm{MPa}\right.$ ou $\left.\mathrm{kgf} / \mathrm{cm}^{2}\right)$;

$\mathrm{Pa}=$ unidade de medida de pressão no SI - Pascal $\left(1 \mathrm{~Pa}=1 \mathrm{~N} / \mathrm{m}^{2}\right)$;

$P C=$ percentual de compactação (\%);

pcf $=$ unidade de medida de peso específico - pound force per cubic feet $(1 \mathrm{pcf}=1$ $\left.\mathrm{lbf} / \mathrm{ft}^{3}=0,01601846 \mathrm{~g} / \mathrm{cm}^{3}=16,01846 \mathrm{kgf} / \mathrm{m}^{3}\right)$;

pci = relação entre pressão aplicada e deslocamento causado (1 pci = 1 psi/pol. = 0,271 MPa/m);

pol. = unidade de medida de distância - polegada $(1$ pol. = 0,0254 m);

psi = unidade de medida de pressão - pound force per square inch (1 psi = 0,070 kgf/ $\left.\mathrm{cm}^{2}=0,007 \mathrm{MPa}\right)$;

$\theta=$ tensão octaédrica normal (MPa ou $\left.\mathrm{kgf} / \mathrm{cm}^{2}\right)$;

$R c=$ raio de curvatura $(m)$;

$S$ = grau de saturação (\%); 
$\sigma=$ tensão $\left(\mathrm{kgf} / \mathrm{cm}^{2}\right)$;

бatm = pressão atmosférica $\left(\mathrm{kPa}\right.$ ou $\left.\mathrm{kgf} / \mathrm{cm}^{2}\right)$;

$\sigma 1$ = tensão principal maior ( $\mathrm{MPa}$ ou $\left.\mathrm{kgf} / \mathrm{cm}^{2}\right)$;

$\sigma 2$ = componente da tensão $\left(\mathrm{MPa}\right.$ ou $\left.\mathrm{kgf} / \mathrm{cm}^{2}\right)$;

$\sigma 3$ = tensão confinante ( $M P a$ ou $\left.\mathrm{kgf} / \mathrm{cm}^{2}\right)$;

$S=$ grau de saturação do solo (\%);

Scampo = grau de saturação do material em campo [in situ] (\%);

$\sigma d=$ tensão desvio (MPa ou $\left.\mathrm{kgf} / \mathrm{cm}^{2}\right)$;

$\mathrm{SI}$ = Sistema Internacional de unidades;

smax = tensão máxima (MPa ou $\left.\mathrm{kgf} / \mathrm{cm}^{2}\right)$;

Swot = grau de saturação no teor de umidade ótima;

$T=$ temperatura $\left({ }^{\circ} \mathrm{C}\right)$;

uf = dano relativo (método da AASHTO/93);

$\tau o c t$ = tensão de cisalhamento octaédrica $\left(\mathrm{MPa}\right.$ ou $\left.\mathrm{kgf} / \mathrm{cm}^{2}\right)$;

$w=$ teor de umidade (\%);

wopt = teor de umidade ótima (\%). 


\section{SUMÁRIO}

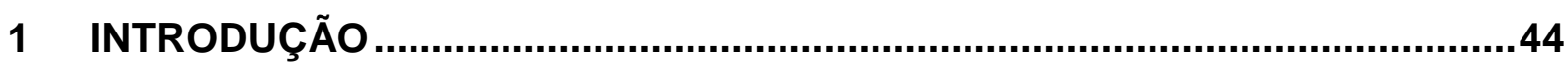

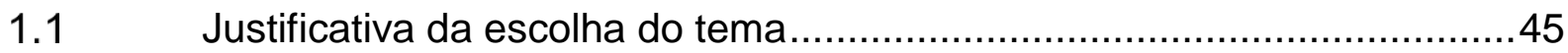

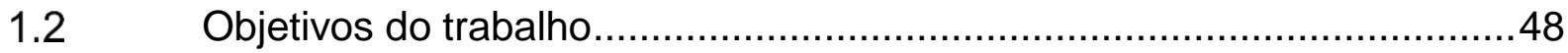

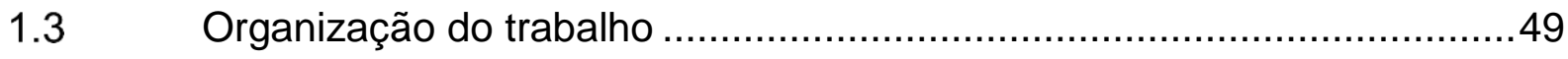

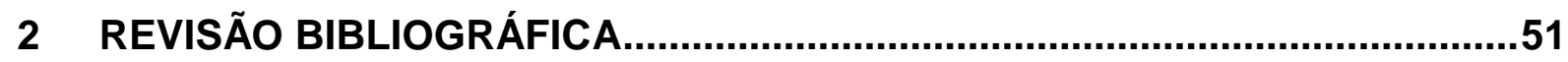

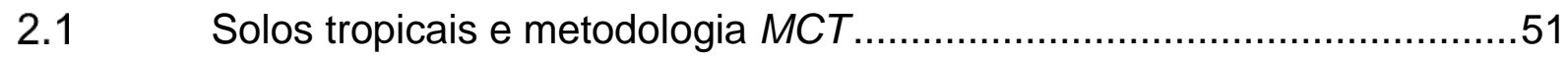

2.1.1 Classificação dos solos pela metodologia MCT ....................................53

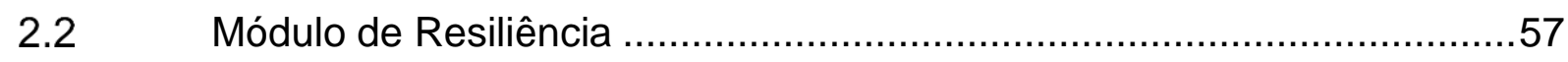

2.2.1 Modelos para representar o módulo de resiliência de solos de laboratório 62

2.2.2 Fatores que influenciam no estado físico e estado de tensões dos solos 67

2.2.3 Modelos para determinação de módulo de resiliência de solos a partir do CBR 96

2.2.4 Modelos para determinação de módulo de resiliência de solos a partir de ensaios de compressão simples

2.2.5 Modelos que levam em conta os parâmetros físicos dos solos e a variação de umidade 103

2.2.6 Estimativa de valores de módulo in situ a partir de ensaios deflectométricos .

2.3 Análise crítica da revisão bibliográfica.............................................129

\section{ENSAIOS DE CAMPO E DE LABORATÓRIO - ESTUDO DE CASO DE UMA} RODOVIA FEDERAL.

3.1 Procedimento adotado para seleção dos pontos de análise .................132

3.2 Seleção de pontos e localização dos poços de inspeção realizados .....137

3.3 Procedimento de abertura dos poços de inspeção...............................142

3.4 Estruturas de pavimento identificadas nos Pls .................................145

3.5 Resultados dos ensaios com LWD (Light Weight Deflectometer) ..........147

3.6 Resumo dos resultados de ensaios de laboratório...............................150

3.7 Comparativo peso específico aparente e umidade in situ versus condição de laboratório 
3.8 Resultados de retroanálise dos módulos do subleito dos locais sondados 160

3.9 Análises comparativas entre os valores de módulo obtidos em campo .163

3.10 Comparativo entre valores de Módulo de resiliência (laboratório $x$

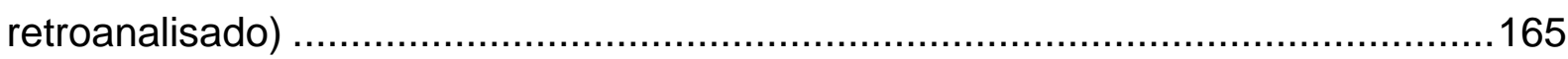

3.11 Previsibilidade do Módulo de Resiliência pelo valor de CBR .................168

3.12 Correlações para solos de graduação grossa ..................................173

Correlações para os solos finos ...................................................176

3.14 Análise comparativa dos modelos propostos ...................................177

3.15 Estudo do comportamento do MR em campo ..................................178

Conclusões parciais do estudo de caso ..........................................180

\section{ENSAIOS DE CAMPO E LABORATÓRIO - ESTUDO DE CASOS DE} RODOVIAS DO ESTADO DE SÃO PAULO

4.1 Montagem de um banco de dados de ensaios de subleito $(B D 1)$.........183

4.2 Correlações obtidas entre os resultados dos ensaios de laboratório .....184

4.3 Estudo teórico para verificação da influência da estrutura no valor o módulo retroanalisado do subleito

4.4 Proposição de metodologia para avaliação de dados de Módulo de Subleito retroanalisado - rodovias estaduais $(\mathrm{SP})$.................................................. 199

4.4.1 Mapeamento Geológico .........................................................200

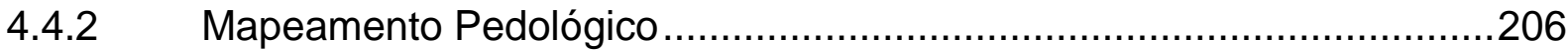

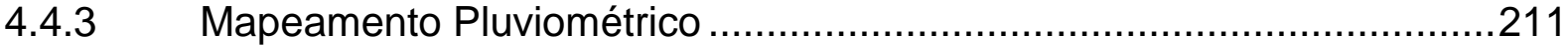

4.4.4 Segmentação pelo tipo de seção de terraplenagem ............................214

4.4.5 Consolidação dos dados de levantamento deflectométrico e retroanálise dos valores de módulo de subleito

4.4.6 Consulta de informações e consolidação do banco de dados deflectométrico $(B D 2)$

4.4.7 Consolidação de um novo banco de dados para segmentos homogêneos $(B D 3) \quad 216$

4.5 Apresentação de resultados da aplicação da metodologia proposta para o trecho piloto (Rodoanel Sul)

4.5.1 Análise dos dados pontuais dos valores de módulo e demais características 
4.5.2 Análise dos dados médios para os segmentos homogêneos. 224

4.6 Discussões, conclusões e recomendações para o trecho piloto .230

4.7 Apresentação de resultados da aplicação da metodologia proposta para rodovia SP 318 (Sítios de solos lateríticos) .231

4.7.1 Análise dos dados pontuais dos valores de módulo e demais características 231

4.7.2 Análise dos dados médios para os segmentos homogêneos .233

4.8 Estudo para os segmentos homogêneos segundo a classificação MCT (BD4) 236

4.8.1 Resultados dos estudos do comportamento estrutural nos segmentos homogêneos (BD4)

\section{ANÁLISE CRÍTICA DOS ESTUDOS E PROPOSIÇÃO DE PARÂMETROS}

PARA FINS DE DIMENSIONAMENTO

5.1 Correspondências entre sítios pedológico/geológico e classificações de solos 239

5.2 Avaliação da influência da pluviosidade no valor do módulo de resiliência retroanalisado do subleito

5.2.1 Análise da influência dos parâmetros de pluviosidade para todo o banco de dados (BD2) 242

5.2.2 Análise da influência dos parâmetros de pluviosidade para determinados sítios pedológicos (BD2) 245

5.3 Avaliação da influência de cada componente estudado no comportamento mecânico do subleito

5.3.1 Análise dos dados pontuais dos valores de módulo e demais características (BD2)

5.3.2 Apresentação das estatísticas para os parâmetros mais importantes (BD2) 254

5.3.3 Análise dos dados médios para os segmentos homogêneos. .256

\section{ANÁLISE DO POTENCIAL DE IMPACTO DA METODOLOGIA PROPOSTA EM RELAÇÃO AOS MÉTODOS ATUAIS DE DIMENSIONAMENTO} 262

6.1 Recomendações gerais para fins de adoção de parâmetros de dimensionamento .262 
6.2 Exemplo de aplicação de metodologia que contempla as variações do

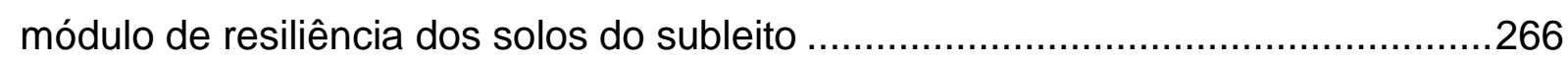

6.2.1 Rodovia SP 099 - Rodovia dos Tamoios ...........................................266

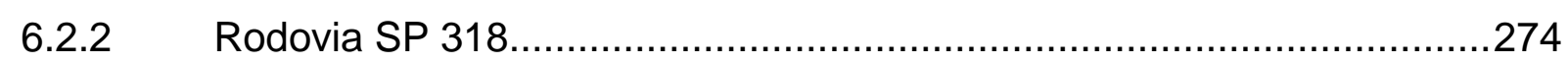

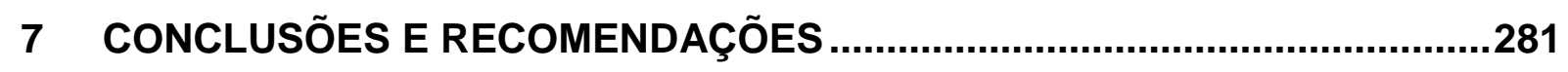

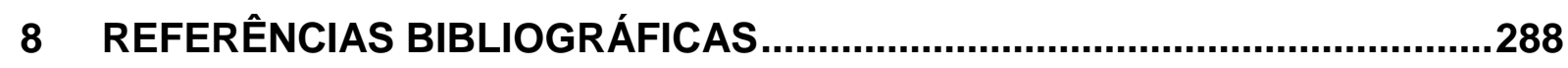

9 ANEXO A - RESULTADOS INDIVIDUAIS DAS SONDAGENS E ENSAIOS ESTUDO DE CASO DE UMA RODOVIA FEDERAL .........................................306

9.1 Poço de Inspeção do km 402 (Pista Norte) …......................................307

$9.2 \quad$ Poço de Inspeção do km 405 (Pista Norte) ….......................................318

9.3 Poço de inspeção do km 414 (Pista Sul) ..............................................329

9.4 Poço de inspeção do km 418 (Pista Norte) ………..............................340

9.5 Poço de inspeção do km 423 (Pista Norte) ...........................................351

9.6 Poço de inspeção do km 429 (Pista Norte) ..........................................362

9.7 Poço de inspeção do km 431 (Pista Norte) ……………......................373

9.8 Poço de inspeção do km 434 (Pista Norte) ………..............................384

9.9 Poço de inspeção do km 456 (Pista Norte) ………..............................395

9.10 Poço de inspeção do km 460 (Pista Norte) ………............................406

9.11 Poço de inspeção do km 482 (Pista Sul) ............................................417

9.12 Poço de inspeção do km 492 (Pista Sul) ............................................428

10 ANEXO B - PARÂMETROS ESTATÍSTICOS DOS SEGMENTOS HOMOGÊNEOS PELA METODOLOGIA MCT (BD4) .....................................436

11 ANEXO C - SEGMENTOS HOMOGÊNEOS EM TERMOS DE SEÇÕES DE TERRAPLENAGEM E SEGMENTOS HOMOGÊNEOS FINAIS DOS BANCOS DE

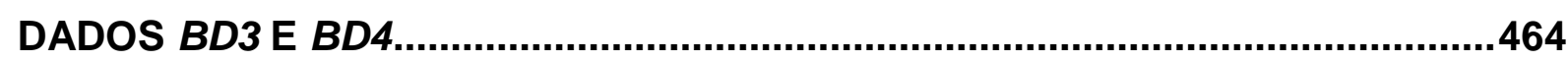

12 ANEXO D - DIAGRAMAS RETIGRÁFICOS DOS SEGMENTOS HOMOGÊNEOS DAS RODOVIAS ESTADUAIS EM ESTUDO ….........................466

13 ANEXO E - GRÁFICOS COM RESULTADOS DE PARÂMETROS COMBINADOS (TODAS AS RODOVIAS).....................................................480

14 ANEXO F - MATRIZES COM ESTATÍSTICAS DOS RESULTADOS

INDIVIDUAIS DO ESTUDO DAS RODOVIAS ESTADUAIS [BD2]. .484 
15 ANEXO G - MATRIZES COM ESTATÍSTICAS DOS RESULTADOS PARA OS SEGMENTOS HOMOGÊNEOS DO BANCO DE DADOS BD3.............................492 16 ANEXO H - DIAGRAMAS RETIGRÁFICOS DAS RODOVIAS ESTADUAIS EM

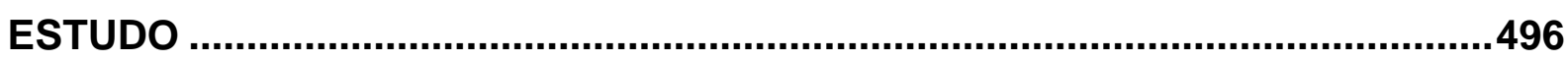




\section{INTRODUÇÃO}

O comportamento mecânico do subleito tem influência determinante no desempenho das estruturas de pavimento, porém, muitas vezes os estudos realizados para elaboração de projetos são bastante simplificados e não levam em conta as variações de comportamento mecânico que podem ocorrer durante o período de serviço. Os solos de subleito são suscetíveis à ação da umidade e seu comportamento mecânico também está diretamente associado ao estado de tensões a que são submetidos no campo, o que torna o processo de modelagem especialmente complexo e iterativo.

De acordo com a revisão bibliográfica realizada, diversas correlações, em especial, para previsão do módulo de resiliência com a variação da umidade, têm sido propostos por pesquisadores com o objetivo de subsidiar diversos procedimentos de dimensionamento de estruturas de pavimento novas ou reabilitadas. Entre as mais difundidas e utilizadas no Brasil e demais países do Continente americano, estão as equações propostas pela AASHTO no guia de dimensionamento de 1993 e mais recentemente no AASHTOWare Pavement ME Design (evolução do MechanisticEmpirical Pavement Design Guide M-E PDG/2002).

Grande parte dos modelos pesquisados não levam em conta as características mineralógicas e de microestruturas peculiares de solos tropicais, que implicam nas propriedades físicas e mecânicas diferenciadas. Existe um conhecimento bastante difundido no Brasil acerca das características destes tipos de solos, porém há necessidade de incorporá-lo aos modelos para utilização de procedimentos de dimensionamento no Brasil. No momento, há uma iniciativa importante de se alterar o método brasileiro empírico de dimensionamento de pavimentos asfálticos em um método teórico-empírico, com a incorporação de modelos de comportamento de solos tropicais. Esta tese tem por objetivo contribuir para o entendimento do comportamento mecânico dos solos de subleito e a previsão deste para o dimensionamento de pavimentos e a compreensão de seu desempenho em serviço. 


\subsection{Justificativa da escolha do tema}

Os métodos de projetos de estruturas de pavimentos são alvos constantes de alterações que visam aumentar a confiabilidade nesta etapa para propor pavimentos duráveis, otimizando custos de execução e de manutenção ao longo da vida útil das estruturas. Neste sentido, a identificação correta das características dos materiais que serão utilizados é um dado de entrada fundamental nos projetos.

Os Estados Unidos desenvolveram nos últimos anos um novo modelo de projeto de pavimentos com uma abordagem empírico-mecanicista nomeado MechanisticEmpirical Pavement Design Guide - MEPDG, cuja proposta é dimensionar estruturas por meio de calibração dos dados de entrada para condições locais, conciliando desempenhos verificados, materiais disponíveis e durabilidade requerida para resistir às solicitações de tráfego e do clima.

No Brasil, os métodos de projeto adotados pelos principais órgãos rodoviários se baseiam em modelos empíricos. Alguns poucos órgãos, como o $D E R / S P$, sugerem verificações mecanicistas a partir de modelos de previsão de desempenho de fontes diversas, sem considerar as condições de contorno que cercaram estas formulações. A Prefeitura do Município de São Paulo considera na norma IP-08/2004 denominada Análise Mecanicista à Fadiga de Estruturas de Pavimento alguns modelos para solos tropicais de calculam o módulo de resiliência destes solos em função do $C B R$, sendo que emprega equações diferenciadas dependendo da natureza dos solos tropicais.

São diversos os entraves ao se projetar pavimentos no Brasil, em especial: a carência de modelos mecanicistas nacionais que levem em conta as características dos materiais disponíveis, bem como os efeitos do clima, as cargas, bem como frequência e tempo de aplicação no comportamento mecânico do pavimento; o crescimento acelerado dos volumes de tráfego que extrapolam em demasiado a previsão de ciclos de aplicação de carga dos modelos em uso, o excesso de carga dos veículos comerciais, etc.

Somam-se às dificuldades da adoção de modelos insuficientes, os problemas relacionados às dimensões continentais do Brasil, que impõem variáveis importantes nos materiais de cada região. Uma rodovia que corta um único estado pode apresentar 
variações extremas nas características dos materiais disponíveis, tanto de solos como de agregados. Além das características dos materiais, o comportamento dos solos utilizados nas camadas de fundação da rodovia está intimamente relacionado às condições climáticas da região, altura do lençol freático e condições gerais de drenagem.

A determinação do módulo de resiliência é um importante indicador do comportamento mecânico dos materiais de pavimentação e tem sido negligenciado repetidamente sem que sejam realizados ensaios nos materiais propostos em projetos de estruturas de pavimentos. É frequente a formulação de projetos com incoerências nos valores de módulo de resiliência adotados para diferentes materiais. As respostas deflectométricas de pavimentos são dependentes do módulo de resiliência do subleito principalmente para pavimentos flexíveis e a fadiga dos revestimentos asfálticos é altamente dependente da resposta resiliente dos subleitos. Existe atualmente uma vasta gama de tipos de materiais de pavimentação, sendo que as diversas variações implicam necessariamente em diferenças nos comportamentos e parâmetros de cada um, de modo que não é adequado adotar valores modulares similares para solos diferentes, além dos expressivos efeitos de se adotar valores meramente estimados.

Apesar de o ensaio para a determinação do módulo de resiliência ser relativamente mais complexo que os ensaios de ruptura, como é o caso do ensaio de $C B R$, é necessário reconhecer sua importância tendo em vista que são as principais características dos materiais na etapa de projeto. Além disso, o controle acerca do comportamento dos materiais executados pode garantir a efetividade do que foi proposto no horizonte de projeto.

Ainda relativa à etapa de projetos de restaurações de pavimentos, observam-se discrepâncias em função do tratamento de dados de levantamentos deflectométricos, utilizados na definição do grau de deterioração de cada camada dos pavimentos avaliados. O ensaio não destrutivo realizado para obtenção da deformabilidade da estrutura fornece dados relacionados ao comportamento efetivo do conjunto de camadas em uma determinada condição de carga e clima. A qualidade de cada camada é estimada por retroanálise das bacias de deflexões com base em espessuras e módulos também estimados. Estes métodos de retroanálise podem resultar em interpretações errôneas acerca da integridade de cada material que constitui a estrutura e, consequentemente, pode resultar em proposições equivocadas de 
restaurações. Neste sentido, a calibração de resultados obtidos por retroanálise com os dados obtidos por ensaios de laboratório contribui não apenas para a interpretação mais correta das condições estruturais de cada camada, mas também para a definição mais precisa das relações ou correções, a depender do material, que devam ser feitas para campo, se houver à disposição resultados de laboratório. Além disso, podem-se avaliar eventuais perdas de rigidez por não alcançar o grau de compactação de laboratório, dentre outros aspectos.

Assim, é importante ressaltar que grande parte dos métodos de dimensionamento de pavimentos atualmente vigentes no Brasil consideram a adoção de um único valor estimado representativo para o módulo de resiliência dos materiais de subleito.

Mesmo no caso de alguns métodos novos que levam em conta a variação de comportamento mecânico dos solos de subleito, como é o caso da metodologia proposta pela AASHTO a partir do ano de 2002 (Mechanistic-Empirical Pavement Design Guide ou M-E PDG), não dispõem de modelos e/ou calibragens específicas voltados a solos encontrados nas regiões tropicais. Assim, a aplicação deste método no Brasil torna especialmente dificultosa sua implementação e utilização para as condições brasileiras, dada a presença de solos tropicais de comportamento diferenciado dos solos considerados no método norte-americano.

Neste contexto, a presente pesquisa tem por objetivo trazer contribuições ao estudo do comportamento mecânico dos subleitos bem como propor ferramentas que possam ser incorporados aos métodos de dimensionamento vigentes no Brasil e aqueles em elaboração e implementação, em especial para alguns tipos de solos encontrados no estado de São Paulo. 


\subsection{Objetivos do trabalho}

A presente pesquisa aplica-se à fase de projeto de pavimentos asfálticos rodoviários e objetiva trazer contribuições ao conhecimento do comportamento mecânico de solos de subleito, de maneira a fornecer dados e procedimentos que possam ser incorporados aos métodos de dimensionamento brasileiros, de modo a incrementar a confiabilidade dos projetos e melhorar o desempenho das estruturas de pavimento no país.

Para alcançar estes objetivos as seguintes etapas foram consideradas:

- Realizar revisão bibliográfica acerca dos modelos presentes na literatura para determinação do módulo de resiliência de projeto, determinação da variação do valor de módulo de resiliência em serviço do subleito e estimativa de vida útil do pavimento;

- Realizar estudos de laboratório e em campo, com o objetivo de obter relações entre os parâmetros do solo, o módulo de resiliência dos materiais e quantificar a influência dos fatores que causam variações de comportamento mecânico dos materiais em campo, especialmente natureza do solo, umidade e condições de compactação.

- Realizar estudos de campo e de laboratório com o objetivo de verificar e quantificar a influência da variação de rigidez nos subleitos e sua implicação no desempenho estrutural dos pavimentos.

- Propor ferramentas e metodologias que possam ser incorporadas aos métodos de dimensionamento, de modo a fornecer maior confiabilidade nos projetos e melhor desempenho das estruturas de pavimento.

- Realizar estudos com o objetivo de validar as metodologias propostas. 


\subsection{Organização do trabalho}

O presente trabalho apresenta-se segmentado em 8 capítulos, conforme descrição a seguir.

O capítulo 1 contém a introdução ao tema, a justificativa do tema e os objetivos do trabalho.

O capítulo 2 apresenta uma breve revisão bibliográfica acerca das características dos solos encontrados nas regiões de clima tropical, bem como a revisão bibliográfica realizada acerca do módulo de resiliência dos materiais de subleito, incluindo as formulações teóricas para sua obtenção em laboratório e os modelos experimentais para sua estimativa a partir de correlações empíricas com outros parâmetros obtidos em ensaios de caracterização e ensaios de resistência.

O capítulo 3 apresenta resultados de estudo de caso realizado em uma rodovia federal com o objetivo de elaborar metodologia de estudo para obtenção de dados e evidências que permitam o desenvolvimento de modelos matemáticos tanto para a estimativa dos valores de módulo de laboratório dos materiais do subleito como para o entendimento e modelagem do comportamento mecânico dos materiais em serviço e sua influência no desempenho das estruturas de pavimentos asfálticos.

O capítulo 4 apresenta resultados de estudo de caso realizado em rodovias estaduais integrantes do Programa de Concessão de Rodovias do Estado de São Paulo, com o objetivo de propor metodologia de estudo para obtenção de dados de campo e demais informações pertinentes, com o objetivo de montagem de bancos de dados e acumulação de dados históricos, no intuito de conseguir subsídios suficientes para o correto entendimento das variáveis que afetam o comportamento mecânico do subleito em serviço.

O capítulo 5 apresenta uma análise crítica dos estudos e a proposição de parâmetros, com base nos estudos realizados, para fins de dimensionamento estrutural de pavimentos asfálticos.

O capitulo 6 apresenta, a título exemplificativo, a aplicação de alguns dos parâmetros propostos ao longo do presente trabalho, a dois casos de projetos reais, ilustrando os 
impactos do uso das metodologias propostas, em relação aos métodos atuais de dimensionamento de pavimentos asfálticos.

O capítulo 7 apresenta as conclusões e considerações finais do trabalho e o capítulo 8 apresenta as referências bibliográficas utilizadas em sua elaboração. 


\section{REVISÃO BIBLIOGRÁFICA}

\subsection{Solos tropicais e metodologia $M C T$}

Grande parte das metodologias de dimensionamento em uso no Brasil tiveram sua origem em pesquisas e métodos empíricos desenvolvidos em outros países, especialmente nos Estados Unidos, região de clima temperado, onde não há ocorrência de solos tropicais. Estas metodologias foram incorporadas aos manuais e normas rodoviárias nacionais, porém sofreram poucas adaptações para levar em conta as condições geológicas brasileiras. Os solos das regiões tropicais apresentam características de resistência, suporte e comportamento mecânico bastante diferenciado dos solos originários de outras regiões, ainda que apresentem características físicas semelhantes (granulometria, plasticidade etc.), o que causa divergência entre os critérios de classificações de solos internacionais e seu potencial de aplicação nas diversas camadas do pavimento, bem como considerações equivocadas para o dimensionamento e a modelagem do comportamento estrutural.

Segundo Bernucci (1995), há vários trabalhos dedicados ao estudo dos solos tropicais, sem, no entanto, haver um consenso quanto à terminologia. A autora cita a classificação utilizada pelo Comitê de Solos Tropicais da Associação Internacional de Mecânica dos Solos e Engenharia de Fundações (Nogami et al., 1985), pela sua simplicidade e por ser apropriada do ponto de vista da engenharia, na qual o solo é classificado como:

- Laterítico quando: a) pertencer aos horizontes A e B de perfis bem drenados, desenvolvidos sob atuação de clima tropical úmido; b) sua fração argila for constituída essencialmente de argilo-minerais do grupo das caulinitas e de hidróxidos e óxidos hidratados de ferro e/ou alumínio, formando esses componentes, estruturas porosas peculiares e agregações altamente estáveis; 
- Saprolítico quando: a) for solo no sentido geotécnico, b) exibir nitidamente estrutura reliquiar, que auxilie na identificação da rocha matriz; c) for autenticamente residual.

As condições tropicais de altas temperaturas, de presença d'água abundante e de boa drenagem são propícias ao intemperismo intenso e rápido. Os solos tropicais lateríticos são formados pelo processo físico-químico avançado de laterização. Possuem espessuras variando entre dezenas de centímetros até 10 a 20 metros (Bernucci, 1987). De acordo com Mitchell (1982), a laterização caracteriza-se pela decomposição de feldspatos e de minerais ferromagnesianos, pela lixiviação da sílica e de bases e, finalmente, pela concentração de óxidos de ferro e/ou alumínio.

Devido à laterização, a fração argila dos solos lateríticos é constituída essencialmente de minerais do grupo da caulinita e de óxidos hidratados de ferro e/ou alumínio. Graças à combinação destes componentes, formam-se estruturas de agregados altamente estáveis, mesmo em contato com a água. Por esta razão, os solos lateríticos, mesmo os mais argilosos, apresentam-se porosos e bastante permeáveis (Bernucci, 1987).

Os solos saprolíticos (sapro, do grego: podre) são aqueles que resultam da decomposição e/ou desagregação in situ da rocha matriz pela ação das intempéries e mantêm, de maneira nítida, a estrutura da rocha que Ihe deu origem (Villibor, 2009). Devido à atuação intensa do intemperismo nas regiões tropicais, com clima quente, chuvas bem distribuídas e relevos suaves, a decomposição da rocha e acúmulo do material decomposto são favorecidos. A espessura da camada resultantes pode atingir dezenas de metros. A macroestrutura é herdada da rocha matriz e é geralmente complexa, longe de ser homogênea. A constituição mineralógica é complexa e dependente da rocha matriz e do grau de intemperização (Bernucci, 1987).

A Figura 2.1 ilustra os locais de ocorrência de solos lateríticos e saprolíticos no Brasil. 

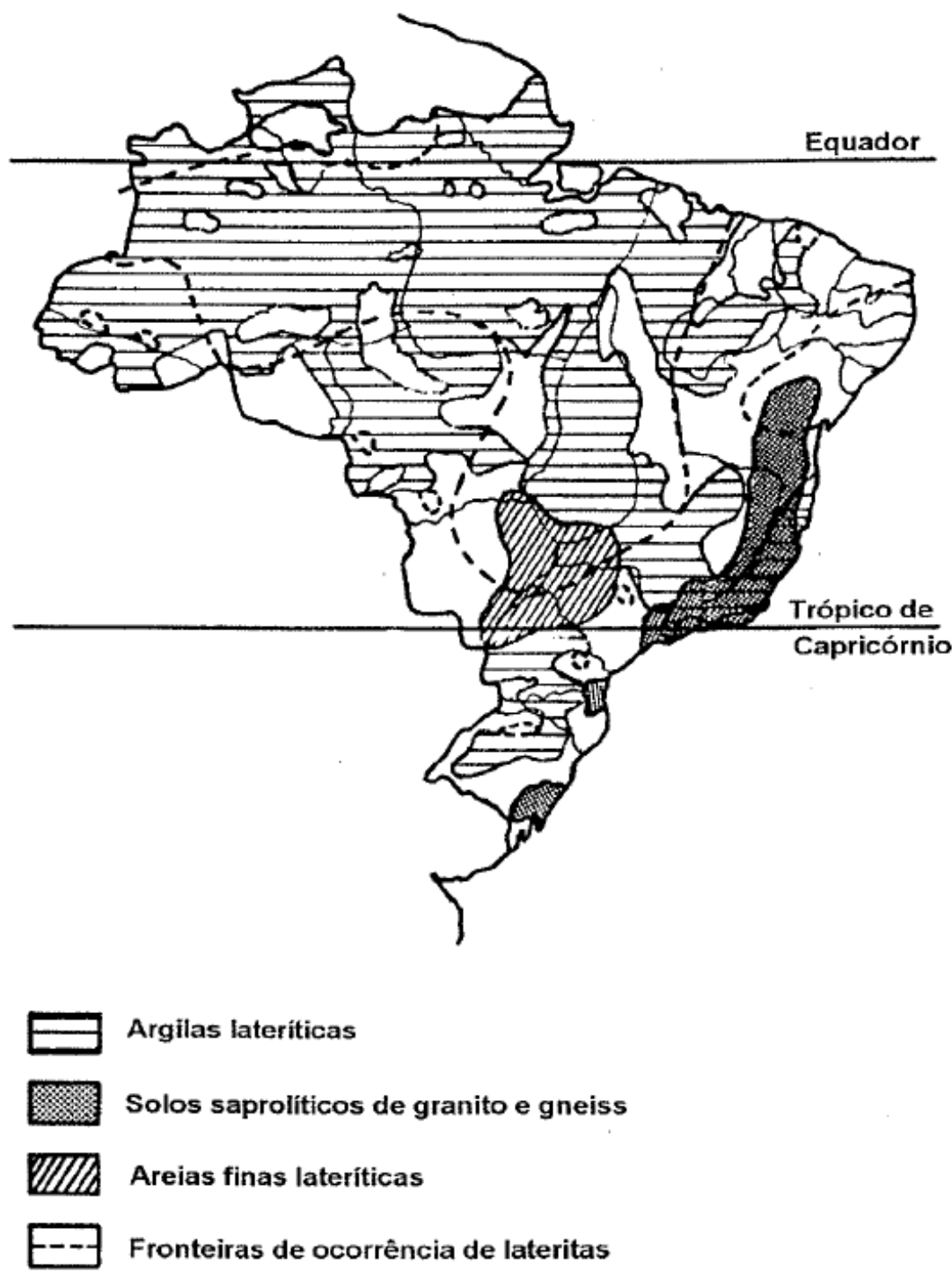

Figura 2.1 - Ocorrência de solos lateríticos e saprolíticos no Brasil (Medina e Motta, 1989)

\subsubsection{Classificação dos solos pela metodologia $M C T$}

O método MCT (miniatura compactada tropical) foi proposto inicialmente com a finalidade de classificar os solos tropicais de forma a separar os solos lateríticos dos não lateríticos e hierarquiza-los segundo suas características mais importantes do ponto de vista viário (Nogami e Villibor, 1981). A partir do sucesso obtido com a aplicação dessa classificação, foi ampliada a MCT para um método mais abrangentes 
incluindo especificações de materiais, estudos mais aperfeiçoados de suas propriedades, técnicas construtivas especiais e de conservação e manutenção (Nogami e Villibor, 1981 apud Bernucci, 1995). Parte do método MCT está hoje à disposição, normatizado por órgãos como $D E R / S P, D N E R, D E R S A$, Cia do Metropolitano de São Paulo, DER/PR, entre outros.

Segundo Villibor (1995) a classificação de solos HRB-AASHTO é a mais utilizada e difundida no meio rodoviário, porém classifica e hierarquiza os solos tropicais de maneira inapropriada. Por exemplo, solos que se classificam no grupo A-7-5, quando adequadamente compactados, podem se comportar como um ótimo subleito, caso laterítico, ou péssimo subleito caso saprolítico (baixa capacidade de suporte, elevada resiliência e elevada expansão), segundo Villibor (1995).

A classificação dos solos com uso da metodologia MCT foi desenvolvida especialmente para o estudo dos solos tropicais e baseada em propriedades mecânicas e hídricas obtidas de corpos de prova compactados de dimensões reduzidas. Essa classificação não utiliza a granulometria, o limite de liquidez e o índice de plasticidade como acontece no caso das classificações geotécnicas tradicionais e separa os solos tropicais em duas grandes classes: os de comportamento laterítico e os de comportamento não laterítico (Villibor, 1995).

Os solos lateríticos e saprolíticos, segunda classificação $M C T$, podem pertencer aos seguintes grupos (Villibor, 1995):

a) solos de comportamento laterítico, designados pela letra $L$, sendo divididos em 3 grupos:

- LA - areia laterítica quartzosa;

- LA’ - solo arenoso laterítico;

- LG' - solo argiloso laterítico;

b) solos de comportamento não laterítico (saprolítico), designados pela letra $N$, sendo subdivididos em 4 grupos: 
- NA - areais, siltes e misturas de areias e siltes com predominância de grão de quartzo e/ou mica, não laterítico.

- NA' - misturas de areias quartzosas com finos de comportamento não laterítico (solo arenoso).

- NS' - solo siltoso não laterítico.

- NG' - solo argiloso não laterítico.

Para se classificar os solos lateríticos e saprolíticos, através da Metodologia MCT, utiliza-se o gráfico da Figura 2.2, no qual a linha tracejada separa os solos de comportamento laterítico dos de comportamento não laterítico (Villibor, 1995).

Segundo Santanna (1998), a sistemática MCT apresenta algumas dificuldades referentes à complexidade e morosidade dos processos de ensaios e cálculo a serem realizados e, portanto, várias pesquisas têm sido conduzidas no sentido de solucionar a complexidade da classificação MCT. Fabbri (1994) desenvolveu um trabalho sobre classificação de solos utilizando como parâmetros a distribuição granulométrica e o ensaio de absorção de azul de metileno pelo método da mancha.

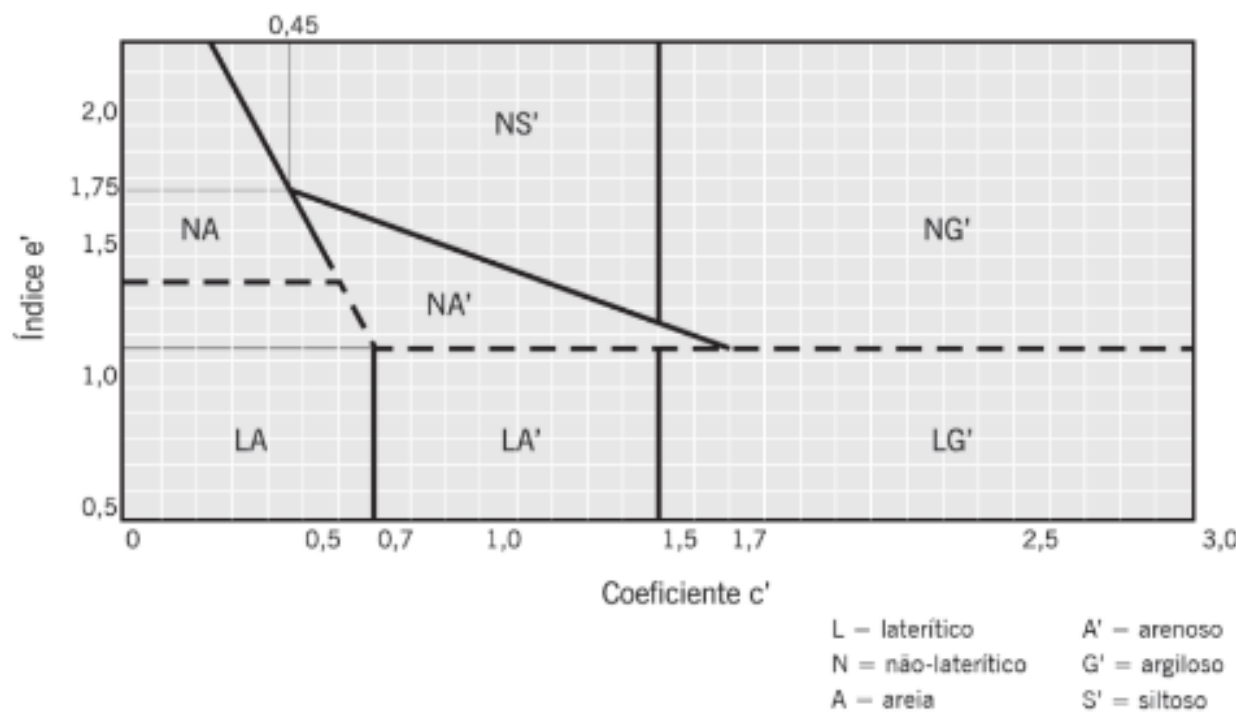

Figura 2.2 - Gráfico para classificação MCT (Nogami e Villibor, 1981 apud Bernucci et al., 2010)

A Tabela 2.1 apresenta as propriedades mecânicas e hidráulicas da classificação MCT de acordo com Nogami e Villibor (1995) enquanto a Tabela 2.2 apresenta as faixas de variação de valores do ensaio de classificação MCT. 
Tabela 2.1 - Dados qualitativos das propriedades mecânicas e hidráulicas da classificação $M C T$, segundo Nogami e Villibor (1995)

\begin{tabular}{|c|c|c|c|c|c|c|c|c|c|c|}
\hline \multicolumn{4}{|c|}{$\begin{array}{c}\text { GRANULOMETRIAS } \\
\text { TiPICAS } \\
\text { Designações do T1-71 do DER- } \\
\text { SP }\end{array}$} & \multirow{2}{*}{ 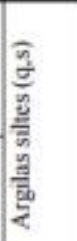 } & \multirow{2}{*}{ 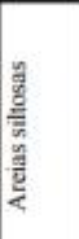 } & \multirow{2}{*}{ 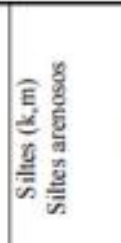 } & \multirow{2}{*}{ 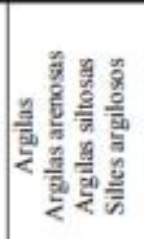 } & \multirow{2}{*}{ 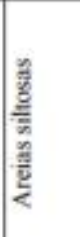 } & \multirow{2}{*}{ 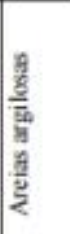 } & \multirow{2}{*}{ 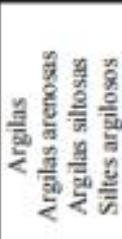 } \\
\hline \multicolumn{4}{|c|}{$\begin{array}{ll}\mathrm{k}=\text { caolinitico } & \mathrm{m}=\text { miciceo } \\
\mathrm{s}=\text { sericitico } & \mathrm{q}=\text { quartzoso }\end{array}$} & & & & & & & \\
\hline \multicolumn{4}{|c|}{ COMPORTAMENTO } & \multicolumn{4}{|c|}{$\mathrm{N}=\mathrm{N}$ șo Lateritico } & \multicolumn{3}{|c|}{$\mathrm{L}=$ Lateritico } \\
\hline \multicolumn{4}{|c|}{ GRUPO MCT } & NA & $\mathrm{NA}^{*}$ & \multirow{2}{*}{$\begin{array}{c}\mathrm{NS}^{\circ} \\
\mathrm{M}, \mathrm{E}\end{array}$} & $\mathrm{NG}^{\prime}$ & LA & $\mathrm{LA}^{*}$ & LG \\
\hline \multirow{6}{*}{$\frac{\frac{y}{2}}{\frac{d}{8}}$} & MINI CBR & \multicolumn{2}{|c|}{$\begin{array}{l}\text { Sem imersåo } \\
\text { Perda por } \\
\text { imersăo }\end{array}$} & $\begin{array}{l}\mathrm{M}, \mathrm{E} \\
\mathrm{B}, \mathrm{M}\end{array}$ & $\begin{array}{l}\mathrm{E} \\
\mathrm{B}\end{array}$ & & $\begin{array}{l}\mathrm{E} \\
\mathrm{E}\end{array}$ & $\begin{array}{l}\mathrm{E} \\
\mathrm{B}\end{array}$ & $\begin{array}{c}\text { E, EE } \\
B\end{array}$ & $\begin{array}{l}\mathrm{E} \\
\mathrm{B}\end{array}$ \\
\hline & \multicolumn{3}{|c|}{ EXPANSĀO } & $\mathrm{B}$ & B & $\mathrm{E}$ & $\mathrm{M}, \mathrm{E}$ & B & B & B \\
\hline & \multicolumn{3}{|c|}{ CONTRACุAO } & B & $\mathrm{B}, \mathrm{M}$ & $\mathrm{M}$ & M, E & B & B,M & M, E \\
\hline & \multicolumn{3}{|c|}{$\begin{array}{c}\text { COEF. DE } \\
\text { PERMEABIL.IDADE }(k)\end{array}$} & $\mathrm{M}, \mathrm{E}$ & B & B, M & $\mathrm{B}, \mathrm{M}$ & $\mathrm{B}, \mathrm{M}$ & B & B \\
\hline & \multicolumn{3}{|c|}{\begin{tabular}{|c|} 
COEF. DE SORÇÃO (s) \\
\end{tabular}} & E & $\mathrm{B}, \mathrm{M}$ & $E$ & $\mathrm{M}, \mathrm{E}$ & $\mathrm{B}$ & B & B \\
\hline & \multicolumn{3}{|c|}{$\begin{array}{l}\text { compactados na massa } \\
\text { especifica aparente seca } \\
\text { máxima da energia normal }\end{array}$} & \multicolumn{4}{|c|}{$\begin{array}{rlrl}\mathrm{EE} & =\text { Muito elevado } & \mathrm{M} & =\text { Médio } \\
\mathrm{E}=\text { Elevado } & \mathrm{B} & =\text { Baixo }\end{array}$} & \multicolumn{3}{|c|}{$\begin{array}{l}\text { Vide Tabela } 2-4 \text { para } \\
\text { equivalente numérico }\end{array}$} \\
\hline \multirow{6}{*}{\multicolumn{4}{|c|}{$\begin{array}{l}\text { Base de pavimento } \\
\text { Ref.subleito compactado } \\
\text { Subleito compactado } \\
\text { Aterro compactado } \\
\text { Proteçào à erosão } \\
\text { Revestimento primário }\end{array}$}} & $\mathrm{n}$ & $4^{\circ}$ & $\mathbf{n}$ & $\mathrm{n}$ & $2^{\circ}$ & $1^{\circ}$ & $3^{\circ}$ \\
\hline & & & & $4^{\circ}$ & $5^{\circ}$ & $\mathrm{n}$ & $\mathrm{n}$ & $2^{\circ}$ & $1^{\circ}$ & $3^{\circ}$ \\
\hline & & & & $4^{\circ}$ & $5^{\circ}$ & $7^{*}$ & $6^{\circ}$ & $2^{\circ}$ & $1^{\circ}$ & $3^{\circ}$ \\
\hline & & & & $4^{\circ}$ & $5^{\circ}$ & $6^{\circ}$ & $7^{\circ}$ & $2^{\circ}$ & $1^{\circ}$ & $3^{\circ}$ \\
\hline & & & & $\mathrm{n}$ & $3^{\circ}$ & $\mathrm{n}$ & $\mathrm{n}$ & $\mathrm{n}$ & $2^{\circ}$ & $1^{\circ}$ \\
\hline & & & & $5^{\circ}$ & $3^{\circ}$ & $\mathrm{n}$ & $\mathrm{n}$ & $4^{\circ}$ & $1^{\circ}$ & $2^{\circ}$ \\
\hline & & & & \multicolumn{7}{|c|}{$\mathrm{n}=$ nầo recomendado } \\
\hline \multirow{2}{*}{\multicolumn{3}{|c|}{$\begin{array}{l}\text { Grupos tradicionais } \\
\text { obtidos de amostras que } \\
\text { se classificam nos grupos } \\
\text { MCT discriminados nos } \\
\text { topos das colunas }\end{array}$}} & $\begin{array}{l}\mathscr{b} \\
\text { gू }\end{array}$ & $\begin{array}{l}\mathrm{SP} \\
\mathrm{SM}\end{array}$ & $\begin{array}{l}\text { MS } \\
\text { SC } \\
\text { ML }\end{array}$ & $\begin{array}{l}\mathrm{SM} \\
\mathrm{CL} \\
\mathrm{ML} \\
\mathrm{MH}\end{array}$ & $\begin{array}{l}\mathrm{MH} \\
\mathrm{CH}\end{array}$ & SP SC & $\mathrm{SC}$ & $\begin{array}{l}\mathrm{MH} \\
\mathrm{ML} \\
\mathrm{CH}\end{array}$ \\
\hline & & & $\frac{\varrho}{\frac{9}{5}}$ & A-2 & $\begin{array}{l}\text { A-2 } \\
\text { A-4 } \\
\text { A-7 }\end{array}$ & $\begin{array}{c}A-4 \\
A-5 \\
A-7-5\end{array}$ & $\begin{array}{c}\text { A-6 } \\
\text { A-7-5 } \\
\text { A-7-5 }\end{array}$ & A-2 & $\begin{array}{l}\mathrm{A}-2 \\
\mathrm{~A}-4\end{array}$ & $\begin{array}{c}\text { A-6 } \\
\text { A- } 7-5\end{array}$ \\
\hline
\end{tabular}

Tabela 2.2 - Faixas de variação dos valores da classificação MCT (Nogami e Villibor, 1995)

\begin{tabular}{|c|c|c|}
\hline $\begin{array}{l}\text { Suporte mini-CBR }(\%) \text {, } \\
\text { com sobrecarga padrão }\end{array}$ & $\begin{array}{c}\text { Muito elevado } \\
\text { Elevado } \\
\text { Médio } \\
\text { Baixo }\end{array}$ & $\begin{array}{c}>30 \\
12 \text { a } 30 \\
4 \text { a } 12 \\
<4\end{array}$ \\
\hline Expansão (\%) & $\begin{array}{c}\text { Elevada } \\
\text { Média } \\
\text { Baixa } \\
\end{array}$ & $\begin{array}{c}>3 \\
0,5 \text { a } 3 \\
<0,5\end{array}$ \\
\hline $\begin{array}{l}\text { Coeficiente de sorção - s } \\
\log (\mathrm{cm} / \sqrt{\min })\end{array}$ & $\begin{array}{l}\text { Elevado } \\
\text { Médio } \\
\text { Baixo } \\
\end{array}$ & $\begin{aligned} &>(-1) \\
&(-1) \text { a }(-2) \\
&<(-2)\end{aligned}$ \\
\hline $\begin{array}{c}\text { Perda de suporte mini-CBR } \\
\text { por imersão }(\%)\end{array}$ & $\begin{array}{l}\text { Elevada } \\
\text { Média } \\
\text { Baixa }\end{array}$ & $\begin{array}{c}>70 \\
40 \text { a } 70 \\
<40\end{array}$ \\
\hline Contração (\%) & $\begin{array}{l}\text { Elevada } \\
\text { Média } \\
\text { Baixa }\end{array}$ & $\begin{array}{l}>3 \\
0,5 \text { a } 3 \\
<0,5\end{array}$ \\
\hline $\begin{array}{c}\text { Coeficiente de } \\
\text { Permeabilidade - k } \\
\log (\mathrm{cm} / \mathrm{s})\end{array}$ & $\begin{array}{l}\text { Elevado } \\
\text { Médio } \\
\text { Baixo }\end{array}$ & $\begin{aligned} &>(-3) \\
&(-3) \mathrm{a}(-6) \\
&<(-6)\end{aligned}$ \\
\hline
\end{tabular}




\subsection{Módulo de Resiliência}

O módulo de resiliência $M R$ é a resposta dinâmica definida como a relação entre a tensão desvio axial repetida $\sigma_{d}$ (que corresponde à diferença entre tensões principais maior e menor) e a deformação axial recuperável $\varepsilon_{r}$ (Yoder \& Witzack, 1975).

$$
M r=\frac{\sigma_{d}}{\varepsilon_{r}}
$$

Segundo Huang (2004) o módulo de resiliência pode ser considerado em alguns casos como representante do módulo de elasticidade na análise das estruturas de pavimento pela teoria geral da elasticidade. $O$ autor cita que a maioria dos materiais de pavimentação não tem comportamento elástico, mas experimentam alguma deformação permanente após cada aplicação de carga; todavia, se o carregamento é suficientemente pequeno comparado à resistência do material e este é repetido por várias vezes e a deformação sob cada repetição de carga é quase completamente recuperável (e proporcional à carga) o comportamento pode ser considerado elástico.

De acordo com o documento NCHRP (2008), o módulo de resiliência é análogo ao módulo de elasticidade usado em teorias elásticas e é definido como a taxa de tensão desvio para a deformação resiliente ou elástica experimentada pelo material sob condições de carregamento repetido que simula o carregamento do tráfego.

A Figura 2.3 apresenta uma representação esquemática do parâmetro do módulo de resiliência $(M R)$. A maioria das bases e subleitos não são elásticas e experimentam deformações permanentes sob cargas repetidas. Todavia, as cargas aplicadas nos ensaios de laboratório para determinação do módulo de resiliência são pequenas quando comparadas com as cargas limites de ruptura e também o resultado da aplicação de um grande número de ciclos de carregamento que reduz a deformação plástica, a deformação medida durante os ciclos de teste é considerado como completamente recuperável ou elástico e, portanto, as deformações recuperáveis são usadas para estimar o módulo de resiliência ou o módulo elástico.

Outras formas de módulos e suas definições são apresentadas na Figura 2.4. A inclinação inicial da curva "tensão-deformação" é chamada de módulo tangente inicial 
(Emax), e o módulo secante (E1) é definido como a inclinação da linha que junta a origem e um ponto na curva tensão-deformação que representa $50 \%$ da tensão desvio última à qual o corpo de prova rompe. O módulo de resiliência $(M R)$ é próximo ao Emax para materiais rígidos, e para solos fracos o módulo se situa entre E1 e Emax. Também, os métodos de laboratório que utilizam testes de carregamento triaxial repetido ( $R L T$ - Repeated Load Triaxial test) medem módulos de resiliência de materiais testados enquanto os métodos não destrutivos de campo que utilizam subrotinas de retroanálise e outras aproximações fornecem o módulo de elasticidade de subleitos e bases.

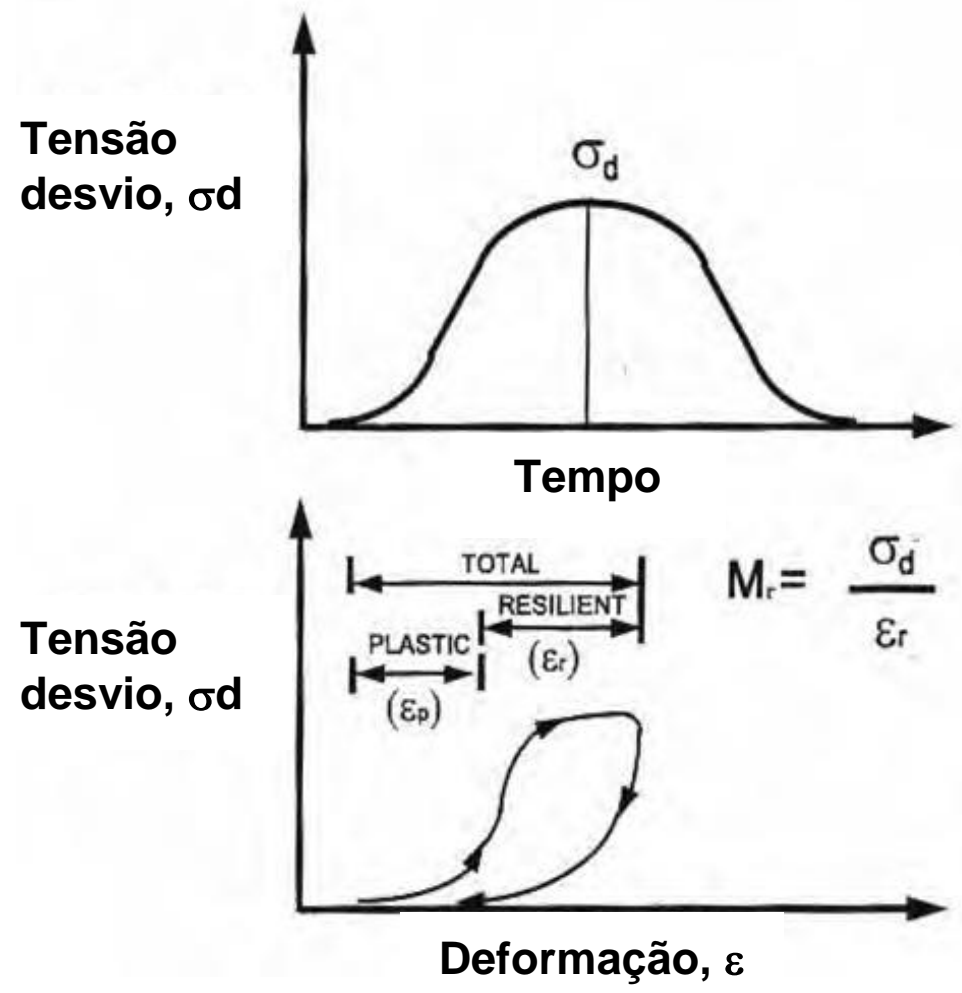

Figura 2.3 - Definição do módulo de resiliência (NCHRP, 2008) 


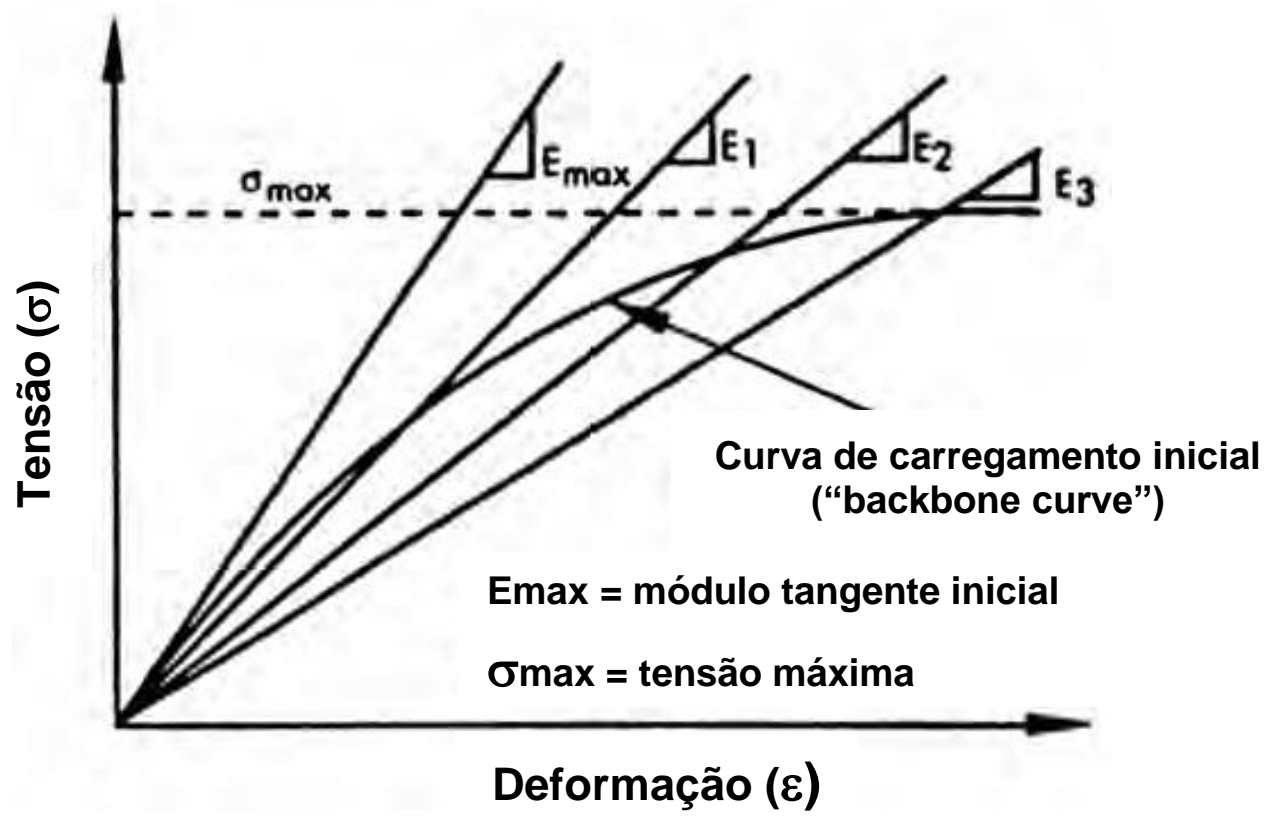

Figura 2.4 - Definições de outros parâmetros elásticos (NCHRP, 2008)

Desde o final da década de 30, Hveem compreendeu, pelas observações dos pavimentos na Califórnia, que a fadiga era um dos fenômenos responsáveis pela ruptura dos materiais, principalmente dos revestimentos asfálticos. Esta observação levou-o a buscar medir em campo, já em 1938, as deflexões dos pavimentos, pois compreendeu que estes deslocamentos pequenos levavam a tensões de tração no revestimento que repetidas vezes, e por ser um sólido não ideal e guardar danos, apresentava fadiga. Foi Hveem que denominou os deslocamentos verticais recuperáveis, quando os pavimentos estão sob carga de roda, de deflexão (Hveem, 1955).

O módulo de resiliência, também denominado por Hveem como tal, foi concebido para diferenciar os solos e materiais granulares dos materiais típicos como aço, vidro, etc., os quais são caracterizados mecanicamente pelo Módulo de Elasticidade.

O módulo de resiliência de um material, introduzido por Hveem, foi determinado a primeira vez em laboratório em ensaio triaxial por Seed e Fead na década de 50, já empregando carregamento repetido (Seed et al., 1962).

O conceito de módulo de resiliência ganhou rapidamente popularidade no meio técnico, devido às evidências que a deflexão (deslocamento resiliente) do pavimento, obtida de equipamentos como a Viga de Benkelman, possuía uma melhor correlação com o desempenho em campo do que os deslocamentos totais permanentes (Seed 
et al., 1962). Nas últimas décadas, o módulo de resiliência tornou-se um modo de caracterização de materiais de pavimentação (de base, sub-base e subleito) internacionalmente reconhecido, principalmente para os materiais granulares e materiais finos/coesivos.

O módulo de resiliência da maior parte dos materiais granulares é dependente do estado de tensão em que o material está aplicado. Muitos modelos já foram propostos ao longo dos anos para incorporar os efeitos do nível de tensão no valor do módulo de resiliência. O equipamento mais utilizado para a determinação do módulo de resiliência em laboratório é por meio do ensaio triaxial de carregamento repetido, que geralmente requer técnicos bem treinados para a operação do equipamento. $O$ ensaio é em linhas gerais o mesmo proposto por Seed e Fead.

A Tabela 2.3 apresenta os procedimentos para determinação do módulo de resiliência de solos em laboratório.

Tabela 2.3 - Procedimentos de laboratório para determinação do módulo de resiliência de solos

(NCHRP, 2008)

\begin{tabular}{|c|c|}
\hline $\begin{array}{l}\text { Procedimento de } \\
\text { Ensaio }\end{array}$ & Detalhes \\
\hline AASHTO T-274-1982 & $\begin{array}{l}\text { Mais antigo procedimento da AASHTO. Não são dados detalhes da sensibilidade dos } \\
\text { dispositivos de medição de deslocamento. Críticas sobre o processo de teste, duração do } \\
\text { teste (5 horas de duração do teste) e falhas prováveis das amostras durante a fase de } \\
\text { condicionamento. Os níveis de tensões do teste são muito severos. }\end{array}$ \\
\hline AASHTO T-292-1991 & $\begin{array}{l}\text { Procedimento de teste AASHTO introduzido em 1991. Sistemas de medidas internos são } \\
\text { recomendados. Sequência de teste foi criticado devida à possibilidade de efeitos de } \\
\text { endurecimento dos solos coesivos. }\end{array}$ \\
\hline AASHTO T-294-1992 & $\begin{array}{l}\text { A AASHTO modificou o procedimento T-292 com diferentes configurações de tensões desvio } \\
\text { e de confinamento e suas sequências. Sistema interno de medidas é seguido. Modelos de } 2 \\
\text { parâmetros (tensão total ou bulk stress para materiais granulares e tensão desvio para solos } \\
\text { coesivos) para analisar os resultados. Críticas para os modelos de análise. }\end{array}$ \\
\hline $\begin{array}{l}\text { Strategic Highway } \\
\quad \text { Research } \\
\text { Program P-46-1996 }\end{array}$ & $\begin{array}{l}\text { Estapas do procedimento P-46 são similares ao procedimento T-294 de 1992. Sistema de } \\
\text { medição externo foi adotado para medição de deslocamentos. Métodos de preparação dos } \\
\text { corpos de prova são diferentes daqueles usados em T-292. }\end{array}$ \\
\hline AASHTO T-307-1999 & $\begin{array}{l}\text { T-307-1999 evoluiu a partir do procedimento P-46. Recomenda o uso de sistema de medição } \\
\text { externo de deslocamentos. Procedimentos diferenciados são seguidos para preparação de } \\
\text { corpos de prova de materiais granulares e coesivos. }\end{array}$ \\
\hline $\begin{array}{l}\text { NCHRP 1-28 A: } \\
\text { Harmonized } \\
\text { Method-2004 (RRD 285) }\end{array}$ & $\begin{array}{l}\text { Este método recente recomenda uma configuração diferente de tensões para ensaio. } \\
\text { Também, um novo modelo de } 3 \text { parâmetros é recomendado para analisar as propriedades } \\
\text { resilientes. O uso de sistema de medição interna é recomendado neste método. }\end{array}$ \\
\hline
\end{tabular}


Bernucci et al. (2010) citam que o método de dimensionamento de pavimentos norteamericano estabelecido na versão de 1986 (com revisão em 1993) substituiu o ISC $(C B R)$ pelo módulo de resiliência do subleito na expressão do dimensionamento e também considerou esse parâmetro no cálculo dos coeficientes estruturais dos materiais asfálticos. Com isso, o módulo de resiliência foi reconhecido como de grande importância no dimensionamento de estruturas de pavimentos asfálticos. A recomendação de substituir o ISC de materiais pelo módulo de resiliência $(M R)$ e outros valores de resistência pela deformabilidade foi baseada nas seguintes razões:

- o $M R$ indica uma propriedade básica do material que pode ser utilizada na análise mecanísticas de sistemas de multiplicas camadas;

- o $M R$ é um método aceito internacionalmente para caracterizar materiais para o projeto de pavimentos e para sua avaliação de desempenho;

- há técnicas disponíveis para estimar o módulo de resiliência em campo com testes rápidos e não-destrutivos, o que facilita a uniformização entre os procedimentos de dimensionamento de pavimentos novos e de reforços de pavimentos antigos.

Bernucci et al. (2010) também citam que se tem utilizado equipamento de carga repetida em laboratório para a determinação do módulo de resiliência de materiais de pavimentação. A Figura 2.5 a seguir ilustra o esquema do equipamento utilizado para os ensaios triaxiais de carga repetida. 

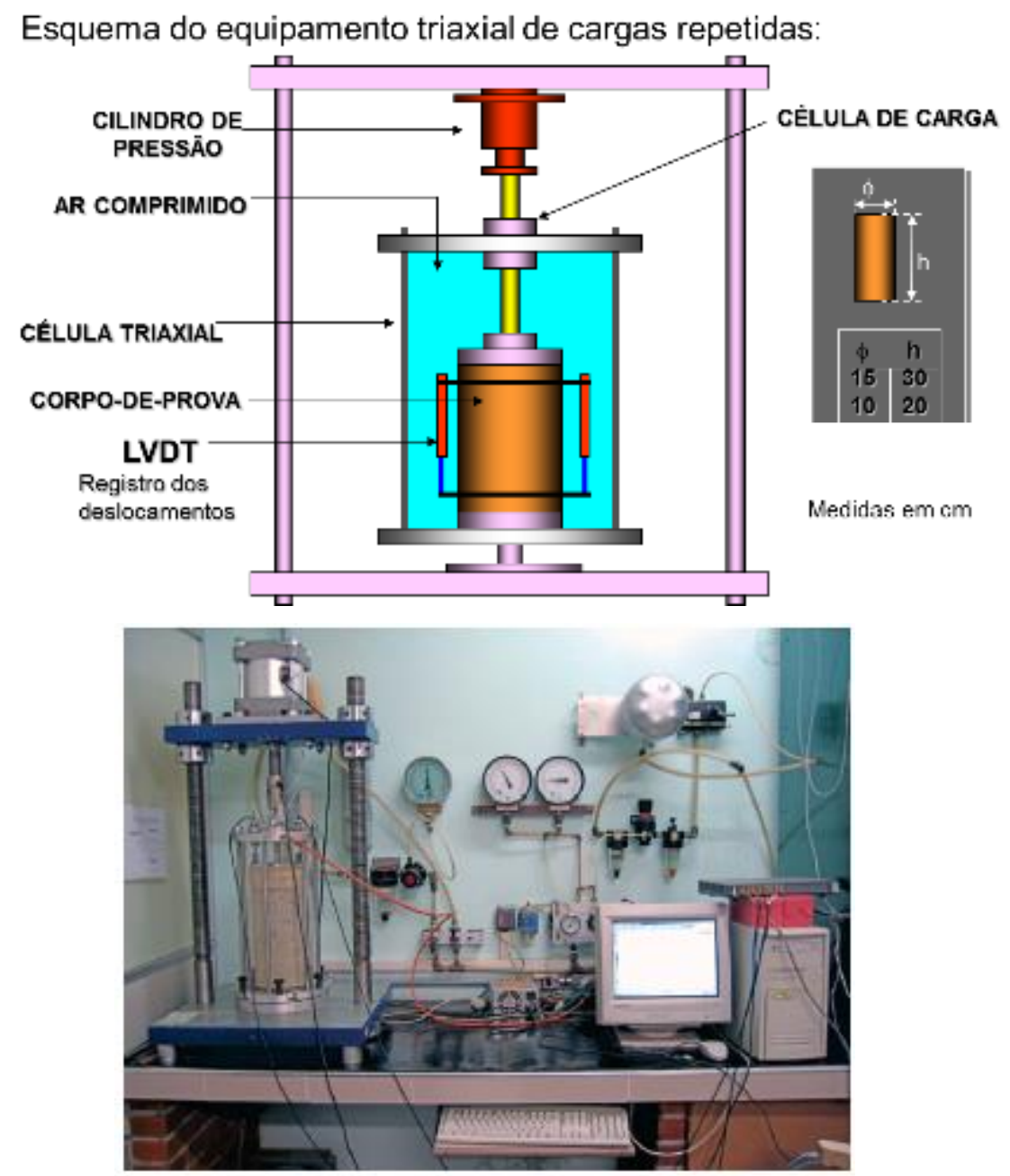

Figura 2.5 - (a) Esquema do equipamento triaxial de cargas repetidas e (b) exemplo do equipamento (Bernucci et al., 2010)

2.2.1 Modelos para representar o módulo de resiliência de solos de laboratório

De acordo com Medina e Motta (2015), o módulo de resiliência de materiais granulares e finos depende da natureza e constituição do solo, das condições de estado e das solicitações das tensões. O primeiro item refere-se à constituição mineralógica, textura das partículas, plasticidade da fração fina, arranjo estrutural das partículas e elos de cimentação natural. Os autores citam que as condições de estado são a massa específica aparente e a umidade e que as solicitações de tensão, aplicadas 
repetidamente, procuram representar a ação do tráfego numa estrutura de pavimento. O ensaio triaxial de cargas repetidas faz-se com solos não saturados quase sempre em condições de drenagem livre. Mantendo-se os demais parâmetros sob especificação, para cada solo o módulo de resiliência poderá ser expresso como uma função do estado de tensões aplicado durante o ensaio, ou seja, modelos matemáticos com constantes experimentais. Os primeiros modelos são historicamente os que se encontram em trabalhos pioneiros como na tese de Hicks (1970) e no documento do TRB (1970) (Medina e Motta, 2015).

Os modelos encontrados na literatura para representação do módulo de resiliência de laboratório de solos e materiais granulares são apresentados a seguir. As seguintes variáveis são componentes dos modelos:

$p_{a}=$ pressão atmosférica (14.7 psi ou 102,9 kPa); $\theta=$ tensão octaédrica normal, somatória de tensões ou bulk stress $\left(\sigma_{1}+\sigma_{2}+\sigma_{3}\right) ; \tau_{o c t}=$ tensão de cisalhamento octaédrica; $k_{1}, k_{2}, k_{3}=$ propriedade do material; $\sigma_{1}, \sigma_{2}, \sigma_{3}=$ componentes principais de tensão. A $\tau_{o c t}$ é medida através da tensão de distorção (cisalhamento) do material, e é definida conforme segue:

$$
\tau_{o c t}=\frac{1}{3} \cdot \sqrt{\left(\sigma_{1}-\sigma_{2}\right)^{2}+\left(\sigma_{1}-\sigma_{3}\right)^{2}+\left(\sigma_{2}-\sigma_{3}\right)^{2}}
$$

Dunlap (1963) apud Hicks \& Monismith (1971) para materiais granulares (MRI21)

$$
M R=k_{1} \cdot p_{a} \cdot\left(\frac{\sigma_{3}}{p_{a}}\right)^{k_{2}}
$$

Seed et al. (1967) apud Nataatmadja \& Parkin (1989) para materiais arenoargilosos (MRI2-2)

$$
M R=k_{1} \cdot p_{a} \cdot\left(\frac{\theta}{p_{a}}\right)^{k_{2}} \text {, para } k_{2}>0
$$

Svenson (1980) apud Cunto (1998) para solos coesivos (MRI2-3)

$$
M R=k_{1} \cdot p_{a} \cdot\left(\frac{\sigma_{d}}{p_{a}}\right)^{k_{2}}
$$


Hicks (1970) apud Barksdale \& Hicks (1973) para solos argilosos (MRI2-4)

$$
\begin{aligned}
& M R=k_{2}+k_{3} \cdot\left(k_{1}-\sigma d\right), \text { para } \sigma_{d}<k_{1} \\
& M R=k_{2}+k_{4} \cdot\left(\sigma d-k_{1}\right), \text { para } \sigma_{d}>k_{1}
\end{aligned}
$$

Wolfe \& Butalia (2004) para solos coesivos (MRI2-5):

$$
\frac{M R}{p a}=k_{1} \cdot\left(\frac{p_{a} \cdot \sigma_{o c t}}{\tau_{o c t}^{2}}\right)
$$

Uzan (1985) apud Santha (1994) (MRI3-1)

$$
M R=k_{1} \cdot p_{a} \cdot\left(\frac{\theta}{p_{a}}\right)^{k_{2}} \cdot\left(\frac{\sigma_{d}}{p_{a}}\right)^{k 3}
$$

MRI3-2 - Witczak \& Uzan (1988) (MRI3-2)

$$
M R=k 1 \cdot p_{a} \cdot\left(\frac{\theta}{p_{a}}\right)^{k 2} \cdot\left(\frac{\tau_{o c t}}{p_{a}}\right)^{k 3}
$$

Pezo (1993) apud Macedo (1996) apud Ferreira (2002) (MRI3-3):

$$
M R=k_{1} \cdot p_{a} \cdot\left(\frac{\sigma_{3}}{p_{a}}\right)^{k 2} \cdot\left(\frac{\sigma_{d}}{p_{a}}\right)^{k 3}
$$

Ni et al. (2002) (MRI3-4)

$$
M R=k_{1} \cdot p_{a} \cdot\left(1+\frac{\sigma_{3}}{p_{a}}\right)^{k 2} \cdot\left(1+\frac{\sigma_{d}}{p_{a}}\right)^{k 3}
$$

Ooi et al. (2004) (MRI3-5)

$$
\begin{aligned}
& M R=k_{1} \cdot p_{a} \cdot\left(1+\frac{\theta}{p_{a}}\right)^{k 2} \cdot\left(1+\frac{\sigma_{d}}{p_{a}}\right)^{k 3} \\
& M R=k_{1} \cdot p_{a} \cdot\left(1+\frac{\theta}{p_{a}}\right)^{k 2} \cdot\left(1+\frac{\tau_{o c t}}{p_{a}}\right)^{k 3}
\end{aligned}
$$


NCHRP Project 1-28A e MEPDG (2004) (MRI3-6)

$$
M R=k_{1} \cdot p_{a} \cdot\left(\frac{\theta}{p_{a}}\right)^{k 2} \cdot\left(1+\frac{\tau_{o c t}}{p_{a}}\right)^{k 3}
$$

O modelo universal não-linear foi desenvolvido no projeto NCHRP 1-28A para caracterização do módulo de resiliência de materiais não tratados, sub-base e subleito, variando entre argilas muito plásticas até bases granulares. Este modelo foi implementado no software $M-E P D G$ contido no novo guia de dimensionamento da AASHTO (NCHRP 1-37A).

Gupta et al. (2007)

$$
M R=k_{1} \cdot p_{a} \cdot\left(\frac{\sigma_{b}-3 \cdot k_{6}}{p_{a}}\right)^{k 2} \cdot\left(k_{7}+\frac{\tau_{o c t}}{p_{a}}\right)^{k 3}+\alpha 1 \cdot\left(\mu_{a}-\mu_{w}\right)^{\beta 1}
$$

Onde $(\mu a-\mu w)$ é a sucção matricial; $k 1, k 2, k 3, k 6$ e $k 7$ são constantes do modelo; $\alpha 1$ e $\beta 1$ são constantes de regressão estimadas a partir do percentual de argila ou do limite de plasticidade. Esta expressão é uma simplificação do modelo de 5 parâmetros. Os parâmetros de $k 6$ e $k 7$ foram reportados serem próximos a 0 e 1 de acordo com os resultados experimentais e análises reportadas por Gupta et al. (2007).

As equações com 3 variáveis são válidas para ambos os tipos de solos granulares e coesivos. Ooi et al. (2004) reconheceram que, embora as equações acima representem os efeitos do estado de tensões externas sobre o módulo de resiliência, eles não levam em conta a tensão de tração interna (sucção) ocasionado por: tipo de solo, estrutura do solo, e o estado físico do solo.

No geral, entretanto essas equações abordam e capturam ambos os efeitos do confinamento externo e da tensão de cisalhamento nas propriedades resilientes em solos granulares e coesivos. Além disso, estes modelos não-lineares podem ser usados em um formato semi-log, que podem resultar em melhores análises de tensões no subleito incluindo tensões de tração. 


$$
M R=10^{(k 1-k 2 \cdot \sigma d)}
$$

Fredlunt et al. (1977) propuseram o modelo semilogarítmico após a realização de ensaios triaxiais em amostras de solos Canadenses.

\section{Aranovich (1985):}

Aranovich (1985) propôs um modelo combinado de comportamento do $M R$ com cinco parâmetros $k$, com o uso de solos de comportamento laterítico. No estudo, ensaiaramse tanto amostra compactadas como indeformadas (corpos de prova esculpidos de blocos), das camadas de pavimento e subleito. Estabeleceram-se correlações dos módulos de resiliência com parâmetros físicos (Medina e Motta, 2015).

$$
\begin{gathered}
M R=[k 1+k 2 \cdot(k 1-\sigma d)] \cdot \sigma 3^{k 5}, \text { para } \sigma d<k 1 \\
M R=[k 2+k 4 \cdot(\sigma d-k 1)] \cdot \sigma 3^{k 5}, \text { para } \sigma d>k 1
\end{gathered}
$$

\section{Drumm et al. (1990)}

$$
M R=\frac{k_{1}+k_{2} \cdot \sigma_{d}}{\sigma_{d}}
$$

O modelo proposto por Drumm et al. (1990) foi obtido através de ensaios de laboratório realizados em onze solos tipos de solos coesivos do estado americano do Tenessee.

\section{Stubstad (2002)}

$$
\log \left(\frac{M r}{p_{a}}\right)=k 1+k 2 \cdot \log \left(\frac{\theta}{p_{a}}\right)+k 3 \cdot \log \left(\frac{\tau_{o c t}}{p_{a}}\right)+k 4 \cdot\left[\log \left(\frac{\tau_{o c t}}{p_{a}}\right)\right]^{2}
$$

Onde: $p a=$ pressão atmosférica; $\theta=$ tensão total (bulk stress); $\tau_{o c t}=$ tensão de cisalhamento octaédrica. 
Johnson et al. (1986)

$$
M R=k_{1} \cdot\left(\frac{J_{2}}{\tau_{\text {oct }}}\right)^{k_{2}}
$$

Onde: $J_{2}=\sigma 1 \cdot \sigma 2+\sigma 2 \cdot \sigma 3+\sigma 1 \cdot \sigma 3=2 \cdot(\sigma 3+\sigma d)+\sigma^{2}$ (segundo invariante da tensão).

\section{Mohammad et al. (1999)}

O modelo octaédrico proposto por Mohammad et al. (1999) baseou-se no estudo de oito tipos de solos diferentes do estado Americano da Louisiana, variando-se a massa específica e os teores de umidade dos corpos de prova.

$$
\frac{M R}{\sigma_{a t m}}=k 1 \cdot\left(\frac{\sigma_{o c t}}{\sigma_{a t m}}\right)^{k 2} \cdot\left(\frac{\tau_{o c t}}{\sigma_{a t m}}\right)^{k 3}
$$

2.2.2 Fatores que influenciam no estado físico e estado de tensões dos solos

Segundo a AASHTO (2002) os seguintes fatores estão relacionados com o estado físico do solo:

a) teor de umidade: todos em igualdade de condições, quanto maior o teor de umidade menor será o módulo; no entanto, a umidade tem dois efeitos distintos:

- pode afetar o estado de tensões: por meio de pressão de sucção ou poropressão; a sucção e teor de água são correlacionados por meio da "curva característica de água no solo";

- pode afetar a estrutura do solo, por meio da destruição da cimentação entre as partículas do solo.

b) peso específico aparente seco: a baixos teores de umidade, o peso específico menor normalmente irá resultar em valores de $M R$ inferiores (há exceções). 
c) grau de saturação: um terceiro parâmetro, exclusivamente definido pelo teor de umidade, peso específico aparente seco (ou índice de vazios) e a gravidade específica dos sólidos (Gs) é o grau de saturação $(S)$.

Os seguintes fatores estão relacionados com o estado de tensões do solo (AASHTO 2002):

d) tensão octaédrica ou somatória de tensões (bulk stress): componente volumétrica total - para condições de teste de laboratório, tais como o ensaio triaxial, essa tensão é determinada a partir de:

$$
\theta=\sigma_{1}+\sigma_{2}+\sigma_{3}
$$

e) tensão de cisalhamento octaédrica: componente desviador total - para condições de testes triaxiais esta tensão é determinada a partir de:

$$
\tau_{o c t}=\frac{1}{3} \cdot \sqrt{\left(\sigma_{1}-\sigma_{2}\right)^{2}+\left(\sigma_{1}-\sigma_{3}\right)^{2}+\left(\sigma_{2}-\sigma_{3}\right)^{2}}
$$

f) pressões de poros / sucção: os materiais granulares e finos utilizados no projeto de pavimento estão geralmente em um estado parcialmente saturado, especialmente se eles se encontram acima da superfície do lençol freático. O estado de tensões em materiais não saturados pode ser caracterizado pelos seguintes parâmetros:

- $\quad(\sigma 3-\sigma a)=$ pressão de confinamento (também chamada de tensão normal);

- $(\sigma 1-\sigma 3)=$ tensão desviadora;

- $(\mu a-\mu w)=$ sucção matricial.

Onde: $\sigma 3$ = pressão de confinamento total; $\sigma 1=$ tensão principal maior total; $\mu a=$ pressão atmosférica; $\mu w=$ poro pressão da água.

g) Fatores relacionados à estrutura / tipo de material:

- Método de compactação;

- Tamanhos de partículas (granulometria e empacotamento);

- Forma da partícula, resistência e textura superficial (relacionado ao atrito/embricamento);

- Natureza das ligações entre as partículas e sua sensibilidade à água (teor de umidade). 
Diversos estudos têm sido realizados com o intuito de avaliar os fatores que afetam as propriedades mecânicas resilientes dos solos. Entre elas podem-se destacar as pesquisas relacionadas a seguir.

Barksdale (1971, 1972) e Terrel et al. (1974) pesquisaram variáveis de laboratório incluindo a forma e a duração do pulso do carregamento na formulação dos testes de laboratório.

Hicks \& Monismith (1971) mais tarde descreveram diversos fatores que influenciaram as propriedades resilientes dos materiais granulares incluindo bases.

Kalcheff \& Hicks (1973), então documentaram os módulos de resiliência realizados em solos granulares incluindo agregados não tratados. Este estudo descreveu os potenciais sequencias e taxas de carregamento recomendadas para testar materiais granulares.

Allen \& Thompson (1974) estudaram a resposta de tensões laterais nas propriedades resilientes de materiais granulares.

Thompson \& Robnett (1976) estudaram as propriedades resilientes de diversos solos de subleito de Illinois na Universidade de Illinois, Urbana, e este estudo reportou o desenvolvimento de correlações entre módulo de resiliência e propriedades de solos de subleito. Os autores propuseram um modelo aritmético para descrever as propriedades resilientes de solos de graduação fina.

Jones \& Witczak (1977) estudaram a influência da umidade de pós compactação nos resultados de módulo de resiliência de argilas siltosas provenientes do subleito de uma rodovia experimental construída em San Diego nos anos 60. Concluíram que podem haver reduções significativas do valor do módulo de resiliência com o aumento do teor de umidade.

Edil \& Motan (1977) estudaram a influência de umidade pós-compactação em um solo do tipo CL da região de Wisconsin - EUA. Os autores verificaram que este tipo de solo é mais sensível à variação de umidade no ramo seco do que no ramo úmido, ou seja, para teores crescentes de wot-2\% até wot, os valores de módulo decresceram exponencialmente cerca de $75 \%$, e a partir daí até wot+2\% decresceram cerca de $25 \%$. 
Preussler (1978) estudou a influência dos métodos de compactação nos valores de MR em um solo arenoso (saprolítico de arenito feldspáltico, utilizado na sub-base do pavimento da BR-290/RS, km 54). As amostras foram compactadas no equipamento reduzido que Souza Pinto (1965) divulgou no país. O autor verificou o aumento de $M R$ com a frequência mais acentuadamente de 40 para 60 ciclos/minuto. Para o pico da curva de compactação Proctor Normal, a $\sigma_{3}$ de 0,1 MPa, o ensaio a 40 ciclos/minuto resultou no módulo de 320 MPa e a 60 ciclos/minuto $(1 \mathrm{~Hz})$, módulo de $650 \mathrm{MPa}$, ou seja, um aumento de $100 \%$. O autor também verificou a influência da duração do carregamento: 0,$14 ; 5$ e 10 segundos, mantendo constante o intervalo entre aplicações consecutivas e relação de tensões. Houve uma diminuição do 450 para $270 \mathrm{MPa}$ do módulo quando a duração do carregamento passou de 0,14 a 5 e $10 \mathrm{~s}$, sendo o ensaio feito para as condições de pico de compactação, $\sigma_{3}$ de 0,1 MPa e $\sigma_{d}$ de 0,3 MPa.

Hull et al. (1980) reportaram resultados de ensaios MR em materiais de base seguindo os procedimentos de ensaio recomendados por Kalcheff e Hicks (1973).

Svenson (1980) verificou que, para teores de umidade de até o valor ótimo, métodos de compactação por impacto na área plena ou amassamento (ou puncionamento aparelho Harvard miniatura) não tem influência na deformação resiliente. Para teores de umidade acima da ótima a moldagem do corpo de prova por amassamento conduz a uma estrutura mais deformável sob cargas repetidas. A autora também observou, também, o efeito do tempo de cura dos corpos de prova de argila vermelha (laterítica) compactada, nas deformações, mesmo na umidade próxima da ótima. Adotou três tempos de cura ou de repouso entre a compactação e o ensaio triaxial: 17 horas, 10 dias, e 20 dias. Quanto maior foi o tempo de repouso, menor a deformação na solicitação dinâmica, porém esta distinção deixou de existir ao atingir-se cerca de 400 aplicações de tensão desvio de 0,075 MPa à tensão confinante de 0,020 MPa (razão $\sigma 1 / \sigma 3$ de 4,7$)$.

Shook et al. (1982) discutiram um método de dimensionamento de pavimentos flexíveis do Asphalt Institute no qual um modelo baseado na tensão total (ou bulk stress) foi utilizado para modelar o comportamento resiliente de solos pouco coesivos. Uzan (1985) explicou as limitações do modelo baseado na tensão total (bulk stress) com duas constantes e então introduziu um modelo de dois parâmetros contemplando 
ambas tensões - tensão total (bulk stress) e tensão desvio com três constantes para simular o comportamento resiliente de subleitos.

Em 1986, a AASHTO publicou o guia de dimensionamento no qual recomendava o uso do módulo de resiliência para caracterizar os materiais. Seguindo esta recomendação, diversas pesquisas e estudos foram iniciados com suporte dos diversos Departamentos de Transportes dos EUA (DOTs). Alguns destes estudos e suas conclusões são sumarizadas na Tabela 2.4 e Tabela 2.5.

Importante citar que o método da AASHTO de 1993 considera a utilização de um valor de $M R$ efetivo, quando do uso da equação de dimensionamento de pavimentos flexíveis, que é um valor médio representativo para todas as estações do ano. O valor é calculado a partir da determinação dos valores de $M R$ para cada mês ou estação do ano, de acordo com os níveis de saturação do solo, decorrentes de precipitações e dos ciclos de congelamento e descongelamento. A partir destes valores de módulo, são determinados os fatores de dano relativo (uf). A partir do valor médio de dano relativo durante os 12 meses do ano, é então obtido o valor de módulo efetivo. A expressão utilizada é a seguinte:

$$
u_{f}=1,18 \times 10^{8} \times M_{R}^{-2,32}
$$

Onde: $u f$ = dano relativo associado ao valor de $M R$ na equação de dimensionamento; $M R=$ módulo de resiliência do material do subleito (psi).

A Figura 2.6 apresenta um exemplo para a determinação do valor representativo do ano ou valor de $M R$ efetivo. 


\begin{tabular}{|c|c|c|}
\hline Month & 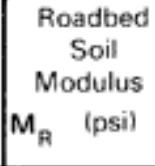 & $\begin{array}{c}\text { Relative } \\
\text { Damage, } \\
u_{f}\end{array}$ \\
\hline Jan & 20,000 & 001 \\
\hline Feb & 20,000 & 001 \\
\hline \multirow{2}{*}{ Mar } & 2,500 & 151 \\
\hline & & $\cdot$ \\
\hline Apr & 4,000 & 051 \\
\hline May & 4,000 & 051 \\
\hline June & 7000 & 013 \\
\hline July & 7,000 & 013 \\
\hline Aug & 7,000 & 013 \\
\hline Sept & 7000 & 013 \\
\hline Oct & 7000 & 013 \\
\hline Nov & 4000 & 051 \\
\hline \multirow{2}{*}{ Dec } & 20,000 & 001 \\
\hline & & \\
\hline Summe & $\Sigma u_{f}=$ & 372 \\
\hline
\end{tabular}

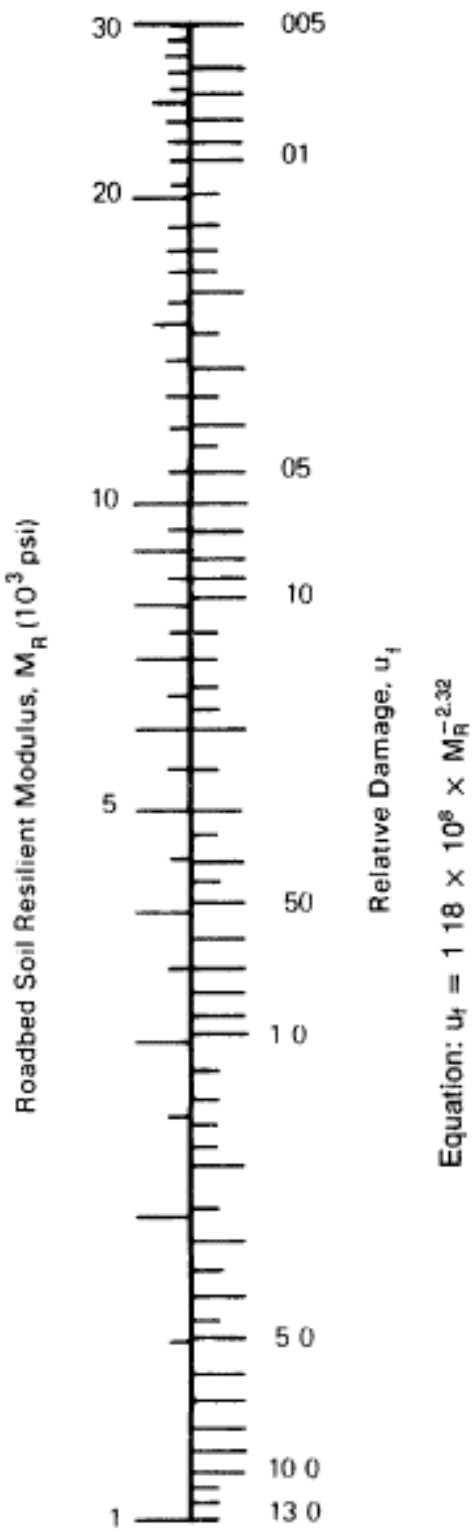

Average $\bar{u}_{f}=\frac{\Sigma_{u_{i}}}{n}=\frac{372}{12}=031$

Effective Roadbed Soil Resilient Modulus, $M_{R}(p s i)=\underline{5,000}$ (corresponds to $\bar{u}_{\mathrm{f}}$ )

Figura 2.6 - Exemplo da determinação do valor de $M R$ para utilização da equação de dimensionamento contida no Guia da AASHTO/93 
Tabela 2.4 - Conclusões a partir de pesquisas em módulo de resiliência entre 1986-1996

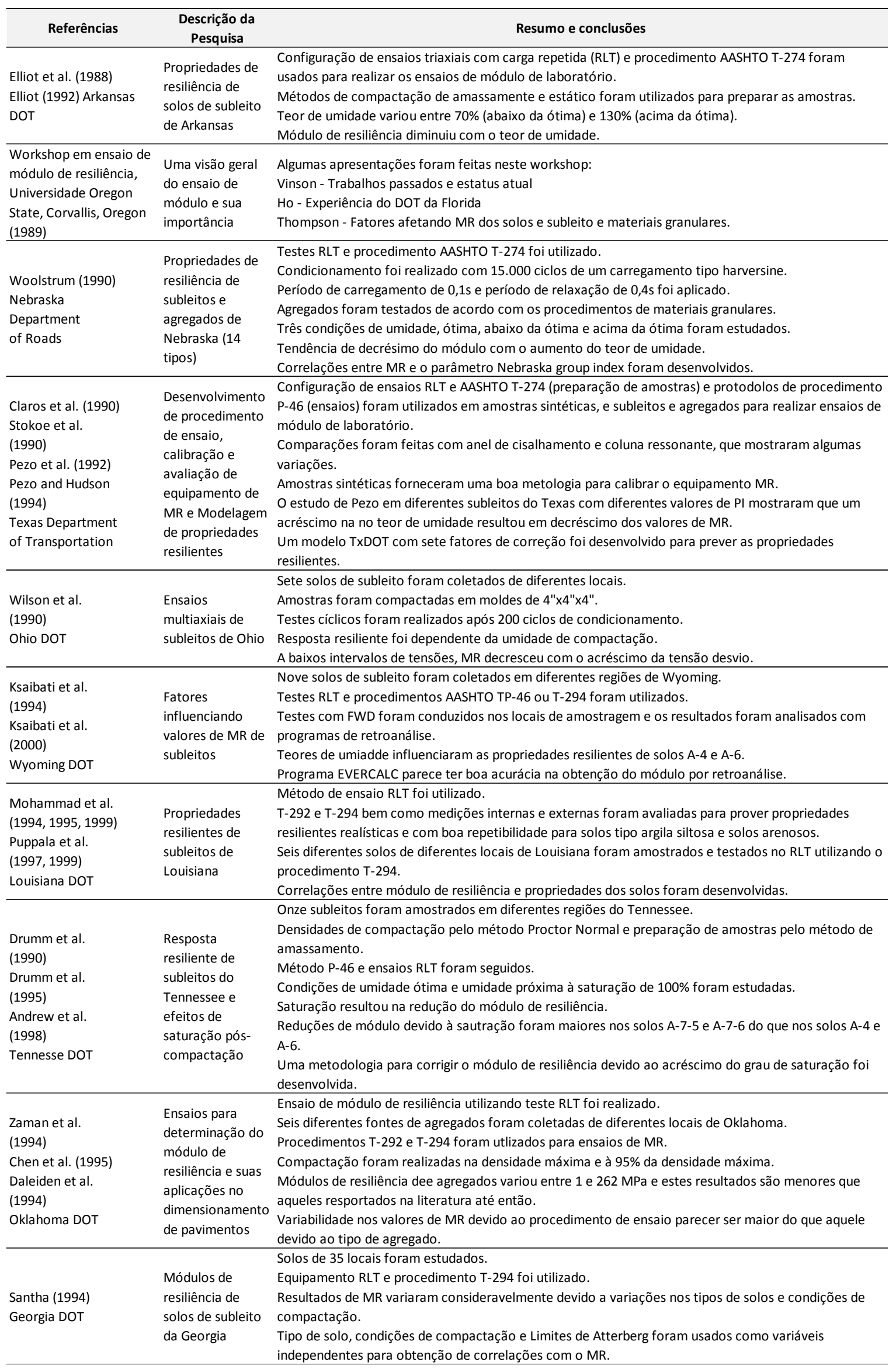


Tabela 2.5 - Características das pesquisas em módulo de resiliência entre 1986 e 1996 (NCHRP, 2008)

\begin{tabular}{|c|c|}
\hline Tópico & Observações \\
\hline Equipamento utilizado & $\begin{array}{l}\text { Testes RLT (método preferido) } \\
\text { Teste de coluna ressonante } \\
\text { Teste de anel de cisalhamento } \\
\text { Teste triaxial cúbico }\end{array}$ \\
\hline $\begin{array}{l}\text { Calibração - repetibilidade e } \\
\text { confiabilidade }\end{array}$ & $\begin{array}{l}\text { Continua sendo problema. Um dos estudos reportou o } \\
\text { uso de amostras sintéticas com propriedades de rigidez } \\
\text { conhecidas. Intevalos amplos de propriedades. }\end{array}$ \\
\hline $\begin{array}{l}\text { Procedimento de teste usado } \\
\text { para RLTs }\end{array}$ & $\begin{array}{l}\text { T-274 foi utilizado nos estudos iniciar seguidos pelos } \\
\text { métodos T-292 e T-294. TP- } 46 \text { também foi utilizado nos } \\
\text { estudos posteriores. Todos os estudos usaram } \\
\text { condicionamento, seguidos pelos ensaios à várias } \\
\text { pressões de confinamento e de desvio. Sequências de } \\
\text { tensões e relações de tensões são diferentes em cada } \\
\text { um destes métodos. }\end{array}$ \\
\hline Tipos de materiais & $\begin{array}{l}\text { Maioria dos estudos focaram em subleitos naturais; } \\
\text { alguns outros estudaram agregados e solos arenosos. }\end{array}$ \\
\hline $\begin{array}{l}\text { Métodos de preparação de } \\
\text { amostras }\end{array}$ & $\begin{array}{l}\text { Maioria dos métodos usam a compactação por impacto } \\
\text { com as energias do ensaio de Proctor. Outros utilizam } \\
\text { métodos de compactação estática e por amassamento. }\end{array}$ \\
\hline Condições de compactação & $\begin{array}{l}\text { Próximo ao teor de umidade ótima. } \\
\text { Diversos estudos investigaram variações nos teores de } \\
\text { umidade de compactação (condições seca e umida em } \\
\text { relação à ótima). }\end{array}$ \\
\hline $\begin{array}{l}\text { Modelos para analisar dados de } \\
\text { MR }\end{array}$ & $\begin{array}{l}\text { Modelos de tensões totais (bulk stress) para materiais } \\
\text { granulares e tensão desvio (solos coesivos) são } \\
\text { frequentemente usados uma vez que são modelos } \\
\text { recomendados pelos procedimentos da AASHTO. }\end{array}$ \\
\hline
\end{tabular}

Elliot \& Thornton (1988) reportaram resultados de ensaios de módulo de resiliência obtidos em diferentes solos coesivos de subleitos de Arkansas. O objetivo principal desta pesquisa foi explicar os efeitos da umidade de campo nos valores de módulo de subleitos compactados. Este estudo também procurou os efeitos dos métodos de compactação e variações do teor de umidade nas propriedades resilientes dos materiais. Os autores realizaram ensaios de $M R$ em corpos de prova, compactados na umidade ótima, e em seguida submetidos a três teores de umidade por secagem e umedecimento por imersão: Wot-2,4\%, Wot+3,1\% e na $W o t+5,6 \%$. Os autores 
propõem a determinação do módulo de resiliência em um determinado período do ano representativo das condições de umidade, de modo a representar as condições médias de umidade de todo o ano. Figura 2.7 a seguir ilustra a variação do módulo de resiliência de um solo argiloso $(\mathrm{CH})$ de Jackport, com respeito às mudanças percentuais no teor de umidade ótima. Um decréscimo no valor de MR próxima a $1 \mathrm{ksi}$ ( 7 $\mathrm{MPa}$ ) foi relatado para um decréscimo percentual no teor de umidade ótima. Um baixo percentual da ótima (abaixo de 100\%) foi chamado de condição "dry of optimum" e um alto percentual em relação à umidade ótima (acima de 100\%) foi chamado de condição "wet of optimum". Conclusões similares foram obtidas com subleitos coesivos neste estudo.

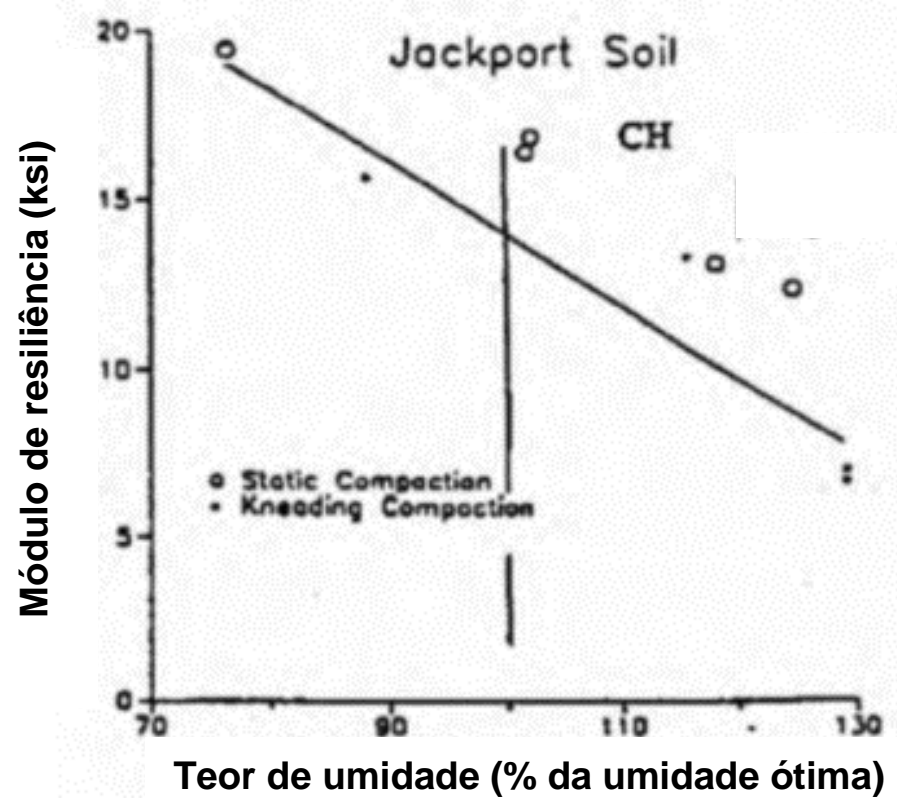

Figura 2.7 - Módulo de resiliência de um solo $\mathrm{CH}$ de Arkansas em função do teor de umidade (Elliot et al., 1988 apud NCHRP, 2008)

Em 1989, um workshop em módulo de resiliência foi realizado na Oregon State University em Corvallis e diversos pesquisadores, práticos e empresas de manufatura de equipamentos discutiram aspectos relacionados a procedimentos de testes, projetos e equipamentos para determinação de $M R$. Este workshop foi fundamental para que os diversos departamentos de transportes dos EUA (DOTs) iniciassem pesquisas acerca das respostas do módulo de resiliências dos solos locais.

Woolstrum (1990) estudaram 14 diferentes solos de Nebraska e chegaram a conclusões similares às de Elliot et al. (1988). Este estudo também desenvolveu 
correlações introduzindo o parâmetro índice de grupo Nebraska (G) como uma variável independente. O procedimento AASHTO T-274 foi utilizado para determinar as propriedades resilientes dos solos locais. Diversos artigos e relatórios foram publicados no começo dos anos 1990 que focaram nas pesquisas em módulo de resiliência realizadas no Texas (Claros et al. 1990; Pezo et al. 1992). Estes estudos mostraram calibração de dispositivos de ensaio $R L T$, uso de outros equipamentos incluindo $R C$ e equipamento de anéis de torção para medir o módulo de cisalhamento, e estimar o módulo de elasticidade ou o módulo de resiliência. Pezo et al. (1992) focou no desenvolvimento de em um modelo universal para prever as propriedades resilientes de subleitos.

Pesquisas instituídas pelo DOT do Texas têm avaliado o uso de amostras de materiais sintéticos para calibração dos dispositivos de determinação de módulo de laboratório, incluindo $R L T, R C$ e anéis de cisalhamento (Claros et al. 1990; Stokoe et al. 1990; Pezo et al. 1992; Pezo \& Hudson, 1994).

Outro estudo realizado por Stokoe et al. (1990) relatou o uso de outros dispositivos como o teste de coluna ressonante $(R C)$ para medir o módulo de amostras sintéticas calibradas.

Wilson et al. (1990) apresentou as conclusões das pesquisas de subleitos de Ohio na qual as propriedades resilientes de subleito foram medidas utilizando uma configuração de teste multiaxial cúbica. A Figura 2.8 a seguir apresenta o dispositivo de teste multiaxial utilizado nesta pesquisa. Os pesquisadores notaram que a singularidade deste equipamento em aplicar tensões em todas as direções e concluíram que este equipamento foi capaz de prever propriedades resilientes de subleitos. O procedimento de teste utilizado nesta pesquisa foi único, e incluiu a aplicação de um nível de pressão de confinamento de 5 psi ( 35 kPa) e diferentes intervalos de tensões desvio de 1 a 8 psi (7 a $56 \mathrm{kPa}$ ). O pulso de tensão desvio foi aplicada a uma taxa de 1 pulso por segundo. Propriedades resilientes foram determinadas baseadas em respostas nas medidas de deformações. Dados de teste típicos com solos granulares de subleito são apresentados na Figura 2.9 a seguir, que mostra a influência da tensão desvio e teor de umidade de compactação nas propriedades do módulo de resiliência. Estes resultados indicam que um acréscimo na tensão desvio resultou em um decréscimo nas propriedades de módulo de 
resiliência. Também, um acréscimo no teor de umidade de compactação resultou em um decréscimo do módulo de resiliência de solos granulares.

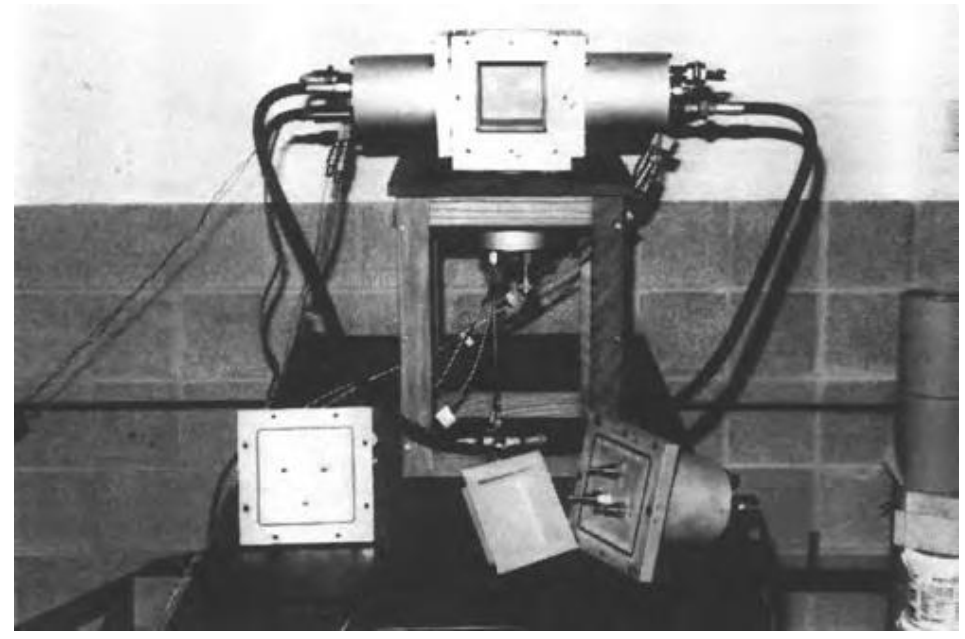

Figura 2.8 - Dispositivo de teste multiaxial (Wilson et al., 1990 apud NCHRP, 2008)

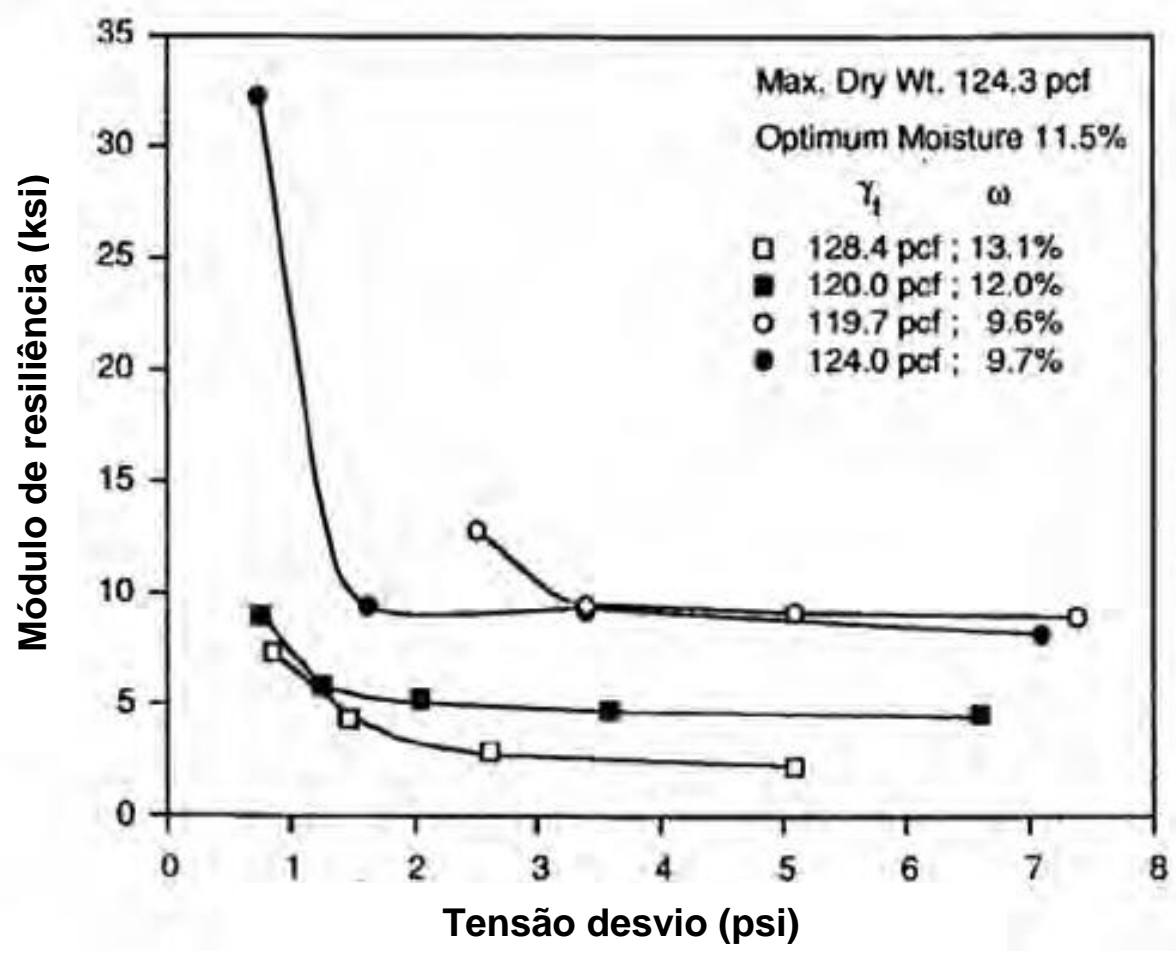

Figura 2.9 - Resultados de módulo de resiliência de subleitos granulares de Ohio (Wilson et al., 1990 apud NCHRP, 2008)

No começo dos anos 1990, Thompson \& Smith (1990), Zaman et al. (1994) e Chen et al. (1994) reportaram os módulos resilientes de agregados de base não tratados utilizando os procedimentos AASHTO T-292 e T-294. Variações dos módulos com 
respeito aos procedimentos de teste e tipos de agregados são explicadas nestes estudos. A Figura 2.10 apresenta os efeitos dos procedimentos de teste nas propriedades resilientes de agregados de Choctaw e Murray em Oklahoma. Resultados de testes indicaram que o procedimento AASHTO T-294 deu origem a valores de módulos superiores aos obtidos com o procedimento T-292, e sua variação foi atribuída aos efeitos da pressão de condicionamento e efeitos de endurecimento no procedimento T-294. Também, este estudo reportou que a variabilidade do $M R$ com respeito ao procedimento de teste foi superior do que a variabilidade com respeito ao tipo de agregado.

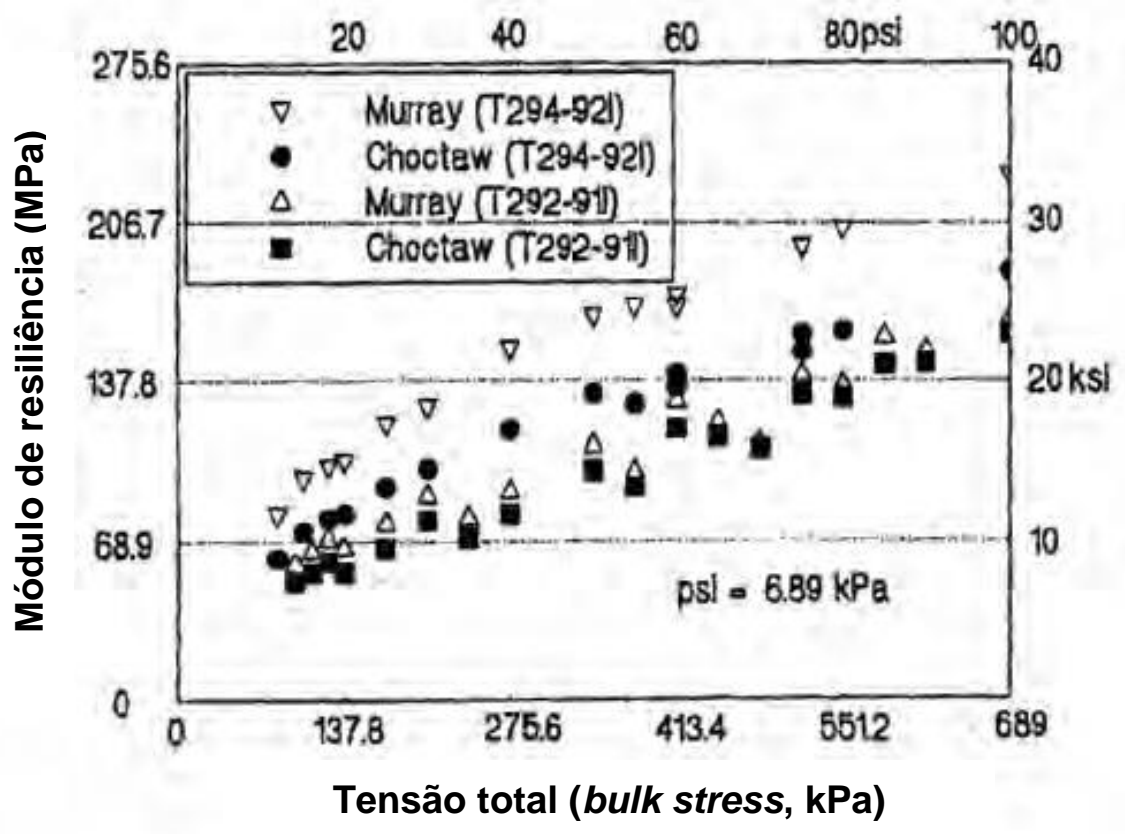

Figura 2.10 - Influência dos procedimentos de teste AASHTO nos resultados de módulo de resiliência de diferentes tipos de agregados (Chen et al., 1994, apud NCHRP, 2008)

Motta et al. (1990) mostram o efeito das condições de moldagem ao longo da curva de compactação para um solo granular laterítico, bem como da posterior embebição dos corpos de prova por quatro dias, conforme prática usual executada na determinação do $C B R$.

Raad et al. (1992) demonstrou que o efeito da umidade no comportamento resiliente de agregados é mais significante em agregado bem graduados e com bastante presença de finos, por facilitar que a água fique presa no interior dos poros, do que em materiais uniformemente graduados, os quais permitem uma drenagem mais rápida da água. 
Li \& Selig (1994) estudaram os efeitos do teor de umidade, massa específica e estado de tensão nos valores de $M R$. Foram analisados 27 resultados de ensaios dinâmicos executados com variação de umidade em onze solos finos, com massas específica constante e 26 resultados de ensaios dinâmicos com variação de umidade em dez tipos de solos finos, com variação de massa específica.

Santha (1994) estudou as propriedades resilientes de subleitos de 35 locais de teste na Georgia, utilizando procedimento T-274. Estes resultados mostraram larga variações no $M R$ com respeito ao tipo de solo e procedimentos de compactação usados nos testes. Os dados medidos foram usados e analisados com os modelos de dois e três parâmetros. O modelo de três parâmetros capturou melhor as propriedades resilientes do que o modelo de dois parâmetros.

Burczyk et al. (1995) reportaram propriedades resilientes de solos de subleito de Wyoming. Uma configuração de teste RLT e um o AASHTO T-294 foi utilizado neste estudo, que também discutiu várias propriedades de solos fundamentais que influenciam as propriedades resilientes de solos de Wyoming. Este estudo também avaliou vários métodos de retroanálise utilizados para interpretar as propriedades resilientes.

Mohammad et al. (1995) estudaram amostras de um solo arenoso e uma argila siltosa (solos classificados como A-3 e A-7-6 segundo a HRB). Os corpos de prova foram compactados na umidade ótima, no ramo seco e no ramo úmido. Os autores concluíram que os valores de $M R$ do solo argiloso diminuem com o aumento da umidade e que o $M R$ dos solos arenosos tem menor sensibilidade à umidade.

Thadkamalla \& George (1995) estudaram dois materiais granulares e dois materiais finos, classificados como A-2, A-2-4, A-4 e A-7-5 pela HRB. Os autores constataram reduções de até $20 \%$ no $M R$ dos solos arenosos e reduções de $50 \%$ a $75 \%$ no $M R$ dos solos finos. Os autores constataram que a queda do $M R$ com o grau de saturação é exponencial para o método da contrapressão e linear para o método da capilaridade. Jones e Witczak (1996) estudaram a influência da umidade de compactação no módulo de resiliência de solos de subleito compostos por argila siltosa em San Diego. Os autores constataram decréscimo do valor do módulo de resiliência de $275 \mathrm{MPa}$ para $52 \mathrm{MPa}$. Os autores obtiveram correlações estatísticas que estimam o valor do módulo resiliente (MR), em função do teor de umidade (w) e do grau de saturação (S). 


$$
\begin{gathered}
\log M R=-0,132 \cdot w+0,013405 \cdot S+2,31909 \text { (Laboratório) } \\
\log M R=-0,111109 \cdot w+0,021699 \cdot S+1,1786(\text { Campo) }
\end{gathered}
$$

Nazarian et al. (1996) apresentou o desenvolvimento de um método de ensaio de $M R$ para agregados de base. Foram utilizados quatro tipos de bases granulares incluindo materiais "Caliche, Limestone, Gravel, e Iron Ore". O ensaio RLT foi utilizado e o procedimento T-294 foi seguido. Configurações do ensaio "bender element test" também foram avaliados. Materiais de base tiveram seus valores de $M R$ variando entre 70 MPa e 210 MPa com material Limestone (calcário) chegando próximo de 300 MPa no teor de umidade ótima. O condicionamento foi eliminado e a selagem foi recomendada em ambas as extremidades dos corpos de prova, que resultaram em maior repetibilidade dos resultados dos testes. Deformações laterais e coeficientes de Poisson foram medidos diretamente nos ensaios. Condicionamento e sequência de testes foram modificados para ensaios futuros no estado.

Berg et al. (1996) apud Bigi e Berg (1996) realizaram ensaios de módulo de resiliência em subleitos não tratados de Minnesota. Dois subleitos argilosos e duas bases com diferentes porcentagens de finos foram ensaiados. As amostras foram compactadas e então saturadas e após submetidas ao congelamento. Testes de módulo de resiliência foram conduzidos em amostras congeladas sujeitas a três diferentes temperaturas abaixo da temperatura de congelamento. Algumas amostras na célula triaxial foram descongeladas e depois submetidas aos ensaios de módulo de resiliência. $O$ pulso tem $1 \mathrm{~s}$ de carregamento e $2 \mathrm{~s}$ de repouso. Amostras congeladas foram testadas sob pressão de confinamento de 10 psi ( 70 kPa) e amostras descongeladas foram submetidas a 4 diferentes pressões de confinamento. Em todos os casos as tensões desvio foram variadas. Módulos muito baixos (menos de $1 \mathrm{ksi}$ ou 7 MPa) foram reportados, que foram atribuídos a erros de calibração. Com uma indução de congelamento, os módulos dos subleitos cresceram até 1.000 ksi ( 7.000 MPa). Para bases não tratadas, o MR foi de 10.000 ksi ( 70.000 MPa) em condições de congelamento. Ambos os materiais de base e subleito exibiram um acréscimo da ordem de 2 a 3 vezes no módulo de resiliência devido ao congelamento. O valor de $M R$ decresceu com um acréscimo na saturação. $O$ valor de $M R$ de todos os solos são dependentes das condições de pressão. Diferentes expressões de regressão são apresentadas. Procedimentos de testes são diferentes dos procedimentos 
recomendados pela AASHTO. Em alguns testes, erros de calibração foram reportados.

Drumm et al. (1990, 1997) estudaram os módulos de resiliência de diferentes tipos de agregados de subleitos do Tennessee utilizando um procedimento de teste SHRP P. 46. A pesquisa focou no desenvolvimento de uma base de dados de módulos de resiliência para subleitos de Tennessee, e também no procedimento T-292, e sua variação foi atribuída ao condicionamento de tensões e efeitos de endurecimento influenciaram nas reduções no módulo de resiliência com respeito à saturação póscompactação. A Figura 2.11 apresenta os efeitos dos teores de umidade póscompactação em termos do grau de saturação no módulo de resiliência de subleitos. Como esperado, um aumento na saturação resultou em um decréscimo nos valore de MR. Esta pesquisa também levou ao desenvolvimento de modelos de regressão para previsão de propriedades resilientes de subleitos. Os autores estudaram a influência da umidade pós-compactação nos valores de $M R$ de solos finos (mais de $50 \%$ passando na peneira \#200), de um conjunto de solos de subleito representativos do estado americano do Tennessee. Foram analisados onze tipos de solos, amostras classificadas como A-4 (3 locais), A-6 (3 locais), A-7-5 (2 locais) e A-7-6 (3 locais). A saturação foi realizada dentro da câmara triaxial. Os autores constataram maiores valores de $M R$ para os solos A-7-5 e A-7-6 para condições originais de compactação e ensaio, porém maior variação dos valores de $M R$ para estes materiais após saturação, em relação aos demais materiais.

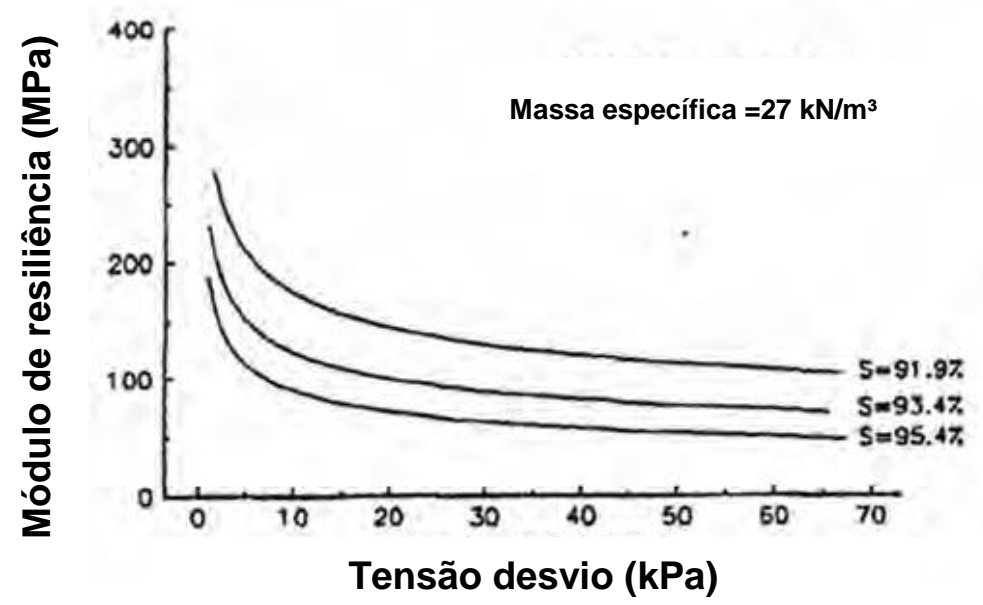

Figura 2.11 - Influência do teor de umidade pós compactação nos resultados de módulo de resiliência (Drumm et al. 1990, 1997) 
Modificações nos procedimentos de ensaios T-294 e T-307 com diferentes especificações de teste ocorreram após 1996. Isto resultou na realização de pesquisas adicionais por parte dos vários DOTs dos EUA para validar as conclusões das pesquisas anteriores e novas pesquisas para determinar o $M R$ de solos locais.

O equipamento de teste primariamente utilizado nos últimos dez anos foi o aparato de teste RLT. Alguns estudos - incluindo aqueles realizados por Nazarian et al (1996), Davich et al. (2004b), e Gupta et al. (2007) - experimentaram o uso de "bender element testing" para determinar o módulo de cisalhamento de pequena deformação, que foi então correlacionado com o módulo de resiliência com um coeficiente de Poisson assumido. A Figura 2.12 a seguir apresenta uma típica configuração de teste "bender element" feita com elementos piezoelétricos usados por Davich et al. (2004b).

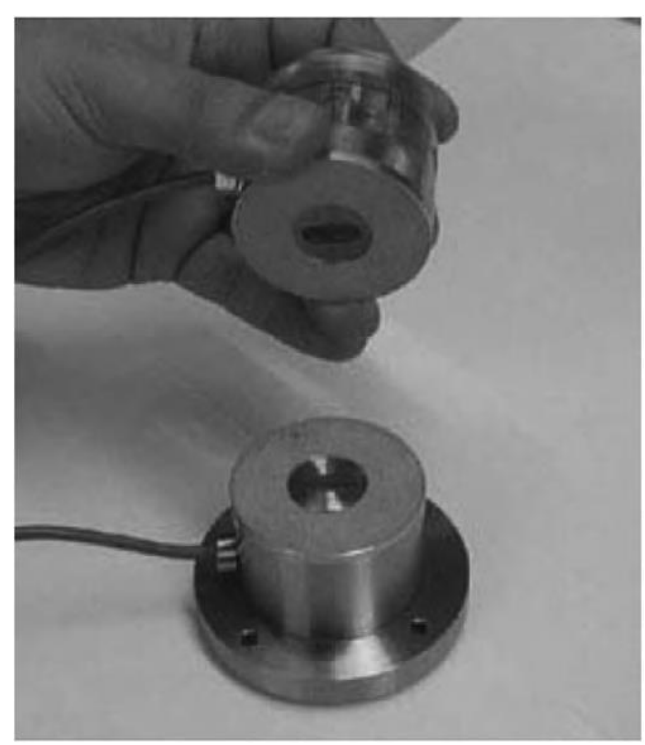

Figura 2.12 - Configuração do ensaio "bender element" utilizado por Davich et al. (NCHRP, 2008)

Um pulso de onda gerada pelo emissor ("bender element") a partir de uma extremidade viajará através do corpo de prova de solo e chega ao receptor (outro "bender element") na outra extremidade. Com base no tempo de percurso de uma onda de cisalhamento e peso específico da amostra de solo, o valor de módulo de cisalhamento de pequena deformação é determinado.

O módulo de cisalhamento de pequena deformação (Gmax) é tipicamente correlacionado com o módulo de resiliência (MR ou Emax) a baixas deformações utilizando a seguinte relação: 


$$
M R=2 \cdot G_{\max } \cdot(1+\mu)
$$

Onde $\mu$ é o coeficiente de Poisson. A Figura 2.13 a seguir apresenta uma comparação típica de $M R$ a partir de resultados de ensaios $R L T$ e Emax a partir de ensaio "bender element". Embora o método "bender element” forneça uma tendência similar àquela das propriedades resilientes a partir do $R L T$, eles não são a mesma medida. Isto é por conta das variações nas deformações nas quais aquelas propriedades são medidas. Outras limitações incluem a dificuldade em interpretar os períodos de tempo de viagem e necessidade de pessoal qualificado e de pessoas com experiência considerável para interpretar esses resultados.

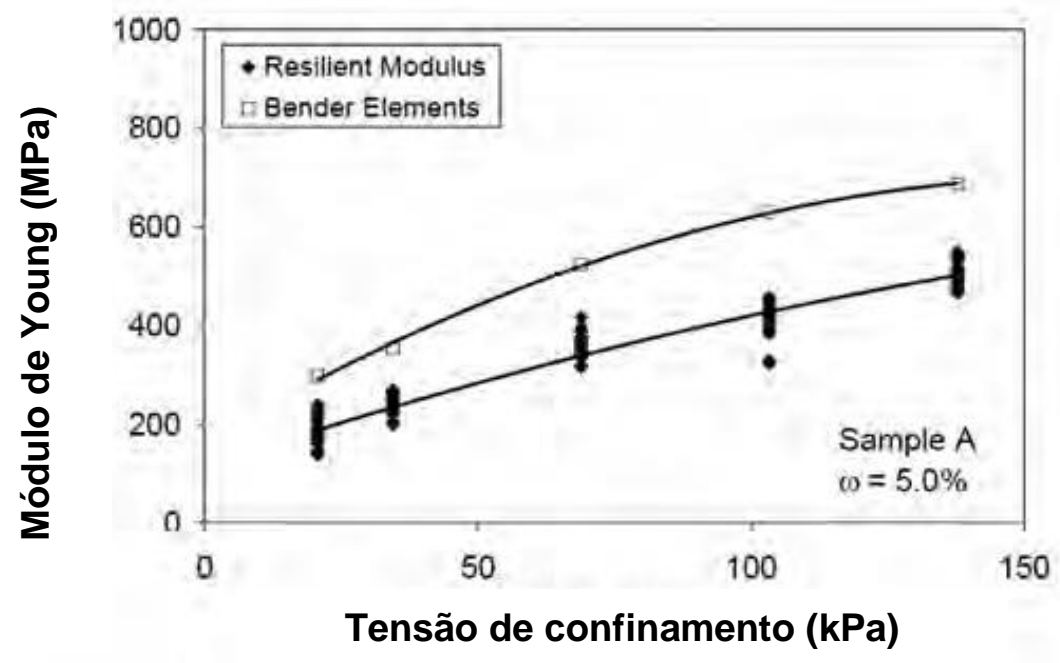

Figura 2.13 - Comparação do módulo elástico a partir dos ensaios RLTe "bender element test" (Davich et al.2004b apud NCHRP, 2008)

Lee et al. (1997) estudaram as propriedades resilientes de subsolos coesivos de Indiana. Foram utilizadas amostras de solos de três subleitos em serviço de Indiana. Método AASHTO T-274 foi usado. Amostras de solos foram preparadas utilizando método de compactação por impacto. A maioria dos resultados de $M R$ variaram entre 30 e $80 \mathrm{MPa}$.

Bernucci (1997) avaliou o efeito da variação de umidade pós-compactação nos valores de $M R$ de solos lateríticos brasileiros. Os materiais estudados foram classificados, de acordo com a metodologia MCT como $L A, L A^{\prime}$ e $L G^{\prime}$. A autora verificou que há pouca influência da imersão em água dos corpos de prova nos valores de $M R$ e que a secagem dos corpos de prova produz um acréscimo significativo nos valores de $M R$ das amostras ensaiadas. A autora cita que aspectos como drenagem, 
temperatura do pavimento, permeabilidade do solo e nível do lençol freático são fatores importantes a serem considerados no projeto e execução de obras rodoviárias. Cita também a importância da existência de acostamentos imprimados e com materiais devidamente escolhidos que aumentam a distância de percolação da água. Rodrigues (1997) estudou a influência da umidade nos valores de $M R$ de solos lateríticos de subleito no Rio Grande do Sul. As amostras estudadas foram classificadas como LG', NA', LG' e LA' pela metodologia MCT e os corpos de prova foram compactados nas condições ótimas da energia de Proctor Normal e submetidas à secagem, umedecimento e ciclo de secagem/umedecimento. $\mathrm{O}$ autor relata que as amostras submetidas ao ciclo de secagem/umedecimento apresentaram valores de $M R 68 \%$ menores que aqueles compactados e ensaiados na umidade ótima, redução superior em relação ao $M R$ obtido nas amostras apenas submetidas à umidificação.

Carmo (1998) propõe duas equações para determinação do módulo de resiliência a partir do módulo tangente inicial determinado em ensaios de compressão não confinada (E0, em $\mathrm{kPa}$ ) para solos argilosos e arenosos.

Gonçalves (1998) estudou a influência da variação da umidade nos valores de $M R$ em um solo argiloso A-7-6 (HRB), LG' (classificação MCT), de subleito do interior de São Paulo. Os corpos de prova compactados na umidade ótima foram submetidos às condições de secagem, umedecimento e umedecimento pós-secagem. Verificou-se redução dos módulos no caso de umidificação e umidificação pós-secagem em relação aos valores de módulo de corpos de prova compactados e ensaiados na umidade ótima.

Andrew et al. (1998) estudaram a influência da variação da umidade sobre o módulo de resiliência em 4 seções de pavimentos flexíveis instrumentadas em diferentes regiões climáticas do estado americano do Tennessee. Foram realizadas medidas mensais com equipamento FWD para avaliar a variação sazonal nos valores de $M R$.

Santos (1998) estudou solos empregados nas rodovias federais do Estado do Mato Grosso. Foram realizadas avaliações estruturais de campo com o emprego da Viga Benkelman. Também foram realizados ensaios de convencionais de caracterização de solos bem como ensaios pelas metodologias MCV de Parsons e MCT, além de ensaios de módulo no equipamento triaxial. Foram obtidas algumas correlações para obtenção do módulo a partir dos parâmetros geotécnicos do solo. 
Janoo et al. (1999) estudaram o módulo de resiliência de subleitos de New Hampshire para dimensionamento de pavimentos. Foram estudados cinco subleitos de New Hampshire. O procedimento TP-46 foi utilizado. Os testes foram conduzidos a várias temperaturas para simular congelamento e descongelamento. Os valores de $M R$ médios a partir das tensões testadas foram usados como módulos efetivos. A compactação por amassamento foi utilizada e os testes foram conduzidos na condição de umidade ótima de compactação. Resultados de $M R$ de subleitos variaram de $5 \mathrm{ksi}$ ( 35 MPa) até 2.646 ksi ( 18.522 MPa) com base no condicionamento de temperatura. Módulos de projeto foram determinados pelas médias dos módulos medidos a diferentes pressões de confinamento. Valores de coeficientes de Poisson medidos foram diferentes daqueles usados para estes tipos de materiais e sua variação foi atribuída à conglomeração das partículas. Correções para o módulo efetivo são baseadas nas condições de temperatura do subleito, e não baseadas na temperatura do ar. Todos os resultados de ensaios foram baseados naqueles compactados na condição de umidade ótima e consequentemente a correção de umidade e peso específico é necessária para obtenção de valores de módulos em outras condições de compactação de acordo com os autores.

George \& Uddin (2000) realizaram testes de MR em amostras de campo e correlações entre $M R$ e dados de Dynamic Cone Penetrometer (DCP) e FWD. Foram estudadas diversas amostras de subleito à diferentes profundidades e a diferentes espaçamentos (200 pés c/c); profundidade de amostragem de até 5 pés com um máximo de 10 pés; amostras de solos de 12 seções. O protocolo AASHTO TP 46 foi seguido. Os valores de $M R$ de laboratório a pressão confinamento de $14 \mathrm{kPa}$ e tensão desvio de $35 \mathrm{kPa}$ foi utilizada como propriedade da camada de subleito. Os valores de $M R$ de subleitos a pressões de confinamento de $14 \mathrm{kPa}$ variaram entre $30 \mathrm{MPa}$ a $270 \mathrm{MPa}$, sendo que os maiores valores foram medidos para amostras das camadas superiores. Dados do ensaio "bender element test" medidos a partir de subleitos compactados não confinados mostraram uma correlação com os valores de $M R$ aferidos de medições internas. Curvas características solo-umidade (SWCC) para todos os quatro tipos de solos foram desenvolvidas para determinar as relações de teor de umidade e sucção. Kiribati et al. (2000) realizaram durante 5 anos, ensaios com equipamentos Dynaflect e FWD em diferentes épocas do ano, com verificação da posição do nível d'água. Os autores verificaram reduções de módulo dos materiais de base e sub-base da ordem 
de 5\% a 35\%, com base nos ensaios realizados com o Dynaflect e da ordem de 96\% com base nos ensaios realizados com o FWD. Verificaram também reduções de módulo de resiliência do subleito da ordem de $8,54 \%$ e $29,41 \%$ (Dynaflect e FWD respectivamente).

Xie (2000) estudou a influência da variação do nível do lençol freático no teor de umidade e nos valores de $M R$ dos materiais de subleito.

Camacho (2002) estudou fluxos não saturados de água em bases de pavimentos construídos com solo arenoso fino laterítico (SAFL).

Maher et al. (2000) estudaram as propriedades de módulo de resiliência de subleitos de New Jersey. Os autores estudaram seis diferentes solos de subleito de New Jersey. O procedimento TP-46 foi utilizado. Três condições de teor de umidade de compactação foram estudadas. Os valores de módulo de resiliência de solos variaram entre 2 e 36 ksi ( 14 a 252 MPa) e esta variação mostrou-se dependente do tipo de solo e das condições de umidade. Solos granulares exibiram rigidez à deformação enquanto os valores de $M R$ sofreram acréscimo com as aplicações de carga desviadora. Subleitos coesivos mostraram enfraquecimento à deformação com um decréscimo no $M R$ com carga desviadora. O teor de umidade mostrou grande influência no módulo de ambos os solos.

Hopkins et al. (2001) estudaram os módulos de resiliência de solos de subleitos de Kentucky. Foram realizados 128 testes com amostras de solos coletadas de vários locais em Kentucky. Amostras foram moldadas no teor de umidade e $95 \%$ do peso específico aparente seco máximo. Método TP-46 foi seguido para os ensaios de $M R$. Amostras de solos compactadas exibiram valores de MR variando entre 20 ksie 28 ksi ( 140 a $196 \mathrm{MPa}$ ) a uma baixa pressão de confinamento de 2 psi ( 14 MPa). Amostras de solos não saturadas desempenharam bem sob os testes de módulo de resiliência, bem como amostras saturadas experimentaram largas deformações, que resultaram em ruptura em alguns casos. Três modelos foram desenvolvidos pela análise dos resultados. Os autores concluíram que há necessidade de um método de ensaio de módulo de resiliência para ser realizada em amostras de solo saturadas e que um critério de aceitação de teste $M R$ deveria ser desenvolvido.

O estudo de Yau e Von Quintus (2002) objetivou o desenvolvimento de relações entre módulo de resiliência e propriedades físicas de materiais granulares e solos. 
Equações de regressões não lineares foram desenvolvidas para cada base e tipo de solo para determinar o módulo de resiliência a um estado de tensões específico utilizando as propriedades físicas dos materiais de base e solos. Os modelos desenvolvidos podem prever as propriedades resilientes razoavelmente. Um importante resultado final desta pesquisa é a necessidade de resultados de testes adicionais para melhorar ou confirmar esses modelos.

Abo-Hashema et al. (2002) estudaram a variação do módulo de resiliência das camadas com do pavimento através dos dados de cinco seções instrumentadas no estado de Idaho e dados de levantamento deflectométrico com equipamento tipo FWD. Os autores estabeleceram equações que correlacionam o teor de umidade com o módulo de resiliência do subleito para vários tipos de solo e regiões climáticas e ainda estabeleceram relações entre $M R$ e o tempo (próximo à função senoidal com ângulo de inclinação negativo).

Silva (2003) estudou dois solos lateríticos (LA'-LG' e LG') de subleito no município de Sinop situado ao norte do estado de Mato Grosso. Ressalta-se que os gráficos apresentados no estudo de Silva (2003) mostram a variação do módulo resiliente apenas com a tensão desvio (ou desviadora). Isto poderia acarretar uma conclusão errônea relacionada com o aparente crescimento do módulo resiliente com o aumento da tensão desvio. O autor relata uma redução discreta de valores de módulo de resiliência com o aumento da umidade por saturação dos corpos de prova.

Heydinger (2003) estudou os solos A-6 (HRB) CL (SUCS) em 18 trechos instrumentados de uma rodovia no estado de Ohio. O autor cita que o MR do subleito pode variar em duas vezes ou mais para alterações no grau de saturação da ordem de $10 \%$ a $15 \%$.

Salem et al. (2003) estudou subleitos de 7 regiões dos Estados Unidos em seções monitoradas do programa LTPP, dividindo as análises para dois grupos de solos solos plásticos e solos não plásticos. Foi verificada a tendência de diminuição do módulo de resiliência do subleito com o aumento da umidade dos solos. Os autores demonstram que o valor de $M R$ retroanalisado pode ser relacionado com o teor de umidade. Os autores contribuíram com a elaboração do Guia de Projeto da AASHTO desenvolvendo o modelo apresentado a seguir, que estima a variação do módulo de resiliência devido às variações do grau de saturação do solo. 


$$
\log \left(\frac{M_{R}}{M_{R_{-} o p t}}\right)=a+\frac{(b-a)}{1+\exp \left[c+d \cdot\left(S-S_{\text {opt }}\right)\right]}
$$

Onde: $M R=$ módulo de resiliência para qualquer grau de saturação (S); $M R \_o p t=$ módulo de resiliência do material na umidade ótima; $S=$ grau de saturação do solo; Sopt = grau de saturação no teor ótimo de umidade; $a, b, c, d=$ parâmetros de regressão do modelo.

Masada et al. (2004) estudaram os módulos de resiliência de solos de subleito e bases de Ohio. Diversos tipos de agregados foram pesquisados com diferentes tipos de graduações. Diversos subleitos de diferentes locais em Ohio foram amostrados e testados. Foi seguido o método TP-46 para os materiais de base e subleito. Os valores de $M R$ de bases variaram entre 3 ksi e 65 ksi ( 21 e $455 \mathrm{MPa})$, e valores médios de bases de agregados variaram entre 9 e 42 ksi ( 63 e $294 \mathrm{MPa})$. Os valores de MR de solos de subleitos variaram de 12 até 24 ksi ( 84 a $168 \mathrm{MPa}$ ) para solos A-4; de 3 a 23 ksi ( 21 a $161 \mathrm{MPa}$ ) para solos A-6; e de 4,5 a $25 \mathrm{ksi}(31,5$ a $175 \mathrm{MPa})$ para solos A-6. Esta pesquisa sumariza várias pesquisas conduzidas no estado de Ohio.

Wolfe and Butalia (2004) estudaram treze amostras de solos de subleito do estado de Ohio. As amostras foram compactadas em condições de umidade ótima, abaixo da ótima e acima da ótima. Foi seguido o Método T-294. Foi utilizado um sistema de LVDTs externos. Ambas as amostras não saturadas (compactadas) e saturadas foram testadas. Os valores de MR de subleitos variaram entre 10 MPa e 120 MPa. Um acréscimo no teor de umidade resultou em uma redução das propriedades resilientes. No caso de solos A-4, saturação resultou em uma redução de $M R$ entre $8 \%$ e $88 \%$ enquanto para solos A-6 e A-7-6 a redução variou de $50 \%$ a $87 \%$ e $44 \%$ a $82 \%$, respectivamente. A instrumentação de campo com tensiômetros e prova de umidade foram recomendados pelos autores para melhor entender padrões de fluxo de umidade nos subleitos, que acaba por influenciar os resultados de $M R$.

George (2004) propõe a previsão de módulo de resiliência a partir de propriedades de solos. Foram estudadas amostras de subleito de 8 diferentes rodovias de Mississippi. O procedimento TP-46 foi seguido. Ensaios $R L T$ e compactação por impacto foi utilizada. Os valores dos módulos de resiliência (MR) variaram entre $50 \mathrm{MPa}$ e 115 MPa. 
Davich et al. (2004b) realizaram testes de módulos de resiliência de solos granulares a baixas deformações. Seis tipos de bases (granulares): finos a areias bem graduadas com finos foram estudadas. Foi utilizado o método LTPP P-46 para realizar os testes de módulo assim como o ensaio "bender element test" foi seguido para realizar ensaios de módulo a baixa deformação. Os módulos de resiliência das bases variaram entre $60 \mathrm{MPa}$ e $800 \mathrm{MPa}$ baseados nas pressões de confinamento e de desvio aplicadas. O valor de $M R$ aumentou com o decréscimo no teor de umidade. Modelo hiperbólico utilizando módulo a baixa deformação e propriedades de resistência ao cisalhamento são usados para prever o módulo de resiliência. Má coesão e extremidades irregulares das amostras resultaram na variação das medidas dos 3 LVDTs. Medições de campo de pequenas deformações podem ser usadas para estimar os módulos de resiliência necessários para o dimensionamento dos pavimentos. Os autores citam que mais estudos são necessários para validar os procedimentos estabelecidos nesta pesquisa.

Gandara et al. (2005) estudaram os efeitos dos finos em agregados de base. Três pressões de confinamento e três tensões desvio para cada pressão de confinamento (similar ao T-307) foram aplicadas. As amostras foram recapadas nas extremidades. LVDTs foram utilizados para medir deformações axiais e radiais. Os agregados testados apresentaram módulo variando entre 25 e 100 ksi ( 175 a 700 MPa). Os autores relataram que os efeitos dos finos nas propriedades de resiliência foram mínimos; todavia, influencia a suscetibilidade à umidade das misturas solo/agregados. O tipo de fino e sua plasticidade tem maior influência na deformação permanente. Testes de tubo sucção (tube suction tests) em agregados foram usados para verificar a suscetibilidade à umidade. Os autores concluem que a porcentagem ótima de finos nos agregados é entre $5 \%$ e $10 \%$. Os autores colocam uma metodologia de campo é necessária para prever o desempenho dos agregados e podem completar os testes de laboratório.

Bennett \& Maher (2005) estudaram as propriedades de módulo de resiliência de agregados de New Jersey. Foram estudados dois diferentes tipos de agregados de três regiões com diferentes tipos de graduação e dois tipos de misturas de agregados com concreto reciclado e agregados de asfalto. O Método TP-46 foi utilizado. Os valores de $M R$ de agregados naturais variaram entre 13 a 23 ksi ( 91 a $161 \mathrm{MPa}$ ) e para misturas de agregados, variaram entre 20 e $40 \mathrm{ksi}(\sim 140$ a $280 \mathrm{MPa})$ a condições 
de pressões próximas àquelas esperadas nos pavimentos. Os autores relatam que a adição de agregados reciclados melhorou as propriedades resilientes dos materiais ensaiados. Relataram que as misturas de agregados de asfalto reciclado têm efeito mais profundo nos valores de $M R$ do que agregados reciclados de concreto. Os autores relataram que quanto mais fina a graduação dos agregados, o módulo de resiliência tende a diminuir.

Ping et al. (2005) simularam os efeitos da variação do lençol freático em um modelo construído em escala real. Foram estudados quatro tipos de estruturas (terraplenagem e subleito) comuns em rodovias da Flórida.

Ooi et al. (2006) desenvolveram correlações para MR de subleitos do Hawaii. Foram estudados subleitos de 4 locais do Hawaii. O procedimento LTPP P-46 (T-307) foi seguido para os testes de MR. Três pressões de confinamento foram utilizadas de acordo com o teste para subleitos coesivos. Os valores de $M R$ de subleitos variaram entre 10 ksi e 35 ksi ( 70 a $245 \mathrm{MPa}$ ) para diversos solos siltosos de subleito e esta variação é dependente das pressões de confinamento e desvio aplicados no teste. Um acréscimo na tensão desvio resultou em um decréscimo no módulo de subleitos. Materiais siltosos com alto índice de plasticidade exibiram menores valores de módulo em relação a solos siltosos com índice de plasticidade baixo. Os autores colocam que a secagem excessiva dos solos amostrados no campo para conhecer os teores de umidade de compactação (solos amostrados no campo a elevados teores de umidade) pode comprometer as propriedades resilientes.

Baus \& Li (2006) realizaram estudos em agregados de base da Carolina do Sul. Foram estudados sete tipos de agregados de base. Testes de carregamento estático e cíclico foram conduzidos em diferentes bases de agregados. Os valores de MR de agregados de base obtidos dos testes de carregamento de placa estática variaram entre $14 \mathrm{e}$ 77 ksi ( 98 e $539 \mathrm{MPa}$ ). Um coeficiente estrutural de 0,18 foi recomendado para bases de agregados no dimensionamento de pavimentos. Os autores relataram que a redução da graduação grossa mostrou uma influência positiva no módulo de resiliência dos materiais. Os autores colocam que é necessária a reavaliação dos coeficientes estruturas através da realização de ensaios de campo.

Richter (2006) apresentou uma visão geral dos diversos fatores que influenciam os módulos de materiais não tratados de locais não congelados. Este relatório centrouse especificamente no teor de umidade sazonal e flutuações de temperatura, bem 
como outros fatores relacionados e como eles influenciaram as propriedades $M R$ retroanalisadas.

Takeda (2006) estudou a influência da gênese, da granulometria e da umidade póscompactação nos valores de módulo de resiliência para 73 amostras de solos do interior paulista (solos lateríticos e não-lateríticos).

Ling et al. (2006) realizaram ensaios de módulo com solos de subleito finos situados em Shanghai, de natureza silto-argilosa, de cor marrom-amarelados, levemente plásticos estabilizados com cal e com cimento-cal, China. Os autores avaliaram os efeitos do tempo de cura, do grau de saturação e dos ciclos de secagem umedecimento nos valores de módulo de resiliência dos materiais. Os autores realizaram estudos de laboratório e de campo e verificaram que os valores obtidos em laboratório se apresentaram superiores aos valores de campo.

As equações obtidas pelos autores estão apresentadas a seguir.

$$
\begin{gathered}
\ln (M R)=4,3222+0,0957 \cdot \ln (T), \text { solo-cal-cimento } \\
\ln (M R)=3,9224+0,0683 \cdot \ln (T) \text {, solo-cal } \\
\ln (M R)=4,3222+0,0957 \cdot \ln (T)+2,1362 \cdot \ln \left(\frac{S_{r 0}}{S_{r 1}}\right), \text { solo-cal-cimento } \\
\ln (M R)=4,3222+0,0957 \cdot \ln (T)+3,831 \cdot \ln \left(\frac{S_{r 0}}{S_{r 1}}\right) \text {, solo-cimento }
\end{gathered}
$$

$\ln (M R)=4,3222+0,0957 \cdot \ln (T)+2,1362 \cdot \ln \left(\frac{S_{r 0}}{S_{r 1}}\right)-0,0518 \cdot \ln (N+1)$, solo-cimento

$$
\ln (M R)=4,3222+0,0957 \cdot \ln (T)+3,831 \cdot \ln \left(\frac{S_{r 0}}{S_{r 1}}\right)-0,1144 \cdot \ln (N+1) \text {, solo-cimento }
$$

Onde: SrO = saturação inicial; Sr1 = saturação; $N=$ número de ciclos de secagem e umedecimento; $T=$ tempo de cura (dias).

Malla \& Joshi (2006) estudaram os módulos de resiliência de subleitos da região de New England. Foram estudados os seguintes tipos de solos: Connecticut: A-2, A-4; 
Maine: A-1, A-2, A-3, A-4, A-5, A-6; Massachusetts: A-1, A-2, A-3, A-4, A-5, A-6; New Hampshire: A-1, A-2, A-4; Vermont: A-1, A-2, A-4, A-6, A-7. Testes AASHTO T-307 foram conduzidos. Testes foram conduzidos em várias condições de teor de umidade de compactação. MR dos solos testados variaram de 30 a 160 MPa. Para solos granulares, $M R$ sofreu acréscimo no seu valor com pressão desvio axial e para solos coesivos, MR sofreu decréscimo com a tensão desvio. Diversos modelos de previsão foram também desenvolvidos para estes solos.

Titi et al. (2006) propõem a determinação de propriedades de módulos de resiliência de solos típicos de Wisconsin. Dezessete solos de diferentes regiões de Wisconsin foram testados (A-1, A-3, A-4). Ensaios AASHTO T-307 foram conduzidos. Testes foram conduzidos em diferentes condições de teores de umidade. MR de solos plásticos variaram entre 15 e $160 \mathrm{MPa}$; $\mathrm{MR}$ de solos não plásticos variaram entre 20 e 140 MPa. MR de solos de subleitos testados variaram entre 10 e 160 MPa. Todos os ensaios mostraram boa repetibilidade. Base de dados foi usada para desenvolver correlações para o nível 3 (MEPDG). Tendências com respeito à pressão confinante e pressão desvio estão de acordo com aqueles reportados na literatura.

Kim \& Labuz (2007) estudaram os módulos de resiliência e resistência de bases com material betuminoso reciclado. Diferentes agregados incluindo pavimento asfáltico reciclado e agregados naturais foram ensaiados. O protocolo de teste NCHRP 1-28A foi utilizado e as amostras de laboratório foram preparadas utilizando método de compactação giratória. Quatro percentuais de RAP foram misturados com agregados naturais e os ensaios de laboratório mostraram que os valores de $M R$ variaram entre 125 e 700 MPa. Os autores relatam que os valores de $M R$ sofreram acréscimo com o acréscimo na tensão de confinamento e a tensão desvio não teve efeito nas magnitudes de módulo. Relatam também que um Incremento na quantidade de RAP resultou em um acréscimo nos valores de módulo dos materiais.

Liang et al. (2007) compararam as respostas obtidas pelo software EICM (Enhanced Integrated Climatic Model), contido no M-E PDG, com medições de campo realizadas em diferentes materiais de bases drenantes de rodovias em Ohio. Os autores verificaram que o EICM mostrou boa capacidade em prever o teor de umidade no interior do pavimento especialmente para os materiais de base e sub-base. Já para os materiais de subleito, foram verificadas pequenas variações entre os valores obtidos pelo software EICM e as medições de campo. Os autores sugerem que uma 
melhoria na acurácia da previsão do teor de umidade pode ser alcançada dividindose o subleito em subcamadas e determinando-se as características de cada subcamada através de ensaios de campo e laboratório, incluindo ensaios de peso específico aparente seco e teor de umidade inicial.

Ping et al. (2007) estudaram módulos de resiliência de subleitos da Florida. Foram estudados 37 solos de subleito de diferentes distritos da Florida. Método AASHTOT307 foi seguido para o ensaio de MR. Outros procedimentos incluindo T-292 e T-294 foram usados nos primeiros testes $M R$. Equipamento $R L T$ foi usado para testar os subleitos. Ambos LVDTs verticais e horizontais foram usados para monitorar deformações verticais e laterais. Os valores de $M R$ dos solos de subleito da Florida variaram de 7 ksi a 26 ksi ( 29 a $175 \mathrm{MPa}$ ), com um valor médio de 14 ksi ( 98 MPa). Duas bases de dados de módulo foram desenvolvidas, uma com grande número de dados de módulos e outras com funções de integração e análise. Propriedades físicas como peso específico aparente seco e teor de umidade e $L B R$ (Limerock Bearing Ratio) influencia as magnitudes de $M R$ para de solos A-2-4 até solos A-3. Um acréscimo no teor de argila e de finos também influencia os valores de $M R$. Propriedade de graduação como coeficiente de uniformidade e coeficiente de curvatura tem menor influência no $M R$. Diversos modelos de previsão foram desenvolvidos para resultados MR. Quanto mais informações dos solos testados, melhores os modelos desenvolvidos.

Ekblad (2007) estudou a influência da variação da umidade nas propriedades resilientes de solos granulares através de duas séries de ensaios: (i) alterando a distribuição granulométrica e (ii) modificando a concentração de mica livre no solo. O autor verificou que a distribuição granulométrica do material tem bastante influência nas propriedades resilientes dos materiais. $O$ autor relata que há menor redução de módulo dos materiais quando saturados, à medida que se aumenta o percentual de material graúdo e diminuindo o percentual de finos. Verificou que o percentual de finos tem bastante influência na redução dos valores de módulo de resiliência dos materiais saturados. O autor verificou que a capacidade de retenção de água dos solos aumenta com a diminuição da granulometria e com o aumento da concentração de mica nos materiais de subleito.

Gupta et al. (2007) estudaram o comportamento resiliente de solos de subleito não saturados e dimensionamento de pavimentos. Foram estudados quatro solos de 
subleito de valores de PI diferenciados. Duas condições de compactação e três matrizes de sucção foram aplicadas a cada condição de compactação e estas sucções foram 0; 22 e 50 psi ( 0; 154 e 350 kPa respectivamente). Testes MR e ensaios "small-strain bender element test" foram conduzidos em todas as amostras. Técnica de translação foi utilizada para aplicar a sucção nas amostras de solos. Procedimento de teste foi baseado no NCHRP 1-28A. Módulos de resiliência baseados em medições de deslocamentos externos variaram entre 10 e $70 \mathrm{MPa}$ e os mesmos variaram entre 10 e 200 MPa quando sistema interno de deslocamentos foi usado. Um acréscimo na sucção matricial resultou em um acréscimo considerável no valor de $M R$. Uma relação semilogarítmica entre $M R$ e sucção matricial foi desenvolvida. Medições internas produziram sempre maiores valores de MR, que são 1,7 a 3 vezes dos valores de $M R$ obtidos com medições externas.

Toros \& Hiltunen (2008) estudaram a influência da umidade e do tempo no módulo de materiais provenientes de 5 jazidas de agregados comumente utilizados como base no estado da Flórida nos EUA. Os autores utilizaram o teste de coluna ressonante. Os autores observaram que o valor do módulo aumenta com o tempo nos corpos de prova submetidos à umidade constante. Os autores atribuem este fato ao aumento da pressão de sucção devido a uma melhor redistribuição da umidade pós-compactação. Os autores também observaram que os caminhos de secagem e umedecimento não são iguais, apresentando histerese. Os autores também relatam que os módulos cresceram com a perda de umidade a taxas maiores no início do que no final do processo de secagem. Estes resultados denotaram que o fenômeno da sucção e da poro-pressão é reversível e repetitivo.

Fernando et al. (2008) realizaram estudos de clima, umidade do solo e ensaios de carga estática (placa) em 254 regiões do estado do Texas (EUA), além de ensaios de laboratório, e utilizaram o procedimento de projeto triaxial modificado do Texas para avaliar o programa FPS (Flexible Pavement System) utilizado pelo Departamento, baseado em retroanálise de levantamentos com FWD (Falling Weight Deflectometer). Os autores desenvolveram um software chamado "Loadgage" para estimar a capacidade de carga do pavimento. Os autores concluíram que as curvas do ensaio triaxial modificado do Texas (Tex-117E), aparentaram ser mais conservadoras em relação aos resultados do ensaio de placa em escalas reais. Os autores sugerem a utilização do programa "Loadgage" para estimar a capacidade de carga dos materiais 
do pavimento, corrigindo-se a resistência do subleito de acordo com a diferença entre a umidade apresentada em campo e aquela do ensaio triaxial.

Nakashima et al. (2008) estudaram as consequências da influência da presença da umidade na vida útil dos pavimentos drenantes. Os autores realizaram dois tipos de ensaios: (i) injeção de água num modelo de vala de infiltração para verificação da magnitude da área saturada, e (ii) medição das alterações nas características elásticas do subleito frente a um aumento do grau de saturação utilizando um FWD (Falling Weight Deflectometer) portátil ou LWD (Light Weigth Deflectometer). Os autores verificaram um acréscimo do módulo da ordem de até $75 \%$, com 0 rebaixamento do lençol freático.

Ferreira (2008) utilizou ferramentas de Data Mining para proceder ao agrupamento das amostras em famílias de solos em termos de comportamento resiliente e desenvolver o respectivo classificador, e Redes Neurais Artificiais para predição dos valores do módulo de resiliência a partir de parâmetros geotécnicos dos solos. Foi utilizada uma base de dados da qual constam 463 amostras de solos de diversas granulometrias e procedências, cujos Ensaios Triaxiais de Cargas Repetidas foram executados no Laboratório de Geotecnia da COPPE/UFRJ no período de 1996 a 2007. Os resultados obtidos permitem sua utilização no desenvolvimento de anteprojetos e sugerem boas possibilidades de aprimoramento mediante melhorias quantitativas e qualitativas da base de dados.

Silva (2009) estudou os efeitos da variação de umidade e, portanto, da sucção em uma estrutura de pavimento construída num modelo físico de verdadeira grandeza que permite a entrada de água por capilaridade pelo subleito, denominado Tanque Teste, com utilização de equipamentos para medição de tensões de sucção nas camadas, bem como para obtenção das curvas características dos materiais. $\mathrm{Na}$ condição de recém-compactada (umidade próxima da ótima), os valores de tensão de sucção medidos foram de cerca de 43 kPa no subleito, 55 kPa na sub-base (material laterítico pedregulhoso) e $3 \mathrm{kPa}$ na base (brita graduada) e com a entrada de água no perfil estes valores tenderam a zero. Houve influência nos valores de deflexão medidos com a variação da umidade no perfil.

Bonzanini (2011) estudou a influência dos tamanhos dos corpos de prova de materiais normalmente utilizados em obras de pavimentação no estado do Rio Grande do Sul, 
sendo: uma areia, um solo arenoso fino laterítico, um solo argiloso e um solo residual de granito (saibro). Pela análise estatística, o autor conclui que somente a areia não apresentou variação significativa do módulo de resiliência com o tamanho do corpo de prova, e para os outros três materiais houve variação, mas nem sempre na mesma direção, ou seja, dependendo do material, o MR aumenta ou diminui com o aumento do corpo de prova.

2.2.3 Modelos para determinação de módulo de resiliência de solos a partir do $C B R$

Várias correlações empíricas foram desenvolvidas para determinação do módulo de resiliência a partir de outros parâmetros em décadas passadas. Van Til et al. (1972) desenvolveram ábacos para correlação do módulo de resiliência do subleito com resultados de R-value, $C B R$ e valor de classificação triaxial do Texas. A maior limitação dessas correlações recai no fato de que elas falham em refletir a natureza dinâmica do carregamento imposto pelo tráfego, ou por serem baseadas em uma amostragem limitada e só poderem ser aplicadas a condições semelhantes (Mohammad et al., 1995). Entre as conclusões apresentadas por George (2004) encontra-se: "correlações simples com a resistência, por exemplo, o ensaio de CBR para estimar o módulo de resiliência devem ser usadas com cautela".

Heukelom e Klomp (1962) apresentaram uma correlação entre o valor de $C B R$ utilizando compactação dinâmica e valores de módulo de resiliência in situ, como ilustrado na equação:

$$
\operatorname{Mr}(p s i)=1500 \times C B R
$$

Os dados usados para desenvolver esta equação variaram de 750 a 3000 vezes o valor do $C B R$. A equação acima já foi extensivamente utilizada em projeto por agências e pesquisadores para solos finos com CBR imerso de $10 \%$ ou menos (George, 2004).

Powell et. all (1984) propôs a seguinte equação: 


$$
\operatorname{Mr}(p s i)=2554 \cdot C B R^{0,64}
$$

O Departamento de Transportes da Georgia testou alguns solos não coesivos em carregamento triaxial repetido seguindo o procedimento de ensaio estabelecido pela AASHTO (Webb e Campbell, 1986). O objetivo foi o de criar uma base de dados em que o módulo de resiliência pudesse ser estimado. Uma equação típica para uma areia argilosa era:

$$
\operatorname{Mr}(p s i)=3116 \times C B R^{0,4779707}
$$

Rada \& Witczak (1981) propuseram equação que teve como base vários ensaios triaxiais, mas somente aplicada para dois estados de tensão ( $q=69$ e $690 \mathrm{kPa}$ ). Isto é, apesar da grande quantidade de ensaios, existe um grande intervalo sem investigação.

$$
\operatorname{Mr}(p s i)=(490 \cdot \log \theta-243) \cdot C B R
$$

Onde: $M R=$ módulo de resiliência do solo (psi); $\theta=$ tensão octaédrica total ( $p s i)$; $C B R=$ Índice de Suporte Califórnia (\%).

Preussler (1983) que fez parte do grupo da COPPE-UFRJ que introduziu os ensaios de resiliência no Brasil publicou vários valores de módulo dependendo da classificação do solo por um método que a relacionasse com a resiliência, e usou para solos argilosos a seguinte relação:

$$
\operatorname{Mr}\left(\mathrm{kgf} / \mathrm{cm}^{2}\right)=326+67 \times C B R
$$

Visser et al (1983), estudando 75 amostras de subleitos de solos lateríticos brasileiros da região do centroeste e sudeste, encontraram para as constantes $K$, da equação $M R=K^{*} C B R$, valores variando de 0,7 a 106,0 , para valores de $C B R$ em $\%$ e $M R$ em MPa. 
O estudo realizado por Bernucci (1995), com dados próprios e de outros pesquisadores, envolvendo 18 amostras de solos, obteve para solos areno-argilosos lateríticos:

$$
\operatorname{Mr}(M P a)=74 \times C B R^{0,50}
$$

Apesar de o CBR ser extremamente utilizado na caracterização de solos de subleito, este é uma medida de resistência ao cisalhamento, que não necessariamente é esperado de correlacionar-se com o módulo, ou rigidez do material. Thompson e Robnett (1976) publicaram sobre a baixa correlação existente entre o $C B R$ e o $M R$ dos solos de Illinois. Outro ponto também relevante é o fato de as relações com o $C B R$ não reconhecerem a dependência do módulo com relação ao estado de tensão do material (Rada \& Witczak, 1981).

O problema fundamental com muitas das equações/correlações desenvolvidas para correlacionar $M R$ e outros parâmetros dos solos, como o $C B R$, é que os testes são considerados empíricos, enquanto o módulo de resiliência é um parâmetro mecanístico que depende de diferentes propriedades do solo, além do estado de tensão em que este se apresenta (em campo, ou no próprio ensaio).

George (2004) desenvolveu uma análise de sensibilidade em várias correlações apresentadas na literatura e verificou que entre os parâmetros/propriedades dos solos, cinco apresentaram maior influência nos resultados de MR: teor de umidade, grau de saturação, material passante na peneira \#200, índice de plasticidade e peso específico aparente.

Cardoso (1987) correlacionou, por meio de ensaios de CBR e testes triaxiais dinâmicos com determinação de módulos de resiliência, a estimativa do módulo de resiliência de solos argilosos finos lateríticos por meio de outros parâmetros, que foram o valor do $C B R$ do primeiro invariante de tensões e da tensão de aplicação vertical (em libras por polegada quadrada), cujo modelo resultante é apresentado a seguir (Balbo 2007).

$$
M r=\frac{179,0412 \times C B R^{1,08774} \times \theta^{1,43833}}{\sigma_{1}^{1,18598}}\left[\mathrm{lb} / \mathrm{pol}^{2}\right]
$$

Onde: $M R=$ módulo de resiliência do solo (lb/pol2); $C B R=$ valor do índice de suporte Califórnia; $\theta=$ tensão octaédrica total; $\sigma_{1}=$ tensão principal maior. 
Preussler (1983) também estabeleceu uma correlação entre o valor do módulo de resiliência e o $C B R$ do solo, para o caso de solos finos tropicais argilosos, para nível de tensão-desvio de 0,2 MPa, para umidades no ponto ótimo ou um pouco acima, após saturação resultante de imersão, por quatro dia do corpo de prova, cujo modelo resultante é apresentado a seguir (Balbo 2007).

$$
M r=32,6+6,7 \times C B R[M P a]
$$

Onde: $M R=$ módulo de resiliência do solo $(M P a) ; C B R=$ valor do índice de suporte Califórnia.

Zaman et al.(1994) estabeleceu uma correlação usando uma média de valores do módulo para quatro níveis de $\theta(14,20,30$ e 100 psi - aproximadamente 98, 140, 210, $700 \mathrm{MPa}$ ), variando em função do parâmetro $B$ (ver Tabela 3.8), conforme mostra a expressão 3.28 .

$$
M r=B \times C B R[M P a]
$$

Onde: $M R=$ módulo de resiliência (psi); $\mathrm{B}$ = variável obtida para cada tipo de material (parâmetro de regressão); $C B R=$ Índice de Suporte Califórnia (\%).

Tabela 2.6 - Variável B para diferentes materiais e níveis de $\theta$ (ZAMAN et al., 1994)

\begin{tabular}{lccccc}
\hline \multirow{2}{*}{ Localidades } & CBR & \multicolumn{5}{c}{ Primeiro invariante de Tensão (q), em psi } \\
\cline { 3 - 6 } & & $\mathbf{1 0 0}$ & $\mathbf{3 0}$ & $\mathbf{2 0}$ & $\mathbf{1 4}$ \\
\hline Comanche & 67 & $\mathbf{4 2 3}$ & $\mathbf{2 4 3}$ & 174 & 165 \\
\hline Cherokee & 132 & 181 & 106 & 96 & 88 \\
\hline Creek & 116 & 226 & 156 & 112 & 97 \\
\hline Choctaw & 284 & 78 & 38 & 26 & 25 \\
\hline Johnston & 226 & 101 & 50 & 42 & 38 \\
\hline Murray & 150 & 164 & 91 & 72 & 65 \\
\hline Média & $\mathbf{1 3 2}$ & $\mathbf{1 9 3}$ & $\mathbf{9 6}$ & $\mathbf{8 2}$ & $\mathbf{7 4}$ \\
\hline
\end{tabular}

Uma referência bem mais abrangente para diversos solos localizados no estado de São Paulo é encontrada nos trabalhos laboratoriais de Salí Franzoni (1990) (Balbo, 2007). 
Tabela 2.7 - Valores de módulo de resiliência para solos do estado de São Paulo (Franzoni, 1990 apud Balbo, 2007)

\begin{tabular}{lllccc}
\hline \multicolumn{1}{c}{ Procedência } & \multicolumn{1}{c}{ Textura } & MCT & HRB & $\begin{array}{c}\text { hot } \\
(\%)\end{array}$ & $\begin{array}{c}\text { Mr } \\
\text { (MPa) }\end{array}$ \\
\hline SP 310/ km 222 & Areia siltosa & LA & A-2-4 & 10 & 150 \\
\hline SP 425/ E280 & Areia & LA' $^{\prime}$ & A-6 & 11 & 250 \\
\hline SP 255/ km 63 & Areia argilosa & LA' $^{\prime}$ & A-6 & 12 & 340 \\
\hline Jazida em S. André (SP) & Argila & LG' $^{\prime}$ & A-7-5 & 27 & 200 \\
\hline SP 333/ km 320 & Argila siltosa & LG' $^{\prime}$ & A-7-5 & 23 & 500 \\
\hline SP 310/ km 257 & Argila siltosa & LG' $^{\prime}$ & A-7-5 & 24 & 300 \\
\hline SP 055/ km 94,9 & Areia & NA' & A-1-B & 14 & 45 \\
\hline SP 280/ km 40 & Silte arenoso & NS' $^{\prime}$ & A-6 & 21 & 32 \\
\hline SP 280 & Silte & NS' & A-7-5 & 22 & 80 \\
\hline SP 310/ km 168,8 & Argila & NG' & A-7-5 & 30 & 125 \\
\hline
\end{tabular}

Valle (1966) apresentou modelos de comportamento resiliente típicos para material granular natural (saprólito de granito) encontrado na faixa litorânea do Estado de Santa Catarina, bem como para brita graduada também de origem granilítica, e os resultados são apresentados na tabela a seguir (Balbo, 2007).

Tabela 2.8 - Modelos resilientes para solos granulares de Santa Catarina (Valle, 1966 apud Balbo, 2007)

\begin{tabular}{ccc}
\hline Tipo & Procedência & $\begin{array}{c}\text { Modelo de } \\
\text { Resiliência } \\
\left(\mathbf{k g f} / \mathbf{c m}^{2}\right)\end{array}$ \\
\hline Saprólito de granito & Jazida de Cedrinho & $M r=4870 \times \sigma_{3}^{0,63}$ \\
\hline Saprólito de granito & Jazia São João Batista & $M r=2950 \times \sigma_{3}^{0,52}$ \\
\hline Brita graduada de granito & Pedreira em Navegantes & $M r=4572 \times \sigma_{3}^{0,42}$ \\
\hline
\end{tabular}

Outras equações citadas por Witczak et al. (1995):

Green e Hall (1975):

$$
\operatorname{Mr}(p s i)=5409 \cdot C B R^{0,711}
$$

South African C.S.I. Research (CSIR):

$$
\operatorname{Mr}(p s i)=3000 \cdot C B R^{0,65}
$$

Lister (1987):

$$
\operatorname{Mr}(p s i)=2555 \cdot C B R^{0,64}
$$


2.2.4 Modelos para determinação de módulo de resiliência de solos a partir de ensaios de compressão simples

\section{Thompson \& Robnett (1979)}

$$
\operatorname{Mr}(k s i)=0,86+0,31 \cdot q_{u}
$$

Onde: $M R$ = módulo de resiliência em psi; qu = resistência à compressão simples.

\section{MRDS 7 - Drumm et al. (1990)}

$$
M R=45,8+0,00052 \cdot E_{0}+0,188 \cdot q u+0,45 \cdot I P-0,216 \cdot \rho-0,25 \cdot S-0,15 \cdot P_{200}
$$

Onde: $M R=$ módulo de resiliência em psi para $\sigma_{d}=41,34 \mathrm{kPa} ; E 0=$ módulo tangente inicial em psi; $q u$ = resistência à compressão simples; $I P$ = índice de plasticidade (\%); $\rho=$ massa específica aparente seca $\left(\mathrm{lbf} / \mathrm{ft}^{3}\right) ; S=$ grau de saturação; $P 200=$ percentual de material passando na peneira \#200.

Lee et al. (1990)

$$
M R=1560+833,80 \cdot S_{u 1 \%}-6,97 \cdot S_{u 1 \%}^{2}
$$

Onde: $M R=$ módulo de resiliência em psi para $\sigma_{d}=41 \mathrm{kPa}$ e $\sigma_{3}=21 \mathrm{kPa}$; $S_{u 1 \%}=$ tensão correspondente à $1 \%$ e deformação axial no ensaio de compressão simples (psi).

\section{MRDS 8 - Farrar \& Turner (1991)}

$$
M R(p s i)=30280-359 \cdot S-325 \cdot \sigma_{d}+237 \cdot \sigma_{c}+86 \cdot P I+107 \cdot S_{200} ; \text { com } \mathrm{R}^{2}=0,663
$$

Onde: $M R=$ módulo de resiliência em psi; $\sigma d=$ tensão desvio; $\sigma c=$ tensão de compressão; PI = índice de plasticidade; S200 = percentual passante na peneira \#200. Esta correlação foi desenvolvida baseada em propriedades resilientes medidas em 13 
materiais de subleito de Yonming (EUA) e é recomendada para solos de graduação fina.

\section{Lee et al. (1997) - subleitos de Indiana (EUA)}

$$
M R=a \cdot S_{u 1 \%}
$$

Onde: $M R=$ módulo de resiliência correspondente à $1 \%$ de deformação axial no ensaio de compressão simples (psi) não drenado; $a$ = constante determinada a partir da Figura 2.14.

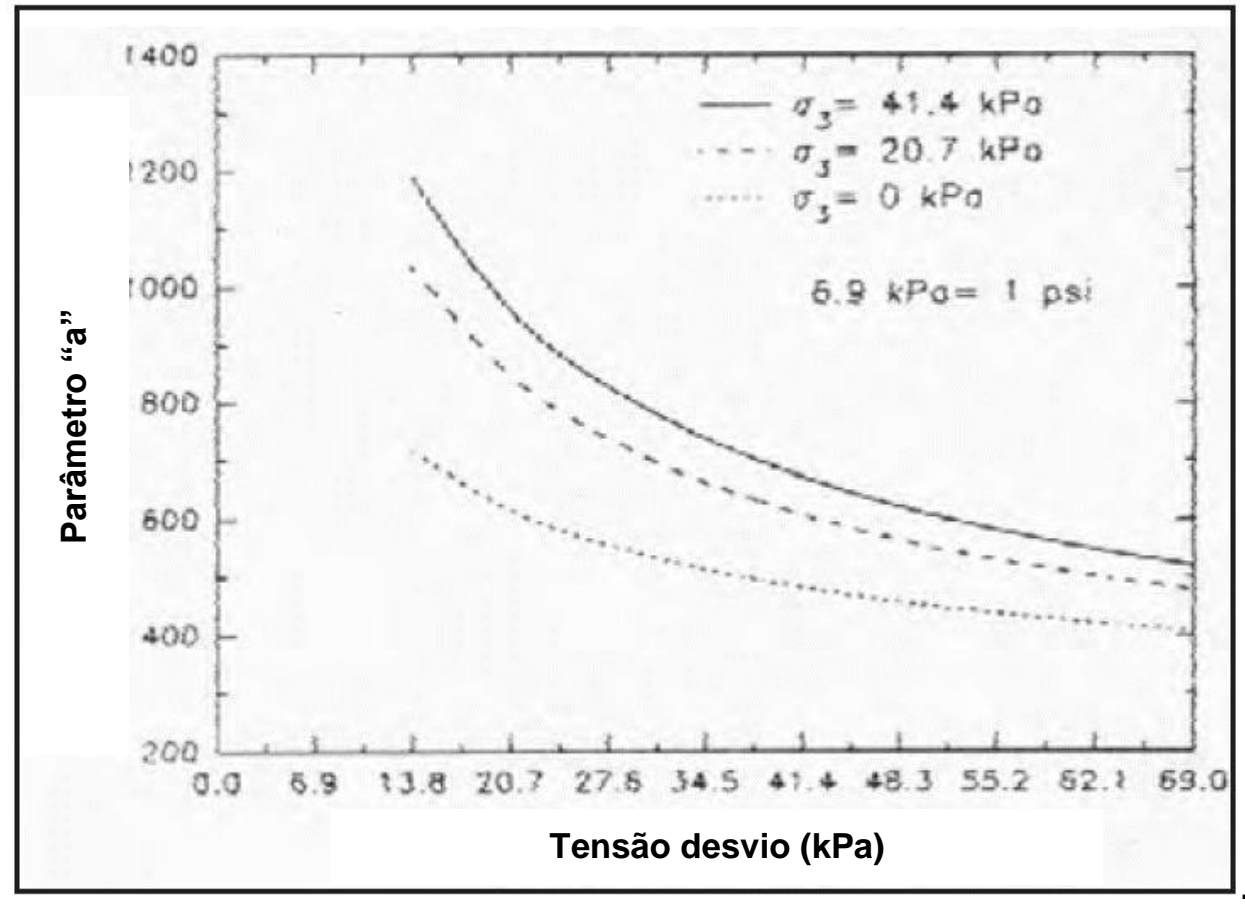

Figura 2.14 - Parâmetro 'a' para estimativa de MR (Leet et al., 1997)

\section{Parreira et al. (1998)}

$$
M R=4,5231 \cdot E_{0} \cdot \sigma_{d}^{-0,3436} \cdot \theta^{0,4393}
$$

Onde: $M R=$ módulo de resiliência em MPa; EO = módulo tangente inicial $(\mathrm{kPa})$; $\sigma d=$ tensão desvio $(k P a) ; \theta=$ primeiro invariante da tensão.

Solos arenosos: 


$$
M R=0,7170 \cdot E_{0}^{0,4668}+2,9016 \cdot \sigma_{1}^{0,7546}+0,3033 \cdot \sigma_{3}^{1,0721}
$$

Onde: $M R=$ módulo de resiliência em MPa; EO = módulo tangente inicial $(\mathrm{kPa})$; $\sigma d=$ tensão desvio $(k P a) ; \sigma 3=$ tensão confinante $(k P a)$;

2.2.5 Modelos que levam em conta os parâmetros físicos dos solos e a variação de umidade

Vários autores têm sugerido, desde a publicação do guia da AASHTO de 1993, o uso de novos modelos de correlação para obtenção dos valores de módulo de resiliência. Estes modelos foram desenvolvidos com base em novos experimentos de campo e laboratório, especialmente nos EUA e Canadá através do programa LTPP (Long Term Pavement Performance).

Em 2002, a AASHTO publicou o seu novo guia de dimensionamento mecanísticoempírico - M-E PDG (Mechanisticall-Empirical Pavement Design Guide), onde realizou uma nova revisão bibliográfica acerca dos modelos presentes na literatura para fazer o uso no software que acompanha o Guia de dimensionamento. Os modelos pesquisados pela equipe que elaborou o projeto levam em conta a variação de umidade nos materiais em relação à umidade ótima de compactação. Alguns dos modelos citados são apresentados na sequência. Também foram relacionados alguns modelos propostos por pesquisadores no Brasil.

\section{Modelo de Jones \& Witczak (1972) para solos argilosos (A-7-6) (MRDS-1)}

$$
\log M_{R}(k s i)=-0,111 \cdot w+0,0217 \cdot S+1,179 ; \mathrm{R}^{2}=0,44
$$

Onde $M R=$ módulo de resiliência $(k s i) ; w=$ umidade de compactação $(\%) ; S=$ grau de saturação (\%).

Esta equação é válida para argilas (A-7-6), por conta de que o modelo foi desenvolvido utilizando alguns tipos amostras de solos argilosos provenientes da California (EUA). 
Os valores $M R$ de laboratório foram obtidos de testes $R L T$ em amostras de argila sob um uma pressão desviadora cíclica máxima de 6 psi ( 42 kPa) e pressão confinante de 2 psi ( 14 kPa).

\section{Modelo de Thompson e Robnett (1979) para solos de graduação fina (MRDS-2)}

$$
M_{R}(k s i)=6,37+0,034 \cdot(\% C L A Y)+0,45 \cdot P I-0,0038 \cdot(\% S I L T)-0,244 \cdot C L A S S ; \mathrm{R}^{2}=0,80
$$

Onde $M R=$ módulo de resiliência $(k s i) ; \quad \mathrm{PI}=$ índice de plasticidade (\%); $(\%$ SILT $)=$ porcentagem de silte; $\quad(\%$ CLAY $)=$ porcentagem de argila; CLASS = classificação do solo pela AASHTO (para solos A7-6, usar 7,6 na expressão).

Os autores estudaram diversos solos de graduação fina de subleito em Illinois (EUA). Os ensaios de módulo de resiliência de laboratório foram obtidos a uma pressão desviadora de 6 psi e pressão de confinamento zero. Válida para solos coesivos.

\section{Constantes de Rada \& Witczak (1981)}

Os autores apresentaram constantes do modelo de $M R$ baseado na tensão total (bulk stress, modelo MR2I-1) para vários tipos de materiais granulares.

Tabela 2.9 - Constantes de modelo baseado na tensão total (modelo 2l-1) por Rada \& Witczak (1981)

\begin{tabular}{|c|c|c|c|c|c|c|c|}
\hline \multirow[b]{2}{*}{ Classe de agregado } & \multirow{2}{*}{$\begin{array}{c}\text { № de } \\
\text { pontos } \\
\text { de dados }\end{array}$} & \multicolumn{3}{|c|}{ Parâmetro k1 (kPa) } & \multicolumn{3}{|c|}{ Parâmetro k2 } \\
\hline & & média & $\begin{array}{l}\text { desvio } \\
\text { padrão }\end{array}$ & intervalo & média & $\begin{array}{l}\text { desvio } \\
\text { padrão }\end{array}$ & intervalo \\
\hline Areia Siltosa & 8 & 11,170 & 5,378 & 4,895 a 26,407 & 0,62 & 13 & 0,36 a 0,80 \\
\hline Areia pedregulhosa & 37 & 33,646 & 29,647 & 5,929 a 88,529 & 0,53 & 17 & 0,24 a 0,80 \\
\hline Mistura de areia-agregado & 78 & 29,992 & 18,133 & 12,962 a 76,325 & 0,59 & 13 & 0,23 a 0,82 \\
\hline Pedra britada & 115 & 49,711 & 51,642 & 11,756 a 390,726 & 0,45 & 23 & $-0,16$ a 0,86 \\
\hline Calcáreo & 13 & 27,786 & 70,602 & 39,300 a 578,194 & 0,40 & 11 & 0,00 a 0,54 \\
\hline Escória & 20 & 167,198 & 132,275 & 64,121 a 636,800 & 0,37 & 13 & 0,00 a 0,52 \\
\hline Todos os dados & 271 & 63,708 & 77,394 & 4,895 a 636,800 & 0,52 & 17 & 0,16 a 0,86 \\
\hline
\end{tabular}




\section{Modelo de Carmichael \& Stuart (1985) (MRDS-5)}

$$
\begin{gathered}
M_{R}(k s i)=37,4-0,45 \cdot P I-0,62 \cdot w-0,14 \cdot S 200+0,18 \cdot \sigma 3-0,32 \cdot \sigma d+36,4 \cdot C H+17,1 \cdot M H \\
\mathrm{R}^{2}=0,80
\end{gathered}
$$

Onde $M R=$ módulo de resiliência $(k s i) ; \mathrm{S} 200=$ percentual passante na peneira \#200 (\%); $\mathrm{CH}$ = fator igual a 1 para solo tipo $\mathrm{CH}$ e 0 para qualquer outro tipo de solo; $\mathrm{MH}$ = fator igual a 1 para solo tipo $\mathrm{MH}$ e 0 para qualquer outro tipo de solo.

Esta correlação é válida para solos de subleito contendo argilas e siltes.

\section{Modelo de Carmichael \& Stuart (1985) para solos granulares e agregados de base (MRDS-5)}

$$
\log M_{R}(k s i)=0,523-0,0225 \cdot \% W+0,544 \cdot \log \theta+0,173 \cdot S M+0,197 \cdot G R
$$

Onde $M R=$ módulo de resiliência $(k s i) ; \% W=$ teor de umidade de compactação (\%); $S M=$ fator igual a 1 para material classificado com $S M$ e 0 para qualquer outro tipo; $G R=$ fator igual a 1 para solos pedregulhosos $(G M, G W, G D$ e $G P)$ e zero para outros solos.

\section{Modelo de Thompson e LaGrow (1988) para solos de graduação fina}

$$
M_{R}(k s i)=4,46+0,098 \cdot C+0,12 \cdot P I
$$

Onde: $M R=$ módulo de resiliência; $P I=$ índice de plasticidade (\%); $C=$ porcentagem de argila.

Os autores estudaram solos de graduação fina de subleitos compactados de Illinois $(E \cup A)$, e propuseram fatores de correção para susceptibilidade à umidade, que precisaria ser aplicado para o módulo de resiliência estimado pela equação. Para argilas, argila siltosa, e lama argilo-siltosa (silty clay loam), o fator de correção é 0,7. Para lama argilosa (clay loam), o fator de correção é 1,5. 


\section{Modelo de Elliot et al. (1988) para solos coesivos (MRDS-6)}

Para $\sigma_{d}=4 p s i$ :

$$
M_{R}(k s i)=11,21+0,17 \cdot(\% C L A Y)+0,20 \cdot P I-0,73 \cdot w_{o p t} ; \mathrm{R}^{2}=0,80
$$

Para $\sigma_{d}=8 p s i$ :

$$
M_{R}(k s i)=9,81+0,13 \cdot(\% C L A Y)+0,16 \cdot P I-0,60 \cdot w_{o p t} ; \mathrm{R}^{2}=0,77
$$

Onde $M R=$ módulo de resiliência $(k s i) ; \quad P I=$ índice de plasticidade (\%); $(\% S I L T)=$ porcentagem de silte; $(\% C L A Y)=$ porcentagem de argila .

Os autores estudaram diversos solos de subleito de Arkansas (EUA).

\section{Modelo de Farrar \& Turner (1991) para solos finos (MRDS-9)}

$$
M_{R}(p s i)=30280-359 \cdot S-325 \cdot \sigma d+237 \cdot \sigma c+86 \cdot P I+107 \cdot S 200 ; \mathrm{R}^{2}=0,663
$$

Os autores estudaram 13 materiais de subleito de Wyoming.

\section{Modelo de Hudson et al. (1994) (MRDS-9)}

$$
\begin{gathered}
\log M_{R}(p s i)=46,93+0,018 \cdot \sigma_{d}+0,033 \cdot \Delta \gamma_{d}-0,114 \cdot L I+0,468 \cdot S+0,0085 \cdot C_{L A S S}{ }^{2} \\
-0,0033 \cdot \Delta w^{2}-0,0012 \cdot \sigma_{c}{ }^{2}+0,0001 \cdot P L^{2}-0,0278 \cdot L I^{2}-0,0017 \cdot S^{2}-38,44 \cdot \log S \\
-0,2222 \cdot \log \left(\sigma_{d}\right) ; \mathrm{R}^{2}=0,70
\end{gathered}
$$

Onde: $\Delta \gamma d=$ desvio do peso específico aparente seco máximo Proctor Normal, que é dado por ( $\gamma d$ - $\gamma d$,máx); $L I=$ índice de liquidez (\%); $\Delta w$ = variação de umidade ótima (\%) (wopt), baseado em ensaios de compactação de Proctor Normal. Expressão é válida para solos coesivos. 
Modelos de Li \& Selig (1994) para solos de subleito de graduação fina (MRDS10)

$$
\begin{gathered}
R m_{1}=\frac{M_{R}}{M_{R(o p t)}}=0,98-0,28 \cdot\left(w-w_{\text {opt }}\right)+0,029 \cdot\left(w-w_{\text {opt }}\right)^{2} ; \mathrm{R}=0,76 \\
R m_{2}=\frac{M_{R}}{M_{R(o p t)}}=0,96-0,18 \cdot\left(w-w_{\text {opt }}\right)+0,0067 \cdot\left(w-w_{\text {opt }}\right)^{2} ; \mathrm{R}=0,83
\end{gathered}
$$

Onde $M R=$ módulo de resiliência no teor de umidade; $w(\%)$ e mesma energia de compactação que $M R(o p t) ; M R(o p t)$ = módulo de resiliência no teor de umidade ótima e peso específico aparente seco máximo wopt(\%) para qualquer energia de compactação.

\section{Modelo de Pezo \& Hudson (1994) (MRDS-11)}

$$
M_{R}=F 0 \cdot F 1 \cdot F 2 \cdot F 3 \cdot F 4 \cdot F 5 \cdot F 6 ; \mathrm{R}^{2}=0,80
$$

Este modelo foi baseado no banco de dados de ensaios de testes de módulo de resiliência de diversas amostras de solos de subleito do Texas (EUA).

Onde: $F 0=9,80 \mathrm{ksi}$ (unidades inglesas) ou $67,60 \mathrm{MPa}$ (unidades no $\mathrm{SI}$ ); $F 1=$ fator de correção para o teor de umidade; $F 2$ = fator de correção para compactação relativa; F3 = correção para plasticidade do solo; $F 4$ = fator de correção para idade da amostra compactada; $F 5=$ fator de correção para pressão de confinamento; $F 6=$ fator de correção pela tensão desviadora. Valores são apresentados na tabela a seguir. $O$ modelo é aplicável somente em solos coesivos. 
Tabela 2.10 - Fatores de correção para o modelo de Pezzo \& Hudson (1994)

\begin{tabular}{cccc}
\hline $\begin{array}{c}\text { Teor de } \\
\text { umidade (\%) }\end{array}$ & $\mathbf{F}_{\mathbf{1}}$ & $\boldsymbol{\gamma} \mathbf{d} / \boldsymbol{\gamma} \mathbf{d}$ máx & $\mathbf{F}_{\mathbf{2}}$ \\
\hline 10 & 4,00 & 100 & 1,00 \\
\hline 15 & 2,00 & 95 & 0,90 \\
\hline 20 & 1,00 & 90 & 0,80 \\
\hline 25 & 0,50 & 85 & 0,70 \\
\hline $\begin{array}{c}\text { Índice de } \\
\text { plasticidade } \\
(\%)\end{array}$ & $\mathbf{F}_{\mathbf{3}}$ & $\begin{array}{c}\text { Idade } \mathbf{~ d a} \\
\text { amostra } \\
\text { (dias) }\end{array}$ & $\mathbf{F}_{\mathbf{4}}$ \\
\hline 10 & 1,00 & 2 & 1,00 \\
\hline 20 & 1,50 & 10 & 1,10 \\
\hline 30 & 2,00 & 20 & 1,15 \\
\hline$>40$ & 2,50 & $>30$ & 1,20 \\
\hline $\begin{array}{c}\sigma \mathbf{c} \\
(\mathbf{k P a})\end{array}$ & $\mathbf{F}_{\mathbf{5}}$ & $\begin{array}{c}\boldsymbol{\sigma} \mathbf{d} \\
\mathbf{( k P a )}\end{array}$ & $\mathbf{F}_{\mathbf{6}}$ \\
\hline 13,8 & 1,00 & 13,8 & 1,00 \\
\hline 27,6 & 1,05 & 27,6 & 0,98 \\
\hline 41,4 & 1,10 & 41,4 & 0,96 \\
\hline & & 55,2 & 0,94 \\
\hline & & 69,0 & 0,92 \\
\hline
\end{tabular}

As propriedades dos solos testados têm os seguintes intervalos: umidade de $10 \%$ a 35\%; compactação relativa de $80 \%$ a $100 \%$, baseado no AASHTO T99; índice de plasticidade de 4\% a 52\%; idade das amostras compactadas de 2 a 188 dias; pressão de confinamento de 13,8 a 41,4 kPa (2 a 6 psi); e tensão desvio de 11 a 102,8 kPa (1,6 a 14,9 psi). Fatores como classificação AASHTO, pressão de assentamento, percentual de finos foram também analisados para esta correlação. Todavia, estes fatores não foram incluídos na correlação. A expressão é válida para solos siltosos e argilosos de subleito. 


\section{Constantes de Titus-Glover \& Fernando (1995)}

Os autores apresentaram constantes do modelo de MR utilizando modelo MR3I-1 em vários materiais. A tabela a seguir apresenta estas constantes e resultados.

Tabela 2.11 - Constantes do modelo de MR (Titus-Glover \& Fernando, 1995)

\begin{tabular}{lccc}
\hline \multicolumn{1}{c}{ Material } & k1 & k2 & k3 \\
\hline Calcáreo (limestone) & 243 & 0,950 & $-6,5 \mathrm{E}-05$ \\
\hline Iron ore & 75 & 1,010 & $-2,2 \mathrm{E}-05$ \\
\hline Areia pedregulosa (sandy gravel) & 152 & 0,880 & $-2,9 \mathrm{E}-04$ \\
\hline Caliche & 322 & 0,880 & $-9,8 \mathrm{E}-05$ \\
\hline Shellbase & 318 & 0,800 & $-9,8 \mathrm{E}-05$ \\
\hline Areia & 498 & 0,770 & $-1,0 \mathrm{E}-02$ \\
\hline Silte & 195 & 0,071 & $-6,5 \mathrm{E}-05$ \\
\hline Argila "magra" (lean clay) & 195 & 0,068 & $-1,9 \mathrm{E}-01$ \\
\hline Argila "gorda" (fat clay) & 122 & 0,190 & $-3,6 \mathrm{E}-01$ \\
\hline
\end{tabular}

\section{Modelo de Berg et al. (1996) (MRDS-12)}

Os autores conduziram um estudo em diversos solos de graduação grossa e apenas um solo de graduação fina de subleitos de Minnesota (EUA). O solo de graduação fina foi preparado em diversos teores de umidade diferentes, mas em apenas um único peso específico aparente seco em torno de 11 pcf.

$$
M_{R}(p s i)=1,518 \cdot 10^{30} \cdot[f(S)]^{-13,85} \cdot[f(\sigma)]^{-0,272}, \mathbf{R}^{2}=0,95
$$

Onde $M R=$ módulo de resiliência $(p s i) ; f(S)=$ saturação normalizada por uma unidade de saturação de $1,0 \% ; f(\sigma)=$ tensão de cisalhamento octaédrica, $\tau$ oct, normalizada por uma unidade de pressão de 1,0psi $(\sim 7,0 \mathrm{kPa})$; e $\tau_{\text {oct }}=(\sqrt{2} / 3) \cdot \sigma d$. O modelo é aplicável somente para solos coesivos.

\section{Constantes de Maher et al. (2000)}

Os autores apresentar constantes do modelo de MR utilizando MR3I-1 em vários solos de subleito de New Jersey (EUA). A tabela a seguir apresenta os resultados. 
Tabela 2.12 - Constantes do modelo de MR para subleitos de New Jersey (Maher et al., 2000)

\begin{tabular}{|c|c|c|c|c|c|c|}
\hline Localização do solo & $\begin{array}{c}\text { Classificação } \\
\text { AASHTO }\end{array}$ & $\begin{array}{l}\text { Tipo de teor } \\
\text { de umidade }\end{array}$ & k1 & k2 & k3 & $\begin{array}{c}\text { Coeficiente de } \\
\text { determinação } \\
\left(\mathbf{R}^{2}\right)\end{array}$ \\
\hline \multirow{3}{*}{ Rt. 23} & \multirow{3}{*}{$A-1-b$} & $2 \%$ úmido & 521,65 & 0,93 & $-0,2068$ & 0,99 \\
\hline & & ótima & 834,48 & 0,6803 & $-0,0792$ & 0,95 \\
\hline & & $2 \% \operatorname{seco}$ & 1032,07 & 0,7713 & $-0,2774$ & 0,94 \\
\hline \multirow{3}{*}{ Rt. 46} & \multirow{3}{*}{ A-2-4 } & $2 \%$ úmido & 314,54 & 0,7532 & $-0,4614$ & 0,94 \\
\hline & & ótima & 410,71 & 0,7026 & $-0,4046$ & 0,91 \\
\hline & & $2 \%$ seco & 410,56 & 0,8072 & $-0,4166$ & 0,96 \\
\hline \multirow{3}{*}{ Rt. 80a } & \multirow{3}{*}{ A-2-4 } & $2 \%$ úmido & 340,97 & 0,7675 & $-0,4948$ & 0,96 \\
\hline & & ótima & 440,57 & 0,5085 & $-0,3913$ & 0,89 \\
\hline & & $2 \% \operatorname{seco}$ & 599,39 & 0,6571 & $-0,2769$ & 0,91 \\
\hline \multirow{3}{*}{ Rt. 295} & \multirow{3}{*}{ A-3 } & $2 \%$ úmido & 344,81 & 0,6029 & $-0,3921$ & 0,91 \\
\hline & & ótima & 399,77 & 0,7107 & $-0,3973$ & 0,93 \\
\hline & & $2 \%$ seco & 413,94 & 0,5674 & $-0,3986$ & 0,96 \\
\hline \multirow{3}{*}{ Rt. 80b } & \multirow{3}{*}{$A-4$} & $2 \%$ úmido & 346,48 & 0,7448 & $-0,5927$ & 0,97 \\
\hline & & ótima & 433,4 & 0,6982 & $-0,3497$ & 0,91 \\
\hline & & $2 \% \operatorname{seco}$ & 585,62 & 0,7453 & $-0,275$ & 0,97 \\
\hline \multirow{3}{*}{ Rt. 206} & \multirow{3}{*}{$A-4$} & $2 \%$ úmido & 273,71 & 0,6052 & $-0,5177$ & 0,92 \\
\hline & & ótima & 389,67 & 0,6515 & $-0,4161$ & 0,94 \\
\hline & & $2 \% \operatorname{seco}$ & 539,87 & 0,7211 & $-0,3934$ & 0,93 \\
\hline \multirow{3}{*}{ Condado de Cuberland } & \multirow{3}{*}{ A-6 } & $2 \%$ úmido & 202,6 & 0,4735 & $-0,8388$ & 0,95 \\
\hline & & ótima & 1278,9 & 0,2636 & $-0,2343$ & 0,94 \\
\hline & & $2 \%$ seco & 1699,32 & 0,231 & $-0,1707$ & 0,92 \\
\hline \multirow{3}{*}{ Condado de Cuberland } & \multirow{3}{*}{$A-7$} & $2 \%$ úmido & 284,32 & 0,3307 & $-0,7753$ & 0,89 \\
\hline & & ótima & 1290,4 & 0,2262 & $-0,1864$ & 0,89 \\
\hline & & $2 \%$ seco & 1430,67 & 0,2748 & $-0,1173$ & 0,88 \\
\hline
\end{tabular}

\section{Modelo de Drumm et al. (1997) para solos de subleito de graduação fina}

$$
M_{R(w e t)}=M_{R(o p t)}+\frac{d M_{R}}{d S} \cdot \Delta S
$$

Onde:

$M R($ wet $)=$ módulo de resiliência na saturação pós-compactação (MPa); $M R(o p t)=$ módulo de resiliência no teor de umidade ótima e peso específico aparente seco máximo $(\mathrm{MPa}) ; \Delta S=$ mudança no grau de saturação de pós-compactação (expresso como número decimal); $d M R / d S$ = gradiente do modulo de resiliência com respeito à saturação, ou a inclinação do $M R$ versus grau da curva de saturação $(M P a)$ (ver Tabela 2.13).

$$
\frac{d M_{R}}{d S}=1,690-194 \cdot(C L A S S)-11,2 \cdot\left[M_{R(o p t)}\right]
$$

Onde: 
CLASS = classificação AASHTO (por exemplo para classe A-4, CLASS=4; A-7-5, $\mathrm{CLASS}=7.5) ; \mathrm{MR}(\mathrm{opt})=$ modulo de resiliência $(\mathrm{MPa})$ no teor de umidade ótimo e peso específico aparente seco máximo; $\sigma \mathrm{c}=41 \mathrm{kPa}(6 \mathrm{psi})$ e od $=28 \mathrm{kPa}(4 \mathrm{psi})$.

Tabela 2.13 - Gradiente de módulo de resiliência com respeito ao grau de saturação

\begin{tabular}{ccc}
\hline Classificação do Solo & $\begin{array}{c}\text { Gradiente do } \\
\text { Módulo de } \\
\text { Resiliência } \\
\text { AASHTO }\end{array}$ & $\begin{array}{c}\text { USCS } \\
\text { (dMR/dS) Medido }\end{array}$ \\
\hline$A-4$ & $\mathrm{CL}$ & -390 \\
\hline $\mathrm{A}-4$ & $\mathrm{CL}$ & -280 \\
\hline $\mathrm{A}-4$ & $\mathrm{ML}$ & -260 \\
\hline $\mathrm{A}-6$ & $\mathrm{CL}$ & -390 \\
\hline $\mathrm{A}-6$ & $\mathrm{CL}$ & -330 \\
\hline $\mathrm{A}-6$ & $\mathrm{CL}$ & -470 \\
\hline $\mathrm{A}-7-5$ & $\mathrm{CH}$ & -810 \\
\hline $\mathrm{A}-7-5$ & $\mathrm{MH}$ & -1540 \\
\hline $\mathrm{A}-7-6$ & $\mathrm{CH}$ & -1780 \\
\hline $\mathrm{A}-7-6$ & $\mathrm{CL}$ & -2390 \\
\hline $\mathrm{A}-7-6$ & $\mathrm{CH}$ & -1560 \\
\hline
\end{tabular}

\section{Modelo de Jones e Witczak (1977) para solos de subleito de graduação fina}

$$
\log M_{R}=c_{1}+c_{2} \cdot(w \%)+c_{3} \cdot(S)
$$

Onde:

$M R=$ módulo de resiliência $(k s i)$ a uma tensão desviadora de 6 psi (42 kPa) e tensão confinante de 2 psi ( 14 kPa); w\% = teor de umidade (\%); S = grau de saturação (\%); $\mathrm{ci}=$ constante de regressão conforme Tabela 2.14 a seguir.

Tabela 2.14 - Constantes de regressão do modelo

\begin{tabular}{ccccc}
\hline Amostras & c1 & c2 & c3 & $\mathbf{R}^{\mathbf{2}}$ \\
\hline Indeformadas & 2,31909 & $-0,13282$ & 0,013405 & 0,97 \\
\hline Deformadas & 1,17869 & $-0,11111$ & 0,021699 & 0,67 \\
\hline
\end{tabular}


Modelo de Jin et al. (1994) para solos de subleito de graduação grossa

$$
\log M_{R}=c_{1}+c_{2} \cdot \log (\theta)+c_{3} \cdot(w \%)+c_{4} \cdot(T)+c_{5} \cdot\left(\gamma_{d}\right)
$$

Onde:

$M R=$ módulo de resiliência $(M P a) ; \theta=$ tensão total ou bulk stress $(k P a) ; w \%=$ teor de umidade (\%); $\mathrm{T}=$ temperatura $\left({ }^{\circ} \mathrm{C}\right) ; \gamma d=$ peso específico aparente seco $\left(\mathrm{kg} / \mathrm{m}^{3}\right)$; $\mathrm{ci}=$ constantes de regressão (conforme Tabela 2.15 a seguir).

Tabela 2.15 - Constantes de regressão do modelo

\begin{tabular}{ccccccc}
\hline Solo & c1 & c2 & c3 & c4 & c5 & $\mathbf{R}^{\mathbf{2}}$ \\
\hline 1 & 0,8956 & 0,278 & $-0,0202$ & $-0,0091$ & 0,0038 & 0,82 \\
\hline 2 & $-3,1895$ & 0,535 & $-0,00862$ & $-0,0084$ & 0,0021 & 0,72 \\
\hline
\end{tabular}

\section{Modelo de Rada e Witczak (1981) para materiais de Base / Sub-base}

$$
\log M_{R}=c_{1}+c_{2} \cdot(S)+c_{3} \cdot P C+c_{4} \cdot \log (\theta)
$$

Onde:

$M R=$ módulo de resiliência (psi); $\theta=$ tensão total ou bulk stress ( $p s i) ; S=$ grau de saturação (\%); PC = Percentual de compactação relativa ao peso específico aparente seco máximo da energia modificada (\%); ci = constantes de regressão são dados na Tabela 2.16 a seguir.

Tabela 2.16 - Coeficientes de regressão (Modelo de Rada e Witczak para materiais de Base/Subbase)

\begin{tabular}{lccccc}
\hline \multicolumn{1}{c}{ Agregado } & $\mathbf{c 1}$ & $\mathbf{c 2}$ & $\mathbf{c 3}$ & $\mathbf{c 4}$ & $\mathbf{R}^{2}$ \\
\hline DGA-limestone-1 & 3,4060 & $-0,0053$ & 0,0119 & 0,4843 & 0,79 \\
\hline DGA-limestone-2 & $-0,3017$ & $-0,0059$ & 0,0505 & 0,4445 & 0,6 \\
\hline CR-6-crushed stone & 1,0666 & $-0,0031$ & 0,0356 & 0,6469 & 0,81 \\
\hline CR-6-slag & 3,2698 & $-0,0040$ & 0,0166 & 0,384 & 0,59 \\
\hline Sand-aggregate blend & 4,1888 & $-0,0033$ & 0,0214 & 0,6785 & 0,83 \\
\hline Bank-run gravel & 0,9529 & $-0,0121$ & 0,0412 & 0,6035 & 0,84 \\
\hline All data & 4,0220 & $-0,0068$ & 0,0071 & 0,5516 & 0,61 \\
\hline
\end{tabular}


Modelos de Santha (1994) para solos de subleito de graduação grossa e fina

$$
M_{R}=k 1 \cdot p a \cdot\left(\frac{\theta}{p a}\right)^{k 2} \cdot\left(\frac{\tau_{o c t}}{p a}\right)^{k 3}
$$

Onde, para Materiais granulares:

$$
M_{R}=k 1 \cdot p a \cdot\left(\frac{\theta}{p a}\right)^{k 2} \cdot\left(\frac{\sigma_{d}}{p a}\right)^{k 3}
$$

$\log k 1=3,479-0,07 \cdot M C+0,24 \cdot \frac{M C}{M O I S T}+3,681 \cdot C O M P+0,011 \cdot S L T+0,006 \cdot C L Y$

$$
-0,025 \cdot S W-0,039 \cdot D E N+0,004 \cdot \frac{S W^{2}}{C L Y}+0,003 \cdot \frac{D E N^{2}}{S 40}
$$

$k 2=6,044-0,053 \cdot M O I S T-2,076 \cdot C O M P+0,0053 \cdot S A T U-0,0056 \cdot C L Y+0,0088 \cdot S W$ $-0,0069 \cdot S H-0,027 \cdot D E N+0,012 \cdot C B R+0,003 \cdot \frac{S W^{2}}{C L Y}-0,31 \cdot \frac{S W+S H}{C L Y}$

$$
\begin{aligned}
& k 3=3,752-0,068 \cdot M C+0,309 \cdot \frac{M C}{M O I S T}-0,006 \cdot S L T+0,0053 \cdot C L Y+0,026 \cdot S H \\
& -0,033 \cdot D E N-0,0009 \cdot \frac{S W^{2}}{C L Y}+0,00004 \cdot \frac{S A T U^{2}}{S H}-0,0026 \cdot(C B R \cdot S H)
\end{aligned}
$$

E para materiais coesivos:

$$
M_{R}=k 1 \cdot p a \cdot\left(\frac{\sigma_{d}}{p a}\right)^{k 3}
$$

$\log k 1=19,813-0,045 \cdot M O I S T-0,131 \cdot M C-9,171 \cdot C O M P-0,037 \cdot S L T+0,015 \cdot L L$ $-0,016 \cdot P I-0,021 \cdot S W-0,052 \cdot D E N+0,00001 \cdot(S 40 \cdot S A T U) ; \mathrm{R}^{2}=0,95$

$$
\begin{aligned}
k 3=10,274-0,097 \cdot & M O I S T-1,06 \cdot \frac{M C}{M O I S T}-3,471 \cdot C O M P+0,0088 \cdot S 40-0,0087 \cdot P I+ \\
+ & 0,014 \cdot S H-0,046 \cdot D E N ; \mathrm{R}^{2}=0,88
\end{aligned}
$$

Onde: $M C=$ teor de umidade (\%); SATU = saturação (\%); COMP = percentual de compactação (\%); MOIST = umidade ótima (\%); S40 = porcentagem passante na peneira \#40 (\%); CLY= porcentagem de argila (\%); SLT= porcentagem de silte (\%); 
$S W=$ expansão (\%); $S H=$ contração (\%); DEN = peso específico aparente seco máximo (pcf); $C B R=$ valor de $C B R$.

\section{Modelos de Yau \& Von Quintus (2002)}

Utiliza o modelo constitutivo MRI3-6.

Pedregulhos:

$k 1=1,3429-0,0051 \cdot P_{3 / 8}+0,0124 \cdot(\% \arg i l a)+0,0053 \cdot L L-0,0231 \cdot w_{s}$

$k 2=0,3311-0,0010 \cdot P_{3 / 8}-0,0019 \cdot(\% \arg i l a)-0,0050 \cdot L L-0,0093 \cdot w_{s}$

$k 3=1,5167-0,0302 \cdot P_{3 / 8}+0,0435 \cdot(\% \arg i l a)+0,0626 \cdot L L+0,0377 \cdot I P-0,2353 \cdot w_{s}$

Solos arenosos:

$k 1=3,2868-0,0412 \cdot P_{3 / 8}+0,0267 \cdot P 4+0,0137(\% \arg$ ila $)+0,0083 \cdot L L$

$-0,0379 \cdot w_{0}-0,0004 \cdot \rho s \quad(2.85)$

$k 2=0,5670+0,0045 \cdot P_{3 / 8}-2,98 \cdot 10^{-6} \cdot P 4-0,0043 \cdot(\%$ silte $)-0,0102 \cdot(\% \arg$ ila $)-0,0041 \cdot L L$

$+0,0045 \cdot w_{0}-3,41 \cdot 10^{-6} \cdot \rho s-0,4582 \cdot\left(\frac{\rho_{s}}{\rho_{d}}\right)+0,1779 \cdot\left(\frac{w_{s}}{w_{0}}\right)$

$k 3=3,5677-0,1142 \cdot P_{3 / 8}-0,0839 \cdot P 4-0,1249 \cdot P 200+0,1030 \cdot(\%$ silte $)+0,1191 \cdot(\% \arg$ ila $)$

$-0,0069 \cdot L L-0,0103 \cdot w_{0}-0,0017 \cdot \rho s-4,3177 \cdot\left(\frac{\rho_{s}}{\rho_{d}}\right)-1,1095 \cdot\left(\frac{w_{s}}{w_{0}}\right)$

Solos siltosos:

$k 1=1,048+0,0177(\% \arg$ ila $)+0,0279 \cdot I P-0,370 \cdot w s$

$k 2=0,5097-0,0286 \cdot I P$

$k 3=-0,2218+0,0047(\%$ silte $)+0,0849 \cdot I P-0,1399 \cdot w s$

Solos argilosos:

$k 1=1,3577+0,0106(\% \arg$ ila $)-0,0437 \cdot w s$

$k 2=0,5193-0,0073 \cdot P 4+0,0095 \cdot P 200-0,0030 \cdot L L-0,0049 \cdot w_{0}$ 


$$
\begin{aligned}
& k 3=1,4258-0,0288 \cdot P_{4}-0,0303 \cdot P 40-0,0521 \cdot P 200+0,0251 \cdot(\% \text { silte })+0,0535 \cdot L L \\
& -0,0672 \cdot w_{0}-0,0026 \cdot \rho d+0,0025 \cdot \rho s-0,6055 \cdot\left(\frac{w_{s}}{w_{0}}\right)
\end{aligned}
$$

Onde: $P 3 / 8$ = percentual passante na peneira \#3/8" (\%); $P 4=$ percentual passante na peneira \#4 (\%); $L L=$ limite de liquidez; $I P=$ índice de plasticidade; (\%silte $)=$ porcentagem de silte (\%); (\%argila) $=$ porcentagem de argila (\%); ws = teor de umidade (\%); w0 = umidade ótima (\%); $\rho s=$ massa específica dos grãos $(\mathrm{kg} / \mathrm{m} 3)$; $\rho d=$ massa específica aparente seca $(\mathrm{kg} / \mathrm{m} 3)$.

\section{Modelo de Wolfe \& Butalla (2004)}

Os autores desenvolveram o modelo $2 \mathrm{I}-5$ com duas constantes $k 1$ e $k 2$.

$$
k 1=a_{1} \cdot \sigma_{3}^{a_{2}}+a_{3} \cdot\left(\frac{S}{100}\right)^{a_{4}}+a_{5} \cdot q_{u}+a_{6} \cdot P I+a_{7} \cdot(L L-w)+a_{8} \cdot(w o p t-w)+a_{9} \cdot\left(P_{200}-a_{10}\right)
$$

$$
k 2=b_{1} \cdot \sigma_{3}^{b_{2}}+b_{3} \cdot\left(\frac{S}{100}\right)^{b_{4}}+b_{5} \cdot q_{u}^{b_{6}}+b_{7} \cdot P I+b_{8} \cdot(L L)
$$

Onde:

$$
\begin{aligned}
& a_{1}=a_{11}+a_{12} \cdot\left(\frac{w_{o p t}-w}{w_{o p t}}\right) \\
& b_{1}=b_{11}+b_{12} \cdot\left(w_{o p t}-w\right)
\end{aligned}
$$

Wopt $=$ umidade ótima de compactação (\%); $w=$ umidade da amostra (\%); s3 = pressão de confinamento $(k P a) ; S=$ grau de saturação $(\%) ; q u$ = resistência à compressão não confinada $(\mathrm{kPa}) ; P I=$ índice de plasticidade; $L L=$ limite de liquidez; $P 200=$ percentual de partículas passante na peneira \#200 $(0,075 \mathrm{~mm})$. 


\section{Constantes de Malla \& Josh (2006)}

Os autores apresentaram constantes do modelo de MR utilizando o modelo MR3I-2 em vários solos de subleito de New England (EUA). Os modelos resultantes são apresentados a seguir.

Graduação grossa (todas as amostras):

$\log (k 1)=-1,77341+0,00017562 \cdot M A X D D+0,02707 \cdot S 3-0,02043 \cdot S 1+0,00501 \cdot S 3 \_8-$ $0,00819 \cdot S N 200+0,00501 \cdot S I L T ; R 2=0,4 ; \mathrm{PR}<\mathrm{W}=0,12(2.98)$

$k 2=-0,49426+0,11250 \cdot M C R+0,00026190 \cdot D D+0,00592 \cdot S 3-0,00398 \cdot S N 40$

$+0,00479 \cdot F S A N D-0,00006099 \cdot C U-0,0000967 \cdot C C ; \mathrm{R} 2=0,45 ; \operatorname{Pr}>(\mathrm{t})=0,31 ; 0,29$

para intercepto \& CC (2.99)

$k 3=-0,44082-0,00232 \cdot M C+0,00021026 \cdot M A X D D-0,00531 \cdot S 1_{-} 2+0,00561 \cdot S N 10-$ 0,00529. SN200; $\operatorname{Pr}>(\mathrm{t})=0,31$ para MC. $\operatorname{Pr}<\mathrm{W}=0,085(2.100)$

Graduação grossa (amostras com $\mathrm{CU}<100)$ :

$\log (k 1)=0,61689-0,00815 \cdot O M C-0,06144 \cdot M C R-0,80003 \cdot D D R-0,00878 \cdot S N 200$

$+0,00624 \cdot S I L T+0,00621 \cdot C L A Y-0,00502 \cdot C C ; \mathrm{R} 2=0,47(2.101)$

$k 2=0,43372+0,00687 \cdot M C+0,00039979 \cdot D D-0,00026666 \cdot M A X D D-0,00331 \cdot S N 40$

$+0,00297 \cdot F S A N D+0,00515 \cdot C C \mathrm{R} 2=0,22 ; \operatorname{Pr}>(\mathrm{t})=0,27$ para intercepto $(2.102)$

$k 3=0,51731-0,00390 \cdot M C-0,43830 \cdot D D R-0,00594 \cdot S 1 \_2+0,00509 \cdot S N 10-$

$0,00070032 \cdot S N 40-0,00418 \cdot S N 200+0,00441 \cdot C L A Y ; \mathrm{R} 2=0,52 ; \operatorname{Pr}<\mathrm{W}=0,0164$

Graduação fina:

$$
\begin{aligned}
& \log (k 1)=6,99969-0,11144 \cdot O M C-1,15320 \cdot M C R-0,00154 \cdot M A X D D+0,01875 \cdot P I \\
& -0,02339 \cdot S 1+0,00445 \cdot S N 200 ; \mathrm{R} 2=0,41(2.104) \\
& k 2=0,55494+0,25904 \cdot M C R-0,00651 \cdot P I-0,00785 \cdot S N 4+0,00712 \cdot S N 40 \\
& -0,00266 \cdot S N 200-0,00318 \cdot C L A Y ; \mathrm{R} 2=0,39 ; \mathrm{Pr}<\mathrm{W}<0,0001(2.105)
\end{aligned}
$$


$k 3=2,08483-0,03626 \cdot M C-0,00044337 \cdot M A X D D+0,01104 \cdot L L-0,02024 \cdot S 1$

$+0,00494 \cdot S N 80+0,01012 \cdot C S A N D+0,00392 \cdot F S A N D+0,00287 \cdot S I L T ; \mathrm{R} 2=0,33$

Onde: $M C=$ umidade da amostra (\%); OMC = umidade ótima (\%); $M C R=$ relação de umidade $(M C R=M C / O M C) ; D D=$ peso específico aparente seco da amostra $(\mathrm{kg} / \mathrm{m} 3)$; $M A X D D=$ peso específico aparente seco máximo $(\mathrm{kg} / \mathrm{m} 3) ; D D R=$ relação de peso específico aparente seco $(D D R=D D / M A X D D) ; L L=$ limite de liquidez; $P L=$ limite de plasticidade; $S 3=$ percentual passante na peneira 3" (\%); S2 = percentual passante na peneira 2" (\%); S1_HALF = percentual passante na peneira 1 1/2" (\%); $S 1$ = percentual passante na peneira 1" (\%); S3_4 = percentual passante na peneira 3/4" (\%); S1_2=percentual passante na peneira 1/2" (\%); S3_8=percentual passante na peneira 3/8" (\%); S2 = percentual passante na peneira 2" (\%); $S 4$ = percentual passante na peneira 4" (\%); SN4 = percentual passante na peneira \#4 (\%); SN10 = percentual passante na peneira \#10 (\%); SN40 = percentual passante na peneira \#40 (\%); SN80 = percentual passante na peneira \#80 (\%); SN200 = percentual passante na peneira \#200 (\%); CSAND = percentual de areia grossa - tamanho de partículas entre 2 e 0,42mm (\%); FSAND = percentual de areia fina - tamanho de partículas entre 0,42 e 0,074mm (\%); SILT = percentual de silte - tamanho de partículas entre 0,074 e 0,002mm (\%);CLAY = percentual de argila - tamanho de partículas menores ou iguais a 0,002mm (\%); CU = coeficiente de uniformidade; $C C=$ coeficiente de curvatura.

\section{Constantes de Titi et al. (2006)}

Os autores apresentaram constantes do modelo de MR utilizando o modelo MR3I-6 (MEPDG) em vários solos de subleito de Wisconsin (EUA). Os modelos resultantes são apresentados a seguir.

Solos de graduação fina:

$$
\begin{aligned}
& k 1=404,166+42,933 \cdot P I+52,260 \cdot \gamma_{d}-987,353 \cdot\left(\frac{w}{w_{o p t}}\right) \\
& k 2=0,25113-0,0292 \cdot P I+0,5573 \cdot\left(\frac{w}{w_{o p t}}\right) \cdot\left(\frac{\gamma_{d}}{\gamma_{d \max }}\right)
\end{aligned}
$$




$$
k 3=-0,20772+0,23088 \cdot P I+0,00367 \cdot \gamma_{d}-5,4238 \cdot\left(\frac{w}{w_{o p t}}\right)
$$

Solos de graduação grossa, não plásticos:

$$
\begin{aligned}
& k 1=809,547+10,568 \cdot P 4-6,112 \cdot P 40-578,337 \cdot\left(\frac{w}{w_{\text {opt }}}\right) \cdot\left(\frac{\gamma_{d}}{\gamma_{d \max }}\right) \quad(2.110) \\
& k 2=0,5661+0,006711 \cdot P_{40}-0,02423 \cdot P_{200}+0,05849 \cdot\left(w-w_{o p t}\right)+0,001242 \cdot\left(w_{\text {opt }}\right) \cdot\left(\gamma_{d \max }\right)
\end{aligned}
$$

$$
k 3=-0,5079-0,041411 \cdot P_{40}+0,14820 \cdot P_{200}-0,1726 \cdot\left(w-w_{o p t}\right)-0,01214 \cdot\left(w_{o p t}\right) \cdot\left(\gamma_{d \max }\right)
$$

Solos de graduação grossa, plásticos:

$$
k 1=8642,873+132,643 \cdot P_{200}-428,067 \cdot(\% \text { silt })-254,685 \cdot P I+197,230 \cdot \gamma_{d}-381,400 \cdot\left(\frac{w}{w_{o p t}}\right)
$$

$$
k 2=2,3250-0,00853 \cdot P_{200}+0,02579 \cdot L L-0,06224 \cdot P I-1,73380 \cdot\left(\frac{\gamma_{d}}{\gamma_{d \max }}\right)+0,20911 \cdot\left(\frac{w}{w_{o p t}}\right)
$$

$$
k 2=-32,5449+0,7691 \cdot P_{200}-1,1370 \cdot(\% \text { silt })+31,5542 \cdot\left(\frac{\gamma_{d}}{\gamma_{d \max }}\right)-0,4128 \cdot\left(w-w_{\text {opt }}\right)
$$

Onde: $P I=$ índice de plasticidade; $L L=$ limite de liquidez; $\gamma d=$ massa específica parente seca $(k N / m 3) ; \gamma d$ max = massa específica aparente seca máxima $(k N / m 3)$; $w=$ teor de umidade (\%); $w$ opt = umidade ótima (\%); P4 = percentual passante na peneira \#4 (\%); P40 = percentual passante na peneira \#40 (\%); P200 = percentual passante na peneira \#200 (\%); (\%clay)=porcentagem de argila (\%); $(\%$ silt $)=$ porcentagem de silte $(\%)$. 
Modelo de Zaman et al. (1994)

Pedregulhos:

$M R=2860,94+275 \cdot c+128 \cdot \sigma_{1} \cdot \tan (\phi)+118 \cdot \theta$

Onde: $c=$ coesão (psi); $\sigma_{1}=$ tensão principal maior $(p s i) ; \phi=$ ângulo de atrito interno; $\theta=$ primeiro invariante de tensão ( $p s i)$.

Modelo da AASHTO/2002 (ME-PDG)

$$
\log \frac{M_{R}}{M_{R(o p t)}}=a+\frac{b-a}{1+E X P\left[\beta+k s \cdot\left(S-S_{o p t}\right)\right]}
$$

Onde:

$a=$ mínimo de $\log (M R / M R o p t) ; b$ = máximo de $\log (M R / M R o p t) ; \beta$ = parâmetro de locação - obtido como uma função de $a$ e $b$ pela imposição da condição de interseção em zero:

$$
\beta=\ln \left(-\frac{b}{a}\right)
$$

$k S$ = parâmetro de regressão;

$(S-S o p t)$ = variação do grau de saturação expresso em decimal (notar que o uso do $S$ na equação foi alterado de percentual para decimal quando o modelo revisado não linear foi adotado). Utilizando os dados disponíveis na literatura e assumindo uma relação de módulos máxima de 2,5 para materiais de graduação fina e 2,0 para materiais de graduação grossa, os valores de $a, b, \beta$ e $k S$ são dados na Tabela 2.17 a seguir.

Tabela 2.17 - Coeficientes de regressão para o modelo

\begin{tabular}{cccl}
\hline Parâmetro & $\begin{array}{c}\text { Materiais de } \\
\text { graduação grossa }\end{array}$ & $\begin{array}{c}\text { Materiais de } \\
\text { graduação fina }\end{array}$ & Comentários \\
\hline$a$ & $-0,3123$ & $-0,5934$ & Parâmetro de regressão \\
\hline$b$ & 0,3000 & 0,4000 & $\begin{array}{c}\text { Assumido conservadoramente, até que mais dados sejam disponíveis } \\
\text { (correspondente a variações de módulo de 2 e 2,5) }\end{array}$ \\
\hline$\beta$ & $-0,0401$ & $-0,3944$ & Obtido utilizando a equação 12-1 \\
\hline ks & 6,8157 & 6,1324 & Parâmetro de regressão \\
\hline
\end{tabular}




\section{Modelos de Takeda (2006)}

Modelo genérico:

$$
\left(\frac{M_{R w}}{M_{R w_{0}}}\right)=a \cdot e^{b \cdot\left(w-w_{0}\right)}
$$

Modelo específico:

$$
\begin{gathered}
\left(\frac{M_{R w}}{M_{R w_{0}}}\right)=e^{-0.43 \cdot\left(w-w_{0}\right)} \\
\mathrm{e} \\
k_{1 w}=k_{1 w 0} \cdot e^{-0.43 \cdot\left(w-w_{0}\right)}
\end{gathered}
$$

Onde:

$M R w$ = módulo de resiliência na umidade que se deseja avaliar; $M R w 0=$ módulo de resiliência na umidade ótima e massa específica seca máxima; $w=$ teor de umidade em que se deseja avaliar MR; w0 = umidade ótima; $k 1 w=$ valor do parâmetro $k 1$ do modelo composto na umidade que se deseja avaliar; $k 1 w 0=$ valor do parâmetro $k 1$ do modelo composto na umidade ótima e massa específica seca máxima; $w=$ teor de umidade em que se deseja avaliar $M R ; w 0=$ umidade ótima.

$$
k 1=-3371+20,60 \cdot L P-371,90 \cdot P_{200}+384,99 \cdot P \arg \text { ila }+387,76 \cdot \text { Psilte }+1648,05 \cdot \rho_{d \max }
$$

$$
k 3=0,37-0,0066 \cdot L P-0,0026 \cdot \text { Psilte }
$$

$$
\begin{aligned}
& k 1=-4396+4,24 \cdot E \mathrm{O}-840,56 \cdot R C S+21,26 \cdot L P+492,54 \cdot \text { Psilte } \\
& +489,05 \cdot P \arg \text { ila }-474,03 \cdot P 200+2177,14 \cdot \rho_{d \max }
\end{aligned}
$$

Onde:

$K 1$ = parâmetro de regressão do modelo composto; $E 0=$ módulo tangente inicial $(\mathrm{MPa}) ; R C S=$ resistência à compressão simples $(\mathrm{MPa}) ; L P$ e $I P=$ respectivamente, limite de plasticidade e índice de plasticidade (\%); Psilte, Pargila, 
$P_{200}=$ respectivamente, teores de silte, argila e finos $(\%) ; \rho_{d m a x}=$ massa específica seca máximo $(\mathrm{g} / \mathrm{cm} 3)$.

Ressalta-se que este estudo foi realizado com solos do Estado de São Paulo.

\section{Modelo de Gupta et al. (2007)}

Os autores propuseram a seguinte expressão para o modelo de previsão de $M R$ baseado em medidas de sucção do solo $(\psi)$.

$$
M R(k P a)=-54105+57898 \cdot \log (\psi), \mathrm{R}^{2}=0,76
$$

Onde:

$M R=$ módulo de resiliência $(k P a) ; \psi=$ sucção do solo $(k P a)$. Esta equação é válida para solos do tipo coesivos testados nesta pesquisa e para tensão total (bulk stress) de 83 kPa e tensão de cisalhamento octaédrica de 19,3 kPa.

2.2.6 Estimativa de valores de módulo in situ a partir de ensaios deflectométricos

Von Quintus e Killingsworth (1998) relataram que as relações entre módulos de laboratório e $F W D$ variaram de 0,1 a 3,5 com base no banco de dados do programa LTPP.

Siekmeier et al. (1999) e Siekmeier (2002) sugeriram que os módulos retroanalisados a partir do FWD são comparáveis com os módulos de resiliência a partir de medições de laboratório em tensões normais octaédricas baixas.

Ping et al. (2002) sugeriu que o $\mathrm{E}_{F W D}$ retroanalisado é de aproximadamente 1,65 vezes maior que os valores de laboratório.

Rahim \& George (10) relataram que os módulos medidos a partir de testes FWD diretamente conduzidas no subleito foram menores e mais próximos aos valores medidos em laboratório que aqueles determinados a partir de testes realizados na 
superfície do pavimento. Além disso, foi sugerido que a razão de valores de módulos FWD retroanalisados e de laboratório variou de 0,85 a 2,0; com um valor médio de 1,4. No geral, Rahim e George (10) reconheceram a necessidade de rever o fator atual de 0,33 aplicado em módulos retroanalisados FWD para determinar os módulos de laboratório porque os resultados de sua pesquisa mostraram menores variações entre módulos medidos e previstos.

Choubane \& McNamara (2000) sugeriram que as deflexões do pavimento medidas a uma distância de 36 pol. do ponto de aplicação de carga são apropriadas para a determinação dos módulos de subleito. Com base em 300 testes de campo FWD realizadas no estado da Flórida, Choubane e McNamara propuseram a equação a seguir para retroanalisar os módulos $F W D$ utilizados para estimar o MR dos solos do subleito. Esta equação será referida como a equação Florida aqui.

$$
E_{F W D}=0,03764 \cdot\left(\frac{P}{d_{r}}\right)^{0,898}
$$

Onde:

$E_{F W D}=$ módulo de resiliência do subleito retroanalisado a partir do ensaio $F W D(p s i)$; $P=$ carga aplicada (lbf); $d r=$ deflexão do pavimento medida a uma distância radial $r$ de 36 pol. $(90 \mathrm{~cm})$.

Malla \& Joshi (2006), também realizaram um estudo para correlacionar os valores de $M R$ medidos em laboratório e os e os módulos $F W D$ retroanalisados sobre a base da base de dados $\angle T P P$. O módulo foi FWD retroanalisado usando software MODCOMP 4.2. Os pesquisadores observaram que os valores de módulo de resiliência retroanalisados foram maiores do que os valores de $M R$ de laboratório realizados para o mesmo local de teste. No entanto, não existe nenhuma relação clara entre os dois valores, que foram atribuídos para a diferença de anos dos ensaios de FWD e da coleta e ensaios das amostras de laboratório.

Nazzal \& Mohammad (2010) realizaram testes de campo em seções de 10 projetos de pavimentação no interior do estado de Louisiana (EUA). As seções testadas cobriram os tipos de solo de subleito mais comuns encontrados em Louisiana (solos classificação A-4, A-6, A-7-5 e A-7-6). 
Tabela 2.18 - Propriedades dos solos incluídos no estudo de Nazzal \& Mohammad (2010)

\begin{tabular}{|c|c|c|c|c|}
\hline Propriedade & $\begin{array}{l}\text { Intervalo } \\
\text { solos A-4 }\end{array}$ & $\begin{array}{l}\text { Intervalo } \\
\text { solos A-6 }\end{array}$ & $\begin{array}{l}\text { Intervalo } \\
\text { solos A-7-5 }\end{array}$ & $\begin{array}{l}\text { Intervalo } \\
\text { solos A-7-6 }\end{array}$ \\
\hline Mr, lab. (ksi) & $6-8$ & $2-14$ & $2-14$ & $1-11$ \\
\hline IP (\%) & $<6$ & $11-23$ & $27-61$ & $15-66$ \\
\hline$\gamma d$ (pcf) & $100-107$ & $94-115$ & $77-103$ & $62-112$ \\
\hline$w(\%)$ & $21-25$ & $9-29$ & $21-37$ & $18-65$ \\
\hline LL (\%) & 28 & $27-40$ & $46-98$ & 41-93 \\
\hline Areia (\%) & 7 & $11-35$ & $4-28$ & $2-32$ \\
\hline Silte (\%) & 70 & $30-72$ & $9-62$ & $14-58$ \\
\hline Argila (\%) & 23 & 8-32 & $27-86$ & $32-84$ \\
\hline \%Passante na \#200 (\%) & 93 & $65-89$ & $72-96$ & $68-98$ \\
\hline
\end{tabular}

Nota: $M r, l a b=M R$ medido em laboratório, $I P=$ índice de plasticidade, $w=$ umidade, $L L=$ limite de liquidez, silte = percentual de silte, argila = percentual de argila, $\gamma d=$ peso específico seco.

Ensaios de módulo de laboratório foram conduzidos no equipamento triaxial de carga repetida. Para comparar as medidas de módulos in situ com as medidas de $M R$ de laboratório, valores de $M R$ representativos de campo foram inicialmente determinados. Isso foi feito através da realização de uma análise de regressão linear com os dados de cada teste $R L T$ para determinar os parâmetros $M R$ do modelo constitutivo generalizado que foi adotado pelo M-E PDG e mostrado na Equação 3.

Os parâmetros obtidos foram então utilizados para calcular o $M R$ com uma tensão de desvio, de 6 psi (42 kPa) e uma pressão de confinamento de 2 psi (14 kPa), que é uma estimativa do estado de tensões encontrado na camada de subleito sob carga de tráfego, utilizando o modelo MRI3-6.

Os autores propõem a seguinte equação para determinação dos valores de módulo in situ, com base nas propriedades físicas dos solos:

$$
M r=-2,24+0,46 \cdot E_{F W D}-1,64 \cdot\left[\frac{w-w_{o m c}}{w_{o m c}}\right]-0,00098 \cdot\left[\frac{w \cdot \gamma d \cdot \text { clay } \%}{\text { silt } \%}\right]+0,107 \cdot w
$$

Onde: 
$w=$ umidade in situ; $w_{o m c}=$ umidade ótima (\%); $\gamma_{d}=$ peso específico aparente seco in situ (psf); clay $\%$ = percentual de argila no solo $(\%)$, silt\% = percentual de silte no solo $(\%)$.

Os autores verificaram que a relação $E_{F W D} / M R$ variou entre 0,51 e 8,1 para os 10 solos de subleito testados. Esta proporção foi maior para valores de $M R$ mais baixos e, portanto, solos do subleito mais fracos. Os autores relataram que a relação $E_{F W D} / M R$ foi significativamente afetada pelo método de retroanálise e que, em geral, o método do software ELMOD 5.1 apresentou valores de razões significativamente menores que os outros métodos. Também verificaram que entre todos os módulos FWD retroanalisados, aqueles usando software ELMOD 5.1.69 tiveram a melhor correlação com o MR medido em laboratório através de testes triaxiais de carga repetida.

Zhang \& Sun (2003) estabeleceram um procedimento para obter o módulo de resiliência do subleito através da teoria do ponto inerte. Os autores geraram 1280 bacias de deflexões (carga de $50 \mathrm{kN}$ e raio de $15 \mathrm{~cm}$ ) para pavimentos com alturas entre 25 a $60 \mathrm{~cm}$ e módulos de subleito entre 25 e $100 \mathrm{MPa}$ que pudessem ser encontrados em situações reais. Utilizando regressão não linear multivariável, os autores apresentaram os seguintes modelos matemáticos a partir dos dados de ensaio com FWD:

$$
\begin{gathered}
R=\left[a 1+a 2 \cdot\left(\frac{H}{E 0}\right)^{a 3}\right] \cdot H^{b} \cdot E_{0}{ }^{c} \\
D c=\left[x 1+x 2 \cdot\left(\frac{H}{E 0}\right)^{x 3}\right] \cdot H^{y} \cdot E_{0}{ }^{z}
\end{gathered}
$$

Onde: $R=$ raio de curvatura da bacia deflectométrica $(m) ; D c=$ deflexão caraterística do pavimento $(0,01 \mathrm{~mm}) ; H=$ altura do pavimento $(\mathrm{cm}) ; E O=$ módulo do subleito (MPa); a1, a2, a3, b, c, x1 x2, x3, y, z são parâmetros de regressão conforme tabela.

Tabela 2.19 - Constantes do modelo para R (Zhang e Sun, 2004)

\begin{tabular}{cccccc}
\hline $\mathbf{H}(\mathbf{c m})$ & $\mathbf{a}_{\mathbf{1}}$ & $\mathbf{a}_{\mathbf{2}}$ & $\mathbf{a}_{\mathbf{3}}$ & $\mathbf{b}$ & $\mathbf{c}$ \\
\hline$<42,5$ & $-87,15$ & 106,4 & 0,0784 & 0,4616 & 0,1464 \\
\hline$>42,5$ & 68,31 & 100,0 & 0,2143 & 0,0909 & 0,3990 \\
\hline
\end{tabular}


Tabela 2.20 - Constantes do modelo para Dc (Zhang e Sun, 2004)

\begin{tabular}{cccccc}
\hline $\mathbf{H}(\mathbf{c m})$ & $\mathbf{x}_{\mathbf{1}}$ & $\mathbf{x}_{\mathbf{2}}$ & $\mathbf{x}_{\mathbf{3}}$ & $\mathbf{y}$ & $\mathbf{z}$ \\
\hline$<42,5$ & 10,56 & 78,42 & 1,182 & $-1,958$ & 0,3171 \\
\hline$>42,5$ & 9,86 & 47,13 & 1,448 & $-1,993$ & 0,4595 \\
\hline
\end{tabular}

De acordo com Pereira (2007), o algoritmo convergente de Zhang e Sun baseado na posição do ponto inerte para retroanalisar o subleito de pavimentos com três camadas, é descrito pelos seguintes passos:

> Passo 1 - obter $H, H=h 1+h 2$ (onde $h 1$ é a espessura do revestimento e $h 2$ a espessura da base).

> Passo 2 - fornecer as deflexões medidas e suas respectivas distâncias de aplicação de carga. Ajustar um valor superior para o módulo resiliente do subleito EOu, um valor inferior EOi e um valor inicial EO. Selecionar o critério de convergência $(\varepsilon)$ e contar $k=0$.

> Passo 3 - Calcular os parâmetros $R C$ e $D c$ do ponto inerte com a altura e o valor inicial de $E 0$ através das expressões acima.

> Passo 4 - Calcular a deflexão medidas $(D m)$ na posição $R C$ baseado nos dados de deflexões medidas.

$>$ Passo 5 - Comparar a deflexão calculada $(D c)$ com a deflexão medida $(D m)$.

$>$ Se $(D c-D m)<e$, ir para o Passo 6;

$>$ Se $D c>D m$, ajustar EOu = EO e EO = [(EO+EOi $/ 2]$;

$>$ Ou se $D c<D m$, ajustar $E 0 i=E O$ e $E O=[(E 0+E O u) / 2]$, ajustar $k=k+1$ e retornar ao Passo 3.

$>$ Passo 6 - parada, $E 0^{*}=[(E O u+E 0 i) / 2]$.

Pereira (2007) propôs uma readaptação das constantes das expressões de Zhang \& Sun (2003) utilizando o carregamento do eixo padrão (8,2 tf) em 19.654 bacias teóricas de deflexões obtidas com o programa Elsym-5. Utilizou os seguintes parâmetros:

$>$ Caga aplicada: eixo padrão de 8,2 tf $(2,05 \mathrm{tf}$ por roda com um raio de 10,75cm);

> Espessura de pavimento: 120 a $90 \mathrm{~cm}$, com variações de 5 em $5 \mathrm{~cm}$;

> Módulo de resiliência da camada equivalente: 200 a 2000 MPa com variações de 50 em 50 MPa;

> Módulo de resiliência do subleito: 20 a 200 MPa com variações de 5 em 5 MPa; 
> Coeficiente de Poisson do subleito: 0,45;

$>$ Coeficiente de Poisson da camada equivalente*: 0,30;

Obs.: * camada equivalente foi definida pelo autor como o conjunto das camadas do pavimento sobre o subleito, com altura total $H$ e um único módulo de resiliência equivalente proporcional à rigidez do conjunto.

O autor obteve as seguintes equações:

$$
\begin{aligned}
& R c=\left[-104,057+114,777 \cdot\left(\frac{H}{E 0}\right)^{0,0158}\right] \cdot H^{0,811} \cdot E_{0}^{-0,171} \\
& D c=\left[11855,85+436,84 \cdot\left(\frac{H}{E 0}\right)^{0,0033}\right] \cdot H^{-0,976} \cdot E_{0}^{-0,693}
\end{aligned}
$$

O autor ainda apresenta a equação para obtenção do módulo da camada equivalente do pavimento:

$$
\log (\text { Meq })=\frac{\log (D 0)+2,526 \cdot \log (H)+2,881 \cdot \log (S)-7,289-1,623 \cdot[\log (H) \cdot \log (S)]}{0,58 \cdot \log (S)+0,443 \cdot \log (H)-0,878-0,434 \cdot[\log (H) \cdot \log (S)]}
$$

Noureldin (1993) propôs um procedimento para determinar o módulo resiliente do subleito ( $E s g)$ através da seguinte expressão:

$$
E s g=\frac{2,149}{r_{x} \cdot D_{x}}
$$

Onde: $r x=$ distância do geofone mais externo em polegadas; $D x=$ deflexão de geofones mais externo em polegadas; $E s g=$ módulo de resiliência do subleito ( $p s i)$. O autor ainda apresenta procedimento para obter o módulo equivalente e a espessura total efetiva do pavimento:

$$
\begin{gathered}
E p=\frac{716-\frac{2,149}{r_{x}}}{D_{0}-D_{x}} \\
T x=\left[\frac{D_{0}-D_{x}}{D_{x} \cdot\left(\frac{r_{x}}{3}-1\right)}\right]^{\frac{1}{3}} \cdot\left(4 \cdot r_{x}{ }^{2}-36\right)^{\frac{1}{2}}
\end{gathered}
$$


Onde: $r x=$ distância do geofone mais externo em polegadas; $D x=$ deflexão de geofones mais externo em polegadas; $E s g=$ módulo de resiliência do subleito (psi).

Repetindo-se as equações apresentadas para $D 1$ a $D 5$ e raio variando entre $r 1$ e $r 5$, obtém-se um gráfico como o ilustrado a seguir para determinação dos respectivos módulos efetivos do subleito e do pavimento a partir da espessura total do pavimento. Nos casos em que não se conhece a espessura total do pavimento, utiliza-se o maior produto entre os dados $\left(r_{x} \times D_{x}\right)$ existentes.

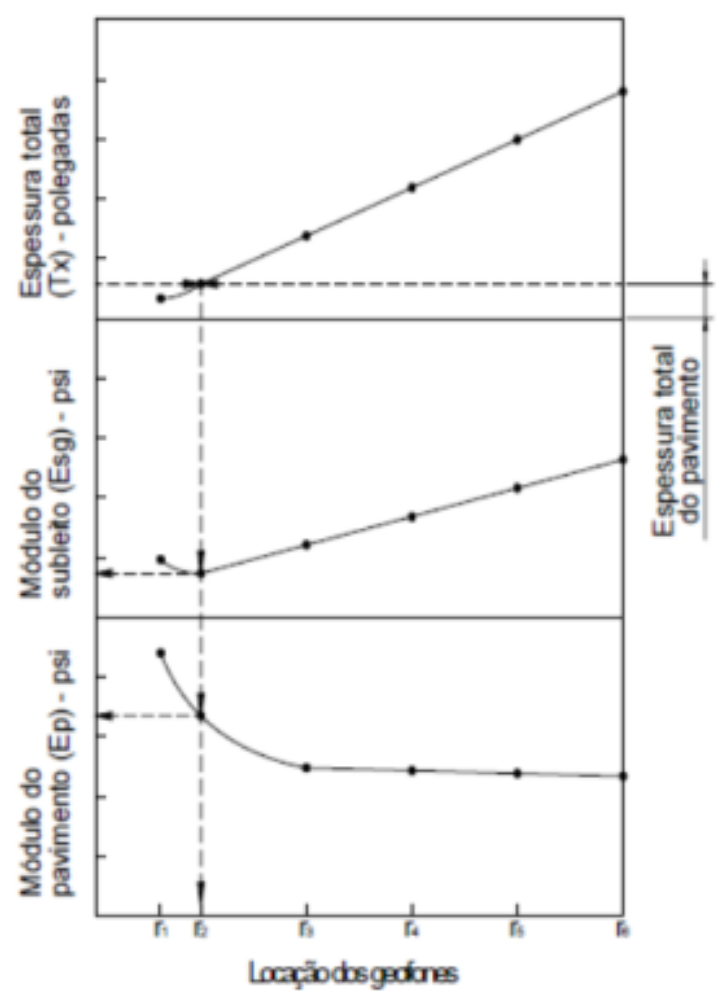

Figura 2.15: Gráfico para determinação dos módulos efetivos do subleito e pavimento de acordo com o procedimento de Noureldin (1993)

Albernaz (1994) realizou uma adaptação no método original de Noureldin, adaptandoo para os resultados de um ensaio com Viga Benkelman. As equações apresentadas a seguir ilustram a obtenção do módulo de resiliência do subleito, o módulo equivalente do pavimento $(E p)$ e o espessura total efetiva $(T x)$, respectivamente.

$$
E s g=\frac{21,193}{r_{x} \cdot D_{x}}
$$




$$
\begin{gathered}
E p=\frac{142-\frac{1,193}{r_{x}}}{D_{0}-D_{x}} \quad(2.137) \\
T x=1,364 \cdot\left[\frac{D_{0}-D_{x}}{D_{x} \cdot\left(\frac{r_{x}}{3,3}-2,54\right)}\right]^{\frac{1}{3}} \cdot\left(4 \cdot r_{x}^{2}-282,3\right)^{\frac{1}{2}}
\end{gathered}
$$




\subsection{Análise crítica da revisão bibliográfica}

Com base na pesquisa realizada, verificou-se que muitos modelos foram desenvolvidos levando-se em conta principalmente dois aspectos: (i) a determinação do módulo de resiliência para condições de umidade ótima de compactação a partir de parâmetros obtidos em ensaios de laboratório (granulometria, peso específico aparente seco, CBR entre outros) e (ii) a variação dos valores de módulo de resiliência dos materiais que pode ocorrer em campo, especialmente por conta do efeito de mudanças no grau de saturação dos solos de subleito.

Pouco se fez no intuito de calibrar os modelos obtidos ou mesmo estabelecer novos modelos para o caso de solos tropicais, por exemplo, solos abundantemente utilizados em fundações de pavimentos brasileiros. Fato este que restringe a aplicação de modelos e softwares empíricos-mecanísticos como é o caso do MEPDG (AASHTO/2002). Pouco também se sabe do dano real causado pela repetição dos ciclos de saturação e secagem a que estão expostos os solos de subleito em serviço. Ainda, dentre as referências bibliográficas encontradas, poucos estudos se preocuparam em verificar, quantificar e definir os principais agentes causadores das variações de comportamento mecânico que de fato ocorrem no campo. Algumas perguntas são recorrentes tais como:

- Quais os níveis de tensões de confinamento e tensões desvio devem ser utilizados como referência para adoção do valor do módulo representativo no dimensionamento e por quê? Este parâmetro é único ou depende de outros fatores?

- Os valores de módulo de resiliência retroanalisados a partir de um determinado deflectômetro instalado, por exemplo, a $120 \mathrm{~cm}$ do ponto de aplicação de carga, pode sofrer influência da espessura total do pavimento asfáltico? Pode sofrer algum outro tipo de influência (tipos e espessuras de materiais de base e revestimento, por exemplo)? Há como estabelecer um fator de correção? O que realmente importa, para um bom desempenho estrutural, a resposta mecânica do conjunto da infraestrutura ou a resposta do subleito em separado? 
- O comportamento mecânico dos solos do subleito é influenciado pelo tipo de seção (corte, aterro ou mista) de terraplenagem? Esta influência é importante?

- Como modelar o comportamento mecânico do subleito em função de índices pluviométricos? Qual ou quais os melhores índices a serem utilizados para estes fins? Como quantificar o benefício dos sistemas de drenagem atuantes nas respostas resilientes dos subleitos?

- Todos os tipos de solos de subleito quando retroanalisados a partir dos dados FWD e o uso da equação da AASHTO/93 e/ou programas de retroanálise (BAKFAA, entre outros) devem ser passíveis de aplicação de fator de correção, tal como propõe a $A A S H T O / 93$ (Cmáx=0,33)? Este número é fixo ou depende de alguma variável do processo?

- Como quantificar e modelar a influência dos diversos ciclos de saturação e secagem dos solos? A repetição destes ciclos pode ocasionar algum tipo de fragilização nos materiais?

- Entre outras.

Assim, o presente trabalho procurou responder a algumas das questões colocadas acima, com o objetivo de investigar e propor respostas e tratamentos adequados a algumas das questões apresentadas, analisando os dados disponíveis de campo e de laboratório. 


\section{ENSAIOS DE CAMPO E DE LABORATÓRIO - ESTUDO DE CASO DE UMA RODOVIA FEDERAL}

O presente estudo de caso foi realizado com o objetivo de coletar dados de ensaios de campo e laboratório para verificar correlações entre índices físicos e mecânicos dos solos, verificar variações no comportamento mecânico dos subleitos por ação da água ou outros fatores, e verificar eventuais reflexos dos diferentes comportamentos mecânicos no desempenho da estrutura de pavimento como um todo. Para realização da pesquisa, foram realizados poços de inspeção no pavimento existente de uma rodovia federal concessionada, onde foram realizados ensaios in situ: umidade, peso específico aparente seco e deflexão com LWD - Light Weight Deflectometer. Também foram coletadas amostras dos materiais do subleito para realização de ensaios de laboratório: granulometria, limites de Atterberg (LL e $L P$ ), classificação $M C T$, compactação, $C B R$, e módulo de resiliência de laboratório.

A Figura 3.1 a seguir apresenta o fluxograma idealizado para determinação dos pontos de análise e Figura 3.2 ilustra o fluxograma para realização dos procedimentos de campo. 


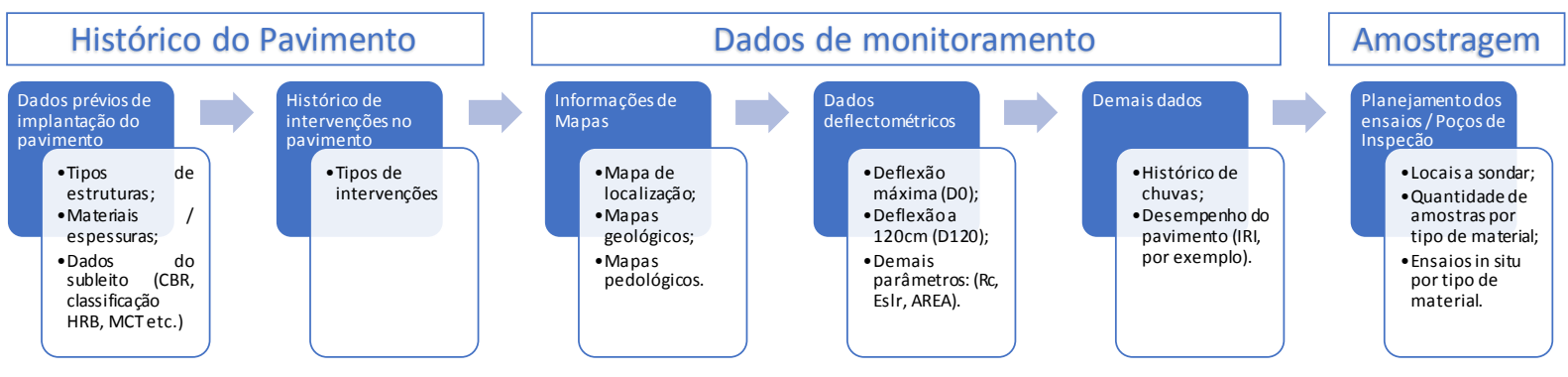

Figura 3.1: Fluxograma idealizado para determinação dos locais a sondar
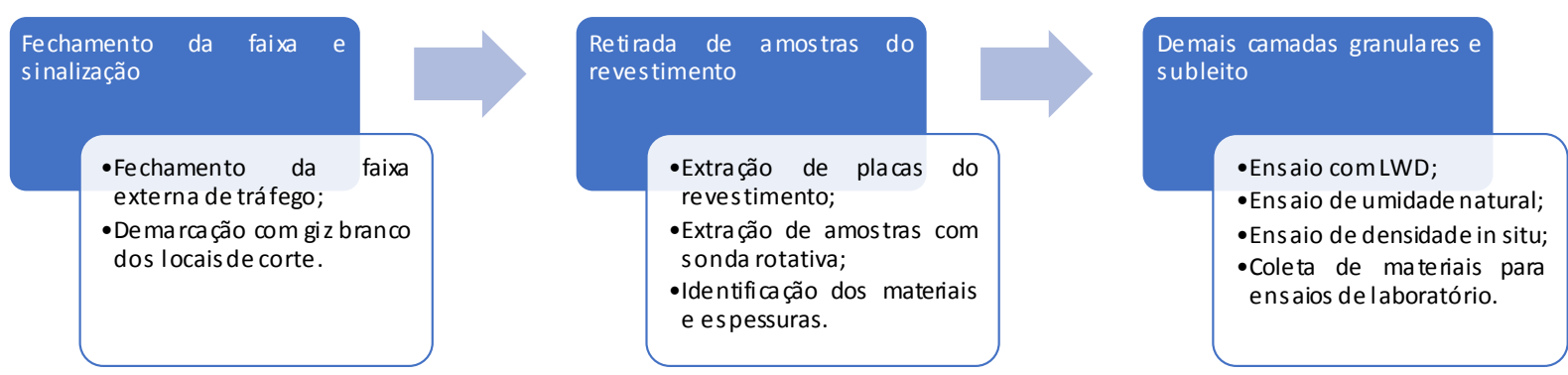

Figura 3.2: Fluxograma dos procedimentos de campo para coleta de amostras ensaios "in situ"

No caso do presente estudo de caso, não se dispunham dos dados históricos do pavimento por se tratar de rodovia antiga, pavimentada nos anos 50 , com diferentes manutenções, alargamentos e duplicações. Deve se ressaltar que grande parte das rodovias brasileiras não possuem dados sobre os pavimentos ou As Built. Assim sendo, para o início dos estudos partiu-se da etapa de coleta de dados de monitoramento. Mais adiante serão dados mais detalhes das etapas que configuraram o presente estudo de caso.

\subsection{Procedimento adotado para seleção dos pontos de análise}

Foram estudados os resultados de monitoração da rodovia em estudo para a seleção de locais em potencial de análise.

Com base na avaliação estrutural do pavimento com o equipamento FWD - Falling Weight Deflectometer, constatou-se que existe grande heterogeneidade de comportamento dos indicadores estruturais ao longo de todo o segmento estudado 
( $D 0$ - deflexão máxima; $D 120$ - deflexão a $120 \mathrm{~cm}$ de distância do ponto de aplicação de carga; $R C$ - Raio de curvatura). Assim sendo, buscaram-se por classificações que conseguissem agrupar o comportamento mecânico da estrutura do pavimento, bem como do subleito, de modo que se possa realizar uma amostragem bem equilibrada, abordando os diferentes "grupos" observados. Identificou-se na literatura correlata o indicador "parâmetro AREA" como sendo um bom indicador da rigidez global da estrutura.

O parâmetro AREA (ou $A R E A / D O$ ) é definido pelo guia de dimensionamento da AASHTO de 1993, e foi originalmente concebido para a avaliação de pavimentos rígidos e retroanálise dos valores de módulo de reação do subleito ( $k$-value) e de módulo de elasticidade do concreto (Epcc). Sua medida equivale à largura virtual que, multiplicada pelo valor da deflexão máxima, resulte na área aproximada da bacia deflectométrica. A expressão para cálculo é a seguinte:

$$
A R E A=15 \cdot\left[1+2 \cdot \frac{D_{30}}{D_{0}}+2 \cdot \frac{D_{60}}{D_{0}}+\frac{D_{90}}{D_{0}}\right]
$$

Onde:

$A R E A$ = parâmetro $A R E A, c m ; D 0, D 30, D 60$ e $D 90$ = Deflexões às distâncias 0,30 , 60 e $90 \mathrm{~cm}$ respectivamente, do ponto de aplicação da carga, em 0,01 $\mathrm{mm}$.

O valor numérico máximo que o parâmetro área pode atingir é aproximadamente $90 \mathrm{~cm}$ e isso ocorrerá quando as medidas de deflexões $D 0, D 30, D 60$ e $D 90$ forem iguais, embora na prática isto não aconteça, mas matematicamente é o limite. As quatro deflexões iguais ou aproximadamente idênticas numericamente indicam uma estrutura extremamente rígida, semelhante à dos pavimentos de concreto de cimento Portland ou pavimentos asfálticos espessos e de elevado módulo de resiliência.

O mínimo valor do parâmetro área é da ordem de $28 \mathrm{~cm}$ e corresponde ao valor determinado para um sistema elástico constituído de apenas uma camada. Isto pode ocorrer quando se efetua o levantamento deflectométrico sobre o topo do subleito, ou seja, analisa-se um semi-espaço infinito. A Tabela 3.1 ilustra a faixa de valores do parâmetro AREA para alguns tipos de pavimentos segundo o WSDOT (2005). 
O segundo critério utilizado será o módulo de resiliência do subleito retroanalisado a partir do valor de $D 120$ - deflexão medida a $120 \mathrm{~cm}$ do centro de aplicação de carga, conforme definido no manual da AASHTO/93 pela equação apresentada a seguir.

$$
M r=C \cdot\left(\frac{0,24 \cdot P}{d_{r} \cdot r}\right)
$$

Onde:

$C=$ fator de correção do módulo de resiliência do subleito $(0,33) ; M R=$ módulo de resiliência do subleito retroanalisado (psi); $P=$ carga aplicada, libras; $d r=$ deflexão medida a uma distância radial $r$ (pol.); $r$ = distância radial em que é realizada a medida (pol.).

Ressalta-se que foi escolhido o valor da deflexão a $120 \mathrm{~cm}$ (D120) para o cômputo dos valores dos módulos de subleito por retroanálise por se tratar de ser o geofones mais afastado do ponto de aplicação de carga nos ensaios realizados com FWD.

\begin{tabular}{|c|c|}
\hline Tipo de Pavimento & $\begin{array}{c}\text { Parâmetro } \\
\text { AREA } \\
\text { (cm) }\end{array}$ \\
\hline Pavimento de Concreto - CCP & $60-90$ \\
\hline $\begin{array}{l}\text { Asfálticos espessos - } \\
\text { Revestimento em CA }>12 \mathrm{~cm}\end{array}$ & $55-75$ \\
\hline Asfálticos delgados & $40-55$ \\
\hline Flexíveis "fracos" & $28-40$ \\
\hline
\end{tabular}

Ainda será utilizado um terceiro indicador para diferenciar a condição estrutural do pavimento nos locais a serem amostrados, o raio de curvatura ( $R C$ ). A expressão de cálculo utilizada para a determinação do raio de curvatura é aquela preconizada pelo DNIT em seu Método de Ensaio DNER-ME-024/94.

O raio de curvatura é um parâmetro indicativo do arqueamento da bacia de deformações na sua porção mais crítica, em geral considerada a $25 \mathrm{~cm}$ do centro da 
carga. A norma DNER PRO11/79, que preconiza procedimentos de cálculo de reforço estrutural para reabilitação de pavimentos asfálticos, estabelece que raios de curvaturas baixos (menores que $100 \mathrm{~m}$ ) indicam condições estruturais críticas da estrutura do pavimento, no caso de pavimentos asfálticos flexíveis.

O cálculo do raio de curvatura em metros é realizado através da expressão indicada a seguir.

$$
R_{C}=\frac{6250}{2 \times\left(D_{0}-D_{25}\right)}
$$

Onde:

$D_{0}=$ Deslocamento vertical recuperável no ponto de aplicação de carga (em $\left.10^{-2} \mathrm{~mm}\right)$;

$D_{25}=$ Deslocamento vertical recuperável distante $25 \mathrm{~cm}$ do ponto de aplicação de carga (em 10-2 $\mathrm{mm}$ ).

Com base na metodologia apresentada, propôs-se inicialmente, para o presente estudo, o plano de amostragem apresentado na Tabela 3.2. 
Tabela 3.2: Plano de amostragem inicialmente proposto

\begin{tabular}{|c|c|c|c|c|c|}
\hline $\begin{array}{l}\text { Classificação } \\
\text { Parâmetro AREA } \\
\text { (WSDOT, 2005) }\end{array}$ & $\begin{array}{l}\text { Intervalo do } \\
\text { parâmetro } \\
\text { AREA (cm) } \\
\text { (WSDOT, } \\
\text { 2005) }\end{array}$ & $\begin{array}{l}\text { Classificação } \\
\text { Subleito }\end{array}$ & $\begin{array}{l}\text { Intervalo de } \\
\text { Esl, retro } \\
(M P a)\end{array}$ & $\begin{array}{c}\text { Intervalo de } \\
\text { Rc } \\
\text { (m) }\end{array}$ & $\begin{array}{c}\text { Quantidade } \\
\text { de } \\
\text { Amostras }\end{array}$ \\
\hline \multirow{7}{*}{ Flexível fraco } & \multirow{7}{*}{$28-40$} & \multirow{3}{*}{ Fraco } & \multirow{3}{*}{$10-50$} & $20-200$ & 1 \\
\hline & & & & $200-600$ & 1 \\
\hline & & & & $600-5000$ & 1 \\
\hline & & Mediano & $50-150$ & $20-5000$ & - \\
\hline & & \multirow{3}{*}{ Forte } & \multirow{3}{*}{$150-500$} & $20-100$ & 1 \\
\hline & & & & $100-500$ & 1 \\
\hline & & & & $500-2000$ & 1 \\
\hline \multirow{7}{*}{ Asfáltico delgado } & \multirow{7}{*}{$40-55$} & \multirow{3}{*}{ Fraco } & \multirow{3}{*}{$10-50$} & $20-200$ & 1 \\
\hline & & & & $200-600$ & 1 \\
\hline & & & & $600-5000$ & 1 \\
\hline & & Mediano & $50-150$ & $20-2000$ & - \\
\hline & & \multirow{3}{*}{ Forte } & \multirow{3}{*}{$150-500$} & $20-200$ & 1 \\
\hline & & & & $200-600$ & 1 \\
\hline & & & & $600-5000$ & 1 \\
\hline \multirow{7}{*}{ Asfáltico espesso } & \multirow{7}{*}{$55-75$} & \multirow{3}{*}{ Fraco } & \multirow{3}{*}{$10-50$} & $20-200$ & 1 \\
\hline & & & & $200-600$ & 1 \\
\hline & & & & $600-5000$ & 1 \\
\hline & & Mediano & $50-150$ & $20-2000$ & - \\
\hline & & \multirow{3}{*}{ Forte } & \multirow{3}{*}{$150-500$} & $20-200$ & 1 \\
\hline & & & & $200-600$ & 1 \\
\hline & & & & $600-5000$ & 1 \\
\hline Total & & & & & 18 \\
\hline
\end{tabular}

${ }^{\star}$ Esl, retro: Módulo de resiliência do subleito no momento em que se mediu a bacia de deflexão, obtido por retroanálise

Importante observar que se priorizou a coleta de amostras de subleitos fracos e fortes (extremos) para poder analisar se esta característica é ou não relevante no comportamento estrutural dos pavimentos e também para se investigar as causas de tais variações de comportamento na infraestrutura. 


\subsection{Seleção de pontos e localização dos poços de inspeção realizados}

No presente estudo de caso, não se dispunham dos dados históricos do pavimento, como já citado anteriormente. Assim sendo, partiram-se dos dados de levantamento deflectométrico, procurando-se priorizar os subleitos de comportamento forte e fraco (extremos), tal como apresentado na Tabela 3.2.

No momento da seleção dos pontos de acordo com a metodologia proposta na Tabela 3.2, verificou-se que algumas das situações idealizadas para coleta não foram encontradas no campo.

Desta maneira, derivou-se para uma classificação mais simples, conforme apresentado na tabela a seguir.

Tabela 3.3: Classificação adotada para o plano de amostragem dos estudos

\begin{tabular}{|c|c|c|c|c|}
\hline \multicolumn{2}{|c|}{$\begin{array}{l}\text { Módulo do Subleito } \\
\text { (MPa) }\end{array}$} & \multicolumn{2}{|c|}{$\begin{array}{l}\text { Raio de Curvatura } \\
\qquad(\mathrm{m})\end{array}$} & \multirow[t]{2}{*}{ Classificação } \\
\hline Mín. & Máx. & Mín. & Máx. & \\
\hline & & 20 & 200 & 1 \\
\hline \multirow[t]{3}{*}{10} & 50 & 200 & 600 & 2 \\
\hline & & 600 & 5.000 & 3 \\
\hline & & 20 & 200 & 4 \\
\hline \multirow[t]{3}{*}{50} & 150 & 200 & 600 & 5 \\
\hline & & 600 & 5.000 & 6 \\
\hline & & 20 & 200 & 7 \\
\hline \multirow[t]{2}{*}{150} & 500 & 200 & 600 & 8 \\
\hline & & 600 & 5.000 & 9 \\
\hline
\end{tabular}

Os dados dos locais selecionados, com base no critério ilustrado acima, são apresentados na Tabela 3.4 a seguir. As deflexões de campo foram previamente corrigidas (normalizadas) para a carga padrão do ensaio de $4.200 \mathrm{kgf}$. 
Tabela 3.4 Locais selecionados para os ensaios de acordo com o plano de amostragem adotado nos estudos

\begin{tabular}{|c|c|c|c|c|c|c|c|c|c|c|c|c|c|}
\hline \multirow[b]{2}{*}{ km } & \multirow[b]{2}{*}{ PISTA } & \multicolumn{7}{|c|}{ Deflexões corrigidas (carga) $(0,01 \mathrm{~mm})$} & \multicolumn{5}{|c|}{ Indicadores } \\
\hline & & Do & D20 & D30 & D45 & D60 & D90 & D120 & $\begin{array}{c}R \\
(m)\end{array}$ & $\begin{array}{c}\text { D0-D45 } \\
(0,01 \\
\mathrm{mm}) \\
\end{array}$ & $\begin{array}{c}\text { Área/ } \\
\text { D0 } \\
(\mathrm{cm})\end{array}$ & $\begin{array}{c}\text { Esl,retro } \\
\text { (MPa) }\end{array}$ & Classif. \\
\hline 402 & NORTE & 19 & 15 & 13 & 13 & 12 & 10 & 8 & 665 & 6 & 63 & 35,0 & 3 \\
\hline 405 & NORTE & 40 & 26 & 18 & 10 & 7 & 5 & 4 & 173 & 30 & 36 & 66,9 & 4 \\
\hline 413 & NORTE & 40 & 30 & 24 & 20 & 13 & 9 & 6 & 253 & 20 & 47 & 43,3 & 2 \\
\hline 418 & NORTE & 49 & 34 & 27 & 16 & 12 & 8 & 5 & 165 & 33 & 41 & 52,6 & 4 \\
\hline 423 & NORTE & 16 & 14 & 13 & 12 & 11 & 9 & 7 & 1.163 & 4 & 67 & 37,8 & 3 \\
\hline 429 & NORTE & 78 & 57 & 42 & 31 & 20 & 13 & 8 & 113 & 47 & 41 & 31,3 & 1 \\
\hline 431 & NORTE & 43 & 30 & 22 & 15 & 9 & 5 & 3 & 187 & 28 & 39 & 90,7 & 4 \\
\hline 434 & NORTE & 68 & 53 & 42 & 31 & 19 & 11 & 7 & 156 & 37 & 45 & 39,9 & 1 \\
\hline 456 & NORTE & 19 & 13 & 10 & 7 & 5 & 4 & 3 & 432 & 11 & 43 & 88,4 & 5 \\
\hline 460 & NORTE & 13 & 9 & 6 & 4 & 3 & 2 & 1 & 595 & 9 & 37 & 215,2 & 8 \\
\hline 521 & NORTE & 17 & 8 & 5 & 3 & 2 & 2 & 1 & 283 & 14 & 29 & 182,7 & 8 \\
\hline 523 & NORTE & 5 & 2 & 2 & 1 & 1 & 1 & 1 & 1.074 & 3 & 35 & 422,9 & 9 \\
\hline 477 & SUL & 39 & 28 & 18 & 11 & 6 & 3 & 2 & 190 & 28 & 34 & 116,9 & 4 \\
\hline 482 & SUL & 9 & 7 & 6 & 5 & 5 & 4 & 4 & 1.257 & 4 & 60 & 70,9 & 6 \\
\hline 492 & SUL & 7 & 5 & 4 & 4 & 4 & 3 & 2 & 1.324 & 3 & 55 & 164,0 & 9 \\
\hline
\end{tabular}

Com base no critério acima, os poços de inspeção (PIs) foram realizados no pavimento existente da rodovia federal em estudo, a BR 116, denominada neste trecho de Rodovia Régis Bittencourt, entre os municípios de Miracatu e Barra do Turvo no estado de São Paulo. A Figura 3.3 a seguir apresenta a localização dos pontos de sondagens (poços de inspeção no pavimento existente) e a Figura 3.4 apresenta o mapeamento geológico dos locais sondados. 


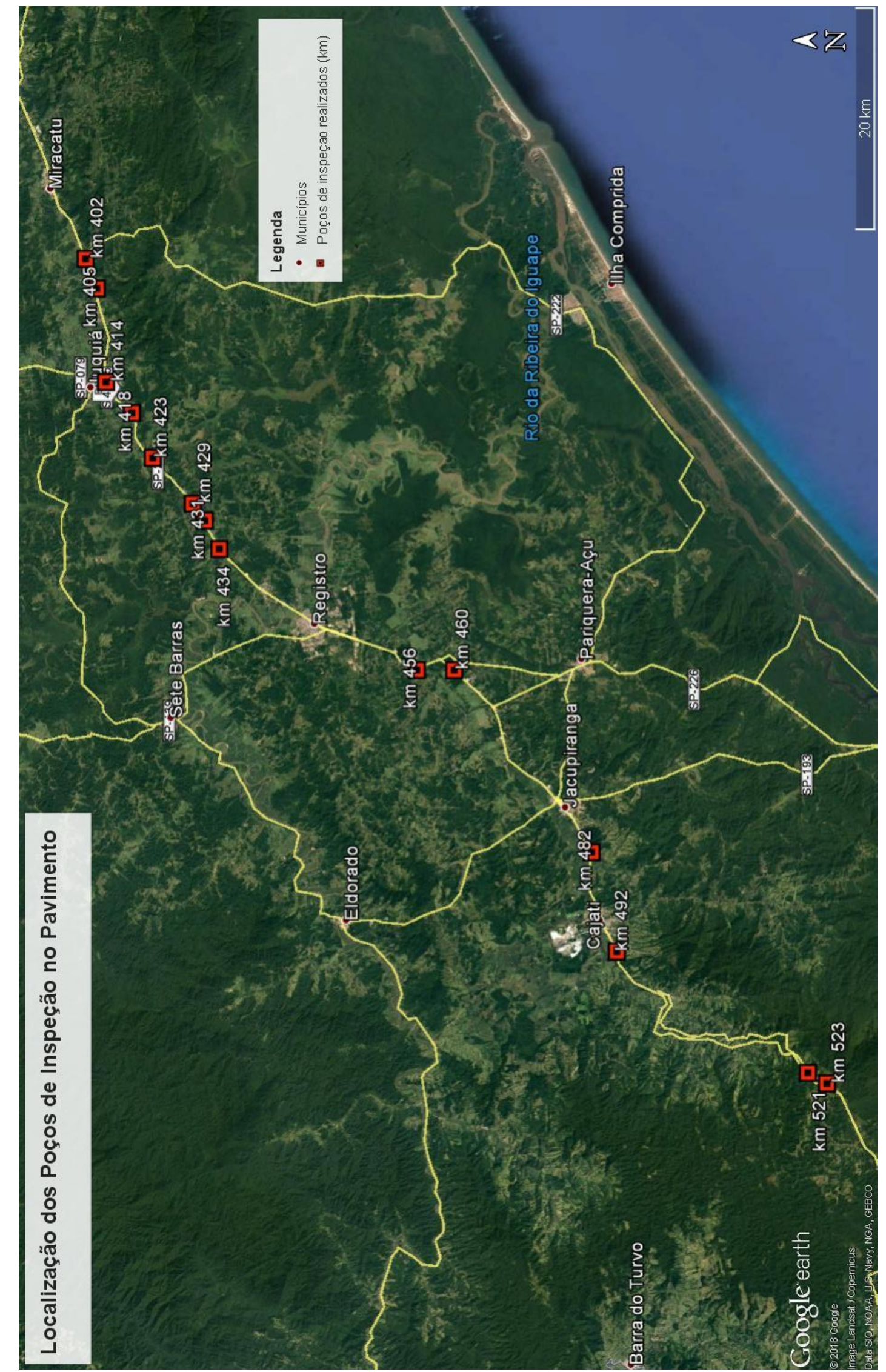

Figura 3.3: Localização dos poços de inspeção realizados em pavimento da rodovia federal em estudo 


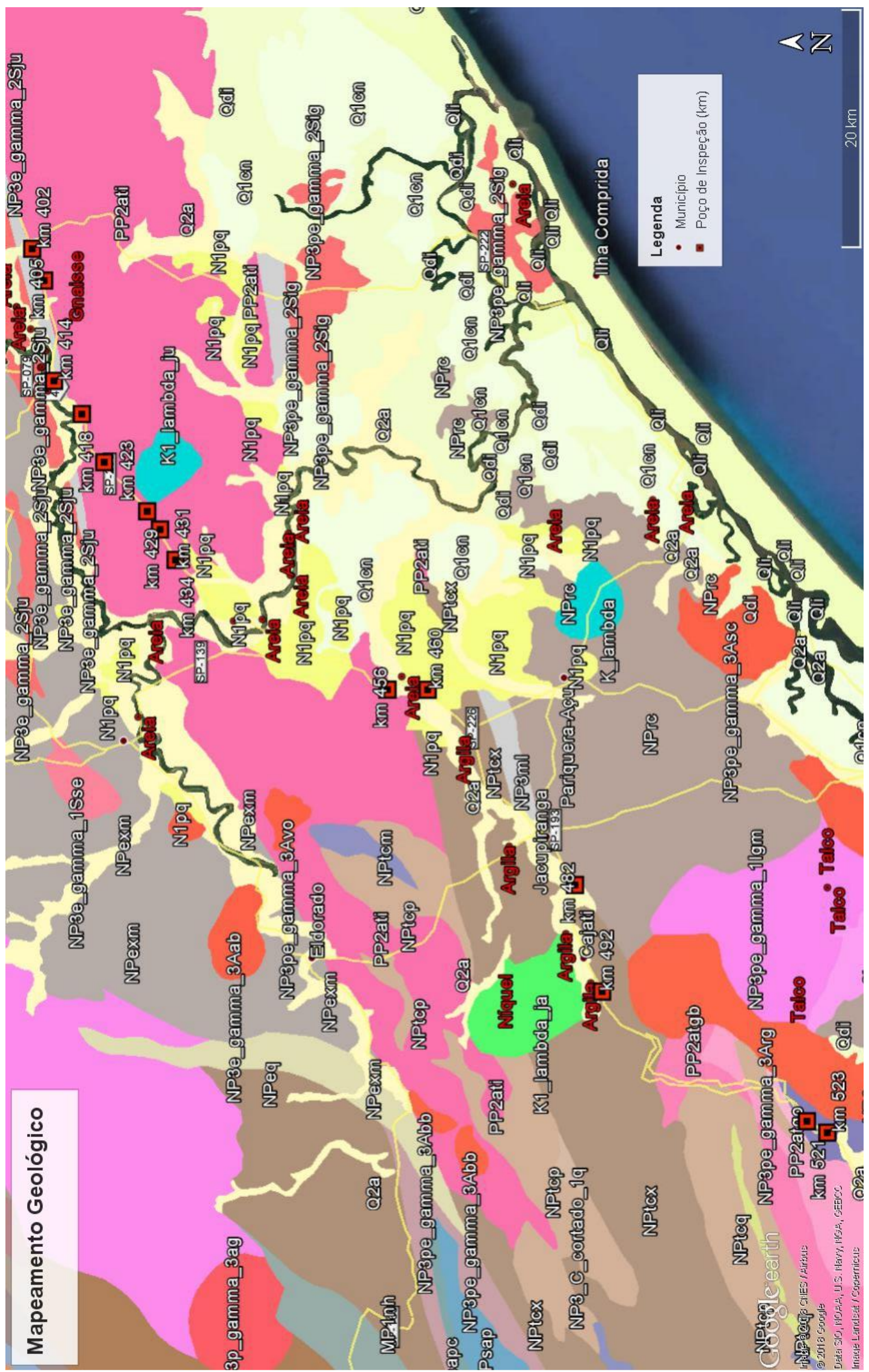

Figura 3.4: Mapeamento Geológico da região onde foram realizados os poços de inspeção 


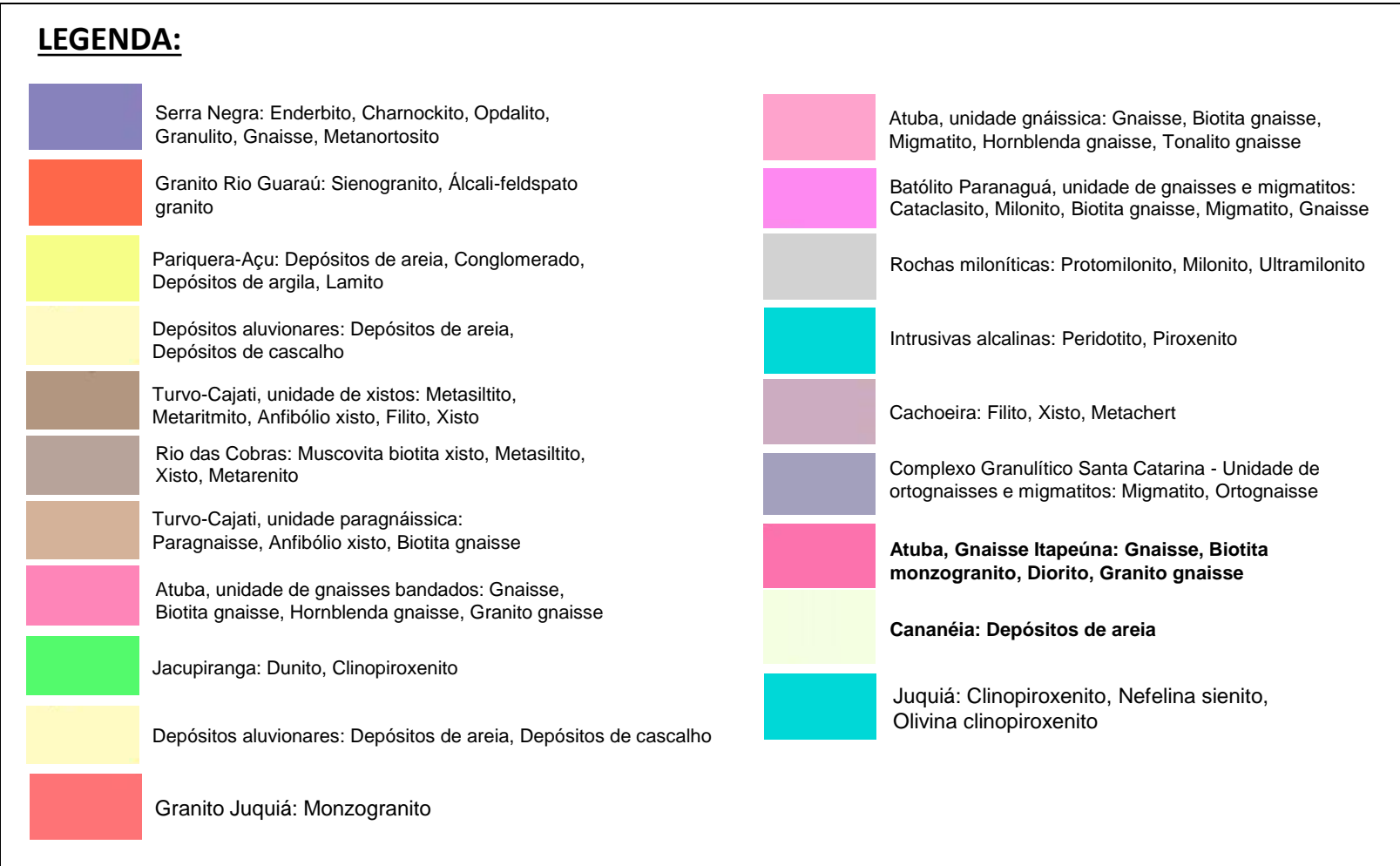

Figura 3.5: Legenda para o mapa geológico da Erro! Fonte de referência não encontrada.

Maiores detalhes de localização de cada ponto são apresentados no ANEXO A RESULTADOS INDIVIDUAIS DAS SONDAGENS E ENSAIOS - ESTUDO DE CASO DE UMA RODOVIA FEDERAL. 


\subsection{Procedimento de abertura dos poços de inspeção}

O procedimento estabelecido para abertura dos poços de inspeção, realização de ensaios in situ e coleta de amostras para ensaios de laboratório é apresentado na sequência.

\section{Procedimentos de campo:}

a) Realizar o fechamento da faixa externa de rolamento na área de interferência do ponto de coleta e sinalizar adequadamente o desvio do tráfego.

b) Fazer o registro fotográfico de todas as etapas do trabalho.

c) Realizar a demarcação, com giz branco, do local de corte para retirada das amostras em placa e cilíndricas. A demarcação deverá ser realizada na faixa de rolamento externa da rodovia no quilômetro exato programado, conforme indicações da Figura 3.6. No pavimento a ser inspecionado, deverão anotados com giz, o marco quilométrico da via, e a numeração das placas, previamente ao início do registro fotográfico. O poço deverá ter medida aproximada de $0,60 \times 0,90 \mathrm{~m}$ (ver Figura 3.6). As placas devem ter medida aproximada de $0,30 \times 0,60 \mathrm{~m}$ (ver Figura 3.6).

d) Realizar sondagem com equipamento de corte rotativo, com diâmetro de 4", imediatamente ao lado da demarcação da janela de inspeção, para coleta das amostras cilíndricas dos materiais do pavimento. A profundidade total de descida da sonda rotativa deve ultrapassar em $5 \mathrm{~cm}$ a espessura da camada a ser extraída, garantindo-se que não ocorra quebra da amostra em ponto intermediário da camada (total de 10 amostras).

e) Realizar corte vertical da camada de revestimento com utilização de equipamento de corte adequado que não danifique o material, para retirada deste em formato de placa ( 3 placas de 0,30x0,60m). Armazenar adequadamente o material para ensaio laboratorial. 
f) Após a retirada de cada camada, posicionar na janela de inspeção, trena para medição das espessuras das camadas e registrar com câmera fotográfica, conforme descrito no item 2 .

g) A depender do tipo de material encontrado na camada subjacente, realizar os ensaios e coletas respectivos, conforme indicado na Tabela 3.5.

h) Em todas as camadas granulares, compostas por materiais pétreos, estabilizados ou solos de reforço e subleito, deverá ser realizado ensaio com LWD.

i) Proceder ao fechamento do poço, com reposição dos materiais, recompactação e fechamento com material asfáltico.

j) Embalar e identificar corretamente as amostras coletadas de cada camada do pavimento inspecionado.

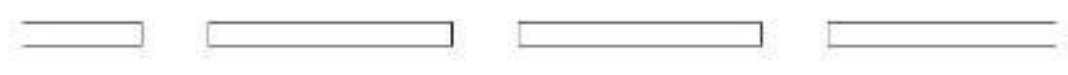

FAIXA DE ROLAMENTO EXTERNA

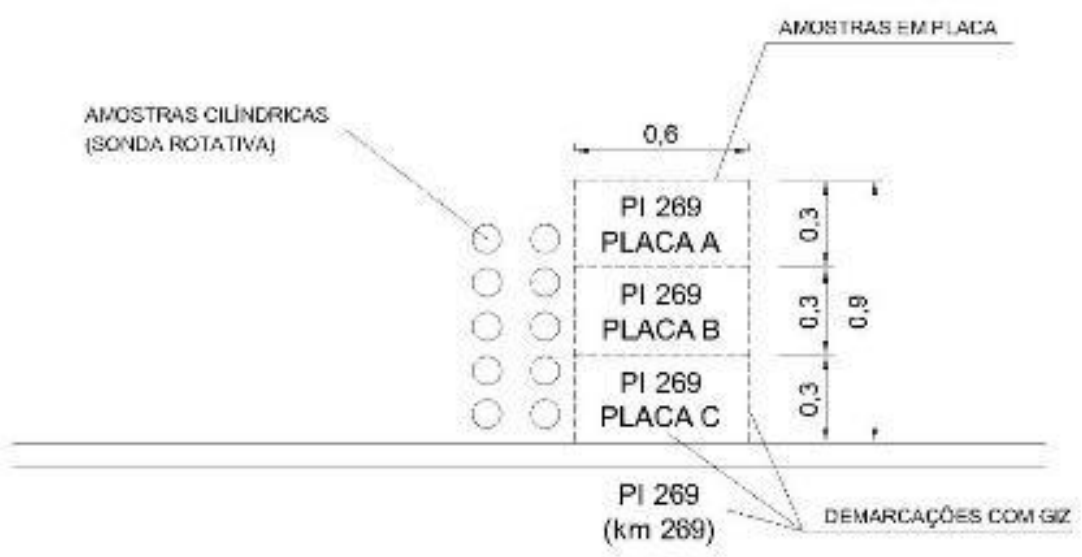

ACOSTAMENTO

Figura 3.6: Diretrizes para abertura dos poços de inspeção e coleta de amostras da pista 
Tabela 3.5: Diretrizes para coleta de amostras para ensaios de laboratório

\begin{tabular}{|c|c|c|c|}
\hline Material & $\begin{array}{l}\text { Procedimento de Campo / Ensaio "in } \\
\text { situ" }\end{array}$ & $\begin{array}{l}\text { Tipo de } \\
\text { amostra }\end{array}$ & Ensaio de Laboratório \\
\hline \multirow{10}{*}{$\begin{array}{c}\text { Materiais pétreos, } \\
\text { estabilizados ou } \\
\text { solos de } \\
\text { reforço/subleito }\end{array}$} & Registro fotográfico & \multirow{5}{*}{-} & \multirow{5}{*}{-} \\
\hline & LWD (regularizar a camada) & & \\
\hline & Umidade natural - frigideira & & \\
\hline & Umidade natural (coleta para ensaio em estufa) & & \\
\hline & Densidade natural - funil e areia & & \\
\hline & \multirow{5}{*}{ Coleta de amostra } & \multirow{5}{*}{$\begin{array}{l}\text { Deformada } \\
\quad(>50 \mathrm{~kg})\end{array}$} & granulometria \\
\hline & & & índices físicos (LL e LP) \\
\hline & & & compactação e CBR \\
\hline & & & módulo de resiliência \\
\hline & & & MCT (pastilha) \\
\hline
\end{tabular}

A Figura 3.7 exemplifica a sequência completa dos procedimentos realizados em campo em um dos locais programados para no presente estudo de caso. A legenda das etapas é apresentada na Tabela 3.6.

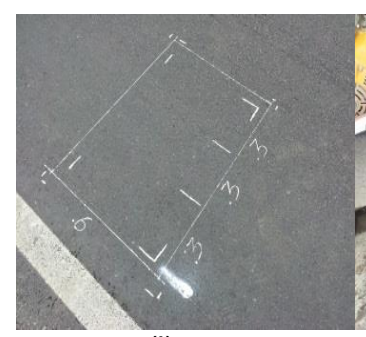

(i)

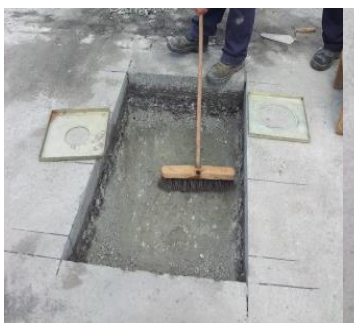

(v)

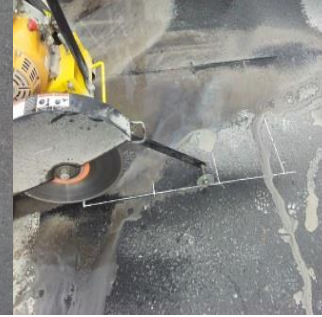

(ii)

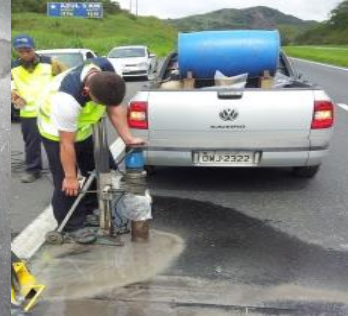

(iii)

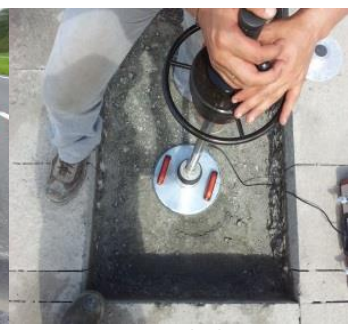

(iv)

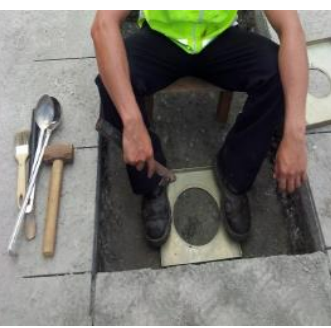

(vi)

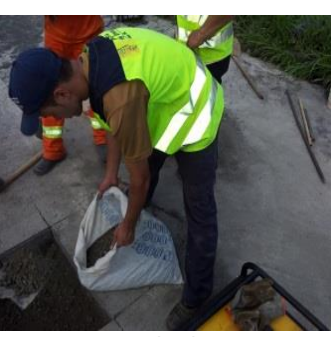

(vii)

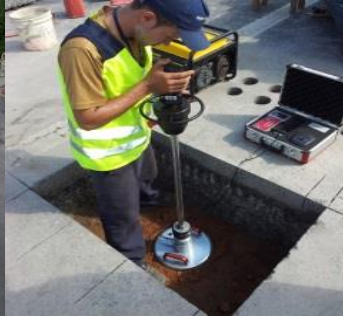

(viii)

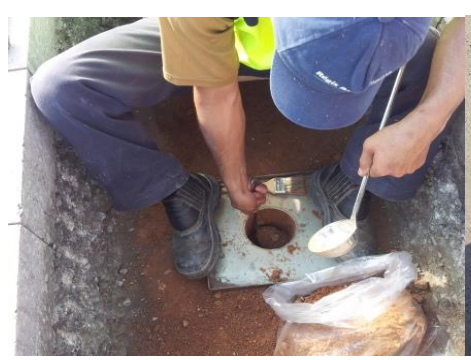

(ix)

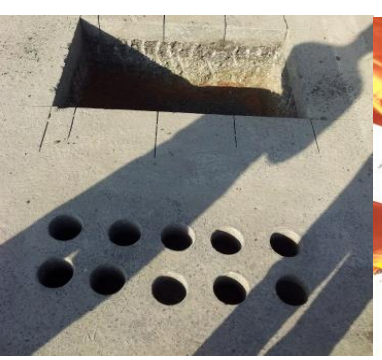

$(\mathrm{x})$

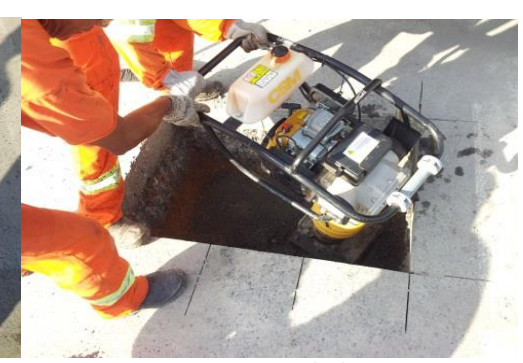

(xi)

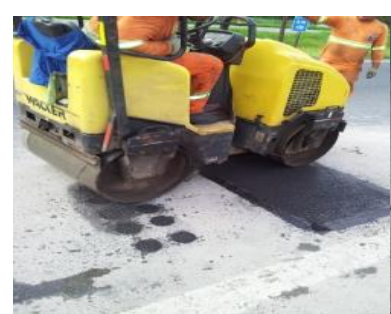

(xii)

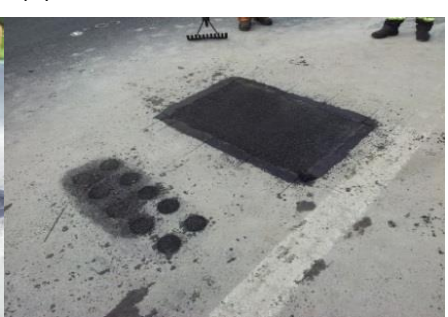

(xiii)

Figura 3.7: Sequência dos procedimentos de campo para realização do presente estudo de caso 
Tabela 3.6: Legenda de descrição das etapas indicadas na Figura 3.7

\begin{tabular}{|c|c|c|c|}
\hline Sequência & Descrição & Sequência & Descrição \\
\hline (i) & Marcação para abertura das janelas & (viii) & Ensaio LWD da camada subjacente \\
\hline (ii) & Corte das placas & (ix) & Ensaio de massa especifica na camada subjacente \\
\hline (iii) & Extração de corpos de prova & $(x)$ & Placas e corpos de prova extraídos \\
\hline (iv) & Ensaio LWD na camada de BGS & $(\mathrm{xi})$ & Fechamento com a primeira camada de BGS \\
\hline (v) & Limpeza da camada & (xii) & Fechamento final com CBUQ \\
\hline (vi) & Ensaio de massa especifica na camada de BGS & (xiii) & Trabalho concluído \\
\hline (vii) & Coleta de amostras & & \\
\hline
\end{tabular}

\subsection{Estruturas de pavimento identificadas nos Pls}

As estruturas identificadas na faixa externa de rolamento das pistas sul (quilometragem crescente) e norte (quilometragem decrescente) são apresentadas na Tabela 3.7 a seguir. Foram identificadas estruturas de pavimentos flexíveis convencionais, pavimentos semirrígidos e pavimentos flexíveis com base betuminosa.

Ressalta-se que nos poços de inspeção dos km 477 (sul), km 521 (norte) e km 523 (norte) não foram coletadas amostras para ensaios de laboratório por dificuldades diversas na extração das amostras do subleito existente. 
Tabela 3.7: Estruturas de pavimento identificadas

\begin{tabular}{|c|c|c|c|c|}
\hline km & Pista & Camada & $\begin{array}{c}\text { Espessura } \\
\text { (cm) }\end{array}$ & Camada \\
\hline \multirow{4}{*}{414} & \multirow{4}{*}{ Sul } & 1 & 11,0 & $\mathrm{CA}$ \\
\hline & & 2 & 27,0 & BASE BETUMINOSA \\
\hline & & 3 & 40,0 & SOLO-BRTA \\
\hline & & 4 & - & SL \\
\hline \multirow{3}{*}{477} & \multirow{3}{*}{ Sul } & 1 & 15,0 & $\mathrm{CA}$ \\
\hline & & 2 & 25,0 & BGS \\
\hline & & 3 & - & $\mathrm{RACHÃO}$ \\
\hline \multirow{3}{*}{482} & \multirow{3}{*}{ Sul } & 1 & 13,0 & $\mathrm{CA}$ \\
\hline & & 2 & 52,0 & BASE BETUMINOSA \\
\hline & & 3 & - & SL \\
\hline \multirow{3}{*}{492} & \multirow{3}{*}{ Sul } & 1 & 14,0 & $\mathrm{CA}$ \\
\hline & & 2 & 40,0 & BASE BETUMINOSA \\
\hline & & 3 & - & SL \\
\hline \multirow{4}{*}{402} & \multirow{4}{*}{ Norte } & 1 & 13,0 & CA \\
\hline & & 2 & 19,0 & BGTC \\
\hline & & 3 & 16,0 & BGS \\
\hline & & 4 & - & SL \\
\hline \multirow{3}{*}{405} & \multirow{3}{*}{ Norte } & 1 & 14,0 & CA \\
\hline & & 2 & 26,0 & BGS \\
\hline & & 3 & - & $\mathrm{SL}$ \\
\hline \multirow{4}{*}{418} & \multirow{4}{*}{ Norte } & 1 & 14,0 & $\mathrm{CA}$ \\
\hline & & 2 & 10,0 & RAP C/ EMULSÃO \\
\hline & & 3 & 25,0 & BGS \\
\hline & & 4 & - & SL \\
\hline \multirow{4}{*}{423} & \multirow{4}{*}{ Norte } & 1 & 10,0 & $\mathrm{CA}$ \\
\hline & & 2 & 20,0 & BGTC \\
\hline & & 3 & 20,0 & BGS \\
\hline & & 4 & - & SL \\
\hline \multirow{4}{*}{429} & \multirow{4}{*}{ Norte } & 1 & 10,0 & $\mathrm{CA}$ \\
\hline & & 2 & 8,0 & RAP C/ EMULSÃO \\
\hline & & 3 & 22,0 & BGS \\
\hline & & 4 & - & SL \\
\hline \multirow{4}{*}{431} & & 1 & 13,0 & $\mathrm{CA}$ \\
\hline & Norte & 2 & 18,0 & BGTC \\
\hline & Norte & 3 & 11,0 & BGS \\
\hline & & 4 & - & SL \\
\hline & & 1 & 13,0 & $\mathrm{CA}$ \\
\hline & & 2 & 10,0 & CAM. CIMENTADA* \\
\hline 434 & Norte & 3 & 18,0 & BGS \\
\hline & & 4 & - & SL \\
\hline & & 1 & 12,0 & $\mathrm{CA}$ \\
\hline & & 2 & 7,0 & BASE BETUMINOSA \\
\hline 456 & Norte & 3 & 17,0 & BGTC \\
\hline & & 4 & 18,0 & BGS \\
\hline & & 5 & - & SL \\
\hline & & 1 & 19,0 & $\mathrm{CA}$ \\
\hline 460 & Norte & 2 & 40,0 & BGS \\
\hline & & 3 & - & SL \\
\hline & & 1 & 15,0 & $\mathrm{CA}$ \\
\hline 521 & Norte & 2 & 44,0 & BASE BETUMINOSA \\
\hline & & 3 & - & SL \\
\hline & & 1 & 16,0 & $\mathrm{CA}$ \\
\hline 523 & Norte & 2 & 70,0 & BASE BETUMINOSA \\
\hline & & 3 & - & SL \\
\hline
\end{tabular}

Onde: $C A$ - concreto asfáltico; BGS - brita graduada simples; RAP C/ EMULSÃO Mistura de agregado de concreto asfáltico reciclado e emulsão asfáltica; BGTC - brita graduada tratada com cimento; $S L$ - subleito. 


\subsection{Resultados dos ensaios com LWD (Light Weight Deflectometer)}

Na sequência da abertura dos poços de inspeção, foram realizados ensaios com $L W D$ nas camadas de sub-base granulares e subleito. Os resultados são apresentados na Tabela 3.8 e Tabela 3.9 a seguir.

Tabela 3.8: Resultados dos ensaios de módulo obtidos com uso do equipamento $L W D$

\begin{tabular}{|c|c|c|c|c|c|c|c|c|c|c|c|c|c|}
\hline \multirow{2}{*}{ km } & \multirow{2}{*}{ PISTA } & \multirow{2}{*}{ Material } & \multirow{2}{*}{ Ponto } & \multirow{2}{*}{ Ensaio } & \multicolumn{4}{|c|}{ Leituras $\mathrm{D}_{0, L W D}\left(10^{-2} \mathrm{~m} \mathrm{~m}\right)$} & \multirow{2}{*}{$\begin{array}{l}\mathrm{E}_{0, \text { equip }} \\
\text { (MPa) }\end{array}$} & \multicolumn{4}{|c|}{$\begin{array}{c}\mathrm{E}_{0, \text { calc }} \\
(\mathrm{MPa})\end{array}$} \\
\hline & & & & & 1 & 2 & 3 & Média & & 1 & 2 & 3 & Média \\
\hline 402 & NORTE & SL & 1 & 1 & 40 & 39 & 36 & 38 & 59 & 57 & 59 & 64 & 60 \\
\hline 402 & NORTE & SL & 2 & 1 & 67 & 62 & 62 & 64 & 35 & 34 & 36 & 37 & 36 \\
\hline 402 & NORTE & SL & 3 & 1 & 34 & 35 & 34 & 34 & 65 & 66 & 65 & 67 & 66 \\
\hline 405 & NORTE & $\mathrm{SL}$ & 1 & 1 & 35 & 34 & 34 & 34 & 66 & 64 & 67 & 67 & 66 \\
\hline 405 & NORTE & SL & 2 & 1 & 87 & 81 & 83 & 84 & 27 & 26 & 28 & 27 & 27 \\
\hline 405 & NORTE & SL & 3 & 1 & 49 & 49 & 43 & 47 & 48 & 47 & 47 & 52 & 48 \\
\hline 414 & SUL & SL & 1 & 1 & 62 & 51 & 48 & 54 & 42 & 36 & 45 & 47 & 43 \\
\hline 414 & SUL & SL & 2 & 1 & 12,7 & 61 & 58 & 60 & 28 & 179 & 37 & 39 & 85 \\
\hline 414 & SUL & SL & 3 & 1 & 12,0 & 62 & 57 & 59 & 28 & 189 & 37 & 40 & 88 \\
\hline 418 & NORTE & SL & 1 & 1 & 39 & 38 & 36 & 38 & 60 & 58 & 60 & 63 & 60 \\
\hline 418 & NORTE & SL & 1 & 2 & 43 & 35 & 32 & 36 & 62 & 53 & 66 & 70 & 63 \\
\hline 418 & NORTE & $\mathrm{SL}$ & 2 & 1 & 35 & 34 & 32 & 34 & 67 & 65 & 67 & 71 & 68 \\
\hline 418 & NORTE & $\mathrm{SL}$ & 2 & 2 & 31 & 30 & 30 & 30 & 74 & 73 & 75 & 76 & 75 \\
\hline 418 & NORTE & $\mathrm{SL}$ & 3 & 1 & 88 & 97 & 91 & 92 & 24 & 26 & 23 & 25 & 25 \\
\hline 418 & NORTE & $\mathrm{SL}$ & 3 & 2 & 92 & 93 & 93 & 92 & 24 & 25 & 24 & 24 & 25 \\
\hline 423 & NORTE & $\mathrm{SL}$ & 1 & 1 & 71 & 70 & 71 & 71 & 32 & 32 & 33 & 32 & 32 \\
\hline 423 & NORTE & $\mathrm{SL}$ & 1 & 2 & 66 & 67 & 63 & 65 & 35 & 34 & 34 & 36 & 35 \\
\hline 423 & NORTE & SL & 2 & 1 & 80 & 89 & 95 & 88 & 26 & 29 & 26 & 24 & 26 \\
\hline 423 & NORTE & $\mathrm{SL}$ & 2 & 2 & 97 & 95 & 97 & 96 & 23 & 23 & 24 & 23 & 24 \\
\hline 423 & NORTE & SL & 3 & 1 & 73 & 74 & 75 & 74 & 31 & 31 & 31 & 30 & 31 \\
\hline 423 & NORTE & SL & 3 & 2 & 77 & 88 & 86 & 84 & 27 & 29 & 26 & 26 & 27 \\
\hline 429 & NORTE & $\mathrm{SL}$ & 1 & 1 & 25 & 25 & 25 & 25 & 91 & 91 & 93 & 91 & 91 \\
\hline 429 & NORTE & SL & 1 & 2 & 24 & 23 & 23 & 23 & 97 & 96 & 99 & 98 & 97 \\
\hline 429 & NORTE & $\mathrm{SL}$ & 2 & 1 & 33 & 33 & 33 & 33 & 68 & 68 & 70 & 69 & 69 \\
\hline 429 & NORTE & SL & 2 & 2 & 31 & 31 & 30 & 31 & 73 & 73 & 74 & 75 & 74 \\
\hline 429 & NORTE & $\mathrm{SL}$ & 3 & 1 & 29 & 29 & 29 & 29 & 77 & 78 & 78 & 77 & 78 \\
\hline 429 & NORTE & SL & 3 & 2 & 28 & 28 & 28 & 28 & 80 & 81 & 80 & 80 & 81 \\
\hline 431 & NORTE & SL & 1 & 1 & 35 & 35 & 30 & 33 & 66 & 65 & 66 & 75 & 69 \\
\hline 431 & NORTE & SL & 2 & 1 & 34 & 34 & 30 & 33 & 67 & 66 & 67 & 77 & 70 \\
\hline 431 & NORTE & SL & 3 & 1 & 34 & 33 & 30 & 32 & 76 & 67 & 70 & 77 & 71 \\
\hline 434 & NORTE & $\mathrm{SL}$ & 1 & 1 & 46 & 43 & 42 & 44 & 52 & 49 & 53 & 54 & 52 \\
\hline 434 & NORTE & SL & 2 & 1 & 38 & 40 & 39 & 39 & 58 & 60 & 57 & 59 & 59 \\
\hline 434 & NORTE & SL & 3 & 1 & 50 & 39 & 39 & 42 & 53 & 45 & 59 & 59 & 54 \\
\hline 456 & NORTE & SL & 1 & 1 & 22 & 19 & 31 & 24 & 106 & 104 & 119 & 73 & 98 \\
\hline 456 & NORTE & $\mathrm{SL}$ & 2 & 1 & 21 & 18 & 24 & 21 & 123 & 107 & 123 & 96 & 109 \\
\hline 456 & NORTE & SL & 3 & 1 & 21 & 18 & 20 & 19 & 90 & 109 & 130 & 114 & 117 \\
\hline 460 & NORTE & $\mathrm{SL}$ & 1 & 1 & 70 & 69 & 72 & 70 & 36 & 32 & 33 & 31 & 32 \\
\hline 460 & NORTE & $\mathrm{SL}$ & 2 & 1 & 63 & 61 & 60 & 61 & 41 & 36 & 37 & 38 & 37 \\
\hline 460 & NORTE & $\mathrm{SL}$ & 3 & 1 & 65 & 66 & 63 & 65 & 38 & 35 & 34 & 36 & 35 \\
\hline 482 & SUL & $\mathrm{SL}$ & 1 & 1 & 55 & 55 & 56 & 55 & 41 & 41 & 41 & 40 & 41 \\
\hline 482 & SUL & $\mathrm{SL}$ & 2 & 1 & 47 & 45 & 41 & 45 & 51 & 48 & 50 & 55 & 51 \\
\hline 482 & SUL & SL & 3 & 1 & 52 & 52 & 49 & 51 & 44 & 44 & 43 & 46 & 44 \\
\hline 492 & SUL & $\mathrm{SL}$ & 1 & 1 & 13 & 14 & 13 & 13 & 169 & 172 & 168 & 171 & 170 \\
\hline 492 & SUL & SL & 2 & 1 & 14 & 14 & 14 & 14 & 162 & 162 & 162 & 166 & 163 \\
\hline 492 & SUL & SL & 3 & 1 & 15 & 15 & 14 & 15 & 154 & 156 & 150 & 159 & 155 \\
\hline 521 & SUL & SL & 1 & 1 & 56 & 61 & 68 & 62 & 37 & 40 & 37 & 33 & 37 \\
\hline 521 & SUL & $\mathrm{SL}$ & 2 & 1 & 87 & 100 & 83 & 90 & 25 & 26 & 23 & 27 & 25 \\
\hline 521 & SUL & SL & 3 & 1 & 52 & 51 & 53 & 52 & 43 & 44 & 45 & 43 & 44 \\
\hline
\end{tabular}


Tabela 3.9: Resultados dos ensaios de módulo obtidos com uso do equipamento $L W D$

\begin{tabular}{|c|c|c|c|c|c|c|c|c|c|c|c|c|c|}
\hline \multirow[t]{2}{*}{ km } & \multirow[t]{2}{*}{ PISTA } & \multirow[t]{2}{*}{ Material } & \multirow[t]{2}{*}{ Ponto } & \multirow[t]{2}{*}{ Ensaio } & \multicolumn{4}{|c|}{ Leituras Do, LWD $\left(10^{-2} \mathrm{~mm}\right)$} & \multirow{2}{*}{$\begin{array}{c}\text { E0, equip } \\
(\mathrm{MPa})\end{array}$} & \multicolumn{4}{|c|}{$\begin{array}{c}\text { E0, calc } \\
(\mathrm{MPa})\end{array}$} \\
\hline & & & & & 1 & 2 & 3 & Média & & 1 & 2 & 3 & Média \\
\hline 402 & NORTE & BGS & 1 & 1 & 67 & 67 & 63 & 66 & 34 & 34 & 34 & 36 & 35 \\
\hline 402 & NORTE & BGS & 2 & 1 & 36 & 37 & 34 & 36 & 63 & 64 & 62 & 66 & 64 \\
\hline 402 & NORTE & BGS & 3 & 1 & 49 & 51 & 52 & 51 & 44 & 46 & 44 & 44 & 45 \\
\hline 405 & NORTE & BGS & 1 & 1 & 23 & 24 & 24 & 23 & 96 & 99 & 96 & 96 & 97 \\
\hline 405 & NORTE & BGS & 2 & 1 & 28 & 28 & 28 & 28 & 80 & 80 & 82 & 80 & 81 \\
\hline 405 & NORTE & BGS & 3 & 1 & 27 & 28 & 28 & 28 & 81 & 83 & 81 & 81 & 82 \\
\hline 414 & SUL & SB & 1 & 1 & 19 & 16 & 16 & 17 & 132 & 118 & 140 & 145 & 134 \\
\hline 414 & SUL & SB & 2 & 1 & 19 & 16 & 16 & 17 & 132 & 120 & 138 & 145 & 135 \\
\hline 414 & SUL & SB & 3 & 1 & 22 & 27 & 24 & 24 & 67 & 105 & 85 & 94 & 95 \\
\hline 414 & SUL & SB & 4 & 1 & 22 & 18 & 19 & 20 & 115 & 105 & 127 & 117 & 117 \\
\hline 414 & SUL & SB & 5 & 1 & 24 & 19 & 17 & 20 & 111 & 94 & 117 & 130 & 114 \\
\hline 414 & SUL & SB & 6 & 1 & 15 & 17 & 16 & 16 & 139 & 149 & 133 & 138 & 140 \\
\hline 418 & NORTE & BGS & 1 & 1 & 30 & 34 & 44 & 36 & 63 & 75 & 67 & 52 & 65 \\
\hline 418 & NORTE & BGS & 1 & 2 & 27 & 25 & 24 & 25 & 89 & 84 & 90 & 95 & 90 \\
\hline 418 & NORTE & BGS & 2 & 1 & 47 & 83 & 47 & 59 & 38 & 48 & 27 & 49 & 41 \\
\hline 418 & NORTE & BGS & 2 & 2 & 50 & 44 & 59 & 51 & 44 & 46 & 51 & 38 & 45 \\
\hline 418 & NORTE & BGS & 3 & 1 & 28 & 28 & 27 & 28 & 82 & 82 & 81 & 85 & 83 \\
\hline 418 & NORTE & BGS & 3 & 2 & 26 & 26 & 26 & 26 & 87 & 87 & 87 & 87 & 87 \\
\hline 423 & NORTE & BGS & 1 & 1 & 32 & 33 & 32 & 32 & 69 & 71 & 69 & 70 & 70 \\
\hline 423 & NORTE & BGS & 1 & 2 & 32 & 32 & 36 & 33 & 68 & 71 & 71 & 64 & 68 \\
\hline 423 & NORTE & BGS & 2 & 1 & 47 & 48 & 45 & 47 & 48 & 48 & 47 & 51 & 49 \\
\hline 423 & NORTE & BGS & 2 & 2 & 47 & 42 & 43 & 44 & 51 & 48 & 53 & 53 & 51 \\
\hline 423 & NORTE & BGS & 3 & 1 & 36 & 30 & 30 & 32 & 71 & 64 & 76 & 75 & 72 \\
\hline 423 & NORTE & BGS & 3 & 2 & 28 & 28 & 27 & 28 & 81 & 80 & 82 & 84 & 82 \\
\hline 429 & NORTE & BGS & 1 & 1 & 34 & 39 & 38 & 37 & 59 & 67 & 58 & 60 & 62 \\
\hline 429 & NORTE & BGS & 1 & 2 & 43 & 39 & 46 & 43 & 53 & 53 & 58 & 49 & 54 \\
\hline 431 & NORTE & BGS & 1 & 1 & 73 & 76 & 61 & 70 & 33 & 31 & 30 & 37 & 33 \\
\hline 431 & NORTE & BGS & 2 & 1 & 68 & 75 & 64 & 69 & 31 & 33 & 30 & 35 & 33 \\
\hline 431 & NORTE & BGS & 3 & 1 & 64 & 71 & 61 & 65 & 36 & 35 & 32 & 37 & 35 \\
\hline 434 & NORTE & BGS & 1 & 1 & 43 & 40 & 42 & 42 & 54 & 52 & 57 & 54 & 54 \\
\hline 434 & NORTE & BGS & 2 & 1 & 116 & 110 & 103 & 110 & 20 & 19 & 21 & 22 & 21 \\
\hline 434 & NORTE & BGS & 3 & 1 & 98 & 87 & 94 & 93 & 24 & 23 & 26 & 24 & 24 \\
\hline 456 & NORTE & BGS & 1 & 1 & 66 & 49 & 30 & 48 & 30 & 35 & 46 & 75 & 52 \\
\hline 456 & NORTE & BGS & 2 & 1 & 74 & 62 & 29 & 55 & 42 & 30 & 37 & 78 & 48 \\
\hline 456 & NORTE & BGS & 3 & 1 & 83 & 49 & 38 & 57 & 69 & 27 & 46 & 60 & 44 \\
\hline 460 & NORTE & BGS & 1 & 1 & 35 & 31 & 30 & 32 & 73 & 65 & 73 & 76 & 71 \\
\hline 460 & NORTE & BGS & 2 & 1 & 27 & 27 & 27 & 27 & 83 & 84 & 84 & 84 & 84 \\
\hline 460 & NORTE & BGS & 3 & 1 & 32 & 32 & 35 & 33 & 75 & 71 & 71 & 65 & 69 \\
\hline 477 & NORTE & BGS & 1 & 1 & 38 & 38 & 34 & 37 & 61 & 59 & 60 & 67 & 62 \\
\hline 477 & NORTE & BGS & 2 & 1 & 37 & 36 & 39 & 37 & 60 & 62 & 63 & 58 & 61 \\
\hline 477 & NORTE & BGS & 3 & 1 & 30 & 29 & 30 & 29 & 77 & 76 & 79 & 77 & 77 \\
\hline
\end{tabular}

Onde: $E 0$,equip = valor de módulo informado pelo equipamento; $E 0, c a l c=$ valor de módulo calculado; $S B$ = solo-brita e $B G S=$ brita graduada simples .

O Valor de módulo calculado $(E 0, c a l c)$ foi obtido através da equação a seguir: 


$$
E_{0}=\frac{A \cdot p \cdot r \cdot\left(1-\mu^{2}\right)}{d_{0}}
$$

Onde:

$E_{0}=$ módulo de elasticidade composto ou equivalente das camadas $(M P a) ; A=$ fator de rigidez da placa (2 para placa flexível e $\pi / 2$ para placa rígida); $r=$ raio da placa (m); $\mu$ = coeficiente de Poisson do material; $d_{0}=$ deflexão máxima ou no ponto de aplicação de carga; $p=$ pressão aplicada (força por unidade de área).

Para determinar o valor de módulo específico da camada superior ao subleito, utilizouse o gráfico e sua respectiva equação propostos por Ferri (2013), conforme indicado na Figura 3.8 a seguir.

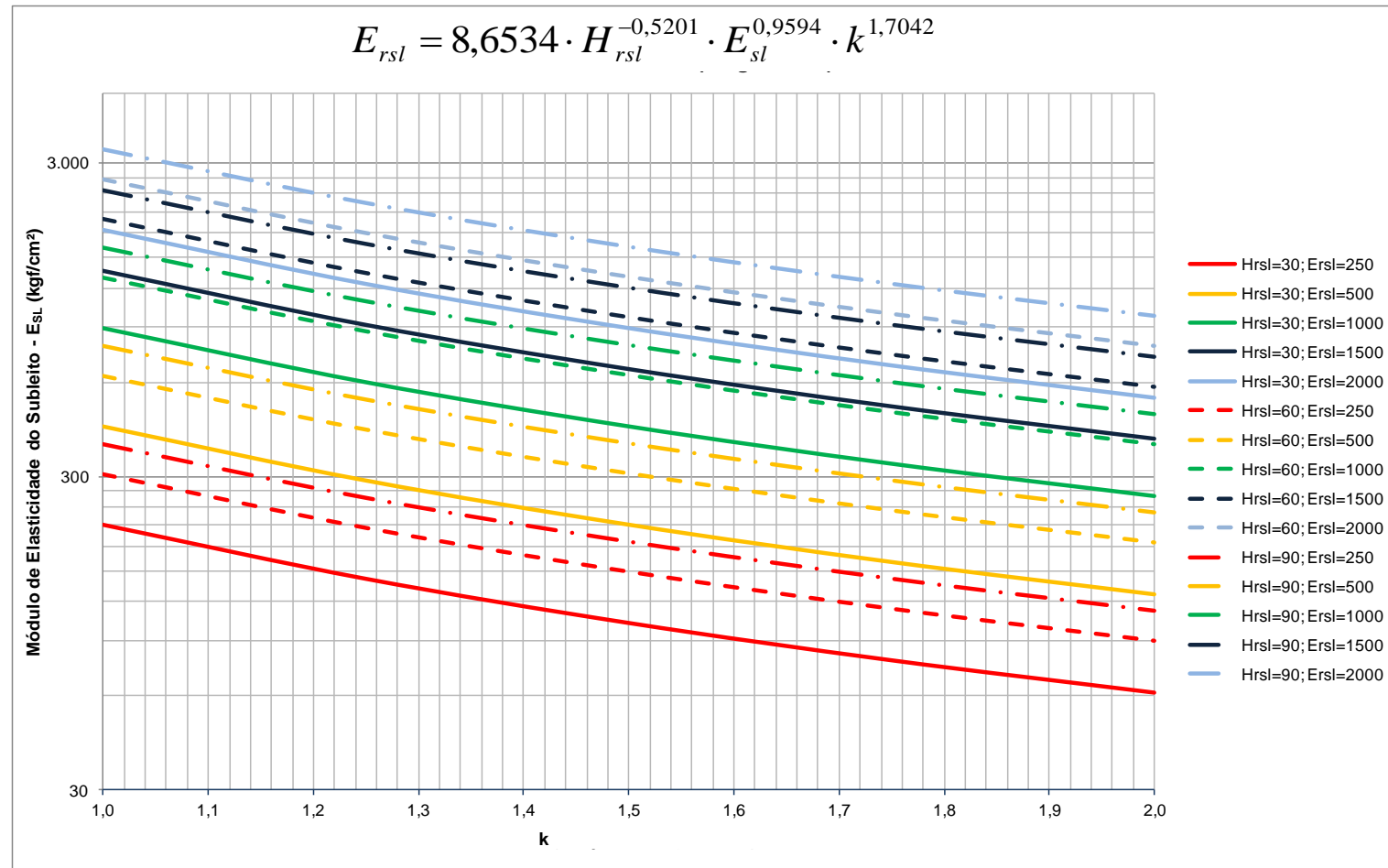

Figura 3.8: Determinação do Módulo da camada sobrejacente ao subleito em função da relação de deflexões e equipamento FWD ou $L W D$

Onde: $E r s \mathrm{l}=$ módulo do reforço do subleito; $\mathrm{Hrsl}$ = espessura do reforço do subleito; $E s l=$ módulo do subleito; $k$ = relação de deflexões (deflexão na camada de subleito divido pela deflexão na camada de reforço do subleito).

A Figura 3.9 a seguir apresenta os valores de módulo de resiliência retroanalisados com uso do $L W D$ para as camadas de sub-base granular e subleito. 


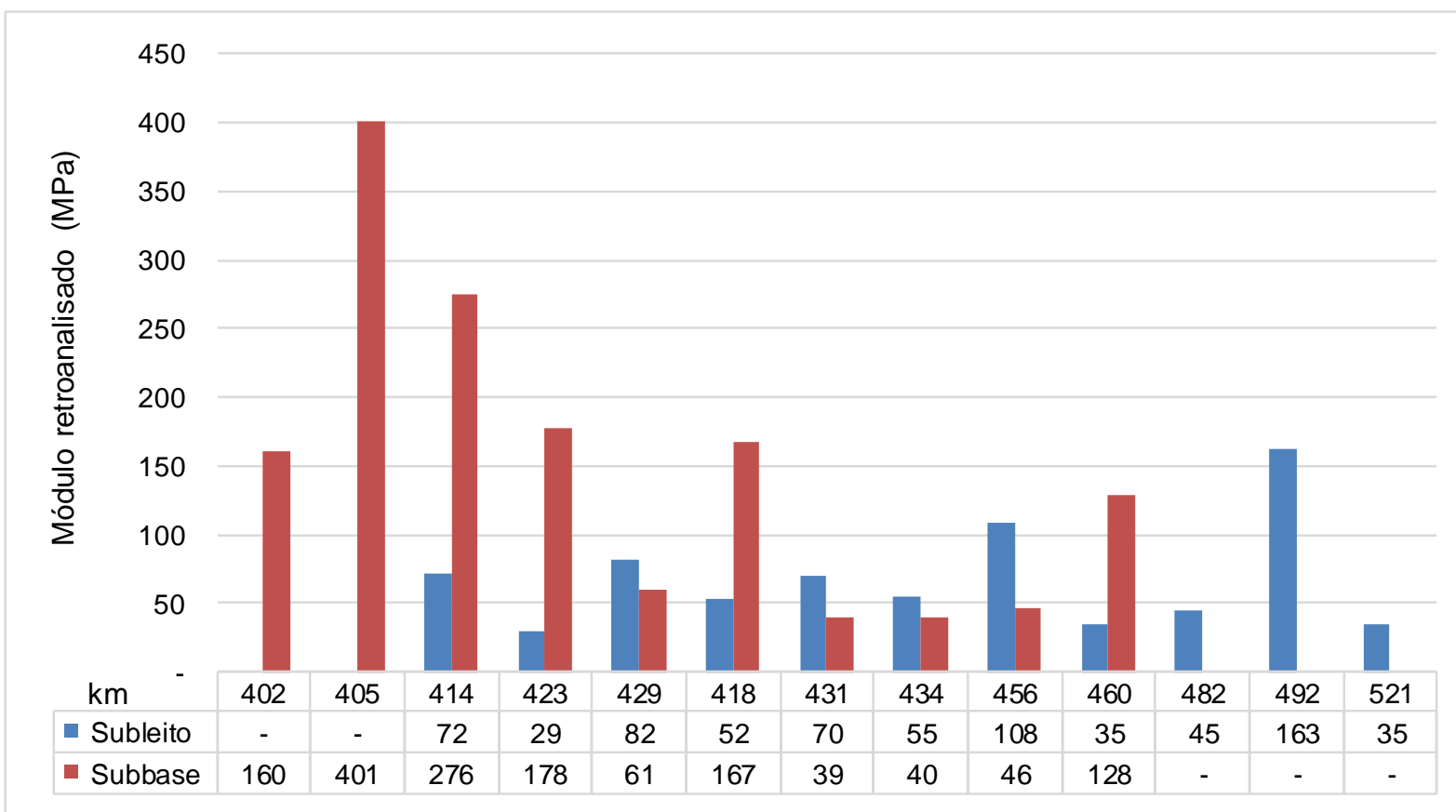

Figura 3.9: Módulos retroanalisados com $L W D$ (camadas de sub-base e subleito)

Pode-se observar que, em alguns casos, não se atingiu a camada de subleito, pois as espessuras de material de empréstimo na sub-base (ou reforço do subleito) eram muito expressivas. Em alguns casos, observou-se que a sub-base era de solo do próprio local, e denominou-se assim de subleito. Além disso, embora fosse expectativa de se encontrar materiais de sub-base com módulo de resiliência superiores aos do subleito, nem sempre esta realidade se confirmou; há várias situações onde a rigidez da camada de sub-base é menor que a do subleito devido à natureza dos materiais empregados, estado de compactação e de umidade.

\subsection{Resumo dos resultados de ensaios de laboratório}

Os resultados dos ensaios realizados bem como algumas tabelas e gráficos de análise estão apresentados no Anexo A do presente documento.

A Tabela 3.10 até Tabela 3.14 a seguir apresentam o resumo dos resultados dos ensaios de caracterização, classificação, compactação, resistência e módulo dos 
materiais de subleito ensaios no decorrer desta pesquisa. A campanha 1 de sondagens indicada nas tabelas representa as amostras coletadas diretamente no subleito da rodovia, enquanto na campanha 2 buscou-se coletar novas amostras no terreno natural / faixa de domínio da rodovia, com o intuito de repetir os testes incrementando o universo amostral. No entanto, grande parte das amostras apresentou pouca semelhança com os materiais da primeira campanha. De toda maneira, as amostras coletadas na segunda campanha foram devidamente caracterizadas e ensaiadas para determinação de classificação MCT e módulo de resiliência de laboratório. Este fato demonstra a heterogeneidade dos materiais empregados e diferentes momentos de pavimentação e manutenção dos pavimentos da rodovia, tornando o estudo de grande complexidade. 
Tabela 3.10: Resultados dos ensaios de campo (peso específico aparente seco, umidade e grau de saturação)

\begin{tabular}{|c|c|c|c|c|c|c|c|c|c|c|c|c|}
\hline \multicolumn{6}{|c|}{ Amostras } & \multicolumn{3}{|c|}{ Condição Cam po } & \multicolumn{4}{|c|}{ Saturação } \\
\hline $\begin{array}{l}\text { Cam_- } \\
\text { panha }\end{array}$ & Rodovia & km & Pista & Material & Amostra & $\underset{(g / \mathrm{cm} 3)}{\rho}$ & $\begin{array}{c}\text { w nat } \\
(\%)\end{array}$ & $\begin{array}{c}\gamma \text { nat } \\
(\mathrm{g} / \mathrm{cm} 3)\end{array}$ & $\gamma \mathbf{s}$ & $\begin{array}{c}\text { e } \\
(\%)\end{array}$ & $\begin{array}{c}\text { S w ot } \\
(\%)\end{array}$ & $\begin{array}{c}\text { S cam po } \\
(\%)\end{array}$ \\
\hline 1 & BR-381 & 6,0 & SUL & Solo (Subleito) & a & 2,703 & ND & ND & 2,70 & 86,4 & 82,9 & ND \\
\hline 1 & BR-381 & 6,0 & SUL & Solo (Subleito) & $\mathrm{b}$ & 2,703 & ND & ND & 2,70 & 86,4 & 82,9 & ND \\
\hline 1 & BR-381 & 6,0 & SUL & Solo (Subleito) & c & 2,703 & ND & ND & 2,70 & 86,4 & 82,9 & ND \\
\hline 1 & BR-381 & 6,0 & SUL & Solo (Subleito) & $d$ & 2,703 & ND & ND & 2,70 & 73,3 & 92,2 & ND \\
\hline 1 & BR-381 & 6,0 & SUL & Solo (Subleito) & e & 2,703 & ND & ND & 2,70 & 73,3 & 92,2 & ND \\
\hline 1 & BR-381 & 6,0 & SUL & Solo (Subleito) & $f$ & 2,703 & ND & ND & 2,70 & 73,3 & 92,2 & ND \\
\hline 1 & BR-381 & 6,0 & SUL & Solo (Subleito) & g & 2,703 & ND & ND & 2,70 & 62,8 & 90,3 & ND \\
\hline 1 & BR-381 & 6,0 & SUL & Solo (Subleito) & $\mathrm{h}$ & 2,703 & ND & ND & 2,70 & 62,8 & 90,3 & ND \\
\hline 1 & BR-381 & 6,0 & SUL & Solo (Subleito) & $\mathrm{i}$ & 2,703 & ND & ND & 2,70 & 62,8 & 90,3 & ND \\
\hline 1 & BR-116 & 402,0 & NORTE & Solo (Subleito) & & ND & 5,5 & 2,143 & 2,60 & 23,2 & 55,4 & 61,6 \\
\hline 1 & BR-116 & 405,0 & NORTE & Solo (Subleito) & & ND & 4,0 & 2,074 & 2,60 & 20,4 & 89,3 & 51,1 \\
\hline 1 & BR-116 & 414,0 & SUL & $\begin{array}{l}\text { Cascalho } \\
\text { (Reforço SL) }\end{array}$ & a & ND & 4,5 & 2,325 & 2,60 & 17,4 & 92,5 & 67,1 \\
\hline 1 & BR-116 & 414,0 & SUL & $\begin{array}{l}\text { Cascalho } \\
\text { (Reforço SL) }\end{array}$ & $b$ & ND & 4,5 & 2,325 & 2,60 & 17,4 & 92,5 & 67,1 \\
\hline 1 & BR-116 & 414,0 & SUL & $\begin{array}{l}\text { Cascalho } \\
\text { (Reforço SL) }\end{array}$ & c & ND & 4,5 & 2,325 & 2,60 & 17,4 & 92,5 & 67,1 \\
\hline 1 & BR-116 & 414,0 & SUL & $\begin{array}{l}\text { Cascalho } \\
\text { (Reforço SL) }\end{array}$ & $d$ & ND & 4,5 & 2,325 & 2,60 & 17,4 & 92,5 & 67,1 \\
\hline 1 & BR-116 & 418,0 & NORTE & Solo (Subleito) & & ND & 6,5 & 2,179 & 2,60 & 26,8 & 87,2 & 62,5 \\
\hline 1 & BR-116 & 423,0 & NORTE & Solo (Subleito) & & ND & 4,3 & 2,416 & 2,60 & 23,2 & 91,8 & 47,6 \\
\hline 1 & BR-116 & 429,0 & NORTE & Solo (Subleito) & & ND & 5,1 & 2,470 & 2,60 & 26,8 & 70,7 & 49,4 \\
\hline 1 & BR-116 & 431,0 & NORTE & Solo (Subleito) & & ND & 7,9 & 2,107 & 2,60 & 25,0 & 82,3 & 82,2 \\
\hline 1 & BR-116 & 434,0 & NORTE & Solo (Subleito) & & ND & 12,3 & 1,856 & 2,85 & 36,4 & 60,9 & 96,4 \\
\hline 1 & BR-116 & 456,0 & NORTE & Solo (Subleito) & & 2,55 & 9,7 & 1,801 & 2,55 & 27,5 & 75,8 & 89,9 \\
\hline 1 & BR-116 & 460,0 & SUL & Solo (Subleito) & a & 2,696 & 17,2 & 1,550 & 2,70 & 55,8 & 97,3 & 83,0 \\
\hline 1 & BR-116 & 460,0 & SUL & Solo (Subleito) & $b$ & 2,696 & 17,2 & 1,550 & 2,70 & 55,8 & 97,3 & 83,0 \\
\hline 2 & BR-116 & 402,0 & NORTE & $\begin{array}{l}\text { Argila siltosa vermelha } \\
\text { (Subleito) }\end{array}$ & & ND & ND & ND & 2,70 & 80,8 & 67,8 & ND \\
\hline 2 & BR-116 & 405,0 & NORTE & $\begin{array}{l}\text { Cascalho variegado } \\
\text { (Subleito) }\end{array}$ & & ND & ND & ND & 2,60 & 27,8 & 98,3 & ND \\
\hline 2 & BR-116 & 413,0 & NORTE & $\begin{array}{l}\text { Cascalho variegado } \\
\text { (Subleito) }\end{array}$ & & ND & ND & ND & 2,60 & 29,0 & 95,1 & ND \\
\hline 2 & BR-116 & 418,1 & NORTE & $\begin{array}{l}\text { Argila siltosa vermelha } \\
\text { (Subleito) }\end{array}$ & & ND & ND & ND & 2,60 & 71,7 & 65,2 & ND \\
\hline 2 & BR-116 & 423,5 & NORTE & $\begin{array}{l}\text { Silte argiloso rosa } \\
\text { (Subleito) }\end{array}$ & & ND & ND & ND & 2,60 & 54,4 & 83,6 & ND \\
\hline 2 & BR-116 & 429,0 & NORTE & $\begin{array}{l}\text { Cascalho variegado } \\
\text { (Subleito) }\end{array}$ & & ND & ND & ND & 2,60 & 27,4 & 82,6 & ND \\
\hline 2 & BR-116 & 431,0 & NORTE & $\begin{array}{l}\text { Argila siltosa amarela } \\
\text { (Subleito) }\end{array}$ & & ND & ND & ND & 2,70 & 86,3 & 62,2 & ND \\
\hline 2 & BR-116 & 434,0 & NORTE & $\begin{array}{l}\text { Argila siltosa rosa } \\
\text { (Subleito) }\end{array}$ & & ND & ND & ND & 2,60 & 59,9 & 89,0 & ND \\
\hline 2 & BR-116 & 456,0 & NORTE & $\begin{array}{l}\text { Silte argiloso } \\
\text { variegado (Subleito) }\end{array}$ & & ND & ND & ND & 2,60 & 59,5 & 80,8 & ND \\
\hline 2 & BR-116 & 460,0 & NORTE & $\begin{array}{l}\text { Argila amarela } \\
\text { (Subleito) }\end{array}$ & & ND & ND & ND & 2,60 & 69,7 & 88,8 & ND \\
\hline 2 & BR-116 & 482,0 & SUL & $\begin{array}{l}\text { Silte argiloso amarelo } \\
\text { (Subleito) }\end{array}$ & & ND & ND & ND & 2,60 & 58,4 & 80,5 & ND \\
\hline 2 & BR-116 & 492,0 & SUL & $\begin{array}{l}\text { Silte argiloso vermelho } \\
\text { (Subleito) }\end{array}$ & & ND & ND & ND & 2,70 & 55,2 & 81,2 & ND \\
\hline
\end{tabular}


Tabela 3.11: Resultados dos ensaios de granulometria

\begin{tabular}{|c|c|c|c|c|c|c|c|c|c|c|c|c|c|c|c|c|c|c|}
\hline \multirow{2}{*}{\multicolumn{6}{|c|}{ Amostras }} & \multicolumn{13}{|c|}{ Granulometria - percentual passante (\%) } \\
\hline & & & & & & \multirow{2}{*}{$\begin{array}{l}50 \\
2 "\end{array}$} & \multirow{2}{*}{$\begin{array}{c}38 \\
11 / 2 "\end{array}$} & \multirow{2}{*}{$\begin{array}{c}25 \\
1 "\end{array}$} & \multirow{2}{*}{$\begin{array}{c}19 \\
3 / 4^{\prime \prime}\end{array}$} & \multirow{2}{*}{$\begin{array}{l}12,5 \\
1 / 2^{\prime \prime}\end{array}$} & \multirow{2}{*}{$\begin{array}{l}9,50 \\
3 / 8^{\prime \prime}\end{array}$} & \multirow{2}{*}{$\begin{array}{c}4,80 \\
4\end{array}$} & \multirow{2}{*}{$\begin{array}{r}2,00 \\
10\end{array}$} & \multirow{2}{*}{$\begin{array}{r}0,42 \\
40\end{array}$} & \multirow{2}{*}{$\begin{array}{l}0,15 \\
100\end{array}$} & \multirow{2}{*}{$\begin{array}{l}0,07 \\
200\end{array}$} & \multirow{2}{*}{$\begin{array}{r}0,05 \\
270\end{array}$} & \multirow{2}{*}{$\begin{array}{r}0,0 \\
F\end{array}$} \\
\hline $\begin{array}{l}\text { Cam_- } \\
\text { panha }\end{array}$ & Rodovia & km & Pista & Material & Amostra & & & & & & & & & & & & & \\
\hline 1 & BR-381 & 6,0 & SUL & Solo (Subleito) & a & 100 & 100 & 100 & 100 & 100 & 100 & 100 & 99 & 90 & 83 & 79 & ND & ND \\
\hline 1 & BR-381 & 6,0 & SUL & Solo (Subleito) & $b$ & 100 & 100 & 100 & 100 & 100 & 100 & 100 & 99 & 90 & 83 & 79 & ND & ND \\
\hline 1 & BR-381 & 6,0 & SUL & Solo (Subleito) & c & 100 & 100 & 100 & 100 & 100 & 100 & 100 & 99 & 90 & 83 & 79 & ND & ND \\
\hline 1 & BR-381 & 6,0 & SUL & Solo (Subleito) & $d$ & 100 & 100 & 100 & 100 & 100 & 100 & 100 & 99 & 90 & 83 & 79 & ND & $N D$ \\
\hline 1 & BR-381 & 6,0 & SUL & Solo (Subleito) & e & 100 & 100 & 100 & 100 & 100 & 100 & 100 & 99 & 90 & 83 & 79 & ND & $N D$ \\
\hline 1 & BR-381 & 6,0 & SUL & Solo (Subleito) & $f$ & 100 & 100 & 100 & 100 & 100 & 100 & 100 & 99 & 90 & 83 & 79 & ND & ND \\
\hline 1 & BR-381 & 6,0 & SUL & Solo (Subleito) & g & 100 & 100 & 100 & 100 & 100 & 100 & 100 & 99 & 90 & 83 & 79 & ND & $N D$ \\
\hline 1 & BR-381 & 6,0 & SUL & Solo (Subleito) & $\mathrm{h}$ & 100 & 100 & 100 & 100 & 100 & 100 & 100 & 99 & 90 & 83 & 79 & ND & $N D$ \\
\hline 1 & BR-381 & 6,0 & SUL & Solo (Subleito) & $\mathrm{i}$ & 100 & 100 & 100 & 100 & 100 & 100 & 100 & 99 & 90 & 83 & 79 & ND & $N D$ \\
\hline 1 & BR-116 & 402,0 & NORTE & Solo (Subleito) & & & $-\cdots$ & ---- 1 & ND ---- & 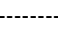 & & 92 & 83 & 56 & ND & 34 & ND & $N D$ \\
\hline 1 & BR-116 & 405,0 & NORTE & Solo (Subleito) & & 100 & 100 & 87 & 82 & 77 & 72 & 60 & 47 & 23 & 15 & 12 & ND & $N D$ \\
\hline 1 & BR-116 & 414,0 & SUL & $\begin{array}{l}\text { Cascalho } \\
\text { (Reforço SL) }\end{array}$ & a & 100 & 100 & 100 & 100 & 97 & 95 & 93 & 78 & 29 & 18 & 15 & ND & $N D$ \\
\hline 1 & BR-116 & 414,0 & SUL & $\begin{array}{l}\text { Cascalho } \\
\text { (Reforço SL) }\end{array}$ & $b$ & 100 & 100 & 100 & 100 & 97 & 95 & 93 & 78 & 29 & 18 & 15 & ND & $N D$ \\
\hline 1 & BR-116 & 414,0 & SUL & $\begin{array}{l}\text { Cascalho } \\
\text { (Reforço SL) }\end{array}$ & c & 100 & 100 & 100 & 100 & 97 & 95 & 93 & 78 & 29 & 18 & 15 & ND & $N D$ \\
\hline 1 & BR-116 & 414,0 & SUL & $\begin{array}{l}\text { Cascalho } \\
\text { (Reforço SL) }\end{array}$ & $d$ & 100 & 100 & 100 & 100 & 97 & 95 & 93 & 78 & 29 & 18 & 15 & ND & $N D$ \\
\hline 1 & BR-116 & 418,0 & NORTE & Solo (Subleito) & & & $-\cdots-\cdots$ & 1 & ND ---. & ----. & & 83 & 72 & 37 & ND & 15 & ND & $N D$ \\
\hline 1 & BR-116 & 423,0 & NORTE & Solo (Subleito) & & & $-\cdots-\cdots$ & - & ND ---- & -...-. & & 68 & 55 & 31 & ND & 15 & ND & $N D$ \\
\hline 1 & BR-116 & 429,0 & NORTE & Solo (Subleito) & & & $-\cdots$ & - & ND ----. & 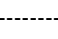 & & 92 & 83 & 56 & ND & 34 & ND & $N D$ \\
\hline 1 & BR-116 & 431,0 & NORTE & Solo (Subleito) & & 100 & 100 & 100 & 100 & 97 & 94 & 84 & 70 & 28 & 20 & 16 & ND & $N D$ \\
\hline 1 & BR-116 & 434,0 & NORTE & Solo (Subleito) & & 100 & 100 & 100 & 96 & 93 & 91 & 86 & 72 & 23 & 10 & 2 & ND & ND \\
\hline 1 & BR-116 & 456,0 & NORTE & Solo (Subleito) & & 100 & 100 & 100 & 99 & 97 & 95 & 87 & 79 & 55 & 39 & 31 & ND & ND \\
\hline 1 & BR-116 & 460,0 & SUL & Solo (Subleito) & a & 100 & 100 & 100 & 100 & 99 & 98 & 97 & 94 & 79 & 64 & 55 & ND & ND \\
\hline 1 & BR-116 & 460,0 & SUL & Solo (Subleito) & b & 100 & 100 & 100 & 100 & 99 & 98 & 97 & 94 & 79 & 64 & 55 & ND & $N D$ \\
\hline 2 & BR-116 & 402,0 & NORTE & $\begin{array}{l}\text { Argila siltosa vermelha } \\
\text { (Subleito) }\end{array}$ & & 100 & 100 & 100 & 100 & 100 & 99 & 98 & 91 & 82 & 76 & 56 & 56 & 24 \\
\hline 2 & BR-116 & 405,0 & NORTE & $\begin{array}{l}\text { Cascalho variegado } \\
\text { (Subleito) }\end{array}$ & & 100 & 99 & 99 & 93 & 89 & 79 & 63 & 34 & 25 & 20 & 14 & 14 & 3 \\
\hline 2 & BR-116 & 413,0 & NORTE & $\begin{array}{l}\text { Cascalho variegado } \\
\text { (Subleito) }\end{array}$ & & 100 & 100 & 99 & 98 & 96 & 91 & 76 & 43 & 33 & 28 & 18 & 18 & 6 \\
\hline 2 & BR-116 & 418,1 & NORTE & $\begin{array}{l}\text { Argila siltosa vermelha } \\
\text { (Subleito) }\end{array}$ & & 100 & 100 & 100 & 100 & 100 & 100 & 99 & 88 & 79 & 73 & 45 & 45 & 12 \\
\hline 2 & BR-116 & 423,5 & NORTE & $\begin{array}{l}\text { Silte argiloso rosa } \\
\text { (Subleito) }\end{array}$ & & 100 & 100 & 100 & 100 & 100 & 100 & 99 & 86 & 75 & 71 & 47 & 47 & 10 \\
\hline 2 & BR-116 & 429,0 & NORTE & $\begin{array}{l}\text { Cascalho variegado } \\
\text { (Subleito) }\end{array}$ & & 100 & 99 & 95 & 92 & 89 & 81 & 67 & 41 & 32 & 26 & 22 & 22 & 8 \\
\hline 2 & BR-116 & 431,0 & NORTE & $\begin{array}{l}\text { Argila siltosa amarela } \\
\text { (Subleito) }\end{array}$ & & 100 & 100 & 100 & 100 & 100 & 100 & 100 & 90 & 83 & 80 & 77 & 77 & 67 \\
\hline 2 & BR-116 & 434,0 & NORTE & $\begin{array}{l}\text { Argila siltosa rosa } \\
\text { (Subleito) }\end{array}$ & & 100 & 100 & 100 & 100 & 100 & 100 & 99 & 80 & 70 & 65 & 43 & 43 & 11 \\
\hline 2 & BR-116 & 456,0 & NORTE & $\begin{array}{l}\text { Silte argiloso } \\
\text { variegado (Subleito) }\end{array}$ & & 100 & 100 & 100 & 100 & 100 & 100 & 99 & 92 & 77 & 61 & 38 & 38 & 4 \\
\hline 2 & BR-116 & 460,0 & NORTE & $\begin{array}{l}\text { Argila amarela } \\
\text { (Subleito) }\end{array}$ & & 100 & 100 & 100 & 100 & 100 & 100 & 99 & 87 & 75 & 68 & 43 & 43 & 15 \\
\hline 2 & BR-116 & 482,0 & SUL & $\begin{array}{l}\text { Silte argiloso amarelo } \\
\text { (Subleito) }\end{array}$ & & 100 & 100 & 100 & 100 & 100 & 100 & 98 & 93 & 80 & 64 & 38 & 38 & 4 \\
\hline 2 & BR-116 & 492,0 & SUL & $\begin{array}{l}\text { Silte argiloso vermelho } \\
\text { (Subleito) }\end{array}$ & & 100 & 100 & 100 & 100 & 100 & 100 & 98 & 95 & 92 & 86 & 58 & 58 & 17 \\
\hline
\end{tabular}


Tabela 3.12: Resultados dos ensaios de granulometria, limites de Atterberg, classificações $H R B$ e MCT

\begin{tabular}{|c|c|c|c|c|c|c|c|c|c|c|c|c|c|c|}
\hline & & & Amost & ras & & & & anulome & tria & & & Clas & HRE & \\
\hline $\begin{array}{l}\text { Cam_- } \\
\text { panha }\end{array}$ & Rodovia & km & Pista & Material & Amostra & $\begin{array}{l}\text { silte+ } \\
\text { argila }\end{array}$ & $\begin{array}{l}\text { areia } \\
\text { fina }\end{array}$ & $\begin{array}{c}\text { areia } \\
\text { média }\end{array}$ & $\begin{array}{c}\text { areia } \\
\text { grossa }\end{array}$ & pedr. & $\begin{array}{l}\text { LL } \\
\text { (\%) }\end{array}$ & $\begin{array}{l}\text { IP } \\
(\%)\end{array}$ & IG & HRB \\
\hline 1 & BR-381 & 6,0 & SUL & Solo (Subleito) & a & 79 & 11 & 10 & 1 & - & 53,0 & 15,6 & 15 & $A-7-5$ \\
\hline 1 & BR-381 & 6,0 & SUL & Solo (Subleito) & $b$ & 79 & 11 & 10 & 1 & - & 53,0 & 15,6 & 15 & A-7-5 \\
\hline 1 & BR-381 & 6,0 & SUL & Solo (Subleito) & c & 79 & 11 & 10 & 1 & - & 53,0 & 15,6 & 15 & A-7-5 \\
\hline 1 & BR-381 & 6,0 & SUL & Solo (Subleito) & $d$ & 79 & 11 & 10 & 1 & - & 53,0 & 15,6 & 15 & A-7-5 \\
\hline 1 & BR-381 & 6,0 & SUL & Solo (Subleito) & $\mathrm{e}$ & 79 & 11 & 10 & 1 & - & 53,0 & 15,6 & 15 & $A-7-5$ \\
\hline 1 & BR-381 & 6,0 & SUL & Solo (Subleito) & $f$ & 79 & 11 & 10 & 1 & - & 53,0 & 15,6 & 15 & A-7-5 \\
\hline 1 & BR-381 & 6,0 & SUL & Solo (Subleito) & g & 79 & 11 & 10 & 1 & - & 53,0 & 15,6 & 15 & A-7-5 \\
\hline 1 & BR-381 & 6,0 & SUL & Solo (Subleito) & $\mathrm{h}$ & 79 & 11 & 10 & 1 & - & 53,0 & 15,6 & 15 & A-7-5 \\
\hline 1 & BR-381 & 6,0 & SUL & Solo (Subleito) & $\mathrm{i}$ & 79 & 11 & 10 & 1 & - & 53,0 & 15,6 & 15 & $A-7-5$ \\
\hline 1 & BR-116 & 402,0 & NORTE & Solo (Subleito) & & 34 & 22 & 27 & 9 & 8 & 0,0 & 0,0 & 0 & A-2-4 \\
\hline 1 & BR-116 & 405,0 & NORTE & Solo (Subleito) & & 12 & 11 & 24 & 14 & 40 & 20,1 & 4,4 & 0 & $A-1-b$ \\
\hline 1 & BR-116 & 414,0 & SUL & $\begin{array}{l}\text { Cascalho } \\
\text { (Reforço SL) }\end{array}$ & a & 15 & 14 & 49 & 15 & 7 & 0,0 & 0,0 & 0 & $A-1-b$ \\
\hline 1 & BR-116 & 414,0 & SUL & $\begin{array}{l}\text { Cascalho } \\
\text { (Reforço SL) }\end{array}$ & $b$ & 15 & 14 & 49 & 15 & 7 & 0,0 & 0,0 & 0 & $A-1-b$ \\
\hline 1 & BR-116 & 414,0 & SUL & $\begin{array}{l}\text { Cascalho } \\
\text { (Reforço SL) }\end{array}$ & c & 15 & 14 & 49 & 15 & 7 & 0,0 & 0,0 & 0 & $A-1-b$ \\
\hline 1 & BR-116 & 414,0 & SUL & $\begin{array}{l}\text { Cascalho } \\
\text { (Reforço SL) }\end{array}$ & $d$ & 15 & 14 & 49 & 15 & 7 & 0,0 & 0,0 & 0 & $A-1-b$ \\
\hline 1 & BR-116 & 418,0 & NORTE & Solo (Subleito) & & 15 & 22 & 35 & 11 & 17 & 0,0 & 0,0 & 0 & $A-1-b$ \\
\hline 1 & BR-116 & 423,0 & NORTE & Solo (Subleito) & & 15 & 16 & 24 & 13 & 32 & 0,0 & 0,0 & 0 & $A-1-b$ \\
\hline 1 & BR-116 & 429,0 & NORTE & Solo (Subleito) & & 34 & 22 & 27 & 9 & 8 & 19,0 & 19,0 & 2 & $A-2-6$ \\
\hline 1 & BR-116 & 431,0 & NORTE & Solo (Subleito) & & 16 & 12 & 42 & 14 & 16 & 23,5 & 8,2 & 0 & A-2-4 \\
\hline 1 & BR-116 & 434,0 & NORTE & Solo (Subleito) & & 2 & 21 & 49 & 14 & 14 & 20,0 & 3,6 & 0 & $A-1-b$ \\
\hline 1 & BR-116 & 456,0 & NORTE & Solo (Subleito) & & 31 & 24 & 24 & 9 & 13 & 27,0 & 9,0 & 0 & A-2-4 \\
\hline 1 & BR-116 & 460,0 & SUL & Solo (Subleito) & a & 55 & 24 & 15 & 3 & 3 & 44,0 & 15,7 & 7 & A-7-6 \\
\hline 1 & BR-116 & 460,0 & SUL & Solo (Subleito) & b & 55 & 24 & 15 & 3 & 3 & 44,0 & 15,7 & 7 & A-7-6 \\
\hline 2 & BR-116 & 402,0 & NORTE & $\begin{array}{l}\text { Argila siltosa vermelha } \\
\text { (Subleito) }\end{array}$ & & 56 & 26 & 10 & 7 & 2 & 63,7 & 26,7 & 14 & A-7-5 \\
\hline 2 & BR-116 & 405,0 & NORTE & $\begin{array}{l}\text { Cascalho variegado } \\
\text { (Subleito) }\end{array}$ & & 14 & 11 & 10 & 29 & 37 & 0,0 & 0,0 & 0 & $A-1-b$ \\
\hline 2 & BR-116 & 413,0 & NORTE & $\begin{array}{l}\text { Cascalho variegado } \\
\text { (Subleito) }\end{array}$ & & 18 & 15 & 10 & 33 & 24 & 0,0 & 0,0 & 0 & $A-1-b$ \\
\hline 2 & BR-116 & 418,1 & NORTE & $\begin{array}{l}\text { Argila siltosa vermelha } \\
\text { (Subleito) }\end{array}$ & & 45 & 34 & 9 & 12 & 1 & 52,5 & 19,5 & 5 & A-7-5 \\
\hline 2 & BR-116 & 423,5 & NORTE & $\begin{array}{l}\text { Silte argiloso rosa } \\
\text { (Subleito) }\end{array}$ & & 47 & 28 & 10 & 13 & 1 & 41,0 & 14,0 & 4 & A-7-6 \\
\hline 2 & BR-116 & 429,0 & NORTE & $\begin{array}{l}\text { Cascalho variegado } \\
\text { (Subleito) }\end{array}$ & & 22 & 10 & 9 & 26 & 33 & 0,0 & 0,0 & 0 & $A-1-b$ \\
\hline 2 & BR-116 & 431,0 & NORTE & $\begin{array}{l}\text { Argila siltosa amarela } \\
\text { (Subleito) }\end{array}$ & & 77 & 6 & 8 & 9 & 0 & 66,9 & 24,9 & 20 & A-7-5 \\
\hline 2 & BR-116 & 434,0 & NORTE & $\begin{array}{l}\text { Argila siltosa rosa } \\
\text { (Subleito) }\end{array}$ & & 43 & 27 & 10 & 20 & 1 & 50,5 & 22,5 & 6 & A-7-6 \\
\hline 2 & BR-116 & 456,0 & NORTE & $\begin{array}{l}\text { Silte argiloso } \\
\text { variegado (Subleito) }\end{array}$ & & 38 & 39 & 15 & 7 & 1 & 36,1 & 16,1 & 2 & A-6 \\
\hline 2 & BR-116 & 460,0 & NORTE & $\begin{array}{l}\text { Argila amarela } \\
\text { (Subleito) }\end{array}$ & & 43 & 32 & 11 & 12 & 1 & 53,2 & 25,2 & 6 & A-7-6 \\
\hline 2 & BR-116 & 482,0 & SUL & $\begin{array}{l}\text { Silte argiloso amarelo } \\
\text { (Subleito) }\end{array}$ & & 38 & 42 & 12 & 5 & 2 & 35,2 & 16,2 & 2 & A-6 \\
\hline 2 & BR-116 & 492,0 & SUL & $\begin{array}{l}\text { Silte argiloso vermelho } \\
\text { (Subleito) }\end{array}$ & & 58 & 34 & 3 & 3 & 2 & 45,2 & 8,2 & 4 & $A-5$ \\
\hline
\end{tabular}


Tabela 3.13: Resultados dos ensaios de compactação, $C B R$ e expansão

\begin{tabular}{|c|c|c|c|c|c|c|c|c|c|c|c|c|c|c|c|}
\hline & & & Amost & tras & & & Clas & HRE & & $\begin{array}{c}\text { Class. } \\
\text { MCT }\end{array}$ & & Compac & tação & e CBR & \\
\hline $\begin{array}{l}\text { Cam_- } \\
\text { panha }\end{array}$ & Rodovia & km & Pista & Material & Amostra & $\begin{array}{l}\text { LL } \\
(\%)\end{array}$ & $\begin{array}{l}\text { IP } \\
(\%)\end{array}$ & IG & HRB & МСT & EN. & $\begin{array}{c}\gamma d \\
(g / c m 3)\end{array}$ & $\begin{array}{l}\text { wot } \\
\text { (\%) }\end{array}$ & $\begin{array}{l}\text { CBR } \\
(\%)\end{array}$ & $\begin{array}{l}\text { Exp. } \\
(\%)\end{array}$ \\
\hline 1 & BR-381 & 6,0 & SUL & Solo (Subleito) & $\mathrm{a}$ & 53,0 & 15,6 & 15 & A-7-5 & ND & $\mathrm{PN}$ & 1,450 & 26,5 & 18 & ND \\
\hline 1 & BR-381 & 6,0 & SUL & Solo (Subleito) & $b$ & 53,0 & 15,6 & 15 & A-7-5 & ND & PN & 1,450 & 26,5 & 18 & ND \\
\hline 1 & BR-381 & 6,0 & SUL & Solo (Subleito) & c & 53,0 & 15,6 & 15 & A-7-5 & ND & PN & 1,450 & 26,5 & 18 & ND \\
\hline 1 & BR-381 & 6,0 & SUL & Solo (Subleito) & $d$ & 53,0 & 15,6 & 15 & A-7-5 & ND & $\mathrm{PI}$ & 1,560 & 25,0 & 30 & ND \\
\hline 1 & BR-381 & 6,0 & SUL & Solo (Subleito) & e & 53,0 & 15,6 & 15 & A-7-5 & ND & $\mathrm{PI}$ & 1,560 & 25,0 & 30 & ND \\
\hline 1 & BR-381 & 6,0 & SUL & Solo (Subleito) & $f$ & 53,0 & 15,6 & 15 & A-7-5 & ND & $\mathrm{PI}$ & 1,560 & 25,0 & 30 & ND \\
\hline 1 & BR-381 & 6,0 & SUL & Solo (Subleito) & $g$ & 53,0 & 15,6 & 15 & A-7-5 & ND & PM & 1,660 & 21,0 & 31 & ND \\
\hline 1 & BR-381 & 6,0 & SUL & Solo (Subleito) & $\mathrm{h}$ & 53,0 & 15,6 & 15 & A-7-5 & ND & PM & 1,660 & 21,0 & 31 & ND \\
\hline 1 & BR-381 & 6,0 & SUL & Solo (Subleito) & $\mathrm{i}$ & 53,0 & 15,6 & 15 & A-7-5 & ND & PM & 1,660 & 21,0 & 31 & ND \\
\hline 1 & BR-116 & 402,0 & NORTE & Solo (Subleito) & & 0,0 & 0,0 & 0 & A-2-4 & NA-NS' & $\mathrm{PI}$ & 2,110 & 5,0 & 47 & 0,00 \\
\hline 1 & BR-116 & 405,0 & NORTE & Solo (Subleito) & & 20,1 & 4,4 & 0 & $A-1-b$ & NS'/NA' & $\mathrm{PI}$ & 2,160 & 7,0 & 35 & 0,01 \\
\hline 1 & BR-116 & 414,0 & SUL & $\begin{array}{l}\text { Cascalho } \\
\text { (Reforço SL) }\end{array}$ & $\mathrm{a}$ & 0,0 & 0,0 & 0 & $A-1-b$ & ND & PM & 2,214 & 6,2 & 58 & 0,00 \\
\hline 1 & BR-116 & 414,0 & SUL & $\begin{array}{l}\text { Cascalho } \\
\text { (Reforço SL) }\end{array}$ & $b$ & 0,0 & 0,0 & 0 & $A-1-b$ & ND & PM & 2,214 & 6,2 & 58 & 0,00 \\
\hline 1 & BR-116 & 414,0 & SUL & $\begin{array}{l}\text { Cascalho } \\
\text { (Reforço SL) }\end{array}$ & c & 0,0 & 0,0 & 0 & $A-1-b$ & ND & PM & 2,214 & 6,2 & 58 & 0,00 \\
\hline 1 & BR-116 & 414,0 & SUL & $\begin{array}{l}\text { Cascalho } \\
\text { (Reforço SL) }\end{array}$ & $d$ & 0,0 & 0,0 & 0 & $A-1-b$ & ND & PM & 2,214 & 6,2 & 58 & 0,00 \\
\hline 1 & BR-116 & 418,0 & NORTE & Solo (Subleito) & & 0,0 & 0,0 & 0 & $A-1-b$ & NG' & $\mathrm{PI}$ & 2,050 & 9,0 & 34 & 0,01 \\
\hline 1 & BR-116 & 423,0 & NORTE & Solo (Subleito) & & 0,0 & 0,0 & 0 & $A-1-b$ & NG' & $\mathrm{PI}$ & 2,110 & 8,2 & 50 & 0,58 \\
\hline 1 & BR-116 & 429,0 & NORTE & Solo (Subleito) & & 19,0 & 19,0 & 2 & A-2-6 & NG' & $\mathrm{PI}$ & 2,050 & 7,3 & 18 & 0,12 \\
\hline 1 & BR-116 & 431,0 & NORTE & Solo (Subleito) & & 23,5 & 8,2 & 0 & A-2-4 & NS'-NA' & $\mathrm{PI}$ & 2,080 & 7,9 & 32 & 0,01 \\
\hline 1 & BR-116 & 434,0 & NORTE & Solo (Subleito) & & 20,0 & 3,6 & 0 & $A-1-b$ & NS'-NA' & $\mathrm{PI}$ & 2,090 & 7,8 & 47 & 0,02 \\
\hline 1 & BR-116 & 456,0 & NORTE & Solo (Subleito) & & 27,0 & 9,0 & 0 & A-2-4 & NS'-NG' & $\mathrm{PI}$ & 2,000 & 8,2 & 16 & 0,74 \\
\hline 1 & BR-116 & 460,0 & SUL & Solo (Subleito) & a & 44,0 & 15,7 & 7 & A-7-6 & LG' & $\mathrm{PI}$ & 1,730 & 20,2 & 5 & 0,26 \\
\hline 1 & BR-116 & 460,0 & SUL & Solo (Subleito) & $b$ & 44,0 & 15,7 & 7 & A-7-6 & LG' & $\mathrm{PI}$ & 1,730 & 20,2 & 5 & 0,26 \\
\hline 2 & BR-116 & 402,0 & NORTE & $\begin{array}{l}\text { Argila siltosa vermelha } \\
\text { (Subleito) }\end{array}$ & & 63,7 & 26,7 & 14 & A-7-5 & NG' & PN & 1,493 & 20,3 & 2 & 6,30 \\
\hline 2 & BR-116 & 405,0 & NORTE & $\begin{array}{l}\text { Cascalho variegado } \\
\text { (Subleito) }\end{array}$ & & 0,0 & 0,0 & 0 & $A-1-b$ & NS'/NA' & PN & 2,035 & 10,5 & 7 & 0,70 \\
\hline 2 & BR-116 & 413,0 & NORTE & $\begin{array}{l}\text { Cascalho variegado } \\
\text { (Subleito) }\end{array}$ & & 0,0 & 0,0 & 0 & $A-1-b$ & NS'-NG' & $\mathrm{PN}$ & 2,016 & 10,6 & 9 & 0,80 \\
\hline 2 & BR-116 & 418,1 & NORTE & $\begin{array}{l}\text { Argila siltosa vermelha } \\
\text { (Subleito) }\end{array}$ & & 52,5 & 19,5 & 5 & A-7-5 & NS'-NG' & PN & 1,514 & 18,0 & 4 & 4,20 \\
\hline 2 & BR-116 & 423,5 & NORTE & $\begin{array}{l}\text { Silte argiloso rosa } \\
\text { (Subleito) }\end{array}$ & & 41,0 & 14,0 & 4 & A-7-6 & NS'/NA' & PN & 1,684 & 17,5 & 3 & 4,10 \\
\hline 2 & BR-116 & 429,0 & NORTE & $\begin{array}{l}\text { Cascalho variegado } \\
\text { (Subleito) }\end{array}$ & & 0,0 & 0,0 & 0 & $A-1-b$ & NS'-NA' & PN & 2,041 & 8,7 & 28 & 0,00 \\
\hline 2 & BR-116 & 431,0 & NORTE & $\begin{array}{l}\text { Argila siltosa amarela } \\
\text { (Subleito) }\end{array}$ & & 66,9 & 24,9 & 20 & A-7-5 & $N G^{\prime}$ & PN & 1,449 & 19,9 & 3 & 1,90 \\
\hline 2 & BR-116 & 434,0 & NORTE & $\begin{array}{l}\text { Argila siltosa rosa } \\
\text { (Subleito) }\end{array}$ & & 50,5 & 22,5 & 6 & A-7-6 & NS'-NG' & PN & 1,626 & 20,5 & 3 & 3,70 \\
\hline 2 & BR-116 & 456,0 & NORTE & $\begin{array}{l}\text { Silte argiloso } \\
\text { variegado (Subleito) }\end{array}$ & & 36,1 & 16,1 & 2 & A-6 & $N S^{\prime} / N A^{\prime}$ & PN & 1,630 & 18,5 & 5 & 3,40 \\
\hline 2 & BR-116 & 460,0 & NORTE & $\begin{array}{l}\text { Argila amarela } \\
\text { (Subleito) }\end{array}$ & & 53,2 & 25,2 & 6 & A-7-6 & LG' & PN & 1,532 & 23,8 & 7 & 0,10 \\
\hline 2 & BR-116 & 482,0 & SUL & $\begin{array}{l}\text { Silte argiloso amarelo } \\
\text { (Subleito) }\end{array}$ & & 35,2 & 16,2 & 2 & $A-6$ & $N S^{\prime} / N^{\prime}$ & $\mathrm{PI}$ & 1,641 & 18,1 & 2 & 3,70 \\
\hline 2 & BR-116 & 492,0 & SUL & $\begin{array}{l}\text { Silte argiloso vermelho } \\
\text { (Subleito) }\end{array}$ & & 45,2 & 8,2 & 4 & A-5 & NS'-NG' & $\mathrm{PI}$ & 1,740 & 16,6 & 2 & 7,20 \\
\hline
\end{tabular}


Tabela 3.14: Resultados dos ensaios de módulo de resiliência em laboratório

\begin{tabular}{|c|c|c|c|c|c|c|c|c|c|c|c|c|c|c|c|c|c|c|}
\hline \multirow{3}{*}{$\begin{array}{l}\text { Cam_- } \\
\text { panha }\end{array}$} & \multirow[b]{3}{*}{ Rodovia } & \multirow{2}{*}{\multicolumn{3}{|c|}{ Amostras }} & \multirow[b]{3}{*}{ Amostra } & \multirow{3}{*}{\begin{tabular}{|c|}
$\begin{array}{c}\text { Class. } \\
\text { HRB }\end{array}$ \\
HRB
\end{tabular}} & \multirow{3}{*}{$\begin{array}{c}\begin{array}{c}\text { Class. } \\
\text { MCT }\end{array} \\
\text { MCT }\end{array}$} & \multicolumn{11}{|c|}{ Ensaio MR $(\sigma 3$ e $\sigma d)$} \\
\hline & & & & & & & & \multicolumn{7}{|c|}{$M R=k 1 \times(\sigma 3)^{\wedge} k 2$} & \multicolumn{3}{|c|}{$M R=k 3 \times(\sigma d)^{\wedge} k 4$} & \multirow[b]{2}{*}{$\begin{array}{c}\text { MR } \\
\text { referência* } \\
\text { (MPa) }\end{array}$} \\
\hline & & km & Pista & Material & & & & $\begin{array}{c}\mathrm{h} \\
\text { mold. } \\
(\%)\end{array}$ & $\begin{array}{l}\text { h pós } \\
\text { sat } \\
(\%)\end{array}$ & $\begin{array}{c}\gamma d \\
(\mathrm{~g} / \mathrm{cm} 3 \\
)\end{array}$ & $\begin{array}{l}\text { En. } \\
\text { mold. }\end{array}$ & $\begin{array}{c}\text { coef. } \\
\text { k1 }\end{array}$ & $\begin{array}{c}\text { coef. } \\
\text { k2 }\end{array}$ & R2 & $\begin{array}{c}\text { coef. } \\
\text { k3 }\end{array}$ & $\begin{array}{c}\text { coef. } \\
\mathrm{k} 4\end{array}$ & R2 & \\
\hline 1 & BR-381 & 6,0 & SUL & Solo (Subleito) & a & $A-7-5$ & ND & 26,5 & - & 1,450 & $\mathrm{~N}$ & 169 & $-0,185$ & 0,47 & 182 & $-0,203$ & 0,840 & 348 \\
\hline 1 & BR-381 & 6,0 & SUL & Solo (Subleito) & b & $A-7-5$ & ND & 26,5 & - & 1,450 & $\mathrm{~N}$ & 209 & $-0,176$ & 0,40 & 220 & $-0,199$ & 0,770 & 415 \\
\hline 1 & BR-381 & 6,0 & SUL & Solo (Subleito) & c & A-7-5 & ND & 26,5 & - & 1,450 & $\mathrm{~N}$ & 210 & $-0,212$ & 0,40 & 216 & $-0,255$ & 0,870 & 488 \\
\hline 1 & BR-381 & 6,0 & SUL & Solo (Subleito) & $d$ & A-7-5 & ND & 25,0 & - & 1,560 & 1 & 399 & 0,004 & 0,00 & 361 & $-0,039$ & 0,210 & 409 \\
\hline 1 & BR-381 & 6,0 & SUL & Solo (Subleito) & e & $A-7-5$ & ND & 25,0 & - & 1,560 & 1 & 621 & 0,067 & 0,22 & 518 & 0,005 & 0,002 & 510 \\
\hline 1 & BR-381 & 6,0 & SUL & Solo (Subleito) & $f$ & $A-7-5$ & ND & 25,0 & - & 1,560 & 1 & 392 & $-0,056$ & 0,12 & 369 & $-0,099$ & 0,540 & 506 \\
\hline 1 & BR-381 & 6,0 & SUL & Solo (Subleito) & $\mathrm{g}$ & $A-7-5$ & ND & 21,0 & - & 1,660 & M & 446 & $-0,072$ & 0,14 & 412 & $-0,127$ & 0,630 & 618 \\
\hline 1 & BR-381 & 6,0 & SUL & Solo (Subleito) & $\mathrm{h}$ & $A-7-5$ & ND & 21,0 & - & 1,660 & M & 403 & $-0,041$ & 0,07 & 377 & $-0,081$ & 0,410 & 488 \\
\hline 1 & BR-381 & 6,0 & SUL & Solo (Subleito) & $\mathrm{i}$ & $A-7-5$ & ND & 21,0 & - & 1,660 & M & 386 & $-0,051$ & 0,12 & 364 & $-0,091$ & 0,560 & 487 \\
\hline 1 & BR-116 & 402,0 & NORTE & Solo (Subleito) & & A-2-4 & NA-NS' & 5,0 & - & 2,050 & 1 & 1.194 & 0,560 & 0,98 & 609 & 0,412 & 0,77 & 109 \\
\hline 1 & BR-116 & 405,0 & NORTE & Solo (Subleito) & & $A-1-b$ & $N S^{\prime} / N^{\prime}$ & 7,0 & - & 2,160 & 1 & 1.382 & 0,610 & 0,95 & 652 & 0,440 & 0,74 & 102 \\
\hline 1 & BR-116 & 414,0 & SUL & $\begin{array}{l}\text { Cascalho } \\
\text { (Reforço SL) }\end{array}$ & a & $A-1-b$ & ND & 6,2 & - & 2,214 & M & 745 & 0,531 & - & 545 & 0,396 & - & 77 \\
\hline 1 & BR-116 & 414,0 & SUL & $\begin{array}{l}\text { Cascalho } \\
\text { (Reforço SL) }\end{array}$ & b & $A-1-b$ & ND & 6,2 & - & 2,214 & M & 711 & 0,509 & - & 482 & 0,348 & - & 81 \\
\hline 1 & BR-116 & 414,0 & SUL & $\begin{array}{l}\text { Cascalho } \\
\text { (Reforço SL) }\end{array}$ & c & $A-1-b$ & ND & 7,7 & 7,7 & 2,214 & M & 814 & 0,586 & - & 515 & 0,397 & - & 67 \\
\hline 1 & BR-116 & 414,0 & SUL & $\begin{array}{l}\text { Cascalho } \\
\text { (Reforço SL) }\end{array}$ & $d$ & $A-1-b$ & ND & 4,2 & 4,2 & 2,214 & M & 596 & 0,092 & - & 535 & 0,051 & - & 402 \\
\hline 1 & BR-116 & 418,0 & NORTE & Solo (Subleito) & & $A-1-b$ & NG' & 9,3 & - & 2,070 & 1 & 876 & 0,517 & 0,96 & 452 & 0,362 & 0,70 & 96 \\
\hline 1 & BR-116 & 423,0 & NORTE & Solo (Subleito) & & $A-1-b$ & NG' & 8,9 & - & 2,120 & 1 & 1.115 & 0,627 & 0,95 & 542 & 0,477 & 0,80 & 77 \\
\hline 1 & BR-116 & 429,0 & NORTE & Solo (Subleito) & & A-2-6 & $N G^{\prime}$ & 7,7 & - & 2,080 & 1 & 754 & 0,481 & 0,96 & 388 & 0,292 & 0,550 & 97 \\
\hline 1 & BR-116 & 431,0 & NORTE & Solo (Subleito) & & A-2-4 & NS'-NA' & 6,6 & - & 2,080 & 1 & 864 & 0,480 & 0,92 & 461 & 0,330 & 0,65 & 111 \\
\hline 1 & BR-116 & 434,0 & NORTE & Solo (Subleito) & & $A-1-b$ & NS'-NA' & 7,9 & - & 2,090 & 1 & 761 & 0,470 & 0,98 & 420 & 0,330 & 0,72 & 102 \\
\hline 1 & BR-116 & 456,0 & NORTE & Solo (Subleito) & & A-2-4 & NS'-NG' & 9,3 & - & 2,000 & 1 & 225 & 0,160 & 0,27 & 139 & $-0,010$ & 0,00 & 114 \\
\hline 1 & BR-116 & 460,0 & SUL & Solo (Subleito) & a & A-7-6 & LG' & 19,3 & - & 1,730 & 1 & 278 & $-0,284$ & 0,54 & 327 & $-0,287$ & 0,82 & 818 \\
\hline 1 & BR-116 & 460,0 & SUL & Solo (Subleito) & b & A-7-6 & LG' & 19,3 & - & 1,730 & 1 & 88 & $-0,450$ & 0,73 & 128 & $-0,410$ & 0,88 & 474 \\
\hline 2 & BR-116 & 402,0 & NORTE & $\begin{array}{l}\text { Argila siltosa vermelha } \\
\text { (Subleito) }\end{array}$ & & A-7-5 & $N G^{\prime}$ & 20,3 & - & 1,493 & $\mathrm{~N}$ & 16 & $-0,530$ & 0,56 & 18 & $-0,620$ & 0,93 & 130 \\
\hline 2 & BR-116 & 405,0 & NORTE & $\begin{array}{l}\text { Cascalho variegado } \\
\text { (Subleito) }\end{array}$ & & $A-1-b$ & $N S^{\prime} / N A^{\prime}$ & 10,5 & - & 2,035 & $\mathrm{~N}$ & 589 & 0,410 & 0,95 & 323 & 0,250 & 0,52 & 102 \\
\hline 2 & BR-116 & 413,0 & NORTE & $\begin{array}{l}\text { Cascalho variegado } \\
\text { (Subleito) }\end{array}$ & & $A-1-b$ & NS'-NG' & 10,6 & - & 2,016 & $\mathrm{~N}$ & 427 & 0,290 & 0,72 & 250 & 0,140 & 0,230 & 124 \\
\hline 2 & BR-116 & 418,1 & NORTE & $\begin{array}{l}\text { Argila siltosa vermelha } \\
\text { (Subleito) }\end{array}$ & & A-7-5 & NS'-NG' & 18,0 & - & 1,514 & $\mathrm{~N}$ & 23 & $-0,510$ & 0,58 & 33 & $-0,500$ & 0,83 & 163 \\
\hline 2 & BR-116 & 423,5 & NORTE & $\begin{array}{l}\begin{array}{l}\text { Silte argiloso rosa } \\
\text { (Subleito) }\end{array} \\
\end{array}$ & & A-7-6 & $N S^{\prime} / N^{\prime}$ & 17,5 & - & 1,684 & $\mathrm{~N}$ & 60 & $-0,090$ & 0,08 & 55 & $-0,150$ & 0,32 & 89 \\
\hline 2 & BR-116 & 429,0 & NORTE & $\begin{array}{l}\text { Cascalho variegado } \\
\text { (Subleito) }\end{array}$ & & $A-1-b$ & NS'-NA' & 8,7 & - & 2,041 & $\mathrm{~N}$ & 407 & 0,390 & 0,91 & 221 & 0,230 & 0,45 & 77 \\
\hline 2 & BR-116 & 431,0 & NORTE & $\begin{array}{l}\text { Argila sitosa amarela } \\
\text { (Subleito) }\end{array}$ & & A-7-5 & NG' & 19,9 & - & 1,449 & $\mathrm{~N}$ & 24 & $-0,430$ & 0,35 & 18 & $-0,640$ & 0,93 & 139 \\
\hline 2 & BR-116 & 434,0 & NORTE & $\begin{array}{l}\text { Argila sittosa rosa } \\
\text { (Subleito) }\end{array}$ & & A-7-6 & NS'-NG' & 20,5 & - & 1,626 & $\mathrm{~N}$ & 28 & $-0,310$ & 0,38 & 31 & $-0,350$ & 0,73 & 95 \\
\hline 2 & BR-116 & 456,0 & NORTE & $\begin{array}{l}\text { Silte argiloso } \\
\text { variegado (Subleito) }\end{array}$ & & A-6 & $N^{\prime} / N^{\prime}$ & 18,5 & - & 1,630 & $\mathrm{~N}$ & 75 & 0,050 & 0,03 & 56 & $-0,060$ & 0,05 & 68 \\
\hline 2 & BR-116 & 460,0 & NORTE & $\begin{array}{l}\text { Argila amarela } \\
\text { (Subleito) }\end{array}$ & & A-7-6 & LG' & 23,8 & - & 1,532 & $\mathrm{~N}$ & 54 & $-0,470$ & 0,58 & 68 & $-0,490$ & 0,92 & 325 \\
\hline 2 & BR-116 & 482,0 & SUL & $\begin{array}{l}\text { Silte argiloso amarelo } \\
\text { (Subleito) }\end{array}$ & & $A-6$ & $N^{\prime} / N^{\prime}$ & 18,1 & - & 1,641 & $\mathrm{~N}$ & 48 & $-0,010$ & 0,00 & 41 & $-0,080$ & 0,09 & 53 \\
\hline 2 & BR-116 & 492,0 & SUL & $\begin{array}{l}\text { Silte argiloso vermelho } \\
\text { (Subleito) }\end{array}$ & & A-5 & NS'-NG' & 16,6 & - & 1,740 & $\mathrm{~N}$ & 23 & $-0,430$ & 0,54 & 29 & $-0,440$ & 0,82 & 118 \\
\hline
\end{tabular}

Obs.: ( $\left.{ }^{*}\right)$ os valores de módulo de referência foram calculados utilizando-se os valores de tensão de confinamento e tensão desvio recomendados pelo manual da da AASHTO/2002, sendo: $\sigma_{3}=0,014 \mathrm{MPa}$ e $\sigma_{d}=0,041 \mathrm{MPa}$.

Pode-se observar que há uma tendência de a umidade do subleito estar mais baixa que a ótima de compactação, fato comum em território brasileiro, já comprovado por várias pesquisas, porém mostra-se claramente que a energia de compactação empregada nos serviços são baixas e não chegam a atingir as de laboratório. A prática 
de não atingir estado compactado adequado no campo é um dos graves problemas da prática executiva de pavimentos brasileira. Outro problema a ser destacado é ainda a ausência de prática das empresas de controle de realizarem a classificação $M C T$, imprescindível nas diversas regiões brasileiras para melhor caracterizar os solos e poder tratá-los quando for o caso.

\subsection{Comparativo peso específico aparente e umidade in situ versus condição de laboratório}

A Figura 3.10 apresenta os gráficos comparativos entre as condições de peso específico aparente e umidade encontradas em campo e os pontos ótimo de umidade e máximo de peso específico aparente obtido das curvas de compactação de laboratório para a energia de compactação adotada (normal para solos finos e intermediária para granulares).

A Tabela 3.15 a seguir apresenta o resumo das informações das condições de umidade e peso específico aparente obtidos em campo e em laboratório.

Tabela 3.15: Comparativo entre ensaios de umidade e peso específico aparente in situ e laboratório

\begin{tabular}{|c|c|c|c|c|c|c|c|c|c|c|}
\hline \multirow[b]{2}{*}{ km } & \multirow[b]{2}{*}{ Pista } & \multirow[b]{2}{*}{$\begin{array}{c}\text { Classificação } \\
\text { HRB / MCT }\end{array}$} & \multicolumn{2}{|c|}{ Método fogareiro } & \multicolumn{2}{|c|}{ Método estufa } & \multicolumn{2}{|c|}{ Laboratório } & \multicolumn{2}{|c|}{ Relação cam po/lab. } \\
\hline & & & $\begin{array}{c}\text { Teor de } \\
\text { Umidade } \\
\text { (\%) }\end{array}$ & $\begin{array}{c}\text { Massa } \\
\text { específica } \\
\text { seca } \\
\left(\mathrm{g} / \mathrm{cm}^{3}\right)\end{array}$ & $\begin{array}{c}\text { Teor de } \\
\text { Umidade } \\
\text { (\%) }\end{array}$ & $\begin{array}{c}\text { Massa } \\
\text { específica } \\
\text { seca } \\
\left(\mathrm{g} / \mathrm{cm}^{3}\right)\end{array}$ & $\begin{array}{c}\text { Umidade } \\
\text { ótima } \\
(\%)\end{array}$ & $\begin{array}{c}\text { Massa } \\
\text { específica } \\
\text { seca máx. } \\
\left(\mathrm{g} / \mathrm{cm}^{3}\right)\end{array}$ & $\begin{array}{c}\text { Teor de } \\
\text { Umidade }\end{array}$ & $\begin{array}{c}\text { Massa } \\
\text { específica } \\
\text { seca } \\
\left(\mathrm{g} / \mathrm{cm}^{3}\right)\end{array}$ \\
\hline 402 & Norte & $\mathrm{A}-2-4$ / NA-NS' & 5,5 & 2,128 & 4,5 & 2,143 & 5,0 & 2,110 & 0,9 & 1,0 \\
\hline 405 & Norte & $A-1-b$ / NS'/NA' & 4,0 & 2,074 & - & - & 7,0 & 2,160 & 0,6 & 1,0 \\
\hline 414 & Sul & $A-1-b /$ - & 4,4 & 2,227 & 4,5 & - & 6,2 & 2,214 & 0,7 & 1,0 \\
\hline 418 & Norte & $A-1-b / N G^{\prime}$ & 7,2 & 2,163 & 6,5 & 2,179 & 9,0 & 2,050 & 0,7 & 1,1 \\
\hline 423 & Norte & $A-1-b$ / NG' & 3,7 & 2,429 & 4,3 & 2,416 & 8,2 & 2,110 & 0,5 & 1,1 \\
\hline 429 & Norte & $\mathrm{A}-2-6$ / NG' & 7,1 & 2,423 & 5,1 & 2,470 & 7,3 & 2,053 & 0,7 & 1,2 \\
\hline 431 & Norte & A-2-4 / NS'-NA' & 7,9 & 2,107 & & & 2,1 & 7,912 & 0,0 & 0,0 \\
\hline 434 & Norte & $A-1-b / N S^{\prime}-N A^{\prime}$ & 10,9 & 1,880 & 12,3 & 1,856 & 2,1 & 7,774 & 5,9 & 0,2 \\
\hline 456 & Norte & A-2-4 / NS'-NG' & 9,9 & 1,797 & 9,7 & 1,801 & 8,2 & 2,000 & 1,2 & 0,9 \\
\hline 460 & Sul & A-7-6 / LG' & 16,1 & 1,566 & 17,2 & 1,550 & 20,2 & 1,730 & 0,9 & 0,9 \\
\hline 482 & Sul & A-2-4 / - & 7,2 & 2,067 & 6,9 & 2,073 & 4,7 & 1,980 & 1,5 & 1,0 \\
\hline 492 & Sul & $A-1-b /-$ & (mate & ial saturado n & momento de & coleta) & 12,3 & 1,840 & - & - \\
\hline
\end{tabular}


Como se pode notar, em muitos casos, a energia de compactação utilizada no laboratório não reproduziu com precisão aquela situação em que o solo se encontrava no campo, pois a deficiência de compactação nos serviços de campo é geral, infelizmente, dificultando a reprodução em laboratório das condições de campo, na obtenção do módulo de resiliência de laboratório. Infelizmente a quantidade de recursos destinada a este estudo não permitiu a realização de novos ensaios, com energias de compactação diferenciadas. Para estudos posteriores dessa mesma natureza, o autor recomenda utilizar pelo menos duas energias de compactação nos ensaios de compactação, para então determinar o $C B R$ e o módulo de resiliência, sendo: (i) energia Proctor Normal e (ii) energia Proctor Modificado.

Observou-se, como já descrito, que às vezes a energia alcançada em campo não atinge a normal e, em outros casos, ao contrário, pode exceder a de laboratório. No primeiro caso, não se pode afirmar que é um problema de especificação (que em geral aceita como limite mínimo 95\% da energia normal, o que deveria ser abolido da especificação de projetos), ou proveniente da falta de controle e fiscalização detalhadas, ou ainda se os numerosos ciclos de secagem e umedecimento pelos quais o solo passa, afetam seu estado, desestruturando os solos, e fazem com que o peso específico aparente de campo seja às vezes tão baixo. No segundo caso, a perda de umidade de certos solos, leva a uma contração e aumento do peso específico aparente seco de campo. Estes fatos demonstram algumas reflexões importantes: maior atenção às especificações e serviços de campo, a drenagem é fundamental para que a umidade de equilíbrio não seja superior à ótima empregada na compactação, que solos sensíveis e expansíveis em presença de água devem ser tratados ou substituídos. 

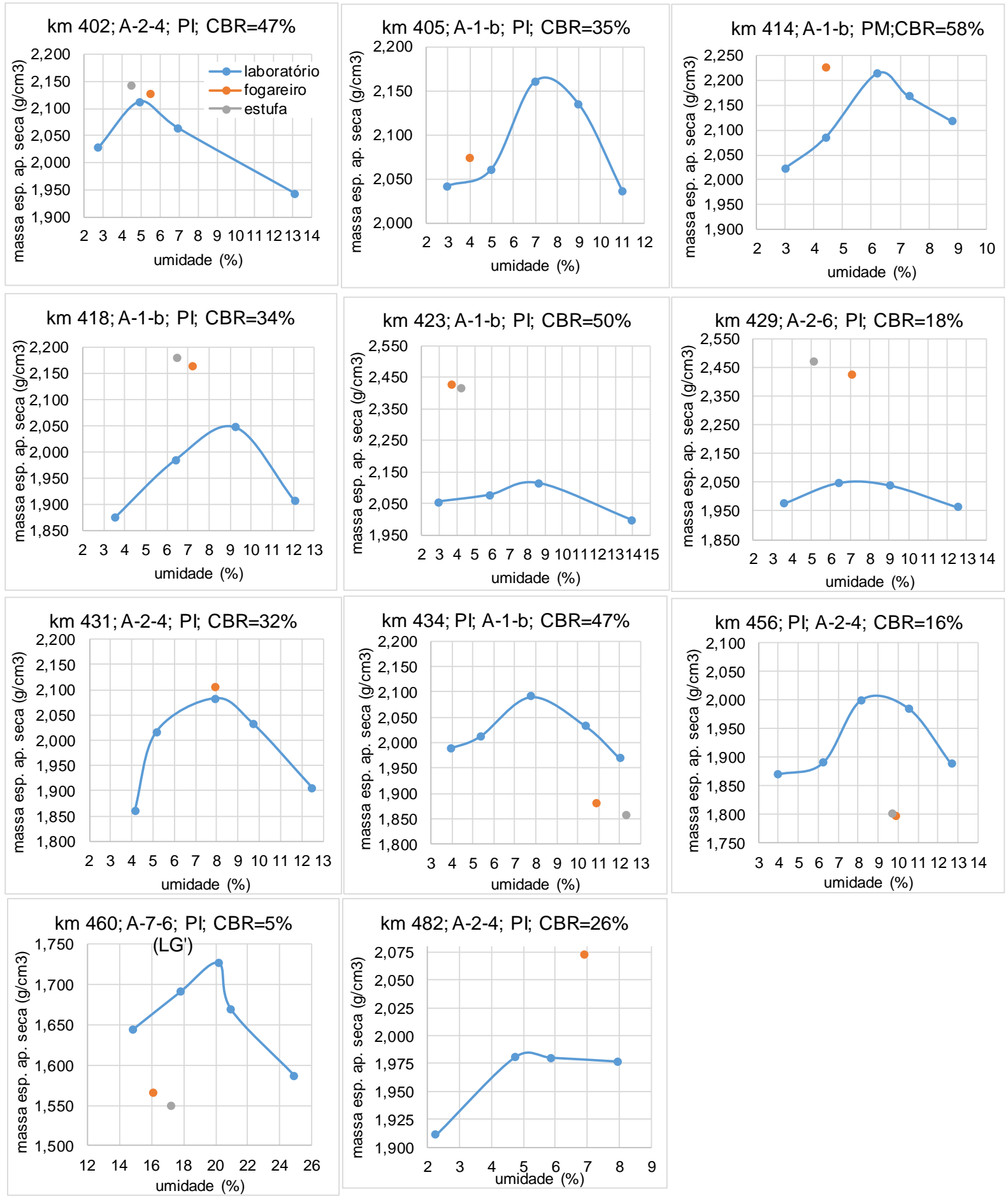

\section{km 482; A-2-4; Pl; CBR=26\%}

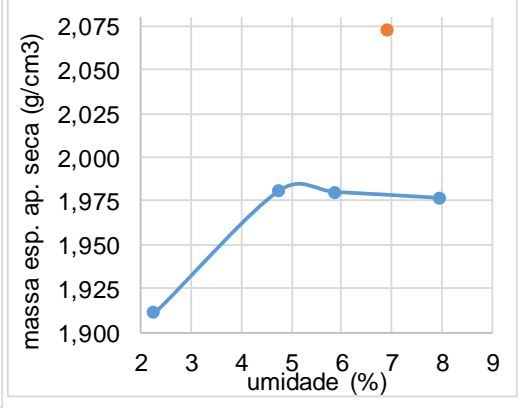

Figura 3.10: Comparativo entre condições de peso específico aparente e umidade de campo versus laboratório (curva de compactação para a energia adotada) 


\subsection{Resultados de retroanálise dos módulos do subleito dos locais sondados}

Os resultados dos ensaios com FWD nos locais em estudo foram retroanalisados a partir da equação 3.2, recomendada pelo método da AASHTO/93.

Os valores de módulo de resiliência retroanalisados pela equação da AASHTO/93 são apresentados na Figura 3.11 a seguir.

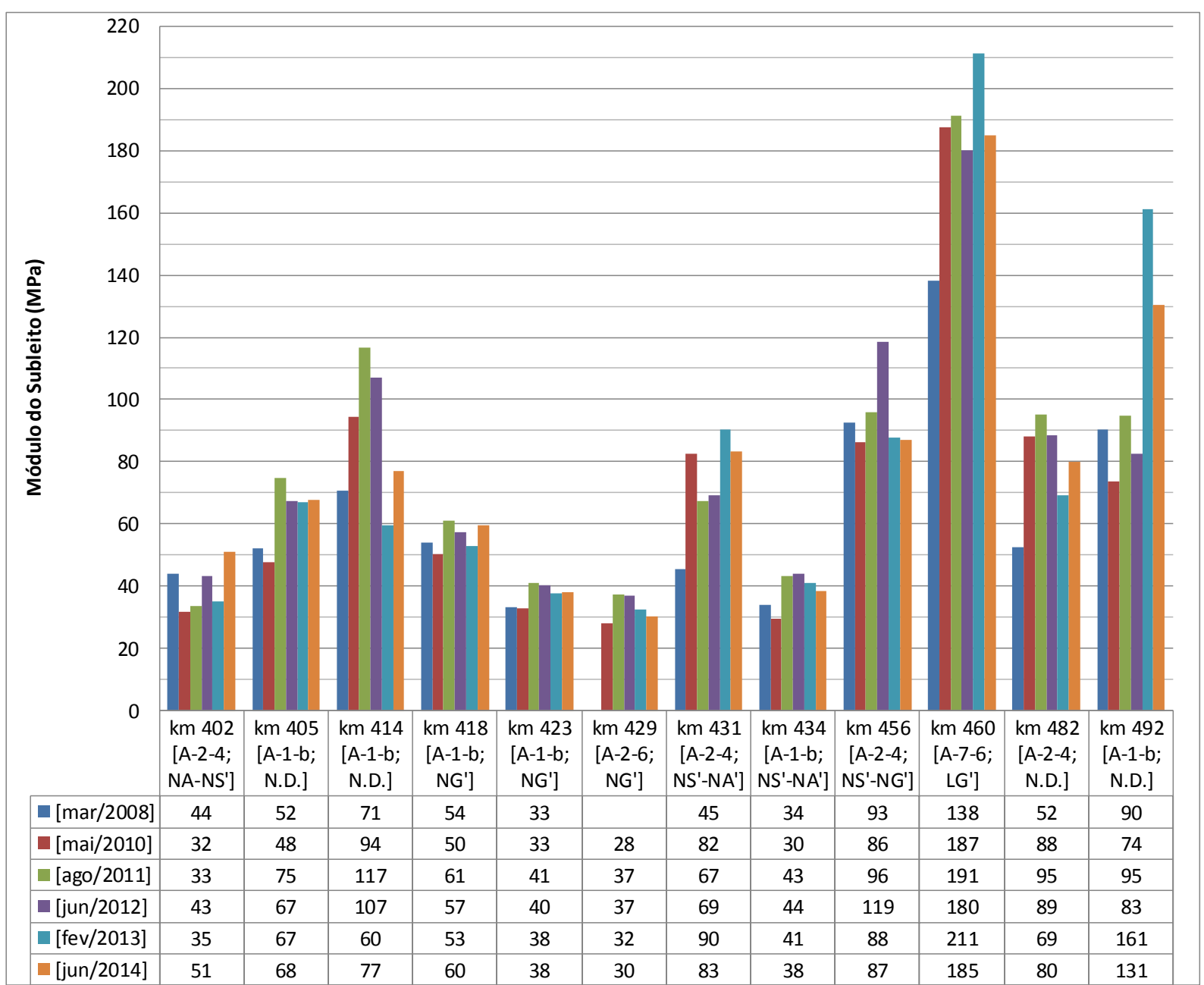

Figura 3.11: Valores de módulo de subleito retroanalisado através da equação da AASHTO/93

Verificam-se variações importantes nos valores de módulo de resiliência retroanalisados, que podem interferir diretamente no comportamento mecânico da estrutura sobrejacente. Para verificar a origem destas variações, recorreu-se aos dados de pluviosidade no período. Os dados são apresentados na sequência. 
A Figura 3.12 a seguir apresenta a pluviosidade horária (Pluvio24H12GMT-mm) nos períodos de antes e durante os levantamentos deflectométricos com FWD. Os dados foram coletados no site da SINDA/INPE (Sistema Integrado de Dados Ambientais / Instituto Nacional de Pesquisas Espaciais), para a Plataforma de Coleta de Dados $(P C D)$ localizada no município de Registro/SP. A Tabela 3.16 apresenta a data exata dos levantamentos nos locais em estudo. 

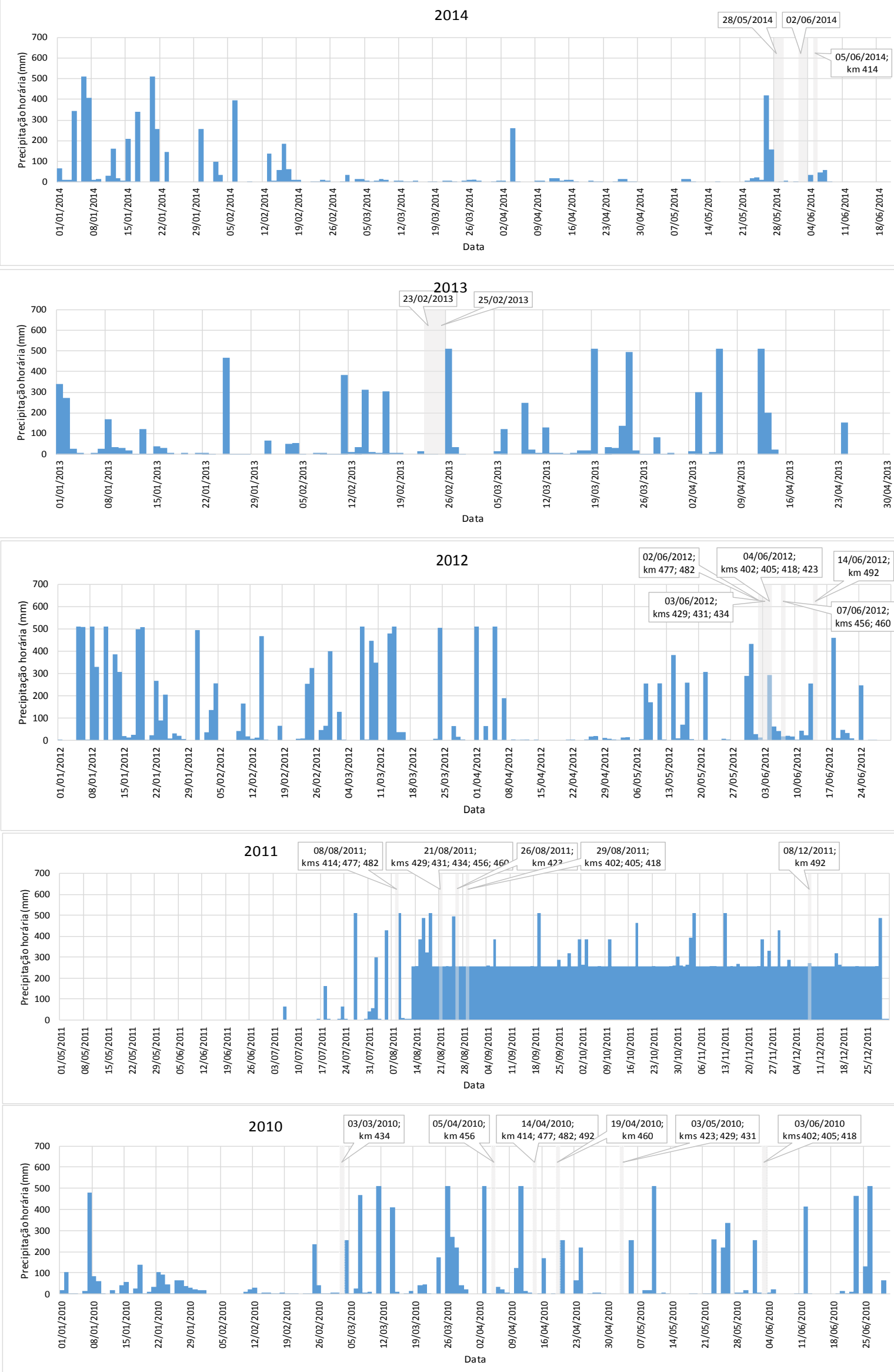

Figura 3.12: Precipitação horária $(\mathrm{mm})$ no período do levantamento com $F W D$ (2010 a 2014) 


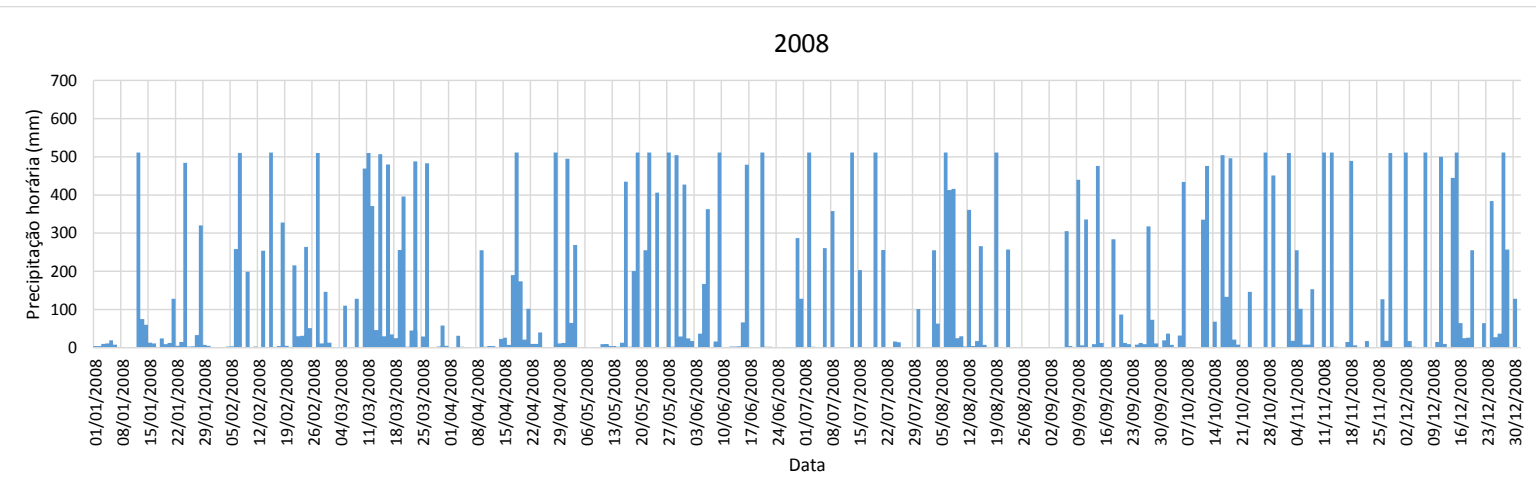

Figura 3.13: Precipitação horária $(\mathrm{mm})$ no período do levantamento com $F W D(2008)$

Tabela 3.16: Data dos levantamentos em cada local estudado

\begin{tabular}{cccccc}
\hline \multirow{2}{*}{$\mathbf{k m}$} & \multicolumn{5}{c}{ Data dos levantamentos com FWD } \\
\cline { 2 - 6 } & $\mathbf{2 0 1 0}$ & $\mathbf{2 0 1 1}$ & $\mathbf{2 0 1 2}$ & $\mathbf{2 0 1 3}$ & $\mathbf{2 0 1 4}$ \\
\hline 402 & 3-jun & 29-ago & 4-jun & 24-fev & 3-jun \\
\hline 405 & 3-jun & 29-ago & 4-jun & 24-fev & 2-jun \\
\hline 414 & 14-abr & 8-ago & 14-jun & 23-fev & 5-jun \\
\hline 418 & 3-jun & 29-ago & 4-jun & 24-fev & 2-jun \\
\hline 423 & 3-mai & 26-ago & 4-jun & 24-fev & 2-jun \\
\hline 429 & 3-mai & 21-ago & 3-jun & 24-fev & 2-jun \\
\hline 431 & 3-mai & 21-ago & 3-jun & 24-fev & 2-jun \\
\hline 434 & 3-mar & 21-ago & 3-jun & 24-fev & 2-jun \\
\hline 456 & 5-abr & 23-ago & 7-jun & 24-fev & 2-jun \\
\hline 460 & 19-abr & 23-ago & 7-jun & 24-fev & 2-jun \\
\hline 482 & 15-abr & 8-ago & 2-jun & 23-fev & 28-mai \\
\hline 492 & 15-abr & 8-dez & 14-jun & 25-fev & 29-mai \\
\hline
\end{tabular}

\subsection{Análises comparativas entre os valores de módulo obtidos em campo}

A partir dos dados obtidos na pesquisa, inicialmente foi realizada uma comparação entre os valores de módulo de resiliência obtidos para o subleito obtidos em campo.

A Figura 3.14 apresenta o comparativo entre os valores de módulo de resiliência retroanalisados a partir da equação da $A A S H T O / 93$ e aqueles obtidos a com o uso do software $B A K F A A \Theta$. Importante ressaltar que em ambos os casos foi utilizado o coeficiente $C=0,33$ recomendado pelo manual da $A A S H T O / 93$ para obtenção de valores de módulo de resiliência do subleito a partir de retroanálise. 
A Figura 3.18 apresenta o comparativo entre os valores de módulo de resiliência retroanalisados a partir da equação da AASHTO/93 e aqueles obtidos através do ensaio de $L W D$ realizado diretamente sobre a camada de subleito.

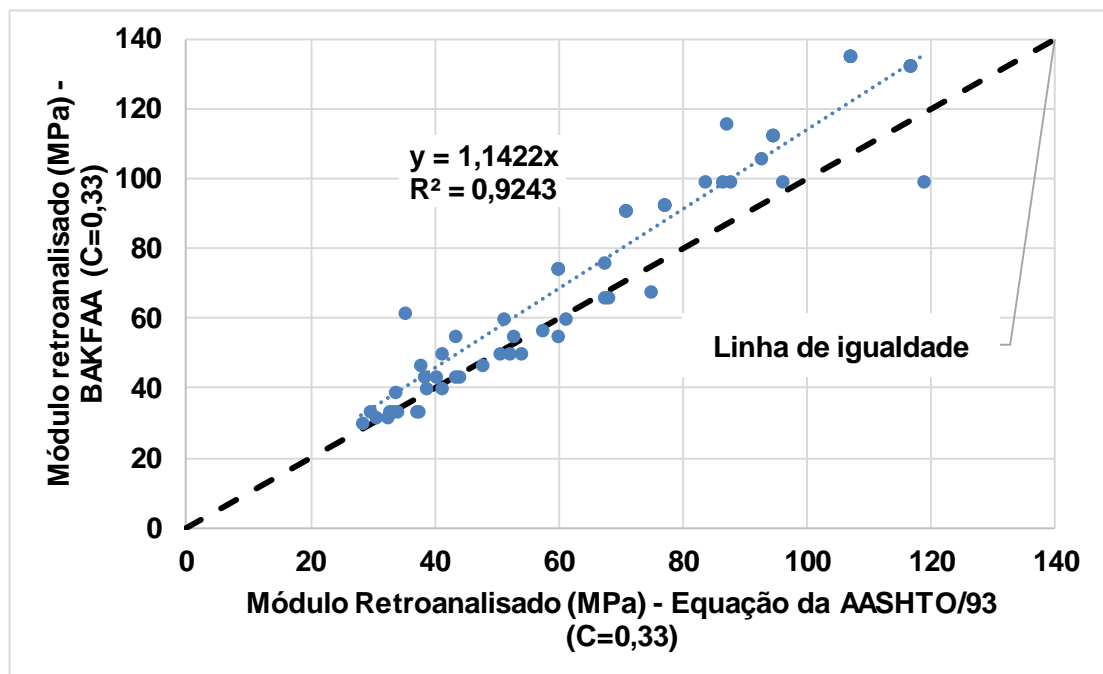

Figura 3.14: Comparativo entre os valores de módulo de resiliência retroanalisados (Equação da ASSHTO/93 versus software BAKFAA)

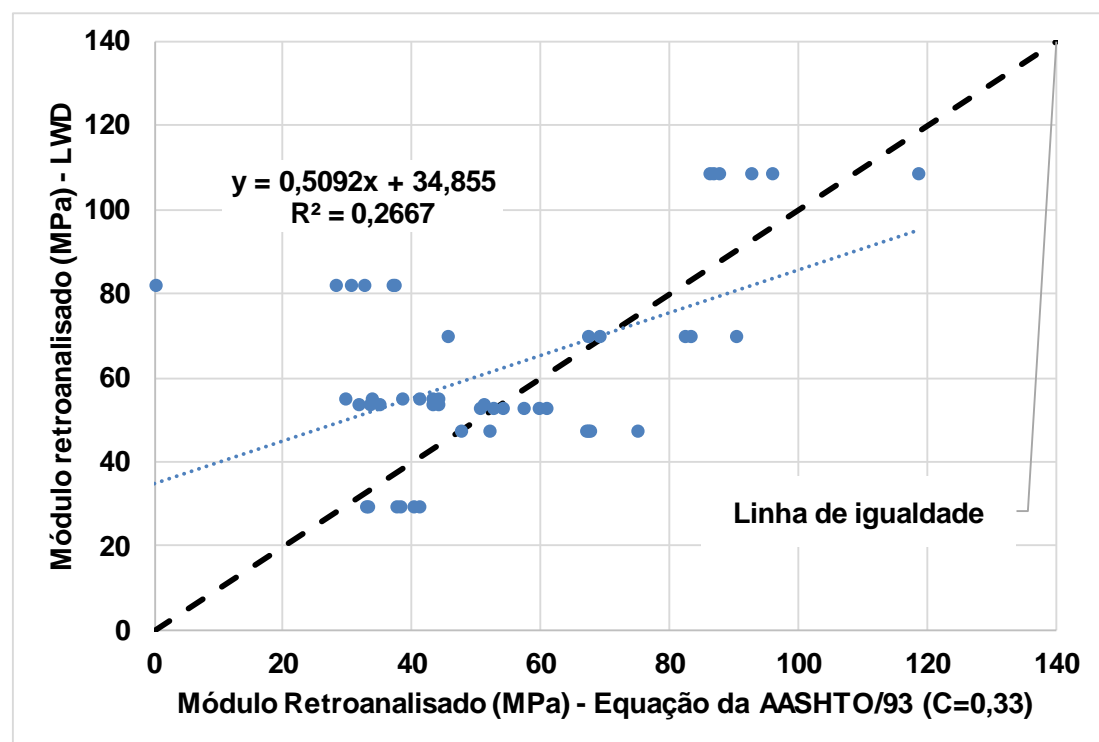

Figura 3.15: Comparativo entre os valores de módulo de resiliência retroanalisados (Equação da ASSHTO/93 versus módulo obtido diretamente com LWD sobre a camada)

Em análise aos gráficos, verifica-se que, apesar do uso do coeficiente $C=0,33$ para ambos os métodos (equação da $A A S H T O / 93$ e $B A K F A A \Theta$ ), os valores retroanalisados com uso do software $B A K F A A \AA$ apresentaram-se, em sua maioria, um pouco 
superiores aos valores obtidos pela equação da $A A S H T O / 93$, mas ainda bem próximos.

Pelo comparativo entre os valores obtidos com uso da equação da AASHTO/93 e com o uso do $L W D$ diretamente sobre a camada, verifica-se bastante dispersão em torno da linha de igualdade e da linha de tendência. Importante ressaltar que são dados de diferentes datas, ou seja, os valores obtidos com a equação da AASHTO/93 são relativos aos dados de monitoramento do pavimento com FWD de diferentes anos enquanto os valores obtidos com uso do $L W D$ são da data específica em que o poço de inspeção foi realizado. Conhecendo-se esta premissa, pode-se verificar que, na maior parte dos casos, o valor lido com o $L W D$ está dentro do espectro de variação dos valores obtidos com a equação da AASHTO/93 a partir dos dados de deflexão anuais do pavimento, com algumas poucas exceções. Estes dados novamente corroboram a importância da consideração da drenagem e da pluviosidade nas análises de dados e conclusões acerca do estado das estruturas de pavimentos.

\subsection{Comparativo entre valores de Módulo de resiliência (laboratório x retroanalisado)}

Com base nos dados obtidos, procurou-se aqui verificar se há uma boa correlação entre os valores de módulo de resiliência dos solos do subleito obtidos no campo e no laboratório. A Figura 3.16 a seguir apresenta os gráficos comparativos entre os valores de módulo de resiliência obtidos em laboratório e em campo a partir dos dados do FWD (equação da $A A S H T O / 93$, com coeficiente $C=0,33$ ) para a rodovia em estudo. 

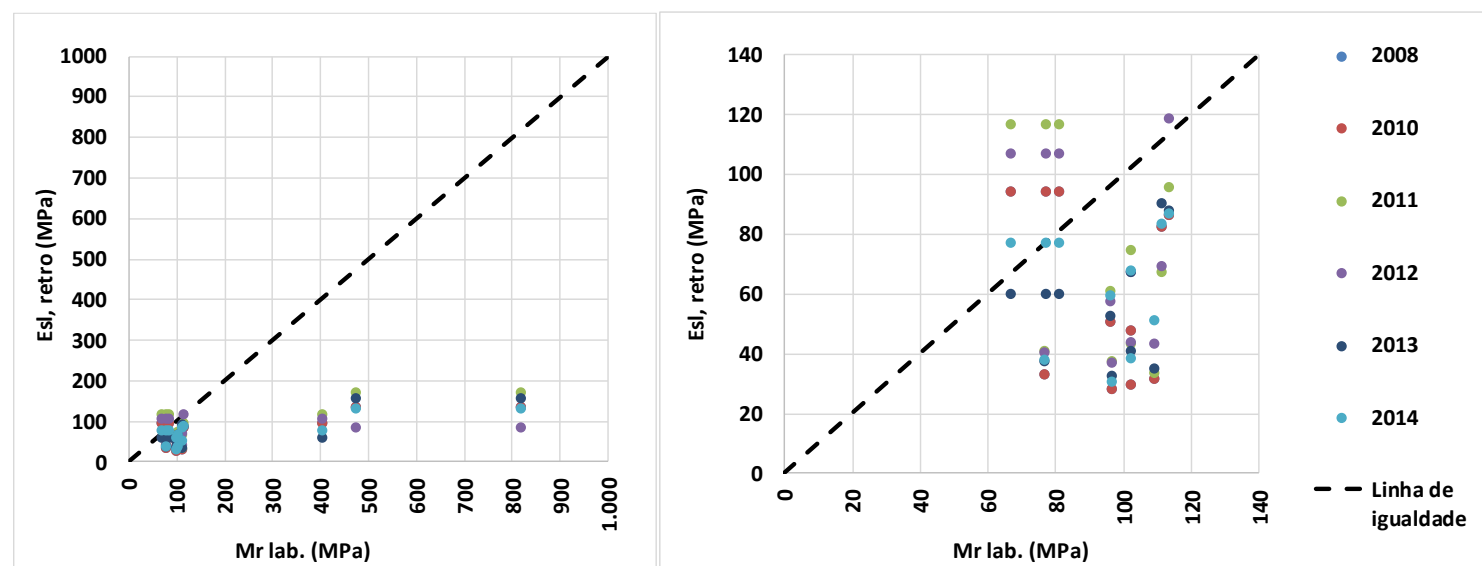

Figura 3.16: Gráficos comparativos entre os valores de módulo obtidos no campo (eq. AASHTO/93, $C=0,33$ ) e no laboratório, sendo: (a) todos os dados e (b) valores de módulo limitados em $140 \mathrm{MPa}$

No primeiro gráfico, verifica-se que, para os valores de módulo de resiliência de laboratório superiores a $120 \mathrm{MPa}$, os valores de módulo de resiliência retroanalisados em campo ficaram muito distantes (menores) dos valores de laboratório. Atribui-se tal comportamento, a algumas prováveis falhas no procedimento da pesquisa, entre elas: (i) as condições de peso específico aparente e umidade utilizadas na compactação dos corpos de prova no ensaio para obtenção dos valores de módulo de resiliência de laboratório não correspondiam às condições de campo, (ii) a condição de secagem do corpo de prova em laboratório da amostra do km 414 sul, por exemplo, pode ter conduzido a tensões de sucção elevadas, elevando demasiadamente o valor do módulo de laboratório, situação que dificilmente se reproduz no campo (valor de módulo de $402 \mathrm{MPa}$ após secagem), (iii) solos finos podem ser extremamente sensíveis às condições de umidade e, em laboratório, podem dar respostas de módulo muito superior ao real de campo, em grande parte das condições de operação do pavimento, (iv) se houver trincamento da camada superior do subleito por perda de umidade, durante o processo executivo, os ensaios de laboratório não conseguem reproduzir, por uma questão de escala e anisotropia do sistema, a reação do conjunto composto por material e trincas, entre outras razões.

Já no segundo gráfico, verifica-se que em algumas situações os valores de módulo de campo e laboratório chegaram bem próximos da igualdade, muito embora as variações dos valores de módulo obtidos no campo tenham se mostrado bastante relevantes. Ou seja, ao que tudo indica, em muitos dos casos, aquela condição específica do solo em que o módulo de laboratório foi aferido, corresponde a apenas uma das muitas condições verificadas no campo. Em alguns outros casos, a condição 
de laboratório provavelmente não correspondeu a nenhuma das situações verificadas no campo.

De qualquer maneira, o gráfico ilustra bem a dificuldade de se prever comportamento do módulo de resiliência em serviço, a partir dos dados de laboratório. Embora se constate esta dificuldade, torna-se relevante e imperioso determinar em laboratório o módulo de resiliência dos solos e materiais de subleito, incentivando-se a se determinar em diferentes condições de compactação (energia) e de umidade, para compreender as possíveis variações que podem ocorrer em campo. A questão de trincamento das camadas de solos finos, por perda de umidade após a compactação, ainda é um desafio para simular as possíveis quedas de módulo de resiliência devido ao processo de contração. 


\subsection{Previsibilidade do Módulo de Resiliência pelo valor de $C B R$}

Com base nos dados obtidos foi possível elaborar o gráfico comparativo entre os modelos de correlação direta $C B R$ e $M R$ da literatura e os valores da correlação direta CBR e $M R$ obtidos em laboratório.

A Figura 3.17 apresenta o gráfico obtido para os materiais coletados na primeira campanha, diretamente no subleito da pista de rolamento. Grande parte dos materiais foi identificada como de natureza granular (arenosa) e comportamento não-laterítico (exceto amostra do $\mathrm{km} \mathrm{460).} \mathrm{As} \mathrm{amostras} \mathrm{foram} \mathrm{compactadas} \mathrm{na} \mathrm{energia}$ intermediária, apresentando elevado valor de $C B R$ (maior parte dos valores acima de $20 \%$ ) por serem materiais com parcela granular. Os pontos em preto representam os resultados de laboratório para os materiais granulares (arenosos) enquanto os pontos em vermelho representam os resultados para os materiais finos (coesivos). Nota-se, porém, que no caso dos materiais granulares/arenosos, os valores de módulo de laboratório não ultrapassam o patamar de $110 \mathrm{MPa}$ (fixando-se $\sigma 3=0,014 \mathrm{MPa}$, para materiais granulares, conforme recomendado pela AASHTO). A única exceção se faz para o solo argiloso de comportamento laterítico (LG') encontrado no poço de inspeção do km 460, que apresentou valor de CBR relativamente baixo (da ordem de $5 \%$ ), porém módulo de resiliência de laboratório da ordem de $900 \mathrm{MPa}$ (fixando-se $\sigma \mathrm{d}=0,041 \mathrm{MPa}$, conforme recomendações da AASHTO). Assim sendo, observou-se fraca correlação direta entre os parâmetros $C B R$ e $M R$ para estas condições, o que corrobora a indicação de alguns pesquisadores brasileiros que recomendam o não emprego do $C B R$ para determinação indireta do módulo de resiliência. Conclui-se que não se deve aplicar a correlação direta da AASHTO/93 para materiais granulares com CBR maior que 15\%, nem tão pouco para solos lateríticos. 


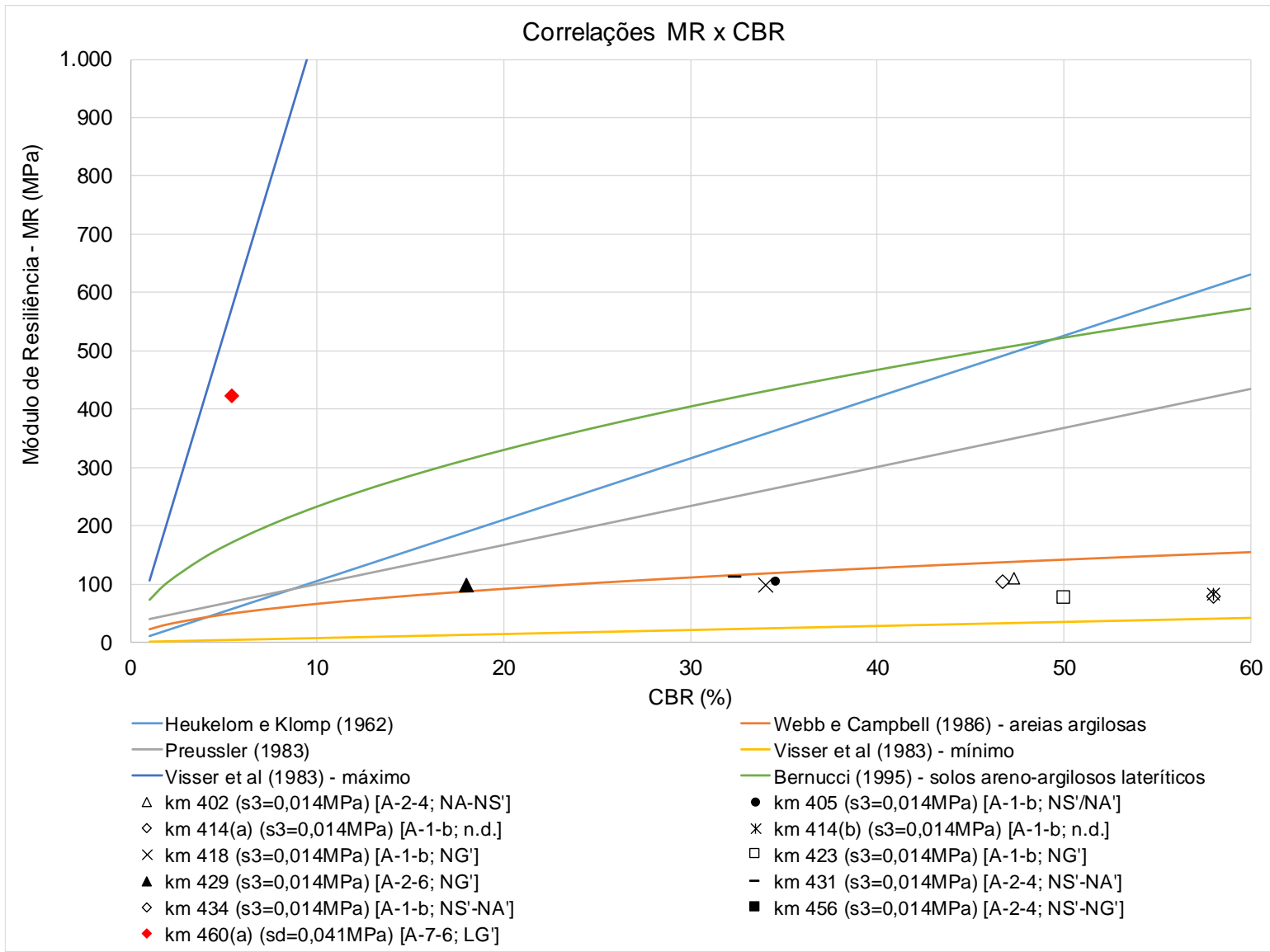

Figura 3.17: Correlações $C B R \times M R$ - campanha 1 - Ensaios na energia Intermediária (modelos da literatura versus resultados obtidos)

O gráfico da Figura 3.18 apresenta o gráfico comparativo para a correlação $C B R \times M R$ para os materiais coletados na $2^{\mathrm{a}}$ campanha (materiais coletados próximos à faixa de domínio da rodovia). As amostras foram compactadas na energia normal. Os pontos vermelhos representam os resultados para os materiais finos (coesivos) enquanto os pontos em preto representam os resultados dos materiais granulares (arenosos).

Notam-se baixa aderência aos modelos da literatura, bem como fracas correlações diretas entre os valores de $C B R$ e $M R$ de laboratório. Com base nesta conclusão, serão estudadas, mais adiante nesta tese, correlações para determinação do módulo de resiliência, a partir de mais parâmetros obtidos em ensaios de solos, além do próprio $C B R$ de laboratório. 


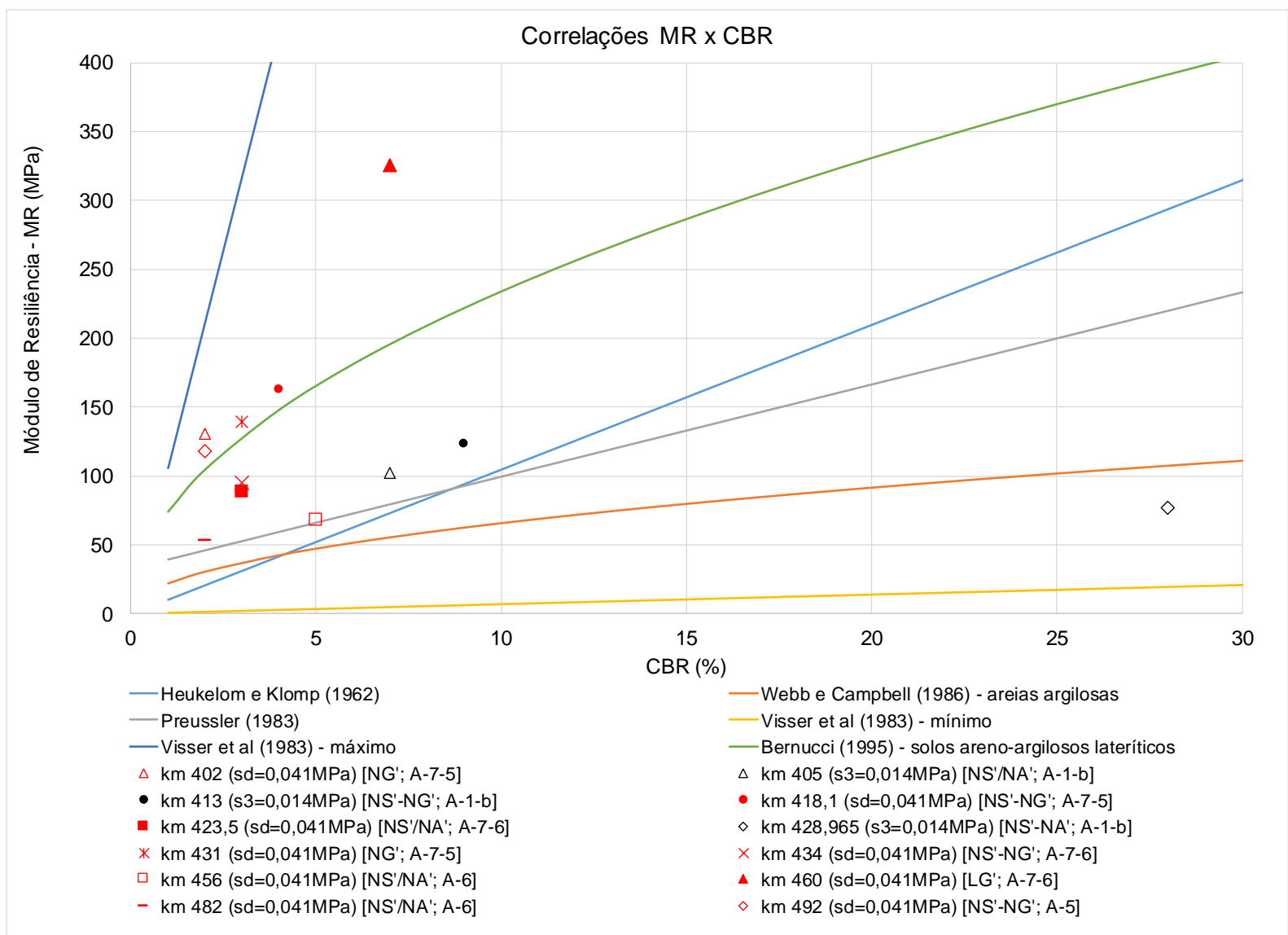

Figura 3.18: Correlações $C B R \times M R$ - campanha 2 - Ensaios na energia Normal (modelos da literatura versus resultados obtidos)

A Figura 3.19 apresenta os gráficos do tipo boxplot para os valores de módulo de resiliência de laboratório obtidos nesta pesquisa, por tipo de solo (classificações $H R B$ e $M C T$ ) e diferentes energias de compactação, enquanto a Figura 3.20 apresenta os gráficos do tipo boxplot para os valores da relação direta $\mathrm{MR} / C B R$ por tipo de solo (classificação $H R B$ e $M C T$ ) e por energias de compactação utilizadas. Nota-se a elevada dispersão de valores de módulo e da relação direta MR/CBR. 


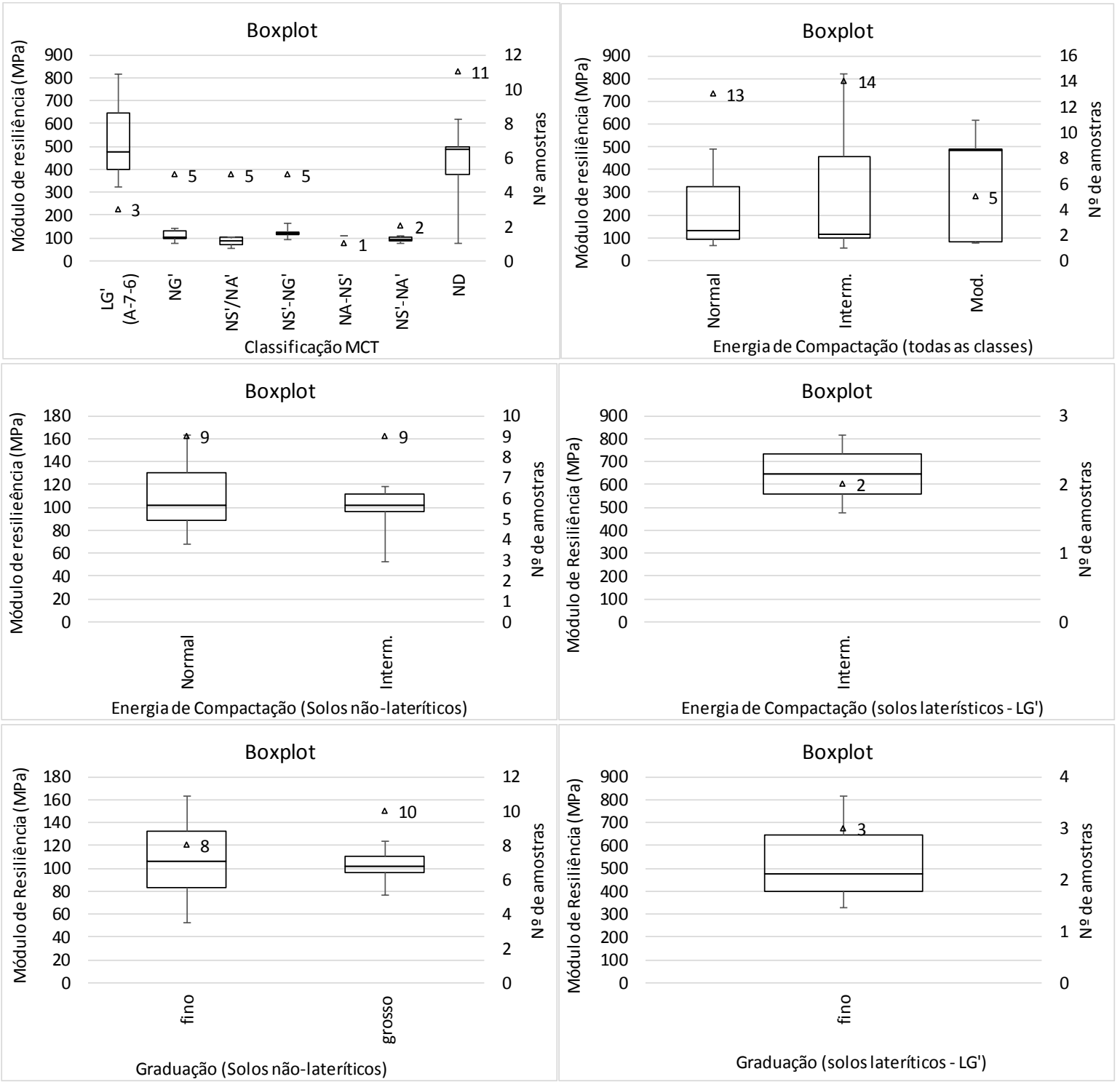

Figura 3.19: Gráficos boxplot dos valores de módulo de resiliência por tipo de solo e energia de compactação (estudo BR-116) 


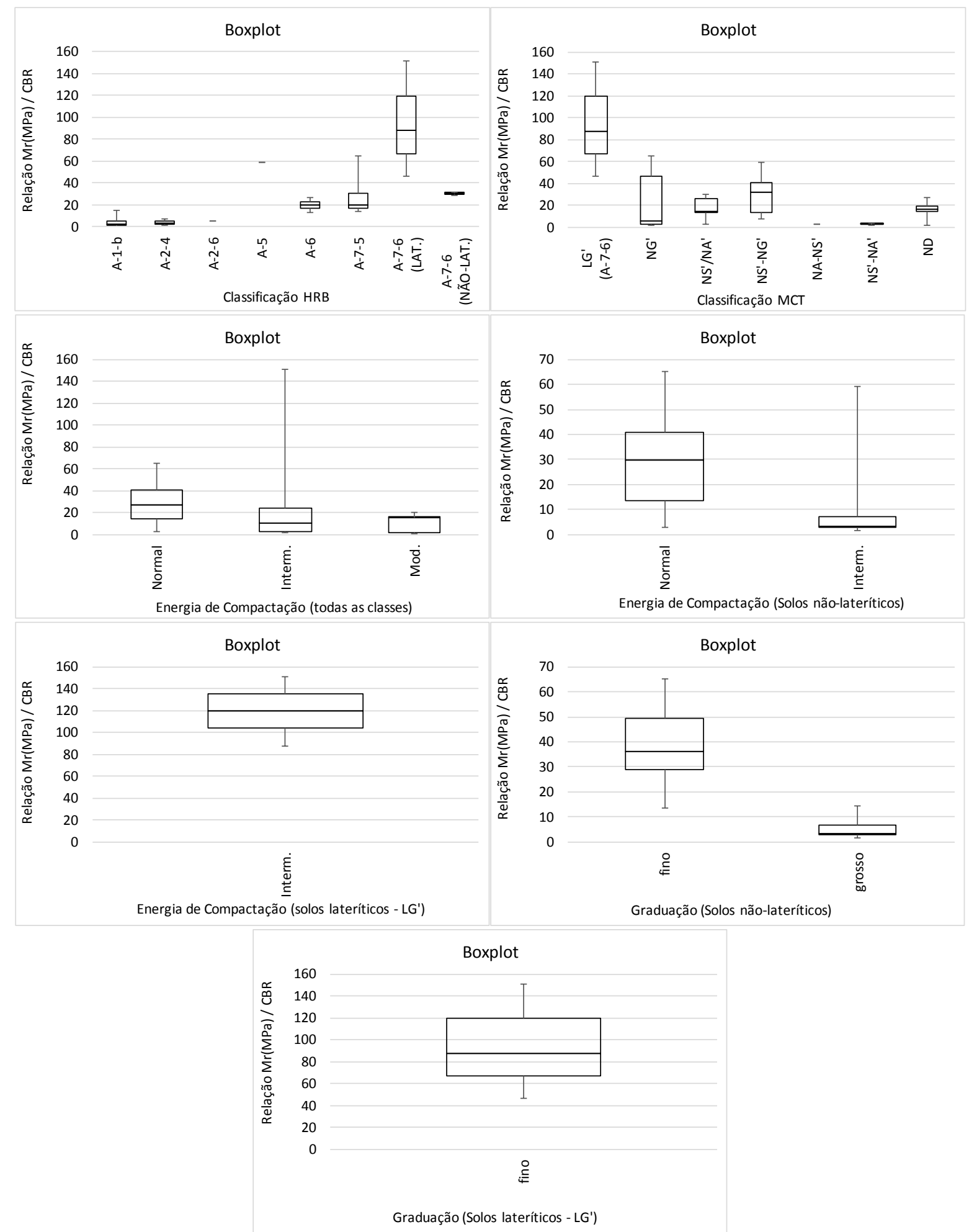

Figura 3.20: Gráficos boxplot dos valores individuais da relação MR/CBR por tipo de solo e energia de compactação (estudo BR-116)

Com base nos gráficos apresentados, nota-se a elevada dispersão de valores de módulo de laboratório, ainda que para um mesmo tipo de material bem como elevada dispersão da relação direta MR/CBR. Por este motivo, serão estudados nos itens 
subsequentes modelos que contemplam outros parâmetros do solo além do valor de $C B R$ de laboratório.

\subsection{Correlações para solos de graduação grossa}

Com base no estudo anterior, optou-se por estudar se há boa correlação entre os valores de módulos de resiliência de laboratório e os parâmetros obtidos nos diversos ensaios. Para os materiais de graduação grossa (arenosos), verificaram-se forte correlação direta entre o parâmetro $k 1$ e: peso específico aparente seco máximo, fraca correlação entre $k 1$ e teor de umidade, e não apresenta correlação com o percentual passante na peneira 200 (Figura 3.21). Já o parâmetro k2, apresentou igualmente forte correlação com o peso específico aparente seco máximo, fraca correlação com o teor de umidade, e com valor de CBR (Figura 3.22). 


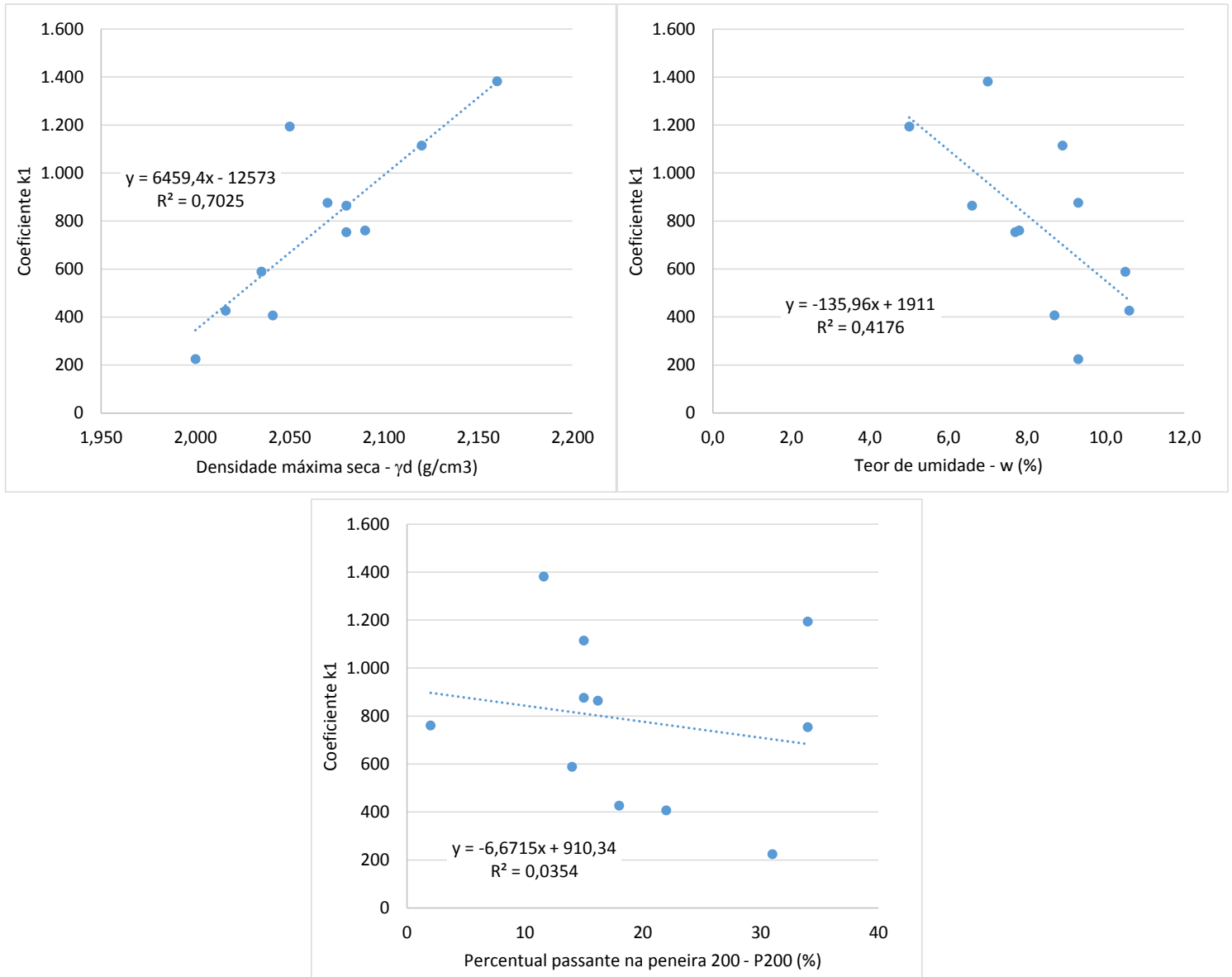

Figura 3.21: Correlações diretas entre o parâmetro $k 1$ e demais parâmetros de solos de graduação grossa não lateríticos 


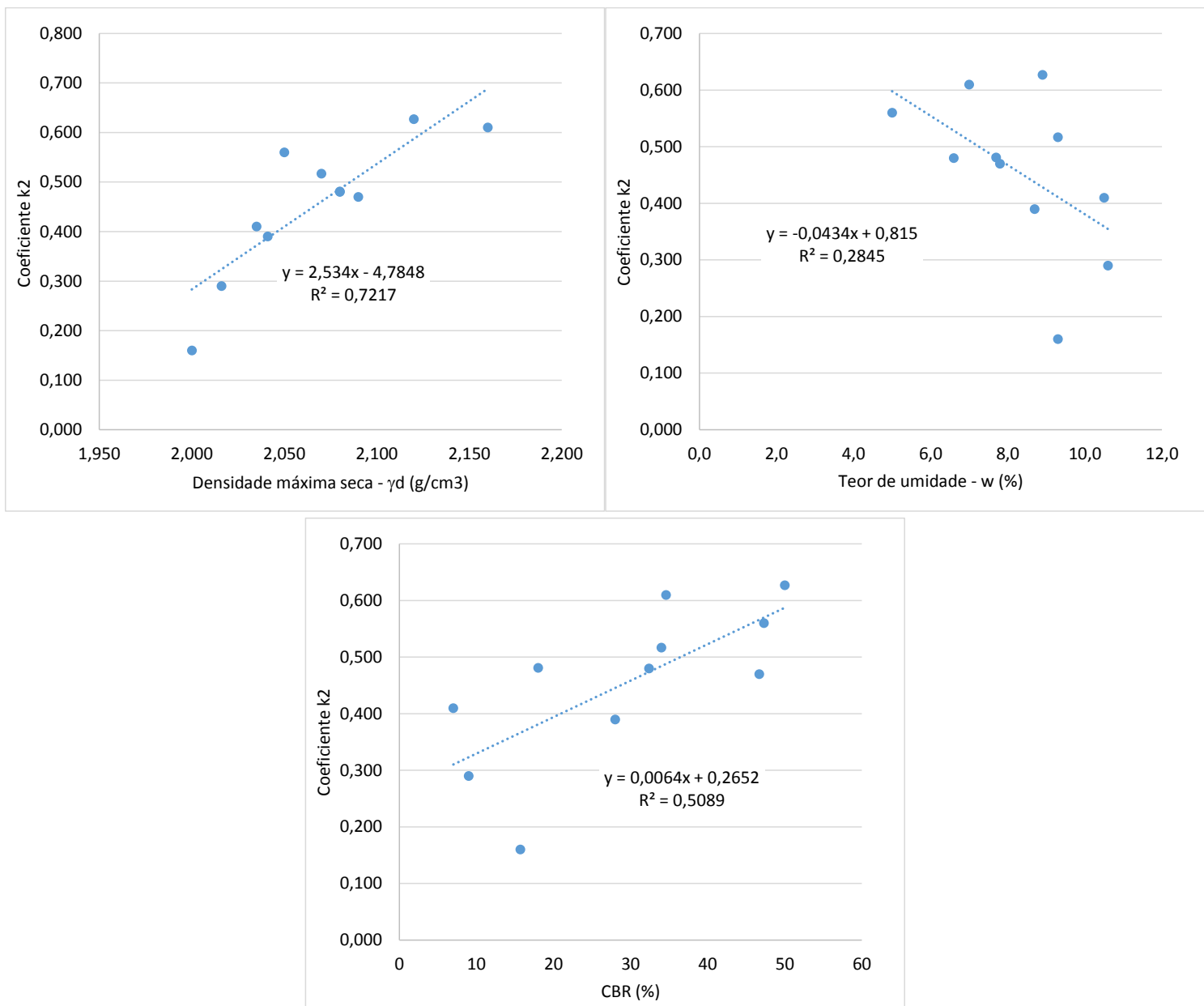

Figura 3.22: Correlações diretas entre o parâmetro $k 2$ e demais parâmetros de solos de graduação grossa não lateríticos

Assim sendo, com base nos gráficos apresentados e em estudos de regressões estatísticas realizadas, propõem-se os seguintes modelos de correlação para os solos estudados na presente pesquisa de graduação grossa (arenosos) não lateríticos, por serem aqueles que melhores resultados apresentaram, diferentemente dos solos finos lateríticos, onde não se constata boas correlações para determinação do módulo de resiliência:

$$
\begin{gathered}
M r(M P a)=k_{1} \cdot \sigma_{3}{ }^{k_{2}} \\
k_{1}=-10240+5584,4 \cdot \gamma_{d}-67,676 \cdot w+1,9511 \cdot P 200 ; R^{2}=0,72 \\
k_{2}=-3,5916+1,9505 \cdot \gamma_{d}-0,0068 \cdot w+0,0024 \cdot C B R ; R^{2}=0,70
\end{gathered}
$$




\subsection{Correlações para os solos finos}

Estudo semelhante ao do item anterior foi realizado para os solos de graduação fina (coesivos) da presente pesquisa. Determinaram-se correlações entre parâmetros k3: valor de $C B R$ (Figura 3.23); e k4: valores de $C B R$, peso específico aparente seco máximo, e teor de umidade (Figura 3.24).

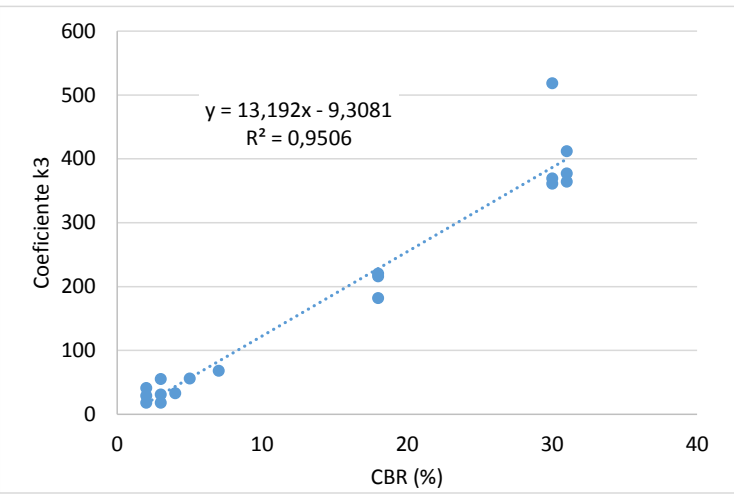

Figura 3.23: Correlações diretas entre o parâmetro $k 3$ e demais parâmetros de solos de graduação fina não lateríticos
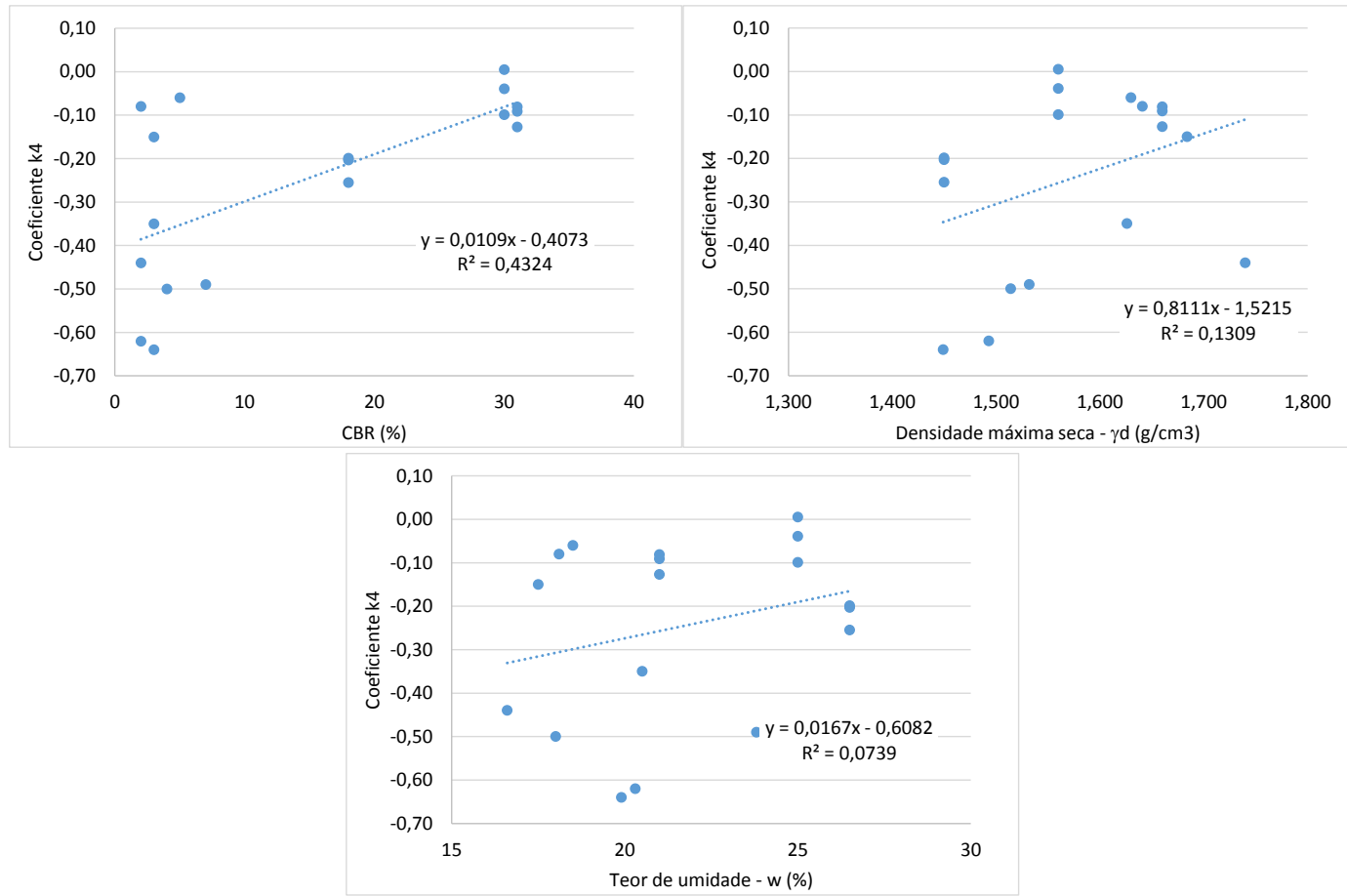

Figura 3.24: Correlações diretas entre o parâmetro k4 e demais parâmetros de solos de graduação fina não lateríticos 
Com base nos gráficos acima e estudos de regressões estatísticas, propõem-se os seguintes modelos de correlação para os solos estudados na presente pesquisa, de graduação fina (coesivos) não lateríticos:

$$
\begin{gathered}
M r(M P a)=k_{3} \cdot \sigma_{d}^{k_{4}} \\
k_{3}=13,192 \cdot C B R-9,3081 ; \mathrm{R}^{2}=0,95 \\
k_{4}=-3,357+0,0058 \cdot C B R+1,5046 \cdot \gamma_{d}+0,0303 \cdot w ; \mathrm{R}^{2}=0,52
\end{gathered}
$$

\subsection{Análise comparativa dos modelos propostos}

Como uma tentativa de validar os modelos propostos, nos itens 3.12 e 3.13 , as fórmulas para determinação de k1, k2, k3 e k4, bem como a determinação do valor do módulo do subleito, as formulações foram aplicadas em um banco de dados de ensaios de subleito contendo dados de um total de 49 rodovias do estado de São Paulo (banco de dados BD1, como será descrito mais adiante no item 4.1). O banco de dados também contém dados de módulo de resiliência retroanalisado do subleito a partir de dados do FWD para alguns dos pontos que puderam ser encontrados a partir do seu posicionamento. Para esta análise, foram utilizados cerca de 96 registros - 20 registros para o solo de graduação grossa não lateríticos e 76 registros para os solos de graduação fina não-lateríticos. Os resultados são apresentados na Figura 3.25 . 

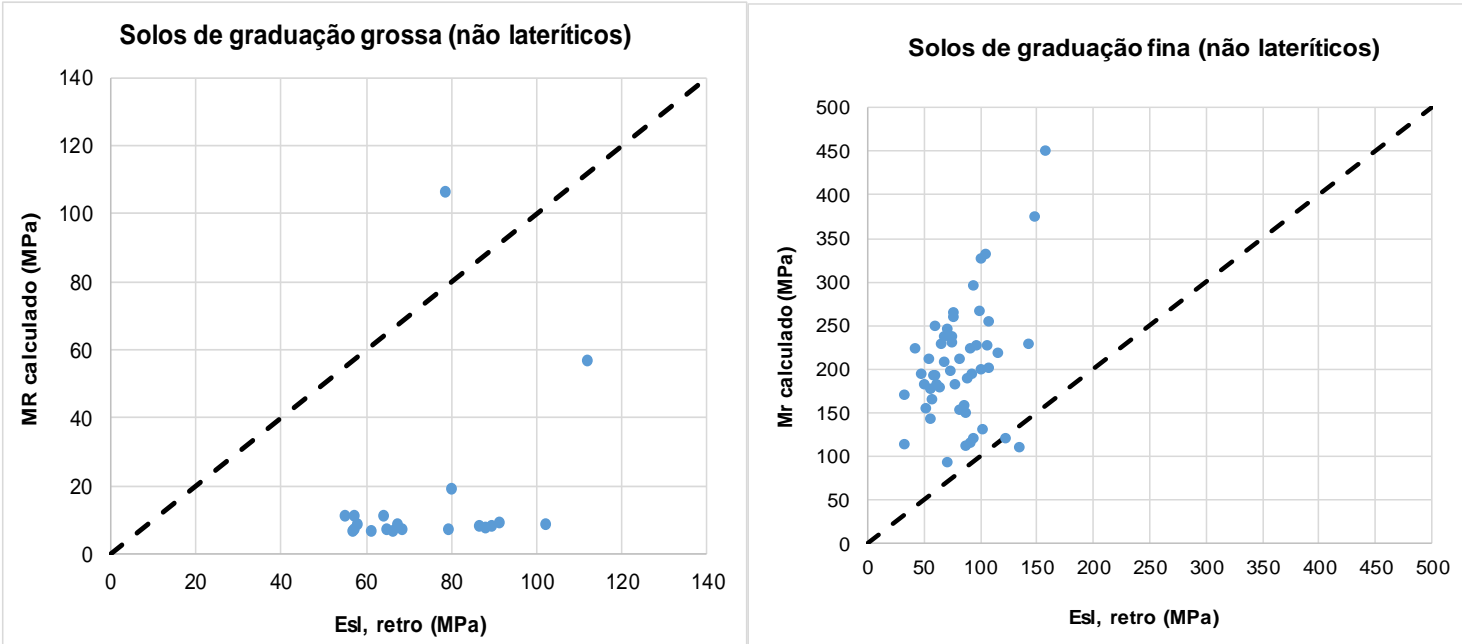

Figura 3.25: Tentativa de validação dos modelos propostos para (a) solos de graduação grossa e (b) solos de graduação fina

Obs.: No caso do modelo para solos de graduação grossa, fixaram-se os valores de k1 como sendo, no mínimo, igual a 10, tendo em vista que a aplicação do modelo resultou em muitos valores negativos do parâmetro e, consequentemente, valores negativos de módulo.

Como se pode verificar, a aplicação dos modelos obtidos no estudo de caso não aderiu adequadamente para solos de outras regiões e/ou natureza, mesmo observando-se as questões de tipo de graduação (fina ou grossa) e da natureza nãolaterítica do solo.

Conclui-se que este tipo de metodologia de modelagem só possa ser aplicada regionalmente, desde que reservada uma amostragem representativa para o local em questão, porém deve-se ter cuidado ao se aplicar para outros tipos de solos, de outras regiões e/ou de outra natureza.

\subsection{Estudo do comportamento do MR em campo}

O gráfico da Figura 3.26 a seguir ilustra a variação dos valores de módulos retroanalisados a partir da equação da AASHTO/93 para os dados disponíveis dos 
levantamentos com FWD dos meses: mar/2008 ; mai/2010; ago/2011; jun/2012; fev/2013 e jun/2014.

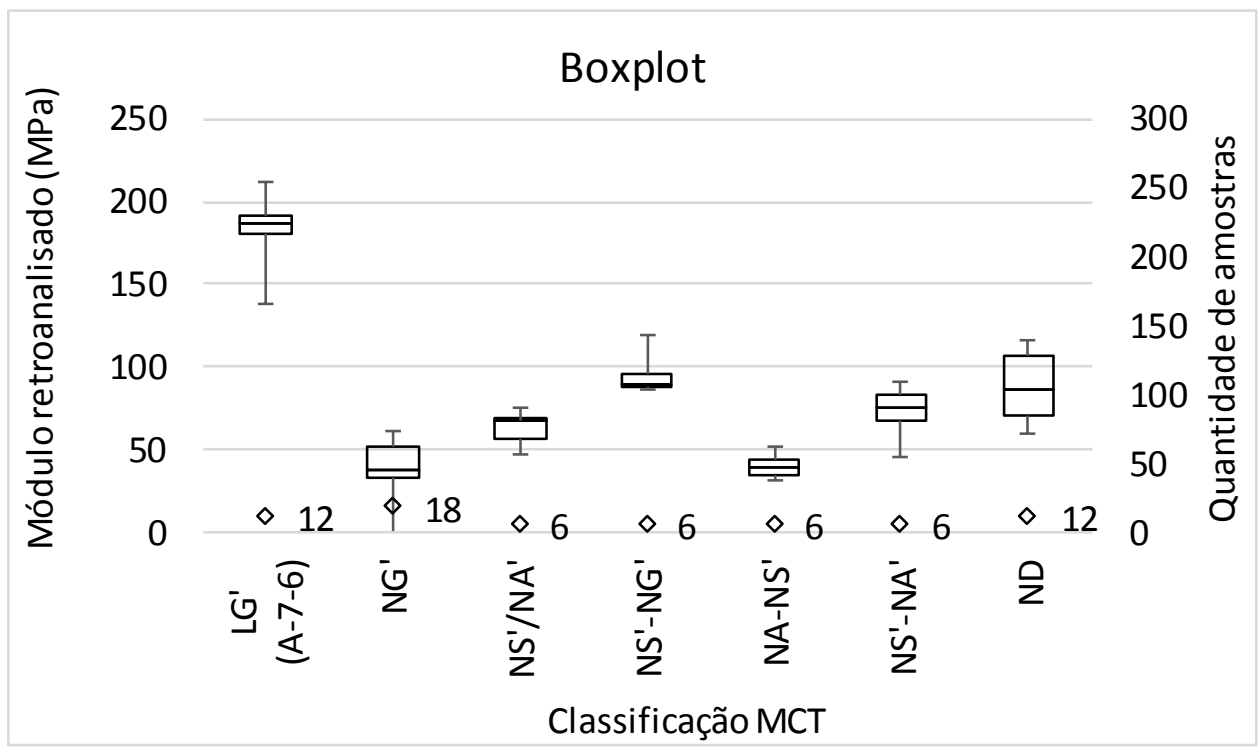

Figura 3.26: Gráficos boxplot dos valores de módulo de resiliência retroanalisados (AASHTO/93) por tipo de solo (estudo BR-116)

Os gráficos da Figura 3.27 a seguir ilustram a variação dos valores de módulos retroanalisados a partir da equação da AASHTO/93 para os dados disponíveis dos levantamentos com FWD para as condições de semana seca (pluviosidade horária máxima menor que $100 \mathrm{~mm}$ e pluviosidade horária média menor que $30 \mathrm{~mm}-5$ dias consecutivos antes dos ensaios com $F W D$ ) e semana chuvosa.
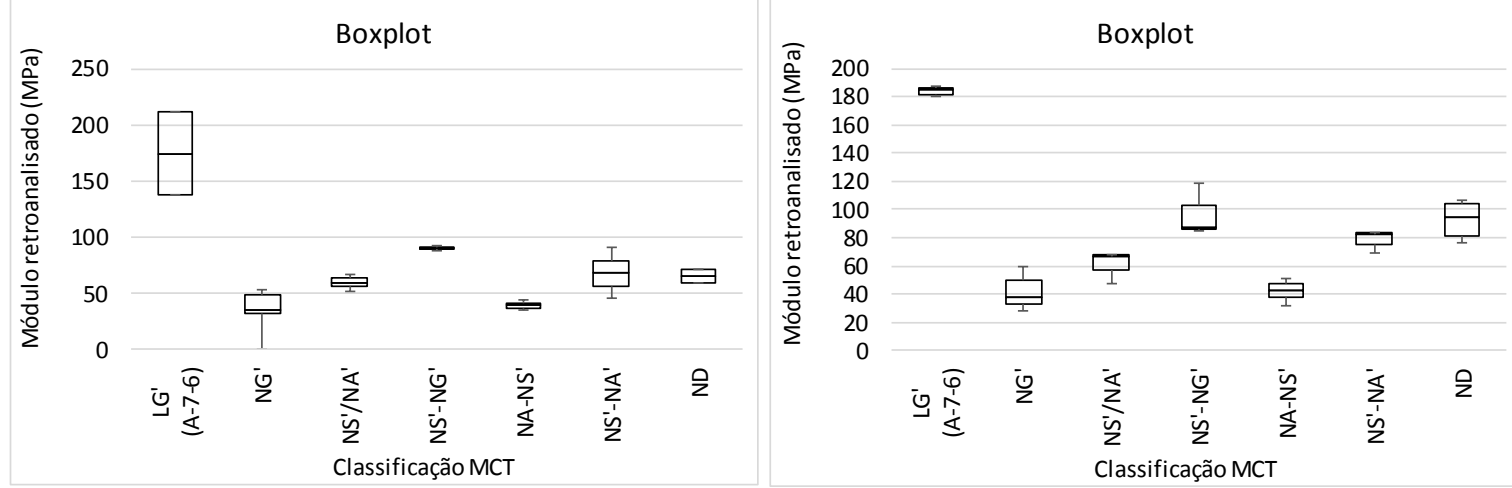

Figura 3.27: Gráficos boxplot dos valores de módulo de resiliência retroanalisados (AASHTO/93) por tipo de solo: (a) semana seca e (b) semana chuvosa 


\subsection{Conclusões parciais do estudo de caso}

Com base nos dados coletados e nas análises realizadas na presente pesquisa, podem-se tecer algumas conclusões, entre elas:

a) Verificou-se bastante razoabilidade na aplicação do coeficiente $c=0,33$, proposto pela $A A S H T O / 93$, na determinação de valores de módulos do subleito retroanalisados a partir dos ensaios de $F W D$, com base nos estudos comparativos entre as diversas metodologias de avaliação da estrutura. A não utilização desta correção pode levar a um cenário bastante desfavorável, pois sobrestima, quando das avaliações da capacidade estrutural do pavimento e dimensionamento de soluções de restauração.

b) Não é recomendável a utilização de relações diretas $M R / C B R$ nos casos de materiais granulares com $C B R$ superior a $12 \%$. Nestes casos, é recomendável a determinação do módulo de resiliência em laboratório dos solos e materiais de subleito, bem como o estudo da influência para diferentes condições de compactação (energia) e de umidade, para compreender as possíveis variações que podem ocorrer em campo. Também não foi verificada uma correlação direta adequada nos demais casos estudados (solos finos e granulares, independentemente do valor de $C B R$ ).

c) Os modelos da literatura que melhor representaram os valores obtidos em campo e laboratório na presente pesquisa foram os seguintes:

- modelo de Rada \& Witczak (1981) para determinação do módulo de materiais granulares nas condições de umidade ótima e peso específico aparente seco máximo relativo à energia intermediária de compactação;

- modelos da AASHTO/2002 e Malla \& Joshi (2006) para reproduzir os efeitos das variações das condições de umidade e peso específico aparente seco de campo para materiais granulares (arenosos).

d) Os modelos propostos na presente pesquisa podem ser utilizados para determinação dos módulos de subleito para materiais granulares e solos finos ocorrentes ao longo do eixo da rodovia em estudo, desde que utilizados com critério e sempre comparando com outros valores e modelos de referência. 
e) Deverá ser aumentado o universo amostral para cada tipo de solo em análise para o entendimento correto do comportamento dos materiais em campo.

Ao longo dos estudos percebe-se cada vez mais que é bem difícil obter correlações válidas entre os parâmetros do solo e o módulo de resiliência do subleito. Além disso, também se nota que o comportamento do módulo em campo (valores retroanalisados) podem ter tendências diferentes para um mesmo tipo de solo, o que leva a crer que o comportamento mecânico aferido "in situ" por retroanálise, venha a ter forte influência de outras características físicas do local em que foi implantado, além simplesmente das características dos solos do subleito. Infere-se que algumas características físicas do local possam ser bastante relevantes tais como: características geológicas e pedológicas locais, regime de chuvas e as características e potencial de drenagem do pavimento e dos tipos de solos; o tipo de seção (corte, aterro ou mista) entre outros. O segundo estudo de caso, realizado em rodovias do estado de São Paulo, objetivará avaliar estas características de campo. 


\section{ENSAIOS DE CAMPO E LABORATÓRIO - ESTUDO DE CASOS DE RODOVIAS DO ESTADO DE SÃO PAULO}

Tendo em vista o capítulo 3 e as conclusões parciais obtidas com o estudo de caso realizado em concessão federal, observou-se que para um estudo mais abrangente, dever-se-ia ampliar a gama de solos pesquisados para melhor compreender a importância do subleito e de suas variações nos projetos de pavimentação. Assim sendo, ampliou-se o estudo, inserindo uma coleta complementar de dados de modo a verificar a aplicabilidade das correlações estudadas no âmbito de uma rodovia para as demais e tornar as análises mais abrangentes.

O presente estudo de casos foi realizado com o objetivo de coletar dados de ensaios de campo e laboratório existentes, pertencente à ARTESP - Agência Reguladora de Transportes do Estado de São Paulo, para verificar correlações entre índices dos solos e variações no comportamento mecânico dos subleitos de pavimentos sujeitos a tráfego pesado e muito pesado do Estado de São Paulo. Para realização da pesquisa, foram coletados dados históricos de ensaios de subleito realizados na fase de projeto, bem como os dados de deflexão realizados com $F W D$ ao longo do período de Concessão para algumas rodovias concedidas do estado de São Paulo. Deve-se ressaltar que infelizmente não há um banco de dados organizado e conjunto da Agência, e os dados estão em geral em documentos separados e dispersos, com conteúdos e forma de apresentação bastante diferentes de concessão para concessão, o que torna a coleta de dados muito complexa. Outras fontes também foram pesquisadas com o objetivo de obterem-se informações das formações geológicas e pedológicas dos locais pesquisados, bem como outras características relevantes ao estudo, com base na experiência do autor. 


\subsection{Montagem de um banco de dados de ensaios de subleito (BD1)}

O primeiro passo para realização deste estudo foi a montagem de um banco de dados consolidado com os resultados de ensaios de campo e laboratório de materiais de subleito ( $B D 1$ ) coletados em documentações de projeto e outras fontes. Grande parte destes ensaios foi realizado com o intuito de subsidiar os projetos de implantação de novas estruturas de pavimento.

Os ensaios de laboratório normalmente realizados para fins de projeto de subleito, conforme preconizado nas instruções de projeto do $D E R / S P$ são ensaios físicos e de determinação de propriedades mecânicas:

- peneiramento (granulometria);

- índices físicos: limites de liquidez e plasticidade;

- compactação;

- $\quad C B R$ e expansão;

- Identificação de classe MCT pelo método das pastilhas.

Outros ensaios recomendados, que deveriam ser incluídos para melhor seleção de solos e adequada caracterização são:

- módulo de resiliência no equipamento triaxial, em diferentes condições de estado;

- umidade natural;

- peso específico aparente natural;

- peso específico real dos grãos.

Infelizmente no material pesquisado, foram poucos os locais onde foram realizados os ensaios de maneira completa (todos os ensaios requeridos e recomendados). Além do que, em muitos dos projetos pesquisados, faltaram dados básicos de localização (quilometragem, pista, coordenadas, etc.) das sondagens para retirada das amostras, 
o que dificultou e muitas vezes impediu o emprego, causando prejuízo do potencial do uso das informações. Ainda assim, muitas informações puderam ser aproveitadas. O banco de dados $B D 1$ contou com dados de ensaios de um total de 49 rodovias do estado de São Paulo, somando um total de 3.894 registros de amostras ensaiadas. Como já citado anteriormente, nem todos os registros puderam ser aproveitados por incompletude nas informações.

\subsection{Correlações obtidas entre os resultados dos ensaios de laboratório}

De posse de um banco de dados organizado pelo autor, a partir de centenas de documentos pesquisados, foi possível trabalhar com os resultados e pesquisar relações entre dados. Já com os dados de 3.894 registros de ensaios de laboratório consolidados, foi possível obter informações relevantes para cada tipo de solo e suas respectivas classificações $M C T$ e $H R B$.

$\mathrm{Na}$ sequência apresentam-se as relações obtidas. Os dados utilizados foram aqueles que obtiveram um número de amostras considerado relevante. Deve ser ressaltado que grande parte dos dados não foi possível de ser utilizada, pois havia evidências de falhas de classificação. Esta é uma informação relevante e será comentada nesta tese. 

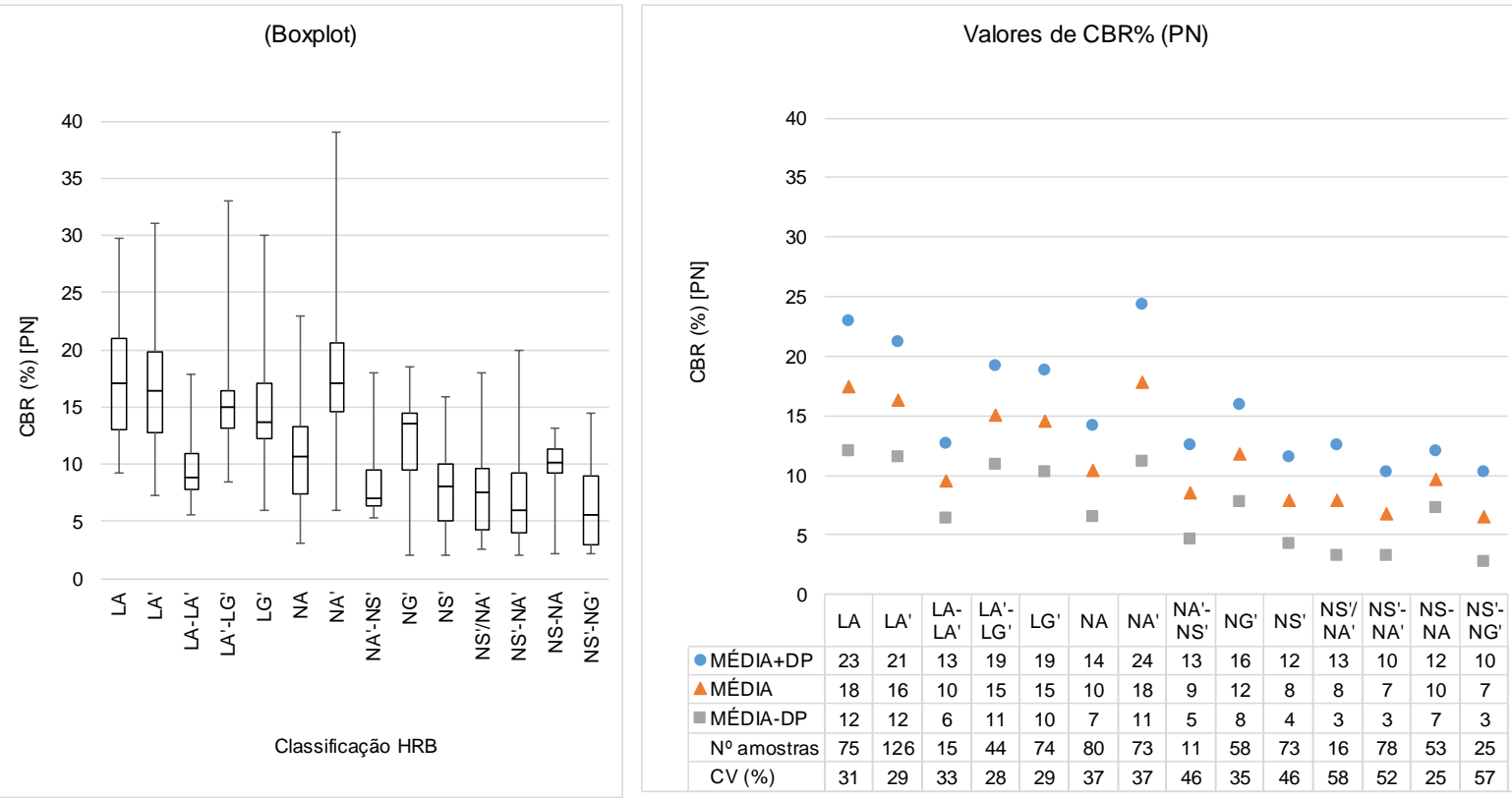

Figura 4.1: Resultados de $C B R$ em função da classificação $M C T$

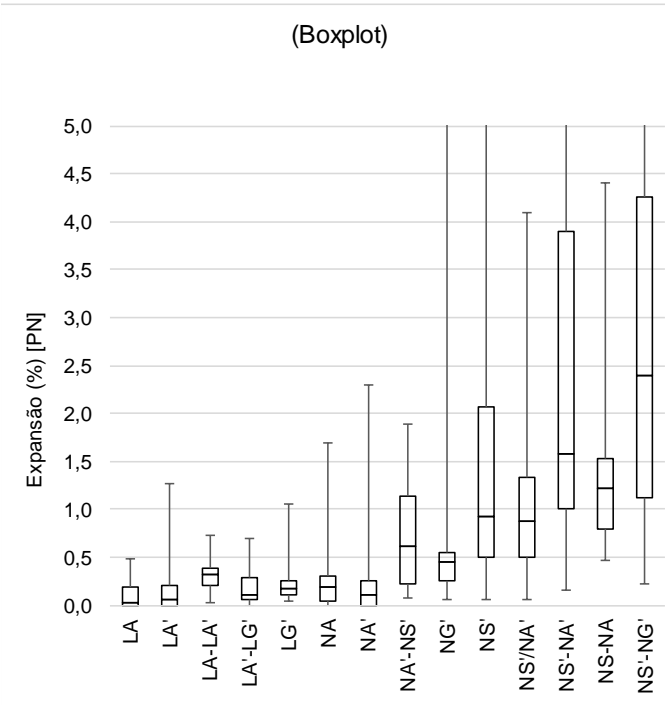

Classificação MCT

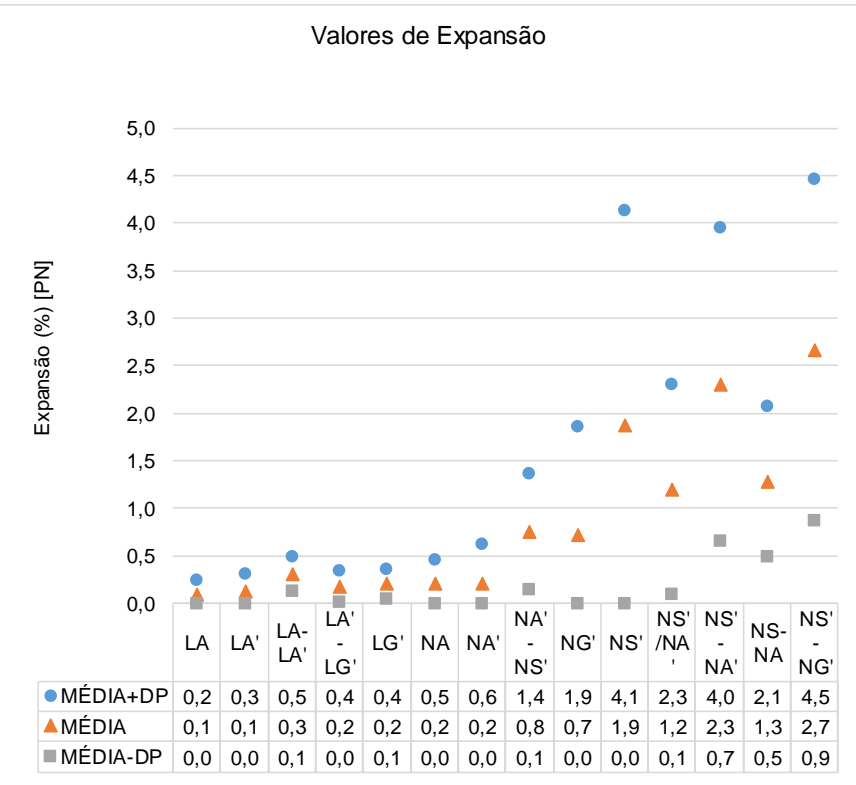

Figura 4.2: Resultados de expansão em função da classificação $M C T$ 

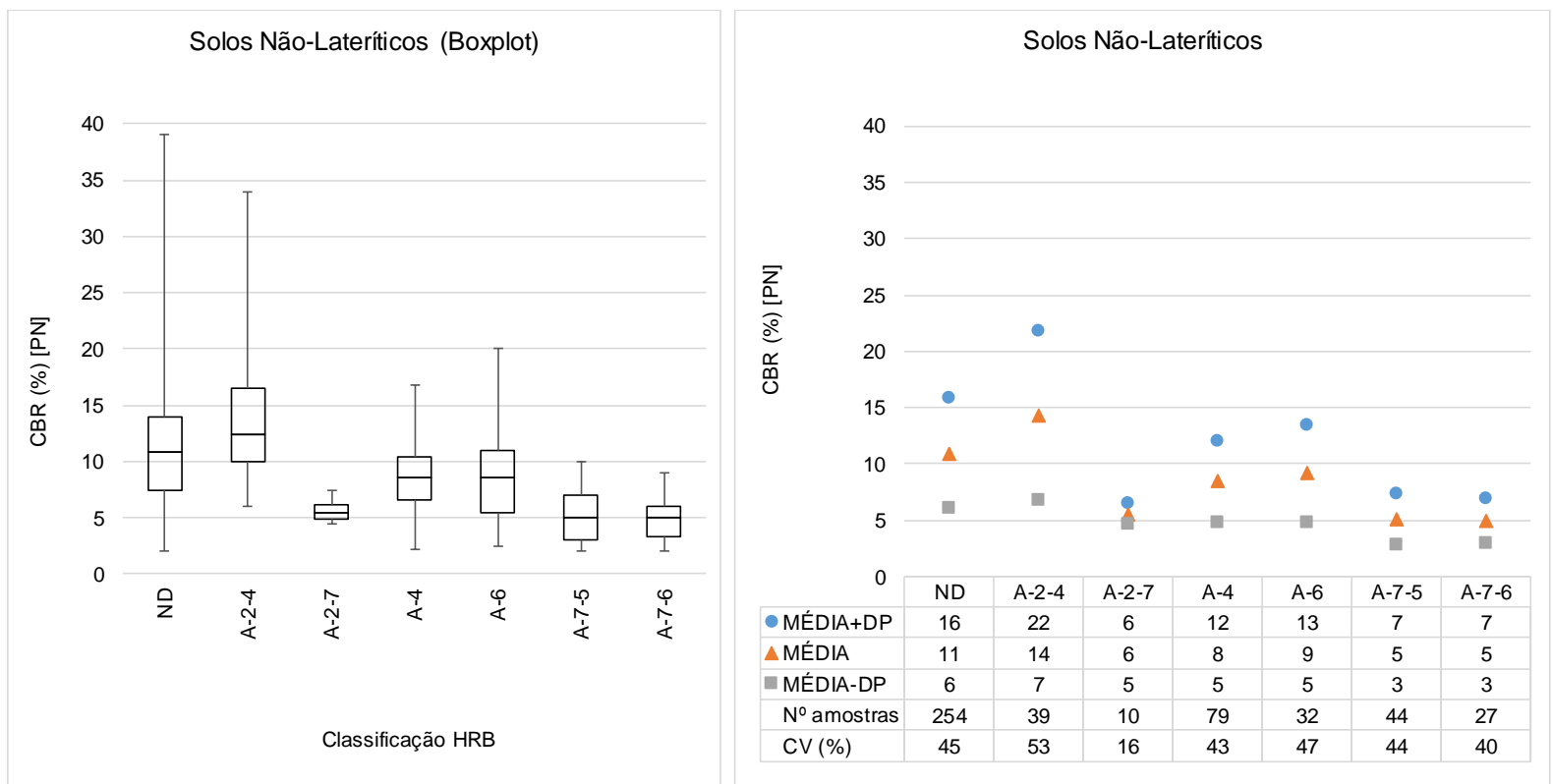

Obs.: ND = não disponível

Figura 4.3: Resultados de $C B R$ em função da classificação HRB (solos classificados como nãolateríticos)
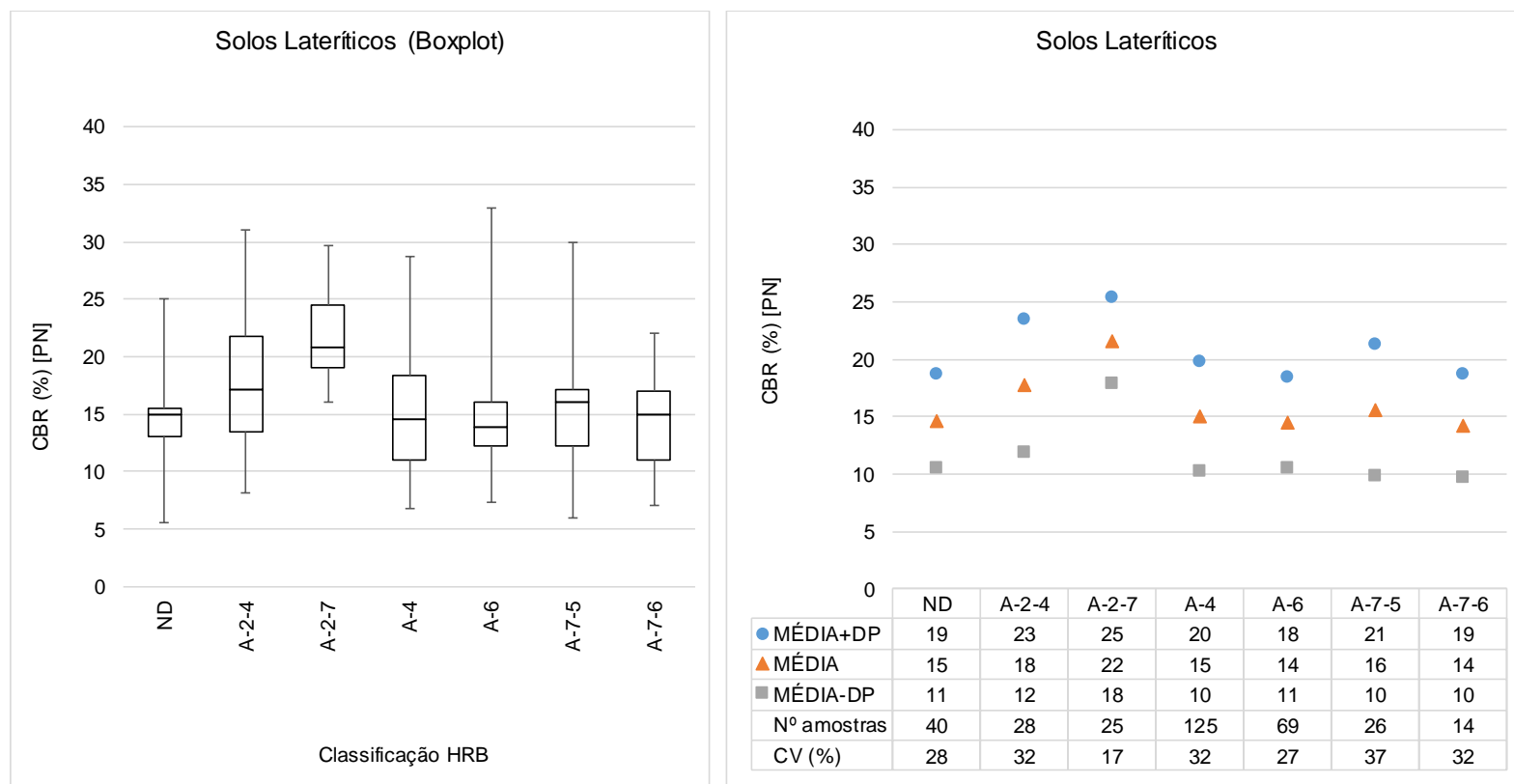

Obs.: ND = não disponivel

Figura 4.4: Resultados de $C B R$ em função da classificação $H R B$ (solos classificados como lateríticos) 

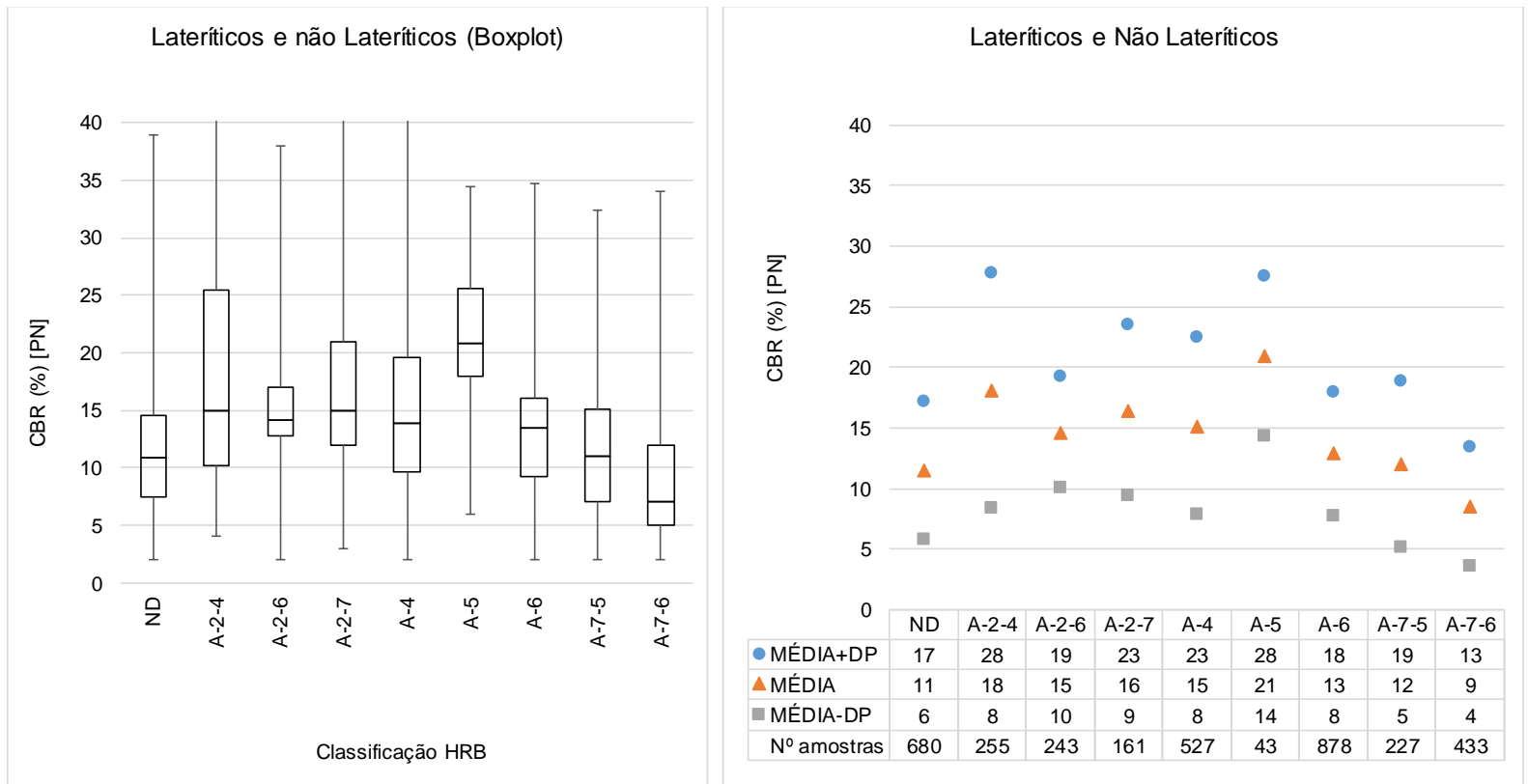

Obs.: ND = não disponível

Figura 4.5: Resultados de $C B R$ em função da classificação $H R B$ (solos lateríticos e não-lateríticos)

É possível verificar que é controversa a relação de $C B R$ com as classes. De posse das classes, não é possível inferir valores de $C B R$. Há tendências de mais arenosos e areno-argilosos apresentarem $C B R$ maiores que os solos finos (siltosos e argilosos, de classe em geral A-4 a A-7). O CBR tende a ser maior para solos de classe $L$ na $M C T$ e de classe NA ou NA', que são os arenosos, em comparação com os demais de classe N. O marcante e importante quanto ao comportamento é a expansão: os solos de classe $L$ e de classes arenosas dos não-lateríticos (menos plásticos) tendem a apresentar baixa expansão e os solos de classe NS' e NG' são expansivos, em contraposição. Confirma-se, portanto, a tendência de solos expansivos apresentarem menores valores de $C B R$, porém a relação não é direta de valores, ou seja, a correlação é fraca.

Mais uma vez confirma-se aqui a dificuldade ou restrição de uso de $C B R$ para inferir propriedades de solos de comportamento lateríticos e, igualmente, de alguns nãolateríticos.

Também foi possível extraírem-se valores estatísticos de $C B R$ e expansão a partir de uma matriz de combinação entre classificações $H R B$ e MCT. A Tabela 4.1 a seguir apresenta a análise realizada para o $C B R$ e a Tabela 4.2 para os valores de expansão. Como se pode notar, o autor tomou o cuidado de não realizar o cálculo estatístico para 
relações com baixo número de amostras (número de amostras inferior a 7 nestes casos).

Tabela 4.1: (a) Média menos desvio-padrão e (b) número de amostras dos valores de CBR para cada combinação de classes de solos (HRB e MCT)
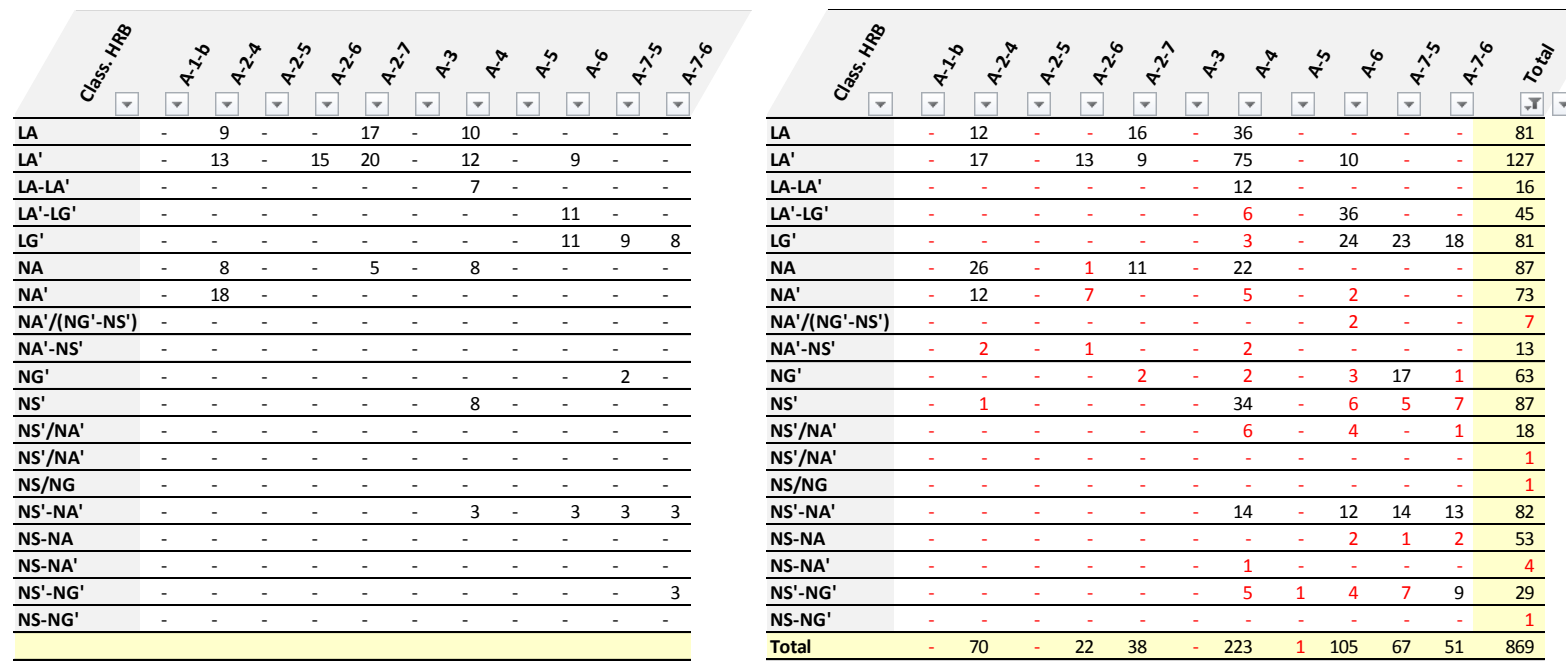

Tabela 4.2: (a) Média mais desvio-padrão e (b) número de amostras dos valores de expansão para cada combinação de classes de solos (HRB e MCT)
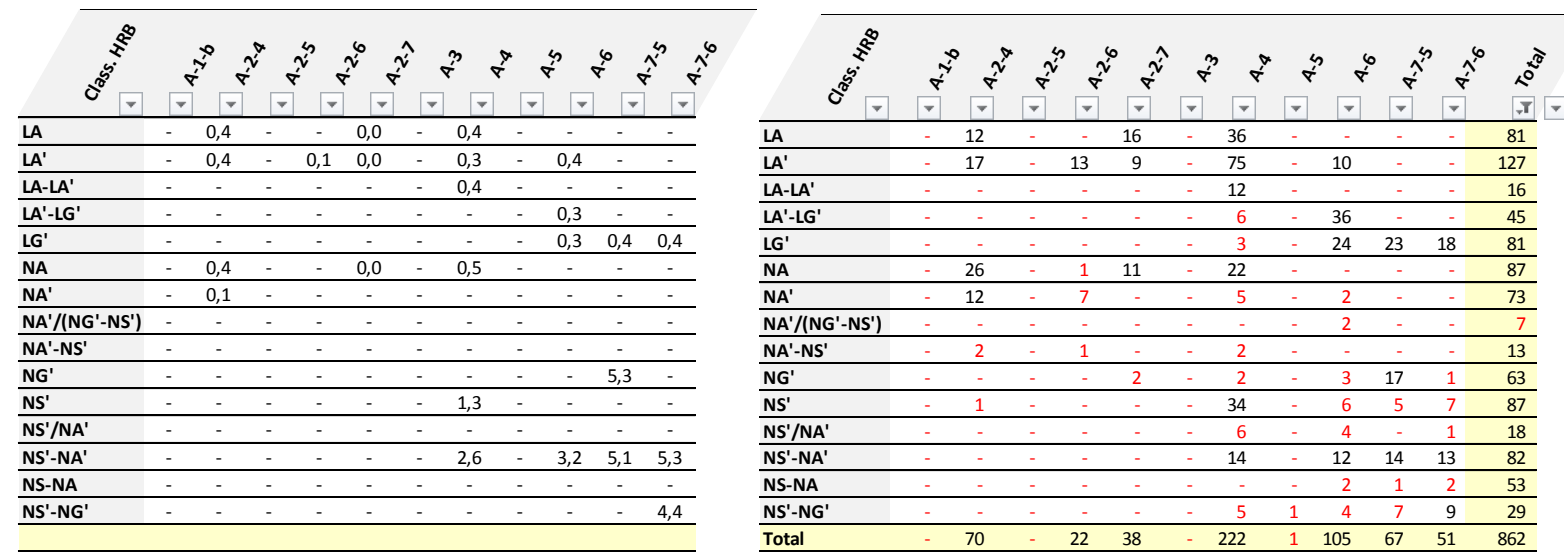

A partir de uma consulta, a um banco de dados de deflexões, de rodovias estaduais concedidas, para alguns registros de ensaios (locais ensaiados), contido no banco de dados $B D 1$, foi possível obterem-se dados módulo de resiliência retroanalisado do subleito - Esl,retro (equação da $A A S H T O / 93$ ).

A partir desta consulta, foi possível elaborar os gráficos apresentados na sequência. 

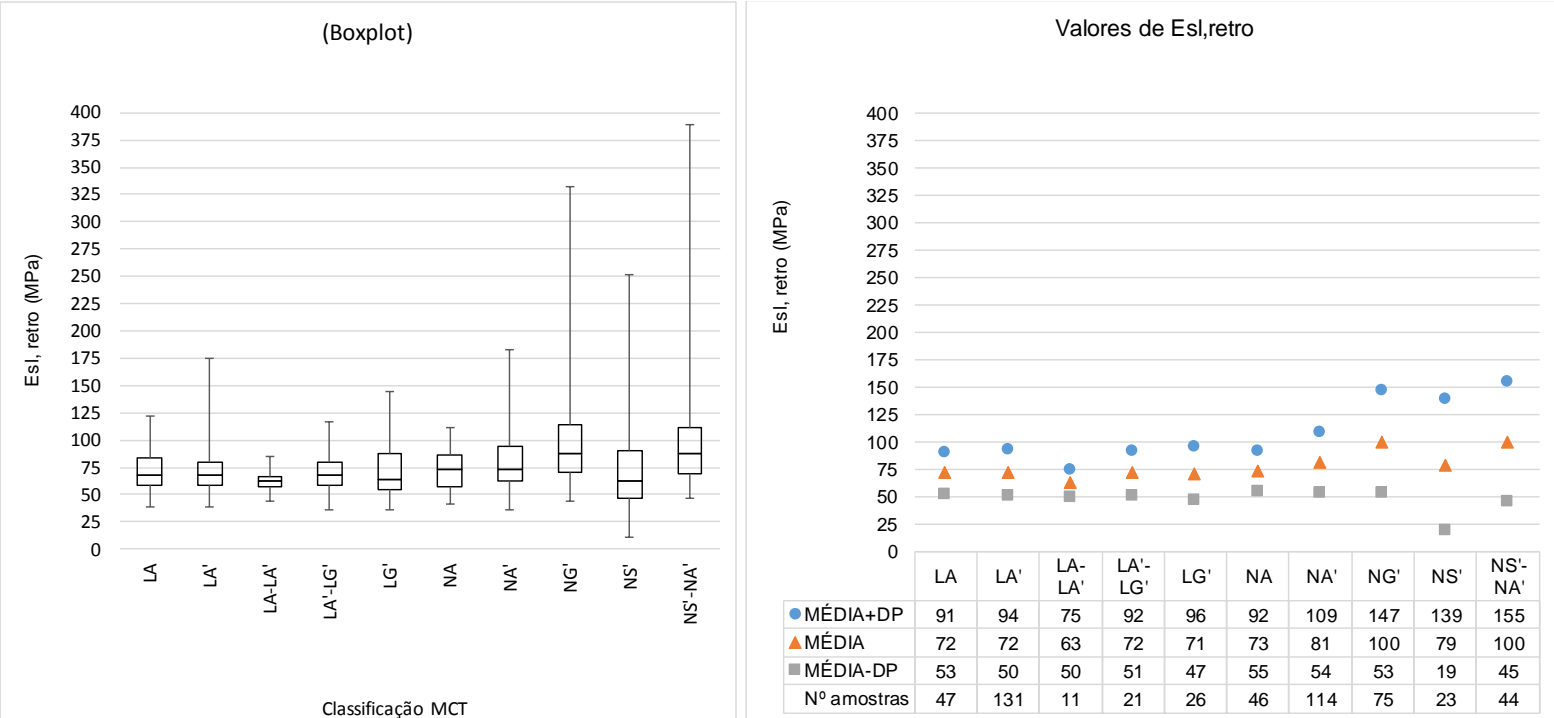

Figura 4.6: Resultados de Esl,retro em função da classificação $M C T$
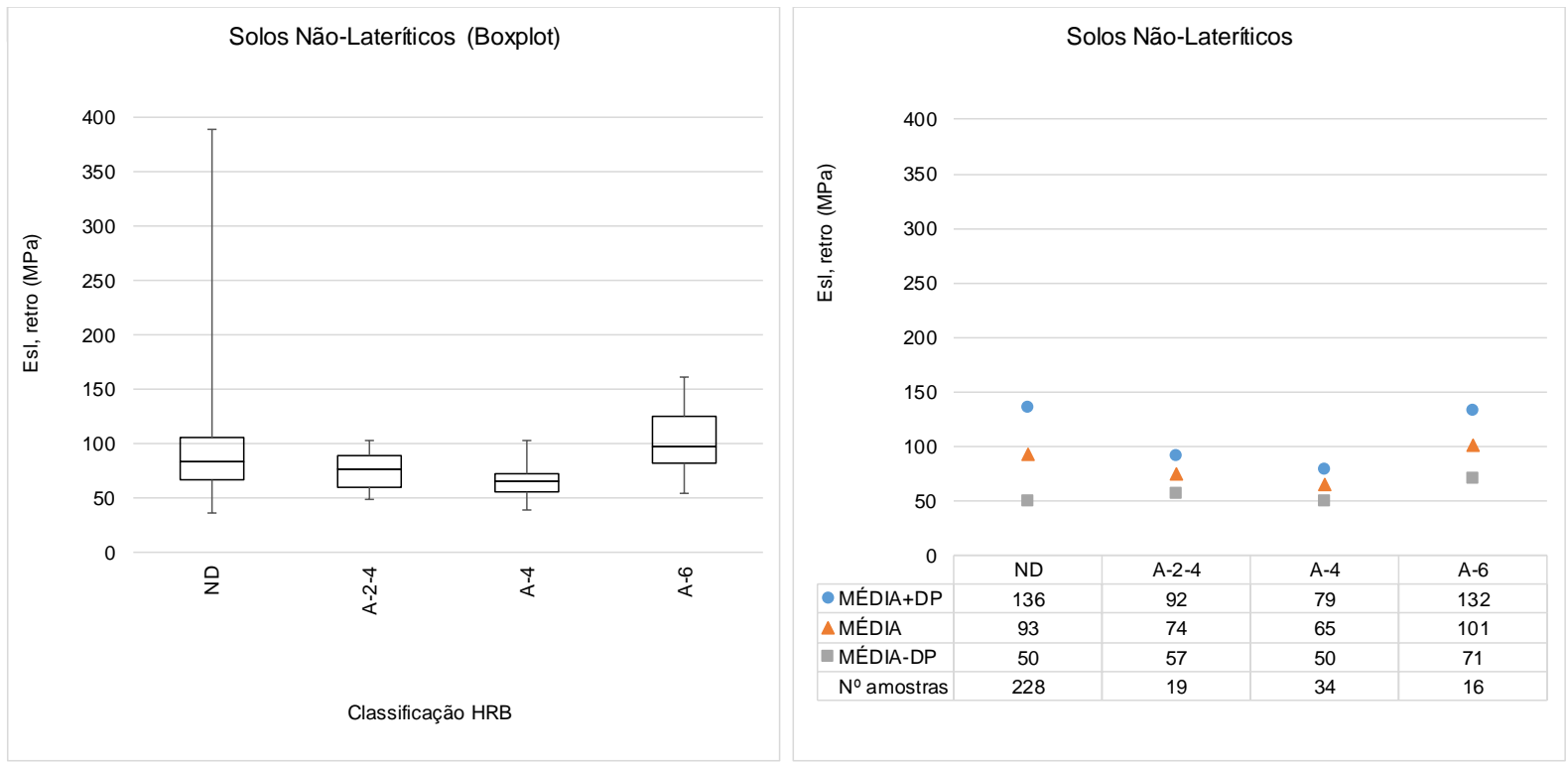

Obs.: ND = não disponive

Figura 4.7: Resultados de Esl,retro em função da classificação HRB (solos classificados como nãolateríticos) 

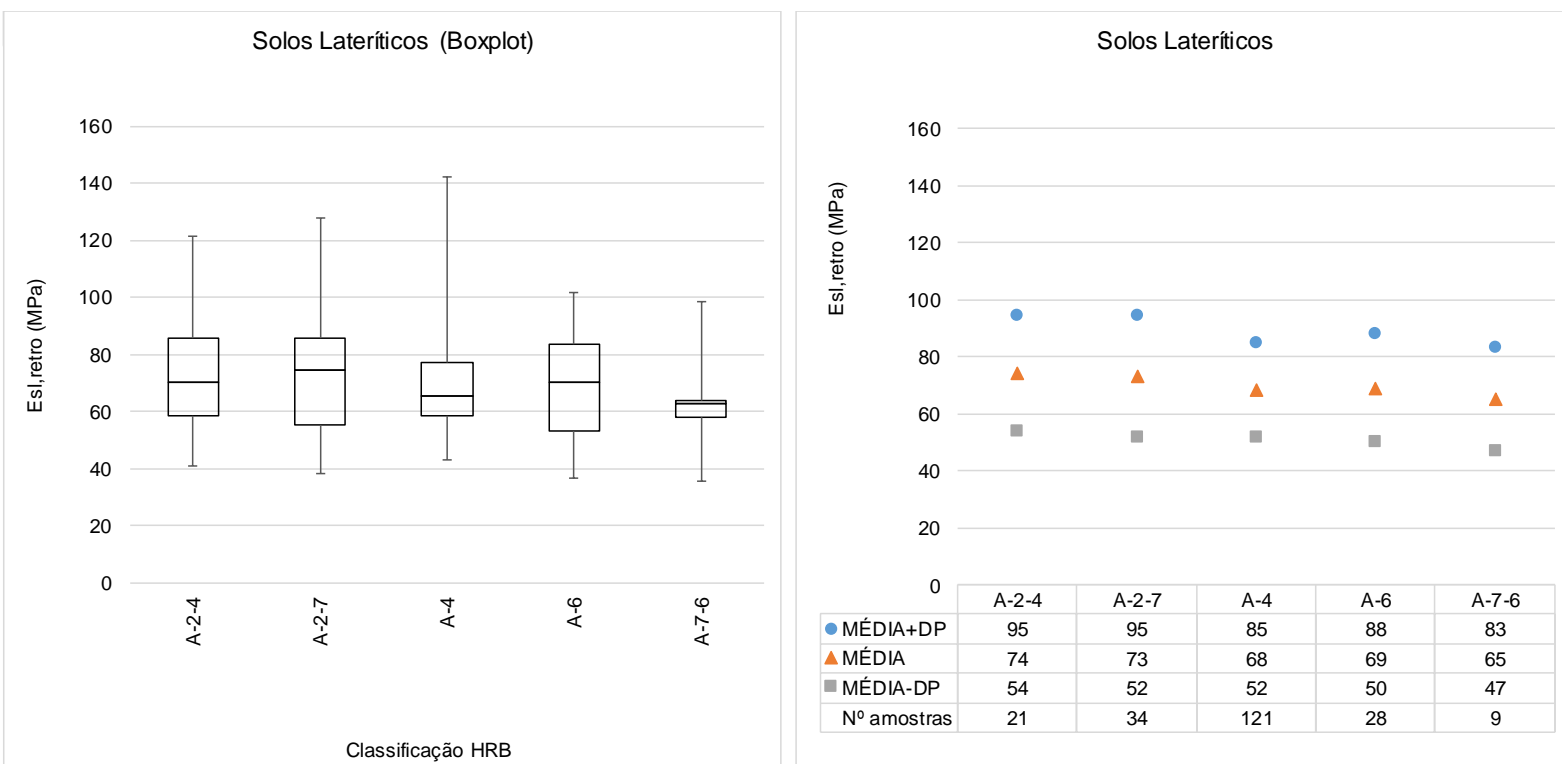

Figura 4.8: Resultados de Esl,retro em função da classificação HRB (solos classificados como lateríticos)
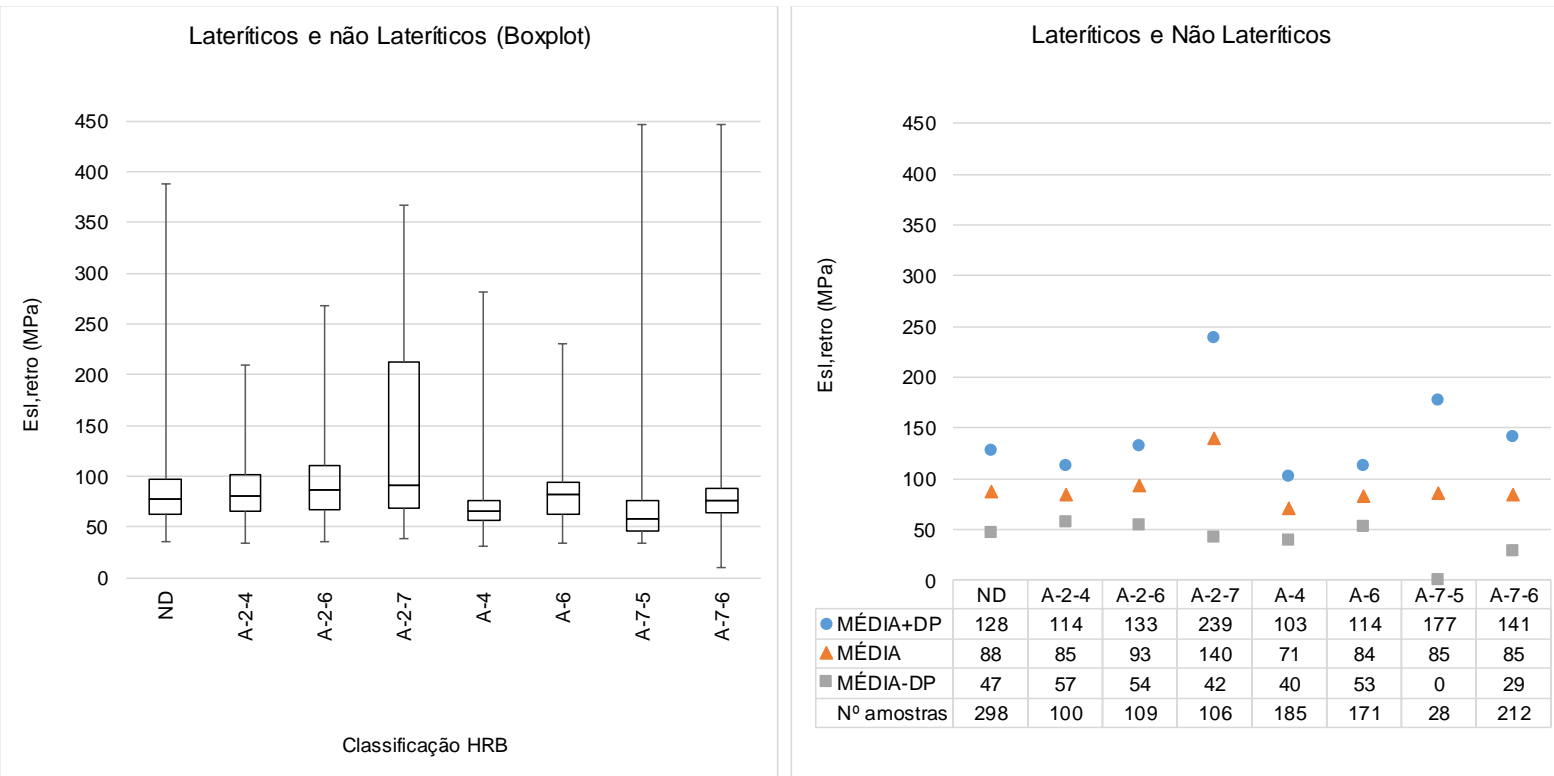

Obs.: ND = não disponível

Figura 4.9: Resultados de Esl,retro em função da classificação HRB (solos lateríticos e não-lateríticos)

Com base nos gráficos notam-se os solos do tipo NS' apresentam maior dispersão de valores de módulo de resiliência do subleito (retroanalisado). Verificam-se que a maior média dos valores de módulo foram obtidas para os solos tipo NG'. Notam-se que os valores de módulo para os solos lateríticos muitas vezes apresentam valores inferiores em relação aos não-lateríticos, porém apresentam menores dispersão de valores. 
Infere-se que isto se dê por conta da menor suscetibilidade destes tipos de materiais à umidade decorrente dos períodos de chuva.

Os tipos de solos NA e NA', apresentaram tendência semelhante à dos solos lateríticos (menor variabilidade nos valores de módulo de resiliência do subleito retroanalisado).

A exemplo da análise estatística que foi realizada para os valores de $C B R$ e expansão, também foram extraídos valores estatísticos do valor de módulo de resiliência retroanalisado do subleito para cada combinação de classes MCT e HRB, conforme apresentado na Tabela 4.3.

Tabela 4.3: (a) Média menos desvio-padrão dos valores de Esl,retro para cada combinação de classes de solos (HRB e MCT)

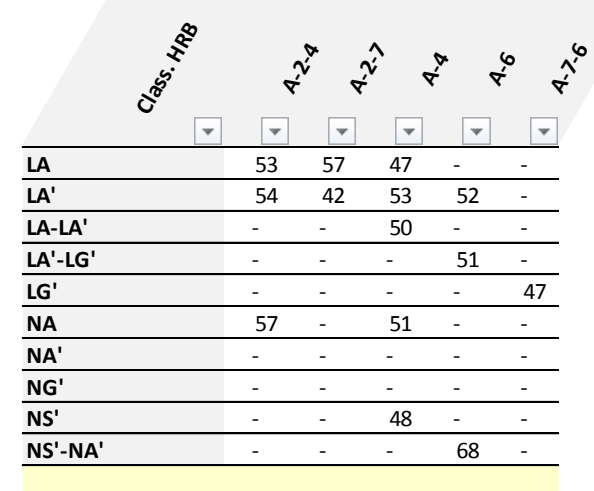




\subsection{Estudo teórico para verificação da influência da estrutura no valor o módulo retroanalisado do subleito}

O breve estudo realizado a seguir, teve por objetivo pesquisar, a partir de modelos teóricos, a influência dos parâmetros mecânicos no valor do módulo retroanalisado do subleito, a partir do uso da correlação proposta pelo método da AASHTO/2002, uma vez que tal modelo será utilizado para a sequência dos estudos.

Para realização deste estudo, utilizou-se um banco de dados contendo 21.127 estruturas simuladas com o software Elsym-5, para um modelo estrutural composto por 3 camadas elásticas.

Os valores utilizados nas simulações foram:

- Módulo do subleito ou infraestrutura (E1) em MPa variando entre os seguintes valores 50, 70, 100, 150, 200, 250, 300, 350, 400, 450, 500;

- Módulo de resiliência da camada de base (E2) em MPa variando entre os seguintes valores: $50,100,200,250,300,400,500,1.000,2.500,5.000,7.500$, 10.000;

- Módulo de resiliência da camada de revestimento (E3) em MPa variando entre os seguintes valores: 1.000, 2.000, 3.500, 5.000;

- Espessura da camada de base ( $h 2) \mathrm{em} \mathrm{cm}$ variando entre os seguintes valores: $10,12,15,17$ e 20 ;

- Espessura da camada de revestimento (h3) em $\mathrm{cm}$ variando entre os seguintes valores: $3,5,7,10,12,15,17,20$;

Como se pode verificar, neste primeiro estudo teórico, a espessura total física do pavimento, considerando a base e o revestimento variou entre 13 e $40 \mathrm{~cm}$.

Nas simulações, foram coletadas as deflexões na superfície do pavimento, às distâncias de 0, 20, 25, 30, 45, 60, $90 \mathrm{e} 120 \mathrm{~cm}$ do ponto de aplicação das cargas. Foi utilizado o carregamento padrão do $F W D$ (carga de $410 \mathrm{kNe}$ raio de contato de $15 \mathrm{~cm}$ ). A partir das deflexões, foram calculados os parâmetros: Raio de curvatura da bacia (RC) em metros, Parâmetro AREA (ou Área/D0) em centímetros, e módulo do subleito 
retroanalisado a partir da equação proposta pelo guia da AASHTO/93 (Esl,retro), em MPa.

A Figura 4.10 a seguir ilustra a relação obtida no estudo teórico para Módulo de resiliência do subleito e Módulo retroanalisado a partir da equação da AASHTO/93. Para este caso, em específico, utilizou-se coeficiente para a equação de $c=0,33$, por se tratar de um estudo puramente teórico.

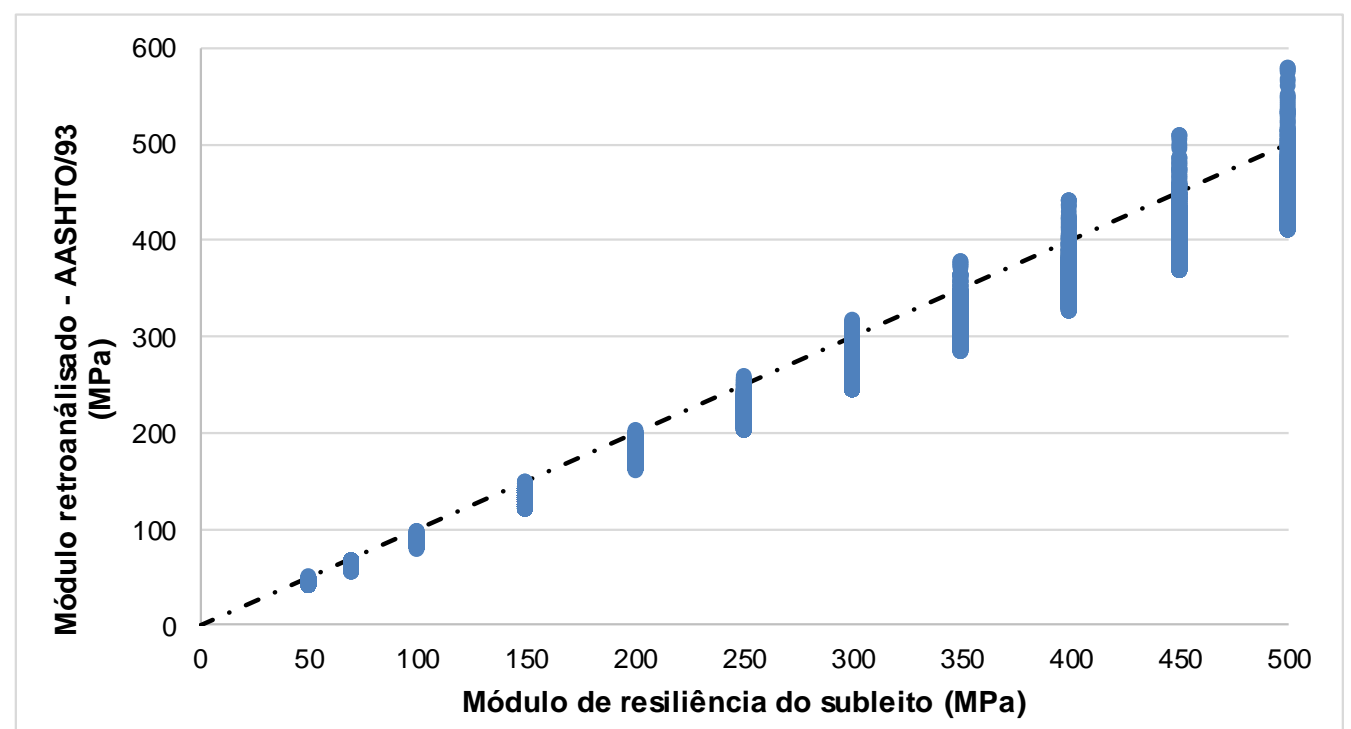

Figura 4.10: Relação obtida no estudo teórico para Módulo de resiliência do subleito (E1) e Módulo retroanalisado a partir da equação da $A A S H T O / 93$

Verificou-se, no universo de casos simulados que a dispersão do valor do módulo retroanalisado pela equação da $A A S H T O / 93$ aumenta com o acréscimo do valor do módulo resiliência real do subleito $(E 1)$.

Também se observou uma relação de módulos (Ersl,retro / E1) variando entre 0,79 e 1,16 .

Para pesquisar a influência de cada parâmetro nesta variação, em relação ao valor ideal $(1,0)$, elaborou-se a Tabela 4.4 apresentada a seguir, que apresenta os valores mínimos e máximos dos parâmetros obtidos nas simulações, que resultaram em cada um dos intervalões de relação de módulo apresentados à esquerda na tabela. 
Tabela 4.4: Parâmetros mínimos e máximos das estruturas em função da relação de módulo (Ersl, retro / E1)

\begin{tabular}{|c|c|c|c|c|c|c|c|c|c|c|c|c|c|c|c|c|c|c|c|c|}
\hline \multicolumn{2}{|c|}{$\begin{array}{c}\text { Relação (Esl,retro / } \\
\text { E1) } \\
\end{array}$} & \multicolumn{2}{|c|}{ E1 (MPa) } & \multicolumn{2}{|c|}{ E2 (MPa) } & \multirow{2}{*}{$\begin{array}{l}\text { Relação } \\
\text { (E1mín / } \\
\text { E2mín) }\end{array}$} & \multicolumn{2}{|c|}{ E3 (MPa) } & \multicolumn{2}{|c|}{ h2 (cm) } & \multicolumn{2}{|c|}{ h3 (cm) } & \multicolumn{2}{|c|}{$\mathrm{Ht}(\mathrm{cm})$} & \multicolumn{2}{|c|}{$\operatorname{Rc}(m)$} & \multicolumn{2}{|c|}{$\begin{array}{c}\text { Do } \\
(0,01 \mathrm{~mm}) \\
\end{array}$} & \multicolumn{2}{|c|}{$\begin{array}{l}\text { Parâmetro } \\
\text { AREA }(\mathrm{cm})\end{array}$} \\
\hline mín & máx & mín & máx & mín & máx & & mín & máx & mín & máx & mín & máx & mín & máx & mín & máx & mín & máx & mín & máx \\
\hline 0,79 & 0,80 & 50 & 150 & 50 & 10.000 & 1,0 & 1.000 & 5.000 & 10 & 20 & 5 & 20 & 20 & 40 & 498 & 674 & 29 & 51 & 61 & 72 \\
\hline 0,80 & 0,81 & 50 & 250 & 50 & 10.000 & 1,0 & 1.000 & 5.000 & 10 & 20 & 3 & 20 & 15 & 40 & 272 & 1.542 & 11 & 60 & 52 & 75 \\
\hline 0,81 & 0,82 & 50 & 500 & 50 & 10.000 & 1,0 & 1.000 & 5.000 & 10 & 20 & 3 & 20 & 15 & 40 & 233 & 1.572 & 6 & 63 & 44 & 76 \\
\hline 0,82 & 0,83 & 50 & 500 & 50 & 10.000 & 1,0 & 1.000 & 5.000 & 10 & 20 & 3 & 20 & 15 & 40 & 191 & 1.599 & 7 & 70 & 39 & 76 \\
\hline 0,83 & 0,84 & 50 & 500 & 50 & 10.000 & 1,0 & 1.000 & 5.000 & 10 & 20 & 3 & 20 & 13 & 40 & 168 & 1.575 & 8 & 74 & 39 & 77 \\
\hline 0,84 & 0,85 & 50 & 500 & 50 & 10.000 & 1,0 & 1.000 & 5.000 & 10 & 20 & 3 & 20 & 13 & 40 & 152 & 1.595 & 8 & 79 & 39 & 77 \\
\hline 0,85 & 0,86 & 50 & 500 & 50 & 10.000 & 1,0 & 1.000 & 5.000 & 10 & 20 & 3 & 20 & 13 & 40 & 128 & 1.563 & 8 & 86 & 39 & 76 \\
\hline 0,86 & 0,87 & 50 & 500 & 50 & 10.000 & 1,0 & 1.000 & 5.000 & 10 & 20 & 3 & 20 & 13 & 40 & 110 & 1.497 & 8 & 93 & 39 & 76 \\
\hline 0,87 & 0,88 & 50 & 500 & 50 & 10.000 & 1,0 & 1.000 & 5.000 & 10 & 20 & 3 & 20 & 13 & 40 & 94 & 1.361 & 9 & 102 & 38 & 76 \\
\hline 0,88 & 0,89 & 50 & 500 & 50 & 10.000 & 1,0 & 1.000 & 5.000 & 10 & 20 & 3 & 20 & 13 & 40 & 79 & 1.272 & 9 & 111 & 38 & 76 \\
\hline 0,89 & 0,90 & 50 & 500 & 50 & 10.000 & 1,0 & 1.000 & 5.000 & 10 & 20 & 3 & 20 & 13 & 40 & 66 & 1.216 & 10 & 122 & 38 & 76 \\
\hline 0,90 & 0,91 & 50 & 500 & 50 & 10.000 & 1,0 & 1.000 & 5.000 & 10 & 20 & 3 & 20 & 13 & 40 & 56 & 1.112 & 10 & 133 & 38 & 75 \\
\hline 0,91 & 0,92 & 50 & 500 & 50 & 10.000 & 1,0 & 1.000 & 5.000 & 10 & 20 & 3 & 20 & 13 & 40 & 50 & 998 & 11 & 148 & 37 & 75 \\
\hline 0,92 & 0,93 & 50 & 500 & 50 & 10.000 & 1,0 & 1.000 & 5.000 & 10 & 20 & 3 & 20 & 13 & 40 & 32 & 936 & 11 & 186 & 30 & 74 \\
\hline 0,93 & 0,94 & 50 & 500 & 50 & 10.000 & 1,0 & 1.000 & 5.000 & 10 & 20 & 3 & 20 & 13 & 40 & 19 & 817 & 12 & 264 & 22 & 75 \\
\hline 0,94 & 0,95 & 50 & 500 & 50 & 10.000 & 1,0 & 1.000 & 5.000 & 10 & 20 & 3 & 20 & 13 & 40 & 21 & 930 & 14 & 250 & 22 & 74 \\
\hline 0,95 & 0,96 & 50 & 500 & 50 & 10.000 & 1,0 & 1.000 & 5.000 & 10 & 20 & 7 & 20 & 19 & 40 & 62 & 777 & 15 & 110 & 33 & 75 \\
\hline 0,96 & 0,97 & 50 & 500 & 50 & 10.000 & 1,0 & 1.000 & 5.000 & 10 & 20 & 7 & 20 & 20 & 40 & 83 & 657 & 17 & 92 & 35 & 73 \\
\hline 0,97 & 0,98 & 50 & 500 & 50 & 7.500 & 1,0 & 1.000 & 5.000 & 10 & 20 & 10 & 20 & 20 & 40 & 85 & 739 & 17 & 77 & 34 & 74 \\
\hline 0,98 & 0,99 & 150 & 500 & 50 & 100 & 3,0 & 1.000 & 5.000 & 10 & 20 & 10 & 20 & 22 & 40 & 89 & 467 & 19 & 69 & 33 & 49 \\
\hline 0,99 & 1,00 & 50 & 500 & 50 & 10.000 & 1,0 & 1.000 & 5.000 & 10 & 20 & 10 & 20 & 22 & 40 & 114 & 736 & 20 & 63 & 35 & 74 \\
\hline 1,00 & 1,01 & 200 & 500 & 50 & 100 & 4,0 & 1.000 & 5.000 & 10 & 20 & 10 & 20 & 22 & 40 & 122 & 433 & 21 & 59 & 36 & 48 \\
\hline 1,01 & 1,02 & 250 & 500 & 50 & 100 & 5,0 & 1.000 & 5.000 & 12 & 20 & 10 & 20 & 24 & 40 & 116 & 450 & 20 & 59 & 36 & 48 \\
\hline 1,02 & 1,03 & 250 & 500 & 50 & 100 & 5,0 & 1.000 & 5.000 & 12 & 20 & 10 & 20 & 24 & 40 & 117 & 418 & 23 & 57 & 35 & 47 \\
\hline 1,03 & 1,04 & 300 & 500 & 50 & 50 & 6,0 & 1.000 & 5.000 & 15 & 20 & 10 & 20 & 27 & 37 & 118 & 397 & 26 & 55 & 36 & 47 \\
\hline 1,04 & 1,05 & 300 & 500 & 50 & 50 & 6,0 & 1.000 & 5.000 & 15 & 20 & 10 & 20 & 27 & 40 & 137 & 410 & 24 & 51 & 37 & 46 \\
\hline 1,05 & 1,06 & 300 & 500 & 50 & 50 & 6,0 & 1.000 & 5.000 & 15 & 20 & 10 & 20 & 27 & 37 & 119 & 369 & 26 & 53 & 36 & 46 \\
\hline 1,06 & 1,07 & 350 & 500 & 50 & 50 & 7,0 & 1.000 & 5.000 & 15 & 20 & 10 & 20 & 27 & 37 & 119 & 399 & 25 & 52 & 36 & 47 \\
\hline 1,07 & 1,08 & 350 & 500 & 50 & 50 & 7,0 & 1.000 & 5.000 & 17 & 20 & 12 & 20 & 29 & 40 & 120 & 300 & 28 & 51 & 35 & 45 \\
\hline 1,08 & 1,09 & 400 & 500 & 50 & 50 & 8,0 & 1.000 & 5.000 & 17 & 20 & 10 & 17 & 29 & 37 & 139 & 312 & 28 & 48 & 38 & 43 \\
\hline 1,09 & 1,10 & 400 & 500 & 50 & 50 & 8,0 & 1.000 & 5.000 & 17 & 20 & 12 & 20 & 29 & 40 & 168 & 279 & 30 & 42 & 38 & 44 \\
\hline 1,10 & 1,11 & 400 & 450 & 50 & 50 & 8,0 & 1.000 & 5.000 & 20 & 20 & 10 & 17 & 30 & 37 & 140 & 302 & 30 & 47 & 37 & 44 \\
\hline 1,11 & 1,12 & 450 & 450 & 50 & 50 & 9,0 & 2.000 & 2.000 & 20 & 20 & 17 & 17 & 37 & 37 & 237 & 237 & 34 & 34 & 42 & 42 \\
\hline 1,12 & 1,13 & 450 & 500 & 50 & 50 & 9,0 & 1.000 & 5.000 & 20 & 20 & 10 & 20 & 30 & 40 & 140 & 269 & 33 & 46 & 37 & 43 \\
\hline 1,13 & 1,14 & 500 & 500 & 50 & 50 & 10,0 & 3.500 & 3.500 & 20 & 20 & 15 & 15 & 35 & 35 & 304 & 304 & 29 & 29 & 44 & 44 \\
\hline 1,14 & 1,15 & 500 & 500 & 50 & 50 & 10,0 & 3.500 & 3.500 & 20 & 20 & 12 & 12 & 32 & 32 & 209 & 209 & 37 & 37 & 40 & 40 \\
\hline 1,15 & 1,16 & 500 & 500 & 50 & 50 & 10,0 & 1.000 & 5.000 & 20 & 20 & 12 & 20 & 32 & 40 & 169 & 271 & 32 & 40 & 38 & 43 \\
\hline
\end{tabular}

Com base na tabela é possível notar que nos casos de estruturas semirrígidas, (valores de módulo de resiliência da base, E2, entre 1.000 e $10.000 \mathrm{MPa}$ ), a relação de módulo (Ersl,retro / E1) é predominantemente inferior à unidade. Tal tendência pode ser confirmada filtrando-se as simulações com módulo de base superior a 1.000 MPa (Figura 4.11) e a dispersão de valores em relação à linha de igualdade é tanto maio quanto maior o módulo de resiliência do subleito (E1), apesar de notaremse outras influências, além desta.

O mesmo não se pode afirmar para estruturas tipicamente flexíveis, pois se filtrando os valores de módulos de resiliência de base iguais ou inferiores a $500 \mathrm{MPa}$, ainda assim, obtêm-se muitos valores oscilando para cima e para baixo da linha de igualdade. 


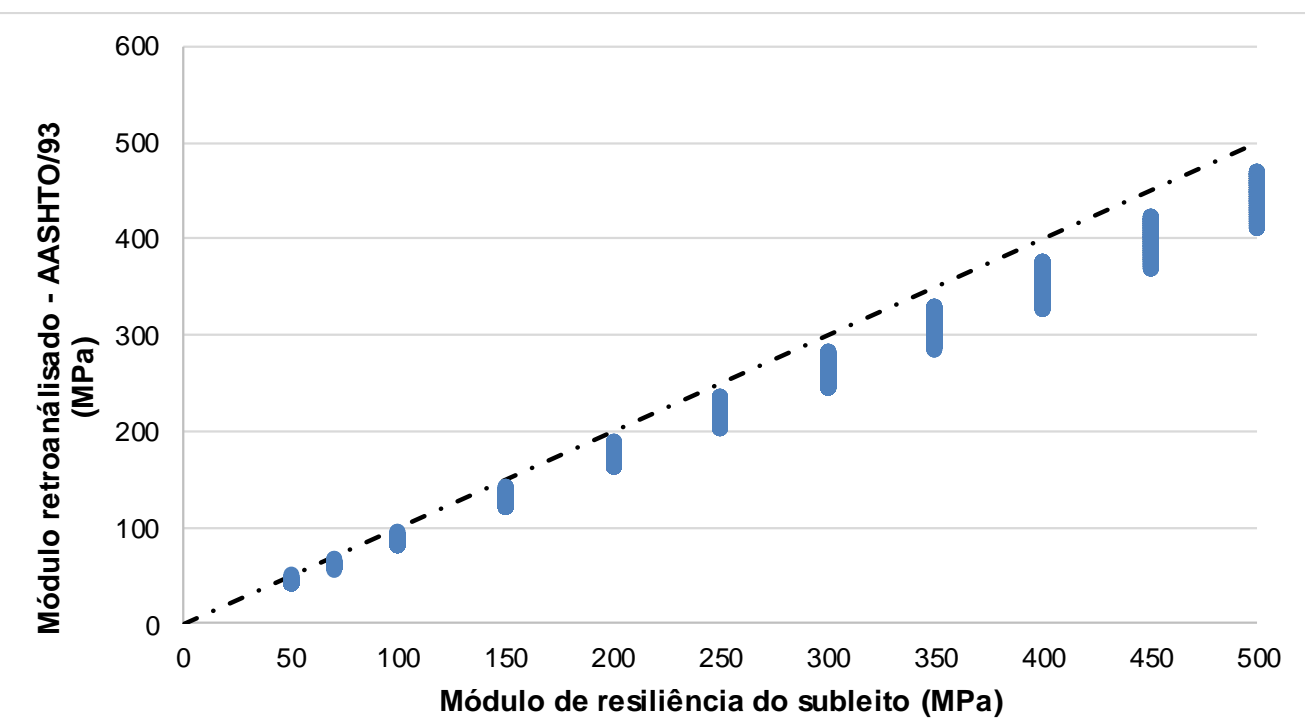

Figura 4.11: Relação obtida no estudo teórico para Módulo de resiliência do subleito $(E 1)$ e Módulo retroanalisado a partir da equação da AASHTO/93 - Pavimentos tipicamente semirrígidos (Módulo E2 igual ou superior a $1.000 \mathrm{MPa}$ )

Para se pesquisar os parâmetros de influência na relação de módulo (Ersl,retro / E1) nos pavimentos tipicamente flexíveis, revisou-se a tabela anterior, agora filtrando-se apenas as estruturas com valor de E2 igual ou inferior a 500 MPa. Os resultados são apresentados na tabela a seguir. 
Tabela 4.5: Parâmetros mínimos e máximos das estruturas em função da relação de módulo

(Ersl,retro / E1) - Pavimentos tipicamente flexíveis (E2 igual ou inferior a $500 \mathrm{MPa}$ )

\begin{tabular}{|c|c|c|c|c|c|c|c|c|c|c|c|c|c|c|c|c|c|c|c|c|}
\hline \multicolumn{2}{|c|}{$\begin{array}{c}\text { Relação (Esl,retro / } \\
\text { E1) }\end{array}$} & \multicolumn{2}{|c|}{ E1 (MPa) } & \multicolumn{2}{|c|}{ E2 (MPa) } & \multirow{2}{*}{$\begin{array}{c}\text { Relação } \\
\text { (E1mín / } \\
\text { E2mín) }\end{array}$} & \multicolumn{2}{|c|}{ E3 (MPa) } & \multicolumn{2}{|c|}{ h2 (cm) } & \multicolumn{2}{|c|}{ h3 (cm) } & \multicolumn{2}{|c|}{$\mathrm{Ht}(\mathrm{cm})$} & \multicolumn{2}{|c|}{$\operatorname{Rc}(\mathrm{m})$} & \multicolumn{2}{|c|}{$\begin{array}{c}\text { D0 } \\
(0,01 \mathrm{~mm}) \\
\end{array}$} & \multicolumn{2}{|c|}{$\begin{array}{l}\text { Parâmetro } \\
\text { AREA }(\mathrm{cm})\end{array}$} \\
\hline mín & máx & mín & máx & mín & máx & & mín & máx & mín & máx & mín & máx & mín & máx & mín & máx & mín & máx & mín & máx \\
\hline 0,79 & 0,80 & 50 & 150 & 50 & 50 & 1,0 & 5.000 & 5.000 & 10 & 20 & 20 & 20 & 30 & 40 & 576 & 582 & 29 & 51 & 61 & 70 \\
\hline 0,80 & 0,81 & 50 & 250 & 50 & 200 & 1,0 & 3.500 & 5.000 & 10 & 20 & 17 & 20 & 27 & 40 & 411 & 612 & 23 & 59 & 56 & 71 \\
\hline 0,81 & 0,82 & 50 & 300 & 50 & 500 & 1,0 & 2.000 & 5.000 & 10 & 20 & 15 & 20 & 25 & 40 & 331 & 708 & 22 & 58 & 55 & 71 \\
\hline 0,82 & 0,83 & 50 & 400 & 50 & 500 & 1,0 & 1.000 & 5.000 & 10 & 20 & 12 & 20 & 25 & 40 & 191 & 745 & 20 & 70 & 53 & 72 \\
\hline 0,83 & 0,84 & 50 & 450 & 50 & 500 & 1,0 & 1.000 & 5.000 & 10 & 20 & 10 & 20 & 24 & 40 & 168 & 760 & 19 & 74 & 52 & 72 \\
\hline 0,84 & 0,85 & 50 & 500 & 50 & 500 & 1,0 & 1.000 & 5.000 & 10 & 20 & 7 & 20 & 22 & 40 & 152 & 776 & 18 & 79 & 51 & 63 \\
\hline 0,85 & 0,86 & 50 & 450 & 50 & 500 & 1,0 & 1.000 & 5.000 & 10 & 20 & 5 & 20 & 22 & 40 & 128 & 789 & 16 & 86 & 52 & 62 \\
\hline 0,86 & 0,87 & 50 & 500 & 50 & 500 & 1,0 & 1.000 & 5.000 & 10 & 20 & 3 & 20 & 20 & 40 & 110 & 804 & 15 & 93 & 49 & 61 \\
\hline 0,87 & 0,88 & 50 & 500 & 50 & 500 & 1,0 & 1.000 & 5.000 & 10 & 20 & 3 & 20 & 20 & 40 & 94 & 816 & 13 & 102 & 46 & 59 \\
\hline 0,88 & 0,89 & 50 & 500 & 50 & 500 & 1,0 & 1.000 & 5.000 & 10 & 20 & 3 & 20 & 19 & 40 & 79 & 827 & 13 & 111 & 44 & 58 \\
\hline 0,89 & 0,90 & 50 & 500 & 50 & 500 & 1,0 & 1.000 & 5.000 & 10 & 20 & 3 & 20 & 17 & 40 & 66 & 845 & 11 & 122 & 42 & 57 \\
\hline 0,90 & 0,91 & 50 & 500 & 50 & 500 & 1,0 & 1.000 & 5.000 & 10 & 20 & 3 & 20 & 17 & 40 & 56 & 845 & 11 & 133 & 40 & 56 \\
\hline 0,91 & 0,92 & 50 & 500 & 50 & 500 & 1,0 & 1.000 & 5.000 & 10 & 20 & 3 & 20 & 15 & 40 & 50 & 803 & 12 & 148 & 37 & 54 \\
\hline 0,92 & 0,93 & 50 & 500 & 50 & 500 & 1,0 & 1.000 & 5.000 & 10 & 20 & 3 & 20 & 13 & 40 & 32 & 715 & 13 & 186 & 30 & 53 \\
\hline 0,93 & 0,94 & 50 & 500 & 50 & 500 & 1,0 & 1.000 & 5.000 & 10 & 20 & 3 & 20 & 13 & 40 & 19 & 670 & 13 & 264 & 22 & 51 \\
\hline 0,94 & 0,95 & 50 & 500 & 50 & 300 & 1,0 & 1.000 & 5.000 & 10 & 20 & 3 & 20 & 13 & 40 & 21 & 635 & 14 & 250 & 22 & 51 \\
\hline 0,95 & 0,96 & 70 & 500 & 50 & 250 & 1,4 & 1.000 & 5.000 & 10 & 20 & 7 & 20 & 19 & 40 & 62 & 605 & 15 & 110 & 33 & 51 \\
\hline 0,96 & 0,97 & 100 & 500 & 50 & 200 & 2,0 & 1.000 & 5.000 & 10 & 20 & 7 & 20 & 20 & 40 & 83 & 563 & 17 & 92 & 35 & 50 \\
\hline 0,97 & 0,98 & 150 & 500 & 50 & 100 & 3,0 & 1.000 & 5.000 & 10 & 20 & 10 & 20 & 20 & 40 & 85 & 555 & 17 & 77 & 34 & 48 \\
\hline 0,98 & 0,99 & 150 & 500 & 50 & 100 & 3,0 & 1.000 & 5.000 & 10 & 20 & 10 & 20 & 22 & 40 & 89 & 467 & 19 & 69 & 33 & 49 \\
\hline 0,99 & 1,00 & 200 & 500 & 50 & 100 & 4,0 & 1.000 & 5.000 & 10 & 20 & 10 & 20 & 22 & 40 & 114 & 460 & 20 & 63 & 35 & 47 \\
\hline 1,00 & 1,01 & 200 & 500 & 50 & 100 & 4,0 & 1.000 & 5.000 & 10 & 20 & 10 & 20 & 22 & 40 & 122 & 433 & 21 & 59 & 36 & 48 \\
\hline 1,01 & 1,02 & 250 & 500 & 50 & 100 & 5,0 & 1.000 & 5.000 & 12 & 20 & 10 & 20 & 24 & 40 & 116 & 450 & 20 & 59 & 36 & 48 \\
\hline 1,02 & 1,03 & 250 & 500 & 50 & 100 & 5,0 & 1.000 & 5.000 & 12 & 20 & 10 & 20 & 24 & 40 & 117 & 418 & 23 & 57 & 35 & 47 \\
\hline 1,03 & 1,04 & 300 & 500 & 50 & 50 & 6,0 & 1.000 & 5.000 & 15 & 20 & 10 & 20 & 27 & 37 & 118 & 397 & 26 & 55 & 36 & 47 \\
\hline 1,04 & 1,05 & 300 & 500 & 50 & 50 & 6,0 & 1.000 & 5.000 & 15 & 20 & 10 & 20 & 27 & 40 & 137 & 410 & 24 & 51 & 37 & 46 \\
\hline 1,05 & 1,06 & 300 & 500 & 50 & 50 & 6,0 & 1.000 & 5.000 & 15 & 20 & 10 & 20 & 27 & 37 & 119 & 369 & 26 & 53 & 36 & 46 \\
\hline 1,06 & 1,07 & 350 & 500 & 50 & 50 & 7,0 & 1.000 & 5.000 & 15 & 20 & 10 & 20 & 27 & 37 & 119 & 399 & 25 & 52 & 36 & 47 \\
\hline 1,07 & 1,08 & 350 & 500 & 50 & 50 & 7,0 & 1.000 & 5.000 & 17 & 20 & 12 & 20 & 29 & 40 & 120 & 300 & 28 & 51 & 35 & 45 \\
\hline 1,08 & 1,09 & 400 & 500 & 50 & 50 & 8,0 & 1.000 & 5.000 & 17 & 20 & 10 & 17 & 29 & 37 & 139 & 312 & 28 & 48 & 38 & 43 \\
\hline 1,09 & 1,10 & 400 & 500 & 50 & 50 & 8,0 & 1.000 & 5.000 & 17 & 20 & 12 & 20 & 29 & 40 & 168 & 279 & 30 & 42 & 38 & 44 \\
\hline 1,10 & 1,11 & 400 & 450 & 50 & 50 & 8,0 & 1.000 & 5.000 & 20 & 20 & 10 & 17 & 30 & 37 & 140 & 302 & 30 & 47 & 37 & 44 \\
\hline 1,11 & 1,12 & 450 & 450 & 50 & 50 & 9,0 & 2.000 & 2.000 & 20 & 20 & 17 & 17 & 37 & 37 & 237 & 237 & 34 & 34 & 42 & 42 \\
\hline 1,12 & 1,13 & 450 & 500 & 50 & 50 & 9,0 & 1.000 & 5.000 & 20 & 20 & 10 & 20 & 30 & 40 & 140 & 269 & 33 & 46 & 37 & 43 \\
\hline 1,13 & 1,14 & 500 & 500 & 50 & 50 & 10,0 & 3.500 & 3.500 & 20 & 20 & 15 & 15 & 35 & 35 & 304 & 304 & 29 & 29 & 44 & 44 \\
\hline 1,14 & 1,15 & 500 & 500 & 50 & 50 & 10,0 & 3.500 & 3.500 & 20 & 20 & 12 & 12 & 32 & 32 & 209 & 209 & 37 & 37 & 40 & 40 \\
\hline 1,15 & 1,16 & 500 & 500 & 50 & 50 & 10,0 & 1.000 & 5.000 & 20 & 20 & 12 & 20 & 32 & 40 & 169 & 271 & 32 & 40 & 38 & 43 \\
\hline
\end{tabular}

Percebe-se que esta análise para os pavimentos flexíveis não é tão trivial, sendo que, aparentemente, quem causa a dispersão da relação é a combinação dos parâmetros. De qualquer modo, percebeu-se que para espessura total do pavimento entre $13 \mathrm{e}$ $20 \mathrm{~cm}$, os valores ficam predominantemente abaixo da linha de igualdade, como ilustra a Figura 4.12. 


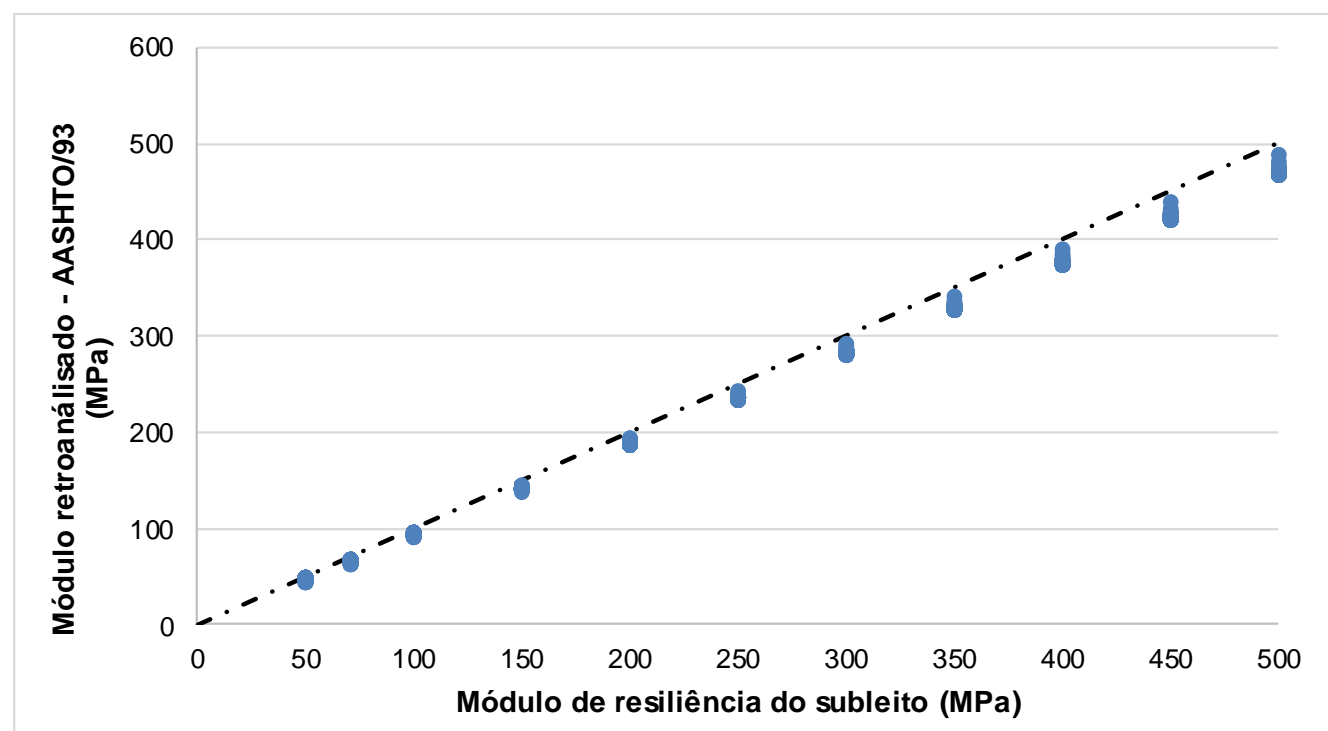

Figura 4.12: Relação obtida no estudo teórico para Módulo de resiliência do subleito ( $E 1)$ e Módulo retroanalisado a partir da equação da AASHTO/93 - Pavimentos tipicamente flexíveis (Módulo E2 igual ou inferior a $500 \mathrm{MPa}$ ) e espessura física total do pavimento entre 13 e $20 \mathrm{~cm}$

Um segundo estudo teórico foi realizado agora para verificar a influência da espessura física total do pavimento na determinação do valor do módulo retroanalisado, em relação ao módulo da camada. Para este estudo foram simulados 27 casos, utilizandose uma estrutura flexível padrão composta por Revestimento asfáltico (módulo de resiliência de $3.500 \mathrm{MPa}$, espessura de $10 \mathrm{~cm}$ ), base granular (módulo de resiliência de $350 \mathrm{MPa}$ e espessura variando entre 30 e $140 \mathrm{~cm}$ ) e subleito/infraestrutura (módulo de resiliência de $40 \mathrm{MPa}$ ). Foi utilizada novamente a equação da AASHTO/93 para realizar a retroanálise dos valores. Foram realizadas 3 retroanálises para cada caso simulado, sendo a primeira utilizando do parâmetro D90, a segunda, o parâmetro $D 120$ e a terceira, o parâmetro $D 150$.

O gráfico da Figura 4.13 a seguir ilustra os resultados desta análise. 


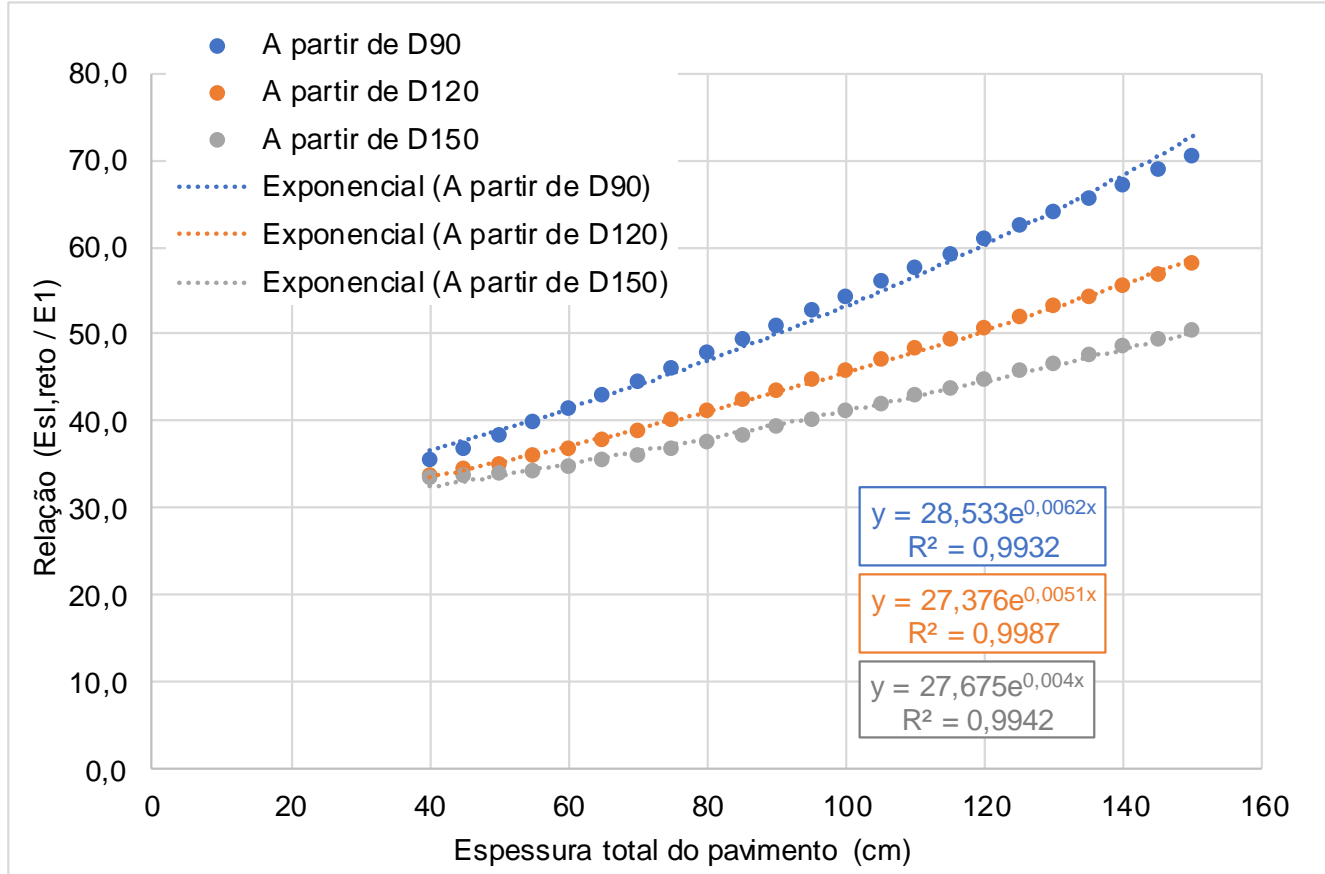

Figura 4.13: Relação (Esl,reto / E1) em função da espessura total do pavimento (segundo estudo teórico)

Como se pode verificar, contatou-se no segundo estudo teórico que, para pavimentos tipicamente flexíveis, quanto maior a espessura física total do pavimento, maior será a relação (Esl,retro / E1), sendo que para espessuras totais abaixo de $50 \mathrm{~cm}$, basicamente se tem uma relação entre 0,8 e 1,0, independente de qual deflexão ( $D 90$, D120 ou D150) tenha sido utilizada na retroanálise. Para espessuras superiores a $50 \mathrm{~cm}$, cada uma das respectivas curvas de relação (Esl,retro / E1) para os diversos parâmetros de deflexão, cruzam o valor desejável da relação $(1,0)$ em um determinado ponto, sendo:

- Curva $D 90$ no valor de espessura total de $55 \mathrm{~cm}$;

- Curva D120 no valor de espessura total de $75 \mathrm{~cm}$;

- Curva D150 no valor de espessura total de $95 \mathrm{~cm}$.

Muito provavelmente, para estruturas diferentes daquelas que foram estudadas nas simulações acima, em termos de módulo de resiliência e espessuras dos materiais, também diferentes serão os formatos das curvas e o ponto de cruzamento do valor ideal $(1,0)$. Assim sendo, considera-se bastante importante, para a retroanálise dos valores de módulo de resiliência do subleito, o conhecimento prévio da espessura total do pavimento, bem como as características das suas camadas, para se que possa realizar o estudo prévio para calibração das curvas e aplicação de um fator de 
correção, com base nas equações de tendência, a partir de estudo teórico semelhante ao realizado.

\subsection{Proposição de metodologia para avaliação de dados de Módulo de Subleito retroanalisado - rodovias estaduais (SP)}

Para elaboração do presente estudo de caso, foram coletados dados históricos de resultados de $F W D$, de algumas rodovias do estado de São Paulo sob Concessão. Mais uma vez ressalta-se que os dados estão contidos de forma dispersa e nem sempre seguem padrão de apresentação, o que dificulta sua análise e correlação com demais dados.

As rodovias selecionadas para o estudo foram as seguintes: SP 021, SP 070, SP 099, SP 147, SP 150, SP 270, SP 280, SP 318 e SP 340.Tais dados foram consolidados em um banco dados deflectométricos, concebido pelo autor, conforme será detalhado mais à frente.

A partir disso, para as rodovias selecionadas para o estudo, buscou-se conhecer as seguintes características / informações:

(i) Sítios geológicos atravessados pelas rodovias;

(ii) Sítios pedológicos atravessados pelas rodovias;

(iii) Precipitação volumétrica histórica acumulada de três dias anteriores à data registrada no levantamento com $F W D$;

(iv) Tipo de seção de terraplenagem (corte, mista ou aterro).

A seguir são explicados cada um dos passos para obtenção das informações pesquisadas. 


\subsubsection{Mapeamento Geológico}

Para realizar a caracterização geológica das rodovias em estudo, foi consultado o sistema GeoSGB - Sistema de Geociências do Serviço Geológico do Brasil (CPRM), disponível no site http://geosgb.cprm.gov.br/.

O serviço do sistema GeoSGB disponibiliza um arquivo tipo kmz do mapeamento geológico digital do estado de São Paulo para visualização no software Google Earth®. Com base nesse mapa e no mapeamento dos marcos quilométricos da rodovia em estudo, foi possível segmentar a rodovia em estudo para cada sítio geológico por ela atravessado.

O mapeamento geológico da região em estudo é apresentado na Figura 4.14 a seguir e a segmentação resultante das rodovias em estudo, de acordo com este critério, é apresentada na Tabela 4.6. A Tabela 4.7 por sua vez apresenta a descrição dos sítios geológicos identificados no âmbito deste estudo. 


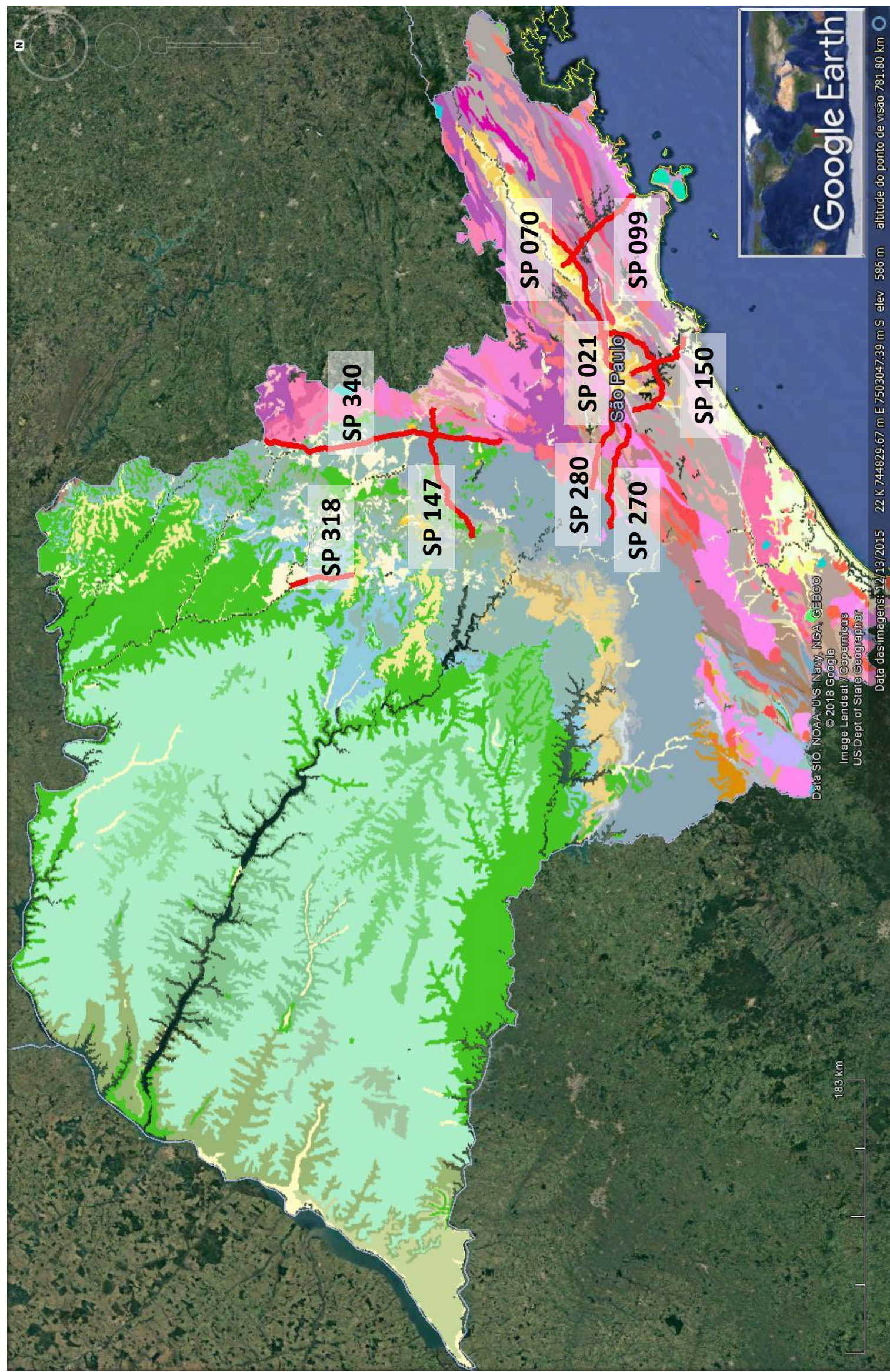

Figura 4.14: Mapeamento dos sítios geológicos de acordo com CPRM (fonte: autor adaptado de GeoSGB e Google Earth $\left.{ }^{8}\right)$ 
A legenda de cores para os sítios pedológicos do mapa da Figura 4.14 é apresentada na Figura 4.15 a seguir.

Do ponto de vista mais simplista, empregado muito pelos engenheiros de pavimentação, pode-se observar que uma parte dos estudos foram realizados nas proximidades da capital, no cristalino brasileiro, incluindo rodovias próximas à bacia do Paraíba. Estas regiões são conhecidas por apresentarem presença de rocha e pedreiras em abundância, e em alguns locais, ocorrências de dezenas de metros de saprólito e solo saprolítico, e apenas espessura de um a dois metros de solos de comportamento laterítico ou transicional. Alguns estudos foram realizados nas regiões do derrame basáltico, muitas vezes com as ocorrências de arenitos intercalados, mais na direção do interior do estado de São Paulo. Estes locais em geral contam com maiores espessuras de solos de comportamento laterítico. 


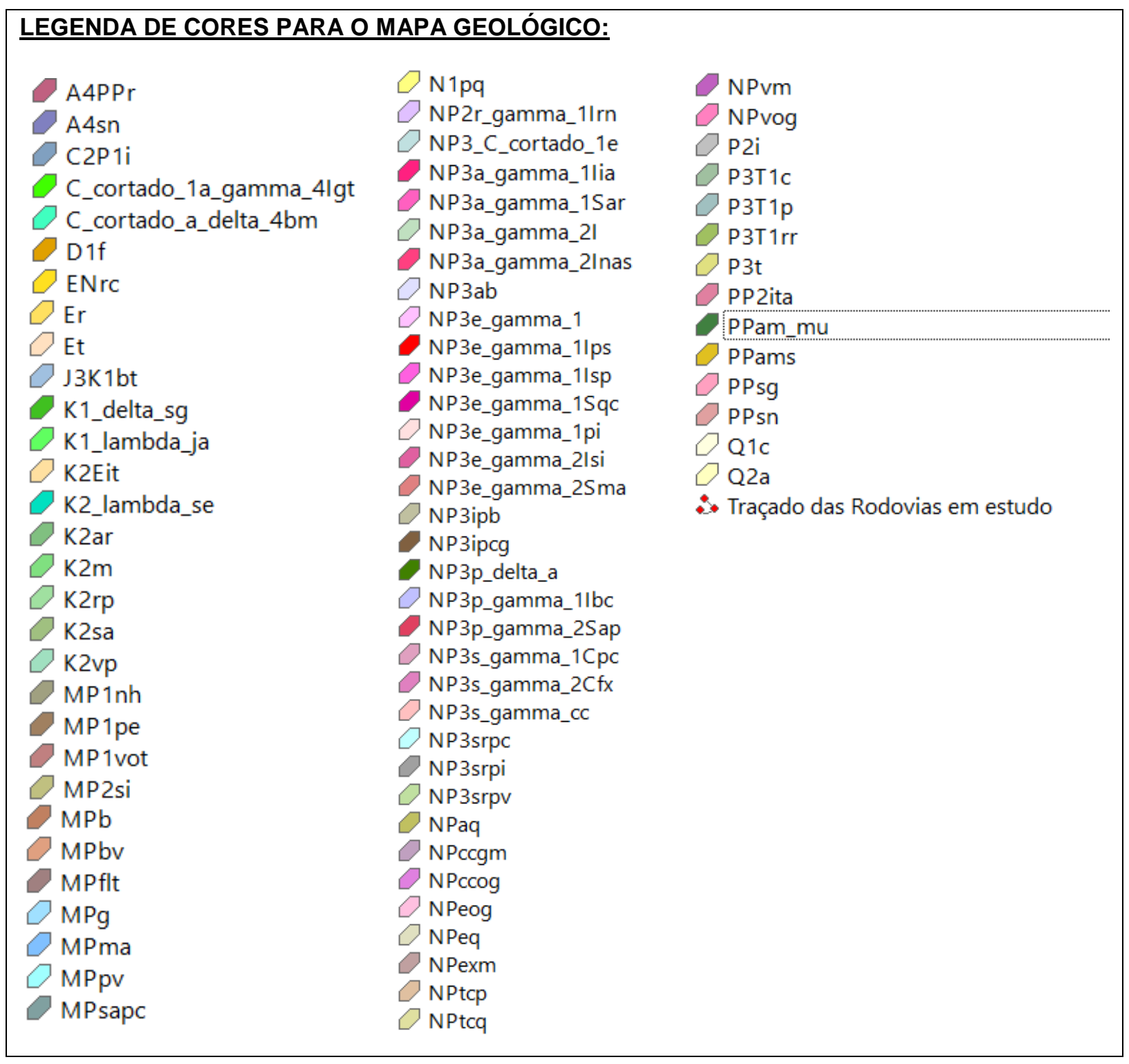

Figura 4.15: Legenda para o mapa dos sítios geológicos de acordo com CPRM (fonte: autor adaptado de GeoSGB e Google Earth $\AA$ ) 
Tabela 4.6: Segmentação das rodovias em estudo pelo critério do sítio geológico (fonte: autor adaptado de GeoSGB/CPRM)

\begin{tabular}{|c|c|c|c|}
\hline Rodovia & $\begin{array}{c}\mathbf{k m} \\
\text { inicial }\end{array}$ & $\begin{array}{c}\mathbf{k m} \\
\text { final }\end{array}$ & $\begin{array}{c}\text { Sigla } \\
\text { (CPRM) }\end{array}$ \\
\hline SP 150 & 9,750 & 12,700 & Npepg \\
\hline SP 150 & 12,700 & 22,510 & $\mathrm{Er}$ \\
\hline SP 150 & 22,510 & 26,510 & Npexm \\
\hline SP 150 & 26,510 & 30,650 & NPepg \\
\hline SP 150 & 30,650 & 41,260 & Npexm \\
\hline SP 150 & 41,260 & 49,870 & Npeog \\
\hline SP 150 & 49,870 & 53,100 & $\mathrm{NP3ml}$ \\
\hline SP 150 & 53,100 & 53,620 & Q2a \\
\hline SP 150 & 53,620 & 62,500 & Qdi \\
\hline SP 150 & 62,500 & 65,600 & Qli \\
\hline SP 070 & 11,190 & 25,200 & Q2a \\
\hline SP 070 & 25,200 & 32,000 & NPepg \\
\hline SP 070 & 32,000 & 35,090 & Q2a \\
\hline SP 070 & 35,090 & 37,200 & NPepg \\
\hline SP 070 & 37,200 & 40,000 & Er \\
\hline SP 070 & 40,000 & 45,000 & NPepg \\
\hline SP 070 & 45,000 & 72,800 & Er \\
\hline SP 070 & 72,800 & 74,080 & Esp \\
\hline SP 070 & 74,080 & 75,930 & Npepg \\
\hline SP 070 & 75,930 & 77,370 & Q2a \\
\hline SP 070 & 77,370 & 81,420 & Npepg \\
\hline SP 070 & 81,420 & 110,000 & Er \\
\hline SP 070 & 110,000 & 112,840 & Et \\
\hline SP 070 & 112,840 & 129,350 & Er \\
\hline SP 070 & 129,350 & 130,400 & $\mathrm{~Np}$ \\
\hline SP 099 & 0,000 & 6,400 & $\mathrm{~Np}$ \\
\hline SP 099 & 6,400 & 10,760 & $\mathrm{Er}$ \\
\hline SP 099 & 10,760 & 14,000 & Npepg \\
\hline SP 099 & 14,000 & 15,000 & $\mathrm{~A} 4 \mathrm{PPr}$ \\
\hline SP 099 & 15,000 & 15,500 & Npepg \\
\hline SP 099 & 15,500 & 17,680 & A4PPr \\
\hline SP 099 & 17,680 & 19,420 & Npepg \\
\hline SP 099 & 19,420 & 24,000 & A4PPr \\
\hline SP 099 & 24,000 & 26,220 & Npepg \\
\hline SP 099 & 26,220 & 26,800 & Npeog \\
\hline SP 099 & 26,800 & 28,700 & NPexm \\
\hline SP 099 & 28,700 & 30,400 & NP3e_gamma_1SsI \\
\hline SP 099 & 30,400 & 32,500 & NPexm \\
\hline SP 099 & 32,500 & 33,600 & NP3a_gamma_2Inas \\
\hline SP 099 & 33,600 & 36,200 & NPexm \\
\hline SP 099 & 36,200 & 40,700 & NP3a_gamma_2Inas \\
\hline SP 099 & 40,700 & 43,100 & NPccq \\
\hline SP 099 & 43,100 & 43,720 & Npccog \\
\hline SP 099 & 43,720 & 52,200 & NPccgp \\
\hline SP 099 & 52,200 & 57,700 & NPccgm \\
\hline SP 099 & 57,700 & 58,600 & NPccgp \\
\hline SP 099 & 58,600 & 62,200 & Npccog \\
\hline SP 099 & 62,200 & 64,300 & NPccgm \\
\hline SP 099 & 64,300 & 82,000 & NP3a_gamma_1lpp \\
\hline SP 099 & 82,000 & 83,200 & Qdi \\
\hline SP 099 & 83,200 & 83,400 & Qli \\
\hline SP 340 & 114,300 & 118,650 & NP3s_gamma_1ljg \\
\hline
\end{tabular}

\begin{tabular}{|c|c|c|c|c|c|c|c|}
\hline Rodovia & $\begin{array}{c}\text { km } \\
\text { inicial }\end{array}$ & $\begin{array}{l}\mathrm{km} \\
\text { final }\end{array}$ & $\begin{array}{c}\text { Sigla } \\
\text { (CPRM) }\end{array}$ & Rodovia & $\begin{array}{c}\text { km } \\
\text { inicial }\end{array}$ & $\begin{array}{l}\mathrm{km} \\
\text { final }\end{array}$ & $\begin{array}{c}\text { Sigla } \\
\text { (CPRM) }\end{array}$ \\
\hline SP 340 & 118,650 & 122,170 & $\mathrm{C} 2 \mathrm{P} 1 \mathrm{i}$ & SP 270 & 54,600 & 61,000 & NP3s_gamma_1lsr \\
\hline SP 340 & 122,170 & 125,450 & k1_delta_sg & SP 270 & 61,000 & 63,500 & MP2si \\
\hline SP 340 & 125,450 & 127,890 & NP3s_gamma_1ljg & SP 270 & 63,500 & 64,500 & NP3s_gamma_1lsr \\
\hline SP 340 & 127,890 & 128,960 & ENrc & SP 270 & 64,500 & 67,100 & MP2si \\
\hline SP 340 & 128,960 & 129,790 & k1_delta_sg & SP 270 & 67,100 & 88,400 & NP3srpi \\
\hline SP 340 & 129,790 & 131,050 & ENrc & SP 270 & 88,400 & 102,800 & NP3s_gamma_2lso \\
\hline SP 340 & 131,050 & 131,400 & NP3s_gamma_1ljg & SP 270 & 102,800 & 115,500 & C2P1i \\
\hline SP 340 & 131,400 & 136,280 & $\mathrm{C} 2 \mathrm{P} 1 \mathrm{i}$ & SP 021 & 30,000 & 39,700 & NPexm \\
\hline SP 340 & 136,280 & 138,160 & ENrc & SP 021 & 39,700 & 47,120 & NPepg \\
\hline SP 340 & 138,160 & 148,210 & $\mathrm{C} 2 \mathrm{P} 1 \mathrm{i}$ & SP 021 & 47,120 & 47,880 & Q2a \\
\hline SP 340 & 148,210 & 150,000 & k1_delta_sg & SP 021 & 47,880 & 48,930 & $\mathrm{Er}$ \\
\hline SP 340 & 150,000 & 154,170 & C2P1i & SP 021 & 48,930 & 53,470 & NPexm \\
\hline SP 340 & 154,170 & 158,590 & Q1c & SP 021 & 53,470 & 62,880 & NP3e_gamma_2Stl \\
\hline SP 340 & 158,590 & 162,000 & $\mathrm{C} 2 \mathrm{P} 1 \mathrm{i}$ & SP 021 & 62,880 & 63,880 & NPexm \\
\hline SP 340 & 162,000 & 164,120 & Q1c & SP 021 & 63,880 & 70,310 & NP3e_gamma_2StI \\
\hline SP 340 & 164,120 & 164,590 & $\mathrm{C} 2 \mathrm{P} 1 \mathrm{i}$ & SP 021 & 70,310 & 74,590 & NPexm \\
\hline SP 340 & 164,590 & 165,770 & ENrc & SP 021 & 74,590 & 86,400 & NPepg \\
\hline SP 340 & 165,770 & 166,790 & $\mathrm{C} 2 \mathrm{P} 1 \mathrm{i}$ & SP 147 & 41,000 & 41,800 & PPsg \\
\hline SP 340 & 166,790 & 168,820 & ENrc & SP 147 & 41,800 & 42,800 & NPaq \\
\hline SP 340 & 168,820 & 170,000 & Q2a & SP 147 & 42,800 & 47,700 & PPsn \\
\hline SP 340 & 170,000 & 179,070 & C2P1a & SP 147 & 47,700 & 52,000 & NPvog \\
\hline SP 340 & 179,070 & 180,000 & Q2a & SP 147 & 52,000 & 55,000 & C2p1i \\
\hline SP 340 & 180,000 & 203,450 & C2P1a & SP 147 & 55,000 & 56,200 & Q1c \\
\hline SP 340 & 203,450 & 203,780 & Q2a & SP 147 & 56,200 & 86,000 & C2p1i \\
\hline SP 340 & 203,780 & 204,890 & k1_delta_sg & SP 147 & 86,000 & 87,700 & P1tt \\
\hline SP 340 & 204,890 & 210,500 & C2P1a & SP 147 & 87,700 & 91,800 & K1_delta_sg \\
\hline SP 340 & 210,500 & 212,930 & Q2a & SP 147 & 91,800 & 92,700 & $\mathrm{P} 2 \mathrm{i}$ \\
\hline SP 340 & 212,930 & 214,710 & k1_delta_sg & SP 147 & 92,700 & 99,000 & P1tt \\
\hline SP 340 & 214,710 & 216,370 & C2P1a & SP 147 & 99,000 & 103,900 & C2p1i \\
\hline SP 340 & 216,370 & 225,860 & Q1c & SP 147 & 103,900 & 106,000 & P1tt \\
\hline SP 340 & 225,860 & 231,410 & C2P1a & SP 147 & 113,000 & 123,500 & P1tt \\
\hline SP 340 & 231,410 & 241,710 & Q1c & SP 147 & 123,500 & 123,900 & P2i \\
\hline SP 340 & 241,710 & 256,000 & C2P1a & SP 147 & 123,900 & 124,500 & K1_delta_sg \\
\hline SP 340 & 256,000 & 257,500 & Q2a & SP 147 & 124,500 & 125,400 & P2i \\
\hline SP 340 & 257,500 & 261,010 & C2P1a & SP 147 & 125,400 & 129,000 & P1tt \\
\hline SP 340 & 261,010 & 259,130 & Q1c & SP 147 & 129,000 & 131,700 & $\mathrm{P} 2 \mathrm{i}$ \\
\hline SP 340 & 259,130 & 263,540 & C2P1a & SP 147 & 131,700 & 135,100 & P1tt \\
\hline SP 340 & 263,540 & 268,640 & Q1c & SP 147 & 0,000 & 136,100 & $\mathrm{P} 2 \mathrm{i}$ \\
\hline SP 340 & 268,640 & 280,000 & C2P1a & SP 147 & 136,100 & 140,700 & P1tt \\
\hline SP 340 & 280,000 & 281,500 & Q2a & SP 147 & 140,700 & 141,100 & K1_delta_sg \\
\hline SP 280 & 13,460 & 17,800 & Q2a & SP 147 & 141,100 & 143,000 & P3T1c \\
\hline SP 280 & 17,800 & 19,000 & MP1vot & SP 318 & 235,400 & 238,230 & K2Eit \\
\hline SP 280 & 19,000 & 42,000 & NP3s_gamma_1lit & SP 318 & 238,230 & 241,410 & Q1c \\
\hline SP 280 & 42,000 & 49,000 & MP2si & SP 318 & 241,410 & 244,920 & K2Eit \\
\hline SP 280 & 49,000 & 54,200 & NP3s_gamma_1lsr & SP 318 & 244,920 & 247,630 & J3K1bt \\
\hline SP 280 & 54,200 & 68,600 & NP3srer & SP 318 & 247,630 & 250,400 & K1_delta_sg \\
\hline SP 280 & 68,600 & 76,200 & NP3s_gamma_21so & SP 318 & 250,400 & 270,000 & J3K1bt \\
\hline SP 280 & 76,200 & 78,200 & NP3srer & SP 318 & 270,000 & 270,720 & K1_delta_sg \\
\hline SP 280 & 78,200 & 79,380 & C2P1i & SP 318 & 270,720 & 270,930 & J3K1bt \\
\hline SP 270 & 34,000 & 46,200 & NP3p_gamma_1lib & SP 318 & 270,930 & 278,740 & Q1c \\
\hline SP 270 & 46,200 & 51,300 & NP3p_gamma_1iv & SP 318 & 278,740 & 280,200 & Q2a \\
\hline SP 270 & 51,300 & 54,600 & MP1vot & & & & \\
\hline
\end{tabular}


Tabela 4.7: Descrição dos sítios geológicos identificados (fonte: autor adaptado de GeoSGB/CPRM)

\begin{tabular}{|c|c|c|}
\hline Sigla & $\begin{array}{l}\text { Abreviação para fins do } \\
\text { presente trabalho }\end{array}$ & Descrição \\
\hline A4PPr & A4PPr & Rio Capivari: Migmatito, Trondhjemito, Gnaisse, Ortognaisse \\
\hline C2P1a & $\mathrm{C} 2 \mathrm{P} 1 \mathrm{a}$ & Aquidauana: Diamictito, Folhelho, Arenito, Siltito \\
\hline C2P1i & C2P1i & Itararé: Arenito, Folhelho, Diamictito, Ritmito \\
\hline ENrc & ENrc & Rio Claro: \\
\hline Er & Er & Resende: Conglomerado, Arenito, Diamictito, Lamito \\
\hline Esp & Esp & São Paulo: Argilito, Arenito conglomerático, Arenito, Siltito \\
\hline Et & Et & Tremembé: Calcário dolomito, Folhelho, Argilito, Marga \\
\hline J3K1bt & J3K1bt & Botucatú: Arenito \\
\hline k1_delta_sg & k1_delta_sg & Serra Geral: Dacito \\
\hline K2Eit & K2Eit & Itaqueri: Arenito, Arenito conglomerático \\
\hline MP1vot & MP1vot & $\begin{array}{l}\text { Votuverava, unidade terrígena: Metasiltito, Filito, Metaconglomerado, } \\
\text { Metarenito }\end{array}$ \\
\hline MP2si & MP2si & Serra do Itaberaba: Xisto, Rocha metapelítica \\
\hline $\mathrm{Np}$ & $\mathrm{Np}$ & $\begin{array}{l}\text { Pindamonhangaba: Arenito, Argilito, Arenito conglomerático, Siltito, } \\
\text { Ortoconglomerado }\end{array}$ \\
\hline NP3a_gamma_1Ipp & NP3a_g_1Ipp & Complexo Pico do Papagaio: Biotita granito \\
\hline NP3a_gamma_2Inas & NP3a_g_2Inas & Granito Natividade da Serra, tipo I: Biotita granito, Monzogranito \\
\hline NP3e_gamma_1SsI & NP3e_g_1SsI & Granito Salto: Biotita granito \\
\hline NP3e_gamma_2Sma & NP3e_g_2Sma & Granito Mauá: Sienogranito, Monzogranito \\
\hline NP3e_gamma_2Stl & NP3e_g_2Stl & Granito Tres Lagos: Granito \\
\hline NP3ml & $\mathrm{NP3ml}$ & Rochas miloníticas: Protomilonito, Milonito, Ultramilonito \\
\hline NP3p_gamma_1iv & NP3p_g_1iv & Granito Itapevi: Biotita monzogranito, Monzogranito \\
\hline NP3p_gamma_1lib & NP3p_g_1lib & Granito Ibiúna: Monzogranito, Granodiorito, Quartzo monzonito \\
\hline NP3s_gamma_1lit & NP3s_g_1lit & Granitóide Itaqui: Granodiorito, Granito \\
\hline NP3s_gamma_1ljg & NP3s_g_1ljg & Jaguariúna: Granito \\
\hline NP3s_gamma_1Isr & NP3s_g_1lsr & Granitóide São Roque: Granodiorito, Biotita monzogranito \\
\hline NP3s_gamma_2Iso & NP3s_g_2Iso & Granito Sorocaba: Monzogranito, Sienogranito, Granodiorito, Granito \\
\hline NP3srer & NP3srer & $\begin{array}{l}\text { São Roque, Formação Estrada dos Romeiros: Metarenito, Metaritmito, } \\
\text { Rocha metapelítica }\end{array}$ \\
\hline NP3srpi & NP3srpi & $\begin{array}{l}\text { São Roque, Formação Piragibu: Filito, Metaconglomerado, Metabasito, } \\
\text { Metabrecha }\end{array}$ \\
\hline NPaq & NPaq & Andrelândia, unidade quartzítica: Muscovita quartzito, Quartzito \\
\hline NPccgm & NPccgm & $\begin{array}{l}\text { Costeiro, unidade granito-gnáissica migmatítica: Migmatito, Gnaisse, Augen } \\
\text { gnaisse }\end{array}$ \\
\hline NPccgp & NPccgp & Costeiro, unidade de gnaisses peraluminosos: Gnaisse, Paragnaisse \\
\hline Npccog & Npccog & $\begin{array}{l}\text { Costeiro, unidade ortognáissica: Migmatito, Biotita gnaisse, Gnaisse, } \\
\text { Ortognaisse }\end{array}$ \\
\hline NPccq & NPccq & Costeiro, unidade quartzítica: \\
\hline Npeog & Npeog & Ortognáissica: Biotita gnaisse, Ortognaisse \\
\hline Npepg & Npepg & Paragnáissica: Biotita gnaisse \\
\hline Npexm & Npexm & Xistos, localmente migmatíticos: Xisto \\
\hline NPvog & NPvog & $\begin{array}{l}\text { Varginha-Guaxupé, unidade ortognáissica migmatítica intermediária: } \\
\text { Migmatito estromático, Albita anatexito, Tonalito gnaisse, Granito gnaisse }\end{array}$ \\
\hline P1tt & P1tt & Tatuí: Siltito \\
\hline $\mathrm{P} 2 \mathrm{i}$ & P2i & Irati: Folhelho \\
\hline P3T1c & P3T1c & Corumbataí: Arenito, Siltito \\
\hline PPsg & PPsg & $\begin{array}{l}\text { São Gonçalo do Sapucaí: Biotita gnaisse, Xisto, Hornblenda gnaisse, } \\
\text { Ortognaisse }\end{array}$ \\
\hline PPsn & PPsn & $\begin{array}{l}\text { Amparo, unidade de migmatitos tonalito-trondhjemíticos: Ortognaisse, } \\
\text { Migmatito estromático, Trondhjemito }\end{array}$ \\
\hline Q1c & Q1c & Depósitos Colúvio-Eluvionares: Depósitos elúvio-coluvionares \\
\hline Q2a & Q2a & Depósitos aluvionares: Depósitos de areia, Depósitos de cascalho \\
\hline Qdi & Qdi & $\begin{array}{l}\text { Coberturas detríticas indiferenciadas: Depósitos de areia, Depósitos de } \\
\text { cascalho, Depósitos de argila }\end{array}$ \\
\hline Qli & Qli & $\begin{array}{l}\text { Depósitos litorâneos indiferenciados: Depósitos de argila, Depósitos de } \\
\text { areia }\end{array}$ \\
\hline
\end{tabular}




\subsubsection{Mapeamento Pedológico}

O mapeamento pedológico foi realizado com base no mapa pedológico digital, também em formato $k m z$ disponibilizado pelo site da SIGEL (Sistema de Informações Geográficas do Setor Elétrico) da ANEEL (Agência Nacional de Energia Elétrica), disponível no site http://sigel.aneel.gov.br/arcgis/rest/services/SIGEL/Tematicos/MapServer/generatek $\mathrm{ml}$, a partir do mapeamento pedológico de solos realizado pela EMBRAPA (Empresa Brasileira de Pesquisa Agropecuária). O arquivo original baixado do site da EMBRAPA trazia as informações de cada sítio pedológico quando apontados os locais no mapa, porém todos eles estavam indicados graficamente com a mesma cor.

Neste sentido, uma adaptação foi realizada pelo autor para fins deste trabalho com o objetivo de separar as 'macro classes' dos sítios pedológicos diversos por cores. A Figura 4.16 na sequencia ilustra o mapa de cores gerado e a Figura 4.17 apresenta as legendas de cada macro classe de natureza pedológica dos solos, de acordo com a classificação utilizada pela EMBRAPA. 


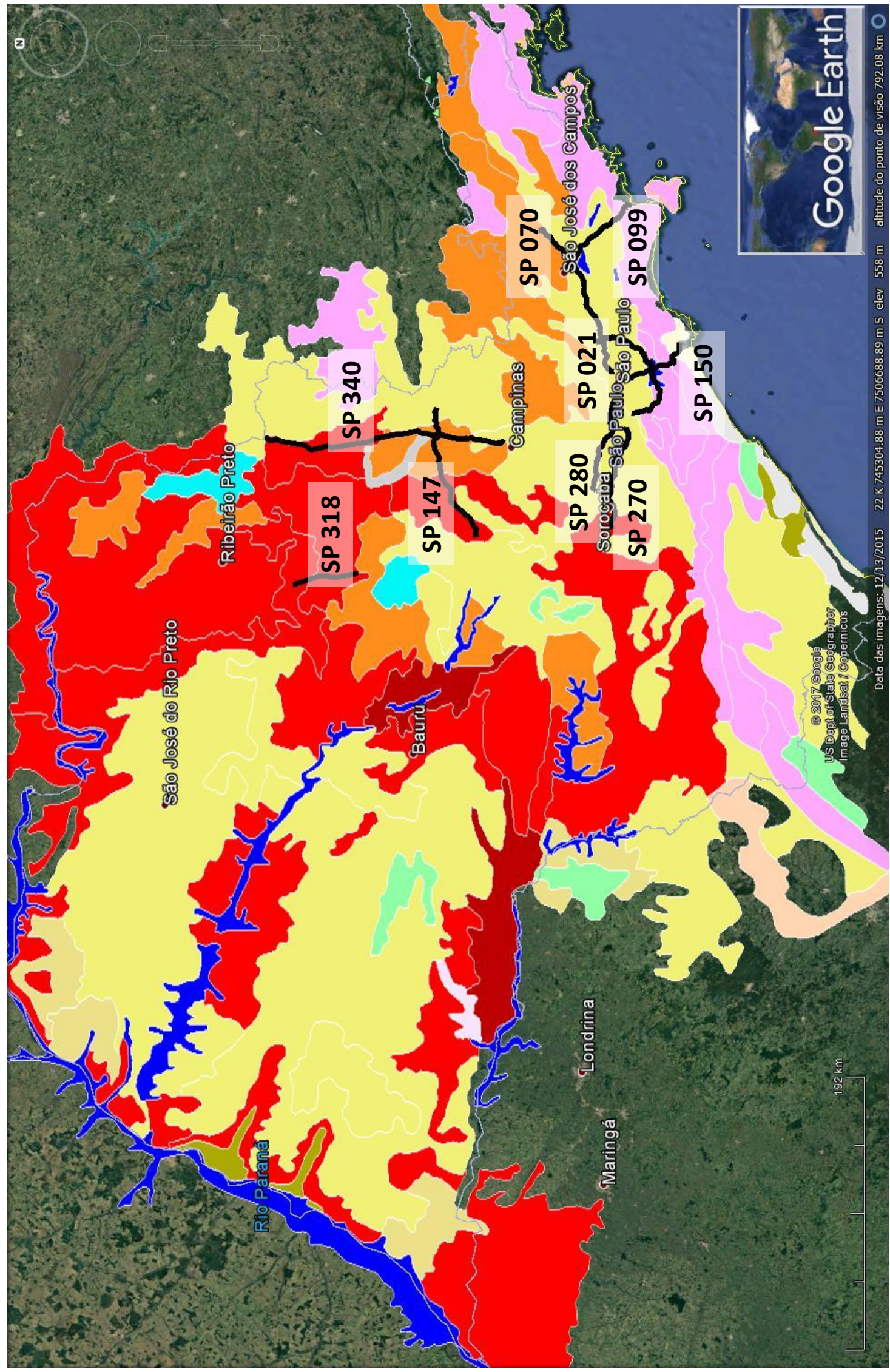

Figura 4.16: Mapeamento dos sítios pedológicos de acordo com EMBRAPA (fonte: autor adaptado de EMBRAPA e Google Earth®) 


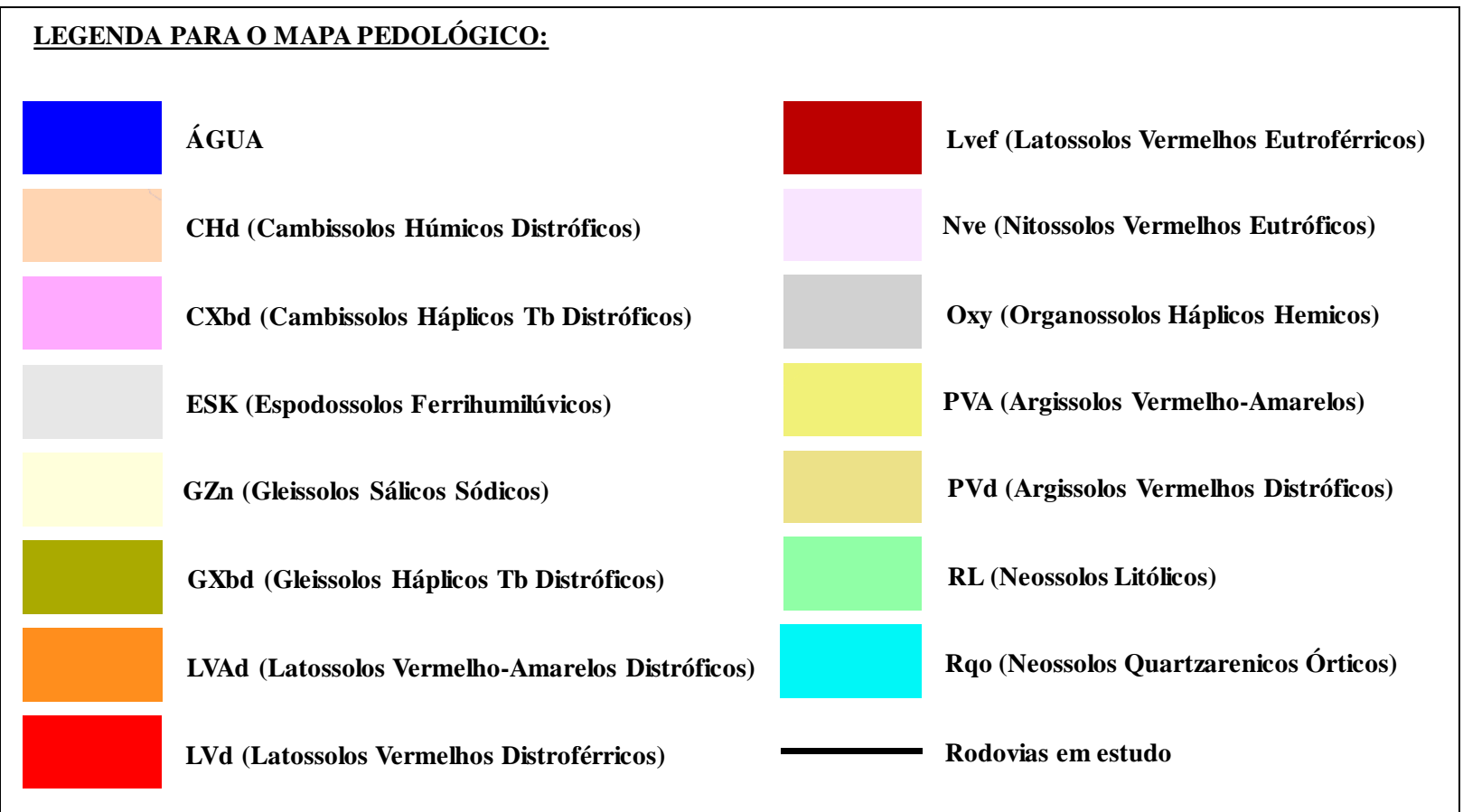

Figura 4.17: Legenda de cores para o mapa pedológico

Transpondo-se então o mapa pedológico com o mapa do traçado das rodovias em estudo, foi possível realizar a segmentação por este critério. Os segmentos resultantes deste trabalho são apresentados na Tabela 4.8 a seguir. A Tabela 4.9 apresenta a descrição da composição das camadas e demais características para os sítios pedológicos descritos na Tabela 4.8.

Pode-se observar que parte importante das rodovias estudadas próximas à capital apresentam ocorrências importantes de cambissolos e argissolos que são em geral solos de comportamento não-laterítico, com ocorrências de dezenas de metros de saprolito e de solo saprolítico, muitos arenosos, alguns silto-arenosos muito expansivos e alguns finos argilosos expansivos. Há ocorrência de pequena espessura de solos de comportamento laterítico ou transicional. Nas regiões das rodovias mais para o interior do estado, nas regiões dos derrames basálticos, pode-se observar a presença de latossolos, em geral em espessuras de metros, de comportamento em geral laterítico, entre LA, LA' e LG', dependendo da quantidade de fração areia presente, proveniente da presença de arenito com basalto na origem da formação dos solos. 
Tabela 4.8: Segmentação da rodovia pelo sítio pedológico atravessado (fonte: autor adaptado de EMBRAPA)

\begin{tabular}{|c|c|c|c|c|c|c|c|}
\hline Rodovia & $\begin{array}{c}\text { km } \\
\text { inicial }\end{array}$ & km final & Sítio Pedológico & Rodovia & km inicial & km final & Sítio Pedológico \\
\hline SP 099 & 0,000 & 4,000 & LVAd7 & SP 270 & 34,000 & 103,000 & PVAd9 \\
\hline SP 099 & 4,000 & 57,500 & PVAd39 & SP 270 & 103,000 & 115,500 & LVd9 \\
\hline SP 099 & 57,500 & 83,640 & CXbd3 & SP 280 & 13,460 & 79,380 & PVAd9 \\
\hline SP 070 & 11,190 & 120,500 & PVAd39 & SP 340 & 114,300 & 118,500 & LVAd3 \\
\hline SP 070 & 120,500 & 130,400 & LVAd7 & SP 340 & 118,500 & 133,000 & PVAd9 \\
\hline SP 147 & 41,000 & 52,000 & PVAe10 & SP 340 & 133,000 & 165,340 & LVAd3 \\
\hline SP 147 & 52,000 & 90,000 & LVAd3 & SP 340 & 165,340 & 168,540 & Oxy2 \\
\hline SP 147 & 90,000 & 118,500 & LVd2 & SP 340 & 168,540 & 196,200 & LVAd3 \\
\hline SP 147 & 118,500 & 123,000 & PVAd9 & SP 340 & 196,200 & 278,360 & LVd1 \\
\hline SP 147 & 123,000 & 143,000 & $\mathrm{LVd} 2$ & SP 340 & 278,360 & 281,500 & PVAd44 \\
\hline SP 150 & 9,750 & 24,000 & PVAd39 & SP 318 & 235,400 & 269,000 & LVdf3 \\
\hline SP 150 & 24,000 & 26,500 & Água & SP 318 & 269,000 & 280,200 & LVd1 \\
\hline SP 150 & 26,500 & 28,680 & CXbd1 & SP 021 & 30,000 & 36,850 & PVAd39 \\
\hline SP 150 & 28,680 & 31,280 & Água & SP 021 & 36,850 & 63,890 & CXbd1 \\
\hline SP 150 & 31,280 & 40,000 & CXbd1 & SP 021 & 63,890 & 76,000 & Água \\
\hline SP 150 & 40,000 & 54,500 & CXbd3 & SP 021 & 76,000 & 82,700 & CXbd1 \\
\hline SP 150 & 54,500 & 65,600 & GZn2 & SP 021 & 82,700 & 86,400 & Água \\
\hline
\end{tabular}


Tabela 4.9: Composição e características dos sítios pedológicos citados (fonte: EMBRAPA)

\begin{tabular}{|c|c|c|}
\hline $\begin{array}{l}\text { Código } \\
\text { EMBRAPA }\end{array}$ & Parâmetro & Descrição \\
\hline \multirow{4}{*}{ CXbd1 } & Composição Solo 1 & Cambissolos Haplicos Tb Distróficos \\
\hline & Composição Solo 2 & - \\
\hline & Composição Solo 3 & - \\
\hline & Área total $(\mathrm{km} 2)$ & 1.854 .013 .796 \\
\hline \multirow{4}{*}{ CXbd3 } & Composição Solo 1 & Cambissolos Haplicos Tb Distróficos \\
\hline & Composição Solo 2 & Latossolos Vermelho-Amarelos Distróficos \\
\hline & Composição Solo 3 & - \\
\hline & Área total (km2) & 9.390 .851 .951 \\
\hline \multirow{4}{*}{ GZn2 } & Composição Solo 1 & Gleissolos Salicos Sodicos \\
\hline & Composição Solo 2 & Gleissolos Tiomorficos Orticos \\
\hline & Composição Solo 3 & Espodossolos Ferriluvicos Hidromorficos \\
\hline & Área total $(\mathrm{km} 2)$ & 421.851 .074 \\
\hline \multirow{4}{*}{ LVAd3 } & Composição Solo 1 & Latossolos Vermelho-Amarelos Distróficos \\
\hline & Composição Solo 2 & Latossolos Vermelhos Distróficos \\
\hline & Composição Solo 3 & - \\
\hline & Área total $(\mathrm{km} 2)$ & 2.316 .256 .312 \\
\hline \multirow{4}{*}{ LVAd7 } & Composição Solo 1 & Latossolos Vermelho-Amarelos Distróficos \\
\hline & Composição Solo 2 & Cambissolos Haplicos Tb Distróficos \\
\hline & Composição Solo 3 & - \\
\hline & Área total (km2) & 8.954 .070 .131 \\
\hline \multirow{4}{*}{ LVAd19 } & Composição Solo 1 & Latossolos Vermelho-Amarelos Distróficos \\
\hline & Composição Solo 2 & Latossolos Vermelhos Distróficos \\
\hline & Composição Solo 3 & Neossolos Quartzarenicos Orticos \\
\hline & Área total (km2) & 3.331 .818 .278 \\
\hline \multirow{4}{*}{ LVAd44 } & Composição Solo 1 & Latossolos Vermelho-Amarelos Distróficos \\
\hline & Composição Solo 2 & Neossolos Quartzarenicos Orticos \\
\hline & Composição Solo 3 & Argissolos Vermelho-Amarelos Distróficos \\
\hline & Área total $(\mathrm{km} 2)$ & 850.307 .513 \\
\hline \multirow{4}{*}{ LVd1 } & Composição Solo 1 & Latossolos Vermelhos Distróficos \\
\hline & Composição Solo 2 & \\
\hline & Composição Solo 3 & - \\
\hline & Área total $(\mathrm{km} 2)$ & 3.046 .554 .504 \\
\hline \multirow{4}{*}{ LVd2 } & Composição Solo 1 & Latossolos Vermelhos Distróficos \\
\hline & Composição Solo 2 & Latossolos Vermelhos Distroférricos \\
\hline & Composição Solo 3 & - \\
\hline & Área total $(\mathrm{km} 2)$ & 3.021 .536 .958 \\
\hline \multirow{4}{*}{ LVdf3 } & Composição Solo 1 & Latossolos Vermelhos Distroférricos \\
\hline & Composição Solo 2 & Latossolos Vermelhos Distróficos \\
\hline & Composição Solo 3 & - \\
\hline & Área total $(\mathrm{km} 2)$ & 4.624 .007 .628 \\
\hline \multirow{4}{*}{ LVd7 } & Composição Solo 1 & Latossolos Vermelhos Distróficos \\
\hline & Composição Solo 2 & Argissolos Vermelhos Distróficos \\
\hline & Composição Solo 3 & - \\
\hline & Área total $(\mathrm{km} 2)$ & 4.037 .577 .838 \\
\hline \multirow{4}{*}{ LVd9 } & Composição Solo 1 & Latossolos Vermelhos Distróficos \\
\hline & Composição Solo 2 & Argissolos Vermelho-Amarelos Distróficos \\
\hline & Composição Solo 3 & - \\
\hline & Área total (km2) & 1.267.937.246 \\
\hline
\end{tabular}

$\begin{array}{ll}\text { Código } & \text { Darâmetro } \\ \text { EMBRAPA } & \text { Descricão }\end{array}$

Composição Solo 1 Latossolos Vermelhos Distróficos

Composição Solo 2 Latossolos Vermel hos Eutroferricos Composição Solo 3 Argissolos Vermel hos Eutróficos Área total (km2) 1.046.756.789 Composição Solo 1 Latossolos Vermelhos Eutroferricos

LVef1 Composição Solo 2

Composição Solo 3 -

Área total (km2) 4.061.243.262

Composição Solo 1 Nitossolos Vermelhos Eutróficos

NVe2 Composição Solo 2 Latossolos Vermelhos Eutroferricos Composição Solo 3 Área total (km2) 570.204 .445

Composição Solo 1 Organossolos Haplicos Hemicos

oxy2 Composição Solo 2 Gleissolos Melanicos Tb Distróficos Composição Solo 3 Gleissolos Haplicos Tb Distróficos Área total (km2) 457.944 .314

Composição Solo 1 Argissolos Vermelho-Amarelos Distróficos Composição Solo 2 Argissolos Vermelhos Eutróficos Composição Solo 3 Latossolos Vermelho-Amarelos Distróficos Área total (km2) 6.257.355.305 Composição Solo 1 Argissolos Vermelho-Amarelos Distróficos

PVAd4 Composição Solo 2 Latossolos Vermelho-Amarelos Distróficos Composição Solo 3 Área total $(\mathrm{km} 2) \quad 5.998 .386 .448$

Composição Solo 1 Argissolos Vermelho-Amarelos Distróficos

PVAd44 Composição Solo 2 Argissolos Vermelho-Amarelos Eutróficos Composição Solo 3 Latossolos Vermelhos Distróficos Área total $(\mathrm{km} 2) \quad 4.989 .848 .457$ Composição Solo 1 Argissolos Vermelho-Amarelos Distróficos

PVAd9 Composição Solo 2 Cambissolos Haplicos Tb Distróficos Composição Solo 3 Área total (km2) 106.958 .759 Composição Solo 1 Argissolos Vermelho-Amarelos Eutróficos

PVAe10 Composição Solo 2 Argissolos Vermelhos Eutróficos Composição Solo 3 Latossolos Vermelhos Distróficos Área total $(\mathrm{km} 2) \quad 2.055 .388 .902$

Composição Solo 1 Argissolos Vermelho-Amarelos Eutróficos

PVAe6 Composição Solo 2 Neossolos Litolicos Eutróficos Composição Solo 3

Área total (km2) 3.384.173.974 Composição Solo 1 Neossolos Litolicos Distróficos

RLd17 Composição Solo 2 Argissolos Vermelho-Amarelos Distróficos Composição Solo 3 Cambissolos Haplicos Tb Distróficos Área total (km2) 198.316.208 


\subsubsection{Mapeamento Pluviométrico}

Para estudar o histórico de chuvas foi consultado o banco de dados hidrológicos do $D A E E$ (Departamento de Águas e Energia Elétrica do Estado de São Paulo), disponível no site http://www.hidrologia.daee.sp.gov.br/. A Figura 4.18 a seguir ilustra o mapa das unidades de gerenciamento de Recursos Hídricos do DAEE/SP.

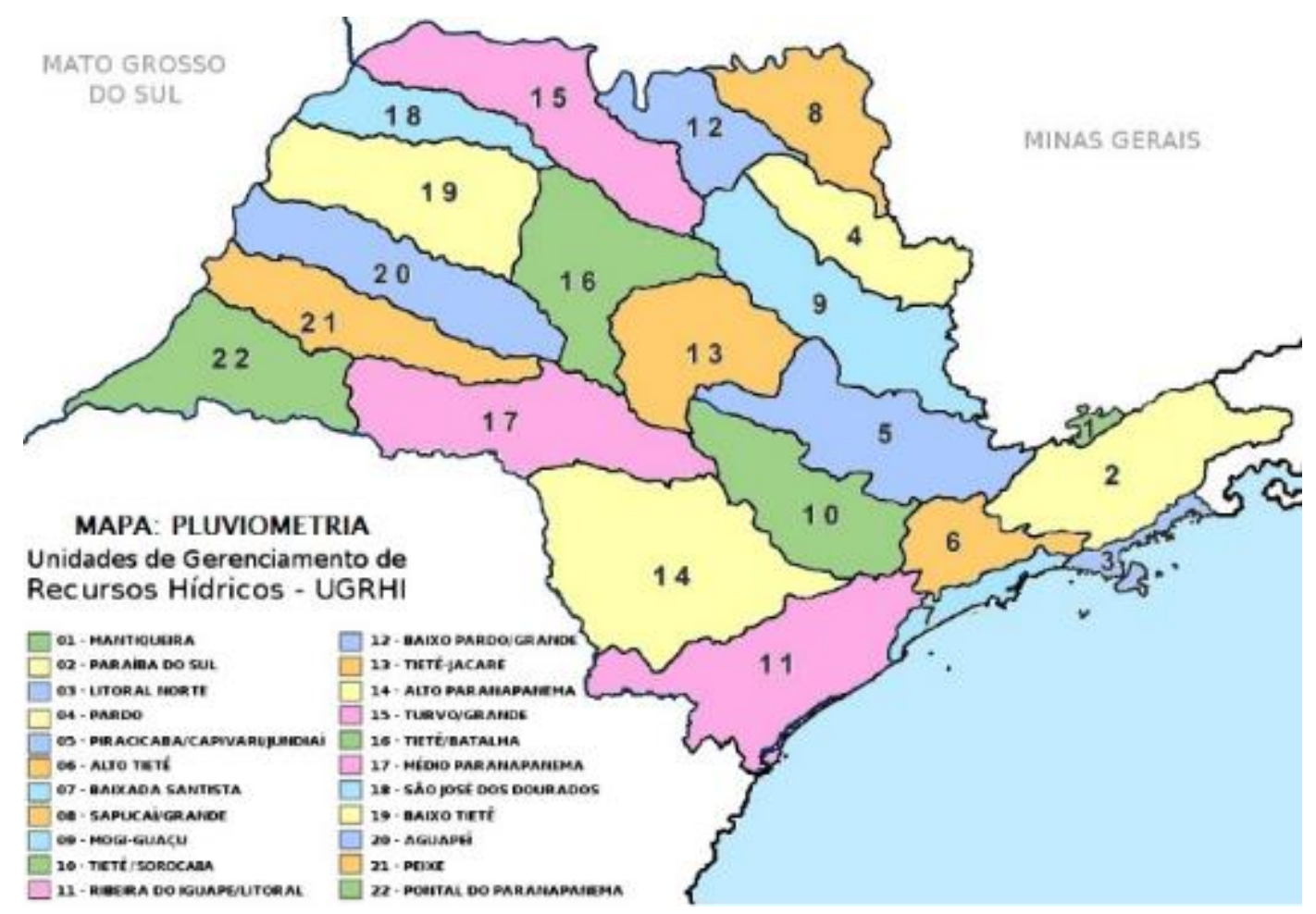

Figura 4.18: Mapa das unidades de gerenciamento de recursos hídricos de acordo com o DAEE/SP

A partir das coordenadas de geolocalização das estações, os pontos foram, um a um, plotados no software Google Earth $\circledast$ gerando-se um novo arquivo tipo $\mathrm{kmz}$, com a localização das estações.

A Figura 4.19 a seguir ilustra mapa contendo o arquivo tipo $\mathrm{kmz}$ gerado com as estações pluviométricas cadastradas para fins deste estudo. 
Os dados históricos das estações pluviométricas cadastradas no mapa foram então consolidados em um banco de dados (planilha eletrônica) específico, para posteriormente serem consultados através de programação de fórmulas.

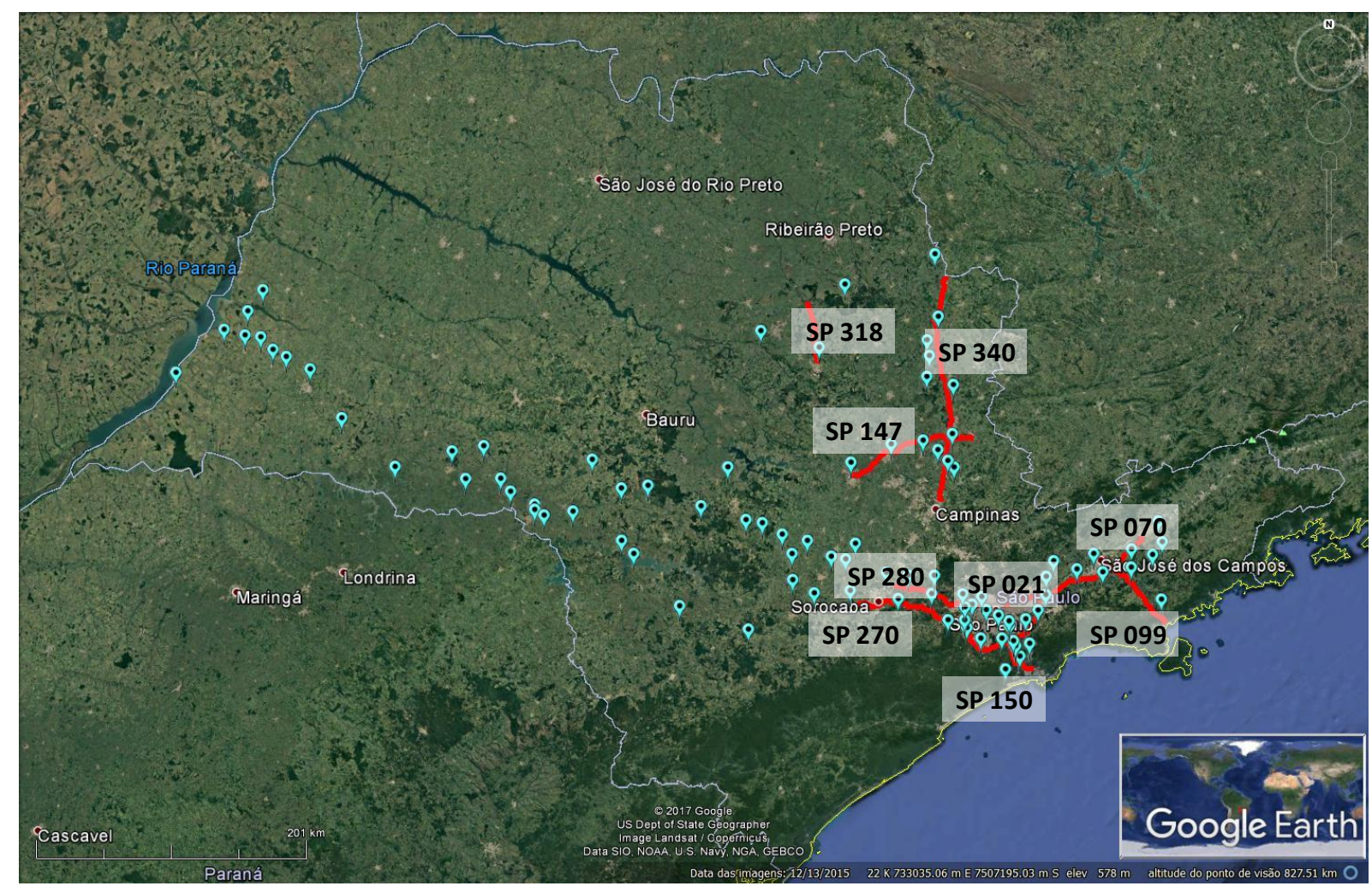

Figura 4.19: Mapeamento das estações pluviométricas cadastradas para análise

A partir do mapa foi realizada uma filtragem prévia das estações com dados atualizados para potencial utilização. Depois de realizada esta seleção, foi possível adotar áreas de influência de cada estação pluviométrica selecionada para o traçado das rodovias em estudo. O detalhamento das áreas de influências adotadas para as rodovias em estudo é apresentado na Tabela 4.10 a seguir. 
Tabela 4.10: Áreas de influência adotadas para as estações pluviométricas nas rodovias em estudo

\begin{tabular}{|c|c|c|c|c|c|c|}
\hline \multirow[b]{2}{*}{$\begin{array}{c}\text { Código da } \\
\text { Estação } \\
\text { (DAEE) }\end{array}$} & \multirow[b]{2}{*}{$\begin{array}{l}\text { Data } \\
\text { inicial dos } \\
\text { registros }\end{array}$} & \multirow[b]{2}{*}{$\begin{array}{l}\text { Data final } \\
\text { dos } \\
\text { registros }\end{array}$} & \multicolumn{4}{|c|}{ Área de influência } \\
\hline & & & Rodovia & $\begin{array}{c}\text { km } \\
\text { inicial }\end{array}$ & $\begin{array}{c}\text { km } \\
\text { final }\end{array}$ & $\begin{array}{l}\text { Distância em } \\
\text { relação ao } \\
\text { eixo da via } \\
(\mathrm{km})\end{array}$ \\
\hline E3-136 & jan-48 & set-16 & SP 021 & 0,000 & 42,455 & 1,5 \\
\hline E3-243 & set-72 & nov-16 & SP 021 & 42,455 & 66,700 & 3,1 \\
\hline E3-162 & jan-99 & dez-16 & SP 021 & 66,700 & 85,065 & 4,1 \\
\hline E3-155 & jan-99 & dez-16 & SP 021 & 85,065 & 96,820 & 1,2 \\
\hline E3-245 & set-72 & out-16 & SP 021 & 96,820 & 113,065 & 4,5 \\
\hline E3-108 & out-61 & nov-16 & SP 021 & 113,065 & 129,106 & 7,4 \\
\hline E3-108 & out-61 & nov-16 & SP 070 & 11,190 & 62,750 & 0,7 \\
\hline E2-031 & nov-42 & dez-16 & SP 070 & 62,750 & 95,750 & 5,9 \\
\hline E2-025 & jan-43 & jul-15 & SP 070 & 95,750 & 117,320 & 7,7 \\
\hline E2-095 & jun-57 & out-16 & SP 070 & 117,320 & 130,400 & 11,9 \\
\hline D3-009 & jan-37 & nov-16 & SP 147 & 41,360 & 72,000 & 11,0 \\
\hline D4-099 & jun-70 & nov-16 & SP 147 & 72,000 & 94,000 & 11,0 \\
\hline D4-064 & out-65 & mai-16 & SP 147 & 94,000 & 124,500 & 5,7 \\
\hline D4-104 & ago-73 & nov-16 & SP 147 & 124,500 & 143,000 & 1,8 \\
\hline E3-162 & jan-99 & dez-16 & SP 150 & 9,700 & 41,000 & 1,5 \\
\hline E3-228 & ago-39 & out-16 & SP 150 & 41,000 & 65,600 & 5,1 \\
\hline E3-031 & jan-37 & mai-16 & SP 270 & 34,000 & 53,500 & 6,4 \\
\hline E4-043 & jan-42 & dez-16 & SP 270 & 53,500 & 84,500 & 9,6 \\
\hline E4-128 & jun-71 & jul-16 & SP 270 & 84,500 & 110,500 & 8,6 \\
\hline E4-019 & jun-57 & nov-16 & SP 270 & 110,500 & 115,500 & 22,7 \\
\hline E3-145 & nov-55 & mar-15 & SP 280 & 13,460 & 19,500 & 5,0 \\
\hline E3-031 & jan-37 & mai-16 & SP 280 & 19,500 & 47,000 & 5,0 \\
\hline E4-043 & jan-42 & dez-16 & SP 280 & 47,000 & 76,950 & 1,4 \\
\hline E4-128 & jun-71 & jul-16 & SP 280 & 76,950 & 79,380 & 3,7 \\
\hline D4-075 & jan-70 & out-16 & SP 318 & 230,000 & 258,000 & 1,4 \\
\hline C4-096 & set-70 & nov-16 & SP 318 & 258,000 & 280,200 & 26,3 \\
\hline D3-042 & dez-42 & nov-16 & SP 340 & 114,100 & 135,200 & 3,4 \\
\hline D4-082 & ago-50 & nov-16 & SP 340 & 135,200 & 145,700 & 4,9 \\
\hline D3-009 & jan-37 & nov-16 & SP 340 & 145,700 & 186,150 & 4,0 \\
\hline C4-097 & out-70 & nov-16 & SP 340 & 186,150 & 229,550 & 8,5 \\
\hline C4-072 & jun-60 & dez-16 & SP 340 & 229,550 & 281,770 & 0,5 \\
\hline
\end{tabular}


4.4.4 Segmentação pelo tipo de seção de terraplenagem

Com base nos levantamentos visuais de campo realizados na rodovia, também puderam ser determinados os tipos de seções de terraplenagem (seções em corte, em aterro ou mistas) ao longo do traçado das rodovias em estudo. O resultado desta compartimentação é apresentado no Anexo C.

4.4.5 Consolidação dos dados de levantamento deflectométrico e retroanálise dos valores de módulo de subleito

Como já citado anteriormente, os dados de levantamento deflectométrico foram coletados a partir das planilhas resultantes do monitoramento anual dos pavimentos que a ARTESP (Agência Reguladora de Transportes do Estado de São Paulo) realiza junto às Concessionárias de serviços responsáveis pela administração das rodovias. Em geral, os levantamentos de deflexão são realizados a cada 2 anos nas rodovias da malha concedida, normalmente fazendo-se uso do equipamento FWD.

Os dados foram consolidados em um só banco de dados concebido pelo autor (planilha eletrônica).

A partir destes dados, foi possível calcular o valor do módulo de resiliência do subleito retroanalisado ( $E s l$,retro ou $E s / r$ ), para cada registro histórico do levantamento, a partir da equação proposta pelo guia de dimensionamento da AASHTO de 1993 (equação 3.2). 
4.4.6 Consulta de informações e consolidação do banco de dados deflectométrico (BD2)

Uma vez formatada a planilha inicial consolidada com os dados históricos de deflexões com o uso do $F W D$, e cada uma das planilhas de compartimentação dos trechos a partir das informações coletadas nos mapas, montou-se uma consulta de modo que, em cada ponto do ensaio com FWD, pudesse ser definida cada uma das características pesquisas, ou seja, (a) o sítio geológico de cada ponto ensaiado; (b) o sítio pedológico de cada ponto ensaiado; (c) o tipo de seção de terraplenagem (corte, mista ou aterro) de cada ponto ensaiado; (e) o índice pluviométrico acumulado para 1, 2, 4 e 8 dias anteriores à data do levantamento deflectométrico para cada um dos pontos de ensaio contidos no cadastro.

A partir dos pontos de registro do $F W D$ também foi possível realizar uma pesquisa prévia no banco de dados de ensaios de subleito (BD1) para se obterem dados qualitativos do material do subleito, se disponível em uma distância máxima de 5 metros do ponto do ensaio (classificação $M C T$ e $H R B$ ). Deve-se fazer uma observação importante quanto a este quesito: foi realizada uma pesquisa simples, onde, se mais de um ensaio estivesse disponível, apenas um dos ensaios seria registrado, de acordo com um determinado critério, para fins de referência. Uma consulta mais completa dos tipos de solos pelas classificações $M C T$ e $H R B$ foi realizada na composição do banco de dados $B D 3$, como será detalhado no item 4.4 .7 a seguir.

A partir deste banco de informações consolidados, denominado nesta tese de Banco de Dados $B D 2$, serão realizados os estudos descritos no item 4.5 em diante. 
4.4.7 Consolidação de um novo banco de dados para segmentos homogêneos $(B D 3)$

Para efeito de análise e comparação entre os dados históricos dos levantamentos com o FWD, foi realizada a segmentação homogênea do trecho, contemplando cada um dos elementos em estudo (sítio pedológico, sítio geológico e tipo de seção de terraplenagem). As características dos segmentos homogêneos adotados para análise são apresentadas no Anexo C - SEGMENTOS HOMOGÊNEOS .

A partir desta segmentação, foi montado outro banco de dados, batizado de Banco de Dados $B D 3$, contendo os segmentos homogêneos identificados e seus respectivos parâmetros estatísticos (média e desvio-padrão) dos elementos em estudo: módulo de resiliência retroanalisado, precipitação acumulada para 1, 2, 4 e 8 dias etc.

Além disso, a partir desta segmentação, também foi possível realizar uma consulta mais completa ao banco de dados de ensaios de materiais de subleito (BD1) descrito no item 4.1 (pág.183), onde se puderam verificar, em alguns locais, algumas características dos solos locais como classificação $M C T$, classificação $H R B$, estatísticas dos valores de CBR e expansão dos solos, entre outras características relevantes.

Obs.: Por se tratar de um banco de dados de segmentos homogêneos, quando da pesquisa dos ensaios de subleito no banco $B D 1$, em muitos casos, dentro de um mesmo segmento foram identificados mais de um tipo de classificação MCT ou HRB. Nestes casos, foram contados quantos ensaios foram identificados para cada uma das respectivas classes. Um resumo desta contagem será apresentado mais adiante no capítulo 5 (Tabela 5.1 e Tabela 5.2). 


\subsection{Apresentação de resultados da aplicação da metodologia proposta para o trecho piloto (Rodoanel Sul)}

Para formatação da metodologia de análise dos dados, optou-se pela seleção de um trecho piloto, no caso o Rodoanel Sul (SP 021). A Figura 4.20 apresenta o mapa da região do Rodoanel Sul. Por sua vez a Figura 4.21 e Figura 4.22 apresentam respectivamente os mapas geológico e pedológico da região atravessada pelo trecho em estudo. Enquanto a Figura 4.23 apresenta a localização das estações pluviométricas utilizadas para fins deste estudo.

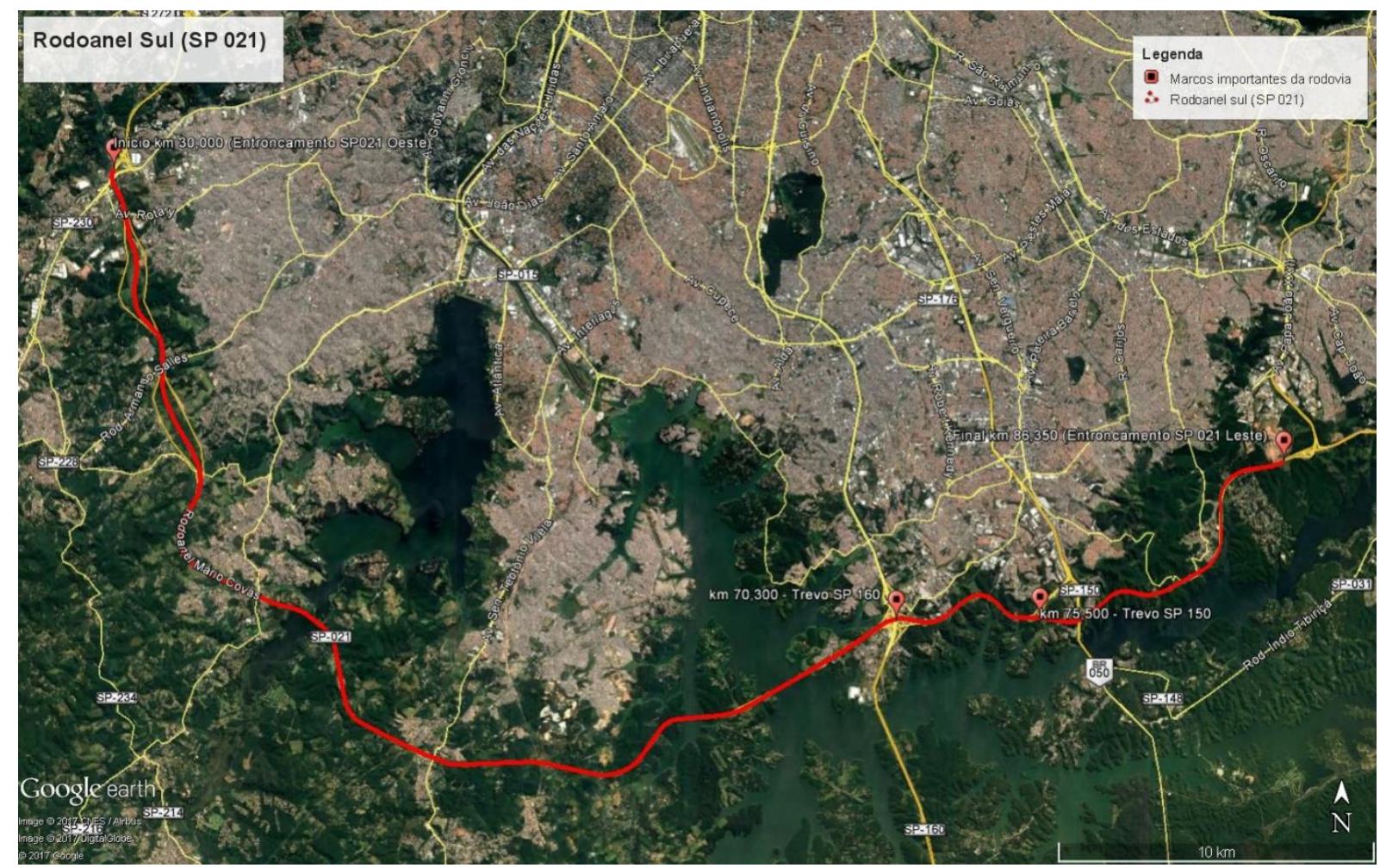

Figura 4.20: Mapa da região (fonte: autor, adaptado de Google Earth®) 


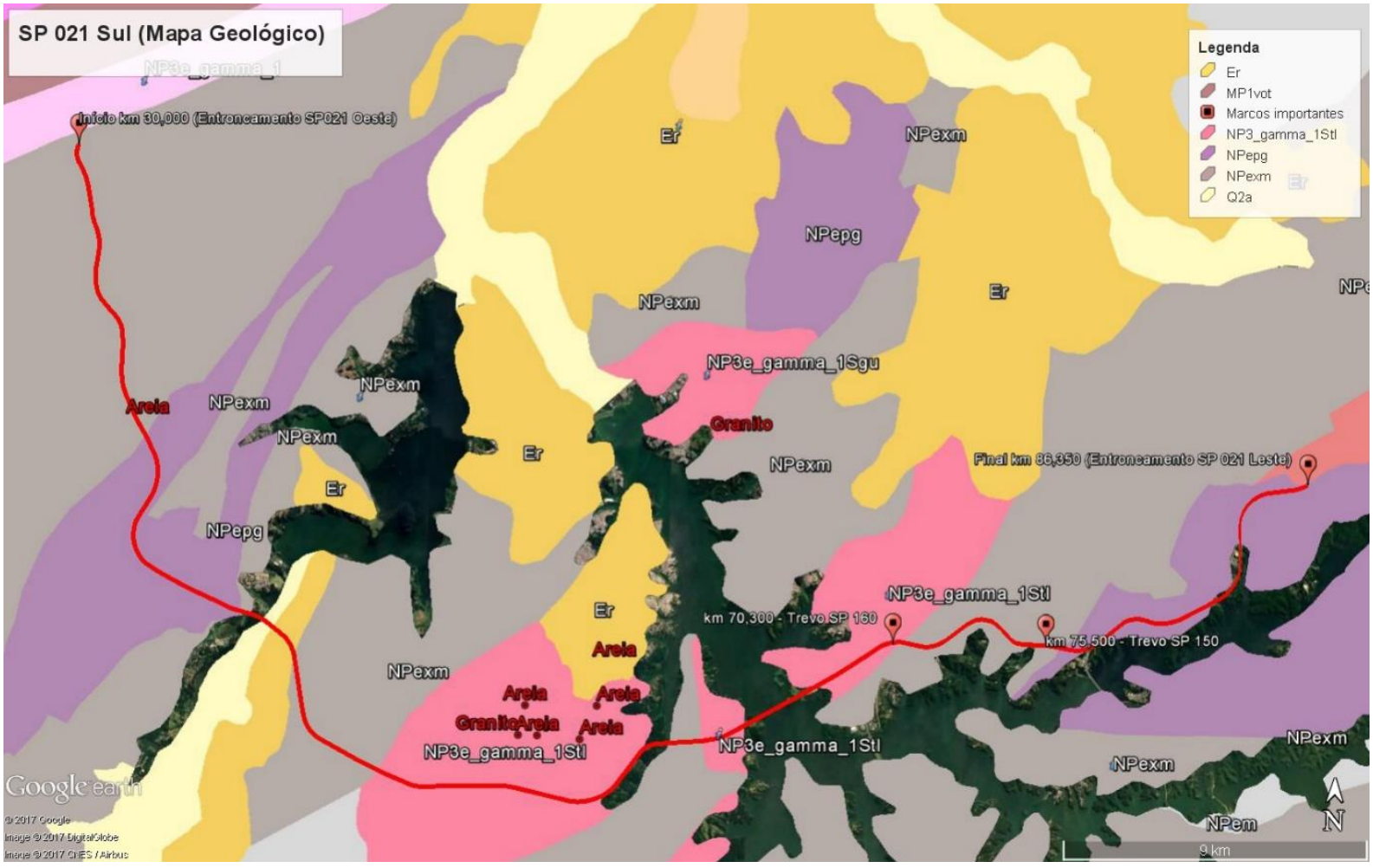

Figura 4.21: Mapa geológico da região (fonte: autor, adaptado de Google Earth® e GeoSGB)

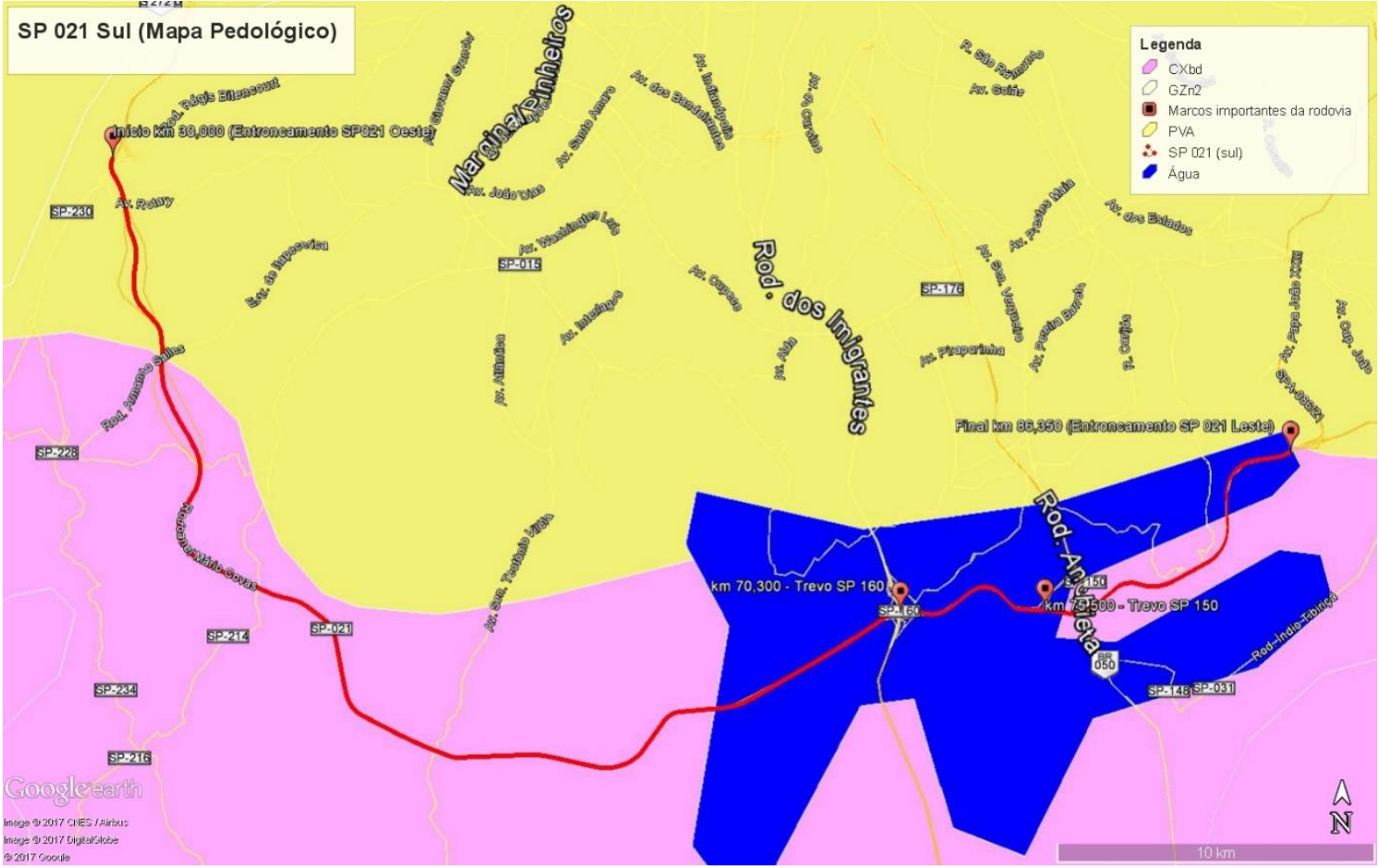

Figura 4.22: Mapa pedológico da região (fonte: autor, adaptado de Google Earth $\circledast$ e EMBRAPA) 


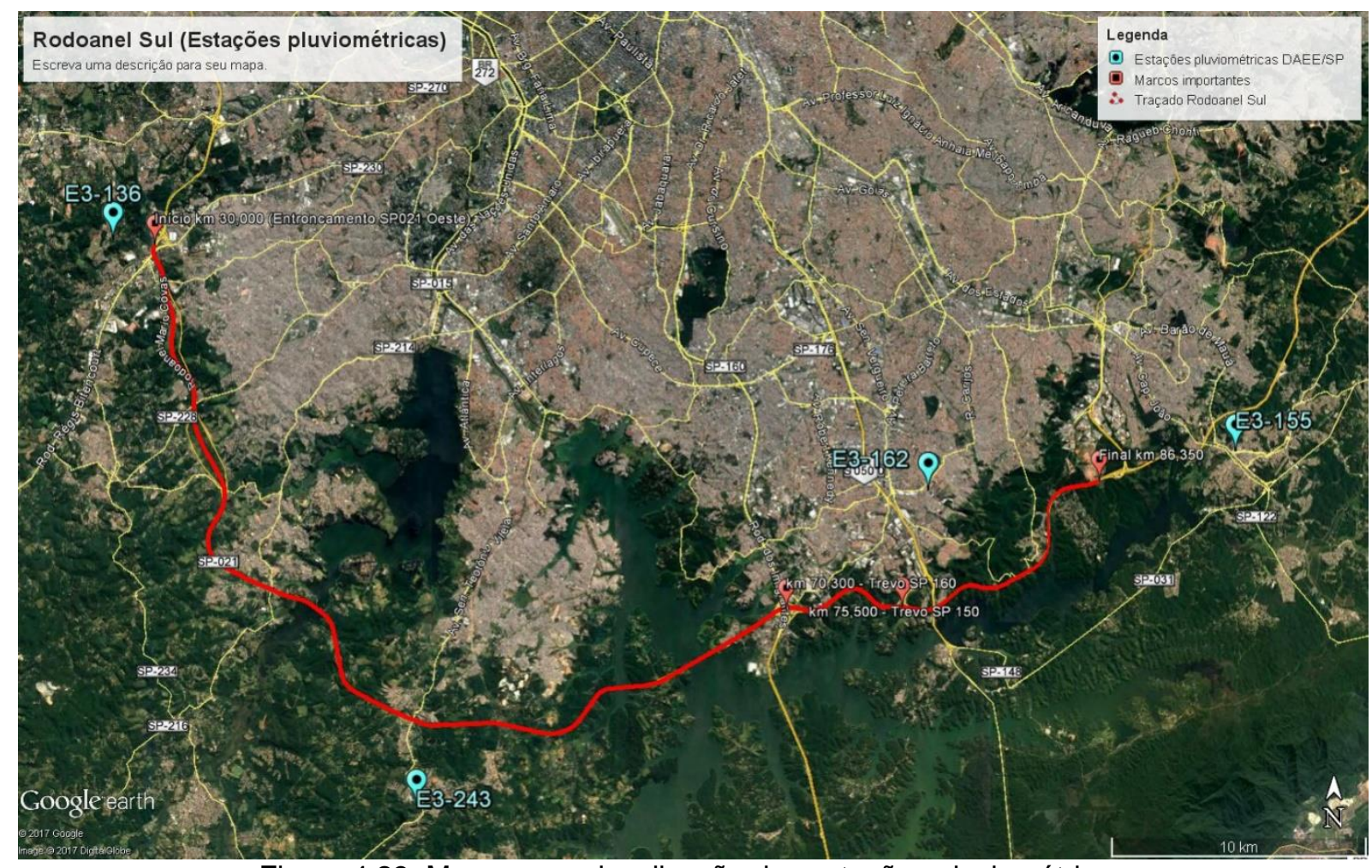

Figura 4.23: Mapa com a localização das estações pluviométricas

4.5.1 Análise dos dados pontuais dos valores de módulo e demais características

A Figura 4.24 a seguir apresenta os resultados pontuais dos valores de módulo de resiliência do subleito retroanalisados a partir da equação do guia da AASHTO/93 para a faixa de rolamento interna (faixa 1).

Verifica-se uma tendência de comportamento razoavelmente coerente entre as duas pistas (crescente e decrescente), excetuando-se alguns segmentos. 


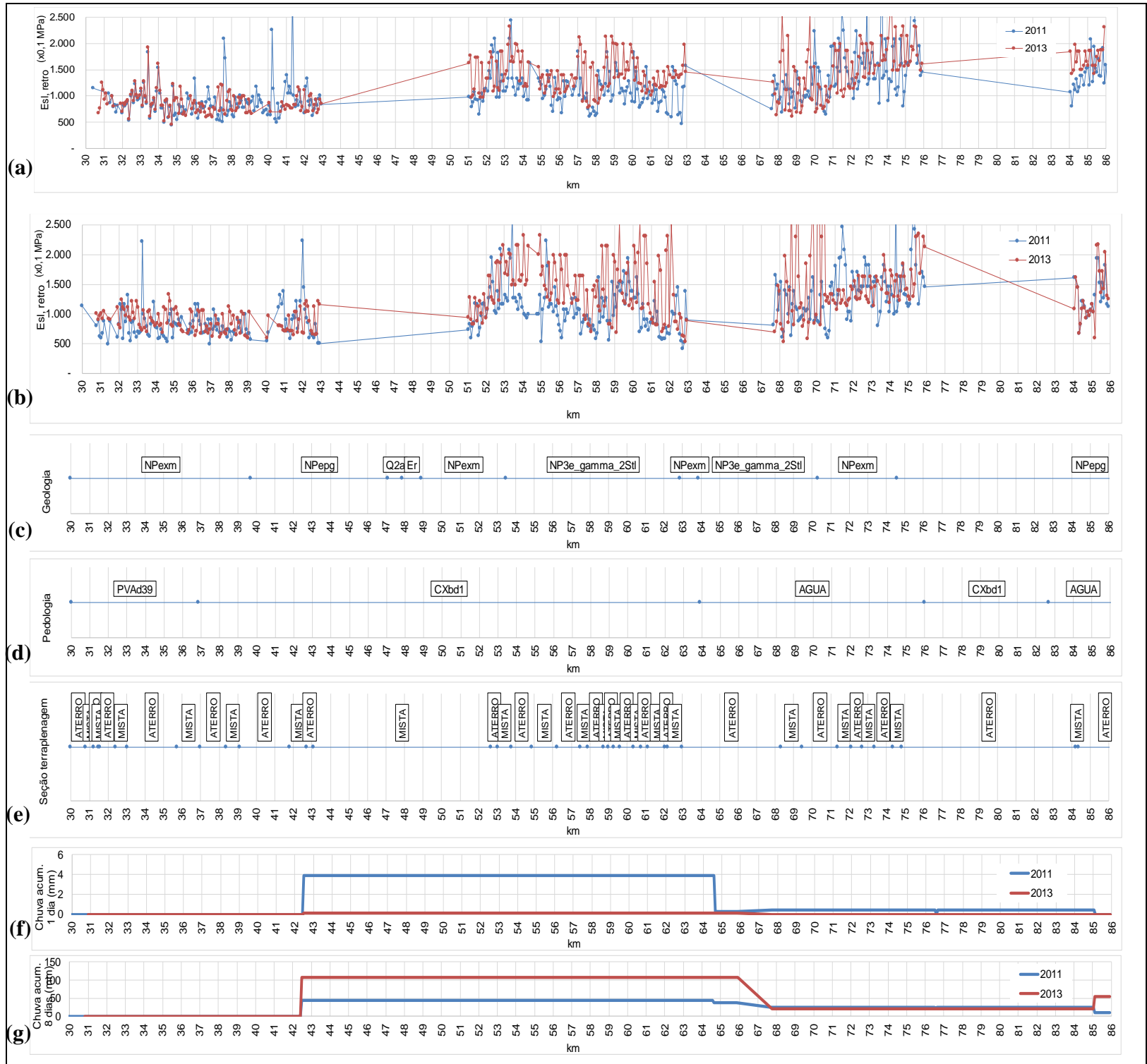

Figura 4.24: Gráficos empilhados de (a) Eslr da pista decrescente, (b) Eslr da pista crescente e diagramas retigráficos da (c) geologia, (d) pedologia, (e) seção de terraplenagem, (f) chuva acumulada de 1 dia, (g) chuva acumulada de 8 dias [BD2]

A Figura 4.25 apresenta a média e o desvio padrão dos valores pontuais de módulo de resiliência retroanalisado do subleito, para ambas as pistas (crescente e decrescente), bem como para todas as faixas de rolamento. O gráfico apresenta também a média dos valores de chuva acumulada para cada um dos segmentos em estudo.

Algumas observações são relevantes e podem ser extraídas de forma geral destes gráficos retigráficos empilhados. Fator interessante de ser observado é que a drenagem do pavimento é suficientemente boa, pois as deflexões não são relacionadas diretamente com as chuvas acumuladas nos 8 dias, mas mais 
significativamente com a de um dia. As deflexões dos quilômetros 51 a 63 demonstram esta afirmação. As deflexões em 2013 eram menores (e os módulos retroanalisados maiores) que em 2011, pois houve chuvas no dia anterior à medida de deflexão no ano de 2011, o que não ocorreu em 2013. No entanto, em 2013, há maior acúmulo de chuvas nos 8 dias anteriores, o que não afetou negativamente as medidas de deflexão.

Para verificar a influência da chuva na variação do comportamento do valor do módulo de resiliência do subleito em serviço, também foram elaborados mais dois gráficos contendo a média e o desvio padrão dos valores de módulo de resiliência retroanalisado, um para a condição de chuva máxima verificada e outro para a condição seca, ou seja, nenhuma chuva registrada no período de 8 dias. 


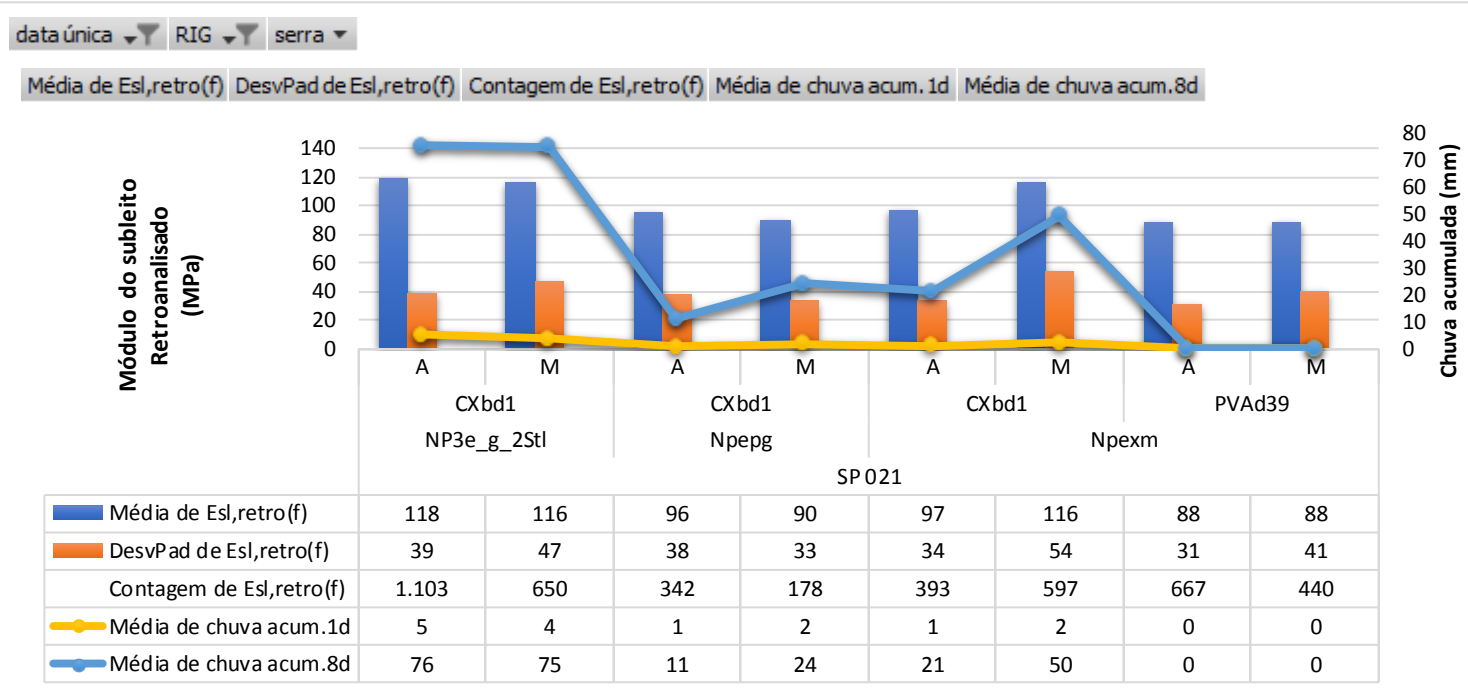

Rodovia -T sítio geológico - sítio Ped. $\mathbf{T}$ seção terrap. V

dataúnica $-\boldsymbol{Y}$ RIG $>$ Y

Média de Esl,retro(f) DesvPad de Esl,retro(f) Contagem de Esl,retro(f) Média de chuva acum. 1d Média de chuva acum.8d
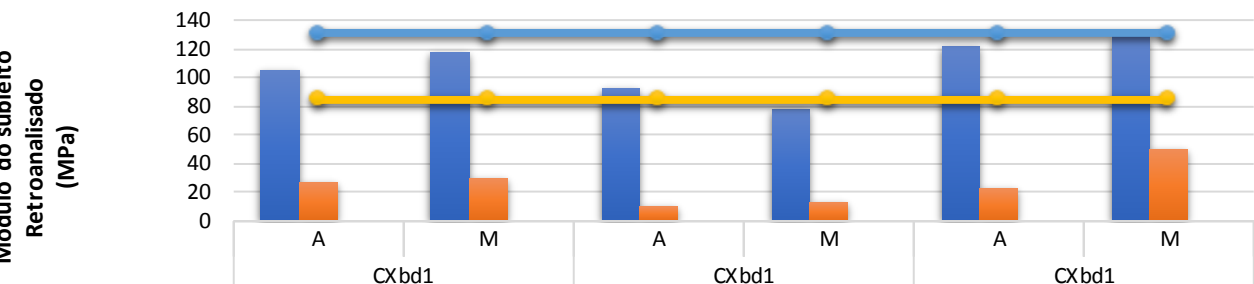

NP3e_g_2Stl

\begin{tabular}{|r|c|c|}
\hline Média de Esl,retro(f) & 106 & \\
\hline DesvPad de Esl,retro(f) & 27 \\
\hline Contagem de Esl,retro(f) & 86 & \\
\hline Média de chuva acum.1d & 51 \\
\hline Média de chuva acum.8d & 79 \\
\hline
\end{tabular}

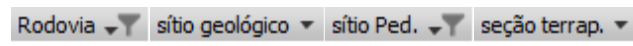

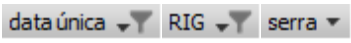

Média de Esl,retro(f) DesvPad de Esl,retro(f) Contagem de Esl,retro(f) Média de chuva acum. 1d Média de chuva acum.8d

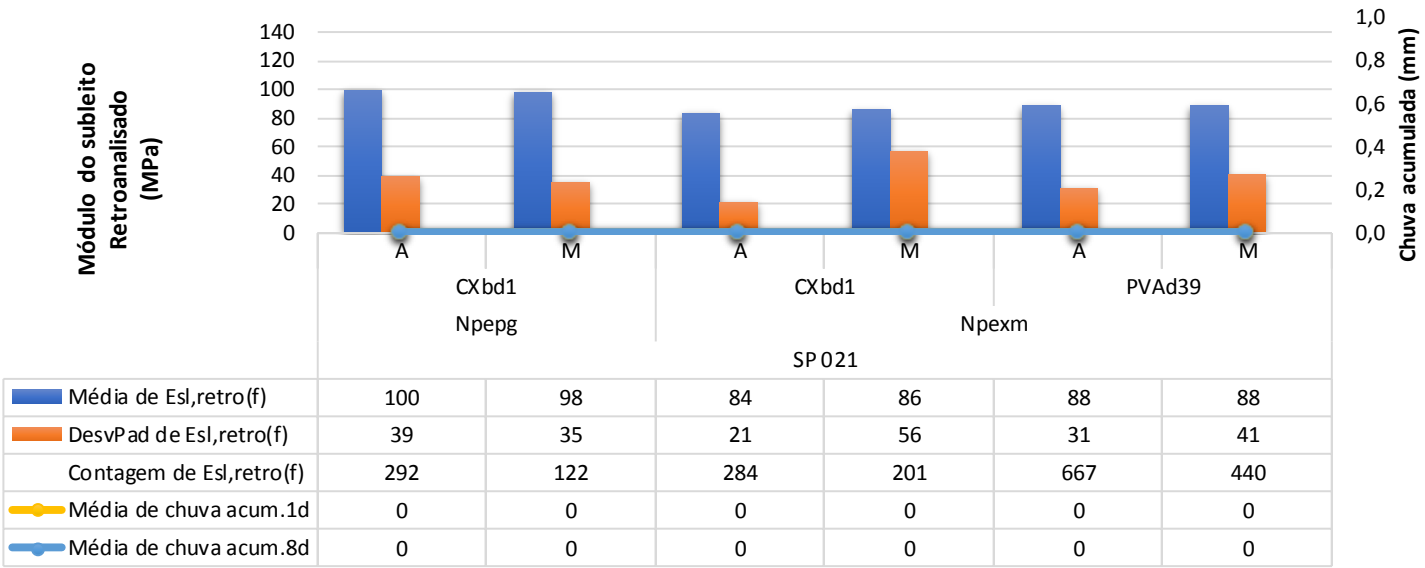

\begin{tabular}{l|l|l|l} 
Rodovia & sítio geológico & sítio Ped. & seção terrap. *
\end{tabular}

Figura 4.25: Média e desvio padrão do módulo de resiliência retroanalisado do subleito e média da chuva acumulada (para 1 dia e para 8 dias) para: (a) condição geral; (b) condição de chuva máxima verificada; (c) nenhuma chuva acumulada em 8 dias [BD2] 


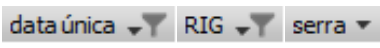

Média de D120cc DesvPad de D120cc2 Contagem de Esl, retro(f) Média de chuva acum.1d Média de chuva acum.8D

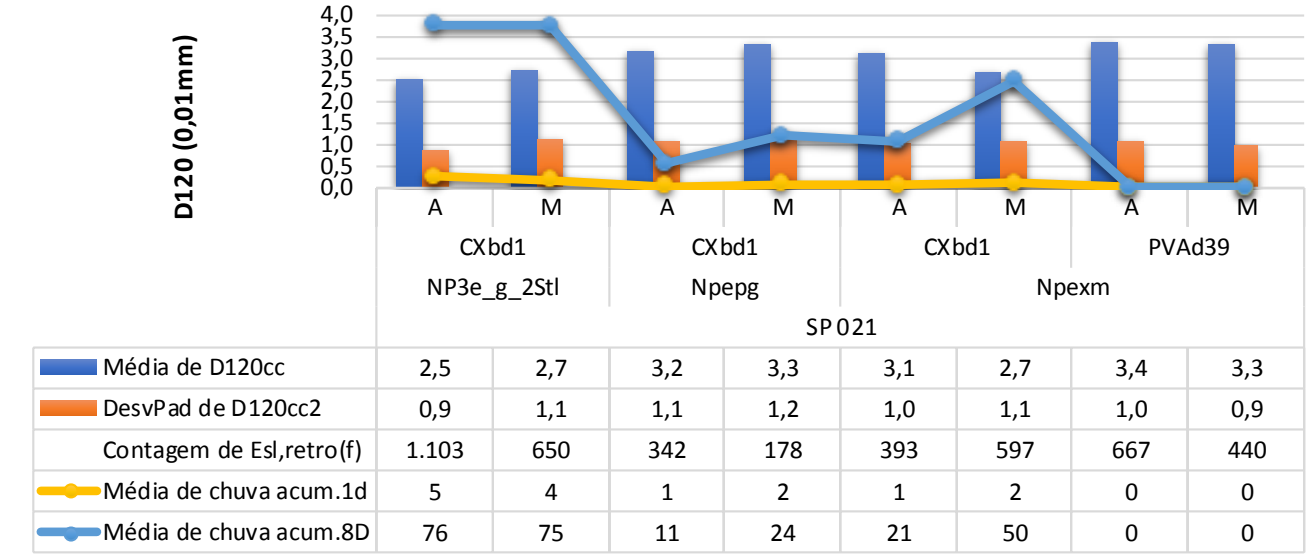

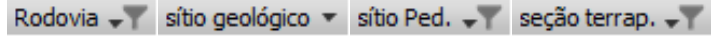

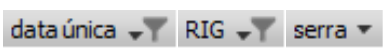

Média de D120cc DesvPad de D120cc2 Contagem de Esl, retro(f) Média de chuva acum.1d Média de chuva acum.8D

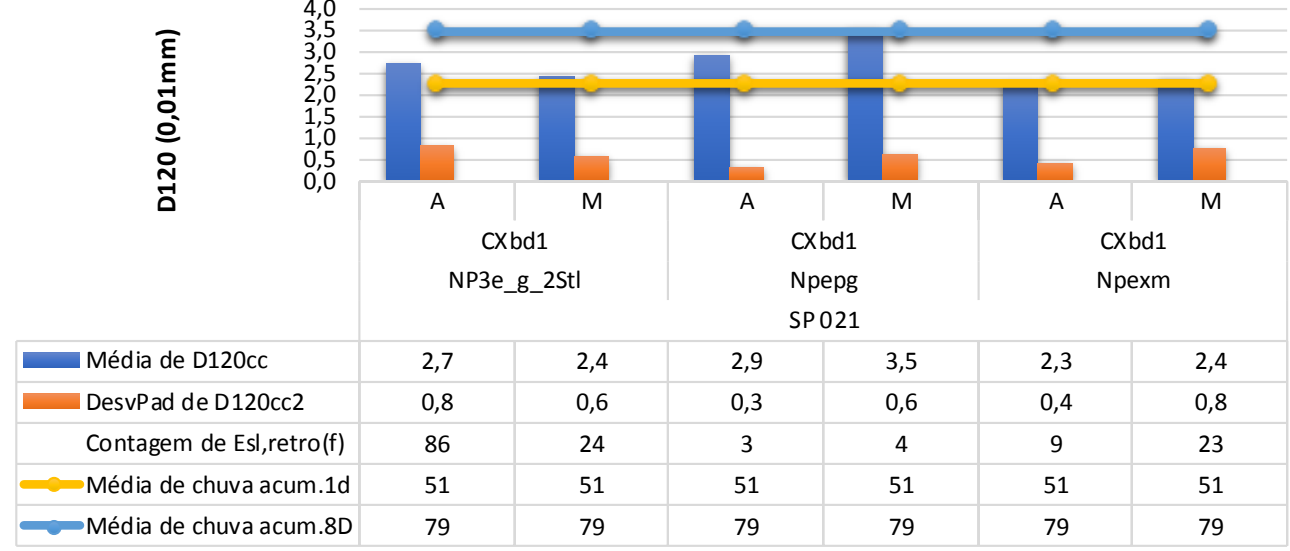

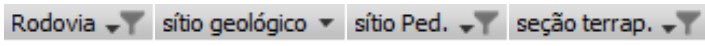

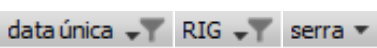

Média de D120cc DesvPad de D120cc2 Contagem de Esl, retro(f) Média de chuva acum. 1d Média de chuva acum.8D

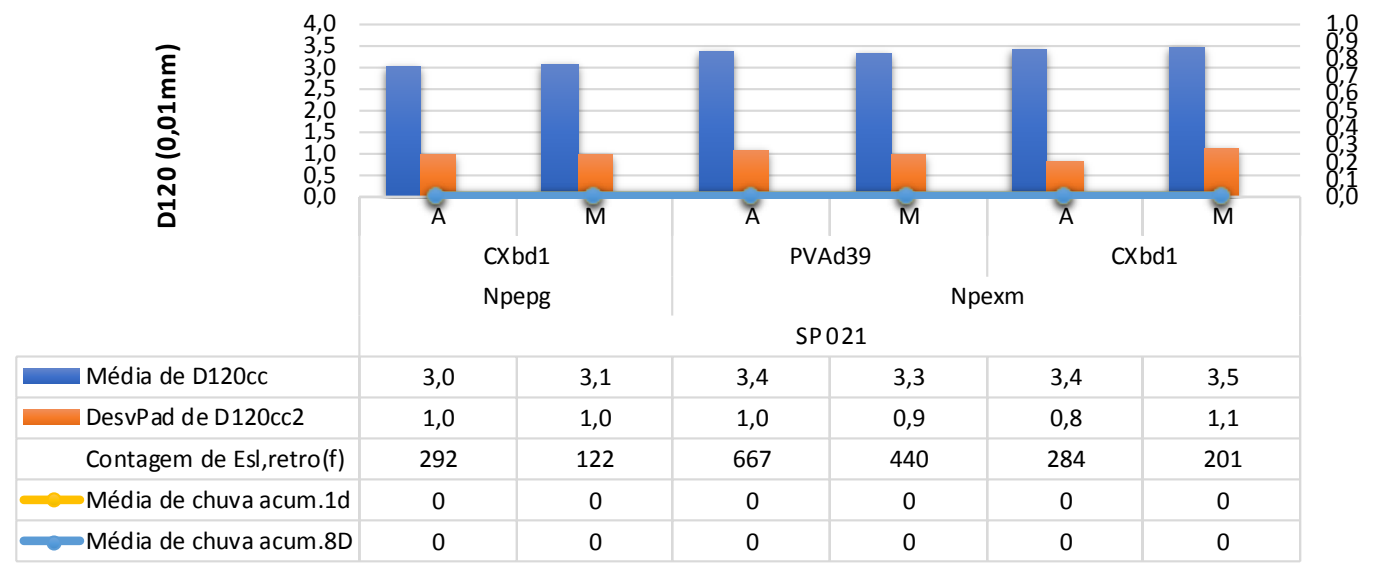

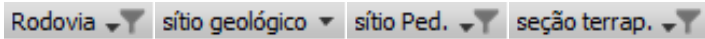

Figura 4.26: Média e desvio padrão do valor de D120 e média da chuva acumulada (para 1 dia e para 8 dias) para: (a) condição geral; (b) condição de chuva máxima verificada; (c) nenhuma chuva acumulada em 8 dias [BD2] 
As regiões no Rodoanel Sul são de ocorrência de solos saprolíticos não-lateríticos, mas a grande movimentação de terra, fazendo com que a maior parte esteja em aterro ou seção mista faz com que o uso de mapas fique, neste caso, limitado para as finalidades desta tese embora algumas conclusões possam ser extraídas. Não deixa de ser válido o uso de mapas geológicos e pedológicos para estudos básicos e planejamento das obras novas e de ressalva para a busca de solos de empréstimo ou de solos estabilizados com cal ou cimento para o subleito da obra. Em análise aos gráficos, verifica-se que, para o segmento onde a geologia foi classificada como NPepg, houve diminuição do valor médio dos módulos na situação de chuva máxima, em relação à situação seca, especialmente para a seção mista, onde de fato se espera maior influência por conta da provável maior proximidade do lençol freático em relação à camada de subleito do pavimento. Já para o trecho geológico NPexm, ao contrário do que se esperava, a tendência da média se inverteu, apesar de o desvio-padrão ter aumentado bastante especialmente na seção mista, a princípio sem uma explicação coerente.

4.5.2 Análise dos dados médios para os segmentos homogêneos

A Figura 4.27 a seguir apresenta os valores médios obtidos para os valores de módulo de resiliência do subleito retroanalisado para os segmentos homogêneos considerados para a pista sentido crescente (todas as faixas de rolamento). Apresenta também os valores médios, para cada segmento, de chuva acumulada de 1 dia e chuva acumulada de 8 dias, antes dos respectivos levantamentos. 
Rodovia 7 .

200520062007200820092010201120122013201420152016

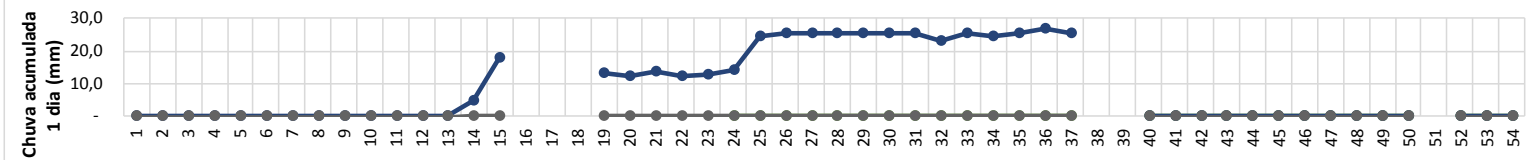

SEG -

\section{Rodovia 7}

200520062007200820092010201120122013201420152016
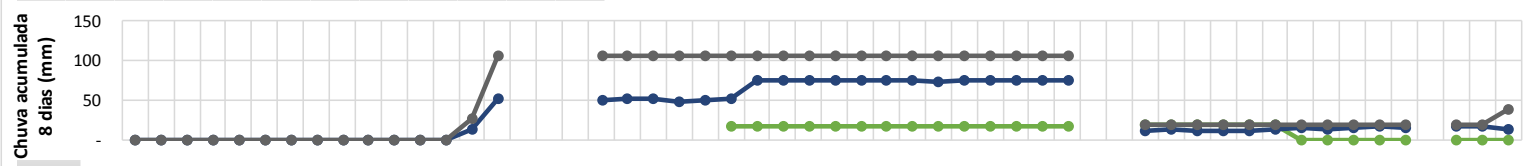

SEG *

Rodovia -7

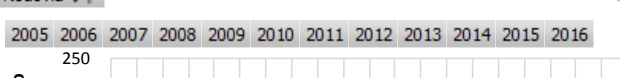

Valores

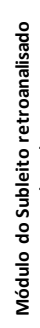

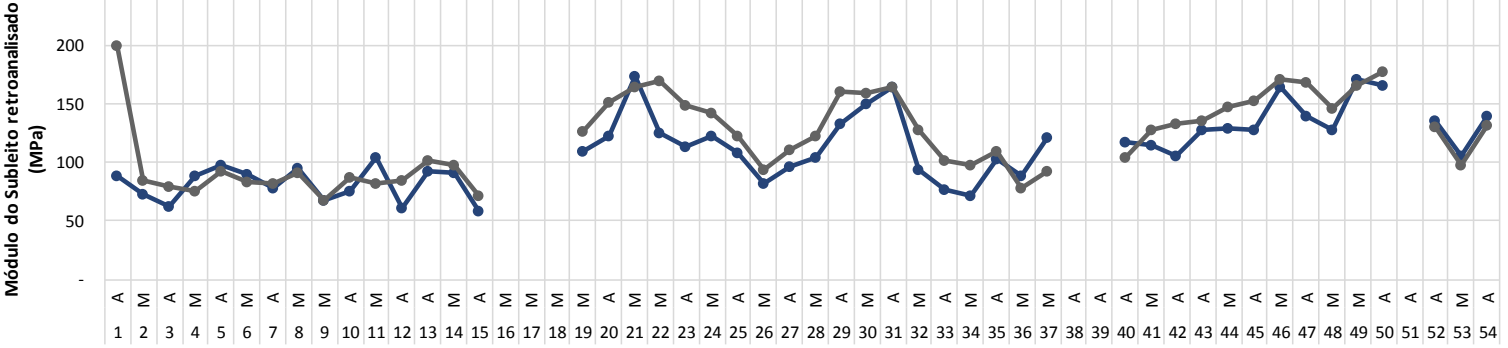

SEG * seção2 *

Segmento Homogêneo (no)

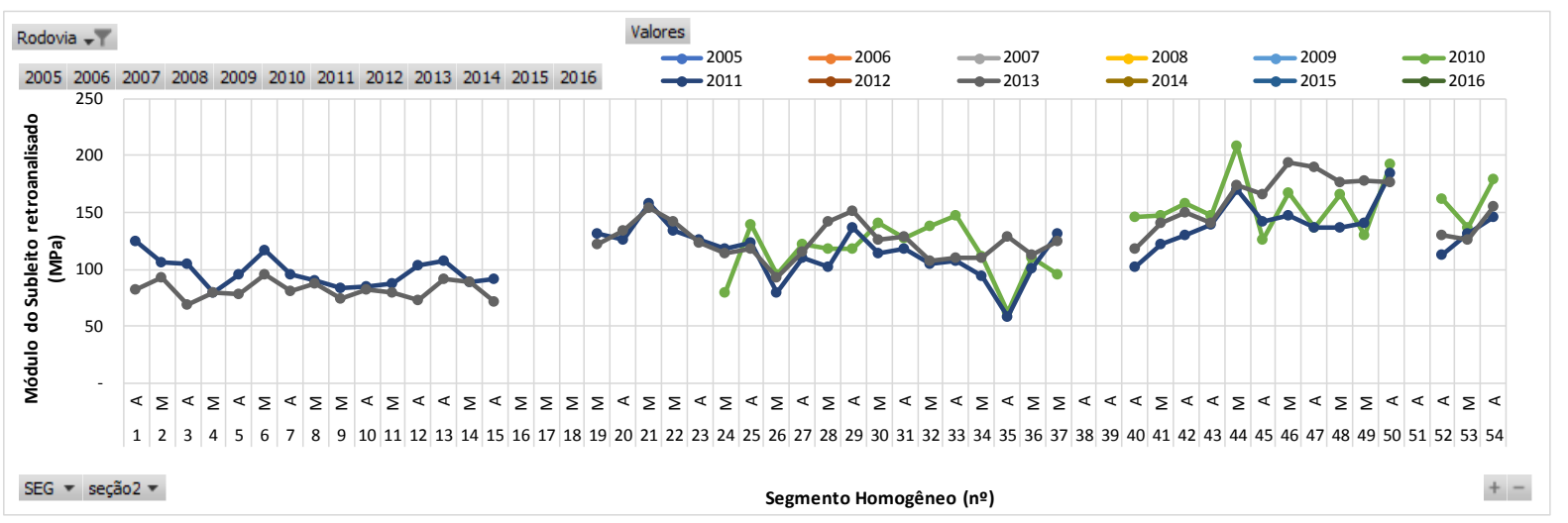

Figura 4.27: Média dos dados de chuva acumulada de (a) 1 dia, (b) 8 dias; (c) média de Eslr da pista crescente e (d) Es/r da pista decrescente para os anos de 2011 e 2013 e para os segmentos homogêneos [BD3]

A partir destes dados, foi então possível realizar a comparação entre os valores médios de cada ano do levantamento, para cada um dos segmentos homogêneos de análise.

Para fins de comparação entre os dados históricos, foi obtida a relação máxima (relação de módulo) entre os valores médios de módulo de cada segmento homogêneo, de acordo com a seguinte equação: 
Onde:

Eslr,máx: valor máximo do módulo de resiliência do subleito calculado para o segmento homogêneo;

Eslr,mín: valor mínimo do módulo de resiliência do subleito calculado para o segmento homogêneo.

Também para fins comparativos, foi realizada uma diferenciação entre as condições de chuva verificadas. Assim, para determinação dos parâmetros estatísticos foi realizada a seguinte categorização:

- seco: comparação entre dois períodos secos; ou seja, quando ambos os valores de módulo (mínimo e máximo) são relativos a períodos sem chuva acumulada nos últimos 8 dias anteriores aos respectivos levantamentos;

- ch1dsu: comparação entre períodos seco e úmido; ou seja, quando, em um dos períodos houve constatação de chuva acumulada de 1 dia diferente de zero (no outro período não houve chuva acumulada nos últimos 8 dias anteriores aos respectivos levantamentos);

- ch1duu: comparação entre dois períodos úmidos; ou seja, quando, em ambos os períodos comparados, houve constatação de chuva acumulada de 1 dia diferente de zero.

- ch8dsu: comparação entre períodos seco e úmido; ou seja, quando, em um dos períodos houve constatação de chuva acumulada de 8 dias diferente de zero (no outro período não houve chuva acumulada nos últimos 8 dias anteriores aos respectivos levantamentos);

- ch8duu: comparação entre dois períodos úmidos; ou seja, quando, em ambos os períodos comparados, houve constatação de chuva acumulada de 8 dias diferente de zero. 
A Figura 4.28 a seguir apresenta a média e o desvio padrão da relação de módulo para as condições de chuva especificadas acima para os diferentes tipos de seções de terraplenagem.

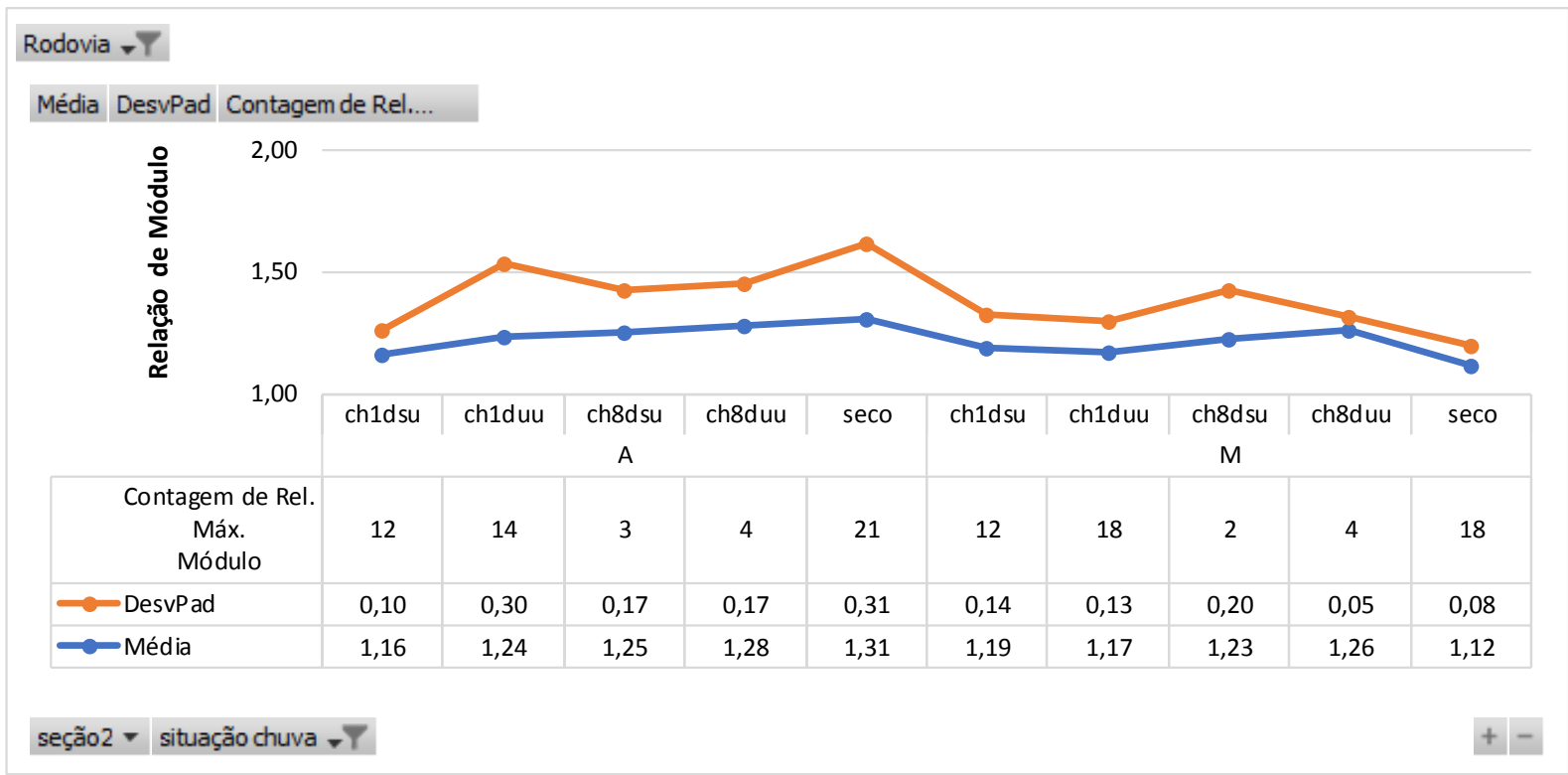

Figura 4.28: Média e desvio padrão da relação de módulo para as situações de chuva especificadas [BD3]

Em análise à figura, se pode concluir que, no caso do rodoanel sul, a variação das condições de umidade teve maior efeito no valor do módulo de resiliência do subleito na seção em aterro (em termos de média mais desvio-padrão). Este fato não era de se esperar, pois em aterro tem-se por expectativa que a drenagem esteja favorecida. Porém, a natureza dos solos pode ser mais importante que estar em aterro, e isto deve ser mais pesquisado. No trecho em aterro se verificou valores de relação de módulo mais elevados, em termos de média mais desvio-padrão, nas situações ch1uu e seco. Já nas seções mistas, os maiores valores, em termos de média e desviopadrão se apresentaram na situação ch8dsu.

A tendência esperada era que, em ambos os casos de tipo de seção de terraplanagem, a situação ch1dsu apresentasse maiores valores de relação de módulo. Atribui-se como possibilidade à inversão nas tendências, o número relativamente baixo de amostras para alguns casos ou o fato da natureza do solo que fica de difícil identificação adequada. 
A Figura 4.29 a seguir apresenta a média e o desvio padrão da relação de módulo para cada um dos parâmetros em análise separadamente, sendo: (a) classificação geológica, (b) classificação pedológica e (c) tipo de seção de terraplenagem. A Figura 4.30, por sua vez, apresenta a mesma análise, porém agora com os parâmetros citados todos combinados.
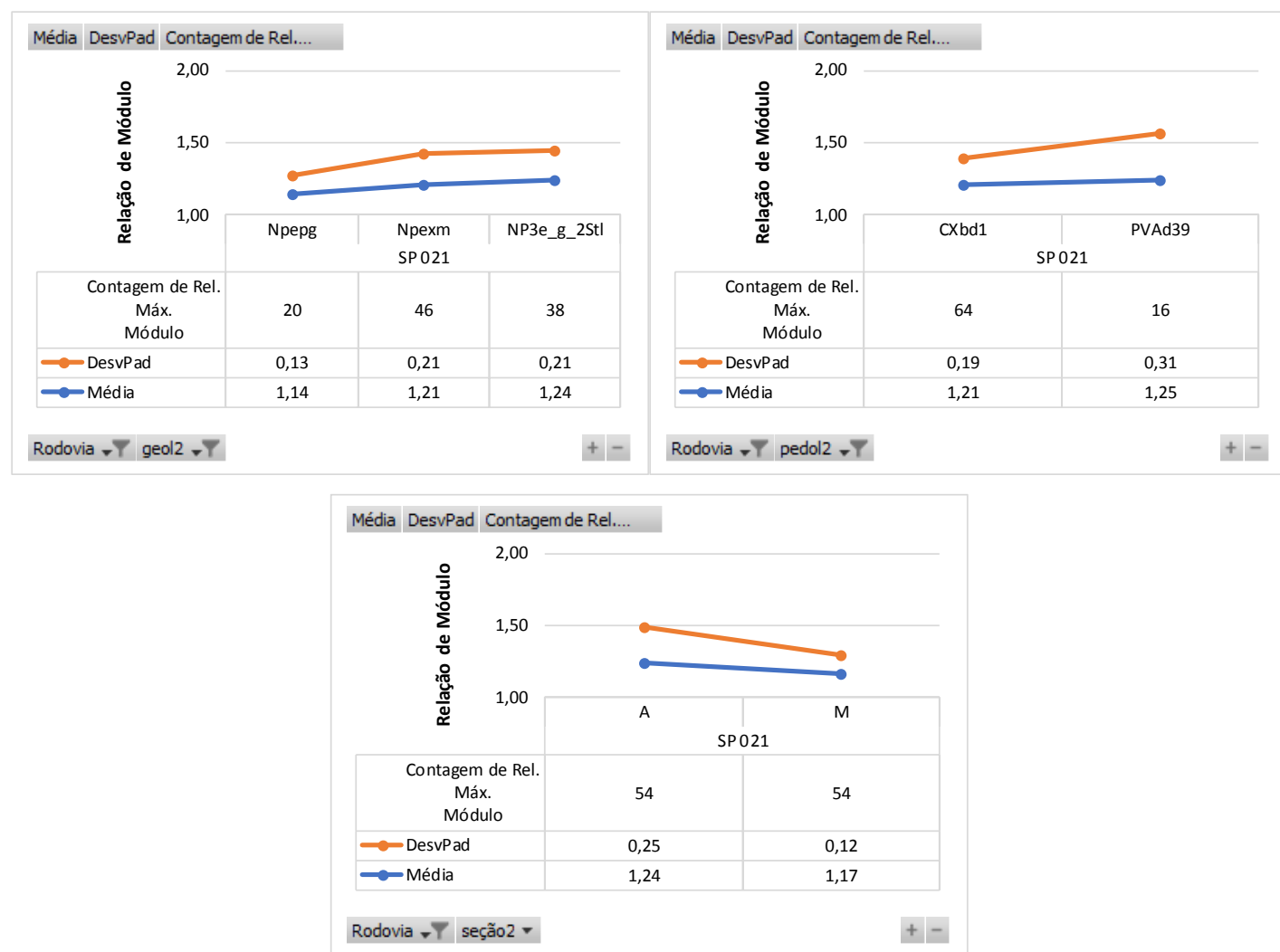

Figura 4.29: Estatísticas da relação de módulo (Es/r,máx / Eslr,mín) para cada um dos parâmetros em estudo, sendo: (a) classificação geológica / classificação pedológica e (b) tipo de seção de terraplenagem $[B D 3]$

Em análise aos gráficos, verificou-se que, em geral, a média da relação de módulo variou entre 1,14 e 1,25, ou seja, variou em torno de 1,20 (cerca de $20 \%$ de variação nos valores de módulo). Somando-se o desvio padrão, os valores médios de relação de módulo chegam a ser ainda maiores, da ordem de 1,30 a 1,50.

Também se verificou uma menor relação de módulo do subleito nas seções sobre o sítio geológico NPepg (média de 1,14), bem como menor dispersão de valores, apesar de o número de amostras ser menor para este sítio. No caso do sítio pedológico, o que apresentou maior relação de módulo foi o sítio PVAd39 (média de 1,25), apresentando uma elevada dispersão de valores também, apesar do número de 
amostras reduzido em relação às demais. Já para a análise do tipo de seção de terraplenagem (aterro ou mista), a seção que apresentou o maior valor de relação de módulo foi a seção em aterro (média de 1,25), bem como maior dispersão de valores.

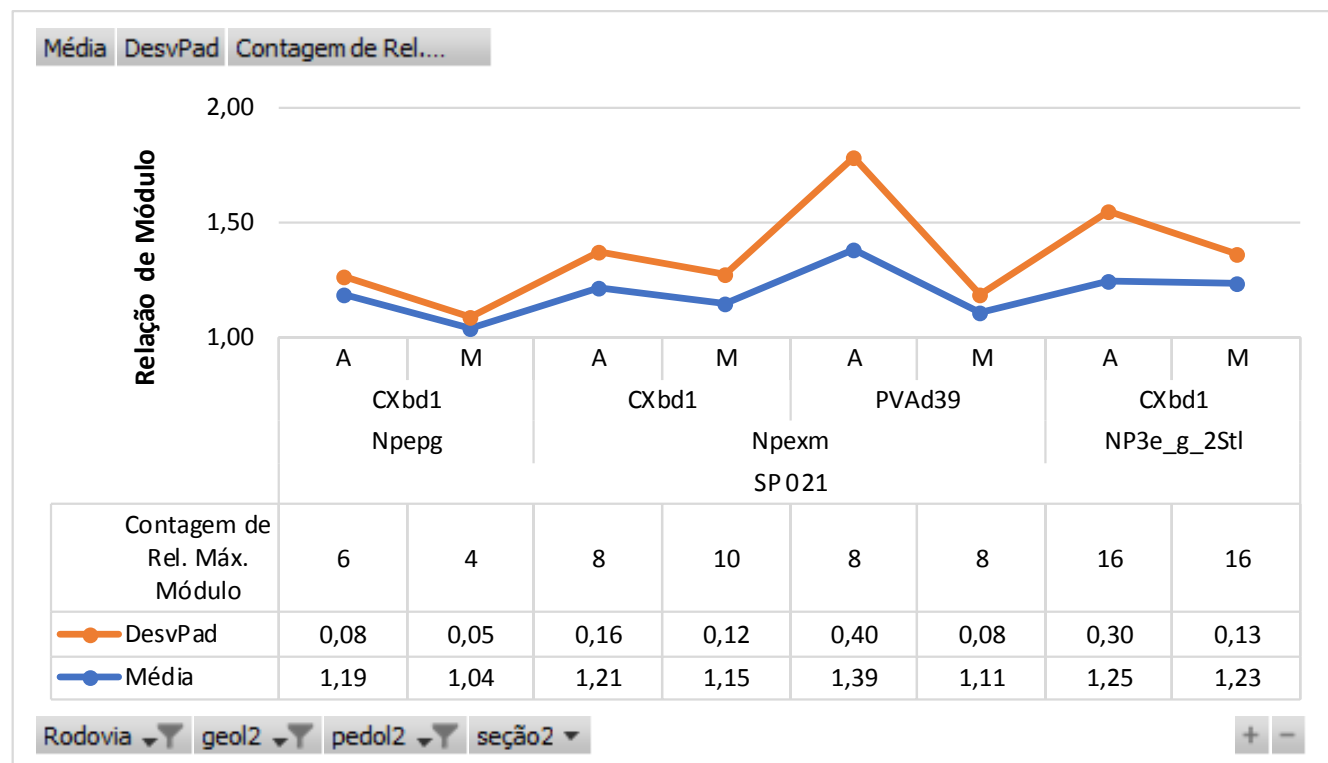

Figura 4.30: Estatísticas da relação de módulo (EsIr,máx / Eslr,mín) para parâmetros combinados [DB3]

Em análise aos gráficos da Figura 4.30, verificam-se valores médios de relação de módulo variando entre 1,04 e 1,39. Somando-se o desvio-padrão, os valores oscilam entre 1,09 e 1,79 .

Também se pode inferir que, para o caso da rodovia em análise, as seções em aterro apresentaram maiores valores médios da relação de módulo, além de apresentarem maior dispersão de valores (maior desvio-padrão de valores em relação à média).

Estes dados comprovam que se deve ter um banco de dados que contenha de forma muito clara a natureza dos solos de aterro, ou de subleito, do estado de compactação dos mesmos, e da eficiência dos sistemas de drenagem, pois estes dados são importantes para serem cruzados com os demais mostrados neste item. 


\subsection{Discussões, conclusões e recomendações para o trecho piloto}

Verificou-se que o padrão do comportamento do módulo de resiliência do subleito varia bastante ao longo da extensão do eixo, apresentando relativamente baixa variação dentro de uma mesma seção (variação que ocorre transversalmente ao eixo, ao se mudar de faixa de rolamento ou de pista). Já a variação que ocorre em uma mesma seção, em períodos diferentes, apesar de tender a seguir um mesmo padrão, apresenta variações que são relevantes e podem prejudicar o desempenho das estruturas de pavimento se não foram devidamente consideradas no dimensionamento.

Também se verifica que alguns padrões de comportamento do módulo de resiliência do subleito muitas vezes não se repetem, e algumas vezes o comportamento é contrário ao que se esperava, por exemplo, no caso da variação de módulo da condição seca (dois períodos sem chuva) ser superior à dos períodos com chuva constatada para as seções em aterro.

Com base em todas as análises do trecho piloto, recomenda-se:

- Levar em conta as variações do valor do módulo do subleito, quando do dimensionamento de pavimentos novos e/ou restauração de pavimentos do rodoanel sul e em sítios geológicos/pedológicos semelhantes, utilizando-se por exemplo, os valores de relação de módulo para cada combinação de parâmetros conhecidos (sítios pedológico/geológico, tipo de seção etc.);

- Armazenar mais dados históricos do mesmo trecho, dentro de metodologia e do formato sugerido, de modo que se possa ter uma amostragem maior, e assim, maior confiabilidade, confirmações e convergências dos valores aqui sugeridos;

- Realizar o mesmo estudo para outras rodovias concedidas do estado de São Paulo, buscando tanto ampliar o espectro de sítios geológicos e pedológicos abrangidos pela pesquisa quanto aumentar a amostragem para os tipos de solos contemplados nesta pesquisa;

- Seguindo a metodologia aqui proposta, incorporar mais dados/variáveis de campo, como por exemplo, resultados de sondagens / poços de inspeção 
(materiais e espessuras das camadas) e respectivos dados de ensaios de laboratório e de campo realizados com amostras retiradas do pavimento existente, testes de eficiência dos drenos, etc.;

- Com base nas análises de uma gama maior de dados, propor modelos matemáticos para previsão do módulo ou da variação deste em serviço;

- Elaboração de um sistema de gerenciamento digital para registro e processamento automático dos dados e calibração de relações e modelos.

\subsection{Apresentação de resultados da aplicação da metodologia proposta para rodovia SP 318 (Sítios de solos lateríticos)}

4.7.1 Análise dos dados pontuais dos valores de módulo e demais características

Os gráficos da Figura 4.31 a seguir apresentam os valores de módulo de resiliência do subleito retroanalisado, para cada combinação de sítio pedológico / sítio geológico e seção de terraplenagem, para três situações distintas de chuva - condição geral, condição de chuva máxima verificada e condição sem chuva acumulada no período de 8 dias. 


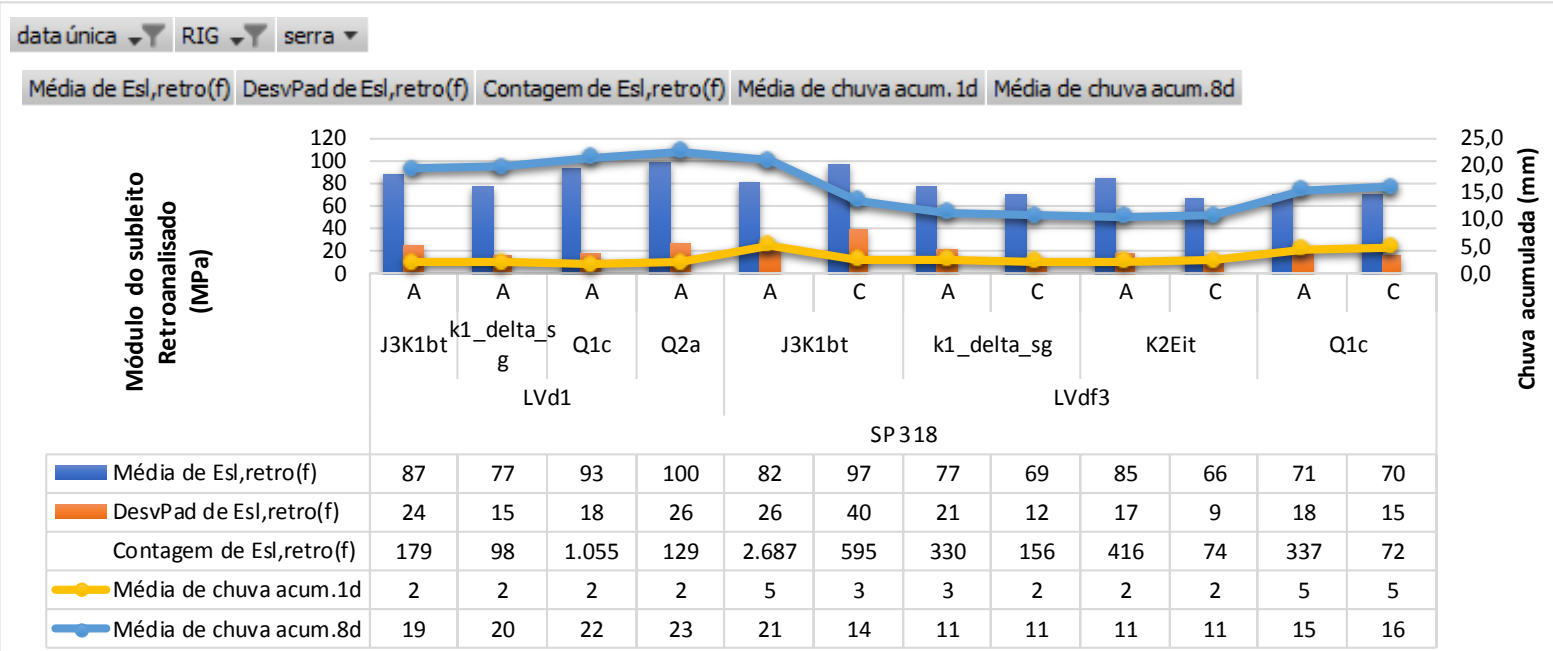

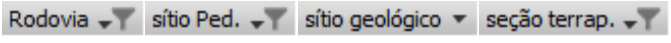

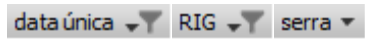

Média de Esl,retro(f) DesvPad de Esl,retro(f) Contagem de Esl,retro(f) Média de chuva acum. 1d Média de chuva acum.8d
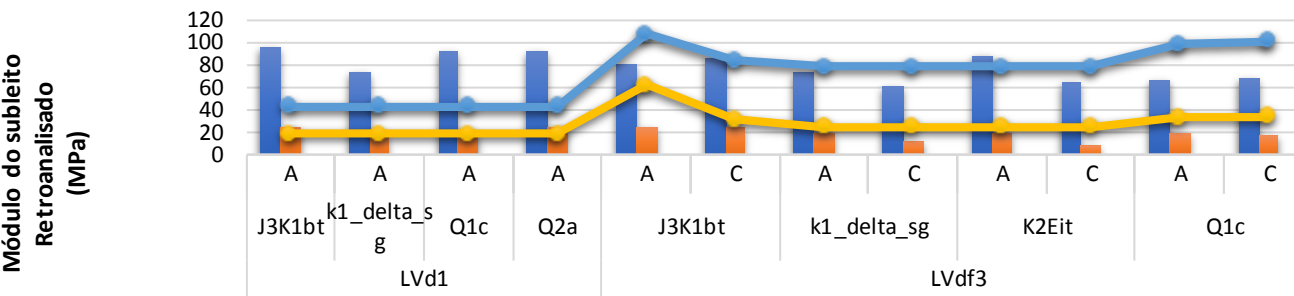

\begin{tabular}{|c|c|c|c|c|c|c|c|c|c|c|c|c|}
\hline Média de Esl,retro(f) & 95 & 73 & 92 & 91 & 82 & 86 & 74 & 62 & 89 & 64 & 67 & 67 \\
\hline DesvPad de Esl,retro(f) & 25 & 16 & 17 & 26 & 25 & 24 & 19 & 12 & 19 & 8 & 20 & 18 \\
\hline Contagem de Esl,retro(f) & 31 & 17 & 195 & 27 & 416 & 93 & 69 & 27 & 73 & 14 & 91 & 20 \\
\hline Média de chuva acum.1d & 10 & 10 & 10 & 10 & 31 & 16 & 13 & 13 & 13 & 13 & 17 & 17 \\
\hline Média de chuva acum.8d & 22 & 22 & 22 & 22 & 54 & 42 & 40 & 40 & 40 & 40 & 49 & 50 \\
\hline
\end{tabular}

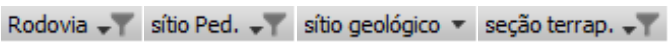

\section{dataúnica $\rightarrow \mathbf{Y}$ RIG $\boldsymbol{\nabla}$ serra $\boldsymbol{V}$}

Média de Esl,retro(f) DesvPad de Esl,retro(f) Contagem de Esl,retro(f) Média de chuva acum.1d Média de chuva acum.8d
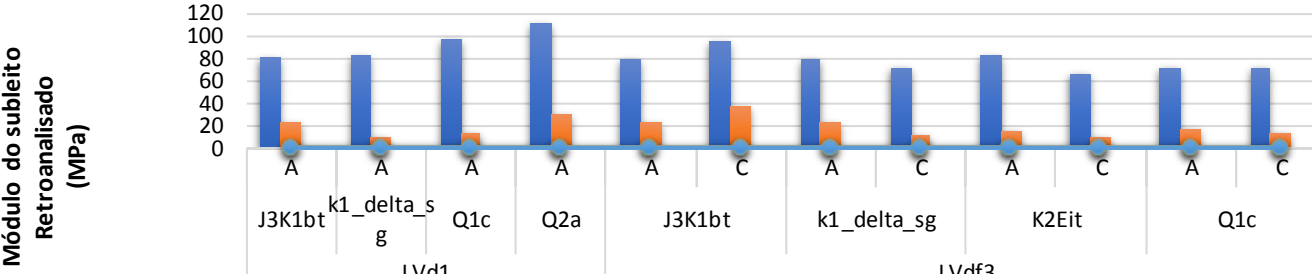

\begin{tabular}{|c|c|}
\hline Média de Esl,retro(f) \\
\hline DesvPad de Esl,retro(f) \\
\hline Contagem de Esl,retro(f) \\
\hline Média de chuva acum.1d \\
\hline Média de chuva acum.8d \\
\hline
\end{tabular}

$$
\begin{array}{l|l|l|l|l|}
\text { J3K1bt } & \text { K1_delta_S } \\
\text { LVd1 } & \text { Q2a } & \text { J3K1bt } & \text { K1_delta_sg } & \text { K2Eit }
\end{array}
$$

Q1c

SP 318

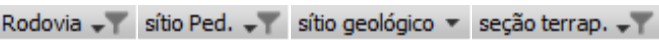

Figura 4.31: Média e desvio padrão do módulo de resiliência retroanalisado do subleito e média da chuva acumulada (para 1 dia e para 8 dias) para: (a) condição geral; (b) condição de chuva máxima verificada; (c) nenhuma chuva acumulada em 8 dias [BD2] 
4.7.2 Análise dos dados médios para os segmentos homogêneos

No Anexo D - DIAGRAMAS RETIGRÁFICOS DOS SEGMENTOS HOMOGÊNEOS DAS RODOVIAS ESTADUAIS EM ESTUDO são apresentados os valores médios obtidos para os valores de módulo de resiliência do subleito retroanalisado para os segmentos homogêneos considerados para a pista sentido crescente (todas as faixas de rolamento).

A Figura 4.32 a seguir apresenta a média e o desvio padrão da relação de módulo para as condições de chuva especificadas acima para os diferentes tipos de seções de terraplenagem.

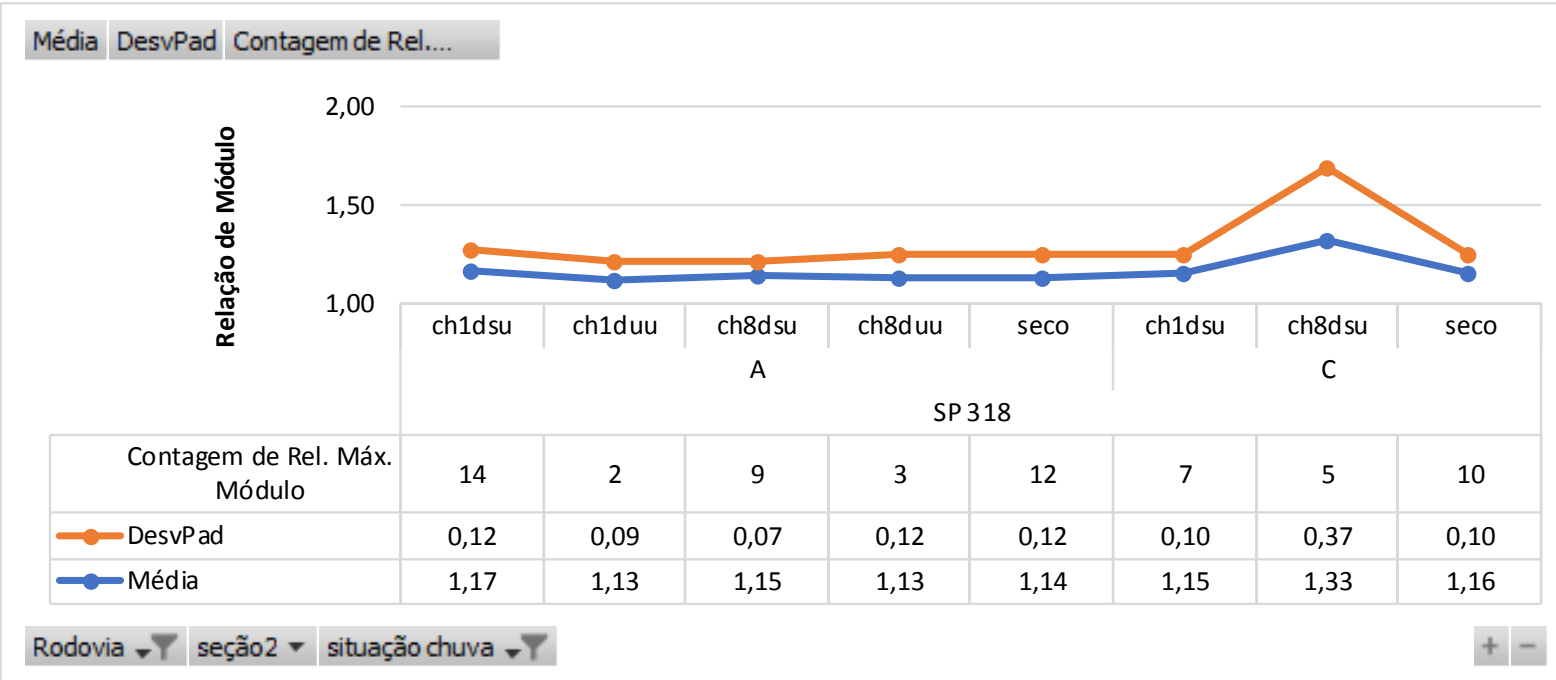

Figura 4.32: Média e desvio padrão da relação de módulo para as situações de chuva especificadas [BD3]

Em análise à figura, se pode concluir que, no caso da SP 318, a variação das condições de umidade teve maior efeito no valor do módulo de resiliência do subleito na seção em corte (em termos de média mais desvio-padrão). No trecho em aterro se verificou valores de relação de módulo mais elevados, em termos de média mais desvio-padrão, nas situações ch1uu e seco. Já nas seções em corte, os maiores valores, em termos de média e desvio-padrão se apresentaram na situação ch8dsu. 
A tendência esperada era que, em ambos os casos de tipo de seção de terraplanagem, a situação ch1dsu apresentasse maiores valores de relação de módulo. Atribui-se como possibilidade à inversão nas tendências, o número relativamente baixo de amostras para alguns casos.

A Figura 4.33 a seguir apresenta a média e o desvio padrão da relação de módulo para cada um dos parâmetros em análise separadamente, sendo: (a) classificação geológica, (b) classificação pedológica e (c) tipo de seção de terraplenagem. A Figura 4.34, por sua vez, apresenta a mesma análise, porém agora com os parâmetros citados todos combinados.

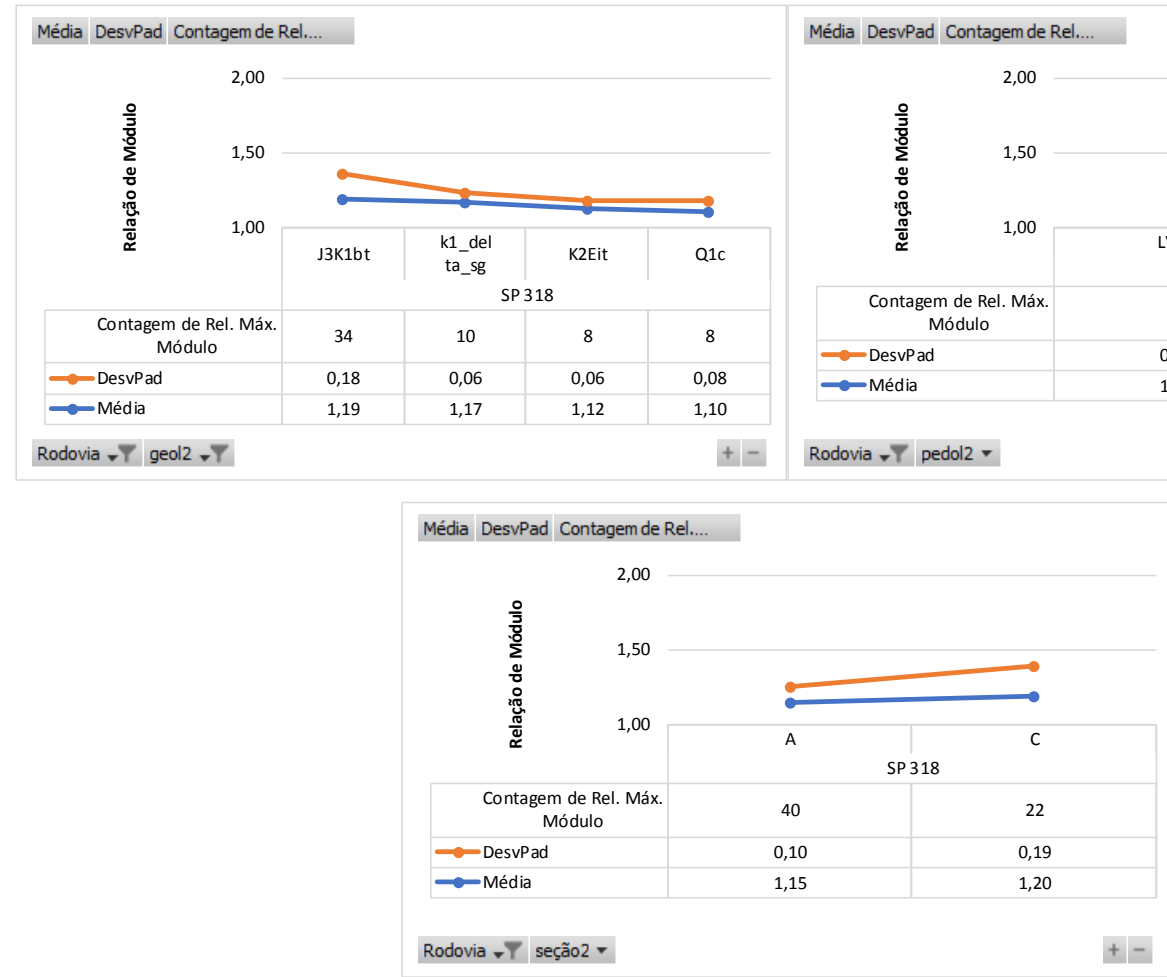

Figura 4.33: Estatísticas da relação de módulo (Eslr,máx / Eslr,mín) para cada um dos parâmetros em estudo, sendo: (a) classificação geológica / classificação pedológica e (b) tipo de seção de terraplenagem $[B D 3]$

Em análise aos gráficos, verificou-se que, em geral, a média da relação de módulo variou entre 1,10 e 1,20, ou seja, variou em torno de 1,10 (cerca de 10\% de variação nos valores de módulo). Somando-se o desvio padrão, os valores médios de relação de módulo chegam a ser ainda maiores, da ordem de 1,30 a 1,50.

Também se verificou uma menor relação de módulo do subleito nas seções sobre o sítio geológico Q1c (média de 1,10), bem como menor dispersão de valores. No caso 
do sítio pedológico, o que apresentou maior relação de módulo foi o sítio $L V d 1$ (média de 1,18). Já para a análise do tipo de seção de terraplenagem (aterro ou corte), a seção que apresentou o maior valor de relação de módulo foi a seção em corte (média de 1,20$)$, bem como maior dispersão de valores $(0,19)$.

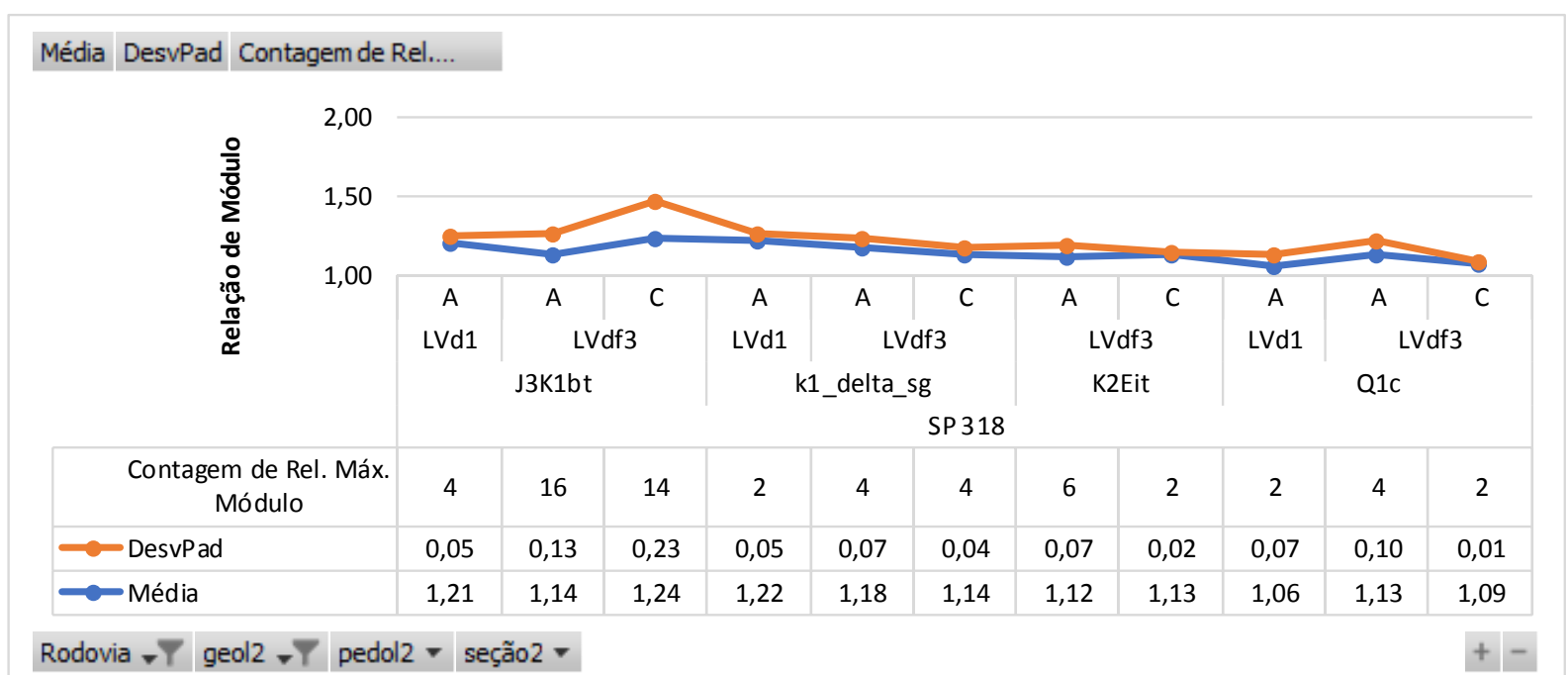

Figura 4.34: Estatísticas da relação de módulo (Eslr,máx / Eslr,mín) para parâmetros combinados [BD3]

Em análise aos gráficos da Figura 4.30, verificam-se valores médios de relação de módulo variando entre 1,06 e 1,24. Somando-se o desvio-padrão, os valores oscilam entre 1,09 e 1,47 .

Também se pode inferir que, para o caso da rodovia em análise, as seções em corte apresentaram maiores valores médios da relação de módulo, além de apresentarem maior dispersão de valores (maior desvio-padrão de valores em relação à média).

Estes dados comprovam que se deve ter um banco de dados que contenha de forma muito clara a natureza dos solos de aterro, ou de subleito, do estado de compactação dos mesmos, e da eficiência dos sistemas de drenagem pois estes dados são importantes para serem cruzados com os demais mostrados neste item. 


\subsection{Estudo para os segmentos homogêneos segundo a classificação $M C T$ (BD4)}

Com base no banco de dados de ensaios ( $B D 1$ ) citado no item 4.2, buscaram-se segmentos que apresentassem certa homogeneidade nos resultados em termos de classificação do solo (especialmente em relação à classificação $M C T$ ), com o objetivo de realizar estudos acerca do comportamento estrutural do pavimento, bem como do subleito isoladamente, através da obtenção do módulo de resiliência do subleito por retroanálise.

Para tanto, procedeu-se à organização dos dados por rodovia e por km sequencial. À medida que foram identificados locais/segmentos sequenciais com a mesma classificação, estes foram separados e agrupados em uma lista, para posterior coleta dos dados de FWD.

Os segmentos selecionados para o estudo são aqueles indicados na Tabela 4.11 a seguir. 
Tabela 4.11: Dados dos segmentos homogêneos com relação ao tipo de solo pela classificação $M C T$

\begin{tabular}{|c|c|c|c|c|c|c|c|c|c|}
\hline \multirow[b]{2}{*}{ Segmento } & \multirow[b]{2}{*}{ Rodovia } & \multirow[b]{2}{*}{ Pista (sentido) } & \multirow[b]{2}{*}{ Faixa } & \multirow[b]{2}{*}{ km inicial } & \multirow[b]{2}{*}{ km final } & \multirow[b]{2}{*}{$\begin{array}{l}\text { Extensão } \\
(\mathbf{k m})\end{array}$} & \multicolumn{3}{|c|}{ Parâmetros do subleito } \\
\hline & & & & & & & $\begin{array}{c}\text { Classificação } \\
\text { MCT }\end{array}$ & $\begin{array}{l}\text { Média de } \\
\text { CBR (\%) }\end{array}$ & $\begin{array}{c}\text { Média de } \gamma d \\
\left(\mathrm{~g} / \mathrm{cm}^{3}\right)\end{array}$ \\
\hline 1 & SP 021 & DECRESCENTE & 2 & 50,400 & 50,700 & 0,300 & $\mathrm{NS}^{\prime}$ & 4 & 1,57 \\
\hline 2 & SP 099 & DECRESCENTE & 2 & 29,950 & 30,050 & 0,100 & NS' & 3 & 1,70 \\
\hline 3 & SP 099 & DECRESCENTE & 2 & 31,000 & 31,200 & 0,200 & $\mathrm{NS}^{\prime}$ & 3 & 1,79 \\
\hline 4 & SP 099 & CRESCENTE & 2 & 34,420 & 34,580 & 0,160 & NS' & 2 & 1,50 \\
\hline 5 & SP 099 & CRESCENTE & 2 & 37,380 & 37,580 & 0,200 & NG' & 11 & 1,66 \\
\hline 6 & SP 099 & CRESCENTE & 2 & 39,080 & 39,380 & 0,300 & $\mathrm{NA}^{\prime}$ & 10 & 1,66 \\
\hline 7 & SP 099 & CRESCENTE & 2 & 39,780 & 39,980 & 0,200 & $N G^{\prime}$ & 11 & 1,66 \\
\hline 8 & SP 099 & CRESCENTE & 2 & 44,550 & 44,650 & 0,100 & $\mathrm{NA}^{\prime}$ & 14 & 1,78 \\
\hline 9 & SP 099 & CRESCENTE & 2 & 46,350 & 46,550 & 0,200 & $\mathrm{NA}^{\prime}$ & 13 & 1,77 \\
\hline 10 & SP 099 & CRESCENTE & 2 & 50,280 & 50,380 & 0,100 & $\mathrm{NA}^{\prime}$ & 10 & 1,78 \\
\hline 11 & SP 099 & CRESCENTE & 2 & 50,880 & 51,100 & 0,220 & $\mathrm{NA}^{\prime}$ & 21 & 1,99 \\
\hline 12 & SP 099 & CRESCENTE & 2 & 52,160 & 52,380 & 0,220 & $\mathrm{NA}^{\prime}$ & 13 & 1,89 \\
\hline 13 & SP 147 & CRESCENTE & 2 & 65,000 & 65,300 & 0,300 & $\mathrm{LA}^{\prime}$ & 15 & 1,66 \\
\hline 14 & SP 147 & CRESCENTE & 2 & 65,500 & 65,705 & 0,205 & $\mathrm{LA}^{\prime}$ & 10 & 1,77 \\
\hline 15 & SP 147 & CRESCENTE & 2 & 65,500 & 65,705 & 0,205 & $\mathrm{LA}^{\prime}$ & 8 & 1,75 \\
\hline 16 & SP 147 & DECRESCENTE & 1 & 67,000 & 67,300 & 0,300 & $\mathrm{LA}^{\prime}$ & 12 & 1,85 \\
\hline 17 & SP 147 & CRESCENTE & 1 & 69,350 & 69,550 & 0,200 & $\mathrm{LA}^{\prime}$ & 7 & 1,76 \\
\hline 18 & SP 147 & CRESCENTE & 1 & 70,300 & 70,455 & 0,155 & $\mathrm{LA}^{\prime}-\mathrm{LG}^{\prime}$ & 9 & 1,82 \\
\hline 19 & SP 147 & CRESCENTE & 1 & 75,255 & 75,705 & 0,450 & LA' $^{\prime}$ & 10 & 1,82 \\
\hline 20 & SP 147 & CRESCENTE & 1 & 77,205 & 77,505 & 0,300 & $\mathrm{NA}^{\prime}$ & 11 & 1,76 \\
\hline 21 & SP 147 & CRESCENTE & 1 & 81,705 & 82,005 & 0,300 & $\mathrm{LG}^{\prime}$ & 10 & 1,74 \\
\hline 22 & SP 147 & CRESCENTE & 1 & 83,400 & 83,505 & 0,105 & LA' $^{\prime}$ & 9 & 1,74 \\
\hline 23 & SP 280 & CRESCENTE & 3 & 29,150 & 29,450 & 0,300 & NS'-NA' & 8 & 1,70 \\
\hline 24 & SP 280 & CRESCENTE & 3 & 29,500 & 29,850 & 0,350 & NS'-NA' & 5 & 1,70 \\
\hline 25 & SP 280 & CRESCENTE & 3 & 29,900 & 30,300 & 0,400 & NS'-NA' & 5 & 1,72 \\
\hline 26 & SP 280 & CRESCENTE & 3 & 30,750 & 30,950 & 0,200 & NS'-NA' & 9 & 1,66 \\
\hline
\end{tabular}

4.8.1 Resultados dos estudos do comportamento estrutural nos segmentos homogêneos $(B D 4)$

Os resultados obtidos referentes à análise estrutural dos pavimentos dos segmentos selecionados são apresentados no Anexo B - PARÂMETROS ESTATÍSTICOS DOS SEGMENTOS HOMOGÊNEOS PELA METODOLOGIA MCT (BD4). 


\section{ANÁlISE CRÍTICA DOS ESTUdOS E PROPOSIÇÃO DE PARÂMETROS PARA FINS DE DIMENSIONAMENTO}

Nesta tese, buscou-se em um primeiro estudo de caso, feito na BR 116, estabelecerse uma metodologia de estudo da influência do subleito no comportamento de pavimentos asfálticos. Foram feitos vários estudos em campo, com abertura de cavas, determinação das condições dos solos in situ, extração de amostras e realização de vários ensaios em laboratório. Estes estudos e a metodologia concebida foram apresentados no capítulo 3.

Tendo em vista a grande diversidade de solos no estado de São Paulo e necessidade de ampliar a gama de materiais e solos pesquisados, foram então selecionadas rodovias concedidas do estado de São Paulo e foram pesquisados numerosos documentos sobre o subleito, seja na condição de novos projetos, como nos dados existentes das concessionárias. Estes dados estão dispersos na maior parte das vezes e o autor desta tese teve que fazer uma pesquisa minuciosa e organizar um banco de dados complexo, como dados cruzados de localização, ocorrências geológicas e pedológicas, terraplenagem da via (cortes, aterros ou seção mista), resultados de ensaios de caracterização dos solos, e resultados existentes de resistência $(C B R)$ e de deformabilidade (módulo de resiliência). Estes bancos de dados foram complementados com dados pluviométricos, pesquisados em estações próximas, e dados de deflectometria enviados pelas concessionárias responsáveis. Os dados destes novos estudos de caso de rodovias estaduais concedidas foram apresentados no capítulo 4. Buscou-se empregar de forma sistemática a metodologia concebida no capítulo 3 para a organização do banco de dados do capítulo 4, porém observou-se a falta de vários dados em grande parte dos arquivos, incongruência de dados, etc.

Este capítulo traz uma análise dos dados organizados e relação entre eles, buscando melhor compreender as eventuais correlações existentes entre resultados de características e propriedades. 


\subsection{Correspondências entre sítios pedológico/geológico e classificações de solos}

Com base no cruzamento dos dados consolidados entre o banco de dados de ensaios com material de subleito e o banco de ensaios de deflexões, foi possível verificar algumas eventuais correspondências entre os sítios geológicos/pedológicos e a classificação dos solos.

A Tabela 5.1 apresenta as correspondências encontradas nos estudos para os sítios Geológicos e a classificação HRB dos prováveis solos de subleito, enquanto a Tabela 5.2 apresenta as correspondências encontradas nos estudos para os sítio pedológico e classificação a MCT dos prováveis solos de subleito.

Tabela 5.1: Correspondências encontradas nos estudos para Sítio Geológico e Classificação HRB

\begin{tabular}{|c|c|c|c|c|c|c|c|c|c|c|}
\hline Classif. HRB & 总 & $\underset{⿱ 亠 䒑}{\stackrel{+}{⿺}}$ & 吕 & 宰 & $\stackrel{m}{<}$ & $\stackrel{+}{\dot{1}}$ & $\stackrel{n}{<}$ & $\stackrel{\varphi}{\dot{1}}$ & 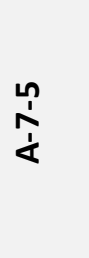 & $\underset{⿱}{\frac{1}{1}}$ \\
\hline C2P1a & - & 8 & - & - & - & 18 & - & - & - & - \\
\hline C2P1i & - & 30 & - & - & - & 130 & - & 42 & 6 & 4 \\
\hline Er & - & - & - & - & - & - & - & 6 & - & - \\
\hline J3K1bt & - & 12 & - & - & - & 16 & - & - & - & - \\
\hline k1_delta_sg & - & - & - & - & - & 14 & - & - & - & - \\
\hline K2Eit & - & 38 & - & - & - & 18 & - & 2 & 2 & - \\
\hline MP1vot & - & - & - & - & - & - & - & 2 & - & - \\
\hline NP3srpi & - & - & - & - & - & 2 & - & - & 2 & 2 \\
\hline Npexm & - & - & - & - & - & - & - & - & - & 4 \\
\hline P1tt & - & - & - & - & - & - & - & - & 2 & - \\
\hline Q1c & - & 12 & - & - & - & 20 & - & - & - & - \\
\hline NP3s_g_1lit & - & - & - & - & - & 13 & - & 44 & 118 & 50 \\
\hline NP3s_g_2lso & - & - & - & - & - & 2 & - & - & - & - \\
\hline NP3p_g_1lib & - & - & - & - & - & - & - & 2 & 2 & - \\
\hline
\end{tabular}


Tabela 5.2: Correspondências encontradas nos estudos para Sítio Pedológico e Classificação MCT [BD3]

\begin{tabular}{|c|c|c|c|c|c|c|c|c|c|c|c|c|c|c|c|c|c|c|c|c|c|c|c|c|c|}
\hline Classif. MCT & $s$ & 5 & 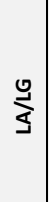 & $\frac{5}{5}$ & ș & 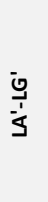 & $\stackrel{0}{5}$ & בَ & $\Sigma$ & š & $\begin{array}{l}\bar{n} \\
\bar{z} \\
\bar{y} \\
\sum \\
\bar{z} \\
z\end{array}$ & $\frac{\sum_{j}^{n}}{\frac{1}{z}}$ & $\frac{\bar{n}}{\underline{\Sigma}}$ & $\begin{array}{l}\sum_{i}^{n} \\
\frac{1}{\alpha} \\
\frac{\delta}{2}\end{array}$ & $\begin{array}{l}\sum_{1}^{n} \\
\frac{1}{2}\end{array}$ & $\begin{array}{l}\sum_{i}^{n} \\
\frac{\dot{s}}{z}\end{array}$ & ¿̃ & $\bar{n}$ & $\sum_{\bar{n}}^{\bar{z}}$ & $\frac{\bar{s}}{\bar{z}}$ & $\sum_{\frac{v}{z}}^{0}$ & 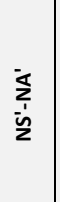 & 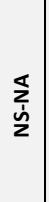 & $\begin{array}{l}\bar{j} \\
\dot{j} \\
\dot{z}\end{array}$ & 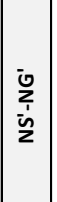 \\
\hline CXbd1 & - & - & - & - & - & - & - & - & - & - & - & - & - & - & - & - & - & 4 & - & - & - & - & - & - & \\
\hline CXbd3 & - & - & - & - & - & - & - & - & 2 & 16 & - & - & - & - & - & - & 4 & - & - & - & - & - & - & - & - \\
\hline LVAd3 & 58 & 56 & - & - & 20 & 24 & - & 10 & 52 & - & - & - & - & - & - & - & - & - & - & - & - & - & - & - & \\
\hline LVd2 & - & - & - & - & - & - & - & 2 & - & - & - & - & - & - & - & - & - & - & - & - & - & - & - & - & - \\
\hline \begin{tabular}{|l|l|} 
LVd9 \\
\end{tabular} & - & - & - & - & - & - & - & - & - & - & - & - & - & - & - & - & - & 2 & - & - & - & - & - & - & \\
\hline LVdf3 & 34 & 104 & - & - & - & - & - & 2 & - & - & - & - & - & - & - & - & 2 & - & - & - & - & - & - & - & \\
\hline PVAd39 & - & 2 & - & - & - & - & - & 2 & 8 & 78 & - & - & 2 & - & - & - & 62 & 10 & - & 2 & - & - & - & - & \\
\hline PVAd9 & - & & - & - & - & - & - & - & & - & - & - & - & 6 & - & - & 2 & 6 & - & - & - & 62 & - & - & 8 \\
\hline
\end{tabular}

O banco de dados mostra que nas regiões de ocorrência geológica k2Eit (na engenharia denominado genericamente de Arenito) tem-se uma tendência de solos mais granulares do tipo A-2-4, embora já ocorram considerável número de solos A-4. Nas regiões de NP3s_gamma (na engenharia denominados genericamente de Granito) há uma maior ocorrência de solos mais finos, plásticos, de classificação A-7.

Os mapas pedológicos dão maior riqueza de informações pois aumentam as probabilidades de compreensão e inferência do tipo de solo que ocorre, embora os movimentos de terra sejam realizados de forma não totalmente coordenados, não programando muitas vezes a reserva dos solos de comportamento laterítico para serem empregados nas camadas finais de aterros e das camadas de regularização do subleito. Porém, pode-se observar que os sítios pedológicos classificados como $L V A$ e $L V d$ mostram tendência de ocorrência de solos de comportamento laterítico e sítios pedológicos classificados como PVAd e CXbd mostram maior tendência de ocorrência de solos não-lateríticos na camada de fundação dos pavimentos. Estas observações são corroboradas por Nogami e Villibor, 1995.

Obviamente que se fosse realizado um melhor cadastro, controle e gestão das informações de projeto (alturas de corte e aterro, mapeamento tridimensional dos horizontes lateríticos e não-lateríticos identificados nas sondagens etc.) bem como das etapas de execução das obras de terraplenagem (cadastro visual dos horizontes resultantes nos cortes, dados de ensaio de controle tecnológico etc.), poderia se ter uma ideia mais acurada dos materiais, bem como dos horizontes resultantes nas camadas finais de terraplenagem (CFT) em cada um dos segmentos. Os estudos adiante mostram que tais informações, apesar de atualmente não serem coletadas, 
poderiam ser de relevância determinante para aumentar confiabilidade dos dados utilizados nos estudos realizados no âmbito desta tese, aumentar os níveis de informações dos bancos de dados e, talvez assim, haveria um potencial maior para se chegar em um nível tal de detalhamento que permita o desenvolvimento de equações ou modelos matemáticos para previsão de comportamentos. Aqui também se deve frisar a importância da consciência em se programar a terraplenagem de modo que se possam estocar os solos superficiais dos sítios lateríticos para utilização na camada final de terraplenagem.

\subsection{Avaliação da influência da pluviosidade no valor do módulo de resiliência retroanalisado do subleito}

Como já citado anteriormente, foram coletados dados de pluviosidade relativos à chuva acumulada de 1 dia, 2 dias, 4 dias e 8 dias imediatamente anteriores à data do levantamento deflectométrico realizado em cada ponto cadastrado no banco de dados histórico de resultados de ensaios com o FWD (BD2). Tais valores foram gravados em 4 colunas diferentes.

Com isso, foi possível verificar qual a relação da pluviosidade, em termos de chuva acumulada para as 4 situações.

Os itens a seguir apresentam algumas análises em relação à avaliação da influência destes parâmetros no valor do módulo de resiliência retroanalisado do pavimento, bem como nos indicadores D120 e D90 (deflexão a $120 \mathrm{~cm}$ do centro de aplicação de carga e deflexão a $90 \mathrm{~cm}$, respectivamente). 
5.2.1 Análise da influência dos parâmetros de pluviosidade para todo o banco de dados $(B D 2)$

Em uma primeira análise, foram relacionados os valores de módulo de resiliência retroanalisado do subleito, com os valores de chuva acumulada para 1 dia. O mesmo foi feito para as colunas de chuva acumulada de 2 dias, 4 dias e 8 dias. Nenhum filtro prévio foi utilizado, ou seja, o estudo foi realizado com todos os dados do banco de dados DB2. Os gráficos da Figura 5.1 ilustram este estudo para todo o banco de dados BD2.
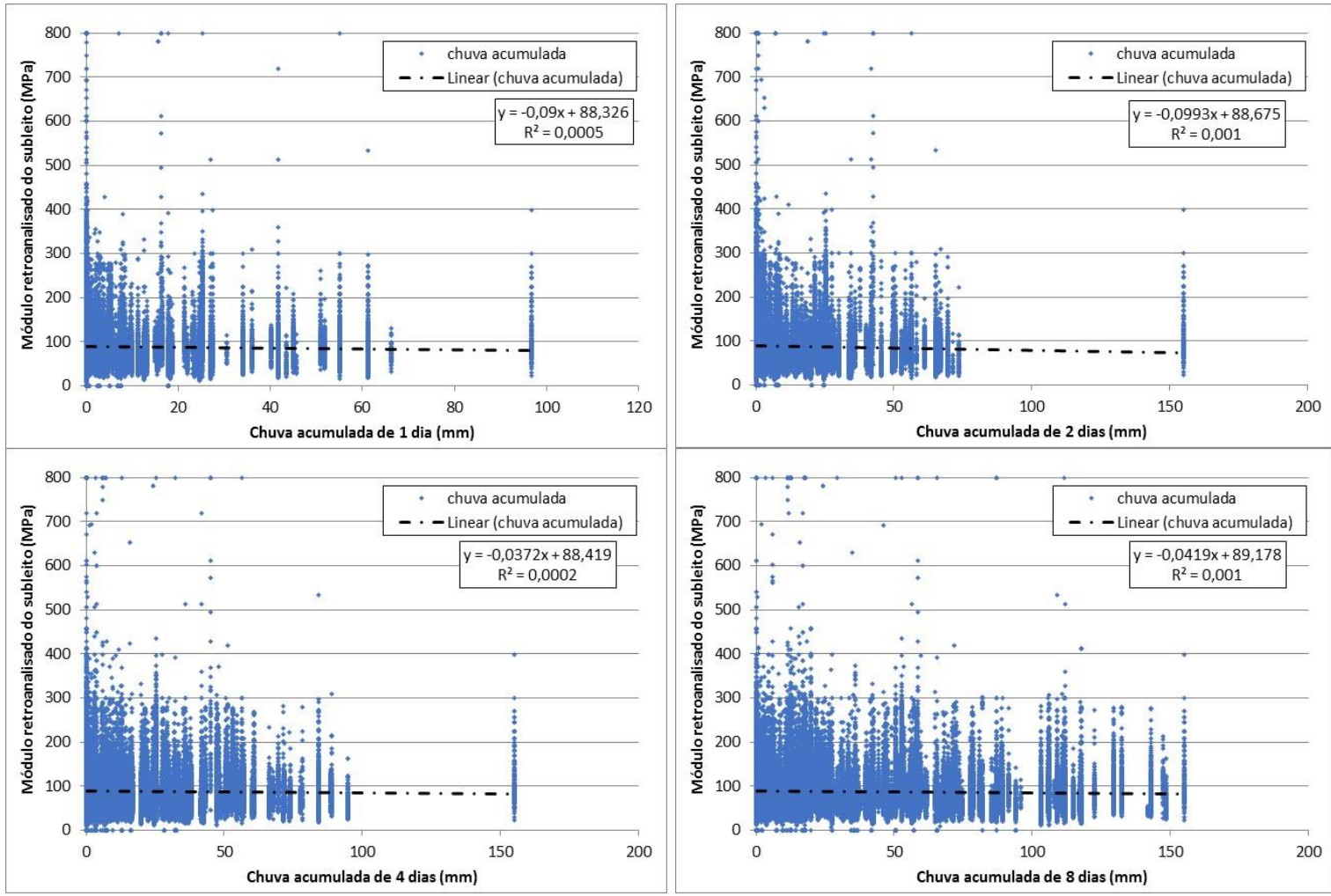

Figura 5.1: Relação entre chuva e valor do módulo de resiliência retroanalisado do subleito para chuva acumulada de 1 dia, 2 dias, 4 dias e 8 dias (BD2)

Como era de se esperar, houve muita dispersão nos dados, não sendo possível estabelecer uma relação matemática confiável (valor de $\mathrm{R}^{2}$ muito baixo). De todo modo, percebe-se que, de acordo com os coeficientes das expressões obtidas, de maneira geral, houve uma tendência de redução dos valores de módulo de resiliência retroanalisados, em todas as situações de chuva. Deve-se observar que a não 
ocorrência de chuva ou leve precipitação mostram uma maior densidade de ocorrência de valores de módulo de resiliência retroanalisados mais elevados que para maiores precipitações.

Também se verifica que os coeficientes angulares das retas obtidas são maiores nos gráficos relativos às chuvas acumuladas de 1 dia e de 2 dias, em relação às chuvas de 4 dias e de 8 dias, deixando indícios que, de maneira geral, as chuvas de 1 dias e de 2 dias tenham, de modo geral, maior influência na redução dos valores de módulo de resiliência do subleito em campo.

Os gráficos da Figura 5.2 e Figura 5.3 a seguir ilustram a mesma análise, porém agora considerando, ao invés dos valores de módulo de resiliência retroanalisados do subleito, os indicadores $D 90$ e $D 120$ (deflexão a $90 \mathrm{~cm}$ e a $120 \mathrm{~cm}$ de distância do ponto de aplicação de carga no ensaio com $F W D$ - valores corrigidos pela carga).
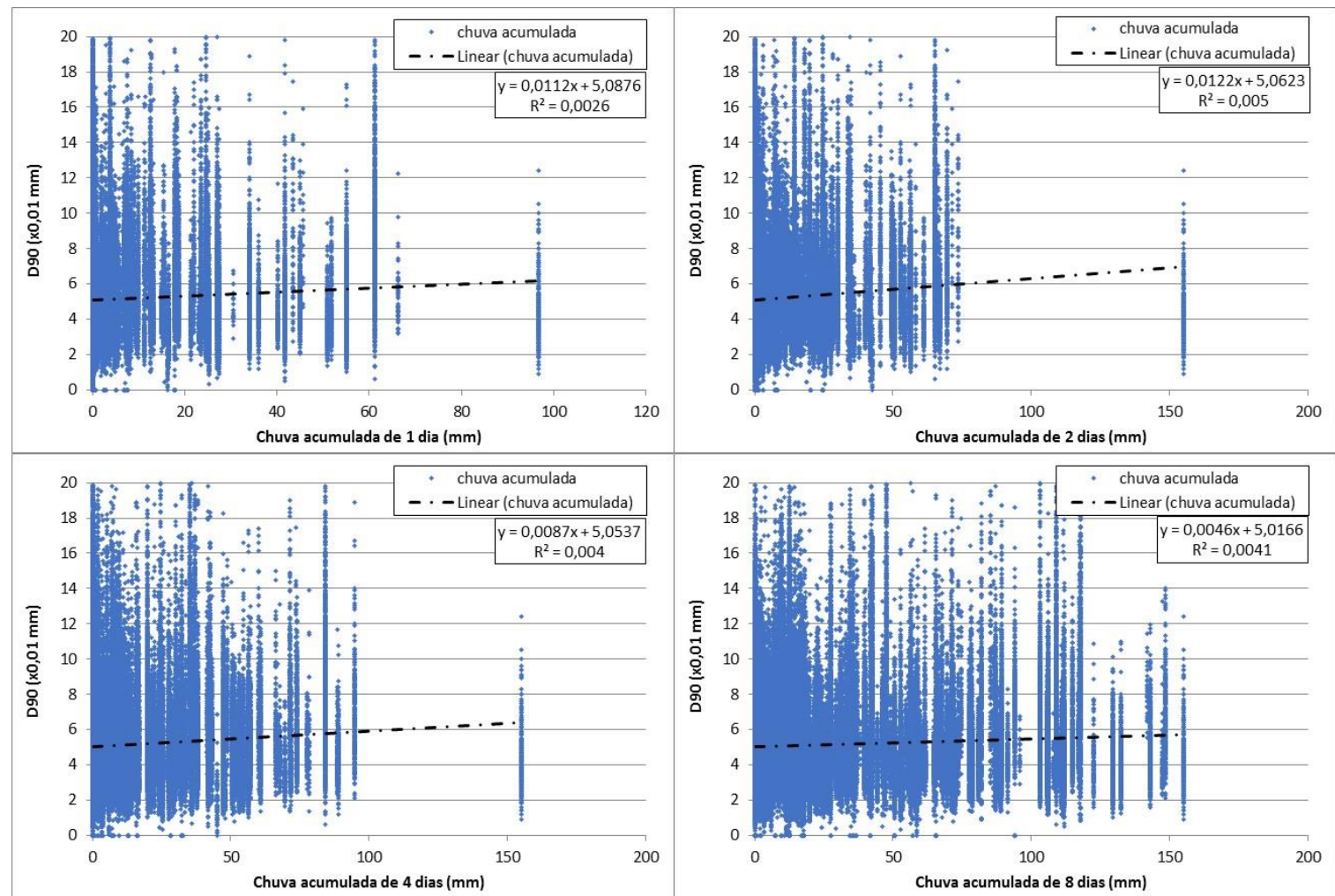

Figura 5.2: Relação entre chuva e valor do D90 para chuva acumulada de 1 dia, 2 dias, 4 dias e 8 dias (BD2) 

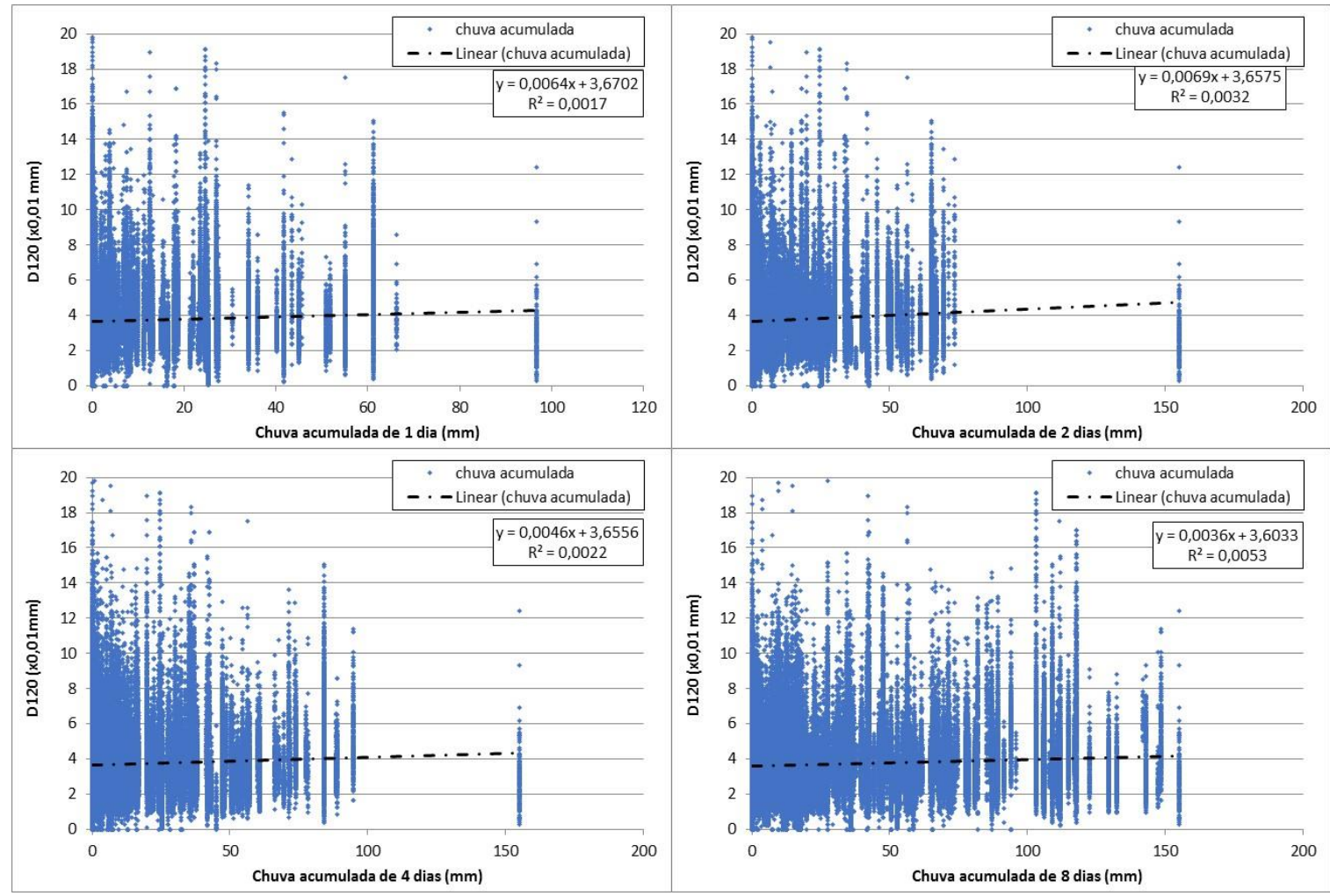

Figura 5.3: Relação entre chuva e valor do D120 para chuva acumulada de 1 dia, 2 dias, 4 dias e 8 dias (BD2)

Para os gráficos de indicadores deflectométricos (D90 e D120), pode-se notar que houve a mesma tendência de dispersão elevada de valores. Verificou-se, como esperado, tendência geral de aumento dos indicadores com o aumento da precipitação acumulada em todos os gráficos. Também, como no caso do módulo, verificou-se que os coeficientes angulares das retas obtidas são maiores nos gráficos relativos às chuvas acumuladas de 1 dia e de 2 dias, em relação às chuvas de 4 dias e de 8 dias, deixando indícios que, de maneira geral, as chuvas de 1 dias e de 2 dias possam ter, de modo geral, maior influência nos indicadores.

Novos estudos devem ser estimulados para as concessionárias realizarem o aumento na carga do FWD para aumentar a deflexão D90 e D120 de modo a reduzir o erro de determinação do módulo de resiliência retroanalisado do subleito, reduzindo assim a influência dos erros inerentes das medidas de deflexão pois aumenta a magnitude das medidas. 
5.2.2 Análise da influência dos parâmetros de pluviosidade para determinados sítios pedológicos (BD2)

Com base na grande dispersão de resultados obtida nos gráficos do item anterior, verificou-se a possibilidade de filtragem dos dados, separando as análises para as condições: (i) sítios pedológicos com potencial elevado de solo laterítico na fundação e (ii) sítios pedológicos com potencial elevado de solo não-laterítico e expansivo na fundação. Os gráficos da Figura 5.4 e Figura 5.5 ilustram, respectivamente, o resultado deste estudo, utilizando os filtros para os sítios lateríticos $\angle V A d 3$ e para sítios não-lateríticos $C X b d 1$ no banco de dados $B D 2$.
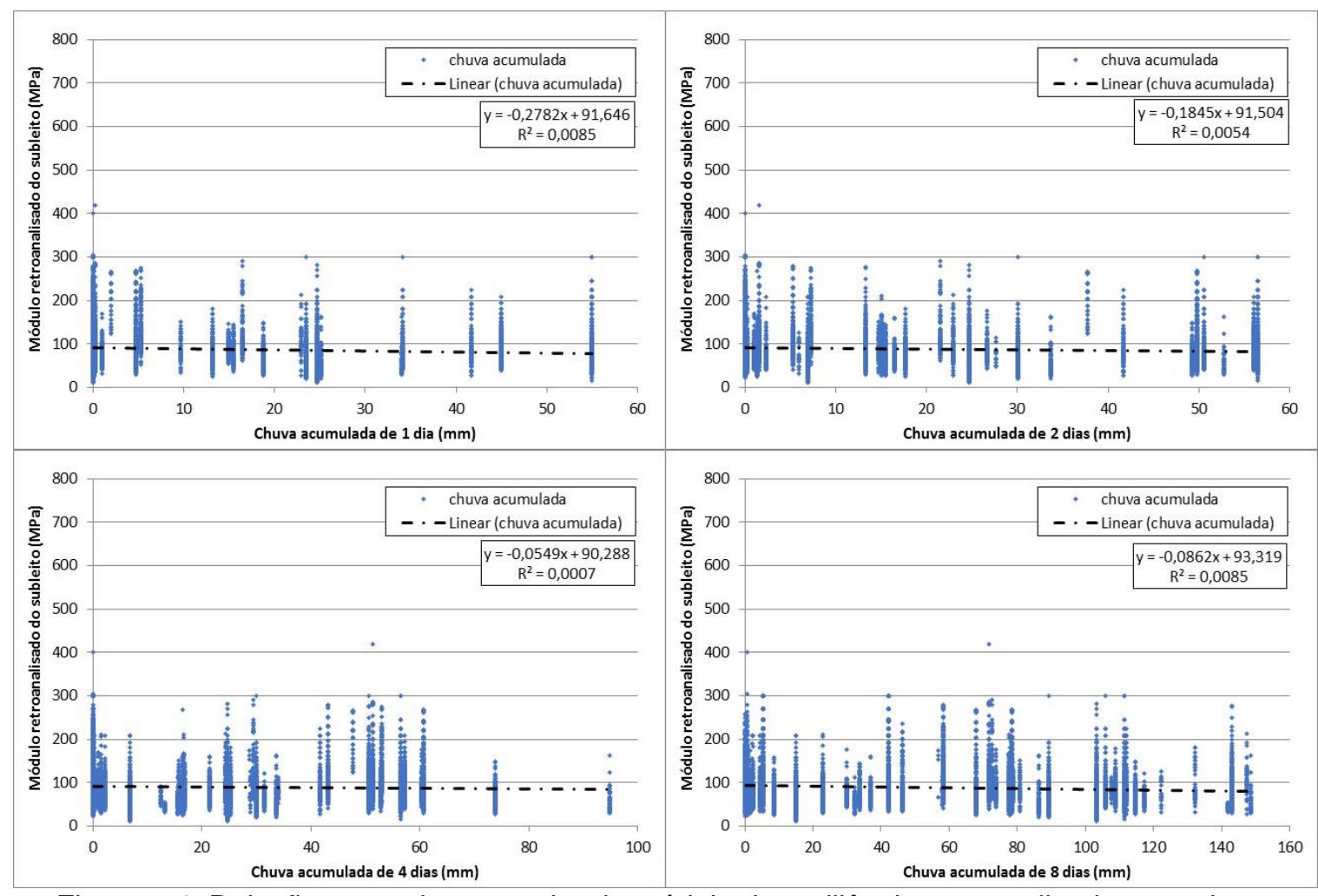

Figura 5.4: Relação entre chuva e valor do módulo de resiliência retroanalisado para chuva acumulada de 1 dia, 2 dias, 4 dias e 8 dias (BD2) - Sítios solos potencialmente lateríticos (LVAd3) 

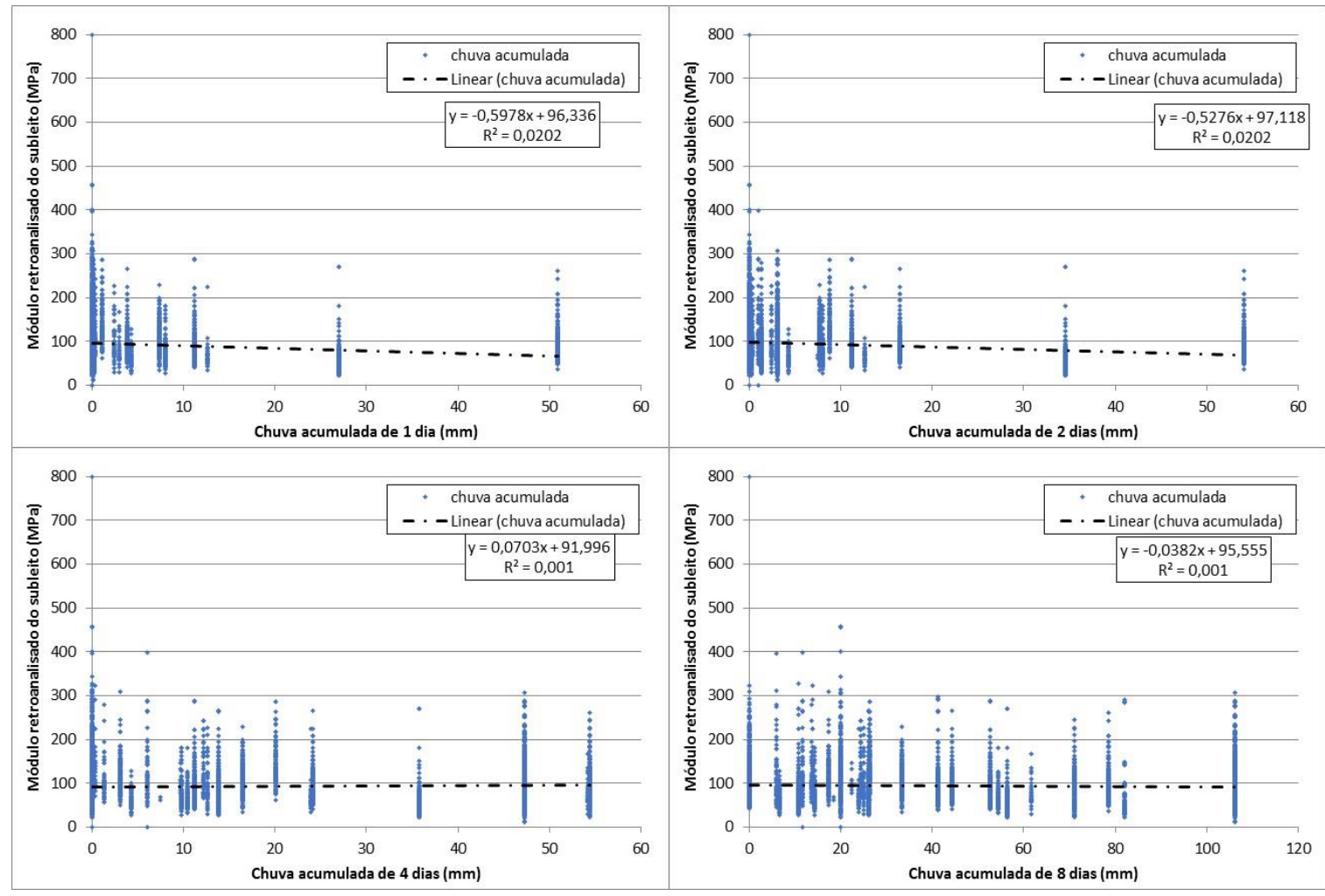

Figura 5.5: Relação entre chuva e valor do módulo de resiliência retroanalisado para chuva acumulada de 1 dia, 2 dias, 4 dias e 8 dias (BD2) - Sítios potenciais solos NS' (CXbd1)

Como se pode verificar nos gráficos, mesmo aplicando os filtros de sítio pedológico, a dispersão de valores de módulo de resiliência retroanalisado do subleito ainda é bastante elevada, não sendo possível obter modelos matemáticos confiáveis até este ponto.

De todo modo, é possível verificar certas tendências, como relatado a seguir:

- Chuvas acumuladas de 1 dia e 2 dias tiveram maior influência na tendência de diminuição do valor de módulo de resiliência retroanalisado do subleito (maior coeficiente angular das retas das linhas de tendência);

- chuvas acumuladas de 1 e 2 dias tiveram maior influência na tendência da diminuição do valor do módulo de resiliência retroanalisado do subleito no sítio pedológico CXbd1, composto por solos não-lateríticos, solos de predominância tipo NS' (não laterítico siltoso) na fundação como se pode verificar na Tabela 5.2. O coeficiente angular foi de $-0,5978$ no sítio $C X b d 1$ enquanto que no sítio $L V A d 3$, foi de $-0,2782$ (um pouco menos que a metade), demonstrando que os solos lateríticos são menos sensíveis à ação da água que os solos não-lateríticos, como era de se esperar. 
Outras tentativas foram realizadas no intuito de se obter uma relação melhor entre as variáveis em estudo. A Figura 5.6 a seguir ilustra a tentativa de aplicação de filtro para sítio pedológico ( $L V A d 3$ ), sítio geológico (Q1c e Q2a), tipo de seção de terraplenagem (corte/aterro).
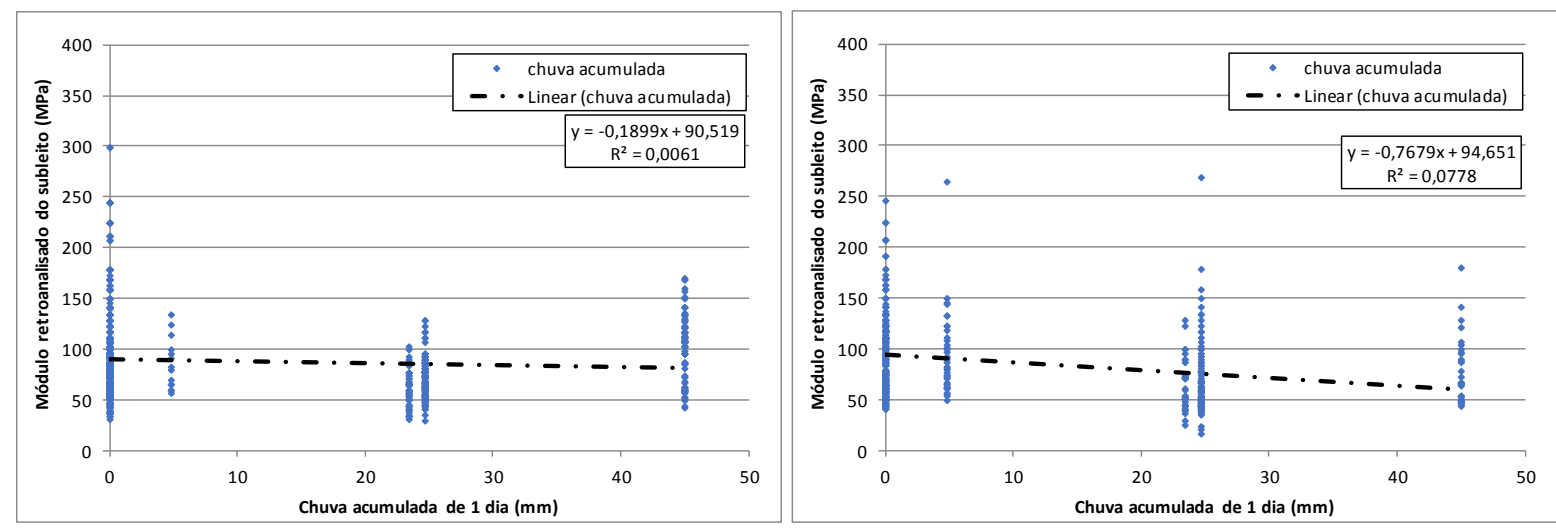

Figura 5.6: Relação entre chuva acumulada de 1 dia e valor do módulo de resiliência retroanalisado (BD2) - sítio pedológico LVAd3, sítios geológicos Q1c e Q2a, seções em (a) corte e (b) aterro

Esperava-se que, em seção de aterro, haveria menor probabilidade de sensibilidade dos solos à precipitação e, portanto, menor redução dos módulos de resiliência. Não se pode afirmar se as seções de corte, devido ao risco de acumulo de água, são melhores drenadas e, dado este fato, são menos afetadas pela precipitação. Estas constatações precisam ser verificadas in situ, em estudos específicos, para se poder afirmar que a drenagem tem este efeito sobre a terraplenagem.

Como se pode verificar nos diversos gráficos apresentados das relações módulo versus chuva acumulada e, em várias tentativas realizadas pelo autor e não especificamente relatadas no presente documento, não foi possível estabelecer uma relação confiável entre as variáveis, devido à elevada dispersão de valores de módulo de resiliência retroanalisado para uma mesma situação de chuva, sítio pedológico, sítio geológico, tipo de seção de terraplenagem, classificação $M C T$ etc. 


\subsection{Avaliação da influência de cada componente estudado no comportamento mecânico do subleito}

5.3.1 Análise dos dados pontuais dos valores de módulo e demais características $(B D 2)$

A Figura 5.7 apresenta a estatística dos valores pontuais de módulo de resiliência do subleito retroanalisados, para cada uma das rodovias contidas no banco de dados das rodovias em estudo para 3 condições de chuvas diferentes. Já a Figura 5.8 até a Figura 5.10 ilustram os valores de módulo para cada uma das características isoladas em estudo (tipo de seção de terraplenagem, sítio geológico e sítio pedológico).

Para análise dos dados pontuais, particionados pelas características em estudo (sítio geológico / pedológico, seção de terraplenagem, além do regime de chuvas) foram montadas matrizes-resumo, contendo os valores estatísticos (média, desvio-padrão e coeficiente de variação etc.) para os parâmetros: módulo de resiliência do subleito retroanalisado e chuva acumulada. Tais matrizes são apresentadas no ANEXO F MATRIZES COM ESTATÍSTICAS DOS RESULTADOS INDIVIDUAIS DO ESTUDO DAS RODOVIAS ESTADUAIS. 


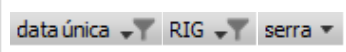

Média de Esl,retro(f) DesvPad de Esl,retro(f) Contagem de Esl,retro(f) Média de chuva acum.

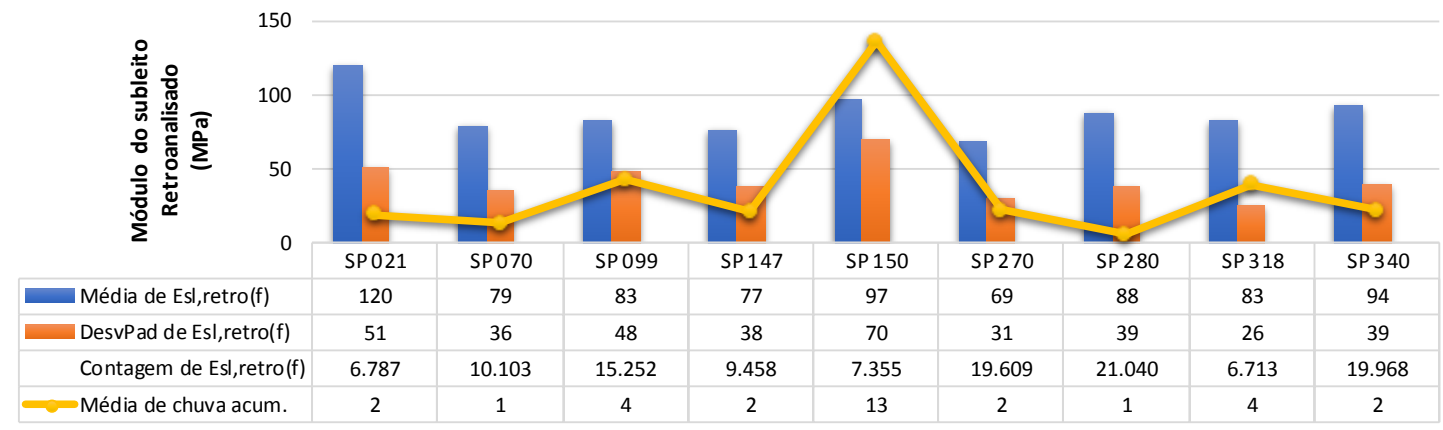

Rodovia $v$

\section{data única - 7 RIG - 7 serra *}

Média de Esl,retro(f) DesvPad de Esl,retro(f) Contagem de Esl,retro(f) Média de chuva acum.

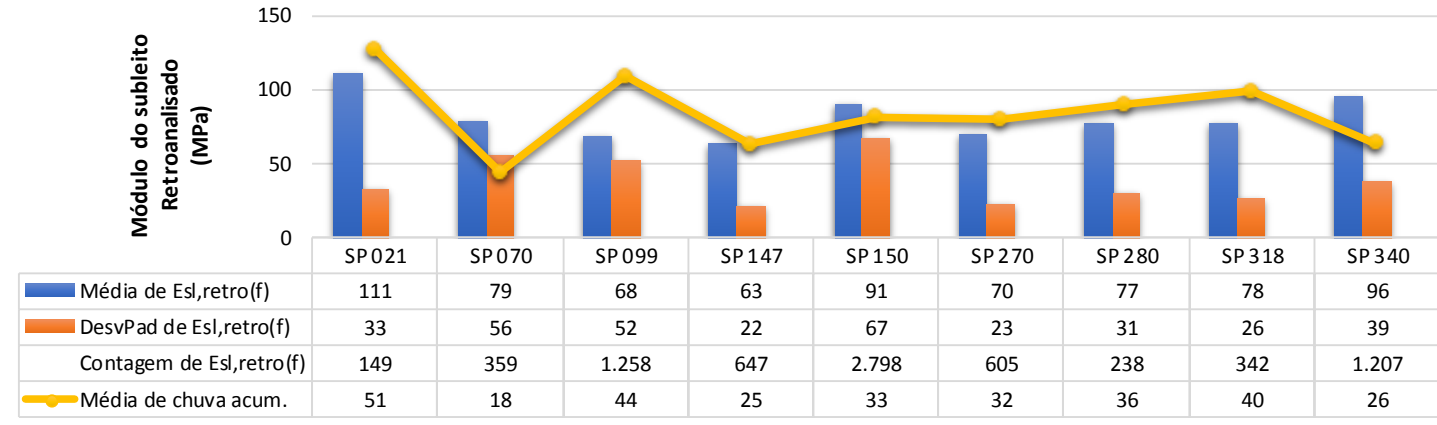

Rodovia -

\section{dataúnica $>$ T RIG $>$ Y serra -}

Média de Esl,retro(f) DesvPad de Esl,retro(f) Contagem de Esl,retro(f) Média de chuva acum.

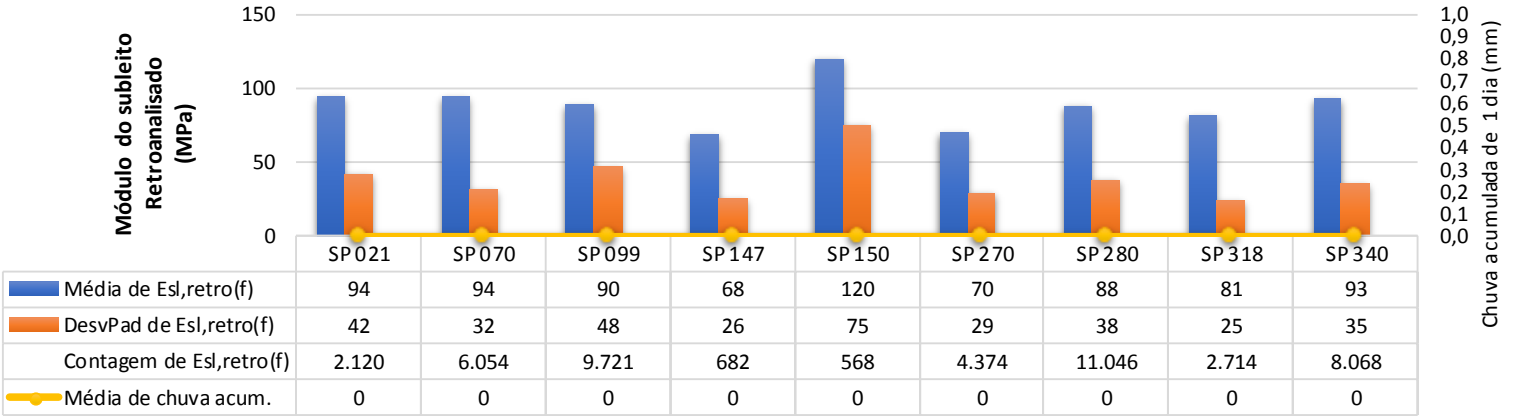

Rodovia -

Figura 5.7: Média e desvio padrão dos valores de módulo de resiliência retroanalisado para cada uma das rodovias em estudo para 3 condições de umidade distintas sendo: (a) condição geral; (b) chuva de 1 dia maior que $15 \mathrm{~mm}$, (c) sem chuva detectada no período de 8 dias [BD2]

Em análise à figura acima, verifica-se que, de maneira geral, com certas exceções, na situação seca o valor do módulo de resiliência retroanalisado apresentou valores médios maiores e menor desvio-padrão em relação à condição úmida. 


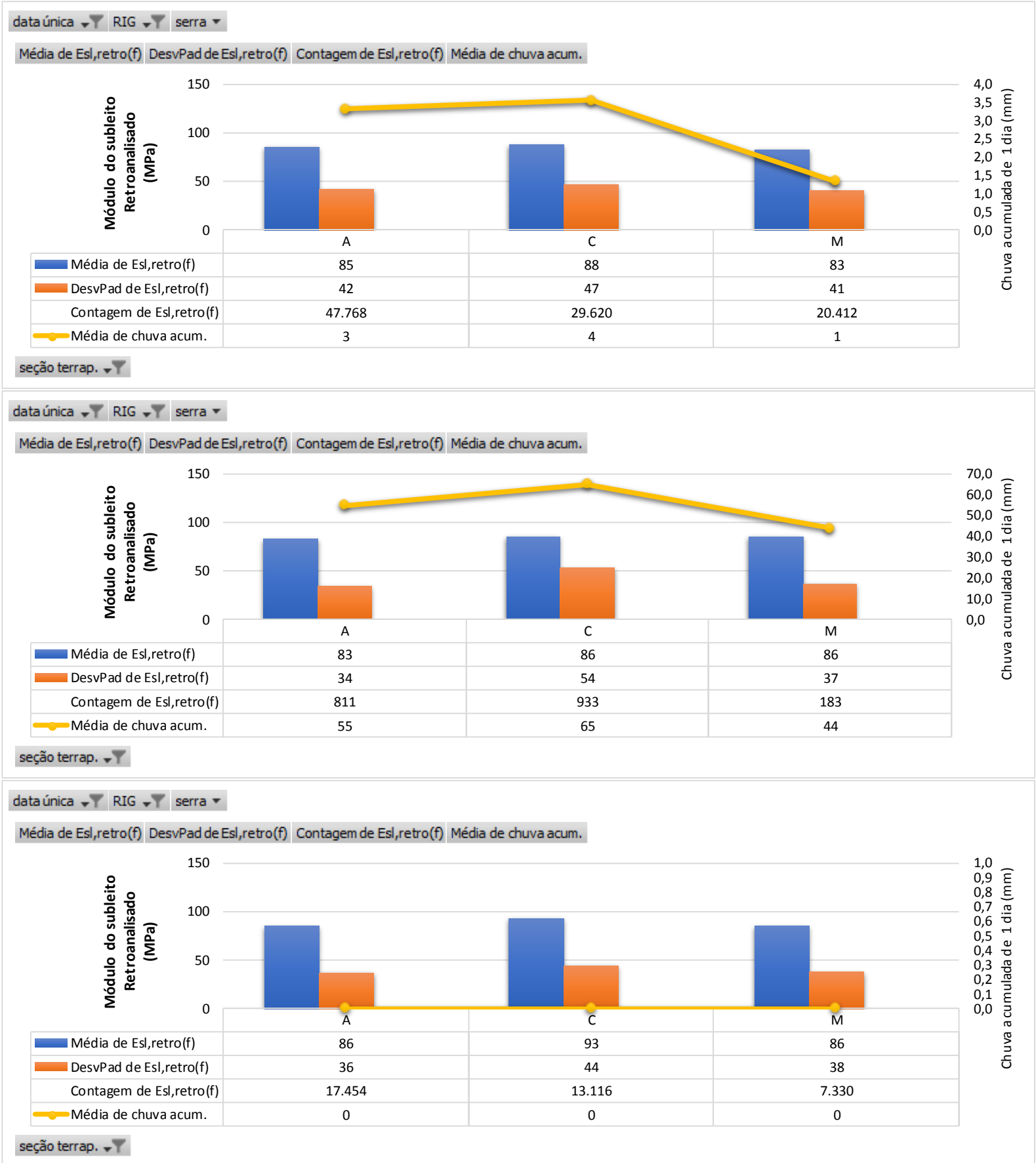

Figura 5.8: Média e desvio padrão dos valores de módulo de resiliência retroanalisado por tipo de seção de terraplenagem para 3 condições de umidade distintas sendo: (a) condição geral; (b) chuva de 1 dia maior que $40 \mathrm{~mm}$, (c) sem chuva detectada no período de 8 dias [BD2] 


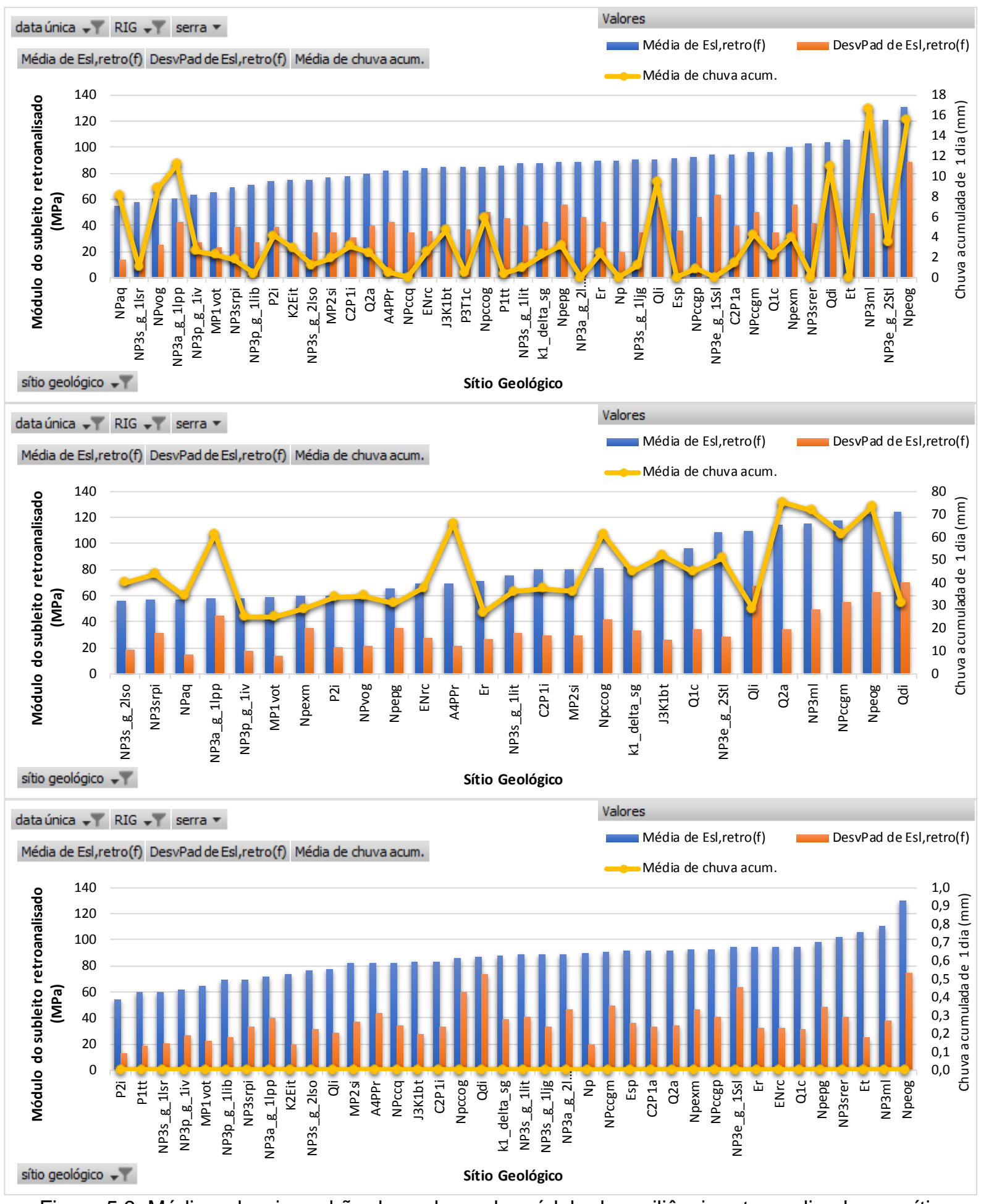

Figura 5.9: Média e desvio padrão dos valores de módulo de resiliência retroanalisado por sítio geológico para 3 condições de umidade distintas sendo: (a) condição geral; (b) chuva de 1 dia maior que $25 \mathrm{~mm}$, (c) sem chuva detectada no período de 8 dias [BD2] 


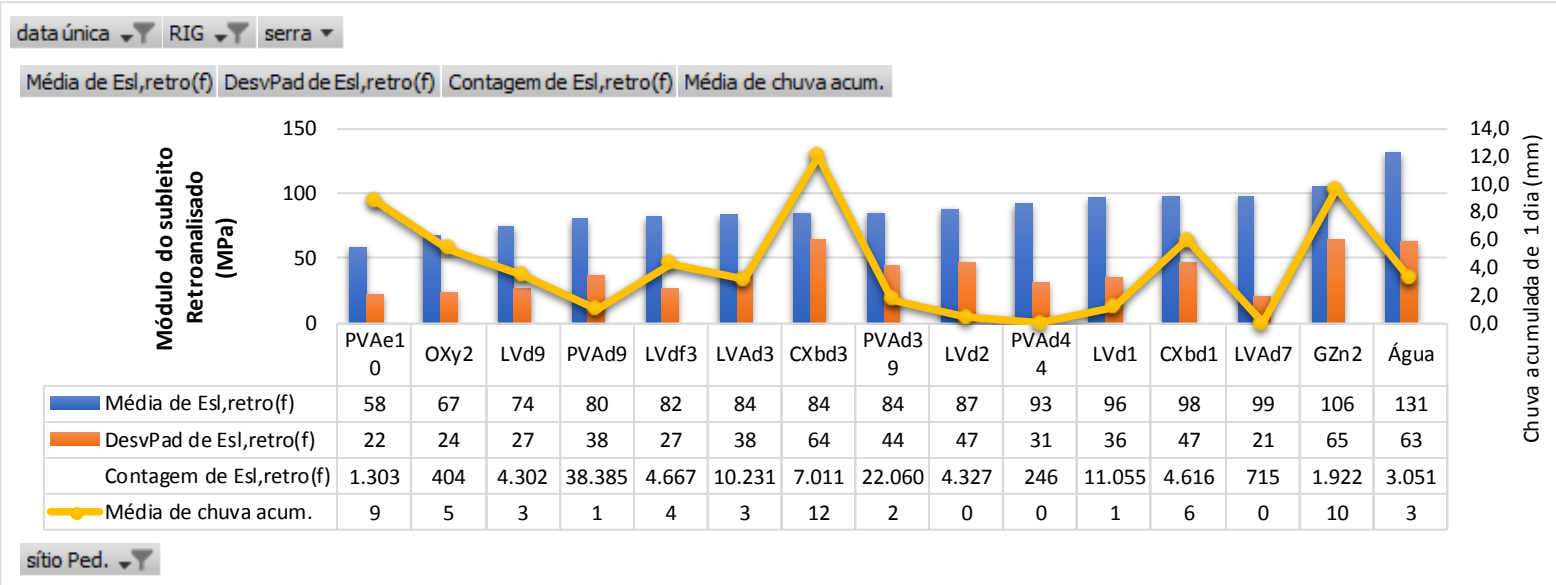

\section{data única $\boldsymbol{Y}$ RIG $\boldsymbol{T} \mathbf{Y}$ serra $\boldsymbol{V}$}

Média de Esl,retro(f) DesvPad de Esl,retro(f) Contagem de Esl,retro(f) Média de chuva acum.

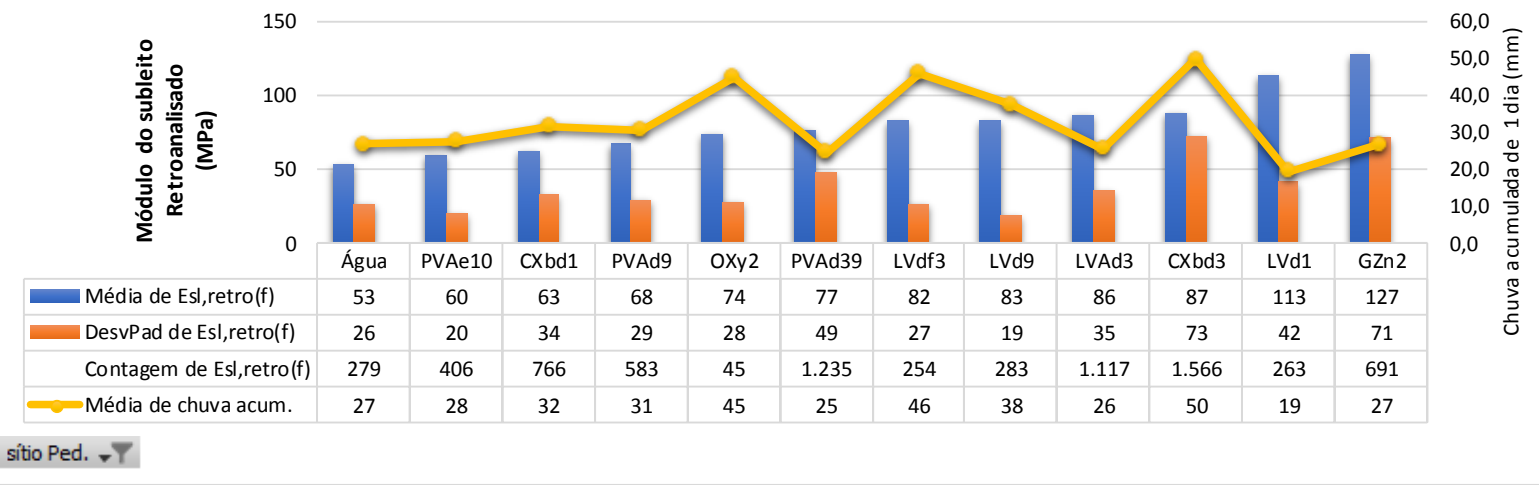

\section{dataúnica $>$ R RIG $>$ serra $~ *$}

Média de Esl,retro(f) DesvPad de Esl,retro(f) Contagem de Esl,retro(f) Média de chuva acum.

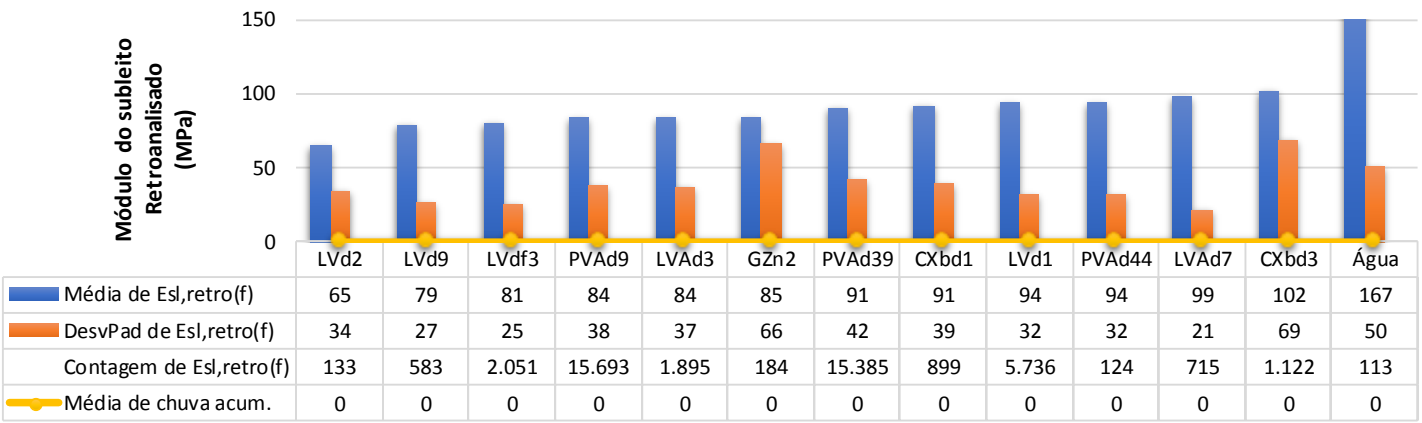

Figura 5.10: Média e desvio padrão dos valores de módulo de resiliência retroanalisado por sítio pedológico para 3 condições de umidade distintas sendo: (a) condição geral; (b) chuva de 1 dia maior que $15 \mathrm{~mm}$, (c) sem chuva detectada no período de 8 dias [BD2]

O termo "Água" se refere ao local do mapa pedológico sem informações de ocorrência com indicação de presença de água (área alagada). 


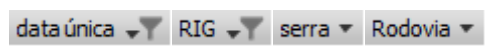

Média de Esl,retro(f) DesvPad de Esl,retro(f) Contagem de Esl,retro(f) Média de chuva acum. 1d Média de chuva acum.8d

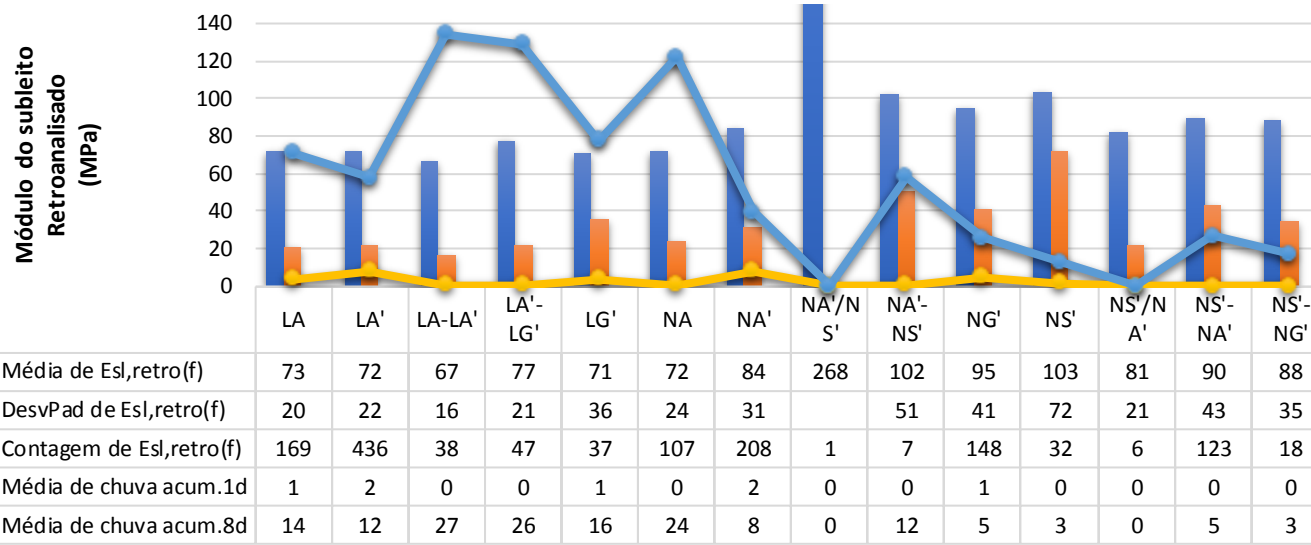

30,0

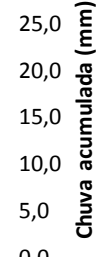

MCT $\rightarrow$

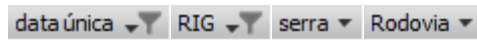

Média de Esl,retro(f) DesvPad de Esl,retro(f) Contagem de Esl,retro(f) Média de chuva acum. 1d Média de chuva acum.8d

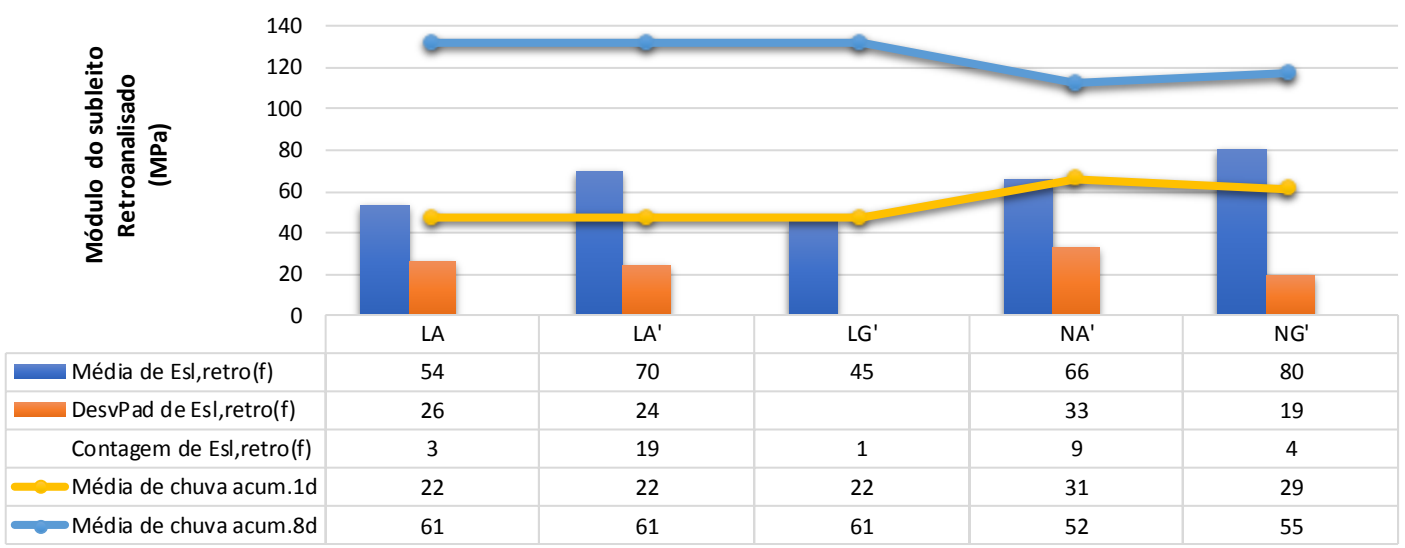

70,0

MCT $\boldsymbol{\nabla}$

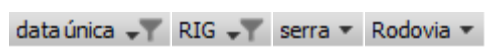

Média de Esl,retro(f) DesvPad de Esl,retro(f) Contagem de Esl,retro(f) Média de chuva acum. 1d Média de chuva acum.8d

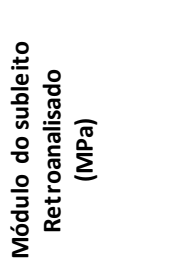

$$
\begin{array}{r}
140 \\
120 \\
100 \\
80 \\
60 \\
40 \\
20 \\
0
\end{array}
$$

Média de Esl,retro(f)

DesvPad de Esl,retro(f) Contagem de Esl, retro(f)

$\longrightarrow$ Média de chuva acum.1d

Média de chuva acum $8 \mathrm{~d}$

$M C T+Y$

Figura 5.11: Média e desvio padrão dos valores de módulo de resiliência retroanalisado por classe MCT identificada para 3 condições de umidade distintas sendo: (a) condição geral; (b) chuva de 1 dia maior que $15 \mathrm{~mm}$, (c) sem chuva detectada no período de 8 dias [BD2] 
Como se pode verificar nos gráficos, de modo geral, com algumas exceções, os valores de módulo de resiliência retroanalisado do subleito para as características estudadas são normalmente maiores na condição seca, como esperado, porém, a ação das chuvas não é tão pronunciada quanto se esperava. Não se sabe se foram evitados os ensaios de FWD nas estações de maior chuva, o que não permite avaliar de forma comparativa mais detalhadamente o efeito da umidade nos módulos de resiliência dos solos. Além disso, apesar de ensaios indicarem muitas vezes solos não-lateríticos, muitos deles são do tipo NA' ou NA que são arenosos, muitas vezes com pouca expansividade. Muitos casos onde estão apontados solos NS' ou NG', as últimas camadas de terraplenagem ou a regularização do subleito pode ter sido alterada para solos de comportamento laterítico, sem registro claro nos estudos constantes nos documentos consultados.

Também se pode verificar que os valores de chuva são diferentes para cada parâmetro estudado, sendo difícil uma comparação entre os valores de módulo de resiliência. Infere-se que para que se consiga modelar adequadamente, para cada combinação de parâmetros, a influência dos parâmetros de chuva, seja necessária acumulação de mais dados históricos e também mais dados de levantamentos deflectométricos em períodos chuvosos. O ideal, para este fim, é que fossem realizados dois levantamentos anuais de deflexões, sendo um no período de chuvas e outro no período de seca.

5.3.2 Apresentação das estatísticas para os parâmetros mais importantes (BD2)

De acordo com as questões abordadas nos itens anteriores, não foi possível considerar a quantidade de precipitação de maneira adequada nas relações com o módulo de resiliência.

De qualquer modo, verificou-se a importância da análise e possível utilização como parâmetro de dimensionamento, dos valores globais de módulo de resiliência retroanalisado do subleito (com ou sem chuva). Assim sendo, para melhor 
visualização dos valores globais de módulo obtidos no estudo, foram elaborados os gráficos boxplot e gráfico de pontos ilustrados na Figura 5.12 a seguir para aquelas características consideradas mais importantes nas análises até então.
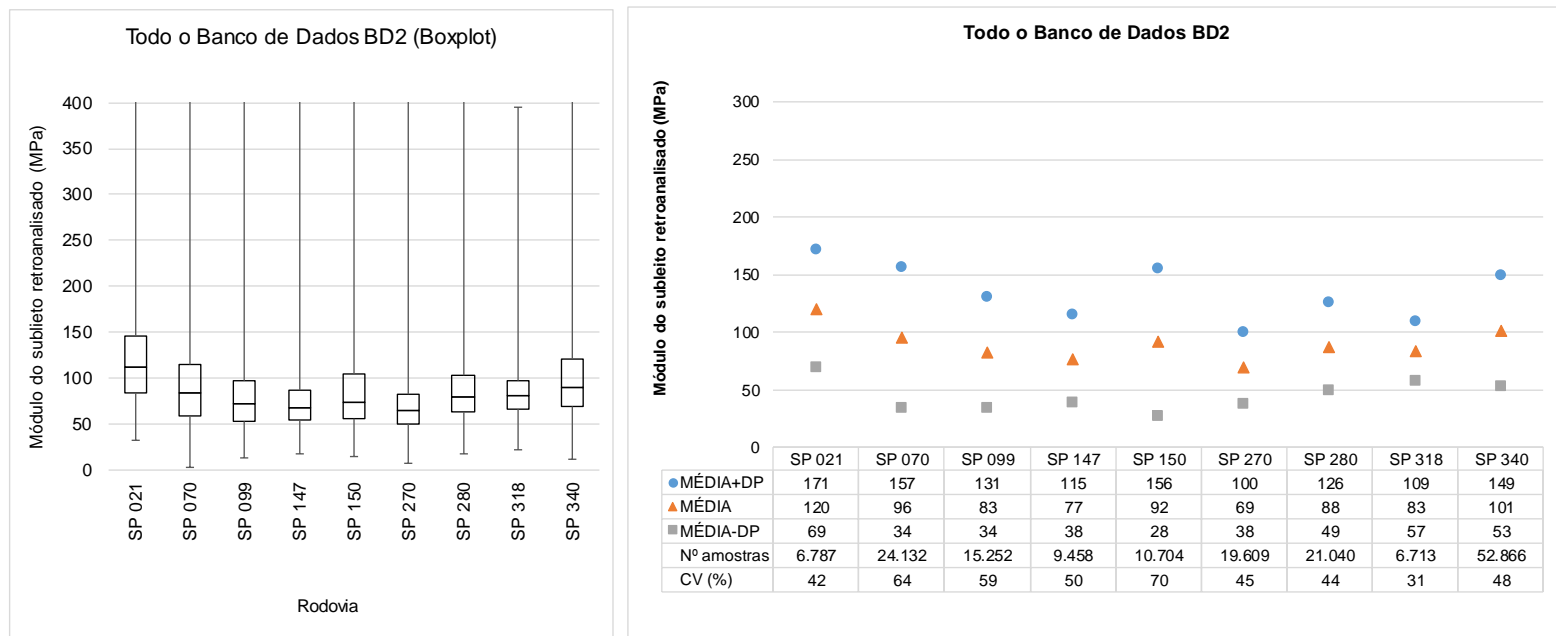

Todo o Banco de Dados BD2 (Boxplot)

Todo o Banco de Dados BD2
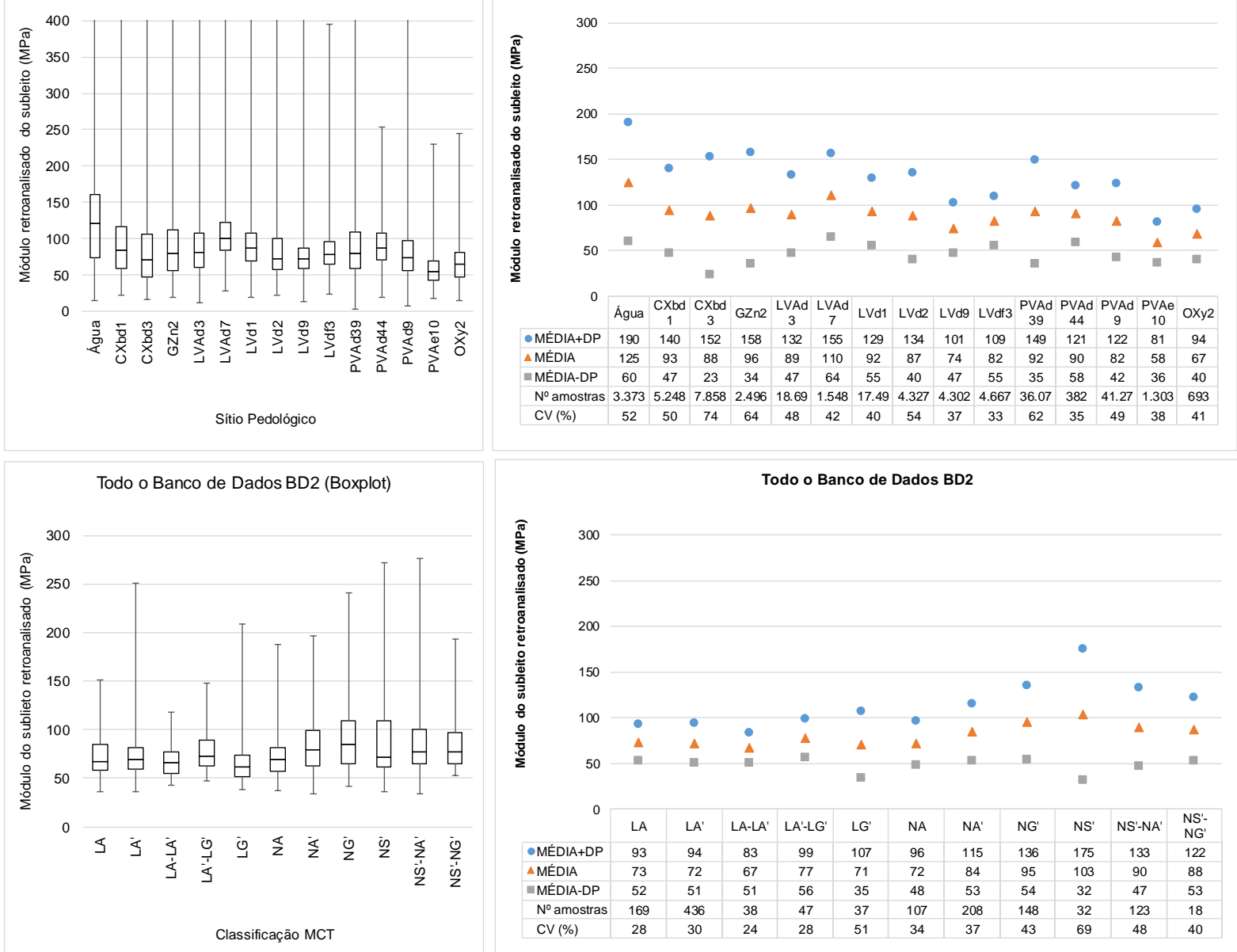

Figura 5.12: Gráficos de estatísticas para os valores globais de módulo obtidos para (a) rodovias em estudo, (b) sítios pedológicos identificados e (c) classes MCT identificadas 
5.3.3 Análise dos dados médios para os segmentos homogêneos

\section{Estatísticas da relação de módulo retroanalisado}

A Figura 5.13 apresenta a média e o desvio padrão da relação de módulo para as condições de chuva especificadas no presente trabalho.

A Figura 5.14 a presenta a média e o desvio padrão da relação de módulo para as condições de chuva especificadas no presente trabalho, além do tipo de seção de terraplenagem.

A Figura 5.15 e Figura 5.16 apresentam os valores de média e o desvio padrão da relação de módulo para cada sítio pedológico e sítio geológico analisado, respectivamente, bem como para cada situação de chuva especificada.

A Figura 5.17 apresenta os valores de média e o desvio padrão da relação de módulo para cada uma das classificações $M C T$ encontradas [BD3], respectivamente, bem como para cada situação de chuva especificada.

As matrizes apresentadas no ANEXO G - MATRIZES COM ESTATÍSTICAS DOS RESULTADOS PARA OS SEGMENTOS HOMOGÊNEOS, por sua vez, apresentam a mesma análise estatística, porém neste caso com os parâmetros citados todos combinados. 


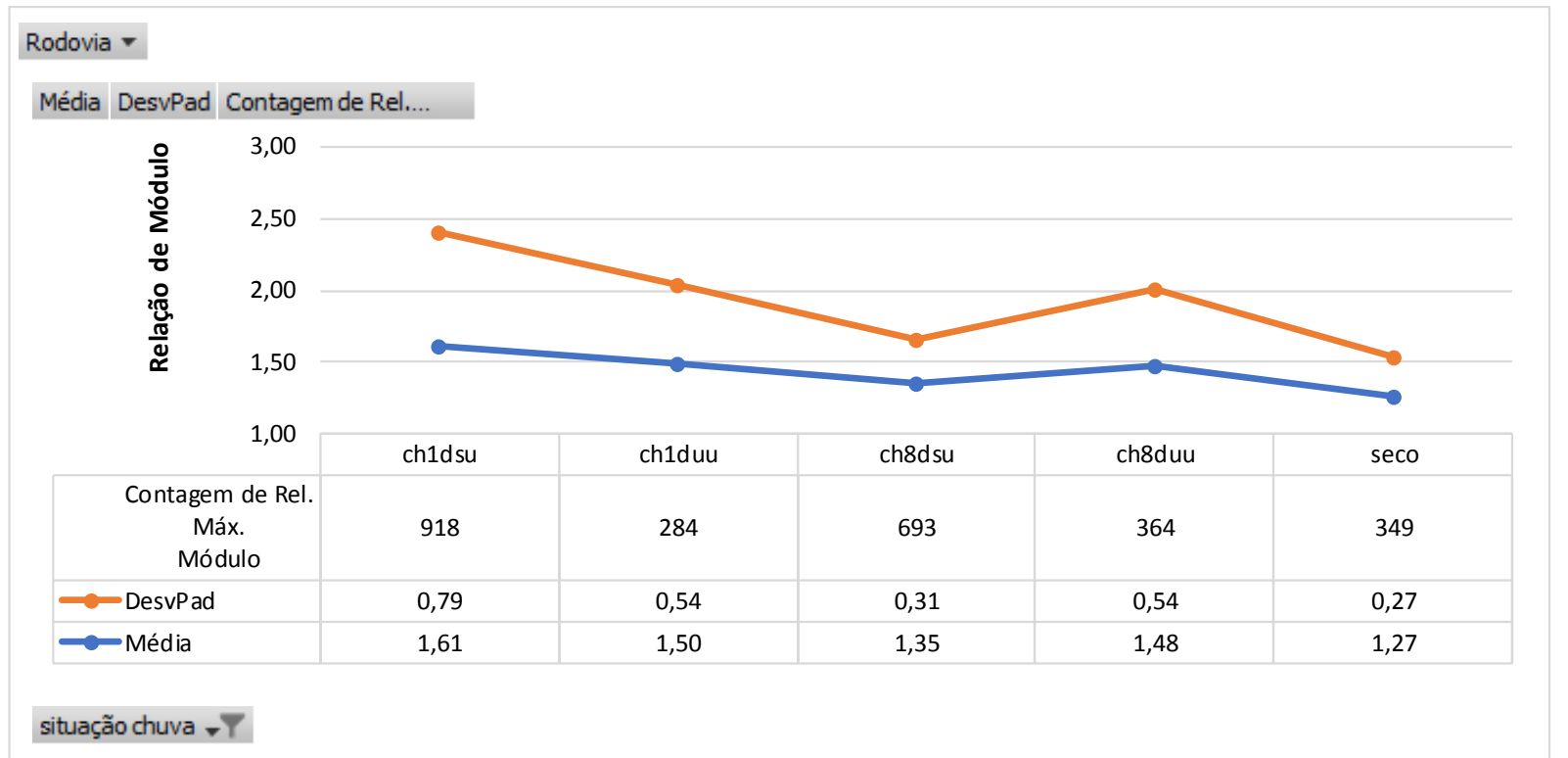

Figura 5.13: Gráfico de média e média+desvio padrão da relação de módulo para as situações de chuva especificadas - todas as rodovias em estudo [BD3]

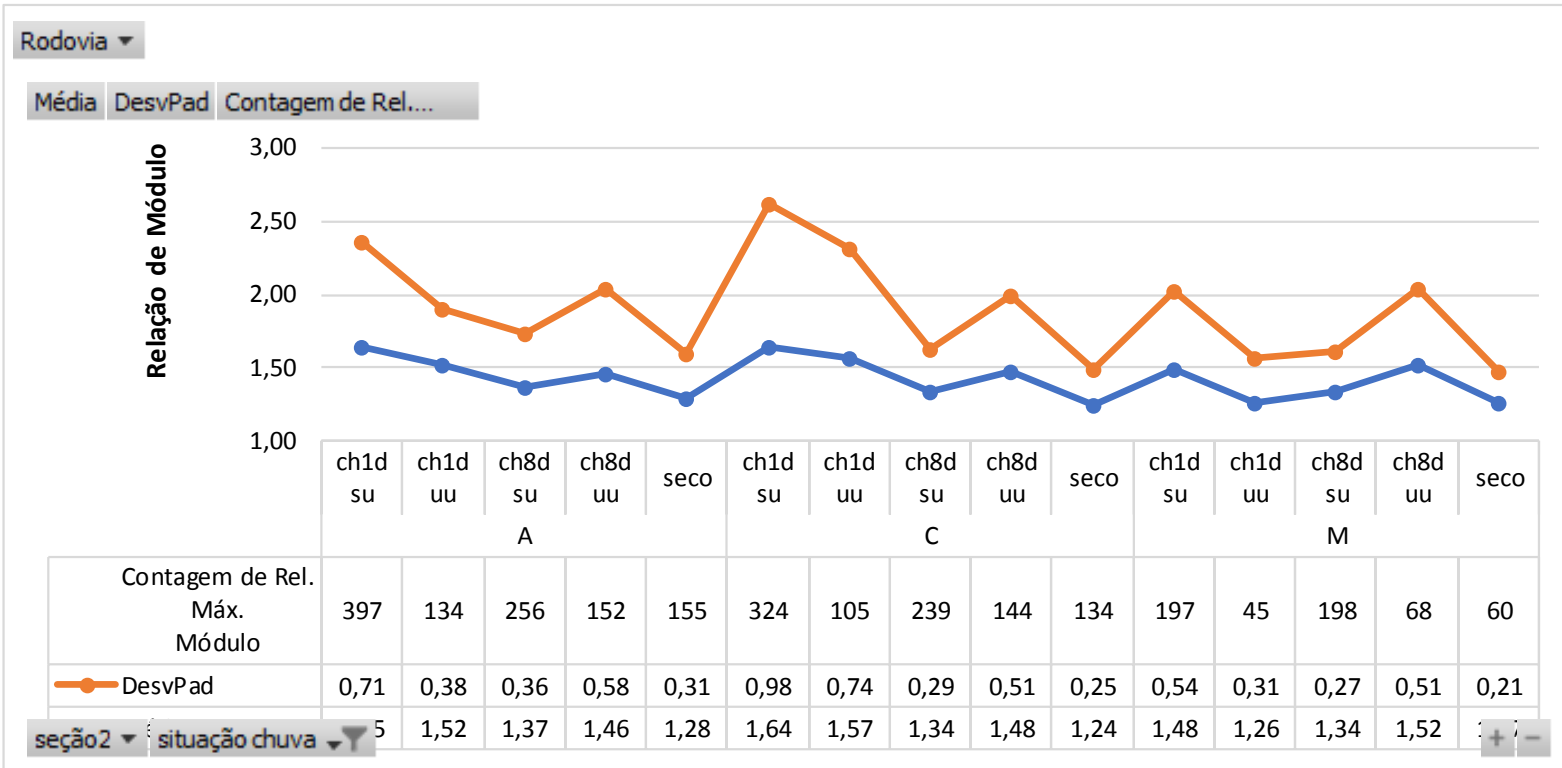

Figura 5.14: Gráfico de média e média+desvio padrão da relação de módulo para as situações de chuva especificadas - todas as rodovias em estudo (função da seção de terraplenagem) [BD3]

Nota: Legenda para as situações comparativas de chuvas:

-seco: comparação entre dois períodos secos; ou seja, quando ambos os valores de módulo (mínimo e máximo) são relativos a períodos sem chuva acumulada nos últimos 8 dias anteriores aos respectivos levantamentos;

•ch1dsu: comparação entre períodos seco e úmido; ou seja, quando, em um dos períodos houve constatação de chuva acumulada de 1 dia diferente de zero (no outro período não houve chuva acumulada nos últimos 8 dias anteriores aos respectivos levantamentos);

-ch1duu: comparação entre dois períodos úmidos; ou seja, quando, em ambos os períodos comparados, houve constatação de chuva acumulada de 1 dia diferente de zero.

•ch8dsu: comparação entre períodos seco e úmido; ou seja, quando, em um dos períodos houve constatação de chuva acumulada de 8 dias diferente de zero (no outro período não houve chuva acumulada nos últimos 8 dias anteriores aos respectivos levantamentos); 
-Ch8duu: comparação entre dois períodos úmidos; ou seja, quando, em ambos os períodos comparados, houve constatação de chuva acumulada de 8 dias diferente de zero.

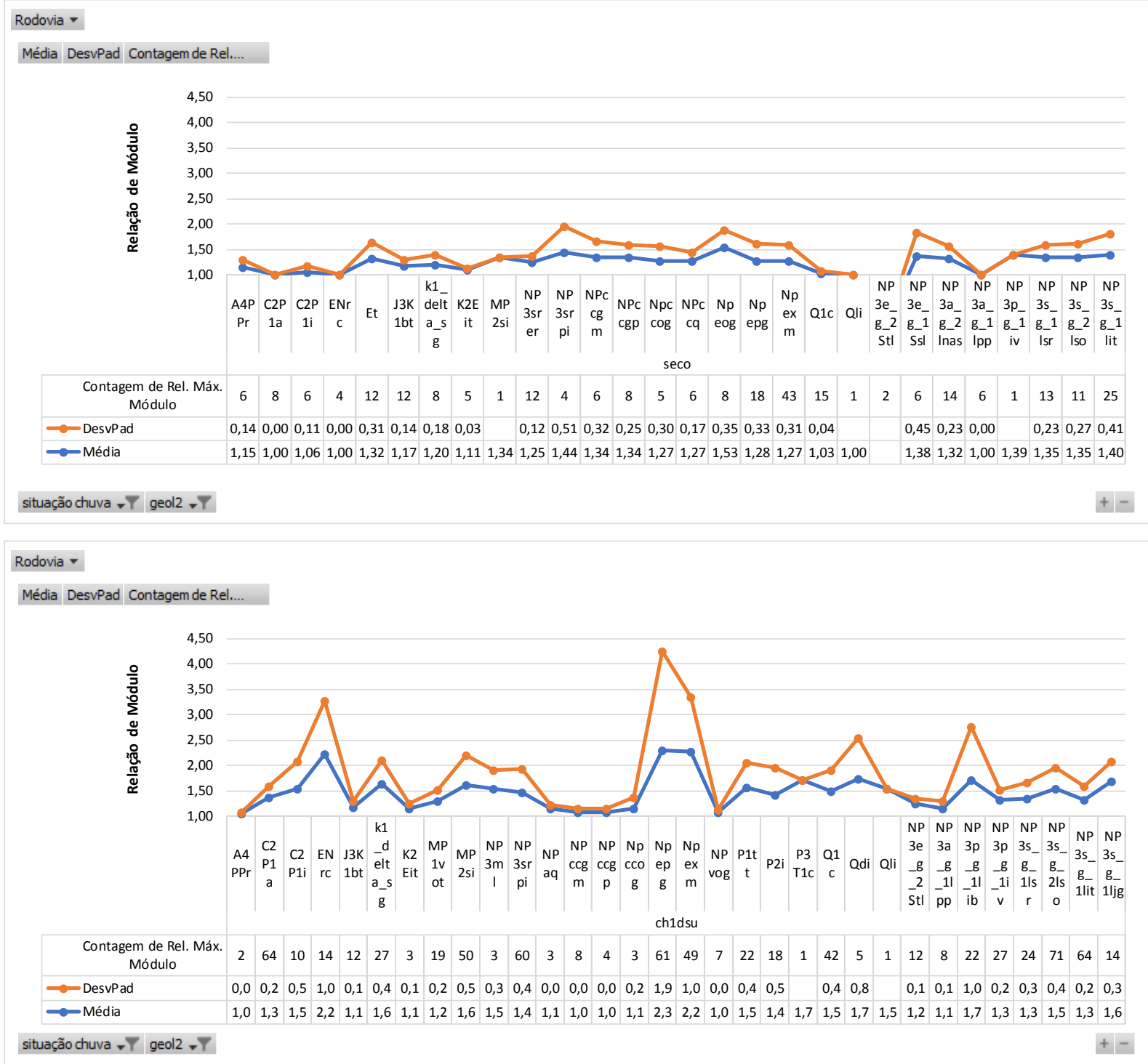

Figura 5.15: Gráficos de média e média+desvio padrão da relação de módulo para as situações de chuva especificadas - todas as rodovias em estudo (função do sítio geológico) [BD3] 


\section{Rodovia}

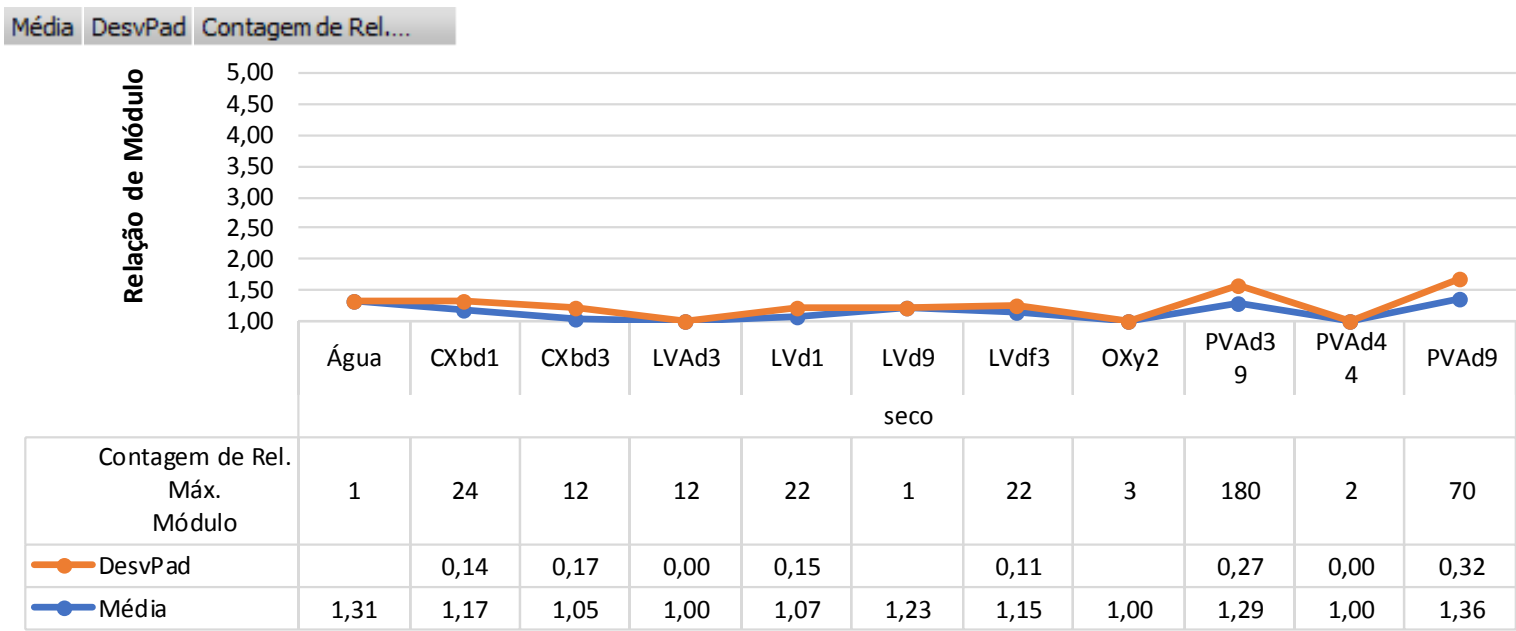

situação chuva $\mathbf{Y}$ pedol2 V

\section{Rodovia}

Média DesvPad Contagem de Rel....

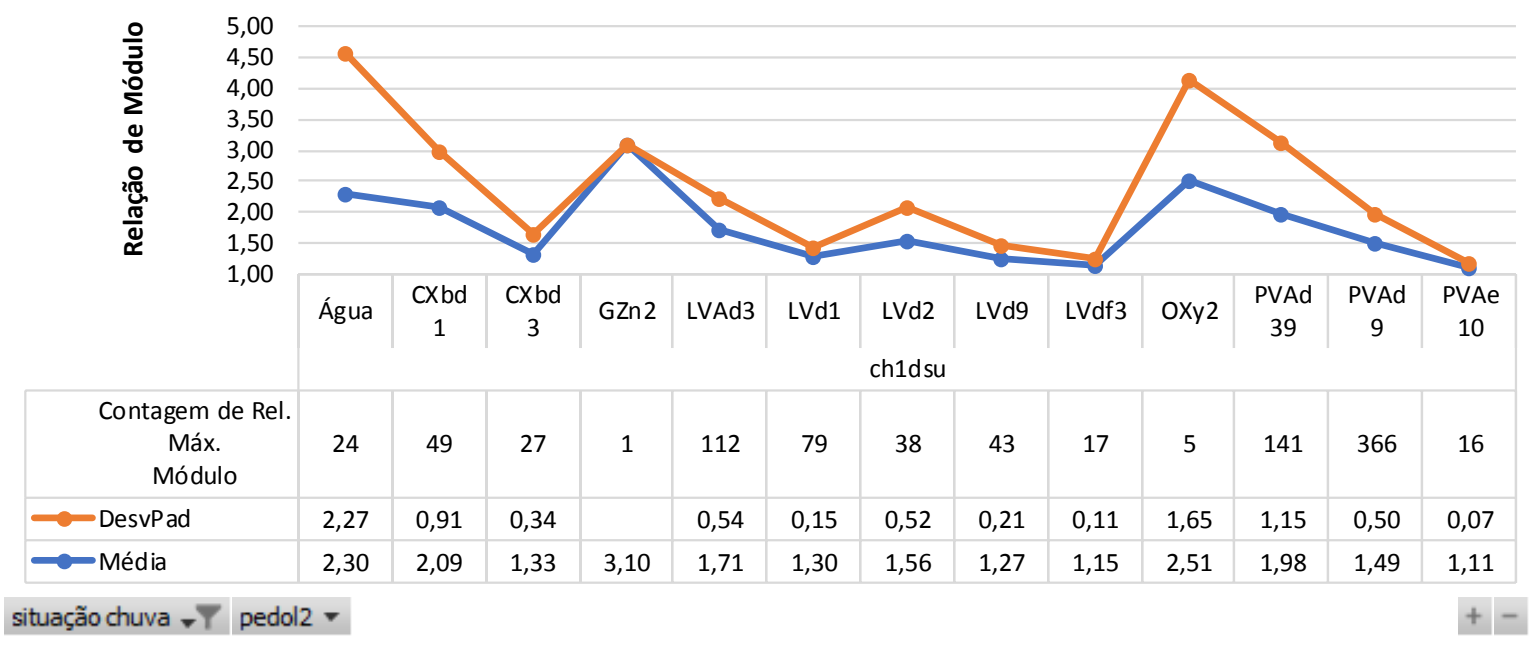

Figura 5.16: Gráficos de média e média+desvio padrão da relação de módulo para as situações de chuva especificadas - todas as rodovias em estudo (função do sítio pedológico) [BD3] 
Rodovia -

Média DesvPad Contagem de Rel.

2,50

$\sum_{0}^{\frac{0}{5}} 2,00$

2,00

胥

Contagem de Rel. Máx Módulo

$$
\multimap \text { DesvPad }
$$

1,50

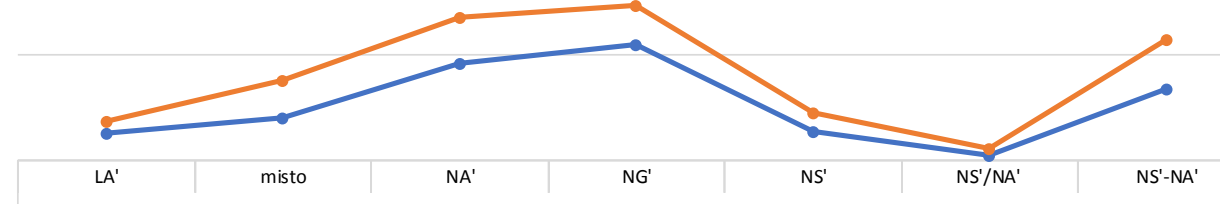

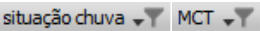

Rodovia -

Média DesvPad Contagem de Rel..

2,50

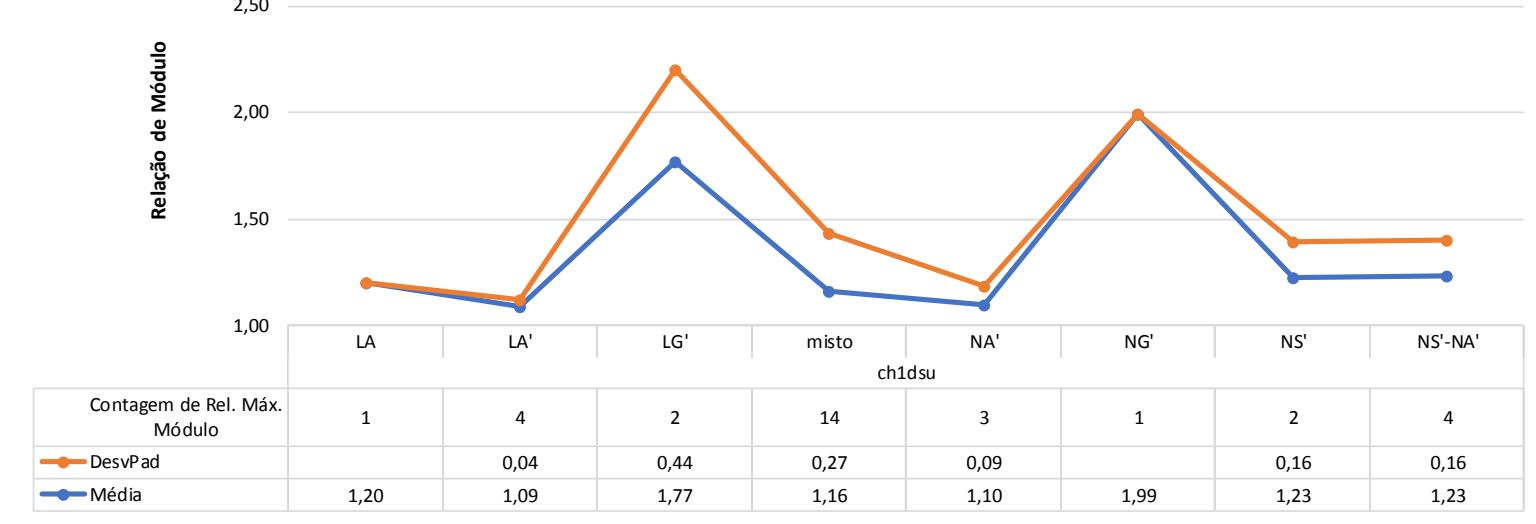

\begin{tabular}{c|c}
\hline 13 & 24 \\
\hline 0,05 & 0,18 \\
\hline 1,13 & 1,20 \\
\hline
\end{tabular}

\begin{tabular}{c|c|c|}
\hline 24 & 6 \\
\hline 0,18 & 0,21 & 0,19 \\
\hline 1,20 & 1,46 & 1,54 \\
\hline
\end{tabular}

\begin{tabular}{l|l|l|}
\hline 6 & 6
\end{tabular}

0,19

\begin{tabular}{c|c|}
\hline 2 & 8 \\
\hline 0,03 & 0,24 \\
\hline 1,02 & 1,33 \\
\hline
\end{tabular}

situação chuva $-Y$ MCT -Y

Figura 5.17: Gráficos de média e média+desvio padrão da relação de módulo para as situações de chuva especificadas - todas as rodovias em estudo (função da classificação $M C T$ ) [BD3] 
Em análise aos gráficos, pode-se verificar:

Como era de se esperar, a maior relação de módulo, em termos de média e desviopadrão, normalmente se deu na situação de chuva ch1dsu (comparação entre condições seca e úmida, com relação à precipitação acumulada de 1 dia). Esta tendência se confirmou em várias oportunidades nos estudos compartimentados para cada uma das rodovias em análise.

Os sítios pedológicos que apresentaram maiores valores de relação de módulo, em termos de média mais desvio-padrão, na situação de chuva ch1du foram os sítios pedológicos Água*, OXy2, PVAd39, GZn2, CXbd1, todos tipicamente de solos nãolateríticos.

Os sítios pedológicos que apresentaram menores valores de relação de módulo, em termos de média mais desvio-padrão, na situação de chuva ch1du, foram os sítios PVAe10, LVdf3, LVd1, LVd9, CXbd3, grande parte, compostos por solos tipicamente lateríticos.

Com relação à análise global das seções de terraplenagem, os valores de relação de módulo apresentaram-se, em geral, tanto em termos de média quanto de desviopadrão, maiores para as seções em corte.

Com relação à análise pela classificação $M C T$, pode-se notar que a amostragem por tipo de solo é pequena para se tirar conclusões generalistas. De qualquer maneira, no estudo, os tipos de solo que apresentaram maiores índices de relação de módulo na situação ch1du foram os solos NG', LG', NS', NS'-NA', solos tipicamente mais finos, mais argilosos ou siltosos. $E$ os que apresentaram menores índices de relação de módulo na condição ch1du foram os tipos NA', LA' e LA, que são mais arenosos.

Conforme pode ser verificado, a variação do módulo do subleito pode ser muito expressiva e isto implica na questão do dimensionamento, que será abordada no capítulo 6. 


\section{ANÁlise dO POTENCIAL DE IMPACTO DA METODOLOGIA PROPOSTA EM RELAÇÃO AOS MÉTOdOS ATUAIS DE DIMENSIONAMENTO}

Com base nos estudos realizados no capítulo 5, verificou-se que os valores de módulo de resiliência do subleito podem apresentar variações expressivas em campo, implicando em um fator de alto risco no caso estruturas dimensionadas a partir de critérios determinísticos.

No presente capítulo serão realizadas algumas recomendações gerais, a título exemplificativo, para adoção de parâmetros estatísticos de módulo de resiliência dos solos de subleito para fins de projeto e dimensionamento de novas estruturas de pavimento, o que não impede absolutamente que outros tipos de abordagens possam ser adotadas, com base nos dados e resultados apresentados no capítulo 5 e nos demais anexos desta tese.

\subsection{Recomendações gerais para fins de adoção de parâmetros de dimensionamento}

Os itens a seguir descrevem as recomendações gerais na adoção dos parâmetros, para cada um dos tipos mais comuns de métodos de dimensionamento utilizados.

a) Caso 1: Adoção de módulo de resiliência do subleito com valor único para o dimensionamento

a1) Para as rodovias estudadas nesta tese 
No caso de adoção de módulo de resiliência do subleito com valor único para o dimensionamento de pavimentos novos em um dos trechos das rodovias em estudo, recomenda-se, por exemplo, a adoção do valor de média menos um fator vezes o desvio padrão, segundo os valores discriminados por rodovia, constantes na Figura 5.7; ou para cada tipo de combinação de parâmetros conhecidos, relatado no ANEXO F - MATRIZES COM ESTATÍSTICAS DOS RESULTADOS INDIVIDUAIS DO ESTUDO DAS RODOVIAS ESTADUAIS.

Esclarece-se que o fator multiplicativo do desvio-padrão diz respeito ao nível de confiabilidade que o projeto exige, ou que o projetista entenda ser razoável para o projeto em questão supondo que a variação dos parâmetros segue uma variação gaussiana dos valores. Sugere-se o fator mínimo de 1,0. A Figura 6.1 a seguir ilustra as probabilidades associadas ao respectivo fator multiplicativo do desvio-padrão para a distribuição normal (gaussiana) de valores.

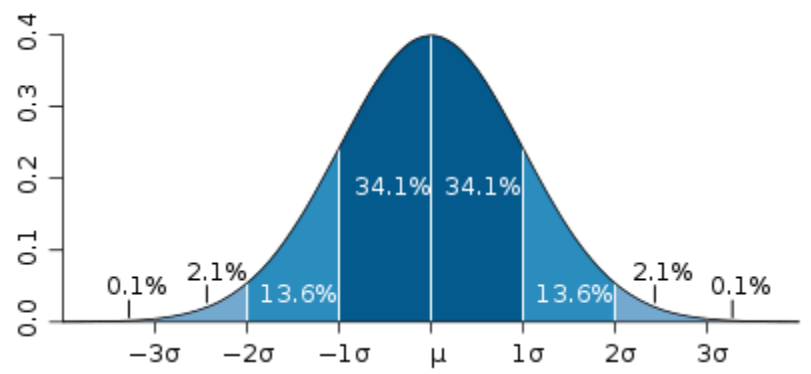

Figura 6.1: Probabilidades associadas à distribuição normal de valores

a2) Para rodovias não contempladas nesta tese

No caso de adoção de módulo de resiliência único para o dimensionamento de pavimentos novos em rodovias que não foram contempladas neste estudo, propõe-se a adoção do valor de média do módulo de resiliência menos um fator vezes o desvio padrão para cada tipo de combinação de parâmetros conhecidos, relatado no ANEXO F - MATRIZES COM ESTATÍSTICAS DOS RESULTADOS INDIVIDUAIS DO ESTUDO DAS RODOVIAS ESTADUAIS.

b) Caso 2: Adoção de metodologia que permita a variação dos parâmetros de módulo de resiliência do subleito 
b1) Para as rodovias estudadas nesta tese

No caso de adoção de metodologia que permita a variação dos parâmetros de módulos de resiliência do subleito, para o dimensionamento de pavimentos novos em uma das rodovias em estudo, recomenda-se a adoção do valor de média mais (ou menos) um fator vezes o desvio-padrão dos valores de módulo, segundo os valores discriminados por rodovia, constantes na Figura 5.7; ou para cada tipo de combinação de parâmetros conhecidos, utilizando-se os valores apresentados no ANEXO F MATRIZES COM ESTATÍSTICAS DOS RESULTADOS INDIVIDUAIS DO ESTUDO DAS RODOVIAS ESTADUAIS.

Ou ainda, caso se prefira trabalhar com a relação de módulo de resiliência mostrado na Figura 5.13 do capítulo 5, recomenda-se a adoção do valor de média mais uma vez um fator vezes o desvio-padrão dos valores de relação de módulo de resiliência, para cada tipo de combinação de parâmetros conhecidos, utilizando-se os valores apresentados no ANEXO G - MATRIZES COM ESTATÍSTICAS DOS RESULTADOS PARA OS SEGMENTOS HOMOGÊNEOS .

Há também a opção de se realizarem ambas as análises e de adotarem-se os valores que se mostrarem mais restritivos, por exemplo.

b2) Para rodovias não contempladas nesta tese

No caso de adoção de metodologia que permita a variação dos parâmetros de módulos de resiliência do subleito, para o dimensionamento de pavimentos novos em rodovias não contempladas nesta tese, recomenda-se a adoção do valor de média mais (ou menos) um fator vezes o desvio-padrão dos valores de módulo, para cada tipo de combinação de parâmetros conhecidos, utilizando-se os valores apresentados no ANEXO F - MATRIZES COM ESTATÍSTICAS DOS RESULTADOS INDIVIDUAIS DO ESTUDO DAS RODOVIAS ESTADUAIS.

Ou ainda, caso se prefira trabalhar com a relação de módulo de resiliência mostrado na Figura 5.13 do capítulo 5, recomenda-se a adoção do valor de média mais uma 
vez um fator vezes o desvio-padrão dos valores de relação de módulo de resiliência, para cada tipo de combinação de parâmetros conhecidos, utilizando-se os valores apresentados no ANEXO G - MATRIZES COM ESTATÍSTICAS DOS RESULTADOS PARA OS SEGMENTOS HOMOGÊNEOS .

Há também a opção de se realizarem ambas as análises e de adotarem-se os valores que se mostrarem mais restritivos, por exemplo.

c) Para determinação de correlação entre parâmetros de laboratório e Módulo de resiliência do solo do subleito ou do reforço do subleito

No caso de rodovias administradas por longo período de tempo, como é o caso das Rodovias concedidas, propõe-se a realização de estudo nos moldes do estudo realizado no capítulo 3 , para obtenção de valores referenciais de módulo de resiliência do subleito a partir de demais parâmetros de laboratório (CBR, expansão, peso específico seco máximo etc.) para fins de controle no campo. Para fins de projeto, deve-se realizar os ensaios de módulo de resiliência em diferentes condições de estado de compactação e de umidade de modo a melhor compreender as variações possíveis.

d) Para determinação de valores referenciais de módulo de resiliência e/ou a variação deste parâmetro

No caso de rodovias administradas por longo período de tempo, como é o caso das Rodovias concedidas, propõe-se a realização de estudo nos moldes do estudo realizado no capítulo 5, para acumulação de dados, determinação de valores referenciais de módulo de resiliência e da variação deste no campo. 


\subsection{Exemplo de aplicação de metodologia que contempla as variações do módulo de resiliência dos solos do subleito}

A fim de ilustrar o potencial de impacto da metodologia proposta nos métodos atuais de dimensionamento, serão apresentadas neste capítulo, algumas análises envolvendo projetos de dimensionamento de pavimento das rodovias estudadas.

Para fins deste estudo, foram utilizadas algumas ferramentas de análise de risco propostas por Ferri (2013), conforme será detalhado nos estudos.

\subsubsection{Rodovia SP 099 - Rodovia dos Tamoios}

Neste caso, será estudado o pavimento novo proposto para a duplicação do trecho de planalto da Rodovia dos Tamoios. Tais obras de implantação foram realizadas pela Governo do Estado, por meio da empresa DERSA - Desenvolvimento Rodoviário S/A, e entregues para administração da iniciativa privada (Concessionária TAMOIOS), no ano de 2015.

A estrutura de pavimento flexível proposto no projeto para a pista principal foi dimensionada pelo método do $D E R / S P$, segundo a instrução de projeto IP-DEP00/001 (DER/SP). O método adotado pelo $D E R / S P$ é determinístico, ou seja, não leva em consideração as possíveis variações dos parâmetros envolvidos no dimensionamento do pavimento.

Assim sendo, as premissas adotadas no projeto foram as seguintes:

- $\quad$ Módulo de resiliência do subleito = $50 \mathrm{MPa}$;

- Número N pela metodologia USACE = 3,2 x 107 (10 anos) repetições de carga equivalentes ao eixo padrão de 80 kN para o período de projeto de 10 anos;

- Número N pela metodologia $A A S H T O=1 \times 10^{7}$ (10 anos) repetições de carga equivalentes ao eixo padrão de $80 \mathrm{kN}$ para o período de projeto de 10 anos. 
A estrutura resultante, segundo o projeto, é aquela apresentada na Figura 6.2.

\begin{tabular}{cl}
\hline \multicolumn{2}{c}{ ESTRUTURA DE PROJETO } \\
\hline $\begin{array}{c}\text { Espessura } \\
(\mathbf{c m})\end{array}$ & \multicolumn{1}{c}{ Materiais } \\
\hline 5,0 & CA POLIMERO \\
\hline 10,0 & CA (BINDER) \\
\hline 15,0 & BGS \\
\hline 30,0 & RACHÃO \\
\hline 40,0 & REFORÇO DO SUBLEITO \\
\hline & \\
\hline
\end{tabular}

Figura 6.2: Estrutura do Pavimento prevista em projeto - Duplicação Tamoios Planalto (SP 099)

Como característica, os métodos determinísticos, por trabalharem com valores únicos, supostamente os valores médios de módulo de resiliência, advindos por correlação do valor de projeto de $C B R$, e espessuras das camadas, tendem ao dimensionamento de estruturas com confiabilidade de $50 \%$, segundo o método da AASHTO 1993, com $R=50 \%$.

Ferri (2013) propõe o uso de uma ferramenta de cálculo para estimar a confiabilidade da estrutura, frente às variações de módulo de resiliência e espessuras que eventualmente podem ocorrer no campo, seja no âmbito construtivo, seja no âmbito da própria natureza dos materiais, como no caso dos materiais do subleito, sujeitos à variação dos valores de módulo especialmente por conta da variação dos níveis de umidade do solo, por conta das chuvas.

Trata-se de uma planilha eletrônica automatizada que simula, através do método de simulação de Monte Carlo, a variação de tais parâmetros (espessuras e módulos), dentro de um intervalo de valores pré-definido pelo usuário para cada material da estrutura. A planilha determina então, para cada uma dessas combinações, o valor 
dos esforços solicitantes na estrutura (deflexão e deformação de tração no revestimento) e, a partir, disso, os valores de número $\mathrm{N}$ admissíveis para cada situação, através dos modelos usuais estabelecidos pela instrução de projeto do $D E R / S P$.

A ferramenta desenvolvida pelo autor considera uma estrutura de três camadas, onde as camadas de reforço do subleito e subleito podem ser substituídas por uma camada de infraestrutura equivalente cuja deflexão em sua superfície seja a mesma calculada para o controle deflectométrico no conjunto subleito/reforço do subleito. Para fins deste estudo, consideraram-se as características do subleito como sendo a média e o desvio-padrão de valores obtidos no estudo da Rodovia SP 099 (Figura 5.7, pág. 249), sendo o valor médio do módulo de 83 MPa e desvio-padrão de 48 MPa. Como se pode verificar, muito embora o valor médio do módulo de resiliência seja superior àquele adotado no projeto, a variação deste parâmetro no campo poderá ocasionar um grande potencial de falha na estrutura como será demonstrado.

Ainda para fins desta análise, como as camadas de base e sub-base granulares (BGS e Rachão) possuem módulos idênticos, de acordo com o projeto apresentado ao órgão rodoviário, também se considerou que esta combinação fosse equivalente a uma única camada de $45,0 \mathrm{~cm}$ de espessura. Com todo o respeito ao projeto, os valores de módulo dos materiais foram ajustados para fins desta análise, de acordo com a experiência do autor, sempre respeitando os limites recomendados pela norma vigente (IP-DE-P00/001 do DER/SP).

A analogia estrutural adotada para fins das análises com a ferramenta desenvolvida para fins deste estudo está representada na Figura 6.3. 


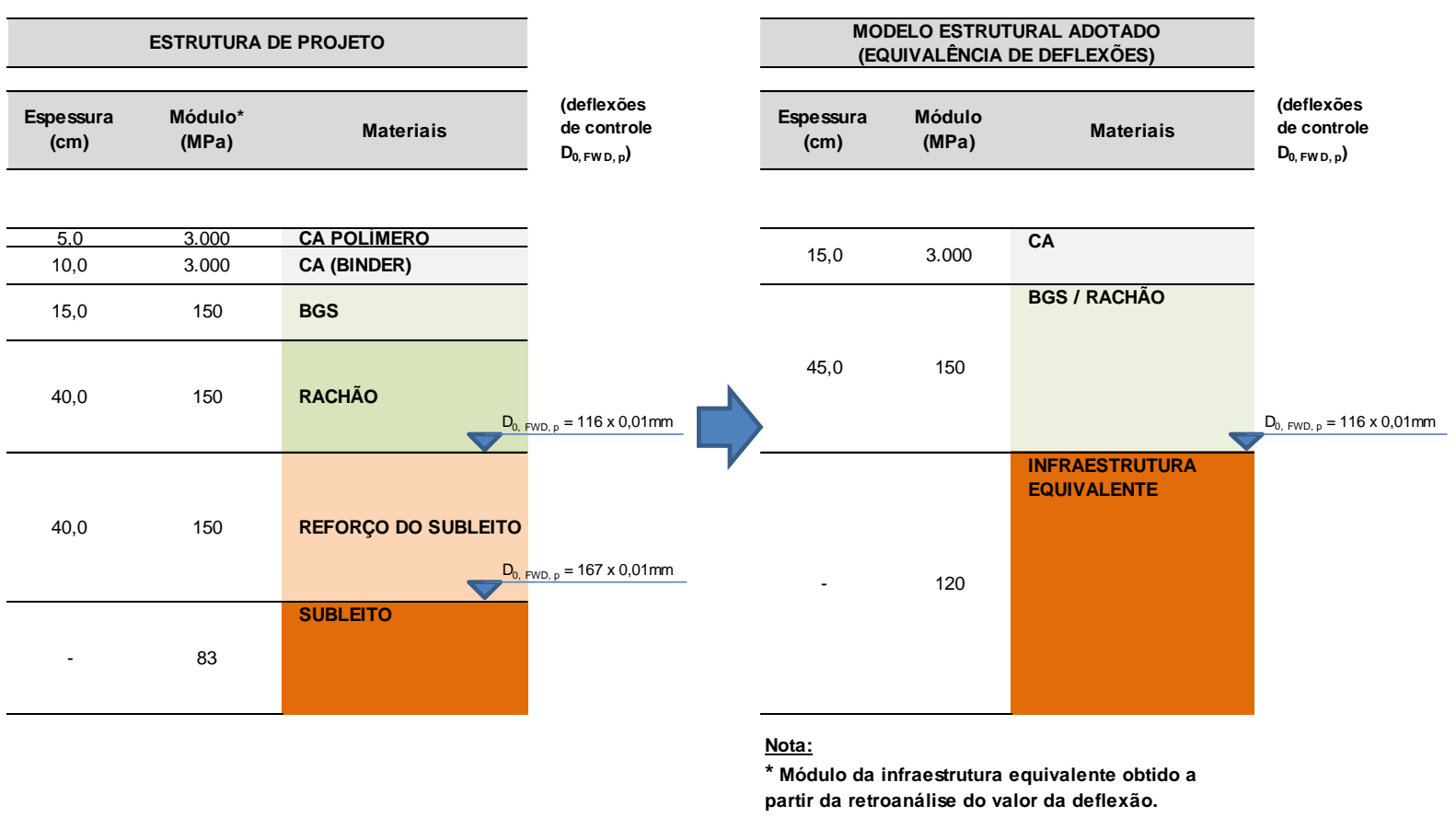

Figura 6.3: Analogia estrutural adotada para fins das análises através da ferramenta desenvolvida por Ferri (2013)

Os resultados das análises são apresentados na Figura 6.4 à Figura 6.6.

Como se pode notar, para fins deste estudo, foi adotada uma variação máxima de $1 \%$ para as espessuras das camadas, na tentativa de praticamente desconsiderar este efeito no estudo estatístico (a ferramenta não permite variação zero nas espessuras). De todo modo, convém lembrar que a norma do $D E R / S P$ permite uma variação na execução das camadas da ordem de $10 \%$.

A variação máxima do módulo da camada de infraestrutura equivalente foi adotada como sendo a variação equivalente à média mais um fator vezes o valor do desviopadrão do módulo de resiliência do subleito obtido no estudo da Rodovia SP 099 (Figura 5.7, pág. 249, sendo a média igual a $83 \mathrm{MPa}$ e o desvio-padrão igual a $48 \mathrm{MPa}$ ), composto com o módulo de resiliência fixo do módulo do reforço do subleito de $150 \mathrm{MPa}$, resultando no valor equivalente de $120 \mathrm{MPa}$. Neste caso, o fator multiplicativo do desvio-padrão variou entre 0,$5 ; 1,0$ e 1,5, e os respectivos valores resultantes de variação do valor de módulo equivalente foram $14 \%$, 32\% e $33 \%$, respectivamente.

Já a variação máxima do módulo das demais camadas foi adotada com um valor mínimo de $1 \%$, para que essa influência fosse, de certo modo, minimizada ou 
desconsiderada, já que a ferramenta não permite variação zero nos valores de módulo.

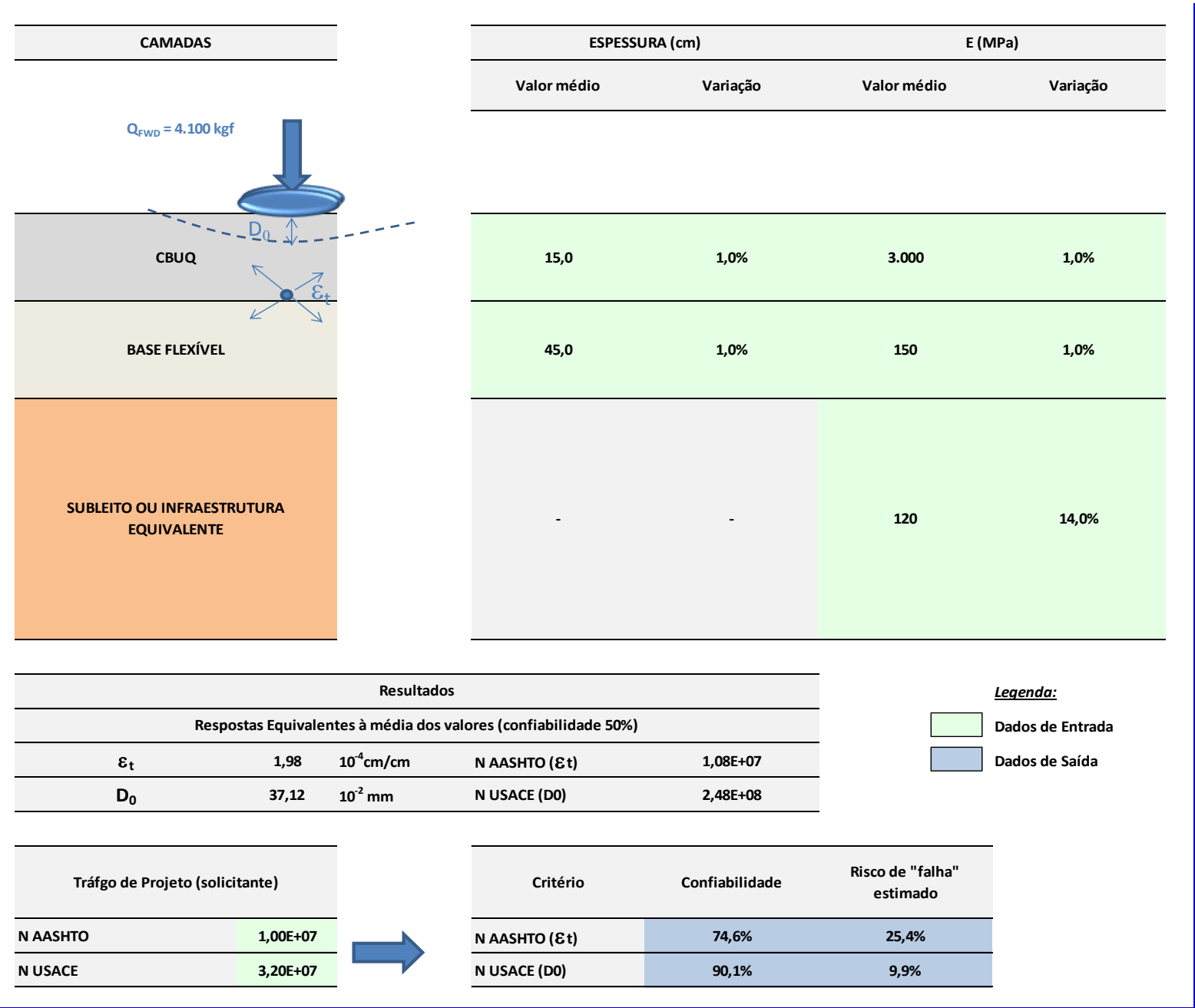

Figura 6.4: Tela de entrada e saída dos dados para as análises através da ferramenta desenvolvida por Ferri (2013) - variação de 0,5 vezes o desvio-padrão (14\%) 


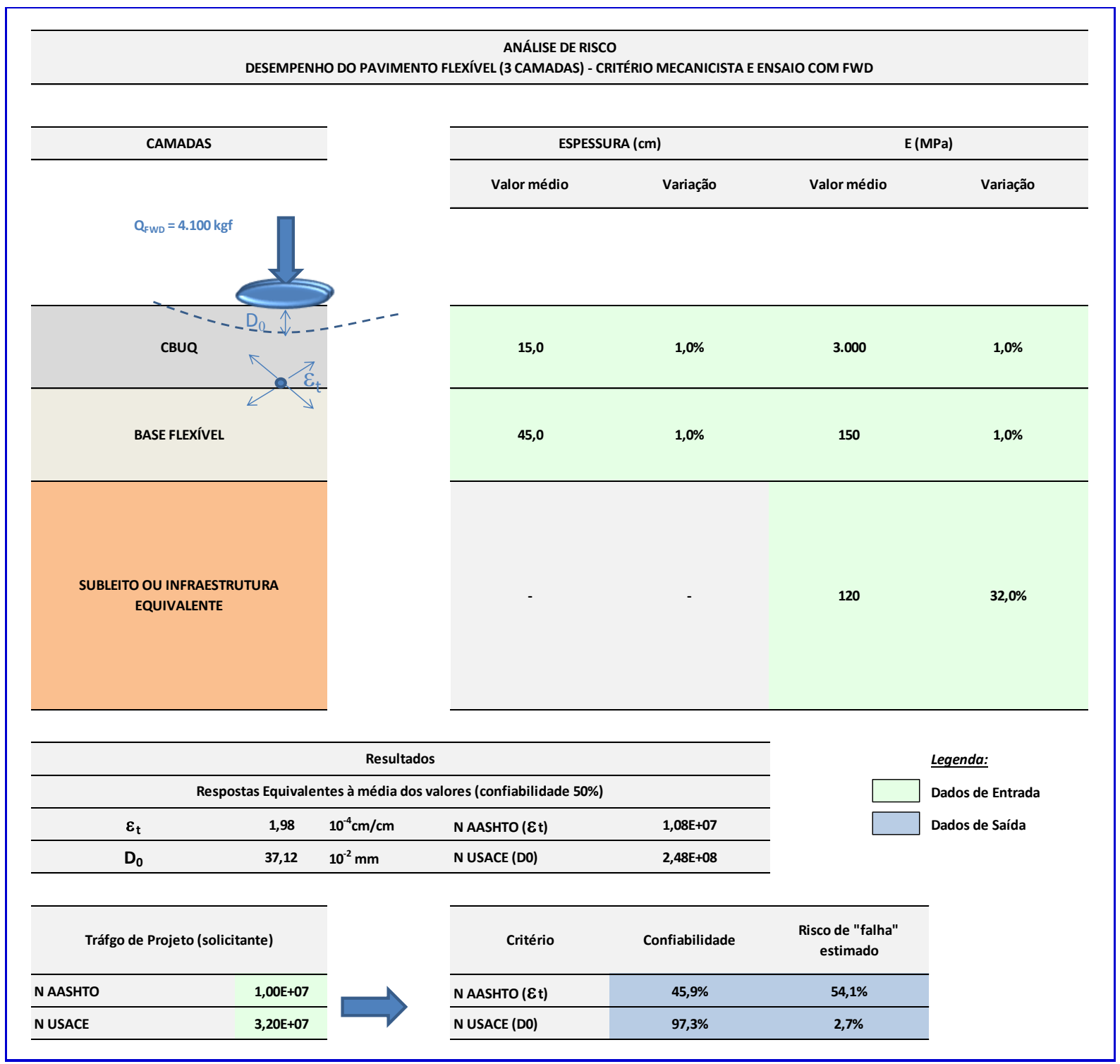

Figura 6.5: Tela de entrada e saída dos dados para as análises através da ferramenta desenvolvida por Ferri (2013) - variação de 1 vez o desvio-padrão (32\%) 


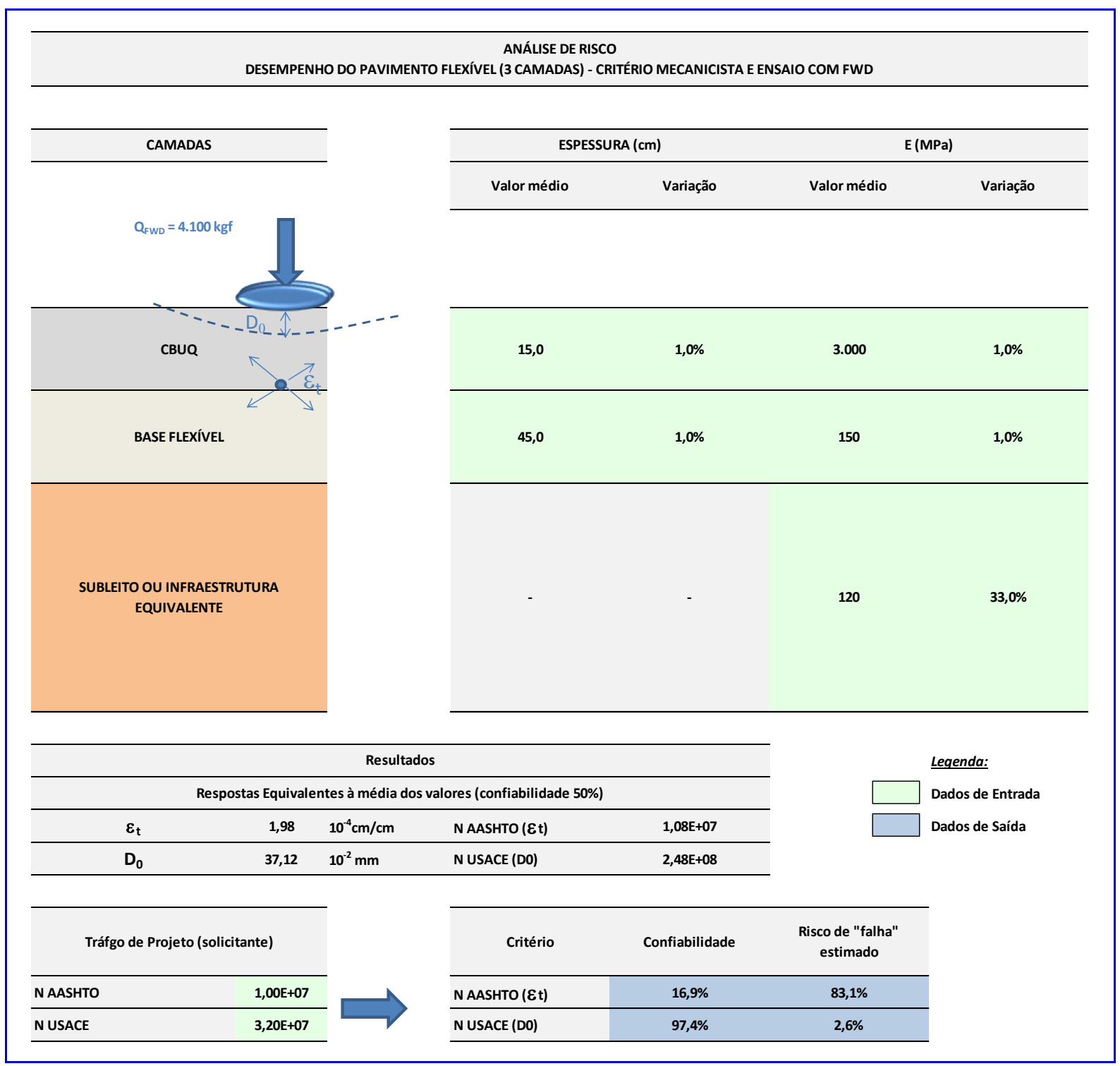

Figura 6.6: Tela de entrada e saída dos dados para as análises através da ferramenta desenvolvida por Ferri (2013) - variação de 1,5 vezes o desvio-padrão (33\%)

A Figura 6.7 apresenta o resultado do valor do nível de confiabilidade da estrutura em função do fator multiplicativo do desvio-padrão dos valores de módulo de resiliência do subleito, de acordo com a metodologia apresentada, e com uso dos valores de média e desvio-padrão de módulo de resiliência do subleito da rodovia SP 099 extraídos dos estudos realizados no capítulo 5 desta tese. 


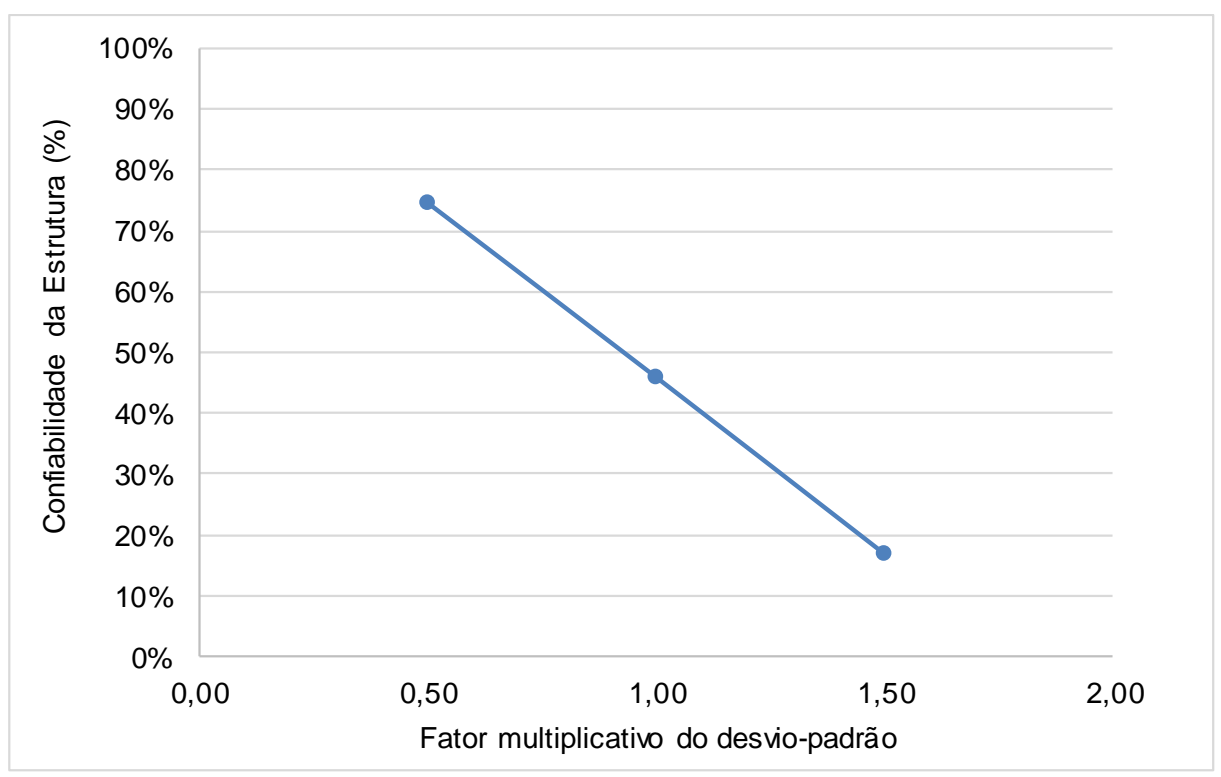

Figura 6.7: Nível de confiabilidade da estrutura em função do fator multiplicativo do desvio-padrão dos valores de módulo do subleito, de acordo com a metodologia proposta por Ferri (2013).

Em análise aos gráficos apresentados, verifica-se que o nível de confiabilidade da estrutura variou entre cerca de $75 \%$ e $17 \%$, variando-se o coeficiente multiplicativo do desvio-padrão entre 0,5 e 1,5. Como se percebe, a variação do comportamento mecânico do subleito pode ter efeitos determinantes para o desempenho da estrutura. Tal efeito de decréscimo do nível de confiabilidade da estrutura poderia ter sido ainda mais pronunciado caso fossem combinados os efeitos de variação das espessuras construtivas no campo - as normas vigentes permitem até $10 \%$ de variação, sem contar também as possíveis variações nos valores de módulo dos demais materiais (módulo de resiliência dos materiais granulares também sofrem variações especialmente em função da umidade, e dos materiais asfálticos especialmente em função da temperatura). 


\subsubsection{Rodovia SP 318}

Neste estudo de caso, será estudada a estrutura do pavimento novo proposta para a duplicação do trecho da rodovia SP 318 do km 237,700 ao km 243,000. Tais obras de implantação foram realizadas pela Concessionária de rodovias responsável pelo respectivo lote de Concessão entre os anos de 2015 e 2016.

A estrutura de pavimento flexível proposto no projeto para a pista principal foi dimensionada pelo método do $D E R / S P$, segundo a instrução de projeto IP-DEP00/001 (DER/SP). O método adotado pelo DER/SP é determinístico, ou seja, não leva em consideração as possíveis variações dos parâmetros envolvidos no dimensionamento do pavimento.

Assim sendo, as premissas adotadas no projeto foram as seguintes:

- $\quad$ Módulo de resiliência do subleito = $93 \mathrm{MPa}$;

- Número $\mathrm{N}$ pela metodologia USACE $=1,76 \times 10^{7}$ (10 anos) repetições de carga equivalentes ao eixo padrão de $80 \mathrm{kN}$ para o período de projeto de 10 anos;

- Número N pela metodologia $A A S H T O=6,79 \times 10^{6}$ (10 anos) repetições de carga equivalentes ao eixo padrão de $80 \mathrm{kN}$ para o período de projeto de 10 anos;

A estrutura resultante, segundo o projeto, é aquela apresentada na Figura 6.8. 


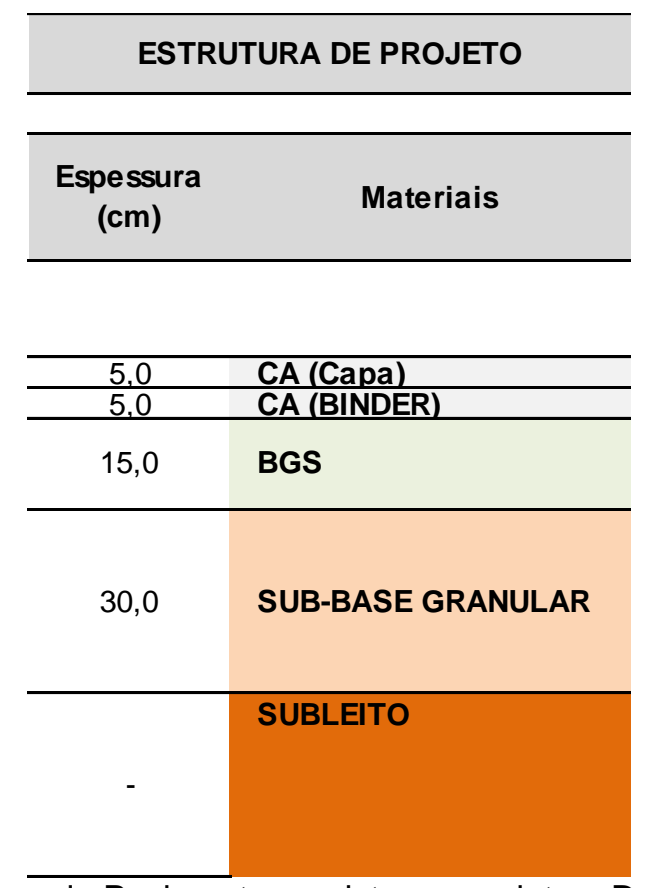

Figura 6.8: Estrutura do Pavimento prevista em projeto - Duplicação (SP 318)

Para fins deste estudo, consideraram-se as características do subleito como sendo a média e o desvio-padrão de valores obtido no estudo da Rodovia SP 318 (Figura 5.7, pág. 249), sendo valor médio do módulo de resiliência de $83 \mathrm{MPa}$ e desvio-padrão do valor de módulo de $26 \mathrm{MPa}$.

Ainda para fins desta análise, como as camadas de base e sub-base granulares possuem módulos parecidos, de acordo com o projeto o apresentado, também se considerou que esta combinação fosse equivalente a uma única camada de $45,0 \mathrm{~cm}$ de espessura. O módulo da camada de base mais sub-base foi fixado em $305 \mathrm{MPa}$.

A analogia estrutural adotada para fins das análises com a ferramenta desenvolvida pelo autor está representada na Figura 6.9. 

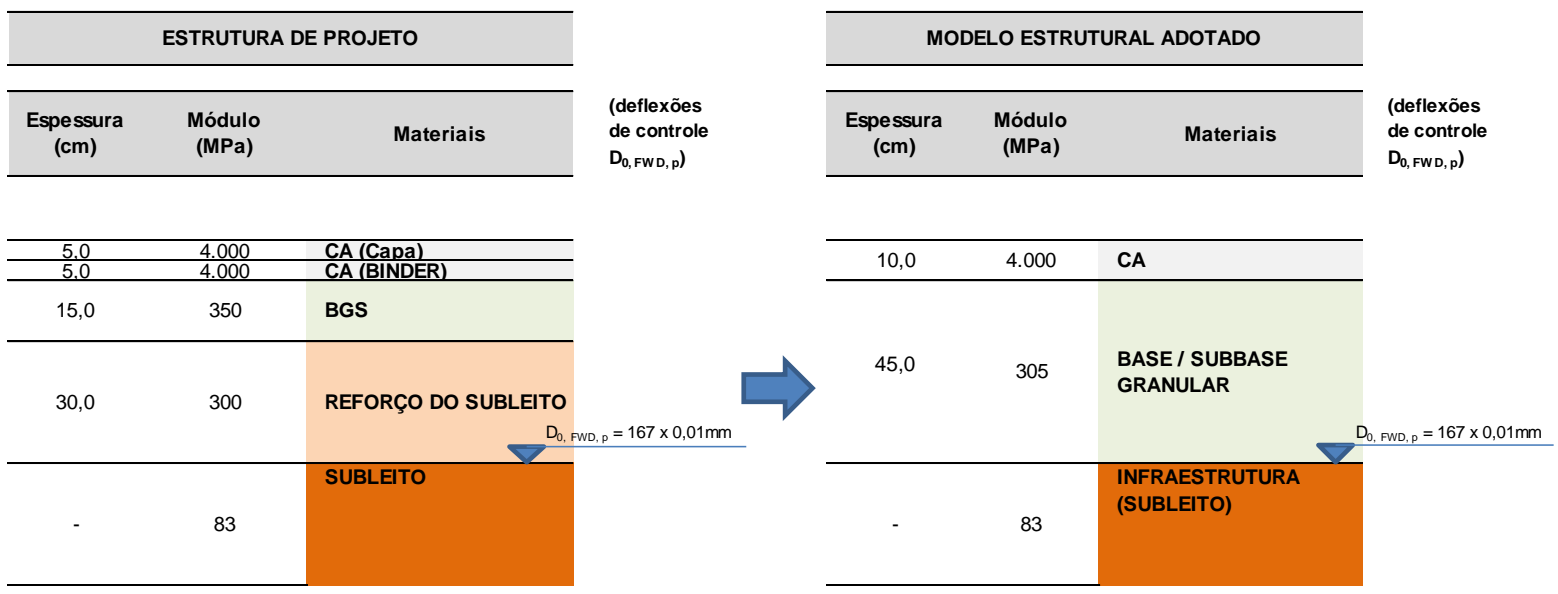

Nota:

${ }^{*}$ Módulo da infraestrutura equivalente obtido a

partir da retroanálise do valor da deflexão.

Figura 6.9: Analogia estrutural adotada para fins das análises através da ferramenta desenvolvida por Ferri (2013)

Os resultados das análises são apresentados na Figura 6.10 à Figura 6.12.

Como se pode notar, para fins deste estudo, foi adotada uma variação máxima de $1 \%$ para as espessuras das camadas, na tentativa de praticamente desconsiderar este efeito no estudo estatístico (a ferramenta não permite variação zero nas espessuras). De todo modo, convém lembrar que a norma do $D E R / S P$ permite uma variação na execução das camadas da ordem de $10 \%$.

A variação máxima do módulo da camada de infraestrutura equivalente foi adotada como sendo a variação equivalente à média mais um fator vezes o valor do desviopadrão do módulo de resiliência do subleito obtido no estudo da Rodovia SP 099 (Figura 5.7, pág. 249, sendo a média igual a 83 MPa e o desvio-padrão igual a $26 \mathrm{MPa}$ ). Neste caso, o fator multiplicativo do desvio-padrão variou entre 0,$5 ; 1,0$ e 1,5 , e os respectivos valores resultantes de variação do valor de módulo equivalente foram $15 \%$, $31 \%$ e $47 \%$, respectivamente.

Já a variação máxima do módulo das demais camadas foi adotada com um valor mínimo de $1 \%$, para que essa influência fosse, de certo modo, minimizada ou desconsiderada, já que a ferramenta não permite variação zero nos valores de módulo. 


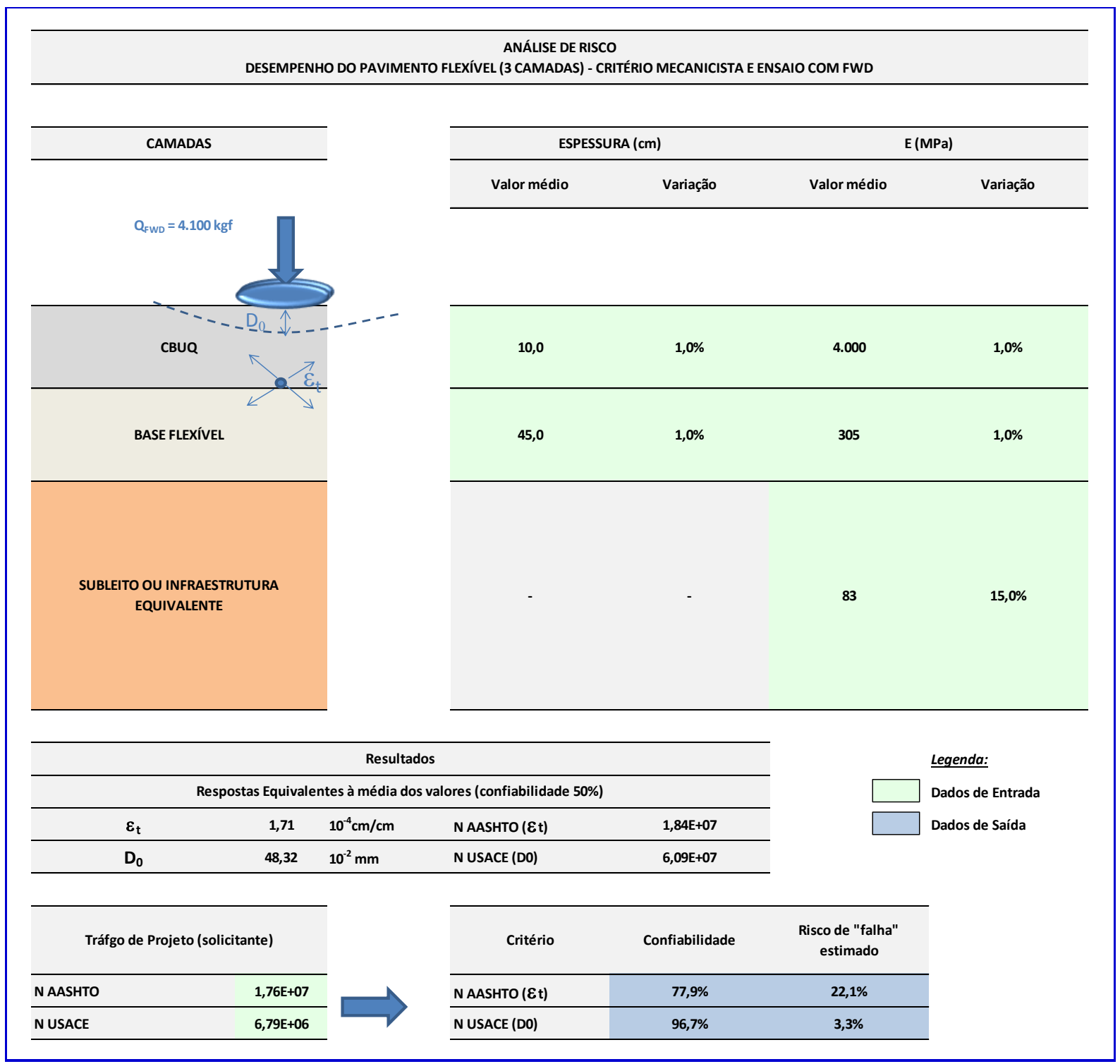

Figura 6.10: Tela de entrada e saída dos dados para as análises através da ferramenta desenvolvida por Ferri (2013) - variação de 0,5 vezes o desvio-padrão (15\%) 


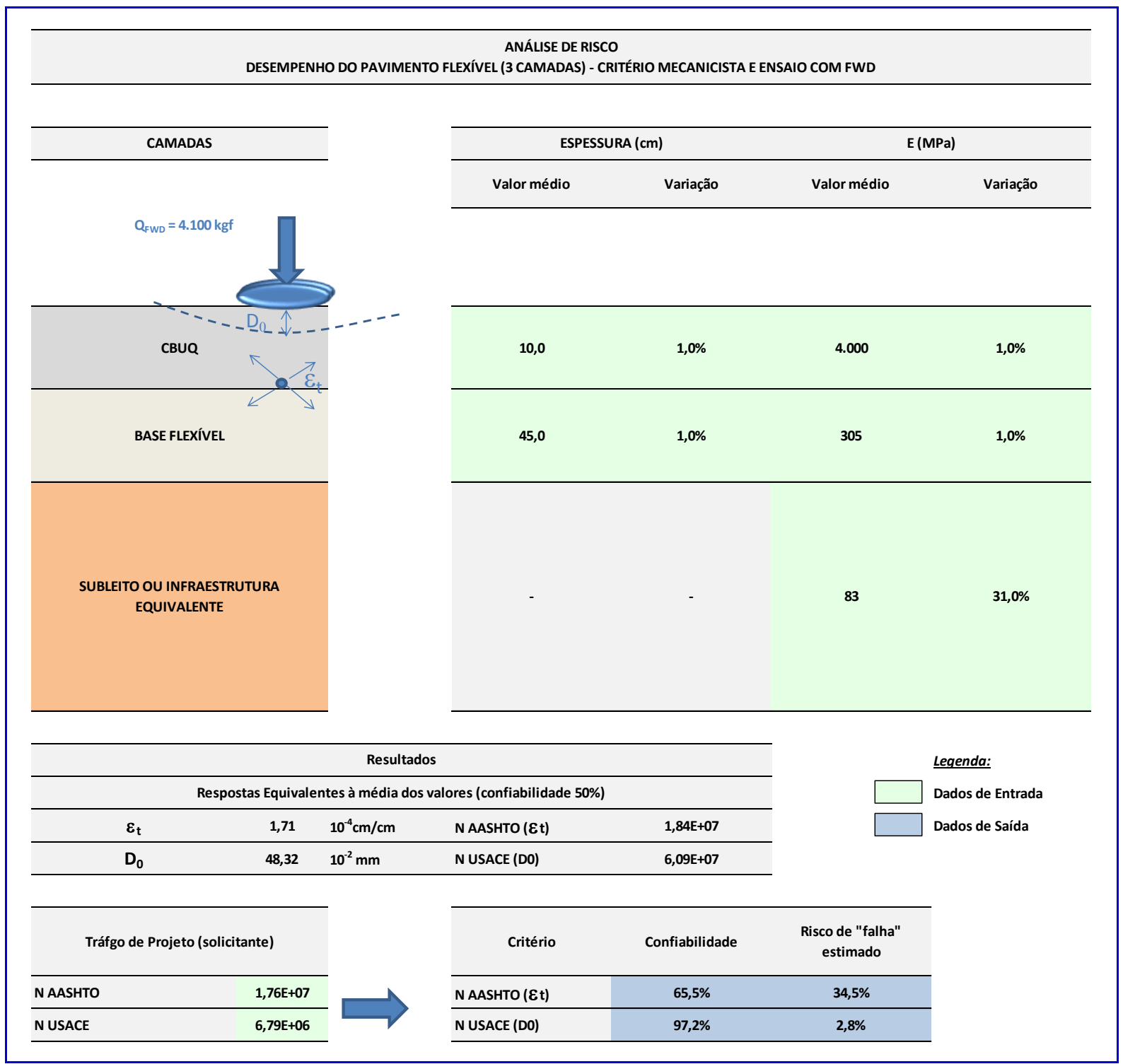

Figura 6.11: Tela de entrada e saída dos dados para as análises através da ferramenta desenvolvida por Ferri (2013) - variação de 1 vez o desvio-padrão (31\%) 


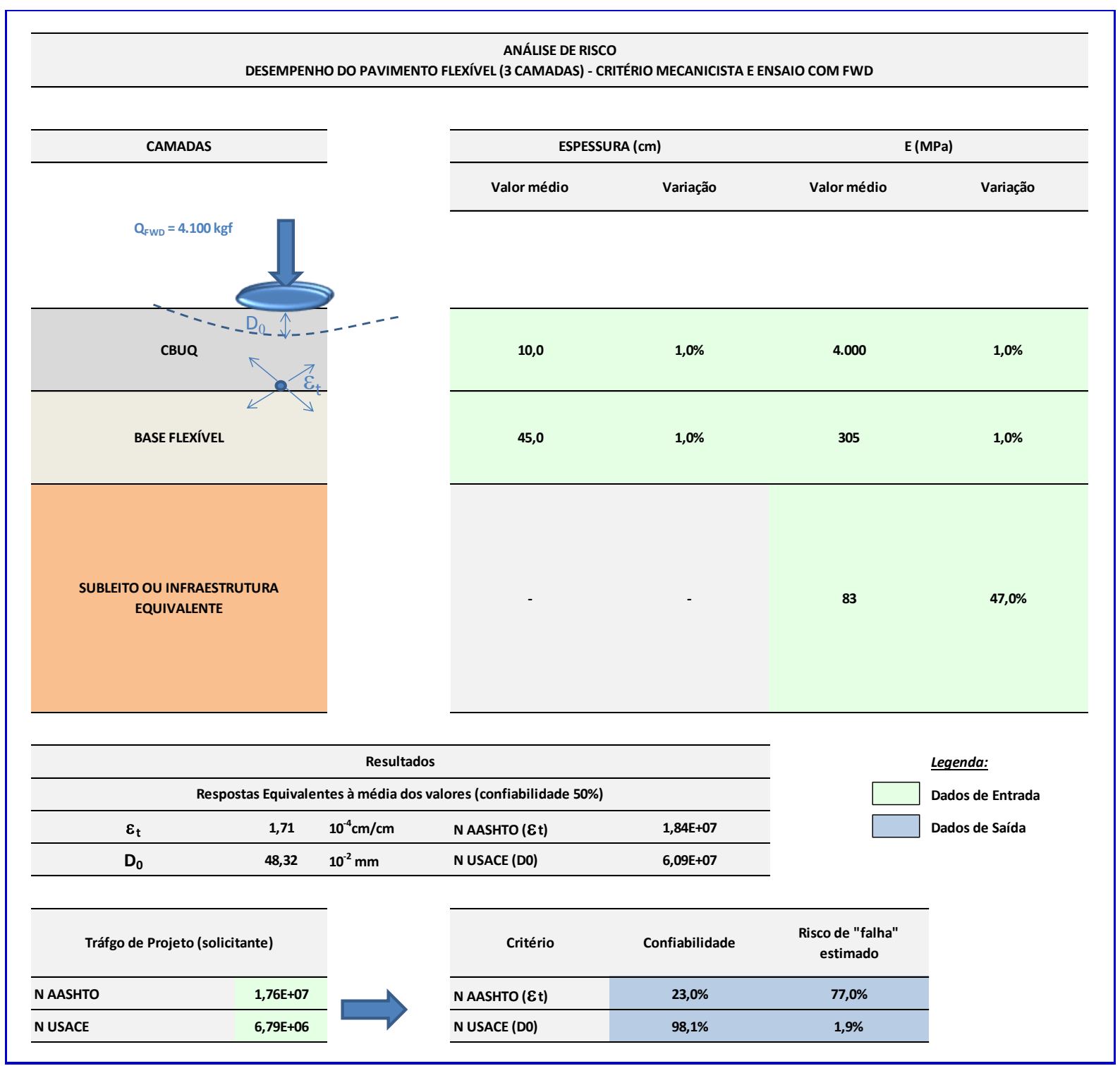

Figura 6.12: Tela de entrada e saída dos dados para as análises através da ferramenta desenvolvida por Ferri (2013) - variação de 1,5 vezes o desvio-padrão (47\%)

A Figura 6.13 apresenta o resultado do valor do nível de confiabilidade da estrutura em função do fator multiplicativo do desvio-padrão dos valores de módulo de resiliência do subleito, de acordo com a metodologia apresentada, e com uso dos valores de média e desvio-padrão de módulo de resiliência do subleito da rodovia SP 318 extraídos dos estudos realizados no capítulo 5 desta tese. 


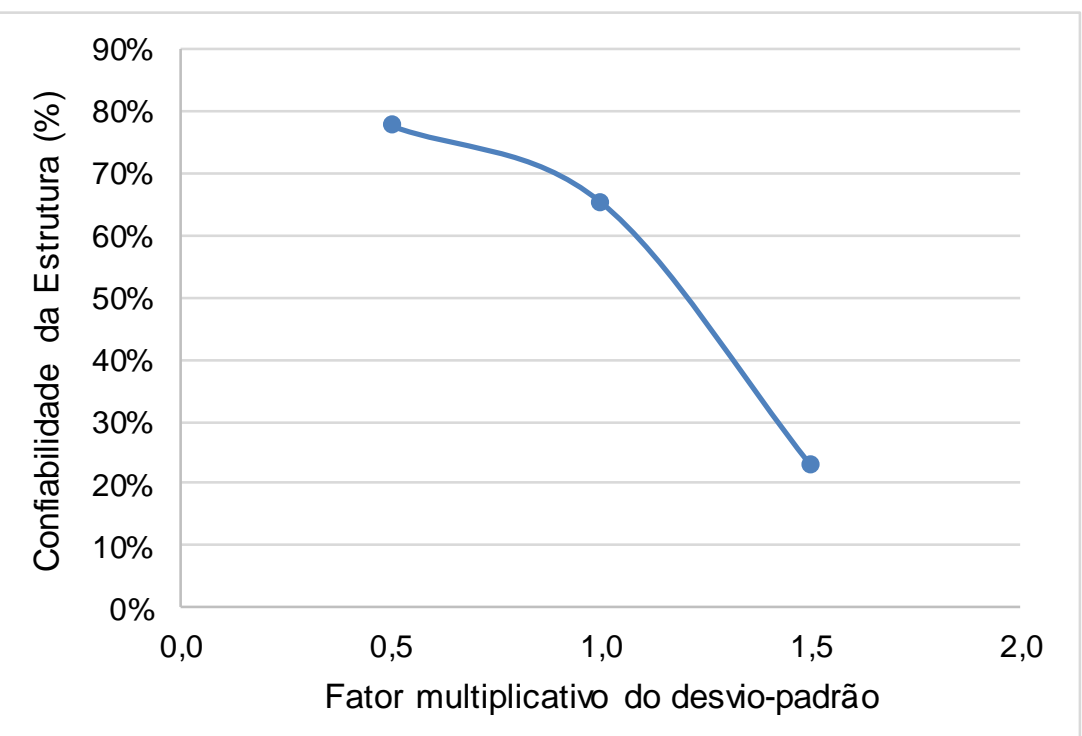

Figura 6.13: Nível de confiabilidade da estrutura em função do fator multiplicativo do desvio-padrão dos valores de módulo do subleito, de acordo com a metodologia proposta por Ferri (2013)

Em análise aos gráficos apresentados, verifica-se que o nível de confiabilidade da estrutura variou entre $78 \%$ e $23 \%$, variando-se o coeficiente multiplicativo do desviopadrão entre 0,5 e 1,5. Como se percebe, a variação do comportamento mecânico do subleito pode ter efeitos determinantes para o desempenho da estrutura. Tal efeito de decréscimo do nível de confiabilidade da estrutura poderia ter sido ainda mais pronunciado caso fossem combinados os efeitos de variação das espessuras construtivas no campo, uma vez que as normas vigentes permitem até $10 \%$ de variação, sem contar também as possíveis variações nos valores de módulo dos demais materiais - módulo de resiliência dos materiais granulares também sofrem variações em serviço especialmente em função da umidade, e o módulo de resiliência dos materiais asfálticos sofrem variações em serviço especialmente em função da temperatura. 


\section{CONCLUSÕES E RECOMENDAÇÕES}

Com base na pesquisa desta tese, algumas conclusões e considerações puderam ser realizadas.

Com base na pesquisa bibliográfica, conclui-se que a grande maioria dos modelos, até então presentes na literatura, foram desenvolvidos levando-se em conta principalmente dois aspectos:

(i) a determinação do módulo de resiliência para condições de umidade ótima de compactação a partir de parâmetros obtidos em ensaios de laboratório (granulometria, peso específico aparente seco, CBR entre outros) e;

(ii) a variação dos valores de módulo de resiliência dos materiais que pode ocorrer em campo, especialmente por conta do efeito de mudanças no grau de saturação dos solos de subleito; deve-se ressaltar que se verificou que há pouquíssimos modelos que levam em conta a natureza dos solos tropicais, sejam lateríticos ou saprolíticos.

Verificou-se também que dentre as referências bibliográficas encontradas, poucos estudos verificaram ou ao menos registraram para os leitores, a quantificação e definição dos principais agentes causadores das variações de comportamento mecânico que de fato ocorrem no campo.

Com base nos dados coletados e nas análises realizadas no estudo de caso para a rodovia federal, puderam-se tecer algumas conclusões, entre elas:

- Verificou-se bastante razoabilidade na aplicação do coeficiente $c=0,33$, proposto pela $A A S H T O / 93$, na determinação de valores de módulos do subleito retroanalisados a partir dos ensaios deflectométricos feitos com $F W D$, com base nos estudos comparativos entre as diversas metodologias de avaliação da estrutura. A não utilização desta correção pode levar a um cenário bastante desfavorável, pois sobrestima, quando das avaliações da capacidade estrutural do pavimento e dimensionamento de soluções de restauração;

- Não é recomendável a utilização de relações diretas do módulo de resiliência a partir de valores de resistência obtidos no $C B R(M R$ em função do $C B R$ ) nos casos de 
materiais granulares com $C B R$ superior a $12 \%$. Nestes casos, é recomendável a determinação do módulo de resiliência em laboratório dos solos e materiais de subleito, bem como o estudo da influência para diferentes condições de compactação (energia) e de umidade, para compreender as possíveis variações que podem ocorrer em campo. Mesmo nos casos quando o CBRé inferior a 12\%, a relação pode não ser adequada. Também não foi verificada uma correlação direta adequada nos demais casos estudados (solos finos e granulares, independentemente do valor de $C B R$ );

- Deve ser aumentado o universo amostral para cada tipo de solo em análise para o entendimento correto do comportamento dos materiais em campo;

- Foram obtidos modelos de correlação entre parâmetros de ensaios de caracterização e mecânicos, para obtenção dos coeficientes k1, k2, k3 e k4 para predição dos valores de módulo de resiliência de solos de laboratório (em função da tensão de confinamento ou da tensão-desvio, caso a caso) para os solos desta rodovia federal estudada;

- Embora tenha se chegado a coeficientes de determinação $\left(R^{2}\right)$ razoáveis, concluiuse que a modelagem / metodologia proposta para obtenção dos valores de módulo de resiliência através de parâmetros de ensaios dos solos possa ser aplicada regionalmente, desde que reservada uma amostragem representativa para o local em questão, porém deve-se ter cuidado ao se aplicar para outros tipos de solos, de outras regiões e/ou de outra natureza;

- Para a correta interpretação dos parâmetros mecânicos do solo, infere-se que seja necessário pelo menos empregar duas energias de compactação diferentes para os ensaios de compactação, $C B R$, expansão e módulo de resiliência. No caso do ensaio de módulo de resiliência também se verifica que é de extrema importância a realização de ensaios após condicionamento (umidade induzida) nos corpos de prova póscompactação para compreensão da variabilidade decorrente de frentes de umidade, secagem, etc.;

Ao longo dos estudos, ampliando-se a pesquisa e repetindo-se as amostragens em campo, percebeu-se cada vez mais que é bastante difícil obter correlações válidas entre os parâmetros do solo e o módulo de resiliência do subleito. Além disso, também se nota que o comportamento do módulo de resiliência em campo (valores 
retroanalisados obtidos pelas deflexões com $F W D$ ) podem ter tendências diferentes para um mesmo tipo de solo, o que leva a crer que o comportamento mecânico aferido "in situ” por retroanálise, venha a ter forte influência de outras características físicas do local em que foi implantado, além simplesmente dos parâmetros / características dos solos do subleito. Infere-se que algumas características físicas do local possam ser bastante relevantes tais como: características geológicas e pedológicas locais, regime de chuvas e as características e potencial de drenagem do pavimento e dos tipos de solos; o tipo de seção (corte, aterro ou mista) entre outros.

Com base no estudo de campo das rodovias estaduais, puderam-se tecer as seguintes conclusões:

- as variações que ocorrem no campo, para os valores de módulo de resiliência do subleito são importantes e não podem ser desprezadas quando da adoção de parâmetros para o dimensionamento;

- dadas as variações que ocorrem para um mesmo conjunto de características em estudo (sítio geológico, sítio pedológico, seção de terraplenagem, pluviometria, classificação do solo etc.), para os dados acumulados até o presente momento, não se conseguiram modelos de correlação adequados, motivo pelo qual se adotou a opção de se trabalhar com parâmetros estatísticos conservadores, por exemplo, para adoção de valor único para o módulo do subleito, considerar média menos um fator estatístico vezes o desvio-padrão;

- nem sempre os sítios pedológicos lateríticos foram aqueles que apresentaram os valores de módulo de resiliência do subleito retroanalisados, porém em grande parte destes sítios, se confirmou a tendência de que tais solos são menos suscetíveis à ação da umidade, no caso representada pela precipitação volumétrica acumulada, em relação aos sítios com predominância de solos saprolíticos, muito embora não tenha sido possível estabelecer correlações confiáveis entre os parâmetros (precipitação volumétrica e módulo de resiliência do subleito, por exemplo);

- a maior relação de módulo de resiliência (maior diferença entre dois valores de módulo de resiliência comparados), em termos de média e desvio-padrão, normalmente se deu na situação de chuva ch1dsu (comparação entre condições seca e úmida, com relação à precipitação acumulada de 1 dia); 
- os sítios pedológicos que apresentaram maiores valores de relação de módulo de resiliência (maior diferença entre dois valores de módulo de resiliência comparados), em termos de média mais desvio-padrão, na situação de chuva ch1du foram os sítios pedológicos Água*, OXy2, PVAd39, GZn2, CXbd1, todos tipicamente de solos nãolateríticos.

- os sítios pedológicos que apresentaram menores valores de relação de módulo de resiliência (maior diferença entre dois valores de módulo de resiliência comparados), em termos de média mais desvio-padrão, na situação de chuva ch1du, foram os sítios PVAe10, LVdf3, LVd1, LVd9, CXbd3, grande parte, compostos por solos tipicamente lateríticos.

- Percebeu-se, no banco de dados de ensaios de solos (BD1), grande número de ocorrência de inconsistências entre a classificação MCT dos materiais, normalmente realizada pelo método expedito (pastilha), e os demais parâmetros do solo ( $C B R$, expansão, granulometria, etc.). Assim, recomenda-se que sejam realizados mais de um ensaio de classificação MCT para cada amostra, de preferência por ambas as metodologias (completa e expedita);

Como conclusões gerais do trabalho, podem ser elencadas as seguintes:

- o nível de informações que normalmente se obtêm na etapa de projeto é praticamente irrelevante para a correta caracterização e entendimento do comportamento mecânico do subleito e, por conseguinte, dos pavimentos, seja pela incompletude de informações, seja pela pouca ou nenhuma exploração da variação de parâmetros (umidade, energia de compactação, eficiência da drenagem etc.), seja pela não consideração de inúmeros outros fatores que afetariam tal comportamento;

- recomendam-se, no mínimo, os seguintes ensaios de laboratório para cada coleta de amostras de subleito: peso específico seco em campo e umidade natural (em campo); granulometria (com sedimentação); limites de liquidez e plasticidade; peso específico aparente seco; curvas de compactação, CBR e expansão com 5 pontos e em pelo menos duas energias de compactação diferentes (energia normal e energia modificada, por exemplo); peso específico real dos grãos; classificação $H R B$; classificação MCT (pelo menos dois ensaios para uma mesma amostra - ensaio muito suscetível a erros de classificação); módulo de resiliência de laboratório no 
equipamento triaxial em pelo menos duas energias de compactação, e com pelo menos duas condições de umidade de pós-compactação diferentes (umidade ótima e $3 \%$ acima da ótima por exemplo, dependendo da granulometria); ensaio de cisalhamento no triaxial para determinação de coesão e ângulo de atrito dos solos e materiais granulares;

- verificou-se que grande parte dos modelos de correlações existentes na literatura entre parâmetros de propriedades físicas e de resistência (como $C B R$ ) de solos com o módulo de resiliência possui aplicação muito restrita, inviabilizando sua aplicação de forma indiscriminada em locais distintos daqueles onde foram obtidas as correlações;

- verificou-se que o módulo de resiliência do subleito em campo apresenta variações de grande magnitude e, portanto, é de difícil previsão, requerendo acumulação de dados históricos, bem como de um cadastro adicional de maior gama de informações. Recomenda-se que maiores quantidades de ensaios sejam realizadas e que permitam verificação, ou dupla checagem, para validação, bem como para futuramente ser possível o estabelecimento de modelos matemáticos mais confiáveis;

- nos estudos, foi possível estabelecer parâmetros estatísticos que podem ser utilizados tanto em métodos de dimensionamento vigentes ou novos, como naquelas que consideram as variações do módulo de resiliência do subleito para determinação do risco de falha, ou da confiabilidade das estruturas;

- os valores de módulo de resiliência aferidos no campo apresentaram variações em níveis elevados, mesmo quando consideradas características idênticas de tipo de solo, sítios pedológicos/geológicos e dados de chuva semelhantes, tornando o estudo bastante complexo e não permitindo até o presente momento, o estabelecimento de modelos matemáticos confiáveis;

- no presente estágio de acumulação de dados, dada a variação elevada dos mesmos, entendeu-se ser mais adequado trabalhar, por enquanto, com valores estatísticos dos dados visando a obtenção de parâmetros referenciais para fins de projetos, no intuito de minimizar o risco de superestimar os valores de módulo de resiliência do subleito, e consequentemente, conceber estruturas com níveis de confiabilidade irrelevantes, praticamente fadadas ao fracasso; 
- a simulação de estruturas de dimensionamento levando em consideração a metodologia proposta por Ferri (2013) mostrou claramente os elevados riscos de dimensionamento sem levar em consideração a confiabilidade. Mostrou-se que as estruturas dimensionadas admitem níveis muito baixos de confiabilidade, o que não é admissível para o nível de tráfego de rodovias concessionadas. A consideração da confiabilidade é um fator imperativo em projetos de pavimentação.

Para melhor compreender tais variações de comportamento, com base nos estudos realizados, sugere-se, para realização de estudos futuros:

- Acumulação de dados históricos de ensaios deflectométricos não destrutivos de vários anos e pelo menos duas condições climáticas em cada ano (clima seco e clima úmido);

- maior controle e validação nas informações obtidas através de sondagens e ensaios de campo e laboratório: realizar contraprova e eliminar eventuais dados contraditórios, por exemplo; registrar localização exata, coordenadas, código da rodovia, pista, número da faixa, cotas de profundidade, data de coleta, etc.;

- sempre que forem coletados materiais de campo para ensaios, realizar caracterização completa, contemplando inclusive a variação de parâmetros (energia de compactação, umidade etc.), quando couber, especialmente no caso dos ensaios de módulo de resiliência de laboratório, imprescindíveis para estudos e projetos;

- na coleta de materiais para ensaios, tomar os cuidados necessários para cadastramento e confirmação dos locais de coleta, bem como certificação de que os materiais coletados de fato representam o subleito; ou se for o caso coletar o solo de ambas as camadas (reforço do subleito e subleito);

- inclusão de mais informações no banco de dados referentes à geologia/pedologia: alturas de corte e aterro do projeto; espessuras dos tipos de materiais/horizontes nas diversas seções de corte e mistas - informações extrapoladas/inferidas a partir de sondagens a percussão;

- instrumentação de algumas seções para futuro cruzamento de dados (especialmente para monitoramento de umidade dos materiais do subleito); 
- informações adicionais ao banco de dados, relativas à estrutura do pavimento: idade, espessura total do pavimento, materiais e espessuras das camadas, tipo de estrutura, presença ou não de drenos / camadas drenantes, idade dos drenos, histórico de intervenções realizadas etc.

- quantidade de informações no banco de dados que permita dupla checagem de informações, e no caso de informações discrepantes, criação de mecanismo para invalidação das mesmas. 


\section{REFERÊNCIAS BIBLIOGRÁFICAS}

ABO-HASHEMA, M.A.; BAYOMY, F. M.; SMITH, R. SALEM, H. M. (2002). Environmental impacts on the subgrade resiliente modulus for Idaho pavements. In: 81 th ANNUAL MEETING OF TRANSPORTATION RESEARCH BOARD. Washington, D. C., january 13-17, 2002. TRB 2002 Annual Meeting CD-ROM.

ALBERNAZ, C. A. V. (1994). Retroanálise do módulo de resiliência de pavimentos flexíveis e de subleitos para fins de anteprojeto, análise estrutural e gerência de pavimento. In: 28 ${ }^{a}$ REUNIÃO ANUAL DE PAVIMENTAÇÃO, 1994, Belo Horizonte, MG, 1994, p.627-682.

ALLEN, J.; M.R. THOMPSON. "Resilient Response of Granular Materials Subjected to Time Dependent Lateral Stresses," Transportation Research Record 510, Transportation Research Board, National Research Council, Washington, D.C., 1974, pp. 1-13.

AMERICAN ASSOCIATION OF STATE HIGHWAY AND TRANSPORTATION OFFICIALS. AASHTO guide for design of pavement structures, Washington, D.C. 1986.

AASHTO Guide for Mechanistic-Empirical Design of New and Rehabilitated Pavement Structures. Illinois, 2002.

- Interim Method of Test for Resilient Modulus of Subgrade Soils and Untreated Base/Subbase Materials, T 292-91I, Washington, D.C., 1991.

. AASHTO Guide for Pavement Structures. AASHTO, ISBN: 1-56051-055-

2. Washington, D.C., 1993.

ANDREW, J. W.; JACKSON, N. M.; DRUMM, E. C. (1998). Measurement of seasonal variations in subgrade properties. In: APPLICATIONS OF GEOTECHNICAL PRINCIPLES IN PAVEMENT ENGINNERING - PROCEEDINGS OF SESSIONS OF GEO-CONGRESS 98. Geotechnical Special Publications, n. 85, p.13-38.

ARA CONSULTING GROUP INC. Guide for mechanistic-empirical design of new and rehabilitated pavement structures. Final Report, National Cooperative Highway Research Program, Transportation Research Board, Washington, D.C. 2004.

ARANOVICH, L. A. S. (1985). Desempenho de pavimentos de baixo custo no Estado do Paraná. Dissertação de Mestrado. COPPE/UFRJ, Rio de Janeiro, RJ. 374p.

BALBO, J. T. Pavimentação Asfáltica: materiais, projetos e restauração. São Paulo, SP: Oficina de Textos, 2007. 
BARKSDALE, R. D.; HICKS, R. G. (1973). Material characterization and layer theory for use in fatigue analyses. Highway Research Board, Special Report n.140. Washington. pp. 20-48.

BARKSDALE, R. G. (1971). Compressive stress pulse times in flexible pavements for use in dynamic testing. Highway Research Record 345. pp. 32-44.

BAUS, R.L.; T. LI. Investigation of Graded Aggregate Bases, FHWA/SCDOT Report No. FHWA-SC-06-03, University of South Carolina, Columbia, Feb. 2006.

BENNETT, T.; M.H. MAHER. The Development of a Performance Specification for Granular Base and Subbase Material, FHWA NJ 2005-03, Rutgers University, Piscataway, N.J., Feb. 2005.

BERNUCCI, L. B. (1995) Considerações sobre o Dimensionamento de pavimentos utilizando solos lateríticos para rodovias de baixo volume de tráfego. Tese de Doutorado. Escola Politécnica da USP.

. (1997). Módulo resiliente de solos lateríticos e sua aplicação ao dimensionamento de pavimentos de vias de baixo volume de tráfego. In: 1 SIMPÓSIO INTERNACIONAL DE PAVIMENTAÇÃO DE RODOVIAS DE BAIXO VOLUME DE TRÁFEGO, 1., Rio de Janeiro, RJ, 1997. Anais. Rio de Janeiro, ABPv. V.2, p.490-508.

BERNUCCI, L. B.; MOTTA, L. M. G.; CERATTI, J. A. P. SOARES, J. (2010). Pavimentação asfáltica: Formação básica para engenheiros, Rio de Janeiro, PETROBRAS, ABEDA, 2010.

BERG, R.L.; S.R. BIGI; J.A.STARK; G.D. DURELL. Resilient Modulus Testing of Materials from Mn/Road Phase 1, Minnesota Road Research Project, CRREL Report 96-19, U.S. Army Cold Regions Research and Engineering Laboratory, Hanover, N.H., Sep. 1996.

BIGI, S.R.; R.L. BERG. Material Testing and Initial Pavement Design Modeling, Minnesota Road Research Project, CRREL Report 96-14, U.S. Army Cold Regions Research and Engineering Laboratory, Hanover, N.H., Sep. 1996.

BONZANINI, J. A. F. (2011). Estudo dos efeitos do tamanho dos corpos de prova no módulo de resiliência de quatro solos. Dissertação de Mestrado. UFRGS, 2011.

BURCZYK, J.M., K. KSAIBATI; R.A. SPRECHER; M.J. FARRAR. "Factors Influencing Determination of a Subgrade Resilient Modulus Value," Transportation Research Record 1462, Transportation Research Board, National Research Council, Washington, D.C., 1995, pp. 72-78.

BURMISTER, D.M. The Theory of Stresses and Displacements in Layered Systems and Application to the Design of Airport Runways. In Proceedings of the Highway Research Board, Vol. 23, National Research Council, Washington, D.C., 1943, pp. 125-148. 
CAMACHO, J. (2002). Peculiaridades de Distribuição de Umidades em Bases de Pavimento de Solo Arenoso Fino Laterítico, Tese de Doutorado, EP-USP, 180p., São Paulo, SP, 2002.

CAPUTO, H. P. (1996). Mecânica dos solos e suas aplicações. Livros Técnicos e Científicos Editora S.A. Rio de Janeiro, RJ.

CARDOSO S. H. (1987). Procedure for flexible airfield pavement design based on permanent deformation. Tese de Doutorado. Universidade de Maryland, Maryland, USA, 1987.

CARMICHAEL, R.F., III; E. STUART. "Predicting Resilient Modulus: A Study to Determine the Mechanical Properties of Subgrade Soils," Transportation Research Record 1043, Transportation Research Board, National Research Council, Washington, D.C., 1985, pp. 145-148.

CARMO, C. A. T. A avaliação do módulo de resiliência através de ensaios triaxiais dinâmicos de dois solos compactados e a sua estimativa a partir de ensaios rotineiros. 1998. 131 f. Dissertação (Mestrado em Engenharia Civil) - Escola de Engenharia de São Carlos, São Carlos, 1998.

CHEN, J.Z.; H. MUSTAQUE; M.T. LATORELLA. Use of Falling Weight Deflectometer and Dynamic Cone Penetrometer in Pavement Evaluation. Transportation Research Record 1655, Transportation Research Board, National Research Council, Washington, D.C., 1999, pp. 145-151.

CHOUBANE, B.;R. L. MCNAMARA. A Practical Approach to Predicting Flexible Pavement Embankment Moduli Using Falling Weight Deflectometer (FWD) Data. Research Report FL/DOT/SMO/00-442. Florida Department of Transportation, State Materials Office, Tallahassee, 2000.

CLAROS, G.; W.R. HUDSON; K.H. STOKOE. Modifications of Resilient Modulus Testing Procedure for Equipment Calibration. Transportation Research Record 1278, Transportation Research Board, National Research Council, Washington, D.C., 1990, pp. 51-62.

CUNTO, F. J. C. (1998). Determinação do módulo de resiliência através de ensaios triaxiais dinâmicos e a sua estimativa a partir de ensaios de compressão simples: estudo de três solos do nordeste brasileiro. São Carlos. 133p. Dissertação (mestrado) - Escola de Engenharia de São Carlos, Universidade de São Paulo.

DALEIDEN, J.F.; B.M. KILLINGSWORTH, A.L. SIMPSON; R.A. ZAMORA. "Analysis of Procedures for Establishing in situ Subgrade Moduli," Transportation Research Record 1462, Transportation Research Board, National Research Council, Washington, D.C., 1994, pp. 102-107.

DEPARTAMENTO NACIONAL DE ESTRADAS DE RODAGEM - DNER. Solos Determinação do Módulo de Resiliência. Norma Rodoviária DNER-ME 131/94. São Paulo: 1994.8 p. 
DAVICH, P.; F. CAMARGO; B. LARSEN; R. ROBERSON; J. SIEKMEIER, Validation of DCP and LWD Moisture Specifications for Granular Materials, Report No. MN/RC2006-20, Office of Materials, Minnesota Department of Transportation, Minneapolis, Aug. 2004a.

DAVICH, P.; J. LABUZ, B. GUZINA; A. DRESCHER. Small Strain and Resilient Modulus Testing of Granular Soils, Report No. 2004-39, Minnesota Department of Transportation, University of Minnesota, Minneapolis, Aug. 2004b.

DRUMM E.C.; REEVES J.S.; MADGETT M.R.; TROLINGER W.D. Subgrade Resilient Modulus Correction for Saturation Effects. ASCE Journal of Geotechnical and Geoenvironmental Engineering, Vol. 123, No. 7, July, 1997, pp. 663-670.

DRUMM E.C., RAINWATER R.N., e REW J., JACKSON N.M., YODER R.E. e WILSON G.V. Pavement Response due to Seasonal Changes in Subgrade Moisture Conditions. Proceedings of the Second Int. Conf. On Unsaturated Soils, 27-30 August, 1998, Beijing, China, Vol. 2.

DRUMM, E. C.; BOATENG-POKU, Y.; PIERCE, T. J. (1990). Estimation of subgrade resilient modulus form standard tests. Journal of Geotechnical and Geoenvironmental Engineering, v.116, n.5, p.774-89.

DUNLAP, W.S. A Report on a Mathematical Model Describing the Deformation Characteristics of Granular Materials, Technical Report 1, Project 2-8-62-27, Texas Transportation Institute, Texas A\&M University, College Station, 1963.

EDIL, T.; C. BENSON. Investigation of the DCP and SSG as Alternative Methods to Determine Subgrade Stability, SPR No. 0092-01-05, University of Wisconsin-Madison, Sep. 2005.

EDIL, T.; C. BENSON; A. SAWANGSURIYA. Resilient Behavior of Unsaturated Subgrade Soils, Interim Report to University of Minnesota, University of WisconsinMadison, Dec. 2006.

EKBLAD, J. 2007. Influence of Water on Coarse Granular Road Material Properties, KTH Biblioteket, Disponível em: <http://www.divaportal.org/kth/abstract.xsql?dbid=4329>, Acesso em: Julho/2007.

ELLIOT, R.P., THORNTON, S.I., 1988, "Resilient Modulus and AASHTO Pavement Design", Transportation Research Record, 1196, TRB, National Research Council, Washington, D.C.

FARRAR, M.J.; J.P. TURNER. Resilient Modulus of Wyoming Subgrade Soils, MPC Report No. 91-1, Mountain Plains Consortium, Fargo, N.D., 1991.

FERNANDO, E.G., OH, J., LIU, W., NAZARIAN, S., MCDANIEL, M., 2008, "Application of Soil-Water Characteristic Relationship in Estimating Load Bearing Capacity for Pavements", TRB Annual Meeting, Washington, D.C. 
FERREIRA J. G. H.; MOTTA, L. M. G. (2002). Análise comparativa de modelos de resiliência de solos e materiais não tratados quimicamente. In: CONGRESSO DE PESQUISA E ENSINO EM TRANSPORTES, 16., Natal, RN, 2002. Anais. Natal, ANPET. v.1, P. 109-120.

FERREIRA, J. G. H. M. (2008). Tratamento de dados geotécnicos para predição de módulos de resiliência de solos e britas utilizando ferramentas de data mining. Tese de Doutorado. Universidade Federal do Rio de Janeiro COPPE/UFRJ.

FERRI, S. (2013). Critérios de aceitação e controle da qualidade da execução de camadas de fundação de pavimentos novos através de métodos deflectométricos. Dissertação de Mestrado. Escola Politécnica da USP.

FLEMING, P.R., FROST, M.W., ROGERS, C.D.F. (2000) "A comparison of Devices for Measuring Stiffness In situ," Proceedings of the Fifth International Conference on Unbound Aggregate In Roads, Nottingham, United Kingdom.

FREDLUND, D. G.; BERGAN, A. T.; WONG, P. K. (1977). Relation between resilient modulus and stress conditions for cohesive subgrade soils. Transportation Research Record, n.642, p.73-81.

FREDLUND, D.G., XING, A., 1994, "Equation for the Soil-Water Characteristic Curve", Canadian Geotechnical Journal, 31, pp 521-532.

FREDLUND, D.G., XING, A., HANG, S., 1994, "Predicting the Permeability Function for Unsaturated Soils Using the Soil-water Characteristic Curve", Canadian Geotechnical Journal, Vol. 31, pp 533-546.

FREDLUND, M.D., FREDLUND, D.G., WILSON, G.W., 1997, "Prediction of soil-water characteristic from grain size distribution and volumetric-mass properties", III Simpósio Brasileiro de Solos Não Saturados, Vol.1, Rio de Janeiro, pp. 13-23.

2002, "Use of the grain size distribution for estimation of the soil-water characteristic curve", Canadian Geotechnical Journal, Vol. 39, pp 1103-1117.

FREDLUND., D. G.; RAHARDJO, H. (1993). Soil mechanics for unsaturated soils. 617p. New York, Willey-Interscience Publications.

FUTAI, M.M., 2002, Estudo teórico-experimental do comportamento de solos tropicais não-saturados: aplicação a um caso de voçorocamento, Tese de Doutorado, COPPEUFRJ, $559 \mathrm{pp}$.

GANDARA, J.A.; A. KANCHERLA; G. ALVARADO; S. NAZARIAN; T. SCULLION. Impact of Aggregate Gradation on Base Material Performance, TxDOT Research Report TX-1502-2, Center for Transportation Infrastructure System, University of Texas at El Paso, Nov. 2005.

GEORGE, K.P. (2004) Resilient Modulus Prediction Employing Soil Index Properties. Relatório Final FHWA/MS-DOT-RD-04-172, Agosto 2004. 
GEORGE, K.P., WAHEED UDDIN (2000) "Subgrade Characterization for Highway Pavement Design", Relatório Final, Mississippi Department of Transportation, December 2000.

GONÇALVES, R.F., 1999, Estudo da influência da variação do teor de umidade no valor do módulo de resiliência de um solo argiloso encontrado em subleito de rodovias no interior paulista, Dissertação de Mestrado em Engenharia de Transportes, USP, São Paulo, 149 p.

GREEN. J. L., e HALL. J. W. JR. (1975). Nondestructive vibratory testing of airport pavements: Experimental test results and development of evaluation methodology and procedure. Report No. FAA -R D73- 205. Vol. I, Federal Aviation Admin. Washington. D.C.

GUDISHALA, RAVINDRA (2004) Development of Resilient Modulus Prediction Models for Base and Subgrade Pavement Layers from In situ Devices Test Results. Dissertação de Mestrado, Louisiana State University, Dezembro 2004.

GUPTA, S., A. RANAIVOSON, T. EDIL, C. BENSON, e A. SAWANGSURIYA, Pavement Design Using Unsaturated Soil Technology, Report No. MN/RC-2007-11, Final Research Report submitted to Minnesota Department of Transportation, University of Minnesota, Minneapolis, May 2007.

HEUKELOM, W., A.J.G. KLOMP (1962). Dynamic Testing as a Means of Controlling Pavements During and After Construction. Proceedings of the First International Conference on Structural Design of Asphalt Pavements, University of Michigan.

HEYDINGER, A.G., 2003, "Evaluation of Seasonal Effects on Subgrade Soils", 82nd Annual Meeting of Transportation Research Board, Washington, D.C.

HICKS R. J. (1970). Factors influencing the resilient properties of granular materials. Tese de Doutorado. Univ. Califórnia, Berkeley, 510p., 1970.

HICKS, R. G.; MONISMITH, C. L. (1971). Factors influencing the resilient response of granular materials. Transportation Research Record., n345, p.15-31.

HOFFMANN, O.J.-M., B.B. GUZINA, e A. DRESCHER, "Stiffness Estimates Using Portable Deflectometer," Transportation Research Record 1869, Transportation Research Board, National Research Council, Washington, D.C., 2004, pp. 59-66.

HOPKINS, T., T.L. BECKHAM, C. SUN, e B. NI, Resilient Modulus of Kentucky Soils, Final Research Report for Kentucky Transportation Cabinet, Kentucky Transportation Center, University of Kentucky, June 2004.

HUANG, Y. H. (2004). Pavement Analysis and Design - 2nd ed. Prentice-Hall, Inc., New Jersey, USA, 2004.

HUANG, W.H., YANG, S.R., KUNG, J.H.S., LIN, H.D.., 2006, "Effect of Matric Suction on Resilient Modulus of Compacted Subgrade Soils", 84th TRB Annual Meeting, Washington, D.C. 
HUDSON, J.M.; E.C. DRUMM; M. MADGETT. Design Handbook for the Estimation of Resilient Response of Fine-Grained Subgrades, Proceedings of the 4th International Conference on the Bearing Capacity of Roads and Airfields, University of Minnesota, Minneapolis, Vol. 2, 1994, pp. 917-931.

HULL, T., T.S. VINSON; R.G. HICKS. "Resilient Properties of Volcanic Materials," Proceedings, 18th Annual Symposium on Engineering Geology and Soils Engineering, Boise, Idaho, Apr. 1980.

HVEEM, F.N. (1955). Pavement Deflections and fatigue failures. 34th annual Meeting, HRB Bulletin 114, pp 43-73.

IRWIN, L.H. Report of the Discussion Group on Practical Limitations and What Can Be Done to Overcome Them. Transportation Research Record 1377, Transportation Research Board, National Research Council, Washington, D.C., 1995.

JANOO, V.C.; J. BAYER; G.D. DURRELL; C.E. SMITH. Resilient Modulus for New Hampshire Subgrade Soils for Use in Mechanistic Pavement Design, ERDC/CRREL 99-14, U.S. Army Cold Regions Research and Engineering Laboratory, Hanover, N.H., 1999.

JANOO, V., J.J. BAYER, e C.C. BENDA, "Effect of Aggregate Angularity on Base Material Properties," Journal of Materials in Civil Engineering, Vol. 16, No. 6, Dec. 2004, pp. 614-622.

JIN M.S., LEE K.W. e KOVACS W.D. Seasonal Variation of Resilient Modulus of Subgrade Soils. ASCE Journal of Transportation Engineering, Vol. 120, No.4, July/August, 1994, pp. 603-616.

KALCHEFF, I.V. e R.G. HICKS, "A Test Procedure for Determining Resilient Properties of Granular Materials," ASTM Journal of Testing and Material Evaluation, Vol. 1, No. 6, 1973, pp. 472-479.

JONES M.P. e WITCZAK M.W. Subgrade Modulus on the San Diego Test Road. Transportation Research Record 641, TRB, National Research Council, 1977, Washington, D.C., pp. 1-6.

JOHNSON, T. C., R. L. Berg, and A. DiMillio. Frost Action Predictive Techniques: An Overview of Research Results. In Transportation Research Record 1089, TRB, National Research Council, Washington, D.C., 1986, pp. 147-161.

KHOURY N. N.; ZAMAN M. M. Transportation Research Record: Journal of the Transportation Research Board, No. 1874, TRB, National Research Council, Washington, D.C., 2004, pp. 99-107.

KIM, W. e J.F. LABUZ, Resilient Modulus and Strength of Base Course with Recycled Bituminous Material, Final Report No. MN/RC-2007-05, Submitted to Minnesota Department of Transportation, University of Minnesota, Minneapolis, 2007. 
KSAIBATI, K., M.L. WHELAN, J. BURCZYK, e M.J. FARRAR, Section of Subgrade Modulus for Pavement Overlay Design Procedures, Wyoming Department of Transportation, University of Wyoming, Laramie, Aug. 1994.

KSAIBATI, K., J. ARMAGHANI, e J. FISHER, "Effect of Moisture on Modulus Values of Base and Subgrade Materials". Transportation Research Record 1716, Transportation Research Board, National Research Council, Washington, D.C., 2000, pp. 20-29.

LAMBE, T. W.; WHITMAN, R. V. (1979). Soil Mechanics, SI Version. John Wiley \& Sons.

LEE, W. BOHRA, N. C.; ALTSCHAEFFL, A. G.; WHITE, T. D. (1995). Resilient modulus of cohesive soils and the effects of freeze-thaw. Canadian Geotechnical Journal, v.32, n.4, p. 559-68.

LEE, W., N.C. BOHRA, A.G. ALTSCHAEFFL, e T.D. WHITE, "Resilient Modulus of Cohesive Soils," Journal of Geotechnical and Geoenvironmental Engineering, Vol. 123, No. 2, Feb. 1997, pp. 131-136.

LI D. e SELIG E.T. Resilient Modulus for Fine Grained Subgrade Soils. ASCE Journal of Geotechnical Engineering, Vol. 120, No. 6, June, 1994, pp. 939-957.

LING, J., XIE, H., GUO, R., 2006, "A Method to Predict Resilient Modulus of Lime and Lime-cement Stabilized Soils Used in Highway Subgrade", 84th TRB Annual Meeting, Washington, D.C.

LIANG, R.Y., 2006, "Field Monitoring of moisture Variations Under Flexible Pavement", 85th TRB Annual Meeting, Washington, D.C..

LIANG, R.Y., RABAB'AH, S., 2007, "Predicting Moisture-dependent Resilient Modulus of Cohesive Soils Using Soil Suction Concept", XIII Conferência Panamericana em Mecânica dos Solos e Engenharia Geotécnica, Venezuela.

LIANG, R.Y., RABAB'AH, S., TAAMNEH, M., 2007, "Evaluation of Enhanced Integrated Climatic Model Predictions Over Different Permeable Base Materials", XIII Conferência Pan-americana em Mecânica dos Solos e Engenharia Geotécnica, Venezuela.

LISTER, N. W.. e POWELL. D. (1987). "Design practices for pavements in the United Kingdom." Proc. 61h Int. Conf. On the Struct. Design of Asphalt Pavements. Ann Arbor. Michigan.

LYTTON, R.L., PUFAHL, D.E., MICHALAK, 1993, An Integrated Model of the Climatic Effects on Pavements, In: FHWA Report No. FHWA-RD-90-033, Mclean, Virginia.

MACEDO, J. A. G. (1996). Interpretação de ensaios deflectométricos para avaliação de pavimentos flexíveis - A experiência com o FWD no Brasil. 456p. Tese de Doutorado. PEC. COPPE, Universidade Federal do Rio de Janeiro. Rio de Janeiro, 1996. 
MAHER, M.H., W.J. PAPP, JR., e N. GUCUNSKI, "Measurement of Soil Resilient Properties Using Noncontacting Proximity Sensors," Transportation Research Record 1584, Transportation Research Board, National Research Council, Washington, D.C., 1996.

MAHER, M.H., T. BENNETT, W.J. PAPP, JR., e N. GUCUNSKI, Resilient Modulus Properties of New Jersey Subgrade Soils, FHWA NJ 2000-01, Rutgers University, Piscataway, N.J., Sep. 2000.

MALLA, R.B. e S. JOSHI, Establish Subgrade Support Values for Typical Soils in New England, Report No. NETCR 57, New England Transportation Consortium, Fall River, Mass., Apr. 2006.

MASADA, T., S.M. SARGAND, B. ABDALLA, e J.L. FIGUEROS, Material Properties for Implementation of Mechanistic-Empirical (ME) Pavement Design Procedures, Final Report, Ohio Department of Transportation, Ohio Research Institute for the Transportation and Environment, Athens, 2004.

MEDINA, J. M.; MOTTA, L. M. G. (2015). Mecânica dos Pavimentos - 3ª ed., Rio de Janeiro, RJ: Interciência, 2015, 638p.

MINER, M. A., Cumulative damage in fatigue. Journal of Applied Mechanics, ASME, EUA, set. p.A-159 a A-164, 1945.

MITCHELL, J. K.; SITAR, N. (1982). Engineering Properties of Tropical Residual Soil. Geotechnical Specialty Conf. on. Eng. And Const. in Tropical and Residual Soils. Honolulu, Hawaii, January 11-14. ASCE.

MOHAMMAD, L.N., A.J. PUPPALA, e P. ALAVILLI, "Influence of Testing Procedure and LVDTs Location on Resilient Modulus of Soils," Transportation Research Record 1462, Transportation Research Board, National Research Council, Washington, D.C., 1994a, pp. 91-101.

. (1995) Resilient Properties of Laboratory Compacted Subgrade Soils, National Academy of Science, Transportation Research Record No. 1504, pp 87-102.

of the Use of Resilient Modulus for Louisiana Soils in Design of Pavements, Final Report No. 283, Louisiana Transportation Research Center, Federal Highway Administration, Louisiana Department of Transportation and Development, June 1994b.

Resilient Properties of Laboratory Compacted Subgrade Soils," Transportation Research Record 1504. Transportation Research Board, National Research Council, Washington, D.C., 1995, pp. 87-102.

MOHAMMAD, L.N., B. HUANG, A.J. PUPPALA, e A. ALLEN, "Regression Model for Resilient Modulus of Subgrade Soil," Transportation Research Record 1687, Transportation Research Board Record, National Research Council, Washington, D.C., 1999, pp. 47-54. 
MOHAMMAD, L.N., H.H. TITI, e A. HERATH, Investigation of the Applicability of Intrusion Technology to Estimate the Resilient Modulus of Subgrade Soil, FHWA/LA00/332, Louisiana Transportation Research Center, Baton Rouge, 2000.

Effect of Moisture Content and Dry Unit Weight on the Resilient Modulus of Subgrade Soils Predicted by Cone Penetration Test, FHWA/LA-00/355, Louisiana Transportation Research Center, Baton Rouge, 2002.

MOHAMMAD, L.N., K. GASPARD, A. HERATH, e M. NAZZAL, comparative Evaluation of Subgrade Resilient Modulus from Non-Destructive, In-Situ and Laboratory Methods, FHWA/LA-06/417, Louisiana Transportation Research Center, Baton Rouge, 2007.

MOTTA, L. M. G.; ARANOVICH, L. A. S.; CERATTI, J. A. P. (1985). Comportamentos resiliente de solos utilizados em pavimentos de baixo custo. Solos e Rochas, v.8, n.3, p.15-42.

NATAATMADJA, A. PARKIN, A. K. (1989). Characterization of granular materials for pavements, Canadian Geotechnical Journal, v.26, p.725-30.

NATAATMADJA, A., "Resilient Modulus of Granular Materials Under Repeated Loading," Proc., 7th International Conference on Asphalt Pavements. University of Nottingham, Nottingham, UK, Vol. 1, 1992, pp. 172-185.

., "On the Response of Granular Unbound Pavement Materials Under Repeated Loading," Proc.,17th Australia Road Research Board Conference, Gold Coast, Australia, Vol. 2, 1994, pp. 99-114.

NATAATMADJA, A., e Y.L. TAN, "Resilient Response of Recycled Concrete Road Aggregates," Technical Note No. 22318, Journal of Transportation Engineering, Vol. 127, No. 5, Sep./Oct. 2001.

NATIONAL COOPERATIVE HIGHWAY RESEARCH PROGRAM (2002). Recommended Standard Method for Routine Resilient Modulus Testing of Unbound Granular Base/Subbase Materials and Subgrade Soils, Protocol 1-28A, Transportation Research Board, National Research Council, Washington, D.C., 2002.

. (2004). NCHRP Research Results Digest 285: Laboratory Determination of Resilient Modulus for Flexible Pavement Design, Transportation Research Board, National Research Council, Washington, D.C., Jan. 2004, 48 pp.

. (2006). NCHRP Research Results Digest 307: Identification of LiabilityRelated Impediments to $\$ 409$ Safety Data Among Transportation Agencies and a Synthesis of Best Practices, Transportation Research Board, National Research Council, Washington, D.C., Sep. 2006, 32 pp.

. (2006). NCHRP Research Results Digest 308: Changes to Mechanistic Empirical Pavement Design Guide Software Through Version 0.900, July 2006, Transportation Research Board, National Research Council, Washington, D.C., 2008, $22 \mathrm{pp}$. 
. (2008). NCHRP Synthesis 382: Estimation Stiffness of Subgrade and Unbound Materials for Pavement Design. Transportation Research Board, National Research Council, Washington, D.C., Jan. 2004, 130 p.

. (1997). NCHRP 1-28A - Laboratory determination of resilient modulus for flexible pavement design - Final Report (NCHRP Web Document 14). Transportation Research Board. 464p.

(2004). NCHRP 1-37A - Guide for mechanistic-empirical design of new and rehabilitated pavement structures - Final Report. Transportation Research Board.

NAZZAL, M. D.; MOHAMMAD L. N. (2010). Estimation of Resilient Modulus of Subgrade Soils Using Falling Weight Deflectometer. Transportation Research Record: Journal of the Transportation Research Board, No. 2186, Transportation Research Board of the National Academies, Washington, D.C., 2010, pp. 1-10.

NAZARIAN, S., Feasibility Study on Improvements to Dynamic Cone Penetrometer, Research Report 3903-2, Center for Highway Materials Research, University of Texas at El Paso, 1998.

. Quality Management of Flexible Pavement Layers with Seismic Methods: Test Methods, Research Report 5-1735-01-P5, Center for Highway Materials Research, University of Texas at El Paso, Nov. 2006.

NAZARIAN, S., M. BAKER, e K. CRAIN, "Use of Seismic Pavement Analyzer in Pavement Evaluation," Transportation Research Record 1505, Transportation Research Board, National Research Council, Washington, D.C., 1995, pp. 1-8.

NAZARIAN, S., R. PEZO, e M. PICRONELL, Testing Methodology for Resilient Modulus of Base Materials, Research Report 1336-1, Center for Geotechnical and Highway Materials Research, University of Texas at El Paso, 1996.

NAZARIAN, S., J. ROJAS, R. PEZO, D. YUAN, I. ABDALLAH, e T. SCULLION, "Relating Laboratory and Field Moduli of Texas Base Materials," Transportation Research Record 1639, Transportation Research Board, National Research Council, Washington, D.C., 1998, pp. 1-11.

NAZARIAN, S., D. YUAN, V. TANDON, e M. ARRELLANO, Quality Management of Flexible Pavement Layers with Seismic Methods, Research Report 1735-3F, Center for Highway Materials Research, University of Texas at El Paso, 2003.

NAZARIAN, S., D. YUAN, e V. TANDON, Quality Management of Flexible Pavement Layers with Seismic Methods, Research Report 0-1735-S, Center for Transportation Infrastructure Systems, University of Texas at El Paso, 2005.

NI, B., T.C. HOPKINS, L. SUN, e T.L. BECKHAM, "Modeling the Resilient Modulus of Soils," Proceedings of the 6th International Conference on the Bearing Capacity of Roads, Railways, and Airfields, Vol. 2, A.A. Balkema Publishers, Rotterdam, the Netherlands, pp. 1131-1142. 
NOGAMI J. S.; VILLIBOR, D. F. (1981). Uma nova classificação para finalidades rodoviárias. Simpósio Brasileiro de Solos Tropicais em Engenharia, COPP/UFRJ CNPq - ABMS; pg. 30-41. Setembro, Rio de Janeiro, RJ.

NOURELDIN, A. S. (1993) New scenario for backcalculation of layer moduli of flexibles pavements. Transportation Research Record no 1384, p.23-28. 1993

OOI, P.S.K., K.G. SANDEFUR, e A.R. ARCHILLA, Correlation of Resilient Modulus of Fine-Grained Soils with Common Soil Parameters for Use in Design of Flexible Pavements Report No. HWY-L-2000-06, Hawaii Department of Transportation, Honolulu, 2006.

PARREIRA, A. B. CARMO, C. A. T. CUNTO, F. J. C. (1998). Estudo do módulo de resiliência de materiais usados em pavimentação. In: REUNIÇAO ANUAL DE PAVIMENTAÇÃO, 31., São Paulo, SP, 1998. Anais. São Paulo, ABPv, v.1, p.233-247.

PEREIRA J. M. B. (2007). Um procedimento de retroanálise para pavimentos flexíveis baseado na teoria do ponto inerte e em modelagem matemática. Dissertação de Mestrado. Escola de Engenharia de São Carlos da USP. São Carlos, SP, 2007.

PEZO, R.F., A General Method of Reporting Resilient Modulus Tests of Soils: A Pavement Engineer's Point of View, Presented at the 72nd Annual Meeting of the Transportation Research Board, Washington, D.C., Jan. 1993.

PEZO, R.F. e W.R. HUDSON, "Prediction Models of Resilient Modulus for Nongranular Materials," Geotechnical Testing Journal, Vol. 17, No. 3, 1994, pp. 349355.

PEZO, R.F., D.S. KIM, K.S. STOKOE, e W.R. HUDSON, Aspects of a Reliable Resilient Modulus Testing System, Presented at the 71st Annual Meeting of the Transportation Research Board, Washington, D.C., Jan. 1992.

PING, W.V. e C. LING, Enhancement of Resilient Modulus Data for the Design of Pavement Structures in Florida, Research Report No. FL/DOT/RMC/BD-543-4, Department of Civil Engineering, FAMU-FSU College of Engineering, Tallahassee, Fla., Sep. 2007.

PING, W.V., E. WU, e Z. YANG, Application of Noncontacting Proximity Sensors for Measuring Soil Resilient Characteristics, Research Report No.FL/DOT/RMC/ 0510815, Department of Civil Engineering, FAMU-FSU College of Engineering, Tallahassee, Fla., Sep. 2000.

PING, W.V., Z. YANG, e Z. GAO, "Field and Laboratory Determination of Granular Subgrade Moduli," Journal of Performance of Constructed Facilities, Vol. 16, No. 4, Nov. 1, 2002, pp. 149-159.

PING, W.V., W. XIONG, e Z. YANG, Implementing Resilient Modulus Test for Design of Pavement Structures in Florida, Research Report No. FL/DOT/RMC/BC-352-6, Department of Civil Engineering, FAMU-FSU College of Engineering, Tallahassee, Fla., Sep. 2003. 
PING, W.V., YANG, Z., HO, R.K.H., 2003, "Full-Scale Laboratory Evaluation of Moisture Effect on Resilient Moduli of Granular Pavement Subgrade Layers", International Journal of Road Materials and Pavement Design, Vol. X, No. X.

PING, W.V., YANG, Z., LIU, J., 2005, "The Influence of High Ground Water Table on Construction of Stabilized Subgrade Layer", 84th TRB Annual Meeting, Washington, D.C.

POWELL, W.D., J.F. POTTER, H.C. MAYHEW, e M.E. NUNN, The Structural Design of Bituminous Roads, TRRL Report LR 1132, Department of Transport, Berkshire, U.K., 1984.

PINTO, C.S. (1964). Primeira pesquisa por equipe. Estudo da dispersão do ensaio CBR. Boletim Técnico no. 6. Associação Brasileira de Pavimentação. Rio de Janeiro.

PORTER, O.J. (1942). Foundations for Flexible Pavements. HRB 22. Pg 100-136.

Vol 115. Pg 461-467. . (1950). Development of the original method for Highway design. ASCE.

PREUSSLER, E.S. (1978). Ensaios Triaxiais Dinâmicos de um Solo Arenoso. Dissertação de Mestrado. COPPE-UFRJ.

(1983). Estudo da deformação resiliente de pavimentos flexíveis e aplicação ao projeto de camada de reforço. Tese de doutorado. COPPE-UFRJ.

PROCTOR, R. R. (1933). Fundamental principles of soil compaction. Engineering News Record, v.111, n. 10, p. 286-289.

PUPPALA, A.J., L.N. MOHAMMAD, e A. ALLEN, "Engineering Behavior of Lime Treated Louisiana Subgrade Soil," Transportation Research Record 1546, Transportation Research Board, National Research Council, Washington, D.C., 1997, pp. 24-31.

"Permanent Deformation Characterization of Subgrade Soils from $R L T$ Test," Journal of Materials in Civil Engineering, Vol. 11, No. 4, Nov. 1999, pp. 274282.

RAAD, L., MINASSIAN, G., GARTIN, S., 1992, "Characterization of Saturated Granular Bases Under Repeated Load", Transportation research record 1369, pp. 7382, Transportation Research Board, Washington, D.C.

RADA, G., M. W. WITCZAK (1981) "Comprehensive Evaluation of Laboratory Resilient Moduli Results for Granular Materials”, Transportation Research Record 810, TRB, National Research Council, Washington, D.C., pp 23-33.

RICHTER, C., "Seasonal Variations in the Moduli of Unbound Pavement Layers," Publication No. FHWA-HRT-04-079, Turner-Fairbanks Highway Research Center, McLean, Va., 2006. 
RODRIGUES, M. R. (1997). Influência da sucção no módulo de resiliência de solos típicos de subleito de pavimentos do Rio Grande do Sul. Dissertação (Mestrado). Porto Alegre, UFRGs. 105p.

SALEM, H. M; BAYOMY, F. M.. AL-TAHER, M. G. (2003). Prediction of seasonal variation of subgrade resilient modulus using $\angle T P P$ data. In: 82th ANNUAL MEETING OF TRANSPORTATION RESEARCH BOARD. Washington, D. C., January 12-16, 2003. TRB 2003 Annual Meeting CD-ROM.

SANTHA B.L. (1994). Resilient Modulus of Subgrade Soils: comparison of Two Constitutive Equations. Transportation Research Record 1462, TRB, National Research Council, Washington, D.C., 1994, pp. 79-90.

SANTOS, JOÃO D. G. (1998). Contribuição ao Estudo dos Solos Lateríticos Granulares como Camada de Pavimento (Tese de Doutorado). Universidade Federal do Rio de Janeiro - COPPE/UFRJ). 339p.

SEED, H.B. e R.L. MCNEILL, "Soil Deformation Under Repeated Stress Applications," ASTM Special Technical Publication, No. 32, 1958, pp. 177-197.

SEED, H.B., C.K. CHAN, e C.E. LEE, "Resilience Characteristics of Subgrade Soils and Their Relation to Fatigue Failures in Asphalt Pavements," Proc., International Conference on the Structural Design of Asphalt Pavements, University of Michigan, Ann Arbor, 1962, pp.611-636.

SEED, H.B., F.G. MITRY, C.L. MONISMITH, e C.K. CHAN, NCHRP Report 35: Prediction of Flexible Pavement Deflections from Laboratory Repeated-Load Tests, Highway Research Board, National Research Council, Washington, D.C., 1967.

SEED, H. B.; MITCHEL, J. K.; CHAN, C. K. (1960). The strength of compacted cohesive soils. Research Conference on Shear Strength of Cohesive Soils. BoulderColorado. p. 877-964.

SEED, H. B.; MITRY, F. G.; MONISMITH, C. L.; CHAN, C. K. (1968). Factor influencing the resilient deformations of untreated aggregate base in two-layer pavements subjected to repeated loading. Highway Research Record, v. 215, 1968.

SEED, H.B. et al. (1958). Effects of repeated loading of the strength and deformation of compacted clay. 34th Annual meeting. HRB. Pg.541-558.

SHOOK, J.F., F.N. FINN, M.W. WITCZAK, e C.L. MONISMITH, "Thickness Design of Asphalt Pavements-The Asphalt Institute Method," Proc., 5th International Conference on the Structural Design of Asphalt Pavements, Vol. 1, the Netherlands, 1982, p. 17-44.

SIEKMEIER, J. A., D. YOUNG, e D. BEBERG. comparison of the Dynamic Cone Penetrometer with Other Tests During Subgrade and Granular Base Characterization in Minnesota. In Nondestructive Testing of Pavements and Backcalculation of Moduli: 3rd Vol., ASTM Special Technical Publication 1375 (S. D. Tayabji and E. O. Lukanen, eds.). ASTM, West Conshohocken, Pa., 1999. 
SIEKMEIER, J. In situ Testing for Mechanistic Empirical Pavement Design.OMRR Research Seminar, Minnesota Department of Transportation, Saint Paul, 2002.

SILVA, B. H. A. (2003). Aplicação das metodologias MCT e resiliente a solos finos do Centro-Norte do Mato Grosso. Dissertação de Mestrado. Instituto Militar de Engenharia. Rio de Janeiro, RJ, 2003.

. (2009). ANÁLISE MECÂNICA DE UM PAVIMENTO RODOVIÁRIO SUBMETIDO À OSCILAÇÃO DO LENÇOL FREÁTICO SIMULADA EM MODELO FÍSICO DE VERDADEIRA GRANDEZA. Tese de Doutorado. COPPE UNIVERSIDADE FEDERAL DO RIO DE JANEIRO, Rio de Janeiro, RJ, 2009.

STOKOE, K.H., II, D.-S. KIM, e R.D. e RUS, "Development of Synthetic Specimens for Equipment Calibration," Transportation Research Record 1278, Transportation Research Board, National Research Council, Washington, D.C., 1990, pp. 63-81.

STUBSTAD, R. N., NCHRP Web Document \#52, Project 20-59 (9), LTPP Data Analysis: Feasibility of Using FWD Deflection Data to Characterize Pavement Construction Quality. TRB, National Research Council, Washington, D.C., 2002.

SUZUKI, C.Y., PEREIRA, A.C.O., AZEVEDO, A.M., TSU, B.S.A., PITA, A.S., 2004, "Conceito de Índice de Severidade para Considerar a Influência da Drenagem Superficial no Desempenho de Pavimentos Asfálticos", 35a Reunião Anual de Pavimentação, Rio de Janeiro.

SVENSON, M. (1980). Ensaios triaxiais dinâmicos de solos argilosos. Tese de Mestrado. COPPE/UFRJ, Rio de Janeiro, RJ.

TAKEDA, M.C., 2006, A Influência da Variação da Umidade Pós-compactação no Comportamento Mecânico de Solos de Rodovias do Interior Paulista, Tese de Doutorado, Escola de Engenharia de São Carlos, USP, São Paulo.

TERREL, R.L., I.S. AWAD, e L.R. FOSS, "Techniques for Characterizing Bituminous Materials using a Versatile Triaxial Testing System," ASTM Special Technical Publication, No. 561, 1974, pp. 47-66.

THADKAMALLA, G. B.; GEORGE, K. P. (1995). Characterization of subgrade soils at simulated field moisture. Transportation Research Record, n.1481, p.21-27.

THOMPSON, M.R. e R.P. ELLIOT, "ILLI-PAVE-Based Response Algorithms for Design of Conventional Flexible Pavements," Transportation Research Record 1043, Transportation Research Board, National Research Council, Washington, D.C., 1985, pp. 50-57.

THOMPSON, M.R. e T.G. LAGROW, A Proposed Conventional Flexible Pavement Thickness Design Procedure, FHWA-IL-UI-223. Illinois University, UrbanaChampaign, Dec. 1988, 47 pp. 
THOMPSON, M.R. e K.L. SMITH, "Repeated Triaxial Characterization of Granular Bases," Transportation Research Record 1278, Transportation Research Board, National Research Council, Washington, D.C., 1990.

THOMPSON, M.R. e Q.L. ROBNETT, Resilient Properties of Subgrade Soils. Final Report-Data Summary, Transportation Engineering Series 14, Illinois Cooperative Highway Research and Transportation Program Series, University of Illinois, Urbana, 1976.

"Resilient Properties of Subgrade Soils," Transportation Engineering Journal, Vol. 105, No. TE1, 1979, pp. 71-89.

. (1976) "Resilient properties of subgrade soils." Journal of Transportation Engineering, ASCE, 105(1), 1976, 71-89.

TITI, H., B. ELIAS, e S. HELWANY, Determination of Typical Resilient Modulus Values for Selected Soils in Wisconsin, SPR 0092-03-11, Wisconsin Department of Transportation, University of Wisconsin, Milwaukee, May 2006.

TITUS-GLOVER, L. e E.B. FERNANDO, Evaluation of Pavement Subgrade Material Properties and Test Procedures, Final Report No. FHWA/TX-96/1335-2, Texas Transportation Institute, Texas A\&M University, College Station, Nov. 1995.

TOROS, U., HILTUNEN, D.R., 2008, "Effects of Moisture and Time on Stiffness of Unbound Aggregate Base Materials", TRB Annual Meeting, Washington, D.C.

TURNBULL, W. J.; FOSTER, C. R. (1956). Stabilization of materials by compaction. Journal of Soil Mechanics and Foundation Division, ASCE, vol. 82, n.2, pp. 934.1934.23.

TRB (2003) Harmonized Test Methods for Laboratory Determination of Resilient Modulus For Flexible Pavement Design. NCHRP Project 1-28 A. Transportation Research Board of the National Academies, Washington, D.C., 2003.

UZAN, J., "Characterization of Granular Materials," Transportation Research Record 1022, Transportation Research Board, National Research Council, Washington, D.C., 1985, pp. 52-59.

"Permanent Deformation in Flexible Pavements," Journal of Transportation Engineering, Vol. 130, No. 1, Jan. 2004, pp. 6-13.

VAN TIL, MCCULLOUGH, B., VALLERGA, B., HICKS, R. (1972) Evaluation of AASHTO Interim Guides for Design of Pavement Structures, NCHRP 128, Highway Research Board.

VALLE, N. (1966) Utilização de solos saprolíticos na pavimentação viária em Santa Catarina. Dissertação de mestrado. Universidade Federal de Santa Catarina, Florianópolis, 1966. 
VENDRAMINI, C.A. e PINTO, C.S. (1974). CBR em função do processo de compactação. V Congr. Brasileiro de Mec. Solos. Vol II pg 71-83.

VERTAMATTI, E. (1988). Contribuição ao conhecimento geotécnico de solos da Amazônia com base na investigação de aeroportos e metodologias MCT e resiliente. São José dos Campos. Tese de Doutorado - Instituto Tecnológico da Aeronáutica.

VILLIBOR. D. F.; NOGAMI, J. S.; FORTES F. Q.; TONATO, J. E. (1995). Pavimento de Baixo Custo com Base de Argila Laterítica. 29a Reunião Anual de Pavimentação, Cuiabá, MT. ABPv.

VON QUINTUS, H., e B. KILLINGSWORTH. Analyses Relating to Pavement Material Characterizations and Their Effects on Pavement Performance. FHWA-RD-97-085. FHWA, McLean, Va., 1998.

WESTERGAARD, H. M. Theory of stresses in road slabs. Proc., 4th Annual Meeting, Highway Research Board, Washington, D.C., 1925.

WILSON, B.E., S.M. SARGAND, G.A. HAZEN, e R. GREEN, "Multiaxial Testing of Subgrade," Transportation Research Record 1278, Transportation Research Board, National Research Council, Washington, D.C., 1990, pp. 91-95

WITCZAK, MATTHEW W., XICHENG QI, MUHMMAD W. MIRZA (1995) "Use of NonLinear Subgrade Modulus in AASHTO Design Procedure", Journal of Transportation Engineering May/June 1995.

WITCZAK, M.W.; J. UZAN, The Universal Airport Pavement Design System, Report 1 of 4, Granular Material Characterization, University of Maryland, College Park, 1988.

WITZACK, M., X. QI, e M.W. MIRZA, "Use of Nonlinear Subgrade Modulus in AASHTO Design Procedures," Journal of Transportation Engineering, Vol. 121, No. 3, May/June 1995, pp. 273-282.

WOLFE, W.E. e T.S. BUTALIA, Seasonal Instrumentation of SHRP Pavements, Final Report for Ohio Department of Transportation, Ohio State University, Columbus, 2004.

WOOLSTRUM, G., "Dynamic Testing of Nebraska Soils and Aggregates," Transportation Research Record 1278, Transportation Research Board, National Research Council, Washington, D.C., 1990, pp. 27-34.

WSDOT EVERSERIES USER GUIDE. Pavement Analysis Computer Software and Case Studies. Washington State Department of Transportation, 2005.

YAU, A. e H. VON QUINTUS, Study of LTPP Laboratory Resilient Modulus Test Data and Response Characteristics, Report No. FHWA-RD-02-051, Federal Highway Administration, McLean, Va., Oct. 2002.

. "Predicting Elastic Response Characteristics of Unbound Materials and Soils," Transportation Research Record 1874, Transportation Research Board, National Research Council, Washington, D.C., 2004, pp. 47-56. 
YODER, E. J. e WITCZAK, M. W. Principles of Pavement Design. John Wiley \& Sons, Inc. USA, 2nd edition, 1975.

ZAMAM, M. Chen, D; LAGUROS, J. Resilient moduli of granular materials. Journal of Transportation Engineering, v.120, n.6, p. 967-88, 1994.

ZHANG, Z.J., Y.M. ABU-FARSAKH, e L. WANG, Evaluation of Trench Backfill at Highway Cross-Drain Pipes, Presented at the 83rd Annual Meeting of the Transportation Research Board, Washington, D.C., Jan. 11-15, 2004.

ZHANG, X; SUN, L. (2003) Backcalculation of Asphalt Pavement Moduli with Convergent Procedure and Unique Solution. Transportation Research Board-2003 Annual Meeting CD-ROM.

ZHANG, X. L. (2004) Novel Method for Backcalcution of Asphalt Pavement Moduli. Transportation Research Board, no 1869, p.67-72. 
9 ANEXO A - RESULTADOS INDIVIDUAIS DAS SONDAGENS E ENSAIOS - ESTUDO DE CASO DE UMA RODOVIA FEDERAL 
Apresentam-se a seguir os resultados mais importantes obtidos em cada um dos poços de inspeção realizados no pavimento.

\subsection{Poço de Inspeção do km 402 (Pista Norte)}

A Figura 9.1 a seguir ilustra a localização do poço de inspeção do km 402 (pista norte) bem como o mapeamento geológico do local. Verifica-se que este pavimento se situa numa área de predominância de solo arenoso e cascalho.

A Tabela 9.1 apresenta o registro histórico de intervenções do pavimento. De acordo com este registro, o pavimento do km 402, pista norte passou por intervenções do tipo reciclagem de base no ano de 2011.

A Tabela 9.2 apresenta a estrutura do pavimento identificada na ocasião da abertura do poço de inspeção. Este pavimento foi identificado como pavimento do tipo semirrígido com base de BGTC.

A Tabela 9.3 e Tabela 9.4 apresentam os resultados estatísticos obtidos a partir do ensaio de $L W D$ sobre as camadas de subleito e camada de sub-base granular. Enquanto a Figura 9.2 apresenta o gráfico comparativo e dos pesos específicos aparentes secos e umidades obtidas em campo e em laboratório (curva de compactação de laboratório versus ensaios de umidade e peso específico aparente seco in situ). Verifica-se que a situação de campo está bastante próxima à condição de umidade ótima e peso específico aparente seco máximo do material ensaiado.

A Figura 9.3 apresenta o resultado da retroanálise da série histórica de deflexões do pavimento em estudo e a Figura 9.4 apresenta os gráficos de tensões calculadas no subleito para duas situações históricas distintas, ilustrando as variações de comportamento do subleito registradas através dos ensaios com FWD.

A Tabela 9.5 apresenta o resumo dos resultados dos ensaios de laboratório realizados com o material do subleito.

A Figura 9.5 apresenta um gráfico comparativo entre o valor de módulo medido em laboratório e os valores de módulo previstos pelos modelos da literatura para as condições de umidade ótima e peso específico aparente seco máximo. Verificou-se 
uma convergência maior para os modelos de Rada \& Witczac (1981), Carmichael \& Stuart (1985) e Jin et. al. - solo 2 (1994).

A Figura 9.6 apresenta um gráfico comparativo entre o valor de módulo in situ medido com $L W D$ e os valores de módulo previstos pelos modelos da literatura para as condições de umidade e peso específico aparente seco aferidos no ensaio in situ. Verificou-se uma convergência maior para os modelos de Malla \& Joshi (2006), e AASHTO/2002 (ME-PDG).

A Figura 9.7 apresenta um gráfico comparativo entre o valor mínimo de módulo in situ medido com FWD (retroanálise) e os valores de módulo previstos pelos modelos da literatura, para as condições de saturação próxima da saturação máxima (adotou-se S próximo a 98\%). Verificou-se uma convergência maior para o modelo de Takeda (2006).

A Figura 9.8 apresenta os gráficos da série histórica dos indicadores estruturais do pavimento (deflexão máxima, raio de curvatura, e deflexão a $120 \mathrm{~mm}$ do ponto de aplicação de carga) no segmento que contempla o local em estudo.

A Figura 9.9 apresenta os gráficos da série histórica dos valores de módulo de resiliência retroanalisado $(F W D)$ e Quociente de Irregularidade ( $Q I)$ no segmento que contempla o local em estudo.

A Figura 9.10 apresenta os dados estatísticos (valores máximos, mínimos, média e média mais ou menos desvio padrão), bem como boxplot dos indicadores estruturais do pavimento no segmento homogêneo determinado para o ponto em estudo. 


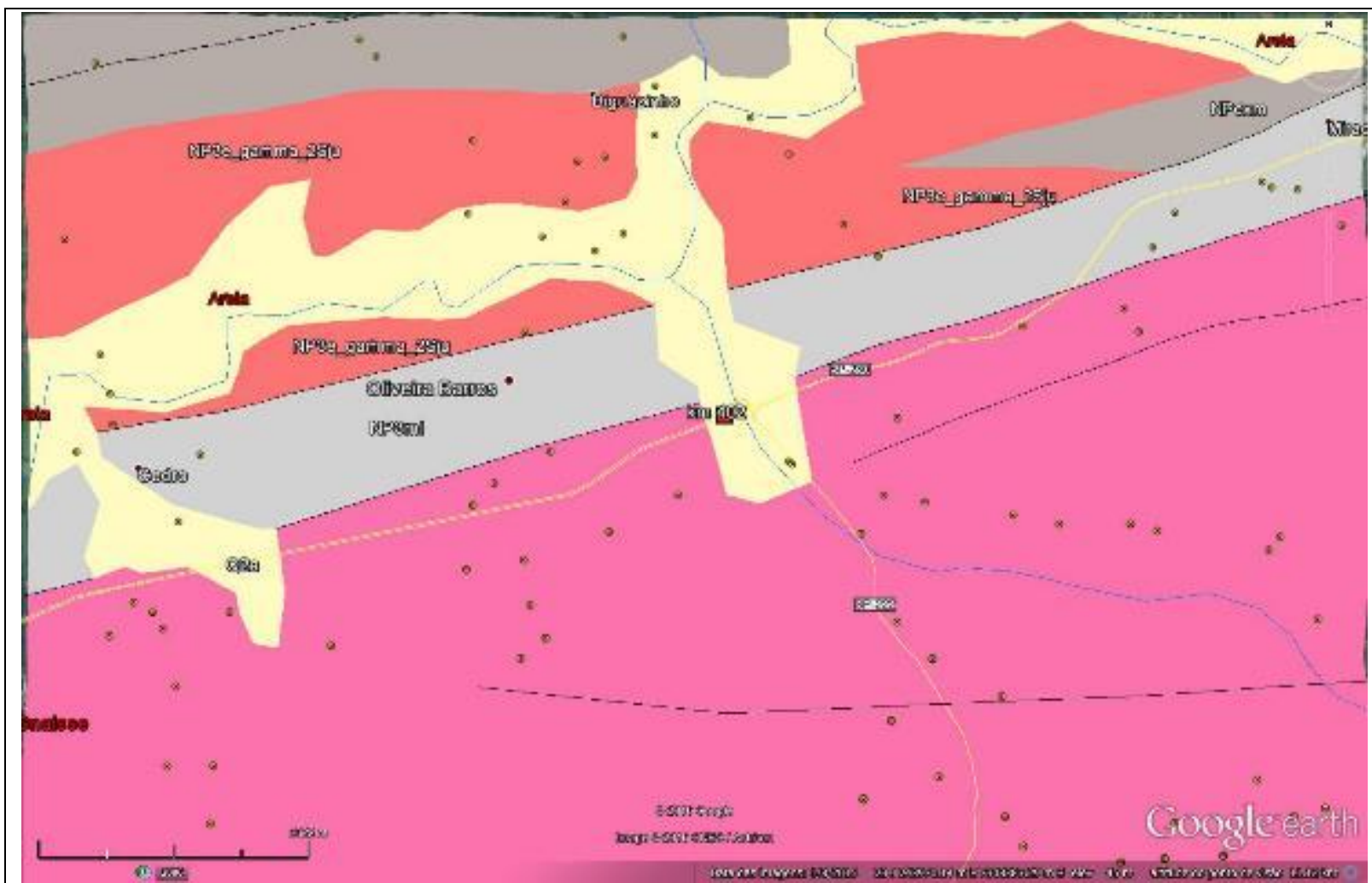

LEGENDA:

Xistos, localmente migmatíticos: Xisto

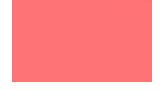

Granito Juquiá: Monzogranito

Rochas miloníticas: Protomilonito,

Milonito, Ultramilonito

Atuba, Gnaisse Itapeúna: Gnaisse, Biotita monzogranito, Diorito, Granito gnaisse

Depósitos aluvionares: Depósitos de areia

Depósitos de cascalho

Afloramentos

Figura 9.1: Mapa Geológico do local sondado - km 402 (Pista Norte)

Fonte: Geobank/Google Earth®

Tabela 9.1: histórico de intervenções informado - km 402 (pista norte)

\begin{tabular}{ccccccc}
$\mathbf{k m}$ & $\begin{array}{c}\mathbf{k m} \\
\text { inicial }\end{array}$ & $\begin{array}{c}\mathbf{k m} \\
\text { final }\end{array}$ & Solução Aplicada & $\begin{array}{c}\text { Larg. } \\
\mathbf{( m )}\end{array}$ & $\begin{array}{c}\text { Esp. } \\
\mathbf{( c m})\end{array}$ & $\begin{array}{c}\text { Data da } \\
\text { Interv. }\end{array}$ \\
\hline \multirow{2}{*}{402} & 401,990 & 402,205 & MICROREVESTIMENTO & 3,80 & 1,00 & $17 / 06 / 2011$ \\
\cline { 2 - 7 } & 401,820 & 402,240 & RECICLAGEM DE BASE & 3,85 & 32,00 & $06 / 07 / 2011$ \\
\hline
\end{tabular}


Tabela 9.2: Estrutura do pavimento da faixa externa - km 402 (pista norte)

\begin{tabular}{|c|c|c|c|c|}
\hline km & Pista & Camada & $\begin{array}{l}\text { Espessura } \\
\text { (cm) }\end{array}$ & Camada \\
\hline \multirow{4}{*}{402} & \multirow{4}{*}{ Norte } & 1 & 13,0 & $C A$ \\
\hline & & 2 & 19,0 & BGTC \\
\hline & & 3 & 16,0 & BGS \\
\hline & & 4 & - & $\mathrm{SL}$ \\
\hline
\end{tabular}

Tabela 9.3: Estatística dos resultados do ensaio com $L W D$

\begin{tabular}{|c|c|c|c|c|c|c|c|c|c|c|c|}
\hline \multicolumn{12}{|c|}{ Resumo } \\
\hline \multirow{2}{*}{ km } & \multirow{2}{*}{ Material } & \multicolumn{5}{|c|}{ Leituras $\mathrm{D}_{0, \mathrm{LWD}}\left(10^{-2} \mathrm{~mm}\right)$} & \multicolumn{5}{|c|}{$E_{0, \text { calc }}\left(\mathbf{k f g} / \mathrm{cm}^{2}\right)$} \\
\hline & & Mín. & Máx. & Média & Desvio & CV(\%) & Mín. & Máx. & Média & Desvio & CV(\%) \\
\hline 402 & BGS & 34 & 67 & 51 & 13 & 26 & 336 & 663 & 477 & 130 & 27 \\
\hline 402 & SL & 34 & 67 & 45 & 14 & 31 & 336 & 669 & 537 & 140 & 26 \\
\hline
\end{tabular}

Tabela 9.4: Estatística dos resultados de determinação do módulo da camada de BGS Resumo

\begin{tabular}{|c|c|c|c|c|c|c|}
\hline \multirow{2}{*}{ km } & \multirow{2}{*}{ Material- } & \multicolumn{5}{|c|}{$E_{\text {sb,retro }}\left(\mathrm{kfg} / \mathrm{cm}^{2}\right)$} \\
\hline & & Mín. & Máx. & Média & Desvio & CV(\%) \\
\hline 402 & BGS & 849 & 2.697 & 1.601 & 738 & 46 \\
\hline
\end{tabular}

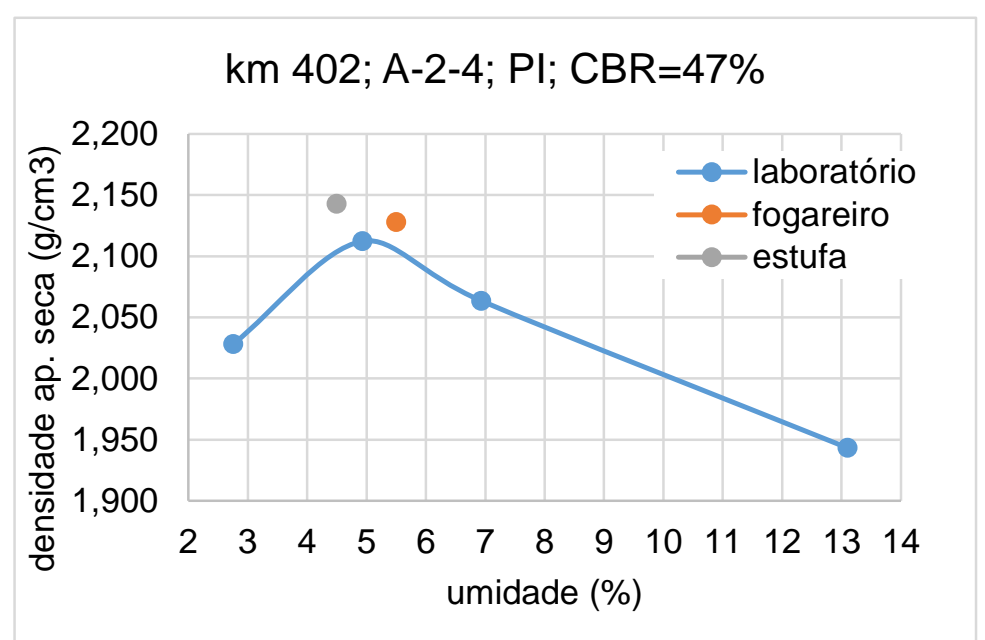

Figura 9.2: Comparativo entre pesos específicos aparentes secos - laboratório x campo (subleito, km 402, norte) 


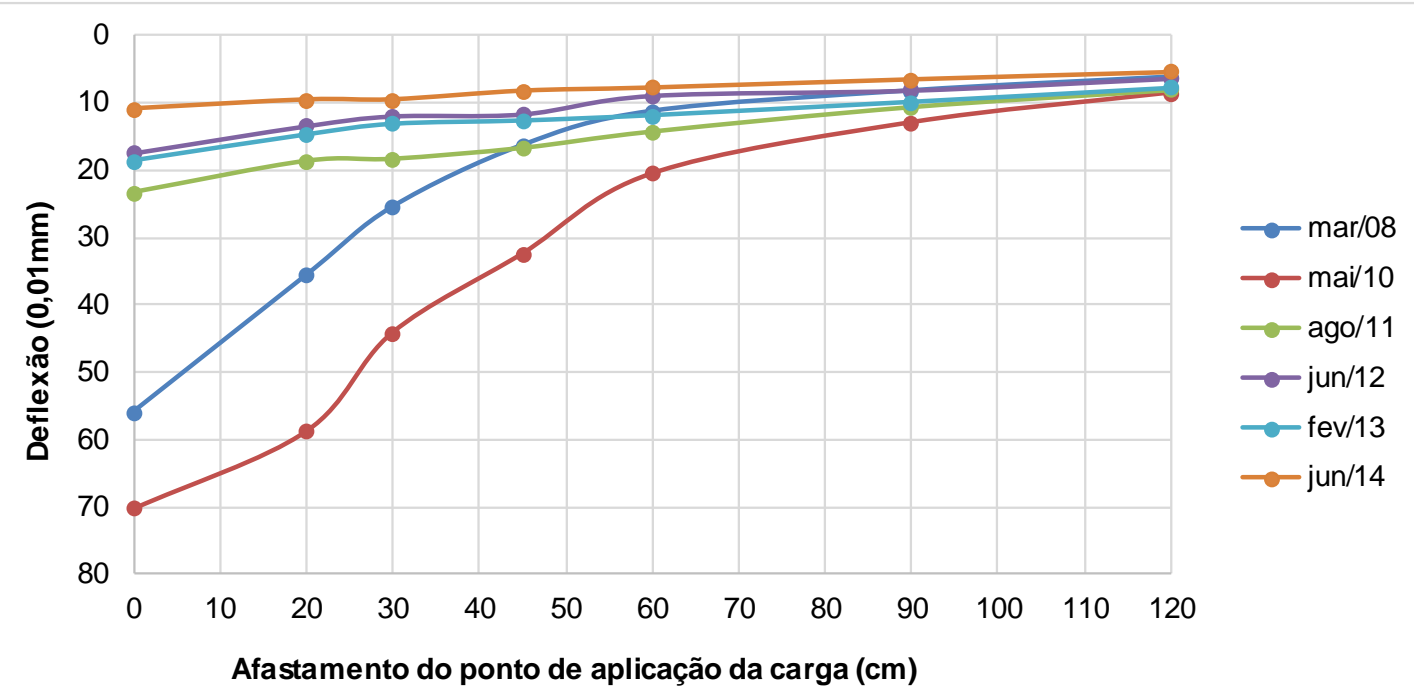

\begin{tabular}{|c|c|c|c|c|c|c|c|c|}
\hline $\begin{array}{c}\text { Mês/ano } \\
\text { Levantamento }\end{array}$ & $\begin{array}{l}\text { Tar } \\
\left({ }^{\circ} \mathrm{C}\right)\end{array}$ & $\begin{array}{l}\text { Tpav } \\
\left({ }^{\circ} \mathrm{C}\right)\end{array}$ & $\operatorname{Er} 1\left(\mathrm{kgf} / \mathrm{cm}^{2}\right)$ & $\mathrm{Eb}\left(\mathrm{kgf} / \mathrm{cm}^{2}\right)$ & Esb $\left(\mathrm{kgf} / \mathrm{cm}^{2}\right)$ & Esl $\left(\mathrm{kgf} / \mathrm{cm}^{2}\right)$ & $\begin{array}{l}\text { Esl x 0,33 } \\
\left(\mathrm{kgf} / \mathrm{cm}^{2}\right)\end{array}$ & $\begin{array}{c}\text { Esl } \\
\text { (AASHTO/ } \\
93 \text { ) }\end{array}$ \\
\hline $\begin{array}{l}\text { Espessuras } \\
(\mathrm{cm})\end{array}$ & & & 13,0 & 19,0 & 16,0 & - & - & - \\
\hline Materiais & & & CA & BGTC & BGS & SL & SL & SL \\
\hline mar/08 & - & - & \multirow{2}{*}{\multicolumn{5}{|c|}{ * Provável estrutura antiga de pavimento flexível }} & 441 \\
\hline $\mathrm{mai} / 10$ & 29 & 37 & & & & & & 317 \\
\hline ago/11 & 25 & 35 & 13.000 & 90.000 & 3.000 & 1.100 & 363 & 335 \\
\hline jun/12 & 26 & 30 & 15.550 & 110.500 & 3.500 & 1.660 & 548 & 431 \\
\hline $\mathrm{fev} / 13$ & 34 & 41 & 19.100 & 120.000 & 3.500 & 1.330 & 439 & 350 \\
\hline jun/14 & 12 & 17 & 83.500 & 130.000 & 3.500 & 1.870 & 617 & 511 \\
\hline
\end{tabular}

Figura 9.3: Retroanálise das bacias de deflexões (série histórica) - km 402 (pista norte)
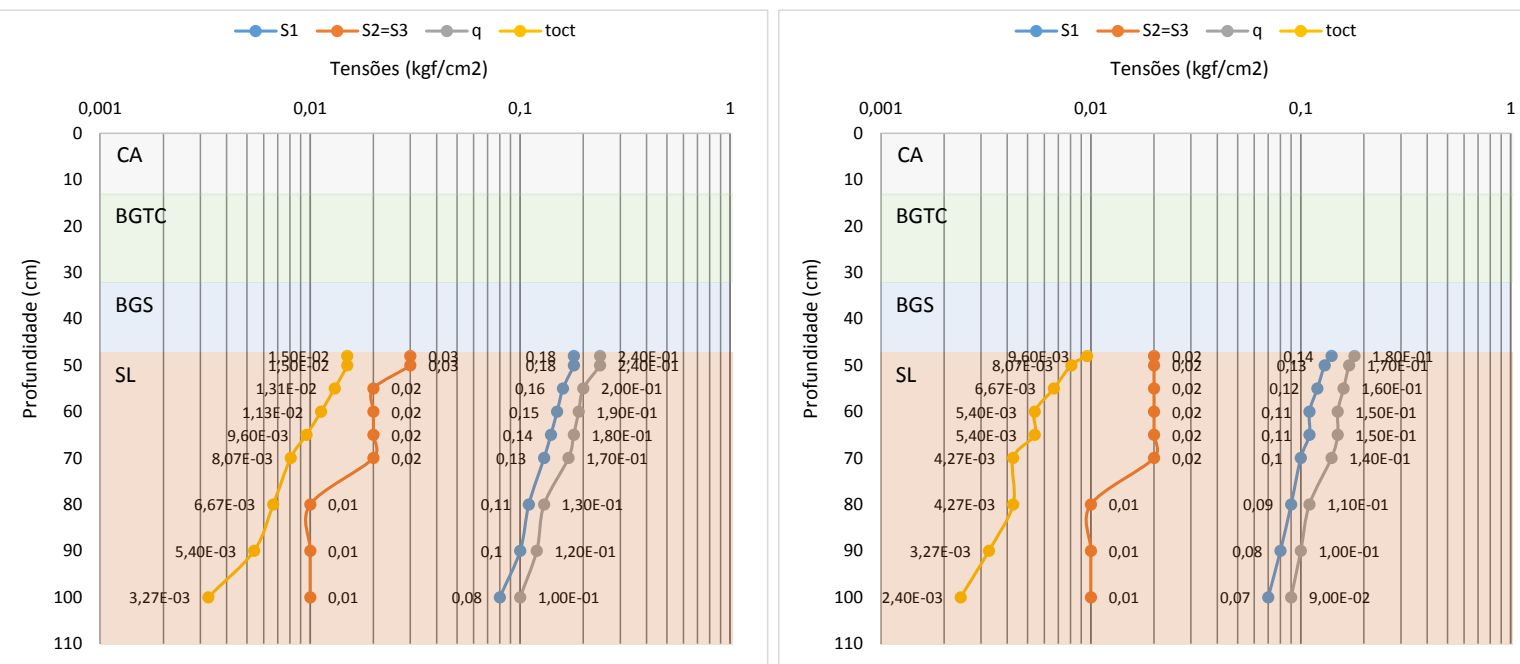

Figura 9.4: Tensões no subleito calculadas para (a) 2011 e (b) 2014 
Tabela 9.5: Resumo dos ensaios realizados com material próximo ao km 402

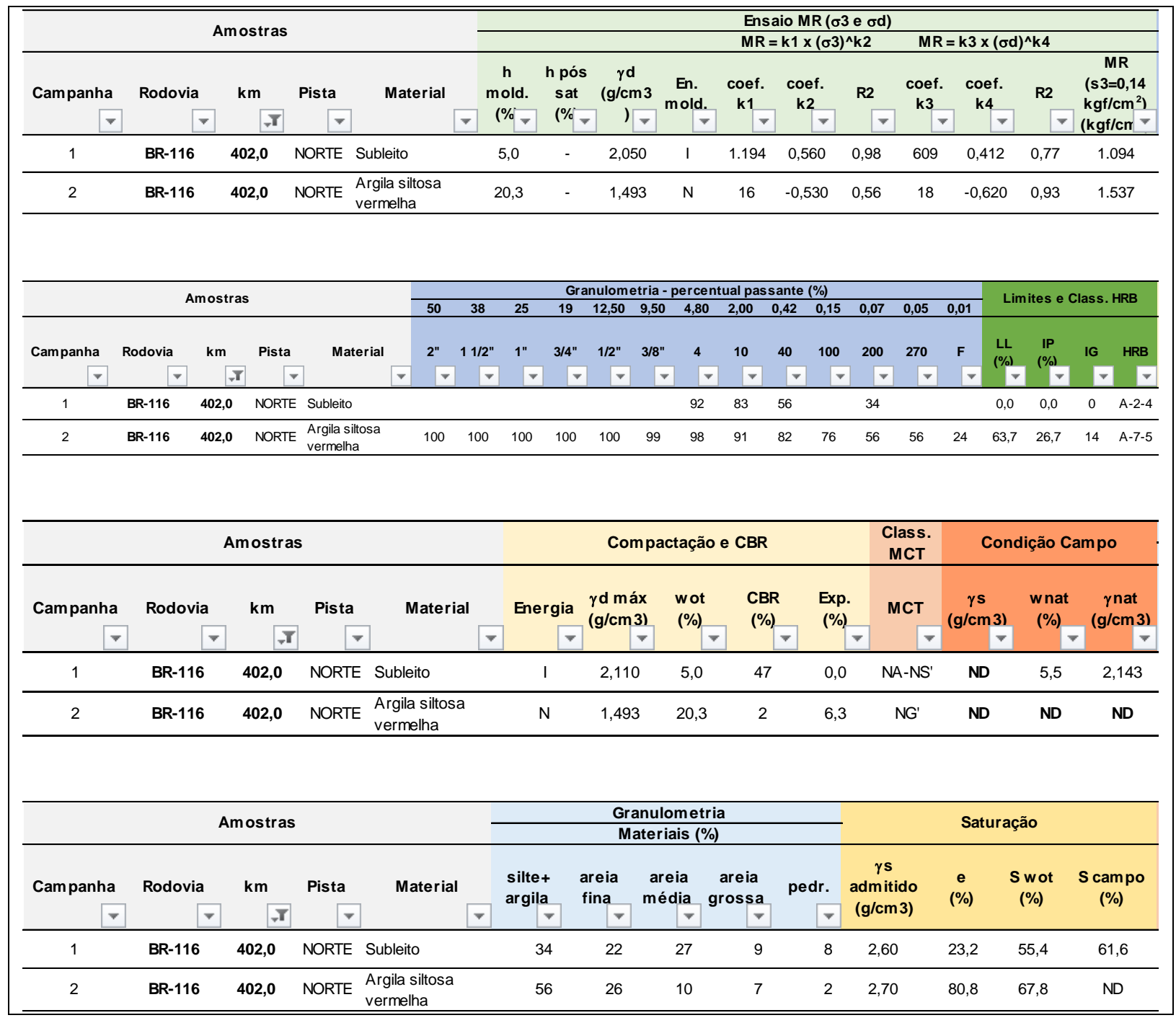




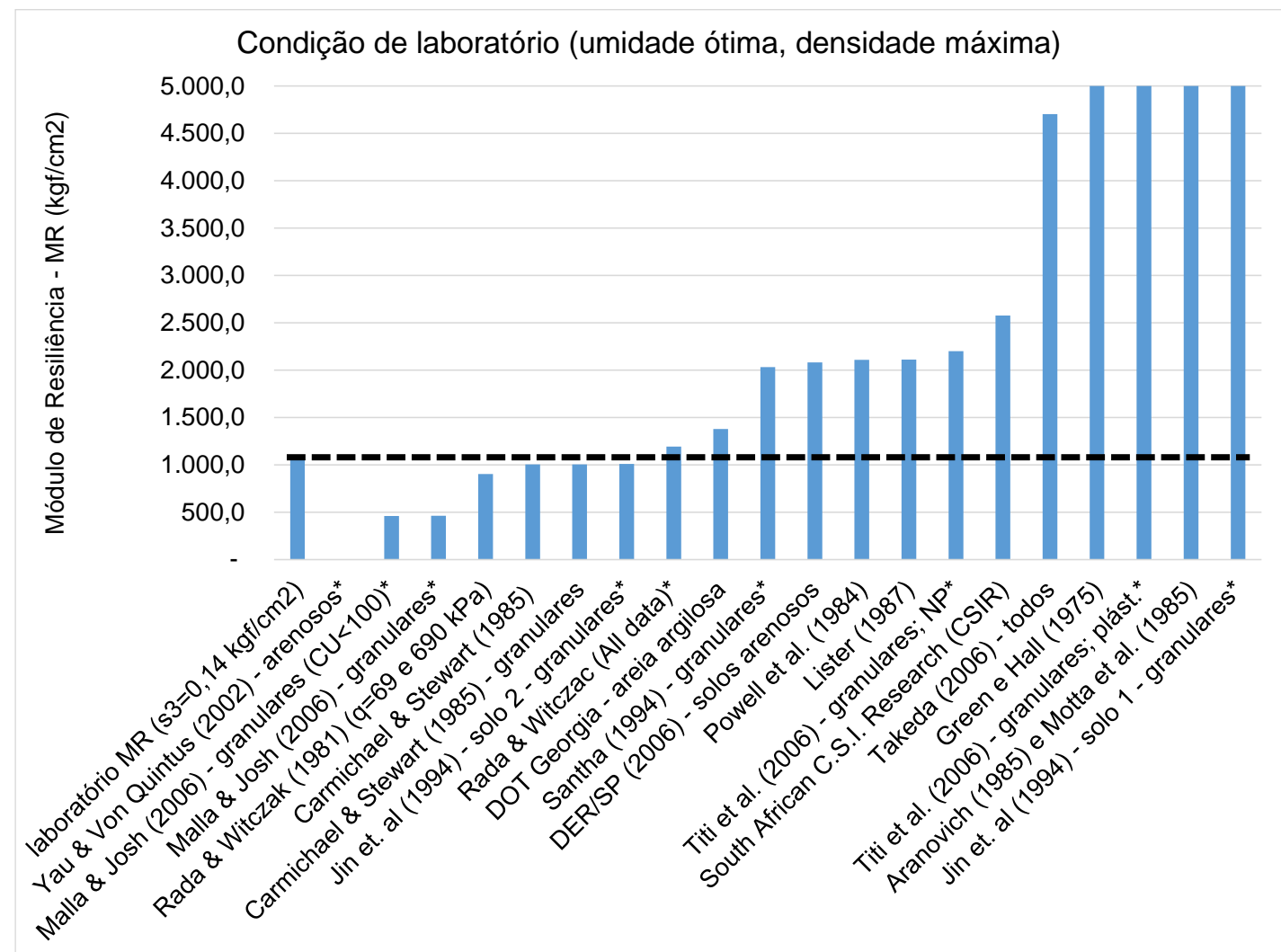

Figura 9.5: Comparativo entre $M R$ de laboratório e modelos de previsão de $M R$ (condição de umidade ótima)

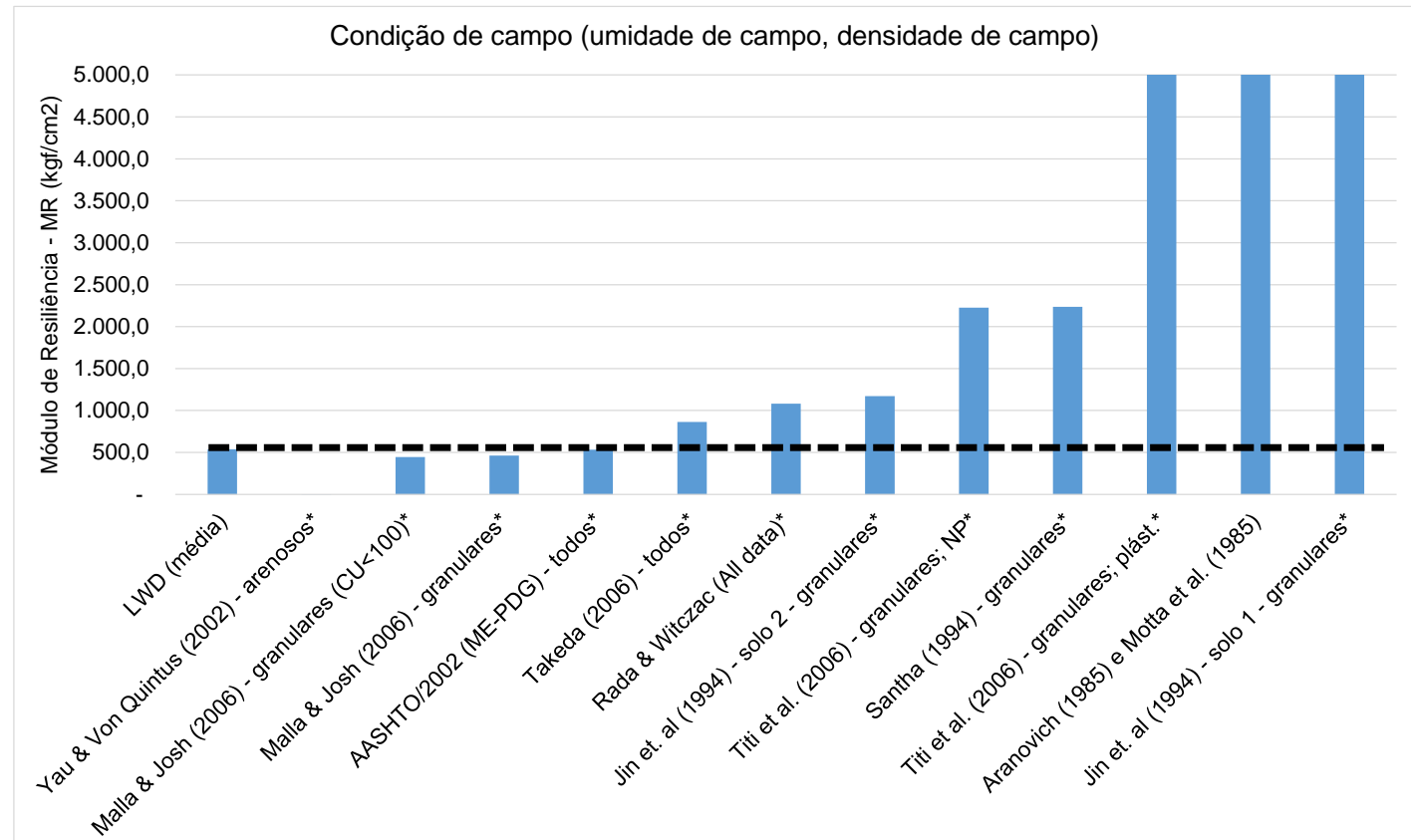

Figura 9.6: Comparativo entre $M R$ in situ $(L W D)$ e modelos de previsão de $M R$ (condição de umidade verificada no campo) 


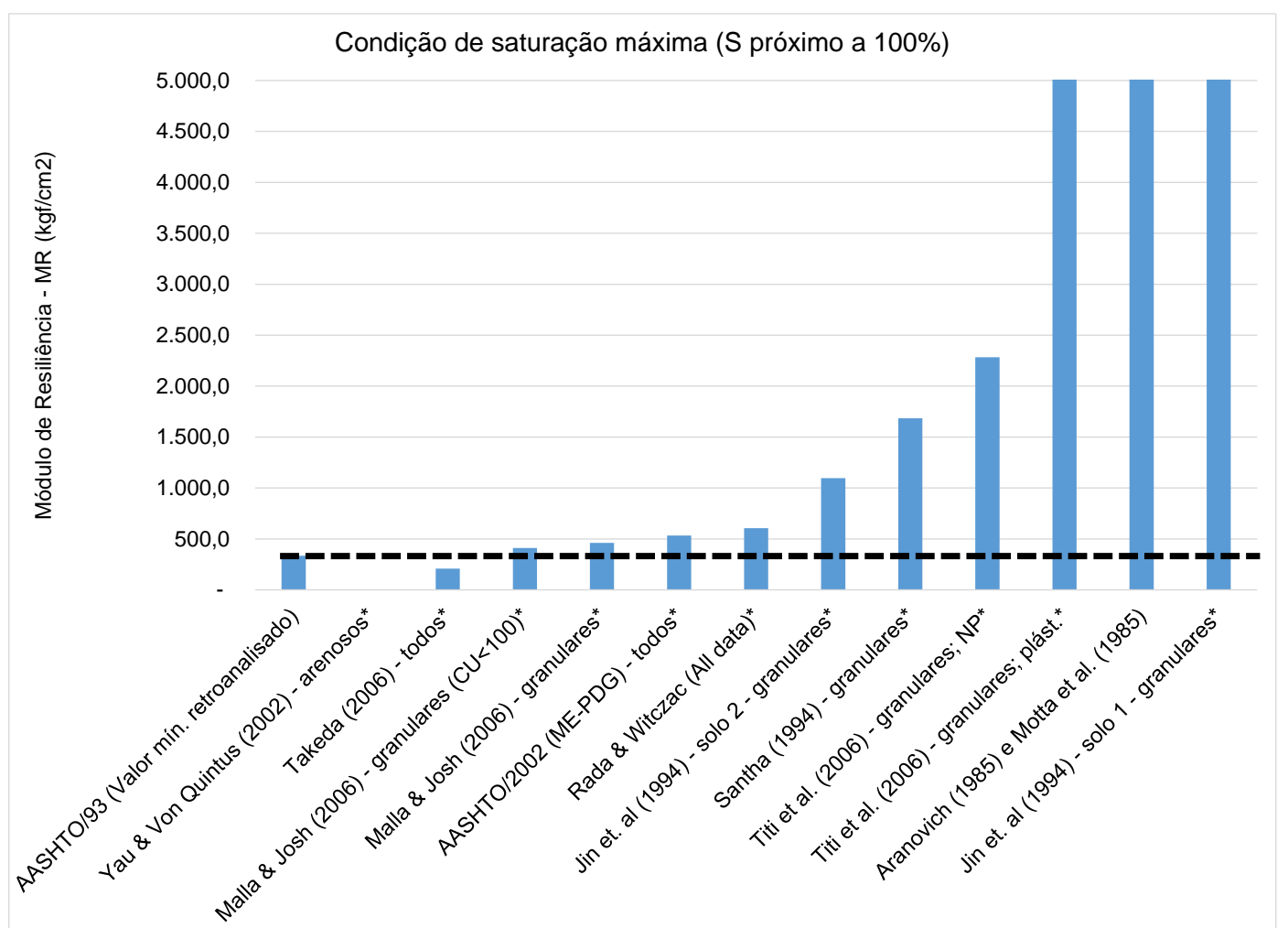

Figura 9.7: Comparativo entre $M R$ in situ mínimo verificado $(F W D)$ e modelos de previsão de $M R$ (condição de saturação próxima a 100\%) 

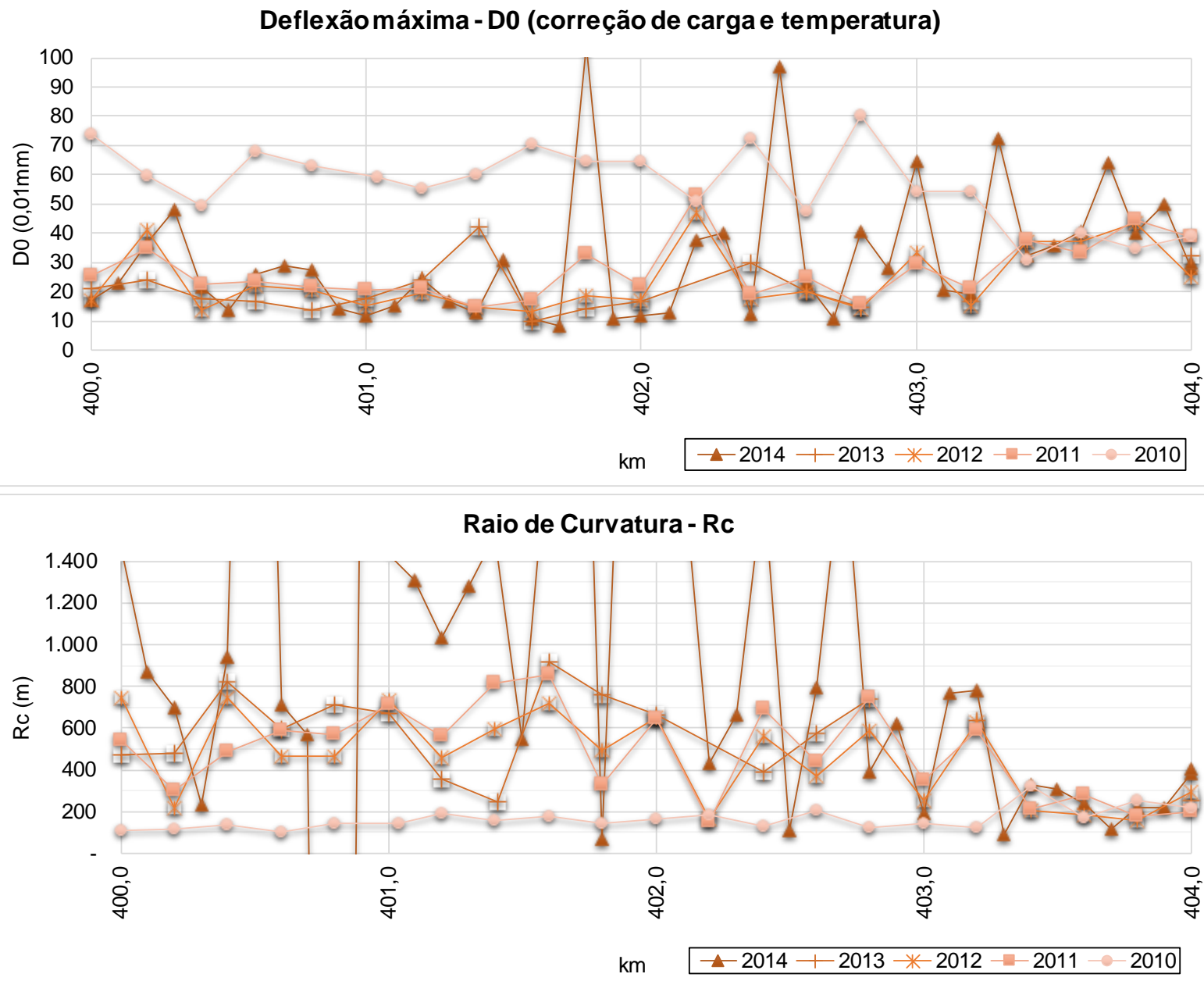

Deflexãoa 120mm - D120

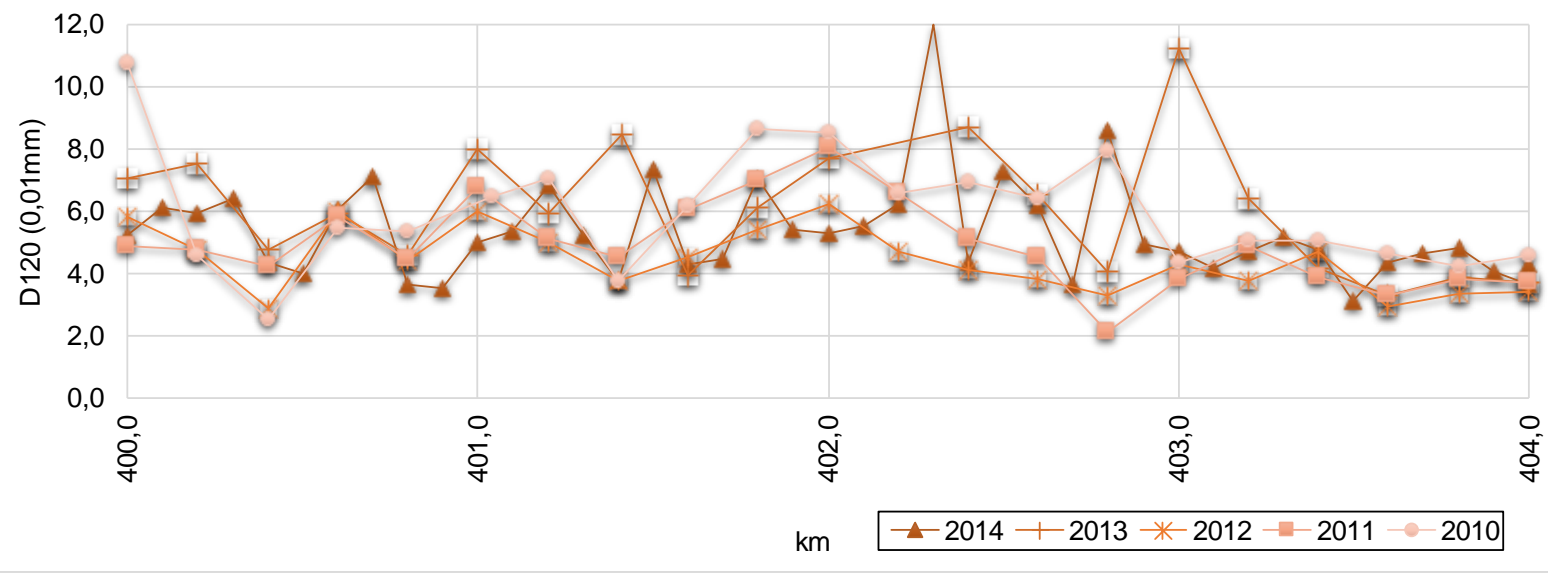

Figura 9.8: Gráficos de série histórica dos indicadores estruturais do pavimento no segmento do km 402 (pista norte) 


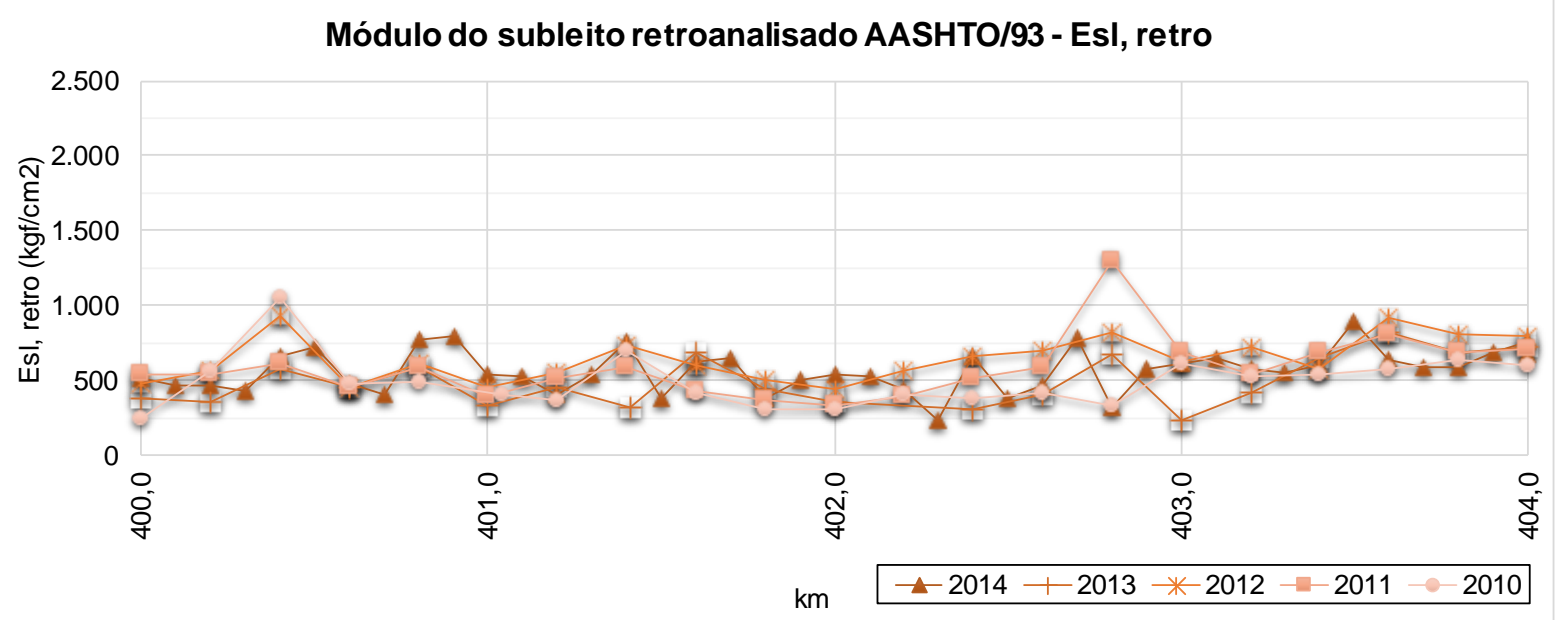

Figura 9.9: Gráficos da série histórica dos dados de módulo de resiliência retroanalisado (FWD) do pavimento no segmento do $\mathrm{km} 402$ (pista norte) 
401,5 402,5 DECRESCENTE
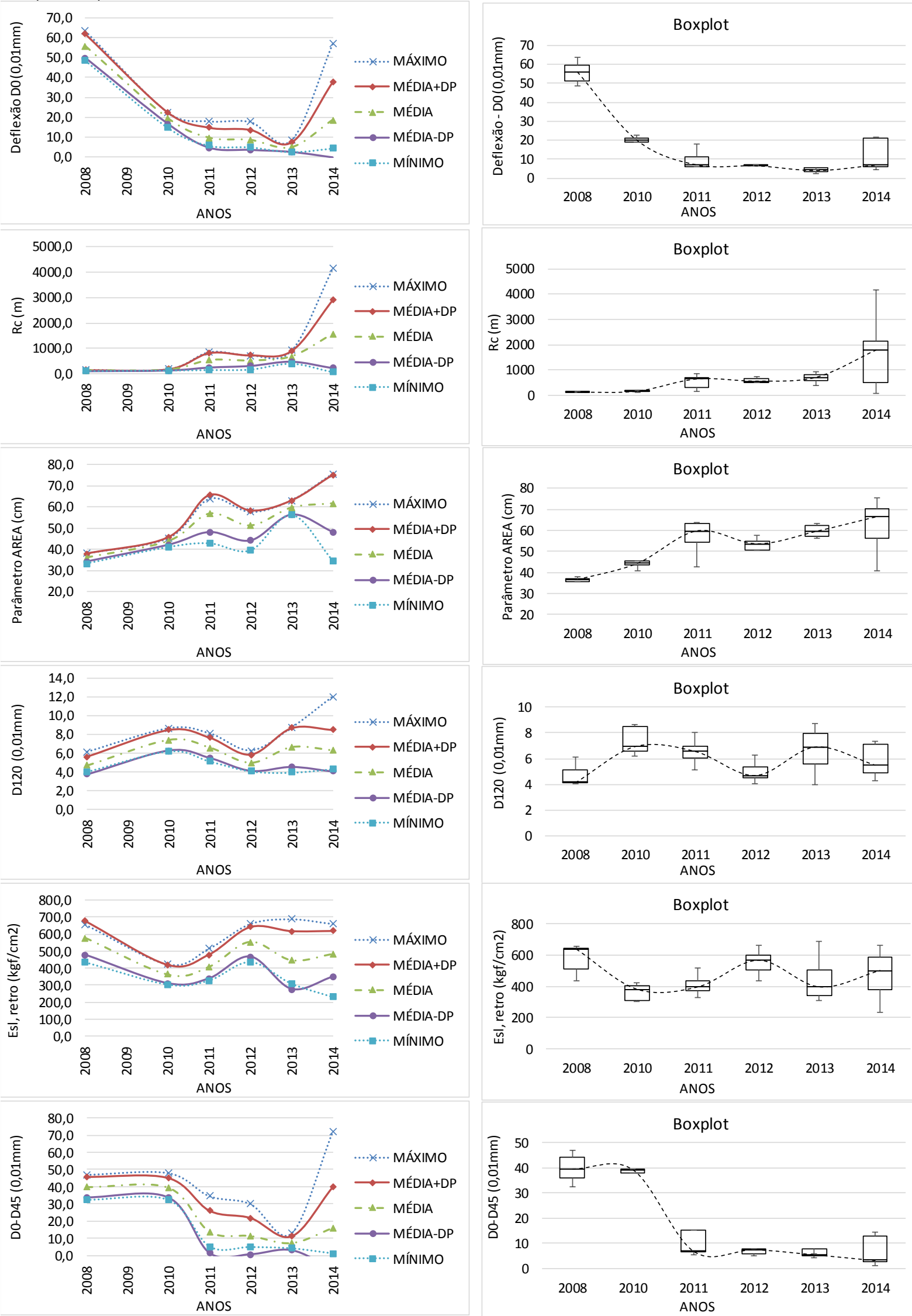

Figura 9.10: Estatísticas dos Parâmetros do pavimento (S. Homogêneo do km 402) 


\subsection{Poço de Inspeção do km 405 (Pista Norte)}

A Figura 9.11 a seguir ilustra a localização do poço de inspeção do km 405 (pista norte) bem como o mapeamento geológico do local.

A Tabela 9.6 apresenta o registro histórico de intervenções do pavimento.

A Tabela 9.7 apresenta a estrutura do pavimento identificada na ocasião da abertura do poço de inspeção. Este pavimento foi identificado como pavimento do tipo flexível com base granular.

A Tabela 9.8 e Tabela 9.9 apresentam os resultados estatísticos obtidos a partir do ensaio de $L W D$ sobre as camadas de subleito e camada de base granular. Enquanto a Figura 9.12 apresenta o gráfico comparativo dos pesos específicos aparentes secos e umidades obtidos em campo e em laboratório (curva de compactação de laboratório versus ensaios de umidade e peso específico aparente seco in situ). Verifica-se que o material no campo está em peso específico aparente seco e umidade bastante inferiores àquelas relativas à condição ótima de compactação.

A Figura 9.13 apresenta o resultado da retroanálise da série histórica de deflexões do pavimento em estudo e a Figura 9.14 apresenta os gráficos de tensões calculadas no subleito para duas situações históricas distintas, ilustrando as variações de comportamento do subleito registradas através dos ensaios com FWD.

A Tabela 9.10 apresenta o resumo dos resultados dos ensaios de laboratório realizados com o material do subleito e dos materiais da faixa de domínio no local.

A Figura 9.15 apresenta um gráfico comparativo entre o valor de módulo medido em laboratório e os valores de módulo previstos pelos modelos da literatura, para as condições de umidade ótima e peso específico aparente seco máximo relativos à energia intermediária de compactação. Verificou-se uma convergência maior para os modelos de Rada \& Witczac (1981), Mall \& Josh (2006)

A Figura 9.16 apresenta um gráfico comparativo entre o valor de módulo in situ medido com $L W D$ e os valores de módulo previstos pelos modelos da literatura, paras as condições de umidade e peso específico aparente seco verificados em campo no momento da abertura do poço de inspeção. Verificou-se uma convergência maior para 
os modelos de Malla \& Joshi - materiais granulares (2006), e AASHTO/2002 (ME$P D G)$.

A Figura 9.17 apresenta um gráfico comparativo entre o valor mínimo de módulo in situ medido com FWD (retroanálise) e os valores de módulo previstos pelos modelos da literatura, para as condições de saturação próxima da saturação máxima (adotouse $\mathrm{S}$ próximo a 98\%). Verificou-se uma convergência maior para o modelo da AASHTO/2002 e Malla \& Joshi - materiais granulares (2006).

A Figura 9.18 apresenta os gráficos da série histórica dos indicadores estruturais do pavimento (deflexão máxima, raio de curvatura, e deflexão a $120 \mathrm{~mm}$ do ponto de aplicação de carga) no segmento que contempla o local em estudo.

A Figura 9.19 apresenta os gráficos da série histórica dos valores de módulo de resiliência retroanalisado $(F W D)$ e Quociente de Irregularidade ( $Q I)$ no segmento que contempla o local em estudo.

A Figura 9.20 apresenta os dados estatísticos (valores máximos, mínimos, média e média mais ou menos desvio padrão), bem como boxplot dos indicadores estruturais do pavimento no segmento homogêneo determinado para o ponto em estudo. 


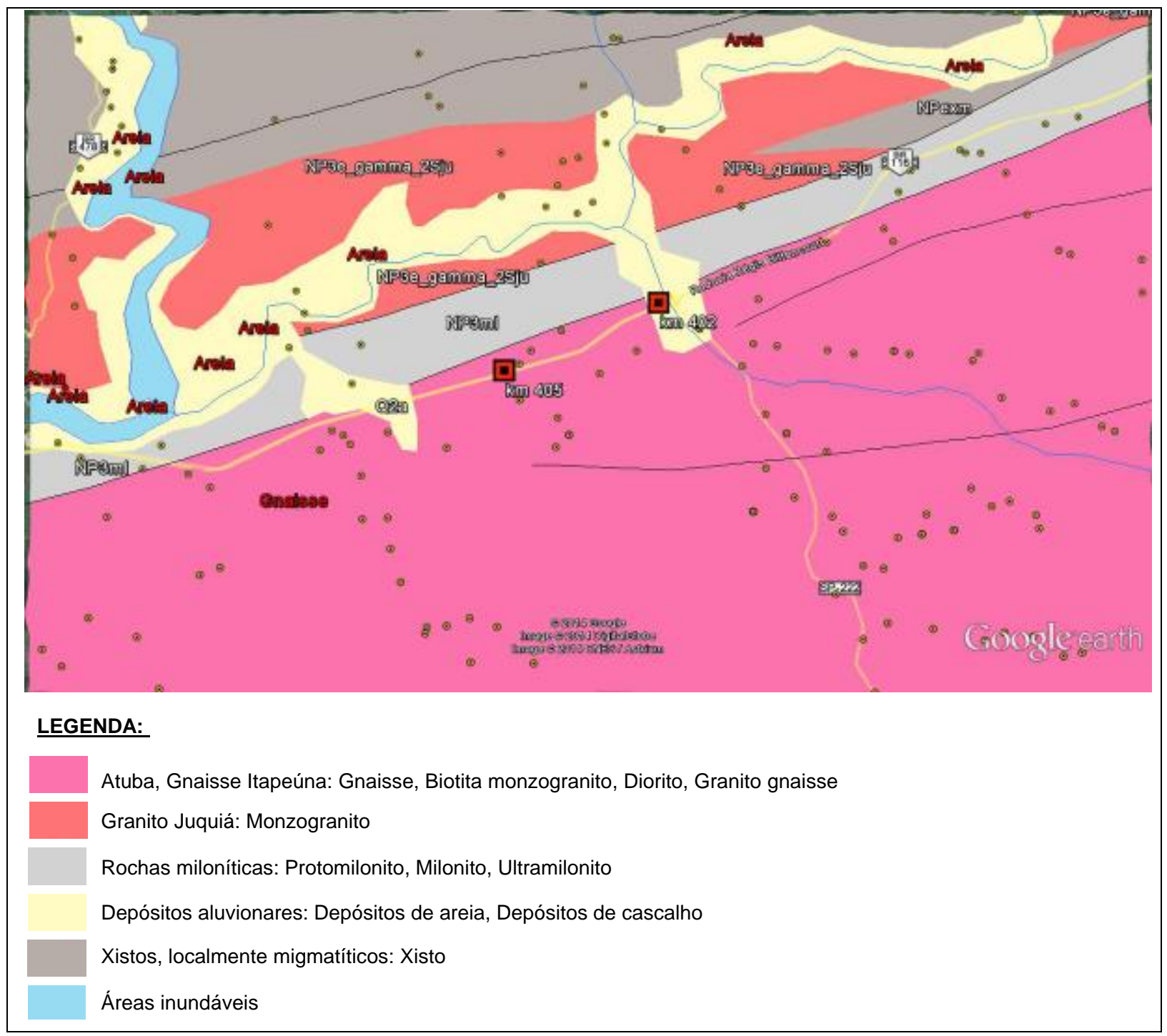

Figura 9.11: Mapa Geológico do local sondado - km 405 (Pista Norte) Fonte: Geobank/Google Earth®

Tabela 9.6: histórico de intervenções informado - km 405 (pista norte)

\begin{tabular}{|c|c|c|c|c|c|c|}
\hline km & $\begin{array}{c}\text { km } \\
\text { inicial }\end{array}$ & $\begin{array}{c}\text { km } \\
\text { final }\end{array}$ & Solução Aplicada & $\begin{array}{l}\text { Larg. } \\
\text { (m) }\end{array}$ & $\begin{array}{l}\text { Esp. } \\
\text { (cm) }\end{array}$ & $\begin{array}{l}\text { Data da } \\
\text { Interv. }\end{array}$ \\
\hline \multirow{7}{*}{405} & 404,851 & 405,008 & FRESAGEM FUNCIONAL & 4,38 & 4,00 & $05 / 07 / 2008$ \\
\hline & 404,800 & 405,512 & REFORÇO DE PAVIMENTO COM ASFALTO BORR & 3,94 & 5,21 & $23 / 10 / 2010$ \\
\hline & 404,979 & 405,000 & FRESAGEM ESTRUTURAL & 4,00 & 6,00 & $21 / 07 / 2011$ \\
\hline & 404,720 & 405,000 & FRESAGEM FINA & 4,00 & 1,50 & $06 / 12 / 2012$ \\
\hline & 404,551 & 405,033 & MICROREVESTIMENTO & 4,30 & 1,20 & $11 / 01 / 2013$ \\
\hline & 404,800 & 405,100 & FRESAGEM FINA & 4,00 & 1,20 & $09 / 04 / 2014$ \\
\hline & 404,785 & 405,110 & MICROREVESTIMENTO & 4,30 & 1,20 & $12 / 06 / 2014$ \\
\hline
\end{tabular}


Tabela 9.7: Estrutura do pavimento da faixa externa - km 405 (pista norte)

\begin{tabular}{ccccc}
\multirow{2}{*}{$\mathbf{k m}$} & Pista & Camada & $\begin{array}{c}\text { Espessura } \\
\text { (cm) }\end{array}$ & Camada \\
\hline \multirow{3}{*}{405} & \multirow{3}{*}{ Norte } & 1 & 14,0 & CA \\
\cline { 3 - 5 } & & 26,0 & BGS \\
\cline { 3 - 5 } & & & - & SL \\
\hline
\end{tabular}

Tabela 9.8: Estatística dos resultados do ensaio com $L W D$

\begin{tabular}{|c|c|c|c|c|c|c|c|c|c|c|c|}
\hline \multirow{2}{*}{ km } & \multirow{2}{*}{ Material } & \multicolumn{5}{|c|}{ Leituras $\mathrm{D}_{0, \mathrm{LWD}}\left(\mathbf{1 0}^{-2} \mathrm{~mm}\right)$} & \multicolumn{5}{|c|}{$E_{0, \text { calc }}\left(\mathrm{kfg} / \mathrm{cm}^{2}\right)$} \\
\hline & & Mín. & Máx. & Média & Desvio & $\mathrm{CV}(\%)$ & Mín. & Máx. & Média & Desvio & CV(\%) \\
\hline 405 & BGS & 23 & 28 & 26 & 2 & 8 & 801 & 986 & 864 & 78 & 9 \\
\hline 405 & SL & 34 & 87 & 55 & 22 & 41 & 260 & 673 & 473 & 171 & 36 \\
\hline
\end{tabular}

Tabela 9.9: Estatística dos resultados de determinação do módulo da camada de BGS

\begin{tabular}{|c|c|c|c|c|c|c|}
\hline \multirow{2}{*}{ km } & \multirow{2}{*}{ Material } & \multicolumn{5}{|c|}{$E_{s b, \text { retro }}\left(\mathrm{kfg} / \mathrm{cm}^{2}\right)$} \\
\hline & & Mín. & Máx. & Média & Desvio & CV(\%) \\
\hline 405 & BGS & 3.724 & 5.303 & 4.257 & 662 & 16 \\
\hline
\end{tabular}

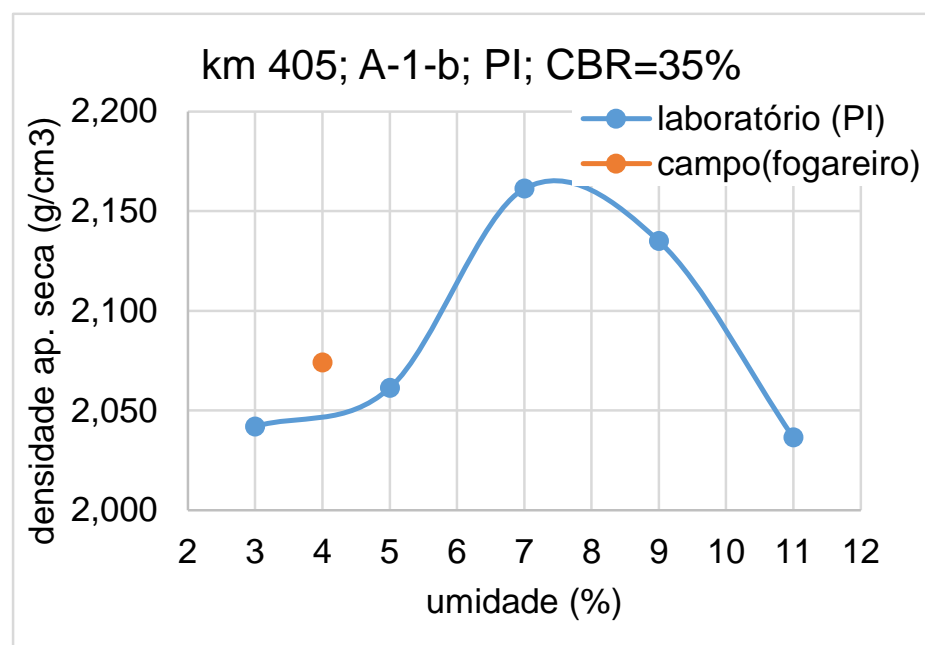

Figura 9.12: Comparativo entre pesos específicos aparentes secos - laboratório x campo (subleito, $\mathrm{km} \mathrm{405,} \mathrm{norte)}$ 


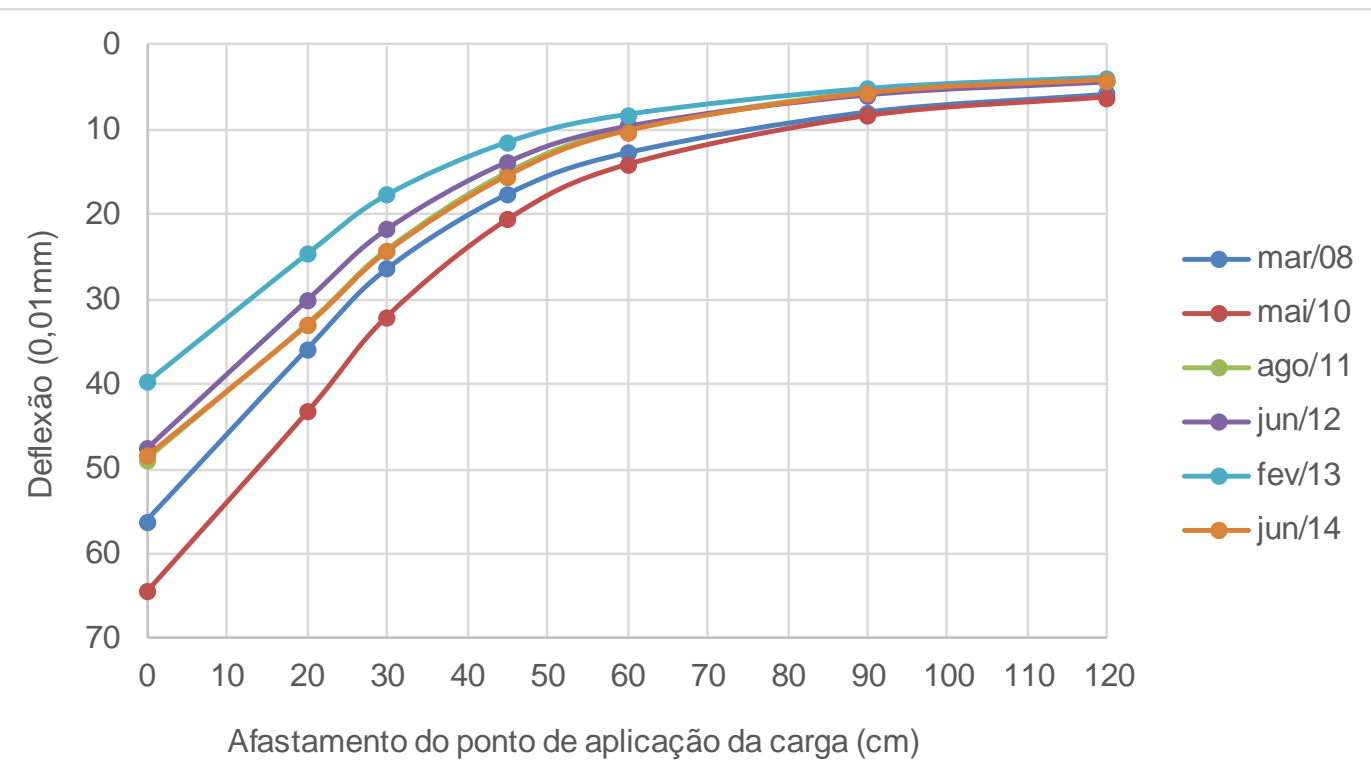

\begin{tabular}{|c|c|c|c|c|c|c|c|}
\hline $\begin{array}{c}\text { Mês/ano } \\
\text { Levantamento }\end{array}$ & $\operatorname{Tar}\left({ }^{\circ} \mathrm{C}\right)$ & $\begin{array}{l}\text { Tpav } \\
\left({ }^{\circ} \mathrm{C}\right)\end{array}$ & $\operatorname{Er} 1\left(\mathrm{kgf} / \mathrm{cm}^{2}\right)$ & $\mathrm{Eb}\left(\mathrm{kgf} / \mathrm{cm}^{2}\right)$ & Esl $\left(\mathrm{kgf} / \mathrm{cm}^{2}\right)$ & $\begin{array}{l}\text { Esl x 0,33 } \\
\left(\mathrm{kgf} / \mathrm{cm}^{2}\right)\end{array}$ & $\begin{array}{c}\text { Esl } \\
\text { (AASHTO/ } \\
93 \text { ) }\end{array}$ \\
\hline $\begin{array}{l}\text { Espessuras } \\
\text { (cm) }\end{array}$ & & & 14,0 & 26,0 & - & - & - \\
\hline Materiais & & & CA & BGS & SL & SL & SL \\
\hline mar/08 & & & 8.600 & 1.500 & 1.500 & 495 & 521 \\
\hline $\mathrm{mai} / 10$ & 30 & 38 & 10.100 & 920 & 1.400 & 462 & 477 \\
\hline ago/11 & 30 & 38 & 14.300 & 1.000 & 2.050 & 677 & 749 \\
\hline jun/12 & 28 & 31 & 10.500 & 1.500 & 2.000 & 660 & 672 \\
\hline $\mathrm{fev} / 13$ & 34 & 40 & 11.000 & 2.100 & 2.300 & 759 & 671 \\
\hline jun/14 & 17 & 25 & 15.000 & 1.000 & 2.000 & 660 & 677 \\
\hline
\end{tabular}

Figura 9.13: Retroanálise das bacias de deflexões (série histórica) - km 405 (pista norte)
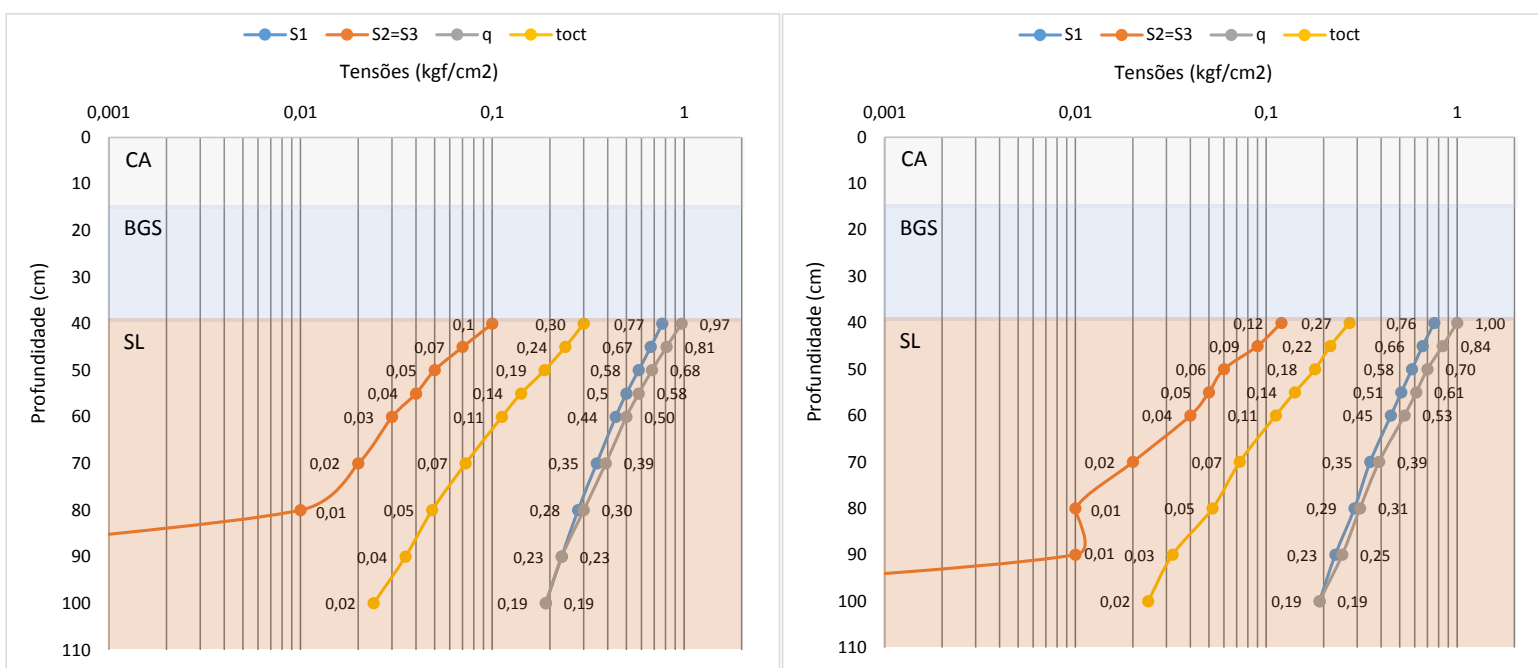

Figura 9.14: Tensões no subleito calculadas para (a) 2010 e (b) 2014 
Tabela 9.10: Resumo dos ensaios realizados com material próximo ao km 405

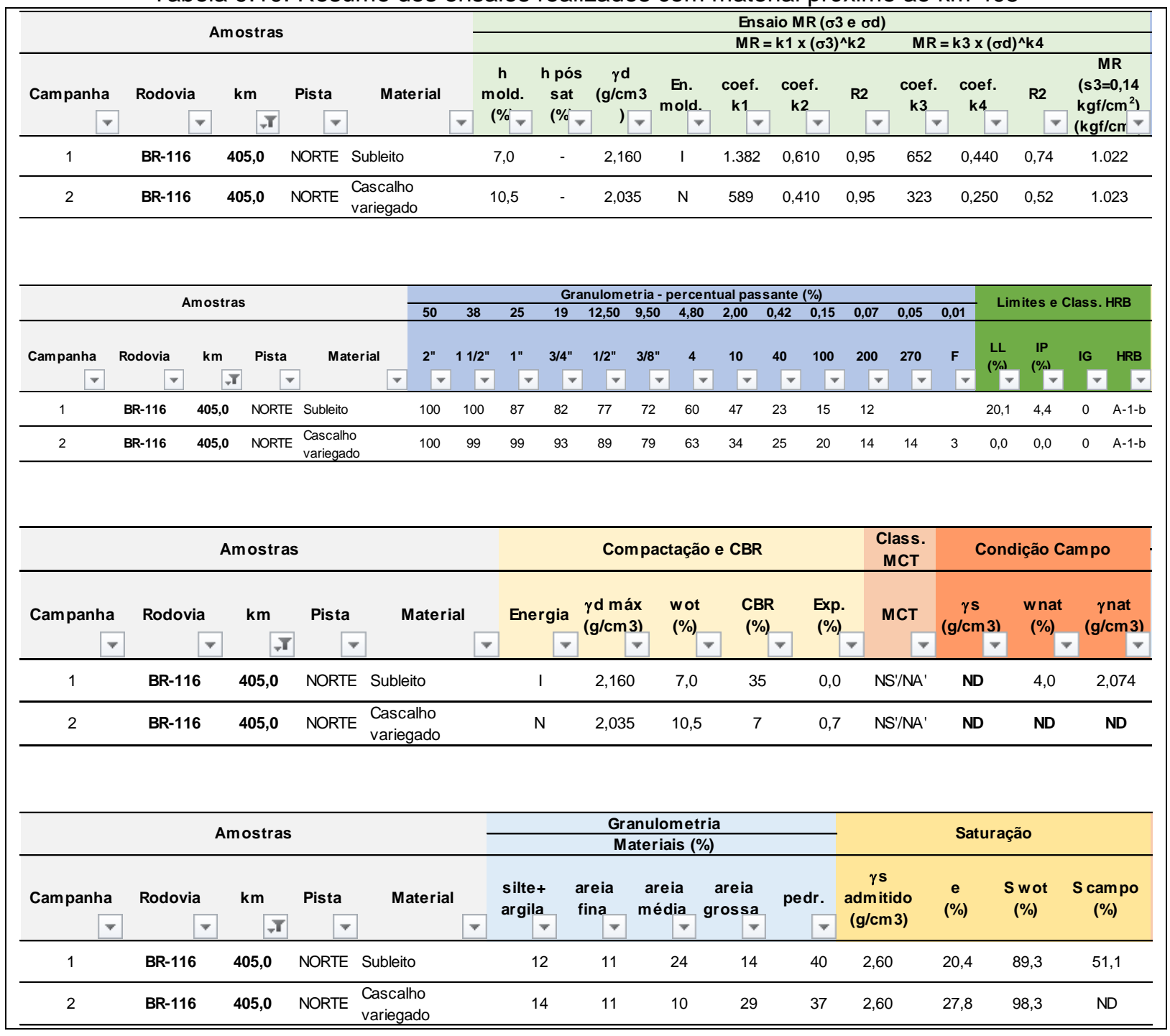




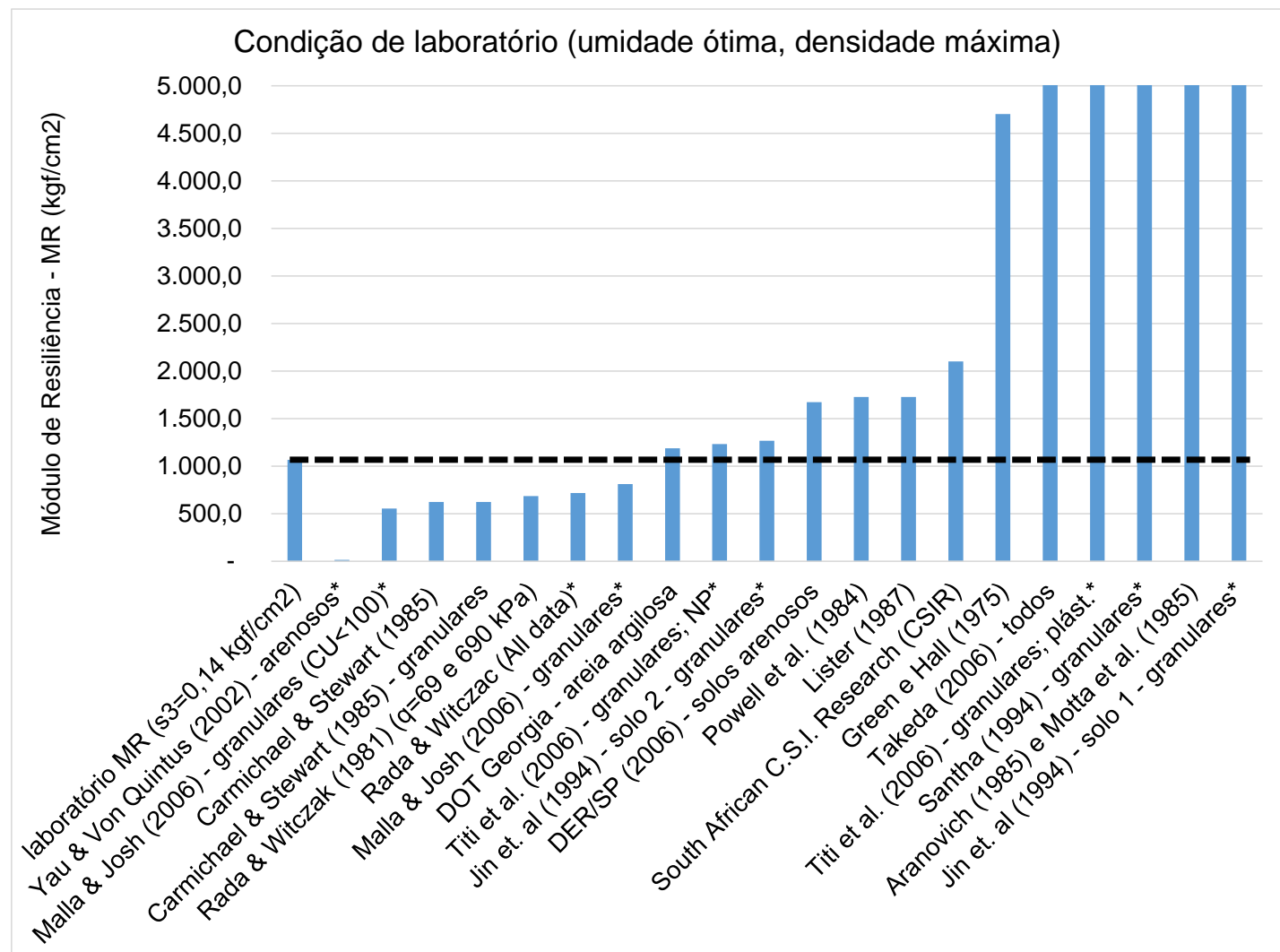

Figura 9.15: Comparativo entre $M R$ de laboratório e modelos de previsão de $M R$ (condição de umidade ótima)

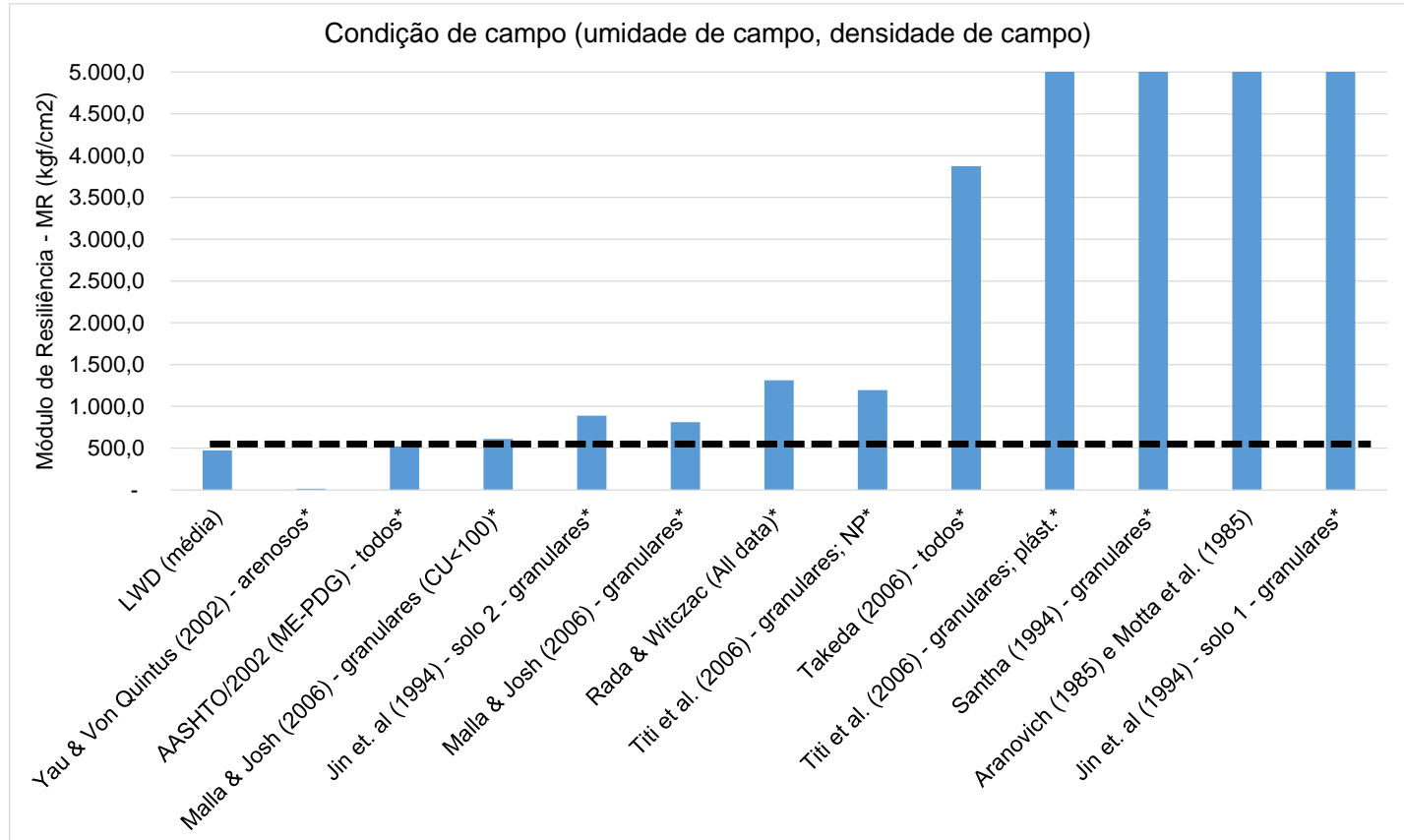

Figura 9.16: Comparativo entre $M R$ in situ $(L W D)$ e modelos de previsão de $M R$ (condição de umidade verificada no campo) 


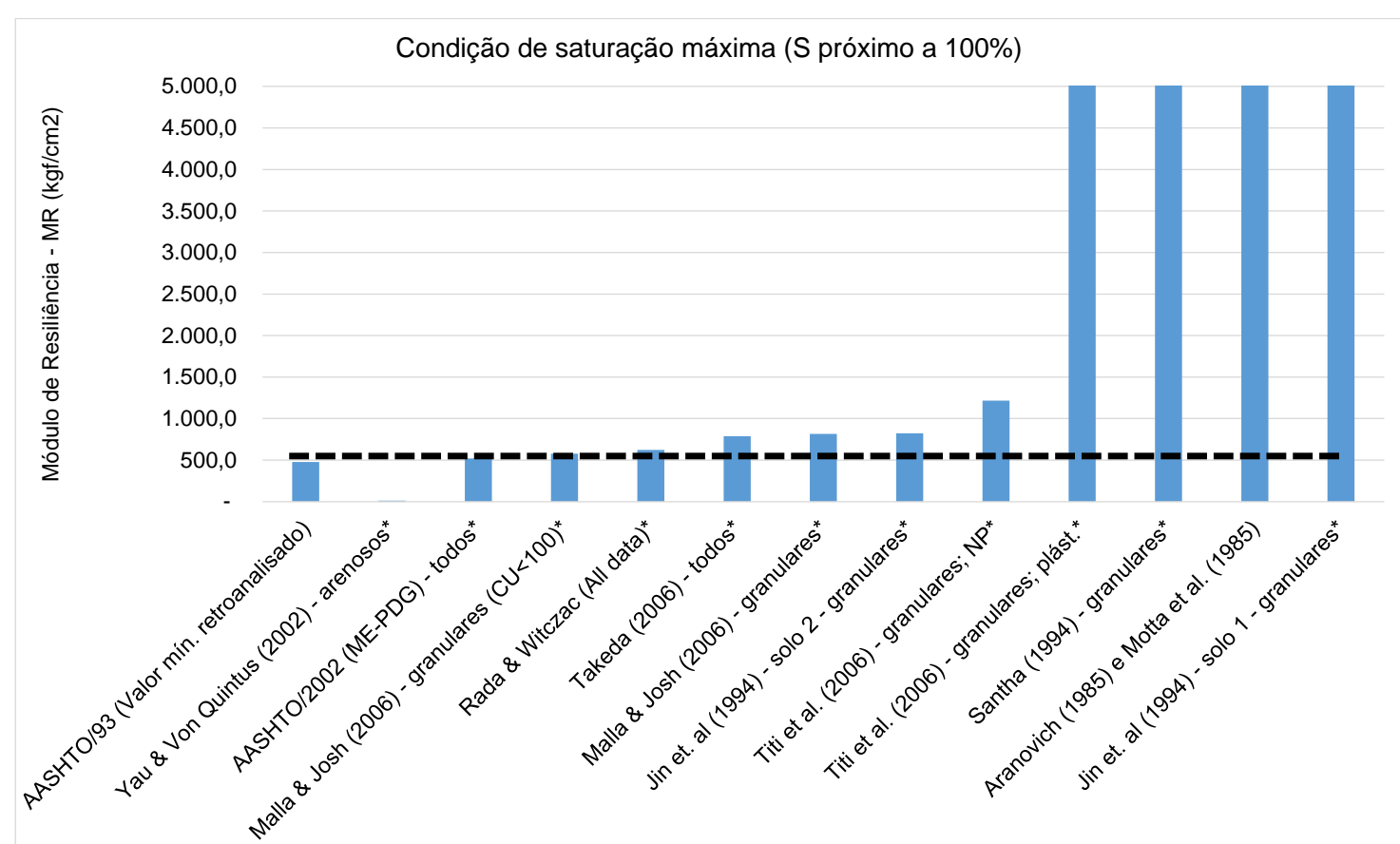

Figura 9.17: Comparativo entre $M R$ in situ mínimo verificado $(F W D)$ e modelos de previsão de $M R$ (condição de saturação próxima a 100\%) 

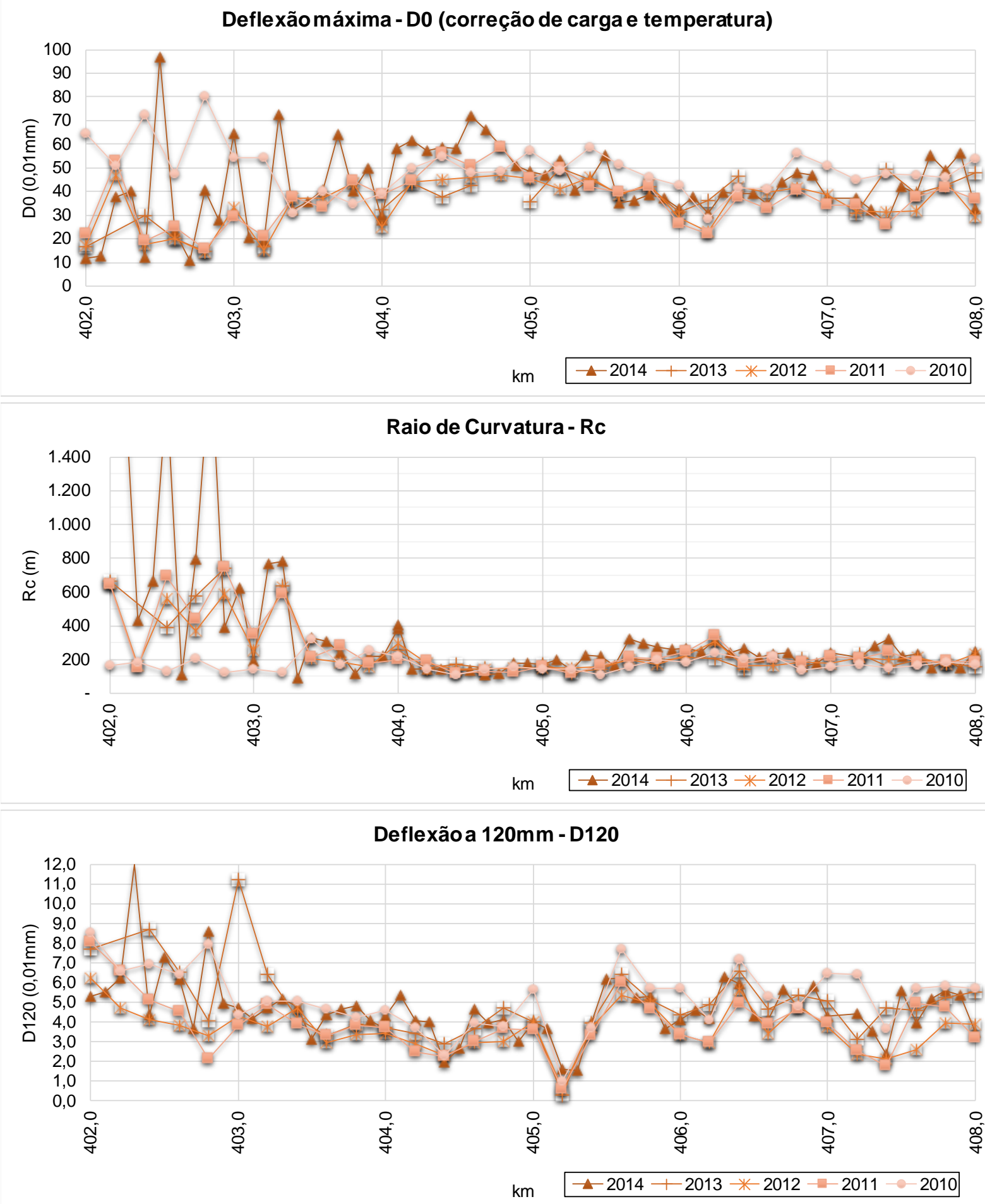

Figura 9.18: Gráficos de série histórica dos indicadores estruturais do pavimento no segmento do km 405 (pista norte) 


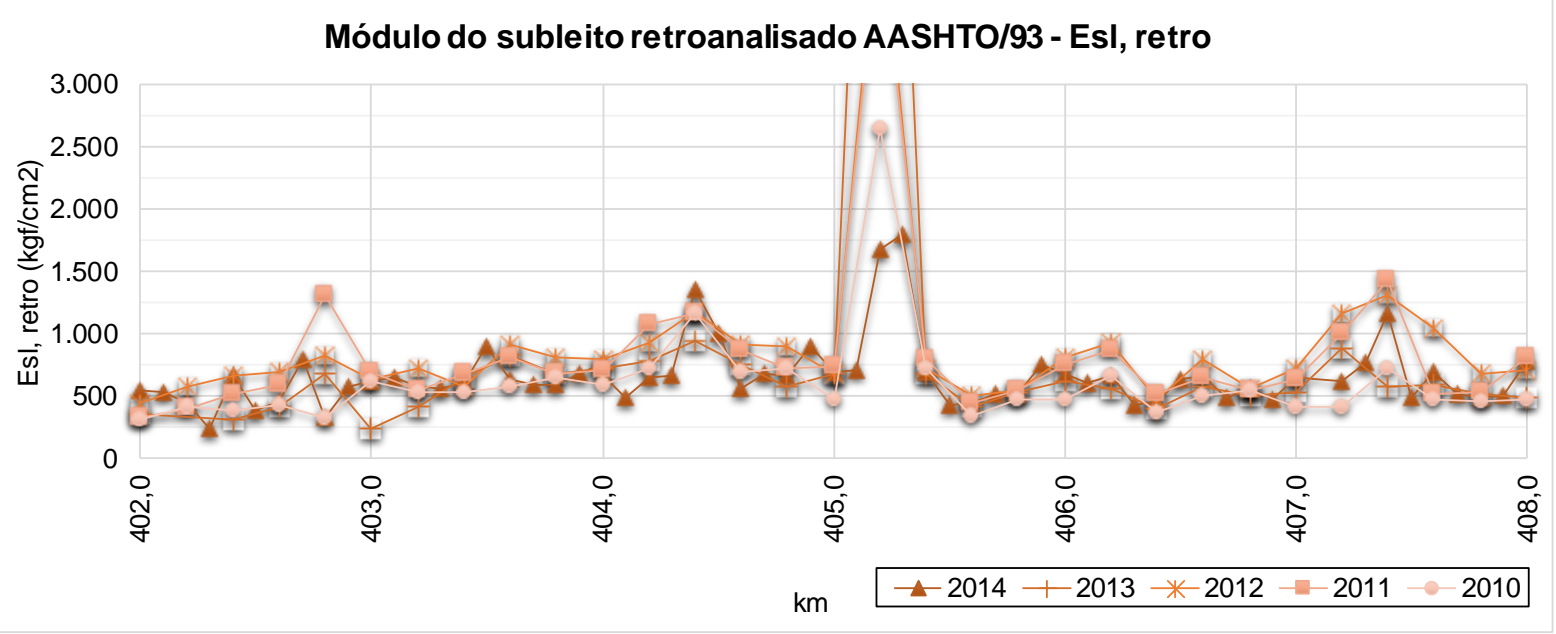

Figura 9.19: Gráficos da série histórica dos dados de módulo de resiliência retroanalisado $(F W D)$ do pavimento no segmento do $\mathrm{km} 405$ (pista norte) 
$404 \quad 405,1$ DECRESCENTE
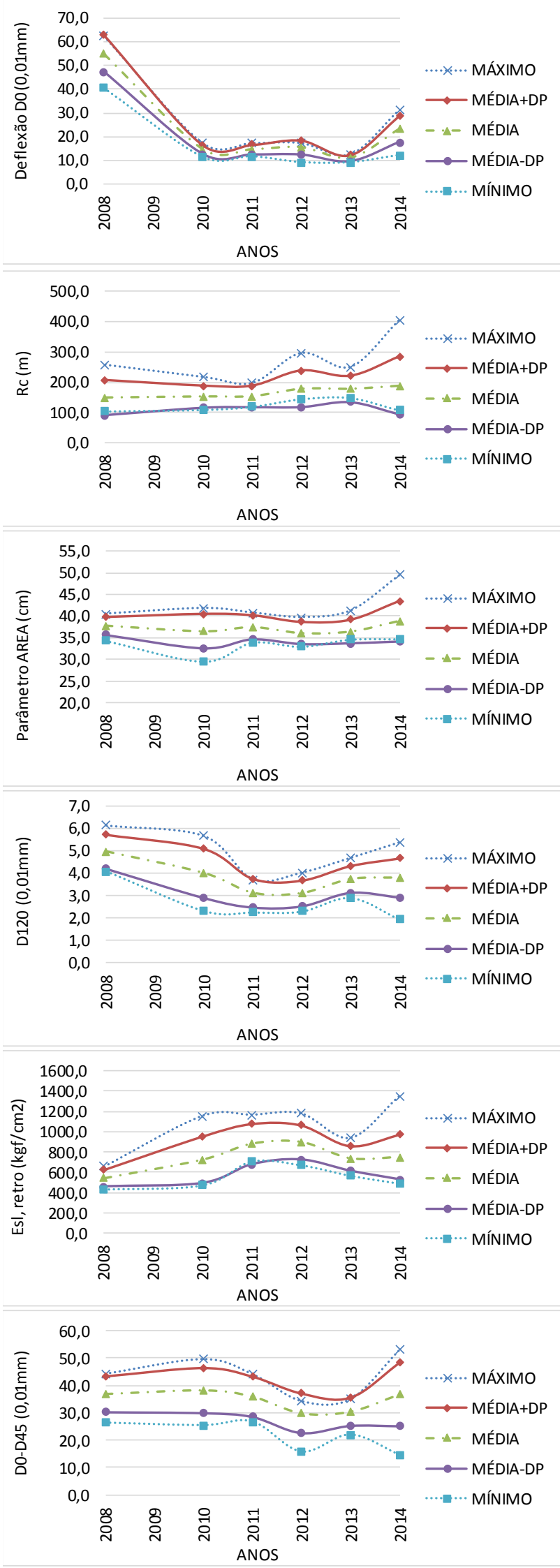

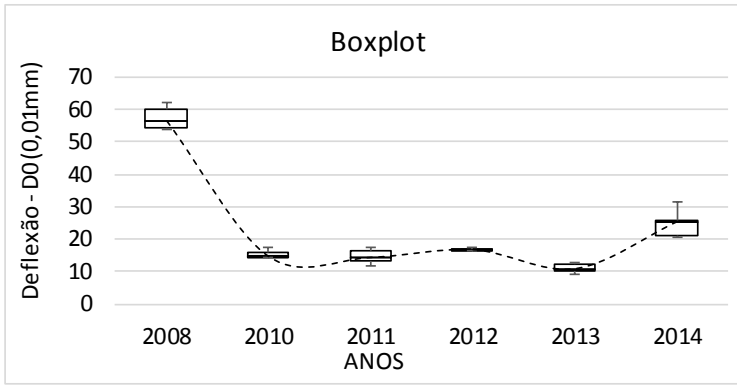

Boxplot

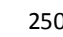

200

छ 150

Ư 100

50

0
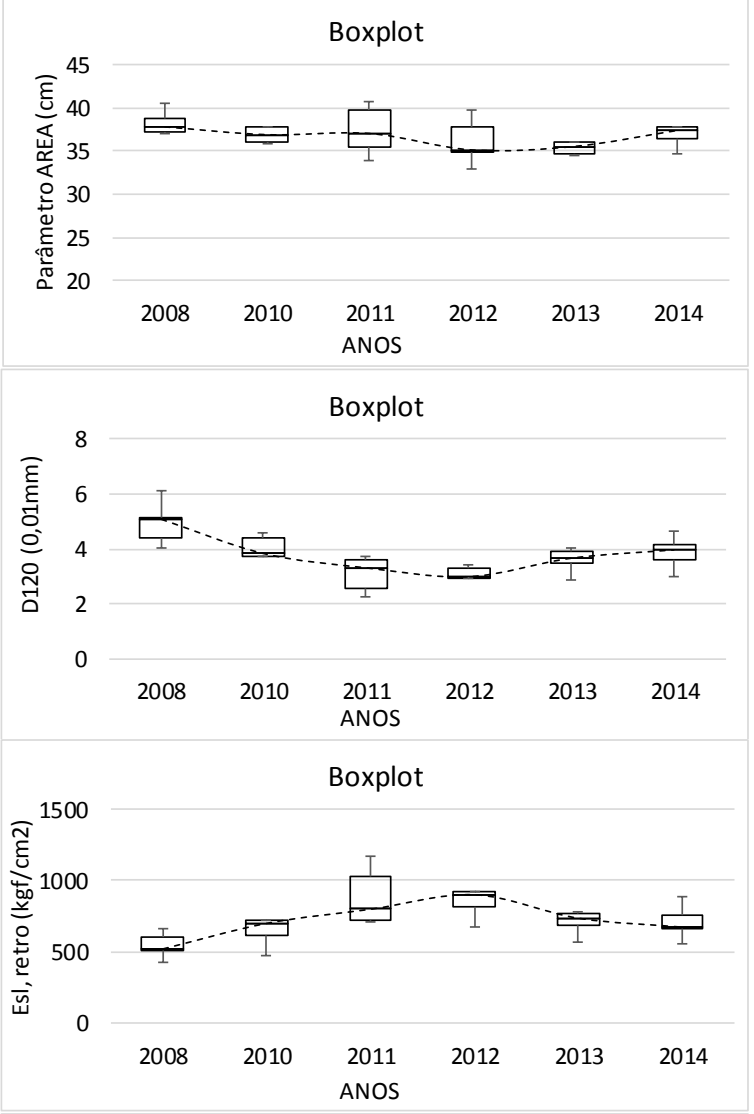

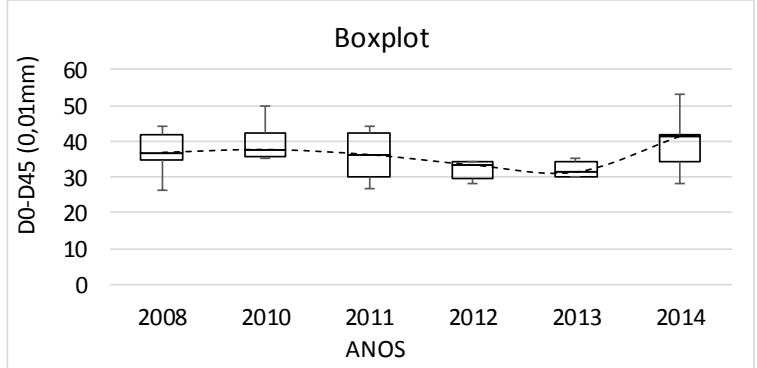

Figura 9.20: Estatísticas dos Parâmetros do pavimento (S. Homogêneo do km 405) 


\subsection{Poço de inspeção do km 414 (Pista Sul)}

A Figura 9.21 a seguir ilustra a localização do poço de inspeção do km 414 (pista sul) bem como o mapeamento geológico do local. Verifica-se uma região de gnaisse.

A Tabela 9.11 apresenta o registro histórico de intervenções do pavimento.

A Tabela 9.12 apresenta a estrutura do pavimento identificada na ocasião da abertura do poço de inspeção. Este pavimento foi identificado como pavimento do tipo flexível com base betuminosa e sub-base de solo-brita.

A Tabela 9.13 e Tabela 9.14 apresentam os resultados estatísticos obtidos a partir do ensaio de $L W D$ sobre as camadas de subleito e camada de base granular. Enquanto a Figura 9.22 apresenta o gráfico comparativo dos pesos específicos aparentes secos e umidades obtidos em campo e em laboratório (curva de compactação de laboratório versus ensaios de umidade e peso específico aparente seco in situ). Verifica-se que o material no campo está em peso específico aparente seco parecido com a peso específico aparente seco máximo relativo a energia intermediária, porém teor de umidade sensivelmente inferior à umidade ótima.

A Figura 9.23 apresenta o resultado da retroanálise da série histórica de deflexões do pavimento em estudo e a Figura 9.24 apresenta os gráficos de tensões calculadas no subleito para duas situações históricas distintas, ilustrando as variações de comportamento do subleito registradas através dos ensaios com FWD.

A Tabela 9.15 apresenta o resumo dos resultados dos ensaios de laboratório realizados com o material do subleito e dos materiais da faixa de domínio no local.

A Figura 9.25 apresenta um gráfico comparativo entre o valor de módulo medido em laboratório e os valores de módulo previstos pelos modelos da literatura, para as condições de umidade ótima e peso específico aparente seco máximo relativos à energia intermediária de compactação. Verificou-se uma convergência maior para os modelos de Carmichael \& Stuart (1985) e Rada \& Witczak (1981).

A Figura 9.26 apresenta um gráfico comparativo entre o valor de módulo in situ medido com $L W D$ e os valores de módulo previstos pelos modelos da literatura, paras as condições de umidade e peso específico aparente seco verificados em campo no 
momento da abertura do poço de inspeção. Verificou-se uma convergência maior para os modelos de Malla \& Joshi (2006), e AASHTO/2002 (ME-PDG).

A Figura 9.27 apresenta um gráfico comparativo entre o valor mínimo de módulo in situ medido com FWD (retroanálise) e os valores de módulo previstos pelos modelos da literatura, para as condições de saturação próxima da saturação máxima (adotouse S próximo a 98\%). Verificou-se uma convergência maior para o modelo de Rada \& Witczak (1981) e Takeda (2006).

A Figura 9.28 apresenta os gráficos da série histórica dos indicadores estruturais do pavimento (deflexão máxima, raio de curvatura, e deflexão a $120 \mathrm{~mm}$ do ponto de aplicação de carga) no segmento que contempla o local em estudo.

A Figura 9.29 apresenta os gráficos da série histórica dos valores de módulo de resiliência retroanalisado ( $F W D$ ) e Quociente de Irregularidade (QI) no segmento que contempla o local em estudo.

A Figura 9.30 apresenta os dados estatísticos (valores máximos, mínimos, média e média mais ou menos desvio padrão), bem como boxplot dos indicadores estruturais do pavimento no segmento homogêneo determinado para o ponto em estudo. 


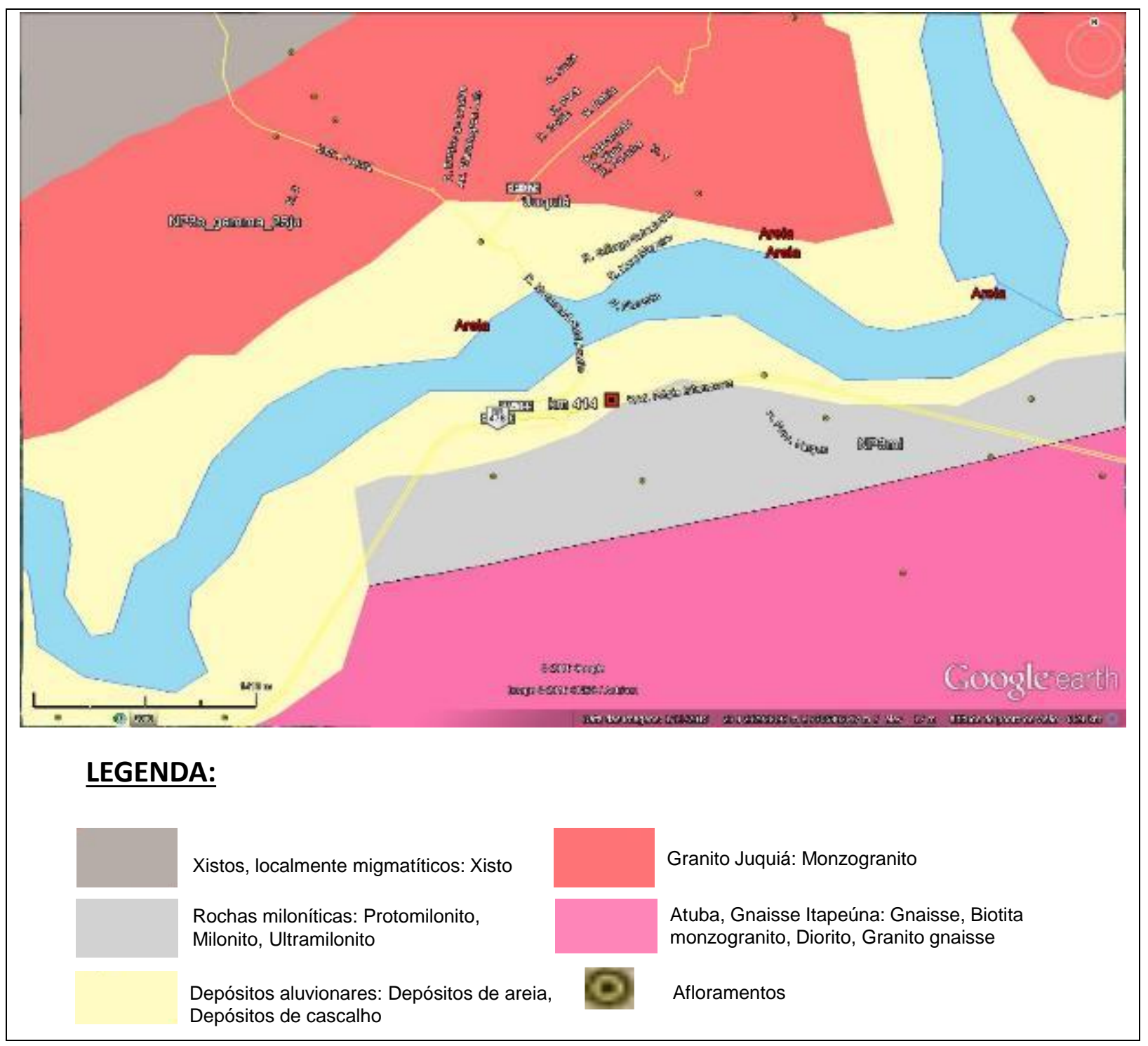

Figura 9.21: Mapa Geológico do local sondado - km 414 (Pista Sul) Fonte: Geobank/Google Earth $\AA$

Tabela 9.11: histórico de intervenções informado - km 414 (pista sul)

\begin{tabular}{ccccccc}
\hline $\mathbf{k m}$ & $\begin{array}{c}\mathbf{k m} \\
\text { inicial }\end{array}$ & $\begin{array}{c}\mathbf{k m} \\
\text { final }\end{array}$ & Solução Aplicada & $\begin{array}{c}\text { Larg. } \\
(\mathbf{m})\end{array}$ & $\begin{array}{c}\text { Esp. } \\
(\mathbf{c m})\end{array}$ & $\begin{array}{c}\text { Data da } \\
\text { Intervenção }\end{array}$ \\
\hline 414,000 & 412,980 & 415,000 & MICROREVESTIMENTO & 4,10 & 1,00 & $19 / 08 / 2010$ \\
\hline
\end{tabular}


Tabela 9.12: Estrutura do pavimento da faixa externa - km 414 (pista sul)

\begin{tabular}{lllll} 
km & Pista & Camada & $\begin{array}{c}\text { Espessura } \\
(\mathbf{c m})\end{array}$ & Camada \\
\hline \multirow{3}{*}{414} & & 1 & 11,0 & CA \\
\cline { 3 - 5 } & \multirow{3}{*}{ Sul } & 2 & 27,0 & BASE BETUMINOSA \\
\cline { 3 - 5 } & & 3 & 40,0 & SOLO-BRITA \\
\cline { 3 - 5 } & & & - & SL \\
\hline
\end{tabular}

Tabela 9.13: Estatística dos resultados do ensaio com $L W D$

\begin{tabular}{|c|c|c|c|c|c|c|c|c|c|c|c|}
\hline \multicolumn{12}{|c|}{ Resumo } \\
\hline \multirow{2}{*}{ km } & \multirow{2}{*}{ Material } & \multicolumn{5}{|c|}{ Leituras $D_{0, \text { LWD }}\left(10^{-2} \mathrm{~mm}\right)$} & \multicolumn{5}{|c|}{$E_{0, \text { calc }}\left(\mathrm{kfg} / \mathrm{cm}^{2}\right)$} \\
\hline & & Mín. & Máx. & Média & Desvio & CV(\%) & Mín. & Máx. & Média & Desvio & CV(\%) \\
\hline 402 & BGS & 34 & 67 & 51 & 13 & 26 & 336 & 663 & 477 & 130 & 27 \\
\hline 402 & $\mathrm{SL}$ & 34 & 67 & 45 & 14 & 31 & 336 & 669 & 537 & 140 & 26 \\
\hline
\end{tabular}

Tabela 9.14: Estatística dos resultados de determinação do módulo da camada de BGS

\begin{tabular}{|c|c|c|c|c|c|c|}
\hline & & & Resur & no & & \\
\hline & & & & retro $(\mathrm{kfc}$ & $\mathrm{g} / \mathrm{cm}^{2}$ ) & \\
\hline & & Mín. & Máx. & Média & Desvio & CV(\%) \\
\hline 402 & BGS & 849 & 2.697 & 1.601 & 738 & 46 \\
\hline
\end{tabular}

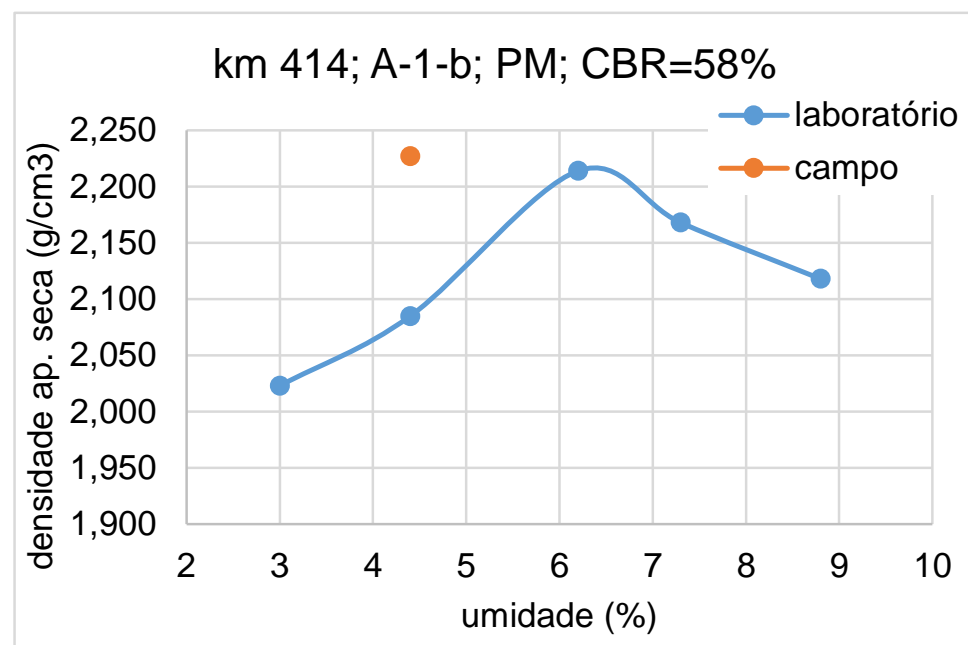

Figura 9.22: Comparativo entre pesos específicos aparentes secos - laboratório x campo (subleito, $\mathrm{km} \mathrm{414,} \mathrm{sul)}$ 


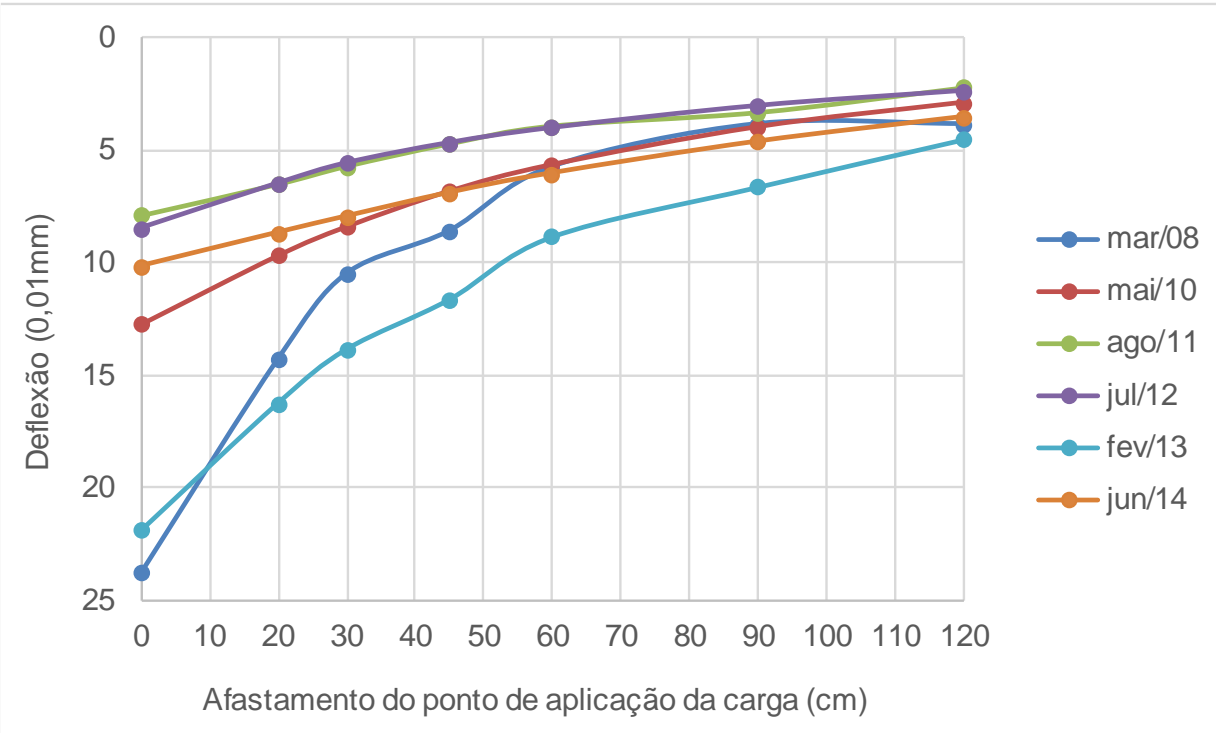

\begin{tabular}{|c|c|c|c|c|c|c|c|c|}
\hline $\begin{array}{c}\text { Mês/ano } \\
\text { Levantamento }\end{array}$ & $\begin{array}{l}\text { Tar } \\
\left({ }^{\circ} \mathrm{C}\right)\end{array}$ & $\begin{array}{l}\text { Tpav } \\
\left({ }^{\circ} \mathrm{C}\right)\end{array}$ & $\operatorname{Er} 1\left(\mathrm{kgf} / \mathrm{cm}^{2}\right)$ & $\mathrm{Eb}\left(\mathrm{kgf} / \mathrm{cm}^{2}\right)$ & $\begin{array}{c}\text { Esb } \\
(\mathrm{kgf} / \mathrm{cm} 2)\end{array}$ & $\mathrm{Esl}\left(\mathrm{kgf} / \mathrm{cm}^{2}\right)$ & $\begin{array}{l}\text { Esl x 0,33 } \\
\left(\mathrm{kgf} / \mathrm{cm}^{2}\right)\end{array}$ & $\begin{array}{c}\text { Esl } \\
\text { (AASHTO/ } \\
\text { 93) }\end{array}$ \\
\hline $\begin{array}{l}\text { Espessuras } \\
(\mathbf{c m})\end{array}$ & & & 11,0 & 27,0 & 40,0 & - & - & - \\
\hline Materiais & & & CA & BASE BETUM. & SOLO-BRITA & SL & SL & SL \\
\hline mar/08 & - & - & 10.100 & 7.140 & 3.950 & 2.750 & 908 & 708 \\
\hline $\mathrm{mai} / 10$ & 35 & 35 & 53.000 & 16.000 & 3.500 & 3.400 & 1.122 & 943 \\
\hline ago/11 & 19 & 23 & 81.600 & 35.700 & 4.700 & 4.000 & 1.320 & 1.165 \\
\hline $\mathrm{jul} / 12$ & 25 & 28 & 80.100 & 30.000 & 5.600 & 4.100 & 1.353 & 1.070 \\
\hline $\mathrm{fev} / 13$ & 34 & 38 & 26.000 & 8.240 & 2.400 & 2.240 & 739 & 597 \\
\hline jun/14 & 14 & 17 & 83.250 & 28.000 & 4.100 & 2.800 & 924 & 769 \\
\hline
\end{tabular}

Figura 9.23: Retroanálise das bacias de deflexões (série histórica) - km 414 (pista sul)
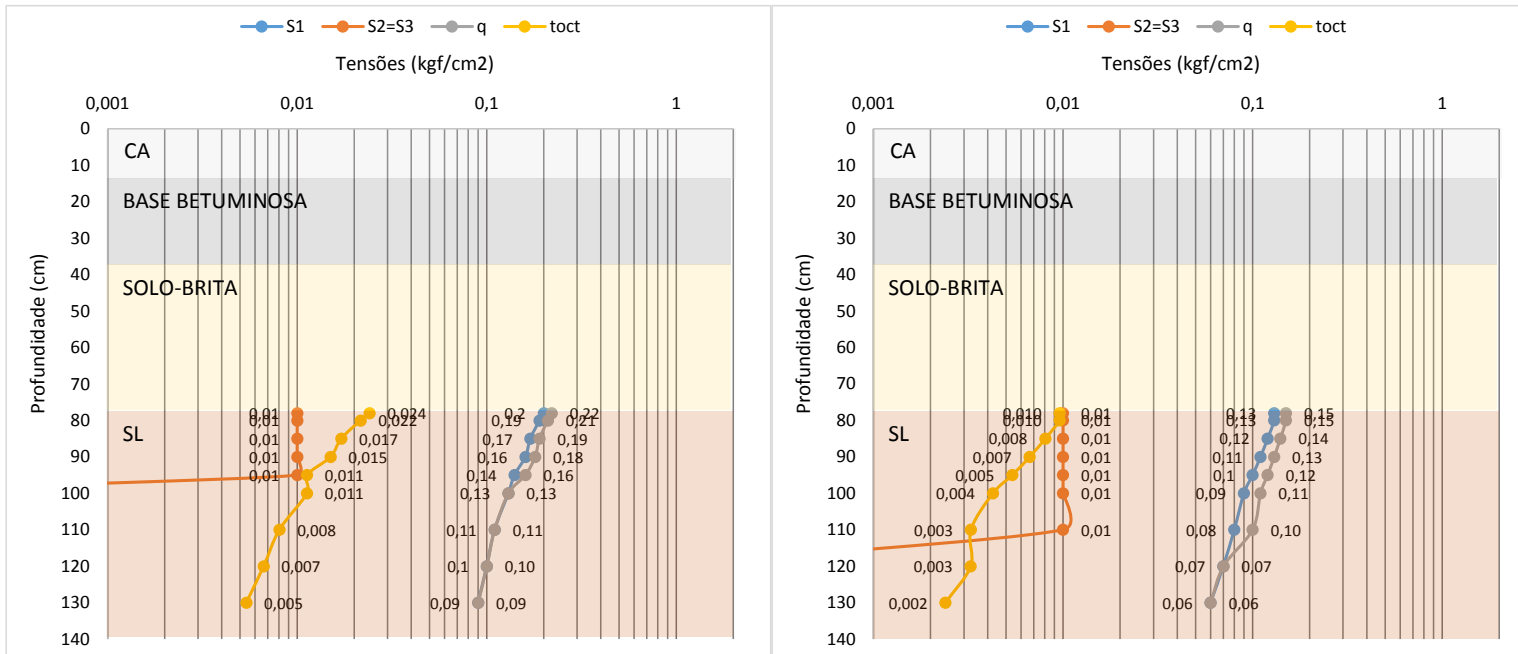

Figura 9.24: Tensões no subleito calculadas para (a) 2013 e (b) 2014 
Tabela 9.15: Resumo dos ensaios realizados com material próximo ao km 414

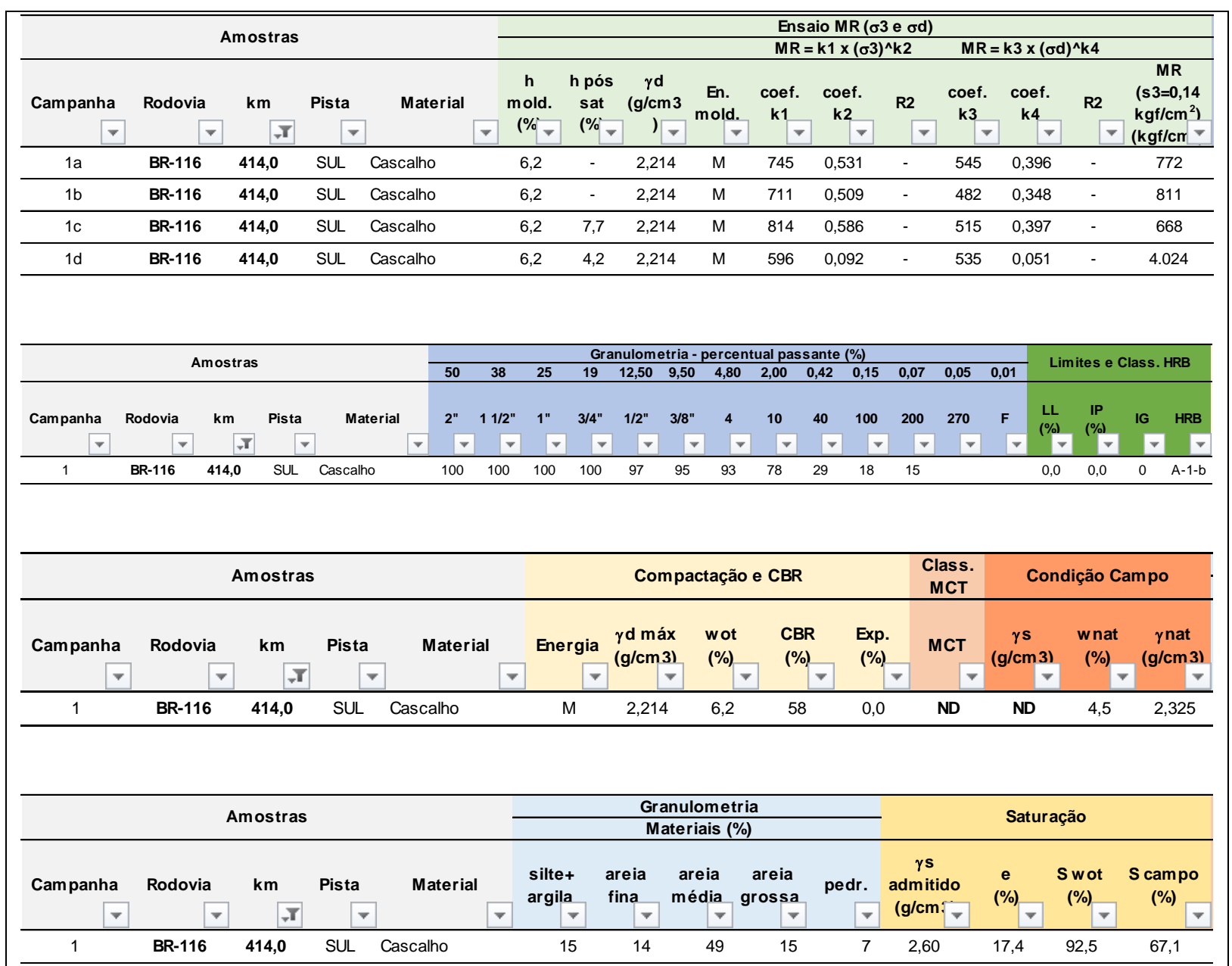




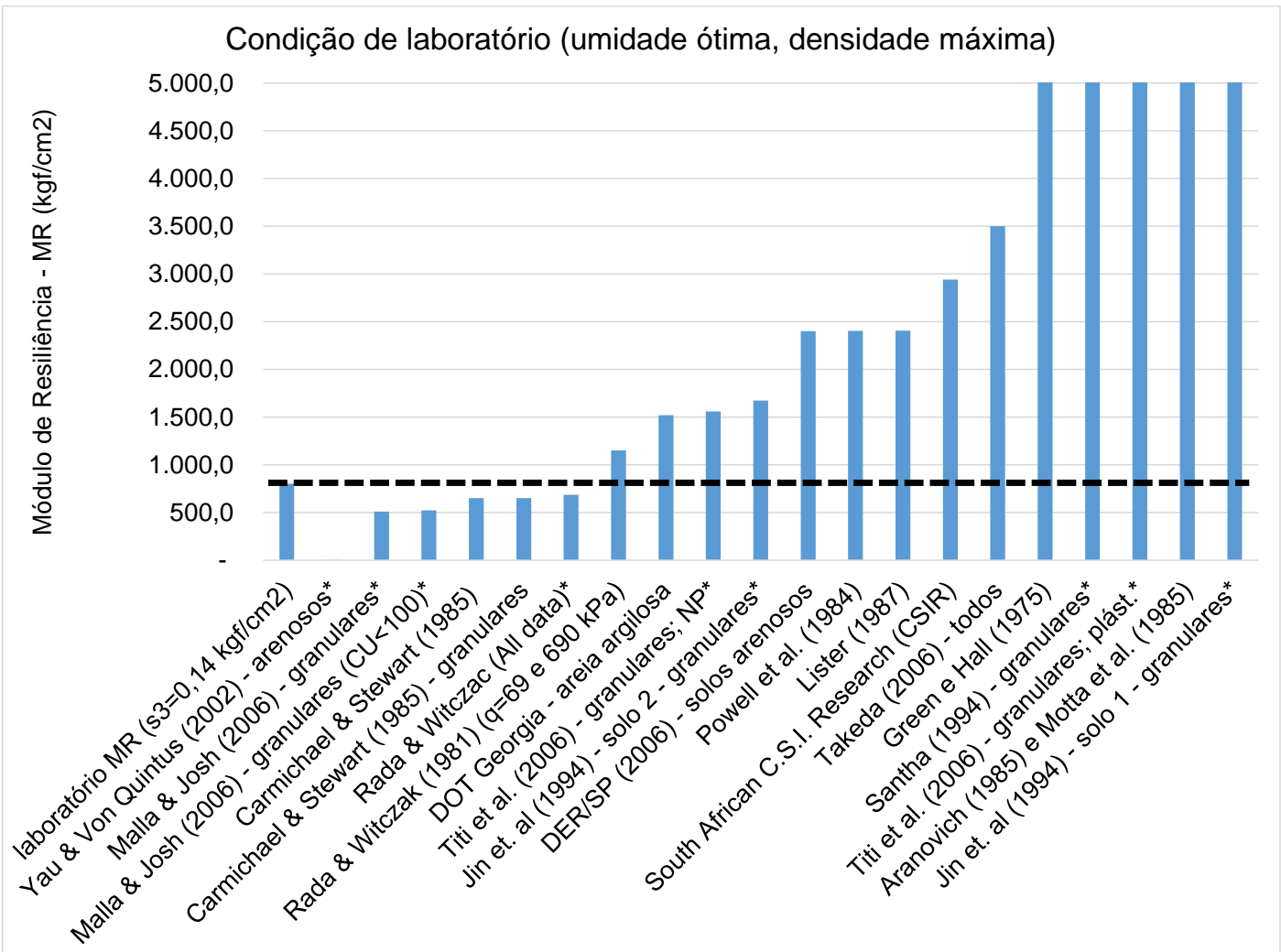

Figura 9.25: Comparativo entre $M R$ de laboratório e modelos de previsão de $M R$ (condição de umidade ótima)

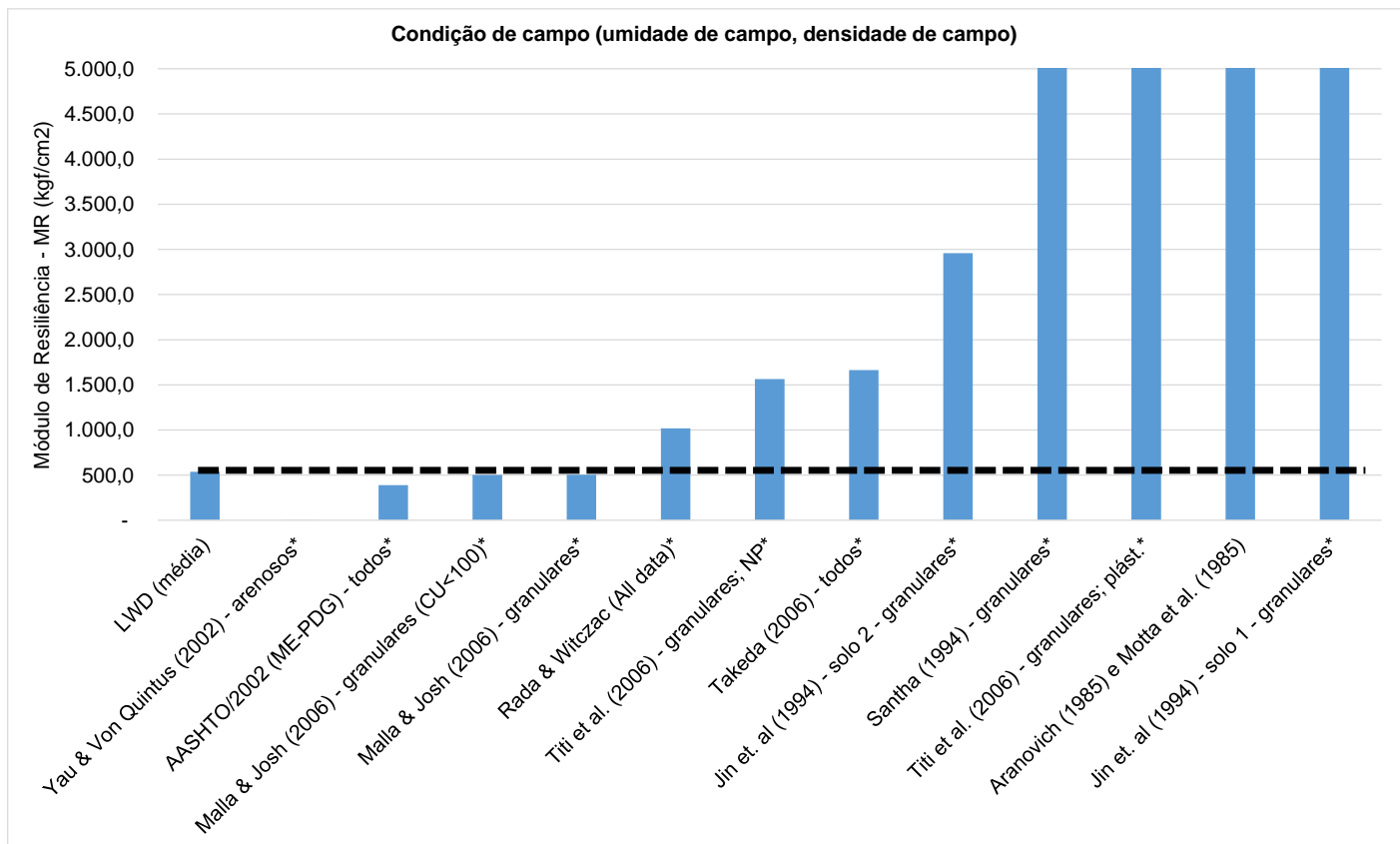

Figura 9.26: Comparativo entre $M R$ in situ $(L W D)$ e modelos de previsão de $M R$ (condição de umidade verificada no campo) 


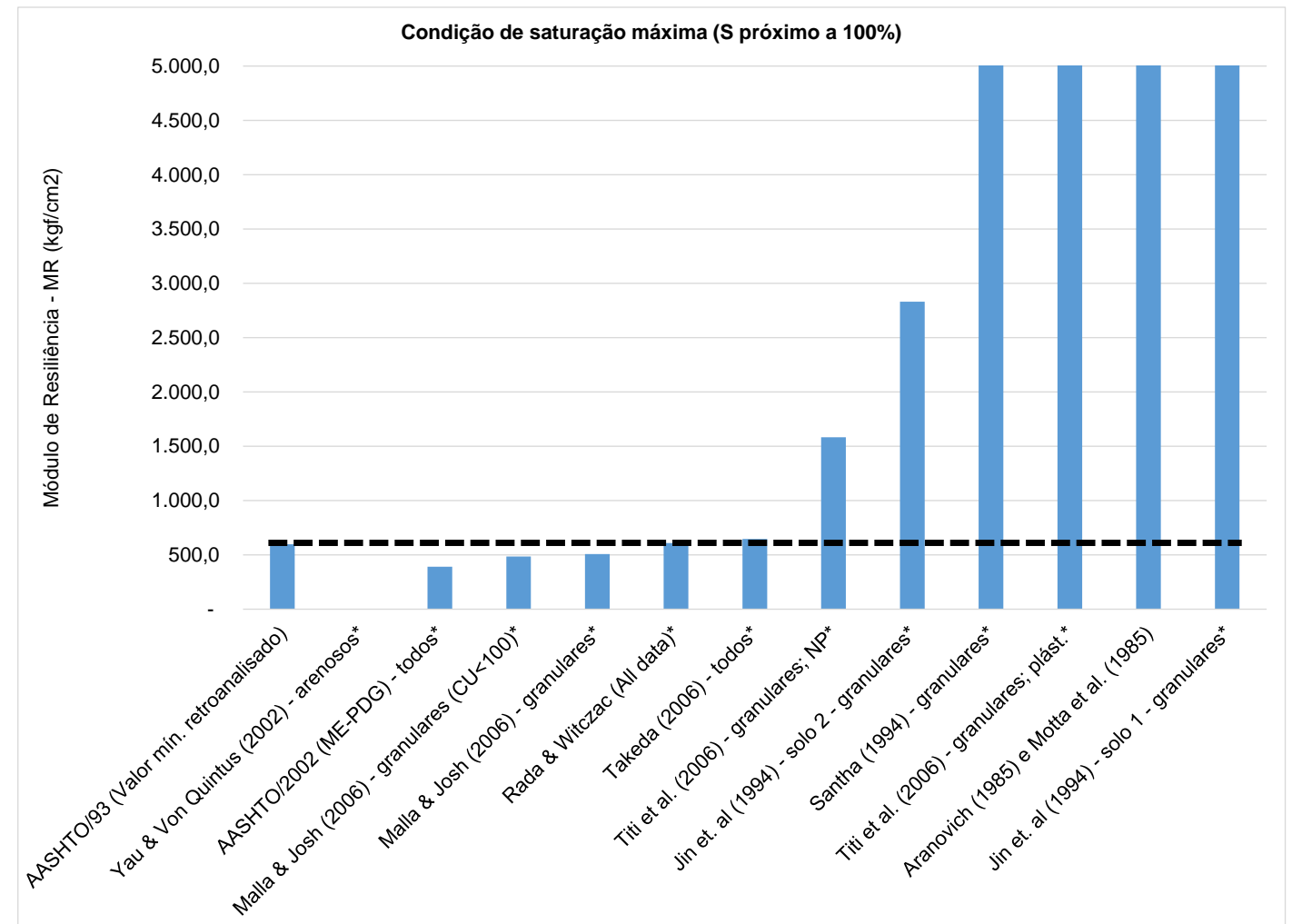

Figura 9.27: Comparativo entre $M R$ in situ mínimo verificado $(F W D)$ e modelos de previsão de $M R$ (condição de saturação próxima a 100\%) 

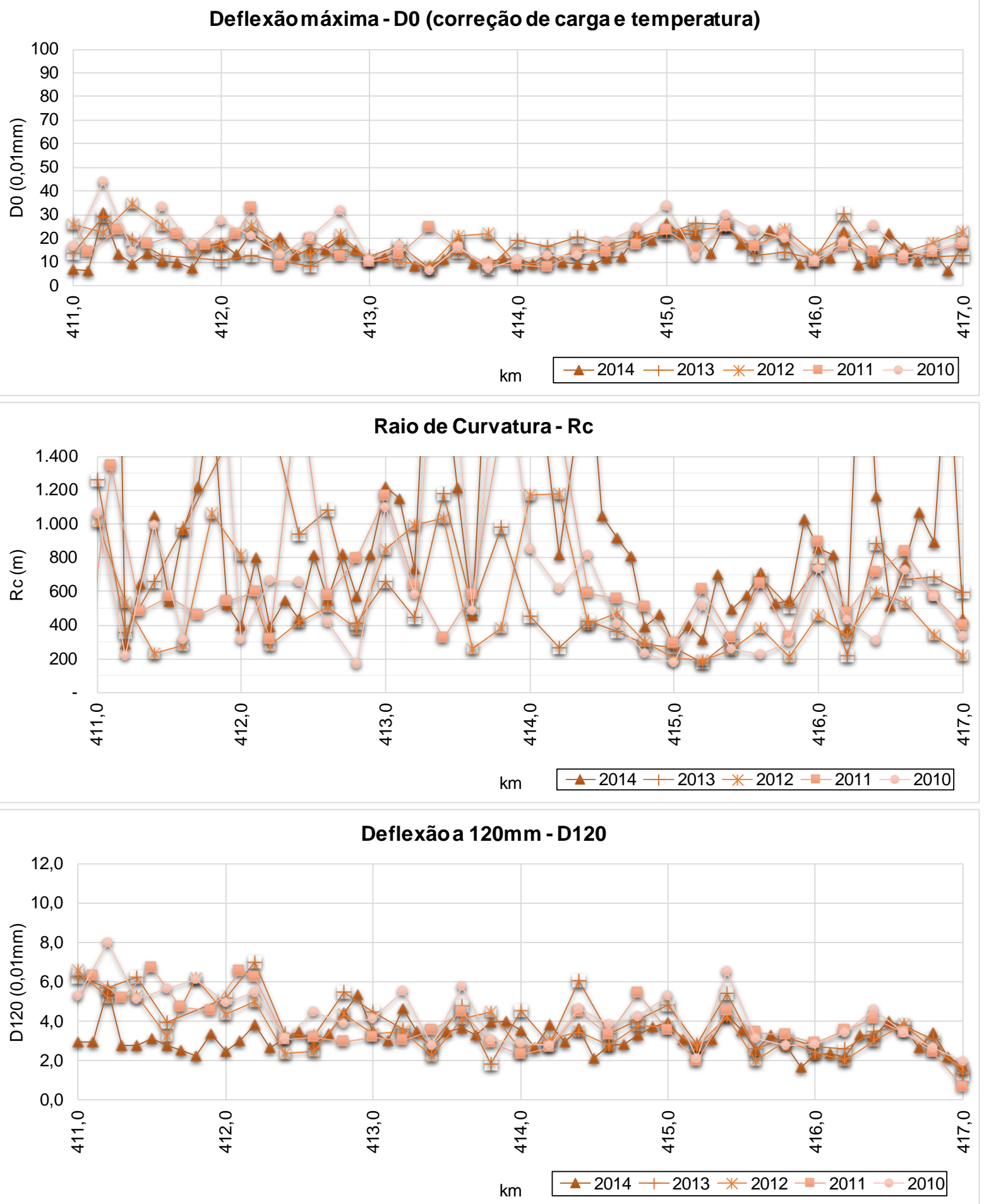

Figura 9.28: Gráficos de série histórica dos indicadores estruturais do pavimento no segmento do km 414 (pista sul) 


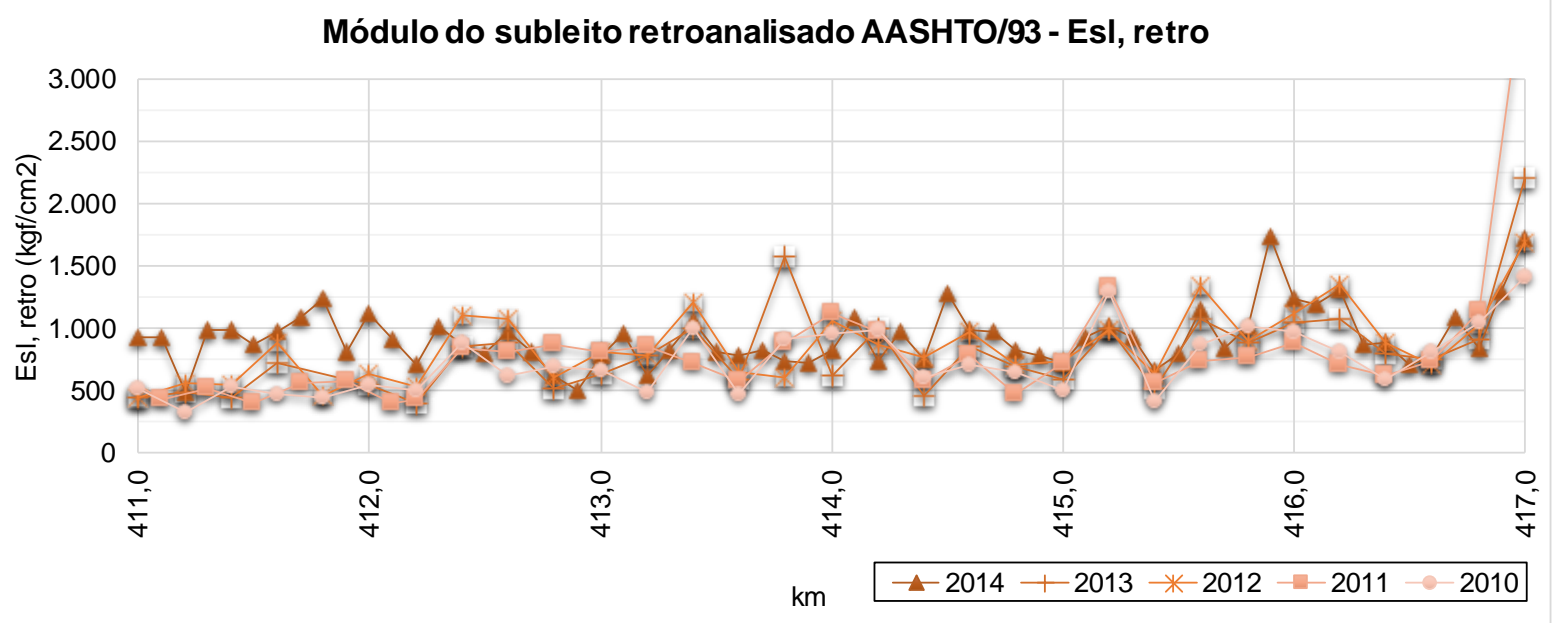

Figura 9.29: Gráficos da série histórica dos dados de módulo de resiliência retroanalisado $(F W D)$ do pavimento no segmento do $\mathrm{km} 414$ (pista sul) 

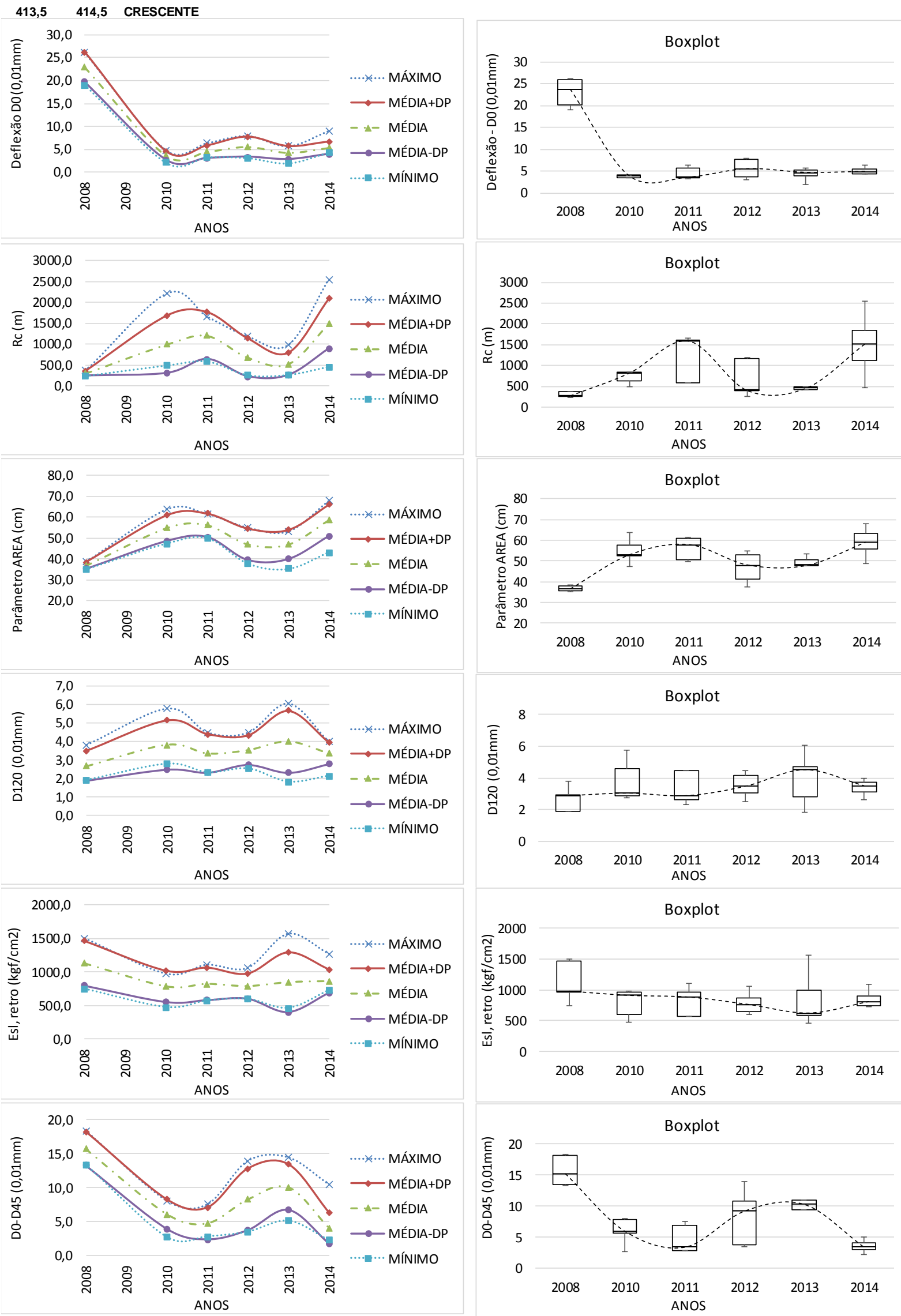

Figura 9.30: Estatísticas dos Parâmetros do pavimento (S. Homogêneo do km 414) 


\subsection{Poço de inspeção do km 418 (Pista Norte)}

A Figura 9.31 a seguir ilustra a localização do poço de inspeção do km 418 (pista norte) bem como o mapeamento geológico do local. Verifica-se uma região com predominância de depósitos de areia e cascalho.

A Tabela 9.16 apresenta o registro histórico de intervenções do pavimento. Verificase que o pavimento sofreu uma intervenção de reciclagem de base com emprego de emulsão asfáltica no ano de 2009.

A Tabela 9.17 apresenta a estrutura do pavimento identificada na ocasião da abertura do poço de inspeção. Este pavimento foi identificado como pavimento do tipo flexível com base betuminosa e sub-base granular.

A Tabela 9.18 e Tabela 9.19 apresentam os resultados estatísticos obtidos a partir do ensaio de $L W D$ sobre as camadas de subleito e camada de base granular. Enquanto a Figura 9.32 apresenta o gráfico comparativo dos pesos específicos aparentes secos e umidades obtidos em campo e em laboratório (curva de compactação de laboratório versus ensaios de umidade e peso específico aparente seco in situ). Verifica-se que o material no campo está com peso específico aparente seco acima do peso específico aparente seco máximo relativo a energia intermediária e umidade ligeiramente inferior à ótima. Infere-se que o material tenha sido compactado na energia modificada.

A Figura 9.33 apresenta o resultado da retroanálise da série histórica de deflexões do pavimento em estudo e a Figura 9.34 apresenta os gráficos de tensões calculadas no subleito, ilustrando o comportamento do subleito registrado através dos ensaios com FWD.

A Tabela 9.20 apresenta o resumo dos resultados dos ensaios de laboratório realizados com o material do subleito e dos materiais da faixa de domínio no local.

A Figura 9.35 apresenta um gráfico comparativo entre o valor de módulo medido em laboratório e os valores de módulo previstos pelos modelos da literatura, para as condições de umidade ótima e peso específico aparente seco máximo relativos à energia intermediária de compactação. Verificou-se uma convergência maior para os modelos de Rada \& Witczak (1981) e Jin et al. (1994). 
A Figura 9.36 apresenta um gráfico comparativo entre o valor de módulo in situ medido com $L W D$ e os valores de módulo previstos pelos modelos da literatura, paras as condições de umidade e peso específico aparente seco verificados em campo no momento da abertura do poço de inspeção. Verificou-se uma convergência maior para os modelos de Malla \& Joshi - materiais granulares (2006), e AASHTO/2002 (MEPDG).

A Figura 9.37 apresenta um gráfico comparativo entre o valor mínimo de módulo in situ medido com FWD (retroanálise) e os valores de módulo previstos pelos modelos da literatura, para as condições de saturação próxima da saturação máxima (adotouse $S$ próximo a $98 \%$ ). Verificou-se uma convergência maior para o modelo da AASHTO/2002 e Malla \& Joshi (2006).

A Figura 9.38 apresenta os gráficos da série histórica dos indicadores estruturais do pavimento (deflexão máxima, raio de curvatura, e deflexão a $120 \mathrm{~mm}$ do ponto de aplicação de carga) no segmento que contempla o local em estudo.

A Figura 9.39 apresenta os gráficos da série histórica dos valores de módulo de resiliência retroanalisado $(F W D)$ e Quociente de Irregularidade $(Q I)$ no segmento que contempla o local em estudo.

A Figura 9.40 apresenta os dados estatísticos (valores máximos, mínimos, média e média mais ou menos desvio padrão), bem como boxplot dos indicadores estruturais do pavimento no segmento homogêneo determinado para o ponto em estudo. 


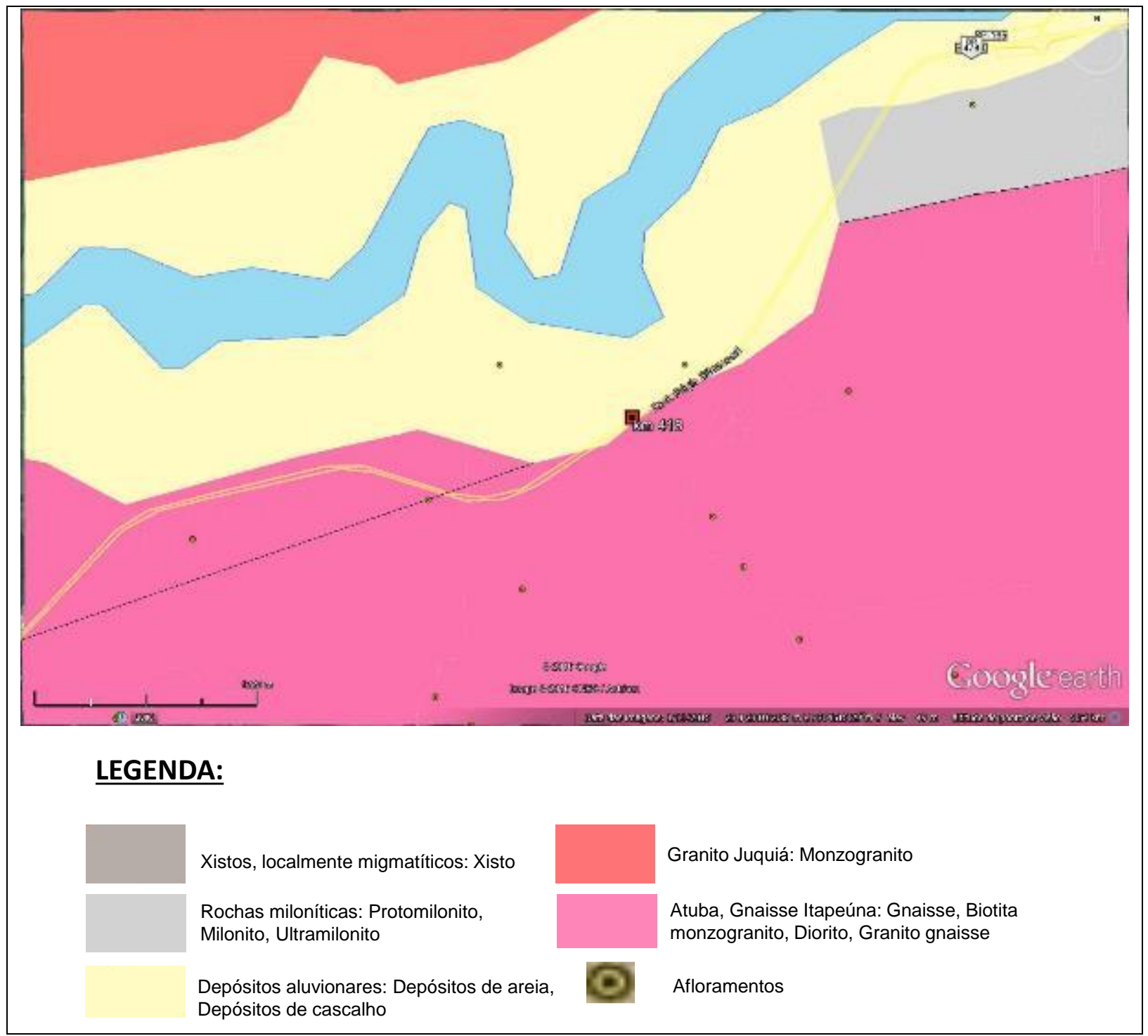

Figura 9.31: Mapa Geológico do local sondado - km 418 (Pista Norte) Fonte: Geobank/Google Earth $\AA$

Tabela 9.16: histórico de intervenções informado - km 418 (pista norte)

\begin{tabular}{ccccccc}
\hline $\mathbf{k m}$ & $\begin{array}{c}\mathbf{k m} \\
\text { inicial }\end{array}$ & $\begin{array}{c}\mathbf{k m} \\
\text { final }\end{array}$ & Solução Aplicada & $\begin{array}{c}\text { Larg. } \\
\mathbf{( m )}\end{array}$ & $\begin{array}{c}\text { Esp. } \\
\mathbf{( c m )}\end{array}$ & $\begin{array}{c}\text { Data da } \\
\text { Interv. }\end{array}$ \\
\hline \multirow{3}{*}{418} & 417,870 & 418,720 & RECICLAGEM DE PAV. ASF. COM EMULSÃO ESP. & 3,80 & 10,00 & $27 / 04 / 2009$ \\
\cline { 2 - 7 } & 417,012 & 419,098 & MICROREVESTIMENTO & 4,10 & 1,20 & $19 / 05 / 2009$ \\
\cline { 2 - 7 } & 417,754 & 418,169 & REFORÇO DE PAVIMENTO COM ASFALTO BORR & 3,60 & 6,00 & $23 / 06 / 2010$ \\
\hline
\end{tabular}


Tabela 9.17: Estrutura do pavimento da faixa externa - km 418 (pista norte)

\begin{tabular}{ccccc}
$\mathbf{k m}$ & Pista & Camada & $\begin{array}{c}\text { Espessura } \\
(\mathbf{c m})\end{array}$ & \multicolumn{1}{c}{ Camada } \\
\hline \multirow{3}{*}{418} & \multirow{3}{*}{ Norte } & 14,0 & CA \\
\cline { 3 - 5 } & & 2 & 10,0 & RAP C/ EMULSÃO \\
\cline { 3 - 4 } & & 3 & 25,0 & BGS \\
\cline { 3 - 4 } & & - & SL \\
\hline
\end{tabular}

Tabela 9.18: Estatística dos resultados do ensaio com $\angle W D$

\begin{tabular}{|c|c|c|c|c|c|c|c|c|c|c|c|}
\hline \multirow{2}{*}{ km } & \multirow{2}{*}{ Material } & \multicolumn{5}{|c|}{ Leituras $\mathrm{D}_{0, \mathrm{LWD}}\left(10^{-2} \mathrm{~m} \mathrm{~m}\right)$} & \multicolumn{5}{|c|}{$E_{0, \text { calc }}\left(\mathrm{kfg} / \mathrm{cm}^{2}\right)$} \\
\hline & & Mín. & Máx. & Média & Desvio & CV(\%) & Mín. & Máx. & Média & Desvio & CV(\%) \\
\hline 418 & BGS & 24 & 83 & 37 & 16 & 42 & 273 & 949 & 684 & 212 & 31 \\
\hline 418 & SL & 30 & 97 & 54 & 28 & 52 & 234 & 758 & 524 & 210 & 40 \\
\hline
\end{tabular}

Tabela 9.19: Estatística dos resultados de determinação do módulo da camada de BGS

\begin{tabular}{lllllll}
\hline & & \multicolumn{5}{c}{$E_{\text {sb,retro }}\left(\mathbf{k f g} / \mathbf{c m}^{2}\right)$} \\
\cline { 3 - 6 } & & Mín. & Máx. & Média & Desvio & $\mathbf{C V}(\%)$ \\
\hline 418 & BGS & 564 & 2.644 & 1.674 & 709 & 42 \\
\hline
\end{tabular}

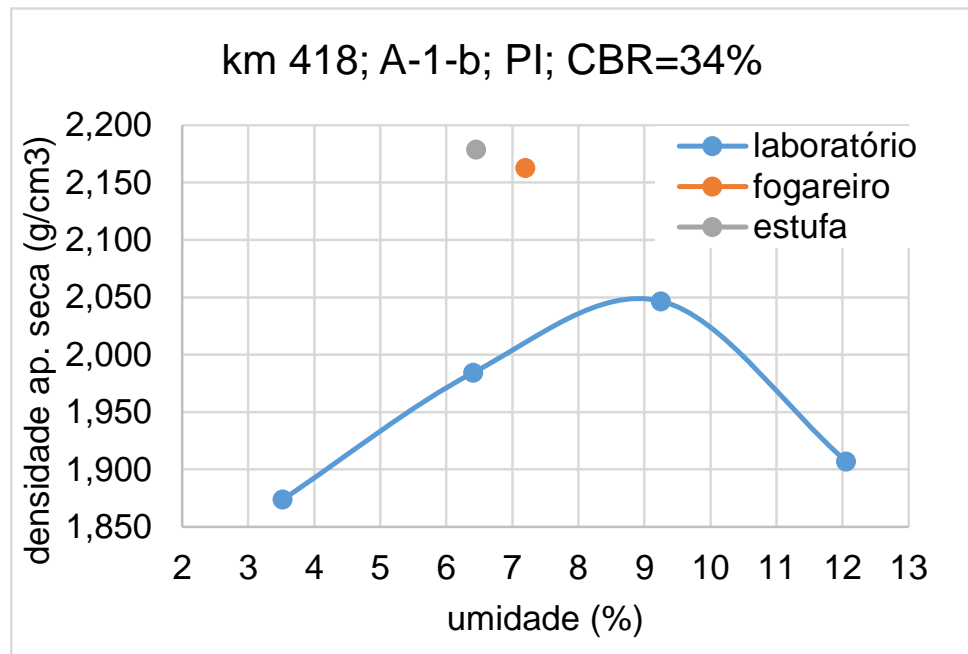

Figura 9.32: Comparativo entre pesos específicos aparentes secos - laboratório x campo (subleito, $\mathrm{km} \mathrm{418,} \mathrm{norte)}$ 


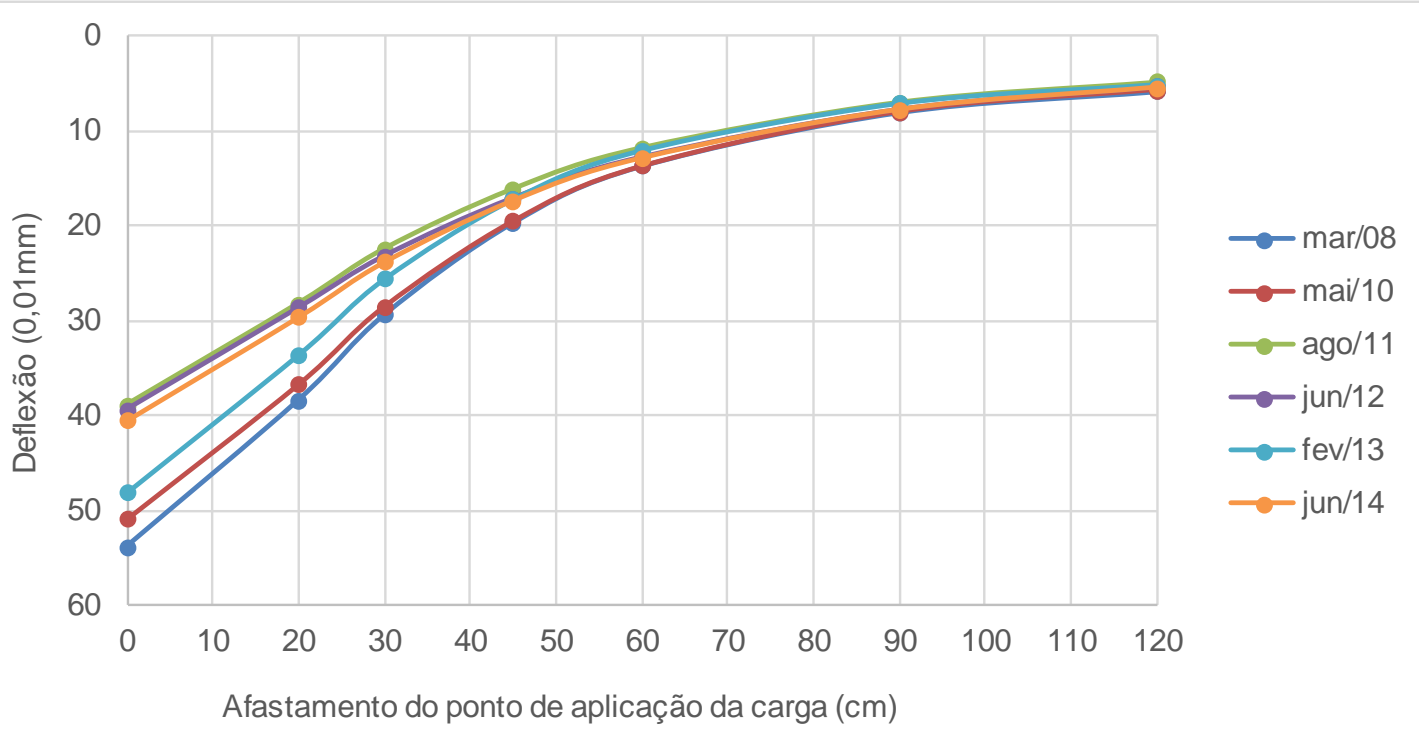

\begin{tabular}{ccccccccc}
\hline $\begin{array}{c}\text { Mês/ano } \\
\text { Levantamento }\end{array}$ & $\begin{array}{c}\text { Tar } \\
\left({ }^{\circ} \mathbf{C}\right)\end{array}$ & $\begin{array}{c}\text { Tpav } \\
\left({ }^{\circ} \mathbf{C}\right)\end{array}$ & $\begin{array}{c}\text { Er1 } \\
\left(\mathbf{k g f} / \mathbf{c m}^{2}\right)\end{array}$ & $\begin{array}{c}\text { Er2 } \\
\left(\mathbf{k g f} / \mathbf{c m}^{2}\right)\end{array}$ & $\begin{array}{c}\text { Eb } \\
\left(\mathbf{k g f} / \mathbf{c m}^{2}\right)\end{array}$ & $\begin{array}{c}\text { Esl } \\
\left(\mathbf{k g f} / \mathbf{c m}^{2}\right)\end{array}$ & $\begin{array}{c}\text { Esl x 0,33 } \\
\left(\mathbf{k g f} / \mathbf{c m}^{2}\right)\end{array}$ & $\begin{array}{c}\text { EsI } \\
\text { (AASHTO } \\
\text { /93) }\end{array}$ \\
\hline $\begin{array}{c}\text { Espessuras } \\
(\mathbf{c m})\end{array}$ & & & $\mathbf{1 4 , 0}$ & $\mathbf{1 0 , 0}$ & $\mathbf{2 5 , 0}$ & - & - & - \\
\hline Materiais & & & CA & $\begin{array}{c}\text { RAP C/ } \\
\text { EMULSÃO }\end{array}$ & BGS & SL & SL & SL \\
\hline mar/08 & - & - & 16.000 & 700 & 1.300 & 1.500 & 495 & 540 \\
\hline mai/10 & 28 & 37 & 16.000 & 1.300 & 1.000 & 1.500 & 495 & 505 \\
\hline ago/11 & 22 & 28 & 16.000 & 5.000 & 1.000 & 1.800 & 594 & 609 \\
\hline jun/12 & 21 & 25 & 15.000 & 7.300 & 1.000 & 1.700 & 561 & 573 \\
\hline fev/13 & 36 & 42 & 12.000 & 2.500 & 1.000 & 1.650 & 545 & 527 \\
\hline jun/14 & 19 & 27 & 16.000 & 5.300 & 1.000 & 1.650 & 545 & 596 \\
\hline
\end{tabular}

Figura 9.33: Retroanálise das bacias de deflexões (série histórica) - km 418 (pista norte)

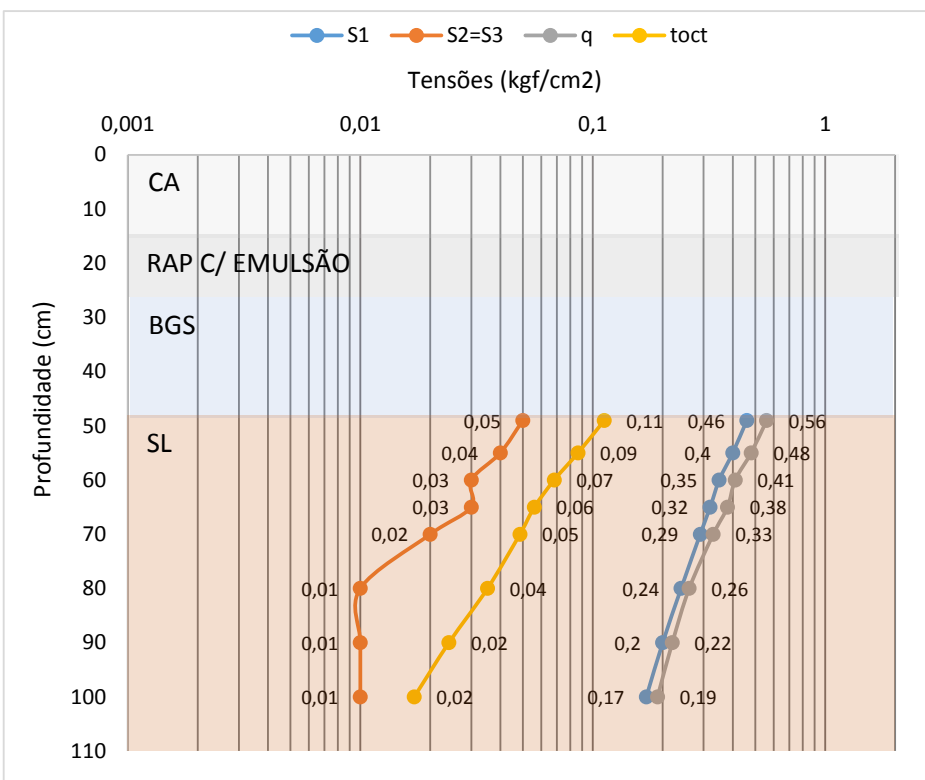

Figura 9.34: Tensões no subleito calculadas para 2014 
Tabela 9.20: Resumo dos ensaios realizados com material próximo ao km 418

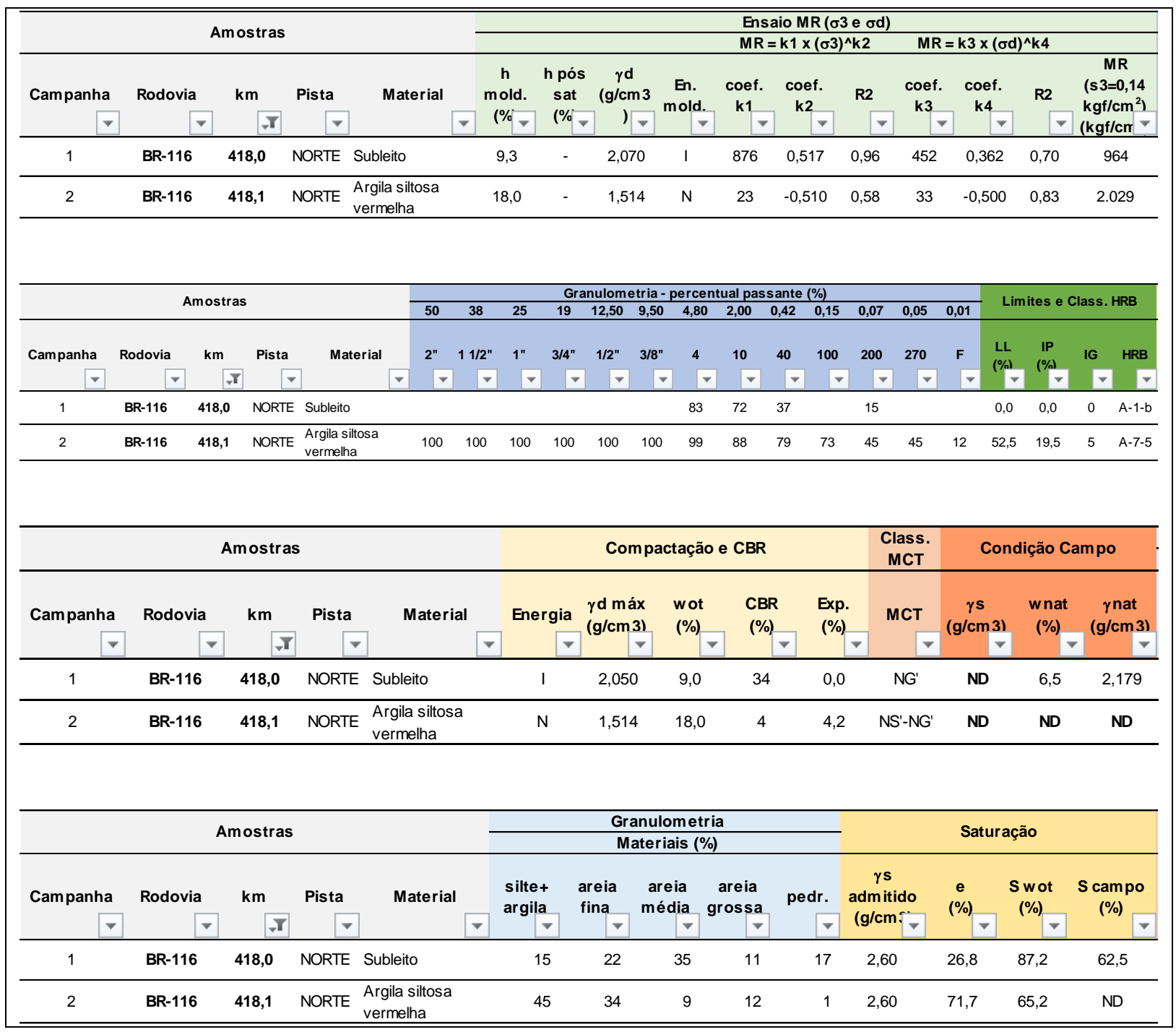




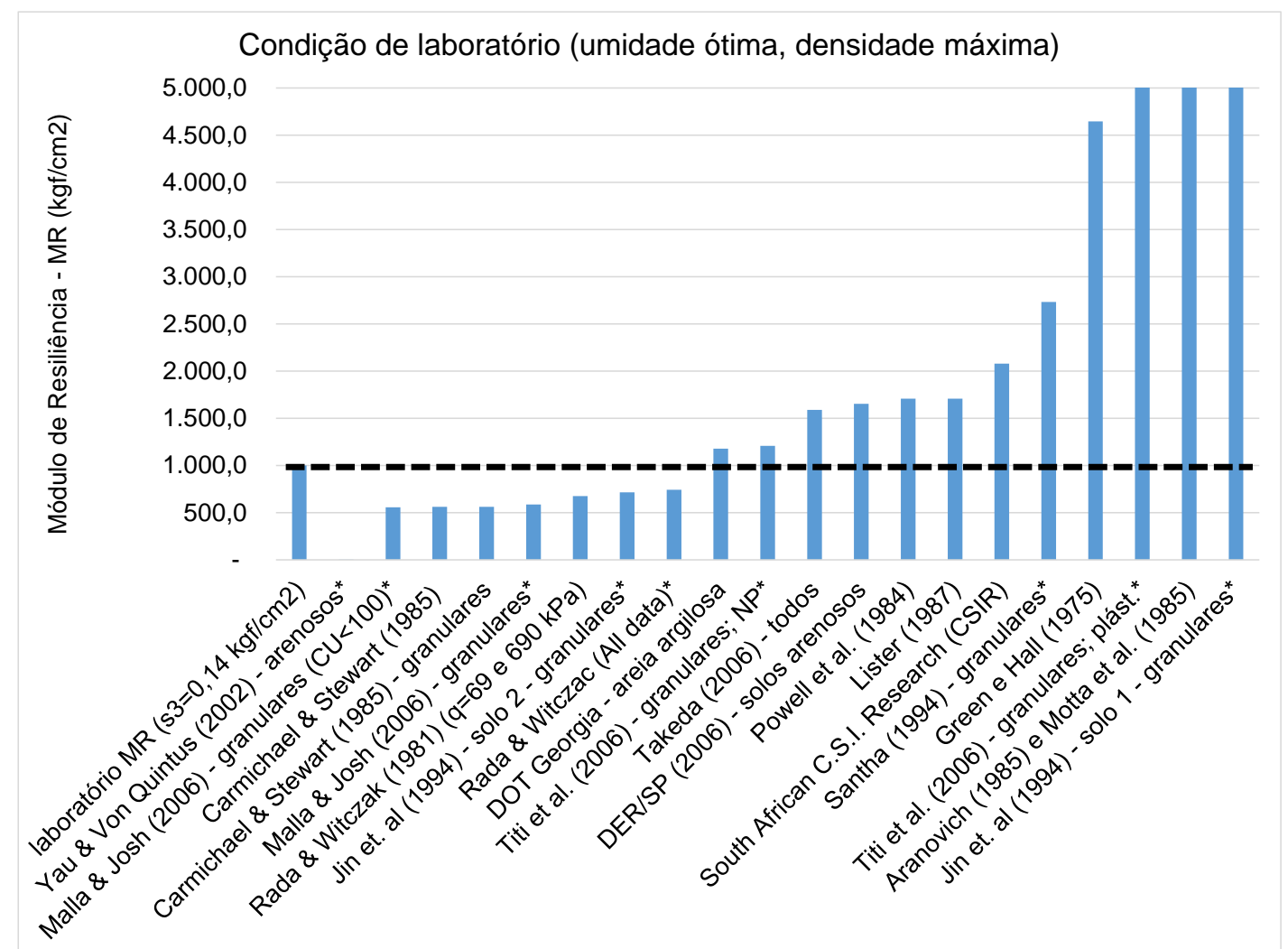

Figura 9.35: Comparativo entre $M R$ de laboratório e modelos de previsão de $M R$ (condição de umidade ótima)

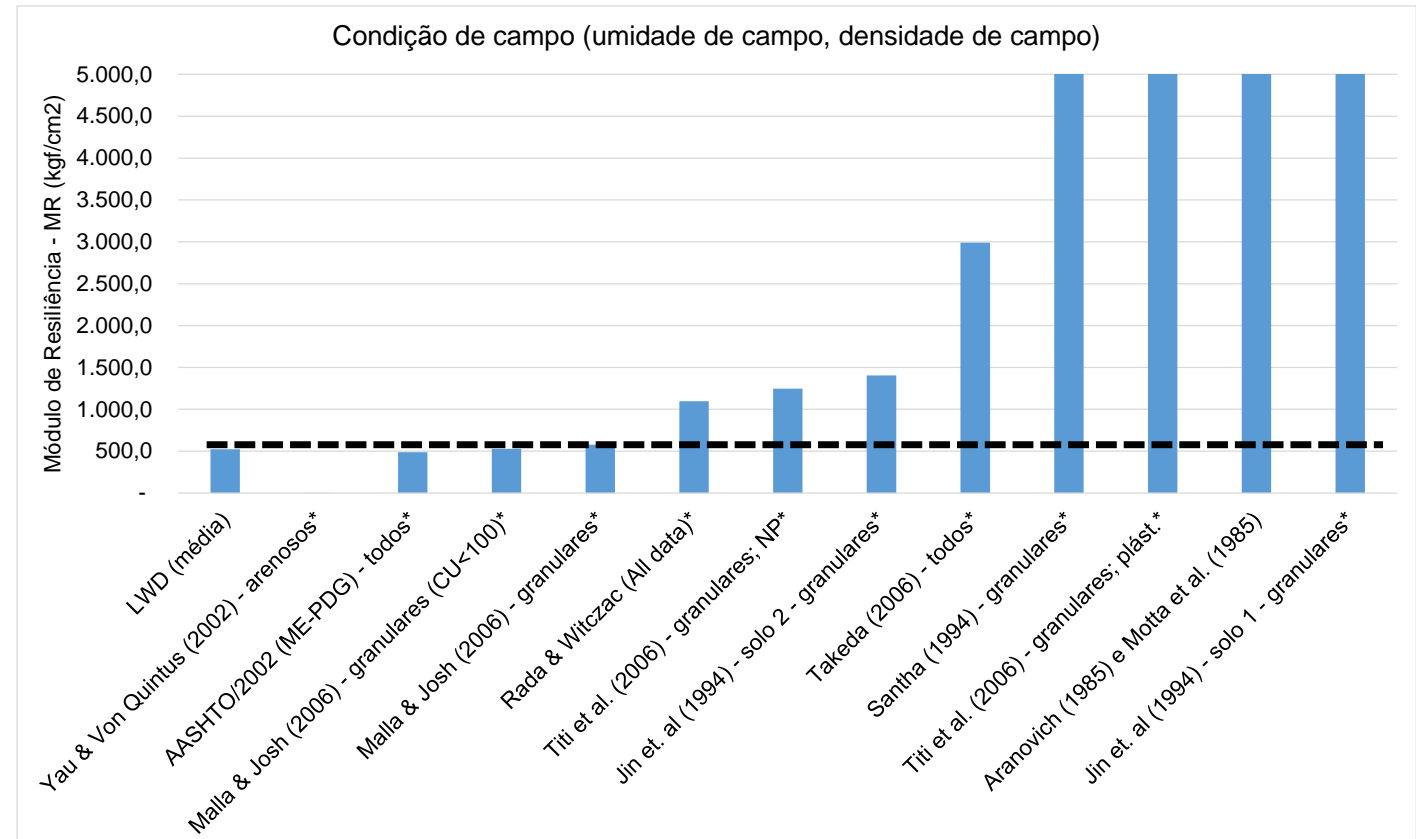

Figura 9.36: Comparativo entre $M R$ in situ $(L W D)$ e modelos de previsão de $M R$ (condição de umidade verificada no campo) 


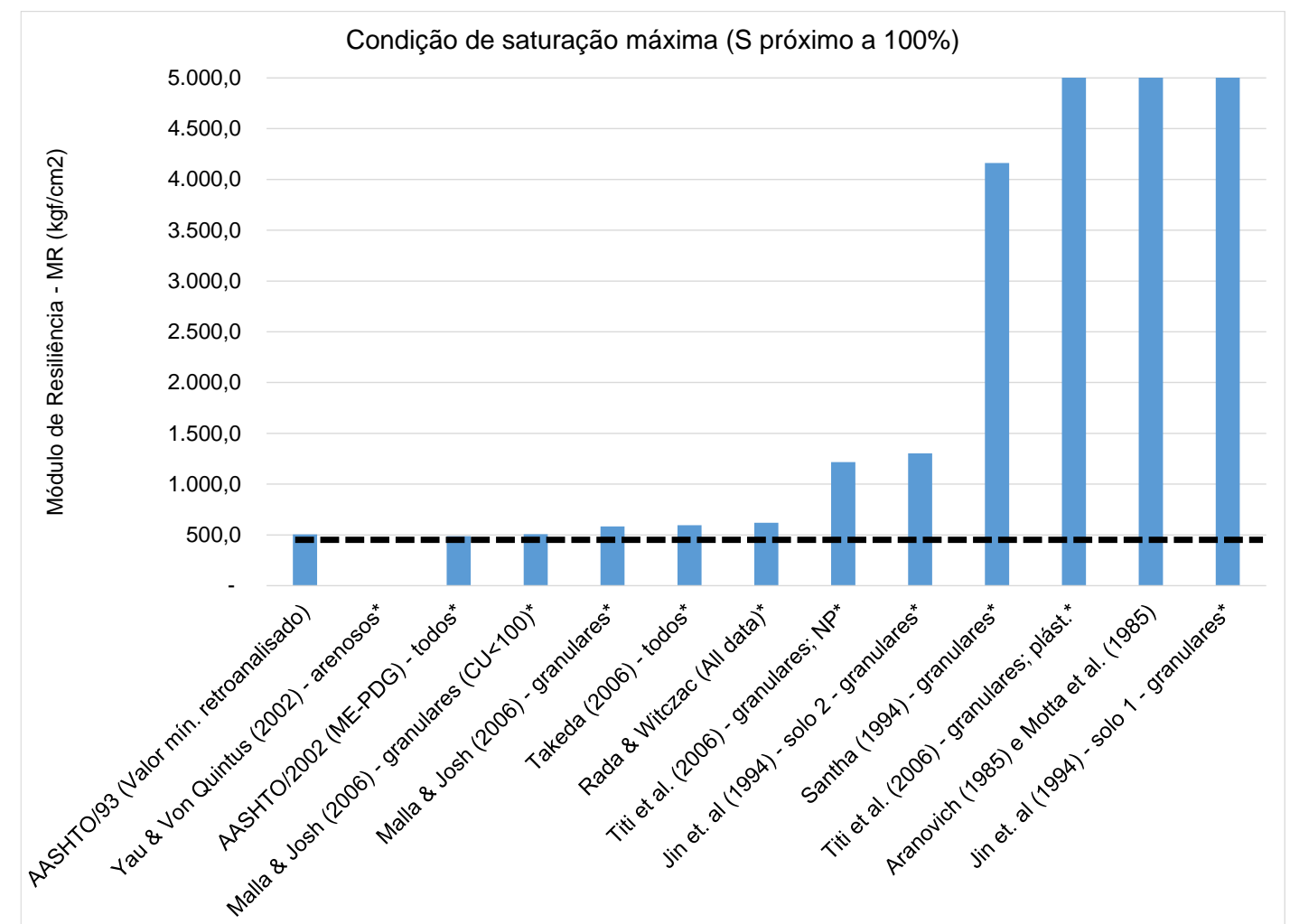

Figura 9.37: Comparativo entre $M R$ in situ mínimo verificado $(F W D)$ e modelos de previsão de $M R$ (condição de saturação próxima a 100\%) 

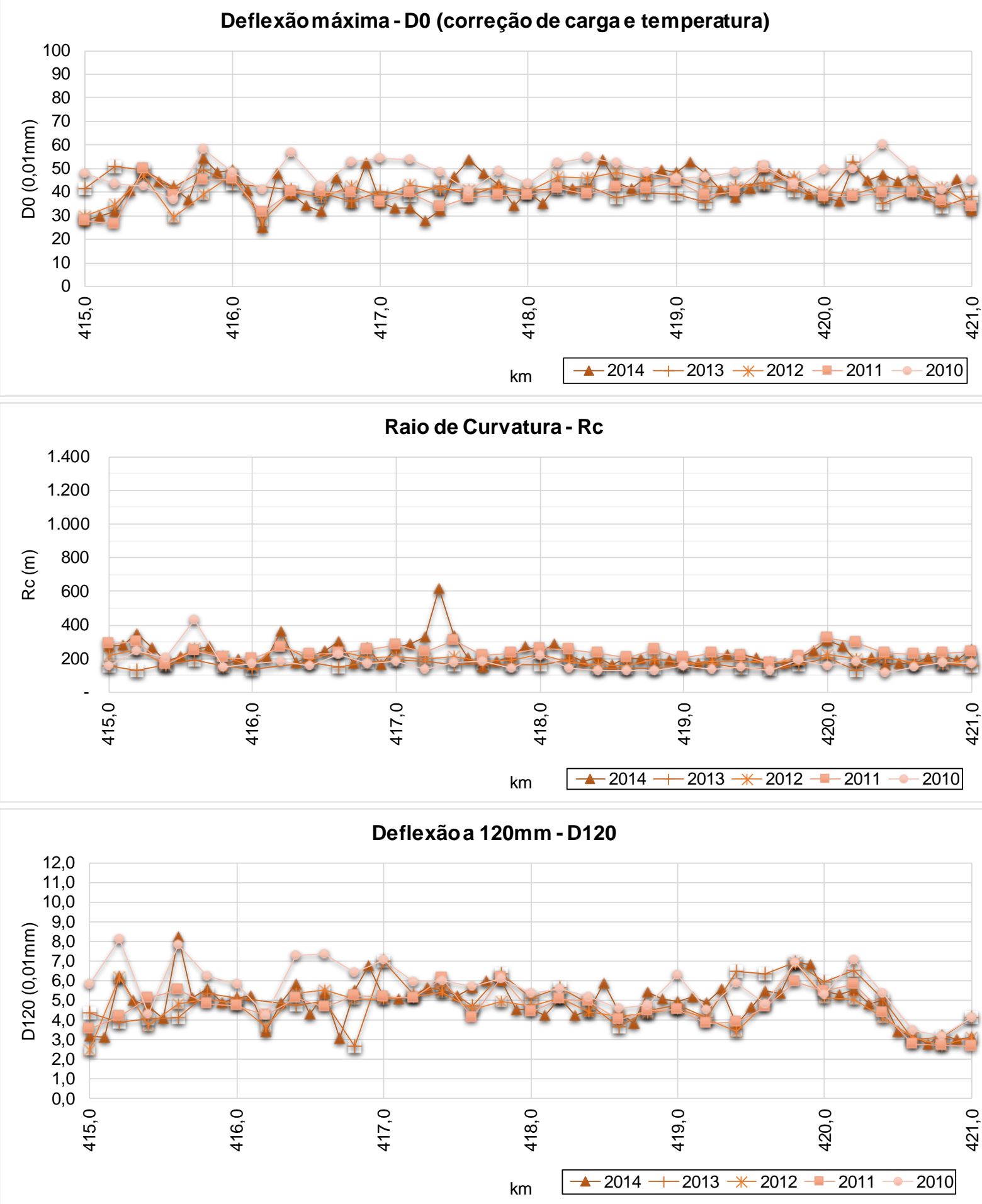

Figura 9.38: Gráficos de série histórica dos indicadores estruturais do pavimento no segmento do $\mathrm{km}$ 418 (pista norte) 


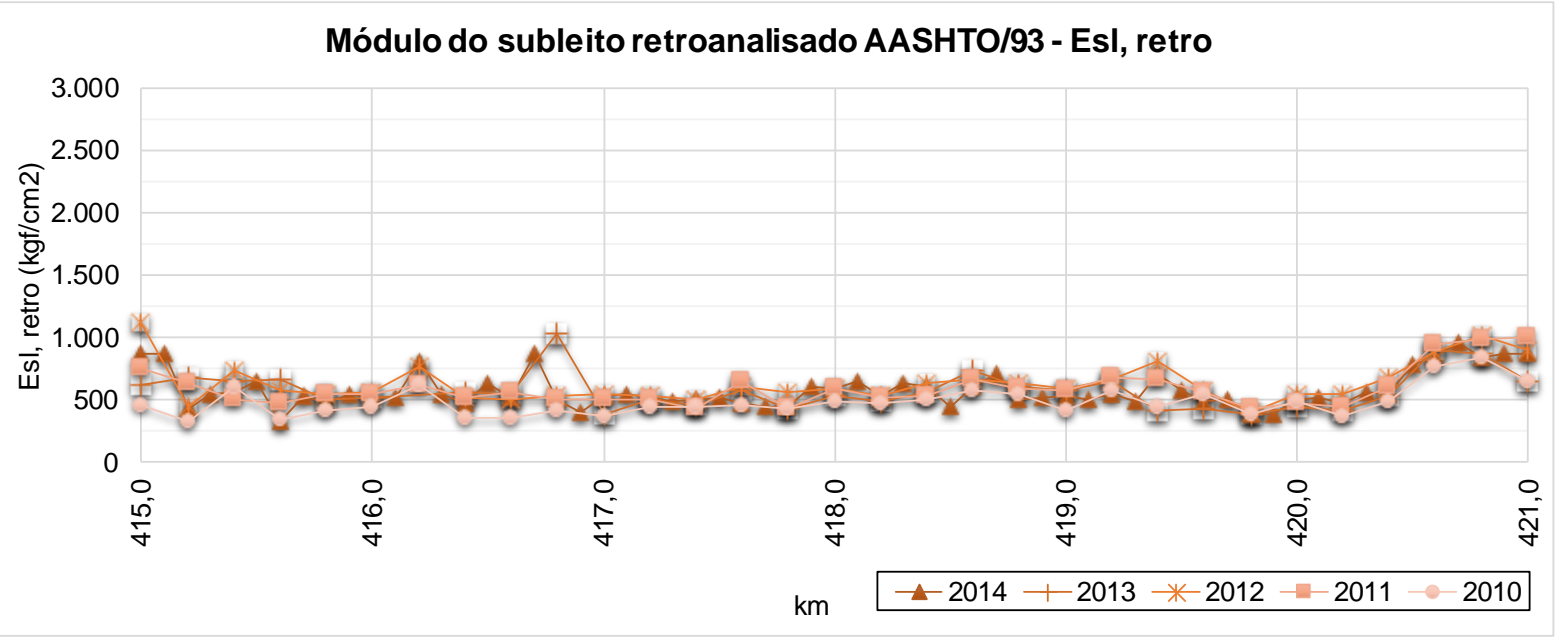

Figura 9.39: Gráficos da série histórica dos dados de módulo de resiliência retroanalisado $(F W D)$ do pavimento no segmento do $\mathrm{km} 418$ (pista norte) 

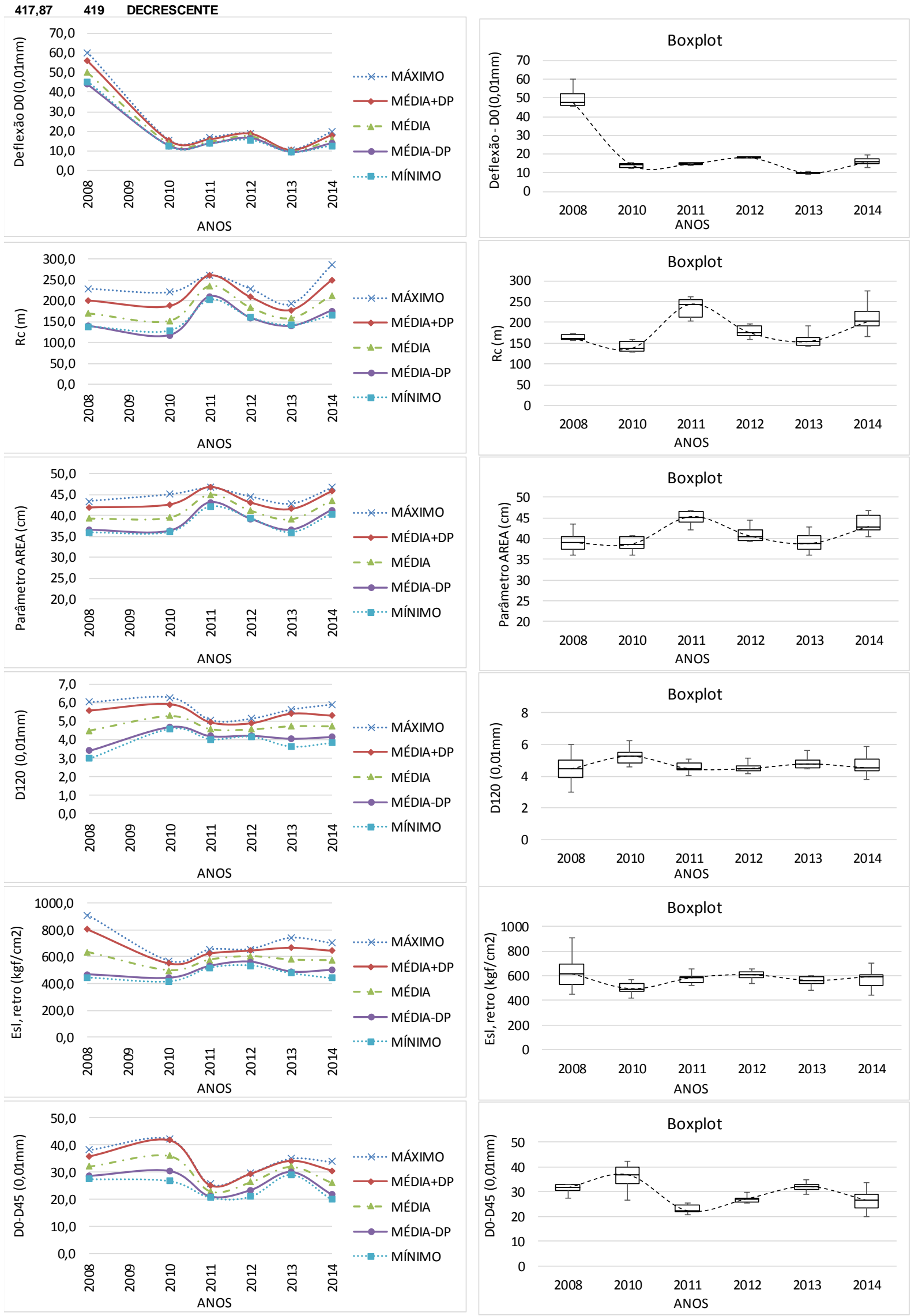

Figura 9.40: Estatísticas dos Parâmetros do pavimento (S. Homogêneo do km 418) 


\subsection{Poço de inspeção do km 423 (Pista Norte)}

A Figura 9.41 a seguir ilustra a localização do poço de inspeção do km 423 (pista norte) bem como o mapeamento geológico do local. Verifica-se uma região com predominância de gnaisse.

A Tabela 9.16 apresenta o registro histórico de intervenções do pavimento. Verificase que o pavimento sofreu uma intervenção de reciclagem de base com emprego de emulsão asfáltica no ano de 2009.

A Tabela 9.17 apresenta a estrutura do pavimento identificada na ocasião da abertura do poço de inspeção. Este pavimento foi identificado como pavimento do tipo semirrígido com base de BGTC.

A Tabela 9.18 e Tabela 9.19 apresentam os resultados estatísticos obtidos a partir do ensaio de $L W D$ sobre as camadas de subleito e camada de base granular. Enquanto a Figura 9.42 apresenta o gráfico comparativo dos pesos específicos aparentes secos e umidades obtidos em campo e em laboratório (curva de compactação de laboratório versus ensaios de umidade e peso específico aparente seco in situ). Verifica-se que o material no campo está com peso específico aparente seco acima do peso específico aparente seco máximo relativo a energia intermediária e umidade sensivelmente inferior à ótima. Infere-se que o material tenha sido compactado na energia modificada.

A Figura 9.43 apresenta o resultado da retroanálise da série histórica de deflexões do pavimento em estudo e a Figura 9.44 apresenta os gráficos de tensões calculadas no subleito para duas situações históricas distintas, ilustrando as variações de comportamento do subleito registradas através dos ensaios com FWD.

A Tabela 9.20 apresenta o resumo dos resultados dos ensaios de laboratório realizados com o material do subleito e dos materiais da faixa de domínio no local.

A Figura 9.45 apresenta um gráfico comparativo entre o valor de módulo medido em laboratório e os valores de módulo previstos pelos modelos da literatura, para as condições de umidade ótima e peso específico aparente seco máximo relativos à energia intermediária de compactação. Verificou-se uma convergência maior para os 
modelos de Carmichael \& Stuart (1985), Malla \& Josh - granulares (2006) e Rada \& Witczak (1981).

A Figura 9.46 apresenta um gráfico comparativo entre o valor de módulo in situ medido com LWD e os valores de módulo previstos pelos modelos da literatura, paras as condições de umidade e peso específico aparente seco verificados em campo no momento da abertura do poço de inspeção. Verificou-se uma convergência maior para os modelos de Malla \& Joshi - materiais granulares (2006), e AASHTO/2002 (MEPDG).

A Figura 9.47 apresenta um gráfico comparativo entre o valor mínimo de módulo in situ medido com FWD (retroanálise) e os valores de módulo previstos pelos modelos da literatura, para as condições de saturação próxima da saturação máxima (adotouse $S$ próximo a 98\%). Verificou-se uma convergência maior para o modelo da AASHTO/2002.

A Figura 9.48 apresenta os gráficos da série histórica dos indicadores estruturais do pavimento (deflexão máxima, raio de curvatura, e deflexão a $120 \mathrm{~mm}$ do ponto de aplicação de carga) no segmento que contempla o local em estudo.

A Figura 9.49 apresenta os gráficos da série histórica dos valores de módulo de resiliência retroanalisado ( $F W D$ ) e Quociente de Irregularidade (QI) no segmento que contempla o local em estudo.

A Figura 9.50 apresenta os dados estatísticos (valores máximos, mínimos, média e média mais ou menos desvio padrão), bem como boxplot dos indicadores estruturais do pavimento no segmento homogêneo determinado para o ponto em estudo. 


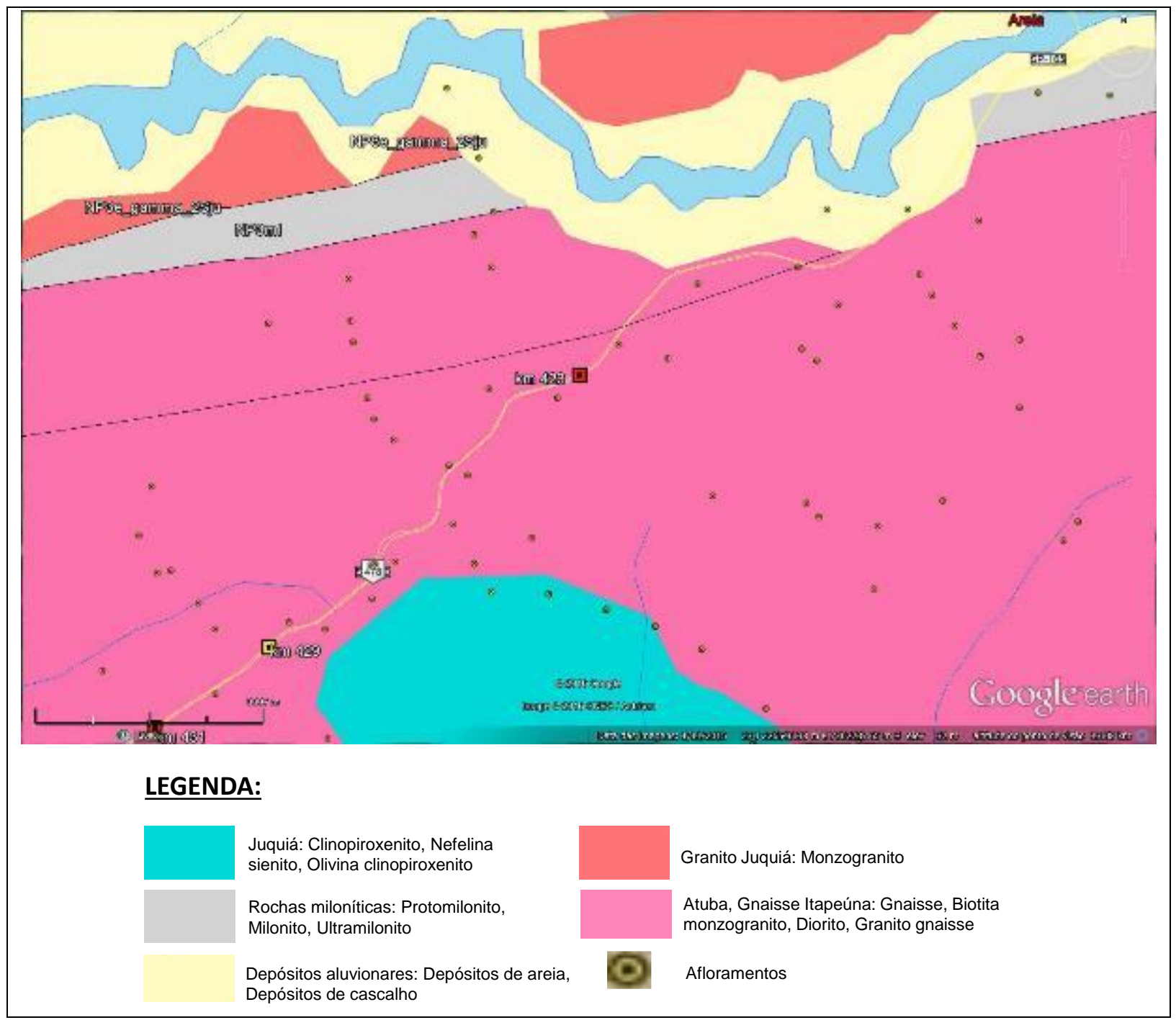

Figura 9.41: Mapa Geológico do local sondado - km 423 (Pista Norte)

Fonte: Geobank/Google Earth $\AA$

Tabela 9.21: histórico de intervenções informado - km 423 (pista norte)

\begin{tabular}{ccclccc}
\hline $\mathbf{k m}$ & $\begin{array}{c}\mathbf{k m} \\
\text { inicial }\end{array}$ & $\begin{array}{c}\mathbf{k m} \\
\text { final }\end{array}$ & \multicolumn{1}{c}{ Solução Aplicada } & $\begin{array}{c}\text { Larg. } \\
\mathbf{( m )}\end{array}$ & $\begin{array}{c}\text { Esp. } \\
\mathbf{( c m})\end{array}$ & $\begin{array}{c}\text { Data da } \\
\text { Interv. }\end{array}$ \\
\hline 422,984 & 423,051 & FRESAGEM FUNCIONAL & 3,55 & 5,01 & $09 / 04 / 2008$ \\
\hline 421,900 & 423,100 & $\begin{array}{l}\text { RECICLAGEM DE PAV. ASF. COM EMULSÃO } \\
\text { ESP. "IN SITU" }\end{array}$ & 3,80 & 10,00 & $23 / 04 / 2009$ \\
\hline 423 & 423,447 & MICROREVESTIMENTO & 4,10 & 1,20 & $07 / 05 / 2009$ \\
\hline 422,557 & 423,349 & 423,040 & MICROREVESTIMENTO & 3,60 & 1,00 & $05 / 12 / 2011$ \\
\hline 423,000 & 423,014 & FRESAGEM ESTRUTURAL & 3,80 & 6,50 & $16 / 02 / 2013$ \\
\hline 423,000 & 423,047 & FRESAGEM ESTRUTURAL & 3,99 & 7,00 & $17 / 06 / 2014$ \\
\hline 422,830 & 423,000 & FRESAGEM ESTRUTURAL & 3,99 & 7,00 & $17 / 06 / 2014$ \\
\hline
\end{tabular}


Tabela 9.22: Estrutura do pavimento da faixa externa - km 423 (pista norte)

\begin{tabular}{ccccc} 
km & Pista & Camada & $\begin{array}{c}\text { Espessura } \\
(\mathbf{c m})\end{array}$ & \multicolumn{1}{c}{ Camada } \\
\hline \multirow{3}{*}{423} & \multirow{2}{*}{ Norte } & 10,0 & CA \\
\cline { 3 - 5 } & & 2 & 20,0 & BGTC \\
\cline { 3 - 4 } & & 20,0 & BGS \\
\cline { 2 - 4 } & & - & SL \\
\hline
\end{tabular}

Tabela 9.23: Estatística dos resultados do ensaio com $L W D$

\begin{tabular}{|c|c|c|c|c|c|c|c|c|c|c|c|}
\hline \multirow{2}{*}{ km } & \multirow{2}{*}{ Material } & \multicolumn{5}{|c|}{ Leituras $\mathrm{D}_{0, \text { LWD }}\left(10^{-2} \mathrm{~m} \mathrm{~m}\right)$} & \multicolumn{5}{|c|}{$E_{0, \text { calc }}\left(\mathrm{kfg} / \mathrm{cm}^{2}\right)$} \\
\hline & & Mín. & Máx. & Média & Desvio & CV(\%) & Mín. & Máx. & Média & Desvio & CV(\%) \\
\hline 423 & BGS & 27 & 48 & 36 & 7 & 20 & 474 & 837 & 653 & 124 & 19 \\
\hline 423 & $\mathrm{SL}$ & 63 & 97 & 80 & 11 & 14 & 234 & 360 & 291 & 41 & 14 \\
\hline
\end{tabular}

Tabela 9.24: Estatística dos resultados de determinação do módulo da camada de BGS

\begin{tabular}{|c|c|c|c|c|c|}
\hline \multirow{2}{*}{ km } & \multirow{2}{*}{ Material } & \multicolumn{4}{|c|}{$E_{s b, r e t r o}\left(\mathrm{kfg} / \mathrm{cm}^{2}\right)$} \\
\hline & & Mín. Máx. & Média & Desvio & CV(\%) \\
\hline 423 & BGS & $1.013 \quad 2.664$ & 1.783 & 556 & 31 \\
\hline
\end{tabular}

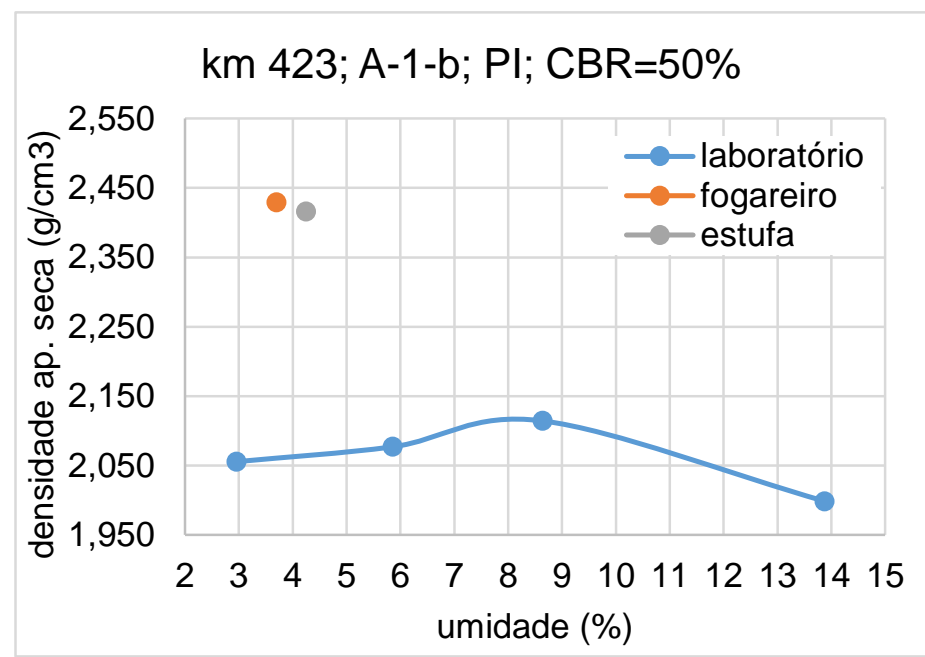

Figura 9.42: Comparativo entre pesos específicos aparentes secos - laboratório x campo (subleito, $\mathrm{km} \mathrm{423,} \mathrm{norte)}$ 


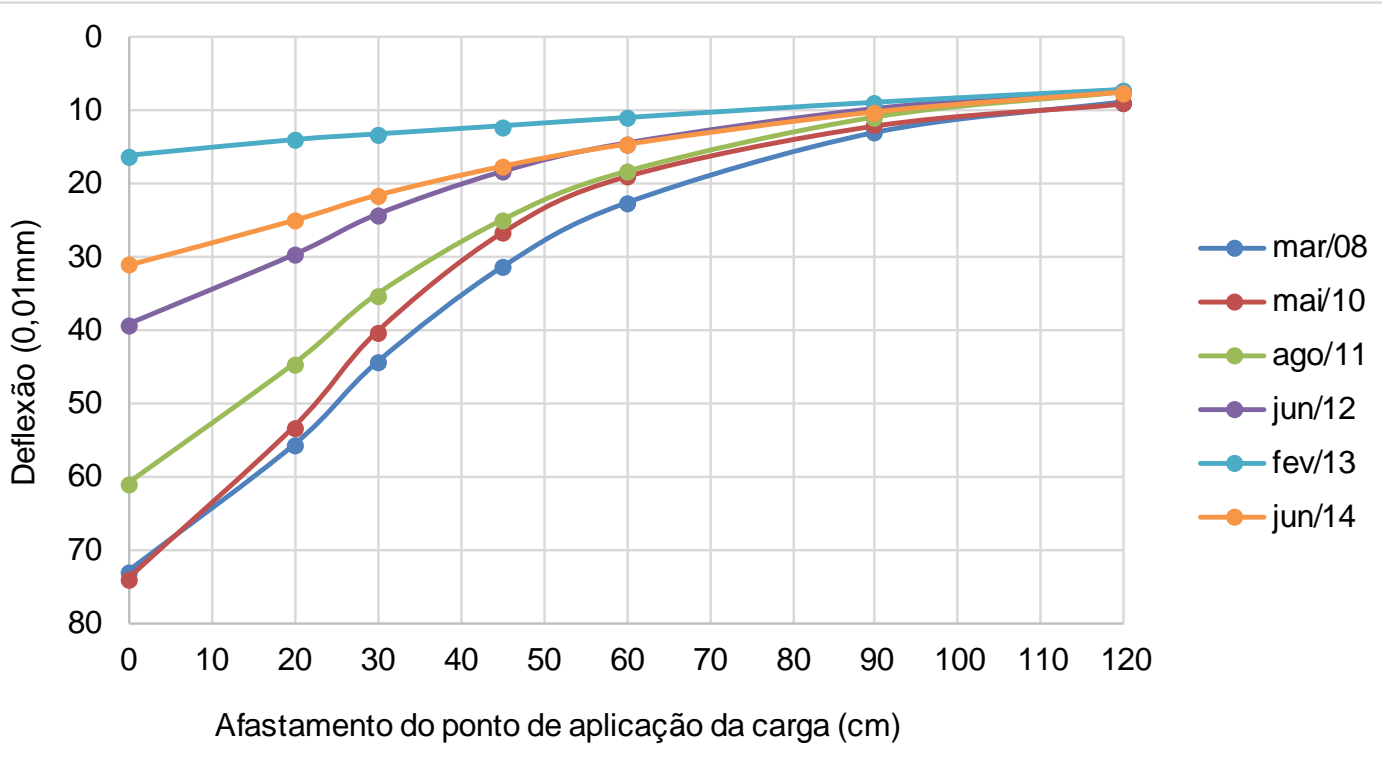

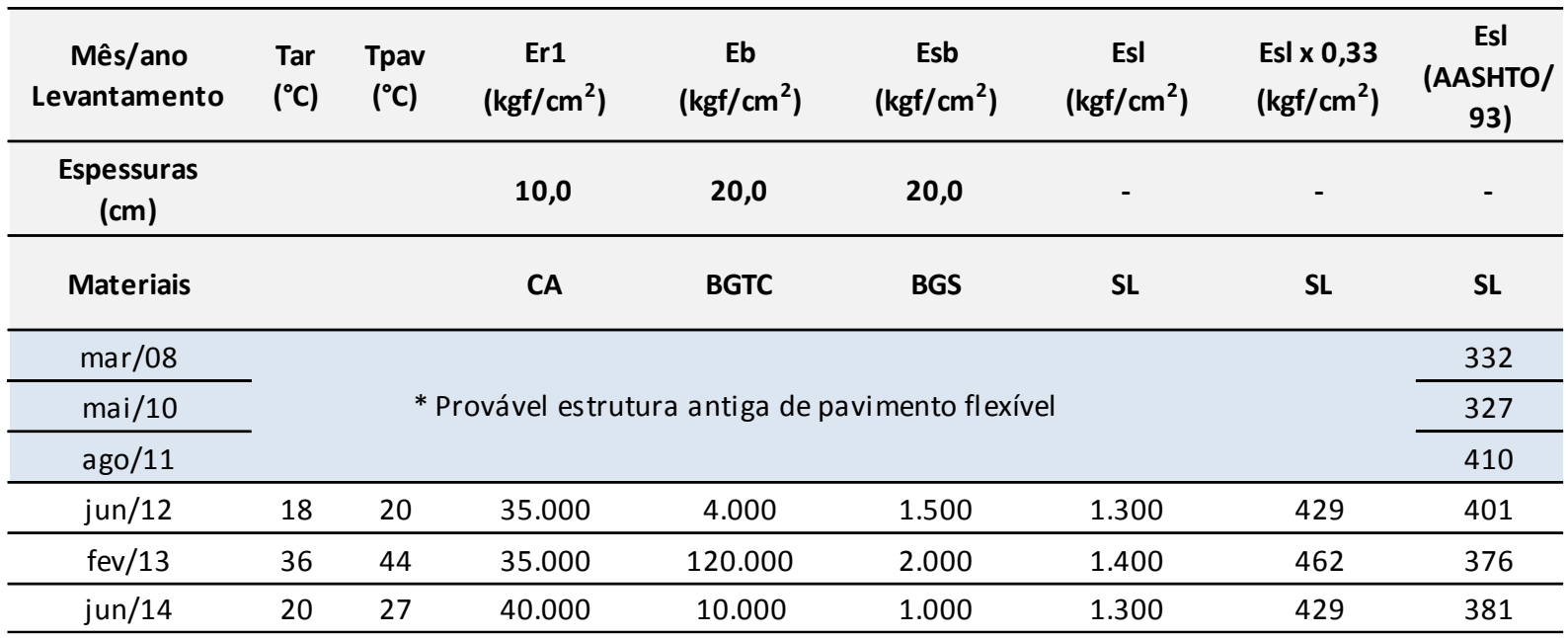

Figura 9.43: Retroanálise das bacias de deflexões (série histórica) - km 423 (pista norte)
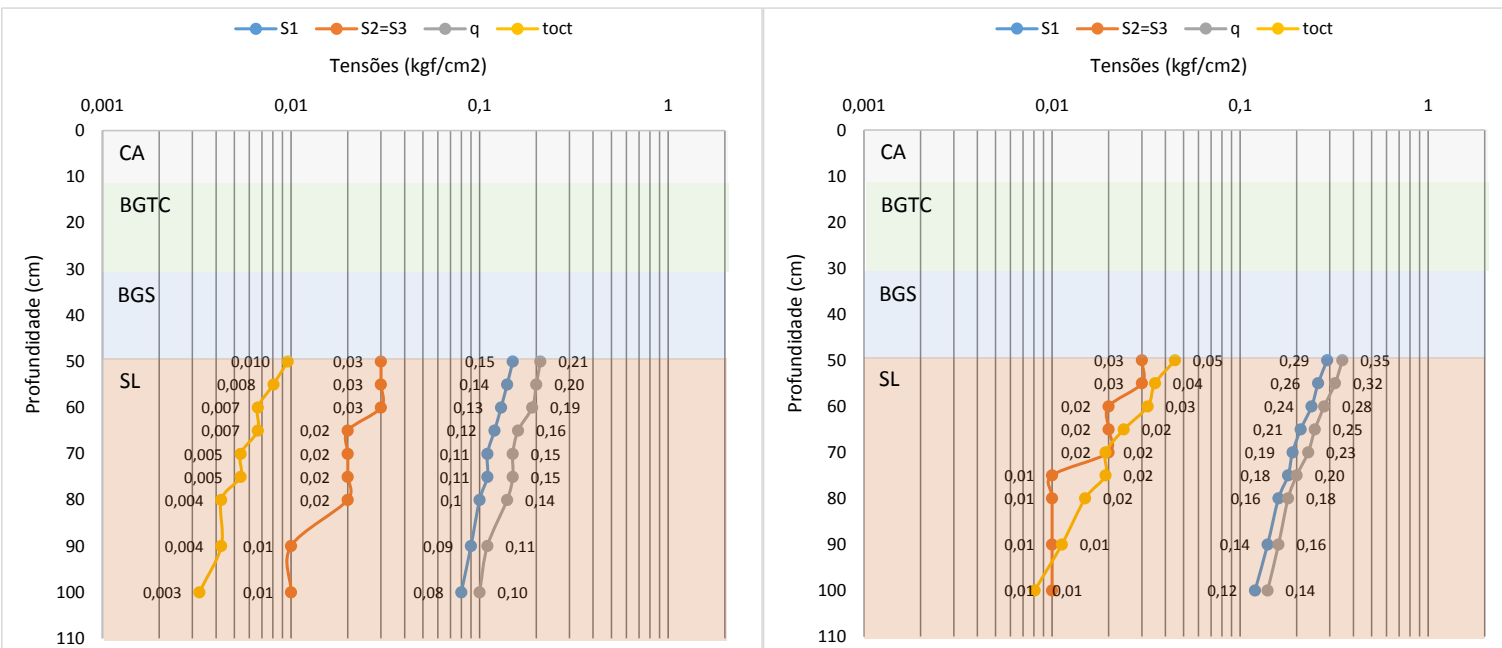

Figura 9.44: Tensões no subleito calculadas para (a) 2013 e (b) 2014 
Tabela 9.25: Resumo dos ensaios realizados com material próximo ao km 423

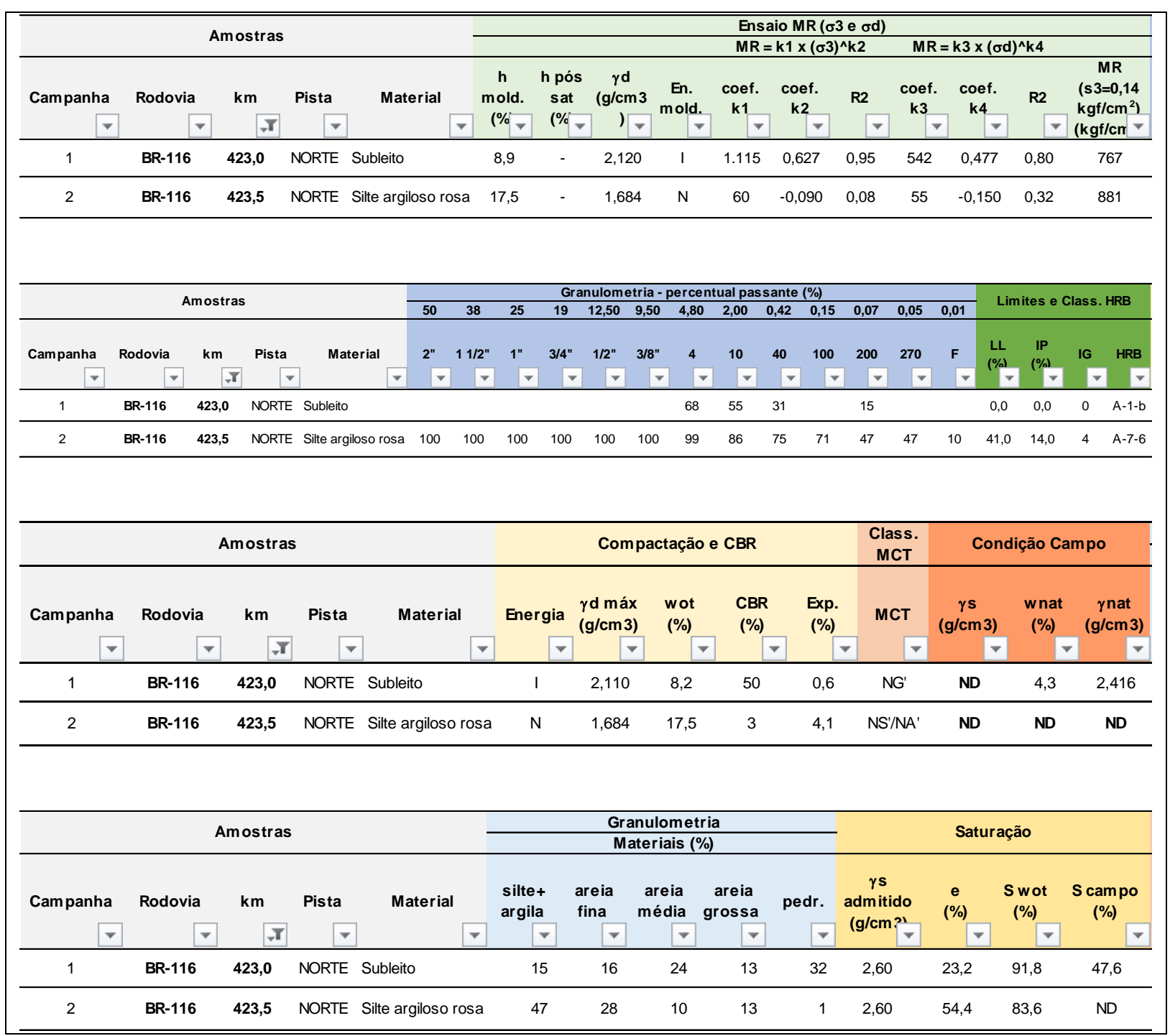




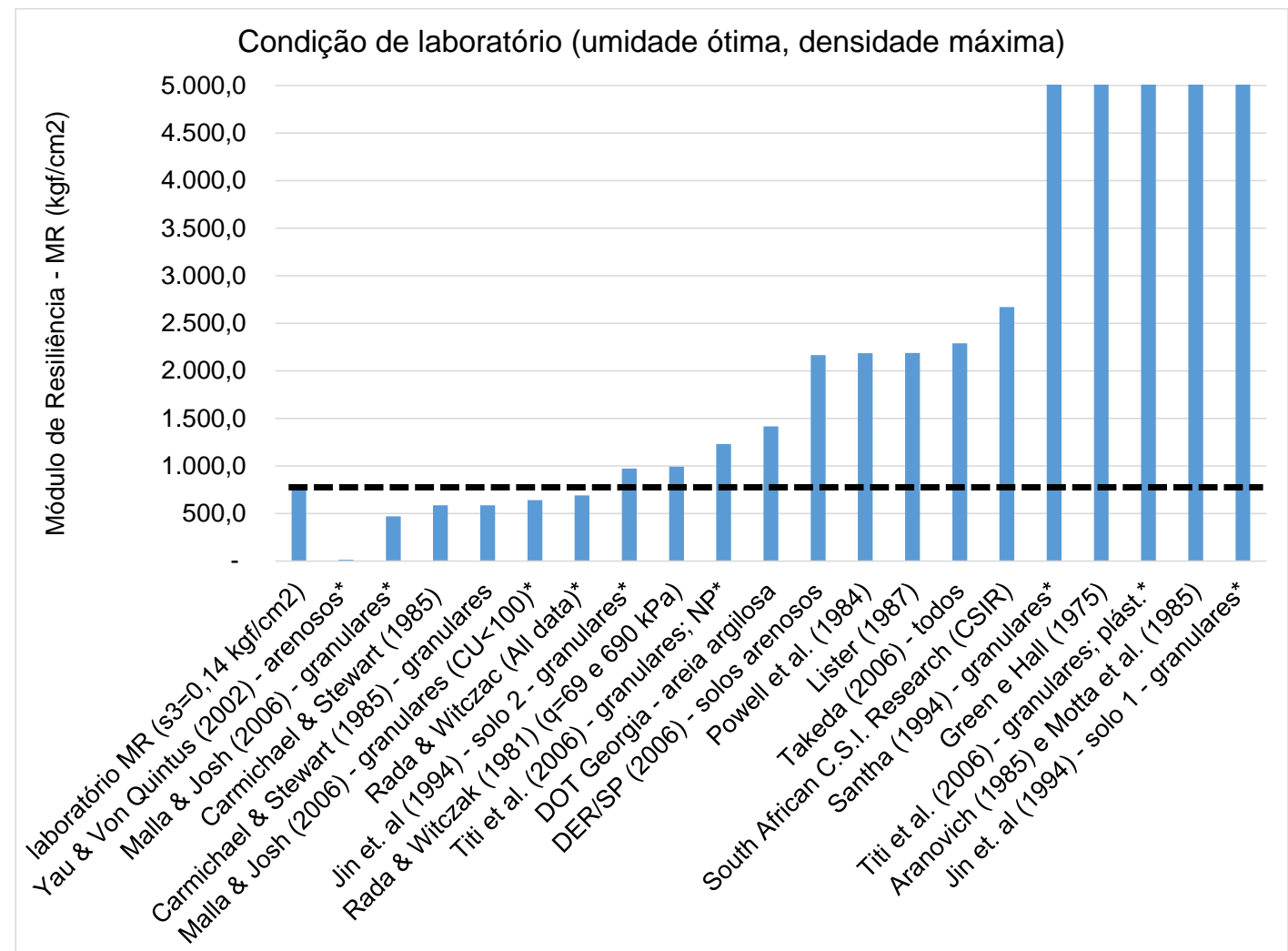

Figura 9.45: Comparativo entre $M R$ de laboratório e modelos de previsão de $M R$ (condição de umidade ótima)

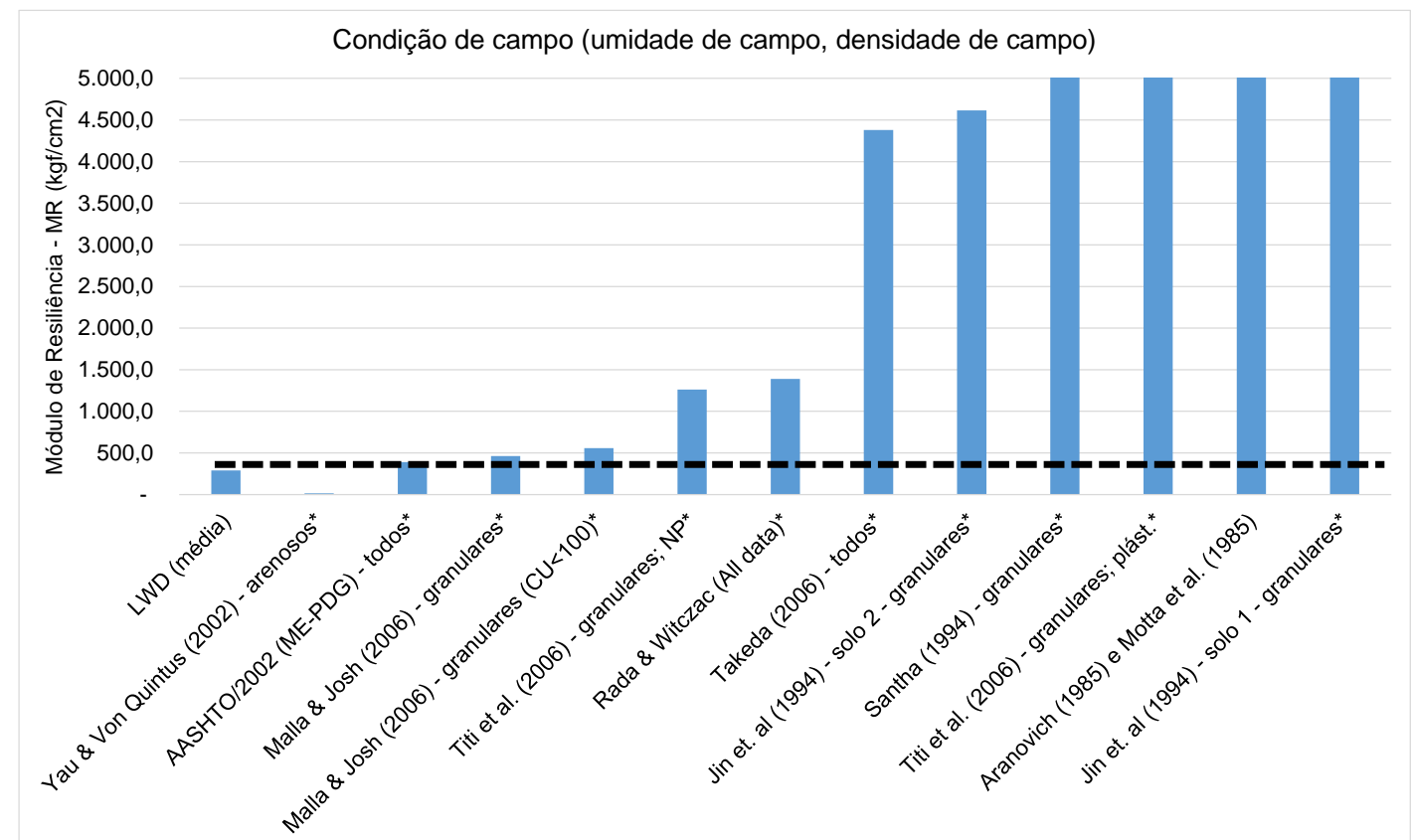

Figura 9.46: Comparativo entre $M R$ in situ $(L W D)$ e modelos de previsão de $M R$ (condição de umidade verificada no campo) 


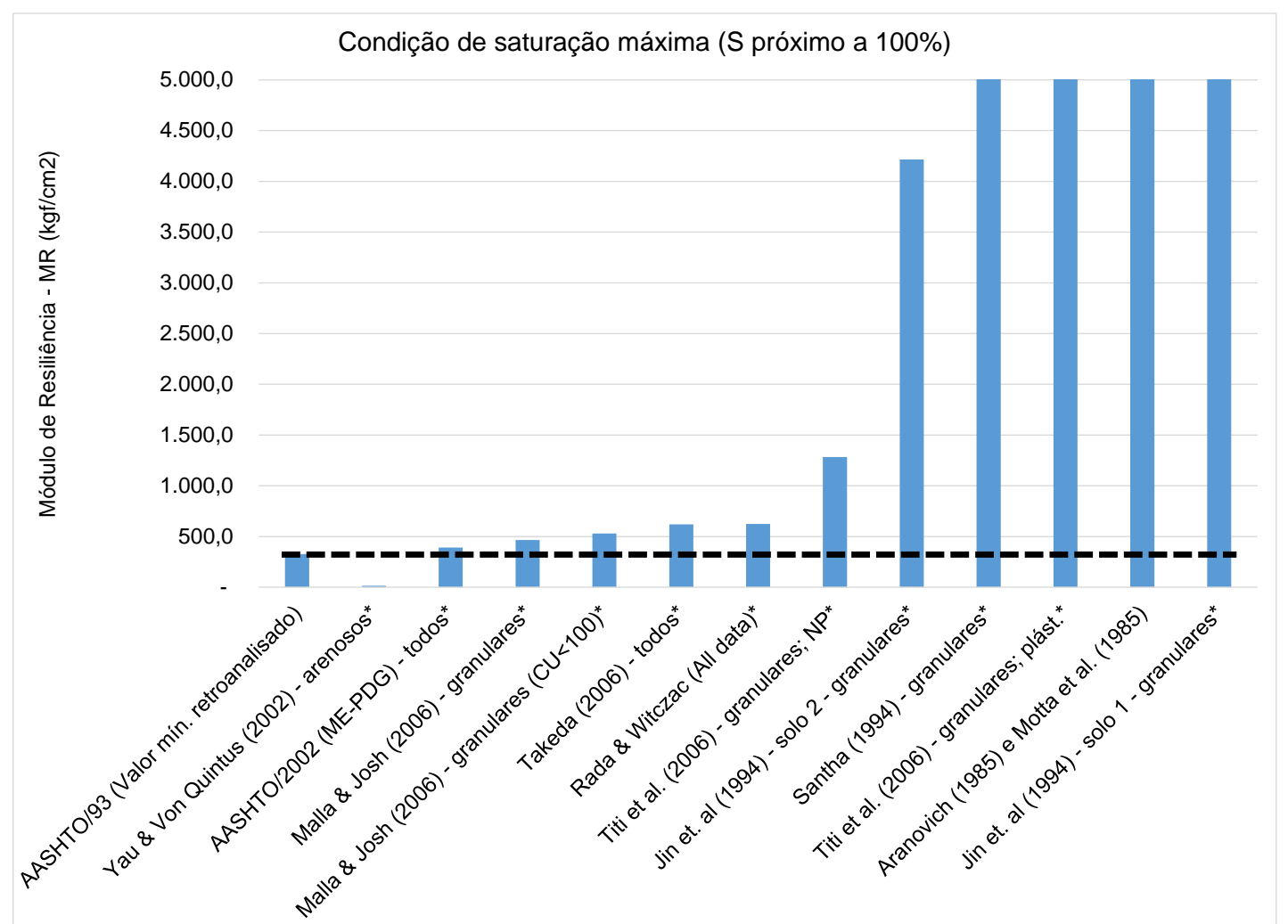

Figura 9.47: Comparativo entre $M R$ in situ mínimo verificado ( $F W D$ ) e modelos de previsão de $M R$ (condição de saturação próxima a 100\%) 

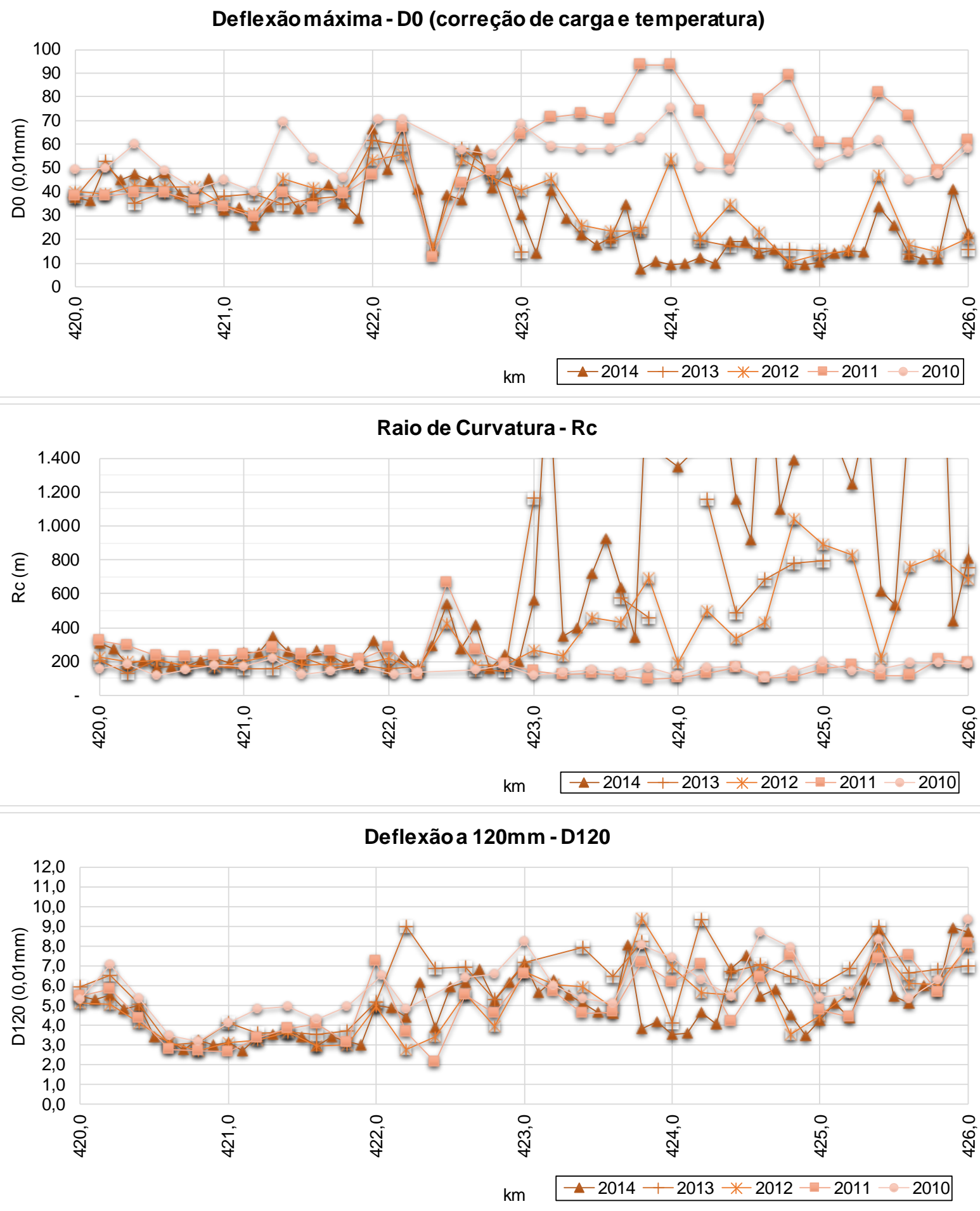

Figura 9.48: Gráficos de série histórica dos indicadores estruturais do pavimento no segmento do km 423 (pista norte) 


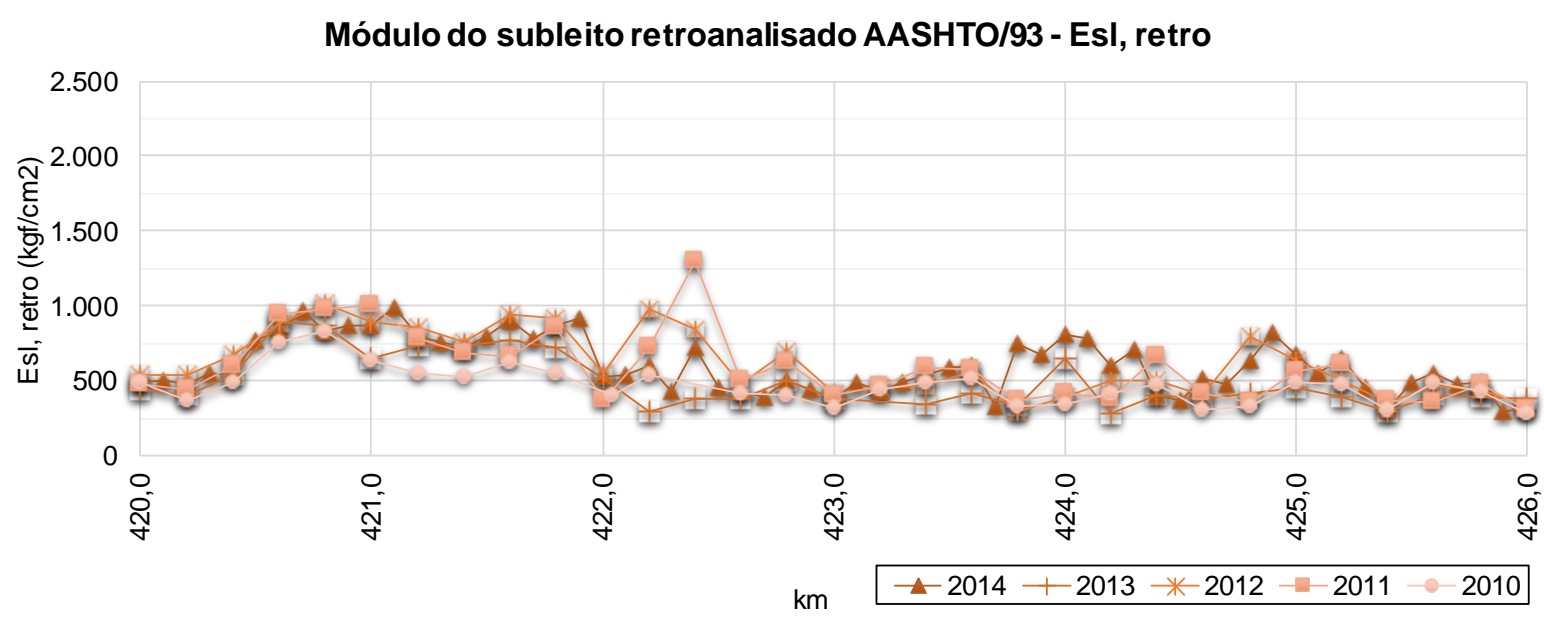

Figura 9.49: Gráficos da série histórica dos dados de módulo de resiliência retroanalisado $(F W D)$ do pavimento no segmento do $\mathrm{km} 423$ (pista norte) 
422,5 423,5 DECRESCENTE
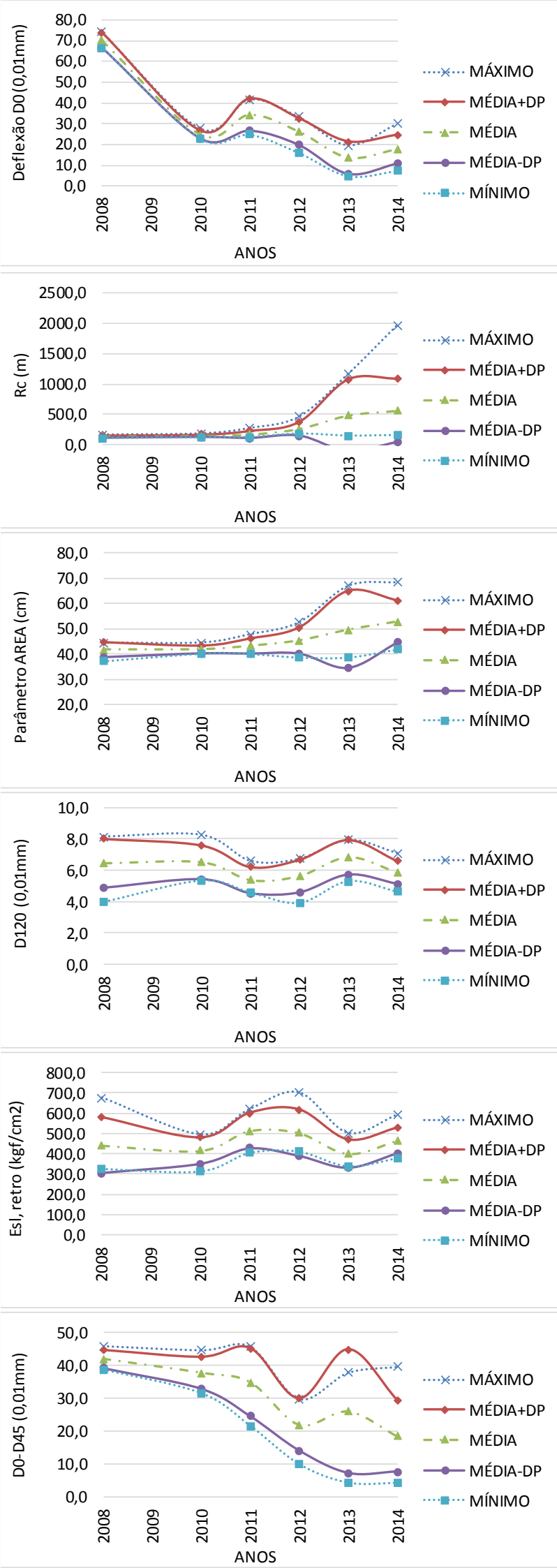
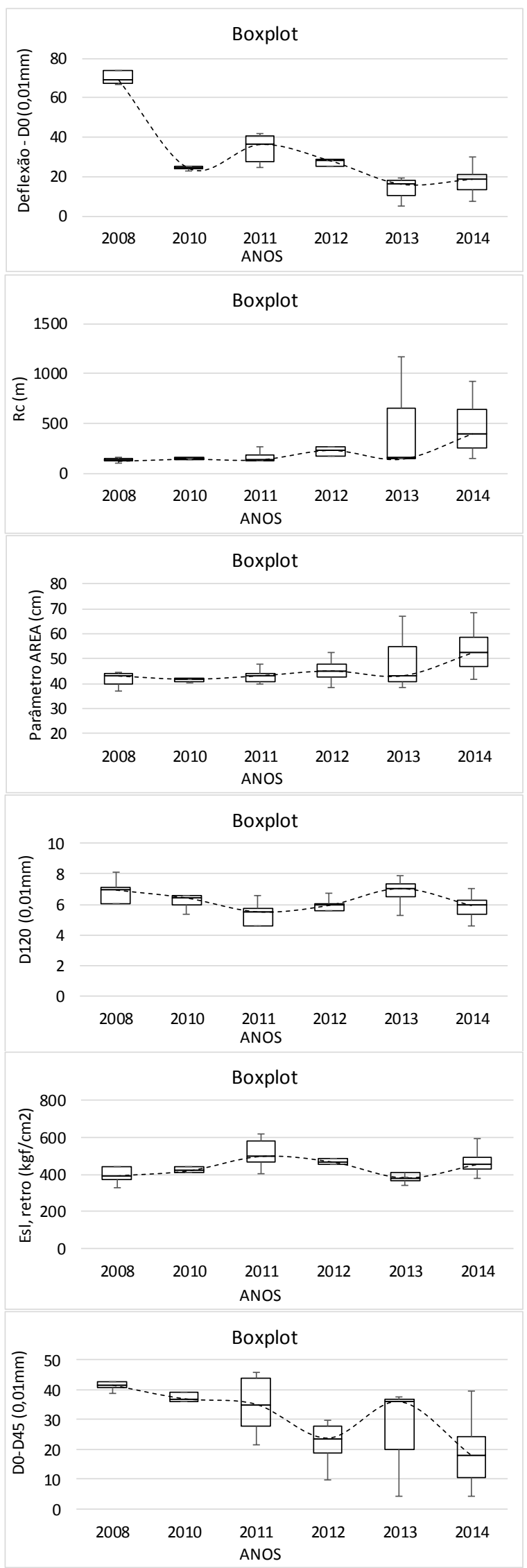

Figura 9.50: Estatísticas dos Parâmetros do pavimento (S. Homogêneo do km 423) 


\subsection{Poço de inspeção do km 429 (Pista Norte)}

A Figura 9.51 a seguir ilustra a localização do poço de inspeção do km 429 (pista norte) bem como o mapeamento geológico do local. Verifica-se uma região com predominância de gnaisse.

A Tabela 9.16 apresenta o registro histórico de intervenções do pavimento. Verificase que o pavimento sofreu uma intervenção de reciclagem de base com emprego de emulsão asfáltica no ano de 2008.

A Tabela 9.17 apresenta a estrutura do pavimento identificada na ocasião da abertura do poço de inspeção. Este pavimento foi identificado como pavimento do tipo semirrígido com base de BGTC.

A Tabela 9.18 e Tabela 9.19 apresentam os resultados estatísticos obtidos a partir do ensaio de $L W D$ sobre as camadas de subleito e camada de base granular. Enquanto a Figura 9.52 apresenta o gráfico comparativo dos pesos específicos aparentes secos e umidades obtidos em campo e em laboratório (curva de compactação de laboratório versus ensaios de umidade e peso específico aparente seco in situ). Verifica-se que o material no campo está com peso específico aparente seco acima do peso específico aparente seco máximo relativo a energia intermediária e umidade ligeiramente inferior à ótima. Infere-se que o material tenha sido compactado na energia modificada.

A Figura 9.53 apresenta o resultado da retroanálise da série histórica de deflexões do pavimento em estudo e a Figura 9.54 apresenta os gráficos de tensões calculadas no subleito para duas situações históricas distintas, ilustrando as variações de comportamento do subleito registradas através dos ensaios com FWD.

A Tabela 9.20 apresenta o resumo dos resultados dos ensaios de laboratório realizados com o material do subleito e dos materiais da faixa de domínio no local.

A Figura 9.55 apresenta um gráfico comparativo entre o valor de módulo medido em laboratório e os valores de módulo previstos pelos modelos da literatura, para as condições de umidade ótima e peso específico aparente seco máximo relativos à energia intermediária de compactação. Verificou-se uma convergência maior para os 
modelos de: DOT Georgia - areia argilosa, Carmichael \& Stuart (1985), Rada \& Witczak (1981) e DER/SP - solos arenosos (2006).

A Figura 9.56 apresenta um gráfico comparativo entre o valor de módulo in situ medido com $L W D$ e os valores de módulo previstos pelos modelos da literatura, para as condições de umidade e peso específico aparente seco verificadas em campo no momento da abertura do poço de inspeção. Verificou-se uma convergência maior para os modelos de Malla \& Joshi - materiais granulares (2006), e AASHTO/2002 (MEPDG).

A Figura 9.57 apresenta um gráfico comparativo entre o valor mínimo de módulo in situ medido com FWD (retroanálise) e os valores de módulo previstos pelos modelos da literatura, para as condições de saturação próxima da saturação máxima (adotouse S próximo a 98\%). Verificou-se uma convergência maior para o modelo Takeda (2006) e Malla \& Joshi (2006).

A Figura 9.58 apresenta os gráficos da série histórica dos indicadores estruturais do pavimento (deflexão máxima, raio de curvatura, e deflexão a $120 \mathrm{~mm}$ do ponto de aplicação de carga) no segmento que contempla o local em estudo.

A Figura 9.59 apresenta os gráficos da série histórica dos valores de módulo de resiliência retroanalisado ( $F W D$ ) e Quociente de Irregularidade (QI) no segmento que contempla o local em estudo.

A Figura 9.60 apresenta os dados estatísticos (valores máximos, mínimos, média e média mais ou menos desvio padrão), bem como boxplot dos indicadores estruturais do pavimento no segmento homogêneo determinado para o ponto em estudo. 


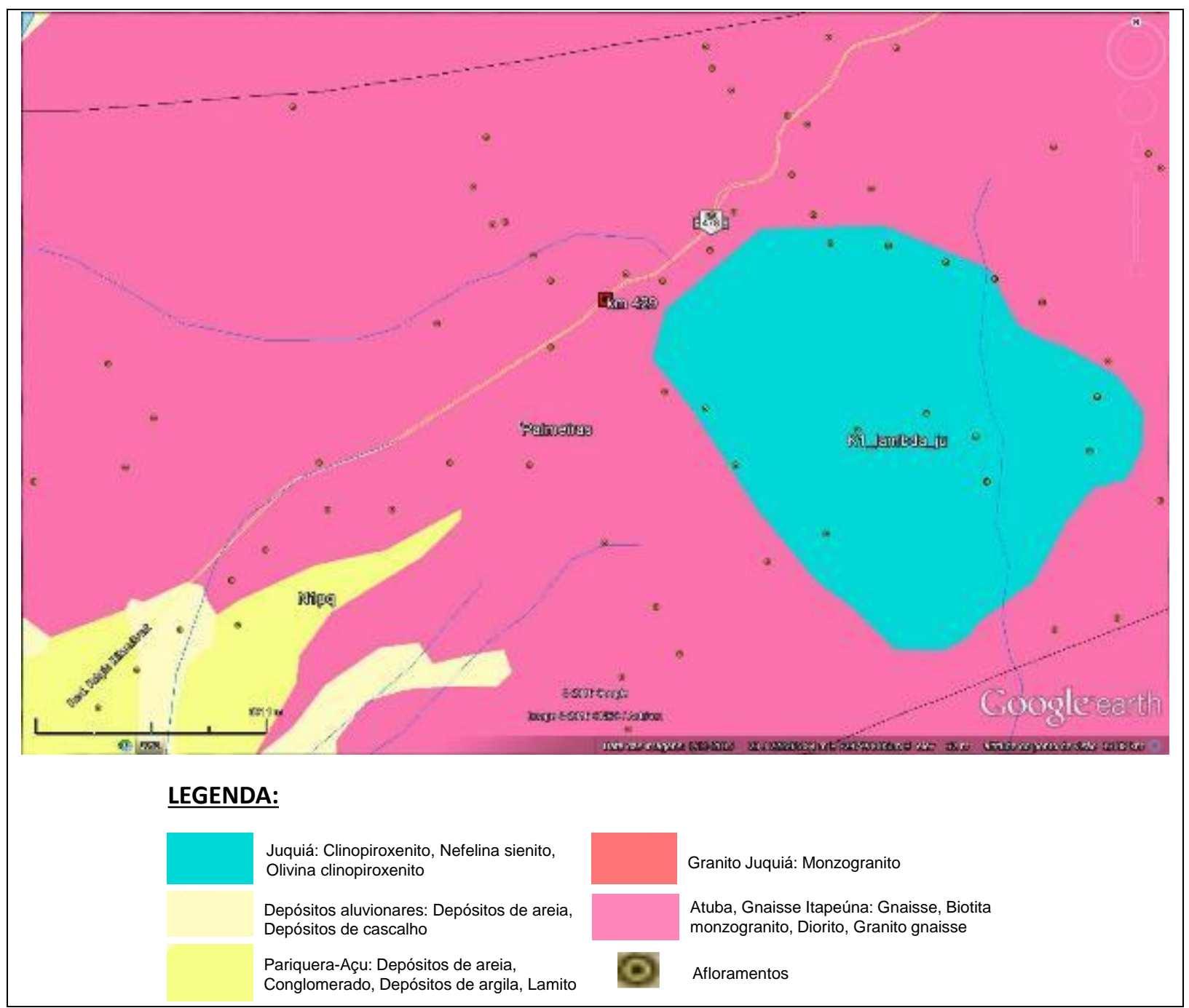

Figura 9.51: Mapa Geológico do local sondado - km 429 (Pista Norte) Fonte: Geobank/Google Earth®

Tabela 9.26: histórico de intervenções informado - km 429 (pista norte)

\begin{tabular}{ccccccc}
\hline $\mathbf{k m}$ & $\begin{array}{c}\mathbf{k m} \\
\text { inicial }\end{array}$ & $\begin{array}{c}\mathbf{k m} \\
\text { final }\end{array}$ & Solução Aplicada & $\begin{array}{c}\text { Larg. } \\
\mathbf{( m )}\end{array}$ & $\begin{array}{c}\text { Esp. } \\
\mathbf{( c m )}\end{array}$ & $\begin{array}{c}\text { Data da } \\
\text { Interv. }\end{array}$ \\
\hline \multirow{4}{*}{429} & 429,000 & 429,030 & FRESAGEM FUNCIONAL & 3,00 & 5,01 & $01 / 04 / 2008$ \\
\hline & 428,950 & 429,340 & FRESAGEM FUNCIONAL & 3,65 & 5,01 & $02 / 04 / 2008$ \\
\cline { 2 - 7 } & 428,550 & 429,850 & RECICLAGEM DE PAV. ASF. COM EMULSÃO ES & 3,80 & 10,00 & $16 / 12 / 2008$ \\
\cline { 2 - 7 } & 428,411 & 429,998 & MICROREVESTIMENTO & 4,10 & 1,20 & $28 / 04 / 2009$ \\
\hline 428,725 & 429,000 & FRESAGEM FUNCIONAL & 4,04 & 5,60 & $16 / 08 / 2012$ \\
\hline
\end{tabular}


Tabela 9.27: Estrutura do pavimento da faixa externa - km 429 (pista norte)

\begin{tabular}{ccccc} 
km & Pista & Camada & $\begin{array}{c}\text { Espessura } \\
\text { (cm) }\end{array}$ & \multicolumn{1}{c}{ Camada } \\
\hline \multirow{3}{*}{429} & & 1 & 10,0 & CA \\
\cline { 3 - 5 } & \multirow{3}{*}{ Norte } & 2 & 8,0 & RAP C/ EMULSÃO \\
\cline { 3 - 4 } & & 3 & 22,0 & BGS \\
\cline { 2 - 4 } & & - & SL \\
\hline
\end{tabular}

Tabela 9.28: Estatística dos resultados do ensaio com $L W D$

\begin{tabular}{|c|c|c|c|c|c|c|c|c|c|c|c|}
\hline \multirow{2}{*}{ km } & \multirow{2}{*}{ Material } & \multicolumn{5}{|c|}{ Leituras $D_{0, \text { LWD }}\left(10^{-2} \mathrm{~mm}\right)$} & \multicolumn{5}{|c|}{$E_{0, \text { calc }}\left(\mathrm{kfg} / \mathrm{cm}^{2}\right)$} \\
\hline & & Mín. & Máx. & Média & Desvio & CV(\%) & Mín. & Máx. & Média & Desvio & CV(\%) \\
\hline 429 & BGS & 34 & 46 & 40 & 4 & 10 & 493 & 673 & 576 & 61 & 11 \\
\hline 429 & SL & 23 & 33 & 28 & 3 & 12 & 679 & 986 & 817 & 102 & 13 \\
\hline
\end{tabular}

Tabela 9.29: Estatística dos resultados de determinação do módulo da camada de BGS

\begin{tabular}{lllllll} 
& & \multicolumn{5}{c}{$E_{\text {sb,retro }}\left(\mathbf{k f g} / \mathbf{c m}^{2}\right)$} \\
\cline { 3 - 6 } & & Mín. & Máx. & Média & Desvio & CV(\%) \\
\cline { 2 - 6 } & & & & & & 110 \\
\hline 429 & BGS & 463 & 787 & 607 & 18 \\
\hline
\end{tabular}

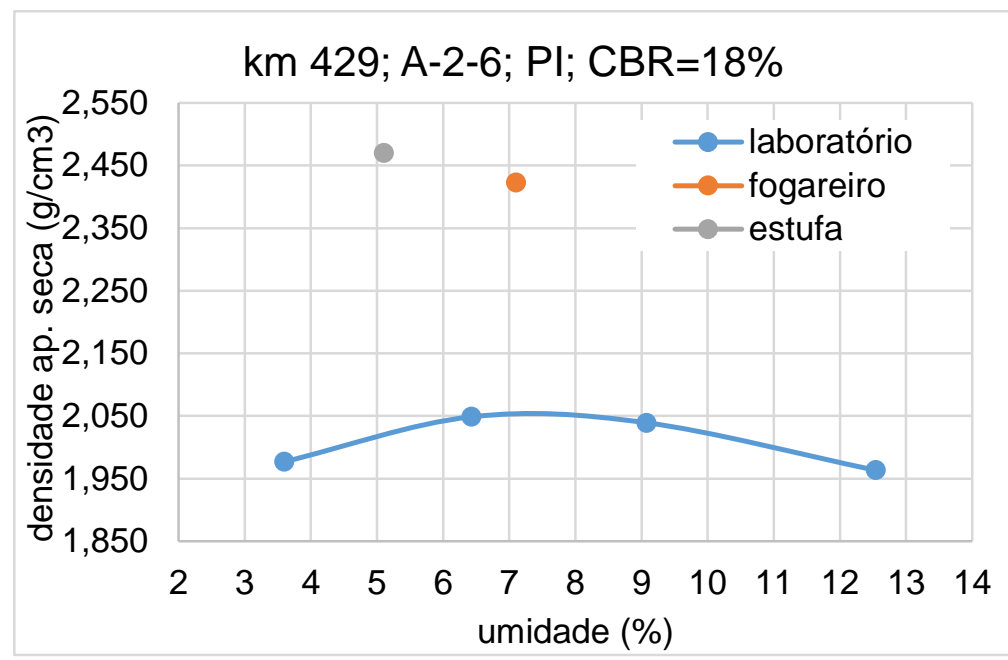

Figura 9.52: Comparativo entre pesos específicos aparentes secos - laboratório x campo (subleito, $\mathrm{km} \mathrm{429,} \mathrm{norte)}$ 


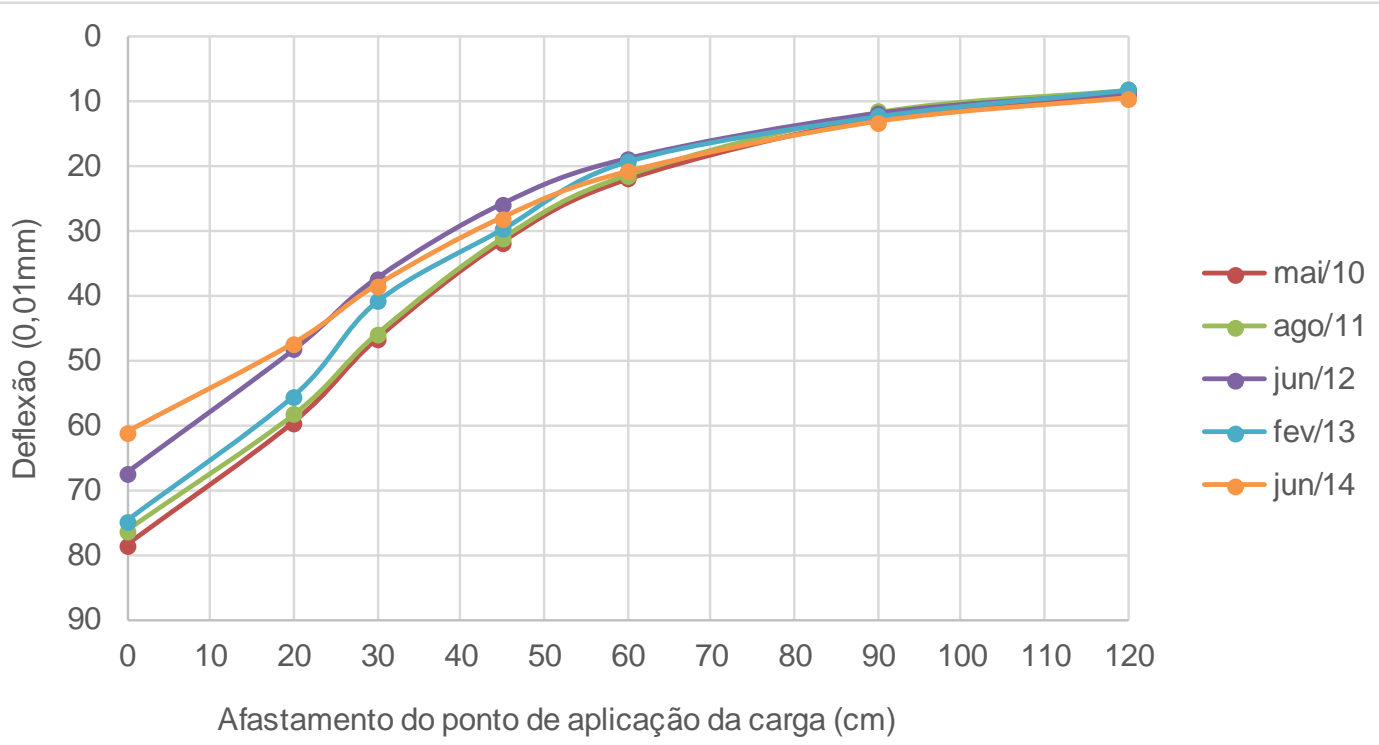

\begin{tabular}{|c|c|c|c|c|c|c|c|c|}
\hline $\begin{array}{c}\text { Mês/ano } \\
\text { Levantamento }\end{array}$ & $\begin{array}{l}\text { Tar } \\
\left({ }^{\circ} \mathrm{C}\right)\end{array}$ & $\begin{array}{l}\text { Tpav } \\
\left({ }^{\circ} \mathrm{C}\right)\end{array}$ & $\begin{array}{c}\text { Er1 } \\
\left(\mathrm{kgf} / \mathrm{cm}^{2}\right)\end{array}$ & $\begin{array}{c}\mathrm{Er} 2 \\
\left(\mathrm{kgf} / \mathrm{cm}^{2}\right)\end{array}$ & $\begin{array}{c}\mathrm{Eb} \\
\left(\mathrm{kgf} / \mathrm{cm}^{2}\right)\end{array}$ & $\begin{array}{c}\text { Esl } \\
\left(\mathrm{kgf} / \mathrm{cm}^{2}\right)\end{array}$ & $\begin{array}{l}\text { Esl x 0,33 } \\
\left(\mathrm{kgf} / \mathrm{cm}^{2}\right)\end{array}$ & $\begin{array}{c}\text { Esl } \\
\text { (AASHTO/ } \\
93 \text { ) }\end{array}$ \\
\hline $\begin{array}{l}\text { Espessuras } \\
\text { (cm) }\end{array}$ & & & 10,0 & 8,0 & 22,0 & - & - & - \\
\hline Materiais & & & CA & $\begin{array}{c}\text { RAP C/ } \\
\text { EMULSÃO }\end{array}$ & BGS & SL & SL & SL \\
\hline mar/08 & \multicolumn{6}{|c|}{ * Provável estrutura antiga de pavimento flexível } & & \\
\hline $\mathrm{mai} / 10$ & 28,0 & 38,0 & 28.000 & 600 & 600 & 900 & 297 & 282 \\
\hline ago/11 & 12,0 & 16,0 & 32.000 & 700 & 500 & 1.000 & 330 & 374 \\
\hline jun/12 & 29,0 & 37,0 & 18.000 & 2.000 & 1.000 & 1.000 & 330 & 371 \\
\hline $\mathrm{fev} / 13$ & 36,0 & 46,0 & 18.000 & 1.200 & 1.000 & 950 & 314 & 325 \\
\hline jun/14 & 19,0 & 27,0 & 35.000 & 2.100 & 1.000 & 950 & 314 & 303 \\
\hline
\end{tabular}

Figura 9.53: Retroanálise das bacias de deflexões (série histórica) - km 429 (pista norte)
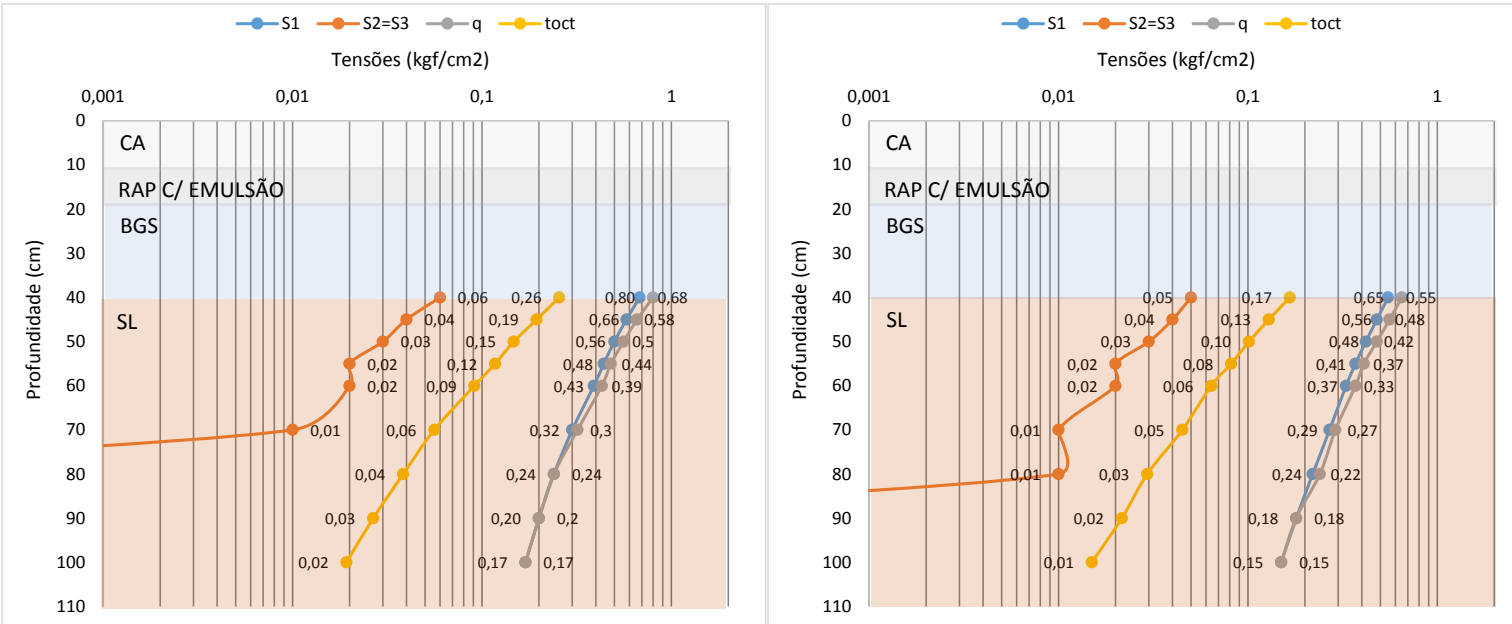

Figura 9.54: Tensões no subleito calculadas para (a) 2013 e (b) 2014 
Tabela 9.30: Resumo dos ensaios realizados com material próximo ao km 429

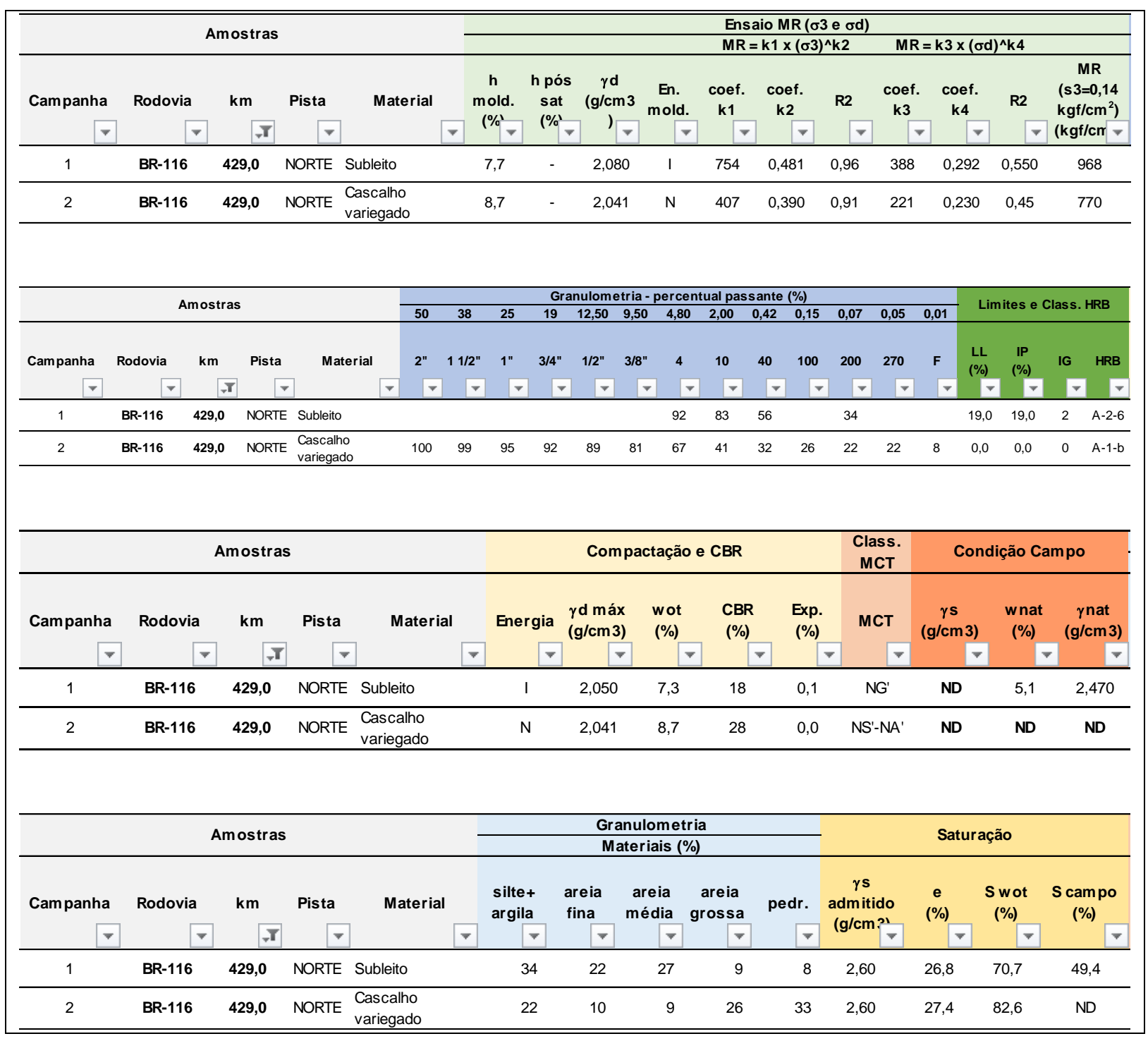




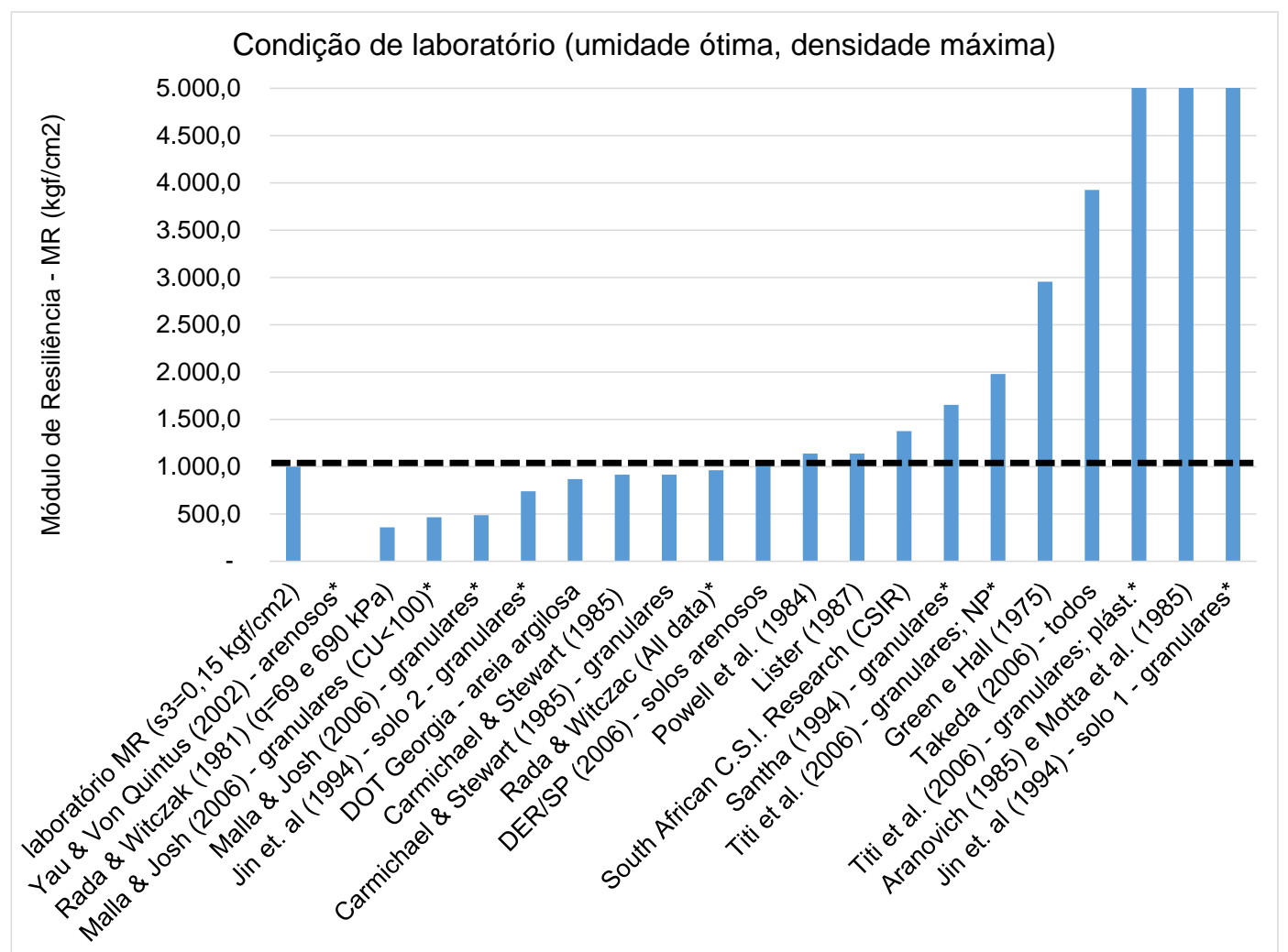

Figura 9.55: Comparativo entre $M R$ de laboratório e modelos de previsão de $M R$ (condição de umidade ótima)

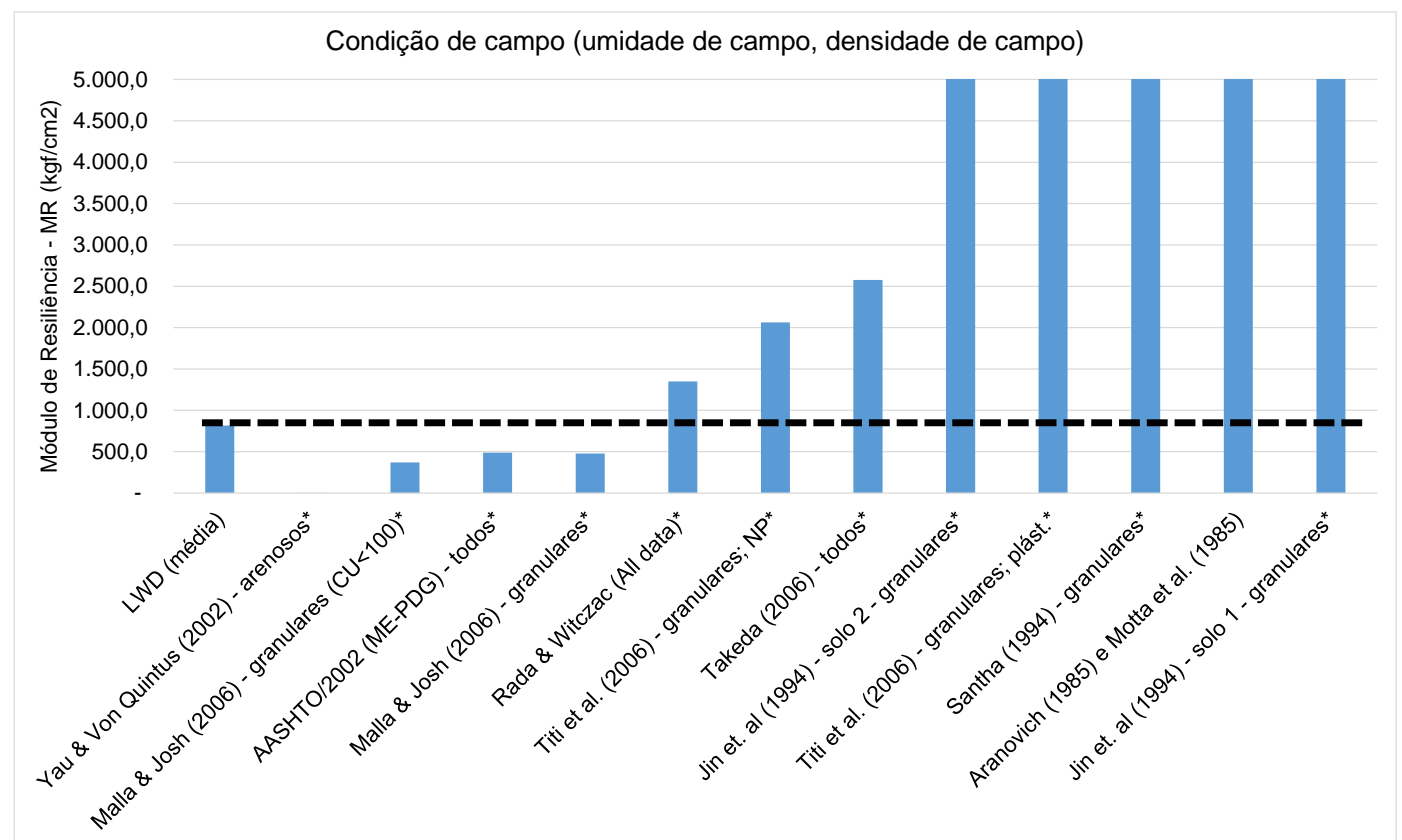

Figura 9.56: Comparativo entre MR in situ (LWD) e modelos de previsão de $M R$ (condição de umidade verificada no campo) 


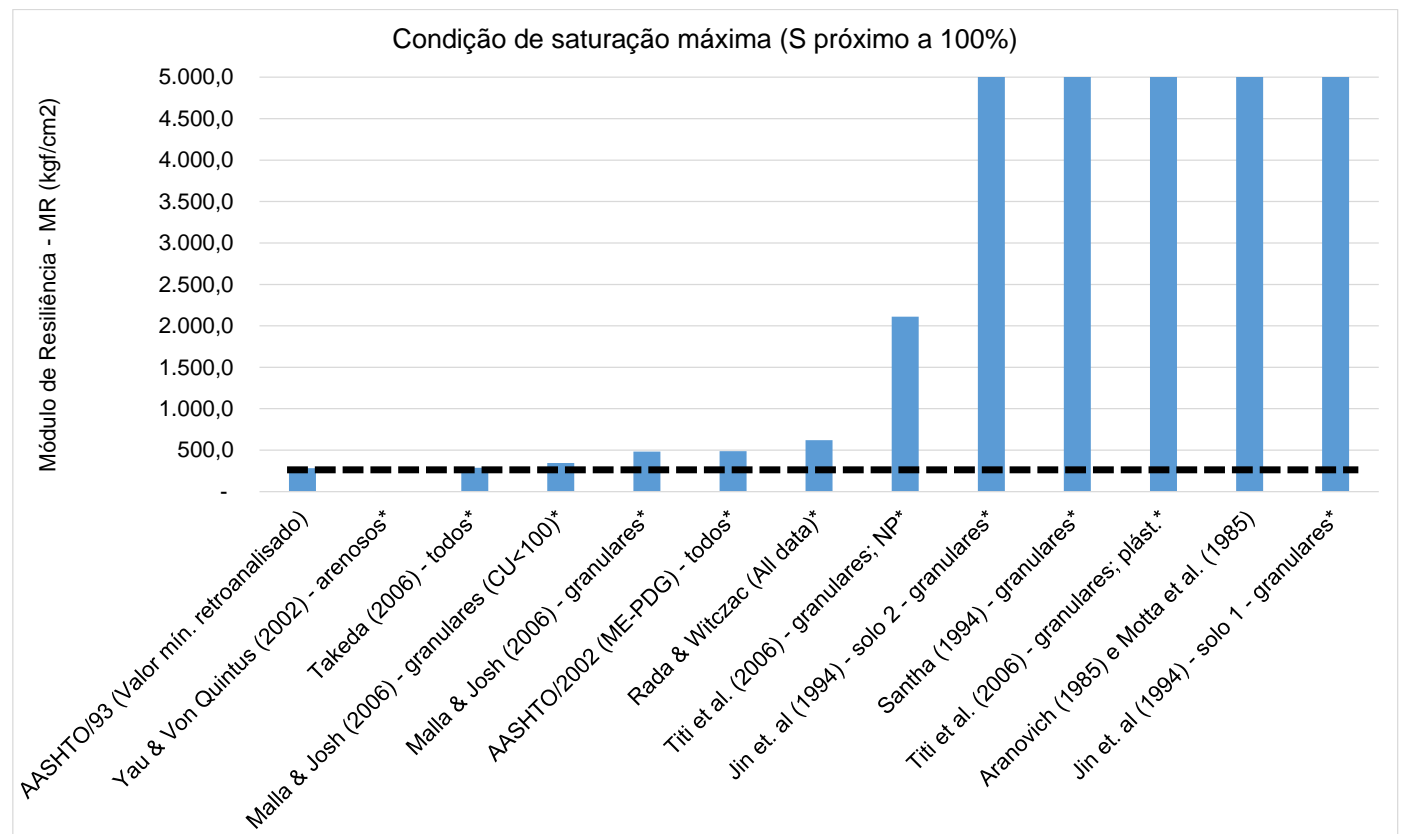

Figura 9.57: Comparativo entre $M R$ in situ mínimo verificado $(F W D)$ e modelos de previsão de $M R$ (condição de saturação próxima a 100\%) 

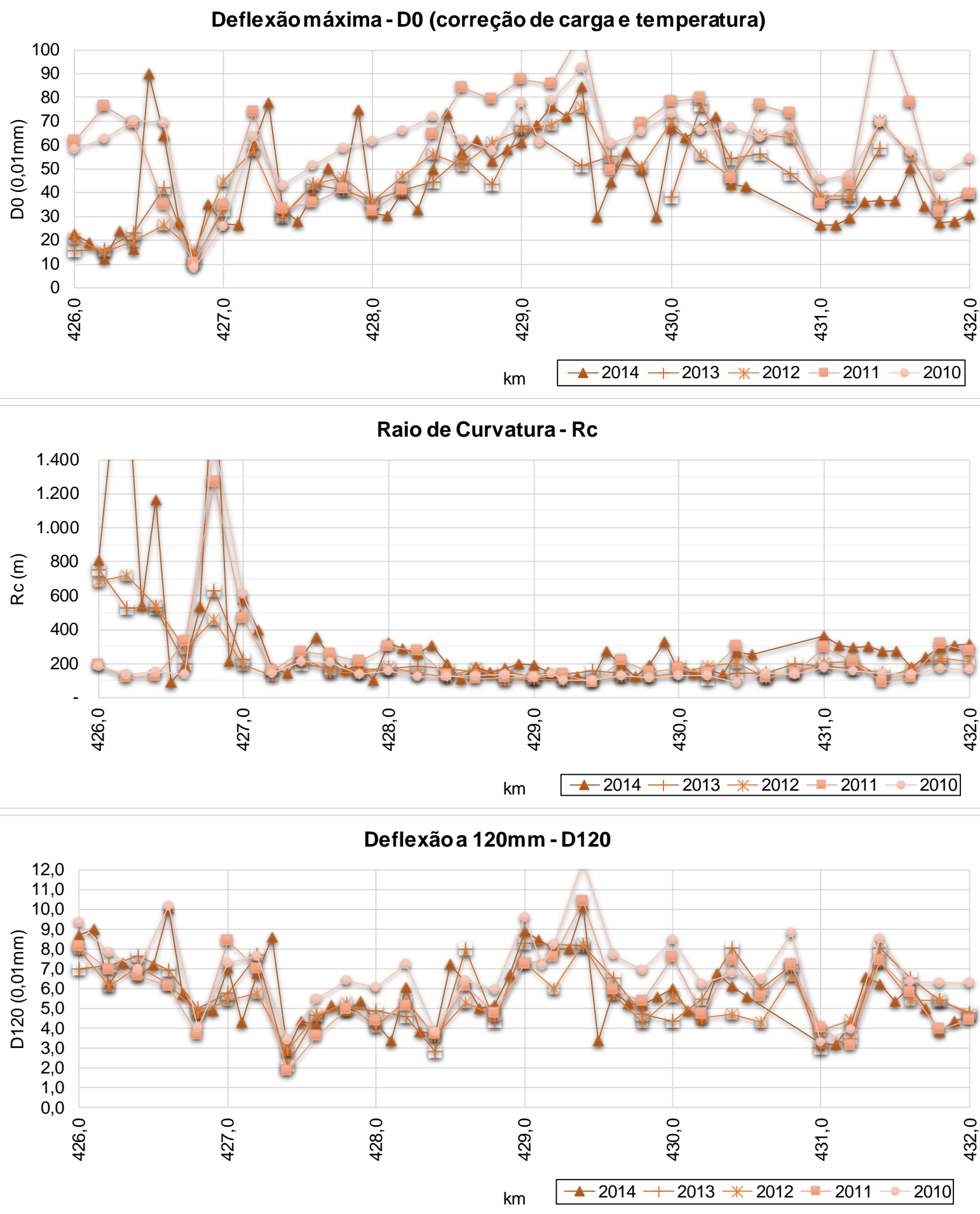

Figura 9.58: Gráficos de série histórica dos indicadores estruturais do pavimento no segmento do km 429 (pista norte) 


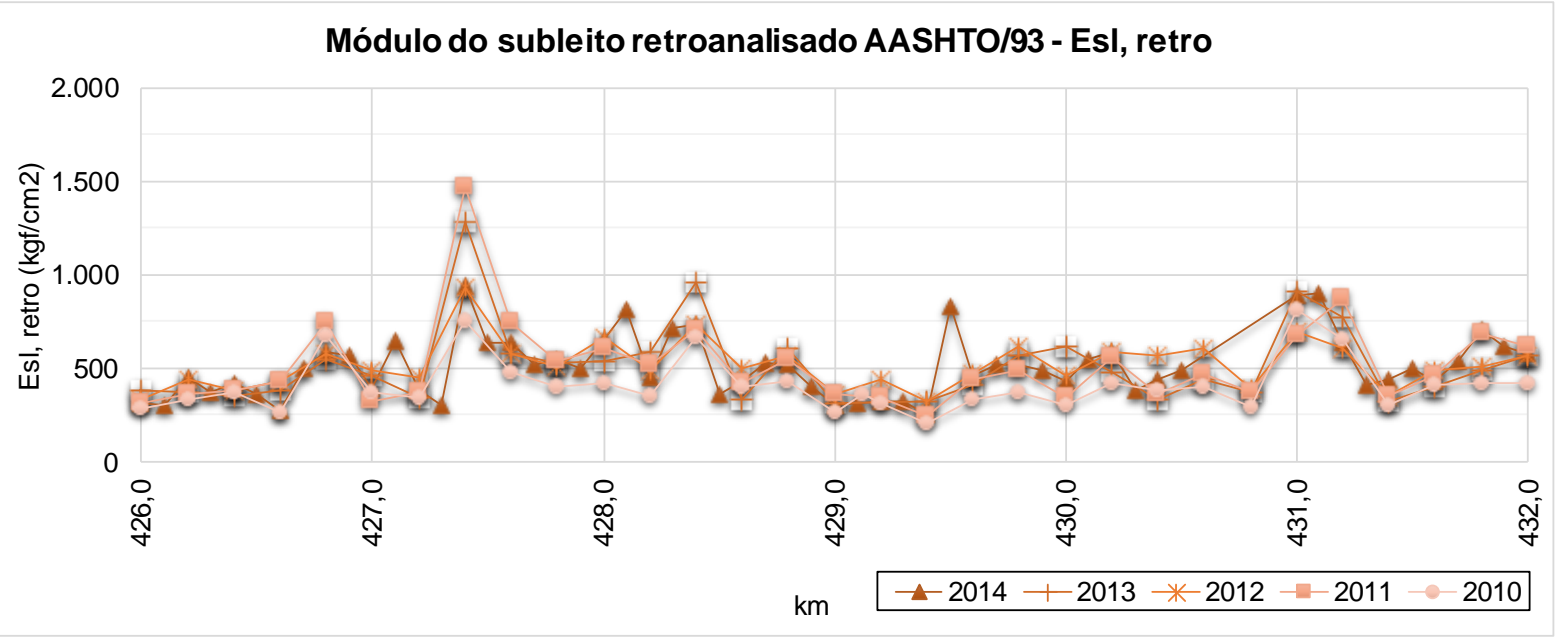

Figura 9.59: Gráficos da série histórica dos dados de módulo de resiliência retroanalisado $(F W D)$ do pavimento no segmento do $\mathrm{km} 429$ (pista norte) 
$428 \quad 429,5$ DECRESCENTE
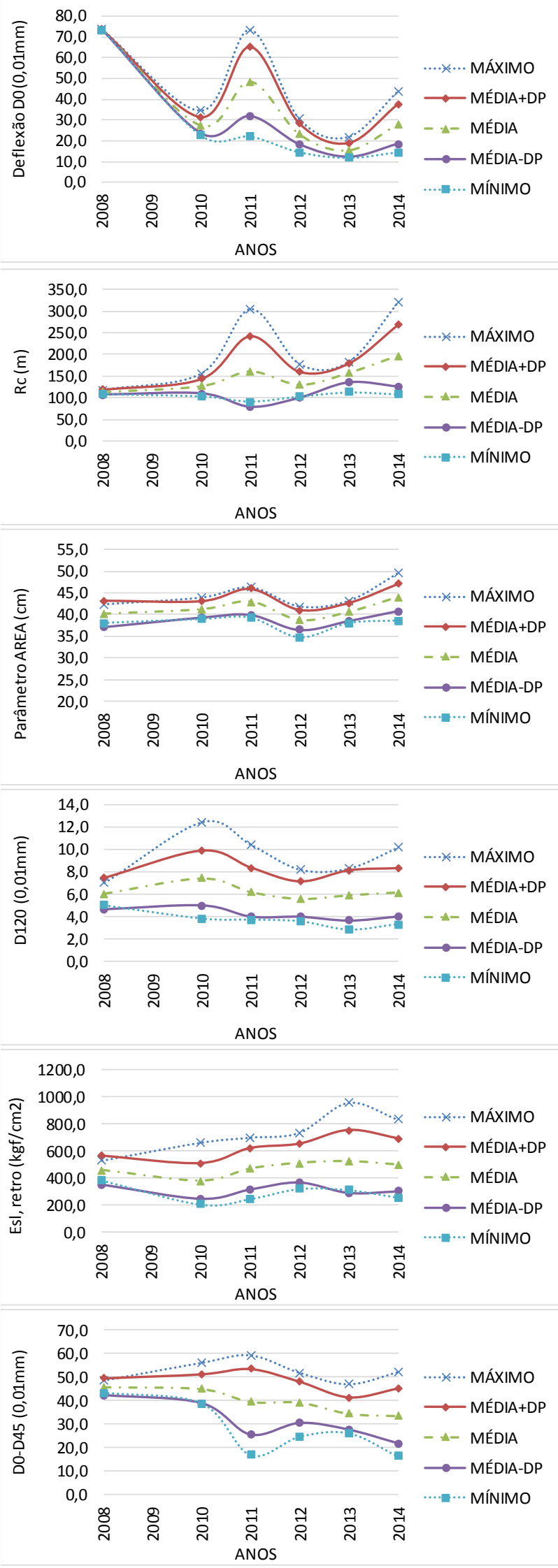
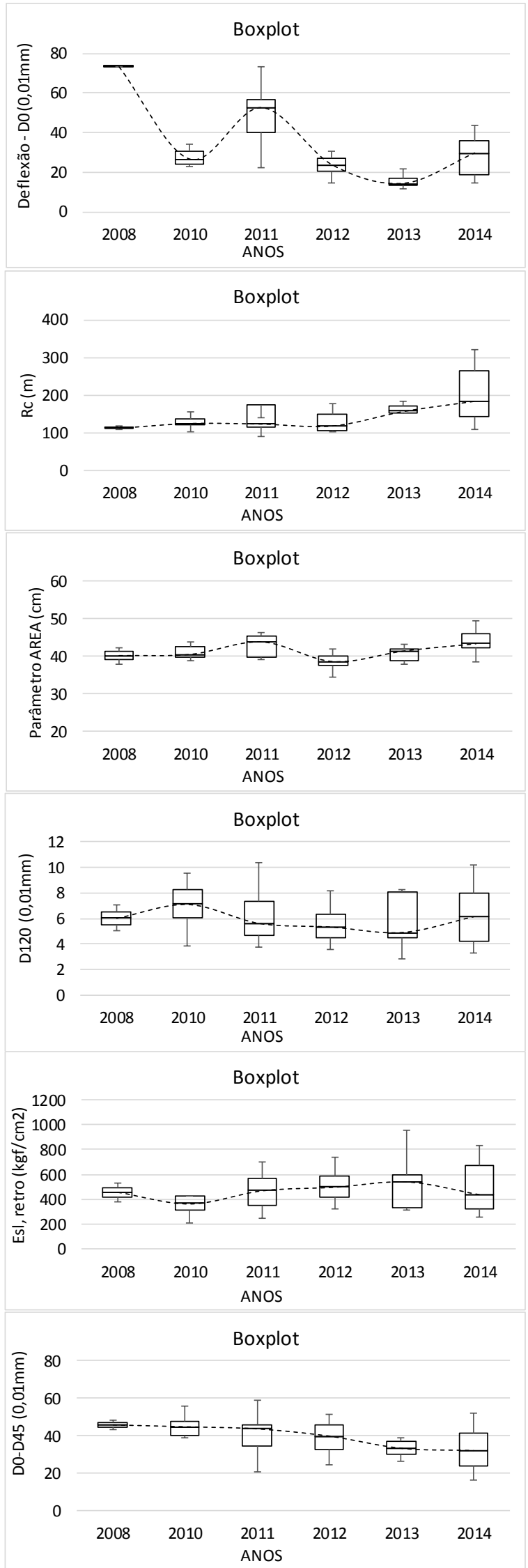

Figura 9.60: Estatísticas dos Parâmetros do pavimento (S. Homogêneo do km 429) 


\subsection{Poço de inspeção do km 431 (Pista Norte)}

A Figura 9.61 a seguir ilustra a localização do poço de inspeção do km 431 (pista norte) bem como o mapeamento geológico do local. Verifica-se uma região com predominância de gnaisse.

A Tabela 9.31 apresenta o registro histórico de intervenções do pavimento. Verificase que o pavimento sofreu uma intervenção de reconstrução do pavimento no ano de 2014.

A Tabela 9.32 apresenta a estrutura do pavimento identificada na ocasião da abertura do poço de inspeção. Este pavimento foi identificado como pavimento do tipo semirrígido com base de BGTC.

A Tabela 9.33 e Tabela 9.34 apresentam os resultados estatísticos obtidos a partir do ensaio de $L W D$ sobre as camadas de subleito e camada de base granular. Enquanto a Figura 9.62 apresenta o gráfico comparativo dos pesos específicos aparentes secos e umidades obtidos em campo e em laboratório (curva de compactação de laboratório versus ensaios de umidade e peso específico aparente seco in situ). Verifica-se que o material no campo está com peso específico aparente seco e umidade bastante próximas da condição ótima para a energia de Proctor Intermediário.

A Figura 9.63 apresenta o resultado da retroanálise da série histórica de deflexões do pavimento em estudo e a Figura 9.64 apresenta os gráficos de tensões calculadas no subleito, ilustrando o comportamento do subleito através dos ensaios com FWD.

A Tabela 9.35 apresenta o resumo dos resultados dos ensaios de laboratório realizados com o material do subleito e dos materiais da faixa de domínio no local.

A Figura 9.65 apresenta um gráfico comparativo entre o valor de módulo medido em laboratório e os valores de módulo previstos pelos modelos da literatura, para as condições de umidade ótima e peso específico aparente seco máximo relativos à energia intermediária de compactação. Verificou-se uma convergência maior para os modelos de Rada \& Witczak (1981), Jin et al. - solo 2 (1994) e DOT Georgia - areia argilosa.

A Figura 9.66 apresenta um gráfico comparativo entre o valor de módulo in situ medido com $L W D$ e os valores de módulo previstos pelos modelos da literatura, para as 
condições de umidade e peso específico aparente seco verificadas em campo no momento da abertura do poço de inspeção. Verificou-se uma convergência maior para os modelos de Malla \& Joshi - materiais granulares (2006), AASHTO/2002 (ME-PDG) e Rada \& Witczak (1981).

A Figura 9.67 apresenta um gráfico comparativo entre o valor mínimo de módulo in situ medido com FWD (retroanálise) e os valores de módulo previstos pelos modelos da literatura, para as condições de saturação próxima da saturação máxima (adotouse S próximo a 98\%). Verificou-se uma convergência maior para o modelo de Malla \& Joshi (2006), Takeda (2006) e AASHTO/2002.

A Figura 9.68 apresenta os gráficos da série histórica dos indicadores estruturais do pavimento (deflexão máxima, raio de curvatura, e deflexão a $120 \mathrm{~mm}$ do ponto de aplicação de carga) no segmento que contempla o local em estudo.

A Figura 9.69 apresenta os gráficos da série histórica dos valores de módulo de resiliência retroanalisado $(F W D)$ e Quociente de Irregularidade $(Q I)$ no segmento que contempla o local em estudo.

A Figura 9.70 apresenta os dados estatísticos (valores máximos, mínimos, média e média mais ou menos desvio padrão), bem como boxplot dos indicadores estruturais do pavimento no segmento homogêneo determinado para o ponto em estudo. 


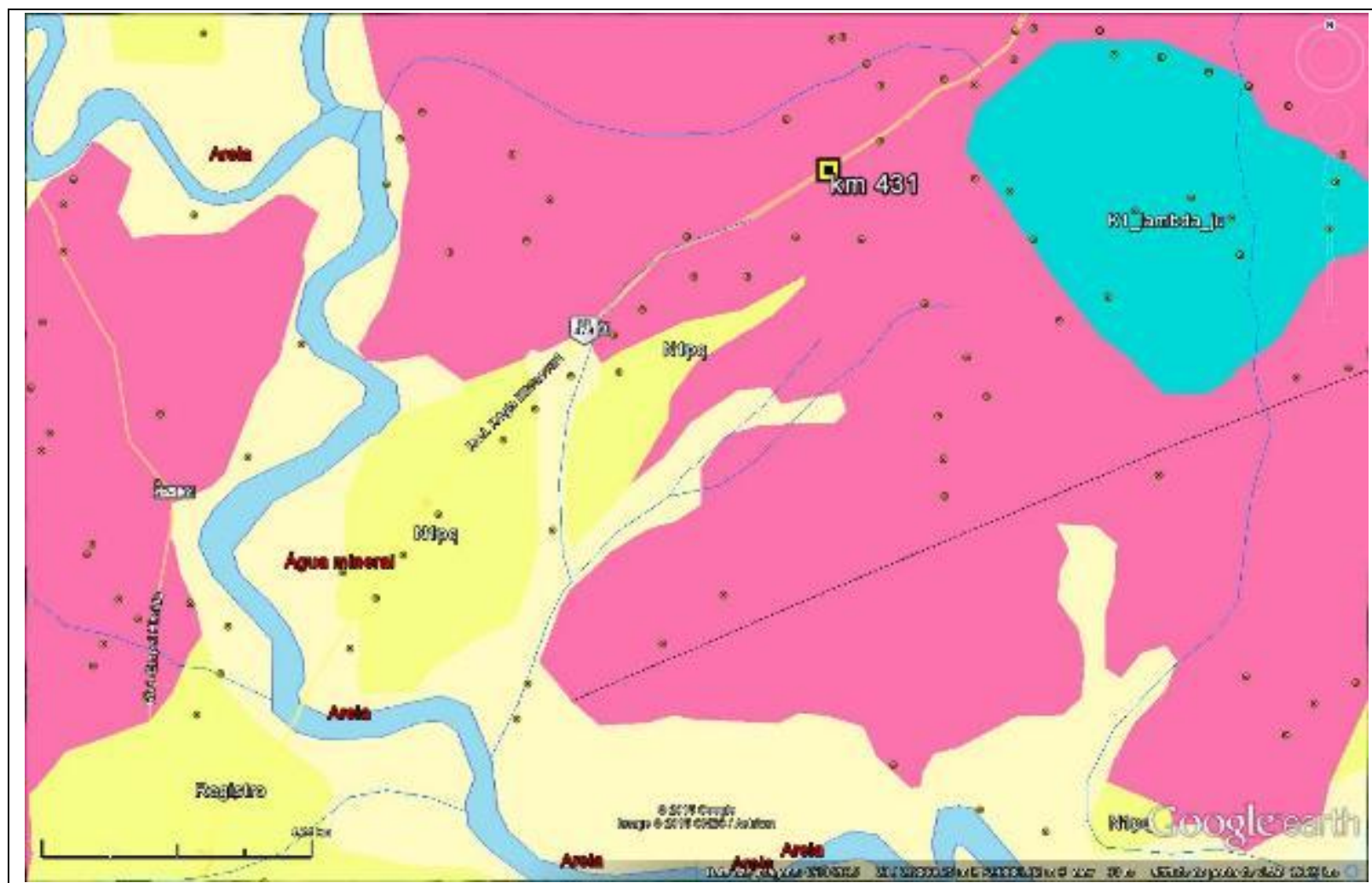

\section{LEGENDA:}

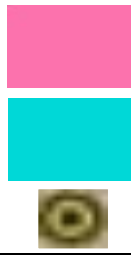

Atuba, Gnaisse Itapeúna: Gnaisse, Biotita monzogranito, Diorito, Granito gnaisse

Depósitos aluvionares: Depósitos de areia,

Juquiá: Clinopiroxenito, Nefelina sienito, Olivina clinopiroxenito Depósitos de cascalho

Pariquera-Açu: Depósitos de areia,

Conglomerado, Depósitos de argila, Lamito

Afloramentos

Figura 9.61: Mapa Geológico do local sondado - km 431 (Pista Norte)

Fonte: Geobank/Google Earth $\AA$

Tabela 9.31: histórico de intervenções informado - km 431 (pista norte)

\begin{tabular}{|c|c|c|c|c|c|c|}
\hline km & $\begin{array}{c}\text { km } \\
\text { inicial }\end{array}$ & $\begin{array}{l}\text { km } \\
\text { final }\end{array}$ & Solução Aplicada & $\begin{array}{l}\text { Larg. } \\
\text { (m) }\end{array}$ & $\begin{array}{l}\text { Esp. } \\
(\mathrm{cm})\end{array}$ & $\begin{array}{l}\text { Data da } \\
\text { Interv. }\end{array}$ \\
\hline \multirow{6}{*}{431} & 430,680 & 431,000 & FRESAGEM FUNCIONAL & 3,76 & 5,01 & $30 / 03 / 2008$ \\
\hline & 431,000 & 431,300 & FRESAGEM FUNCIONAL & 3,76 & 5,01 & $30 / 03 / 2008$ \\
\hline & 430,450 & 431,750 & RECICLAGEM DE PAV. ASF. COM EMULSÃO ESP. "IN SITU" & 3,80 & 10,00 & $13 / 12 / 2008$ \\
\hline & 429,998 & 431,547 & MICROREVESTIMENTO & 4,10 & 1,20 & $22 / 04 / 2009$ \\
\hline & 430,910 & 431,250 & REFORÇO DE PAVIMENTO COM ASFALTO BORRACHA $20 \%$ & 3,60 & 5,50 & $04 / 06 / 2010$ \\
\hline & 430,630 & 431,000 & RECONSTRUÇÃO DE PAVIMENTO & 4,00 & 97,00 & $13 / 06 / 2014$ \\
\hline
\end{tabular}


Tabela 9.32: Estrutura do pavimento da faixa externa - km 431 (pista norte)

\begin{tabular}{ccccc} 
km & Pista & Camada & $\begin{array}{c}\text { Espessura } \\
\text { (cm) }\end{array}$ & Camada \\
\hline \multirow{3}{*}{431} & \multirow{3}{*}{ Norte } & 1 & 13,0 & CA \\
\cline { 3 - 5 } & & 2 & 18,0 & BGTC \\
\cline { 3 - 5 } & & 3 & 11,0 & BGS \\
\cline { 3 - 5 } & & & - & SL \\
\hline
\end{tabular}

Tabela 9.33: Estatística dos resultados do ensaio com $\angle W D$

\begin{tabular}{|c|c|c|c|c|c|c|c|c|c|c|c|}
\hline \multirow{2}{*}{ km } & \multirow{2}{*}{ Material - } & \multicolumn{5}{|c|}{ Leituras $\mathrm{D}_{0, \mathrm{LWD}}\left(10^{-2} \mathrm{~mm}\right)$} & \multicolumn{5}{|c|}{$E_{0, \text { calc }}\left(\mathbf{k g} / \mathrm{cm}^{2}\right)$} \\
\hline & & Mín. & Máx. & Média & Desvio & CV(\%) & Mín. & Máx. & Média & Desvio & CV(\%) \\
\hline 431 & BGS & 61 & 76 & 68 & 6 & 8 & 300 & 372 & 335 & 28 & 8 \\
\hline 431 & SL & 30 & 35 & 33 & 2 & 7 & 654 & 766 & 699 & 48 & 7 \\
\hline
\end{tabular}

Tabela 9.34: Estatística dos resultados de determinação do módulo da camada de BGS

\begin{tabular}{|c|c|c|c|c|c|c|}
\hline \multirow{2}{*}{ km } & \multirow{2}{*}{ Material } & \multicolumn{5}{|c|}{$E_{\text {sb,retro }}\left(\mathrm{kfg} / \mathrm{cm}^{2}\right)$} \\
\hline & & Mín. & Máx. & Média & Desvio & CV(\%) \\
\hline 431 & BGS & 324 & 468 & 394 & 56 & 14 \\
\hline
\end{tabular}

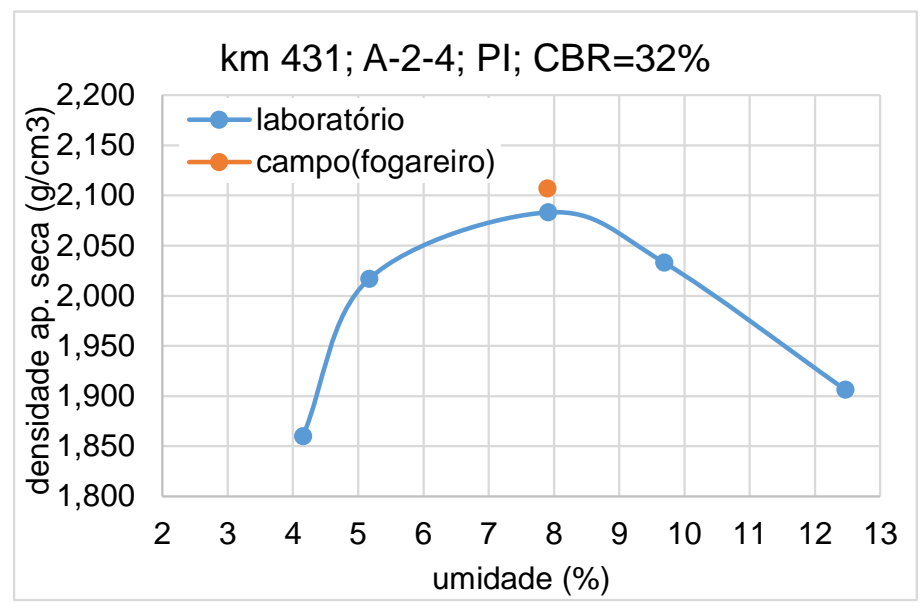

Figura 9.62: Comparativo entre pesos específicos aparentes secos - laboratório x campo (subleito, $\mathrm{km} \mathrm{431,} \mathrm{norte)}$ 


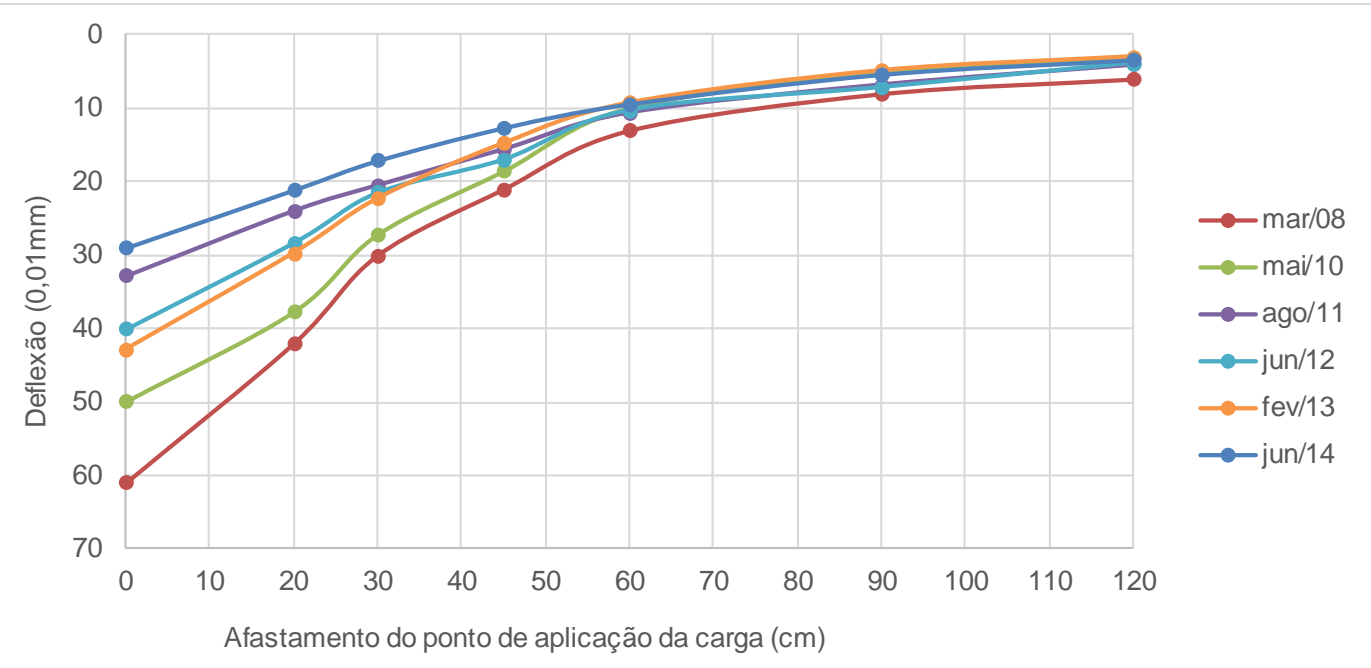

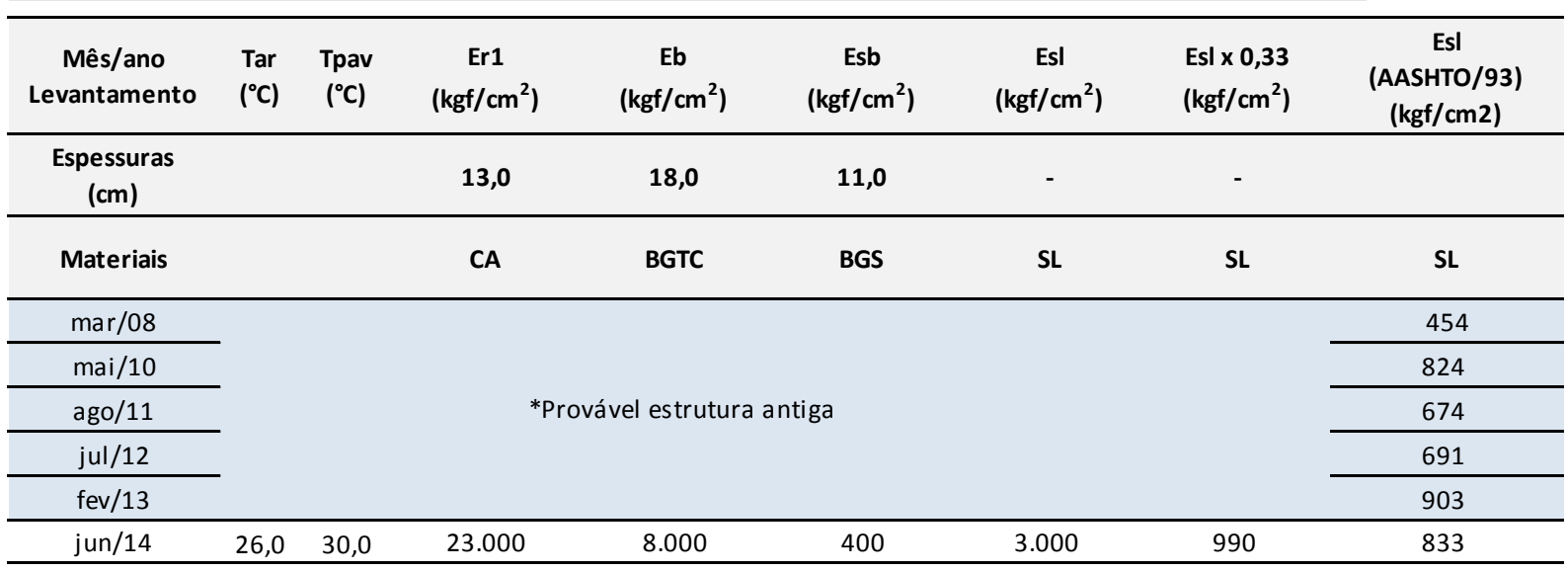

Figura 9.63: Retroanálise das bacias de deflexões (série histórica) - km 431 (pista norte)

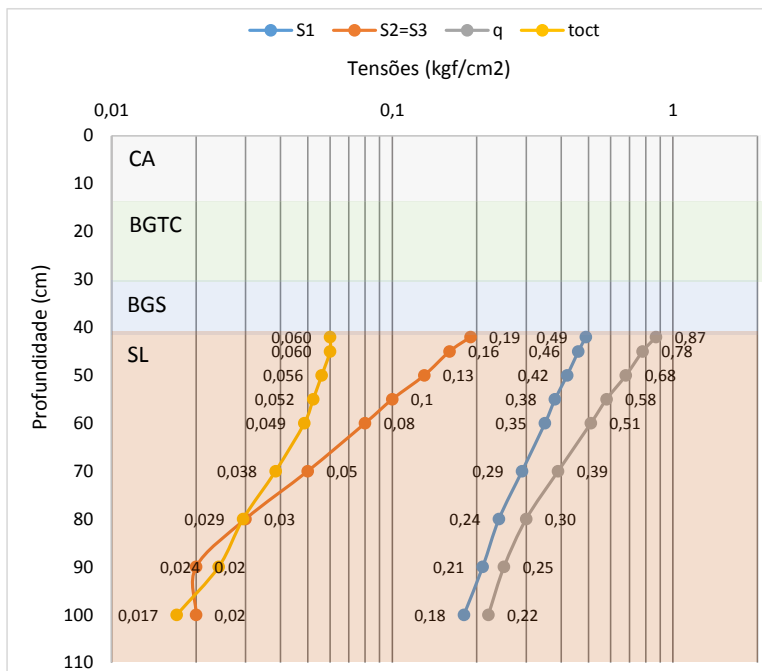

Figura 9.64: Tensões no subleito calculadas para 2014 
Tabela 9.35: Resumo dos ensaios realizados com material próximo ao km 431

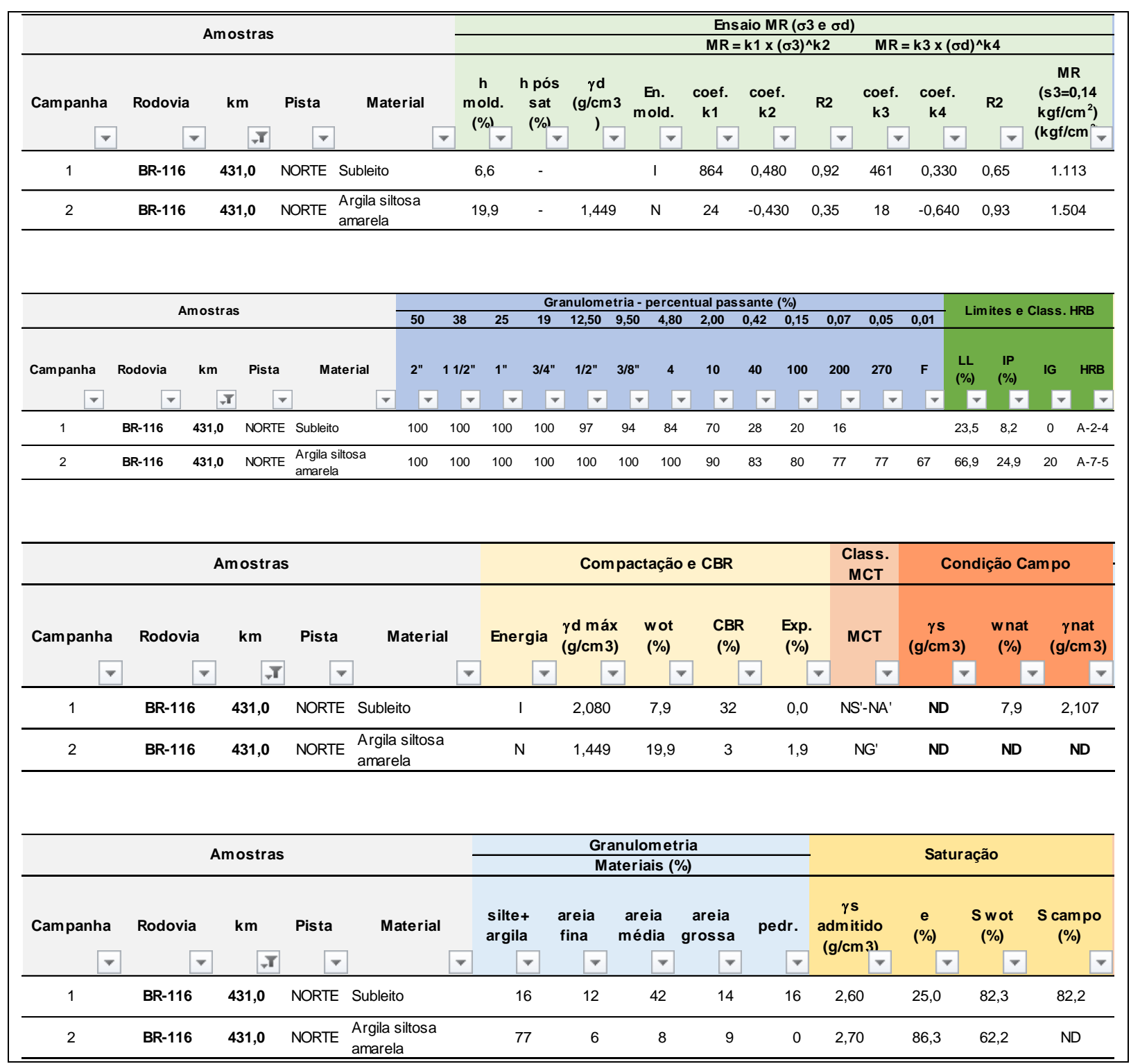




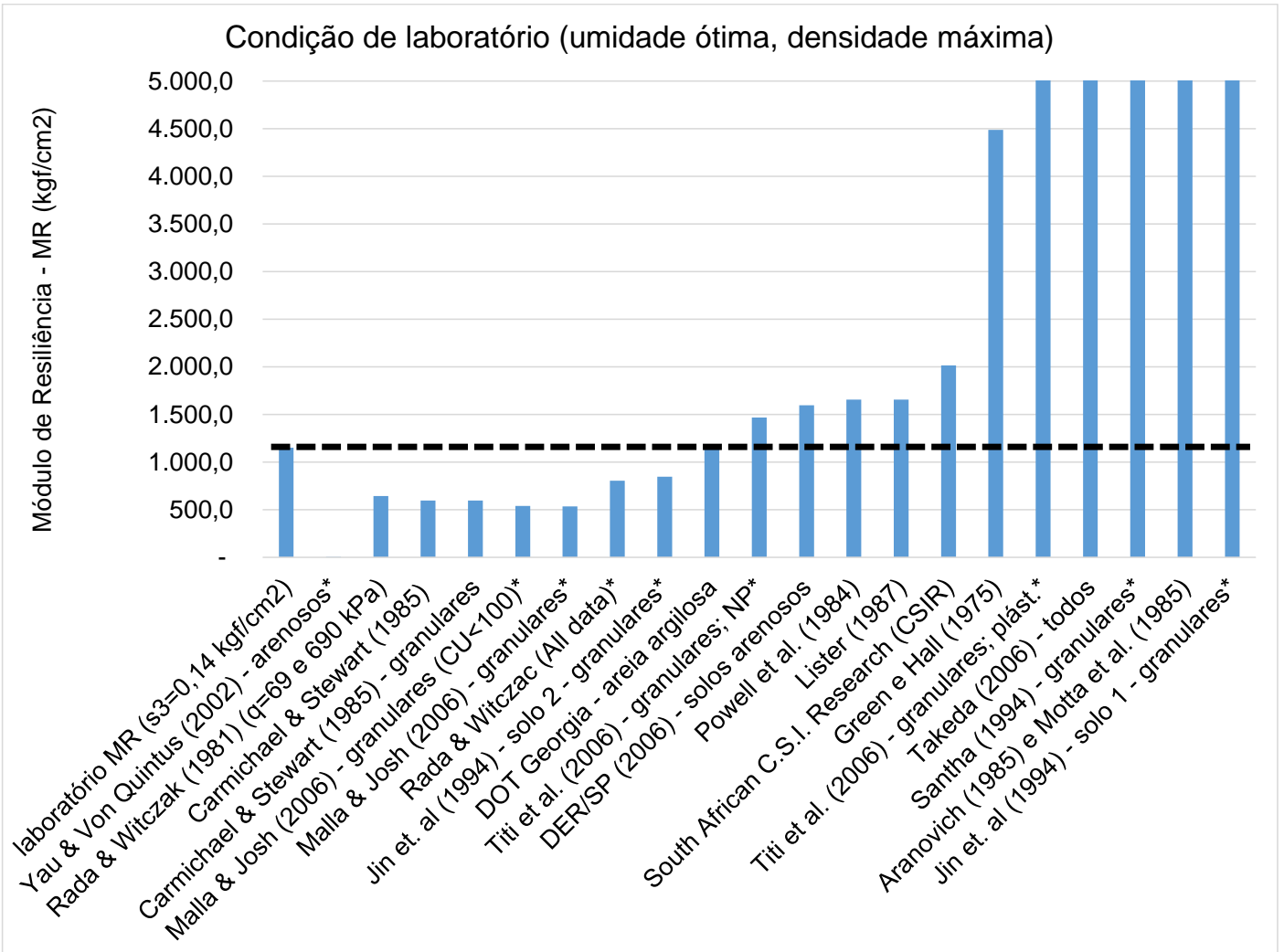

Figura 9.65: Comparativo entre $M R$ de laboratório e modelos de previsão de $M R$ (condição de umidade ótima)

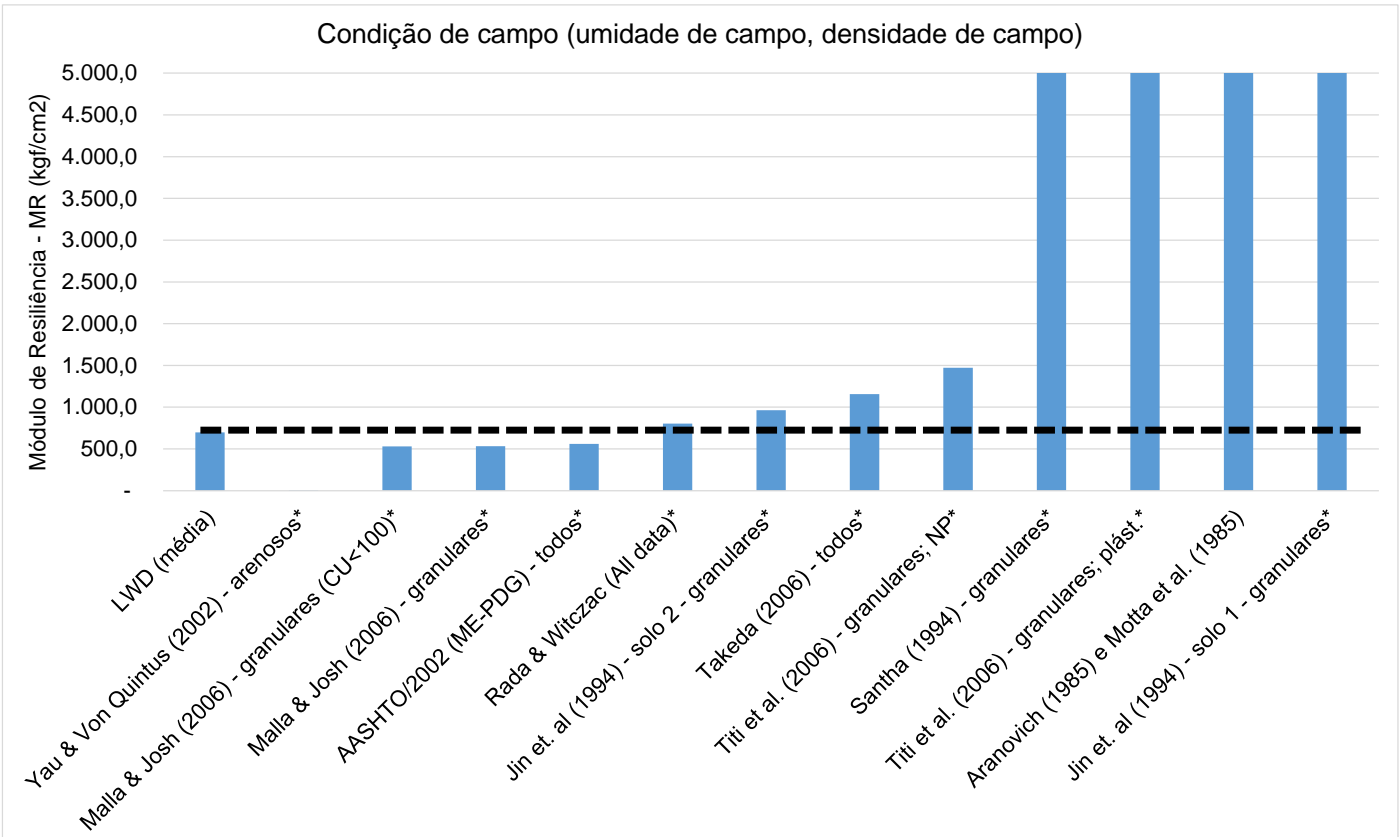

Figura 9.66: Comparativo entre MR in situ (LWD) e modelos de previsão de $M R$ (condição de umidade verificada no campo) 


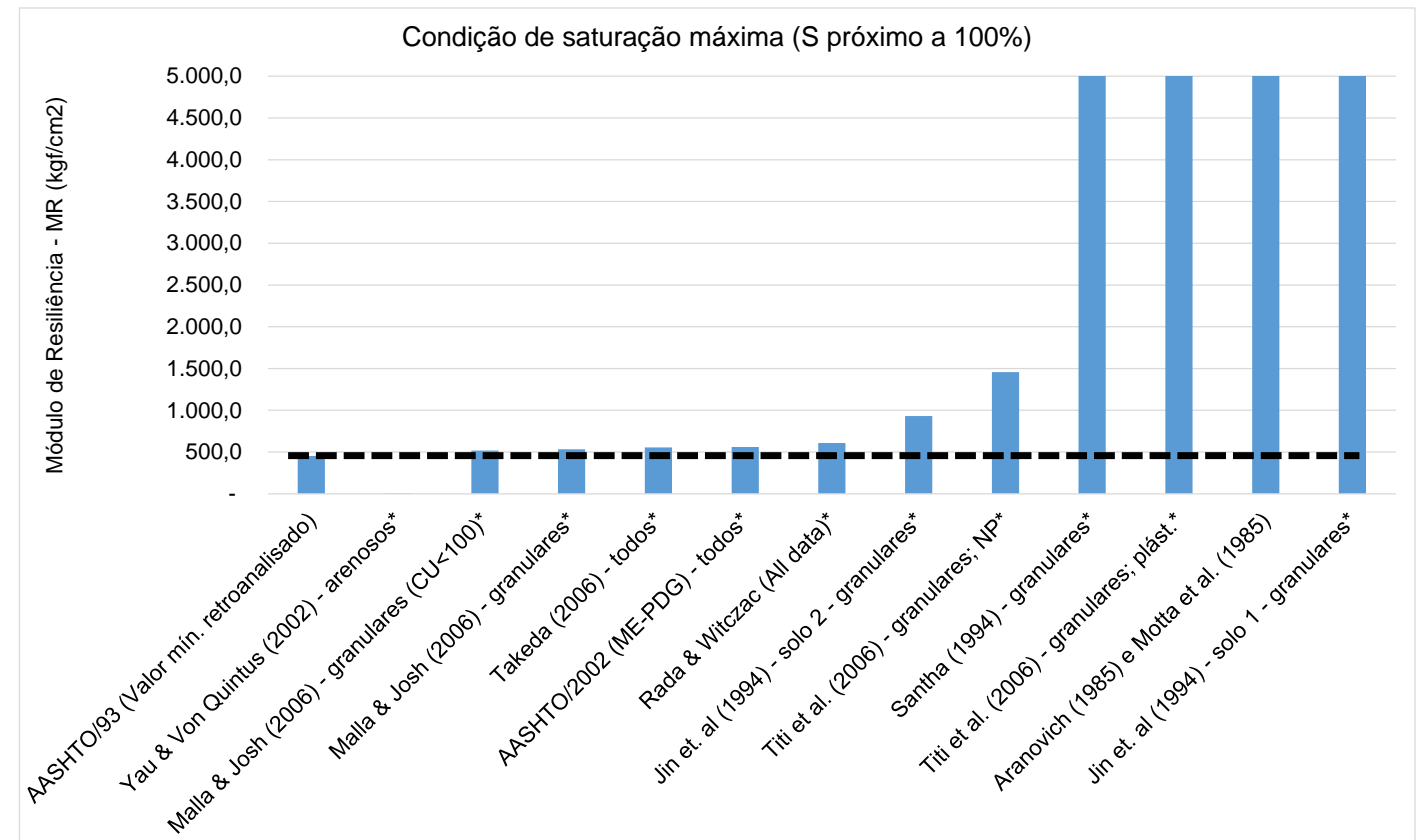

Figura 9.67: Comparativo entre $M R$ in situ mínimo verificado $(F W D)$ e modelos de previsão de $M R$ (condição de saturação próxima a 100\%) 

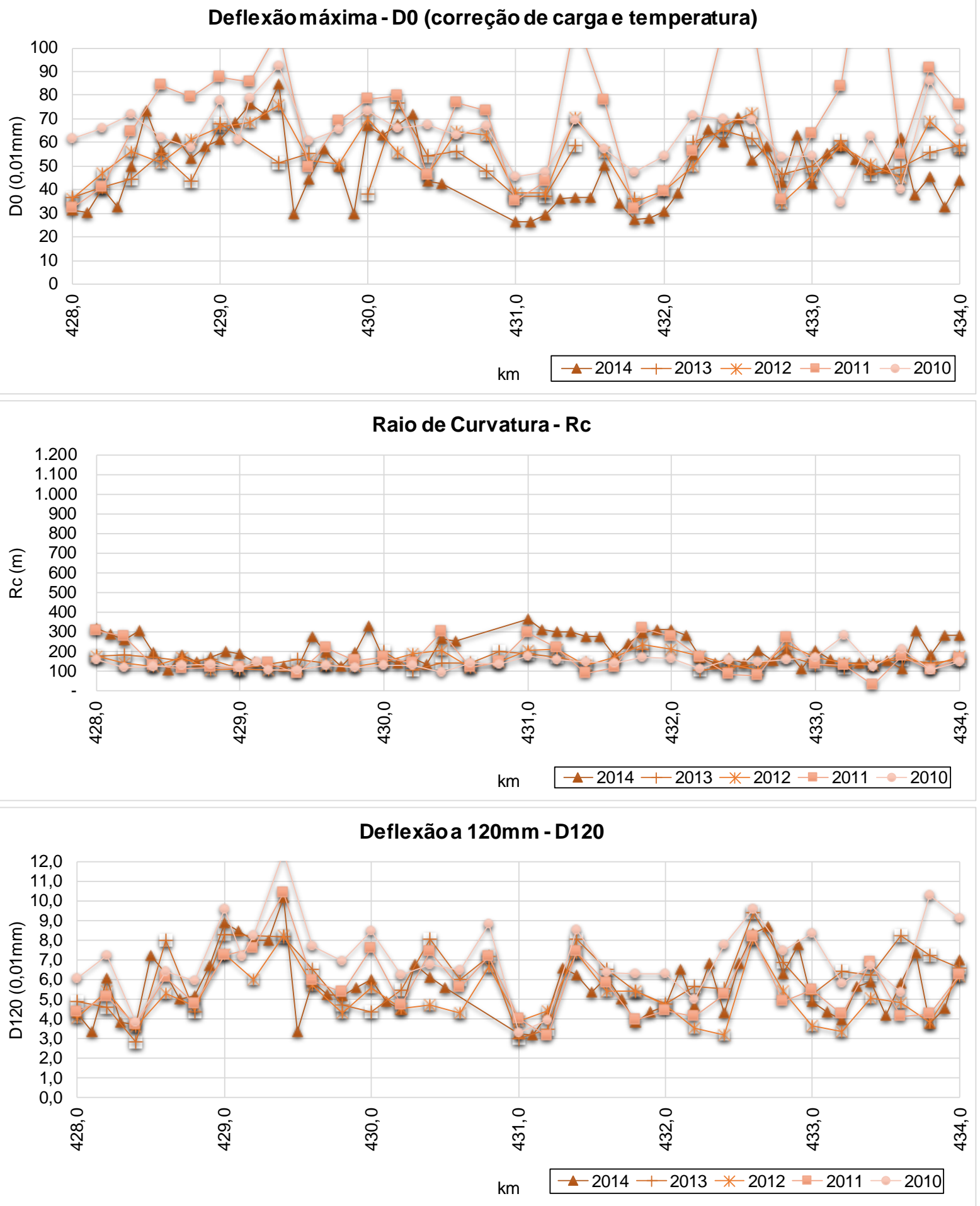

Figura 9.68: Gráficos de série histórica dos indicadores estruturais do pavimento no segmento do km 431 (pista norte) 


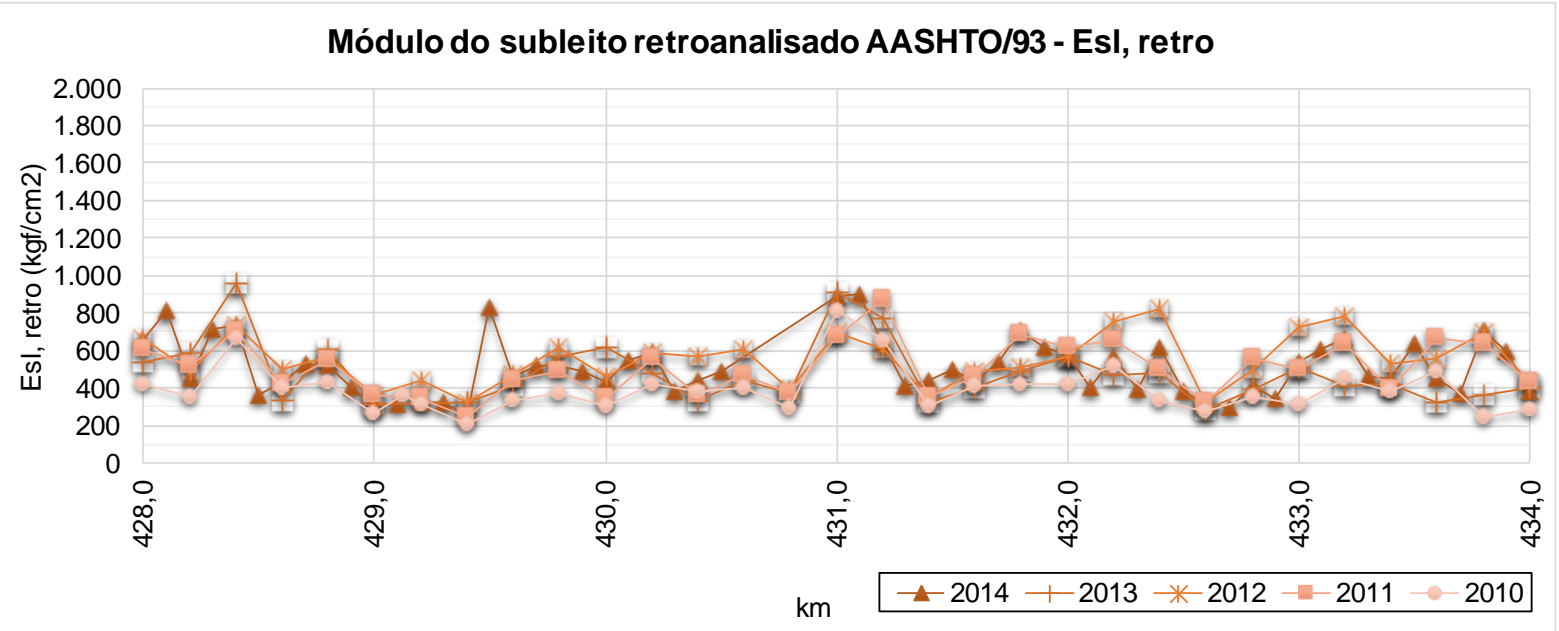

Figura 9.69: Gráficos da série histórica dos dados de módulo de resiliência retroanalisado $(F W D)$ do pavimento no segmento do $\mathrm{km} 431$ (pista norte) 
430,5 431,7 DECRESCENTE
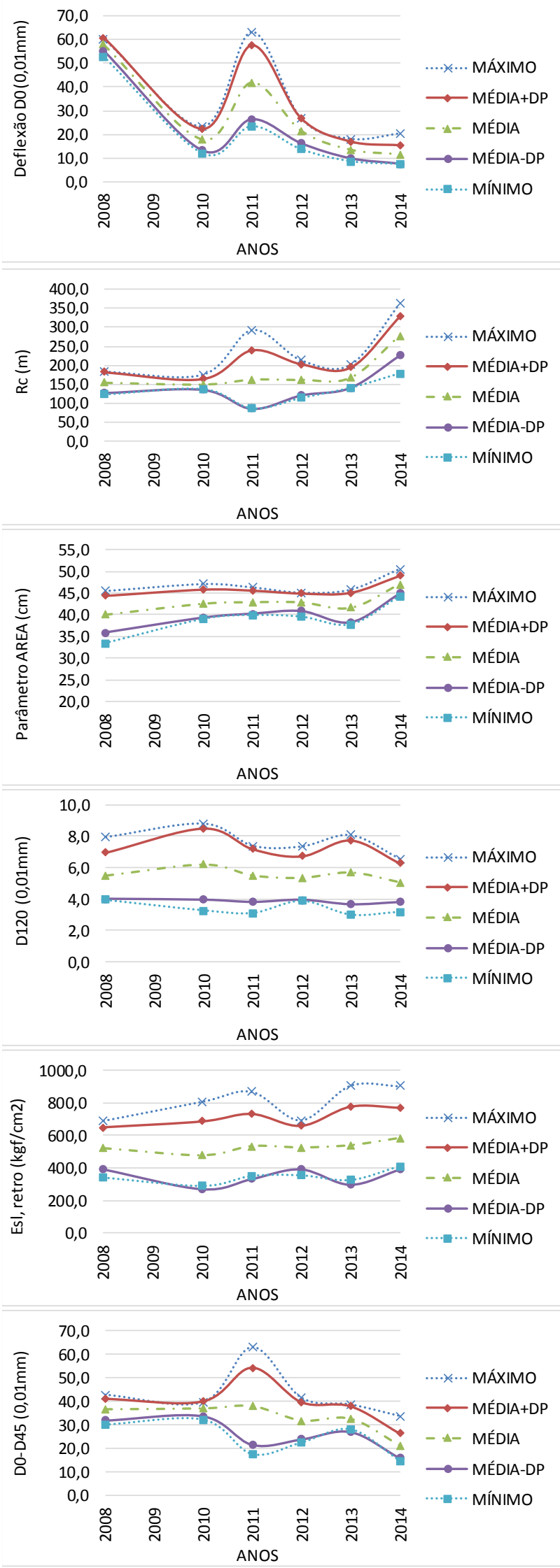
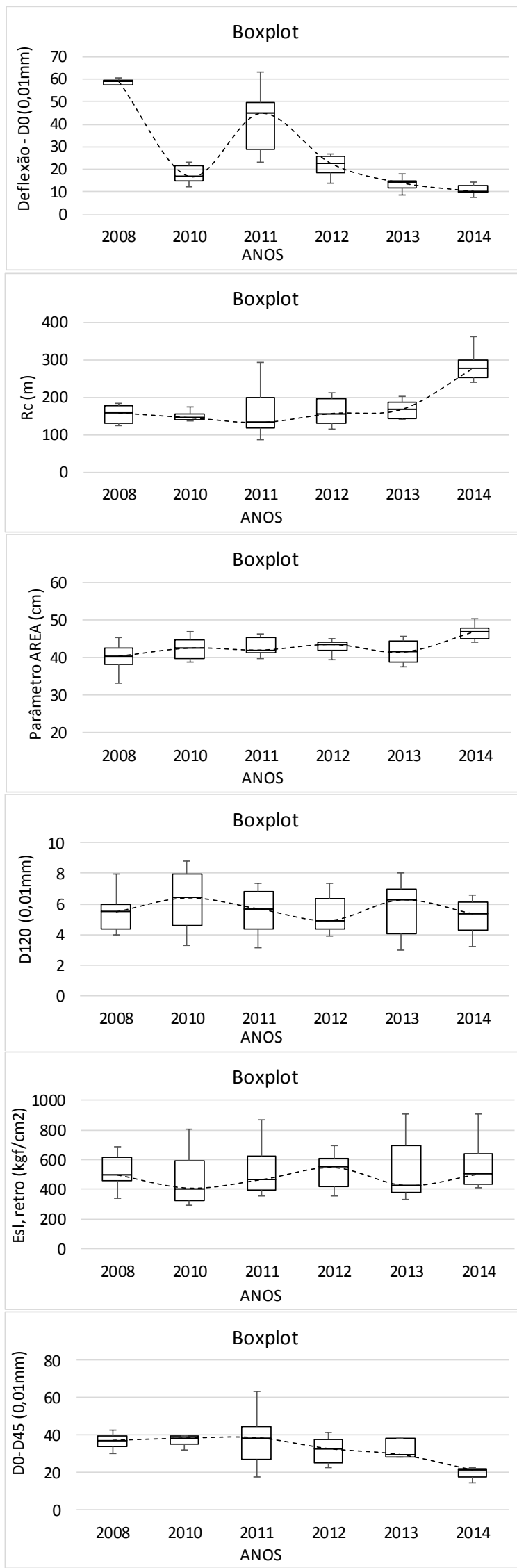

Figura 9.70: Estatísticas dos Parâmetros do pavimento (S. Homogêneo do km 431) 


\subsection{Poço de inspeção do km 434 (Pista Norte)}

A Figura 9.71 a seguir ilustra a localização do poço de inspeção do km 434 (pista norte) bem como o mapeamento geológico do local. Verifica-se uma região com predominância de gnaisse.

A Tabela 9.36 apresenta o registro histórico de intervenções do pavimento. Verificase que o pavimento sofreu uma intervenção de fresagem estrutural no ano de 2013.

A Tabela 9.37 apresenta a estrutura do pavimento identificada na ocasião da abertura do poço de inspeção. Foi encontrada uma cada cimentada na base do pavimento, conferindo características de comportamento de pavimento semirrígido.

A Tabela 9.38 e Tabela 9.39 apresentam os resultados estatísticos obtidos a partir do ensaio de $L W D$ sobre as camadas de subleito e camada de base granular. Enquanto a Figura 9.72 apresenta o gráfico comparativo dos pesos específicos aparentes secos e umidades obtidos em campo e em laboratório (curva de compactação de laboratório versus ensaios de umidade e peso específico aparente seco in situ). Verifica-se que o material no campo está com peso específico aparente seco sensivelmente abaixo do peso específico aparente seco máximo relativo a energia intermediária e umidade sensivelmente superior à ótima. Infere-se que o material tenha sido compactado na energia normal e estava saturada no momento da abertura do poço.

A Figura 9.73 apresenta o resultado da retroanálise da série histórica de deflexões do pavimento em estudo e a Figura 9.74 apresenta os gráficos de tensões calculadas no subleito, ilustrando o comportamento do subleito registrado através dos ensaios com FWD.

A Tabela 9.40 apresenta o resumo dos resultados dos ensaios de laboratório realizados com o material do subleito e dos materiais da faixa de domínio no local.

A Figura 9.75 apresenta um gráfico comparativo entre o valor de módulo medido em laboratório e os valores de módulo previstos pelos modelos da literatura, para as condições de umidade ótima e peso específico aparente seco máximo relativos à energia intermediária de compactação. Verificou-se uma convergência maior para os modelos de Jin et al. (1994), Rada \& Witczak (1981), Titi et al.- granulares (2006). 
A Figura 9.76 apresenta um gráfico comparativo entre o valor de módulo in situ medido com $\angle W D$ e os valores de módulo previstos pelos modelos da literatura, para as condições de umidade e peso específico aparente seco verificadas em campo no momento da abertura do poço de inspeção. Verificou-se uma convergência maior para os modelos de Malla \& Joshi - materiais granulares (2006), AASHTO/2002 (ME-PDG) e Rada \& Witczak (1981).

A Figura 9.77 apresenta um gráfico comparativo entre o valor mínimo de módulo in situ medido com FWD (retroanálise) e os valores de módulo previstos pelos modelos da literatura, para as condições de saturação próxima da saturação máxima (adotouse S próximo a $98 \%$ ). Verificou-se uma convergência maior para o modelo de Jin et al. - solo 2 (1994).

A Figura 9.78 apresenta os gráficos da série histórica dos indicadores estruturais do pavimento (deflexão máxima, raio de curvatura, e deflexão a $120 \mathrm{~mm}$ do ponto de aplicação de carga) no segmento que contempla o local em estudo.

A Figura 9.79 apresenta os gráficos da série histórica dos valores de módulo de resiliência retroanalisado $(F W D$ ) e Quociente de Irregularidade $(Q I)$ no segmento que contempla o local em estudo.

A Figura 9.80 apresenta os dados estatísticos (valores máximos, mínimos, média e média mais ou menos desvio padrão), bem como boxplot dos indicadores estruturais do pavimento no segmento homogêneo determinado para o ponto em estudo. 


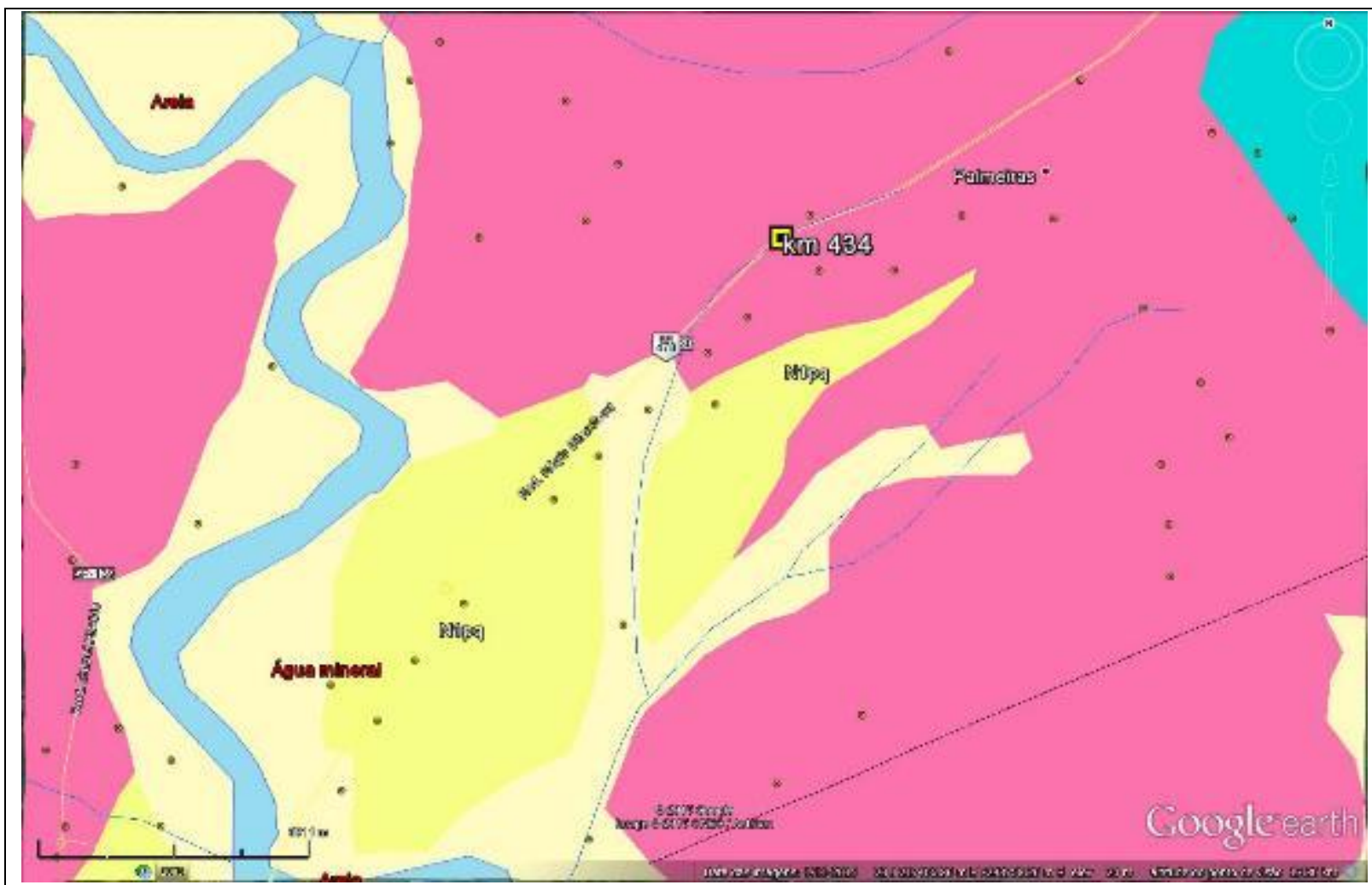

\section{LEGENDA:}

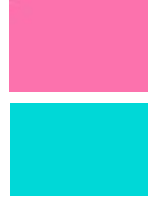

Atuba, Gnaisse Itapeúna: Gnaisse, Biotita

Depósitos aluvionares: Depósitos de areia, monzogranito, Diorito, Granito gnaisse

\section{Depósitos de cascalho}

Juquiá: Clinopiroxenito, Nefelina sienito, Olivina clinopiroxenito

Pariquera-Açu: Depósitos de areia,

Conglomerado, Depósitos de argila, Lamito

\section{Afloramentos}

Figura 9.71: Mapa Geológico do local sondado - km 434 (Pista Norte) Fonte: Geobank/Google Earth ${ }^{\circledR}$

Tabela 9.36: histórico de intervenções informado - km 434 (pista norte)

\begin{tabular}{ccclccc}
\hline \multirow{2}{*}{$\mathbf{k m}$} & $\begin{array}{c}\mathbf{k m} \\
\text { inicial }\end{array}$ & $\begin{array}{c}\mathbf{k m} \\
\text { final }\end{array}$ & Solução Aplicada & $\begin{array}{c}\text { Larg. } \\
\text { (m) }\end{array}$ & $\begin{array}{c}\text { Esp. } \\
\text { (cm) }\end{array}$ & $\begin{array}{c}\text { Data da } \\
\text { Interv. }\end{array}$ \\
\hline \multirow{3}{*}{434} & 432,227 & 435,386 & MICROREVESTIMENTO & 4,30 & 1,20 & $27 / 09 / 2011$ \\
\cline { 2 - 7 } & 434,000 & 434,007 & FRESAGEM FUNCIONAL & 3,86 & 5,20 & $22 / 10 / 2012$ \\
\cline { 2 - 7 } & 434,000 & 434,338 & FRESAGEM ESTRUTURAL & 3,88 & 6,00 & $16 / 02 / 2013$ \\
\hline
\end{tabular}


Tabela 9.37: Estrutura do pavimento da faixa externa - km 434 (pista norte)

\begin{tabular}{|c|c|c|c|c|c|}
\hline km & Pista & Camada & $\begin{array}{c}\text { Espessura } \\
(\mathrm{cm})\end{array}$ & Camada & $\begin{array}{l}\text { Materiais } \\
\text { ensaiados }\end{array}$ \\
\hline \multirow{4}{*}{434} & \multirow{4}{*}{ Norte } & 1 & 13,0 & CA & \\
\hline & & 2 & 10,0 & CAM. CIMENTADA* & \\
\hline & & 3 & 18,0 & BGS & \\
\hline & & 4 & - & SL & \\
\hline
\end{tabular}

Tabela 9.38: Estatística dos resultados do ensaio com $L W D$

\begin{tabular}{|c|c|c|c|c|c|c|c|c|c|c|c|}
\hline \multicolumn{12}{|c|}{ Resumo } \\
\hline \multirow{2}{*}{ km } & \multirow{2}{*}{ Material } & \multicolumn{5}{|c|}{ Leituras $D_{0, \text { LWD }}\left(10^{-2} \mathrm{~mm}\right)$} & \multicolumn{5}{|c|}{$E_{0, \text { calc }}\left(\mathbf{k f g} / \mathrm{cm}^{2}\right)$} \\
\hline & & Mín. & Máx. & Média & Desvio & CV(\%) & Mín. & Máx. & Média & Desvio & CV(\%) \\
\hline 434 & BGS & 40 & 116 & 82 & 31 & 38 & 195 & 571 & 332 & 161 & 49 \\
\hline 434 & $\mathrm{SL}$ & 38 & 50 & 42 & 4 & 10 & 454 & 595 & 549 & 50 & 9 \\
\hline
\end{tabular}

Tabela 9.39: Estatística dos resultados de determinação do módulo da camada de BGS

\begin{tabular}{|c|c|c|c|c|c|c|}
\hline \multirow{2}{*}{ km } & \multirow{2}{*}{ Material- } & \multicolumn{5}{|c|}{$E_{s b, \text { retro }}\left(\mathbf{k f g} / \mathrm{cm}^{2}\right)$} \\
\hline & & Mín. & Máx. & Média & Desvio & CV (\%) \\
\hline 434 & BGS & 144 & 900 & 400 & 325 & 81 \\
\hline
\end{tabular}

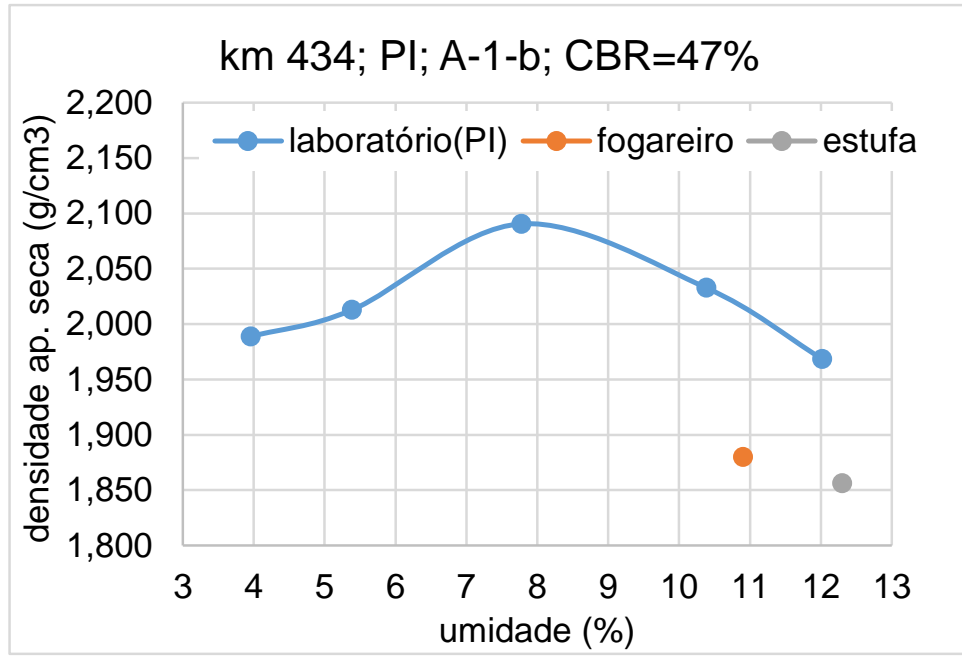

Figura 9.72: Comparativo entre pesos específicos aparentes secos - laboratório x campo (subleito, km 434, norte) 


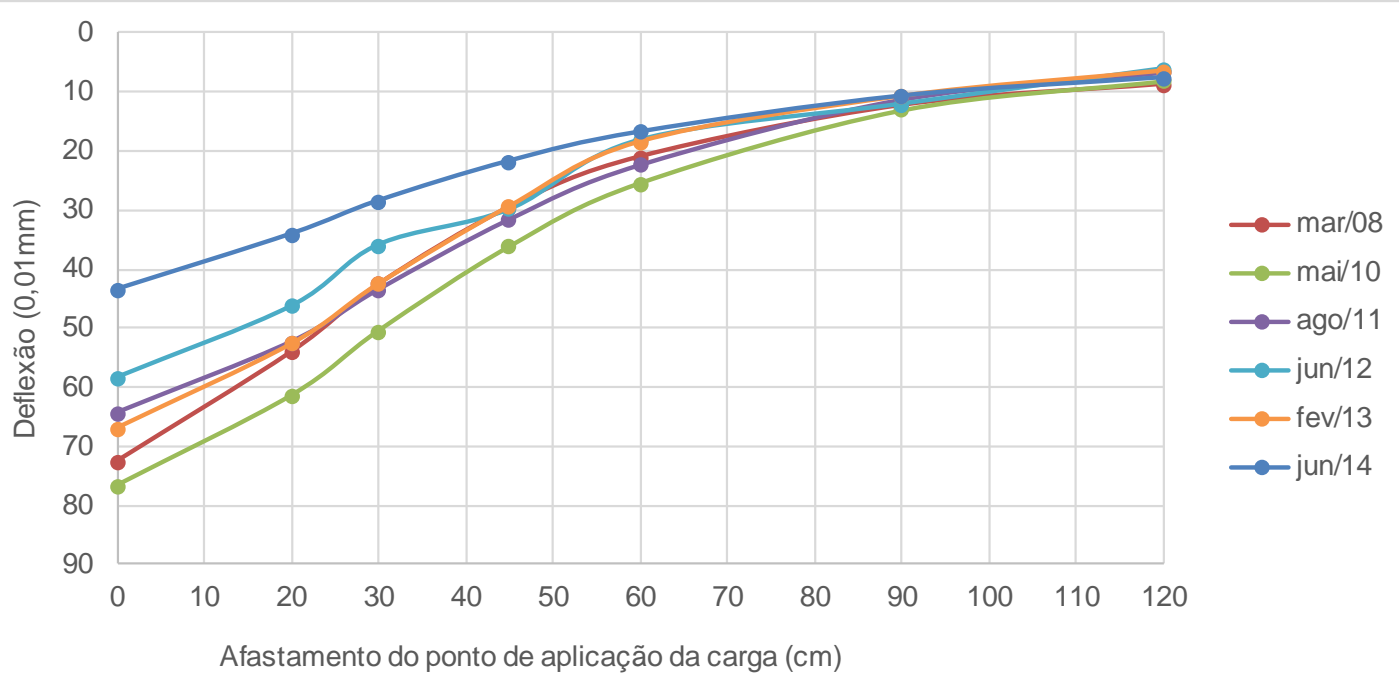

\begin{tabular}{|c|c|c|c|c|c|c|c|c|}
\hline $\begin{array}{c}\text { Mês/ano } \\
\text { Levantamento }\end{array}$ & $\begin{array}{l}\text { Tar } \\
\left({ }^{\circ} \mathrm{C}\right)\end{array}$ & $\begin{array}{l}\text { Tpav } \\
\left({ }^{\circ} \mathrm{C}\right)\end{array}$ & $\begin{array}{c}\text { Er1 } \\
\left(\mathrm{kgf} / \mathrm{cm}^{2}\right)\end{array}$ & $\begin{array}{c}E b \\
\left(\mathrm{kgf} / \mathrm{cm}^{2}\right)\end{array}$ & $\begin{array}{c}\text { Esb } \\
\left(\mathrm{kgf} / \mathrm{cm}^{2}\right)\end{array}$ & $\begin{array}{c}\text { Esl } \\
\left(\mathrm{kgf} / \mathrm{cm}^{2}\right)\end{array}$ & $\begin{array}{c}\text { Eslx0,33 } \\
\left(\mathrm{kgf} / \mathrm{cm}^{2}\right)\end{array}$ & $\begin{array}{c}\text { Esl } \\
\text { (AASHTO/ } \\
93 \text { ) }\end{array}$ \\
\hline $\begin{array}{l}\text { Espessuras } \\
\text { (cm) }\end{array}$ & & & 13,0 & 10,0 & 18,0 & - & & \\
\hline Materiais & & & CA & (CAM. CIMENTADA) & BGS & & & \\
\hline $\mathrm{mar} / 08$ & & & & \multirow{5}{*}{ *Provável estrutura ant } & & & & 338 \\
\hline $\mathrm{mai} / 10$ & & & & & & & & 296 \\
\hline ago/11 & & & & & & & & 432 \\
\hline $\mathrm{jul} / 12$ & & & & & & & & 439 \\
\hline $\mathrm{fev} / 13$ & & & & & & & & 410 \\
\hline jun/14 & 20,0 & 27,0 & 25.000 & 5.000 & 1.000 & 1.200 & 396 & 384 \\
\hline
\end{tabular}

Figura 9.73: Retroanálise das bacias de deflexões (série histórica) - km 434 (pista norte)

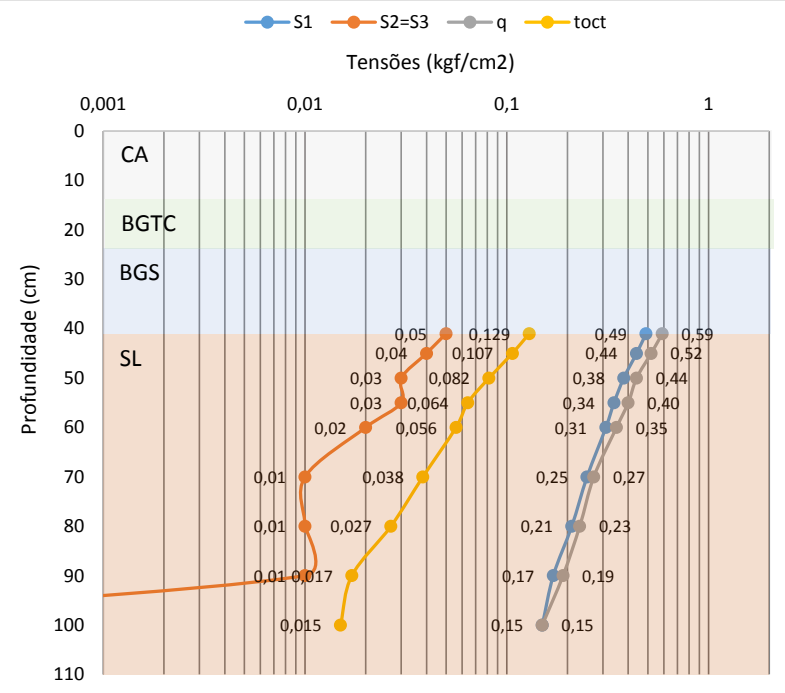

Figura 9.74: Tensões no subleito calculadas para 2014 
Tabela 9.40: Resumo dos ensaios realizados com material próximo ao km 434

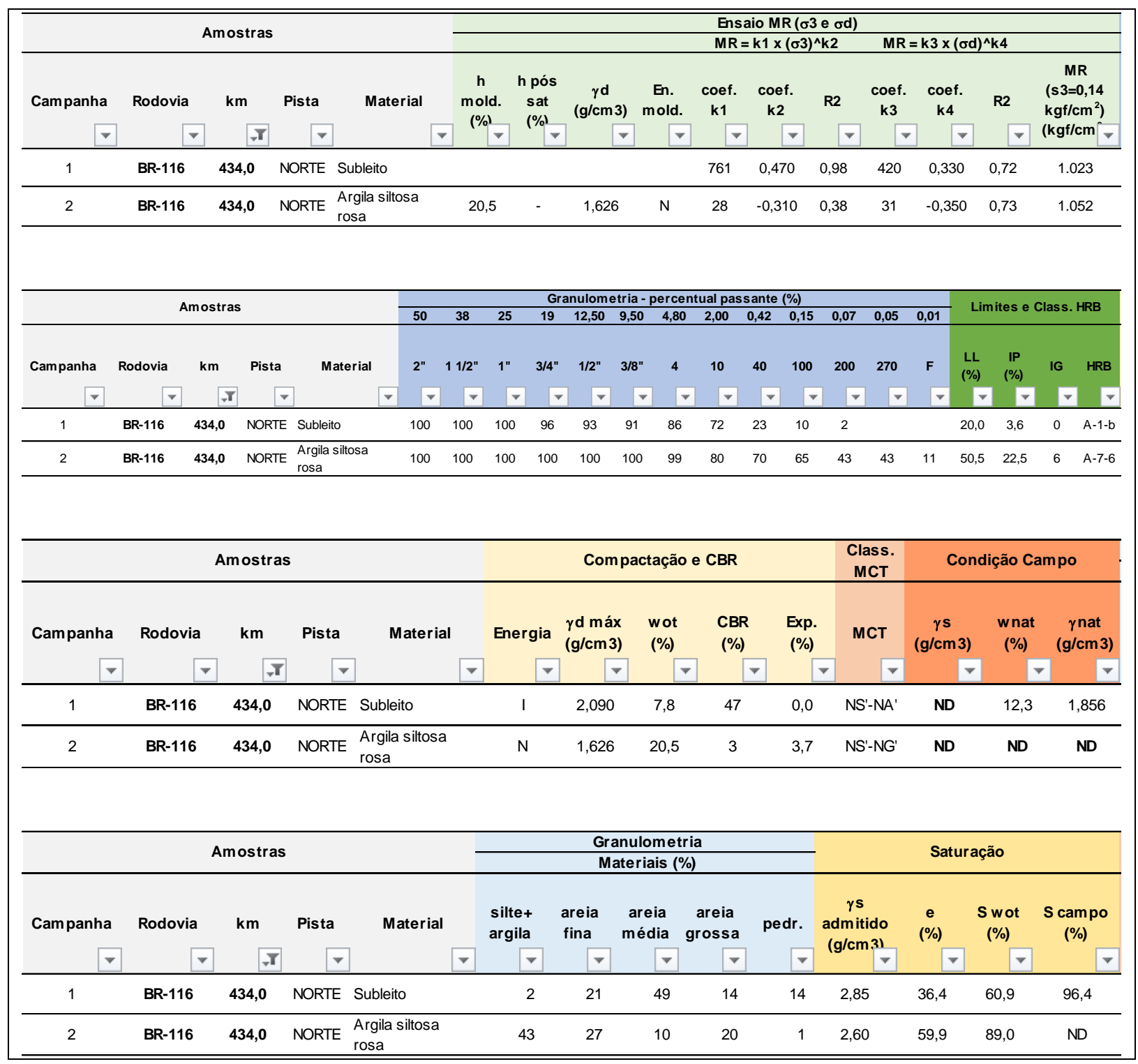




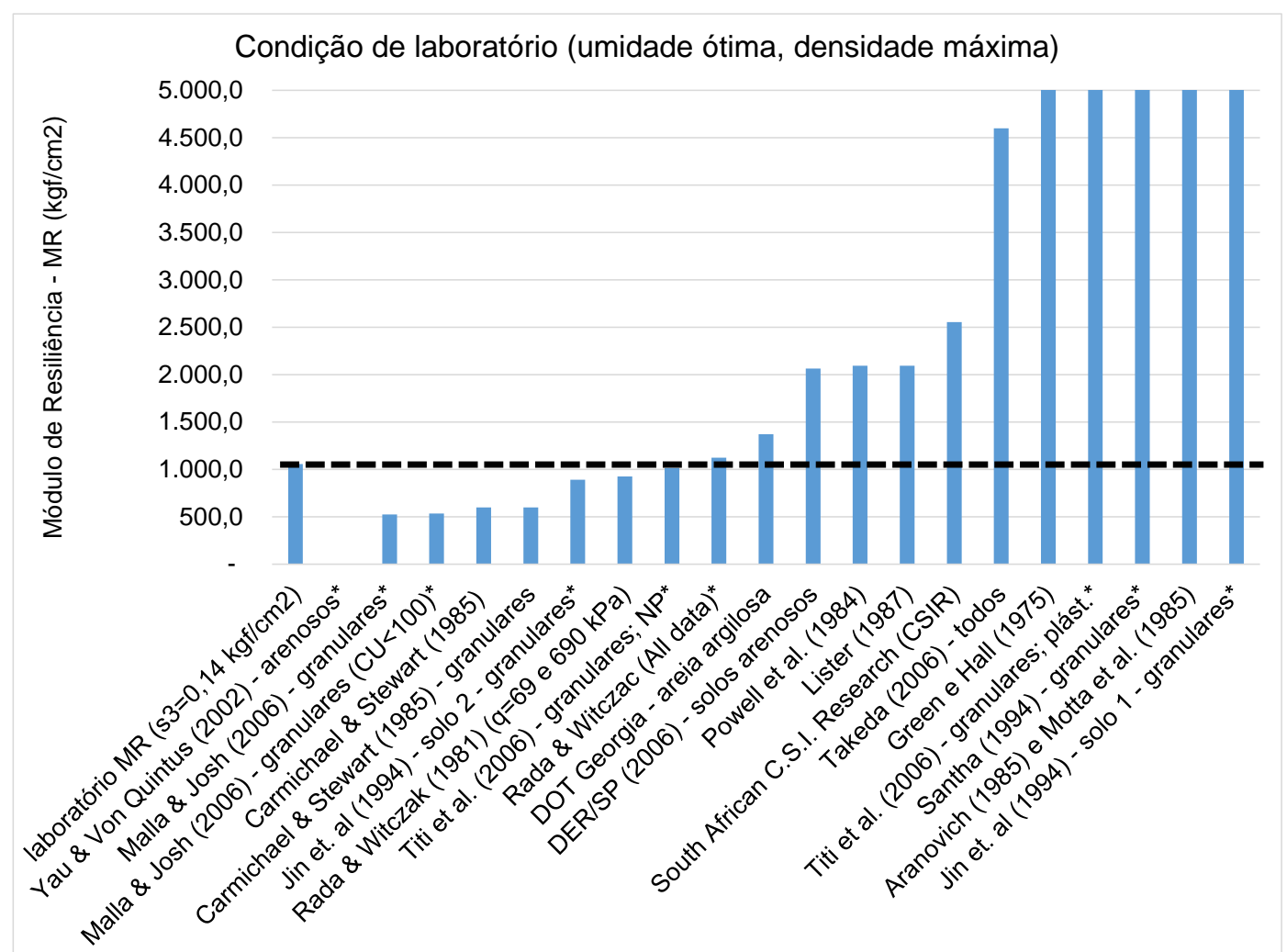

Figura 9.75: Comparativo entre MR de laboratório e modelos de previsão de $M R$ (condição de umidade ótima)

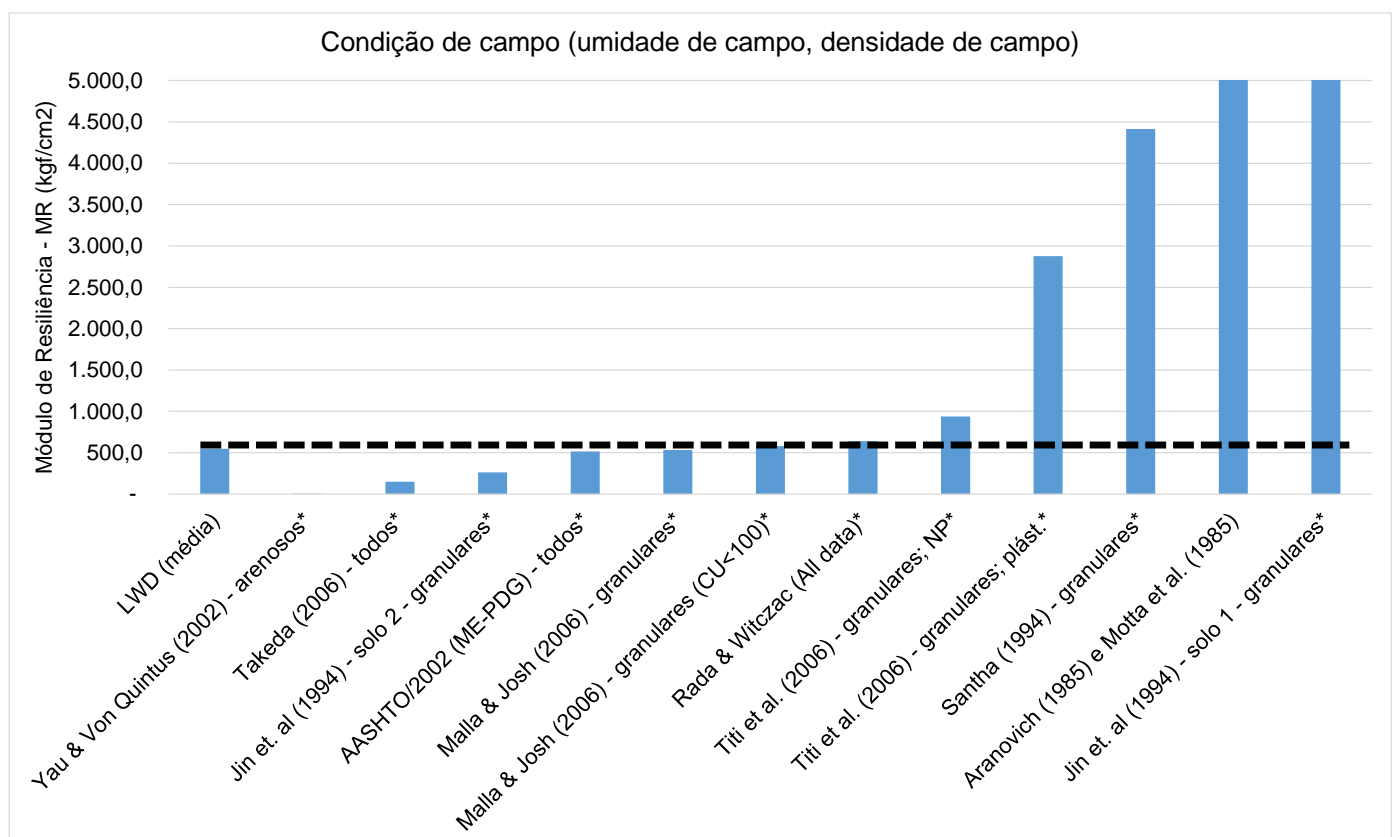

Figura 9.76: Comparativo entre $M R$ in situ $(L W D)$ e modelos de previsão de $M R$ (condição de umidade verificada no campo) 


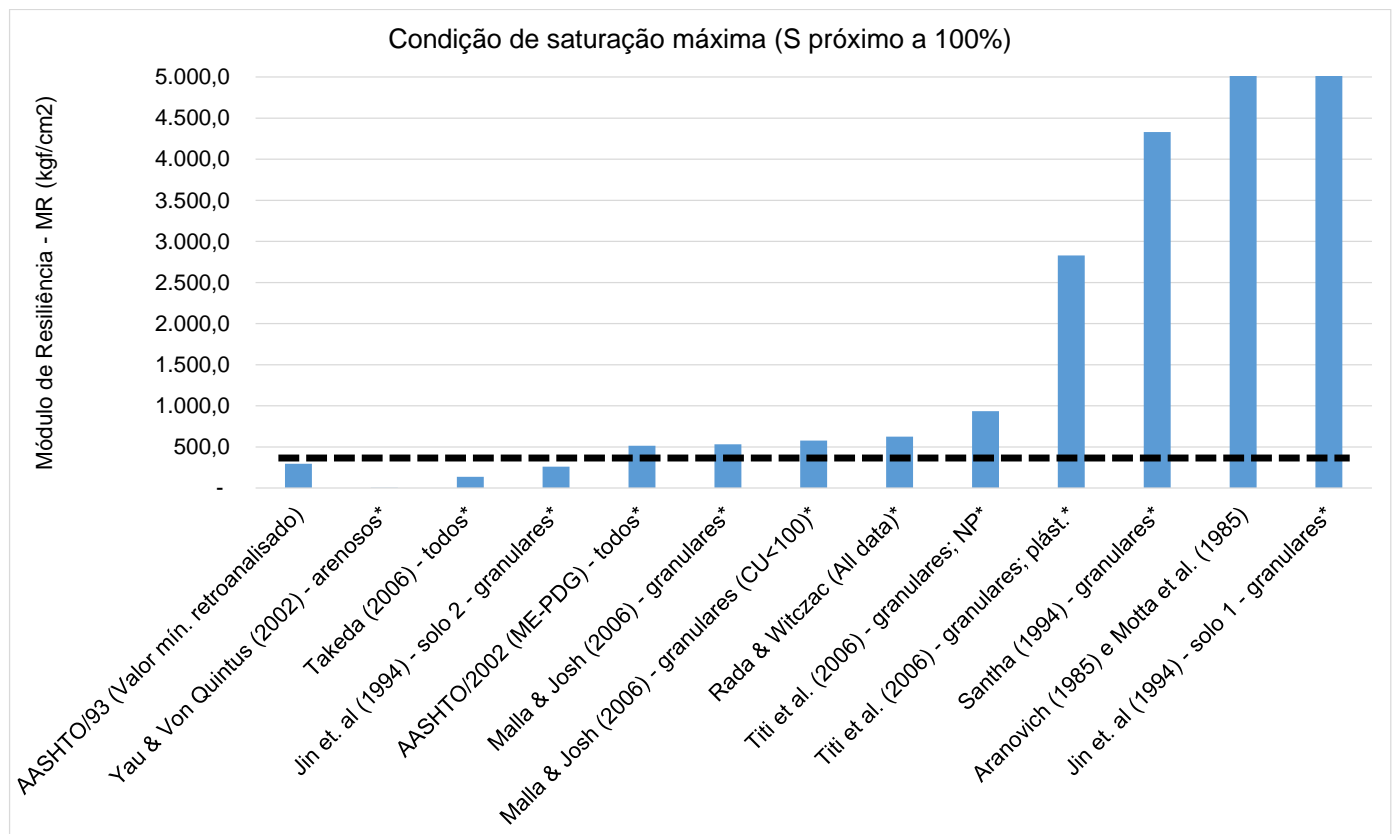

Figura 9.77: Comparativo entre $M R$ in situ mínimo verificado $(F W D)$ e modelos de previsão de $M R$ (condição de saturação próxima a 100\%) 

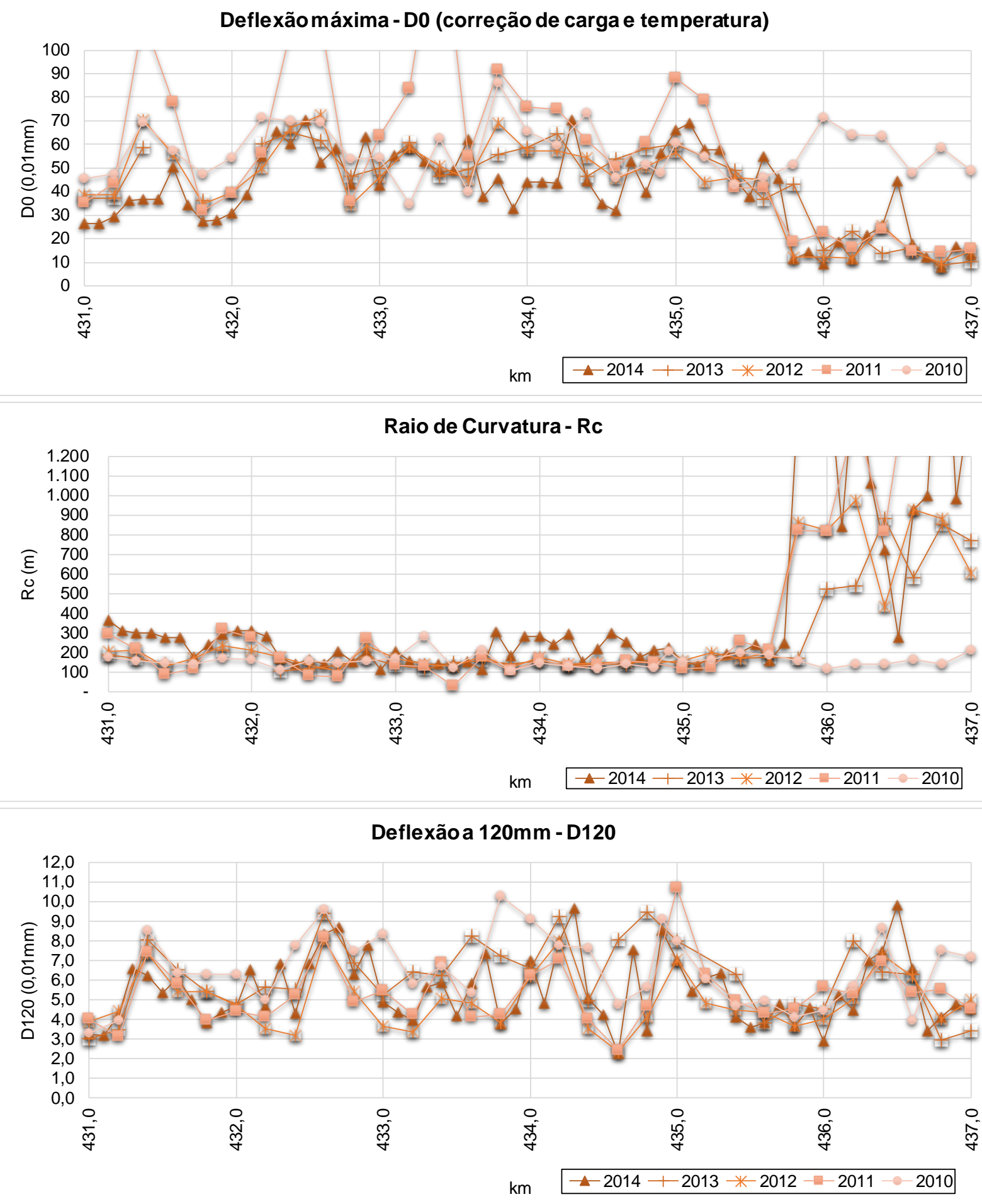

Figura 9.78: Gráficos de série histórica dos indicadores estruturais do pavimento no segmento do km 434 (pista norte) 


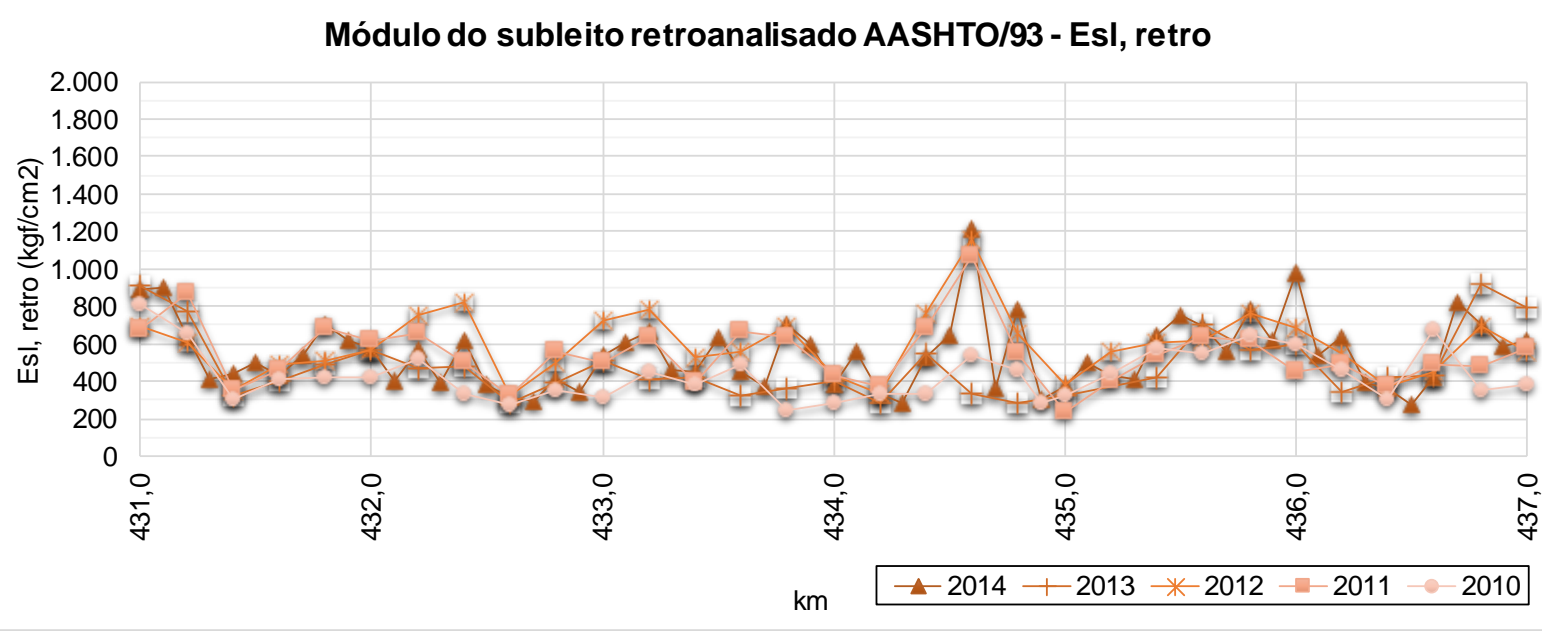

Figura 9.79: Gráficos da série histórica dos dados de módulo de resiliência retroanalisado $(F W D)$ do pavimento no segmento do $\mathrm{km} 434$ (pista norte) 
433,5 434,5 DECRESCENTE
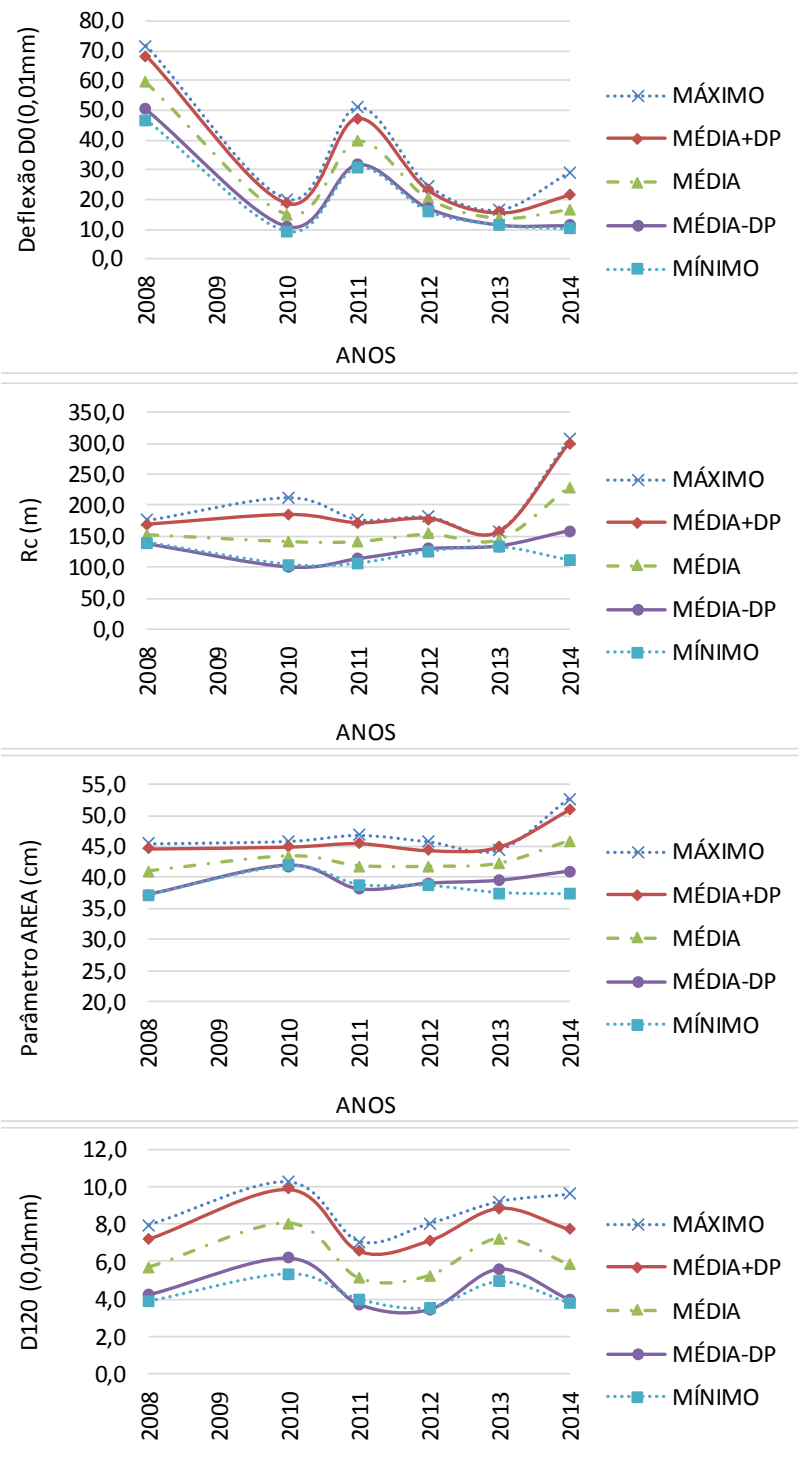
ANOS
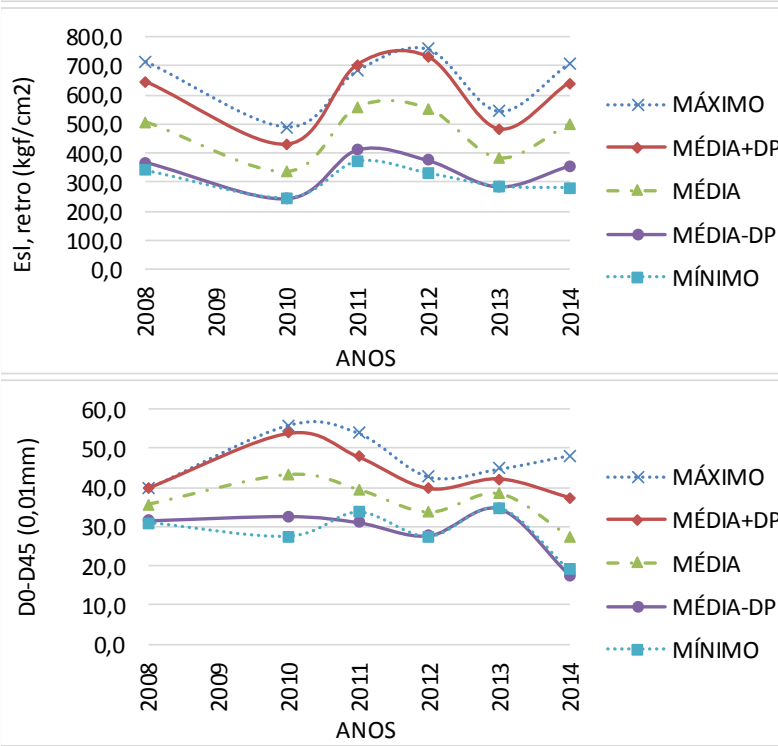

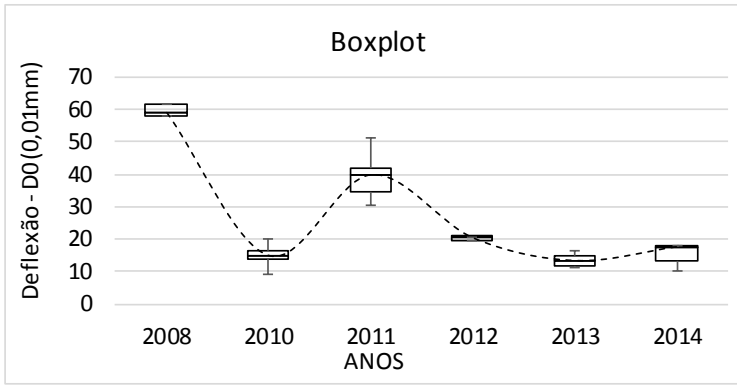

Boxplot

400

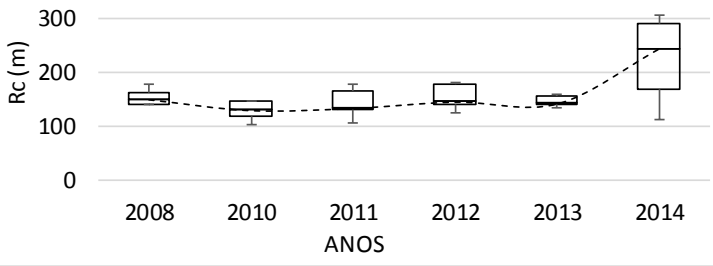

Boxplot
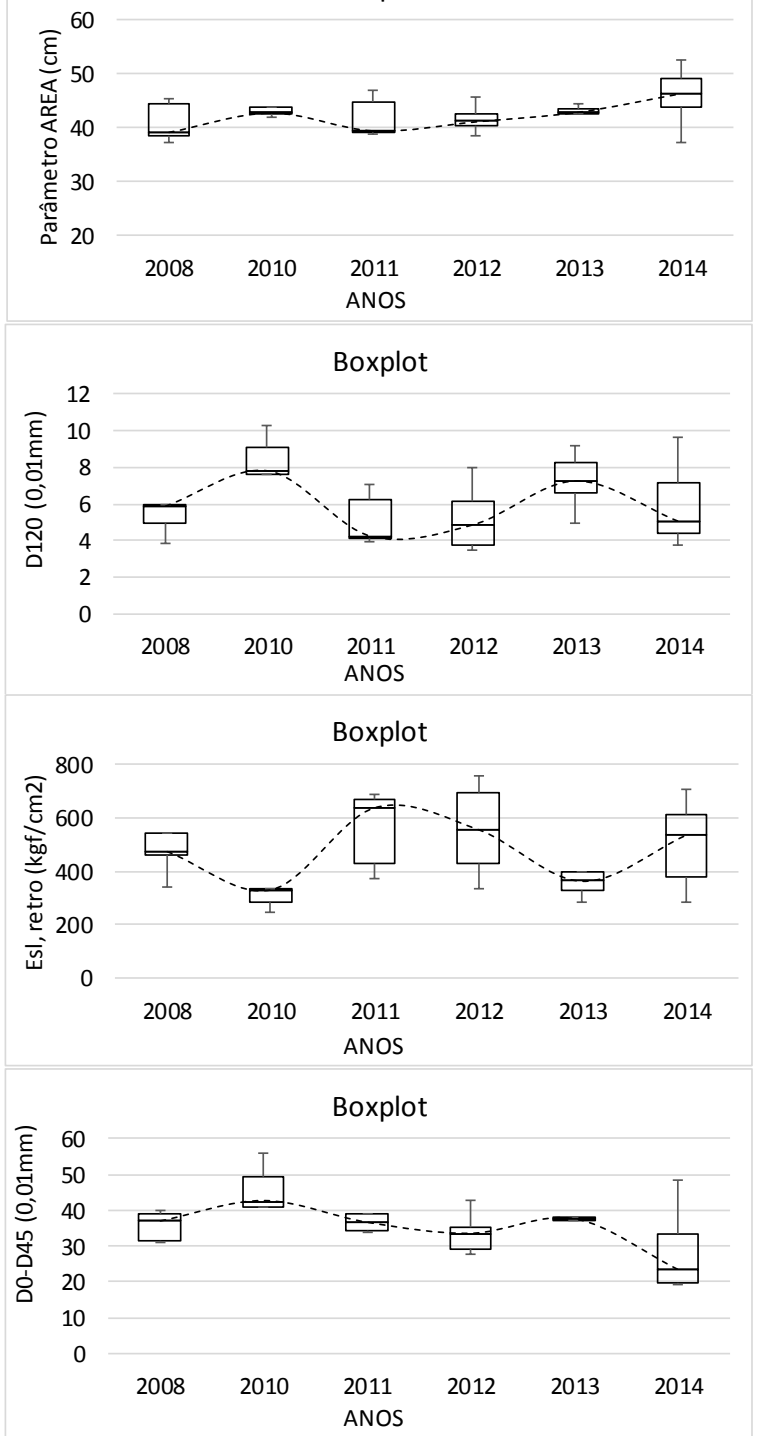

Figura 9.80: Estatísticas dos Parâmetros do pavimento (S. Homogêneo do km 434) 


\subsection{Poço de inspeção do km 456 (Pista Norte)}

A Figura 9.81 a seguir ilustra a localização do poço de inspeção do km 456 (pista norte) bem como o mapeamento geológico do local. Verifica-se uma região com predominância de gnaisse.

A Tabela 9.36 apresenta o registro histórico de intervenções do pavimento. Verificase que o pavimento sofreu uma intervenção de fresagem estrutural no ano de 2009.

A Tabela 9.37 apresenta a estrutura do pavimento identificada na ocasião da abertura do poço de inspeção. Foi encontrada uma cada cimentada na base do pavimento, conferindo características de comportamento de pavimento semirrígido.

A Tabela 9.38 e Tabela 9.39 apresentam os resultados estatísticos obtidos a partir do ensaio de $L W D$ sobre as camadas de subleito e camada de base granular. Enquanto a Figura 9.82 apresenta o gráfico comparativo dos pesos específicos aparentes secos e umidades obtidos em campo e em laboratório (curva de compactação de laboratório versus ensaios de umidade e peso específico aparente seco in situ). Verifica-se que o material no campo está com peso específico aparente seco sensivelmente abaixo do peso específico aparente seco máximo relativo a energia intermediária e umidade próxima à ótima em relação à energia intermediária de compactação. Infere-se que o material tenha sido compactado na energia normal.

A Figura 9.83 apresenta o resultado da retroanálise da série histórica de deflexões do pavimento em estudo e a Figura 9.84 apresenta os gráficos de tensões calculadas no subleito, ilustrando o comportamento do subleito registrado através dos ensaios com FWD.

A Tabela 9.40 apresenta o resumo dos resultados dos ensaios de laboratório realizados com o material do subleito e dos materiais da faixa de domínio no local.

A Figura 9.85 apresenta um gráfico comparativo entre o valor de módulo medido em laboratório e os valores de módulo previstos pelos modelos da literatura, para as condições de umidade ótima e peso específico aparente seco máximo relativos à energia intermediária de compactação. Verificou-se uma convergência maior para os modelos o DER/SP - solos arenosos (2006), Powell et al. (1984), Lister (1987) e South Africa C.S.I.R. 
A Figura 9.86 apresenta um gráfico comparativo entre o valor de módulo in situ medido com $L W D$ e os valores de módulo previstos pelos modelos da literatura, para as condições de umidade e peso específico aparente seco verificadas em campo no momento da abertura do poço de inspeção. Verificou-se uma convergência maior para os modelos da AASHTO/2002 (ME-PDG), Takeda (2006) e Rada \& Witczak (1981).

A Figura 9.87 apresenta um gráfico comparativo entre o valor mínimo de módulo in situ medido com FWD (retroanálise) e os valores de módulo previstos pelos modelos da literatura, para as condições de saturação próxima da saturação máxima (adotouse S próximo a 98\%). Verificou-se uma razoabilidade maior do modelo de Rada \& Witczak (1981).

A Figura 9.88 apresenta os gráficos da série histórica dos indicadores estruturais do pavimento (deflexão máxima, raio de curvatura, e deflexão a $120 \mathrm{~mm}$ do ponto de aplicação de carga) no segmento que contempla o local em estudo.

A Figura 9.89 apresenta os gráficos da série histórica dos valores de módulo de resiliência retroanalisado ( $F W D$ ) e Quociente de Irregularidade (QI) no segmento que contempla o local em estudo.

A Figura 9.90 apresenta os dados estatísticos (valores máximos, mínimos, média e média mais ou menos desvio padrão), bem como boxplot dos indicadores estruturais do pavimento no segmento homogêneo determinado para o ponto em estudo. 


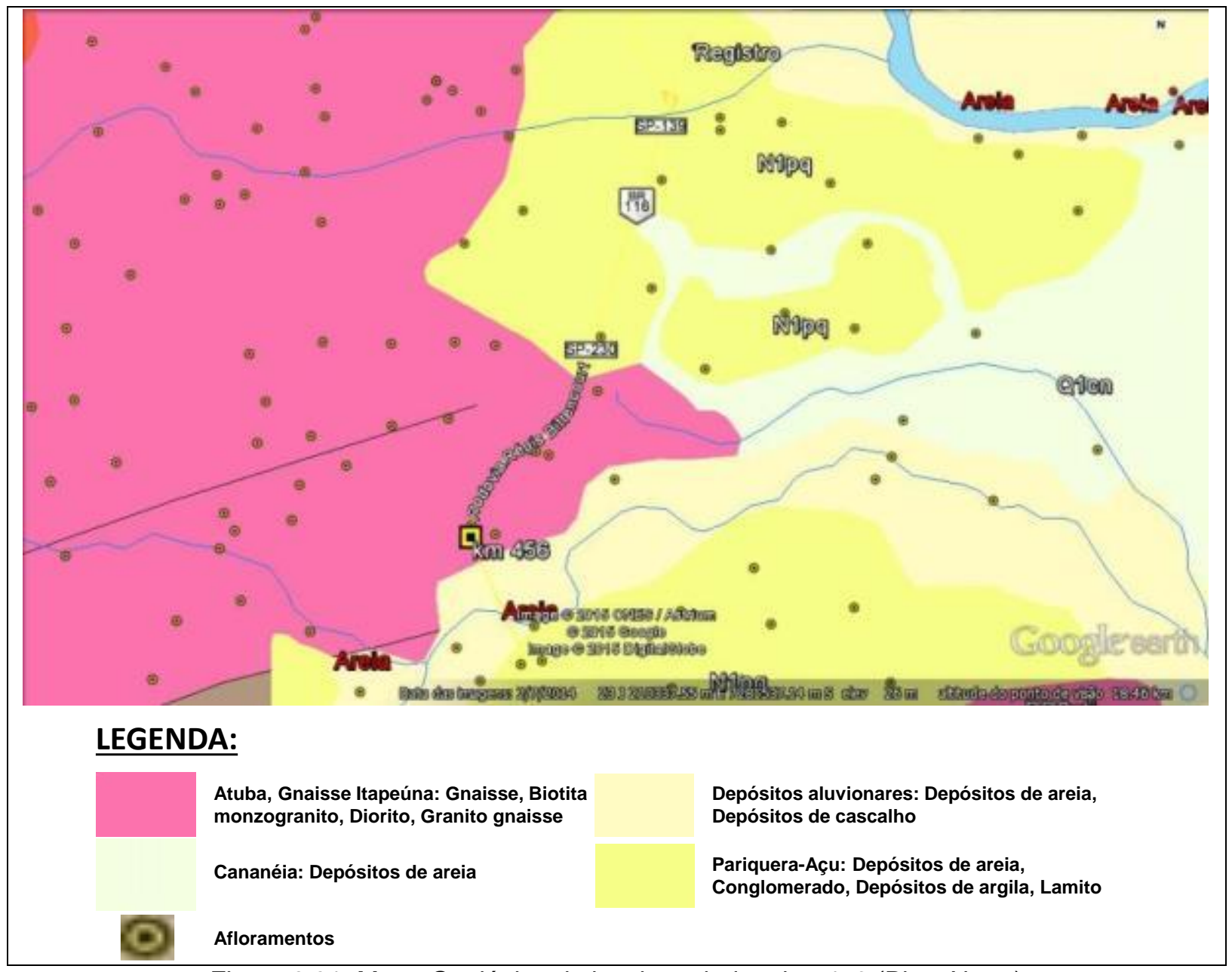

Figura 9.81: Mapa Geológico do local sondado - km 456 (Pista Norte) Fonte: Geobank/Google Earth®

Tabela 9.41: histórico de intervenções informado - km 456 (pista norte)

\begin{tabular}{ccccccc}
\hline $\mathbf{k m}$ & $\begin{array}{c}\mathbf{k m} \\
\text { inicial }\end{array}$ & $\begin{array}{c}\mathbf{k m} \\
\text { final }\end{array}$ & Solução Aplicada & $\begin{array}{c}\text { Larg. } \\
\text { (m) }\end{array}$ & $\begin{array}{c}\text { Esp. } \\
\text { (cm) }\end{array}$ & $\begin{array}{c}\text { Data da } \\
\text { Interv. }\end{array}$ \\
\hline \multirow{3}{*}{456} & 455,949 & 456,046 & FRESAGEM ESTRUTURAL & 3,80 & 9,50 & $11 / 12 / 2009$ \\
\cline { 2 - 7 } & 455,993 & 456,000 & FRESAGEM FUNCIONAL & 3,90 & 5,00 & $03 / 09 / 2011$ \\
\cline { 2 - 7 } & 454,870 & 458,289 & MICROREVESTIMENTO & 4,20 & 1,20 & $05 / 10 / 2011$ \\
\cline { 2 - 7 } & 455,790 & 456,000 & FRESAGEM FUNCIONAL & 3,70 & 5,05 & $18 / 12 / 2014$ \\
\hline
\end{tabular}

Tabela 9.42: Estrutura do pavimento - km 456 (pista norte)

\begin{tabular}{|c|c|c|c|c|}
\hline km & Pista & Camada & $\begin{array}{c}\text { Espessura } \\
(\mathrm{cm})\end{array}$ & Camada \\
\hline \multirow{5}{*}{456} & \multirow{5}{*}{ Norte } & 1 & 12,0 & CA \\
\hline & & 2 & 7,0 & BASE BETUMINOSA \\
\hline & & 3 & 17,0 & BGTC \\
\hline & & 4 & 18,0 & BGS \\
\hline & & 5 & - & SL \\
\hline
\end{tabular}


Tabela 9.43: Estatística dos resultados do ensaio com $L W D$

\begin{tabular}{|c|c|c|c|c|c|c|c|c|c|c|c|}
\hline \multirow{3}{*}{ km } & \multicolumn{10}{|c|}{ Resumo } & \\
\hline & \multirow{2}{*}{ Material } & \multicolumn{5}{|c|}{ Leituras $D_{0, \text { LWD }}\left(10^{-2} \mathrm{~mm}\right)$} & \multicolumn{5}{|c|}{$E_{0, \text { calc }}\left(\mathbf{k f g} / \mathrm{cm}^{2}\right)$} \\
\hline & & Mín. & Máx. & Média & Desvio & CV(\%) & Mín. & Máx. & Média & Desvio & CV(\%) \\
\hline 456 & BGS & 29 & 83 & 53 & 19 & 36 & 273 & 777 & 482 & 187 & 39 \\
\hline 456 & $\mathrm{SL}$ & 18 & 31 & 22 & 4 & 19 & 727 & 1.296 & 1.083 & 168 & 16 \\
\hline
\end{tabular}

Tabela 9.44: Estatística dos resultados de determinação do módulo da camada de BGS

\begin{tabular}{lllllll}
\hline \multicolumn{6}{c}{ Resumo } \\
\hline \multirow{4}{*}{ km Material } & \multicolumn{4}{c}{$E_{\text {sb,retro }}\left(\mathbf{k f g} / \mathbf{c m}^{2}\right)$} \\
\cline { 3 - 6 } & & Mín. Máx. Média Desvio & CV(\%) \\
\hline 456 & BGS & 163 & 969 & 464 & 304 & 66 \\
\hline
\end{tabular}

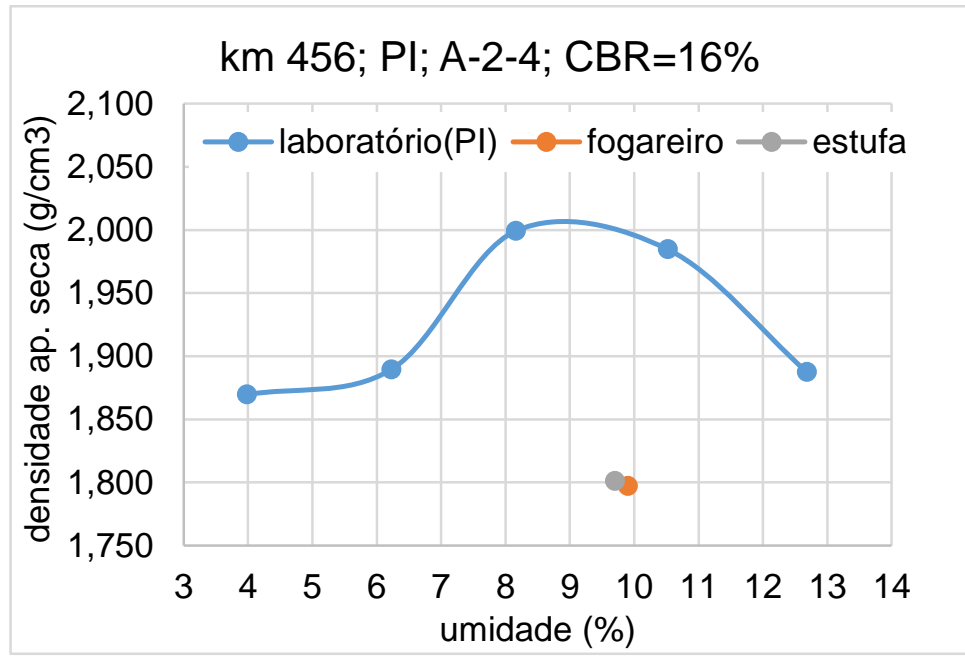

Figura 9.82: Comparativo entre pesos específicos aparentes secos - laboratório x campo (subleito, km 456, norte) 


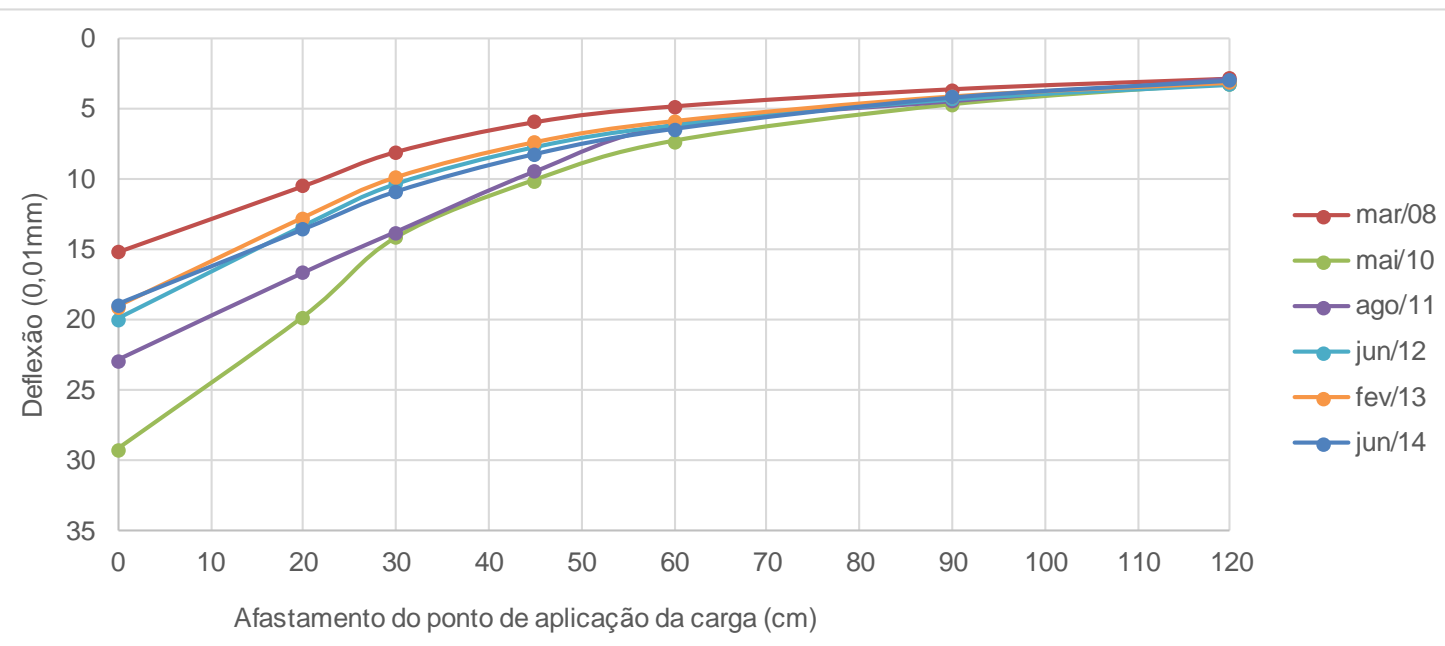

\begin{tabular}{cccccccccc}
\hline $\begin{array}{c}\text { Mês/ano } \\
\text { Levantamento }\end{array}$ & $\begin{array}{c}\text { Tar } \\
\left({ }^{\circ} \mathbf{C}\right)\end{array}$ & $\begin{array}{c}\text { Tpav } \\
\left({ }^{\circ} \mathbf{C}\right)\end{array}$ & $\begin{array}{c}\text { Er1 } \\
\left(\mathbf{k g f} / \mathbf{c m}^{2}\right)\end{array}$ & $\begin{array}{c}\text { Er2 } \\
\left(\mathbf{k g f} / \mathbf{c m}^{2}\right)\end{array}$ & $\begin{array}{c}\text { Eb } \\
\left(\mathbf{k g f} / \mathbf{c m}^{2}\right)\end{array}$ & $\begin{array}{c}\text { Esb } \\
\left(\mathbf{k g f} / \mathbf{c m}^{2}\right)\end{array}$ & $\begin{array}{c}\text { Esl } \\
\left(\mathbf{k g f} / \mathbf{c m}^{2}\right)^{*}\end{array}$ & $\begin{array}{c}\text { Eslx0,33 } \\
\left(\mathbf{k g f} / \mathbf{c m}^{2}\right)\end{array}$ & $\begin{array}{c}\text { Esl } \\
(\text { AASHTO/ } \\
\mathbf{9 3})\end{array}$ \\
\hline $\begin{array}{c}\text { Espessuras } \\
(\mathbf{c m})\end{array}$ & & & $\mathbf{1 2 , 0}$ & $\mathbf{7 , 0}$ & $\mathbf{1 7 , 0}$ & $\mathbf{1 8 , 0}$ & - & - & \\
\hline Materiais & & & $\mathbf{C A}$ & $\begin{array}{c}\text { CAM. } \\
\text { BETUM. }\end{array}$ & BGTC & BGS & $\mathbf{S L}$ & $\mathbf{S L}$ & $\mathbf{S L}$ \\
\hline mar/08 & - & - & 55.000 & 2.000 & 43.500 & 1.050 & 3.200 & 1.056 & 926 \\
\hline mai/10 & 31,0 & 32,0 & 20.000 & 1.200 & 15.000 & 1.500 & 3.000 & 990 & 861 \\
\hline ago/11 & 16,0 & 21,0 & 50.000 & 1.200 & 15.000 & 1.500 & 3.000 & 990 & 959 \\
\hline jun/12 & 16,0 & 18,0 & 30.000 & 4.000 & 15.000 & 2.500 & 3.000 & 990 & 1.186 \\
\hline fev/13 & 35,0 & 43,0 & 30.000 & 4.000 & 15.000 & 2.500 & 3.000 & 990 & 877 \\
\hline jun/14 & 19,0 & 21,0 & 40.000 & 5.000 & 15.000 & 1.000 & 3.500 & 1.155 & 869 \\
\hline
\end{tabular}

Figura 9.83: Retroanálise das bacias de deflexões (série histórica) - km 456 (pista norte)
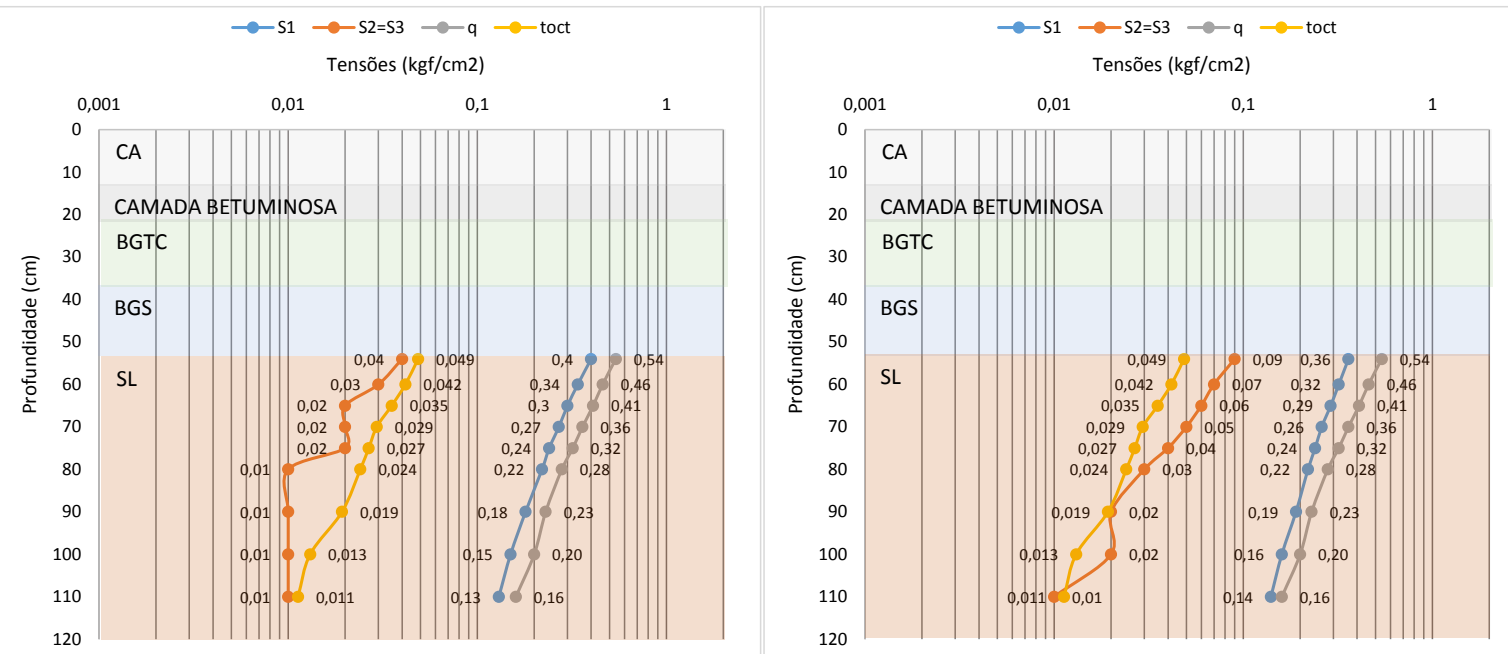

Figura 9.84: Tensões no subleito calculadas para (a) 2013 e (b) 2014 
Tabela 9.45: Resumo dos ensaios realizados com material próximo ao km 456

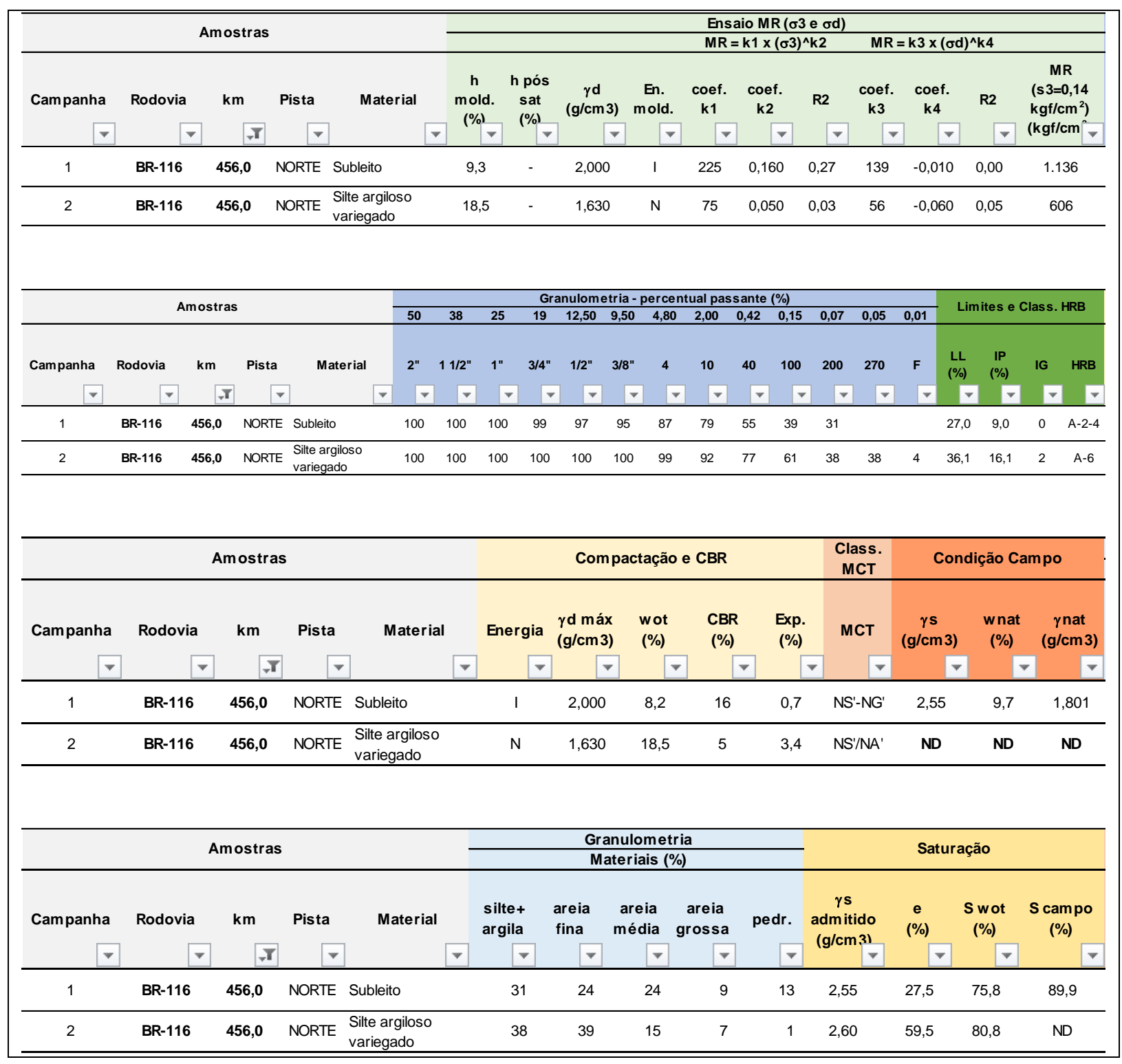




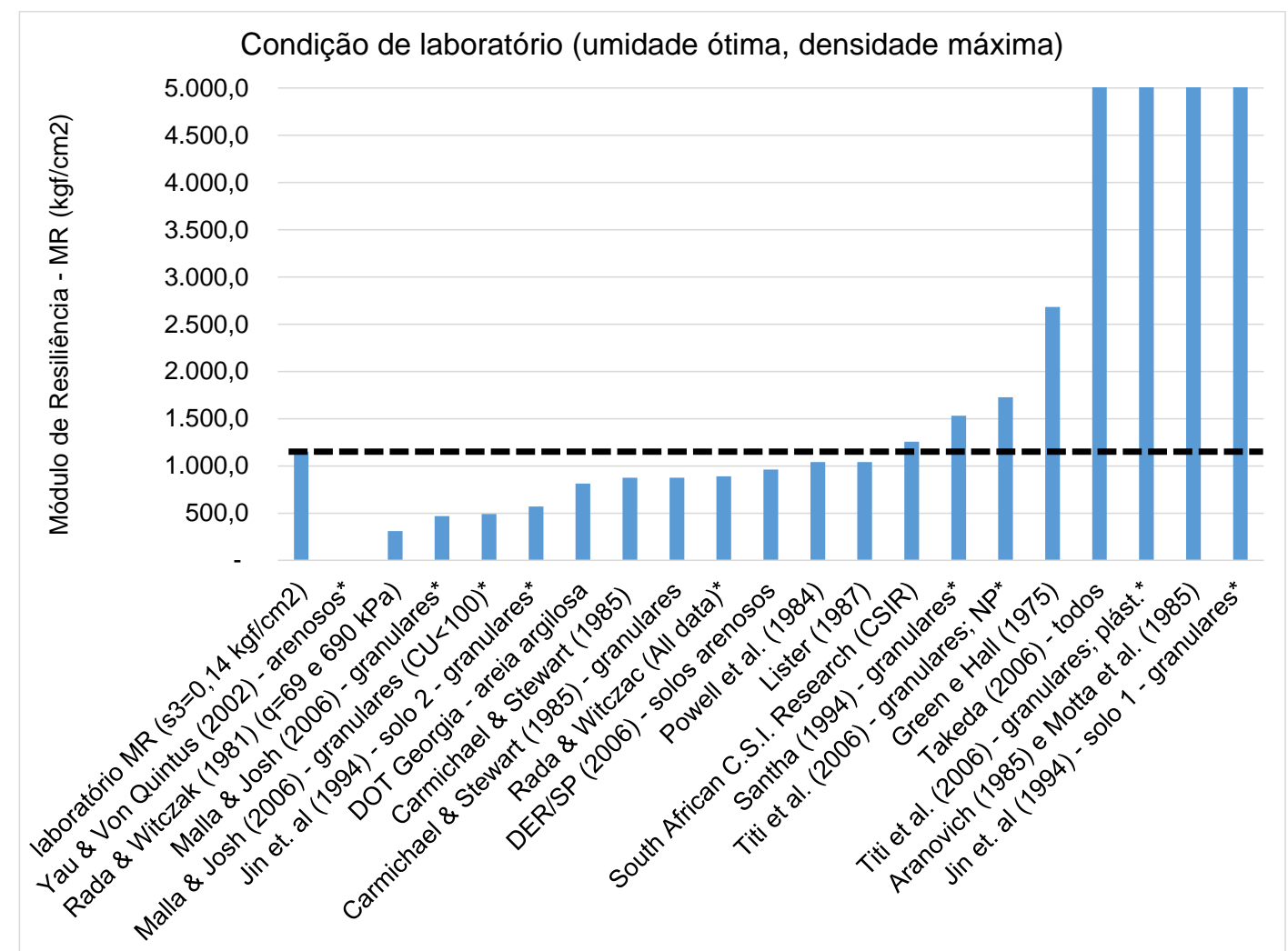

Figura 9.85: Comparativo entre $M R$ de laboratório e modelos de previsão de $M R$ (condição de umidade ótima)

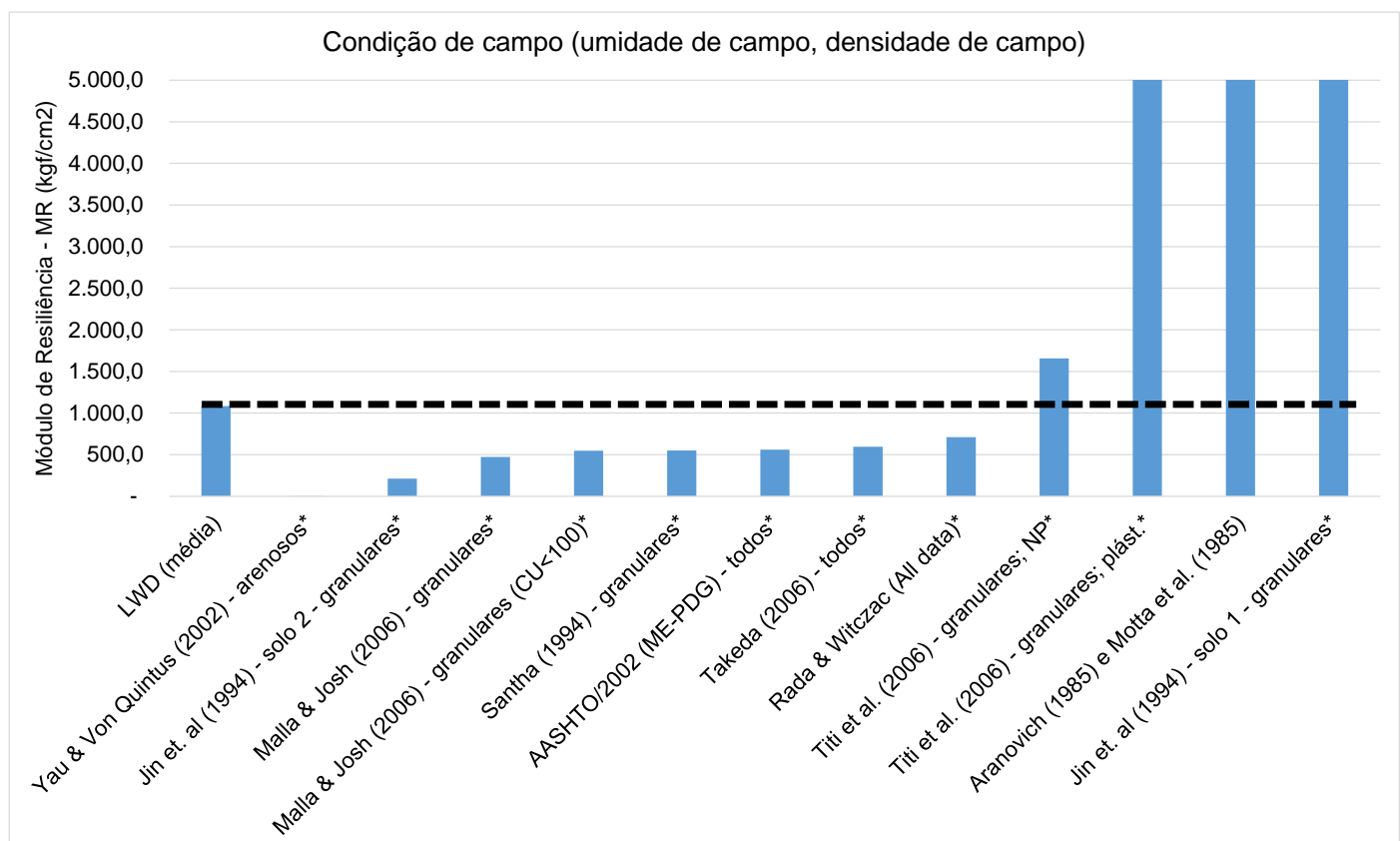

Figura 9.86: Comparativo entre $M R$ in situ $(L W D)$ e modelos de previsão de $M R$ (condição de umidade verificada no campo) 


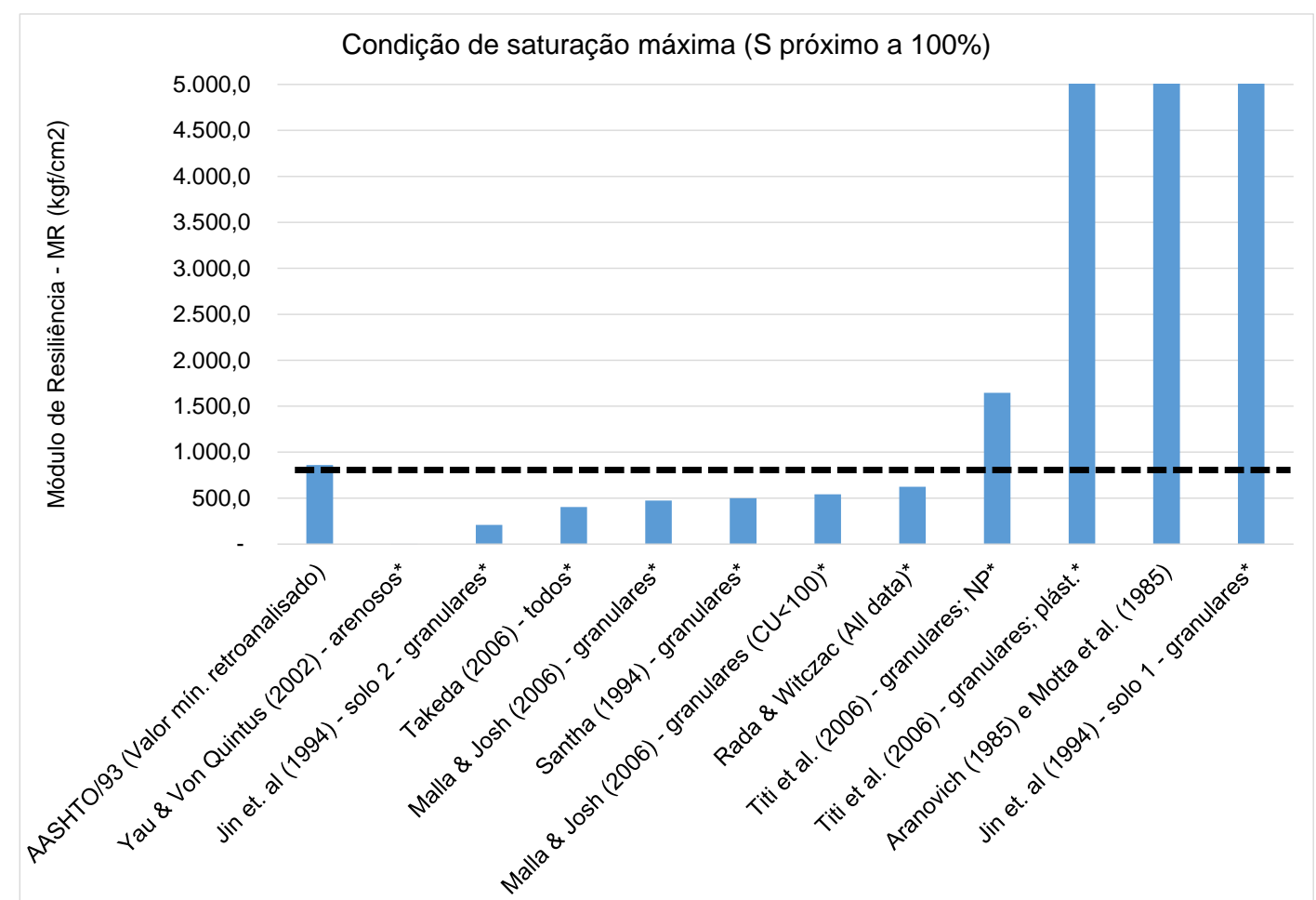

Figura 9.87: Comparativo entre $M R$ in situ mínimo verificado $(F W D)$ e modelos de previsão de $M R$ (condição de saturação próxima a 100\%) 

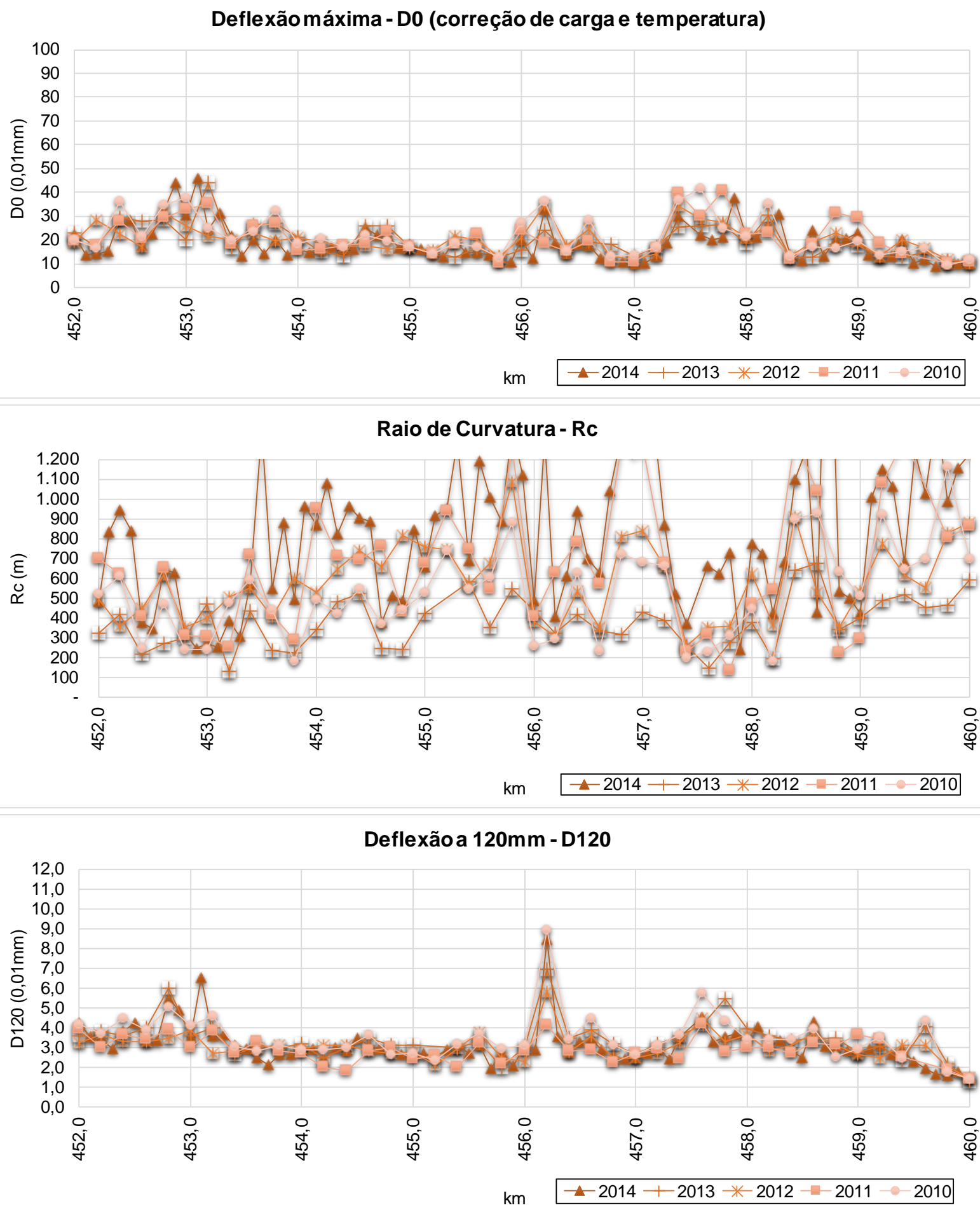

Figura 9.88: Gráficos de série histórica dos indicadores estruturais do pavimento no segmento do km 456 (pista norte) 


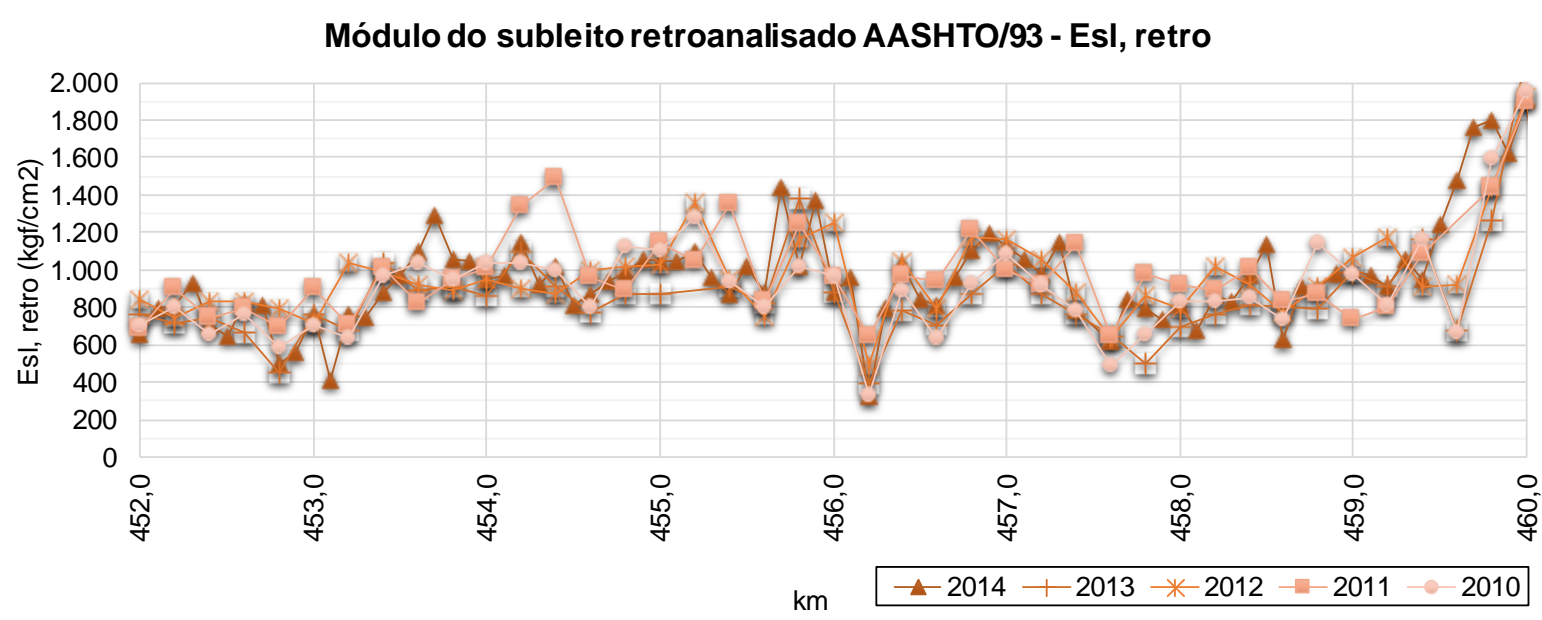

Figura 9.89: Gráficos da série histórica dos dados de módulo de resiliência retroanalisado $(F W D)$ do pavimento no segmento do $\mathrm{km} 456$ (pista norte) 
455,5 456,5 DECRESCENTE
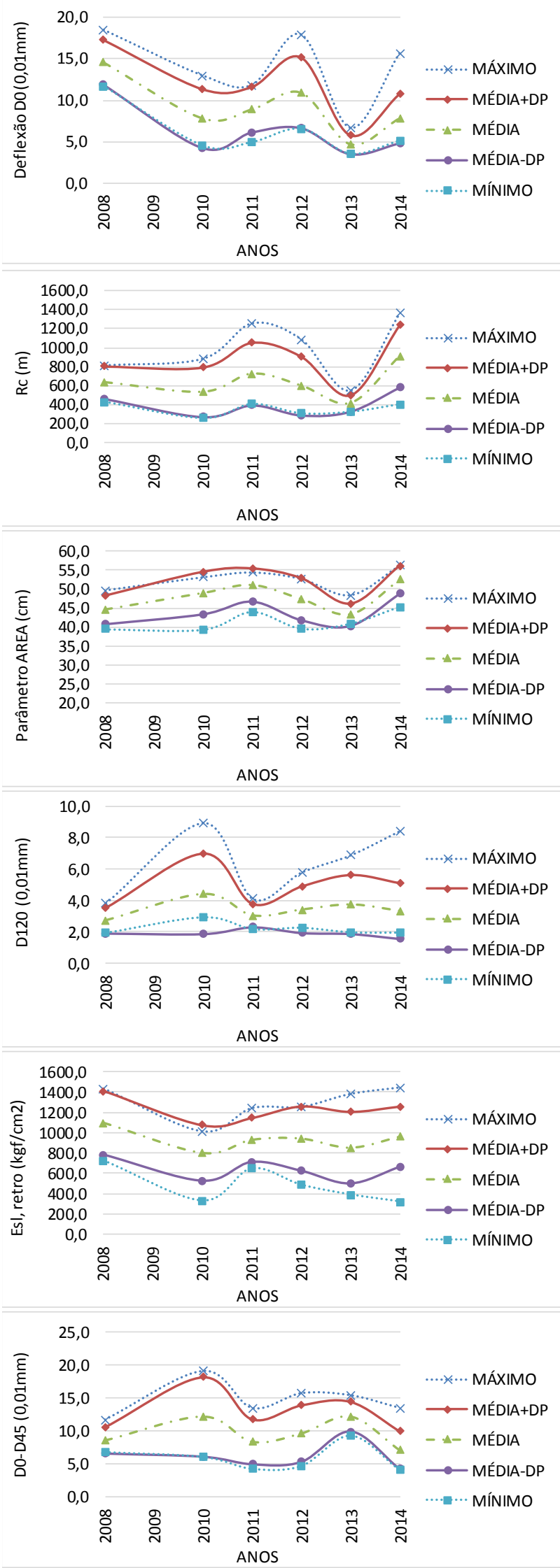
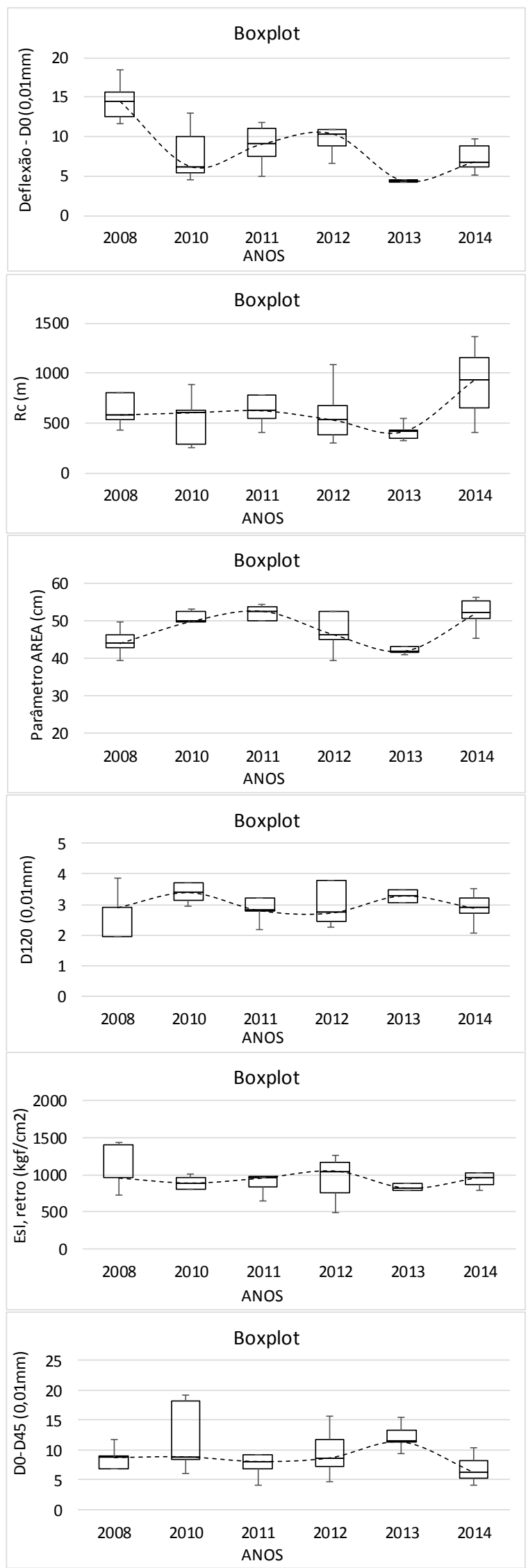

Figura 9.90: Estatísticas dos Parâmetros do pavimento (S. Homogêneo do km 456) 


\subsection{Poço de inspeção do km 460 (Pista Norte)}

A Figura 9.91 a seguir ilustra a localização do poço de inspeção do km 460 (pista norte) bem como o mapeamento geológico do local. Verifica-se uma região de depósito de areia e argila.

A Tabela 9.46 apresenta o registro histórico de intervenções do pavimento. Verificase que o pavimento sofreu uma intervenção de fresagem estrutural no ano de 2009.

A Tabela 9.47 apresenta a estrutura do pavimento identificada na ocasião da abertura do poço de inspeção. Trata-se de pavimento flexível, confeccionado com base granular.

A Tabela 9.48 e Tabela 9.49 apresentam os resultados estatísticos obtidos a partir do ensaio de $L W D$ sobre as camadas de subleito e camada de base granular. Enquanto a Figura 9.92 apresenta o gráfico comparativo dos pesos específicos aparentes secos e umidades obtidos em campo e em laboratório (curva de compactação de laboratório versus ensaios de umidade e peso específico aparente seco in situ). Verifica-se que o material no campo está com peso específico aparente seco e teor de umidade sensivelmente abaixo da condição ótima de compactação relativa a energia intermediária. Infere-se que o material tenha sido compactado na energia normal e que se encontrava relativamente seco na ocasião da abertura do poço.

A Figura 9.93 apresenta o resultado da retroanálise da série histórica de deflexões do pavimento em estudo e a Figura 9.94 apresenta os gráficos de tensões calculadas no subleito, ilustrando o comportamento do subleito registrado através dos ensaios com FWD.

A Tabela 9.50 apresenta o resumo dos resultados dos ensaios de laboratório realizados com o material do subleito e dos materiais da faixa de domínio no local.

A Figura 9.95 apresenta um gráfico comparativo entre o valor de módulo medido em laboratório e os valores de módulo previstos pelos modelos da literatura, para as condições de umidade ótima e peso específico aparente seco máximo relativos à energia intermediária de compactação. Não se verificou convergência com nenhum dos modelos apresentados. 
A Figura 9.96 apresenta um gráfico comparativo entre o valor de módulo in situ medido com $\angle W D$ e os valores de módulo previstos pelos modelos da literatura, para as condições de umidade e peso específico aparente seco verificadas em campo no momento da abertura do poço de inspeção. Verificou-se uma convergência maior para os modelos de Berg et al. (1996) e Malla \& Josh - solos finos (2006).

A Figura 9.97 apresenta um gráfico comparativo entre o valor mínimo de módulo in situ medido com FWD (retroanálise) e os valores de módulo previstos pelos modelos da literatura, para as condições de saturação próxima da saturação máxima (adotouse $\mathrm{S}$ próximo a $98 \%$ ). Verificou-se uma razoabilidade maior dos modelos de Pezo \& Hudson - solos coesivos (1994) e AASHTO/2002.

A Figura 9.98 apresenta os gráficos da série histórica dos indicadores estruturais do pavimento (deflexão máxima, raio de curvatura, e deflexão a $120 \mathrm{~mm}$ do ponto de aplicação de carga) no segmento que contempla o local em estudo.

A Figura 9.99 apresenta os gráficos da série histórica dos valores de módulo de resiliência retroanalisado $(F W D)$ e Quociente de Irregularidade $(Q I)$ no segmento que contempla o local em estudo.

A Figura 9.100 apresenta os dados estatísticos (valores máximos, mínimos, média e média mais ou menos desvio padrão), bem como boxplot dos indicadores estruturais do pavimento no segmento homogêneo determinado para o ponto em estudo. 


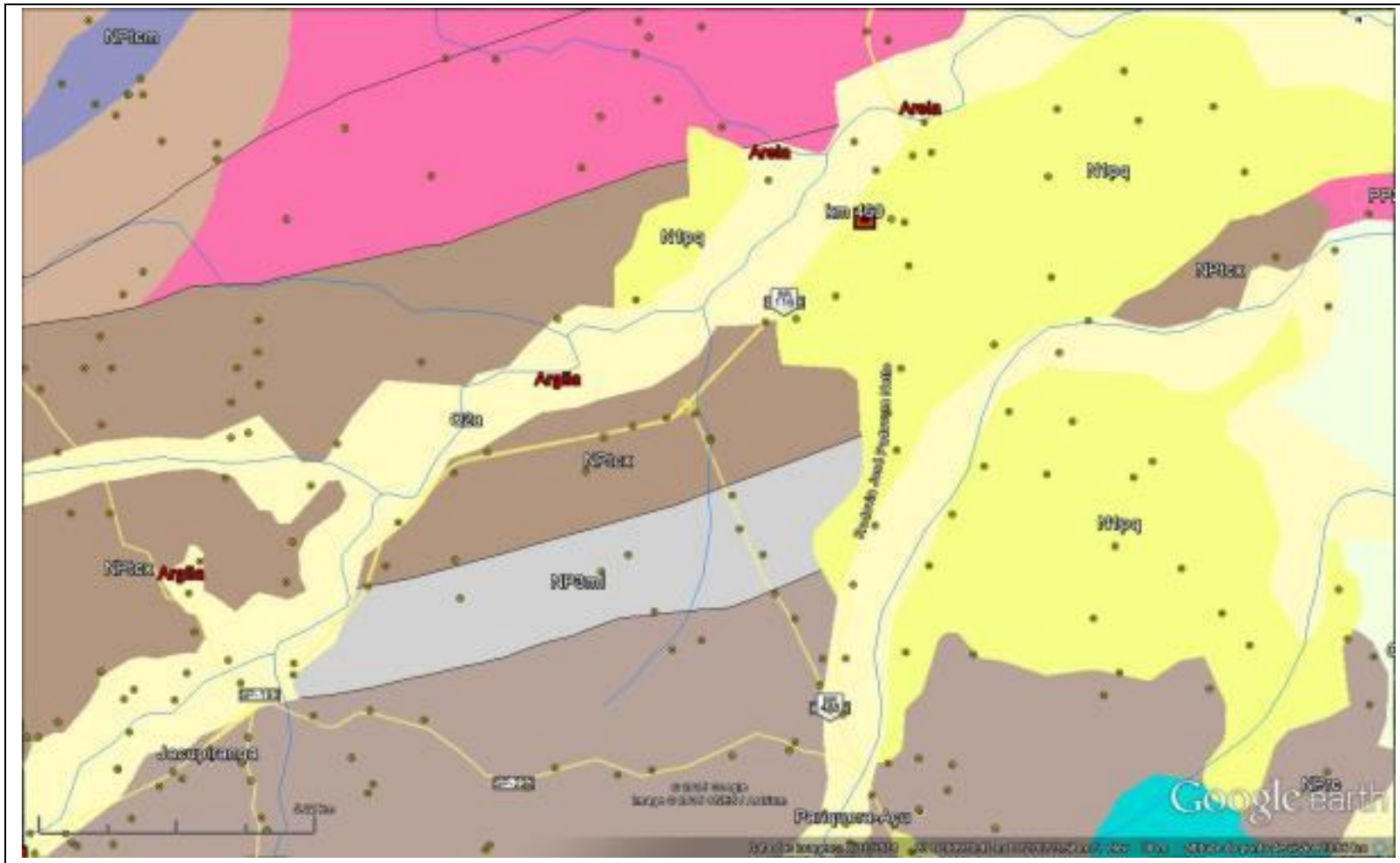

\section{LEGENDA:}

Pariquera-Açu: Depósitos de areia, Conglomerado, Depósitos de argila, Lamito

Depósitos aluvionares: Depósitos de areia, Depósitos de cascalho

Turvo-Cajati, unidade de xistos: Metasiltito, Metaritmito, Anfibólio xisto, Filito, Xisto

Rio das Cobras: Muscovita biotita xisto, Metasiltito, Xisto, Metarenito

Turvo-Cajati, unidade paragnáissica: Paragnaisse, Anfibólio xisto, Biotita gnaisse

Atuba, unidade de gnaisses bandados: Gnaisse, Biotita gnaisse, Hornblenda gnaisse, Granito gnaisse

Granito Rio Guaraú: Sienogranito, Álcali-feldspato granito

Batólito Paranaguá, unidade de gnaisses e migmatitos: Cataclasito, Milonito, Biotita gnaisse, Migmatito, Gnaisse

Rochas miloníticas: Protomilonito, Milonito, Ultramilonito

Intrusivas alcalinas: Peridotito, Piroxenito

Afloramentos

Figura 9.91: Mapa Geológico do local sondado - km 460 (Pista Norte)

Fonte: Geobank/Google Earth® 
Tabela 9.46: histórico de intervenções informado - km 460 (pista norte)

\begin{tabular}{ccccccc}
\hline $\mathbf{k m}$ & $\begin{array}{c}\mathbf{k m} \\
\text { inicial }\end{array}$ & $\begin{array}{c}\mathbf{k m} \\
\text { final }\end{array}$ & Solução Aplicada & $\begin{array}{c}\text { Larg. } \\
\mathbf{( m )}\end{array}$ & $\begin{array}{c}\text { Esp. } \\
\mathbf{( c m})\end{array}$ & $\begin{array}{c}\text { Data da } \\
\text { Interv. }\end{array}$ \\
\hline \multirow{4}{*}{460} & 459,987 & 460,006 & FRESAGEM ESTRUTURAL & 1,00 & 6,00 & $01 / 12 / 2009$ \\
\cline { 2 - 7 } & 457,625 & 460,300 & MICROREVESTIMENTO & 4,40 & 1,20 & $19 / 01 / 2010$ \\
\cline { 2 - 7 } & 459,945 & 460,005 & FRESAGEM FUNCIONAL & 3,90 & 5,00 & $18 / 08 / 2011$ \\
\cline { 2 - 7 } & 459,416 & 461,708 & MICROREVESTIMENTO & 4,20 & 1,20 & $29 / 09 / 2011$ \\
\hline & 459,857 & 460,112 & MICROREVESTIMENTO & 4,20 & 1,20 & $08 / 05 / 2013$ \\
\hline
\end{tabular}

Tabela 9.47: Estrutura do pavimento da faixa externa - km 460 (pista norte)

\begin{tabular}{ccccc}
\hline \multirow{2}{*}{$\mathbf{k m}$} & Pista & Camada & $\begin{array}{c}\text { Espessura } \\
(\mathbf{c m})\end{array}$ & Camada \\
\hline \multirow{3}{*}{460} & \multirow{2}{*}{ Norte } & 1 & 19,0 & $\mathrm{CA}$ \\
\cline { 3 - 5 } & & 2 & 40,0 & $\mathrm{BGS}$ \\
\cline { 3 - 5 } & 3 & - & $\mathrm{SL}$ \\
\hline
\end{tabular}

Tabela 9.48: Estatística dos resultados do ensaio com $\angle W D$

\begin{tabular}{|c|c|c|c|c|c|c|c|c|c|c|c|}
\hline \multirow{2}{*}{ km } & \multirow{2}{*}{ Material } & \multicolumn{5}{|c|}{ Leituras $D_{0, \text { LWD }}\left(10^{-2} \mathrm{~mm}\right)$} & \multicolumn{5}{|c|}{$E_{0, \text { calc }}\left(\mathrm{kfg} / \mathrm{cm}^{2}\right)$} \\
\hline & & Mín. & Máx. & Média & Desvio & CV(\%) & Mín. & Máx. & Média & Desvio & CV(\%) \\
\hline 460 & BGS & 27 & 35 & 31 & 3 & 10 & 648 & 840 & 747 & 78 & 10 \\
\hline 460 & SL & 60 & 72 & 65 & 4 & 6 & 315 & 378 & 348 & 22 & 6 \\
\hline
\end{tabular}

Tabela 9.49: Estatística dos resultados de determinação do módulo da camada de BGS

\begin{tabular}{|c|c|c|c|c|c|c|}
\hline \multirow{2}{*}{ km } & \multirow{2}{*}{ Material } & \multicolumn{5}{|c|}{$E_{\text {sb,retro }}\left(\mathrm{kfg} / \mathrm{cm}^{2}\right)$} \\
\hline & & Mín. & Máx. & Média & Desvio & CV(\%) \\
\hline 460 & BGS & 1.001 & 1.558 & 1.282 & 228 & 18 \\
\hline
\end{tabular}

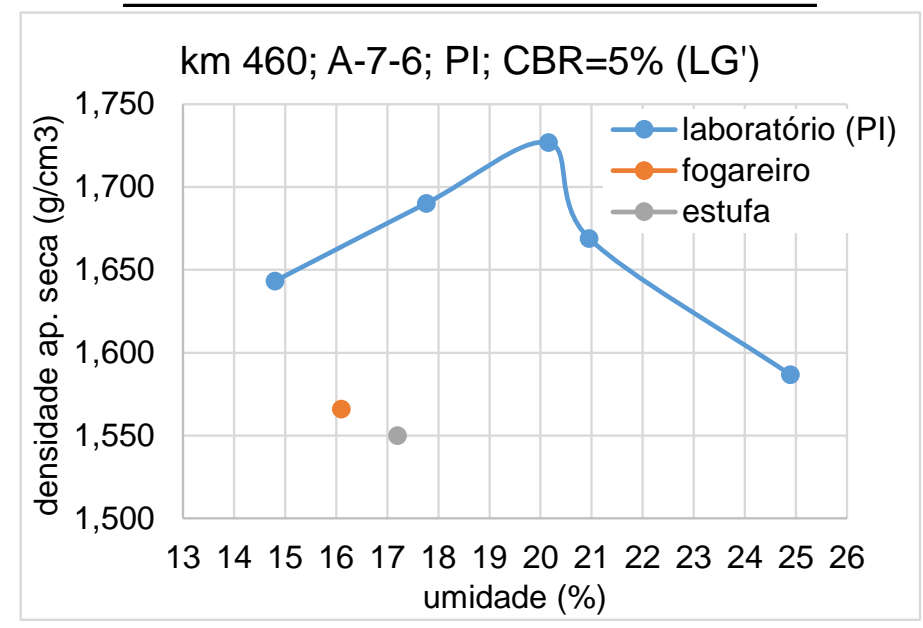

Figura 9.92: Comparativo entre pesos específicos aparentes secos - laboratório x campo (subleito, $\mathrm{km} \mathrm{460,} \mathrm{norte)}$ 


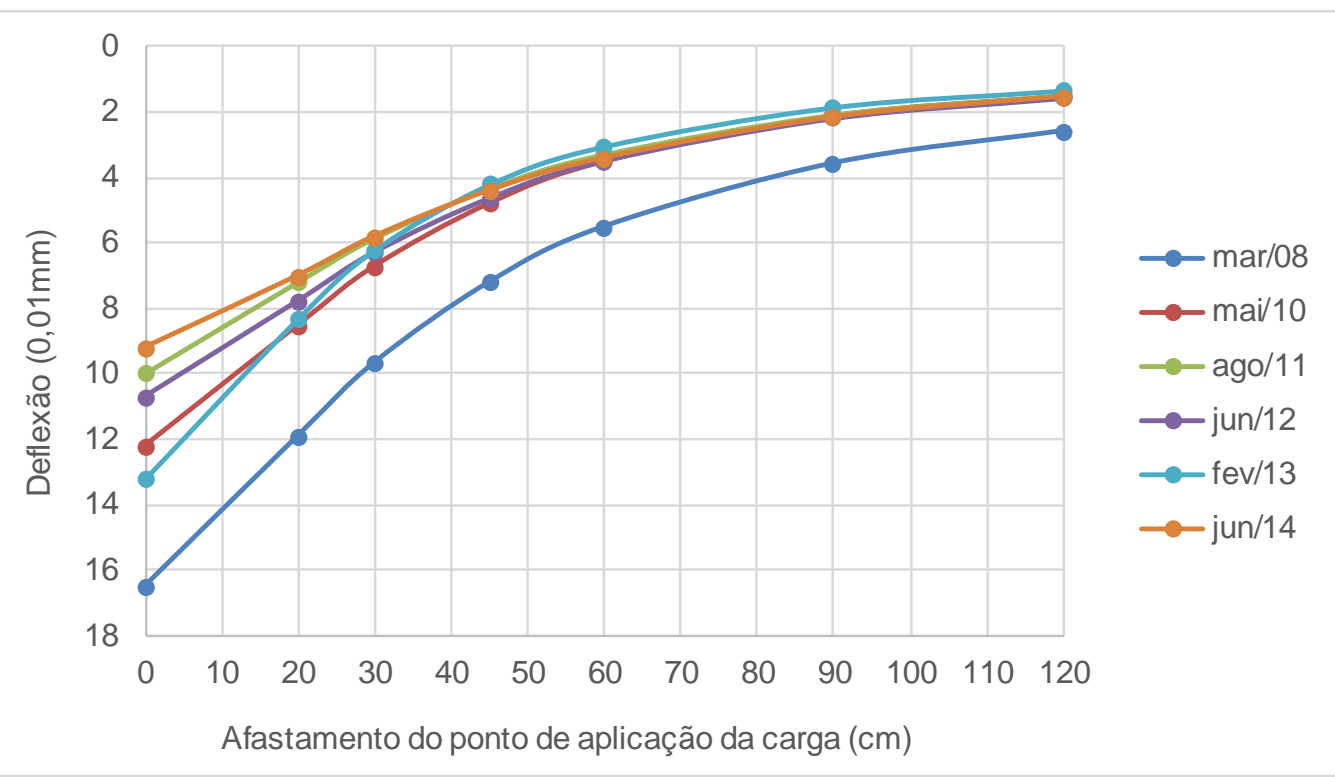

\begin{tabular}{|c|c|c|c|c|c|c|c|}
\hline $\begin{array}{c}\text { Mês/ano } \\
\text { Levantamento }\end{array}$ & $\operatorname{Tar}\left({ }^{\circ} \mathrm{C}\right)$ & $\begin{array}{l}\text { Tpav } \\
\left({ }^{\circ} \mathrm{C}\right)\end{array}$ & $\operatorname{Er} 1\left(\mathrm{kgf} / \mathrm{cm}^{2}\right)$ & $\mathrm{Eb}\left(\mathrm{kgf} / \mathrm{cm}^{2}\right)$ & Esl $\left(\mathrm{kgf} / \mathrm{cm}^{2}\right)$ & $\begin{array}{l}\text { Esl x 0,33 } \\
\left(\mathrm{kgf} / \mathrm{cm}^{2}\right)\end{array}$ & $\begin{array}{c}\text { Esl } \\
\text { (AASHTO/ } \\
93 \text { ) }\end{array}$ \\
\hline $\begin{array}{c}\text { Espessuras } \\
(\mathrm{cm})\end{array}$ & & & 19,0 & 40,0 & - & - & - \\
\hline Materiais & & & CA & BGS & SL & SL & SL \\
\hline mar/08 & \multicolumn{6}{|c|}{ * Provável estrutura antiga de pavimento flexível } & 1.382 \\
\hline $\mathrm{mai} / 10$ & 20,0 & 27,0 & 41.000 & 5.000 & 6.200 & 2.046 & 1.874 \\
\hline ago/11 & 16,0 & 21,0 & 53.000 & 6.200 & 6.000 & 1.980 & 1.911 \\
\hline jun/12 & 18,0 & 20,0 & 50.000 & 5.500 & 5.800 & 1.914 & 1.800 \\
\hline $\mathrm{fev} / 13$ & 35,0 & 42,0 & 27.000 & 5.500 & 6.800 & 2.244 & 2.112 \\
\hline jun/14 & 17,0 & 20,0 & 75.000 & 6.000 & 6.200 & 2.046 & 1.850 \\
\hline
\end{tabular}

Figura 9.93: Retroanálise das bacias de deflexões (série histórica) - km 460 (pista norte)
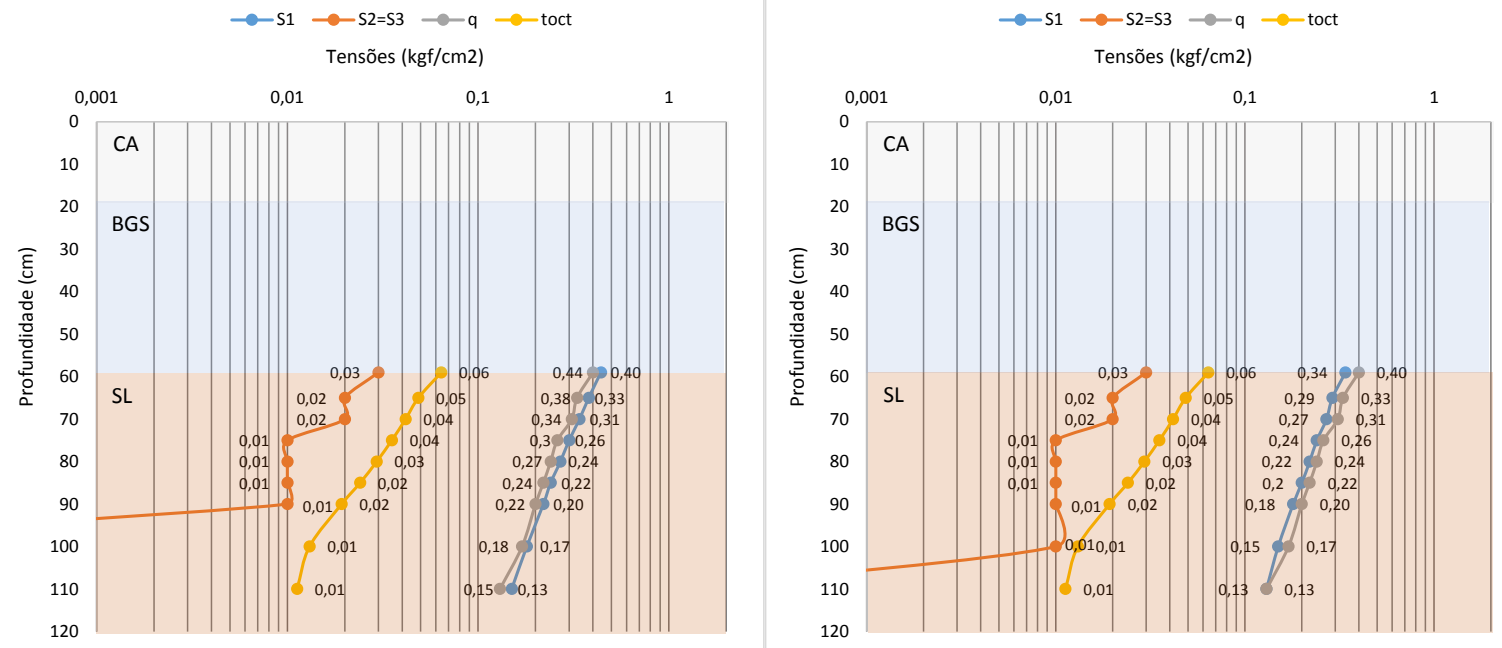

Figura 9.94: Tensões no subleito calculadas para (a) 2013 e (b) 2014 
Tabela 9.50: Resumo dos ensaios realizados com material próximo ao km 460

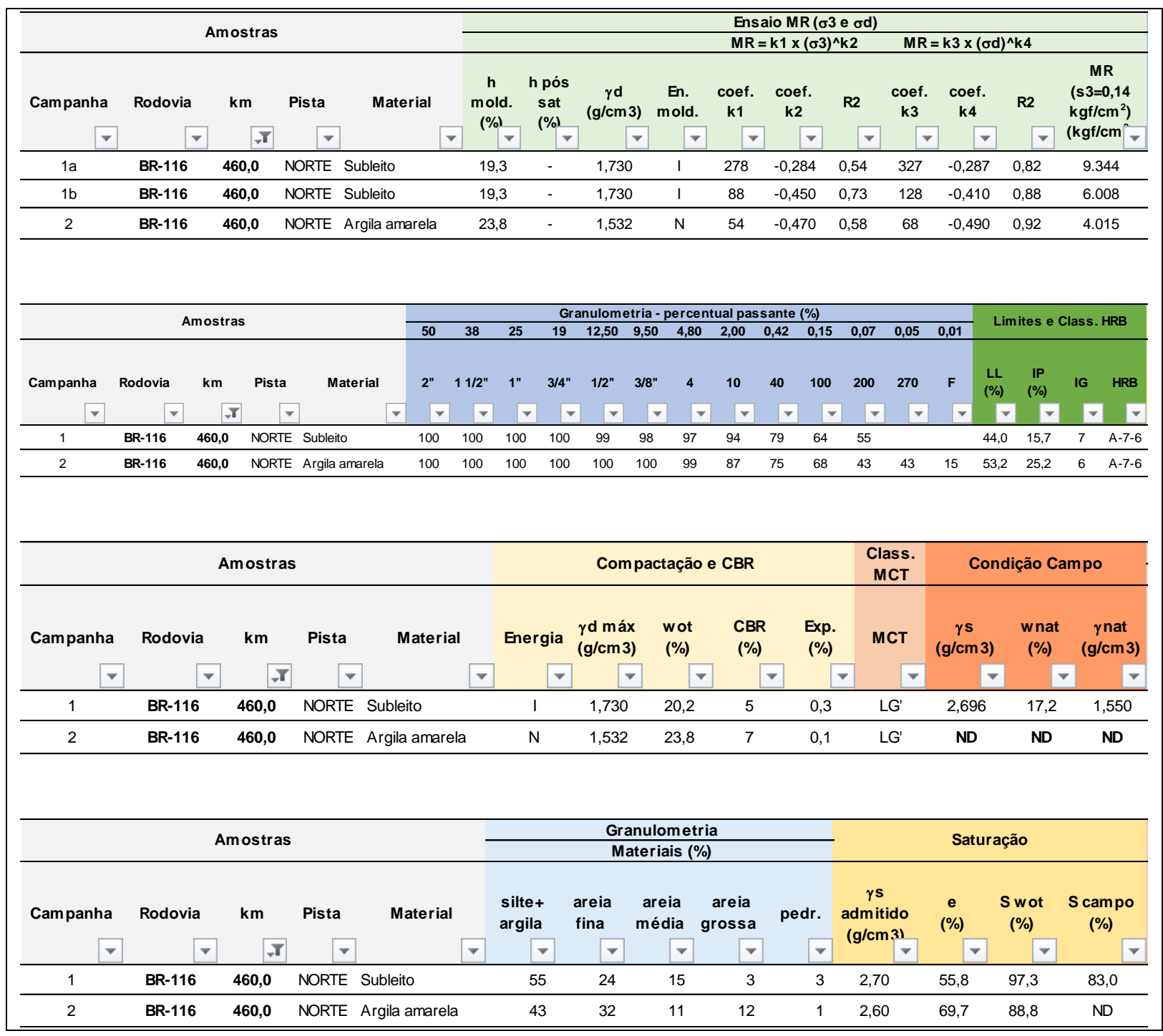




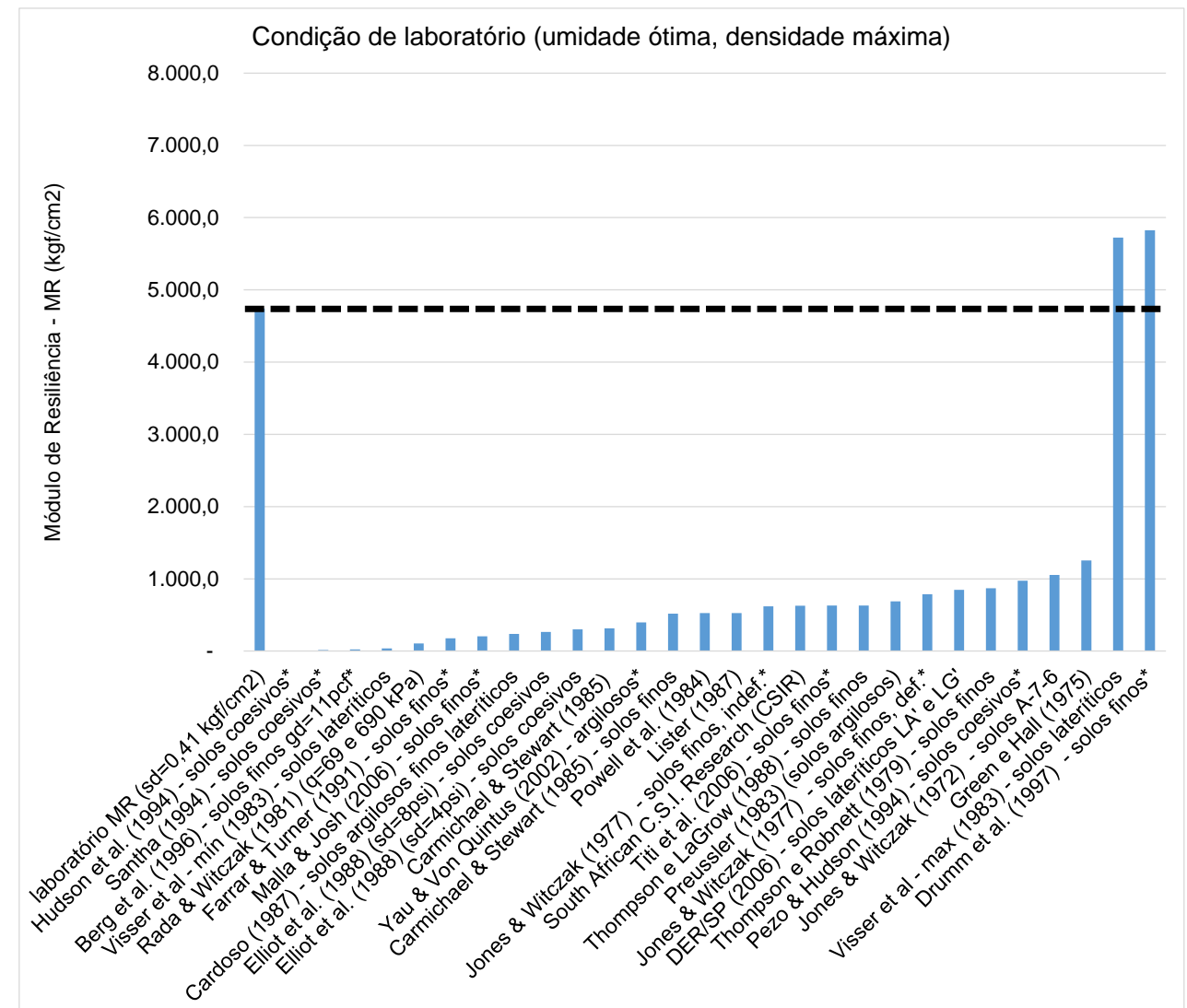

Figura 9.95: Comparativo entre $M R$ de laboratório e modelos de previsão de $M R$ (condição de umidade ótima)

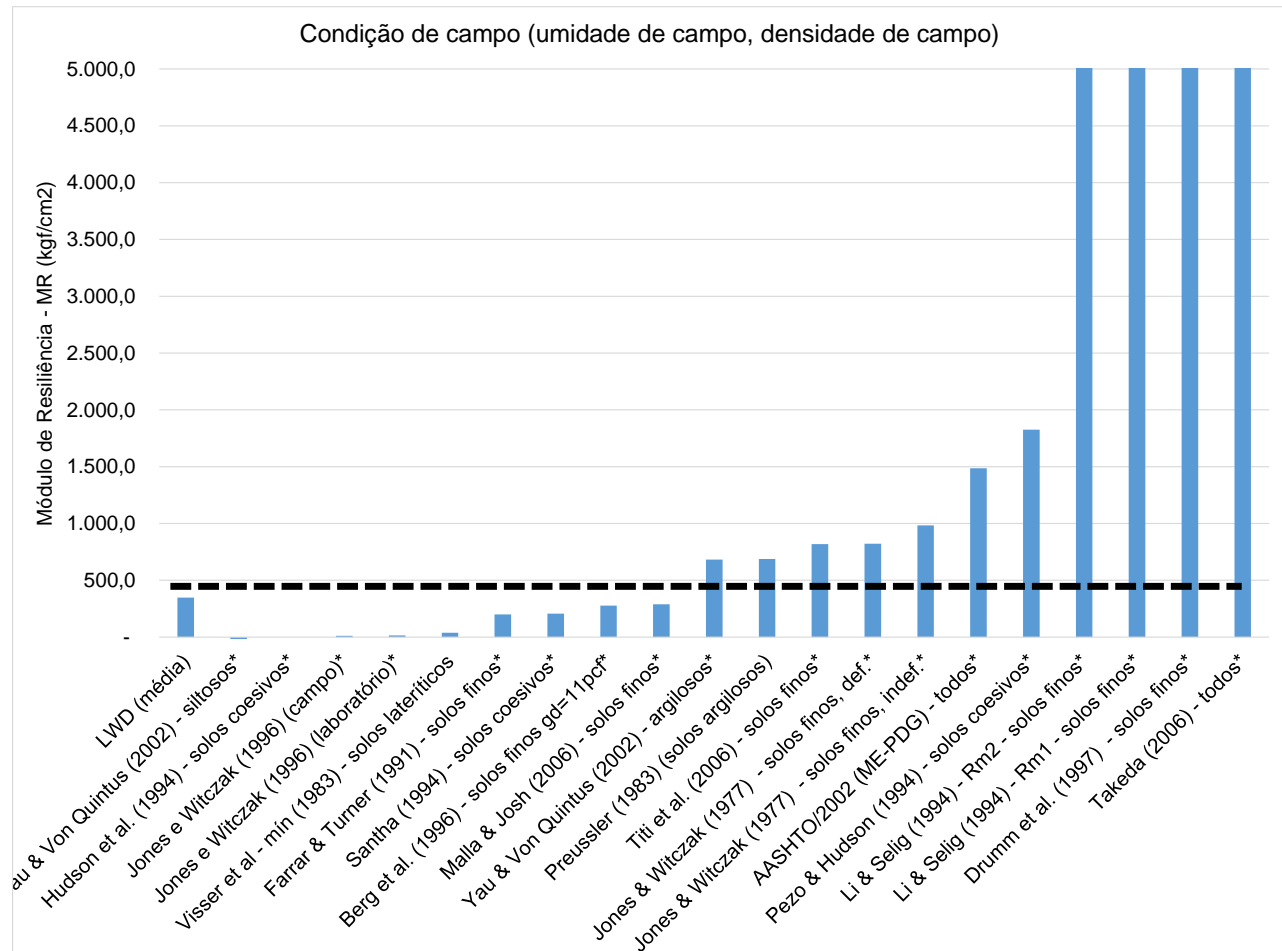

Figura 9.96: Comparativo entre $M R$ in situ $(L W D)$ e modelos de previsão de $M R$ (condição de umidade verificada no campo) 


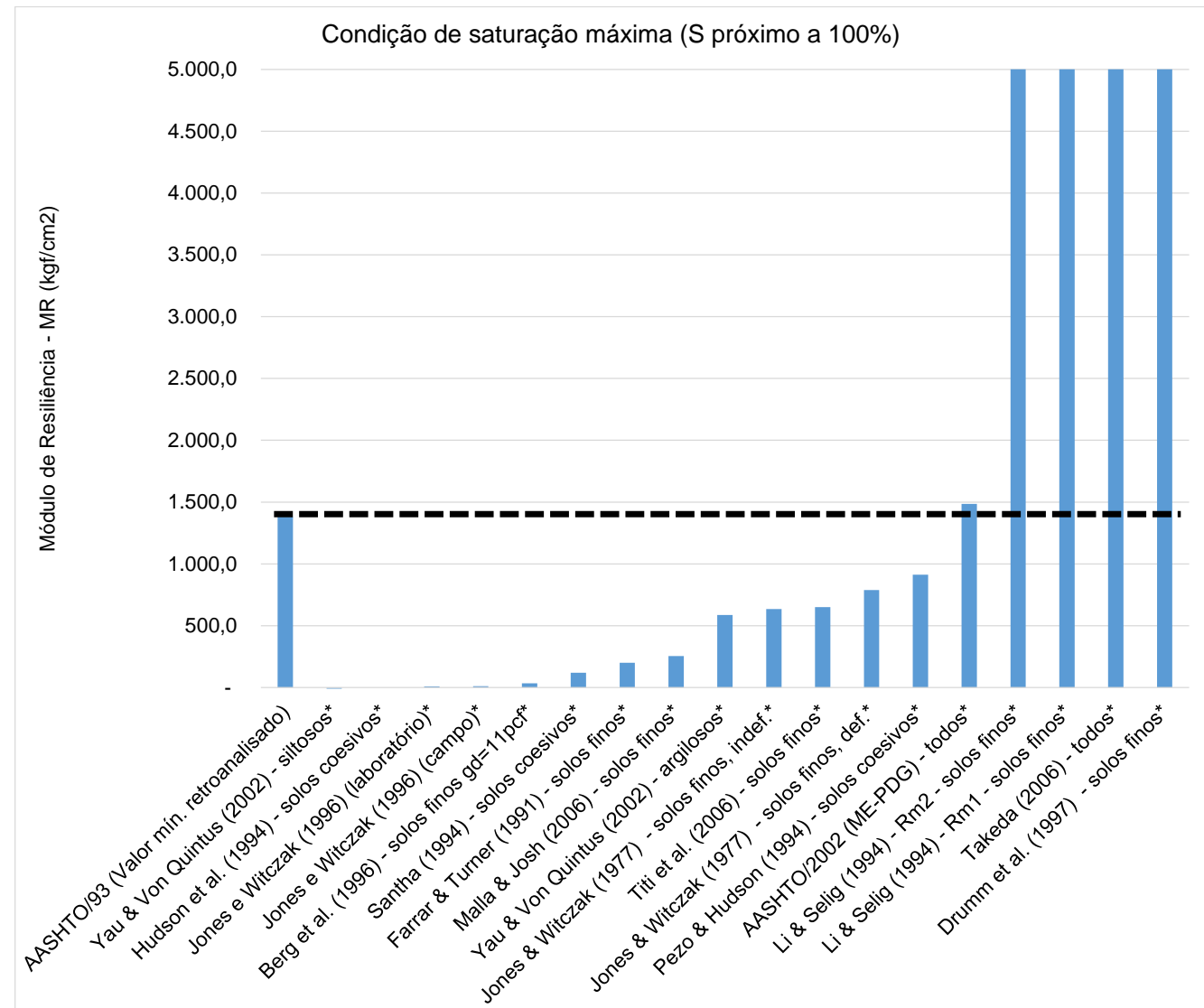

Figura 9.97: Comparativo entre $M R$ in situ mínimo verificado $(F W D)$ e modelos de previsão de $M R$ (condição de saturação próxima a 100\%) 

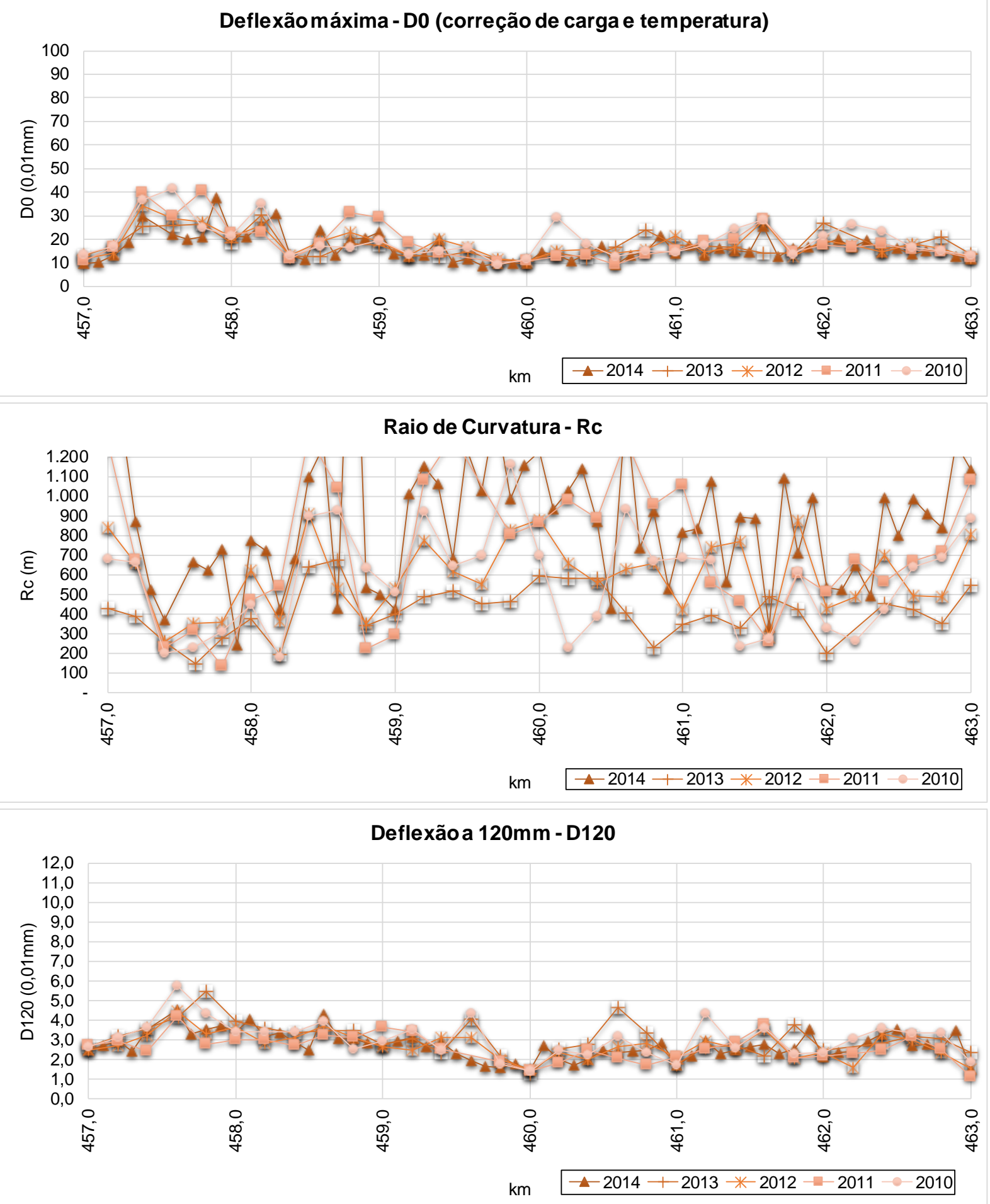

Figura 9.98: Gráficos de série histórica dos indicadores estruturais do pavimento no segmento do km 460 (pista norte) 


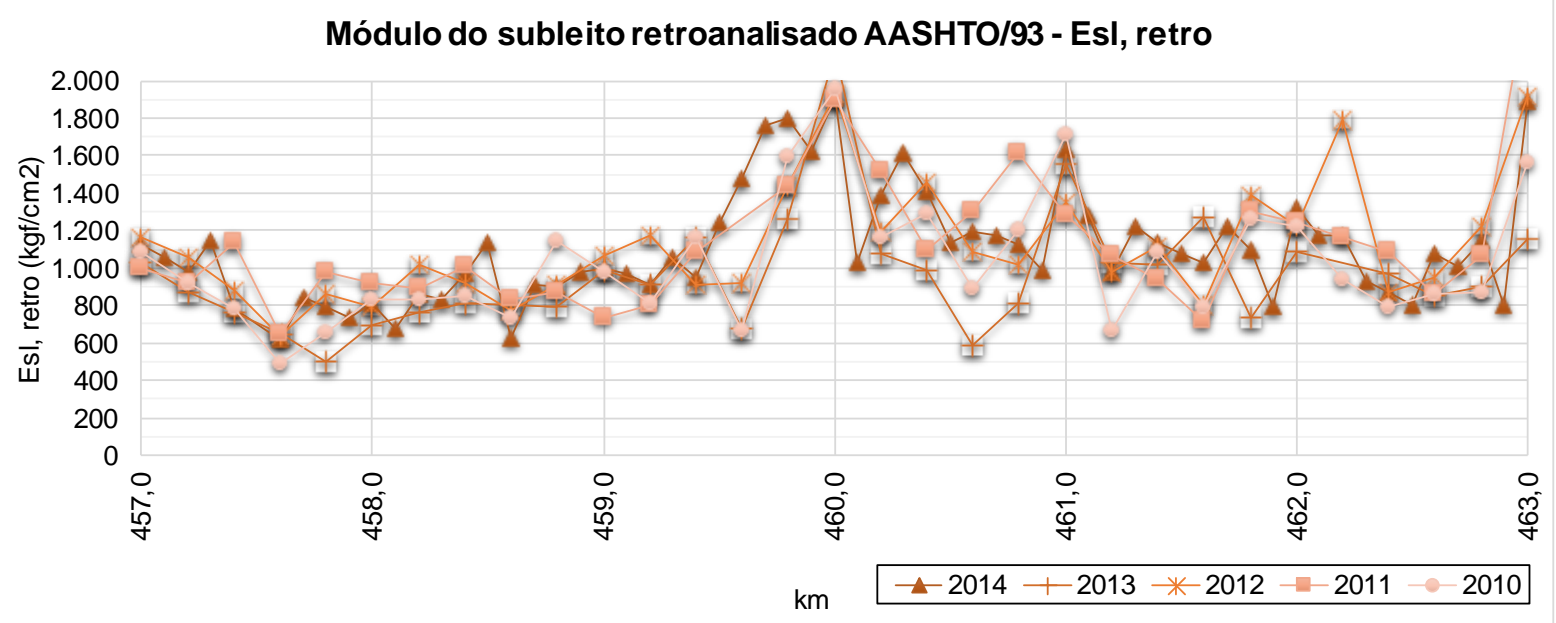

Figura 9.99: Gráficos da série histórica dos dados de módulo de resiliência retroanalisado $(F W D)$ do pavimento no segmento do $\mathrm{km} 460$ (pista norte) 
$459,8 \quad 460,2 \quad$ DECRESCENTE
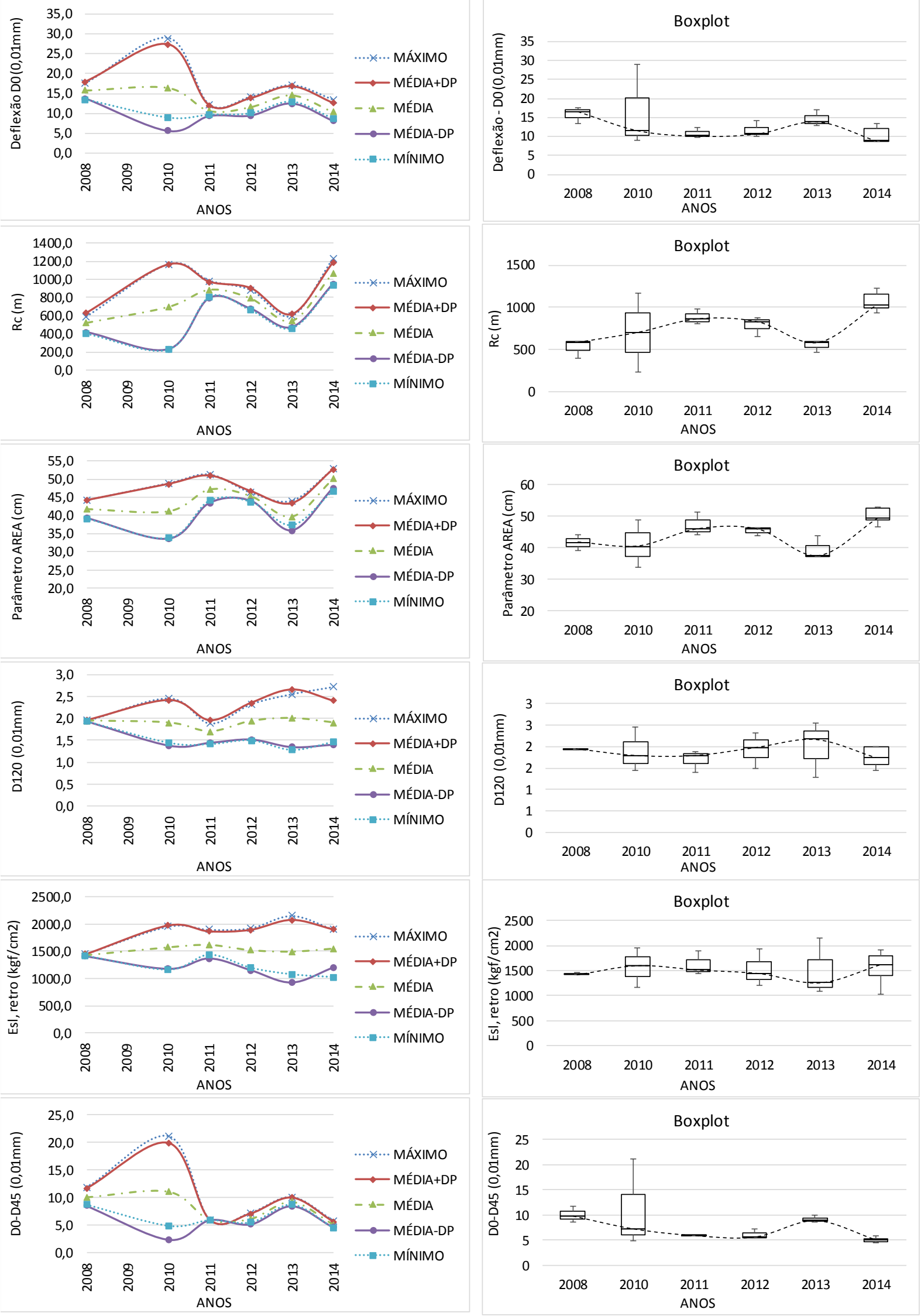

Figura 9.100: Estatísticas dos Parâmetros do pavimento (S. Homogêneo do km 402) 


\subsection{Poço de inspeção do km 482 (Pista Sul)}

A Figura 9.101 a seguir ilustra a localização do poço de inspeção do km 482 (pista sul) bem como o mapeamento geológico do local. Verifica-se uma região de depósito de areia e cascalho.

A Tabela 9.51 apresenta o registro histórico de intervenções do pavimento.

A Tabela 9.52 apresenta a estrutura do pavimento identificada na ocasião da abertura do poço de inspeção. Trata-se de pavimento composto basicamente por materiais asfálticos (revestimento e base).

A Tabela 9.53 apresenta os resultados estatísticos obtidos a partir do ensaio de LWD sobre as camadas de subleito. Enquanto a Figura 9.102 apresenta o gráfico comparativo dos pesos específicos aparentes secos e umidades obtidos em campo e em laboratório (curva de compactação de laboratório versus ensaios de umidade e peso específico aparente seco in situ). Verifica-se que o material no campo está com peso específico aparente seco sensivelmente superior ao peso específico aparente seco máximo relativa à energia intermediária e teor de umidade sensivelmente superior à condição de umidade ótima da mesma energia. Infere-se que o material tenha sido compactado originalmente na energia modificada e que se encontrava com grau de saturação elevado na ocasião da abertura do poço.

A Figura 9.103 apresenta o resultado da retroanálise da série histórica de deflexões do pavimento em estudo e a Figura 9.104 apresenta os gráficos de tensões calculadas no subleito, ilustrando o comportamento do subleito registrado através dos ensaios com FWD.

A Tabela 9.54 apresenta o resumo dos resultados dos ensaios de laboratório realizados com o material do subleito e dos materiais da faixa de domínio no local.

A Figura 9.105 apresenta um gráfico contendo os valores de módulo previstos pelos modelos da literatura para a condição de umidade ótima (energia intermediária). Como não foram realizados os ensaios de módulo de laboratório, não foi possível realizar comparações.

A Figura 9.106 apresenta um gráfico comparativo entre o valor de módulo in situ medido com $L W D$ e os valores de módulo previstos pelos modelos da literatura, para 
as condições de umidade e peso específico aparente seco verificadas em campo no momento da abertura do poço de inspeção. Verificou-se uma convergência maior para os modelos de Malla \& Joshi (2006).

A Figura 9.107 apresenta um gráfico comparativo entre o valor mínimo de módulo in situ medido com FWD (retroanálise) e os valores de módulo previstos pelos modelos da literatura, para as condições de saturação próxima da saturação máxima (adotouse S próximo a 98\%). Verificou-se uma razoabilidade maior dos modelos de Malla \& Joshi (2006).

A Figura 9.108 apresenta os gráficos da série histórica dos indicadores estruturais do pavimento (deflexão máxima, raio de curvatura, e deflexão a $120 \mathrm{~mm}$ do ponto de aplicação de carga) no segmento que contempla o local em estudo.

A Figura 9.109 apresenta os gráficos da série histórica dos valores de módulo de resiliência retroanalisado $(F W D)$ e Quociente de Irregularidade ( $Q$ I) no segmento que contempla o local em estudo.

A Figura 9.110 apresenta os dados estatísticos (valores máximos, mínimos, média e média mais ou menos desvio padrão), bem como boxplot dos indicadores estruturais do pavimento no segmento homogêneo determinado para o ponto em estudo. 


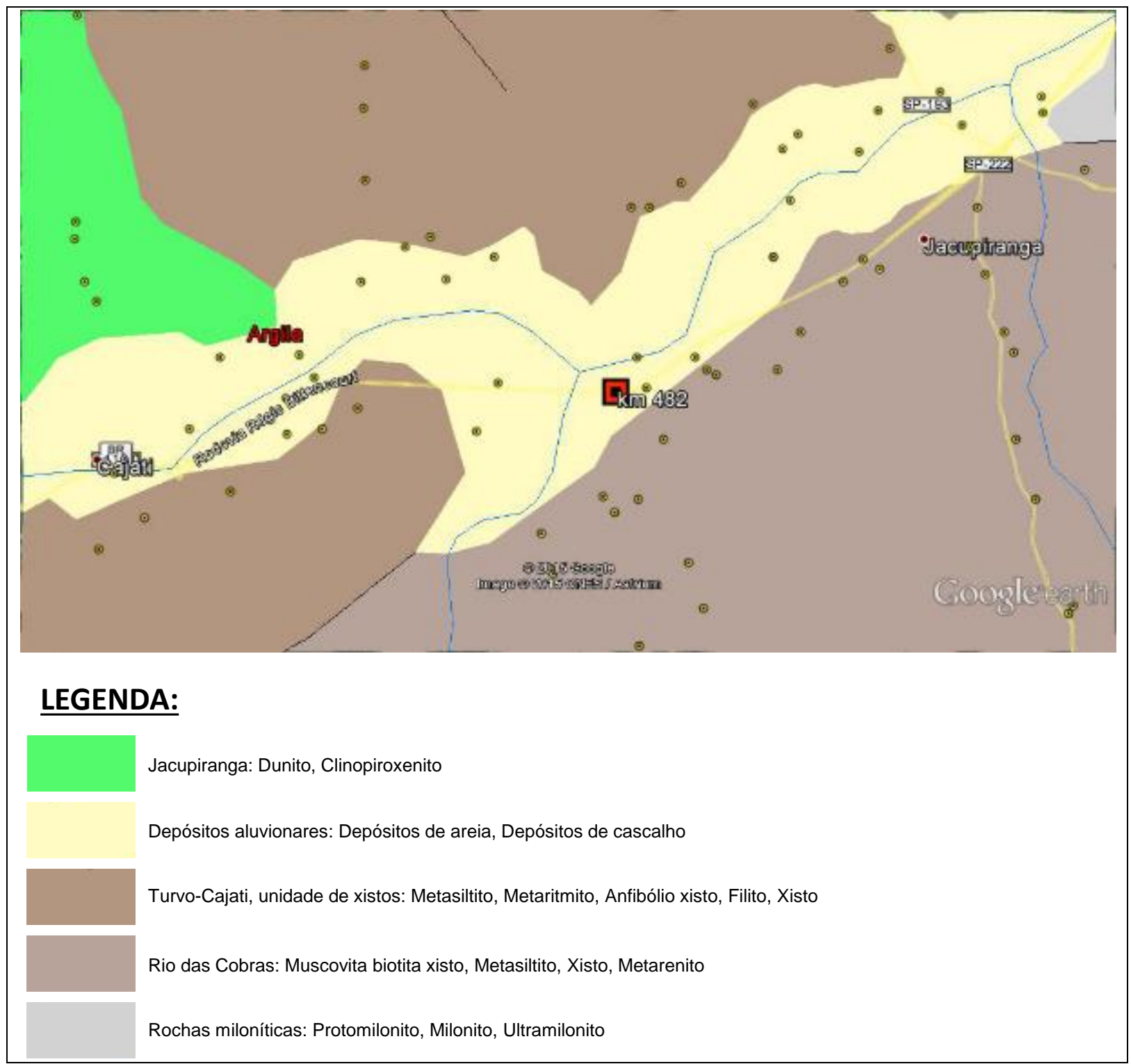

Figura 9.101: Mapa Geológico do local sondado - km 482 (Pista Sul) Fonte: Geobank/Google Earth ${ }^{\circledR}$

Tabela 9.51: histórico de intervenções informado - km 482 (pista sul)

\begin{tabular}{ccccccc}
\hline $\mathbf{k m}$ & $\begin{array}{c}\mathbf{k m} \\
\text { inicial }\end{array}$ & $\begin{array}{c}\mathbf{k m} \\
\text { final }\end{array}$ & Solução Aplicada & $\begin{array}{c}\text { Larg. } \\
(\mathbf{m})\end{array}$ & $\begin{array}{c}\text { Esp. } \\
(\mathbf{c m})\end{array}$ & $\begin{array}{c}\text { Data da } \\
\text { Intervenção }\end{array}$ \\
\hline 482,000 & 481,000 & 482,569 & MICROREVESTIMENTO & 4,30 & 1,20 & $18 / 08 / 2012$ \\
\hline
\end{tabular}


Tabela 9.52: Estrutura do pavimento da faixa externa - km 482 (pista sul)

\begin{tabular}{|c|c|c|c|c|}
\hline km & Pista & Camada & $\begin{array}{l}\text { Espessura } \\
\text { (cm) }\end{array}$ & Camada \\
\hline \multirow{3}{*}{482} & \multirow{3}{*}{ Sul } & 1 & 13,0 & CA \\
\hline & & 2 & 52,0 & BASE BETUMINOSA \\
\hline & & 3 & - & SL \\
\hline
\end{tabular}

Tabela 9.53: Estatística dos resultados do ensaio com $L W D$

\begin{tabular}{|c|c|c|c|c|c|c|c|c|c|c|c|}
\hline \multicolumn{12}{|c|}{ Re sumo } \\
\hline \multirow{2}{*}{$\mathrm{km}$} & \multirow{2}{*}{ Material } & \multicolumn{5}{|c|}{ Leituras $\mathrm{D}_{0, \text { Lwo }}\left(10^{-2} \mathrm{~mm}\right)$} & \multicolumn{5}{|c|}{ E0, os:o $\left(\mathrm{kfg} / \mathrm{cm}^{2}\right)$} \\
\hline & & Mín. & Máx. & Média & Desvio & $\mathrm{CV}(\%)$ & Mín. & Máx. & Média & Desvio & $\mathrm{CV}(\%)$ \\
\hline 482 & SL & 41 & 58 & 50 & 5 & 10 & 404 & 550 & 454 & 49 & 11 \\
\hline
\end{tabular}

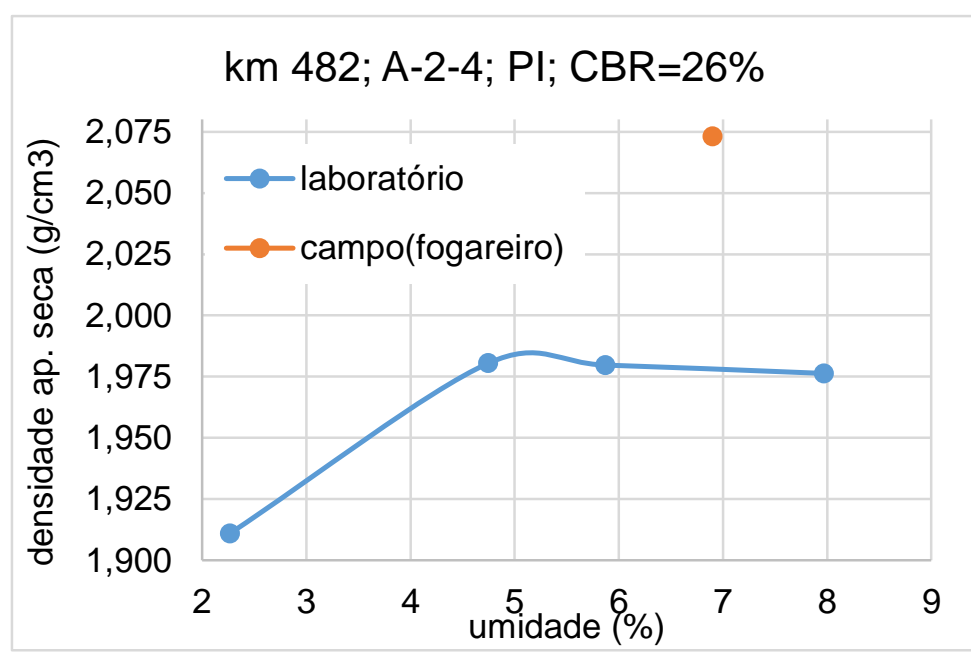

Figura 9.102: Comparativo entre pesos específicos aparentes secos - laboratório x campo (subleito, $\mathrm{km} \mathrm{482,} \mathrm{sul)}$ 


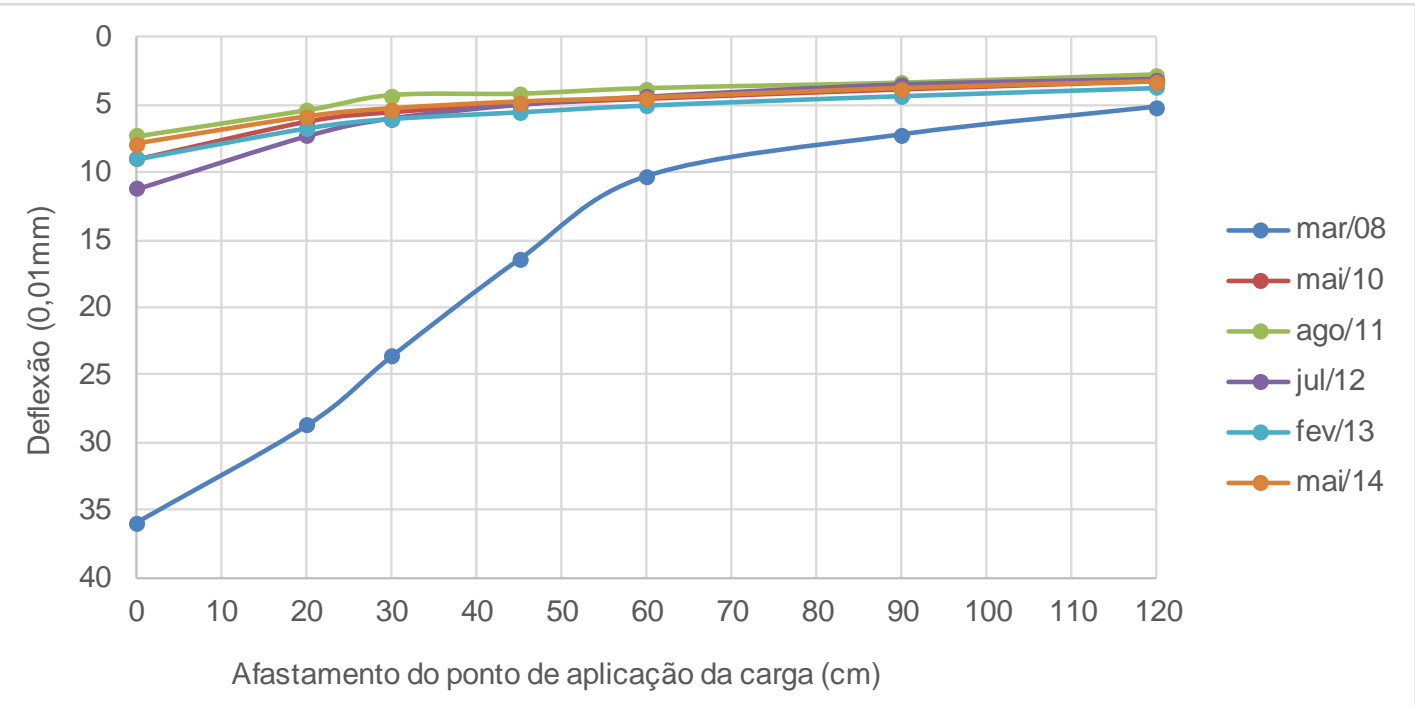

\begin{tabular}{|c|c|c|c|c|c|c|c|}
\hline $\begin{array}{c}\text { Mês/ano } \\
\text { Levantamento }\end{array}$ & $\operatorname{Tar}\left({ }^{\circ} \mathrm{C}\right)$ & $\begin{array}{l}\text { Tpav } \\
\left({ }^{\circ} \mathrm{C}\right)\end{array}$ & $\operatorname{Er} 1\left(\mathrm{kgf} / \mathrm{cm}^{2}\right)$ & $\mathrm{Eb}\left(\mathrm{kgf} / \mathrm{cm}^{2}\right)$ & Esl $\left(\mathrm{kgf} / \mathrm{cm}^{2}\right)$ & $\begin{array}{l}\text { Eslx0,33 } \\
\left(\mathrm{kgf} / \mathrm{cm}^{2}\right)\end{array}$ & $\begin{array}{c}\text { EsI } \\
\text { (AASHTO } \\
\text { /93) }\end{array}$ \\
\hline $\begin{array}{l}\text { Espessuras } \\
\text { (cm) }\end{array}$ & & & 13,0 & 52,0 & - & - & \\
\hline Materiais & & & CA & BASE BETUMINOSA & SL & SL & \\
\hline $\mathrm{mar} / 08$ & \multicolumn{6}{|c|}{ * Provável estrutura antiga de pavimento flexível } & 525 \\
\hline $\mathrm{mai} / 10$ & 32,0 & 35,0 & 32.700 & 34.000 & 2.850 & 941 & 879 \\
\hline ago/11 & 23,0 & 29,0 & 41.200 & 46.800 & 3.200 & 1.056 & 950 \\
\hline $\mathrm{jul} / 12$ & 21,0 & 31,0 & 28.300 & 18.300 & 3.450 & 1.139 & 886 \\
\hline $\mathrm{fev} / 13$ & 30,0 & 34,0 & 44.500 & 37.000 & 2.450 & 809 & 691 \\
\hline $\mathrm{mai} / 14$ & 22,0 & 25,0 & 46.000 & 46.000 & 2.640 & 871 & 800 \\
\hline
\end{tabular}

Figura 9.103: Retroanálise das bacias de deflexões (série histórica) - km 482 (pista sul)

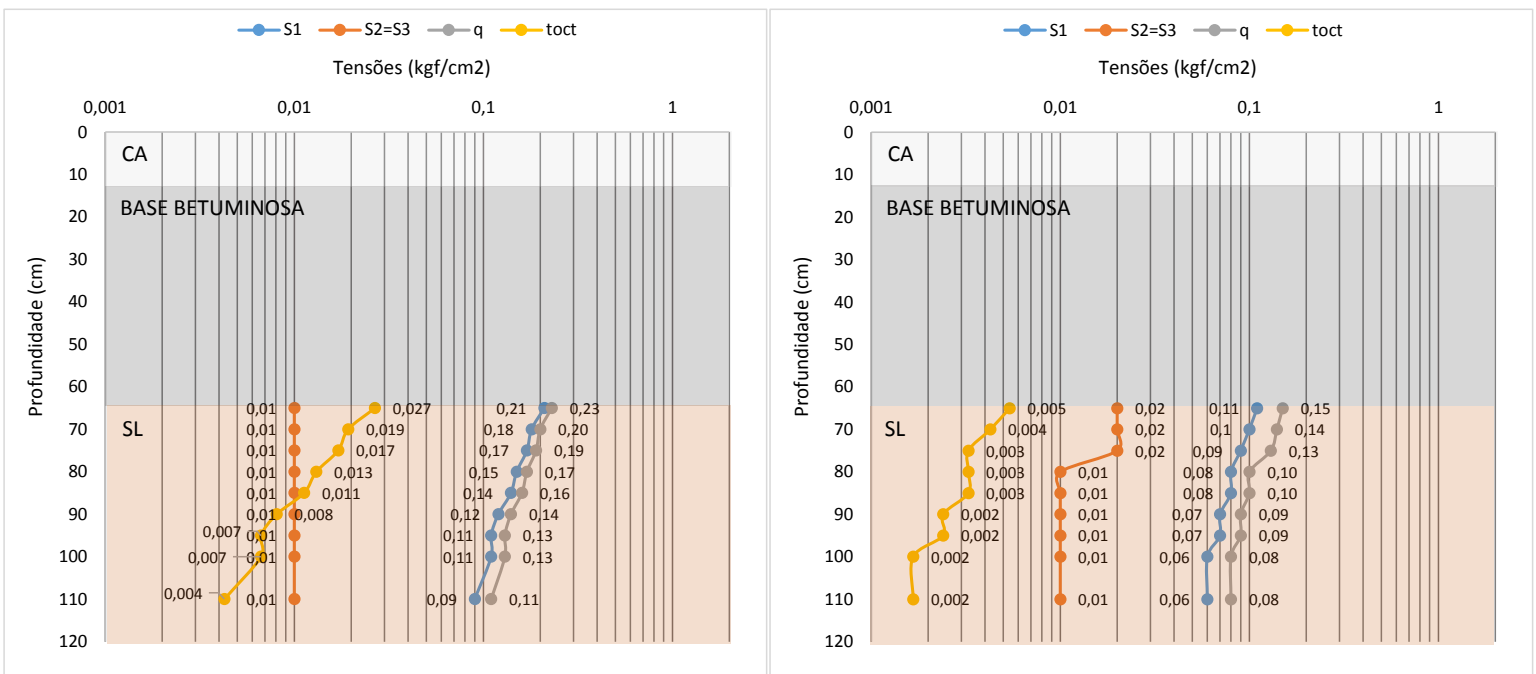

Figura 9.104: Tensões no subleito calculadas para (a) 2012 e (b) 2014 
Tabela 9.54: Resumo dos ensaios realizados com material próximo ao km 482

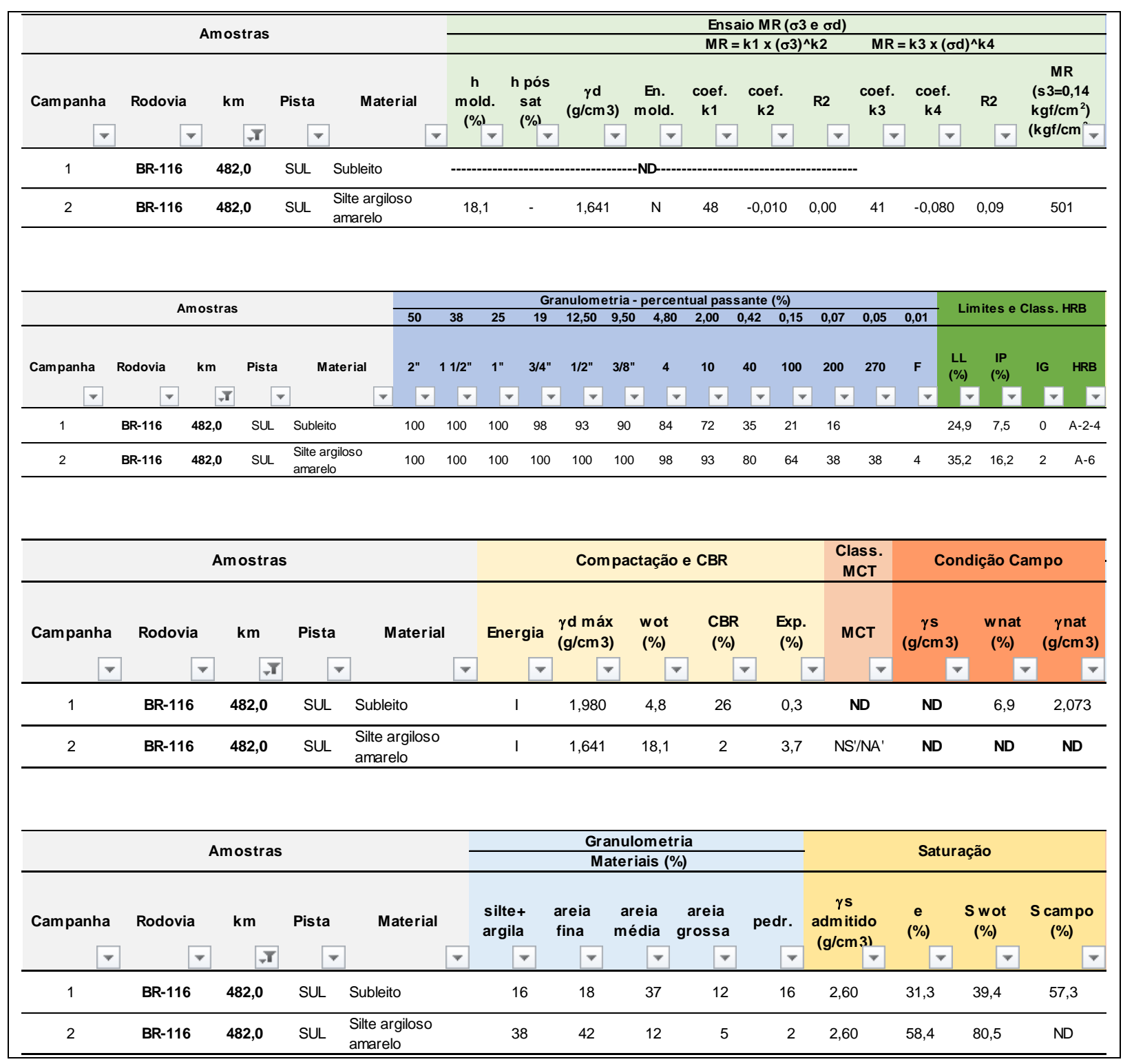




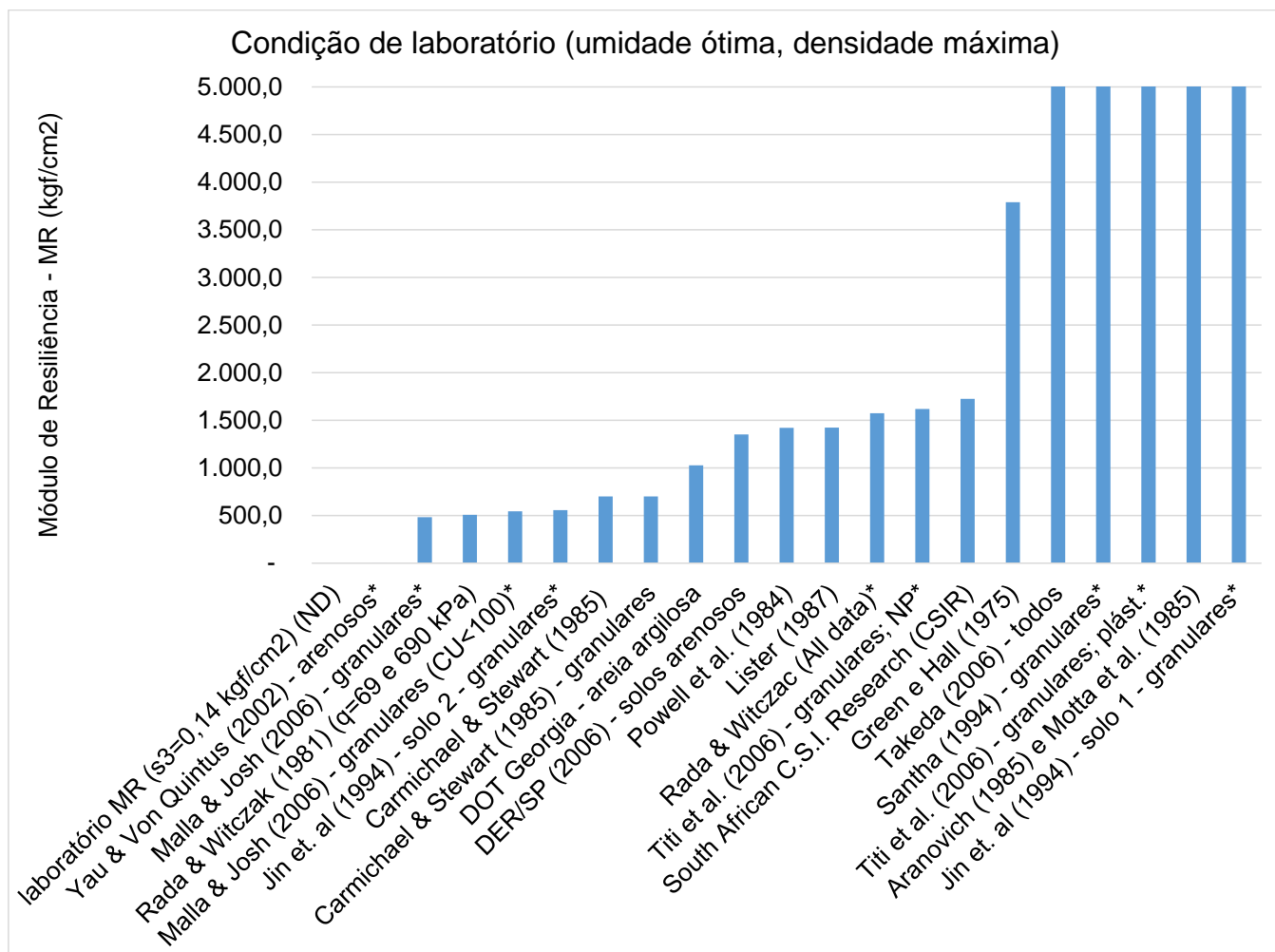

Figura 9.105: Comparativo entre $M R$ de laboratório e modelos de previsão de $M R$ (condição de umidade ótima)

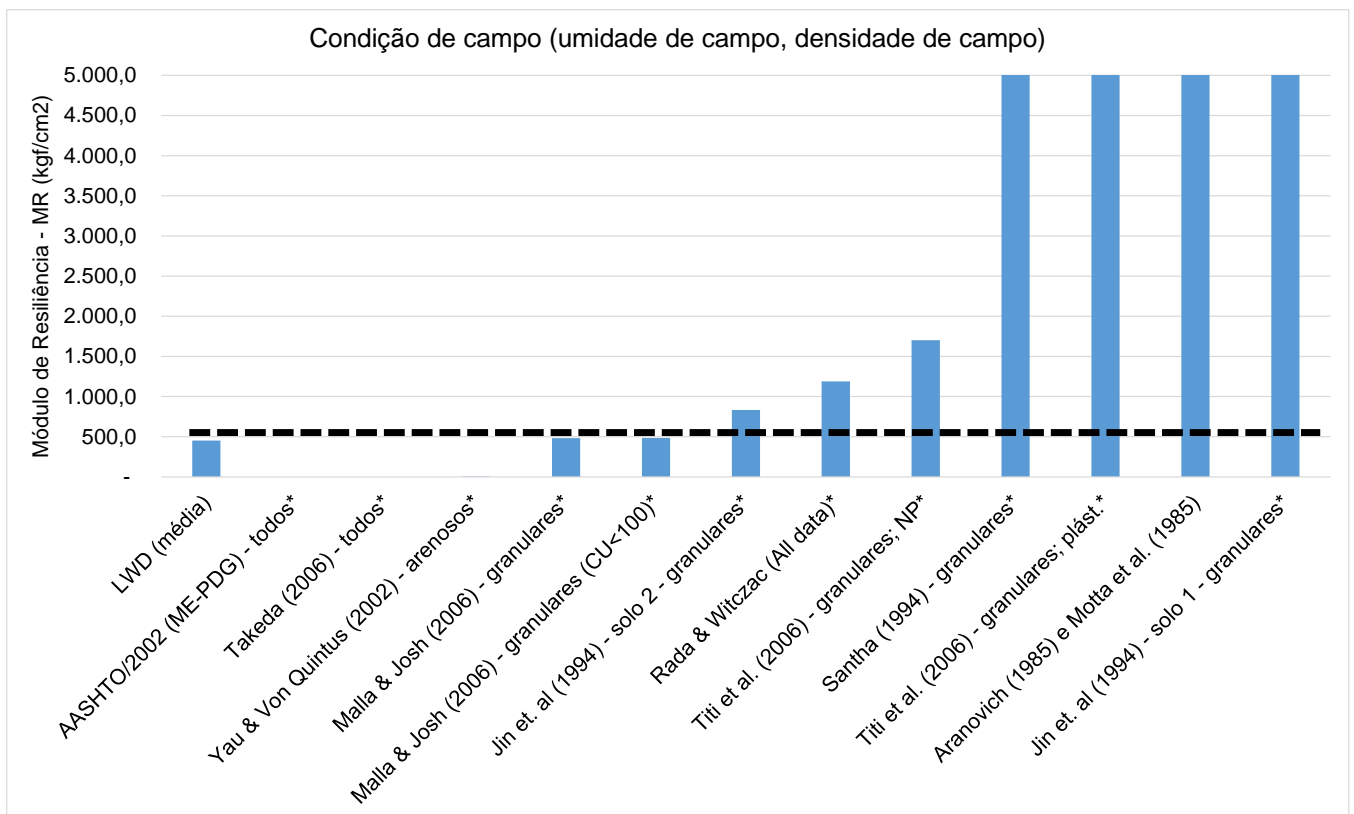

Figura 9.106: Comparativo entre $M R$ in situ (LWD) e modelos de previsão de $M R$ (condição de umidade verificada no campo) 


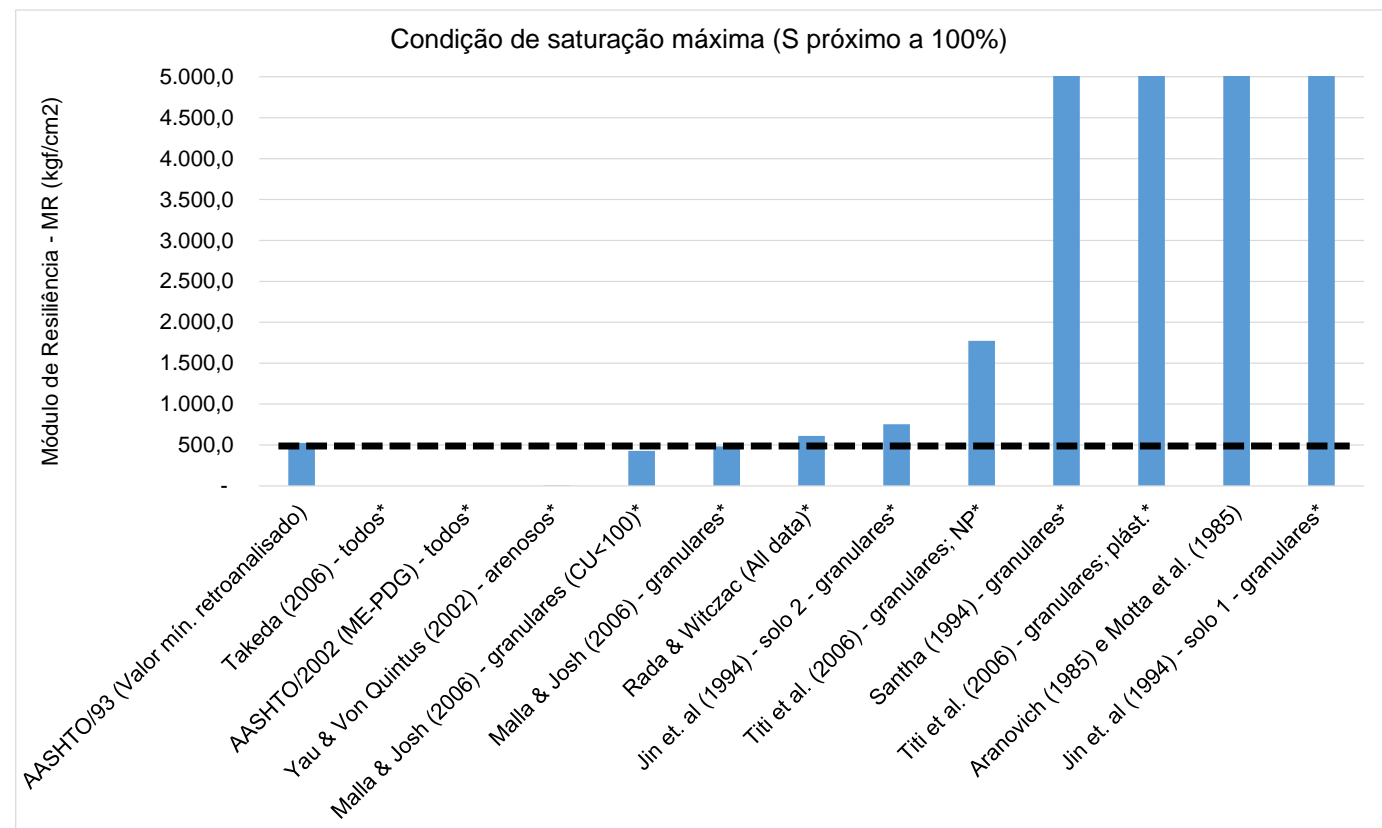

Figura 9.107: Comparativo entre MR in situ mínimo verificado $(F W D)$ e modelos de previsão de $M R$ (condição de saturação próxima a 100\%) 

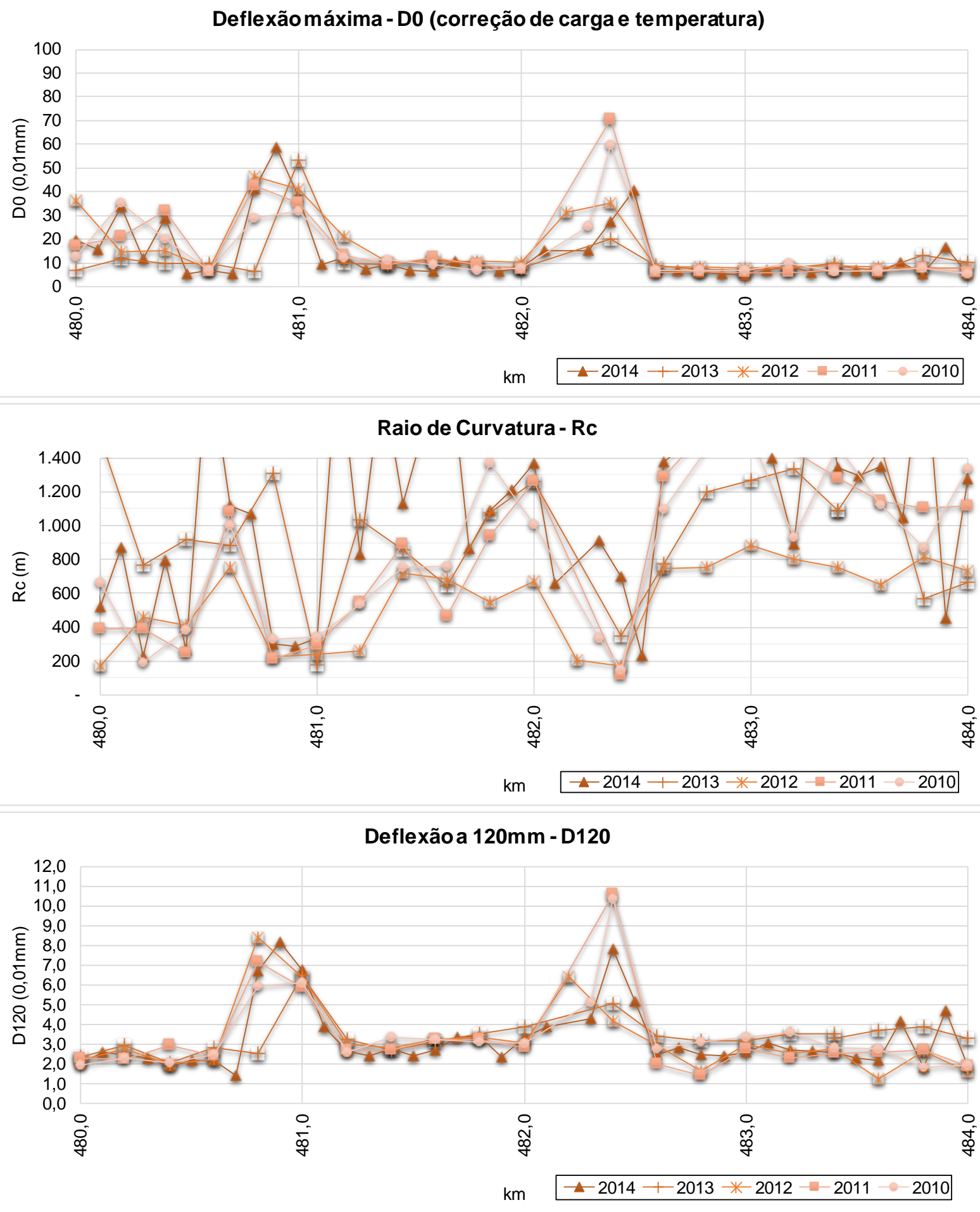

Figura 9.108: Gráficos de série histórica dos indicadores estruturais do pavimento no segmento do km 482 (pista sul) 


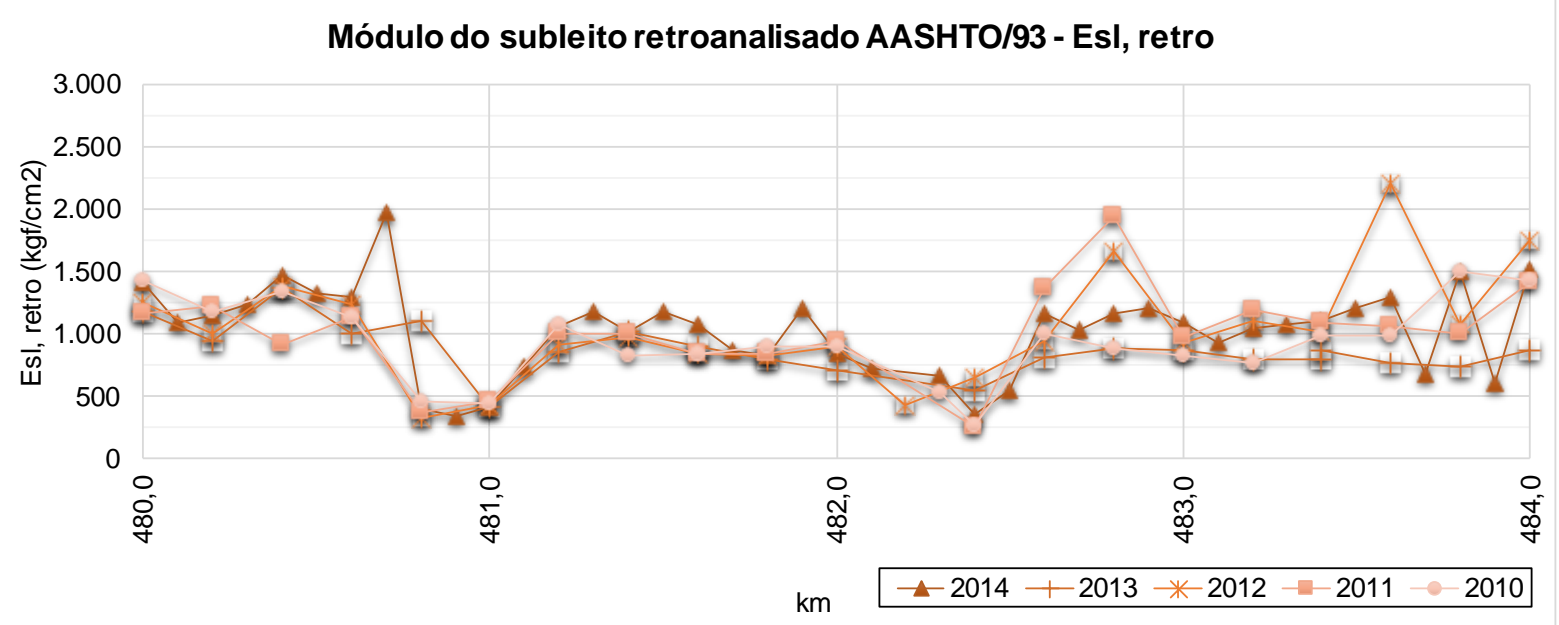

Figura 9.109: Gráficos da série histórica dos dados de módulo de resiliência retroanalisado $(F W D)$ do pavimento no segmento do km 482 (pista sul) 
481,5 482,5 CRESCENTE
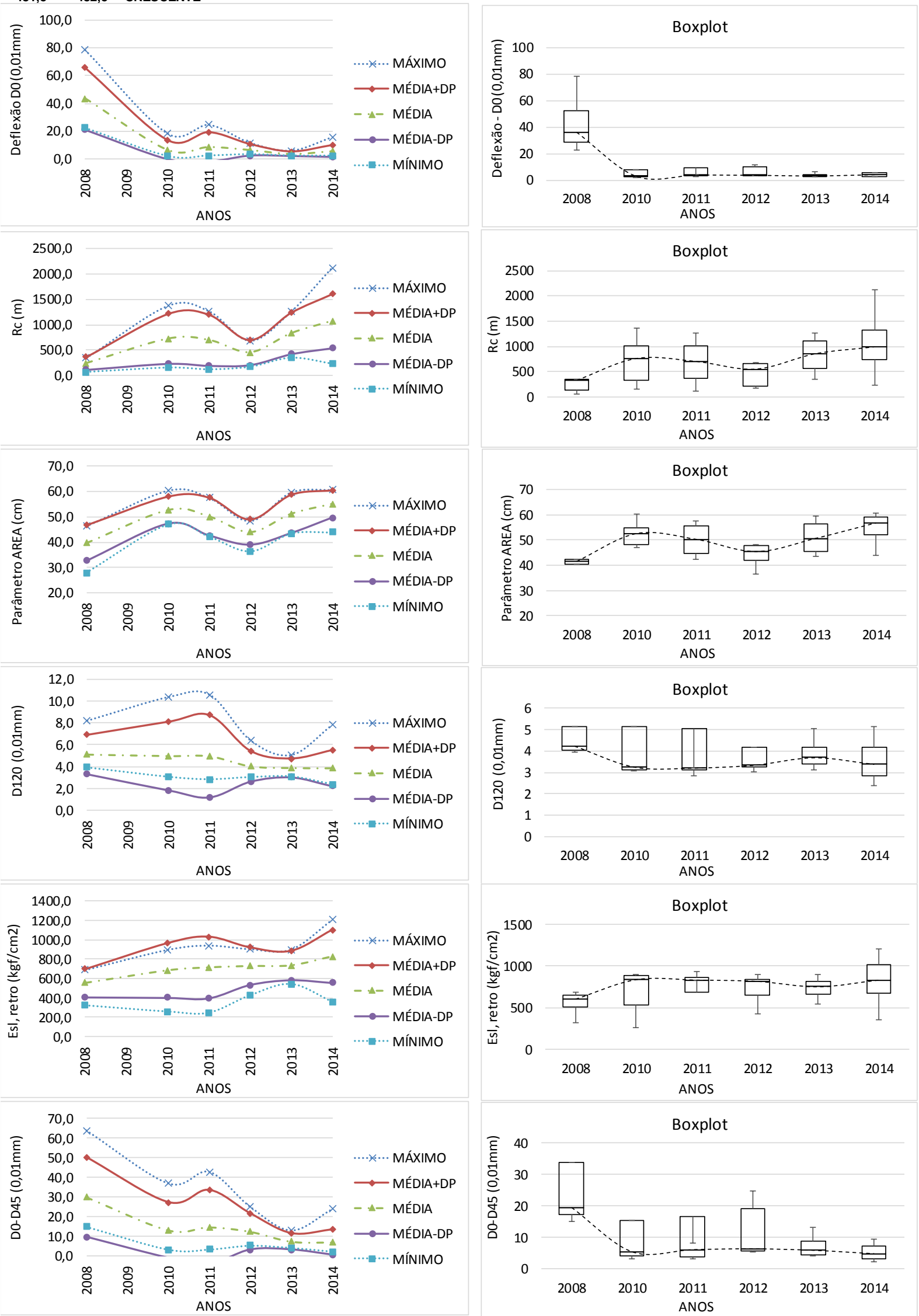

Figura 9.110: Estatísticas dos Parâmetros do pavimento (S. Homogêneo do km 482) 


\subsection{Poço de inspeção do km 492 (Pista Sul)}

A Figura 9.111 a seguir ilustra a localização do poço de inspeção do km 482 (pista sul) bem como o mapeamento geológico do local. Verifica-se uma região com predominância de xistos.

A Tabela 9.55 apresenta o registro histórico de intervenções do pavimento.

A Tabela 9.56 apresenta a estrutura do pavimento identificada na ocasião da abertura do poço de inspeção. Trata-se de pavimento composto basicamente por materiais asfálticos (revestimento e base)..

A Tabela 9.57 apresenta os resultados estatísticos obtidos a partir do ensaio de LWD sobre as camadas de subleito.

A Figura 9.112 apresenta o resultado da retroanálise da série histórica de deflexões do pavimento em estudo e a Figura 9.113 apresenta os gráficos de tensões calculadas no subleito, ilustrando o comportamento do subleito registrado através dos ensaios com FWD.

A Tabela 9.58 apresenta o resumo dos resultados dos ensaios de laboratório realizados com o material do subleito e dos materiais da faixa de domínio no local.

A Figura 9.114 apresenta um gráfico contendo os valores de módulo previstos pelos modelos da literatura para a condição de umidade ótima (energia intermediária). Como não foram realizados os ensaios de módulo de laboratório, não foi possível realizar comparações.

A Figura 9.115 apresenta um gráfico comparativo entre o valor mínimo de módulo in situ medido com FWD (retroanálise) e os valores de módulo previstos pelos modelos da literatura, para as condições de saturação próxima da saturação máxima (adotouse S próximo a 98\%). Verificou-se uma razoabilidade maior dos modelos de Malla \& Joshi (2006) e Rada \& Witczak (1981).

A Figura 9.116 apresenta os gráficos da série histórica dos indicadores estruturais do pavimento (deflexão máxima, raio de curvatura, e deflexão a $120 \mathrm{~mm}$ do ponto de aplicação de carga) no segmento que contempla o local em estudo. 
A Figura 9.117 apresenta os gráficos da série histórica dos valores de módulo de resiliência retroanalisado $(F W D)$ e Quociente de Irregularidade $(Q /)$ no segmento que contempla o local em estudo.

A Figura 9.118 apresenta os dados estatísticos (valores máximos, mínimos, média e média mais ou menos desvio padrão), bem como boxplot dos indicadores estruturais do pavimento no segmento homogêneo determinado para o ponto em estudo.

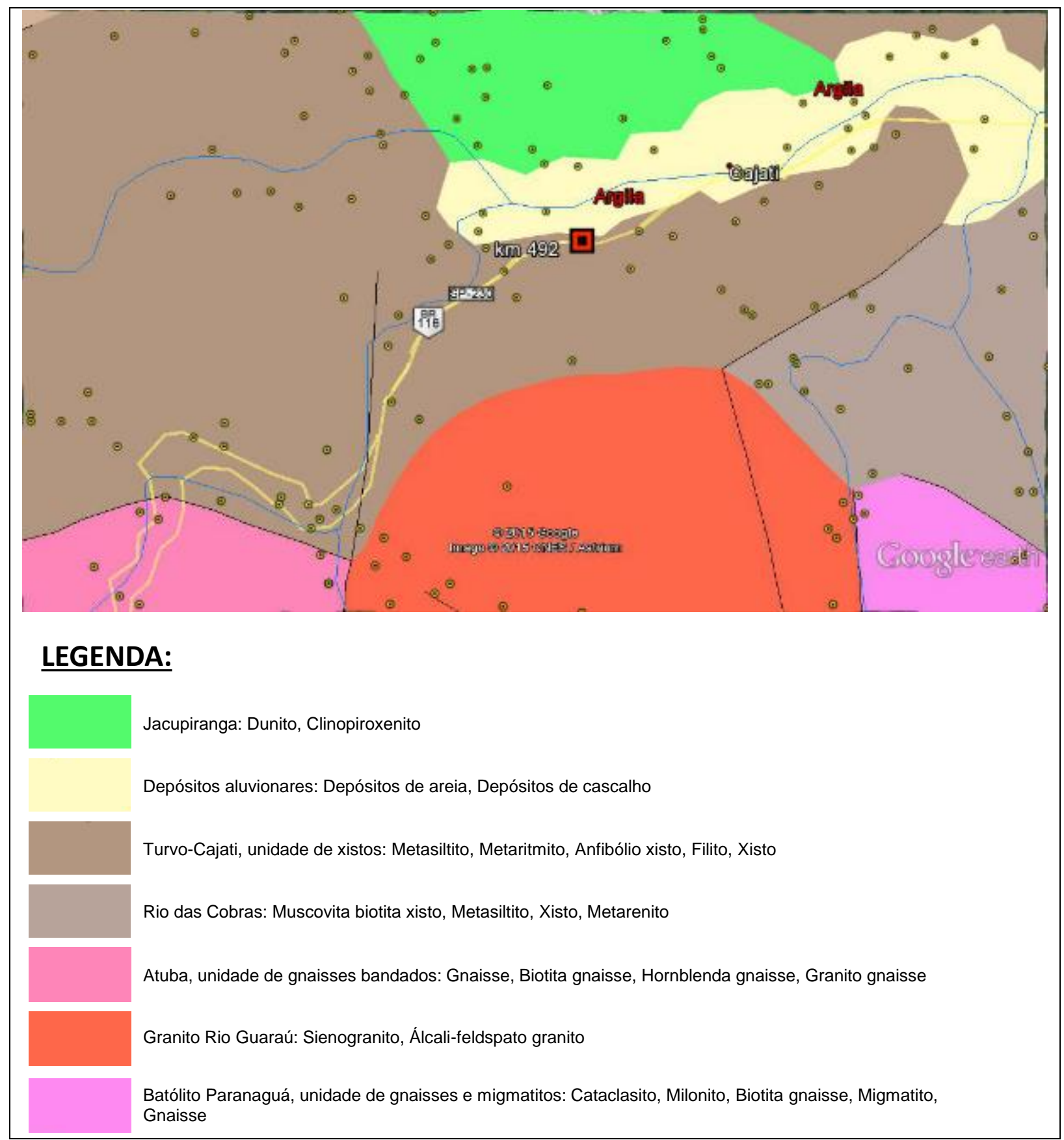

Figura 9.111: Mapa Geológico do local sondado - km 492 (Pista Sul)

Fonte: Geobank/Google Earth ${ }^{\circledR}$ 
Tabela 9.55: histórico de intervenções informado - km 492 (pista sul)

\begin{tabular}{|c|c|c|c|c|c|c|}
\hline km & $\begin{array}{c}\text { km } \\
\text { inicial }\end{array}$ & $\begin{array}{l}\text { km } \\
\text { final }\end{array}$ & \multicolumn{2}{|c|}{ Solução Aplicada } & $\begin{array}{l}\text { Larg. } \\
\text { (m) }\end{array}$ & $\begin{array}{l}\text { Esp. } \\
\text { (cm) }\end{array}$ \\
\hline 492,000 & 490,270 & 492,922 & \multicolumn{2}{|c|}{ MICROREVESTIMENTO } & 4,20 & 1,20 \\
\hline & \multicolumn{6}{|c|}{ Tabela 9.56: Estrutura do pavimento da faixa externa - km 492 (pista su } \\
\hline & km & Pista & Camada & $\begin{array}{c}\text { Espessura } \\
(\mathrm{cm})\end{array}$ & \multicolumn{2}{|c|}{ Camada } \\
\hline & \multirow{3}{*}{492} & \multirow{3}{*}{ Sul } & 1 & 14,0 & \multicolumn{2}{|l|}{ CA } \\
\hline & & & 2 & 40,0 & \multicolumn{2}{|c|}{ BASE BETUMINOSA } \\
\hline & & & 3 & - & \multicolumn{2}{|l|}{ SL } \\
\hline
\end{tabular}

Tabela 9.57: Estatística dos resultados do ensaio com $\angle W D$

\begin{tabular}{|c|c|c|c|c|c|c|c|c|c|c|c|}
\hline \multirow{2}{*}{ km } & \multirow{2}{*}{ Material } & \multicolumn{5}{|c|}{ Leituras $\mathrm{D}_{0, \text { LWD }}\left(10^{-2} \mathrm{~mm}\right)$} & \multicolumn{5}{|c|}{$E_{0, \text { calc }}\left(\mathbf{k f g} / \mathrm{cm}^{2}\right)$} \\
\hline & & Mín. & Máx. & Média & Desvio & $\mathrm{CV}(\%)$ & Mín. & Máx. & Média & Desvio & CV(\%) \\
\hline 492 & $\mathrm{SL}$ & 13 & 15 & 14 & 1 & 4 & 1.502 & 1.718 & 1.628 & 70 & 4 \\
\hline
\end{tabular}

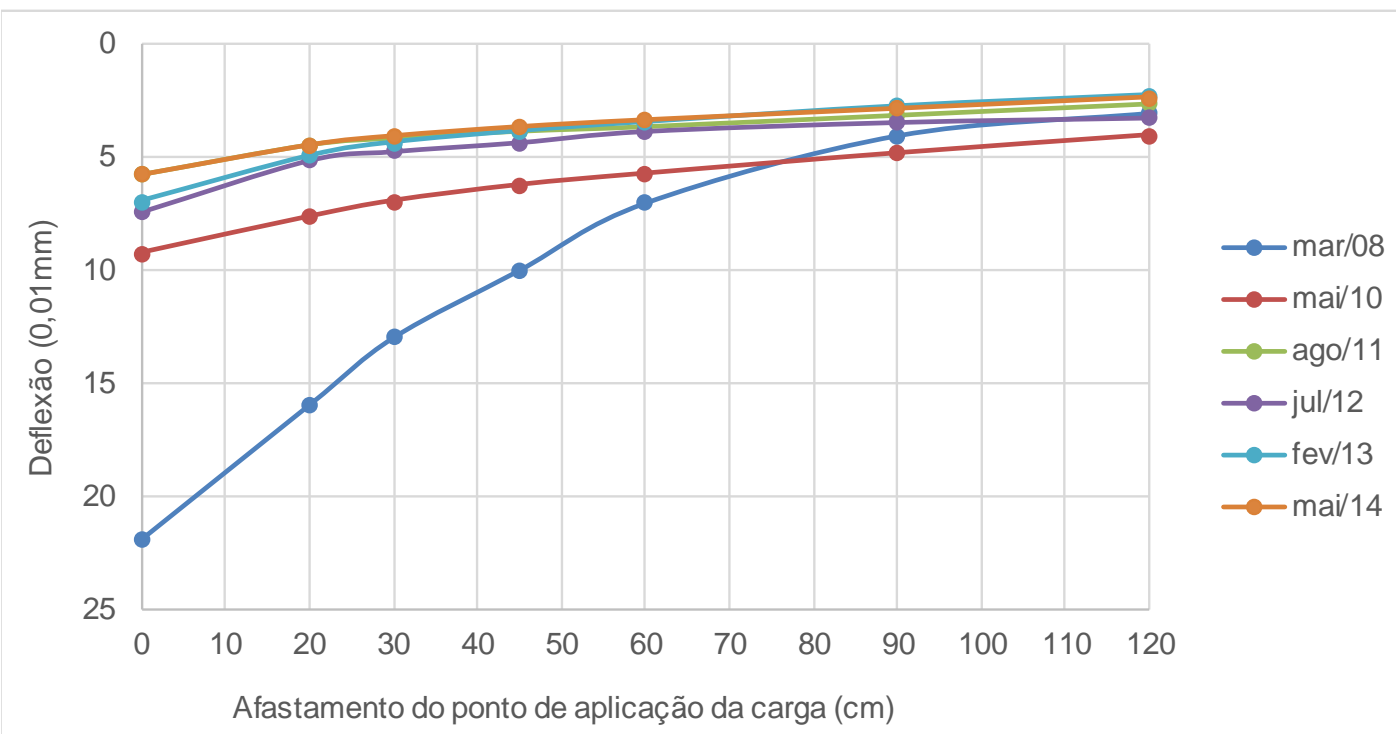

\begin{tabular}{|c|c|c|c|c|c|c|c|}
\hline $\begin{array}{c}\text { Mês/ano } \\
\text { Levantamento }\end{array}$ & $\operatorname{Tar}\left({ }^{\circ} \mathrm{C}\right)$ & $\begin{array}{l}\text { Tpav } \\
\left({ }^{\circ} \mathrm{C}\right)\end{array}$ & $\operatorname{Er} 1\left(\mathrm{kgf} / \mathrm{cm}^{2}\right)$ & $\mathrm{Eb}\left(\mathrm{kgf} / \mathrm{cm}^{2}\right)$ & Esl $\left(\mathrm{kgf} / \mathrm{cm}^{2}\right)$ & $\begin{array}{l}\text { Eslx0,33 } \\
\left(\mathrm{kgf} / \mathrm{cm}^{2}\right)\end{array}$ & $\begin{array}{c}\text { Esl } \\
\text { (AASHTO/ } \\
93 \text { ) }\end{array}$ \\
\hline $\begin{array}{l}\text { Espessuras } \\
\quad(\mathrm{cm})\end{array}$ & & & 14,0 & 40,0 & - & - & - \\
\hline Materiais & & & CA & BASE BETUMINOSA & SL & SL & SL \\
\hline mar/08 & \multicolumn{6}{|c|}{ * Provável estrutura antiga de pavimento flexível } & 903 \\
\hline $\mathrm{mai} / 10$ & 31,0 & 34,0 & 90.000 & 35.000 & 2.350 & 776 & 736 \\
\hline ago/11 & 16,0 & 19,0 & 70.000 & 99.000 & 3.400 & 1.122 & 949 \\
\hline $\mathrm{jul} / 12$ & 25,0 & 30,0 & 30.000 & 98.000 & 3.100 & 1.023 & 827 \\
\hline $\mathrm{fev} / 13$ & 36,0 & 44,0 & 50.000 & 47.500 & 4.600 & 1.518 & 1.612 \\
\hline $\mathrm{mai} / 14$ & 22,0 & 27,0 & 81.000 & 72.000 & 4.200 & 1.386 & 1.305 \\
\hline
\end{tabular}


Figura 9.112: Retroanálise das bacias de deflexões (série histórica) - km 492 (pista sul)

$\because \mathrm{s} 1 \rightarrow \mathrm{s} 2=\mathrm{s} 3 \rightarrow \mathrm{q} \rightarrow$ toc Tensões (kgf/cm2)

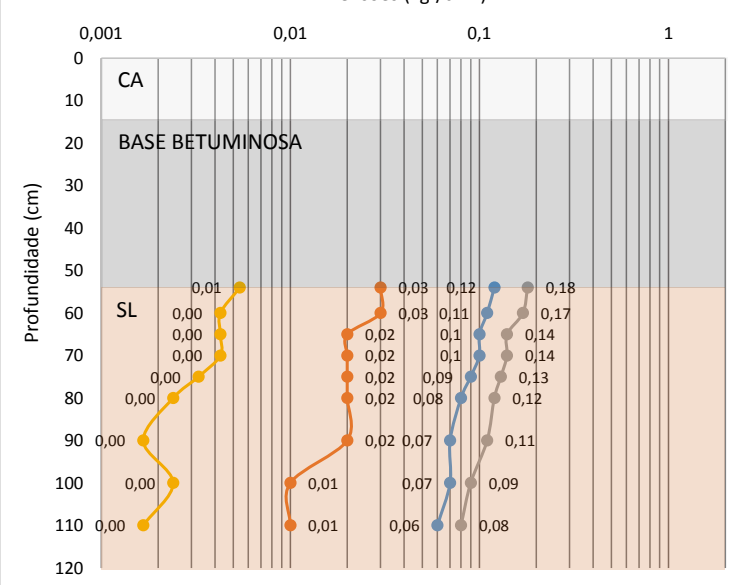

$\rightarrow-s 1 \rightarrow-s 2=s 3 \rightarrow-q-$ toct Tensões (kgf/cm2)

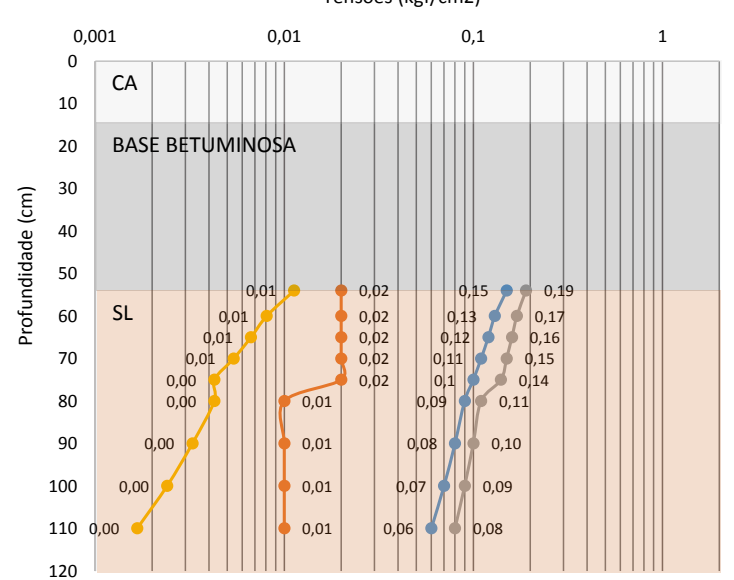

Figura 9.113: Tensões no subleito calculadas para (a) 2013 e (b) 2014

Tabela 9.58: Resumo dos ensaios realizados com material próximo ao km 492

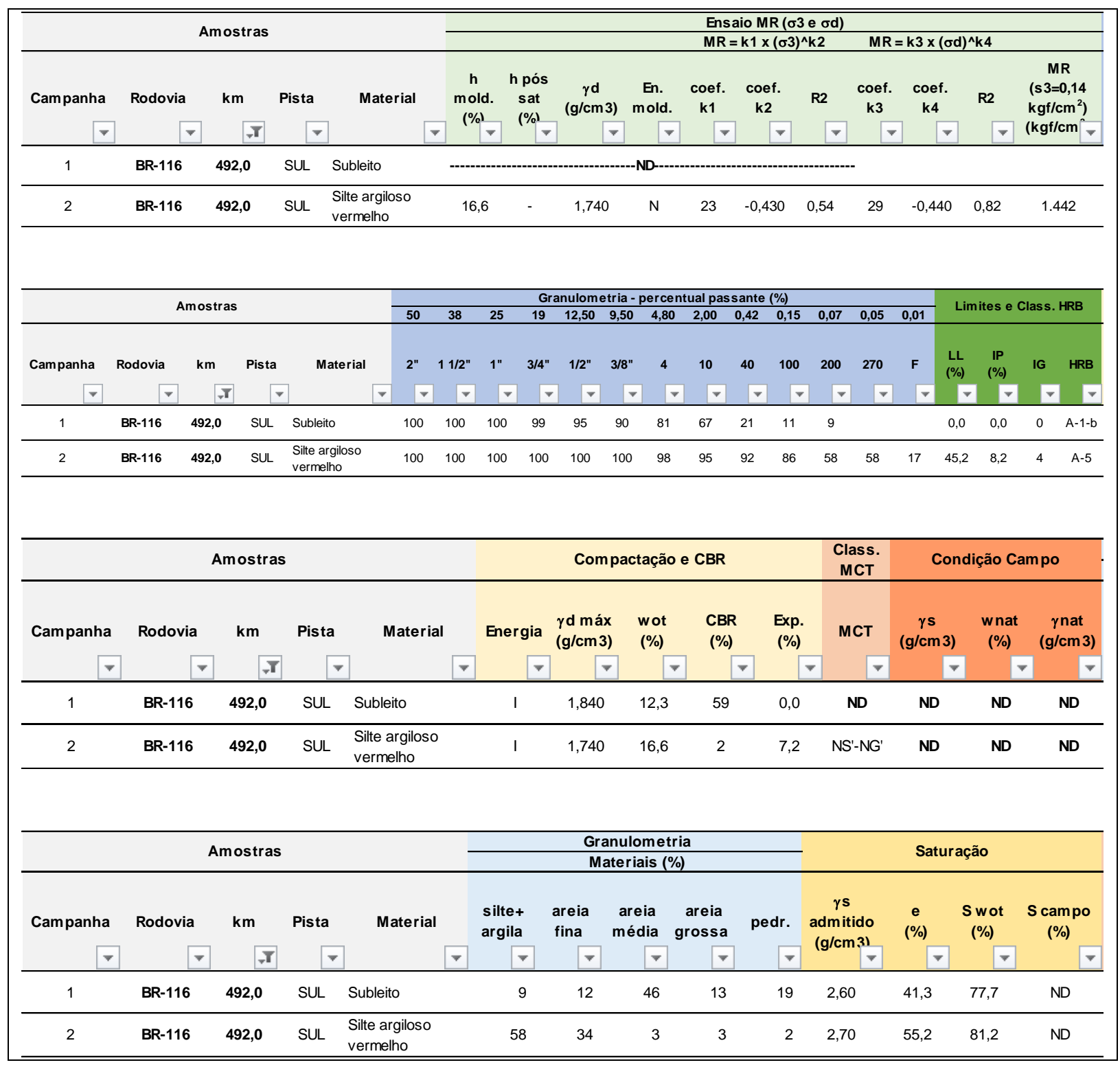




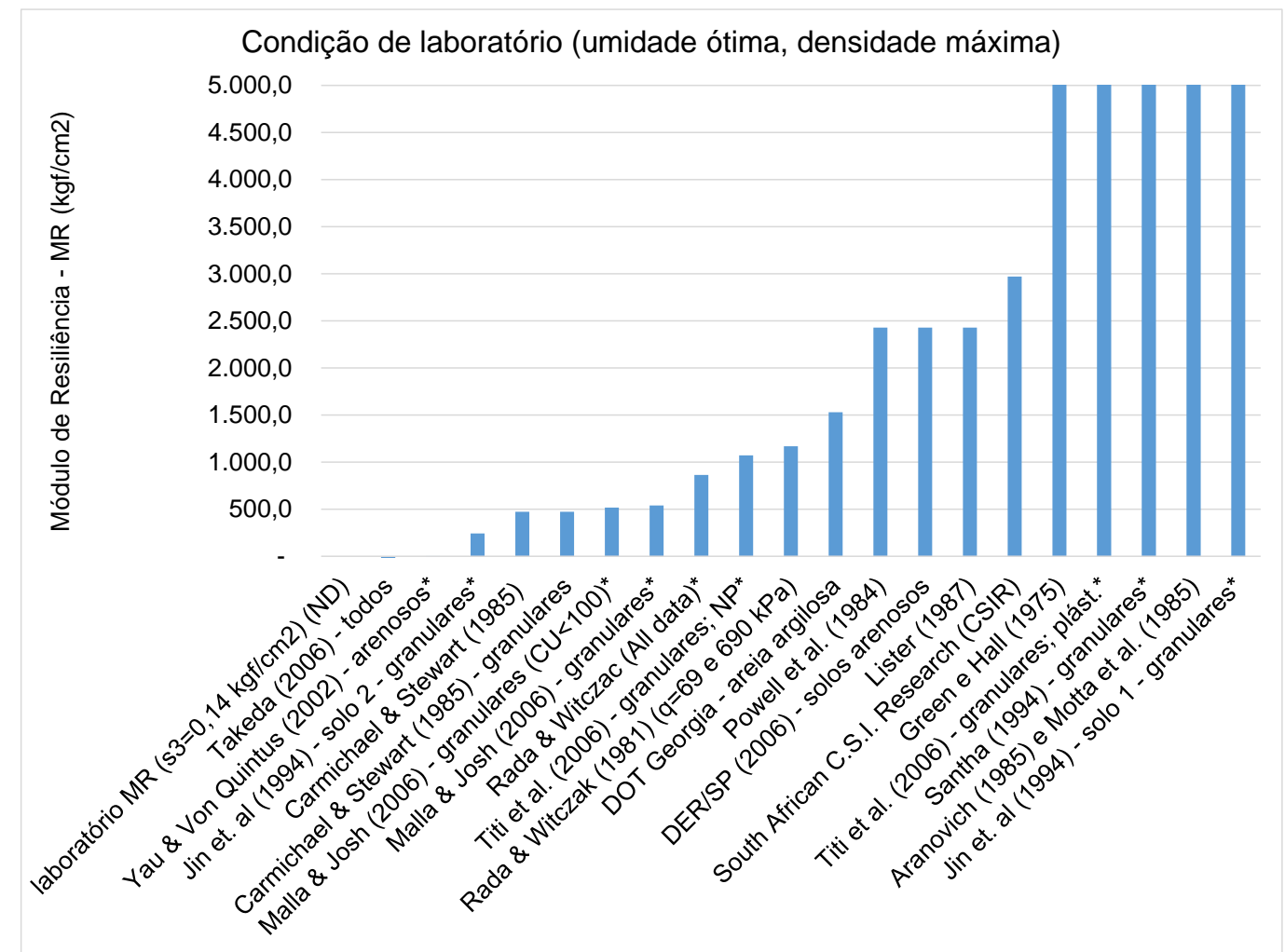

Figura 9.114: Comparativo entre $M R$ de laboratório e modelos de previsão de $M R$ (condição de umidade ótima)

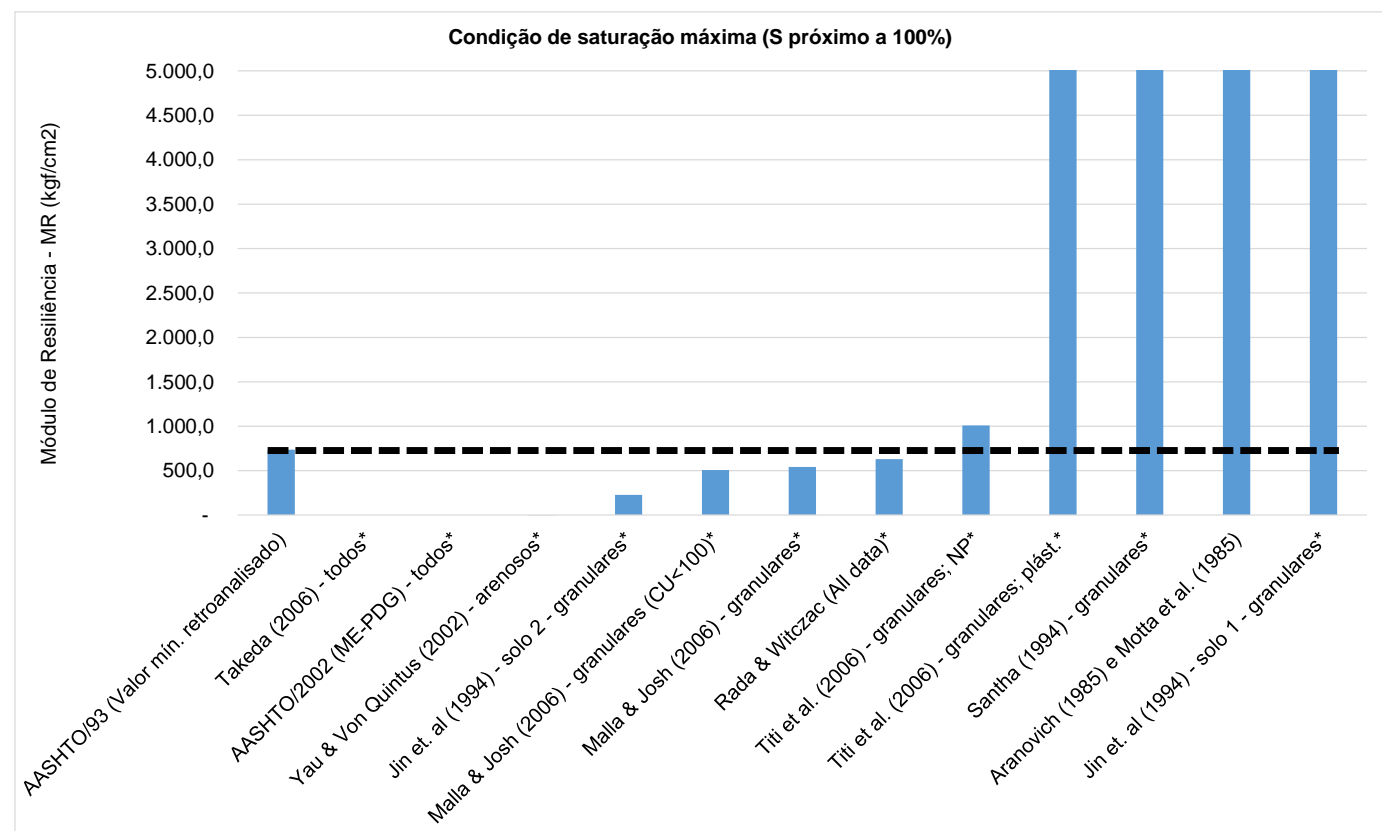

Figura 9.115: Comparativo entre $M R$ in situ mínimo verificado $(F W D)$ e modelos de previsão de $M R$ (condição de saturação próxima a 100\%) 

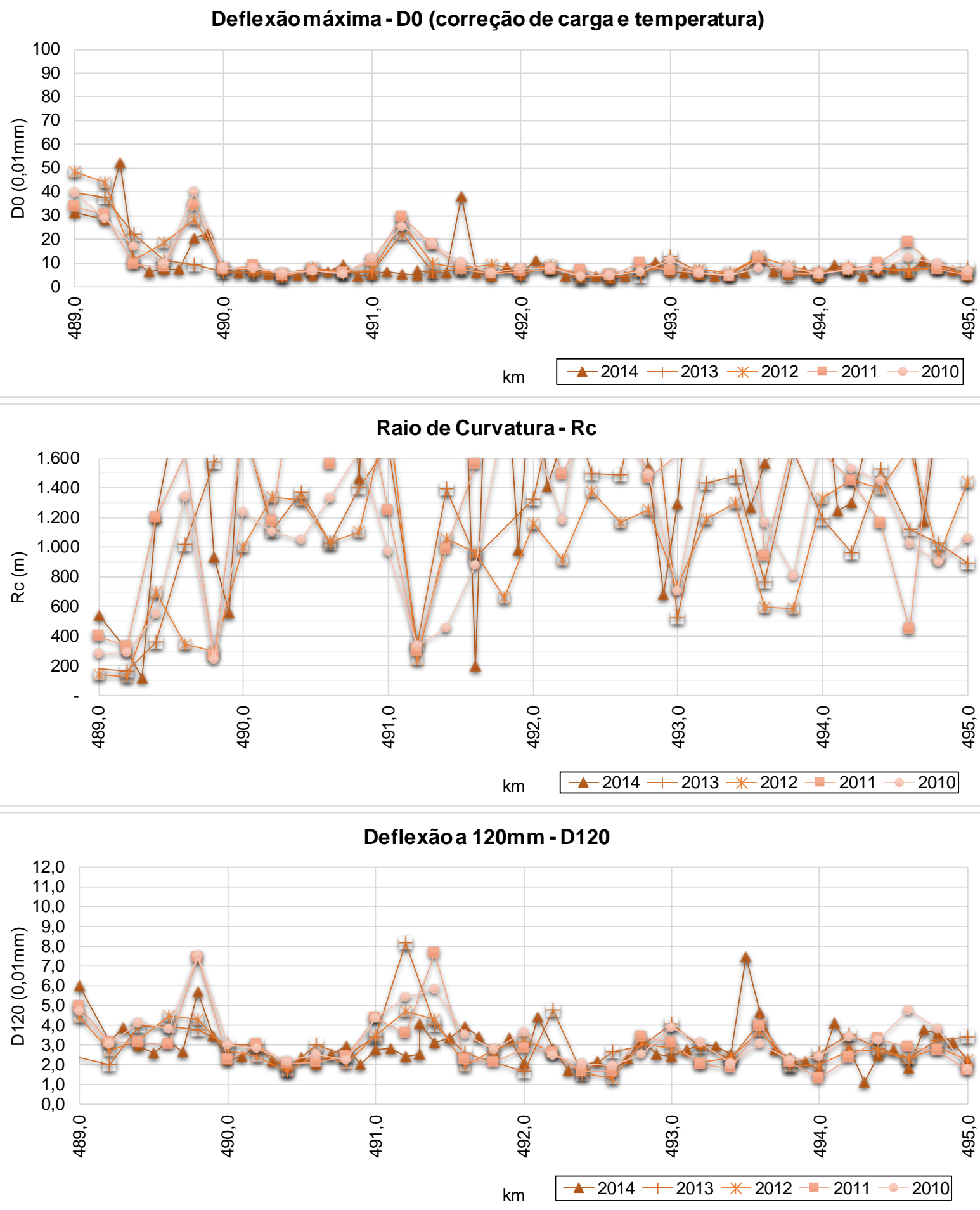

Figura 9.116: Gráficos de série histórica dos indicadores estruturais do pavimento no segmento do km 492 (pista sul) 


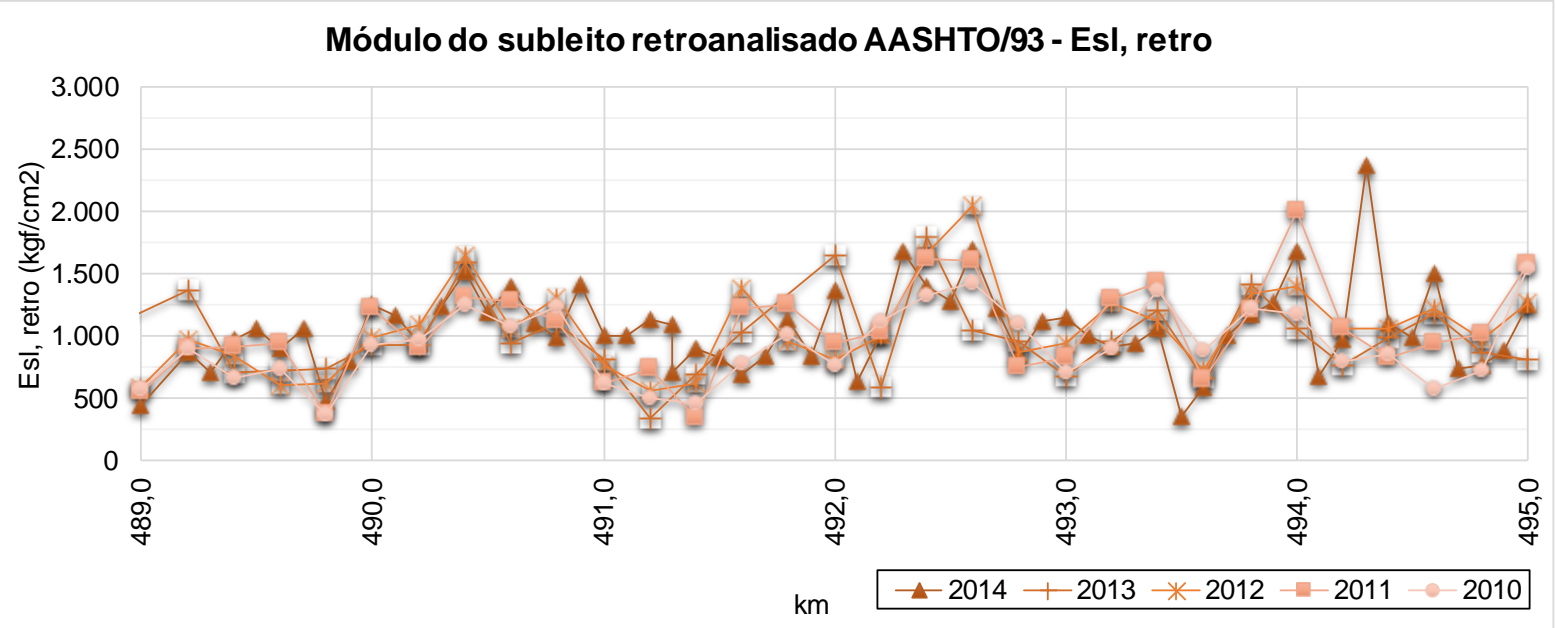

Figura 9.117: Gráficos da série histórica dos dados de módulo de resiliência retroanalisado $(F W D)$ do pavimento no segmento do $\mathrm{km} 492$ (pista sul) 
491,5 492,5 CRESCENTE
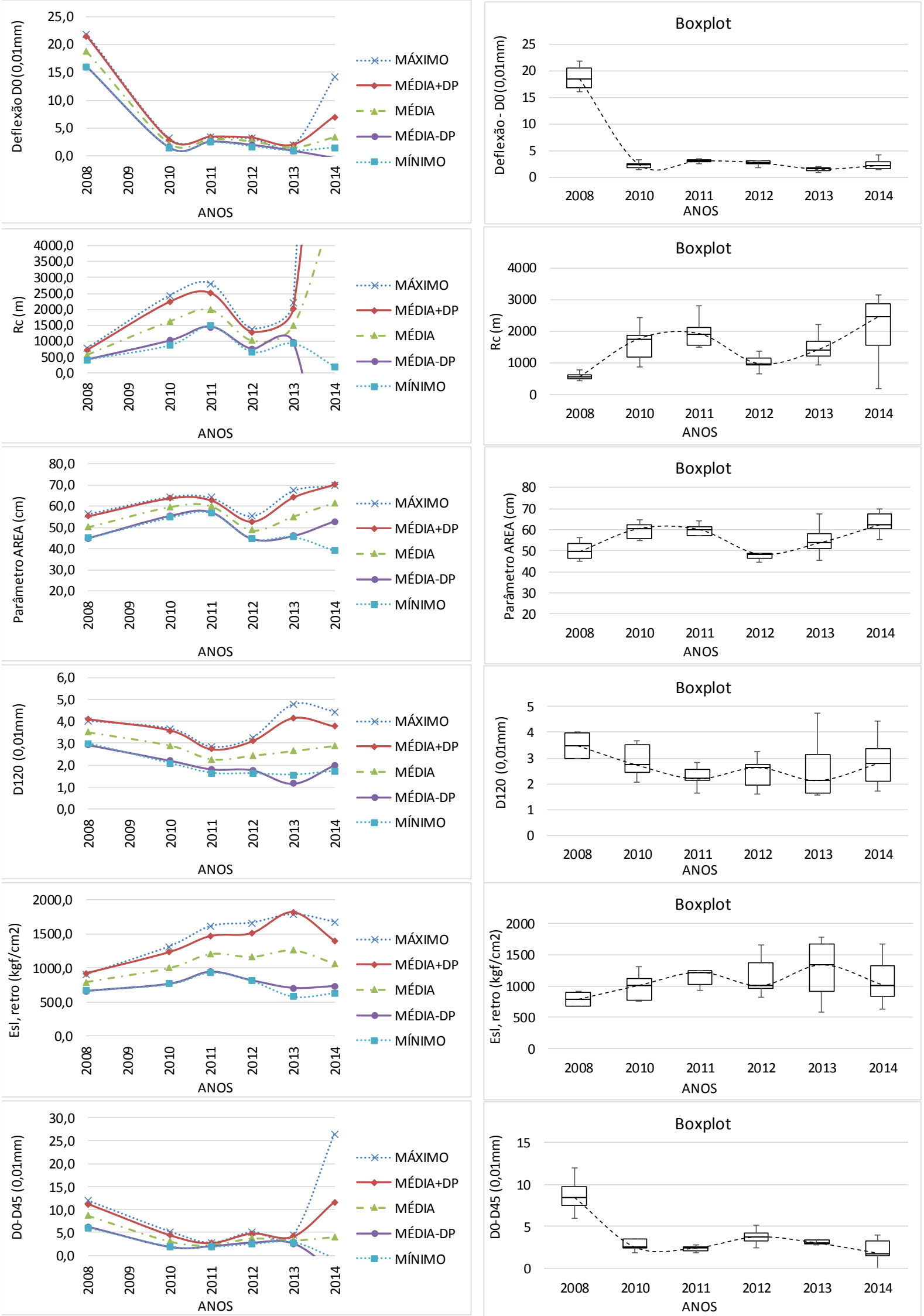

Figura 9.118: Estatísticas dos Parâmetros do pavimento (S. Homogêneo do km 492) 
10 ANEXO B - PARÂMETROS ESTATÍSTICOS DOS SEGMENTOS HOMOGÊNEOS PELA METODOLOGIA MCT (BD4) 
$\mathbf{5 0 , 4} 50,7$ DECRESCENTE

NS'

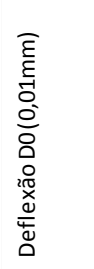
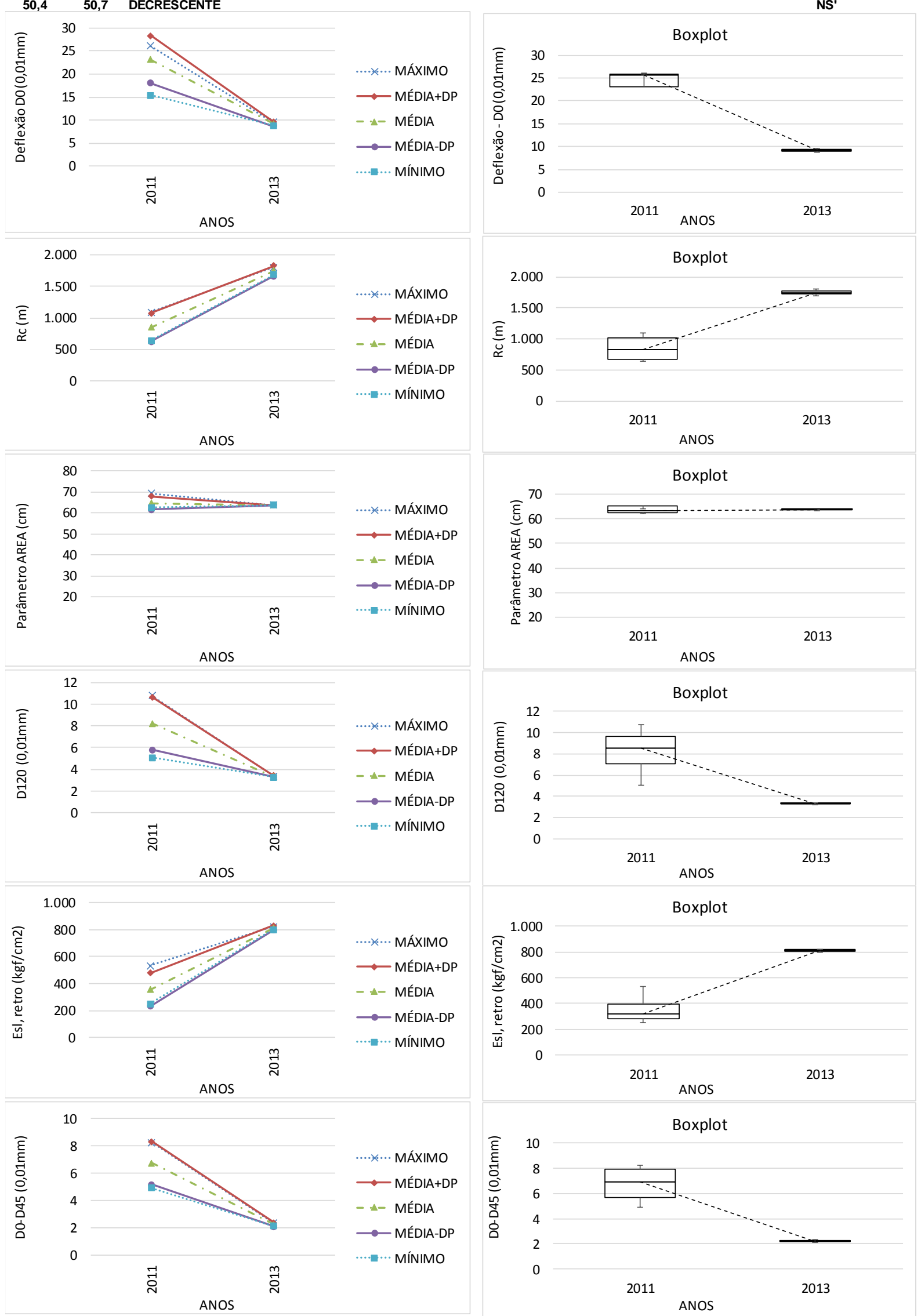

Figura 10.1: Estatísticas dos Parâmetros do pavimento (S. Homogêneo 1 - NS') 
29,95 30,05 DECRESCENTE
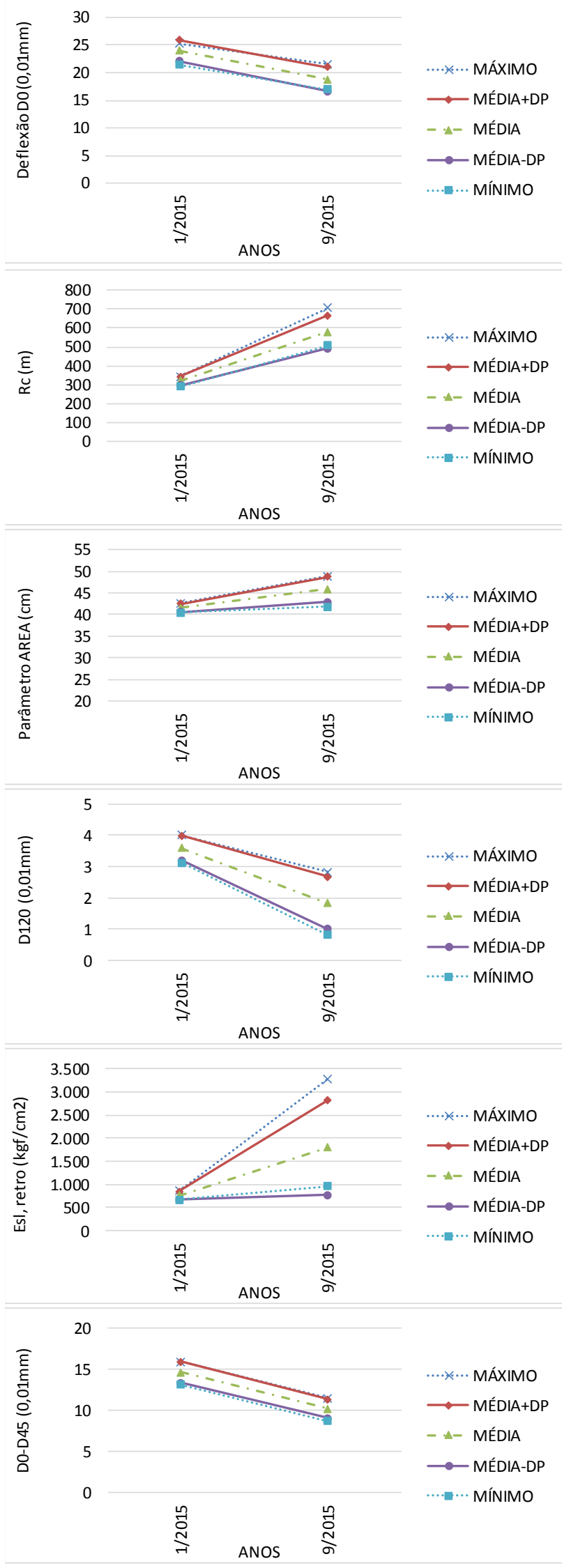

NS'
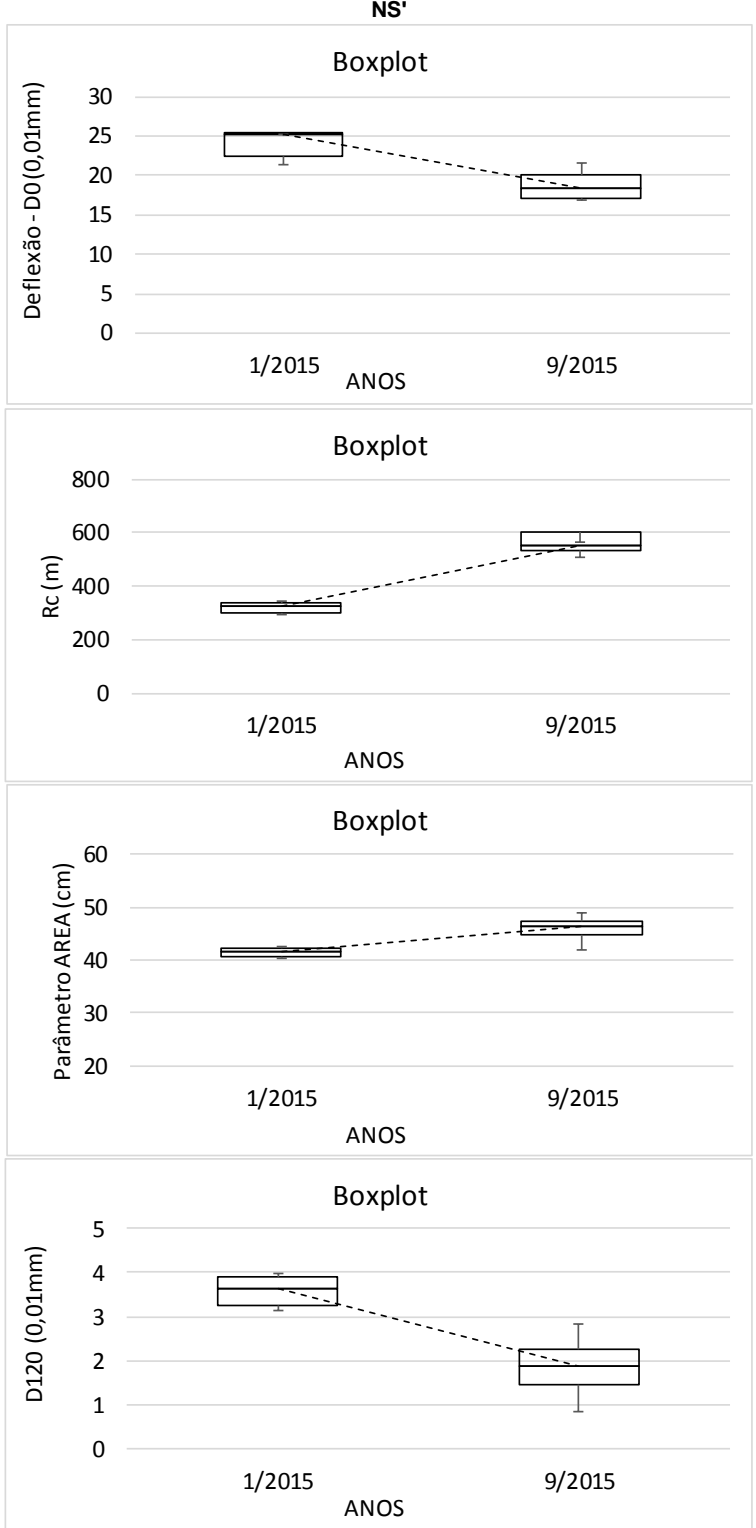

Boxplot

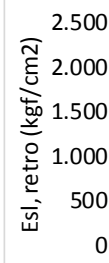

500
000
500
000
500
0

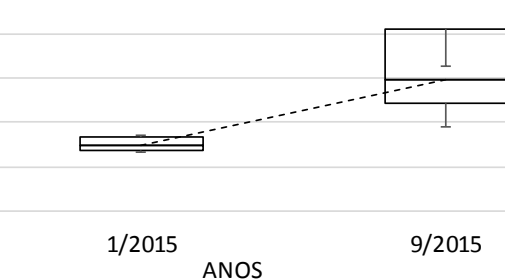

Boxplot

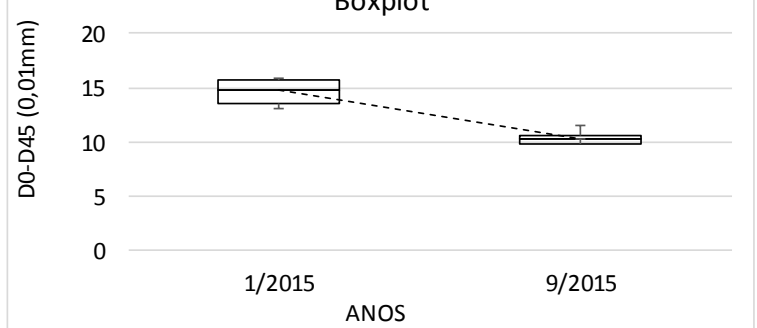

Figura 10.2: Estatísticas dos Parâmetros do pavimento (S. Homogêneo 2 - NS') 
3131,2 DECRESCENTE
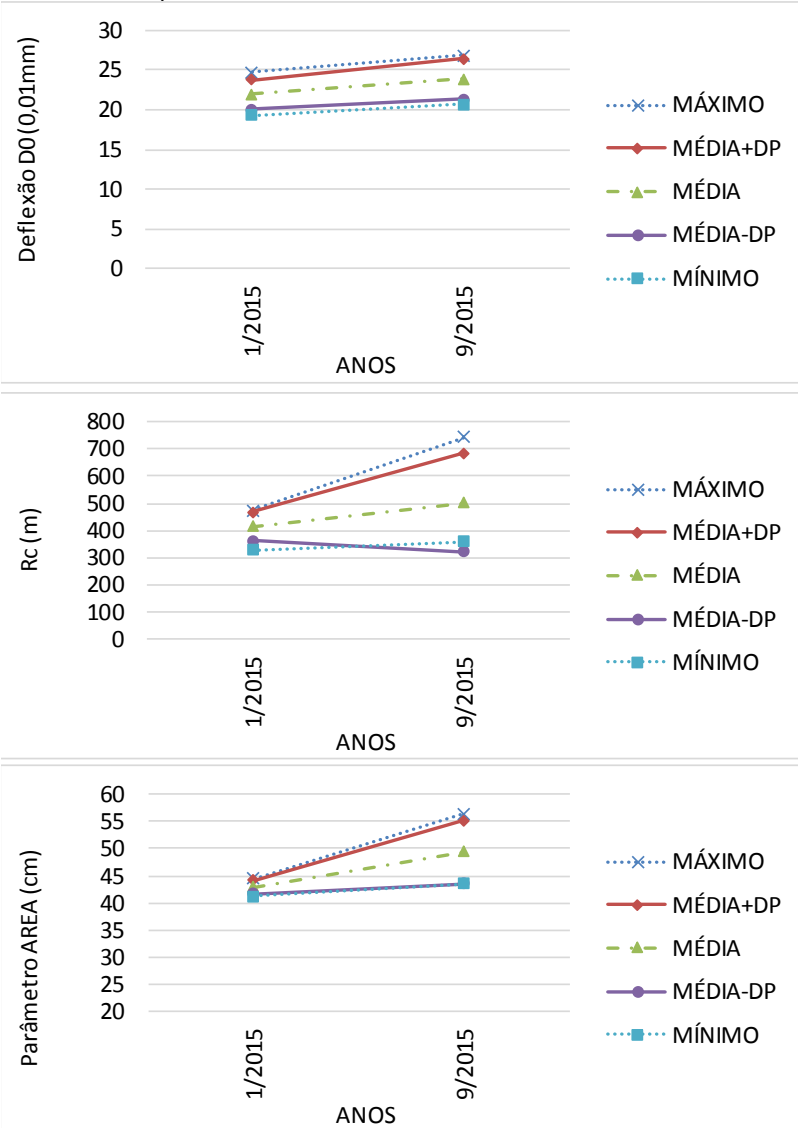

$\longrightarrow$ MÉDIA+DP

- $\triangle$ - MÉDIA

$\longrightarrow$ MÉDIA-DP

........ MÍNIMO

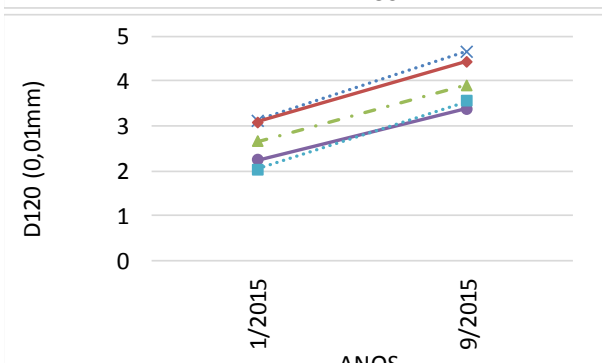

ANOS
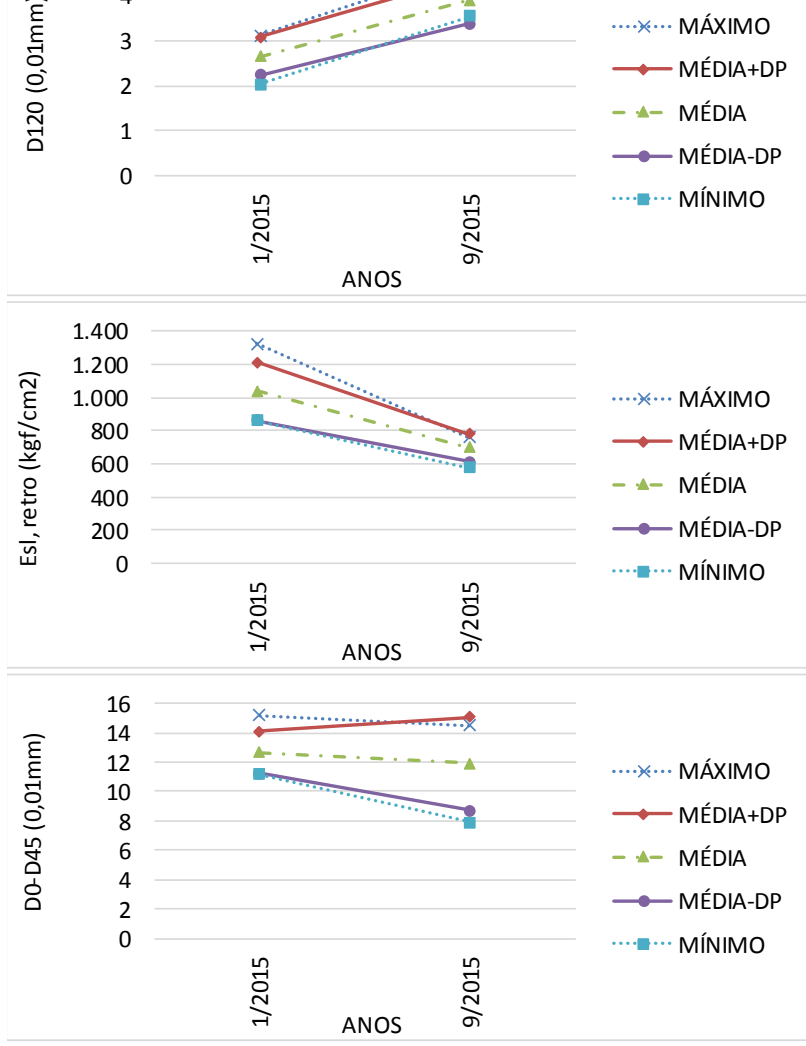

$\because$ MÉDIA+DP

- - MÉDIA

$\longrightarrow$ MÉDIA-DP

.... MÍNIMO
NS'

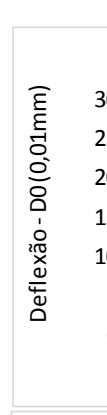

Boxplot

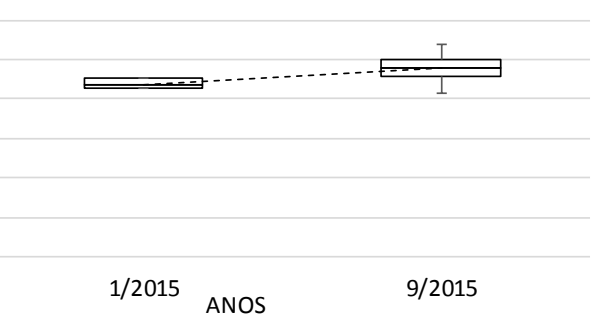

Boxplot

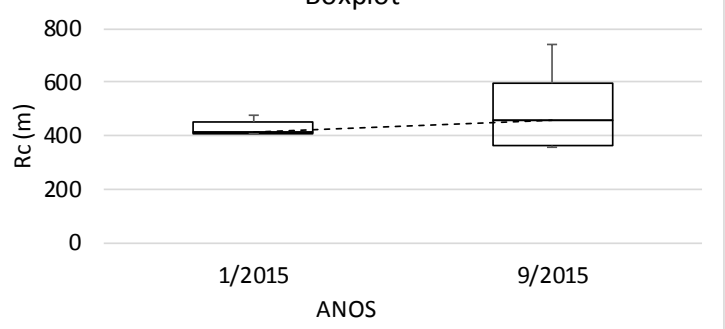

Boxplot

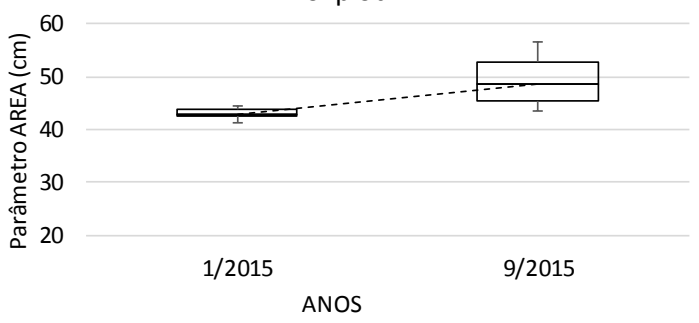

Boxplot

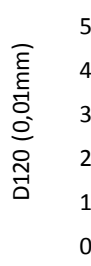
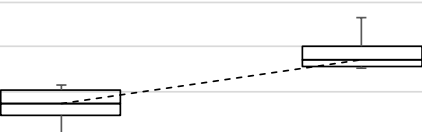

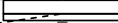

ANOS

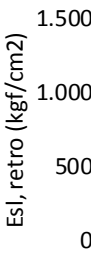

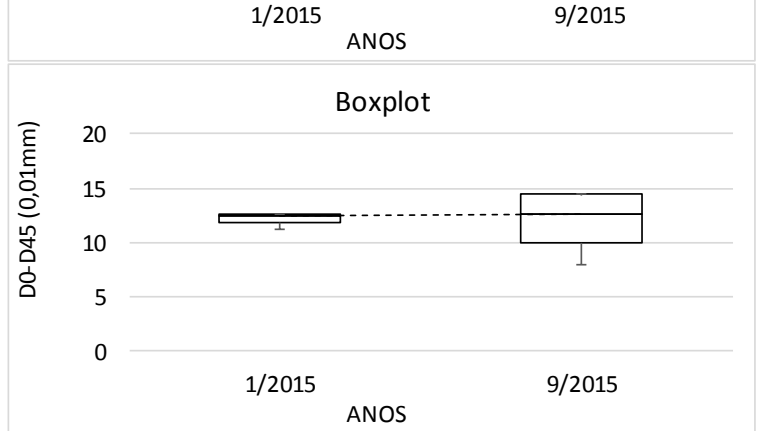

Figura 10.3: Estatísticas dos Parâmetros do pavimento (S. Homogêneo 3 - NS') 


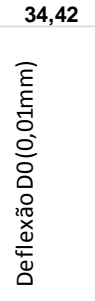

34,58 CRESCENTE
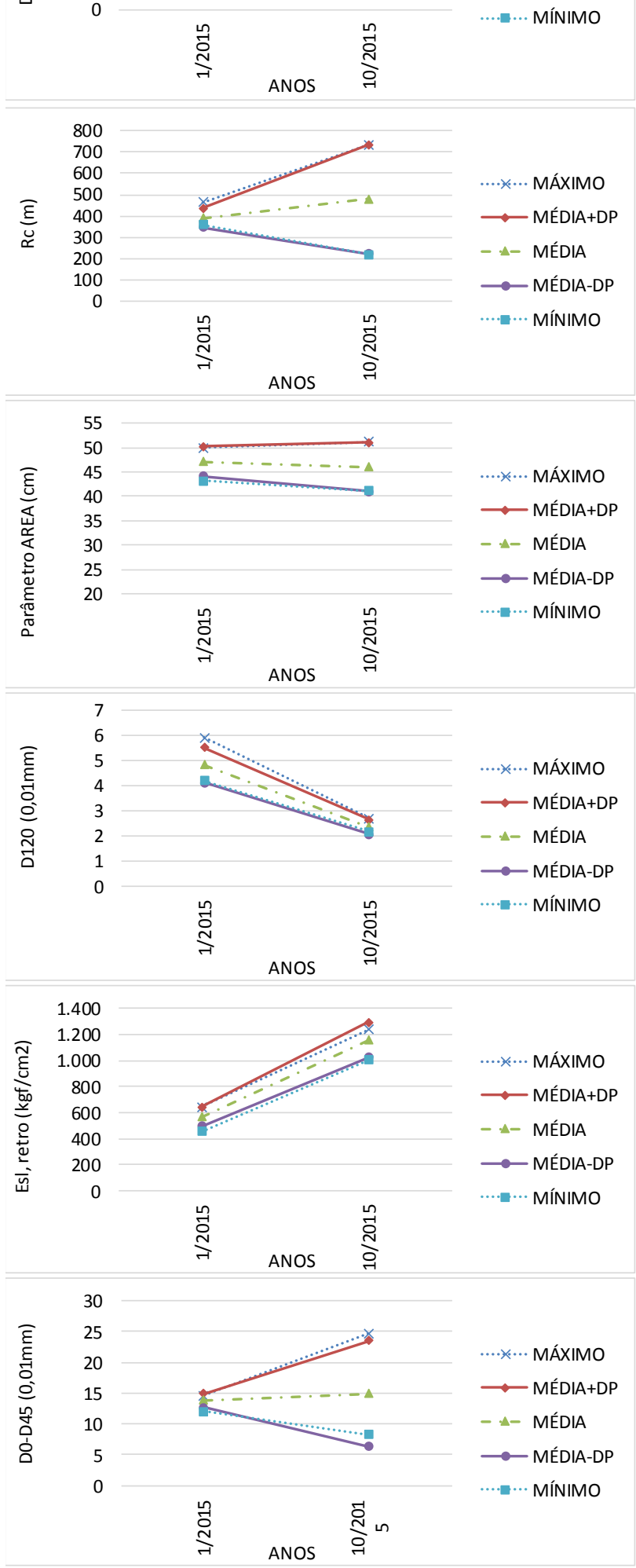

NS'
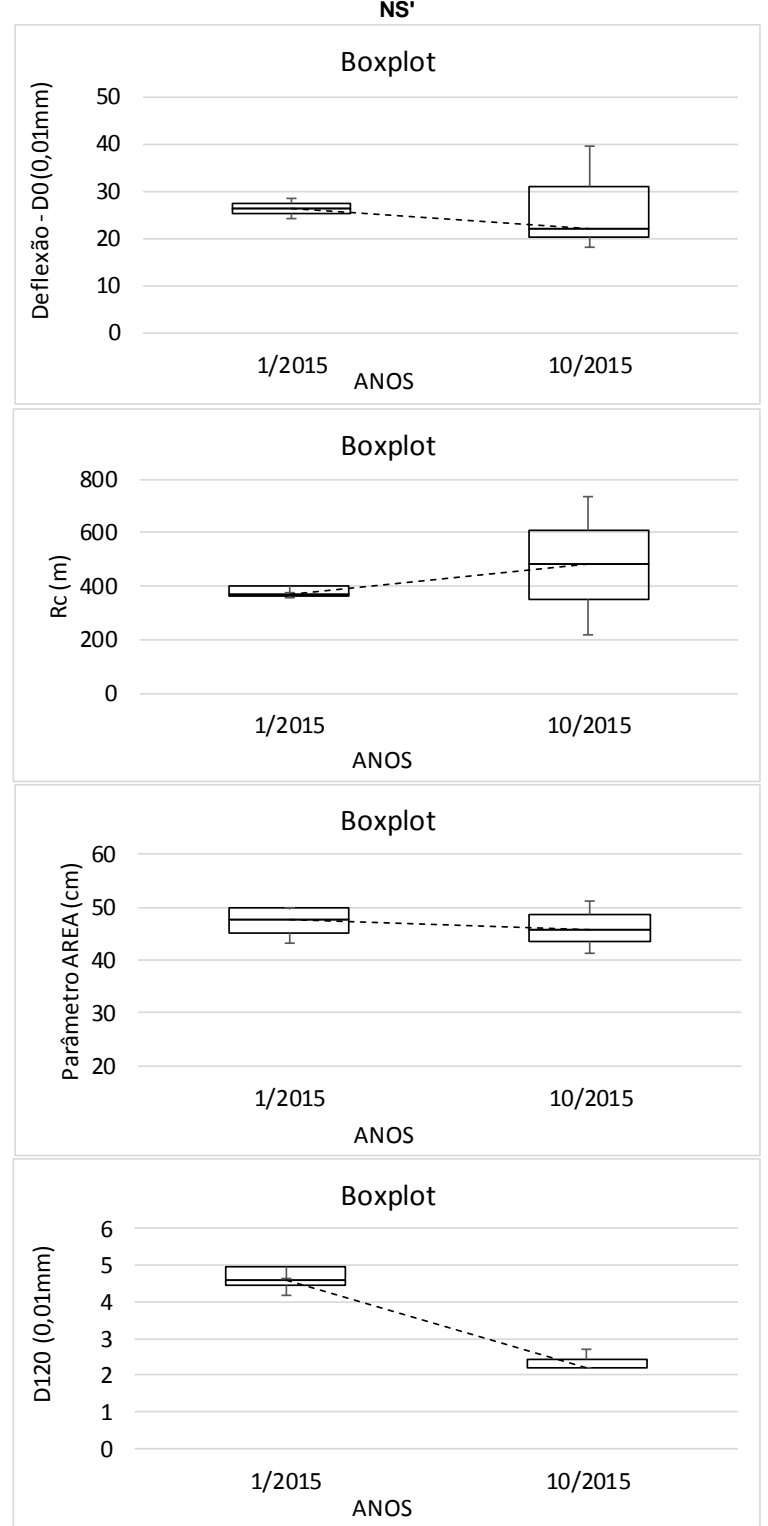

Boxplot

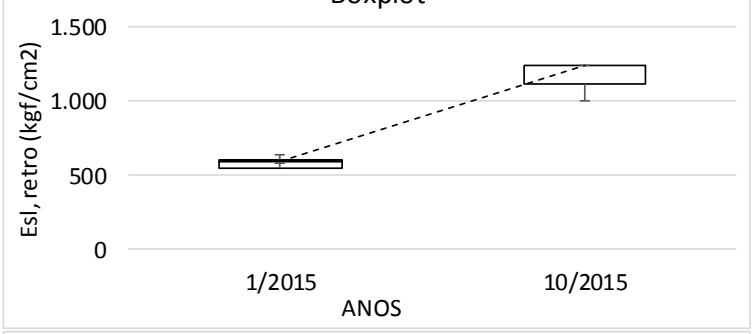

Boxplot

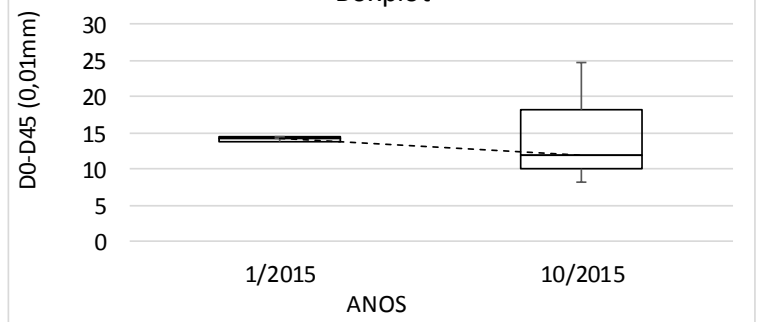

Figura 10.4: Estatísticas dos Parâmetros do pavimento (S. Homogêneo 4 - NS') 
$$
\text { 政 }
$$

34,42 34,58 CRESCENTE
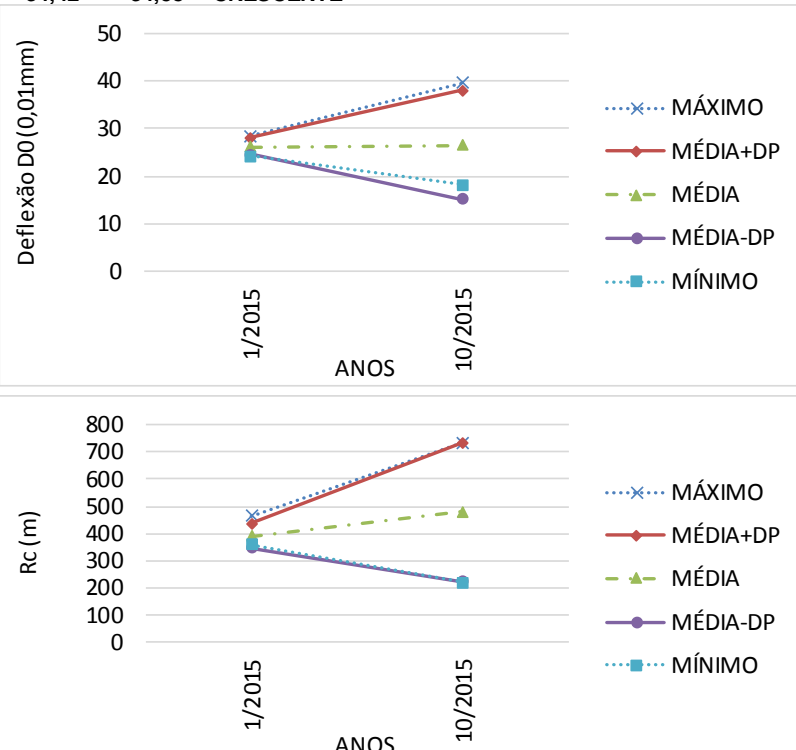

....... MÁXIMO

$\smile$ MÉDIA+DP

- - MÉDIA

$\longrightarrow$ MÉDIA-DP

........ MÍNIMO

ANOS

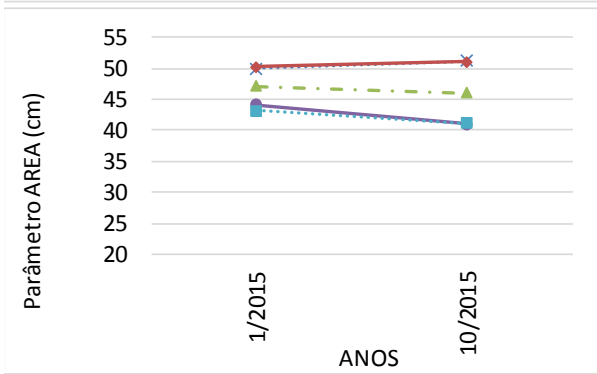

....... MÁXIMO

$\multimap$ MÉDIA+DP

- - MÉDIA

$\longrightarrow$ MÉDIA-DP

-... MÍ́NIMO

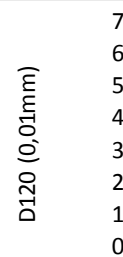
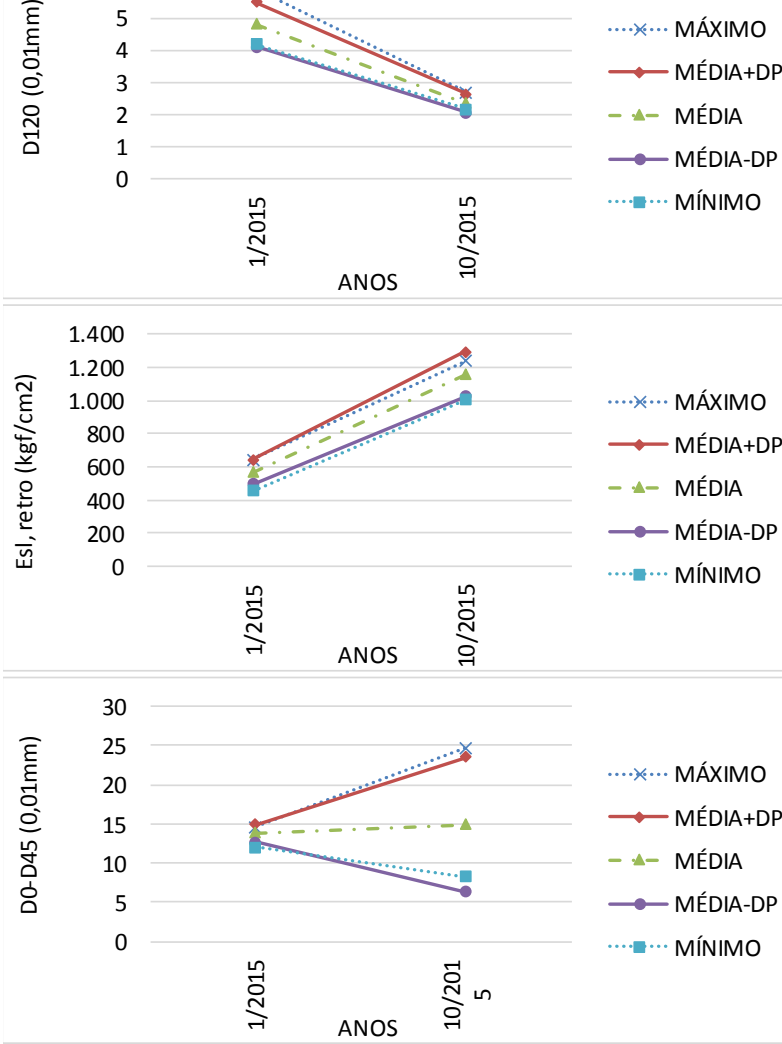

$\because$ MÉDIA+DP

- $\triangle$ - MÉDIA

$\longrightarrow$ MÉDIA-DP

.... MÍNIMO
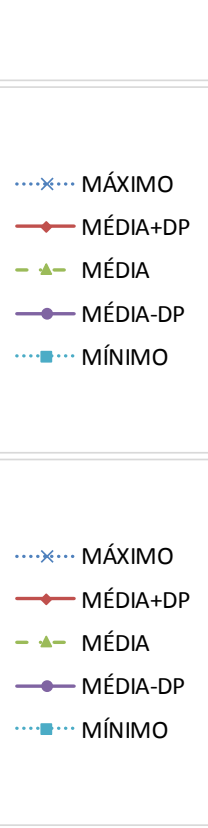

NS'

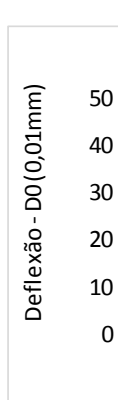

Boxplot

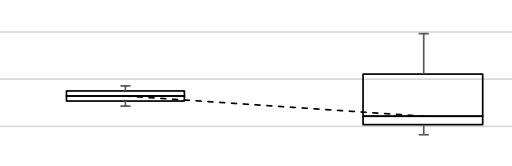

$1 / 2015$

ANOS

$10 / 2015$

Boxplot

800
$\underbrace{\underline{\Xi}}_{\mathscr{\Xi}} 400$
200
0

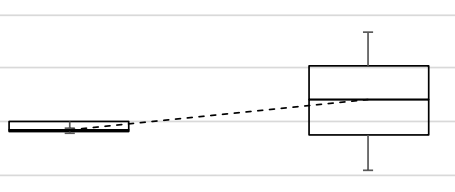

0

$1 / 2015$

$10 / 2015$

ANOS

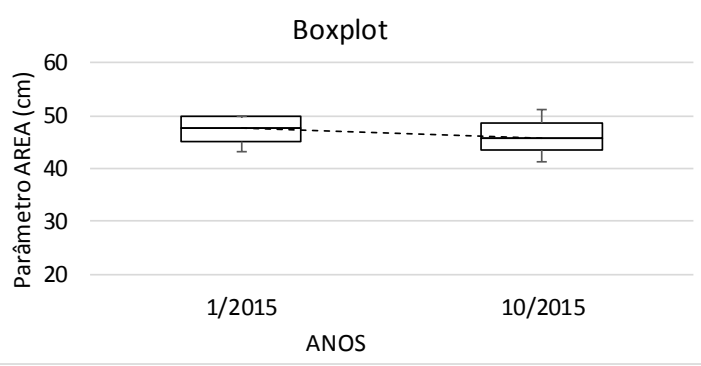

Boxplot

\section{Boxplot}
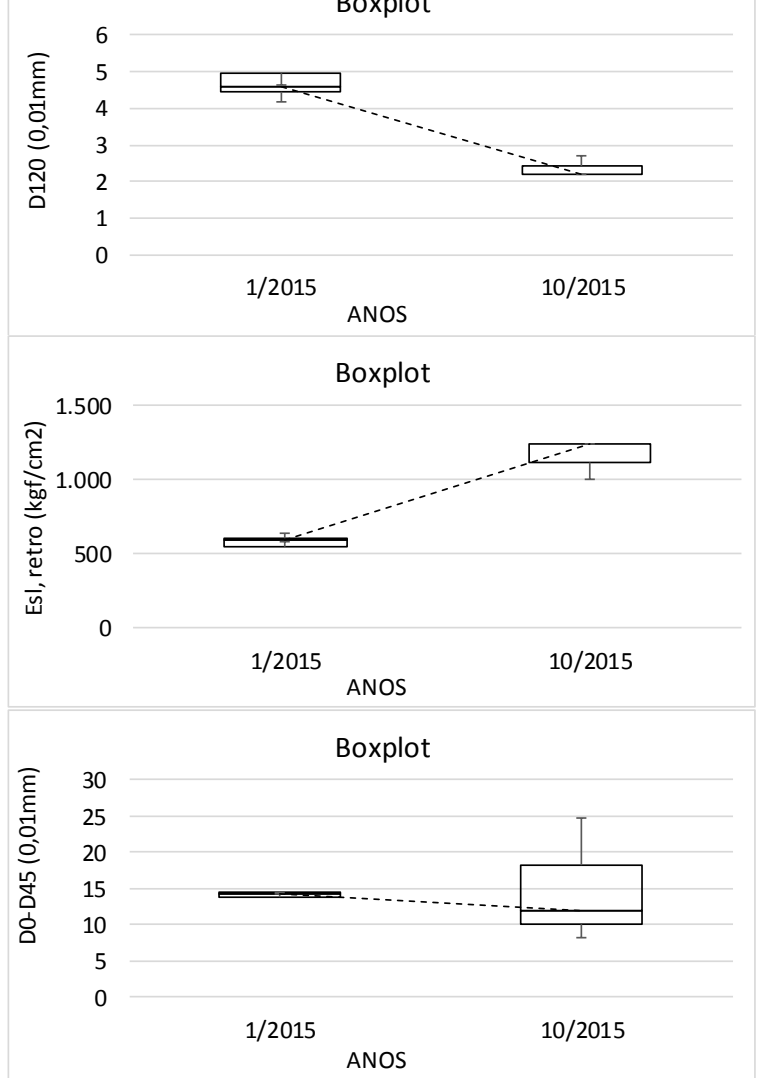

Figura 10.5: Estatísticas dos Parâmetros do pavimento (S. Homogêneo 5 - NG') 
$39,08 \quad 39,38 \quad$ CRESCENTE
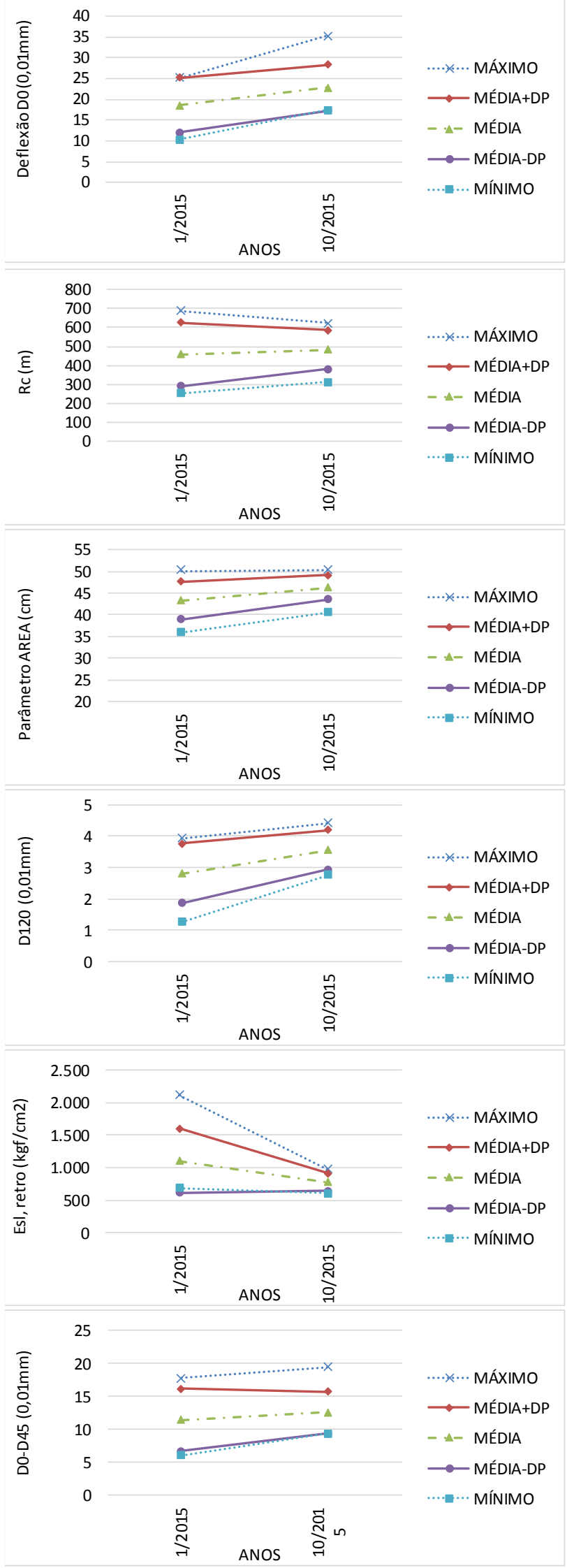

NA'
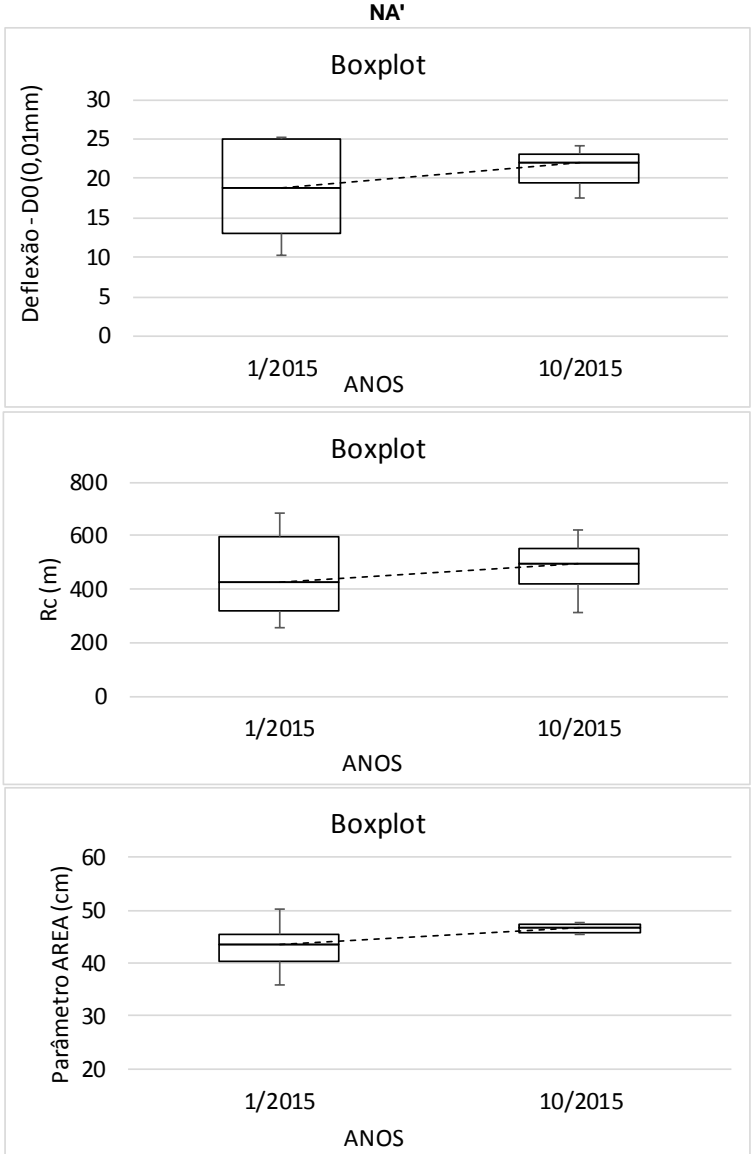

Boxplot

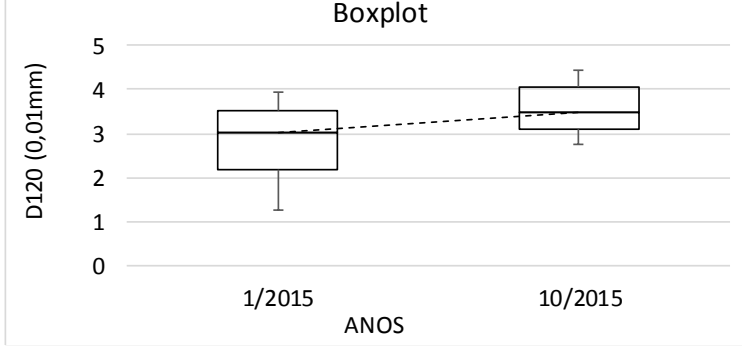

Boxplot
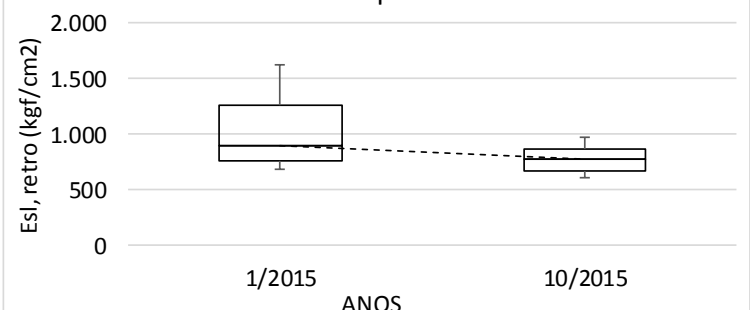

Boxplot

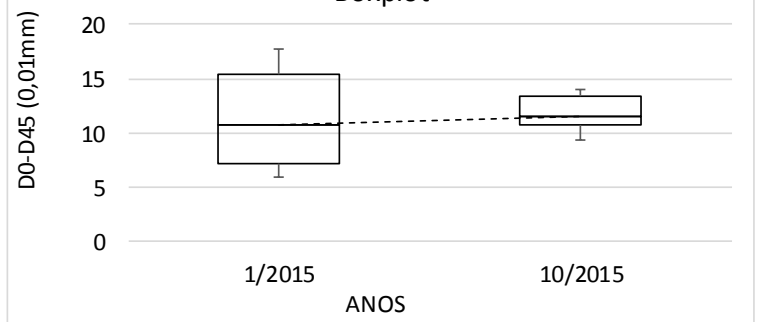

Figura 10.6: Estatísticas dos Parâmetros do pavimento (S. Homogêneo 6 - NA') 


$$
\text { है }
$$

$39,78 \quad 39,98$ CRESCENTE

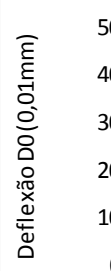
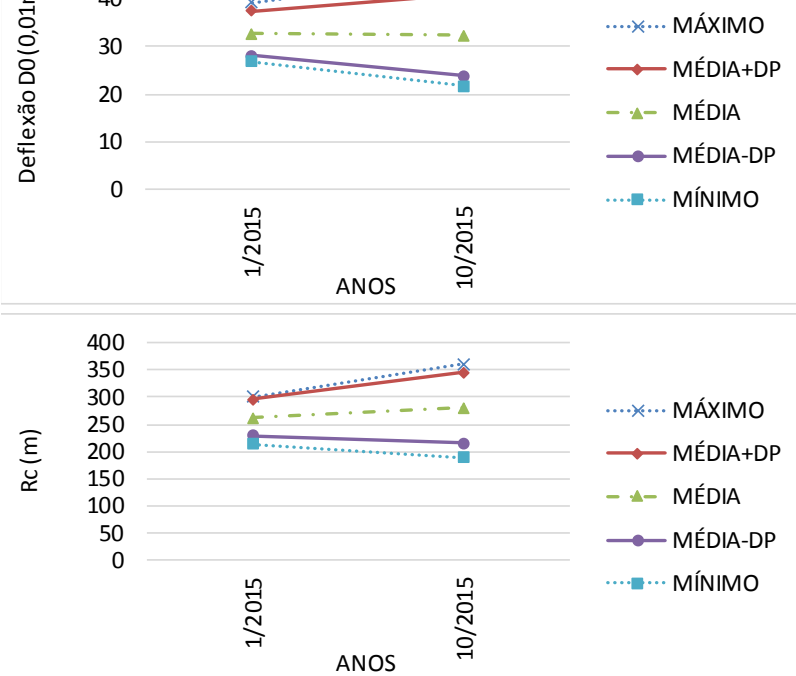

...*... MÁXIMO

$\because$ MÉDIA+DP

- $\triangle$ - MÉDIA

$\longrightarrow$ MÉDIA-DP

........ MÍNIMO

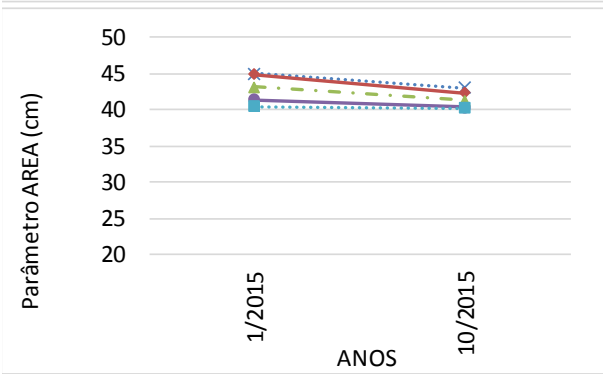

...*... MÁXIMO

$\multimap$ MÉDIA+DP

- - MÉDIA

$\because$ MÉDIA-DP

..... MÍNIMO

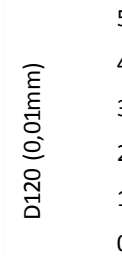

望
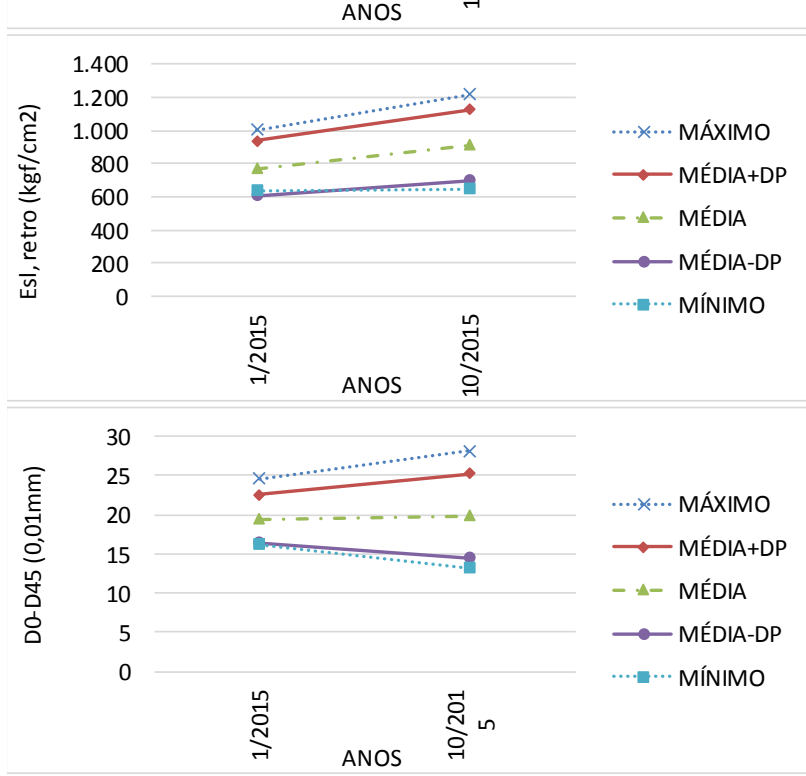

NG'

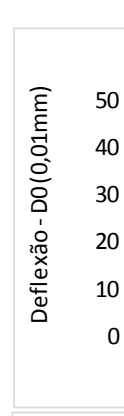

Boxplot
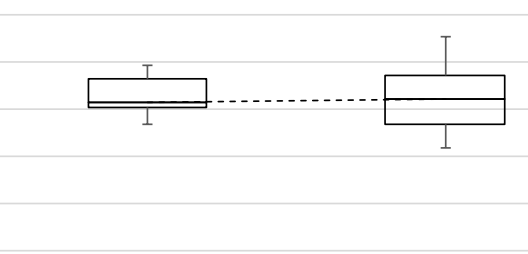

1/2015 ANOS

$10 / 2015$
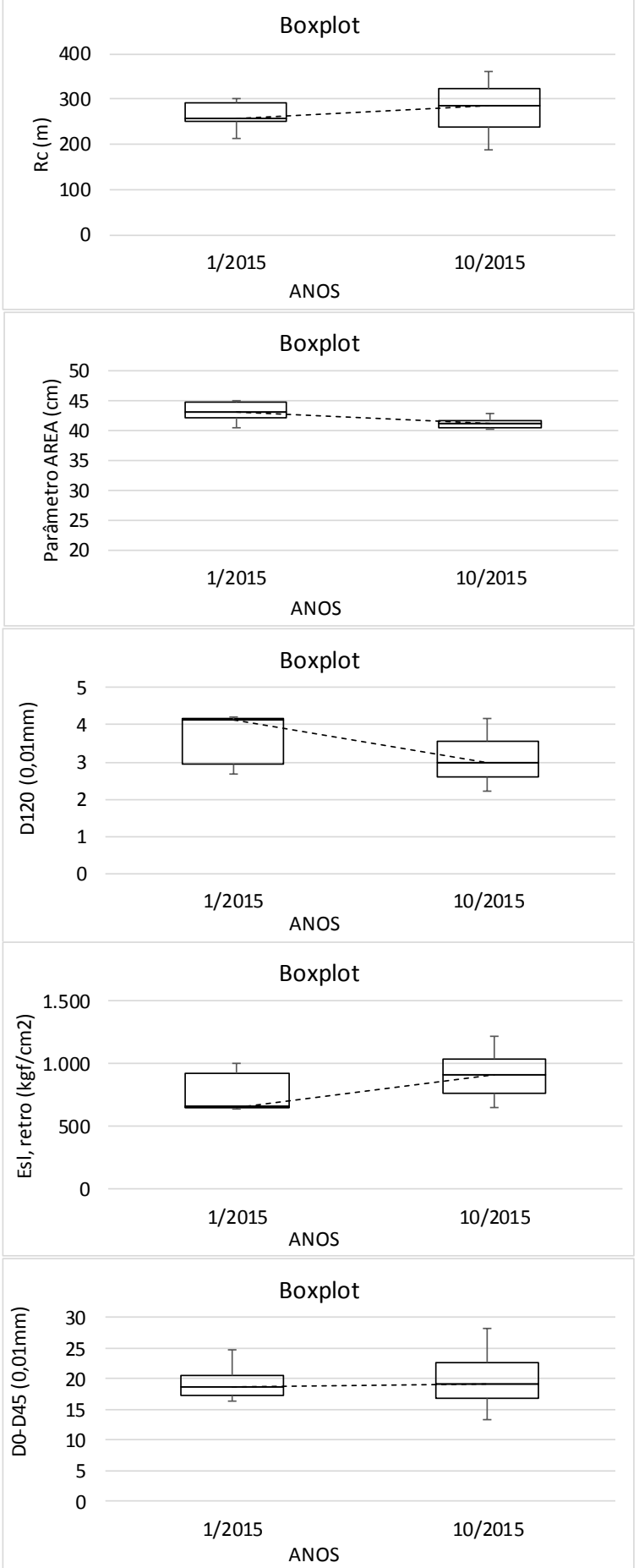

Figura 10.7: Estatísticas dos Parâmetros do pavimento (S. Homogêneo 7 - NG') 

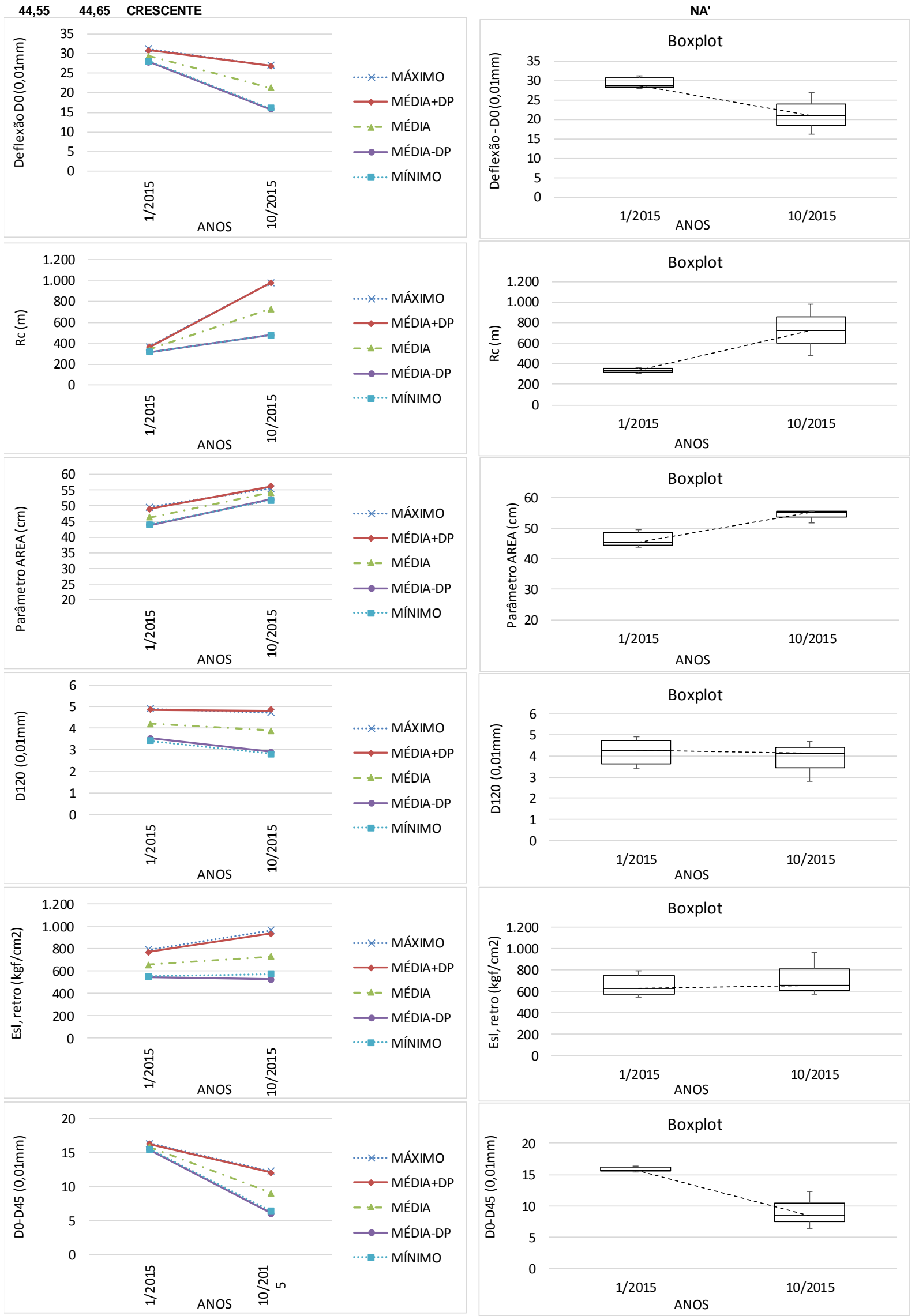

Figura 10.8: Estatísticas dos Parâmetros do pavimento (S. Homogêneo 8 - NA') 


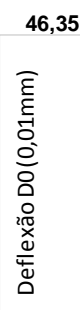

46,55 CRESCENTE
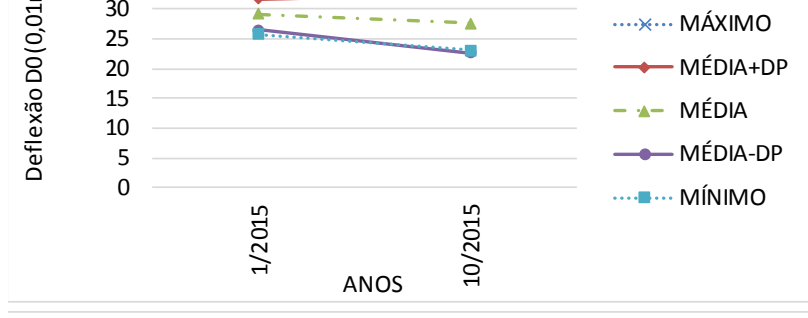

........ MÍNIMO
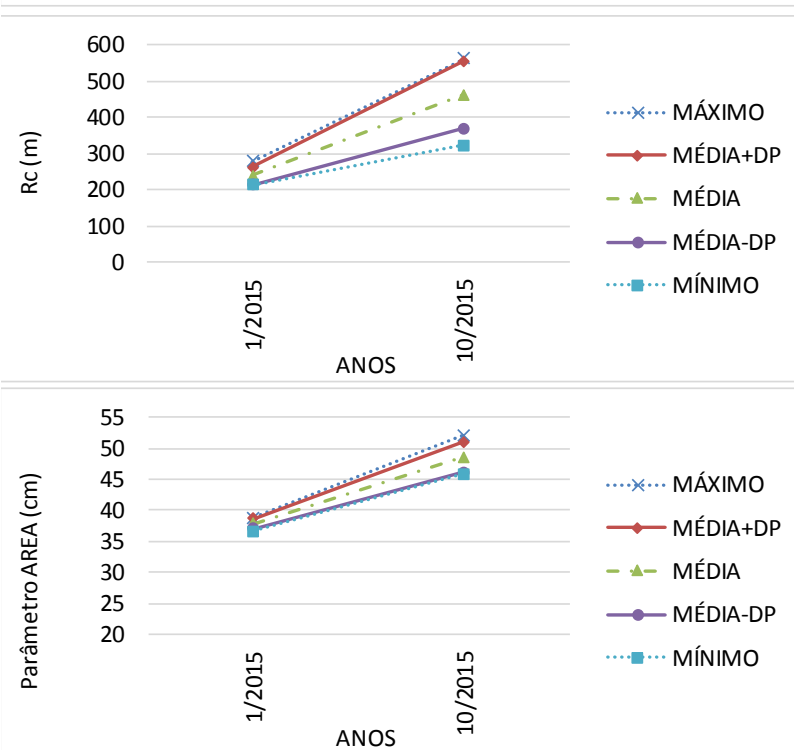

$\cdots * \cdots$ MÁXIMO

$\longrightarrow$ - MÉDIA+DP

- - MÉDIA

$\longrightarrow$ MÉDIA-DP

-..... MÍNIMO
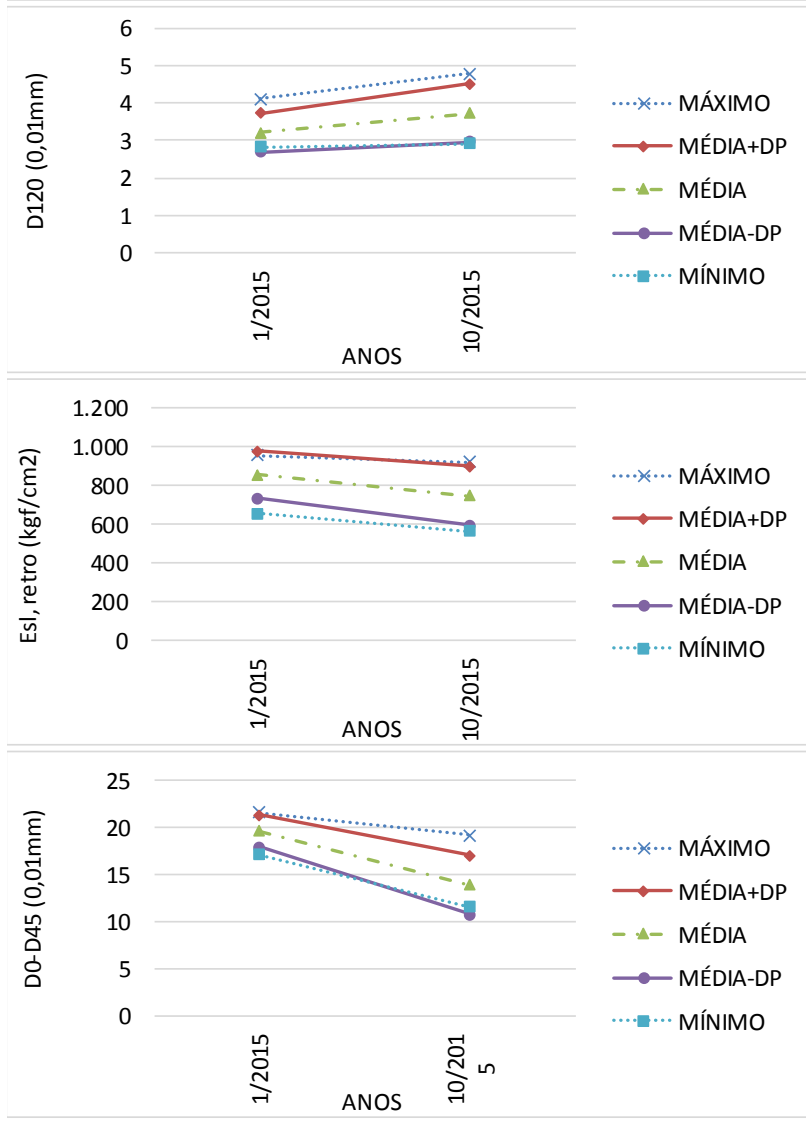
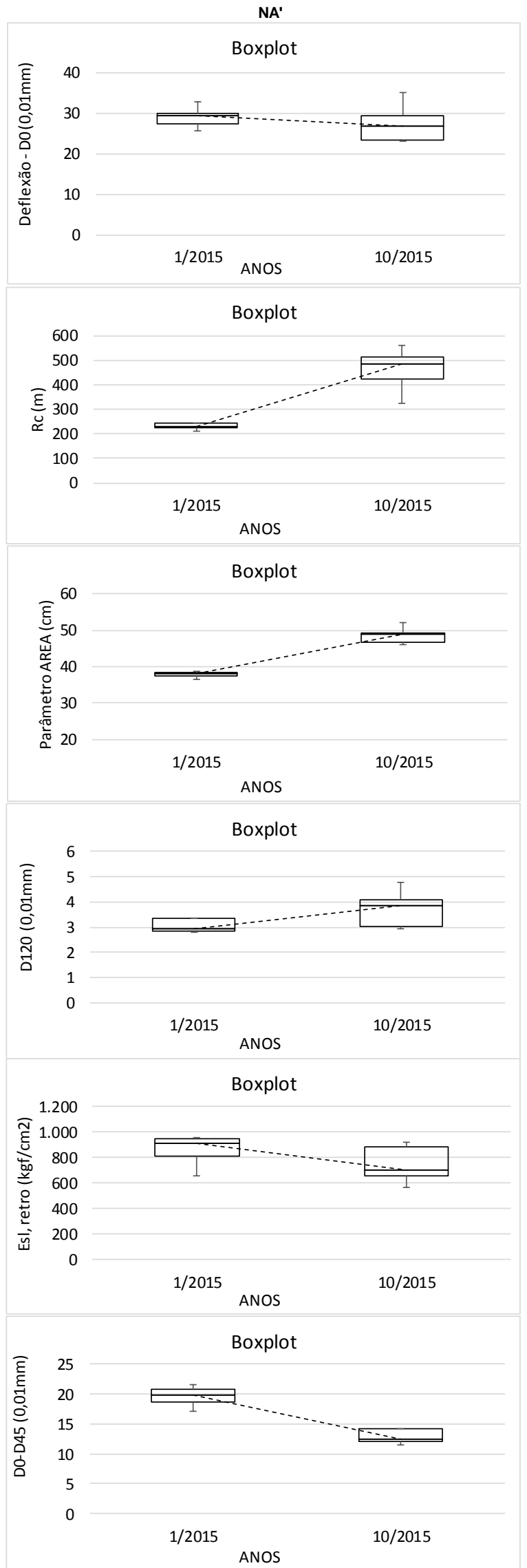

Figura 10.9: Estatísticas dos Parâmetros do pavimento (S. Homogêneo 9 - NA') 

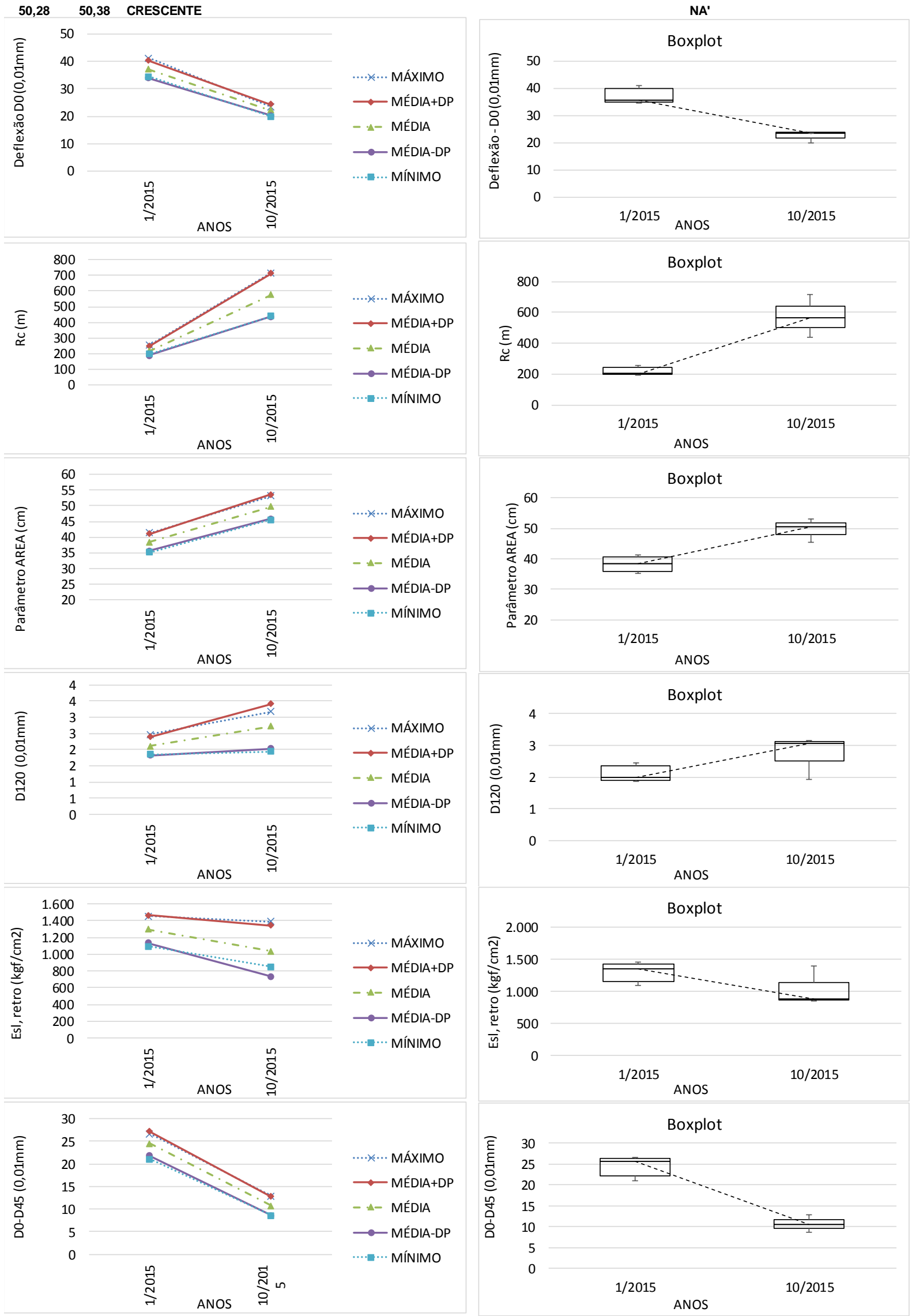

Figura 10.10: Estatísticas dos Parâmetros do pavimento (S. Homogêneo 10 - NA') 


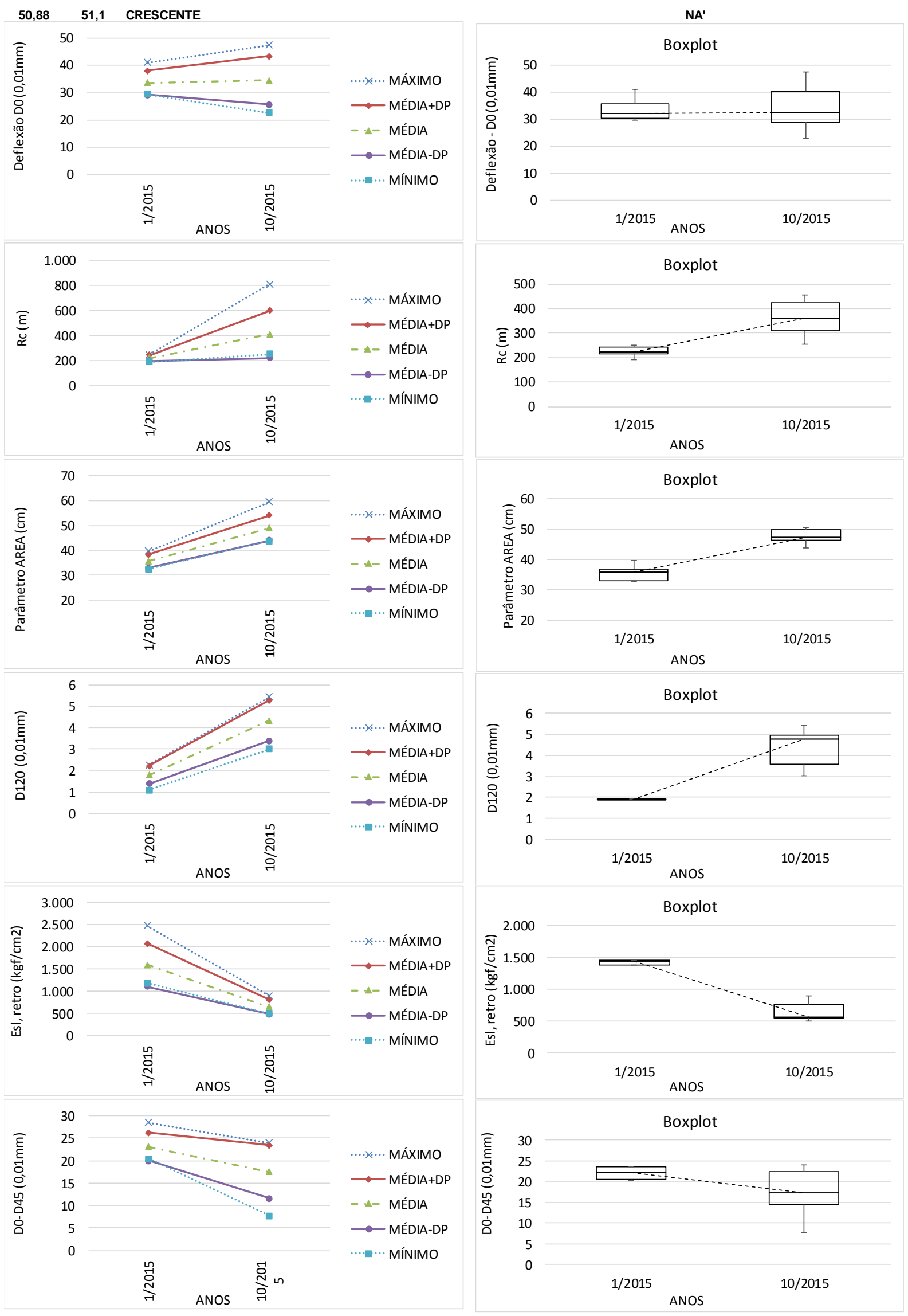

Figura 10.11: Estatísticas dos Parâmetros do pavimento (S. Homogêneo 11 - NA') 
52,16 52,38 CRESCENTE
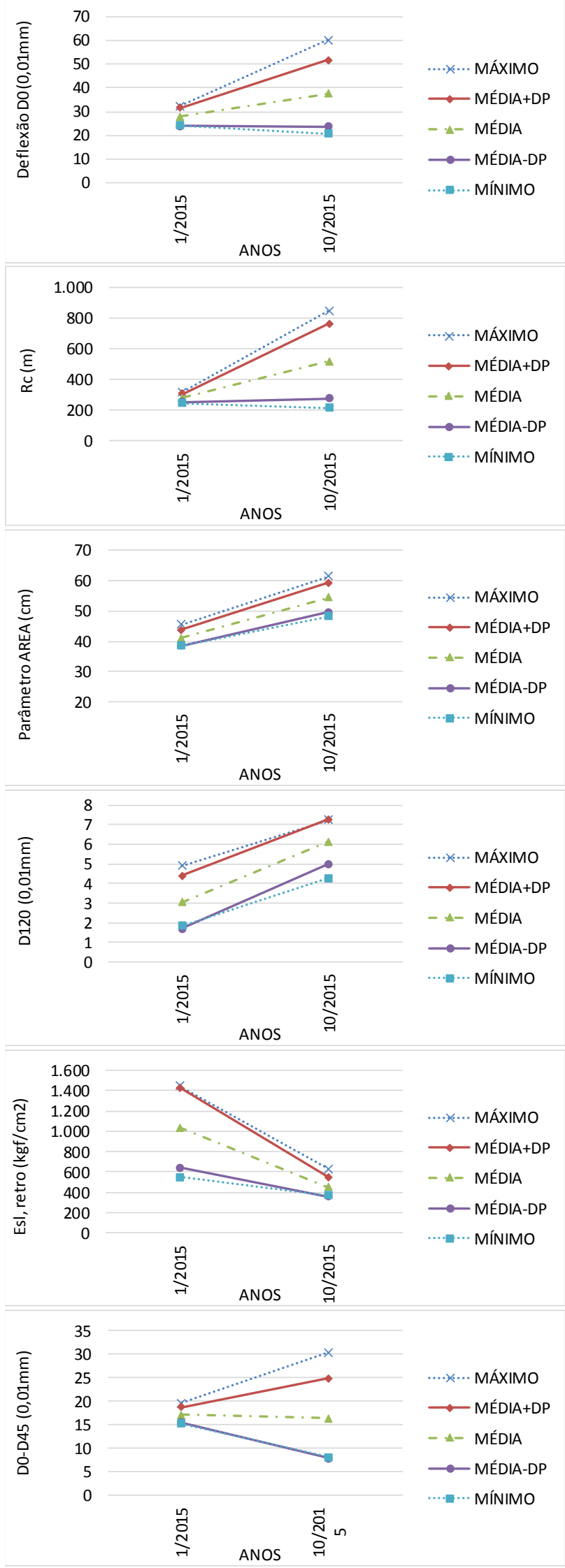

NA'
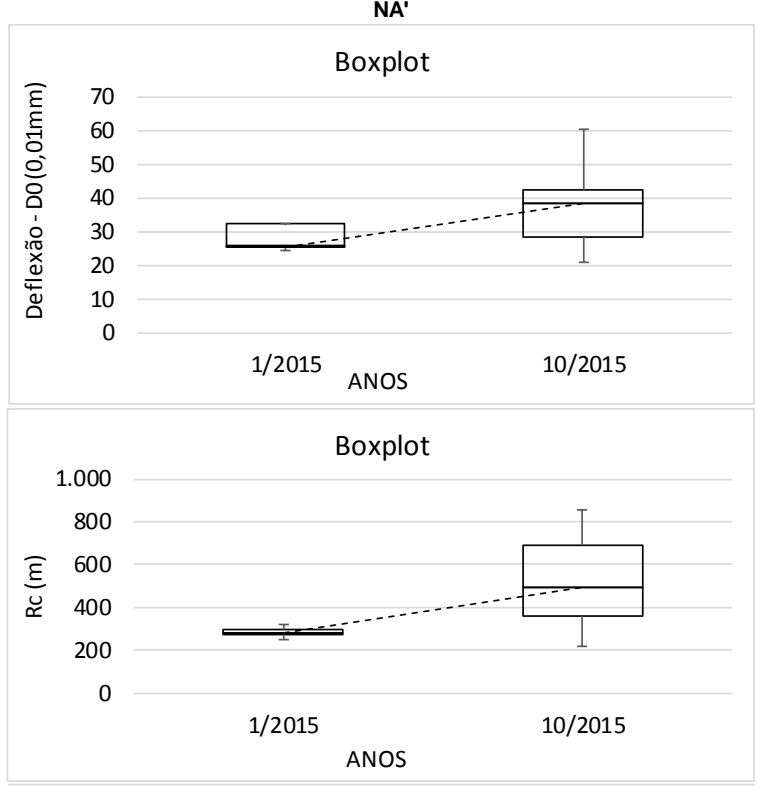

Boxplot

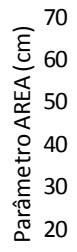

70
60
40
30
20
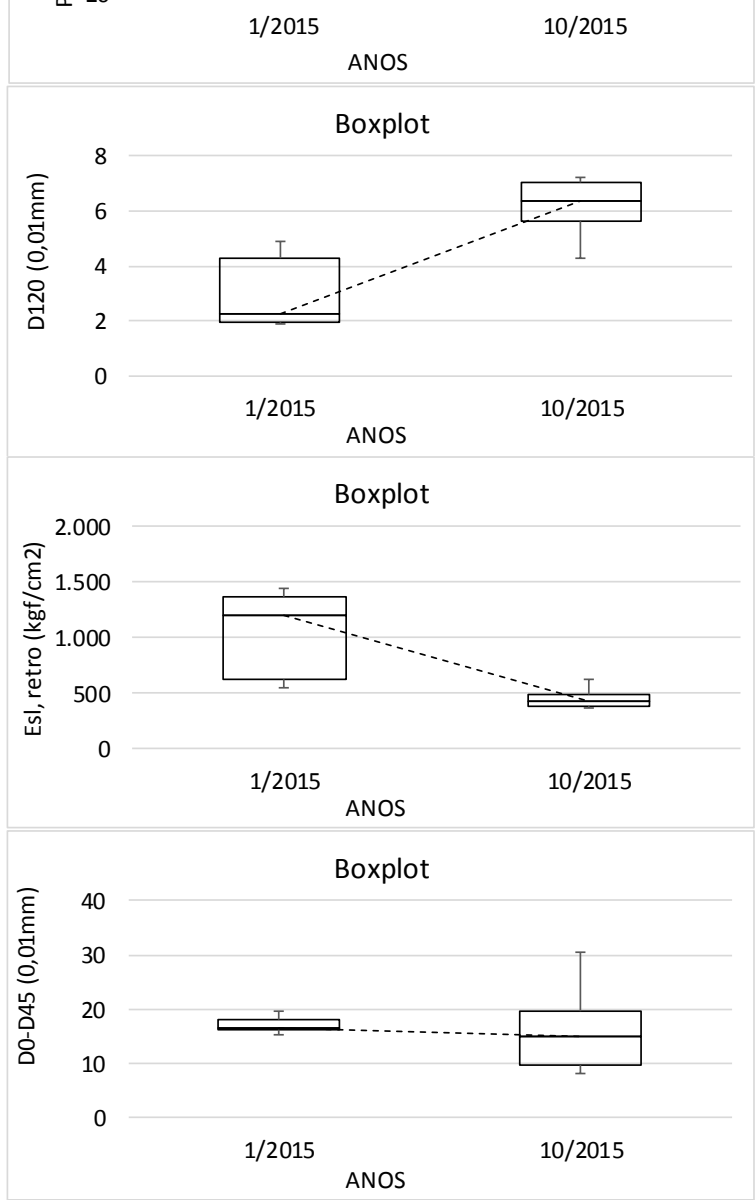

Figura 10.12: Estatísticas dos Parâmetros do pavimento (S. Homogêneo 12 - NA') 
$58,84 \quad 59,08$ CRESCENTE

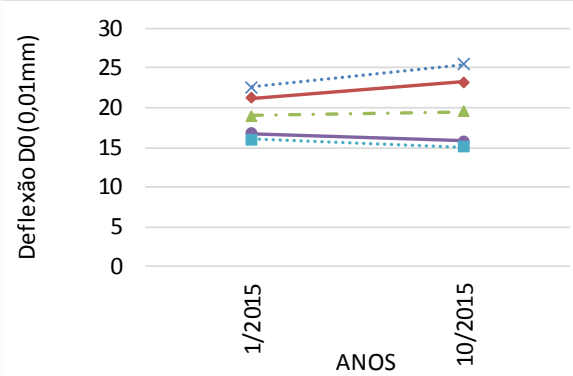

........ MÁXIMO

$\multimap$ MÉDIA+DP

- . - MÉDIA

— MÉDIA-DP

....... MÍNIMO

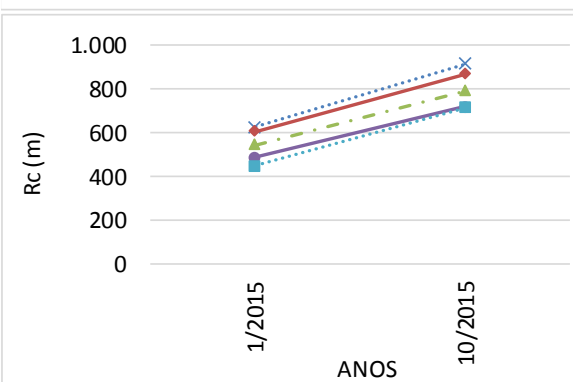

…… MÁXIMO

— MÉDIA+DP

- A- MÉDIA

$\longrightarrow$ MÉDIA-DP

........ MÍNIMO

ANOS
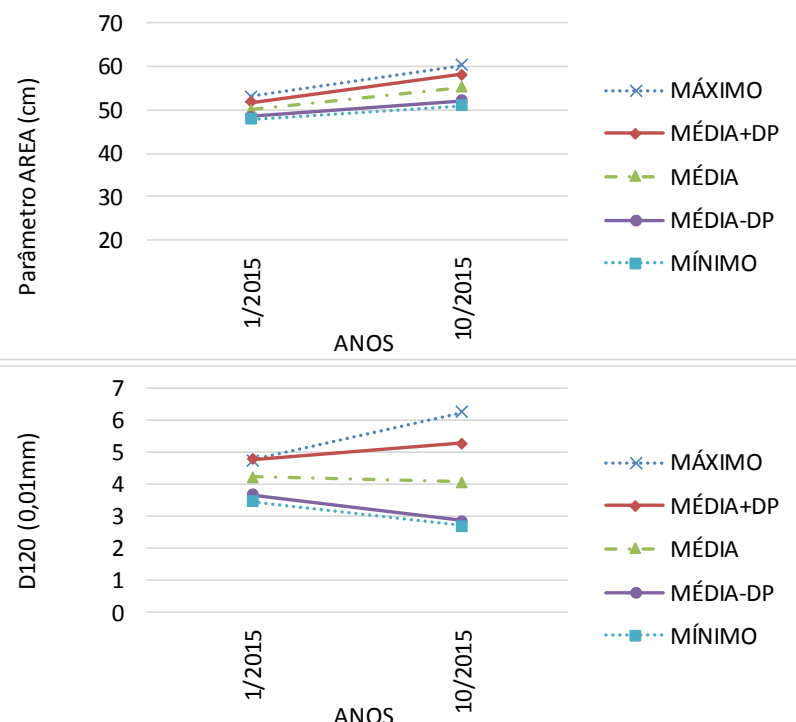

....*... MÁXIMO

$\because$ MÉDIA+DP

- $\triangle$ - MÉDIA

$\longrightarrow$ MÉDIA-DP

....... MÍNIMO

ANOS

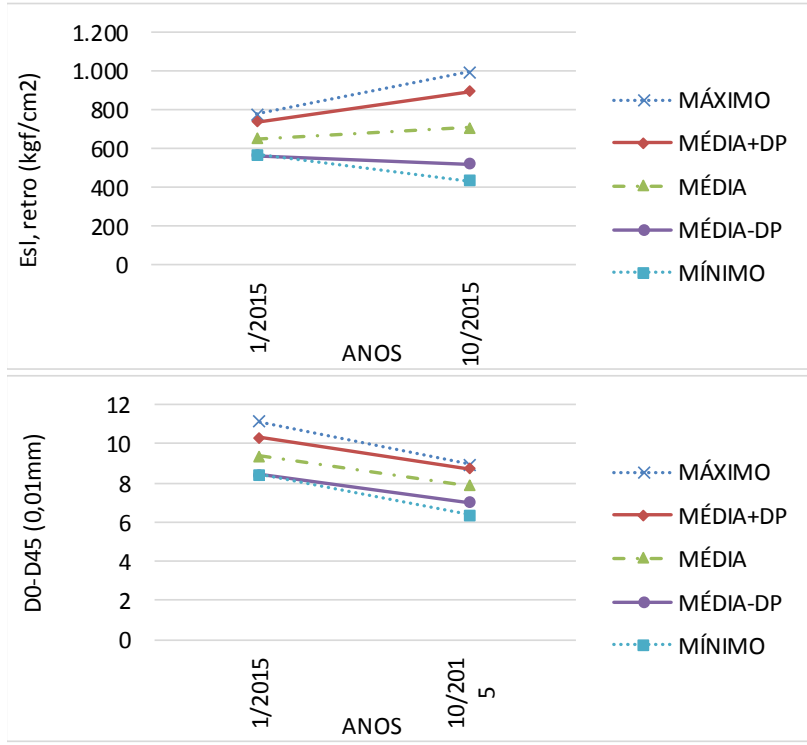

NA'
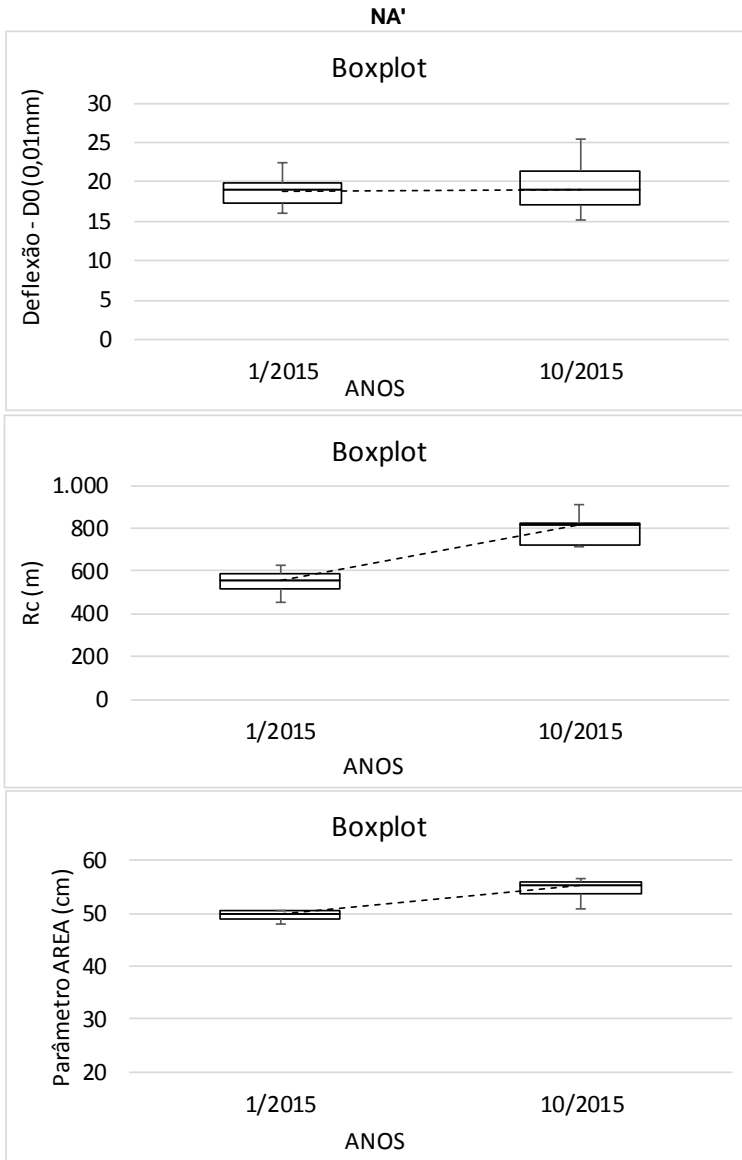

Boxplot

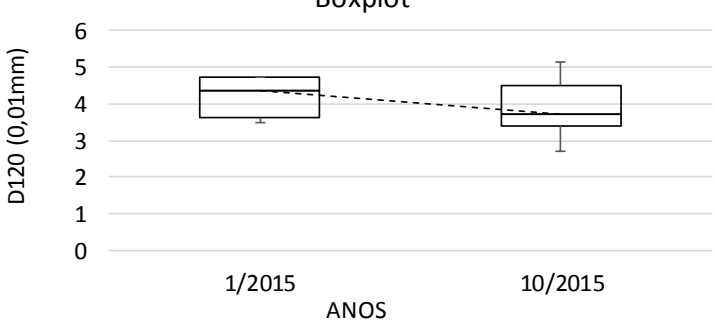

Boxplot

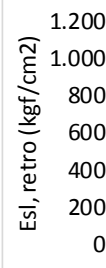

200

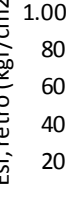

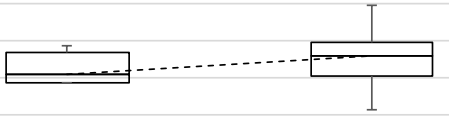

$1 / 2015$

$10 / 2015$

ANOS

Boxplot

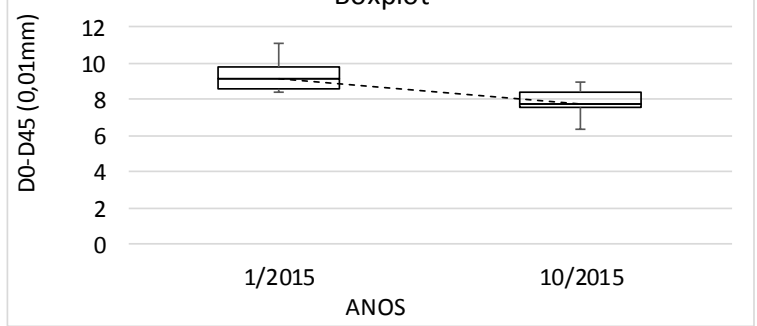

Figura 10.13: Estatísticas dos Parâmetros do pavimento (S. Homogêneo 13 - NA') 
$65 \quad 65,3$ CRESCENTE

LA'
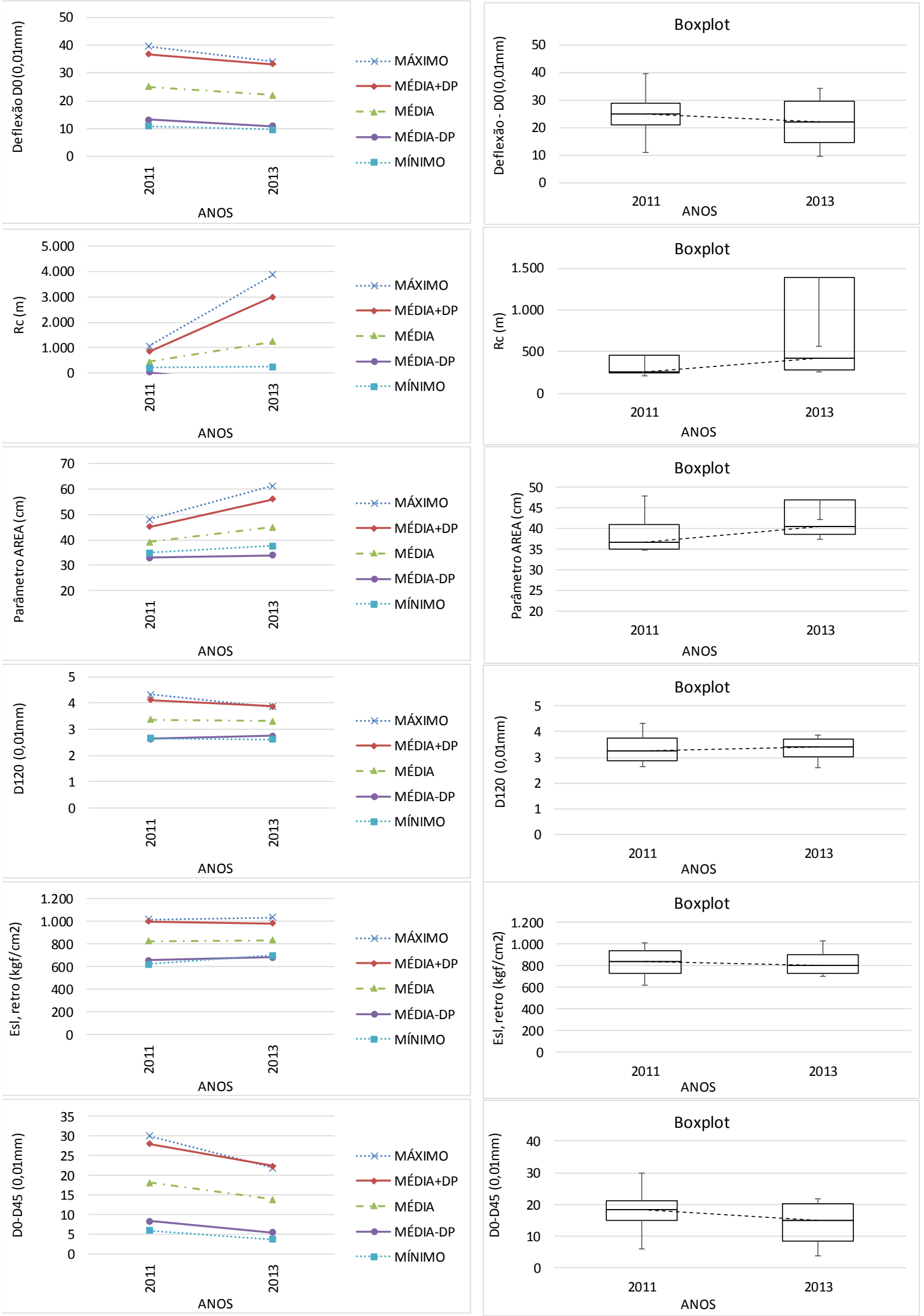

Figura 10.14: Estatísticas dos Parâmetros do pavimento (S. Homogêneo 14 - NA') 
65,5 65,705 CRESCENTE
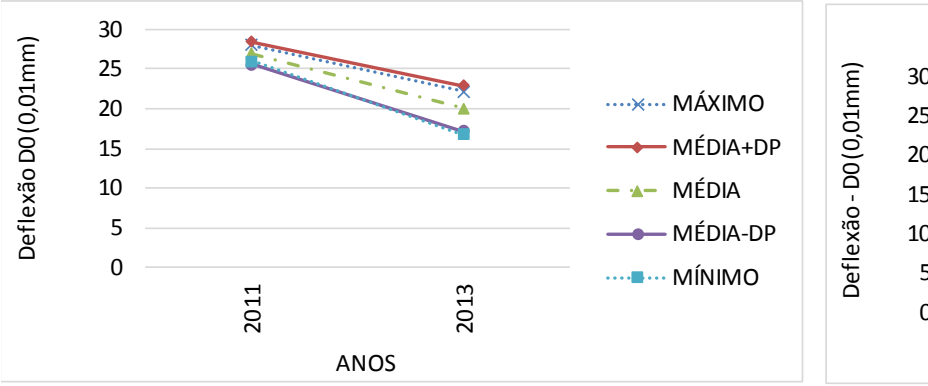

LA'
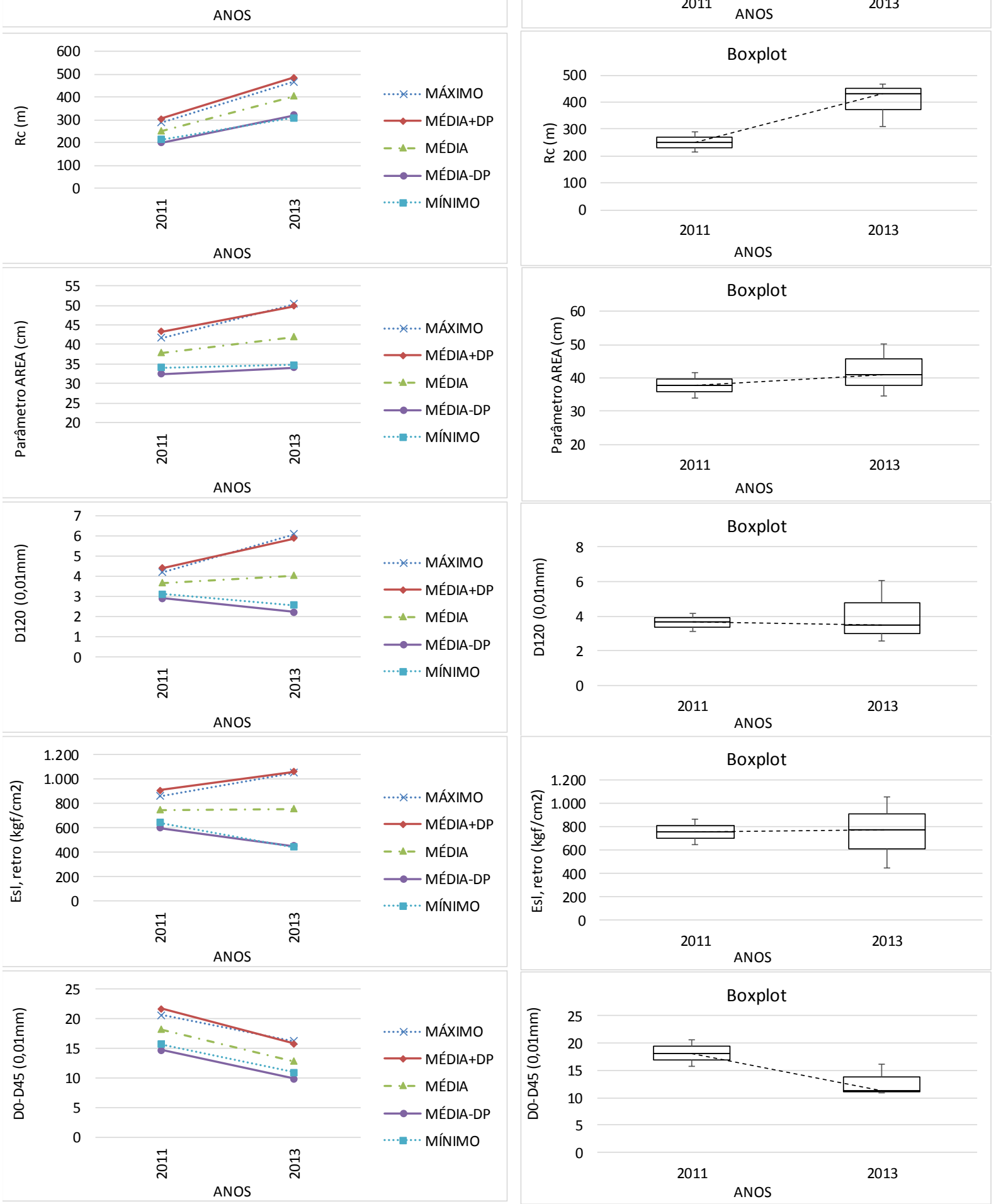

Figura 10.15: Estatísticas dos Parâmetros do pavimento (S. Homogêneo 15 - NA') 
$67 \quad 67,3$ DECRESCENTE
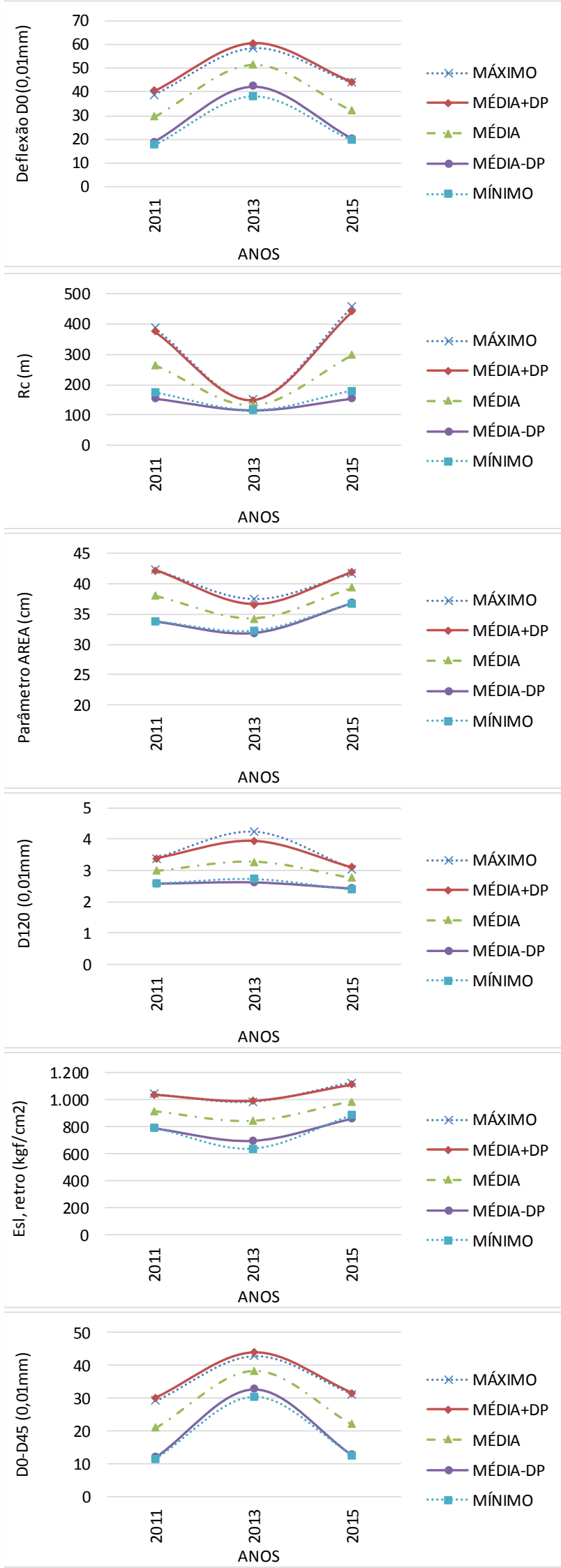
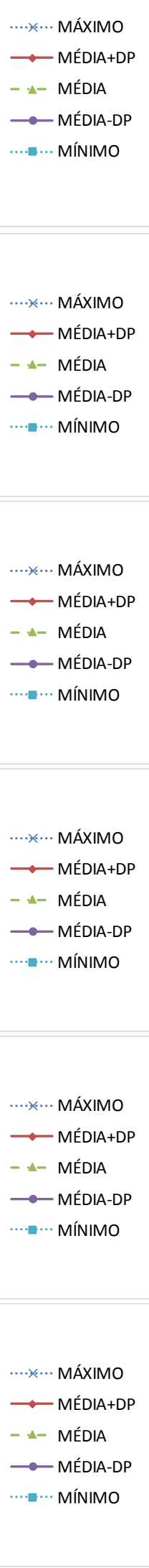

LA'

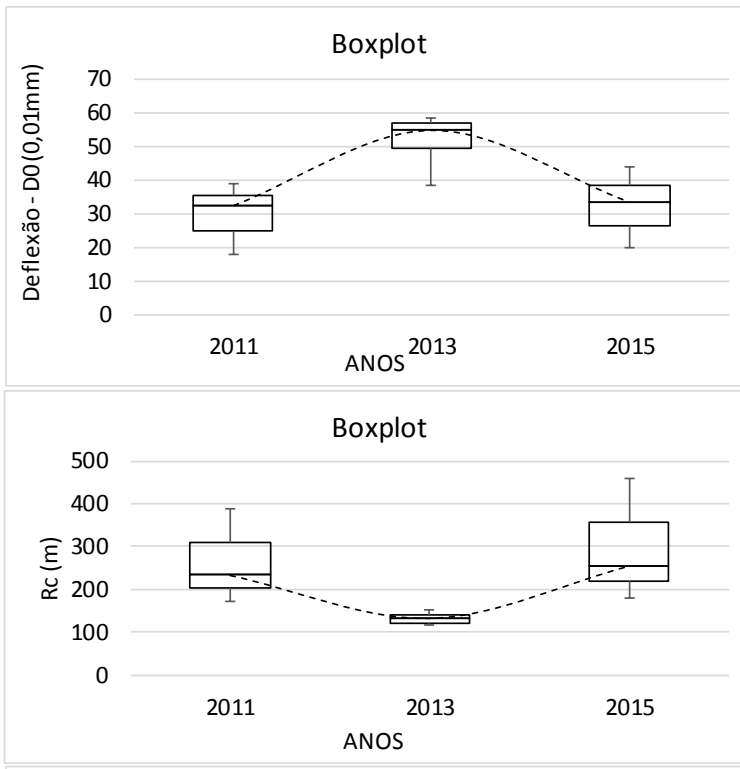

Boxplot

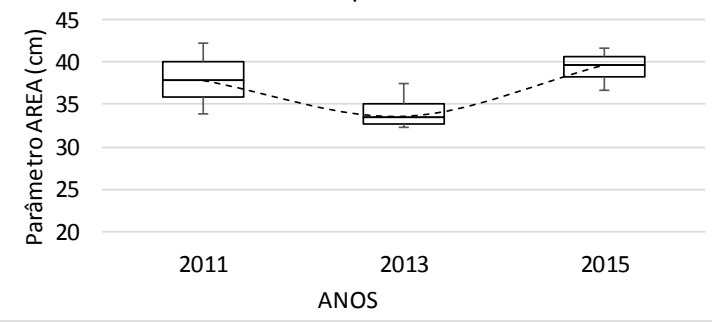

Boxplot

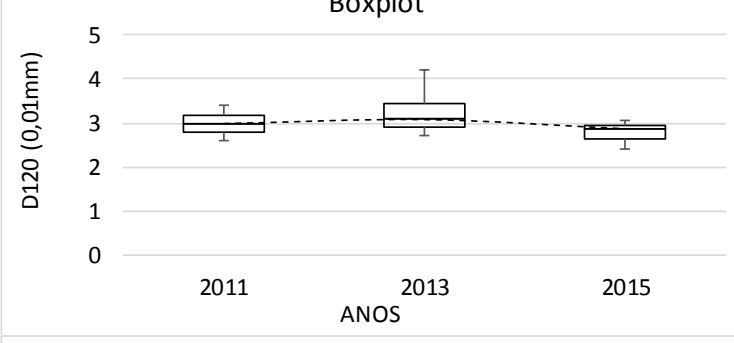

Boxplot
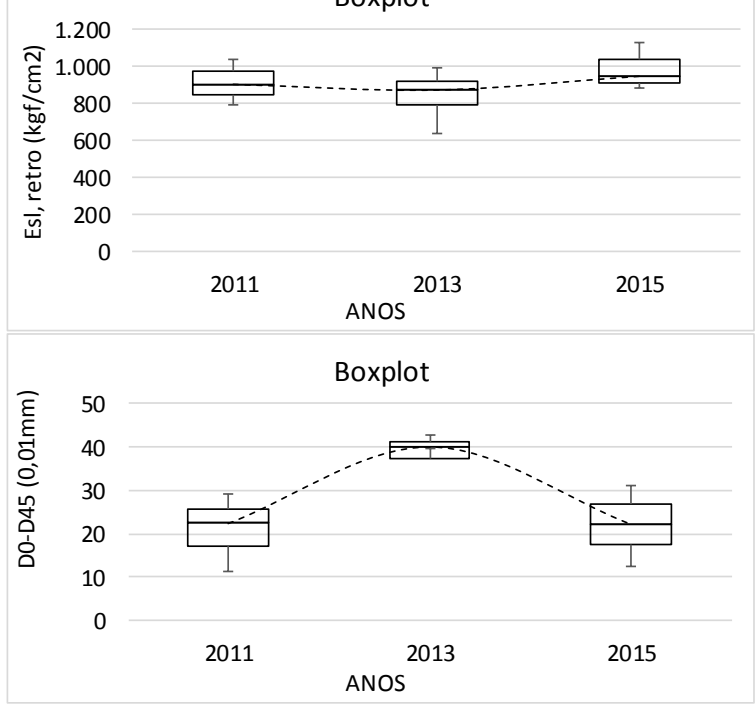

Figura 10.16: Estatísticas dos Parâmetros do pavimento (S. Homogêneo 16 - LA') 

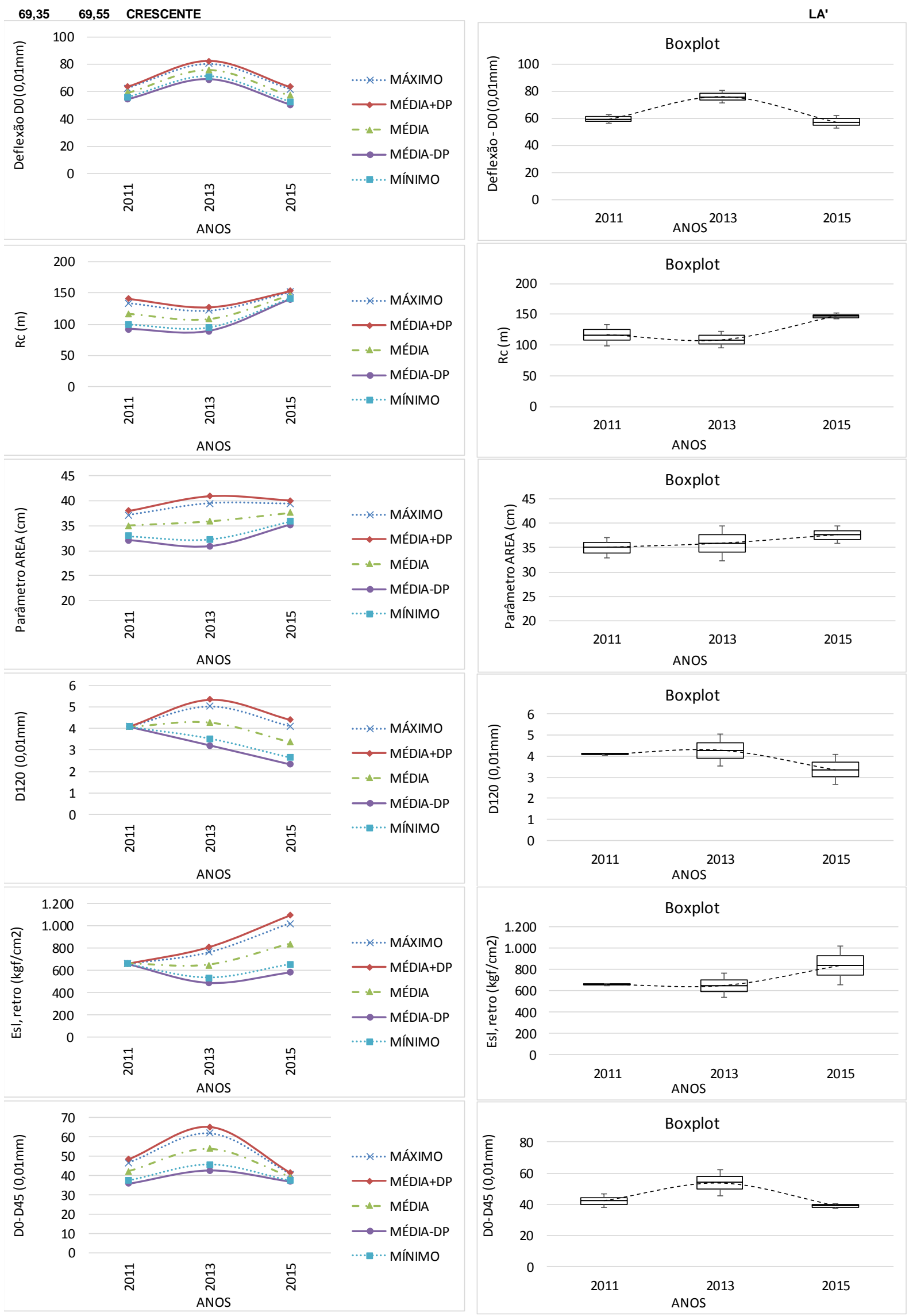

Figura 10.17: Estatísticas dos Parâmetros do pavimento (S. Homogêneo 17 - LA') 
70,3 70,455 CRESCENTE
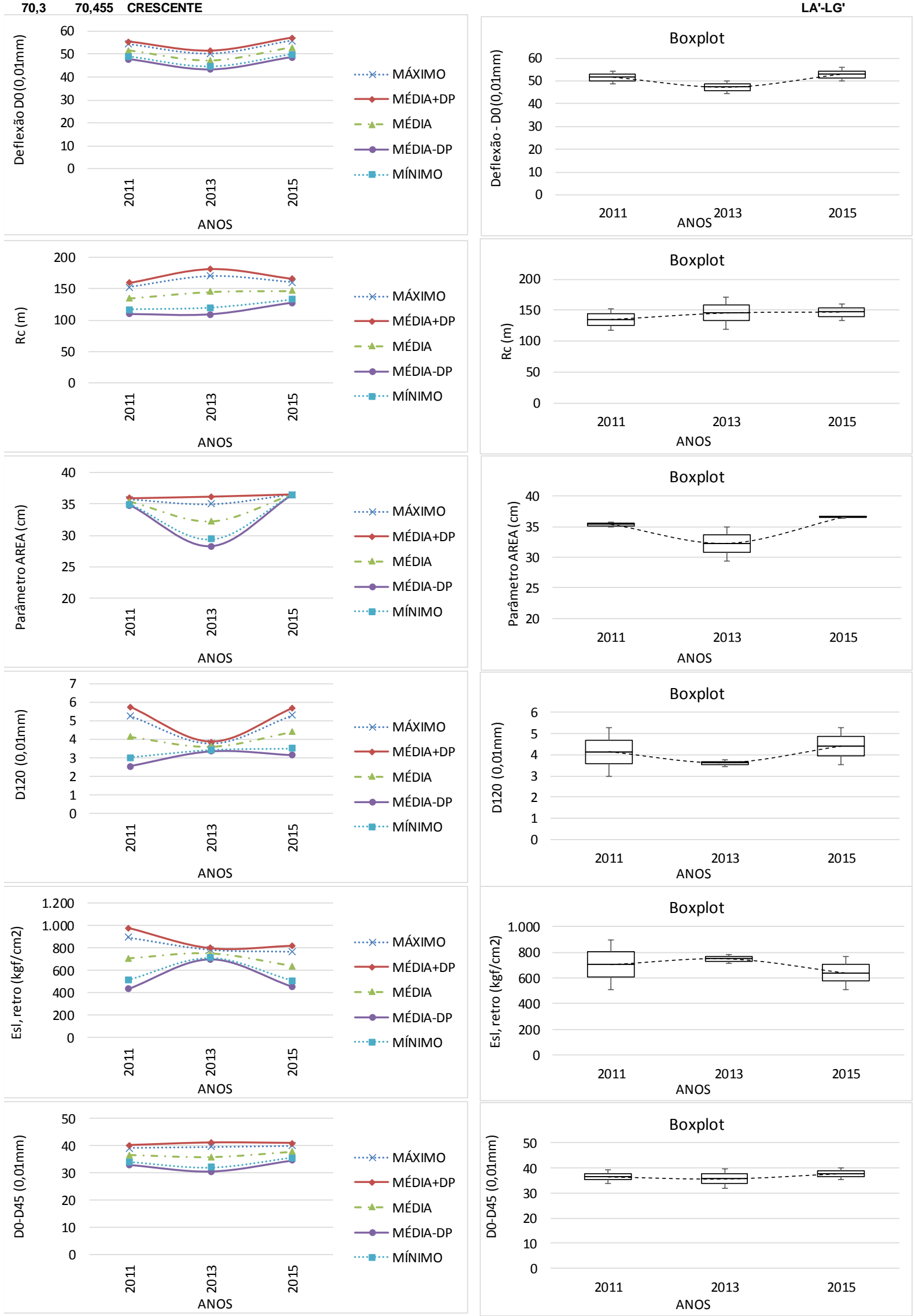

Figura 10.18: Estatísticas dos Parâmetros do pavimento (S. Homogêneo 18 - LA'-LG') 
75,255 75,705 CRESCENTE
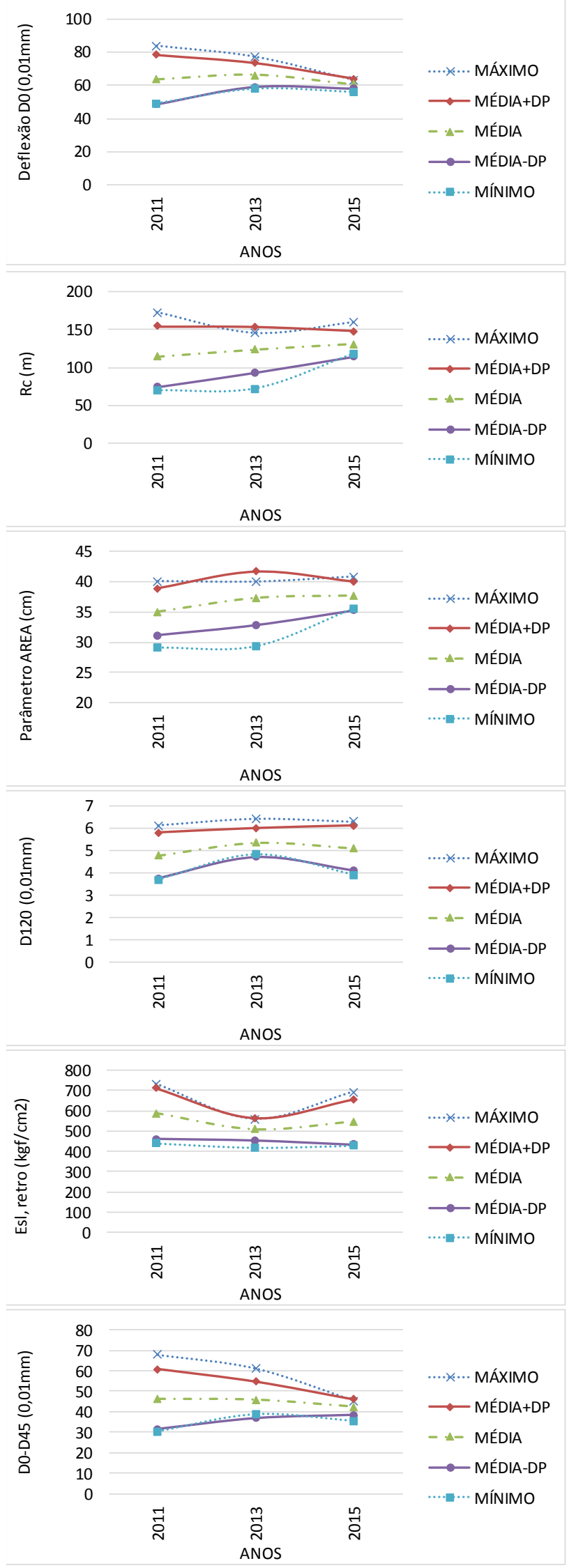

LA'

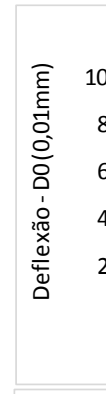

Boxplot
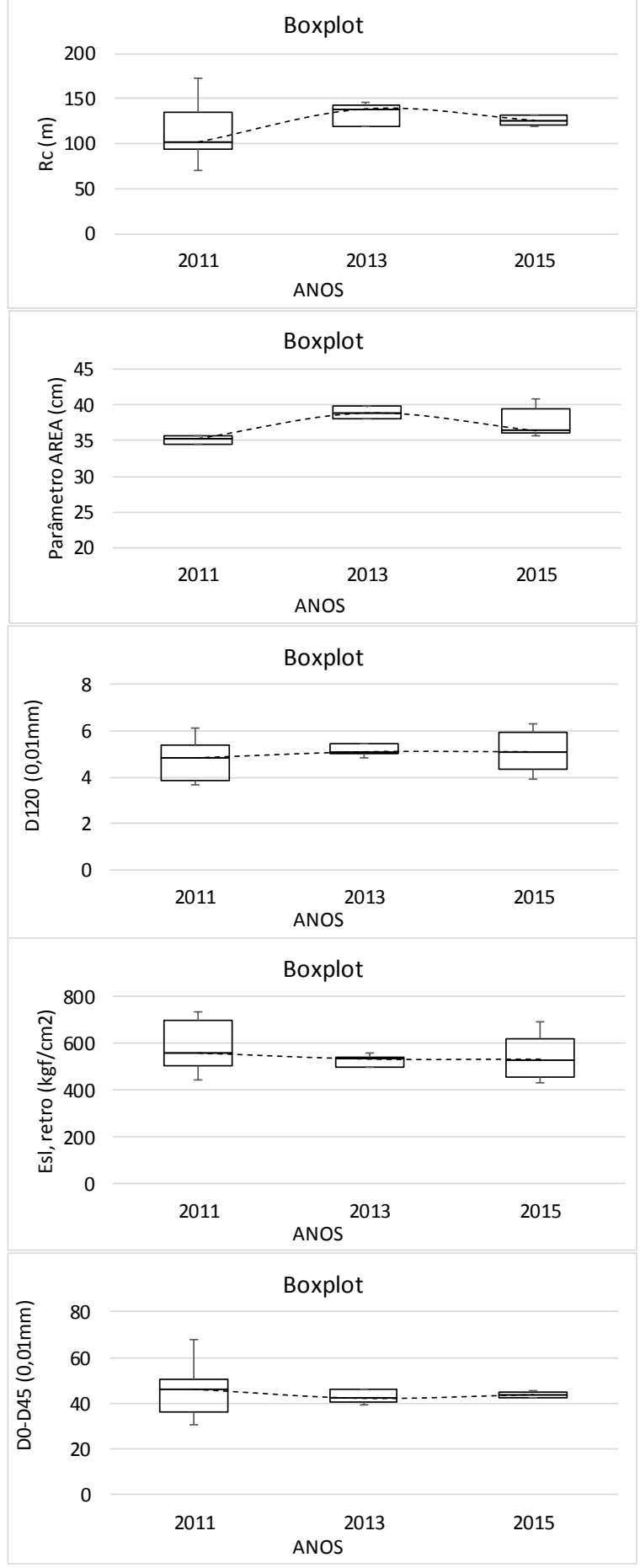

Figura 10.19: Estatísticas dos Parâmetros do pavimento (S. Homogêneo 19 - LA') 
77,205 77,505 CRESCENTE
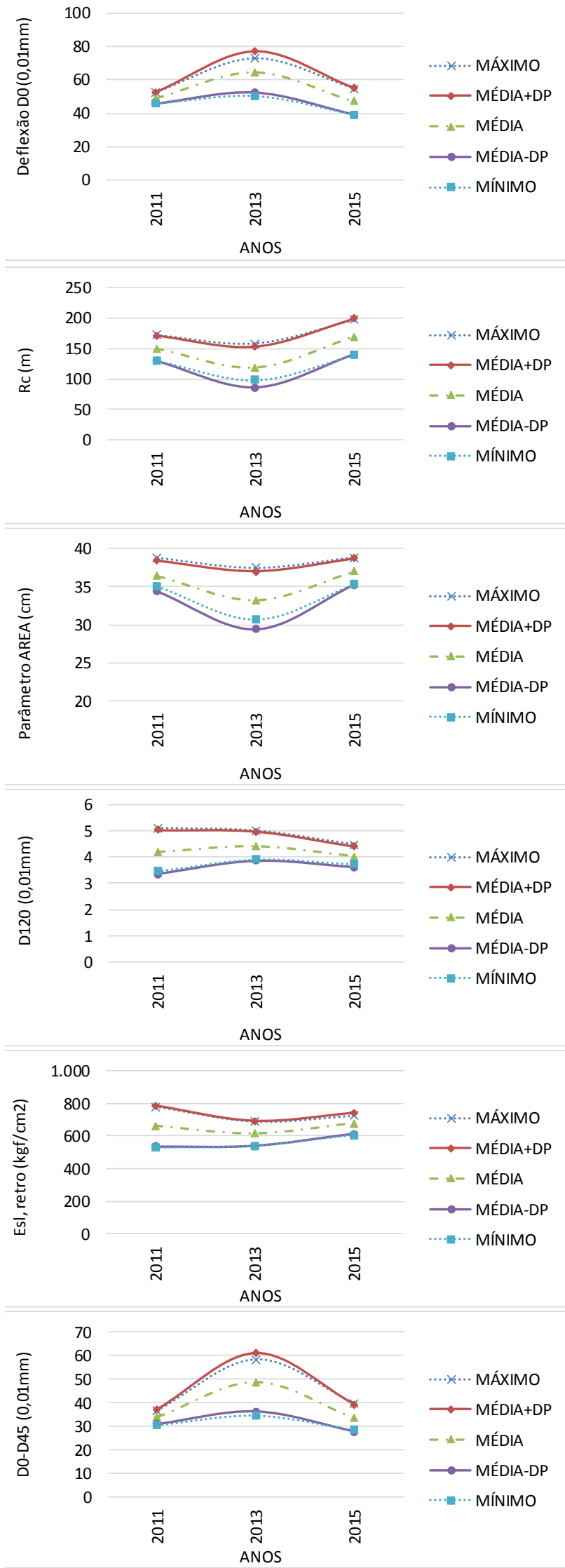

........ MÍNIMO

- $\triangle$ - MÉDIA

$\multimap$ MÉDIA-DP

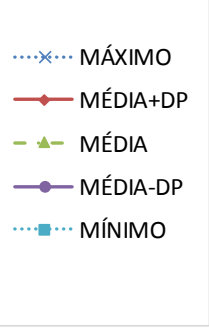

(

$$
\text { . }
$$
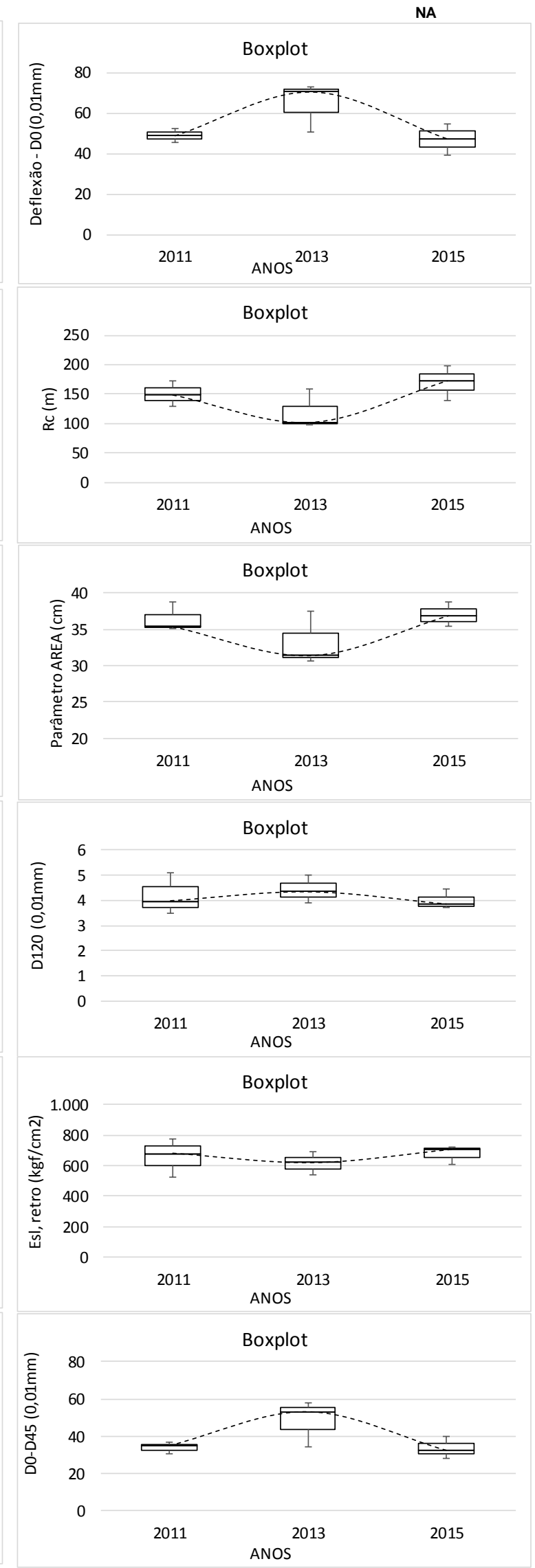

Figura 10.20: Estatísticas dos Parâmetros do pavimento (S. Homogêneo 20 - NA) 
81,705 82,005 CRESCENTE

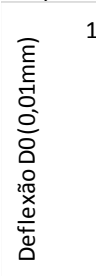

$$
\begin{array}{r}
80 \\
60 \\
40 \\
20 \\
0
\end{array}
$$
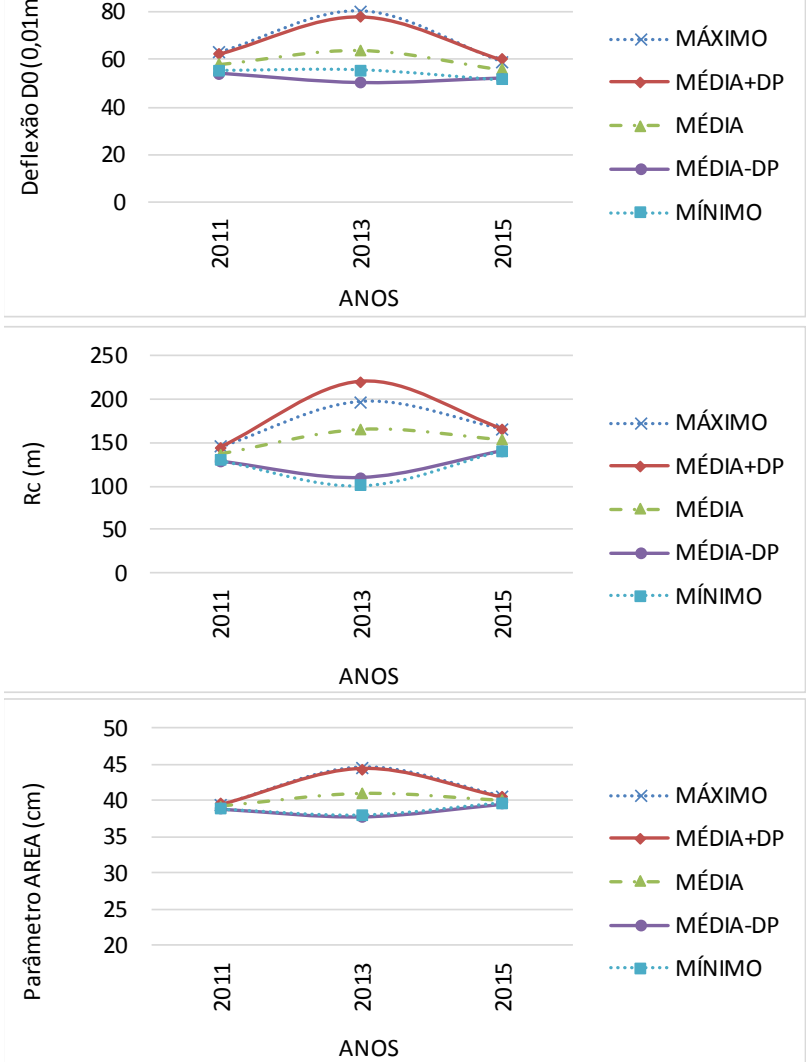$$
\text { - } \triangle \text { - MÉDIA }
$$$$
\longrightarrow \text { MÉDIA-DP }
$$$$
\text { ........ MÍNIMO }
$$

हี
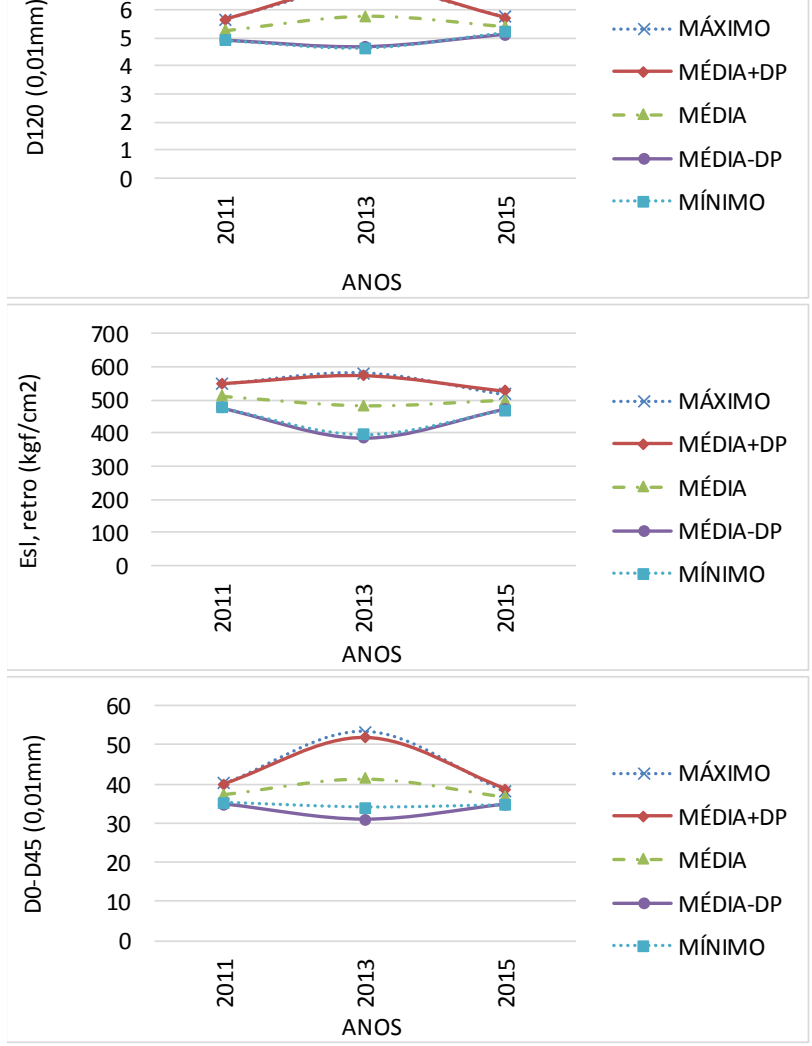

LG'
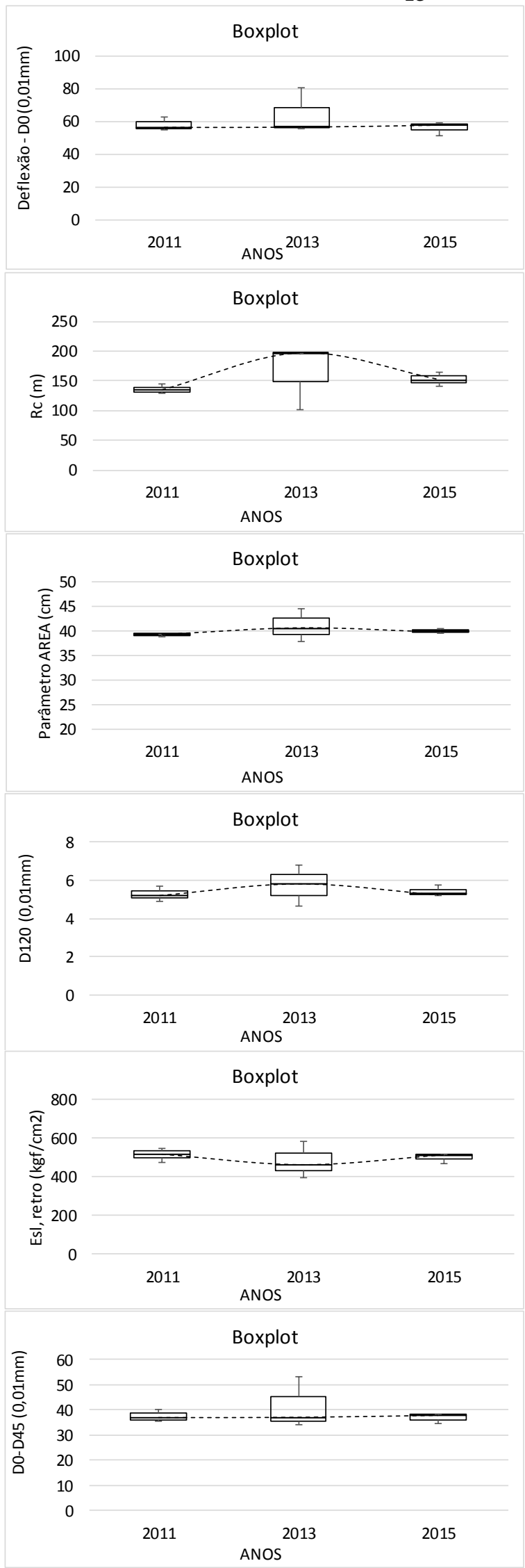

Figura 10.21: Estatísticas dos Parâmetros do pavimento (S. Homogêneo 21 - LG') 
83,4 83,505 CRESCENTE
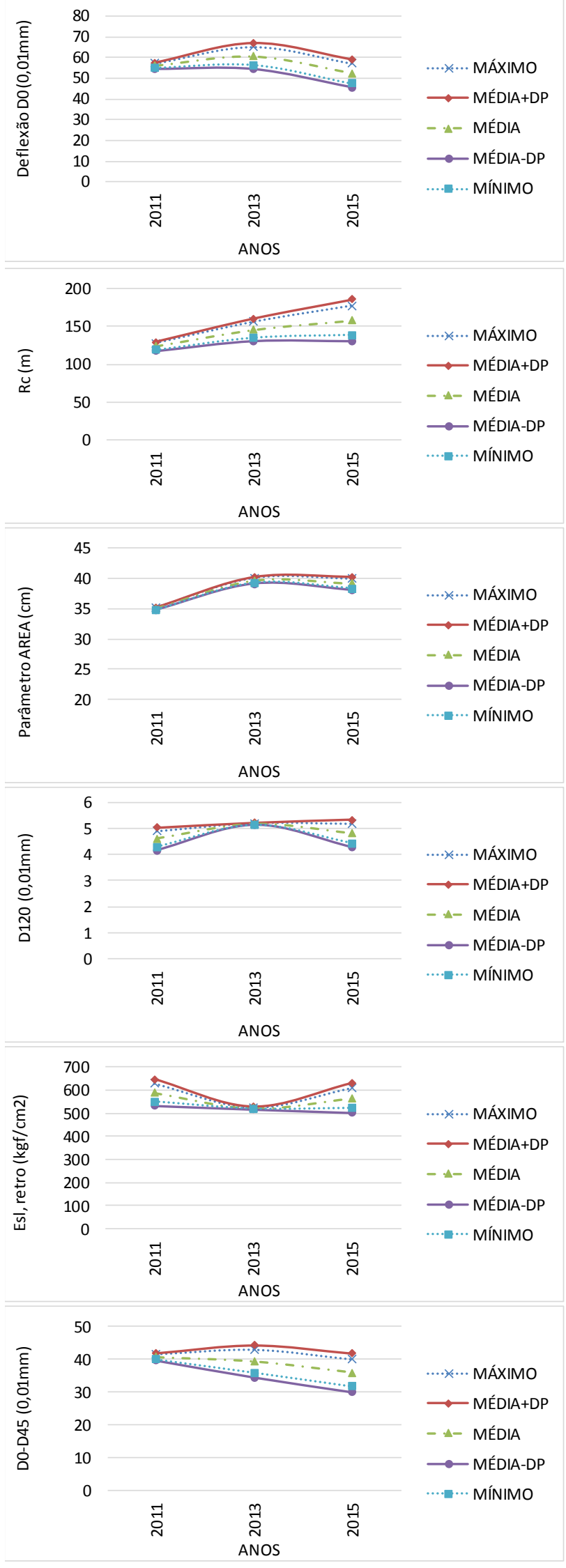

LA'
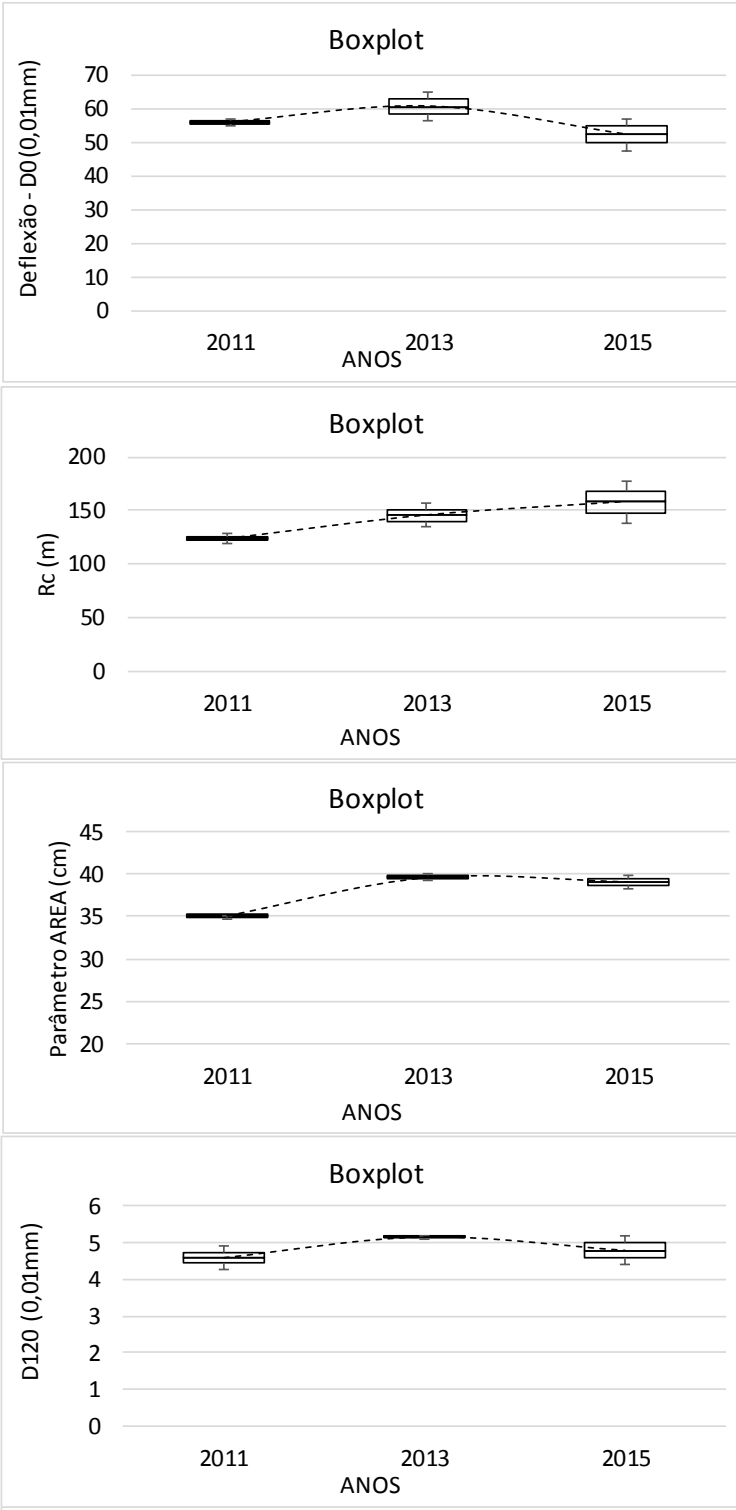

Boxplot
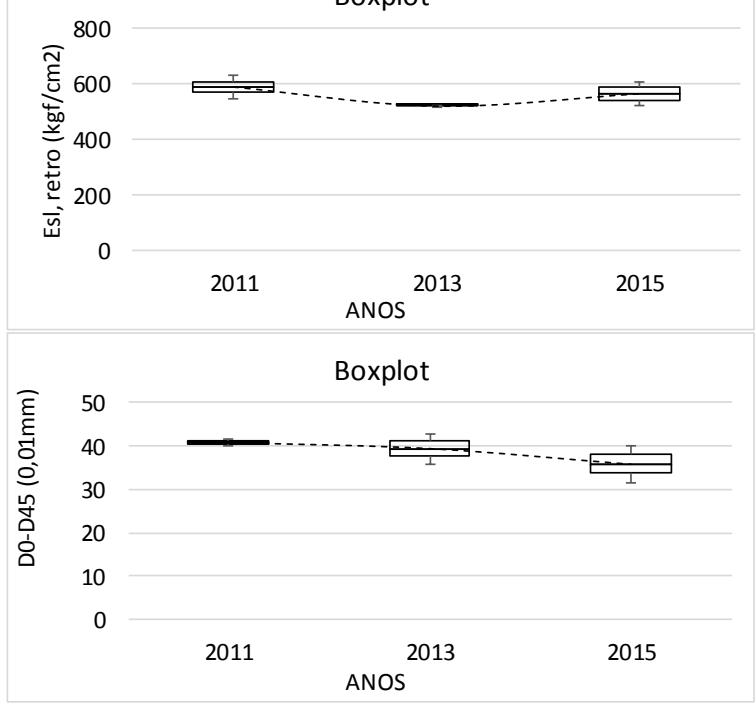

Figura 10.22: Estatísticas dos Parâmetros do pavimento (S. Homogêneo 22 - LA') 
29,15 29,45 CRESCENTE
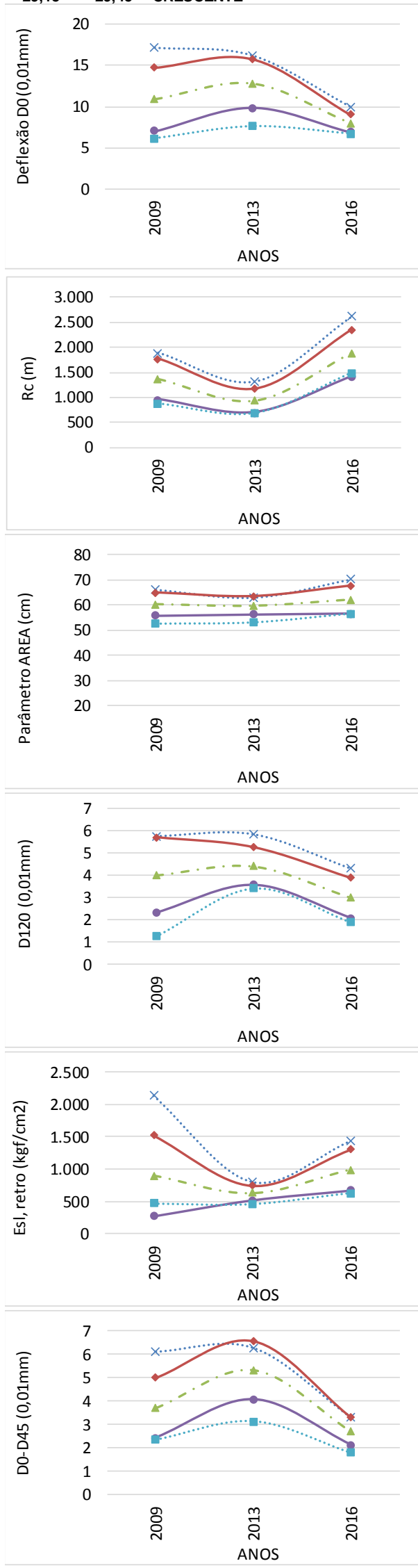
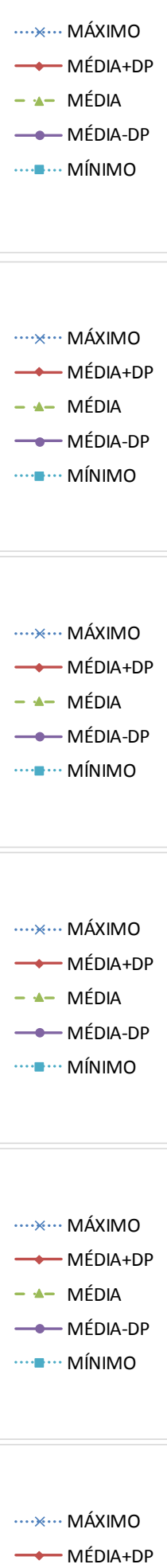

- - MÉDIA

....... MÍNIMO $\longrightarrow$ MÉDIA-DP
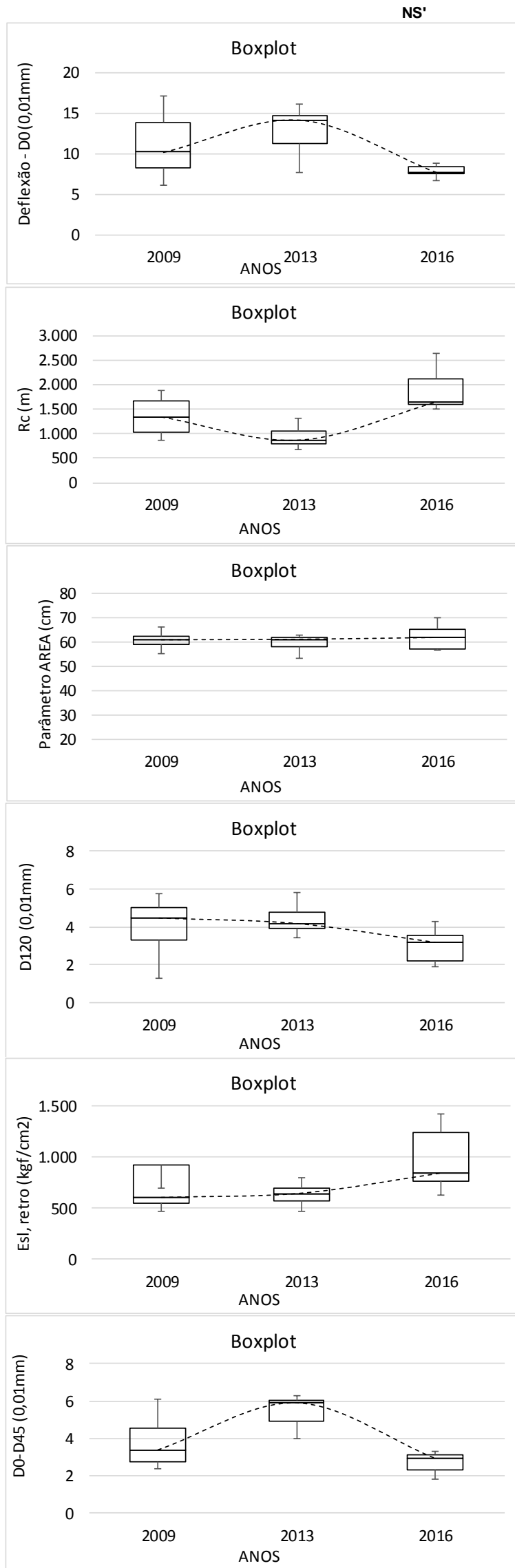

Figura 10.23: Estatísticas dos Parâmetros do pavimento (S. Homogêneo 23 - LA') 

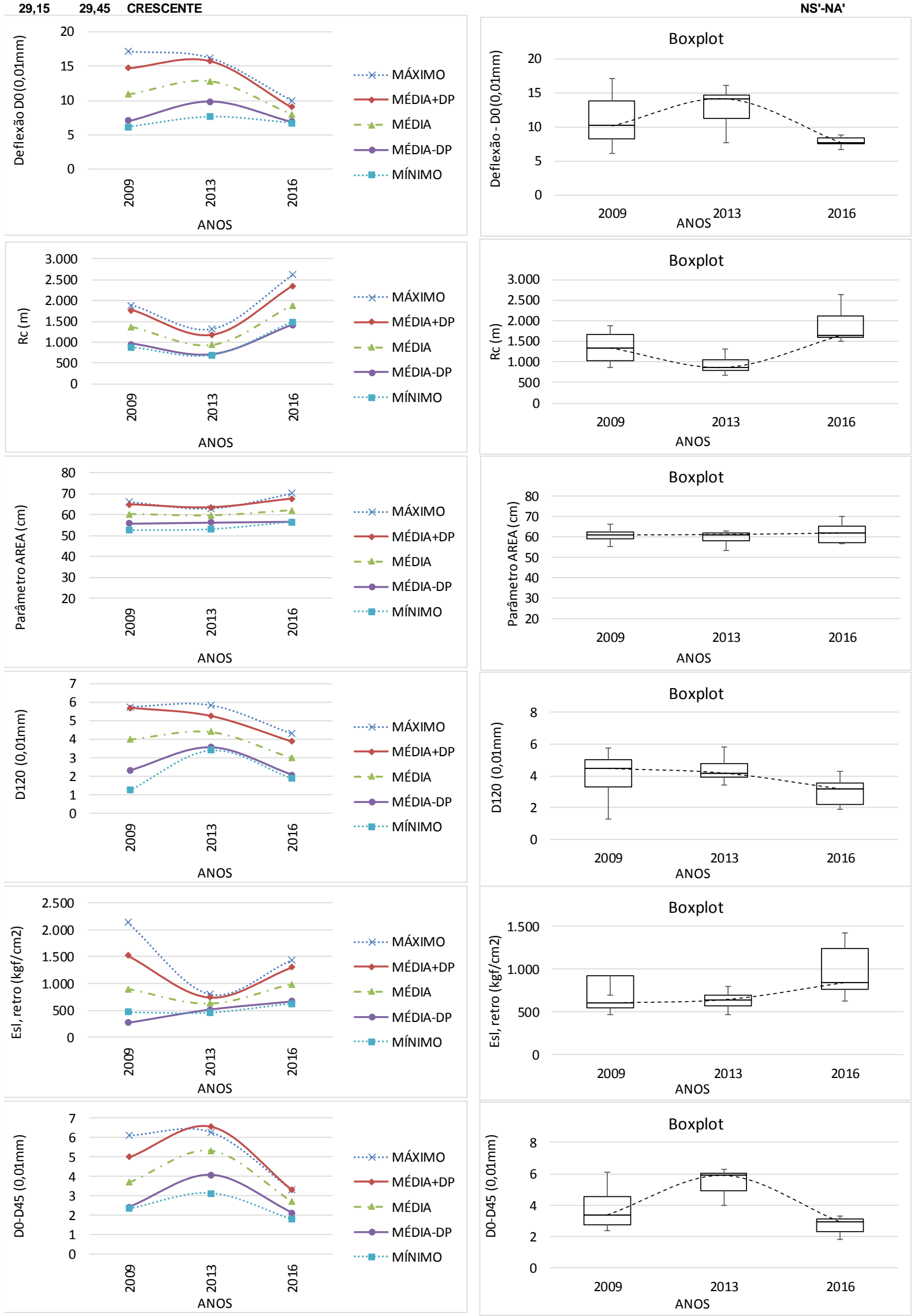

Figura 10.24: Estatísticas dos Parâmetros do pavimento (S. Homogêneo 23 - NS'-NA') 

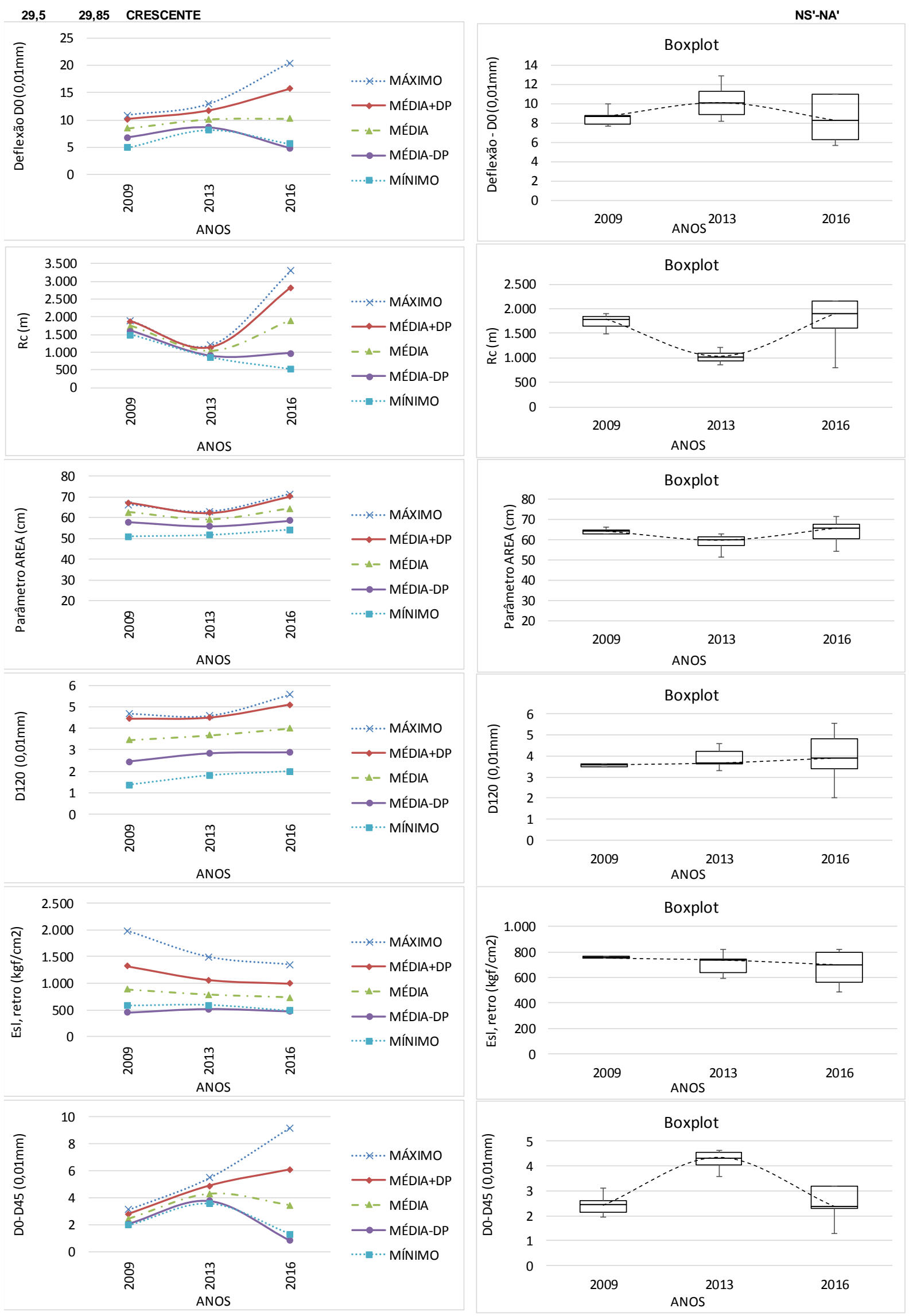

Figura 10.25: Estatísticas dos Parâmetros do pavimento (S. Homogêneo 24 - NS'-NA') 

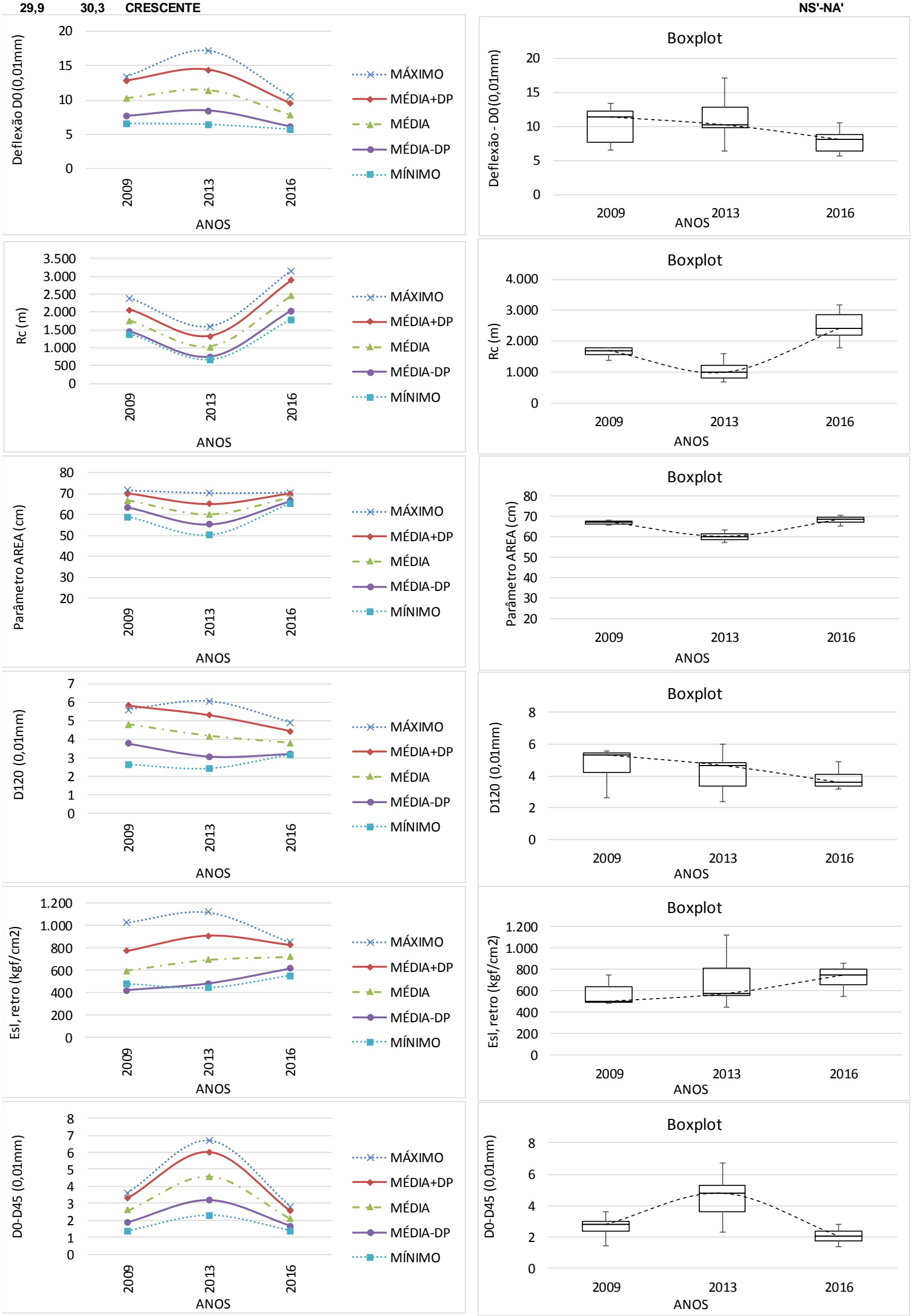

Figura 10.26: Estatísticas dos Parâmetros do pavimento (S. Homogêneo 25 - NS'-NA') 

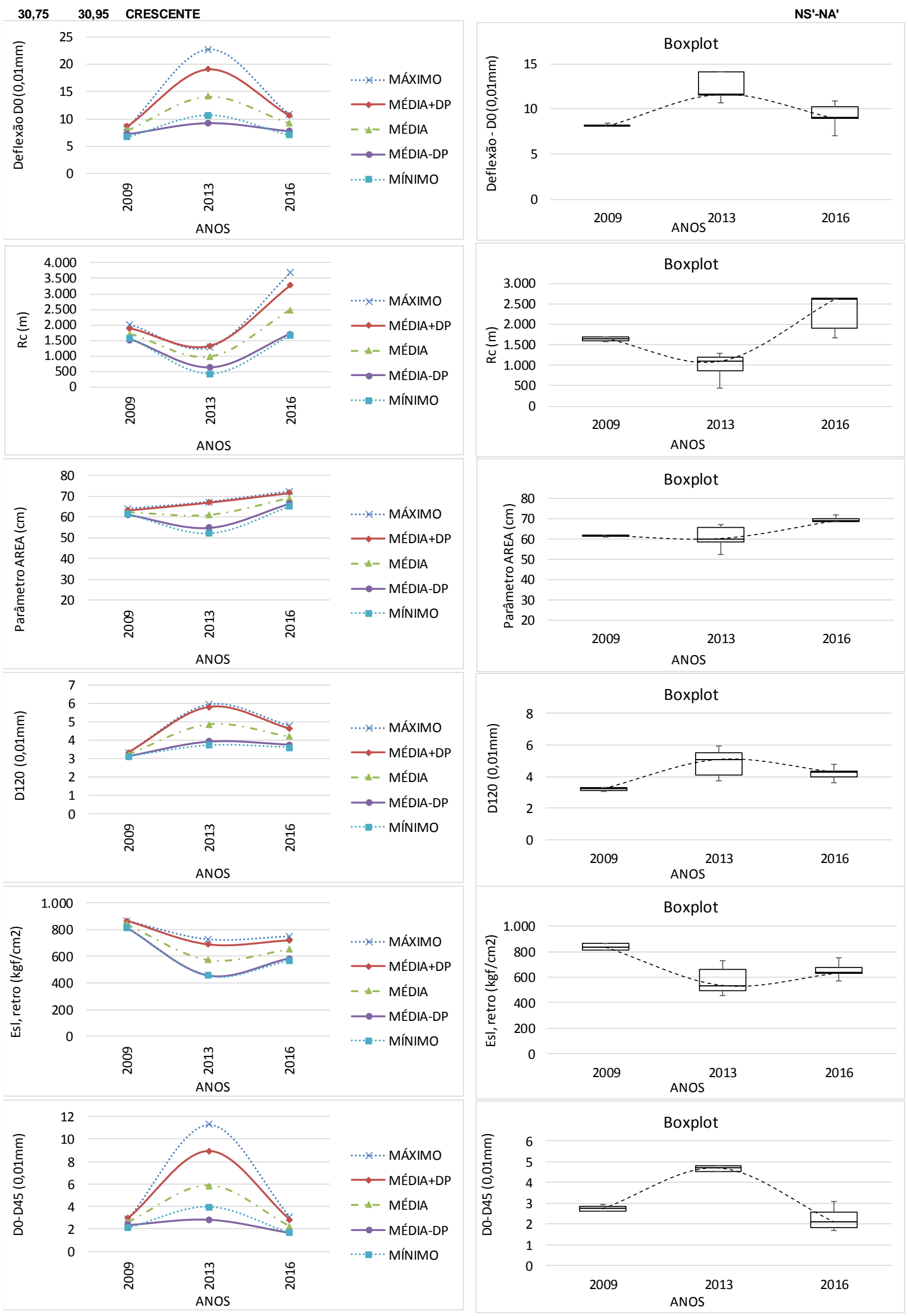

Figura 10.27: Estatísticas dos Parâmetros do pavimento (S. Homogêneo 26 - NS'-NA') 
11 ANEXO C - SEGMENTOS HOMOGÊNEOS EM TERMOS DE SEÇÕES DE TERRAPLENAGEM E SEGMENTOS HOMOGÊNEOS FINAIS DOS BANCOS DE DADOS BD3E BD4 
(Conteúdo apresentado

em

formato

planilha

eletrônica

"Anexo C_SegmentosHomogêneos.xlsx"), 
12 ANEXO D - DIAGRAMAS RETIGRÁFICOS DOS SEGMENTOS HOMOGÊNEOS DAS RODOVIAS ESTADUAIS EM ESTUDO 


\section{SP 070 (parte A)}

Rodolia $\rightarrow 7$

200520052007200820092010201120122013201420152016

(2005 20062007200820092010201120122013201420152016

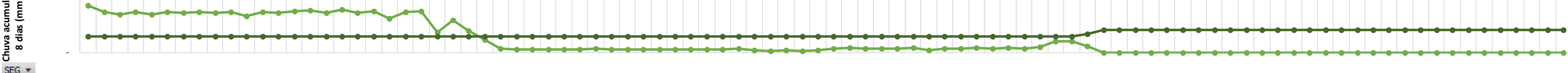

Rodovia -7

200520062007200820092010201120122013201420152016

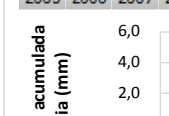

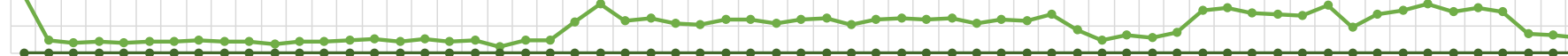

SEG

Rodovia at

200520062007200820092010201120122013201420152016

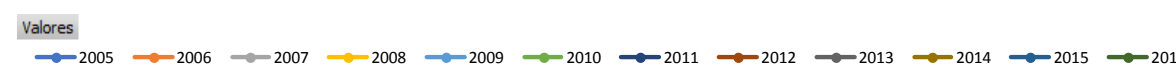

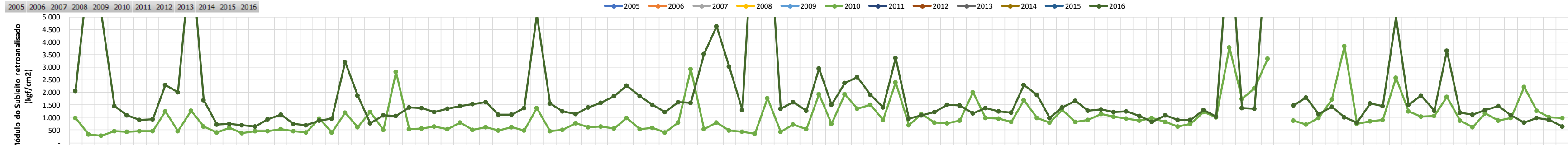

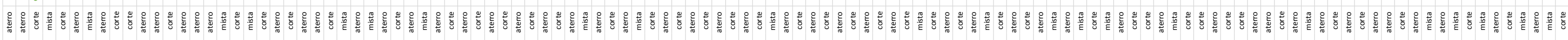

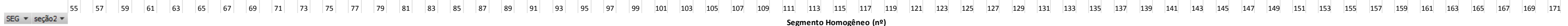

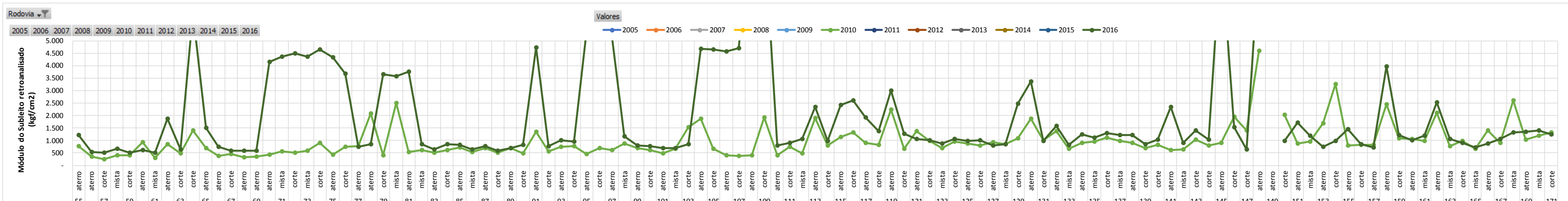

$\operatorname{seg} \rightarrow$ sesaion -5

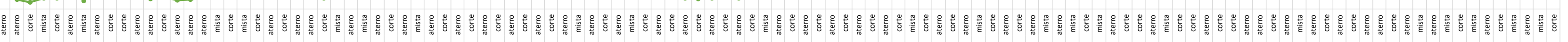

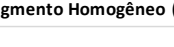




\section{SP 070 (parte B)}

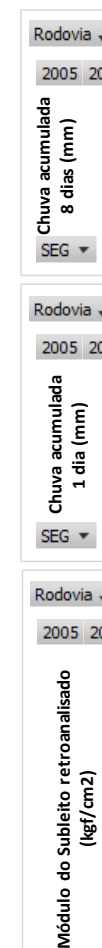

20062007200820092010201120122013201420152016

100
50

SEG

Rodoviva 57

200520062007200820092010201120122013201420152016

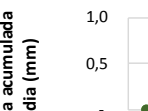

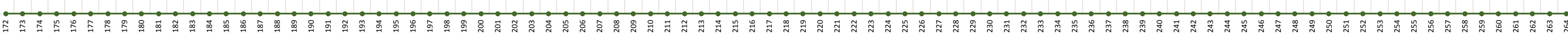

200520052007200820092010201120122013201420152016

$\underset{\text { Valoes }}{\rightarrow-2005} \rightarrow-2006 \rightarrow-2007 \rightarrow-2008 \rightarrow-2009 \rightarrow-2010 \rightarrow-2011 \rightarrow-2012 \rightarrow-2013 \rightarrow-2014 \rightarrow-2015 \rightarrow-2016$

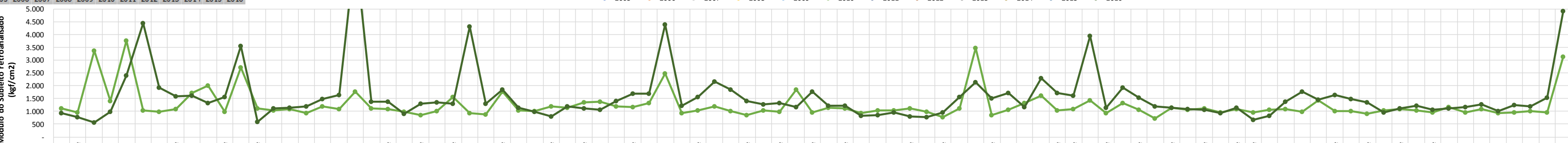

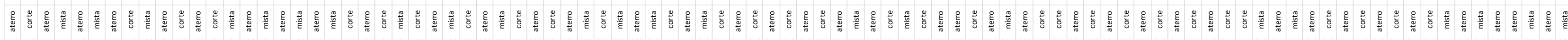

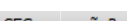

Rodovia oy

200520052007200820092010201120122013201420152016 Segmento Homogenene (ñ)

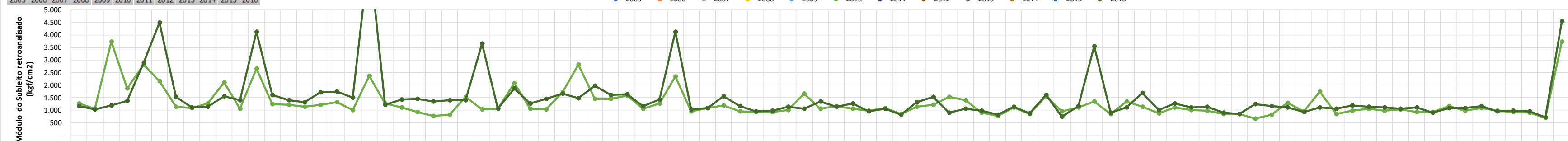

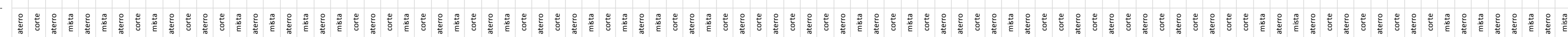
$\sec \rightarrow$ segsion Segmento Homogeneneo(no) 


\section{SP 099}

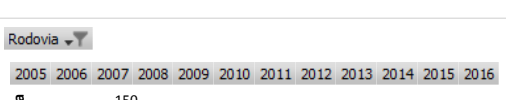

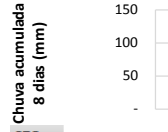

SEG-

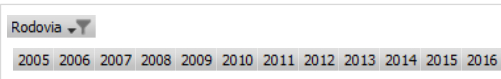

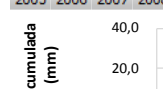

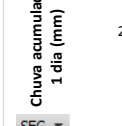

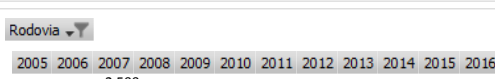

2005200620072000200202002

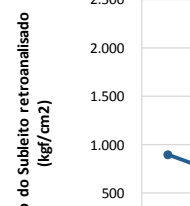

高

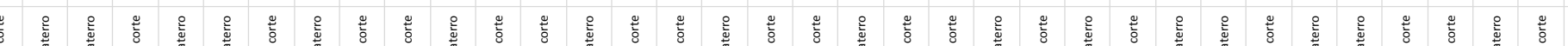

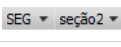

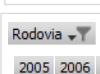

200520052007200020092010201120122013201420152016

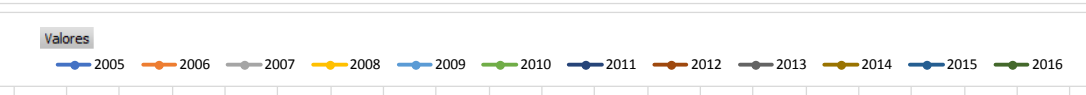

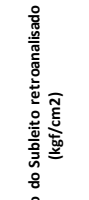

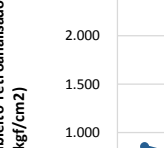

${ }^{500}$

(1)

$\underset{\text { Nabers }}{\rightarrow-2005} \rightarrow-2006 \rightarrow-2007 \rightarrow-2008 \rightarrow-2009 \rightarrow-2010 \rightarrow-2011 \rightarrow 2012 \rightarrow-2013 \rightarrow-2014 \rightarrow-2015 \rightarrow-2014$

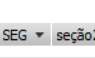

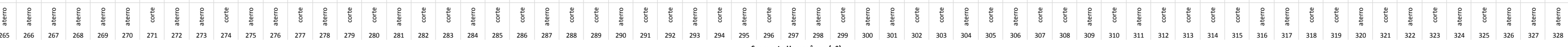




\section{SP 147 (parte A)}

\section{Rodovia $\rightarrow$}

Média de MD CHVvod (2011) Média de MD CHVI8d (2013) Média de MD CHVId (2015)

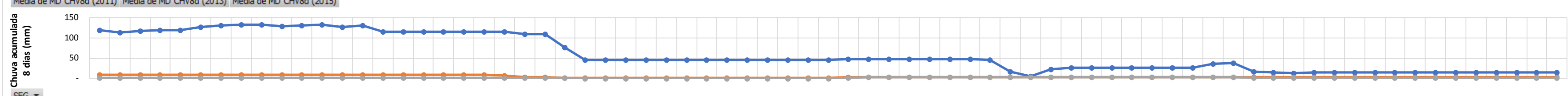

\section{Rodovia -7}

\section{(2013) Média de MD CHVII (2015)}

等

SEG -

\section{Rodovia}

Média de MD Estr (2011) Média de MD Est (2013) Méda de MD Estr (2015)

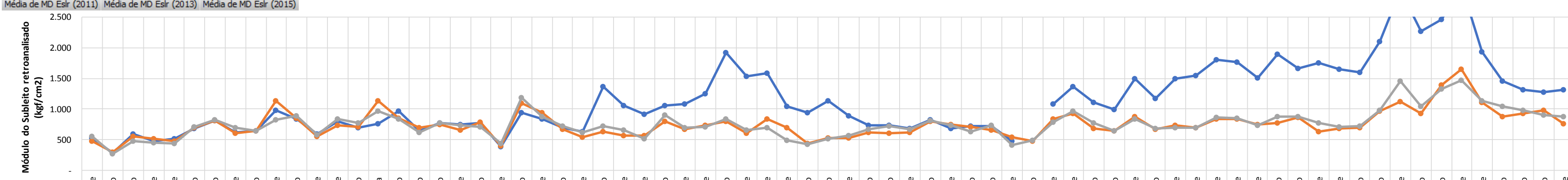

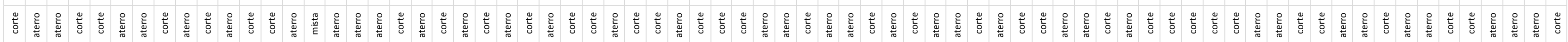

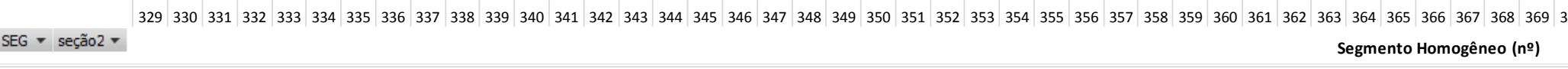

\section{Módia o de MD Estr (2011) Média de MD Estr (2013) Média de MD Estr (2015)}

\begin{tabular}{l}
2.500 \\
2.000 \\
1.500 \\
1.000 \\
500 \\
\hline
\end{tabular}
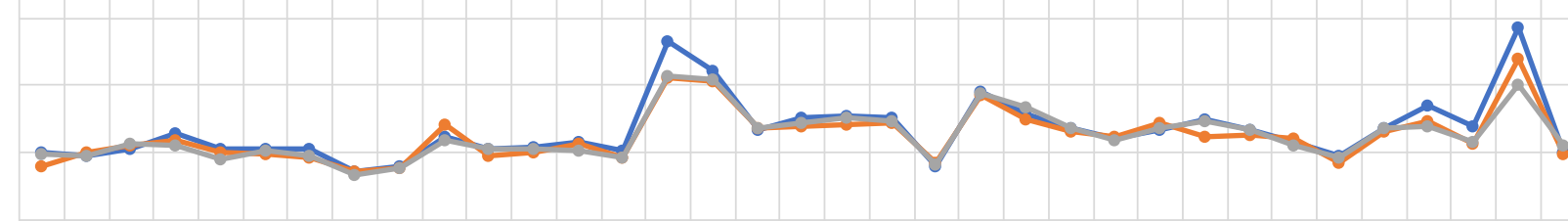


\section{SP 147 (parte B)}

Rodovia $\rightarrow$

Média de MD CHV8d (2005) Média de MD CHV8d (2007) Média de MD CHV8d (2009)
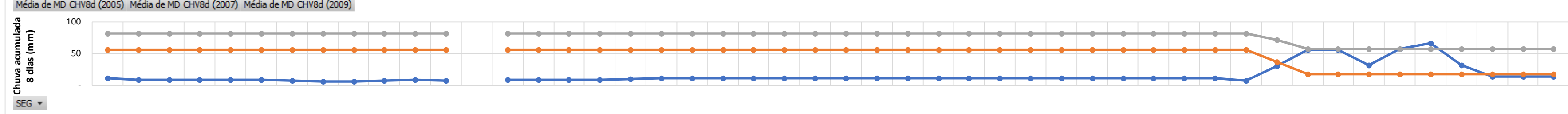

Rodovia $\rightarrow$

Média de MD CHVId (2005) Média de MD CHVId (2007) Média de MD CHVId (2009)
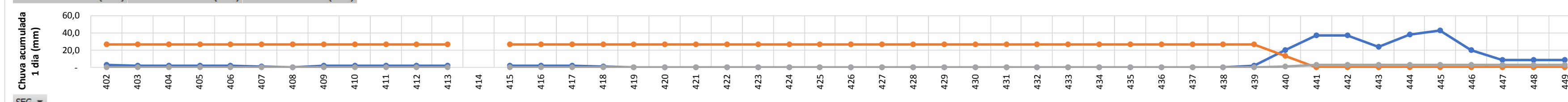

\section{Rodovia -7}

200520072009

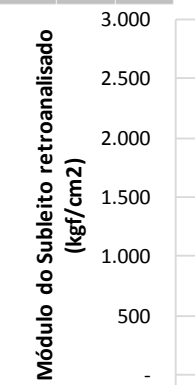

Valores

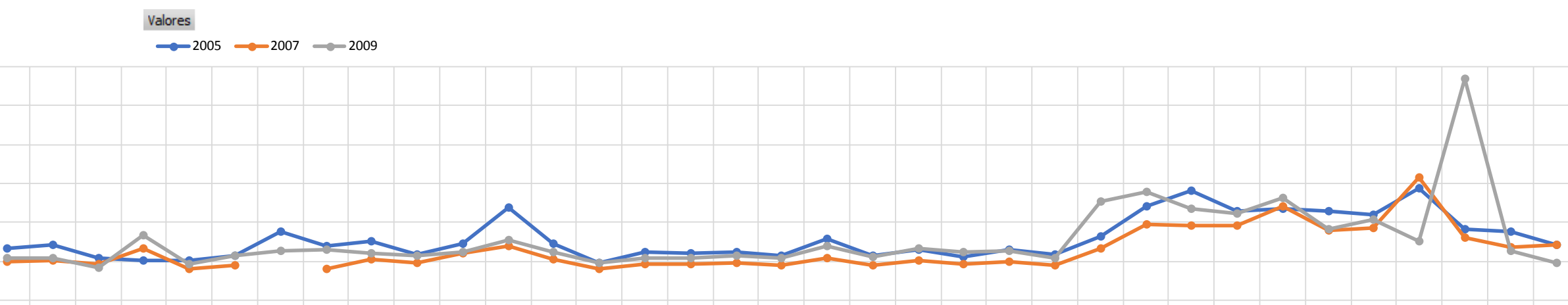

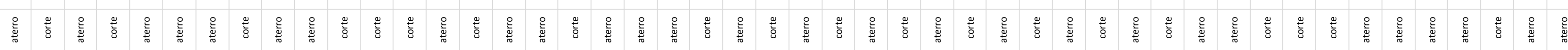

SEG - seç̃o2 -

Rodovia -7

200520072009

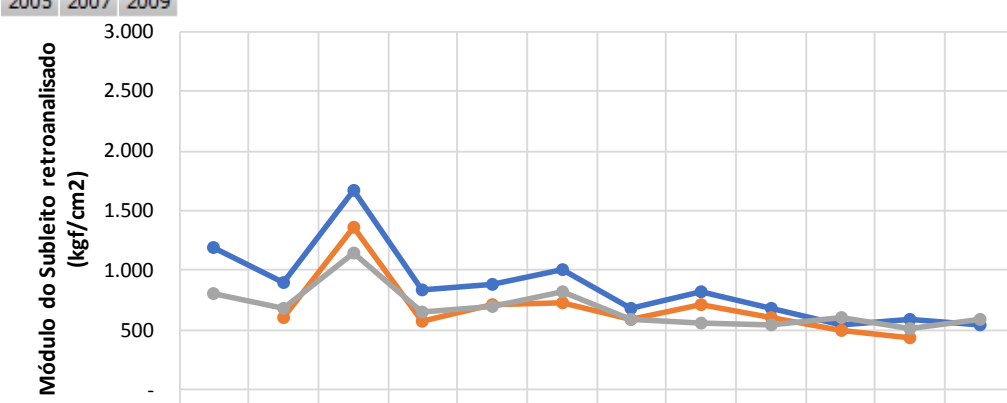

$\underset{\text { Valoes }}{\rightarrow-2005} \rightarrow-2007 \rightarrow-2009$ Segmento Homogêneo (no) 
472

SP 150
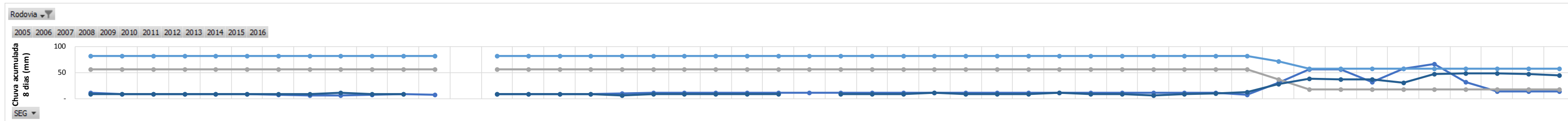

Rodovia -7

200520062007200820092010201120122013201420152016
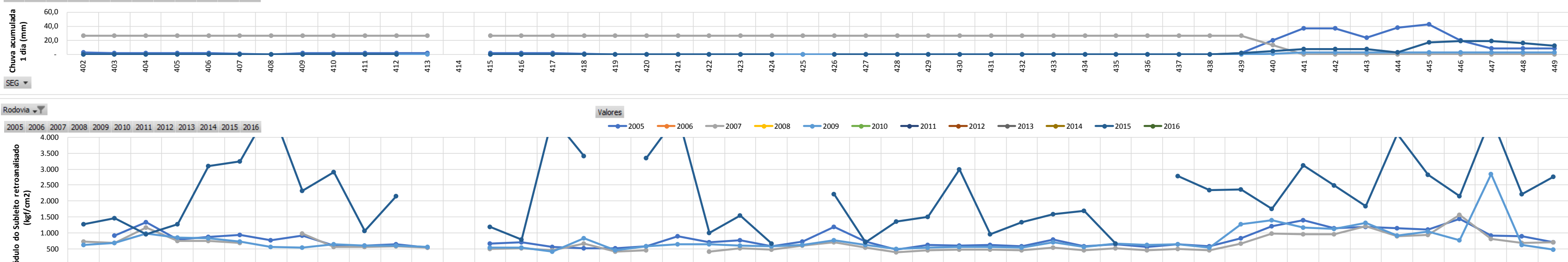

40

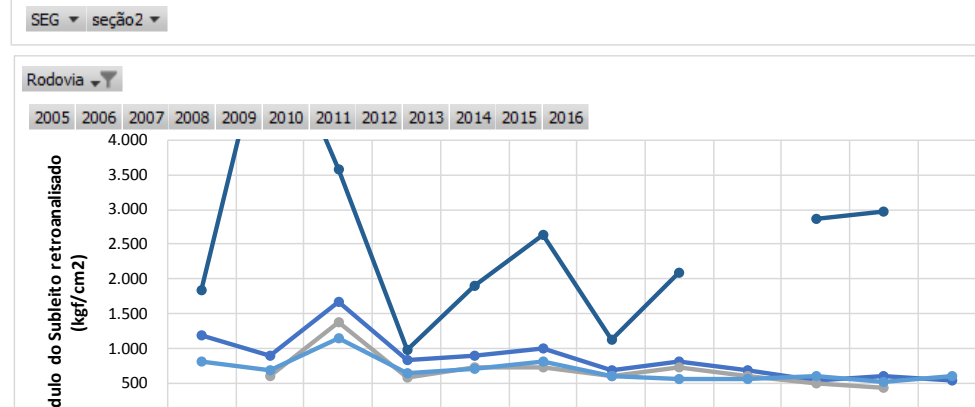

Segmento Homogêneo (noํ)

Rodovia - 7

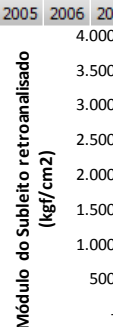
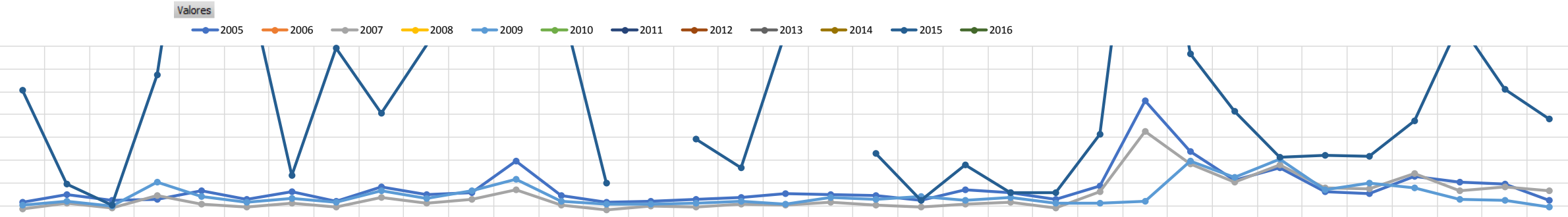

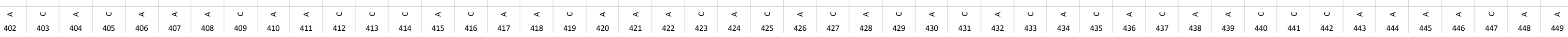

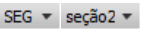

Segmento Homogêneo (no) 
SP 270 (parte A)

Rodovia -7

200520062007200820092010201120122013201420152016

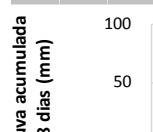

(1)

$y=0$

5

Rodocia 57

20092010201120122013201420152015

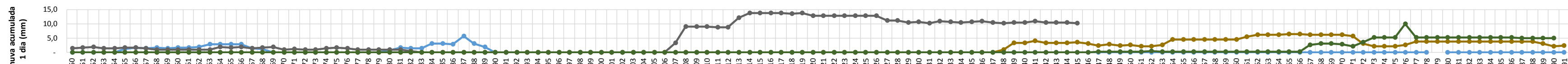

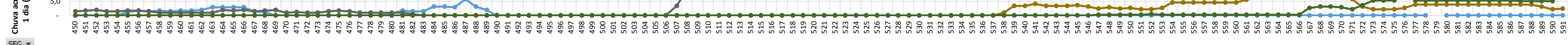

Rodovia -7

2005200620072008200920102011201220132014201520

$\underset{\text { Valores }}{\rightarrow-2005 \rightarrow-2006 \rightarrow-2007 \rightarrow-2008 \rightarrow-2009 \rightarrow-2010 \rightarrow-2011 \rightarrow-2012 \rightarrow-2013 \rightarrow-2014 \rightarrow-2016} \rightarrow \rightarrow$

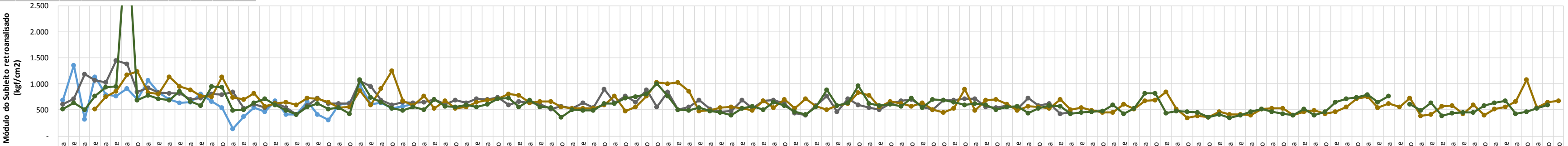

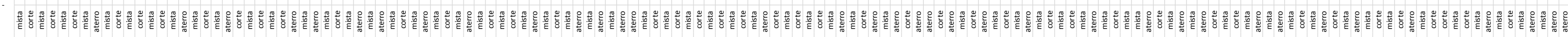

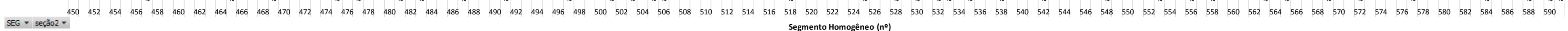
Redovia -7

2005220062007200820092010201120122013201420152016

Vaderes

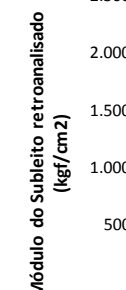

$\rightarrow-2005 \rightarrow-2006 \rightarrow-2007 \rightarrow-2008 \rightarrow-2009 \rightarrow-2010 \rightarrow-2011 \rightarrow-2012 \rightarrow-2013 \rightarrow-2014 \rightarrow-2015 \rightarrow-2016$

1.000

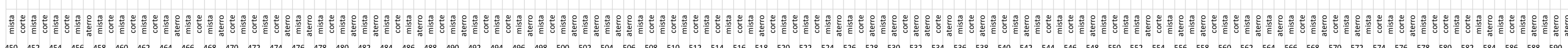

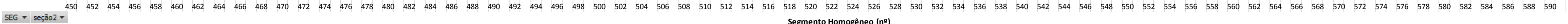




\section{SP 270 (parte B)}

Rodovia a 7 T

200520062007200820092010201120122013201420152016

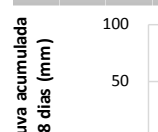

SEG -

Rodovia a 7

200520062007200820092010201120122013201420152016

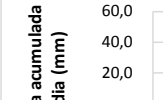

SEG -

Rodovia $\rightarrow 7$

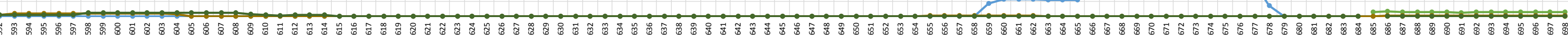

200520062507200820092010201120122013201420152016

$\stackrel{\text { Valoes }}{\rightarrow-2005 \rightarrow-2006 \rightarrow-2007 \rightarrow-2008 \rightarrow-2009 \rightarrow-2010 \rightarrow-2011 \rightarrow-2012 \rightarrow-2013 \rightarrow-2014 \rightarrow-2015 \rightarrow-2016}$

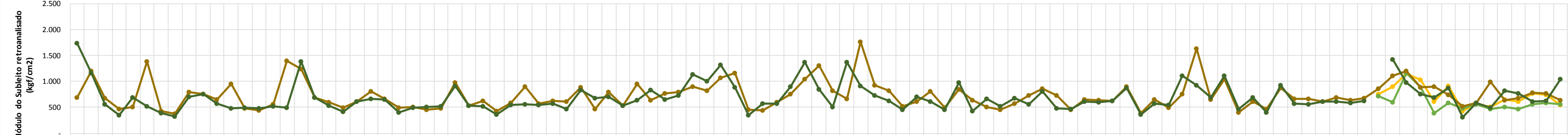

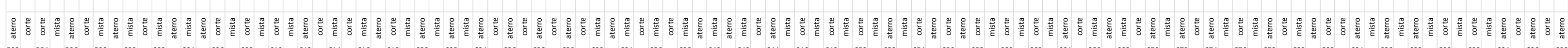

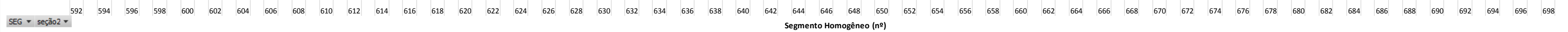

20052006

200520062007200820092010201120122013201420152016

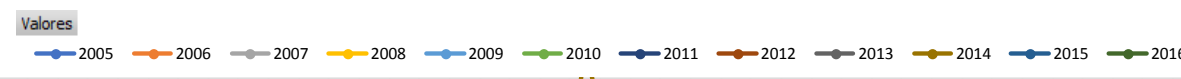

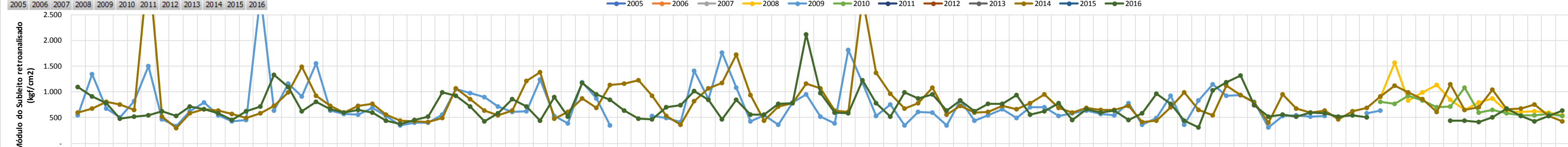

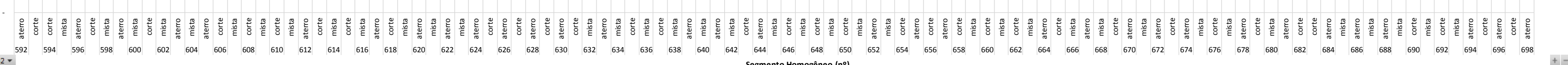

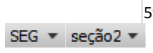




\section{SP 270 (parte C)}

Rodovia a 5

200520062007200820092010201120122013201420152016

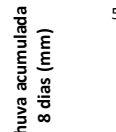

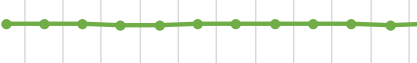

seG -

Rodovia 20.7

200520062007200820092010201120122013201420152016

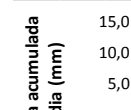

SEG-

Rodovia a 7 2005 20062007200

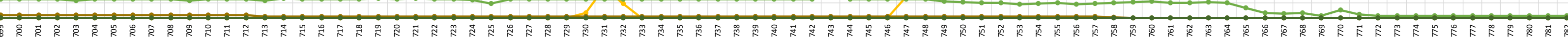

200520062007200820092010201120122013201420152016

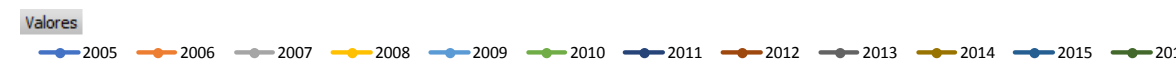

(1500

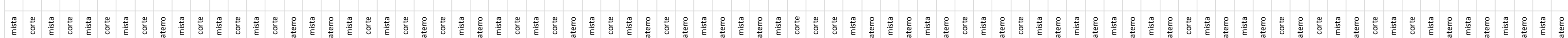

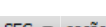

Rodovia ar

2005200252007200320092010201120122013201420152016

$\stackrel{\text { Valoes }}{\rightarrow-2005} \rightarrow-2006 \rightarrow-2007 \rightarrow-2008 \rightarrow-2009 \rightarrow-2010 \rightarrow-2011 \rightarrow-2012 \rightarrow-2013 \rightarrow-2014 \rightarrow-2015 \rightarrow-2015$

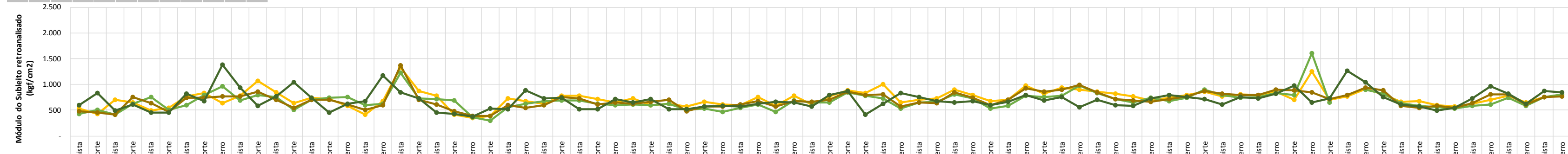

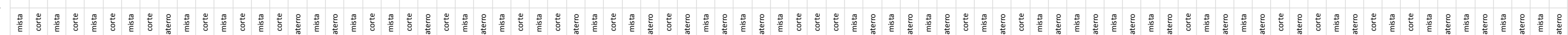

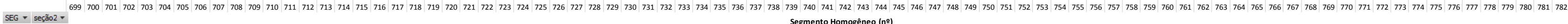




\section{SP 280}

Rationery

2005200620072008200920102011202122013201420152015

150
0

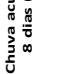

ment

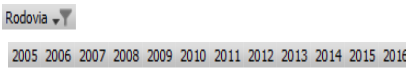

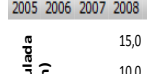

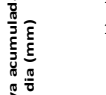
T 120

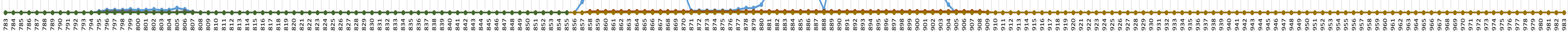

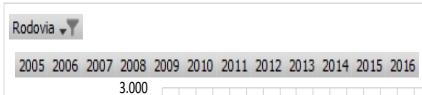

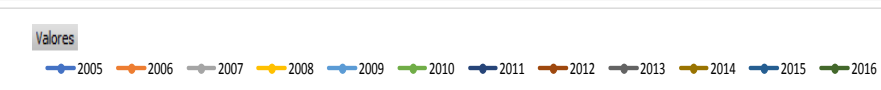

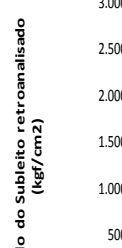
2500
2000
1500
1000
500

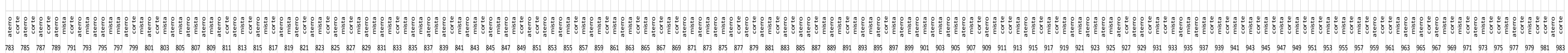

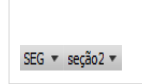
Rodovia 5

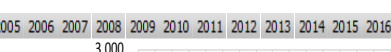

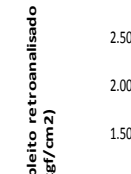

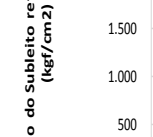

s

$\mathrm{S} 6 \mathrm{G} \rightarrow \operatorname{sic} 202$

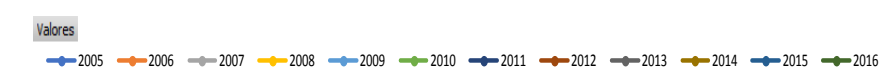

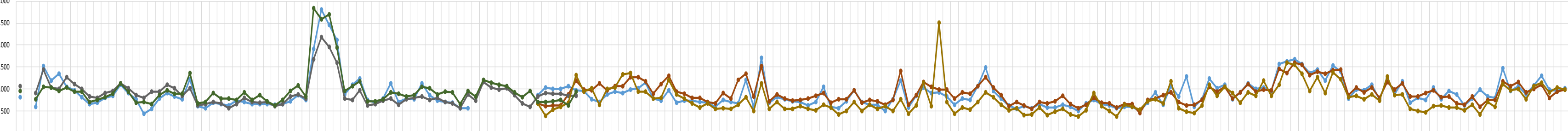

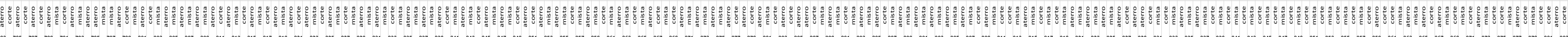


SP 318

Rodovia $\rightarrow$ T

200520062007200820092010201120122013201420152016

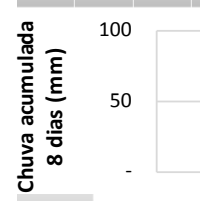

Redovia - -7

200520062007200820092010201120122013201420152016

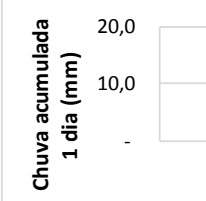
SEG -

Rodovia -7

200520062007200820092010201120122013201420152016

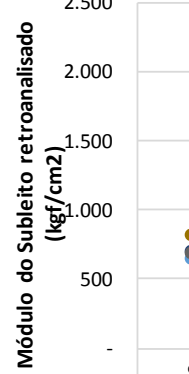

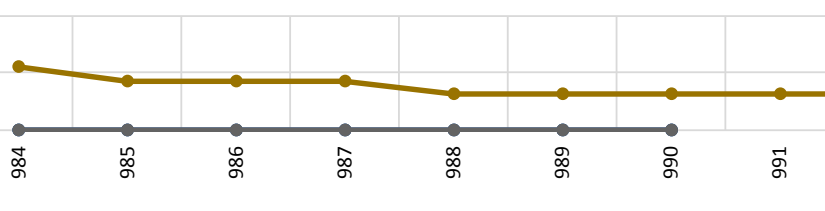

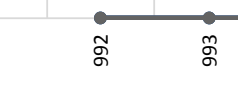

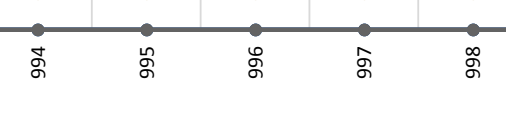

Valores

\section{SEG - seção - 98}

\section{Rodovia -7}

200520062007200820092010201120122013201420152016

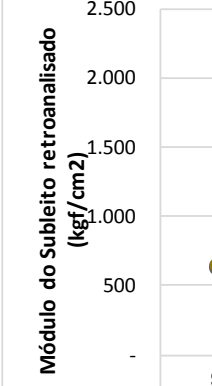

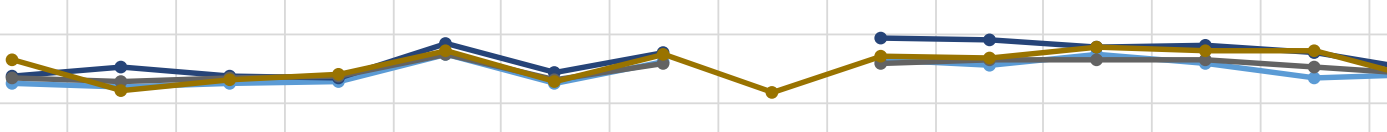

$=$

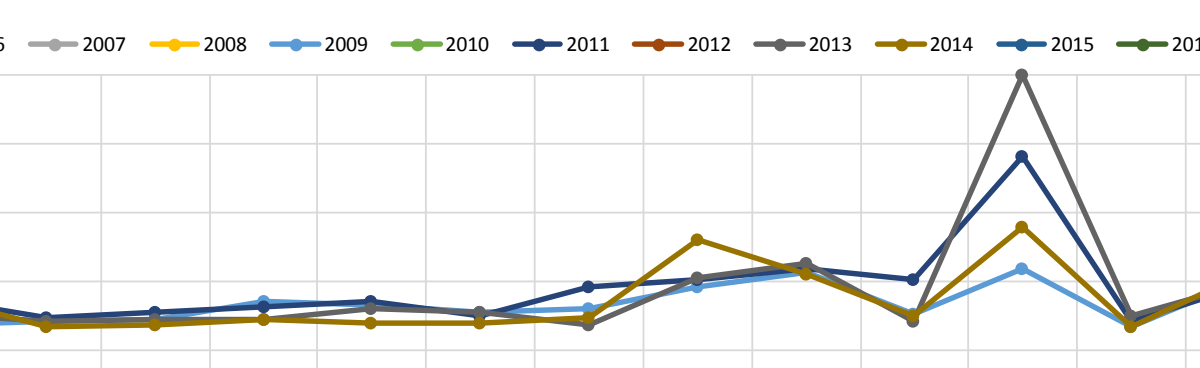

SEG - seção v

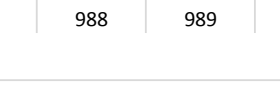


SP 340 (parte A)

Rodowia 7 .

2005200622007200820092010201120122013201420152016

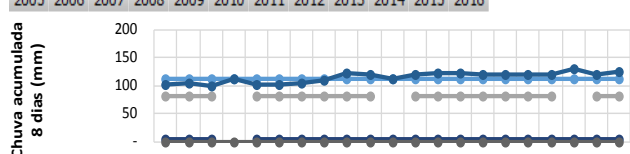

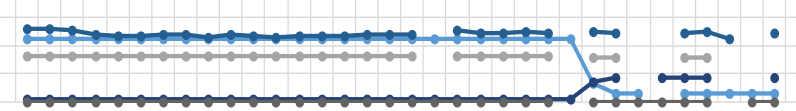

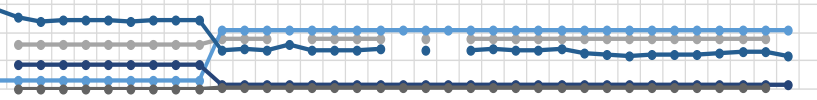

$\square$

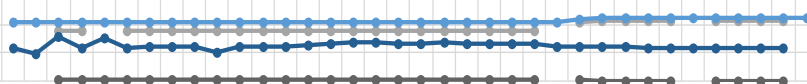

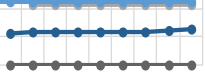

Rodovia 7

200520062007200820092010201120122013201420152016

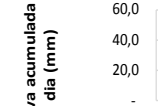

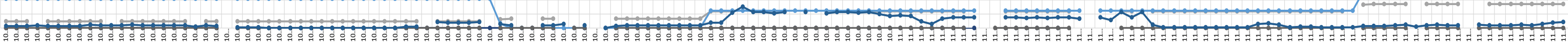

Rodovia 7 T 20052206220272008200920102011201220132014201520206 valoes

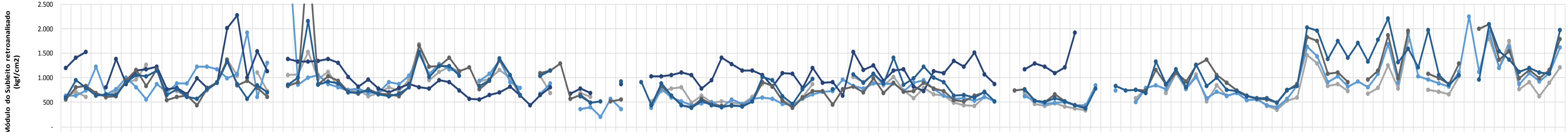

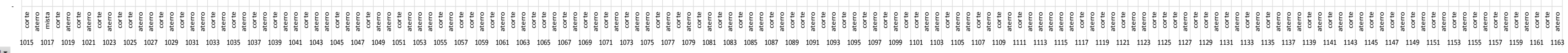

SEG - seço:

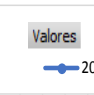

2005200622007200820092010201120122013201420152015

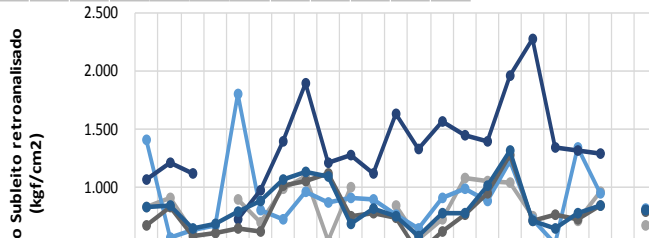

500

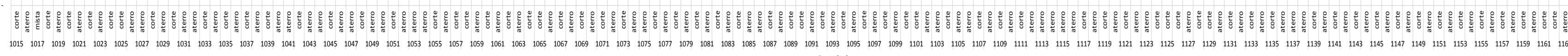
$566 \rightarrow$ segan 2 


\section{SP 340 (parte B)}

Redovia 7 .

2020520062007200220092010201120122013201420152016

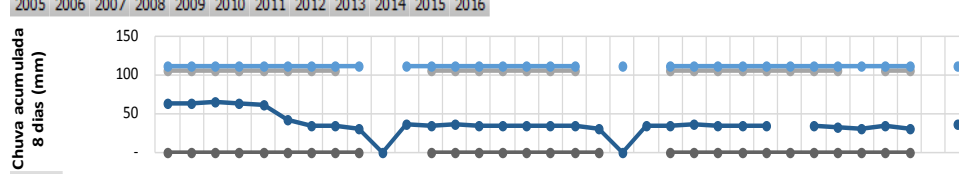

두 $\square \square$

SEG -

Rodovis 7

20120092010201120122013201420152015

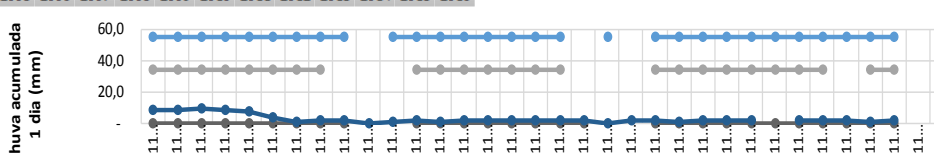

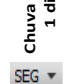

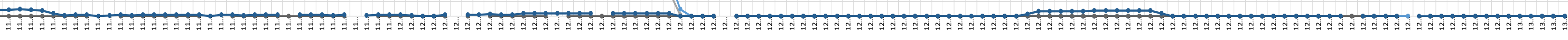

Rodovia 7

2005200620072200820022010201120122013201420152016

values

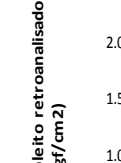

${ }^{2000}$

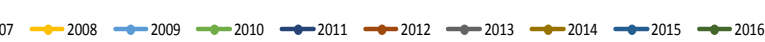

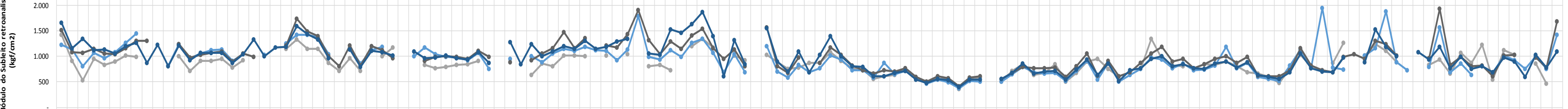

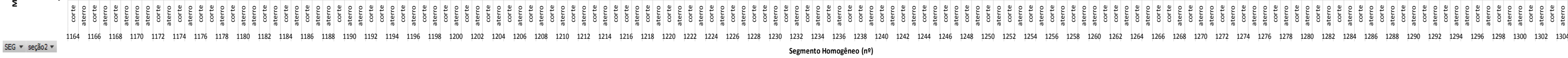
200520062007200820092010201120122013201420152016 $\stackrel{\text { values }}{\rightarrow-2005} \rightarrow 2006 \rightarrow 2007 \rightarrow 2008 \rightarrow 2009 \rightarrow-2010 \rightarrow 2011 \rightarrow 2012 \rightarrow 2013 \rightarrow 2014 \rightarrow 2015 \rightarrow 2016$

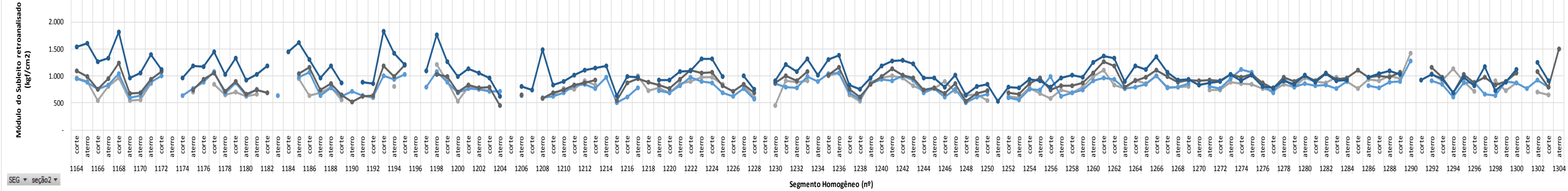


13 ANEXO E - GRÁFICOS COM RESULTADOS DE PARÂMETROS COMBINADOS (TODAS AS RODOVIAS) 


\section{Rodovia -}

Média de média Essr_SH DesvPad demédia Essi_SH Contagem de média Eslr_SH Média de D chuva máxima 1d

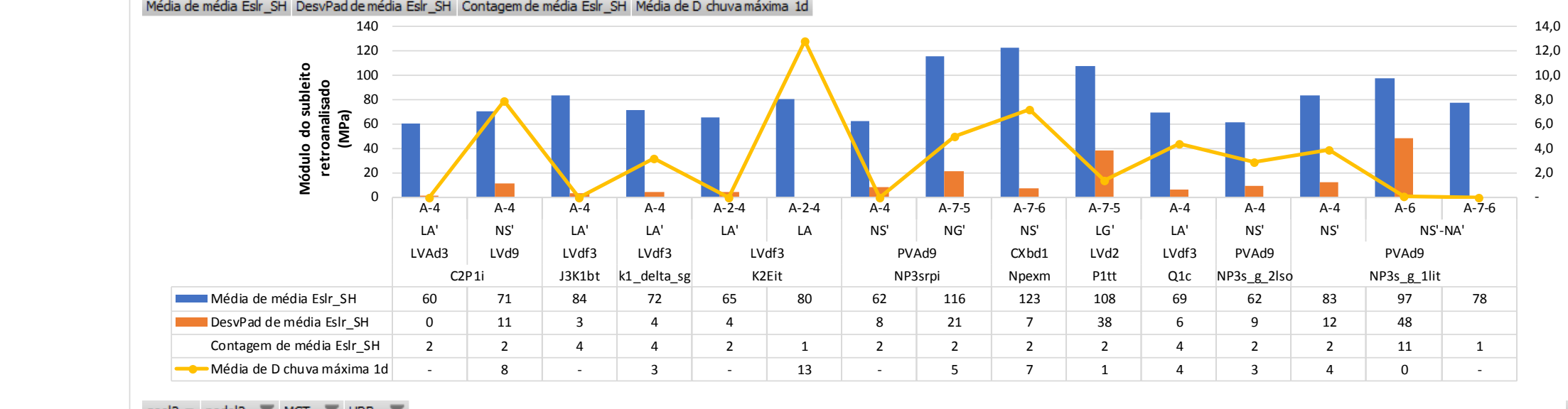

geol2 - pedol2 $\rightarrow$ MCT $\rightarrow$ T HRB $\rightarrow$ T

$+-$

Figura 13.1: Estatísticas dos valores de módulo de resiliência retroanalisado - todas as rodovias (sítios geológico /pedológico; classificações MCT e HRB) $[B D 3]$

Rodovia -

Média de média Esl__SH DesvPad de média Eslr_SH Contagem de média Eslr_SH Média de D chuva máxima 1d

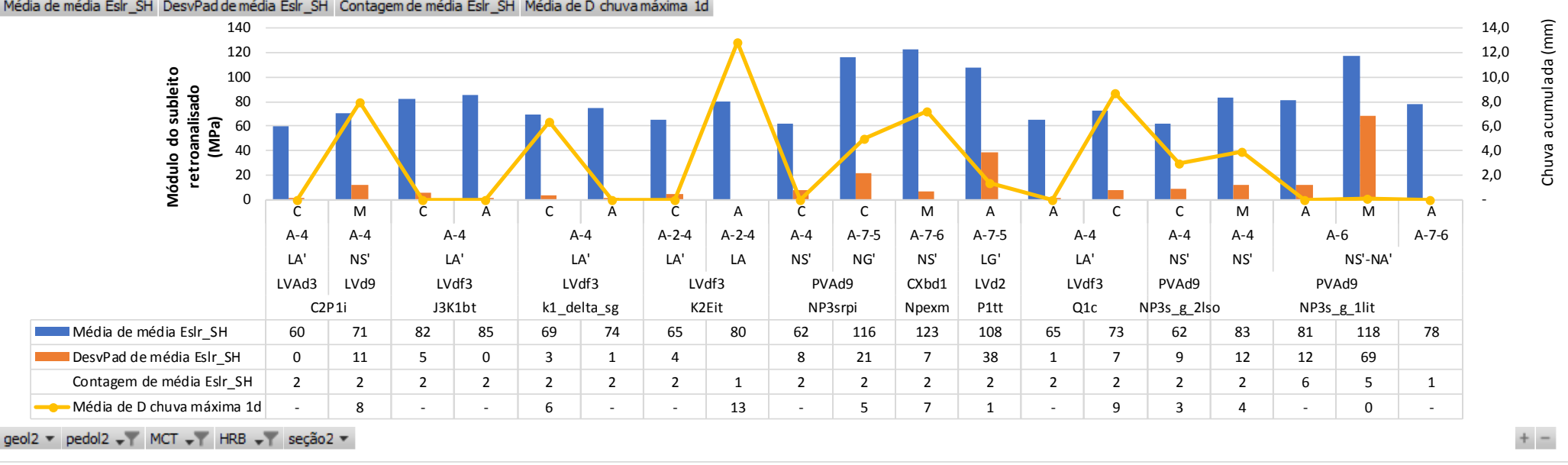


Figura 13.2: Estatísticas dos valores de módulo de resiliência retroanalisado - todas as rodovias (sítio pedológico; classificações MCT e HRB; tipo de seção

Rodovia de terraplanagem) [BD3]

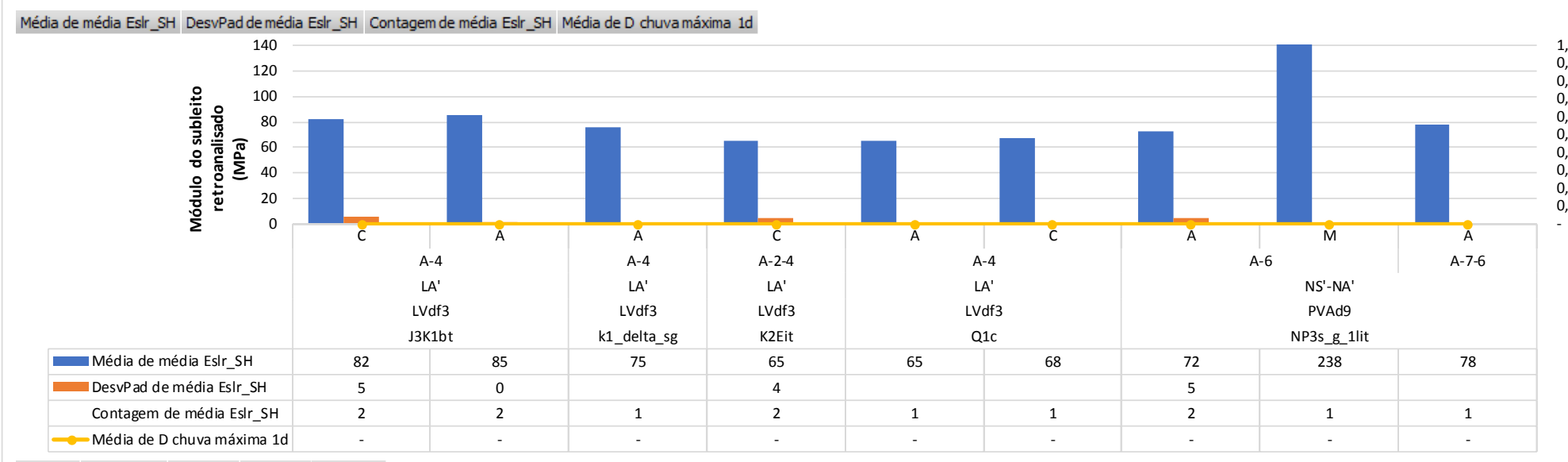

geol2 - pedol2 $\rightarrow$ MCT $\rightarrow$ HRB $\rightarrow$ seção2 -

Figura 13.3: Estatísticas dos valores de módulo de resiliência retroanalisado - todas as rodovias, nenhuma chuva acumulada em 8 dias (sítios geológico /pedológico; classificações $M C T$ e $H R B$, tipo de seção de terraplenagem) [BD3] 


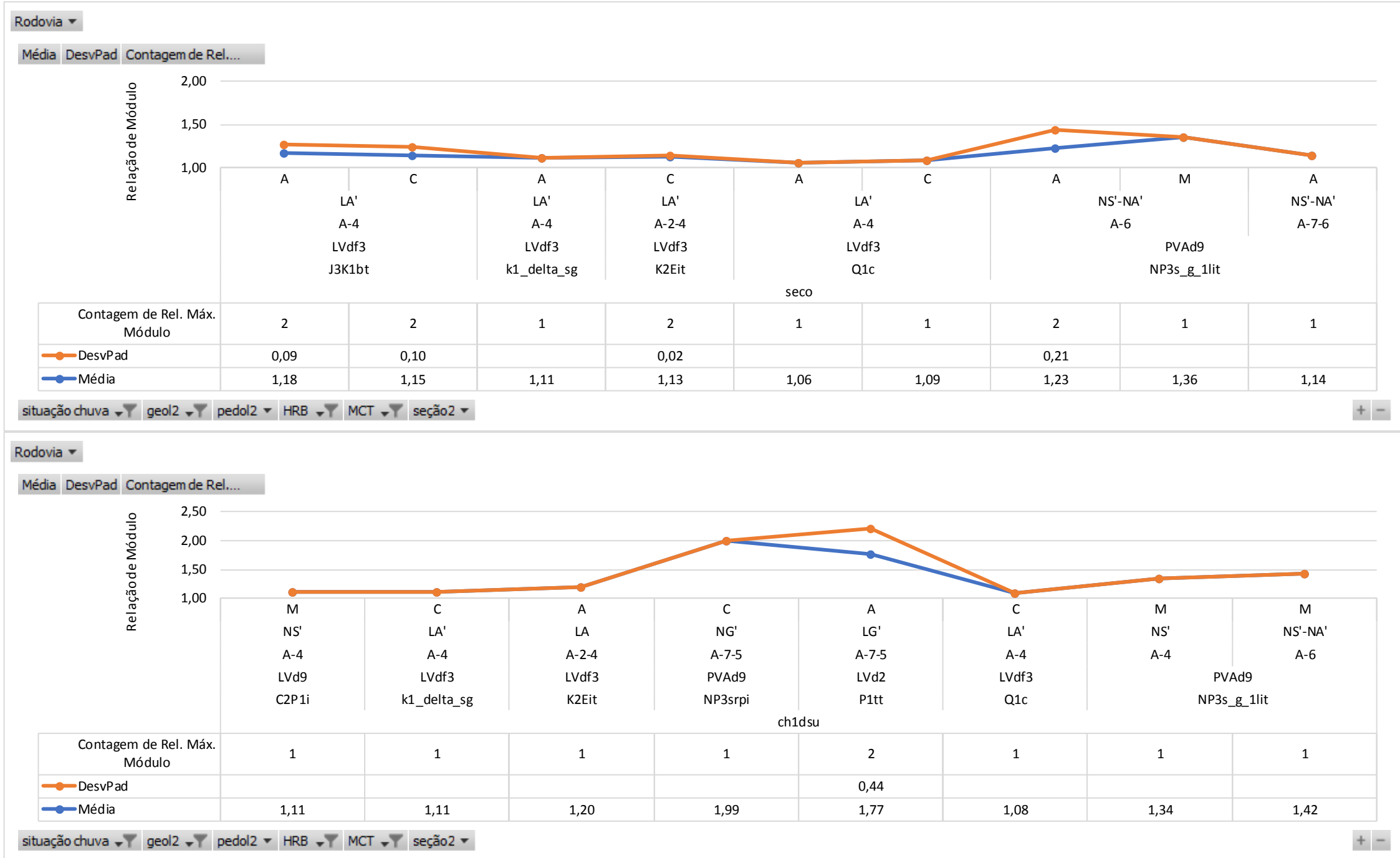

Figura 13.4: Estatísticas dos valores de relação de módulo retroanalisado - todas as rodovias (sítios geológico e pedológico; classificações MCT e HRB; tipo de seção de terraplanagem) (condições de chuva especificadas) [BD3] 
14 ANEXO F - MATRIZES COM ESTATÍSTICAS DOS RESULTADOS INDIVIDUAIS DO ESTUDO DAS RODOVIAS ESTADUAIS [BD2] 
Tabela 14.1: Matriz com estatísticas dos valores pontuais de módulo [MPa] (todos os tipos de seções de terraplenagem) [BD2]

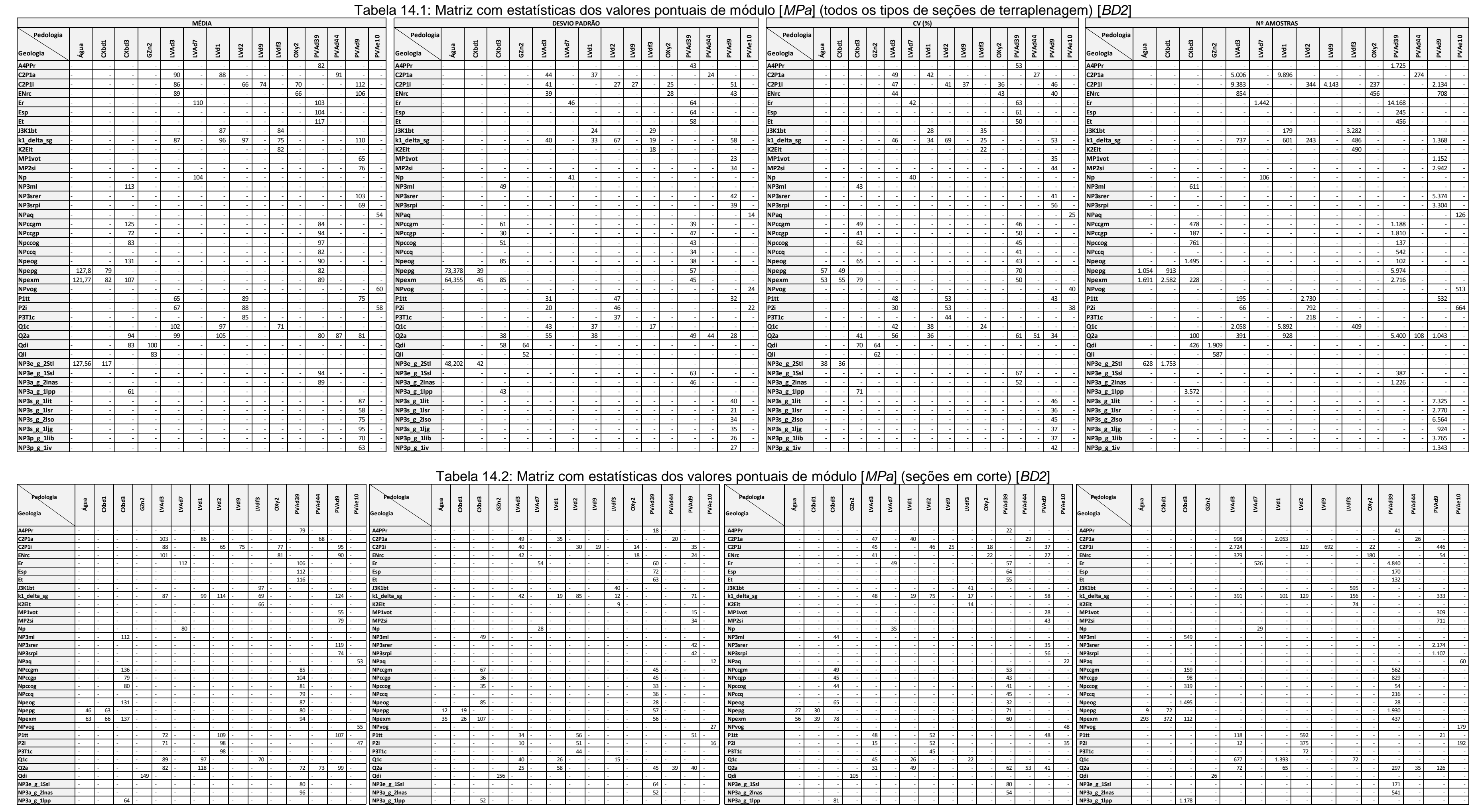


Tabela 14.3: Matriz com estatísticas dos valores pontuais de módulo [MPa] (seções em aterro) [BD2]

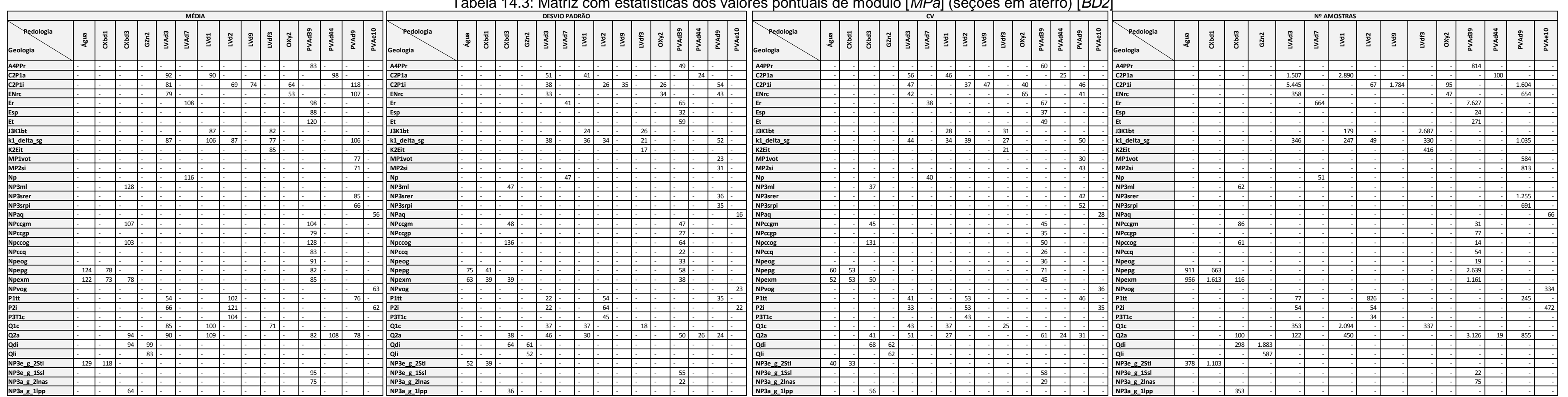

Tabela 14.4: Matriz com estatísticas dos valores pontuais de módulo [MPa] (seções mistas) [BD2]

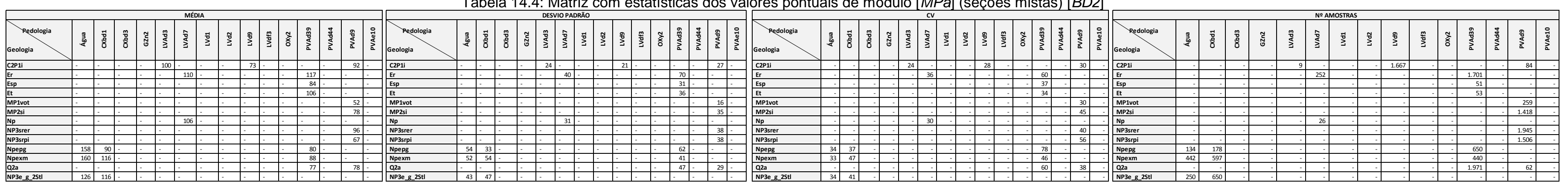


Tabela 14.5: Matriz com estatísticas dos valores pontuais de chuva acumulada [mm] (todas as seções) [BD2]

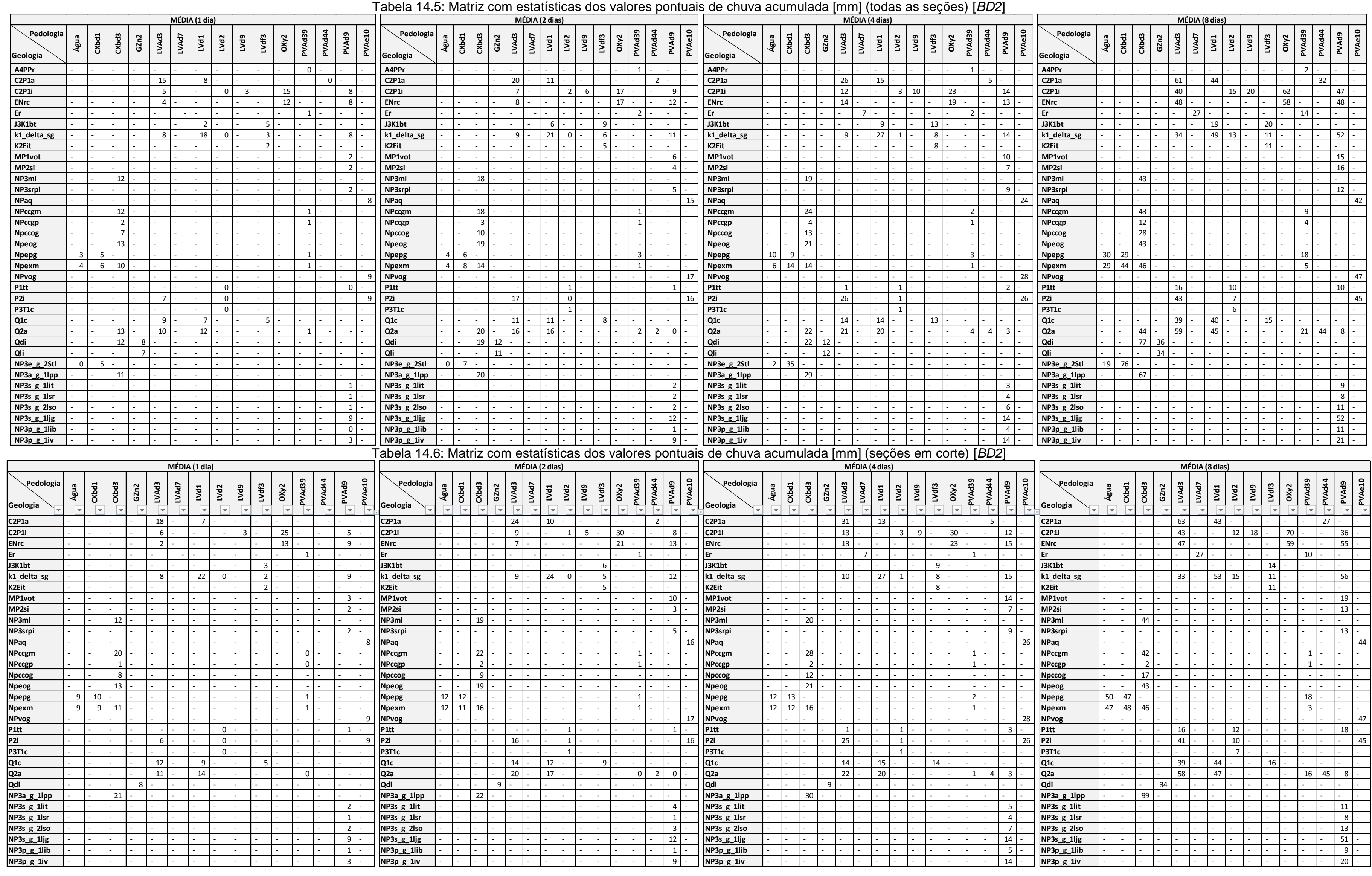


Tabela 14.7: Matriz com estatísticas dos valores pontuais de chuva acumulada [mm] (seções em aterro) [BD2]

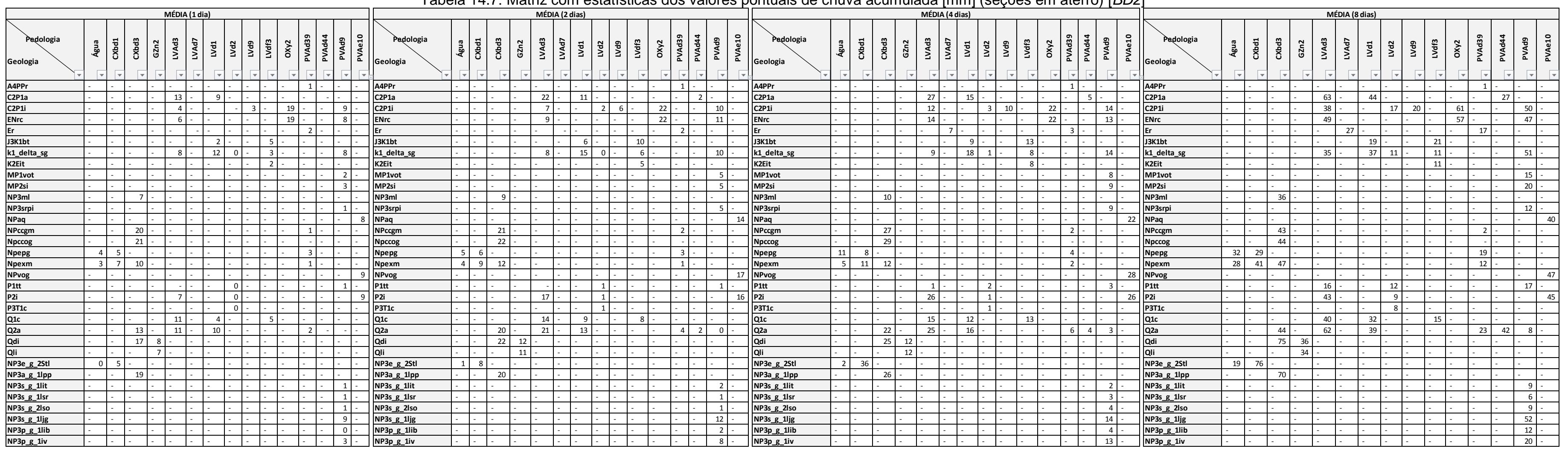

\begin{tabular}{|c|c|c|c|c|c|c|c|c|c|c|c|c|c|c|c|c|c|c|c|c|c|c|c|c|c|c|c|c|c|c|c|c|c|c|c|c|c|c|c|c|c|c|c|c|c|c|c|c|c|c|c|}
\hline \multicolumn{13}{|c|}{ MÉDIA (1 dia) } & \multicolumn{25}{|c|}{ MÉDIA (2 dias) } & \multicolumn{14}{|c|}{ MÉDIA (8 dias) } \\
\hline $\int_{\text {Geologia }}^{\text {Pedologia }}$ & 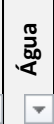 & & & & & & & & & $\frac{2}{3}$ & & 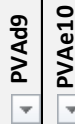 & Geologia & 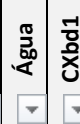 & & V్ & $\frac{m}{a^{2}}$ & & 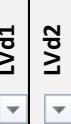 & & \begin{tabular}{l|l}
$\frac{m}{3}$ \\
$\frac{\tilde{x}}{\partial}$ \\
$V$
\end{tabular} & 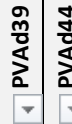 & 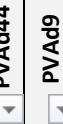 & $\frac{\sqrt{2}}{2}$ & Geologia $_{\text {Pedologia }}^{\text {a }}$ & 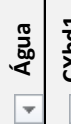 & & 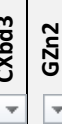 & $\begin{array}{l}\frac{m}{4} \\
\frac{8}{2}\end{array}$ & 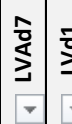 & & $\frac{8}{2}$ & $\frac{m}{\frac{m}{2}}$ & $\frac{\tilde{z}}{\partial}$ & & & & Geologia & ר. & 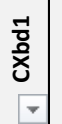 & $\begin{array}{l}\frac{0}{0} \\
\frac{0}{2} \\
\frac{1}{2}\end{array}$ & & & & & & & $\begin{array}{c}\tilde{z} \\
\frac{\tilde{z}}{v}\end{array}$ & & & \\
\hline C2P1i & 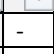 & -1 & & 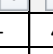 & & & & 4 & & - & - & $\cdots$ & C2P1i & & & & 11 & & & 6 & & -1 & 13 & $3-$ & C2P1i & & & & 16 & & & 11 & & & - & & $5-$ & C2P1i & & - & & 3 & & & & 20 & & & & & \\
\hline & & & & & & - & & & & 0 & - & $-2-$ & Er & & & & & & & - & & 0 - & & - & Er & & & & & \begin{tabular}{l|l}
7 & - \\
\end{tabular} & - & & & & 0 & & - & & & - & & & 27 & $1-$ & & - & & - & 6 & & \\
\hline MP1vot & & & & & & & & & & - & - & $2-$ & 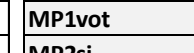 & & & & & & & - & & - - & & $6-$ & MP1vot & & & & & & & & & & 4 & & & MP1vot & & & & & & & & & & & & & \\
\hline MP2si & & & & & & & & & & - & - & $1-$ & MP2si & & & & & & & - & & -- & & $3 .-$ & MP2si & & & & & & & & & & & & & MP2si & & - & & & & & & - & & & - & & \\
\hline NP3srpi & & & & & & - & 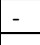 & - & - & - & - & $2-$ & NP3srpi & & 4 & & - & -1. & - & - & -1 & $-2-$ & & $5 .-$ & NP3sspi & & & & & - & & & & & & & $3 .-$ & \begin{tabular}{|l} 
NP3ssrpi \\
Pla
\end{tabular} & & & & & & & & - & & & & & \\
\hline Npepg & $\frac{1}{1}$ & $\frac{2}{2}$ & & & & & & & & 0 & & -1 & & & & & - & -3 & -5 & - & -1 & 0 - & & & & & $\frac{12}{23}$ & & & - & & & & & 1 & & & 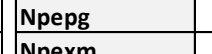 & $\frac{17}{19}$ & 24 & & & & & & & & & 17 & & \\
\hline Npexm & 1 & & & & & - & & - & - & - & - & -- & & & & & - & - & & - & & -1 & & & Npexm & & 23 & & & & & & & & & & & Npexm & 19 & 50 & & & & & & & & & & & \\
\hline Q2a & & -1 & & E & & - & & - & - & 0 & & -1 & Q2a & & - & & - & -1 & - & - & -- & $0-$ & 0 & $0 .-$ & & & & & E & - & - & - & - & & 1 & & $1-$ & Q2a & & - & & & & - & & & & & 18 & & \\
\hline NP3e_g_2St1 & 0 & \begin{tabular}{|l|l|} 
\\
\end{tabular} & & & & - & & - & & & & -- & NP3e____st & & & & - & $-1-$ & - & - & & & & - & NP3e____SSt & \begin{tabular}{l|l}
3 & 3 \\
\end{tabular} & 33 & & - & - & - & - & & & & & - & NP3e_g_2stl & 20 & 75 & & & & & & & & & & & \\
\hline NP3s____llit & & & & & & & & & & - & - & \begin{tabular}{|l|l}
$1-$ \\
\end{tabular} & NP3s_g__lit & & & & - & -3 & & & & & 2 & $2 .-$ & NP3s_g__lit & & & & - & & $-1-$ & - & & & & & $3 .-$ & NP3s $g_{-}$ & & & & & & - & & & & & - & & 9 \\
\hline NP3s_g__lsr & & & & & & & & & & & & $1-$ & S_g__llsr & & & & - & - & & - & & $-1-$ & 2 & $2-5$ & NP3s_g__lsr & & & & & & & - & & & - & & $5 .-$ & NP3s $g_{-}$ & & & & & & & & & & - & & & 8 \\
\hline $\begin{array}{l}\text { NP3s____lso } \\
\text { NP30 o 1ili }\end{array}$ & & & & & & & & & & & & \begin{tabular}{l|l}
1 & - \\
0 & -
\end{tabular} & 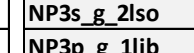 & & & & 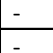 & & & - & & & $\frac{2}{1}$ & $\begin{array}{l}2- \\
\end{array}$ & 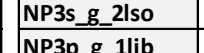 & & & & & & & & & & & & 5 & 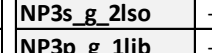 & & & & & & & & -5 & & - & & & $\frac{2}{2}$ \\
\hline$\frac{\text { NP33___lib }}{\text { NP3p__liv }}$ & & & -1 & |- & & T- & & - & & & $\mid-$ & \begin{tabular}{|l|l}
0 & - \\
2
\end{tabular} & NP3p____liv & & $1-$ & & {$[-$} & & $1-$ & & - & & $\frac{1}{9}$ & & 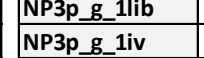 & & & & & & & & & & & & & $\mid$ & & & & & & & & & & & & & $\frac{2}{1}$ \\
\hline
\end{tabular}


Tabela 14.9: Matriz com estatísticas dos valores de módulo (MPa), condição seca - nenhuma chuva acumulada em 8 dias [mm] (todas as seções) [BD2]

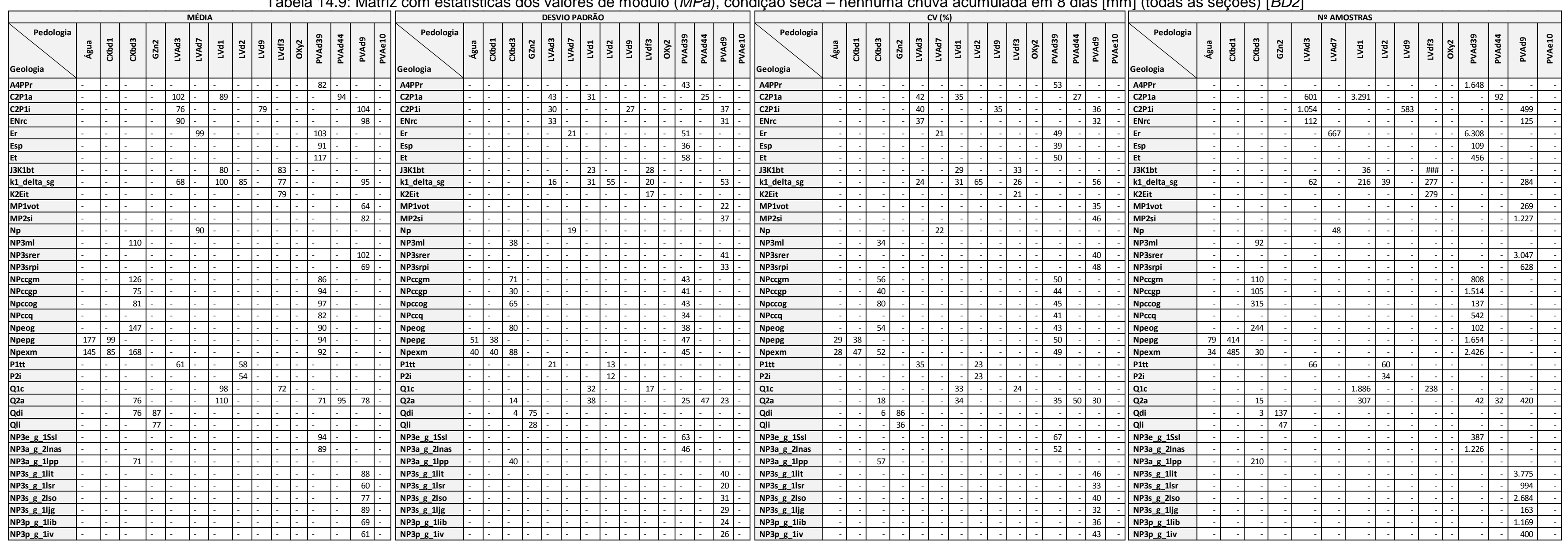


Tabela 14.10: Matriz com estatísticas dos valores de módulo (MPa), condição seca - nenhuma chuva acumulada em 8 dias [mm] (seções em corte) [BD2]

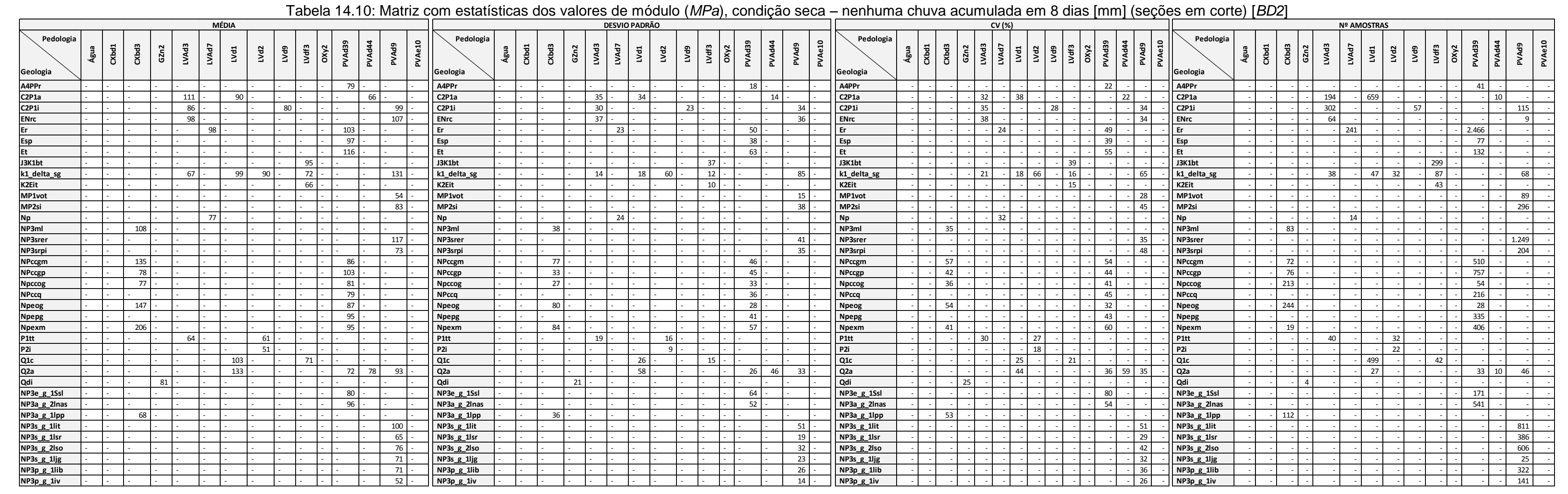


Tabela 14.11: Matriz com estatísticas dos valores de módulo (MPa), condição seca - nenhuma chuva acumulada em 8 dias [mm] (seções em aterro) [BD2]

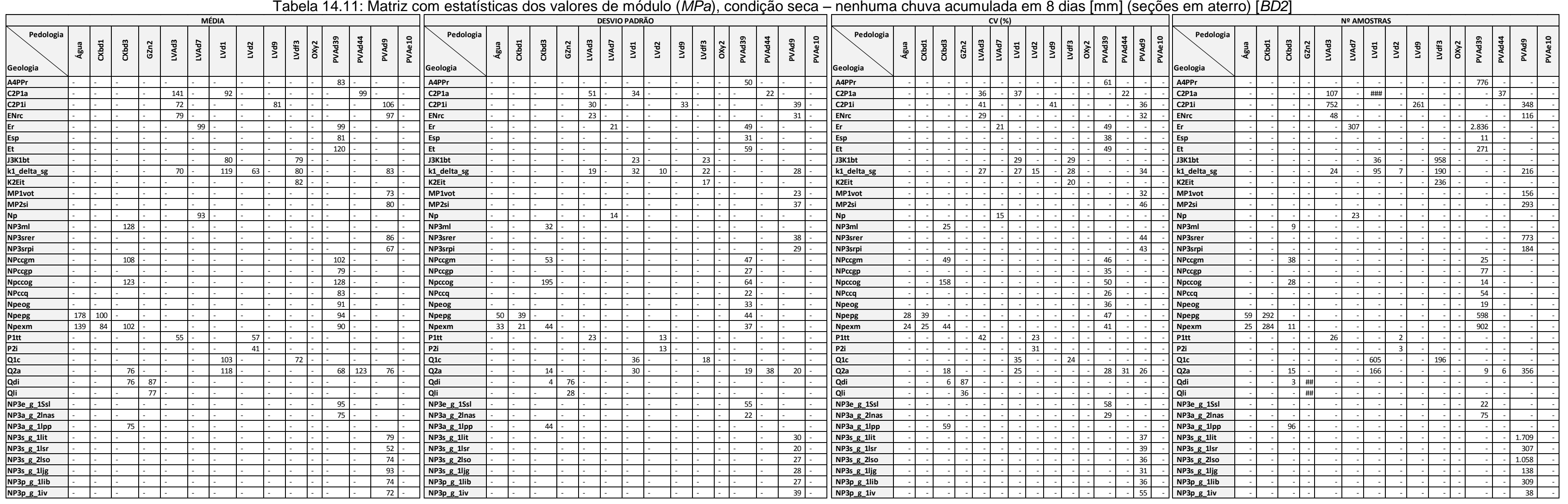

Tabela 14.12: Matriz com estatísticas dos valores de módulo (MPa), condição seca - nenhuma chuva acumulada em 8 dias [mm] (seções mistas) [BD2]

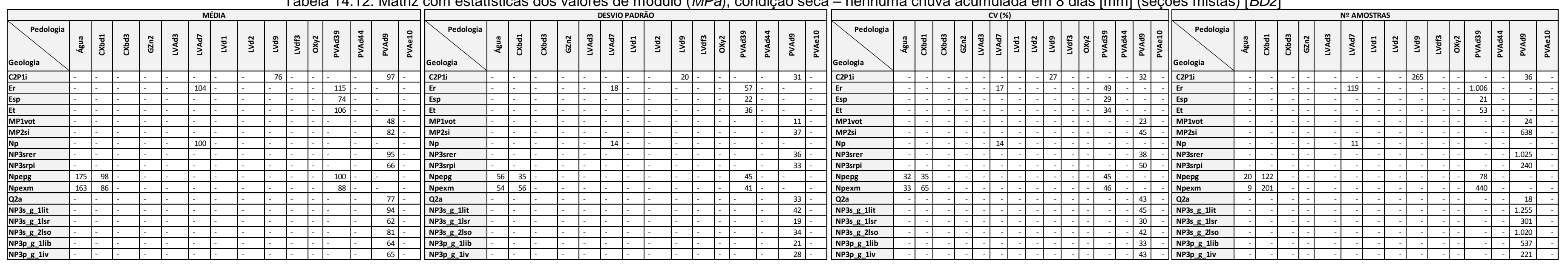


15 ANEXO G - MATRIZES COM ESTATÍSTICAS DOS RESULTADOS PARA OS SEGMENTOS HOMOGÊNEOS DO BANCO DE DADOS $B D 3$ 
Tabela 15.1: Matriz com estatísticas dos valores de Relação de Módulo* (todas as seções) [BD3]

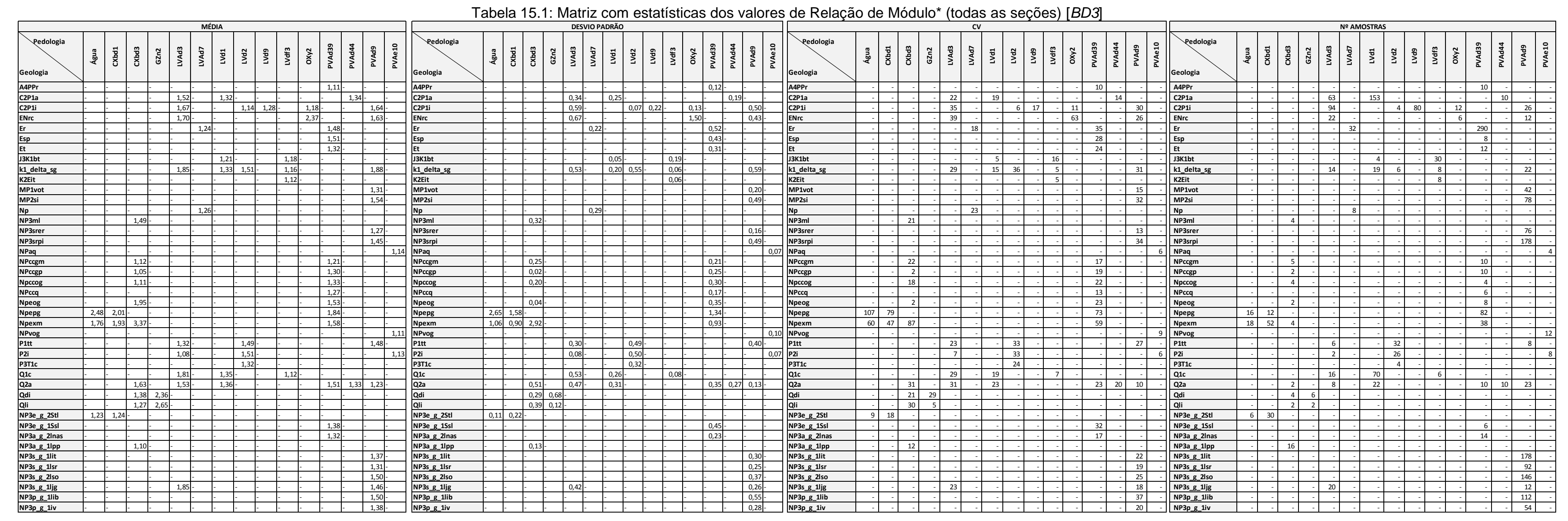


Tabela 15.2: Matriz com estatísticas dos valores de Relação de Módulo* (seções em corte) [BD3]

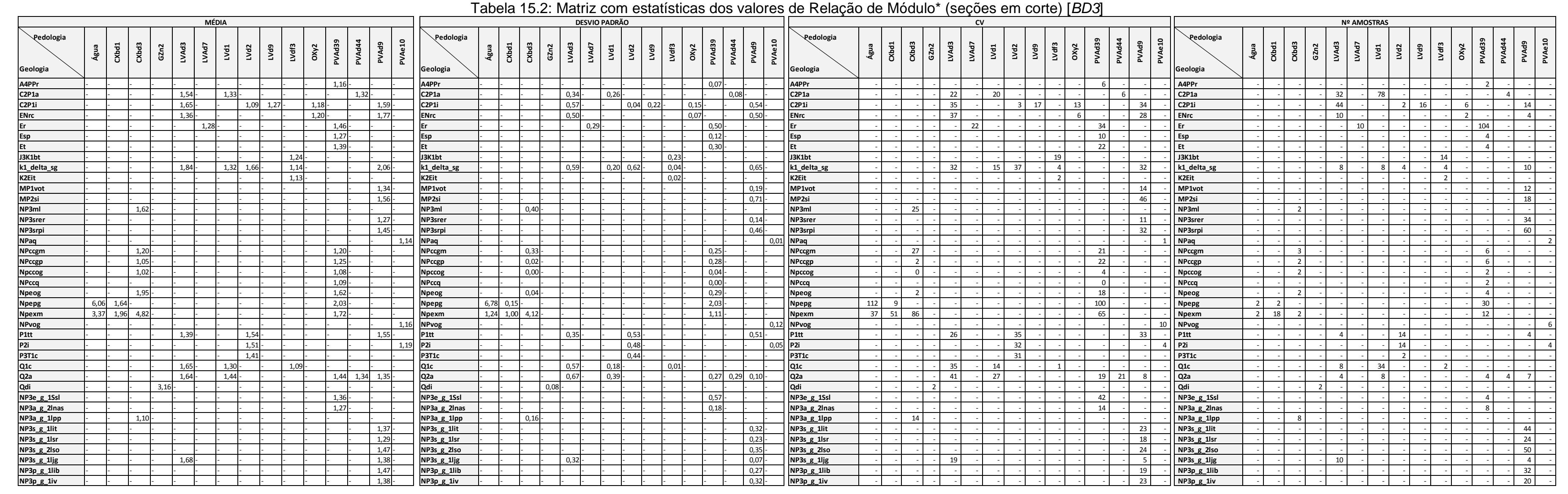




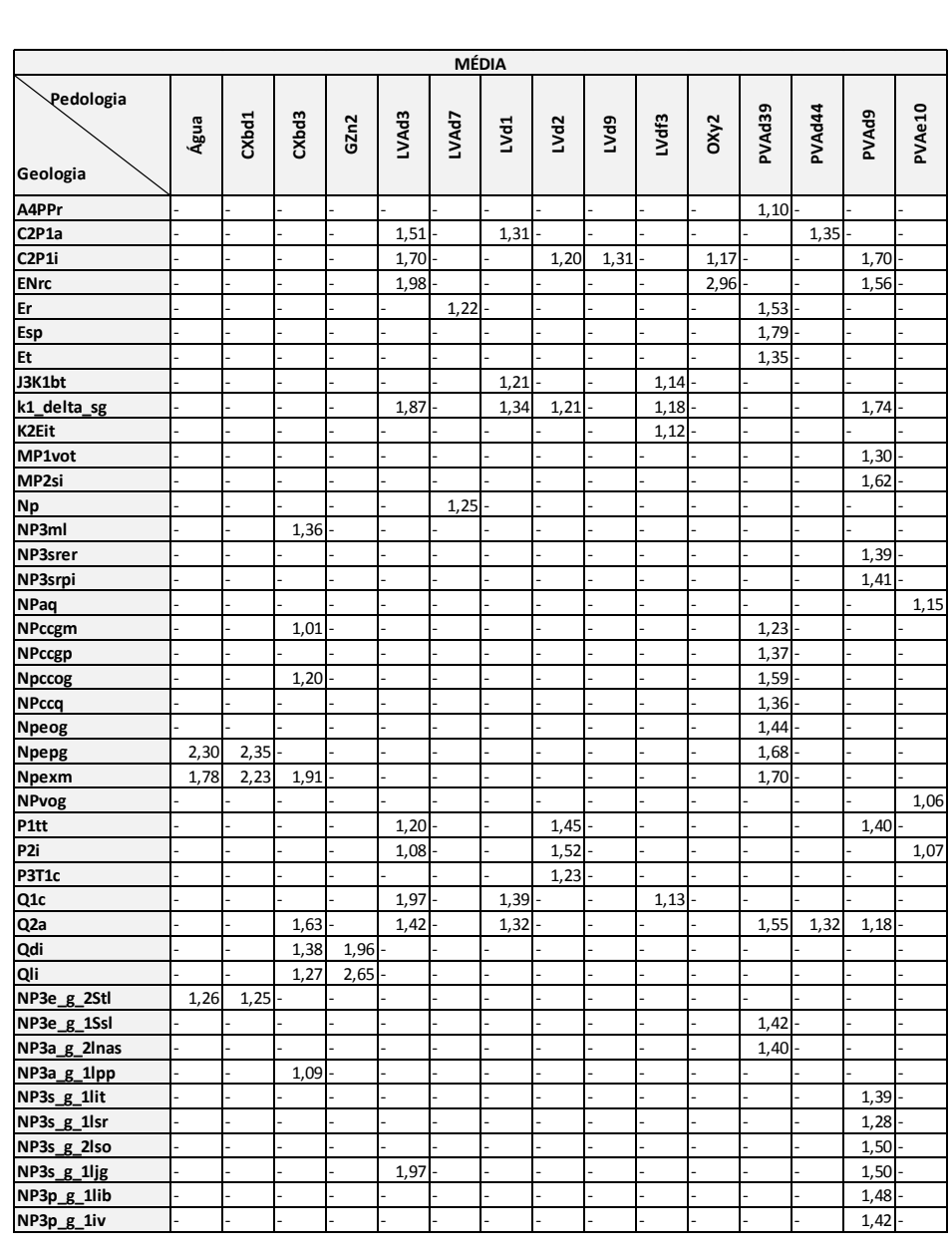

Tabela 15.3: Matriz com estatísticas dos valores de Relação de Módulo* (seções em aterro) [BD3]
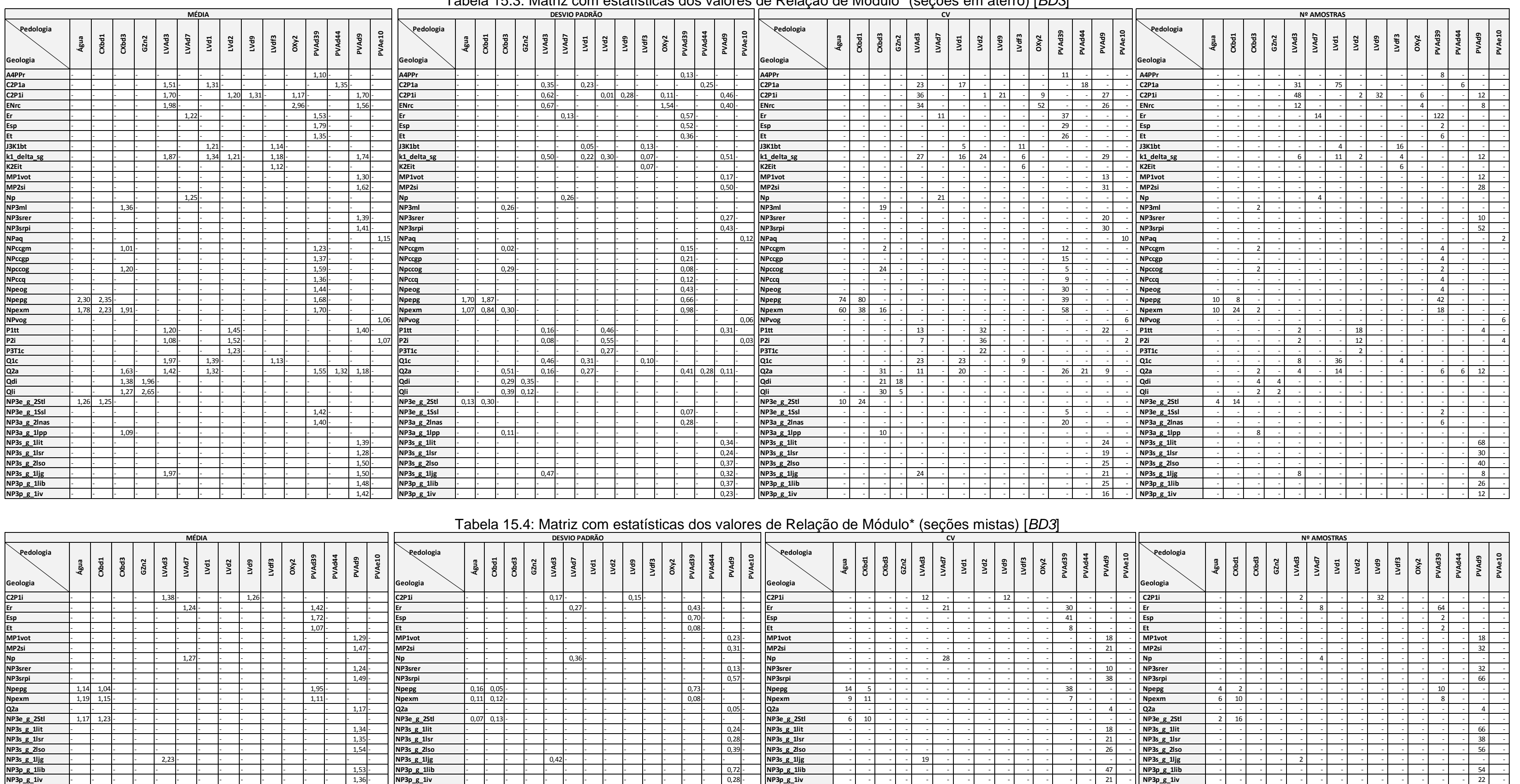

Tabela 15.4: Matriz com estatísticas dos valores de Relação de Módulo* (seções mistas) [BD3]

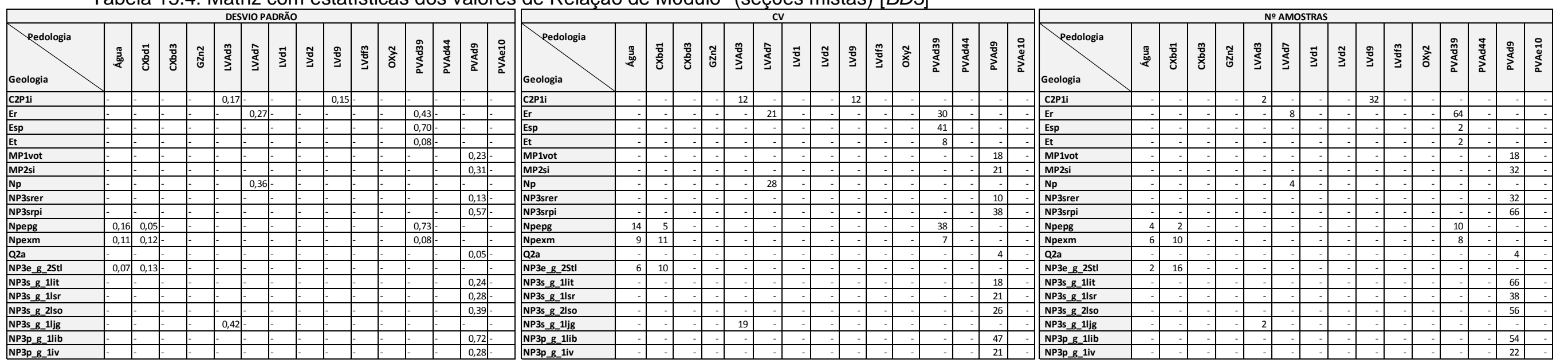


16 ANEXO H - DIAGRAMAS RETIGRÁFICOS DAS RODOVIAS ESTADUAIS EM ESTUDO 


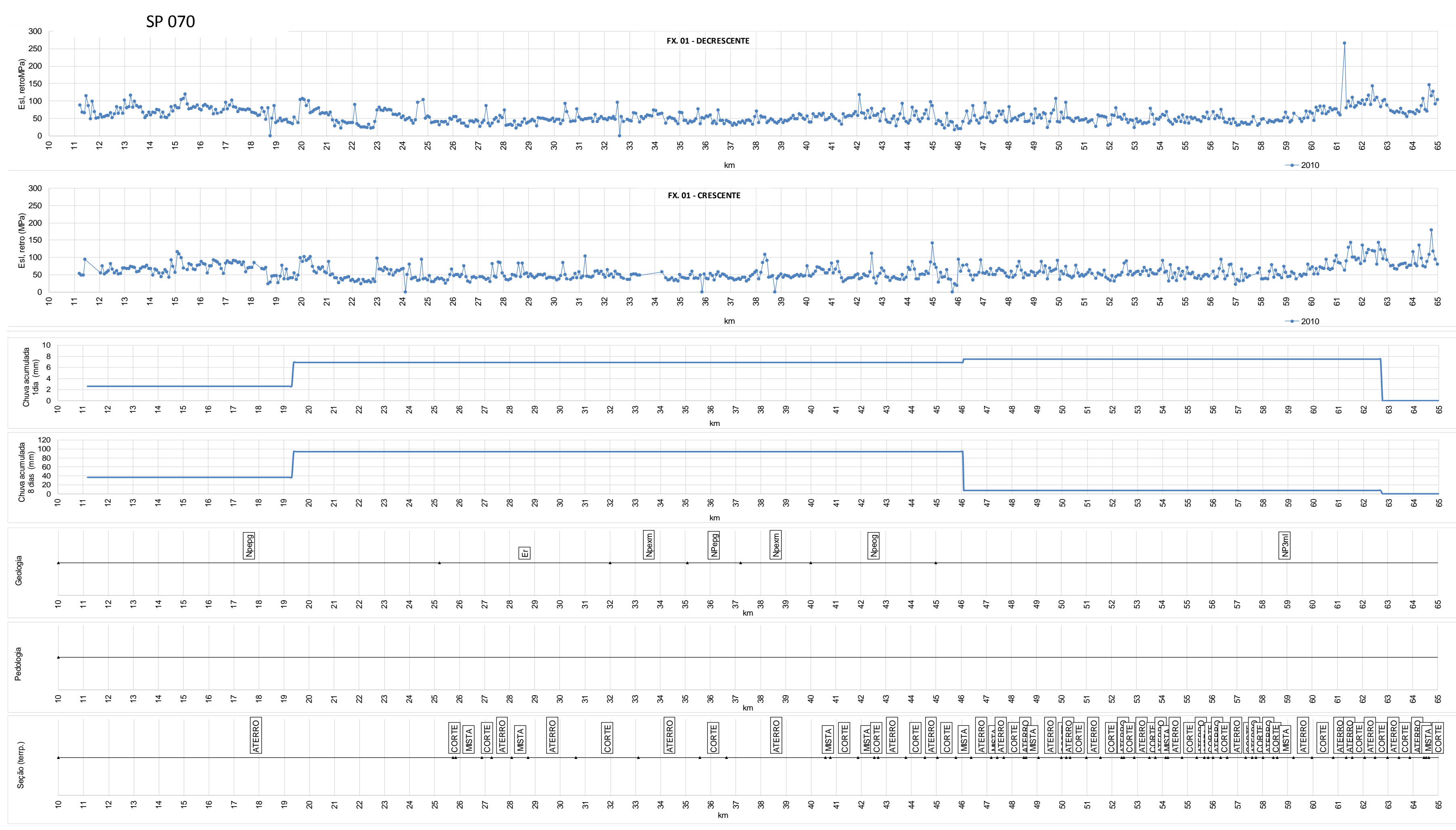


SP 070 (cont.)

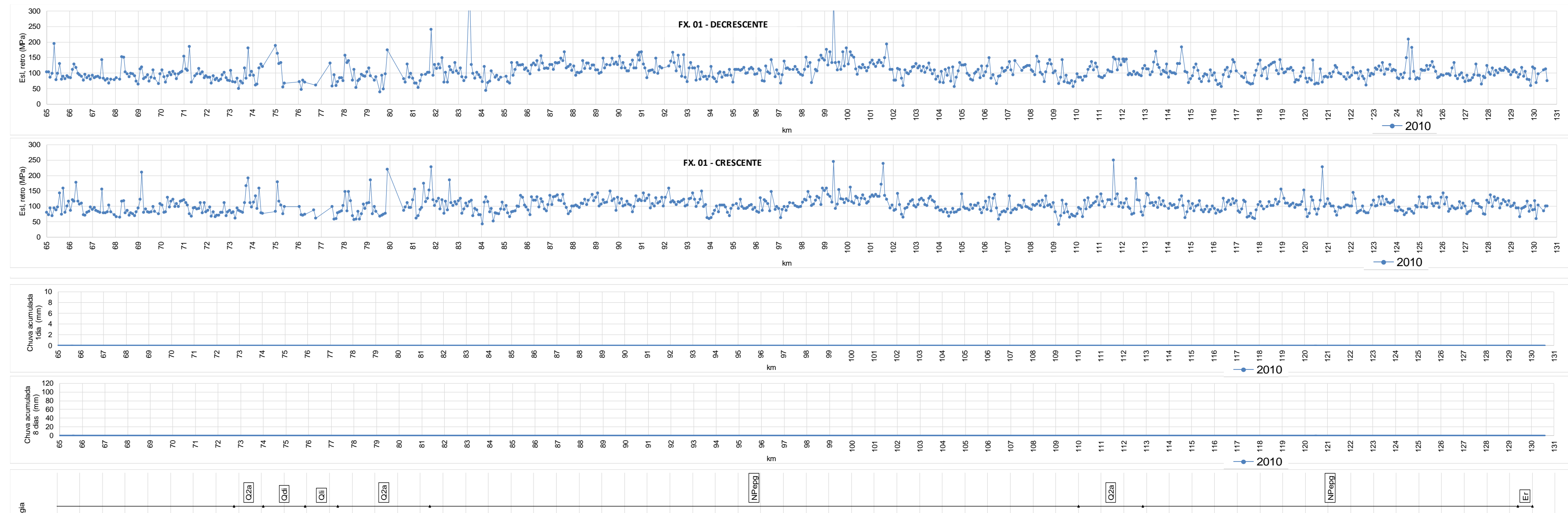
$\frac{\frac{\pi}{5}}{\frac{0}{8}}$

டி ஜ PVAc39

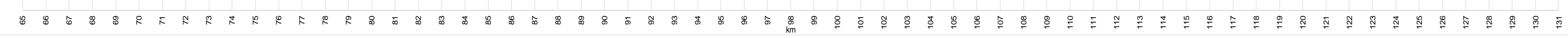

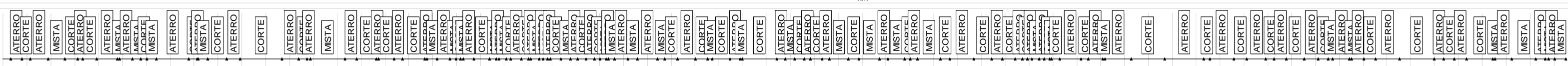

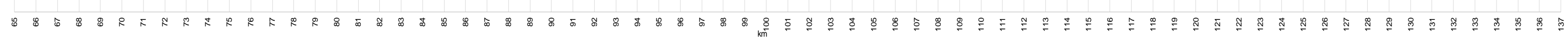




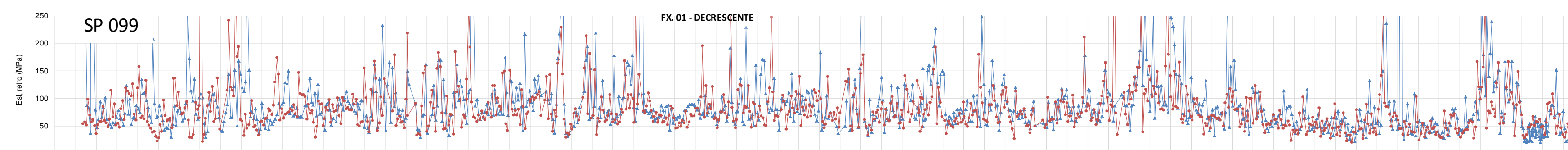

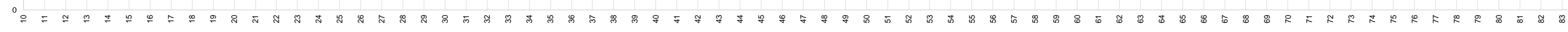

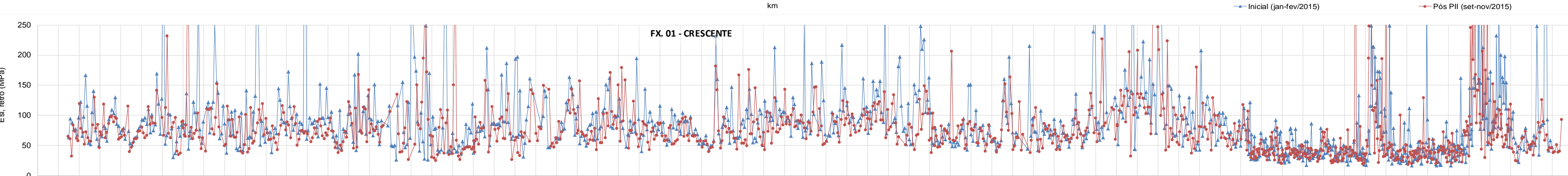

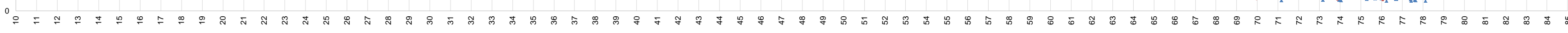

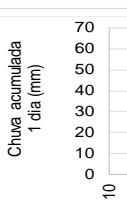

\#-Inicial (jan-fev2015) $\rightarrow$ Pós PIII (set-novi2015)

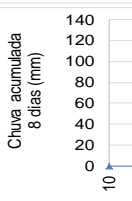

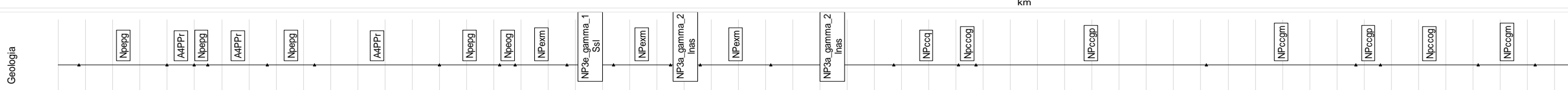

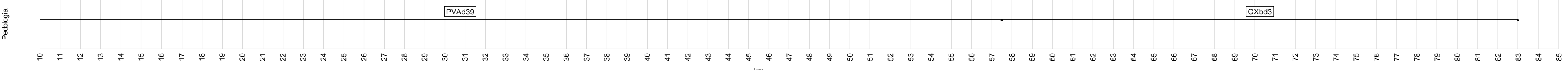

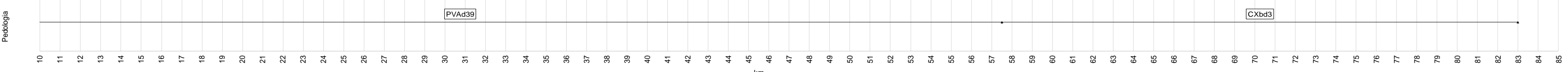

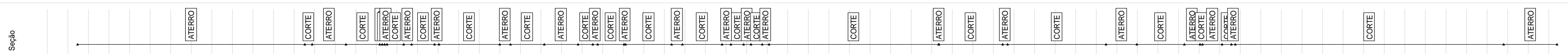

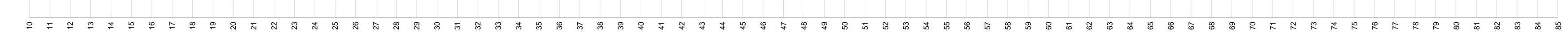




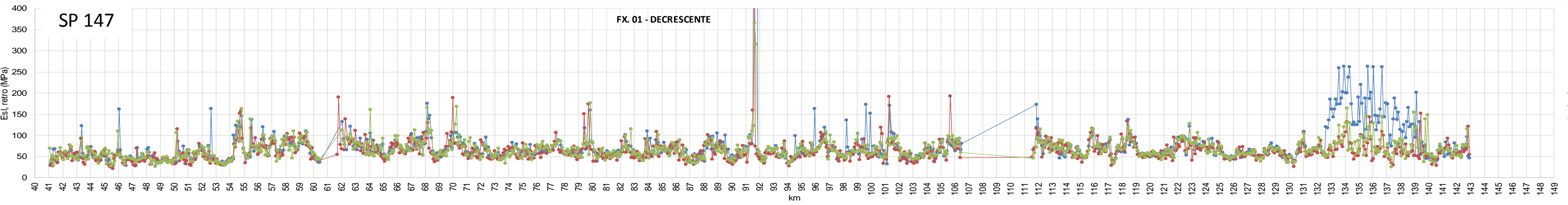

400

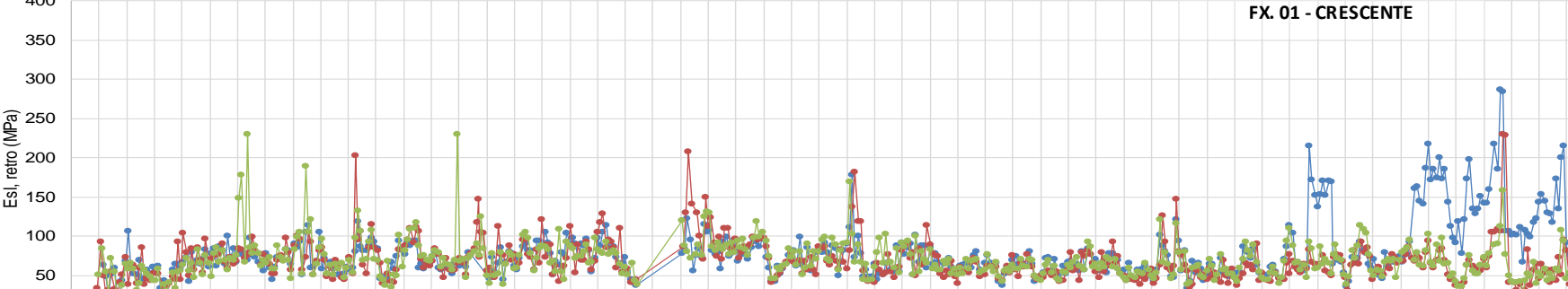

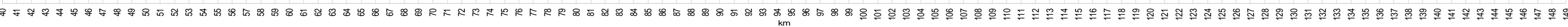

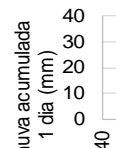

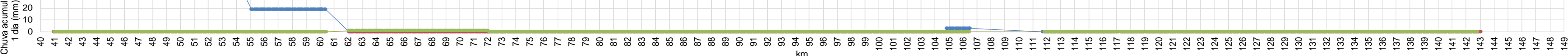

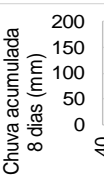

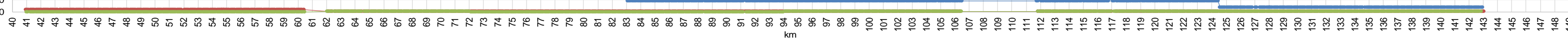

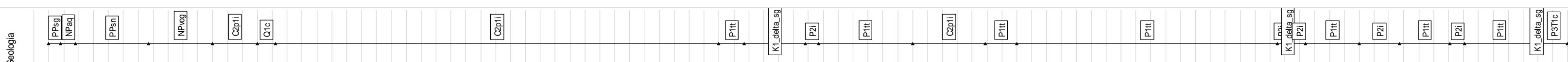

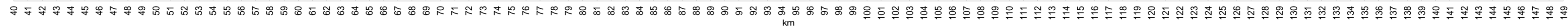

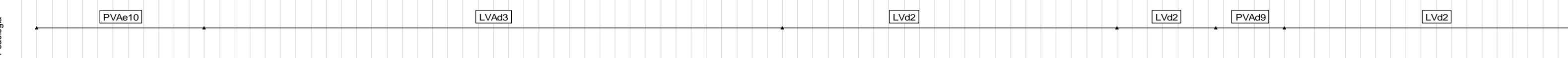

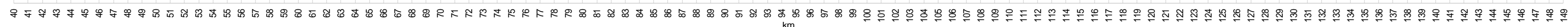

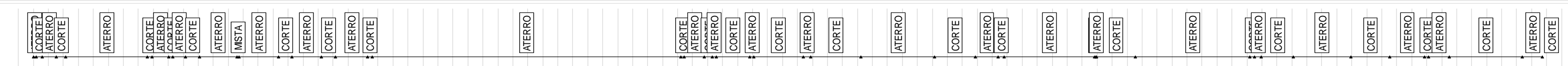



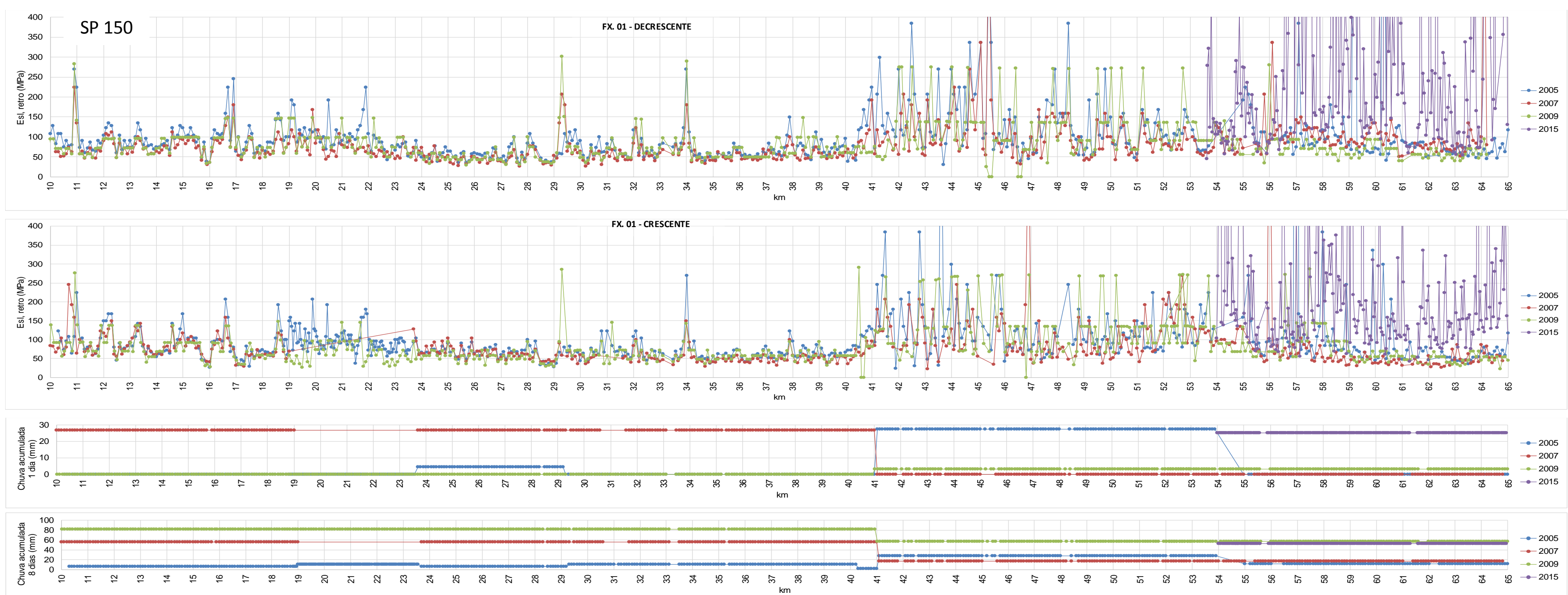

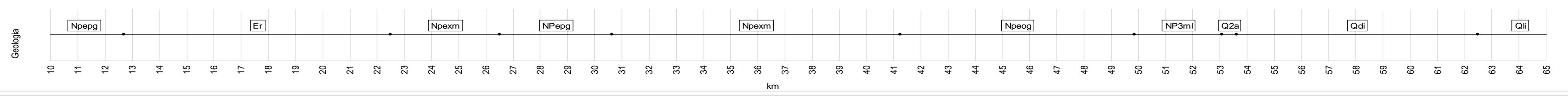

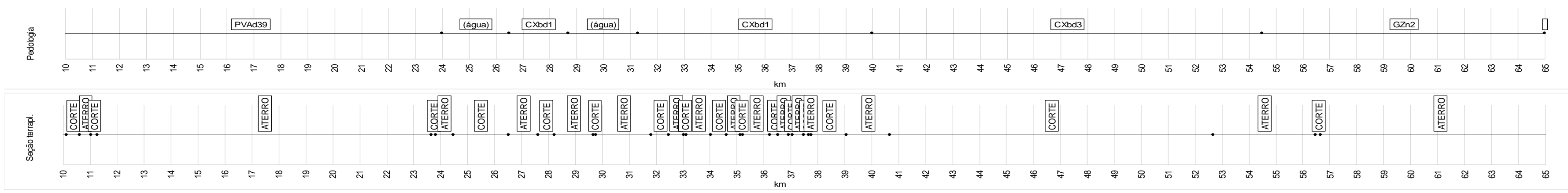




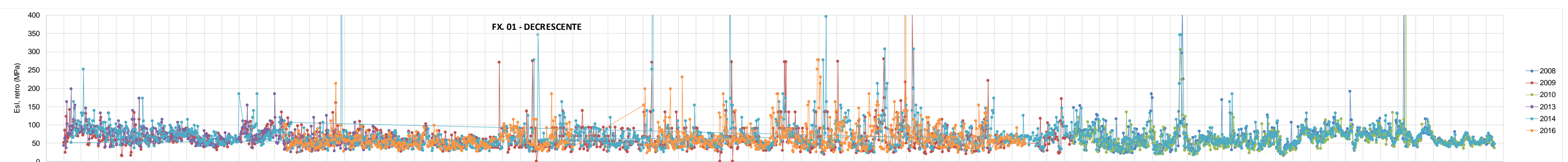

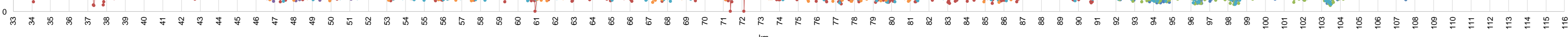
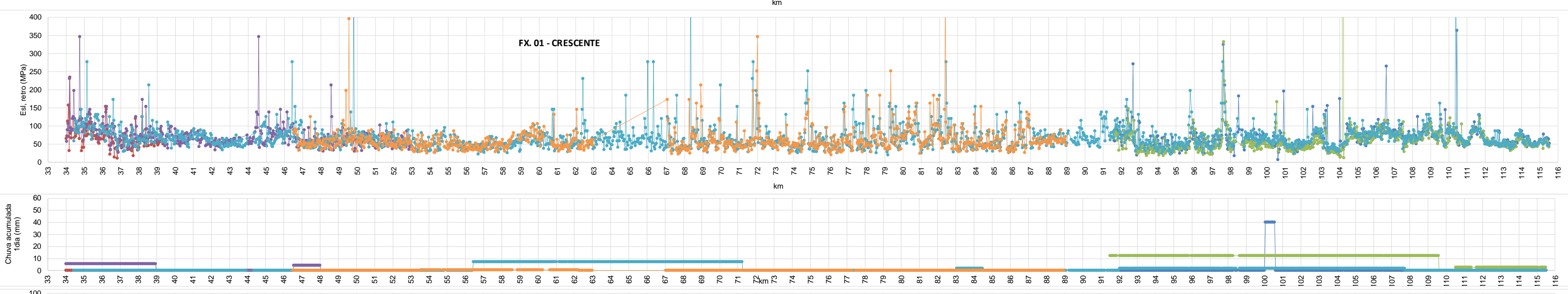

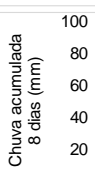

100
80
60

${ }_{8}^{20}$

$\frac{\mathrm{m}}{\mathrm{g}}$

PVAd9

$\frac{\mathrm{m}}{\mathrm{s}}$

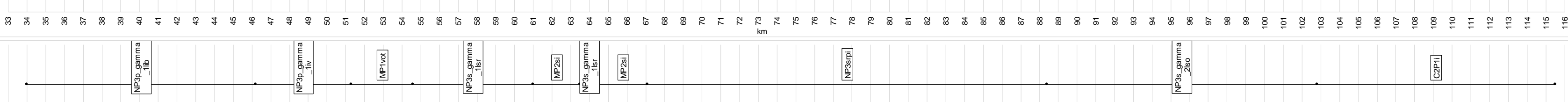

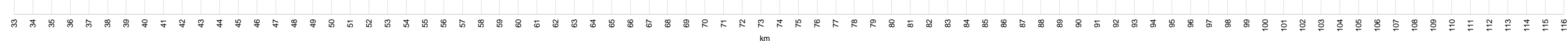

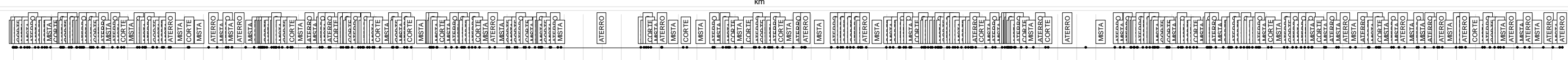

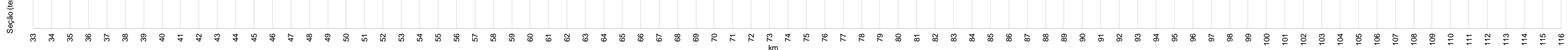



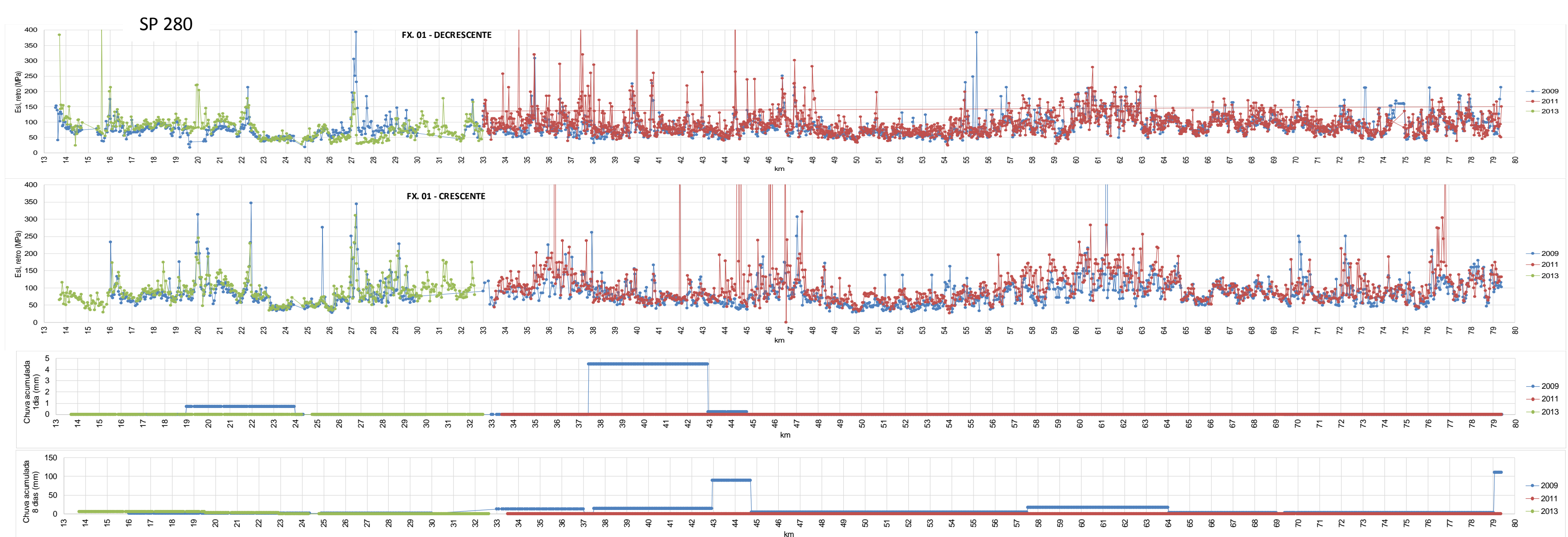

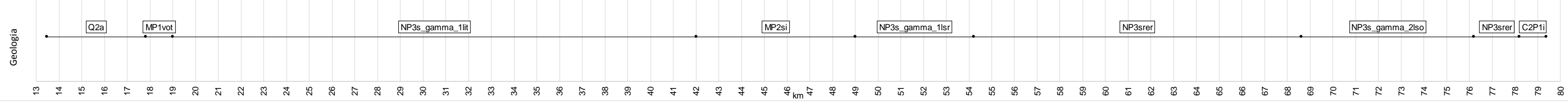

$\frac{\frac{\mathrm{m}}{\mathrm{g}}}{\mathrm{g}}$ PVAd9 高 


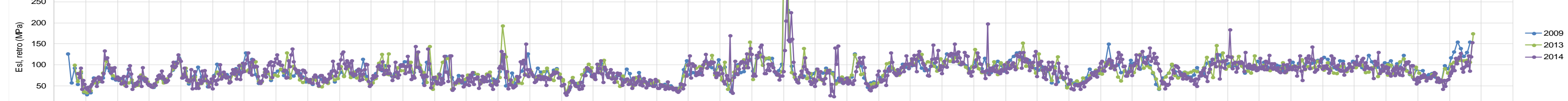

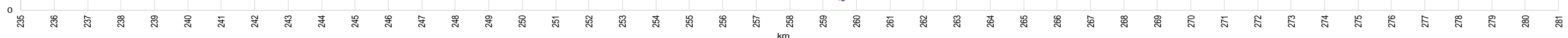

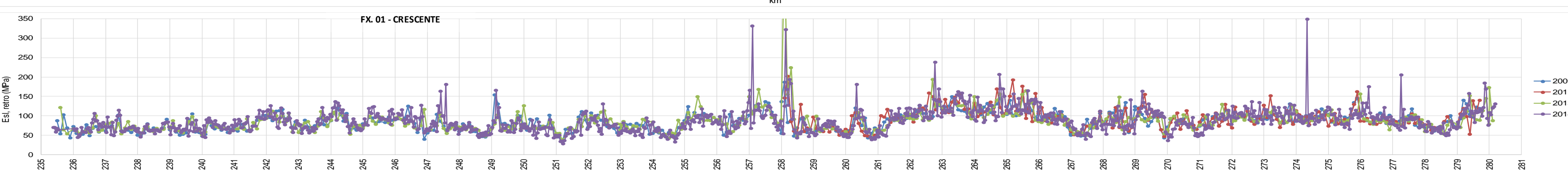

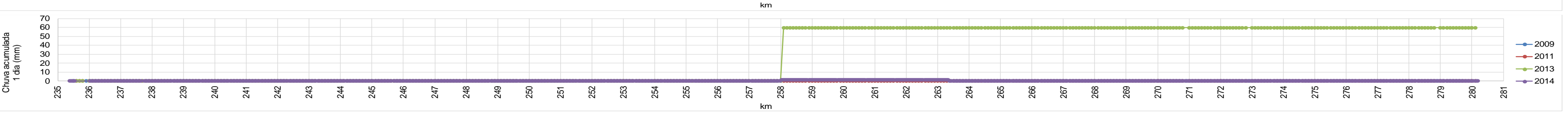

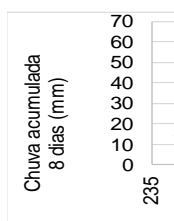
$\frac{\sqrt{5}}{\frac{5}{8}}$

\begin{tabular}{|c|c|c|c|c|c|c|c|c|}
\hline 鱼 & : & $\begin{array}{l}\text { 㯖 } \\
\end{array}$ & 兽 & $\mid$ & 总 & 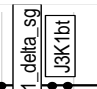 & : & 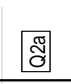 \\
\hline
\end{tabular}

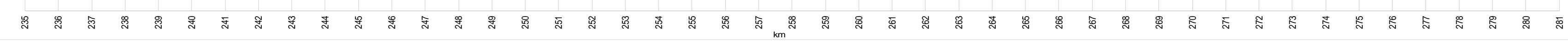
$\frac{\frac{6}{5}}{\frac{3}{2}}$ LVofis LVv11

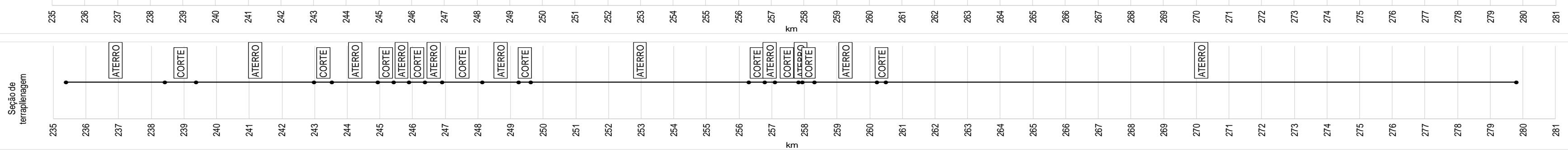




\section{SP 340}

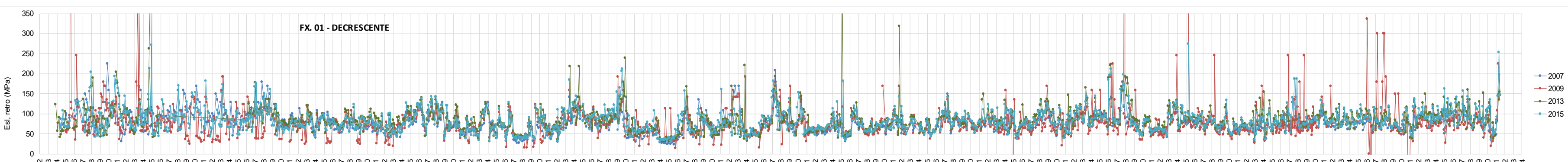

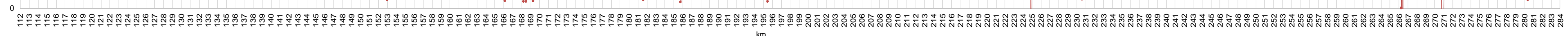

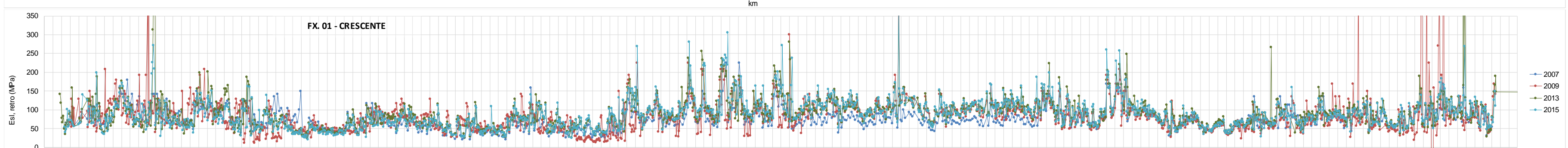

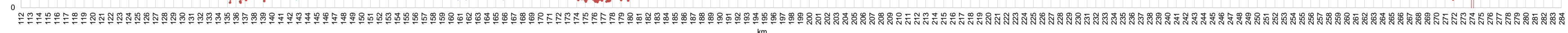

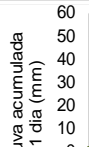

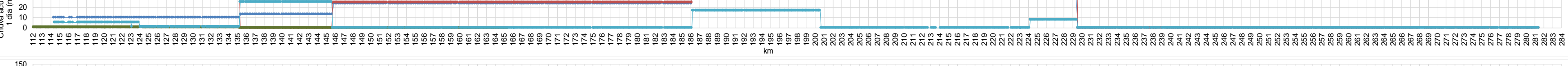

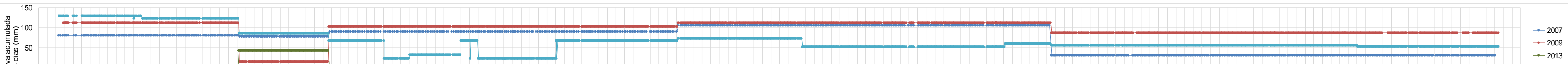

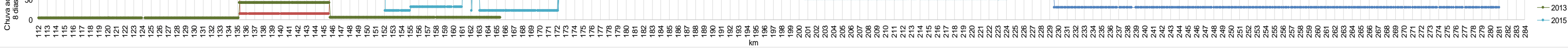

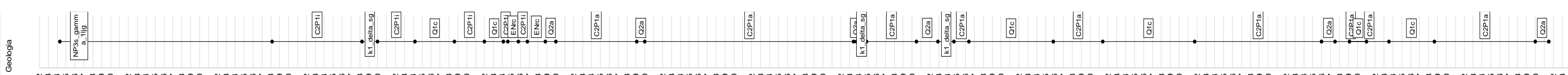

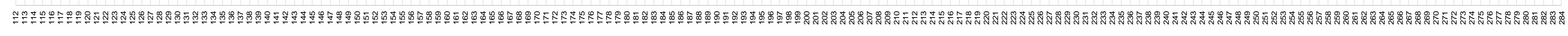

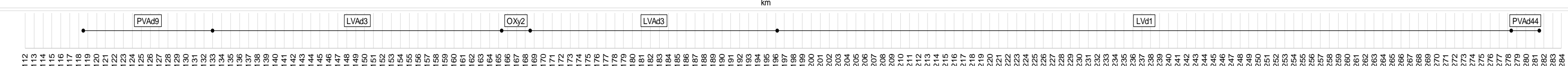

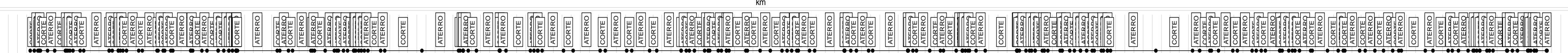

兽 